\title{
Question d'honneur
}

Les notions d'honos, honestum et honestas dans la République romaine antique

MATHIEU JAGOTOT 


\section{Question d'honneur}

Les notions d'honos, honestum et honestas dans la République romaine antique

\section{Mathieu Jacotot}

DOl : 10.4000/books.efr.5464

Éditeur: Publications de l'École française de Rome Année d'édition : 2013

Date de mise en ligne : 8 juillet 2019

Collection : Collection de l'École française de Rome

EAN électronique : 9782728313617

\section{Cbooks}

http://books.openedition.org

Édition imprimée

EAN (Édition imprimée) : 9782728309610

Nombre de pages : 818

\section{Référence électronique}

JACOTOT, Mathieu. Question d'honneur : Les notions d'honos, honestum et honestas dans la République romaine antique. Nouvelle édition [en ligne]. Rome : Publications de l'École française de Rome, 2013 (généré le 21 septembre 2021). Disponible sur Internet : <http://books.openedition.org/efr/5464>. ISBN : 9782728313617. DOI : https://doi.org/10.4000/books.efr.5464.

(c) Publications de l'École française de Rome, 2013

Conditions d'utilisation :

http://www.openedition.org/6540 
Cet ouvrage est diffusé en accès ouvert dans le cadre du projet OpenEdition Books Select.

Ce programme de financement participatif, coordonné par OpenEdition en partenariat avec Knowledge Unlatched et le consortium Couperin, permet aux bibliothèques de contribuer à la libération de contenus provenant d'éditeurs majeurs dans le domaine des sciences humaines et sociales.

La liste des bibliothèques ayant contribué financièrement à la libération de cet ouvrage se trouve ici :

https://www.openedition.org/22515.

This book is published open access as part of the OpenEdition Books Select project.

This crowdfunding program is coordinated by OpenEdition in partnership with Knowledge Unlatched and the French library consortium Couperin. Thanks to the initiative, libraries can contribute to unlatch content from key publishers in the Humanities and Social Sciences.

Discover all the libraries that helped to make this book available open access: https: / $/$ www.openedition.org/22515?lang $=e n$.

\section{IIIJ Qopenedition couperinore}






\section{QUESTION D'HONNEUR}



COLLECTION DE L'ÉCOLE FRANÇAISE DE ROME 479

\section{QUESTION D'HONNEUR}

LES NOTIONS D'HONOS, HONESTUM ET HONESTAS DANS LA RÉPUBLIQUE ROMAINE ANTIQUE 
Jacotot, Mathieu, 1980-

Question d'honneur : les notion d'honos, honestum et honestas dans

la République romaine antique / Mathieu Jacotot

Rome : École française de Rome, 2013

(Collection de l'École française de Rome, 0223-5099 ; 479)

ISBN 978-2-7283-0961-0 (br.)

1. Honneur -- Rome 2. Honnêteté -- Rome 3. Morale pratique -- Rome

4. Roma -- 510-30 av. J.-C. (République)

CIP - Bibliothèque de l'École française de Rome

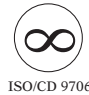

(C) - École française de Rome - 2013

ISSN 0223-5099

ISBN 978-2-7283-0961-0 
À la mémoire de ma mère 



\section{SOMMAIRE}

Page

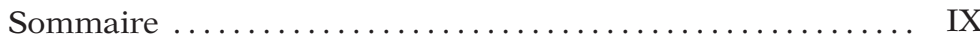

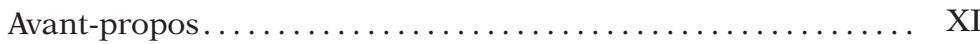

INTRODUCTION GÉNÉRALE .......................... 1

Première PARTIE

\section{LE LEXIQUE: LES MOTS ET LEUR SENS}

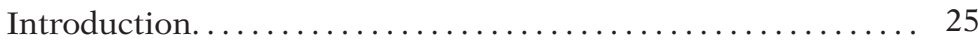

Chapitre 1 - ANALYSE SÉMANTIQUE D'HONOS ............... 31

Chapitre 2 - ANALYSE SÉMANTIQUE D'HONESTUS ................ 115

Chapitre 3 - AnALYSE SÉmantique d'HonestAS .............. 163

Conclusion de la première partie......................... 187

DEUXIÈME PARTIE

LA PRATIQUE: FONCTIONNEMENTS ET USAGES

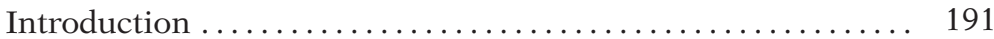

Chapitre 4 - Les Structures de L'HONNEUR................ 195

Chapitre 5 - LES FORMES DE L'HONOS .................... 241

Chapitre 6 - L'ACCÈs À L'HONNEUR : CAUSES ET CONDITIONS . . . . . . . . . 299

Chapitre 7 - LES EFFETS DE L'HONNEUR ................. 355

Chapitre 8 - LES FONCTIONS DE L'HONNEUR ................ 393

Chapitre 9 - La GESTION DE L'HONNEUR .................... 429

Chapitre 10 - LE CODE DE L'HONNEUR .................. 461

Chapitre 11 - Le dieu Honos . . . . . . . . . . . . . . . . . . . . . . . . . 507

Conclusion de la deuxième partie ........................... 539

TROISIÈME PARTIE

\section{APPROCHES INTELLECTUELLES ET REPRÉSENTATIONS}

Introduction 
Chapitre 12 - Plaute: L'HonNeur À L'ÉPREuve de la Comédie .... . 547

Chapitre 13 - Caton: L'Honneur du Censeur............. 577

Chapitre 14 - Les ÉPITAPHES DES SCIPIONS: LA MOBILISATION DE

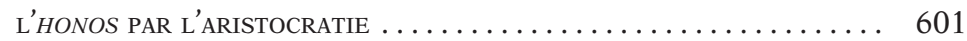

Chapitre 15 - TÉrence: L'HONNEUR EN DEMI-TEINTE .......... 621

Chapitre 16 - LuCILIUS: L'HONNEUR À LA CROISÉE DES CHEMINS. . . . . 637

Chapitre 17 - La RHÉtoriQUe À HeRENNIUS: LA MATURATION CONCEPTUELLE D'HONESTUM.......................... 667

Chapitre 18 - LUCRÈCE: LA CRITIQUE ÉPICURIENNE DE L'HONOS ...... 683

Chapitre 19 - CÉSAR: L'HONOS ET LA FIGURE DE L'IMPERATOR ...... 705

Chapitre 20 - SALluSte: L'HISTORIEN D'Un HONNEUR EN CRISE..... 723

Conclusion de la troisième partie ................. 749

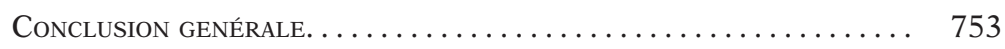

SourcES ET BIBLIOGRAPHIE. ...................... 761

INDEX LOCORUM . . . . . . . . . . . . . . . . . . . . . . . . . 799

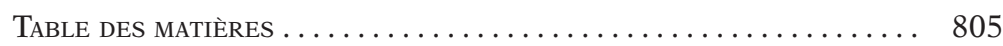




\section{AVANT-PROPOS}

Ce livre est issu d'une thèse de doctorat de troisième cycle, préparée sous la direction de Carlos Lévy, puis soutenue à l'Université de Paris-Sorbonne le 14 novembre 2009, devant un jury présidé par John Scheid et composé de Jean-Michel David, Michèle Ducos, Giovanna Garbarino, Carlos Lévy, Aldo Setaioli et Jean-François Thomas. De nombreuses suggestions m'ont été faites à cette occasion et m'ont permis d'améliorer significativement mon travail. À chacun des membres de mon jury, jadresse tous mes remerciements.

Je souhaite exprimer ma reconnaissance particulière à Carlos Lévy qui a dirigé mes recherches avec une attention sans faille. Sa grande rigueur, ses conseils aussi riches que précis et son exceptionnelle disponibilité ont été très précieux tout au long de ces années.

J'ai également eu la chance de bénéficier de l'aide de plusieurs savants français et étrangers auxquels je témoigne toute ma gratitude. Aldo Setaioli m'a fait profiter de ses talents de philologue aux débuts de ma recherche et l'a ensuite suivie avec une bienveillante attention. Daniel Petit a su m'éclairer sur de délicates questions d'étymologie indo-européenne. Jean-François Thomas m'a guidé de ses conseils sur la manière d'aborder le lexique latin et la sémantique et, sans ménager son temps, a relu les pages que j'avais écrites sur ce sujet. François Bérard m’a aidé dans l'interprétation de plusieurs inscriptions républicaines. Gualtiero Calboli et Jean-Louis Ferrary m'ont tous deux permis, par leurs nombreuses suggestions, de mieux interpréter les épitaphes des Scipions. John Scheid a bien voulu me faire bénéficier de sa science de la religion romaine à propos du culte du dieu Honos. Thomas Bénatouil m’a donné de précieuses indications bibliographiques dans le domaine des sciences sociales.

Je remercie également mes camarades Renaud Alexandre et Charles Guérin qui m'ont indiqué bien des ouvrages utiles et ont relu plusieurs passages de mes travaux de doctorant. Les discussions que nous avons pu avoir et les recherches que nous avons conduites, avec d'autres jeunes chercheurs, dans le cadre de l'association "Compitum» et du séminaire "Pensée et Modes de Pensée à Rome», se sont révélées aussi stimulantes que fructueuses pour mon propre travail.

Mes recherches, enfin, n'auraient pas trouvé la même issue sans l'appui de mes proches. L'attention et la confiance inébranlable de mon père m'ont soutenu tout au long de ces années. Mon épouse Aurélia m’a apporté une aide décisive par ses relectures et ses conseils mais aussi par son soutien quotidien, sa patience et sa compréhension. 



\section{INTRODUCTION GÉNÉRALE}

En 48 avant J. -C. , après la bataille de Pharsale et la victoire de César sur Pompée, Cicéron, qui après de longues hésitations avait rejoint le camp des pompéiens, prit le chemin du retour vers l'Italie. Quelques mois après, alors qu'il séjournait à Brindes, il rencontra César. Ce dernier ne lui manifesta pas d'animosité et lui accorda son pardon: Cicéron pouvait alors rentrer à Rome. La situation politique y était radicalement changée: le forum était réduit au silence, les lieutenants de César tenaient la ville et la domination du nouveau maître de l'Vrbs s'installait progressivement. Placé devant l'impossibilité de jouer un rôle dans les affaires de l'État et frappé par la dégradation des institutions républicaines, Cicéron se résout alors à se retirer de la vie publique pour se consacrer à l'étude. Dès 46 , il entreprend la rédaction d'ouvrages de rhétorique puis de dialogues et traités destinés à doter la langue latine d'une philosophie. Au début de l'une de ces œuvres, les Seconds Académiques, Cicéron revient sur la discipline à laquelle il a décidé de se consacrer dorénavant. Il défend, contre l'opinion de son interlocuteur Varron, l'utilité d'un exposé de la philosophie en langue latine et évoque les raisons qui l'ont amené à l'entreprendre:

Ego autem Varro (dicam enim ut res est), dum me ambitio dum honores dum causae, dum rei publicae non solum cura sed quaedam etiam procuratio multis officiis implicatum et constrictum tenebat, animo haec inclusa habebam et ne obsolescerent renouabam cum licebat legendo; nunc uero et fortunae grauissimo percussus uulnere et administratione rei publicae liberatus doloris medicinam a philosophia peto et otii oblectationem hanc honestissimam iudico.

«Quant à moi, Varron (je dirai les choses comme elles sont), tant que l'ambition, les honneurs, les affaires judiciaires, le souci de la république et plus encore son administration me tenaient enfermé et enserré par de nombreuses obligations, je conservais ces connaissances philosophiques en moi et, pour ne pas qu'elles dépérissent, je les ravivais quand je le pouvais par des lectures. Mais à présent que je suis atteint par la fortune d'une très grave blessure et que je suis libéré de la gestion des affaires publiques, je cherche dans la philosophie un remède à ma douleur et je considère ce doux loisir comme tout à fait honorable ${ }^{1}$. »

(Cic. Ac. Post. I, 11).

\footnotetext{
${ }^{1}$ Sauf mention contraire, toutes les traductions sont nôtres.
} 
C'est en raison de la nouveauté du contexte politique que Cicéron s'est tourné vers l'étude et la philosophie. La défaite des pompéiens, la montée en puissance de César et l'effondrement de la république l'ont écarté de la gestion de l'État mais lui ont simultanément ouvert la possibilité de se consacrer au loisir intellectuel, qui adoucit sa retraite forcée et rend moins pénible le douloureux spectacle du naufrage de la république. Ce texte constitue donc une justification par Cicéron de sa nouvelle activité. De ce fait, il met en avant l'aspect problématique, en des circonstances normales, d'une vie tournée vers le travail intellectuel et située hors de l'action publique. Ce n'est pas que la philosophie soit une activité répréhensible en soi mais elle pose problème quand on est, comme Cicéron, un homme public de très haut statut. Ce problème est, pour reprendre les termes employés par Cicéron, une question d'honneur. Ce que Cicéron veut montrer dans ce passage, c'est que la philosophie est, en raison du contexte particulier de la domination césarienne, une pratique qui n'est pas déshonorante mais au contraire tout à fait conforme à l'honneur (honestissimam). L'homme d'État doté d'un fort prestige doit, en temps normal, observer un code de conduite rigoureux; se tourner vers l'étude serait mettre en péril son honneur. Mais deux choses ont changé: d'une part, Cicéron a renoncé à mener une vie publique, ce qui a pour conséquence d'alléger le poids des contraintes sociales et morales qui pèsent sur lui; d'autre part, la vie civique est dans un état de déliquescence, ce qui transforme les exigences de l'honneur.

\section{Hommage, prestige, dignité: la notion d'honneur}

\section{Aspects et approches de l'honneur}

Le texte des Seconds Académiques est particulièrement intéressant car il témoigne de la représentation que se font les aristocrates romains de la notion d'honneur. Elle est composée de deux aspects fondamentaux. L'honneur apparaît d'abord comme une donnée sociale et politique: Cicéron mentionne au début du texte les honneurs qu'il a accumulés au cours de sa vie, marques d'estime et charges publiques. Ces hommages de nature diverse, ajoutés à ses actions passées, lui ont procuré un très grand prestige. L'honneur est donc la considération de l'homme public, née du regard favorable des autres et des marques d'estime qu'on lui décerne, notamment sous la forme de charges politiques; cette considération procure influence et autorité. Le second aspect de l'honneur, indissociable du premier, est moral et psychologique. Cicéron articule en effet au statut élevé de l'homme public l'existence de règles de vie contraignantes. Le prestige oblige à se conformer à un code d'honneur. L'honneur est ainsi la dignité qui interdit de se livrer à certaines actions et impose d'observer des normes de conduite pour ne pas perdre la face. Ces normes ne sont pas fixées définitivement puisque des activités nouvelles, comme la philosophie, peuvent y entrer. 
Outre qu'il met bien en avant ces deux aspects de l'honneur, le texte de Cicéron a aussi l'intérêt de montrer qu'au moins deux approches différentes de cette notion sont possibles à Rome. L'honneur peut, en premier lieu, être envisagé comme un vécu: Cicéron connaît les différentes formes d'hommage, les qualités qui y donnent droit ou encore les usages politiques du prestige; il a ressenti au cours de sa vie les avantages et les contraintes de l'honneur. Le Romain est de ce fait susceptible de rencontrer une "question d'honneur», au sens où l'honneur pose des difficultés pratiques qu'il faut résoudre et peut donner lieu à discussion. Mais l'honneur est aussi, en second lieu, un objet de pensée sur lequel il est possible de spéculer, comme le fait Cicéron quand il cherche à mesurer son évolution à l'aune du changement de la vie publique. L'honneur est une réalité intellectuelle qui fait l'objet d'une réflexion, d'une évaluation et d'une conceptualisation: il peut être à Rome «question d'honneur» au sens où l'on met l'honneur en question, en s'interrogeant sur sa nature, en le soumettant à l'examen, voire en le mettant en cause. Il y a donc une expérience mais aussi une pensée de l'honneur.

\section{Objet de l'étude}

Ce sont ces différents aspects de l'honneur, socio-politique, moral et psychologique, et les diverses façons, pratique et réfléchie, dont il est envisagé à Rome que notre étude voudrait essayer d'approcher. Nous entendons analyser la manière dont les Romains ont formulé, pratiqué et théorisé cet honneur, qu'il s'agisse de la marque d'estime concrète, du prestige social ou de la dignité morale. Nous tenterons d'éclairer la nature de la considération sociale et des marques d'honneur à Rome, leurs mécanismes, leurs soubassements, leurs effets et leur place dans le fonctionnement de la cité. Nous observerons les exigences de la dignité et du code de l'honneur, ses normes, ses archétypes et son évolution. Nous confronterons à la pratique de l'honneur l'élaboration intellectuelle qu'en ont proposé les Romains, en nous interrogeant sur l'usage idéologique, littéraire ou philosophique qui a pu en être fait. Nous interrogerons notamment la place de l'honneur dans l'éthique romaine ainsi que son rapport avec la vertu et le bien moral. La "question d'honneur», si elle se pose pour les Romains, se pose aussi pour nous puisque nous ambitionnons dans cet ouvrage de nous interroger en profondeur sur cette notion afin d'en affiner la compréhension.

\section{Problèmes posés par la notion d'honneur}

La notion d'honneur semble parcourir l'œuvre de Cicéron: ce dernier fustige les manquements à l'honneur de ses ennemis politiques ${ }^{2}$,

${ }^{2}$ Verrès: Cic. Verr. II, I, 32 ; Catilina: Cic. Catil. I, 13; Pison: Cic. Pis. 65; Antoine: CIc. Phil. II, 47. 
souligne l'honorabilité des clients qu'il défend dans les procès ${ }^{3}$, rappelle qu'il a conquis prestige et marques d'honneur ${ }^{4}$ ou s'interroge au début de la guerre civile sur le parti qu'il est honorable de suivre ${ }^{5}$. La thématique de l'honneur se retrouve également chez les autres auteurs de l'époque républicaine, par exemple chez Plaute, qui met en scène la disgrâce de jeunes gens qui fréquentent les courtisanes, ou chez Salluste, qui fustige le déshonneur de son époque et rappelle la dignité des ancêtres ${ }^{7}$. La notion d'honneur semble donc présente dans des textes nombreux et de nature extrêmement diverse. Mais cette omniprésence, qui paraît indiquer une importance particulière de l'honneur dans la culture romaine, n'est-elle pas plutôt le signe du caractère flou, et donc peu adapté, de cette notion? Des pans entiers de la morale et de la vie sociale romaines semblent en effet pouvoir être ramenés sous le concept d'honneur, sans que cela n'éclaire particulièrement leur nature. Il nous faut donc sérieusement interroger la validité épistémologique de cette notion. Il se pose aux modernes une authentique "question d'honneur» car la notion d'honneur, appliquée au monde romain, est sujette à discussion et implique de résoudre des difficultés d'ordre méthodologique. Ces dernières pourront être perçues à travers l'évaluation de deux études de l'honneur à Rome, celle de C. Barton et celle de J. E. Lendon, qui constituent pratiquement, à notre connaissance, les seules monographies d'envergure consacrées à cet objet ${ }^{8}$.

Le premier problème posé par la notion d'honneur est un problème de définition. Il s'agit en effet d'un concept complexe, aux sens multiples ${ }^{9}$. Or les travaux de C. Barton et de J. E. Lendon ne s'attardent guère à éclaircir ce qu'ils entendent par "honour".

${ }^{3}$ Cic. Rab. Perd. 27; Flac. 100 ; Sest. 86.

${ }^{4}$ Cic. Mur. 17; Sest. 73.

${ }^{5}$ CIC. Att. VIII, 15, 2.

${ }^{6}$ Le déshonneur du jeune homme de comédie est un thème récurrent. Voir par exemple les réprimandes du pédagogue Lydus à Pistoclère (PL. Bac. 158-162).

${ }^{7}$ L'idée court dans le procmium du De coniuratione Catilinae.

${ }^{8}$ C. A. BARTON, Roman Honor: the Fire in the Bones, Berkeley, University of California Press, 2001; J. E. Lendon, Empire of Honour. The Art of Government in the Roman World, Oxford, Clarendon Press, 1997. Un article de ce dernier auteur, paru en 2011, n'a pas pu être consulté à la date où nous achevons cet ouvrage (J. E. LENDON, "Roman Honor» in Peachin, M., The Oxford Handbook of Social Relations in the Roman World, Oxford, Oxford University Press, 2011, p. 377-403). L'étude de F. STIPPEL, Ehre und Ehrerziehung in der Antike, Würzburg, K. Triltsch, 1939, est extrêmement brève et consacrée presque exclusivement à l'Antiquité grecque; on n'y trouve que quelques pages sur les hommages dans le monde romain (p. 44-47). Les travaux sur des marques d'honneur particulières (triomphes, statues, décorations militaires, etc.), sur des notions d'envergure plus limitée, comme la pudeur ou l'infamie, ou sur la morale romaine et le mos maiorum en général, sont en revanche très nombreux et seront indiqués au fur et à mesure de notre travail.

${ }^{9}$ C'est ce que mettent bien en avant différentes contributions de l'ouvrage de H. DrévILLON et D. VentuRino (éds.), Vivre et penser l'honneur à l'époque moderne, Rennes, P.U.R., 2011. 
C. Barton l'envisage comme un faisceau d' "émotions ${ }^{10}$ mais sa définition initiale est loin d'être stable: l'honneur ne possède en réalité pas de contenu précis dans son étude car il épouse la forme de chacune des notions romaines rencontrées, qu'il s'agisse de uirtus, gloria ou pudor. La définition de J. E. Lendon est plus fournie mais pas vraiment plus claire puisque l'auteur parle du "system of thought and emotion we call honour " ${ }^{11}$. Il semble ainsi l'envisager comme un ensemble organisé de représentations mentales et de sentiments. Cette approche très intellectualisée nous paraît trop réductrice pour rendre compte d'une notion au spectre beaucoup plus large. L'aspect social et politique de l'honneur, sensible dans le texte de Cicéron cité précédemment, ainsi que son articulation à un code de comportement sont totalement occultés. Les deux études consacrées à l'honneur à Rome nous semblent donc n'exploiter qu'un aspect de la notion, sa dimension psychologique, c'est-à-dire l'intuition de règles de conduite organisées, le sens de l'honneur. Et encore cet aspect est-il insuffisamment défini. C'est pourquoi il nous paraît utile, pour mesurer la pertinence d'une application de la notion d'honneur à l'Antiquité romaine, de nous tourner vers les sciences sociales, qui ont formalisé de manière plus satisfaisante cet objet. Dans les années 1960 à 1990, plusieurs sociologues ont travaillé sur le phénomène de l'honneur et tout un courant de l'anthropologie anglo-saxonne a étudié cette notion dans les cultures du bassin méditerranéen ${ }^{12}$. Deux de ces travaux ont proposé des définitions éclairantes du phénomène abordé. F. Stewart, dans ses travaux sur l'honneur des Bédouins du Sinaï, a théorisé cette notion selon une tripartition ${ }^{13}$. Il distingue l'honneur externe, trait social, qui est la bonne réputation et le prestige

${ }^{10}$ Barton, Roman Honor, p. 9.

${ }^{11}$ Lendon, Empire of Honour, p. 1.

12 L'approche sociologique est représentée, notamment, par G. C. Homans, Social Behaviour: its Elementary Forms, Londres, Routledge, 1961; W. J. Goode, The Celebration of Heroes. Prestige as a Social Control System, Berkeley, University of California Press, 1978 et P. Bourdieu, Trois études d'ethnologie kabyle, Paris, Seuil, 2000. Voir l'analyse rétrospective de ces études par E. НАтсH, "Theories of Social Honor», American Anthropologist, 91, 1989, p. 341-353. L'approche anthropologique a porté sur des sociétés grecque (J. K. CAMPBell, Honour, Family and Patronage, Oxford, Clarendon Press, 1964), andalouse (J. A. PITT-RIVERs, Anthropologie de l'honneur: la mésaventure de Sichem, Paris, Le Sycomore, 1983), galicienne (C. L. Tolosana, "The Ever-Changing Faces of Honour", in Albera, D., Blok, A. et Bromberger, C. (éds.), L'Anthropologie de la Méditerranée, Paris, Maisonneuve et Larose, 2001, p. 133-147), berbère (R. JAmous, Honneur et baraka. Les structures sociales traditionnelles dans le Rif, Paris, Maison des Sciences de l'Homme, 1981) et bédouine (L. ABu-Lughod, Veiled Sentiments: Honor and Poetry in a Bedouin Society, Berkeley, University of California Press, 1986 ; F. H. STEWART, Honor, Chicago, University of Chicago Press, 1994). Plusieurs autres contributions sont rassemblées dans l'ouvrage de J. G. Peristiany (éd.), Honour and Shame: the Values of Mediterranean Society, Londres, Weidenfeld \& Nicolson, 1966.

${ }^{13}$ STEWART, Honor, p. 13-30. 
d'un individu, de l'honneur interne, qualité morale, qui est l'intégrité et le respect de règles morales. À ces deux facettes, objectives, s'en ajoute une troisième, l'honneur subjectif, qui est le savoir qu'a un individu de sa propre valeur et le sentiment que cette valeur lui donne droit au respect de son entourage. Une seconde approche théorique de l'honneur est proposée par J. Pitt-Rivers. Elle recoupe en partie la précédente mais a la singularité de prendre davantage en compte les marques d'honneur matérielles et de relier les différents aspects de l'honneur:

"L'honneur est la valeur qu'une personne possède à ses propres yeux mais c'est aussi ce qu'elle vaut au regard de ceux qui constituent sa société. C'est le prix auquel elle s'estime, l'orgueil auquel elle prétend, en même temps que la confirmation de cette revendication par la reconnaissance sociale de son excellence et de son droit à la fierté. » ${ }^{14}$

Nous retrouvons ici ce que F. Stewart appelle l'honneur subjectif ainsi que l'honneur externe, le second apparaissant comme la confirmation du premier. Il est aussi question de l'honneur interne, l'honorabilité, qui est la source de l'honneur externe et des marques d'honneur:

«Le sentiment que vous avez de l'honneur vous inspire une conduite honorable qui, reconnue comme telle, vous établit une réputation finalement consacrée par l'octroi d'honneurs. L'honneur ressenti devient l'honneur qu'on brigue et cet honneur brigué vous revient sous forme d'honneurs rendus. $»^{15}$

Ces deux approches anthropologiques nous paraissent être parvenues à formaliser de manière claire et systématique la notion d'honneur, qui articule trait social, qualité morale et disposition psychologique.

Cependant, le fait que l'on puisse donner de l'honneur une définition raisonnée ne signifie pas qu'il soit pertinent d'appliquer ce concept à l'Antiquité romaine. L'honneur pose en effet trois autres difficultés qui rendent son usage problématique. La première réside dans le caractère étranger de cette notion à la culture romaine. S'il est possible de parvenir à une compréhension relativement claire de ce qu'est l'honneur, cette définition est valable pour les modernes qui la formulent et n'a pas a priori de sens pour une culture éloignée dans le temps et l'espace. Parler de "l'honneur des Romains », c'est risquer de projeter des représentations modernes sur l'Antiquité et de tomber dans l'anachronisme et l'ethnocentrisme. On risque ainsi de déformer les réalités antiques en recourant à des présupposés et des schémas de fonctionnement qui leur sont étrangers. Cette altération de l'objet

\footnotetext{
${ }^{14}$ Pitt-Rivers, Anthropologie de l'honneur, p. 18.

${ }^{15}$ Ibid., p. 19.
} 
analysé est illustrée par certains aspects de l'étude de C. Barton. En faisant de l'honneur un élément-clef de l'intériorité des Romains et un signe de la richesse de leur vie émotionnelle, elle recourt à une conception de l'honneur comme disposition psychologique intérieure, ce qui l'amène à projeter sur la réalité antique des éléments qui n'en sont pas issus, par exemple quand elle avance que la confession des fautes est un point central de l'honneur, avant même le développement de cette pratique par le christianisme ${ }^{16}$. L'usage de concepts extérieurs à une culture pour expliquer cette dernière n'est pas en soi illégitime mais il devient hautement problématique lorsqu'il touche l'objet principal de l'étude et qu'il reste, comme chez C. Barton, totalement implicite, sans jamais être envisagé comme une hypothèse de travail ${ }^{17}$.

Un deuxième écueil est celui de la circularité. Il est possible, comme on l'a vu, d'arriver à une définition assez fine de l'honneur; mais prendre pour objet d'étude un concept théorique préalablement défini a tendance à mener celui qui l'utilise à une étude tautologique si des précautions méthodologiques ne sont pas prises. En effet, le savant qui s'intéresse à l'honneur dans la culture romaine à partir d'une définition extérieure cherchera à retrouver dans cette culture des éléments de cette définition. Il est possible d'utiliser des concepts complexes prédéfinis pour l'étude d'une culture passée, mais il faut les employer comme outils annexes et non comme objets centraux de l'investigation, sans quoi on occulte toute l'originalité du phénomène étudié sous des notions préfabriquées et donc inadaptées. Plusieurs pratiques sociales et normes morales romaines peuvent effectivement être rapprochées de l'honneur, mais en faisant de cet objet le cœur de l'enquête, on ne fait que rassembler des objets disparates sous un concept artificiel. L'inconvénient de cette démarche apparaît quand C. Barton déclare que la uirtus est le mot latin le plus proche de la

${ }^{16}$ Voir Barton, Roman Honor, p. 1-2 et l'ensemble du chapitre 5, "The spirit

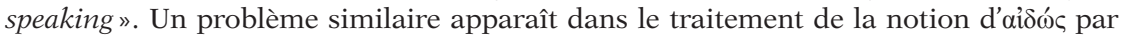
D. L. Cairns. Ce dernier commence par poser une définition moderne de la honte, nourrie des apports de l'anthropologie et de la psychanalyse, et cherche ensuite à retrouver cette dernière dans les textes qu'il parcourt au lieu de tâcher de dégager progressivement les singularités de l'aỉóç grec (D. L. CAIRns, Aidôs. The Psychology and Ethics of Honour and Shame in Ancient Greek Literature, Oxford, Clarendon Press, 1993, p. 1-47).

${ }^{17}$ Certains des anthropologues ayant travaillé sur l'honneur ont eux-mêmes pris conscience de la difficulté méthodologique posée par ce concept: M. Herzfeld a souligné que l'usage de notions comme "honour» ou "shame» par les savants anglo-saxons pour identifier des normes et des pratiques étrangères très différentes de la culture des observateurs a occasionné l'instillation d'éléments absents de la culture observée. Voir M. HeRzFELD, "Honour and Shame: Some Problems in the Comparative Analysis of Moral Systems ", Man, 15, 1980, p. 339-351: "it is however reduced and obscured by the apriorism, circularity and ethnocentrism inherent in the use of such inefficient Englishlanguage glosses for the purpose of cross-cultural analysis» (p. 339). 
notion d'honneur ${ }^{18}$; en raisonnant ainsi, elle recherche dans la culture antique des éléments qui s’adaptent à sa définition préconçue de l'honneur et les agglomère à cette dernière, sans souligner leur originalité.

Une dernière difficulté posée par l'usage de la notion d'honneur à propos de l'Antiquité romaine réside dans la simplification outrancière qu'elle donne de la société et de la culture antiques. Parler d'honneur, c'est en effet utiliser un concept unique alors qu'il n'y a pas à Rome d'unité, ni dans la pratique ni dans la pensée, des objets recouverts par ce concept. Recourir à «l'honneur» revient à écraser sous une dénomination faussement élémentaire une très riche constellation de notions composée de dignitas, pudor, uirtus, honos, auctoritas, entre autres. La notion d'honneur unifie des pratiques, des vertus, des idées politiques et des concepts éthiques très variés et très nuancés qui, s'ils ont des points communs, ne peuvent être ramenés à une notion unique. Dans son analyse de l'honneur, J. E. Lendon réunit ainsi sous le concept d'honneur des réalités aussi diverses que le conflit de dignitas entre Pompée et César lors de la guerre civile, la gloria paradoxale des acteurs et l'auctoritas d'Auguste ${ }^{19}$. De tels rapprochements conduisent à une simplification excessive et à l'élaboration d'un concept artificiel ${ }^{20}$.

Pour ces différentes raisons, la notion d'honneur ne nous semble pas pouvoir constituer le point de départ de notre étude. Cela ne signifie pas que nous renoncerons totalement à l'utiliser. Ce concept, pourvu qu'il soit convenablement défini, revêt en effet un réel intérêt mais doit être utilisé avec prudence. Nous le placerons à l'horizon de notre travail et non en son centre: nous le garderons en vue, à titre de modèle de réflexion, d'outil comparatif ainsi que de possible point d'arrivée de notre étude.

Les notions d'honos, honestum et honestas

\section{Intérêt méthodologique}

Pour réaliser une approche pertinente du prestige social et de la dignité morale, sur le plan pratique et théorique, nous avons choisi de recourir à une notion proprement romaine. Si l'on revient au texte de Cicéron que nous citions au début de cette introduction, on

${ }^{18}$ C. A. Barton, «Savage Miracles: the Redemption of Lost Honor in Roman Society and the Sacrament of the Gladiator and the Martyr ", Representations, 45, 1994, p. 41-71, à la p. 63.

${ }^{19}$ LENDOn, Empire of Honour, p. 35, 99-100 et 129.

${ }^{20}$ Ce problème est aussi apparu dans les études anthropologiques de l'honneur méditerranéen où la notion d'honneur a tendu à recouvrir de façon abusive celles de chasteté, noblesse, courage et vengeance. Voir HerzFeld, «Honour and Shame», p. 343 $s q q$. 
remarque en effet la présence de deux termes qui paraissent proches de l' "honneur»: Cicéron évoque au début du passage les honores qu'il a obtenus, ces marques de distinction, notamment politiques, qui le contraignaient à adopter une conduite digne. Puis il souligne que la philosophie est devenue une activité honestissima, très honorable, à cause des bouleversements de la cité et de sa retraite hors de la vie publique. Cicéron recourt ainsi au terme honos et à l'adjectif dérivé honestus pour résoudre la question d'honneur à laquelle il fait face: ce sont les honores qui imposent une conduite honesta. Ce sont ces deux notions, honos et honestum, ainsi que celle d'honestas, qui n'apparaît pas dans le texte mais est étroitement liée aux deux précédentes, que nous avons choisi de placer au centre de notre étude.

Elles ont, nous semble-t-il, l'intérêt de ne pas tomber sous le coup des difficultés épistémologiques précédemment identifiées et de pouvoir résoudre la «question d'honneur» qui se pose aux modernes. L'honos n'est pas une notion étrangère à la culture romaine; elle se trouve au contraire solidement ancrée en son sein, étant présente dès les débuts de la littérature latine. Nous risquons donc moins, en nous fondant sur cet objet indigène, de rester totalement dépendants d'un point de vue moderne et de déformer les réalités romaines, puisque nous partirons de l'intérieur de la culture observée.

Faire de l'honos et de ses dérivés notre objet principal permet aussi de ne pas nous fonder sur une définition préconçue et trop élaborée puisque nous ne connaissons pas ces notions de manière intime; cette approche nous offre donc la possibilité de prêter une plus grande attention à leur singularité et d'élucider progressivement, au contact des textes, la complexité de leur nature.

Enfin, ces notions donnent à notre enquête un objet plus restreint que «l'honneur» mais aussi plus précis et dont l'unité n'est pas factice. C'est donc à l'honos, l'honestum et l'honestas que nous nous intéresserons essentiellement. Par commodité, cependant, nous emploierons parfois le terme d'«honneur» pour désigner les trois notions situées au centre de notre travail.

\section{Enjeux de l'étude}

Le faisceau de notions que nous avons pris comme objet central présente un intérêt majeur pour la compréhension de la culture romaine. L'honos et l'honestum sont en effet des termes très fréquents dans les textes anciens: à l'époque républicaine, par exemple, à la notable exception de Catulle, aucun auteur majeur ne les ignore l'un et l'autre. Sur le plan des pratiques, des phénomènes comme l'octroi d'honores par le général à ses soldats ou par une cité à ses bienfaiteurs, la suprématie de l'aristocratie par l'entremise de son honos, la progression dans le cursus honorum, l'honestas des ancêtres ou à l'inverse l'infamie des acteurs, prostituées et gladiateurs constituent des caractéristiques essentielles de la cité romaine. 
Une étude de l'honos, de l'honestum et de l'honestas ne permet pas seulement d'approcher un aspect important de la culture romaine. Elle donne aussi l'occasion de saisir, par un biais extrêmement riche, la romanité dans sa singularité et sa complexité. L'enjeu de notre enquête va donc au-delà de la compréhension des notions qui en sont l'objet principal. Ces dernières se situent en effet au carrefour du social, du politique, de l'éthique et du religieux et permettent d'obtenir, par une sorte de raccourci, une vue en coupe de la culture romaine. L'étude de l'honos nous permettra d'abord d'enrichir notre vision des rouages de la société romaine. L'analyse de l'octroi des marques d'honneur éclairera la complexité des relations entre les individus, leur dynamique et leurs enjeux. Elle nous permettra de pénétrer dans le réseau complexe du don, du bienfait et de la reconnaissance et de voir comment se produit à Rome la cohésion du corps social.

L'enjeu de cette étude est aussi politique. Il s'agira de voir, à travers l'étude de l'honos, comment le pouvoir s'exerce dans d'autres espaces que les institutions et par d'autres moyens que la coercition. Nous pourrons aussi approcher au plus près de la conception que se font les Romains du service de l'État à travers l'examen de leur représentation des charges du cursus honorum. Nous verrons aussi comment les groupes dominants utilisent les grandes notions sociopolitiques comme armes idéologiques ou instruments d'affirmation identitaire.

Notre enquête nous donnera aussi l'occasion d'apprécier l'évolution de la morale romaine. L'étude des motifs pour lesquels l'honos est décerné ou perdu et des jugements sur ce qui est honorable ou déshonorant permet de prendre la mesure des normes morales qui structurent la société et de voir leur changement au cours du temps. L'honos est, en outre, une valeur essentielle du mos maiorum, cet ensemble de règles de conduite et de modèles de comportement ancestraux; l'évolution de son importance au fil du temps permettra donc d'observer les modulations du jugement porté sur la morale romaine traditionnelle. L'approche des processus d'hommage et de prestige montrera aussi comment une société ancienne parvient à se réguler elle-même.

Enfin, notre investigation autorisera une étude des modes de pensée romains. Ils seront révélés, d'une part, par les pratiques de l'honneur: les usages, les rites, les pratiques sont les symptômes de certaines conceptions du monde. Ils seront abordés, d'autre part, par la réflexion théorique et savante sur l'honneur. Nous pourrons notamment mesurer, à travers l'évolution de l'approche intellectuelle de l'honestum, devenu au I ${ }^{\mathrm{er}}$ siècle un concept de la philosophie morale, comment une pensée abstraite et spéculative s'est progressivement développée à Rome. 


\section{État de la recherche}

Malgré leur importance, les notions d'honos, d'honestum et d'honestas ont été presque totalement délaissées par la science moderne. D'importants travaux ont été consacrés, depuis le début du $\mathrm{XX}^{\mathrm{e}}$ siècle, à des notions de la culture romaine, notamment par la philologie allemande: les recherches sur les Wertbegriffe sont anciennes dans le monde germanique ${ }^{21}$ et se sont poursuivies dans la seconde moitié du $\mathrm{XX}^{\mathrm{e}}$ siècle, sous l'égide notamment de $\mathrm{H}$. Drexler, H. Opperman puis V. Pöschl ${ }^{22}$. Ils continuent encore aujourd'hui ${ }^{23}$. Cette approche philologique des notions politiques, sociales et morales de Rome a aussi été adoptée par des savants d'autres pays, comme J. Hellegouarc'h, G. Dumézil, É. Benveniste, D. C. Earl et L. R. Lind, pour ne citer que ceux qui se sont intéressés à des ensembles assez larges de notions ${ }^{24}$; plusieurs autres contributions, portant sur un terme précis, ont également été apportées ${ }^{25}$. Cependant, si certaines notions, telles que fides, humanitas, auctoritas ou uirtus ont fait l'objet d'investigations très approfondies, honos et ses dérivés ont été beaucoup moins étudiés. Deux dissertations allemandes leur sont consacrées, celle d'I. Stutz et celle de F. Klose ${ }^{26}$, mais, si elles dessinent

${ }^{21}$ Voir le bilan rétrospectif établi par G. Thоме, Zentrale Wertvorstellungen der Römer, Bamberg, C. C. Buchner, 2000, p. 7 sqq. Sur l'histoire de l'étude des notions en Allemagne et sur son rapport avec les événements contemporains, voir P. L. SchmidT, «Zwischen Werttheorie, Begriffsgeschichte und Römertum. Zur Politisierung eines wissenschaftlichen Paradigmas », in Haltenhoff, A., Heil, A. et Mutschler, F.-H. (éds.), Römische Werte als Gegenstand der Altertumswissenschaft, Munich, K. G. Saur, 2005, p. 3-21 ainsi que S. ReBenich, «Römische Wertbegriffe: Wissenschaftsgeschichtliche Anmerkungen aus althistorischer Sicht», in Haltenhoff, A., Heil, A. et Mutschler, F.-H. (éds.), Römische Werte als Gegenstand der Altertumswissenschaft, Munich, K. G. Saur, 2005, p. 23-46.

22 H. Oppermann (éd.), Römische Wertbegriffe, Darmstadt, Wissenschaftliche Buchgesellschaft, 1967; V. Pöschl, "Politische Wertbegriffe in Rom», A\&A, 26, 1980, p. 1-17; H. DreXLER, Politische Grundbegriffe der Römer, Darmstadt, Wissenschaftliche Buchgesellschaft, 1988.

${ }_{23}$ Thome, Zentrale Wertvorstellungen der Römer; M. Braun, A. Haltenhoff et F. -H. Mutschler (éds.), Moribus antiquis res stat Romana. Römische Werte und römische Literatur im 3. und 2. Jh. v. Chr., Munich, K. G. Saur, 2000.

${ }^{24}$ J. Hellegouarc' H, Le Vocabulaire latin des relations et des partis politiques sous la République, Paris, Les Belles Lettres, 1963 ; G. DumézIL, Idées romaines, Paris, Gallimard, 1969; É. Benveniste, Le Vocabulaire des institutions indo-européennes, Paris, Minuit, 1969 ; D. C. EARL, The Moral and Political Tradition of Rome, Londres, Thames \& Hudson, 1967; L. R. Lind, "The Tradition of Roman Moral Conservatism», in Deroux, C. (éd.), Studies in Latin Literature and Roman History 1, Bruxelles, Latomus, 1979, p. 7-58.

${ }^{25}$ Il serait trop long de toutes les citer ici. Nous nous permettons de renvoyer sur ce point à la suite de notre développement, où plusieurs d'entre elles apparaîtront, ainsi qu'à notre bibliographie.

${ }^{26}$ I. Stutz, Honos. De vocabuli significatione Romana, Diss., Berlin, 1924 ; F. KLose, Die Bedeutung von honos und honestus, Diss., Breslau, 1933. 
des perspectives intéressantes, elles passent trop rapidement sur les problèmes posés et présentent un manque de systématicité. Outre ces monographies, un article d'H. Drexler ${ }^{27}$ trace à grands traits les sens d'honos, sans étudier honestus. Il faut aussi signaler le développement rapide mais stimulant que consacre J. Hellegouarc'h à honos dans son livre sur le vocabulaire politique républicain, un article de S. Gori qui aborde honos et munus chez Pline le Jeune et quelques remarques d'A. Espigares Pinilla ${ }^{28}$. Ces différentes études ont toutes leur intérêt mais demandent à être complétées et approfondies, d'autant qu'elles n'abordent les notions que d'un point de vue philologique, sans s'interroger sur les pratiques et les théories de l'honneur. Seul un article de Ph. Moreau sur l'usage de l'expression honoris gratia et un court passage de l'ouvrage de K.-J. Hölkeskamp consacré à la noblesse envisagent l'honos sous ces aspects, mais ils restent très partiels ${ }^{29}$. Il faut noter, enfin, l'ouvrage que $\mathrm{M}$. S. Milhous a consacré à l'iconographie du dieu Honos; il propose un important catalogue d'images mais reste, comme il est normal, limité à l'étude des représentations de la divinité et explore peu les autres aspects de la notion ${ }^{30}$.

\section{Points problématiques et objectifs}

Un premier examen des notions d'honos, d'honestum et d'honestas fait apparaître un certain nombre de problèmes fondamentaux dont le traitement pourra servir de fil directeur à notre enquête. Ces notions semblent, à première vue, malléables et polymorphes. Pour prendre l'exemple d'honos, le terme est employé dans des domaines très différents: il y a un honos privé, celui que l'on fait à l'hôte que l'on reçoit, un honos public, celui dont on jouit dans la cité auprès de ses concitoyens, un honos politique, la charge publique du magistrat, ou encore un honos sacré, celui rendu aux dieux ou aux défunts. Cette plasticité de la notion est aussi perceptible dans la variété des contextes où elle apparaît, puisqu'on la rencontre dans le monde mythique de la tragédie, sur la scène comique, dans les discours politiques, les traités

${ }^{27}$ H. Drexler, «Honos », in Oppermann, H. (éd.), Römische Wertbegriffe, Darmstadt, Wissenschaftliche Buchgesellschaft, 1967, p. 446-467.

${ }^{28}$ Hellegouarc'H, Vocabulaire, p. 383-388; S. Gori, "Le nozioni di honos e munus in Plinio il Giovane », in PANI, M. (éd.), Epigrafia e territorio, Bari, Edipuglia, 1994, vol. 3, p. 353-373; A. EsPigares Pinilla, «Claves para la historia de un cultismo: 'honesto'. 1, Antigüedad y Edad Media », $C F C(L), 28$ (2), 2008, p. 65-81.

${ }^{29} \mathrm{P}$. Moreau, "Quem honoris causa appello. L'usage public des noms de personne et ses règles à Rome ", in Champeaux, J. et Chassignet, M. (éds.), Aere perennius. Hommage à Hubert Zehnacker, Paris, P.U.P.S., 2006, p. 293-308; K.-J. HöLKESKAMP, Die Entstehung der Nobilität. Studien zur sozialen und politischen Geschichte der Römischen Republik im 4. Jhdt. v. Chr., Stuttgart, F. Steiner, 1987, p. 210-211.

${ }^{30}$ M. S. Milhous, Honos and Virtus in Roman Art, Ph. D., Boston University, Boston, 1992. 
rhétoriques et les textes philosophiques. Il nous faudra donc nous interroger sur sa cohérence: l'unité de la notion est-elle seulement lexicale? Sa diversité est-elle irréductible?

Il ne faut pas non plus perdre de vue que nos trois notions, loin d'être isolées, appartiennent à un ensemble très complexe de concepts et valeurs socio-politiques et morales. L'honos est proche de notions comme la gloria, la laus, le decus, la gratia, la dignitas, l'auctoritas. Quant à l'honestum et l'honestas, ils ne sont pas sans rapport avec la probitas, la uirtus ou le pudor, par exemple. On ne peut, sous peine de fausser notre représentation des modes de pensée romains, extraire l'honos de cette sphère notionnelle propre à la tradition romaine. Nous aurons donc à examiner ce qui fait la singularité de notre objet et la manière dont il s'articule à ces autres notions. Nous chercherons également à voir s'il existe des liens, autres que linguistiques, entre honos et les deux notions connexes, honestas et honestum.

Nous aurons aussi à apprécier le rapport qui a pu s'installer entre les pratiques concrètes de l'honneur et leur approche réflexive. Nos trois notions se prêtent en effet à une lecture confrontant la pratique et la théorie. Elles désignent, d'une part, des phénomènes sociaux, tels que l'hommage d'une personne à une autre, le prestige au sein de la collectivité ou la conduite conforme aux idéaux de la société. Mais ces notions sont aussi, d'autre part, mobilisées sur le plan théorique: les Romains utilisent l'honestum comme concept technique en rhétorique et en philosophie, s'interrogent sur la valeur réelle de l'honos et réfléchissent sur le contenu des normes de l'honestas. Il y a pour les Romains eux-mêmes une «question d'honneur». Ce sont des objets à la fois pratiques et théoriques et il nous sera donc loisible de confronter leurs deux facettes. Le phénomène, parce qu'il est à la fois une conduite matérielle et un objet construit par des discours savants, s'est-il scindé en deux objets différents? Comment la pensée de l'honneur a-t-elle changé la pratique de l'honos et de l'honestum?

Les notions qui sont au centre de notre étude évoluent dans le temps. Nous aurons donc également à examiner leur changement historique, dans leur usage et dans l'approche réflexive qu'en font les Romains. Pour ce faire, une attention particulière devra être dévolue à deux facteurs. On s'attachera, d'une part, aux changements des institutions et de la société, dont les bouleversements ont des répercussions sur les divers aspects de la vie romaine. On observera, d'autre part, le rôle joué par l'influence de la culture hellénique, qui se fait de plus en plus forte à l'époque républicaine. La notion d'honestum devra faire l'objet d'un examen particulièrement attentif car elle a été, tout au long des deux derniers siècles de la République, élaborée de manière conceptuelle, au point de devenir un élément central de l'axiologie et de la philosophie morale, notamment chez Cicéron. Enrichi par un

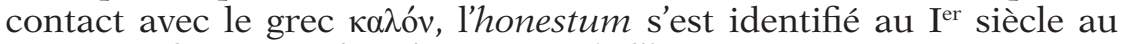
souverain bien moral et s'est écarté de l'honneur. 
Enfin, nous ne pouvons occulter la proximité entre les notions romaines étudiées et le concept anthropologique d' "honneur». Ce dernier ne peut constituer, comme nous l'avons vu, le point de départ de notre recherche, mais nous aurons à interroger le rapport qu'entretiennent avec lui l'honos et l'honestum.

\section{Méthode adoptée}

\section{Trois approches complémentaires}

Pour aborder les différents aspects de l'honos, de l'honestum et de l'honestas, nous associerons trois approches complémentaires sur le plan méthodologique. Les travaux consacrés à l'étude des notions romaines, signalés plus haut ${ }^{31}$, ne les envisagent, le plus souvent, que comme des mots dont il faut éclairer le sens; ils se livrent donc à une analyse sémantique de leurs occurrences dans les textes. Une telle approche, si elle est, comme nous allons le voir, indispensable, nous paraît cependant réductrice. Notre objet est en effet constitué par des notions qu'il ne faut pas limiter à des unités lexicales. La notion est un élément riche et complexe: au-delà du mot, elle est aussi un vécu, c'està-dire un ensemble de conduites concrètes et d'objets pratiques, ainsi qu'une idée, une réalité intellectuelle susceptible de divers usages plus ou moins théoriques. C'est donc à ces trois niveaux qu'il faut l'aborder.

Le premier niveau d'approche est de nature sémantique. Pour éviter deux écueils que nous avons identifiés, l'application d'une définition extérieure et la déformation anhistorique et ethnocentrique, il est nécessaire de prêter attention à la signification des mots étudiés par une analyse sémasiologique, qui part des mots pour aller vers les idées ${ }^{32}$.

Cette approche sémantique gagnera à être complétée par une étude de l'honos comme pratique. Nous observerons donc les comportements, les usages et les rites concernés par ces notions, ainsi que leurs significations et leurs fonctions ${ }^{33}$. L'objectif ne sera pas de donner une

${ }^{31}$ Voir supra p. 11.

32 Dans son étude de la honte à Rome, R. A. KASTER, Emotion, Restraint and Community in Ancient Rome, Oxford, Oxford University Press, 2005, a le souci de partir de la notion romaine de pudor mais n'élucide pas préalablement les sens du mot. Son analyse se révèle par conséquent flottante car il passe régulièrement de la «honte » au "sens de l'honneur» et à la «retenue» que désigne pudor sans jamais distinguer ces différents aspects de la notion. Nous tâcherons de nous souvenir de l'avertissement sensé formulé par G. Dumézil: "Avant d'engager un mot latin au service de quelque théorie que ce soit, il faut l'analyser dans ses contextes, avec ses résonances spécifiques, et sans idée préconçue» (DumézIL, Idées romaines, p. 152).

${ }^{33}$ Notre méthode sera proche de celle suivie par M. McDonnell, Roman Manliness. Virtus and the Roman Republic, Cambridge, Cambridge University Press, 2006, qui unit à l'étude des sens du mot uirtus une investigation sur ses formes concrètes et ses usages pratiques. Voir aussi la manière dont R. Langlands, Sexual morality in Ancient Rome, 
description exhaustive des pratiques de l'hommage et de l'honorabilité mais d'insister sur leur rôle et leur sens à l'échelle individuelle et collective. Le regard que nous porterons sur ces objets sera de type anthropologique car nous aurons à cœur de placer au centre de l'étude l'homme romain et ses usages de l'honneur et d'étudier ces derniers de l'intérieur, sans employer, ici non plus, de définition préconçue. Nous ne nous interdirons pas, cependant, de recourir à des concepts et des modèles de réflexion empruntés aux sciences sociales qui nous permettront d'aller au-delà d'une simple observation de l'honneur et de nous acheminer vers son interprétation.

Rome n'est pas une société figée et close sur elle-même. La pratique de l'honos et de l'honestum évolue et connaît des dysfonctionnements; elle est aussi et surtout constamment interrogée, critiquée, contestée. Il y a à Rome une réflexion de plus en plus poussée sur les notions qui nous intéressent et il est donc nécessaire d'envisager une troisième approche de l'honneur: l'honos et ses dérivés seront analysés comme données intellectuelles et représentations mentales. L'idée d'honneur peut prendre trois formes qu'il nous faudra toutes envisager. Elle peut être concept, dans le domaine de la philosophie et de la rhétorique, et prendre donc place dans la pensée abstraite et savante. Elle peut être valeur, dans la réflexion morale et la pensée politique. Nous aurons donc à l'aborder d'un point de vue axiologique et idéologique chez des auteurs qui l'emploient à d'autres fins que la constitution d'un savoir. Les idées d'honos, d'honestas et d'honestum peuvent enfin être images, quand elles prennent une place importante dans le travail spécifiquement littéraire des auteurs.

\section{Période retenue}

Nous avons choisi de limiter notre investigation à l'époque de la République, et plus précisément à la période qui va de la fin du $\mathrm{III}^{\mathrm{e}}$ siècle, moment de l'apparition dans les textes latins des notions étudiées, à la disparition de cette République. Cette dernière peut être placée à différentes dates; nous la situons à la fin des années 40 avant notre ère. La période est en effet marquée par deux événements qui en font un tournant historique. En 43, Octave, Antoine et Lépide forment le triumvirat, magistrature qui consacre une nouvelle forme de pouvoir autocratique et personnel, situé en dehors de l'ancien jeu des institutions républicaines ${ }^{34}$. En 42, la bataille de Philippes

Cambridge, Cambridge University Press, 2006, analyse la pudicitia dans le domaine du lexique et dans celui de la morale sexuelle.

${ }^{34}$ Sur l'importance du triumvirat comme césure historique, voir J.-M. DAVID, $L a$ République romaine de la deuxième guerre punique à la bataille d'Actium. 218-31, Paris, Seuil, 2000, p. 252 et F. Hinard (éd.), Histoire romaine. Tome I. Des origines à Auguste, Paris, Fayard, 2000, p. 842. 
voit l'écrasement des dernières forces républicaines, conduites par Brutus et Cassius, et signe la mort de la République. L'usage d'un terme chronologique aussi précis peut paraître peu approprié pour l'étude de notions, éléments difficiles à faire entrer dans un cadre strictement délimité. Il est cependant nécessaire, dans la mesure où nous étudierons essentiellement des textes, de placer une césure assez précise qui permette de sélectionner un corpus bien déterminé d'auteurs. C'est aussi en raison de l'usage important que nous ferons des sources écrites que nous concentrerons notre propos sur la période où Rome voit la naissance et le développement de sa littérature. La période retenue nous conduira donc des œuvres de Plaute et d'Ennius, premiers textes où apparaissent les termes d'honos et d'honestum, aux derniers discours et traités de Cicéron, mort en 43 , aux textes du corpus césarien, dont la publication s'achève vers 42 , et à l'œuvre de Varron et de Salluste ${ }^{35}$. Nous laisserons de côté les textes de Cornelius Nepos, qui sont plus tardifs, ainsi que les Bucoliques de Virgile qui, si elles ont été publiées à la fin des années 40 , sont d'une inspiration et d'un genre très différents de ceux de nos autres textes et appartiennent déjà, par leur contenu idéologique et intellectuel, à une autre époque. Ce sont donc les deux derniers siècles de la République qui constitueront notre cadre de travail. Nous utiliserons cependant parfois, de manière ponctuelle, des données relatives à la période précédente ou à l'époque impériale.

La période retenue nous paraît constituer un champ d'observation à la fois cohérent et intéressant. Sur le plan historique, les deux derniers siècles de la République représentent une période de profonde mutation, avec la conquête de nouveaux territoires et d'importants changements sociaux et économiques. C'est aussi l'époque qui voit l'apogée de la res publica, de ses institutions et de son aristocratie, puis leur crise et leur destruction avec la montée des grands imperatores et les déchirements des guerres civiles. L'honos, comme mécanisme social et politique, est situé au cœur de ces bouleversements. Il s'agit aussi d'une période particulièrement riche sur le plan intellectuel, puisqu'elle voit la maturation de la littérature latine et des arts romains, l'essor de disciplines nouvelles, comme la rhétorique et la philosophie, et l'approfondissement des contacts avec la culture hellénique. Les notions que nous étudions ont profité de ces divers enrichissements. La période retenue est aussi caractérisée par l'évolution des mœurs des Romains: de nouvelles pratiques se développent, les règles de conduite se modifient et la crise générale de la cité au I ${ }^{\text {er }}$ siècle touche

\footnotetext{
${ }^{35}$ Par souci de cohérence, et pour ne pas scinder le corpus d'un seul et même auteur, nous inclurons dans notre ensemble de textes le De re rustica de Varron, publié en 37 et les Histoires de Salluste, parues entre 39 et 36. Sur les dates de publication de ces œuvres, voir les notices consacrées à chaque auteur par R. Herzog et P. L. Schmidt (éds.), Handbuch der lateinischen Literatur der Antike, Munich, C. H. Beck, 1989-.
} 
également le mos maiorum et ses principes. La fin de la République constitue donc un cadre privilégié pour l'étude de cette valeur et de cette norme morale qu'est l'honneur. L'étendue diachronique retenue est, enfin, suffisamment large pour nous permettre d'observer l'honos et l'honestum à leur naissance et d'en voir la maturation. Elle est aussi restreinte à cette durée d'environ deux cents ans pour ne pas donner à notre enquête des proportions démesurées.

\section{Usage des sources}

Notre enquête s'appuiera principalement sur des textes puisque son objet est d'étudier un ensemble de notions qui nous ont été transmises par l'écrit. Nous nous intéresserons donc aux différentes productions de l'époque républicaine, quel que soit le genre auxquelles elles appartiennent. Nous exploiterons aussi les inscriptions où apparaissent honos, honestum et honestas; elles sont peu nombreuses mais projettent sur ces notions un éclairage original. Nous recourrons aussi, de manière plus occasionnelle, à d'autres types de sources, archéologiques et numismatiques notamment. Elles seront surtout convoquées pour l'étude des formes prises par les marques d'honneurs et pour notre recherche sur le dieu Honos. L'étude de l'ensemble des statues, arcs et autres monuments honorifiques dépasserait les limites de notre travail et ne sera donc pas menée.

Les textes que nous utiliserons seront majoritairement issus de la période qui constitue le cadre de notre étude. Afin de ne pas accroître de façon exagérée le volume de cet ouvrage et d'éviter de projeter sur l'honneur de la République des éléments étrangers, nous limiterons l'utilisation des textes qui évoquent cette époque mais n'ont été rédigés qu'après qu'elle fut révolue. Pour l'étude des représentations intellectuelles de l'honos, nous n'utiliserons pas d'auteurs comme Tite Live, Valère Maxime ou Aulu Gelle. Bien que la période républicaine fasse, par exemple, l'objet du récit de Tite Live, l'historien est imprégné d'une idéologie, d'une morale et de représentations appartenant à une autre époque. Pour l'étude de l'honos et de l'honestum en tant que pratiques, l'usage de ces sources plus tardives est moins problématique car il s'agit d'approcher des éléments objectifs. Malgré tout, nous n'y recourrons que de manière prudente car une distorsion des pratiques et faits relatés est toujours possible ${ }^{36}$.

Les sources de langue grecque seront aussi sollicitées, mais dans un esprit différent. Les auteurs qui traitent de l'histoire romaine pourront être utilisés, de façon ponctuelle, pour éclairer certains

${ }^{36}$ Voir par exemple, à propos d'un honos, les aspects problématiques de la représentation livienne du triomphe républicain (T. ITGEnSHORST, Tota illa pompa. Der Triumph in der römischen Republik, Göttingen, Vandenhoeck \& Ruprecht, 2005, p. 148-158). 
faits ou comportements. Mais les notions romaines qui font l'objet de notre recherche n'apparaissent naturellement pas dans ces textes qui seront donc moins mobilisés que les œuvres latines. Chez les écrivains grecs qui, comme Polybe, rédigent leur œuvre à la période qui nous intéresse, nous aurions pu chercher à étudier une notion équivalente à l'honos, comme la $\tau$ luń qui en semble proche à première vue. Mais l'établissement d'une telle identité est discutable, comme nous le verrons, et pose des difficultés méthodologiques. L'étude des notions grecques de l'honneur constitue un problème à part entière qu'il ne s'agit pas de traiter ici. En revanche, ces sources pourront utilement être exploitées à un autre niveau. Elles nous serviront à établir une comparaison entre des notions grecques et romaines perçues comme

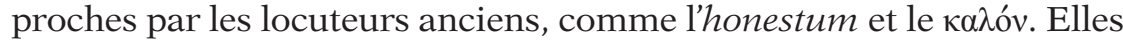
permettront aussi d'évaluer l'influence de la pensée grecque sur la réflexion romaine, dans des champs tels que l'évaluation du prix des marques d'honneur ou encore la définition de l'honorabilité. Il nous reste à préciser la manière dont nous solliciterons les textes latins. Le texte littéraire n'est pas un objet monolithique, mais peut revêtir plusieurs statuts. Il peut être envisagé comme document historique susceptible de nous renseigner sur une pratique ou un ensemble de realia. C'est aussi un texte littéraire, inscrit dans son époque, qui poursuit des fins esthétiques. Il révèle également une pensée, voire une idéologie. Il peut enfin receler un niveau discursif par lequel l'auteur juge et construit un objet au moment où il le représente à ses lecteurs. Nous solliciterons donc les textes de manière plurielle, du point de vue linguistique, historique, littéraire, philosophique et culturel. Une telle démarche pose cependant un problème dont il faut être conscient, à défaut de pouvoir totalement le résoudre. Si l'approche linguistique, littéraire et philosophique des textes antiques paraît assez légitime, il en va autrement de l'approche historique qui consiste à les exploiter comme témoignages sur des comportements disparus. Est-il justifié d'utiliser les sources textuelles comme indices sur les pratiques de l'honos? S'agissant de sources littéraires, leur rapport au réel est plus complexe qu'un rapport de pure reproduction. Les sources sont en outre l'expression de la subjectivité de leur auteur. Faut-il donc renoncer à les exploiter pour étudier les formes concrètes de l'honos? Cela ne nous semble pas devoir être le cas. Les œuvres historiques et les discours des orateurs, qui représentent une part importante de notre corpus, obéissent certes à des intentions qui peuvent les amener à présenter les faits sous un certain jour mais non à les déformer totalement. Les pratiques sociales décrites, les événements historiques mentionnés ne sont pas le fruit de l'imagination des auteurs. Ces derniers les interprètent - et il nous appartient d'apprécier cette interprétation - mais n'en bouleversent pas radicalement les contours. Même les œuvres de fiction comme les comédies ne sont pas de pures fantaisies. Il y a un horizon d'attente auquel le dramaturge est 
sensible, ainsi qu'un "horizon de compréhension ${ }^{37}$ qui impose des références connues et des points d'ancrage dans le réel. Le théâtre plautinien, par exemple, est un théâtre du jeu qui ne cherche pas à donner un reflet du réel, mais ce jeu doit rester compréhensible et entretient donc un rapport avec la réalité. Pour reprendre les propos tenus par Pseudolus dans la pièce du même nom, le poète compose un mendacium, une histoire qui n'a pas existé, mais a le souci de rendre ce «mensonge» ueri simile, vraisemblable ${ }^{38}$. Une approche des conduites sociales et morales de Rome à travers les textes littéraires ne nous paraît donc pas illégitime. Il faut cependant garder à l'esprit que notre étude de la pratique de l'honos et de l'honestum sera surtout une étude des représentations de cette pratique par les Romains. Nous n'accéderons pas de manière directe à l'honos romain mais plutôt à une image de l'honos. Nous appréhenderons la manière dont les anciens s'attendaient à ce que l'honneur fonctionne, au moins autant que son fonctionnement réel. C'est aussi en ce sens que notre étude concernera les mentalités et non seulement les comportements. Cependant, pour nous rapprocher de la pratique effective de l'honneur et tenter de pallier la vision subjective des textes, notre étude opérera un croisement des différentes sources et une observation panoramique des auteurs de la période, afin de dégager, par une vue d'ensemble, des constantes véridiques. C'est pourquoi nous aurons à associer, dans un premier temps, des textes d'époque et de nature différentes. Ce mélange n'est pas exempt d'inconvénients mais il nous permettra de déceler un noyau dur d'éléments concernant nos notions. Ce n'est qu'ensuite que nous reviendrons sur les variations propres à chaque auteur et à chaque genre littéraire.

\section{Plan adopté}

Conformément aux principes méthodologiques que nous avons posés, notre recherche est construite autour de trois approches successives. La première partie sera consacrée à l'étude du lexique de l'honneur: nous nous intéresserons aux mots honos, honestum et honestas et à leur sémantisme. Chacun de ces termes sera abordé dans un chapitre dédié (chapitres 1, 2 et 3).

Une fois établi le sens précis de chacune de ces notions, nous nous intéresserons, dans une deuxième partie, à la pratique de l'honneur.

${ }^{37}$ Nous empruntons la notion à Herzog et Schmidt (éds.), Handbuch der lateinischen Literatur der Antike, p. 21. Face aux problèmes posés par l'étude des realia chez Plaute, les auteurs notent: «er ist ein authentisches Zeugnis für den nicht zu unterschätzenden Verständnishorizont seines Publikums. »

${ }^{38}$ Pl. Pseud. 403. Voir aussi la Rhet. Her. I, 13: Argumentum est ficta res, quae tamen fieri potuit, uelut argumenta comoediarum; «la fiction est un récit inventé qui aurait pu cependant se produire, comme les sujets de comédie» (trad. Achard). 
Nous placerons au centre de l'enquête les fonctionnements de l'honos, de l'honestum et de l'honestas, et les usages qu'en font les Romains dans leur vie. Nous commencerons par en établir les structures essentielles, de nature symbolique et économique (chapitre 4). Nous étudierons ensuite les formes concrètes prises par l'honos et en proposerons une typologie et une interprétation d'ensemble (chapitre 5). Les deux chapitres suivants (6 et 7) envisageront les préalables et les conséquences de l'honneur: ils seront consacrés, respectivement, aux motifs et conditions d'accès à l'honneur, puis à ses effets positifs et négatifs. La mise en avant des avantages et contraintes apportés par l'honos nous amènera à nous interroger sur l'utilisation qui peut en être faite. Nous étudierons donc les fonctions de l'honneur, qui sont morales, sociales et politiques (chapitre 8 ). Nous resterons ensuite dans le domaine des usages de l'honneur, mais en déplaçant le regard vers la personne qui bénéficie de l'honos: nous envisagerons la manière dont le sujet s'y rapporte, pour le conquérir, le préserver ou le transmettre (chapitre 9). Nous placerons ensuite l'accent sur l'honestum et l'honestas: nous nous interrogerons sur leur place au sein de la morale romaine et sur la possibilité d'analyser leur fonctionnement comme celui d'un " code d'honneur». Nous aborderons pour cela les normes de l'honestas, leur diversité, leurs archétypes et leurs fondements sociaux (chapitre 10). Notre étude de la pratique de l'honneur s'achèvera avec une enquête sur le dieu Honos, sa nature, son culte et sa signification idéologique et politique (chapitre 11).

Notre troisième partie sera consacrée à la pensée de l'honneur chez les auteurs latins. Elle envisagera l'honos, l'honestum et l'honestas comme idées, images, valeurs et concepts chez les écrivains qui présentent un usage suffisamment significatif de ces notions ${ }^{39}$. Elle s'intéressera aux représentations mentales qu'en ont les auteurs et aux approches intellectuelles qu'ils en font. L'accent sera mis sur l'élaboration progressive de concepts et l'émergence d'une théorie sur ces objets. Pour ce faire, nous suivrons dans les chapitres 12 à 20 un fil chronologique, en traitant des écrivains des deux derniers siècles de la République, de Plaute à Salluste. Cette approche fera ressortir des lignes de force dans l'histoire intellectuelle de l'honos et de l'honestum et mettra en valeur les évolutions sur une période assez longue. Un auteur de premier plan, Cicéron, sera cependant absent de ce panorama. Nous aurons fréquemment à utiliser les textes de l'Arpinate comme sources dans la première puis la deuxième partie, mais l'analyse de la pensée cicéronienne de l'honneur ne sera pas menée dans la troisième partie de cet ouvrage: l'ampleur de l'œuvre

\footnotetext{
${ }^{39}$ Des auteurs utilisés pour notre étude sémantique et pratique ne réapparaîtront donc pas dans notre troisième partie. Ce sera le cas, par exemple, d'Ennius, Accius, Sisenna ou Publilius Syrus.
} 
oratoire et théorique de Cicéron, ainsi que la richesse et la complexité de ses analyses de l'honos et de l'honestum réclament en effet la convocation de nombreux textes et la présentation de développements assez amples, toutes choses qui excèderaient les limites de notre livre. L'étude de la pensée cicéronienne fait encore l'objet de notre travail de recherche actuel et donnera lieu ultérieurement à une publication sous forme de volume indépendant. 

PREMIÈRE PARTIE

LE LEXIQUE: LES MOTS ET LEUR SENS 



\section{INTRODUCTION}

Notre projet consistant à étudier les notions d'honos, d'honestum et d'honestas dans leur singularité romaine, il est nécessaire de commencer l'investigation par une analyse des mots eux-mêmes et de leur sens. L'approche sémantique permet en effet de replacer les notions dans un contexte qui leur est propre, celui de la langue latine, et d'éviter ainsi de projeter sur elles des caractéristiques étrangères. L'analyse sémantique est en outre une façon de donner une assise solide à la suite de notre étude: elle offre un aperçu des différents domaines dans lesquels s'exerce l'honos et une première approche des pratiques sociales et morales de l'honneur; des travaux comme ceux de G. Dumézil et É. Benveniste ont déjà montré comment la linguistique pouvait ouvrir la voie à l'analyse des realia ${ }^{1}$. Cette investigation sur le sens des mots ouvre aussi des perspectives sur l'histoire de l'idée d'honneur: la structure sémantique d'honos, la nature de son sens premier ou la façon dont les sens nouveaux surgissent sont des données à exploiter pour la compréhension des modes de pensée romains. La sémantique constitue un moyen privilégié pour accéder à la connaissance des concepts². Notre démarche sera donc sémasiologique: nous partons des mots pour nous acheminer vers les idées ${ }^{3}$.

\footnotetext{
${ }^{1}$ Dumézil a montré la fécondité d'une étude serrée du vocabulaire pour comprendre le fonctionnement d'une culture: l'étude philologique et sémantique de mots comme fides, maiestas, ius, avec les outils de la grammaire comparée, lui permet d'analyser de manière solide les pratiques romaines et ce qu'il nomme l' «idéologie» de Rome (voir par exemple les notions étudiées dans son ouvrage Idées romaines). Benveniste, même s'il déclare se contenter d'une étude de la signification des mots et laisser à d'autres leur désignation, remarque que «des vocables d'abord peu différenciés ont assumé progressivement des valeurs spécialisées et constituent ainsi des ensembles traduisant une évolution profonde des institutions, l'émergence d'activités ou de conceptions nouvelles» (Le Vocabulaire des institutions indo-européennes, vol. 1, p. 11).

${ }^{2}$ Sur le rapport de la sémantique et de l'histoire des idées, voir les remarques de Tноме, Zentrale Wertvorstellungen der Römer, vol. 1, p. 27-28. Des analyses sémantiques du vocabulaire latin ont déjà été menées pour étudier la pensée romaine: c'est l'objet du travail de B. A. Krostenko, Cicero, Catullus and the Language of Social Performance, Chicago, University of Chicago Press, 2001. L'auteur y conduit une étude culturelle du vocabulaire de l'élégance et de la grâce.

${ }^{3}$ Sur les traitements sémasiologique et onomasiologique du lexique, voir C. BAYLON et X. Mignot, Initiation à la sémantique du langage, réimpr., Paris, A. Colin, 2007, p. 120.
} 


\section{Problèmes}

Une première difficulté surgit, paradoxalement, de la transparence des mots honos et honestas que le lecteur moderne a naturellement tendance à rapprocher des termes "honneur» et "honnêteté ». Il ne faut pas se laisser abuser par la parenté entre le français et le latin car les mots latins ne recouvrent pas, dans le cas qui nous intéresse, le même champ sémantique que celui des mots français. Pour ne donner qu'un exemple, l' «honneur» dans son acception fréquente de «dignité morale», que l'on trouve dans l'expression "agir conformément à l'honneur», est loin d'être un sens essentiel d'honos; il est en revanche central dans le sémantisme d'honestas, qui n'est donc pas seulement un équivalent de ce que nous entendons par "honnêteté ». Les langues ne procédant pas à la même catégorisation linguistique du réel, la notion contemporaine d' "honneur» a peu de chance de trouver un équivalent exact en latin. De fait, plusieurs termes latins sont susceptibles de pouvoir traduire le mot « honneur », selon l'aspect que l'on privilégie: honos (l'honneur concret ou l'estime dont on jouit), fides (la loyauté), pudor (le sens de l'honneur), entre autres.

Une deuxième difficulté provient de l'apparente proximité d'honos et d'honestas avec plusieurs autres notions importantes de la langue latine. Nous aurons à apprécier la singularité d'honos et de ses dérivés par rapport à deux aires sémantiques, le vocabulaire de la notoriété et du prestige social d'une part (gloria, laus, gratia, auctoritas, dignitas), et celui de la moralité d'autre part (uirtus, fides, pudor, uerecundia). Il faudra aussi analyser les rapports de sens entretenus par les trois termes étudiés. Honos et honestas, notamment, peuvent avoir certains sens en commun; il nous appartiendra d'évaluer leur degré de synonymie.

Enfin, une dernière difficulté réside dans la souplesse sémantique des mots qui nous intéressent. Comme nous le signalions en introduction, ces notions sont malléables et peuvent désigner des réalités différentes: une situation comme le "prestige», un acte comme l' «hommage», une fonction comme la "charge publique», etc. Ils sont en outre utilisés dans des domaines variés (religieux, politique, esthétique ou moral) et des genres littéraires très divers. Nous aurons donc à enquêter sur leur cohérence sémantique.

\section{Méthode}

Afin de mener l'étude sémantique d'honos et de ses dérivés, nous avons choisi de nous inspirer des procédés de l'analyse sémique. Il s'agit bien de nous en inspirer, et non de l'appliquer de façon aussi systématique et étendue que cela a pu être fait dans le domaine latin. D'abord parce que nous ne pouvons, dans le cadre de notre travail, la mettre en œuvre avec autant d'ampleur et de précision que c'est le cas dans les études exclusivement sémantiques des notions latines. 
Ensuite parce que nous ne nous interdirons pas de faire appel à d'autres méthodes d'investigation qui relèvent d'une autre conception de la langue et du vocabulaire.

L'analyse sémique est une méthode d'analyse du sens élaborée par différents linguistes et notamment, en France, par B. Pottier, R. Martin et F. Rastier ${ }^{4}$. Dans le domaine latin, les travaux de C. Moussy ont ouvert la voie dans ce domaine, qui a ensuite été exploré par C. Nicolas, qui a travaillé sur le phénomène du calque sémantique, É. Gavoille, à propos du mot ars, ou J.-F. Thomas, à propos du vocabulaire de la notoriété ainsi que du déshonneur et de la honte ${ }^{5}$. L'analyse sémique consiste à définir le sens d'une unité lexicale par la mise en avant d'une suite d'unités minimales et distinctives de sens, qualifiées le plus souvent de "sèmes " ${ }^{6}$. L'ensemble des sèmes forme le "sémème ", c'està-dire la totalité des traits sémantiques d'un sens donné. Le sémème se compose d'un sème générique, commun à des unités appartenant à des ensembles lexicaux différents, et de sèmes spécifiques de portée plus restreinte qui permettent d'opposer des sémèmes voisins ${ }^{7}$. L'analyse sémique nous paraît présenter plusieurs atouts pour le travail que nous avons à mener. Elle se révèle d'abord plus rigoureuse et plus approfondie qu'une analyse paraphrastique traditionnelle. Raisonner en termes de présence ou d'absence de traits distinctifs impose d'avancer en profondeur dans la signification du mot. La constitution, parfois contraignante, d'un sémème précis oblige à clarifier certains traits de sens qui restent sans cela dans l'obscurité. On aboutit ainsi

4 B. Pottier, "Vers une sémantique moderne», Travaux de Linguistique et de Littérature, 2, 1964, p. 107-137; B. PotTiER, Sémantique générale, Paris, P.U.F., 1992; R. Martin, Pour une logique du sens, Paris, P.U.F., 1983 ; F. Rastier, Sémantique interprétative, Paris, P.U.F., 1987.

${ }^{5}$ Voir par exemple C. Moussy, "Les métaphores lexicalisées et l'analyse sémique», in Lavency, M. et Longrée, D. (éds.), Actes du vème colloque de linguistique latine, Louvain, CILL, 1989, p. 309-319 ainsi que C. Nicolas, Vtraque lingua. Le calque sémantique: domaine gréco-latin, Louvain, Peeters, 1996; É. Gavollle, Ars. Étude sémantique de Plaute à Cicéron, Louvain, Peeters, 2000; J.-F. Thomas, Gloria et laus. Étude sémantique, Louvain, Peeters, 2002; J.-F. Thomas, Déshonneur et honte en latin: étude sémantique, Louvain, Peeters, 2007.

${ }^{6}$ Pour une description plus approfondie de la nature de l'analyse sémique, on se reportera aux textes théoriques cités précédemment. Voir aussi la présentation synthétique de Baylon et Mignot, Initiation à la sémantique du langage, p. 123-129, d'I. TAMBA, La Sémantique, 5e éd., Paris, P.U.F., 2005, p. 21-23 et d'A. Lehmann et F. Martin-Berthet, Introduction à la lexicologie, $2^{\mathrm{e}}$ éd., Paris, A. Colin, 2005, p. 23-34.

${ }^{7}$ C'est sans doute B. Pottier qui a le plus contribué à faire connaître cette analyse par sèmes, avec sa description, désormais classique, des lexèmes constituant le champ sémantique des "sièges» (PotTiER, "Vers une sémantique moderne»). Il observe ainsi, pour prendre un exemple, que le trait distinctif /avec accoudoirs/ permet d'opposer "fauteuil » à un autre type de siège comme "chaise». La méthode a été ensuite approfondie, notamment pour y introduire l'étude des sèmes introduits par le contexte ou par la connotation (RASTIER, Sémantique interprétative, chap. II). 
à une description riche et nuancée du sens. En outre, l'analyse par sèmes permet d'opérer une distinction claire et efficace entre les sens d'un même mot: l'ajout ou l'effacement de certains sèmes entre deux sens permet de mesurer la distance qui sépare ces deux signifiés; on peut alors observer la manière dont ils s'articulent les uns aux autres, selon des rapports logiques et chronologiques. Robert Martin a élaboré pour cela des outils précieux que nous emploierons ${ }^{8}$. Enfin, l'analyse sémique permet de clarifier les points communs et les divergences entre des mots dont les sens sont perçus confusément comme proches car elle met en évidence les sèmes partagés et ceux qui ne le sont pas.

Cette méthode ne va pas cependant sans quelques défauts dont il faut être conscient ${ }^{9}$, afin de tenter de les corriger. La décomposition par sèmes peut être jugée artificielle car elle n'est pas nécessairement perçue par le locuteur. L'analyse sémique permet une claire compréhension mais risque aussi de figer le fonctionnement de la langue. Les relations sémantiques entre les mots, les contours du sens d'un terme ne sont jamais d'une précision scientifique. La chaîne sémique est rigide, alors que le sens du mot a des contours mouvants. Par ailleurs, quelle est la validité objective d'un sème choisi par le sémanticien? Et pourquoi y aurait-il un nombre fini de sèmes? Plus généralement, on rencontre avec cette méthode le problème central qui se pose à la sémantique. Est utilisé, pour décrire le sens d'un mot, un métalangage lui-même composé de mots. Il est donc difficile d'échapper à la circularité.

Toutes ces difficultés ne peuvent être levées dans leur ensemble, mais il nous semble que, par le recours à des approches sémantiques complémentaires, il est possible d'essayer d'en résoudre quelques-unes. Plutôt que de considérer la décomposition par sèmes comme une fin en soi, il faut la voir comme un outil de travail. Ce découpage sémique peut paraître artificiel, mais c'est sans doute le lot de toute analyse qui entreprend d'éclairer le sens, réalité au moins aussi intuitive qu'objectivement définissable. Cet aspect un peu artificiel de l'analyse peut être estompé par le recours, complémentaire, à la traduction, qui fait correspondre une unité lexicale à une autre. Nous l'emploierons donc, en ne nous contentant pas de rendre chaque sens latin par un seul mot français, mais par un ensemble de plusieurs mots, qui permettra de faire sentir autant que de faire comprendre le sens renfermé par honos et honestas. Nous éviterons dans la mesure du possible de recourir au mot «honneur» qui, s'il est souvent l'équivalent le plus adapté en contexte, échoue à faire sentir les singularités des différents

\footnotetext{
${ }^{8}$ Voir Martin, Pour une logique du sens, p. 75-95.

${ }^{9}$ Les linguistes qui mettent en œuvre l'analyse sémique reconnaissent le bien-fondé de certaines des critiques auxquelles elle s'expose. Voir Nicolas, Calque, p. 80-81 et Thomas, Déshonneur et honte, p. 5.
} 
sens étant donné sa polysémie en français ${ }^{10}$. Nous étudierons également les mots en relation de synonymie et d'antonymie avec honos et honestas. Une telle approche permettra de mieux différencier les significations: le fait qu'un mot puisse être un synonyme partiel de termes appartenant à des réseaux de sens totalement différents est un indice de sa polysémie ${ }^{11}$. En ce qui concerne le choix des sèmes, il est difficile d'atteindre une objectivité absolue mais on peut contrôler leur validité. Il faut d'abord, pour chaque trait de sens repéré, tester plusieurs sèmes et voir celui qui est le plus efficace. Nous nous aiderons pour ce faire des ouvrages de lexicographie moderne, mais aussi des glossaires et commentaires linguistiques produits par les Anciens eux-mêmes. Pour éviter une prolifération des sèmes pour un même sens, nous distinguerons les sèmes essentiels, actualisés en permanence, des sèmes «virtuels » dont la présence, quoique fréquente, est plus aléatoire ${ }^{12}$. Cela nous permettra de dégager pour chaque sens un noyau sémantique et des traits de sens périphériques qui viennent s'y greffer. Nous tenterons d'exprimer en pourcentage la présence de ces sèmes virtuels. Les sèmes ne doivent pas être multipliés, sous peine de faire perdre à l'analyse sa clarté et sa pertinence mais, en raison des nuances complexes que recèle le vocabulaire qui fait l'objet de ce travail, nous aurons parfois à présenter des sémèmes fournis.

\section{Plan de la première partie}

L'adoption d'une présentation chronologique ne nous est pas parue pertinente: notre champ est en effet relativement limité dans le temps et, surtout, le sémantisme des termes étudiés fait preuve d'une assez grande stabilité. Nous aborderons donc successivement honos, honestus et honestas, en passant en revue leurs différents sens. Chacun

${ }^{10}$ Cf. KLose, Bedeutung, p. 11, qui note les mêmes difficultés à rendre honos par l'allemand «Ehre».

11 Voir M. Fruyt, "Nature et limites de la polysémie», in Soutet, O. (éd.), La Polysémie, Paris, P.U.P.S., 2005, p. 23-36, qui reprend un exemple étudié par D. Conso. Forma a comme synonyme facies et figura (" aspect, visage »), mais aussi regula ( règle»). Forma appartient à deux réseaux de sens qui n'ont rien en commun et doit donc être tenu pour polysémique (p. 27). La spécificité du référent auquel le mot s'applique est aussi un critère pour distinguer les significations d'un même mot (THomas, Déshonneur et honte, p. 5-6).

12 Nous empruntons la notion de sème virtuel à J.-F. Thomas. Voir Thomas, Déshonneur et honte, p. 7. F. Rastier a montré qu'aux sèmes «inhérents » qui sont activés en permanence quel que soit le contexte, peuvent s'ajouter des sèmes "afférents", plus instables (RASTIER, Sémantique interprétative, passim). La sémantique élaborée par G. Kleiber fait une place importante aux traits sémantiques obligatoires et facultatifs avec la création de la notion de "prototype» et d'objets plus ou moins distants de ce prototype (G. Kleiber, La Sémantique du prototype. Catégories et sens lexical, Paris, P.U.F., 1990). 
sera étudié en plusieurs étapes. Nous proposerons d'abord pour le sens concerné une ou plusieurs traductions. Nous en donnerons ensuite une description par traits de sens, qui constituera l'essentiel du travail. Enfin, une conclusion évaluera, pour chaque sens, son lien avec les autres acceptions du mot et son rapport avec les synonymes ou antonymes. 


\section{CHAPITRE 1}

\section{ANALYSE SÉMANTIQUE D'HONOS}

\section{Préambule linguistique et étymologiQue sur honOS}

Avant de commencer notre investigation sémantique, il faut interroger les caractéristiques linguistiques et morphologiques du mot honos, dont dérivent honestus et honestas, et essayer d'en savoir un peu plus sur ses origines et son étymologie. L'héritage d'honos dans les langues romanes est bien connu: en sont issus le français honneur, l'italien onore, l'espagnol honor ou honra', le portugais honra.

\subsection{Morphologie}

Le mot existe sous deux formes concurrentes: hŏnōs, -ōris, et hŏnŏr, -ōris. Honos est la forme la plus ancienne et c'est aussi, sur l'ensemble de la latinité, la plus fréquente: on compte environ quatre cents occurrences du nominatif honos pour deux cents d'honor ${ }^{2}$. La forme honos est de loin la plus employée tout au long de la République: Caton, Térence et Salluste n'utilisent qu'elle; Cicéron n'emploie que trois fois la forme en -or dans l'ensemble de son œuvre. Honor apparaît pour la première fois chez Plaute puis se rencontre assez régulièrement jusqu'au début de l'époque impériale, moment où il prend le dessus sur honos. Quintilien considère qu'honos est vieilli3 ${ }^{3}$. Mais la forme ancienne honos persiste pendant toute la latinité. Isidore de Séville la connaît encore: il souligne la proximité entre $s$ et $r$, et note que les anciens utilisaient plus volontiers la terminaison en -os, ce qui n'est plus l'usage à son époque 4 . En poésie, on n'observe pas toujours cette évolution conduisant à l'effacement d'honos au profit d'honor.

${ }^{1}$ Sur honor et honra en espagnol, voir J. C. BAROJA, « Honour and Shame: A Historical Account of Several Conflicts ", in Peristiany, J. G. (éd.), Honour and Shame. The Values of Mediterranean Society, Londres, Weidenfeld \& Nicolson, 1966, p. 79-95 et C. Chauchadis, Honneur, morale et société dans l'Espagne de Philippe II, Paris, CNRS, 1984, p.28-32.

${ }^{2}$ Ces données chiffrées ne sont qu'approximatives. Une faute du copiste, écrivant une terminaison à la place d'une autre, est en effet toujours envisageable, même si apparemment les manuscrits font bien la différence entre les deux orthographes; les leçons d'un même texte ne présentent guère en effet d'hésitation entre la forme en -os ou en -or.

${ }^{3}$ Quint.IO I, 4, 13.

${ }^{4}$ Isid. Orig. I, 27, 23. 
Les deux terminaisons n'ont en effet pas la même valeur métrique, et les poètes choisissent l'une ou l'autre en fonction de la prosodie: -os est long, -or est court ${ }^{5}$. Le passage d'honos à honor s'est réalisé en deux temps. La forme primitive du mot, non attestée, devait être honos, *honosis. Par rhotacisme, le -s-intervocalique est devenu - $r$-, produisant la forme honos, honoris. Puis, sous l'influence des cas obliques, le $-s$ final de honos a eu tendance à être remplacé par $-r$, provoquant l'abrègement du -o- en finale (de hŏnōs à hŏnŏr) ${ }^{6}$. Il faut signaler enfin une particularité graphique qui apparaît exclusivement dans les inscriptions: on connaît un génitif honorus ${ }^{7}$, qui rappelle d'autres génitifs présents dans les textes épigraphiques comme Venerus ou Caesarus, par exemple. Cette désinence -us au génitif est issue de *os qui alternait à époque ancienne avec la terminaison *es qui a de son côté produit la désinence -is que nous rencontrons en latin classique ${ }^{8}$.

Honos, oris est un dérivé formé sur un radical hon-, et pourvu d'une suffixation en -os. Il appartient donc à la catégorie des dérivés en -os (ou -or), comme furor, odor, labor ou pudor ${ }^{9}$. La suffixation latine en -os n'est pas sans équivalent dans les autres langues indoeuropéennes et peut être éclairée par la grammaire comparée. Il s'agit d'une des formes prises en latin par le suffixe indo-européen *-es-/-os-,

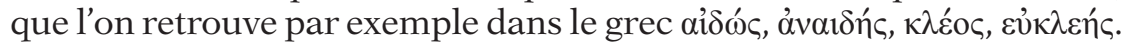
Ce suffixe *-es-/-os- fournit dans les langues indo-européennes des substantifs abstraits de deux types:

1) Des noms neutres, le plus souvent, que l'on observe par

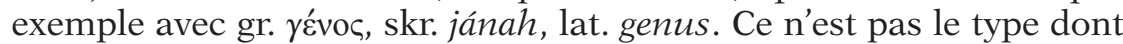
relève honos tel que nous le connaissons (qui est masculin), mais il est fort probable qu'il ait existé un neutre ancien *honos, -eris dont nous n'avons pas d'attestation. En effet, les dérivés en honest- tels que honestus ou honestare impliquent l'existence d'un ancien neutre *honos, -eris, dont ces dérivés sont issus, par une suffixation en *-to-.

2) Le suffixe *-es-/-os- fournit aussi des substantifs abstraits

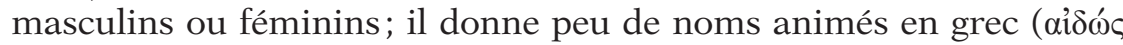

${ }^{5}$ C'est ce que rappelle Serv.Aen. I, 253: plerumque poetae ' $r$ ' in 's' mutant causa metri; 'os' enim longa est, 'or' breuis: "La plupart des poètes changent le 'r' en 's' pour des raisons métriques; en effet 'os' est long, 'or' est bref. »

${ }^{6}$ Sur le rhotacisme et l'extension analogique de $-r$ à certains nominatifs, voir A. Meillet et J. Vendryes, Traité de grammaire comparée des langues classiques, 5e éd., Paris, H. Champion, 1966, p. 75 et P. MonteIL, Éléments de phonétique et de morphologie du latin, Paris, Nathan, 1970, p. 181-182.

${ }^{7}$ Dans la Lex parieti faciundo de Pouzzoles (CIL I², 698, 2, 11).

${ }^{8}$ Ernout, Morphologie historique du latin, $3^{\mathrm{e}}$ éd., Paris, C. Klincksieck, 1953, p. 40.

9 Sur ce point et pour les remarques suivantes, voir H.Quellet, Les Dérivés latins en -or. Étude lexicographique, statistique, morphologique et sémantique, Paris, C. Klincksieck, 1969, passim. 
par exemple), mais beaucoup en latin, où il prend le timbre $o$ : amor, dolor, error, labor, odor, pudor, ... ${ }^{10}$ Honos appartient à ce type.

Du point de vue du sens, le suffixe *-es-/-os- servait en indo-européen à constituer des noms d'action, ce que l'on observe bien avec

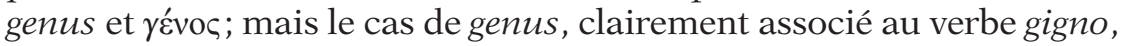
n'est pas la règle en latin: le mot en -os ne se rattache pas systématiquement à un verbe et honos n'a pas la même valeur de nom d'action que genus ${ }^{11}$. Cependant, le terme est masculin, et non pas neutre: c'est un animé et il y a une notion de vie dans le mot, comme dans amor, dolor ou fauor. Le suffixe sur lequel le dérivé honos est formé lui apporte donc une fraction de sens importante: le terme recèle la notion d'un procès actif.

\subsection{La présence du mot dans la langue latine}

Honos est un mot courant. D’après le dénombrement effectué par interrogation de la base de données Phi 5.3, il y a plus de 3500 occurrences du mot dans les textes latins, des origines jusqu'au V'eiècle. À titre de comparaison, on est proche de la fréquence d'un mot comme officium (environ 3000 occurrences); honos se rencontre plus que pudor (1000 occurrences), mais moins que uirtus (5000 occurrences).

Plusieurs raisons nous conduisent à penser qu'honos est un terme présent depuis longtemps dans la langue latine. Tout d'abord, ainsi que le remarque $\mathrm{H}$. Quellet, la suffixation en -or, à laquelle honor se rattache, cesse d'être productive à la fin de l'époque cicéronienne: peu de nouveaux mots en -or font leur apparition après la fin de la République. Nous avons vu en outre qu'honor appartient à la souscatégorie des dérivés en -or isolés de toute forme verbale en -ere, qui sont précisément les plus anciens des dérivés en -or. L'existence d'une terminaison en -os, remplacée ultérieurement par -or, signale le caractère archaïque du $\operatorname{mot}^{12}$.

${ }^{10}$ Sur ce sujet, voir A. MeIllet, Introduction à l'étude comparative des langues indoeuropéennes, $3^{e}$ éd., Paris, Hachette, 1912, p.240-242, ainsi que MeIllet et Vendryes, Traité de grammaire comparée des langues classiques, p. 404.

${ }^{11}$ Monteil, Éléments, p. 175. La définition que donne M.Leumann des dérivés en -or est donc inexacte: ces substantifs sont, selon le grammairien, des noms abstraits tirés de verbes de la $2^{\text {ème }}$ conjugaison: "Verbalabstrakta $z u$ Intransitiven der 2. Konjug, d.h.zu Zustandsverben der äußeren Erscheinung auf -ere, und daher auch indirekt neben Adjektiven auf -idus» (M.Leumann, J.B. Hofmann et A. Szantyr, Lateinische Grammatik, Munich, C.H.Beck, 1963-1979, au vol.1, p.379, § 330 B). Mais cette observation n'est valable en réalité que pour un nombre limité de masculins en -or. Dans le cas d'honos, entre autres, il n'y a pas de verbe en -ere dont le mot serait un abstrait verbal, ni non plus d'adjectif en -idus.

${ }^{12}$ Les termes qui présentent cette terminaison appartiennent en effet au vocabulaire latin le plus antique: c'est le cas d'honos, mais aussi de lepos ou mos par exemple. Voir Leumann, Hofmann et Szantyr, Lateinische Grammatik, vol.1, p. 179, § 180 F. 
Les premières occurrences d'honos se situent pour nous à la fin du III ${ }^{\mathrm{e}}$ siècle. On les rencontre chez Ennius ${ }^{13}$ et dans les comédies de Plaute $^{14}$. H. Quellet estime qu'il devait être en usage un siècle avant les occurrences que nous en avons dans les textes; le mot existait donc probablement dans le vocabulaire latin dès l'extrême fin du IV siècle ou au début du $\mathrm{III}^{\mathrm{e}}$ siècle $^{15}$. L'ancienneté du mot honos laisse penser qu'il ne s'agit pas d'un emprunt lexical fait par le latin à une autre langue. Cette impression est confirmée par l'examen de la morphologie du mot qui indique bien qu'honos n'est pas un xénisme ${ }^{16}$. Quand le latin emprunte un terme étranger, il le fait sous une forme productive; par exemple, pour la catégorie des mots latins en -or, le latin recourrait au type -ere, -or, -idus, que l'on trouve par exemple avec calere, calor, calidus ou splendere, spendor, splendidus. Cette forme est commode et permet de produire un verbe, un substantif et un adjectif. Mais rien de tel ne se produit pour honor: le substantif est isolé. Le mot a donc toutes les chances d'être propre au latin. Le caractère latin d'honos est revendiqué par le grammairien du IV siècle Charisius. Il évoque le mot honos dans ses Artis grammaticae libri $V$, au chapitre De idiomatibus, et explique que certains termes, qu'il qualifie d'idiomata, n'appartiennent qu'au latin sans avoir été empruntés au grec. Honos fait partie de ceux-là ${ }^{17}$.

\subsection{L'étymologie d'honos}

L'étymologie d'honos est très incertaine et pose des problèmes difficiles à résoudre ${ }^{18}$. Les étymologies avancées pour honos procèdent de deux manières: soit elles expliquent le mot de manière interne au lexique latin, soit elles recourent à la grammaire comparée des langues indo-européennes.

\subsubsection{Honos issu de onus}

Le Dictionnaire étymologique latin de M. Bréal et A. Bailly indique que «le sens primitif de honos semble avoir été 'charge' (v.onus). Aulu Gelle cite l'orthographe honeratus, honustus (pour oneratus, onustus). L'aspiration du h manque souvent $» .{ }^{19}$

${ }^{13}$ Enn. Trag. frg. CVII Jocelyn; Evh. frg. 42 Traglia.

${ }^{14}$ Dans le Miles gloriosus par exemple, situéle plus souvent entre 206 et 204 (PL.Mil. 1075).

${ }^{15}$ Voir aussi sur ce point KLOSE, Bedeutung, p. 9.

16 Sur le xénisme, voir Nicolas, Calque. Voir aussi, sur les emprunts lexicaux, Lehmann et Martin-Berthet, Introduction à la lexicologie, p. 8.

${ }^{17}$ Char. 379, 1-11.

${ }^{18}$ Le DELL considère qu'il n'y a "pas d'étymologie » (p. 299). Le dictionnaire étymologique de Walde-Hofmann, le $T L L$ et l'OLD estiment que la plupart des propositions faites sont très incertaines.

${ }^{19}$ M. Bréal et A. BaIlly, Dictionnaire étymologique latin, 4e éd., Paris, C. Klincksieck, 1967 s.v.honor. 
Le dictionnaire donne comme exemples de cette absence d'aspiration ira, anser, omnes, onus. Cette étymologie faisant dériver honos de onus était déjà avancée par Varron, qui cite à l'appui de son interprétation un vers tiré d'une comédie anonyme:

Honos ab onere: itaque honestum dicitur quod oneratum, et dictum:

Onus est honos qui sustinet rem publicam.

«Honos (honneur) d'après onus (charge): c'est pourquoi est dit 'honoré' ce qui est 'chargé', et on dit: 'C'est un poids que la charge de celui qui soutient la République'.»

(VARr. $L L \mathrm{~V}, 73)$.

Le rapprochement fait par Varron, et repris par M. Bréal et A. Bailly ${ }^{20}$, est séduisant: il éclaire un des sens d'honos, la «considération », qui serait, de manière imagée, le "poids» d'une personne dans la vie publique de la cité; on comprendrait aussi comment le mot a pu désigner une magistrature, fonction politique qui est naturellement "pesante», et que l'on traduit d'ailleurs en français par "charge ». Cette étymologie permet de poser à l'origine du mot une image bien concrète qui expliquerait les différentes significations et de faire dériver honos d'un autre terme latin qui l'aurait engendré ${ }^{21}$. Mais plusieurs éléments la rendent irrecevable ${ }^{22}$. On ne trouve jamais dans la littérature latine la forme *onos ou *onestus pour honos ou honestus. Le $h$ est constant et les grammairiens anciens considèrent eux-mêmes l'absence d'aspiration dans honos comme un barbarisme ${ }^{23}$. Seules quelques inscriptions donnent la forme sans aspiration $^{24}$. Mais elles sont peu nombreuses, et il s'agit sans doute d'une faute du lapicide plutôt que d'une orthographe concurrente

${ }^{20}$ V.Pisani considère également que l'étymologie de Varron est la bonne, aussi bien du point de vue phonétique, morphologique que sémantique (V.PISANI, "Latino honos », Paideia, 2, 1947, p. 27-28).

${ }^{21}$ Sur la conception "germinatoire» que se fait Varron du lexique latin, M. BARATIN et F.Desbordes, L'Analyse linguistique dans l'Antiquité classique. I. Les théories, Paris, C. Klincksieck, 1981, p. 41.

${ }^{22}$ L'erreur de Varron est causée par sa tendance à vouloir rapprocher deux mots qui apparaissent comme voisins par leur graphie ou leur sonorité. Voir J.ColLART, Varron, grammairien latin, Paris, Les Belles Lettres, 1954, p. 279. Elle relève de sa conception générale du lexique, fondé sur des primigenia uerba créés par un onomathothète et auxquels l'étymologiste doit remonter, de proche en proche (S. RoESCH, «Le rapport de res et uerbum dans le De Lingua latina de Varron", in Baratin, M. et Moussy, C. (éds.), Conceptions latines du sens et de la signification, Colloque du centre A. Ernout, Université de Paris IV, 4, 5 et 6 juin 1996, Paris, P.U.P.S., 1996, p.65-80).

${ }^{23}$ C'est le cas par exemple d'Audax (GLK VII, 362, 15).

${ }^{24}$ Voir par exemple CIL III, 8203, 9; X, 4724, 6; XI, 3939, 10. 
qui présenterait un lien de parenté avec onus ${ }^{25}$. En outre, en latin le $h$ initial est parfois supprimé pour donner au mot une fausse proximité étymologique avec un autre terme, comme pour hastatus (soldat armé du javelot, ou centurion) écrit astatus pour le rapprocher de adstatus ${ }^{26}$. Létymologie proposée par Varron nous paraît donc à rejeter. À l'inverse, onus ne s'écrit pas honus avant le Moyen-Âge ${ }^{27}$. Une parenté entre honos et un hypothétique *honus, mis pour onus, est donc à exclure. Certes, Aulu Gelle dit que les Anciens connaissaient les formes honera et honustum:

H litteram, siue illam spiritum magis quam litteram dici oportet, inserebant eam ueteres nostri plerisque uocibus uerborum firmandis roborandisque, ut sonus earum esset uiridior uegetiorque; atque id uidentur fecisse studio et exemplo linguae Atticae [...] Sic 'honera', sic 'honustum' dixerunt. In his enim uerbis omnibus litterae seu spiritus istius nulla ratio uisa est, nisi ut firmitas et uigor uocis quasi quibusdam neruis additis intenderetur.

«La lettre h ou l'aspiration, s'il vaut mieux dire ainsi, les anciens, chez nous, l'inséraient pour soutenir et renforcer la sonorité de beaucoup de mots afin qu'ils s'entendissent de façon plus vigoureuse et puissante; et ils paraissent avoir fait cela par goût et imitation de la langue attique. [...] Ainsi on a dit honera (des poids), honustum (chargé). Car dans tous ces mots il n'existe aucune justification rationnelle de cette lettre ou de cette aspiration, si ce n'est d'augmenter la force et la vigueur du son en y ajoutant pour ainsi dire un peu de nerf. »

(GELL. II, 3, 1-4).

Mais Aulu Gelle souligne bien qu'il n'y a aucune justification rationnelle à cette aspiration et qu'il s'agit d'un effet de la parole des individus et non pas de la langue. On sait que l'aspiration a été, à une époque, une véritable mode, raillée par Catulle ${ }^{28}$. Les textes ne présentent rien de tel, et les très rares honustus (pour onustus) que l'on peut y trouver sont des fautes de copistes toujours corrigées par les éditeurs. Plusieurs grammairiens ont pris soin de distinguer les deux termes dans leurs ouvrages. On lit ainsi dans l'Appendix de Probus:

Inter honestum et onustum hoc interest, quod honestum nobilem designat, onustum uero onus ferentem demonstrat.

${ }^{25} \mathrm{M}$. Leumann remarque à ce propos que les chutes du $h$ - pour les mots à $h$-initial se produisent essentiellement dans les inscriptions (Leumann, Hofmann et Szantyr, Lateinische Grammatik, vol.1, p.173, § 178 IIIA).

${ }^{26}$ Ibid.

${ }^{27}$ Voir à ce sujet l'article de R. PEIPER, « Vermischte Bemerkungen und Mittheilungen zu römischen Dichtern zum Theil aus Handschriften », RhM, 32, 1877, p. 519-520.

${ }^{28}$ Catul. 84. Catulle se moque d'Arrius qui affecte de mettre dans tous les mots des ' $h$ ' aspirés. 
«Entre honestus et onustus, la différence est la suivante: honestus signifie 'noble', mais onustus désigne une personne portant une charge.»

(Рвов., App., GLK IV, 201, 35).

Même si les termes n'étaient pas apparentés, ils prêtaient manifestement à confusion ${ }^{29}$. Les textes littéraires, de leur côté, ont joué de cette proximité phonique, mais sans que cela soit l'indice d'une parenté étymologique ${ }^{30}$. Aucun auteur avant Cicéron ne fait le rapprochement entre onus et honos, à part peut-être le vers que cite Varron, emprunté à une palliata anonyme. Par la suite, les auteurs créent certes des effets de paronomase, mais la distinction sémantique entre les deux mots est fermement établie. On trouve par exemple chez Tite Live:

oneratus magis quam honoratus

«chargé plutôt qu'honoré»

(Liv. XXII, 30, 4).

ou chez Ovide:

non honor est sed onus species laesura ferentis.

«Ce n'est pas un honneur mais un fardeau, un masque destiné à blesser ceux qui le portent.»

(Ov. Her. IX, 30).

Il y a ici jeu de mots, mais pas jeu étymologique. Les manuscrits présentent parfois aussi quelques incertitudes, quoique peu nombreuses, entre onus, honus et honos ${ }^{31}$. Honos et onus ne sont donc pas apparentés. Cependant, même si l'étymologie donnée par Varron ne possède pas de valeur scientifique, il ne faut pas pour autant la négliger, car elle est significative de la conception que les Romains se font de l'honos, notamment en politique: la magistrature est un honneur, mais c'est aussi un fardeau.

${ }^{29}$ La morphologie d'onustus est spécifique, peut-être pour éviter la confusion avec honestus: J.Manessy Guitton remarque qu'onustus est le seul dérivé d'onus avec un vocalisme $-u$ - (les autres dérivés sont en -e-, comme onerare, onerosus,...): J. ManessyGuiton, Recherches sur les dérivés nominaux à bases sigmatiques en sanscrit et en latin, Dakar, Publications de l'Université, 1963, p.67.

${ }^{30}$ Sur le jeu de mots onus-honos, C.BLÜMLeIN, "Zum Wortspiele onus-honor», Archiv für lateinische Lexikographie, 8, 1893, p. 586.

${ }^{31}$ Voir par exemple l'apparat critique de Cic.Inu. II, 177: honos $H^{2} P S^{2} I$ (leçon à retenir): honus $H^{1} S^{l}$ onus $V$. 


\subsubsection{Honor issu de in ore}

Cette hypothèse est soutenue par A.Zimmermann dans son dictionnaire étymologique ${ }^{32}$. De même que insula serait issu de in salo, honor serait issu de in ore; on aurait en latin ancien la forme *en ose qui serait devenue (h)onos, le premier $o$ passant à $e$ comme celui de *hemo qui donne homo. A.Zimmermann considère que in honore esse serait alors une sorte de redoublement de in ore esse. On perçoit le lien de sens qu'on pourrait établir entre honos, qui désigne la considération dont on jouit, la renommée, et la formule in ore esse: jouir de l'honos, c'est "être sur toutes les lèvres". Mais aucun argument sérieux ne vient étayer cette étymologie. La comparaison faite par A.Zimmermann avec insula dessert en réalité son raisonnement: l'hypothèse selon laquelle insula dérive d'*insulus lui-même issu de *en salos ( qui se trouve dans la mer») est une étymologie erronée ${ }^{33}$. Le rapprochement entre honor et in ore paraît tout aussi arbitraire et soulève plusieurs difficultés: on ne voit pas, notamment, d'où proviendrait l'aspiration initiale d'honos. Cette étymologie nous paraît donc difficilement justifiable.

\subsubsection{Honos et la racine ${ }^{*} z g^{h} O n-$}

Outre les étymologies internes au latin, d'autres hypothèses ont été faites en recourant à la grammaire comparée des langues indoeuropéennes. Ainsi, F. A. Wood rapproche honos du gothique gansjan ( «causer»), et les fait dériver tous deux d'une base commune * $z g^{h}$ onos, *seghonos- ( force, pouvoir ») ${ }^{34}$. Cette hypothèse ne peut cependant être retenue: on ne voit pas, d'abord, le lien sémantique entre honos et gansjan ni entre honos et la racine proposée. Ensuite, la reconstruction d'une ancienne base commune * $z g^{h} \mathrm{On}$ - est très improbable: la forme gansjan dérive d'une racine * $g^{h} e w$-, comme l'indique W. P. Lehmann ${ }^{35}$, qui ne peut remonter à * $\mathrm{zg}^{h} \mathrm{On}$ -

32 A.Zimmermann, Etymologisches Wörterbuch der lateinischen Sprache, Hanovre, Hahnschen, 1915, s.v.honos.

${ }^{33}$ Voir sur insula le DELL p.319. Cette étymologie est avancée par certains grammairiens anciens; voir par exemple MART. CAP.VI, 643: quod in salo sint, insulae uocitantur.

${ }^{34}$ F. A. Wood, Post-Consonantal ' $w$ ' in Indo-European, Philadelphie, Linguistic Society of America, 1926, p. 83.

35 W.P. Lehmann, A Gothic Etymological Dictionnary, Leiden, Brill, 1986, s.v. *gansjan. Lehmann exclut tout rapprochement avec un autre terme d'une langue indo-européenne. 


\subsubsection{Honos et la racine $* g^{\text {uh }} e n-$}

Une autre reconstruction avait été suggérée par F. A. Wood, dans une publication antérieure, et a été également formulée, de manière plus développée, par A. Debrunner ${ }^{36}$. Ils proposent tous deux de rapprocher honos de la racine indo-européenne * $g^{\text {uh } h} e n$ - Cette racine est attestée: elle désigne l'action de "gonfler», d' "enfler», et se retrouve dans le vieil indien āhanás et le grec $\varepsilon \dot{\theta} \theta \eta v \hat{\omega}^{37}$. Honos désignerait donc le fait d'être rempli, plein, l'abondance. Pour A. Debrunner, cela convient bien au sens premier d'honos, qui est selon lui le sens esthétique de «beauté». Cette interprétation pose diverses difficultés qu'A. Walde a bien mises en évidence ${ }^{38}$. Il serait d'une part surprenant que, placée à l'initiale, la postpalatale avec articulation labiovélaire * $g^{u h}$ - produise en latin $h$-; cette occlusive correspond en réalité au $f$ - latin à l'initiale et au $u$ (consonne) entre voyelles. A. Debrunner ne paraît pas l'ignorer mais explique cette bizarrerie par une origine sabine du mot: un terme rural (l' "abondance» agricole) aurait ainsi été importé dans la Rome urbaine. Cette provenance sabine du mot est douteuse: on ne trouve pas d'exemple probant d'un traitement sabellique d'une initiale * $g^{\underline{u} h}$ - en $h$-. Un autre élément est particulièrement gênant pour la validité de l'hypothèse d'A. Debrunner: la "beauté» n'est assurément pas le sens premier d'honos, ainsi que nous aurons l'occasion de le voir ${ }^{39}$; le lien de la racine $* g^{\text {uh }}$ en- avec honos paraît donc extrêmement ténu.

\subsubsection{Honos et la racine $* g^{h} e n-$}

A. Walde propose, à titre d'hypothèse, de rapprocher honos du moyen irlandais gen («sourire, rire»). Honos serait alors issu de la racine indo-européenne $* g^{h}$ en- («se comporter amicalement») et signifierait «comportement amical, agréable ${ }^{40}$. L'irl. gen existe bien, mais son étymologie est inconnue. H.Pedersen le rapproche du grec

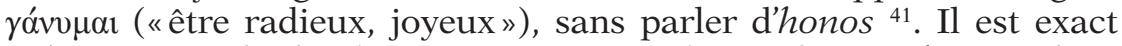
qu'un $g$ - initial irlandais peut correspondre en latin à $h$ - initial, et impliquer donc une racine commune $* g^{h}$. La racine $* g^{\bar{h}} e n-$ pourrait se retrouver en latin au degré $o$, et la reconstruction proposée

${ }^{36}$ F. A. Wood, «Some Latin Etymologies », CPh 11, 1916, p. 208-211 et A. Debrunner, «Honor», IF, 51, 1933, p. 195.

${ }^{37}$ Voir A. WALDE, Vergleichendes Wörterbuch der indogermanischen Sprachen, Berlin, W. De Gruyter, 1927-1932, au vol. 1, p. 679 et J. РокоRNY, Indogermanisches etymologisches Wörterbuch, Bern, Francke, 1959, au vol.1, p. 491.

${ }^{38} L E W$, vol. 1, p. 656.

${ }^{39}$ Voir p. 99.

${ }^{40}$ WALDE, Vergleichendes Wörterbuch der indogermanischen Sprachen, vol. 1, p. 583.

${ }^{41}$ H.Pedersen, Vergleichende Grammatik der keltischen Sprachen, Göttingen, Vandenhoeck und Ruprecht, 1909-1913, vol.1, p. 96. 
par A. Walde ne se heurte donc pas à des incohérences phonétiques. Cependant, nous ne possédons pas d'autres termes issus de dialectes indo-européens qui pourraient être rapprochés de cette racine, dont le latin et l'irlandais apportent les seules attestations ${ }^{42}$. Il nous paraît aventureux de proposer une étymologie à partir de la seule comparaison entre deux langues ${ }^{43}$. La reconstruction d'A. Walde demeure donc hypothétique, mais il faut souligner que c'est celle qui heurte le moins la réalité des faits. Sur le plan sémantique, notamment, le rapprochement avec une racine désignant le "comportement amical» n'est pas dénué de fondements: comme nous aurons l'occasion de le constater dans les textes, honos désigne essentiellement la «marque d'honneur», l' «hommage». Et le mot suppose l'octroi d'un bienfait, en signe d'estime. Honos pourrait donc bien appartenir à un ensemble morphologique et sémantique désignant une relation sociale amicale et bienveillante.

\subsubsection{Honos et le lexique italique}

En raison de ressemblances morphologiques frappantes, on a rapproché honestus, le principal dérivé d'honos, d'une forme oscoombrienne, hanustu. On trouve le mot dans une inscription osque de Corfinium $^{44}$ dont la dernière ligne est la suivante:

lexe. lifar. dida. uus. deti. hanustu. herentas.

Il semblerait que le termehanustu soit un adjectif qualifiantherentas, mais son sens est incertain, comme le rappelle J. Untermann ${ }^{45}$ : on a proposé comme équivalent de ce mot honesta, mais aussi onustum, uenustatem, pulchra. Létymologie est elle aussi inconnue, notamment en raison de l'incertitude du sens premier du mot. Le rapport avec le latin reste donc difficile à établir. Au terme de cet examen, l'étymologie d'honos reste donc très problématique, et en l'absence de résultat probant il nous faut passer à l'étude détaillée de son sémantisme d'après les textes littéraires et épigraphiques dont nous disposons.

${ }^{42}$ La racine n'apparaît ni dans le dictionnaire de Pokorny ni dans H. Rix, Lexikon der indogermanischen Verben, Wiesbaden, L. Reichert, 2001.

${ }^{43}$ On se souviendra, à cet égard, de la mise en garde d'A. Meillet: "Les rapprochements qui ne s'étendent pas à plus de deux dialectes sont peu sûrs, sauf raisons particulières, car la ressemblance de deux mots exprimant le même sens dans deux langues différentes peut être due à une rencontre fortuite» (MEILLET, Introduction, p. 367).

${ }^{44}$ H. RIx, Sabellische Texte, Heidelberg, C. Winter, 2002, Pg. 9, p. 73.

45 J. Untermann, Wörterbuch des Oskisch-Umbrischen, Heidelberg, C. Winter, 2000, p. 317 . 


\section{IDENTIFICATION DES SENS D'HONOS}

Sept sens autonomes d'honos peuvent être identifiés par l'analyse sémique. Nous ajoutons à ces derniers un huitième cas, spécifique, où le mot renvoie à la divinité Honos. Les sens retenus, numérotés pour plus de commodité, sont les suivants:

S1: «Marque d'honneur, hommage. »

S2: "Considération.»

S3: "Charge publique. »

S4: «Dignité, honorabilité.»

S5: «Récompense.»

S6: «Beauté, majesté. »

S7: Divinité Honos.

Tous ces sens ne sont pas relevés tels quels par les ouvrages de lexicographie. Le TLL divise honos selon qu'il désigne un acte ou une chose ${ }^{46}$. L'acte peut être intellectuel, et honos désignerait alors l' «estime» comme sentiment, ou concret, et honos renvoie alors à un "hommage», intervenant dans le domaine privé, public, ou sacré. Quant à l'honos comme chose, l'auteur de l'article multiplie les subdivisions, d'une manière qui n'est pas toujours claire ni indispensable: c'est notamment le cas de la principale dichotomie retenue, qui différencie honos désignant un «instrument de distinction » d'honos comme "chose distinguant par elle-même ». Au sein de l'honos comme chose qui distingue par elle-même, le TLL différencie la chose selon qu'elle parvient vers le sujet ou est fermement attachée à lui; dans le premier cas, un sens d'honos comme équivalent de magistratus est isolé; dans le second cas, honos est rapproché de gloria, laus, dignitas. Mais l'article ne montre pas ce qui fait la singularité d'honos par rapport à ces notions. Enfin, un sens esthétique est retenu, où honos désigne l' «ornement» ou la «beauté». L'article du TLL possède de très nombreuses ramifications ${ }^{47}$ qui ne donnent pas une image claire et cohérente du sémantisme d'honos. L'OLD est plus synthétique: il distingue l' "estime» (comme sentiment ou comme état "enjoyed by the recipient »); la "marque d'estime»; le "privilège»; la "charge politique»; et enfin la "beauté» ou "grâce physique. » Le dictionnaire de F. Gaffiot regroupe certains de ces sens, en proposant cinq entrées: "honneur, témoignage de considération»; "charge, magistrature»; "honneurs» dans un contexte religieux; "honoraires»; "beauté». Quelques lignes de force se dégagent, mais aucune de ces présentations n'est exactement identique à une autre et il nous faudra donc

${ }^{46}$ TLL vol. VI, 3, col.2916, 1.83 et col.2923, 1.9.

${ }^{47}$ Nous en donnons ici un aperçu simplifié. 
observer avec minutie l'émergence de tel ou tel sens. Les textes de notre corpus recouvrant environ deux siècles, il est utile de présenter quelques données statistiques sur les occurrences de chaque sens. Pour essayer de discerner quelques évolutions dans le temps, nous distinguons trois périodes chronologiques: le "premier II ${ }^{\mathrm{e}}$ siècle» (fin du $\mathrm{III}^{\mathrm{e}}$ siècle et premier tiers du $\mathrm{II}^{\mathrm{e}}$ siècle), époque de l'affirmation de la puissance romaine sur le bassin méditerranéen, de l'hellénisation culturelle et de la constitution de la littérature latine autour notamment de Plaute, Ennius et Caton, premiers grands auteurs latins ${ }^{48}$. Le "second $\mathrm{II}^{\mathrm{e}}$ siècle» (des années 160 aux années 120), époque des annexions territoriales, de la mutation économique et d'un nouvel hellénisme autour de Scipion Émilien; en littérature s'exprime la "génération de 160 », pour reprendre l'expression de P. Grimal, avec notamment Térence, Afranius, Accius ou Lucilius. Enfin, le Ir siècle lato sensu (entre 120 et 42), siècle de la crise de l'aristocratie et de la République, depuis la mort de Gaius Gracchus jusqu'au triumvirat et à la bataille de Philippes. C'est l'époque de Lucrèce, Cicéron, César, Salluste, entre autres. Des données statistiques sont présentées dans le tableau qui suit.

\begin{tabular}{|c|c|c|c|c|c|c|c|c|}
\hline HONOS & $\begin{array}{c}\text { S1: } \\
\text { Marque } \\
\text { d'honneur, } \\
\text { hommage }\end{array}$ & $\begin{array}{c}\text { S2: } \\
\text { Considé- } \\
\text { ration }\end{array}$ & $\begin{array}{c}\text { S3: } \\
\text { Charge } \\
\text { publique }\end{array}$ & $\begin{array}{c}\text { S4: } \\
\text { Dignité, } \\
\text { honorabilité }\end{array}$ & $\begin{array}{l}\text { S5: } \\
\text { Récom- } \\
\text { pense }\end{array}$ & $\begin{array}{c}\text { S6: } \\
\text { Beauté, } \\
\text { majesté }\end{array}$ & $\begin{array}{c}\text { S7: } \\
\text { Dieu } \\
\text { Honos }\end{array}$ & $\underline{\text { Total }}$ \\
\hline Plaute & 25 & 11 & 2 & 2 & & & & 40 \\
\hline Ennius & 1 & 1 & & & & & & 2 \\
\hline Caton & 4 & 2 & 1 & & & & & 7 \\
\hline Inscriptions & 2 & & & & & & 1 & 3 \\
\hline Fragments & 1 & & & & & & & 1 \\
\hline $\begin{array}{l}\text { Total 1 }{ }^{\mathrm{er}} \\
\text { II }^{\mathrm{e}} \text { siècle }\end{array}$ & 33 & 14 & 3 & 2 & & & 1 & 53 \\
\hline Térence & 2 & 1 & & & 1 & & & 4 \\
\hline Pacuvius & 1 & & & & & & & 1 \\
\hline Lucilius & 2 & 2 & & & & & & 4 \\
\hline Scip. Émilien & & & 2 & & & & & 2 \\
\hline C. Gracchus & & 2 & & & & & & 2 \\
\hline Volc.-Sedig. & & & 1 & & & & & 1 \\
\hline Accius & & 2 & & & & & & 2 \\
\hline
\end{tabular}

${ }^{48}$ Caton, dont la mort a lieu en 149 , est à cheval avec la période suivante mais les textes où apparaissent les notions qui nous intéressent sont surtout ceux du début de sa vie, c'est pourquoi nous l'incluons dans cette période. 


\begin{tabular}{|l|c|c|c|c|c|c|c|c|}
\hline Inscriptions & 1 & 1 & 2 & 1 & & & & 5 \\
\hline Fragments & 1 & & 1 & & & & & 2 \\
\hline $\begin{array}{l}\text { Total 2d } \\
\text { II } \text { siècle }^{\mathbf{y}}\end{array}$ & $\mathbf{7}$ & $\mathbf{8}$ & $\mathbf{6}$ & $\mathbf{1}$ & $\mathbf{1}$ & & & $\mathbf{2 3}$ \\
\hline Met. Numid. & 2 & & & & & & & 2 \\
\hline Sisenna & 2 & & & & & & & 2 \\
\hline Rhet. Her. & 4 & 3 & 1 & & & & & 8 \\
\hline Lucrèce & 1 & 9 & & & & 3 & & 13 \\
\hline Cicéron & 323 & 141 & 180 & 3 & 5 & & 7 & 659 \\
\hline $\begin{array}{l}\text { Oratoria } \\
\text { Rhetorica }\end{array}$ & 179 & 73 & 126 & 3 & 3 & & 2 & 386 \\
Philosophica \\
Epistulae
\end{tabular}

On voit que le sens le plus fréquent est celui de "marque d'honneur», représenté dans environ $50 \%$ des occurrences, suivi par "considération » et "charge publique », qui apparaissent chacun dans 20 à $25 \%$ des cas. Les autres sens regroupent environ $5 \%$ des occurrences du mot. Le sémantisme d'honos est donc articulé autour de trois sens principaux. Honos est employé dans tous les genres littéraires mais est surtout représenté dans la prose oratoire et historique et, dans une moindre mesure, dans les textes de théâtre. Il est en revanche peu fréquent dans la poésie: il n'apparaît qu'une petite vingtaine de fois chez Lucilius, Lucrèce et Varron d'Atax réunis et n'existe pas dans le corpus de Catulle. Si l'on compare les trois périodes chronologiques retenues, l'usage du mot est beaucoup plus important au 
$\mathrm{I}^{\mathrm{er}}$ siècle, mais cela s'explique par l'état de nos sources qui sont bien plus abondantes à ce moment; Cicéron rassemble à lui seul deux tiers des occurrences. On observe une stabilité globale du sémantisme à travers le temps: tous les sens principaux existent dès les origines et la proportion relative de leur usage est sensiblement identique, avec une domination du sens "marque d'honneur", sauf au $\mathrm{II}^{\mathrm{e}}$ siècle, mais le petit nombre de fois où le mot apparaît ne rend pas cette variation très significative. Le sémantisme d'honos s'enrichit progressivement puisqu'au $\mathrm{II}^{\mathrm{e}}$ siècle apparaît le sens «récompense» et au $\mathrm{I}^{\mathrm{er}}$ siècle le sens «beauté ». Mais l'évolution la plus notable est l'important développement du sens «charge publique». Il prend en effet une grande importance au ${ }^{\mathrm{er}}$ siècle alors qu'il est peu représenté auparavant.

Nous avons inclus dans notre corpus Quintus Cicéron, car c'est à ce dernier que nous attribuons la paternité du Commentariolum petitionis $^{49}$. Nous avons aussi signalé les occurrences de nos notions dans le livre VIII du Bellum Gallicum, dans le Bellum Alexandrinum, le Bellum Africanum et le Bellum Hispaniense, qui ont été écrits à la fin de notre période, mais nous les plaçons sous l'entrée du pseudo-César car le dictateur ne semble pas en être l'auteur ${ }^{50}$. Nous avons exclu les deux Lettres à César et l'Invective contre Cicéron attribuées à Salluste, dont l'authenticité et la date restent très douteuses ${ }^{51}$.

\section{3. «MARque D’honneur, hommage » (S1)}

Honos désigne le signe d'estime qu'une personne adresse à une autre, le geste ou l'objet par lequel elle donne une marque de sa considération. Ou, pour prendre le point de vue du destinataire, honos renvoie à une marque distinctive possédée par un individu, qui signale le prestige dont il jouit. Quand il a ce sens, honos peut être traduit par "marque d'honneur», "hommage», "témoignage de considération ». Honos se rapproche alors de mots comme praemium, pretium, ornamentum ou decus. Ce sens d'honos est le plus fréquent (environ la moitié des occurrences) et apparaît dès les premiers emplois du mot.

49 Les arguments contre l'attribution à Q. Cicéron, qui reposent sur la critique externe du manuscrit, la personnalité de Quintus et le style de l'œuvre, nous semblent avoir été réfutés par l'étude de D. NARDo, Il Commentariolum petitionis. La propaganda elettorale nella 'ars' di Quinto Cicerone, Padoue, Liviana Editrice, 1970 et celle de J.-M.David, S. Demougin, E.Deniaux et al., "Le Commentariolum petitionis de Quintus Cicéron: état de la question et étude prosopographique », $A N R W$, I, 3, 1973, p. 239-277.

${ }^{50}$ C'est l'opinion de la plupart des éditeurs de ces textes. Voir les éditions dans la C.U.F.de J.Andrieu (Bellum Alexandrinum, p.vIII et Xv), J.-Cl.Richard (Bellum Africanum) et N. Diouron (Bellum Hispaniense, p. XI). Sur la question de l'authenticité de ces œuvres, voir aussi M.Schanz et C. Hosıus, Geschichte der römischen Literatur, $4^{\mathrm{e}}$ éd., Munich, C.H.Beck, 1927, p.343-345.

${ }^{51}$ Voir notre chapitre 20 sur Salluste. 


\subsection{Acception active et acception passive}

Nous regroupons sous le même sens ("marque d'honneur, hommage»), deux acceptions qui ne sont pas, à strictement parler, identiques, mais qu'il est bien souvent difficile de distinguer dans les textes: honos peut désigner l' «hommage», l'acte par lequel on honore autrui, ou bien la "marque d'honneur », c'est-à-dire le moyen qui est employé pour honorer autrui, l'objet concret. Il y a, en somme, une acception active et une acception passive du même sens: l'action d'honorer d'une part, la marque d'honneur d'autre part ${ }^{52}$. Un texte de l'Aulularia, issu du prologue dit par le lare, permet de bien percevoir ce qui les différencie:

Vbi is obiit mortem qui mihi id aurum credidit,

Coepi obseruare, ecqui maiorem filius

Mihi honorem haberet quam eius habuisset pater.

Atque ille uero minus minusque impendio

Curare minusque me impertire honoribus.

[...]

Huic filia una est; ea mihi cottidie

Aut ture aut uino aut aliqui semper supplicat;

Dat mihi coronas. Eius honoris gratia

Feci thesaurum ut hic reperiret Euclio,

Quo illam facilius nuptum, si uellet, daret.

«Lorsqu'il mourut, celui qui m’avait confié son or,

J'ai commencé à observer si son fils

M'honorerait plus que ne l'avait fait son père.

Mais voilà qu'il se soucie encore moins - et beaucoup moins ! -

De m'octroyer des honneurs.

[...]

Il a une fille unique; elle, c'est tous les jours

Qu'elle me fait des offrandes: de l'encens, du vin, toujours quelque chose;

Elle me donne des couronnes. Pour lui rendre hommage,

J'ai fait découvrir le trésor par cet Euclion,

Pour qu'il puisse la marier plus facilement, s'il en a envie.»

(PL.Aul.15-19 et 23-27).

Honorem habere désigne quelque chose de concret, de visible, que le lare peut obseruare. Il s'agit de l' "hommage», action qui implique un sujet et un objet: l'honos est détenu par quelqu'un (haberet), mais destiné à un autre (mihi). Le singulier suggère une action assez générale. En revanche, avec impertire honoribus, on passe à un autre sens, celui de "marques d'honneur». Il s'agit de la chose possédée, et non du geste accompli: le pluriel incite à voir quelque chose de très concret;

${ }^{52}$ Cette différence est relevée par H. Drexler: l'honos peut désigner «der Ausdruck einer bestimmten Wertschätzung» ou bien «in anderen Stellen gewinnt das äußere Zeichen Selbständigkeit, ist selbst die Ehre, die man jemandem erweist »(DREXLER, «Honos », p. 464). 
le verbe impertire construit avec l'ablatif de l'objet fait également percevoir un objet plus matériellement cernable ${ }^{53}$. Enfin, il est question un peu plus loin de la nature de ces honores: tur, uinum, coronas (v. 24-25). Les honores renvoient donc aux marques d'honneur ${ }^{54}$. Mais les deux valeurs sont très proches: c'est surtout l'opposition du singulier et du pluriel qui permet de les distinguer. Dans bien des cas la distinction est difficile à faire, et c'est pourquoi nous parlons ici d' "acceptions" et les regroupons sous un même sens, en proposant deux traductions possibles, "marque d'honneur» et "hommage " ${ }^{55}$.

Ces deux acceptions ne sont cependant pas exactement sur le même plan. L'aspect actif tend en effet à être prépondérant dans les textes, quand il est possible de le déceler. Des arguments de nature linguistique confirment cette prééminence. Dans son étude sur les dérivés latins en -or, H. Quellet tente de déterminer le sémantisme de l'ensemble de ces mots sur des critères linguistiques ${ }^{56}$. Son hypothèse est qu'il existe pour les substantifs, comme pour les verbes, des aspects, et que c'est à partir de notions aspectuelles qu'on peut définir objectivement le sémantisme. Selon H.Quellet, "les substantifs en -or indiquent un procès autonome et imperfectif ${ }^{57}$. "Autonome», parce que la production n'en est rapportée à aucun agent; le procès est représenté comme un événement qui se manifeste. Il est aussi «imperfectif », parce qu'il dure de manière indéterminée et "est envisagé dans son déroulement, à l'exclusion de son origine et de son terme ${ }^{58}$. Ces considérations de nature linguistique concordent avec les observations que nous avons faites à partir de la morphologie et avec les données des textes. H. Quellet souligne avec raison que ces mots en -or désignent un procès, une action: honos se distingue par exemple d'honestas parce que ce dernier terme n'offre pas de valeur active. Il est également intéressant d'observer qu'honos a un aspect imperfectif. On le constate par exemple dans ce vers des Captifs, où l'un des prisonniers dit en parlant du vieil Hégion:

Me hic ualere et seruitutem seruire huic homini optumo

Qui me honore honestiorem semper fecit et facit.

\footnotetext{
${ }^{53}$ Impertire aliquem aliqua re signifie "partager quelque chose avec quelqu'un » ou "faire un présent». Sur la distinction de ces deux significations, voir Mrlhous, Honos and Virtus in Roman Art, p. 81.

${ }^{54} \mathrm{~F}$. Klose souligne bien la différence des deux acceptions dans ce texte, en même temps que le lien qui les unit: honos subsume d'une certaine façon les honores: «honos [...] ist also hier ein Sammelbegriff für die verschiedenen einzelnen honores, die dem Lar erwiesen werden müssen »(KLose, Bedeutung, p. 14).

55 Il faudrait, théoriquement, distinguer deux sémèmes, mais la différence nous paraît trop contextuelle pour justifier cette distinction.

${ }^{56}$ Quellet, Les Dérivés latins en -or, p. 97 sqq.

${ }^{57}$ Quellet, Les Dérivés latins en -or, p. 131.

${ }^{58}$ Ibid.
} 
«Je vais bien et je suis en servitude ici, au service de cet excellent homme Qui, par les honneurs qu'il m'accorde, a fait et continue de faire de moi un homme plus honoré.»

(PL.Cap. 391-392).

La durée indéterminée de l'honos dont le prisonnier est l'objet est clairement exprimée par semper fecit et facit. Il n'y a pas de bornes clairement assignables au procès de l'honos ${ }^{59}$. En revanche, la dimension «autonome » de ce procès est moins nette que ne le suggère H. Quellet qui systématise un élément contextuel: on rencontre de très nombreuses occurrences où honos est rapporté au sujet qui donne l'honos ou à celui qui en bénéficie. L'usage d'un possessif ou d'un complément du nom permet de désigner le donateur ${ }^{60}$ ou bien le donataire ${ }^{61}$.

\subsection{Un bienfait}

Honos désigne fondamentalement un bienfait, c'est-à-dire un geste qui a des effets favorables pour son destinataire ou un objet avantageux qui améliore la situation d'un tiers. Fréquemment associé à beneficium, ornamentum, commodum, pretium ou cultus, avec lesquels il entre parfois en relation de synonymie, et opposé à contumelia, ignominia, poena ou supplicium, honos relève de la catégorie générale du geste favorable ${ }^{62}$. Par «bienfait», nous entendons aussi bien l'acte de bienfaisance que le bien octroyé, afin de couvrir les deux acceptions signalées plus haut ${ }^{63}$. L'honos est dans les textes un avantage qui profite à son détenteur. On lit dans la Rhétorique à Herennius:

Causa est ea quae induxit ad maleficium commodorum spe aut incommodorum uitatione, cum quaeritur num quod commodum maleficio appetierit, num honorem, num pecuniam, num dominationem, num aliquam cupiditatem aut amoris aut eiusmodi libidinis uoluerit explere ut num quod incommodum uitarit: inimicitias, infamiam, dolorem, supplicium.

«Le motif c'est ce qui a poussé à mal faire dans l'espoir d'obtenir des avantages ou d'éviter des désagréments. On cherche si l'accusé a désiré obtenir grâce à son forfait un avantage, un honneur, de l'argent, du pouvoir; s'il a voulu assouvir une passion amoureuse ou une passion du même genre; ou s'il a voulu éviter quelque désagrément: inimitiés, mauvaise réputation, douleur, châtiment. »

(Rhet.Her. II, 3 ; trad. Achard modifiée).

${ }^{59}$ Voir aussi PL. Aul. 17-19.

${ }^{60}$ Voir par exemple PL.Cist. 4; Cic.Verr. II, V, 37; Agr.II, 1 et II, 64; Rab.Perd.16; Dom.118; Off. II, 31; SaLL.Iug. 85, 17.

${ }_{61}$ Voir par exemple Cic.Leg.II, 22; Brut.117; Mur.55; Sull.49; Att.VI, 4, 2; Fam.XVI, 1, 1; VARR. LL VI, 19.

${ }^{62} \mathrm{~F}$. Rastier parle pour ce type de classe minimale de « taxème » (RASTIER, Sémantique interprétative, p. 61 sqq.).

${ }_{63}$ Pour quelques cas où l'acception active est bien visible, voir CIc.Rab.Perd.3; Rep.I, 7. Pour l'acception passive, voir Cat. frg. I, 18 ORF ; Cic. Flac. 25. 
L'honos est placé sous la catégorie des commoda, au même titre que l'argent et le pouvoir, et constitue un objet attirant que l'on s'efforce d'obtenir. Dans le De officiis, il est classé parmi les secundae res, les «avantages » ${ }^{64}$. L'acte de bienveillance qu'est l'honos apparaît aussi quand il prend la forme d'une faveur, voire d'un cadeau, comme celui que fait la lena au jeune homme de l'Asinaria:

Nec meum quidem edepol, ad te ut mittam gratiis.
Verum aetatis atque honoris gratia hoc fiet tui:
Quia nobis lucro fuisti potius quam decori tibi,
Si mihi dantur duo talenta argenti numerata in manum,
Hanc tibi noctem honoris causa gratiis dono dabo.

«Et ce n'est pas mon habitude non plus, par Pollux, de te l'envoyer gratis.

Cependant, en raison de ton âge, et pour te faire honneur, voilà ce qu'on fera: Puisque tu nous as procuré plus de profit que de prestige à toi-même,

Si on me donne deux talents d'argent bien comptés en mains,

Cette nuit-ci, c'est pour t'honorer, gratis, cadeau! que je te la donnerai.»

(PL.As.190-194).

L'honos consiste à offrir au iuuenis une nuit d'amour avec une courtisane, à lui octroyer un avantage dont la matérialité est tout sauf accessoire. Le bienfait concret auquel renvoie honos est ici patent et apparaît également quand l'honos prend la forme d'un héritage laissé à une veuve ou d'une somme d'argent offerte à la personne qu'on veut honorer ${ }^{65}$. L'honos occasionne une dépense de la part de celui qui le donne et un bénéfice pour celui qui le reçoit, bénéfice dont le prix est pesé, comme dans le Pro Flacco:

Delectum est oppidum, quo in oppido uno pecunia a tota Asia ad honores L. Flacci poneretur. Haec pecunia tota ab honoribus translata est in quaestum et faenerationem; recuperata est multis post annis.

«On a fait choix d'une ville pour y déposer l'argent donné par l’Asie entière pour honorer L. Flaccus. Tout cet argent, on l'a détourné de cette destination pour le faire valoir et l'employer à des prêts usuraires. Il n'a été repris que bien des années après. »

(Cic. Flac. 56; trad. Boulanger).

Cicéron se scandalise de l'usage qui a été fait de l'argent destiné à honorer Flaccus, qui n'a pas été employé à son profit mais pour le bénéfice d'une autre personne que celle qui devait être honorée. L'importance matérielle de l'honos est parfois précisée, et ce souvent avec des expressions superlatives telles que maximus honos ou amplissimus honos ${ }^{66}$. La tournure récurrente praeditus honore suggère bien

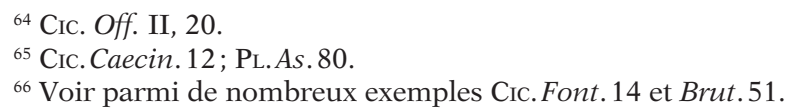


quant à elle que l'honos est quelque chose d'avantageux dont on est "doté » ${ }^{67}$. Même quand honos n'implique pas de profit matériel réel, il peut être explicitement désigné comme un beneficium:

Ad hoc uiritim, uti quemque ob militare facinus pecunia aut honore extulerat, conmonefacere benefici sui et eum ipsum aliis ostentare.

«Puis, s'adressant à chaque soldat l'un après l'autre, à tous ceux qu'il avait pour un exploit militaire récompensés par de l'argent ou une marque d'honneur, il rappelait le bienfait qu'il leur avait accordé, et les montrait aux autres. »

(SALL.Iug. 49, 4).

Avant la bataille du Muthul, Metellus rappelle les bienfaits qu'il a octroyés à ses soldats et en distingue deux sortes, pecunia et honos. Beneficia et honores sont souvent associés dans des expressions binaires $^{68}$. Honos s'oppose aux termes qui désignent des méfaits hostiles, tels que les attaques, dommages et préjudices. Dans le De inuentione, Cicéron préconise, quand l'accusé choisit d'avouer, de commencer par formuler des excuses, puis de supplier:

Postea, si facultas erit, se aut consanguineum aut magnis uiris aut primis amicum esse et amplitudinem suae uoluntatis, nobilitatem generis, eorum qui se saluum uelint dignitatem ostendere, et cetera ea quae personis ad honestatem et amplitudinem sunt adtributa cum conquestione, sine arrogantia, in se esse, ut honore potius aliquo quam ullo supplicio dignus esse uideatur.

«Ensuite, si la possibilité s'offre, il évoquera ses liens de sang ou d'amitié avec des personnages importants ou de premier plan, l'étendue de son dévouement, la noblesse de sa race et le rang de ceux qui veulent son salut, et il dira sans arrogance, tout en suscitant la compassion, qu'il possède toutes les autres marques octroyées à l'honorabilité et au prestige, de manière à paraître plus digne d'être honoré que puni.»

(CIc.Inu.II, 107 ; trad. Achard).

La supplication doit s'appuyer sur les qualités de la personne et sur les services rendus, afin que l'accusé évite le supplicium, la punition désastreuse, et paraisse au contraire digne d'un honos, d'une récompense avantageuse. Cicéron se plaît ailleurs à opposer honos et miseriae, ou encore honos et calamitas ${ }^{69}$. Le sème générique d'honos «marque d'honneur» nous semble donc être celui de /bienfait/.

\subsection{Le signe d'estime}

Ce qui fait la singularité de l'honos par rapport aux autres bienfaits ou avantages qui peuvent être accordés à un tiers, c'est qu'il ne

${ }^{67}$ Cic. Imp. Pomp. $71 ;$ Mur. 4.

${ }^{68}$ CIc. Verr. II, V, 82; Clu. 57; Pis. 32; Fam.XIII, 53, 2.

${ }^{69}$ Voir entre autres Cic. Flac. 1 ; Sull. 66 ; Dom. 119. 
fait pas qu'apporter un profit. Il est aussi porteur d'une signification. C'est un objet ou un geste qui dit quelque chose: il manifeste l'estime. Dans l'Asinaria, le vieux Déménète, à qui son fils a confié l'irrépressible désir qui l'habite, veut lui montrer l'estime qu'il a pour lui suite à sa confession:

Praesertim quom is me dignum quoi concrederet

Habuit, me habere honorem eius ingenio decet.

Quom me adiit, ut pudentem gnatum aequomst patrem,

Cupio esse amicae quod det argentum suae.

"Surtout, comme il m’a jugé digne de lui servir de confident,

Il convient que je rende hommage à son bon caractère.

Puisqu'il est venu me voir, comme il est juste qu'un fils respectueux le fasse avec son père,

Je désire qu'il ait de l'argent à donner à sa maîtresse. »

(PL.As. 80-83)

L'honos que le père souhaite donner à son fils est une marque concrète de l'estime et de l'affection qu'il a pour lui et qu'il veut rendre manifeste. La notion de signe apparaît parfois de façon explicite dans les textes: Cicéron rapproche ainsi les honores donnés à Curion de signa beneuolentiae dans une lettre à Atticus ${ }^{70}$. Quelle est la nature de l'estime que l'honos signifie? Il s'agit d'une appréciation favorable, d'une évaluation positive. C'est pourquoi l'attitude de Cicéron vis-à-vis de Vatinius est paradoxale:

Quare ne tibi hunc honorem a me haberi forte mirere, quod interrogem quem nemo congressu, nemo aditu, nemo suffragio, nemo ciuitate, nemo luce dignum putet $[\ldots]$.

«Ne va donc pas par hasard t'étonner, si je te fais l'honneur de t'interroger, quand personne ne te juge digne d'une rencontre, personne d'une approche, personne d'un suffrage, personne du titre de citoyen, personne de la lumière du jour $[\ldots]$..

(CIc. Vat. $1-2$; trad. Cousin).

L'honos est, en principe, accordé à quelqu'un quand on le juge (putet) positivement, qu'on le considère comme une personne de mérite (dignum). Le De republica met en relation de façon similaire les honores octroyés à un homme avec le fait qu'il fasse l'objet d'un jugement positif (dignissimus omni fortuna iudicetur) ${ }^{71}$. Honos implique ainsi dans son sémantisme une évaluation intellectuelle. Revenant sur

\footnotetext{
${ }^{70}$ Cic. Att. II, 18.

${ }^{71}$ Cic. Rep. III, 28.
} 
ses relations passées avec César, Cicéron note que tous les honores qu'il a reçus de lui s'expliquent par le iudicium de César à son endroit:

Consul ille egit eas res, quarum me participem esse uoluit; quibus ego si minus adsentiebar, tamen illius mihi iudicium gratum esse debebat. Me ille ut quinqueuiratum acciperem rogauit; me in tribus sibi coniunctissimis consularibus esse uoluit; mihi legationem, quam uellem, quanto cum honore uellem, detulit.

«Pendant son consulat, il a pris des mesures auxquelles il désirait me voir m'associer. Si je ne les approuvais guère, son jugement à mon égard ne devait pas moins m'être agréable. Il m'a prié d'accepter d'être l'un des Cinq; il a voulu que je fusse l'un des trois consulaires étroitement associés à sa politique; il m'a offert la mission de légat que je voudrais, avec tous les honneurs que je pouvais souhaiter. »

(Cic.Prou. 41 ; trad. Cousin modifiée).

L'estime signifiée peut aussi parfois se teinter d'affection, comme lorsque l'honos est conféré à un ami proche ou bien encore au conjoint $^{72}$. Deux traits de sens se dégagent:/signe / d'estime/.

\subsection{Les fondements de l'honos}

Les énoncés évoquant l'honos mettent très fréquemment en relief les raisons qui président à cet honos; honos désigne donc un bienfait dont l'apparition s'appuie sur des motifs. Nous avons vu avec le texte de l'In Vatinium cité précédemment que l'honos est donné à celui qui en est jugé dignus, qui détient les mérites qui légitiment son obtention. Or on voit fréquemment réapparaître dans les textes la formule dignus honore, pour renvoyer à différents comportements jugés positivement. Les vertus personnelles font ainsi le mérite:

Aliis ego te uirtutibus, continentiae, grauitatis, iustitiae, fidei, ceteris omnibus, consulatu et omni honore semper dignissimum iudicaui.

«Ce sont d'autres vertus, ta modération, ton sérieux, ton équité, ta loyauté et toutes les autres qui, à mon avis, t'ont toujours rendu tout à fait digne du consulat et de tout honneur.»

(Cic.Mur.23).

Cicéron s'adresse ici à Sulpicius et estime que ses qualités éthiques le rendent digne d'honneur. Parfois, le fait de mériter l'honos possède plus de prix que l'honos lui-même:

Equidem primum ut honore dignus essem maxime semper laboraui, secundo ut existimarer; tertium mihi fuit illud quod plerisque primum est, ipse honos, qui eis denique debet esse iucundus quorum dignitati populus Romanus testimonium, non beneficium ambitioni dedit.

${ }^{72}$ PL. Cist. $1-5$ et Cic. Caecin. 12. 
"Quant à moi, j'ai d'abord surtout travaillé en permanence à être digne d'un honneur, ensuite à en être jugé digne; j'ai placé au troisième rang ce qui se trouve chez beaucoup de gens au premier rang, l'honneur lui-même, qui, tout compte fait, doit être agréable à ceux à qui le peuple romain a donné un témoignage de leur mérite, et non une récompense pour leurs manœuvres électorales.»

(CIc. Planc. 50).

Cicéron fait passer la grauitas et la magnitudo animi qui fondent ses prétentions à l'honos avant l'obtention de l'honos lui-même. L'honos est motivé par la dignitas de l'individu honoré. On perçoit ici un premier lien entre cette notion de dignitas et l'honos: la dignitas, entendue comme "mérite», justifie l'octroi de l'honos ${ }^{73}$. Les mérites qui donnent naissance à l'honos sont surtout de nature morale. Le courage à la guerre en fait partie, de même que la gestion droite des affaires publiques ou une attitude fidèle ${ }^{74}$. Ces qualités et comportements peuvent être désignés de manière globale par le terme de uirtus, qui apparaît dans les textes comme une source fréquente d'honos ${ }^{75}$. Salluste écrit ainsi dans le Bellum Iugurthinum:

Verum ex eis magistratus et imperia, postremo omnis cura rerum publicarum minime mihi hac tempestate cupiunda uidentur, quoniam neque uirtuti honos datur neque illi, quibus per fraudem is fuit, tuti aut eo magis honesti sunt.

«Mais parmi ces moyens de trouver la gloire, les magistratures, les commandements militaires, bref, toute activité politique ne me semblent nullement désirables à notre époque, parce que ce n'est pas la vertu qui vaut l'honneur, et parce que les gens qui l'ont acquis par fraude n'en sont ni plus en sûreté ni plus considérés. »

(SALL.Iug. 3, 1; trad. Ernout modifiée).

Salluste déplore qu'à son époque ce ne soit plus la uirtus qui permette d'obtenir l'honos mais la fraus. Les res gestae et les vertus personnelles ne sont cependant pas le seul motif d'honos: les contextes mettent à plusieurs reprises en évidence une autre source, qui réside dans la naissance ou le statut social. La différenciation entre uirtus et

${ }^{73}$ Pour une semblable relation entre les deux notions, voir aussi Cic.Inu. II, 161 et Flac. 1 où le terme honos est repris par l'expression praemium dignitatis. Sur l'articulation des deux notions, voir infra p. 299 et 382.

${ }^{74}$ Respectivement, SAll.Iug. 49, 4 ; Cic.Planc. 64 ; CAEs. BG V, 54, 4.

75 Sur le sémantisme de uirtus, voir A. N. VAN Omme, Virtus. Een semantiese studie, Diss., Utrecht, 1946; K. BüchNER, "Altrömische und horazische virtus », in OPPERMANN, H.(éd.), Römische Wertbegriffe, Darmstadt, Wissenschaftliche Buchgesellschaft, 1967, p.376-401; W. EISENHut, Virtus romana. Ihre Stellung im römischen Wertsystem, Munich, W.Fink, 1973; F.-H.Mutschler, "Virtus und kein Ende?», Poetica, 32, 2000, p. 23-49; F.-H. Mutschler, «Virtus 2002: zur Rolle der 'römischen Werte' in der Altertumswissenschaft», Gymnasium, 110 (4), 2003, p.363-385 et McDonnell, Roman Manliness. Sur la complexité de la notion et son articulation avec honos, voir infra p. 307 (et note 25). 
nobilitas à la source de l'honos constitue tout l'objet du discours de Marius dans le Bellum Iugurthinum: il critique avec véhémence les nobiles qui fondent leur prétention à l'honos sur leur appartenance à une grande famille de Rome ${ }^{76}$. En dehors du contexte politique, le statut particulier de l'individu peut aussi justifier l'honos. On lit ainsi dans les Captifs:

Per fortunam incertam et per mei te erga bonitatem patris, Perque conseruitium commune quod hostica euenit manu Ne me secus honore honestes quam quom seruibas mihi, Atque ut qui fueris et qui nunc sis meminisse ut memineris.

«Par la fortune capricieuse et par la bonté que mon père t'a manifestée, Par la servitude commune où le bras de l'ennemi nous a placés,

Ne va pas m'honorer par moins d'honneurs que lorsque tu étais à mon service,

Et qui tu as été et qui tu es à présent, fais en sorte de t'en souvenir, de ne pas l'oublier.»

(PL.Cap. 245-248).

Philocrate donne à son esclave Tyndare des recommandations avant qu'ils n'inversent leurs rôles afin de tromper Hégion qui les retient prisonniers. Quand Tyndare fera semblant d'être le maître, il n'en devra pas moins témoigner des égards à Philocrate, qui reste son dominus, malgré la mascarade, et a droit en tant que tel à ces honores. Un autre statut particulier peut motiver l'honos, celui de dieu ou de défunt. La divinité a droit aux marques d'honneurs ${ }^{77}$, de même que celui qui a rejoint le monde des morts. Lucilius se scandalise ainsi qu'un défunt, qui est sans doute Tibérius Gracchus, ne reçoive pas l'honos d'une sépulture ${ }^{78}$. Devant cette diversité des sources d'honos, il ne nous paraît pas possible de préciser du point de vue sémantique les mérites qui justifient son obtention; nous nous en tiendrons donc au sème de /certains mérites/.

Les textes permettent cependant de préciser la relation entre le bienfait désigné par honos et les mérites sur lesquels il repose. Il s'agit d'un trait de sens important car il donne à honos sa singularité par rapport à beneficium par exemple. À la différence du «bienfait», l'honos n'est pas en effet conféré de manière gratuite et spontanée car il constitue une réponse aux mérites qui sont à sa source. L'honos intervient en retour d'un acte ou d'une qualité, comme on le voit avec les prépositions employées pour introduire le mérite à l'origine de l'honos: pro suivi de l'ablatif, $o b$ suivi de l'accusatif sont utilisés à plusieurs reprises et indiquent bien une réciprocité, un échange entre le mérite

${ }^{76}$ Voir par exemple SALL.Iug. 85, 17-20. Sur le conflit entre uirtus et dignitas pour l'accès à l'honos, voir infra p. 339 sqq.

${ }^{77}$ CAT. frg. XII, 73 ORF.

${ }^{78}$ LucIL. frg. XXVII, 10 Charpin = 691 Marx. 
d'une part et l'honos d'autre part ${ }^{79}$. Cette impression est confirmée par la définition que donne Cicéron de l'honos dans le Brutus:

Cum honos sit praemium uirtutis indicio studioque ciuium delatum ad aliquem, qui eum sententiis, qui suffragiis adeptus est, is mihi et honestus et honoratus uidetur.

«Puisque l'honneur est une récompense de la vertu accordée à quelqu'un par le jugement et l'affection des concitoyens, celui qui l'obtient par leurs décisions et leurs suffrages me semble à la fois honorable et honoré.»

(CIC.Brut. 281).

Le texte fait bien ressortir la part prise par le iudicium et l'affection de l'entourage dans l'octroi de l'honos mais définit surtout l'honos comme un praemium uirtutis. Le rôle essentiel de la uirtus est confirmé et l'honos apparaît comme une récompense, un avantage conféré à l'individu en retour de cette uirtus digne d'être valorisée. Semblable proximité entre honos et praemium apparaît dans plusieurs autres textes ${ }^{80}$. Cet aspect compensatoire de l'honos nous permet de préciser le sémantisme du mot: l'honos est lié à la notion d'estime mais aussi à celle de reconnaissance, trait de sens que les contextes actualisent à plusieurs reprises. Nous retiendrons donc comme sèmes pour les différents traits de sens identifiés: /octroyé en reconnaissance / de certains mérites/.

\subsection{L'effet social de l'honos}

Les contextes dans lesquels se rencontre honos font apparaître un trait de sens important qui porte sur les effets engendrés par cet honos au sein de la collectivité à laquelle appartient le bénéficiaire. Ce trait sémantique apparaît quand on compare honos aux termes qui lui sont opposés, contumelia et ignominia. Au bienfait signe d'estime qu'est l'honos, répond l'affront fait à l'individu, qui s'en prend à sa dignité et entraîne une détérioration de son prestige. Parlant de C.Curion, tribun de la plèbe en 90 et légat de Sylla contre Mithridate en 76, Cicéron prend quelques précautions oratoires:

[...] C. Curio, quem ego hominem honoris potius quam contumeliae causa nominatum uolo.

${ }^{79}$ Voir par exemple Cat.frg.XLII, 168, ORF; Sall.Iug.49, 4; Cic.Inu.II, 115; CIc.Brut. 54; Phil.V, 38; Att. V, $21,7$.

${ }^{80}$ TRF inc. frg. 30-31; Cic. Inu. II, 113 et 114; De or. I, 232 et III, 107. Sur ce point, voir Z. Hoffmann, "Der Wertbegriff honos in den Komödien von Plautus», $A C D$, 24, 1988, p. 24-35 ; F. KLose, «Altrömische Wertbegriffe (honos und dignitas)», NJAB, 1938, p. $268-278$. 
«Gaius Curion, homme que je souhaite nommer pour l'honorer et non pour l'offenser. »

(CIc. Verr.I, 7).

S'il le nomme, c'est par égard pour lui, pour lui donner une marque d'estime et non pour l'insulter. L'honos apparaît donc, à travers l'opposition à contumelia comme l'inverse de l'injure ou de l'avanie ${ }^{81}$. C'est encore plus sensible avec ignominia, qui est peut-être le meilleur antonyme d'honos quand ce mot a le sens de «marque d'honneur». On le voit dans un discours prononcé par César:

In se uno non seruari, quod sit omnibus datum semper imperatoribus, ut rebus feliciter gestis aut cum honore aliquo aut certe sine ignominia domum reuertantur exercitumque dimittant.

"Contre lui seul on supprime ce qui a toujours été accordé à tous les généraux, de rentrer à Rome, après une campagne heureuse, ou avec quelque honneur, ou en tout cas sans flétrissure, et de licencier ensuite leur armée. »

(CAEs.BC I, 85, 10; trad. Fabre).

César s'indigne du traitement injuste qu'il subit; après ses succès, il doit obtenir l'honos et non l'ignominia. L'ignominia est un affront qui dégrade la personne visée et porte gravement atteinte à son honorabilité ${ }^{82}$. L'antonymie avec honos apparaît dans les diverses strates du sémantisme. Si honos repose sur des mérites, l'ignominia est motivée par l'infraction aux règles essentielles de la morale sociale, et si honos indique un bienfait qui récompense ces mérites, l'ignominia est une sanction infligée par les autorités en réponse à un méfait ${ }^{83}$.

${ }^{81}$ Voir aussi l'opposition entre honos et contumelia dans CIC. Agr. II, 61; CAEs. BC II, 32, 14. Aulu Gelle transmet un fragment d'un discours de Metellus Numidicus (III, 7 ORF) qui présente une occurrence d'honos à laquelle il donne le même sens que contumelia; le grammairien rapproche honos de termes qui possèdent à la fois une acception positive et négative, comme dolus, facinus, periculum, uenenum, etc. Cette analyse est erronée: les termes cités par le grammairien ont à l'origine un sens négatif (comme dolus; DELL p. 182) ou un sens neutre qui a évolué de manière négative (periculum signifie d'abord "essai, épreuve», puis "danger, risque»-DELL p.498; uenenum "décoction» puis «poison»-DELL p.719). Rien de tel ne peut être observé pour honos. Aucun texte ne permet en outre de lui donner le sens d' "affront»; dans le passage que cite Aulu Gelle, honos signifie «marque d'honneur» et est employé par antiphrase ironique.

${ }^{82}$ Sur cet aspect de l'ignominia, CIc. Verr.II, 3, 97; Rep.IV, 7, frg. 5; CAEs. BC I, 85, 8; Liv. II, 27, 6; Sen.Ben.II, 8, 1. Voir l'analyse qu'en fait Thomas, Déshonneur et honte, p. 294-306: «Ignominia s'oppose à honor dans des structures ad ignominiam, ignominiae causa signifiant que la finalité de la décision est bien de faire perdre toute estime et toute valorisation à l'intérieur de la collectivité» (p. 298). Voir aussi M. KASER, «Infamia und ignominia in den römischen Rechtsquellen », ZRG, 73, 1956, p. 220-278.

${ }^{83}$ C'est une «décision émanant de l'autorité qui objective la disqualification sociale » (Tномаs, Déshonneur et honte, p. 300). Le terme d'ignominia s'applique notamment au blâme infligé par les censeurs. 
L'antagonisme sémantique apparaît aussi dans les conséquences qu'impliquent les deux termes. Parlant de Balbus, accusé d'avoir usurpé la citoyenneté, Cicéron s'exclame:

Vbi igitur est crimen? Quod eum Pompeius ciuitate donauit. Huius crimen? Minime, nisi honos ignominia putanda est.

«Où est donc le crime? Pompée lui a offert le droit de cité. Est-ce le crime de Balbus? Pas du tout, à moins qu'un honneur ne doive être considéré comme une humiliation.»

(CIc. Balb.7).

L'octroi de la citoyenneté n'est pas l'objet du procès: c'est un honos que Pompée a octroyé à Balbus, ce n'est pas une ignominia. Alors que l'ignominia provoque une disqualification sociale, l'honos, lui, a des effets positifs et améliore la position du sujet au sein de la collectivité: ici, Balbus est agrégé au groupe des citoyens par l'honos qui lui est fait. Il s'agit maintenant de préciser le bénéfice social indiqué par l'honos, de voir ce qui fait pendant à /l'impossibilité de mériter l'estime collective/ engendrée par l'ignominia ${ }^{84}$.

La marque d'honneur place celui qui la reçoit au premier plan et le sépare de la masse des autres personnes. Dans le De republica, Cicéron rappelle la conduite tenue par les anciens vis-à-vis des acteurs:

Cum artem ludicram scaenamque totam in probro ducerent, genus id hominum non modo honore ciuium reliquorum carere, sed etiam tribu moueri notatione censoria uoluerunt.

«Comme ils jugeaient déshonorant tout ce qui touche à l'art théâtral et à la scène, ils résolurent non seulement de priver ceux qui s'y adonnaient de toute distinction que pouvaient obtenir les autres citoyens, mais encore de les exclure de leur tribu, en vertu de la note censoriale.»

(Cic.Rep.IV, 13, frg. 1; trad. Bréguet).

Le probrum naissant de la représentation scénique interdit toute possibilité d'honos et entraîne une notatio censoriale qui les relègue dans une tribu à part ${ }^{85}$. La notatio marque et sépare les acteurs des autres citoyens, et possède les effets inverses de l'honos, apte lui aussi à induire une ségrégation, mais de nature positive, à élever au-dessus de la masse des ciues. Et de fait, la distinction apportée par l'honos prend souvent la forme d'un ascendant sur les autres. Les honores conférés à Octave l'élèvent au-dessus des autres hommes et ceux que le général en chef accorde à un soldat lui donnent une position supérieure à celle des autres combattants ${ }^{86}$. L'élévation que connaît le

\footnotetext{
${ }^{84}$ C'est le sème retenu par J.-F. Thomas, Ibid., p. 299.

${ }^{85}$ Sur la condition des acteurs, voir infra p. 309.

${ }^{86}$ Cic. Phil. V, 48; SalL.Iug. 49, 4.
} 
sujet honoré se fait au sein de la collectivité à laquelle il appartient, et prend donc la forme d'une amélioration du statut. Cette singularisation apportée par l'honos peut aussi prendre la forme de l'illustration: l'honos valorise la personne en lui conférant un éclat visible. Plusieurs images explicitent cette idée. L'individu, d'abord peut être «orné» par un honos. On rencontre à plusieurs reprises le syntagme ornatus honore ou honoribus ${ }^{87}$. Le terme est aussi associé directement à ornamentum ${ }^{88}$ ou apparaît dans des constructions du type honore decorare $^{89}$. Il arrive aussi que l'honos soit métaphoriquement présenté comme porteur d'une lumière qui fait resplendir son possesseur. Dans l'exorde du deuxième discours sur la loi agraire, Cicéron dit ne pas bénéficier de l'éclat qu'apporte l'honneur des ancêtres:

Mihi, Quirites, apud uos de meis maioribus dicendi facultas non datur, non quo non tales fuerint qualis nos illorum sanguine creatos disciplinisque institutos uidetis, sed quod laude populari atque honoris uestri luce caruerunt.

«Quant à moi, Quirites, je ne peux parler devant vous de mes ancêtres, non pas qu'ils furent différents de ce que vous me voyez être, moi qui suis né de leur sang et ai été éduqué par leurs leçons, mais parce qu'ils n'ont pas bénéficié de la gloire auprès du peuple et de l'éclat qu'apportent vos honneurs. »

(CIC.Agr.II, 1).

La lux honoris n'a pas brillé pour les ancêtres de Cicéron puisque ce dernier est un homo nouus. L'honos se rapproche ici de la gloire (laus), fréquemment présentée comme porteuse d'une splendeur brillante $^{90}$. Ces différents textes actualisent l'idée d'un effet social positif de l'honos, qu'il s'agisse de distinction, d'élévation ou d'illustration. Cet aspect peut être synthétisé en un seul sème: l'honos est ce qui /confère une position éminente dans la société/.

\subsection{Les autres effets de l'honos}

Il est possible d'établir avec plus de précision les contours sémantiques de l'honos tels qu'ils sont dessinés par les textes en nous intéressant à des traits de sens qui ne sont pas systématiquement actualisés mais peuvent être virtualisés ${ }^{91}$. Le terme d'honos implique dans certains cas, outre une position sociale éminente, une autorité sur l'entourage, non pas sous la forme d'un pouvoir officiel mais d'une influence plus diffuse. Cherchant à donner des preuves de la culpabilité des Mamertins et de leur complicité avec Verrès, Cicéron fait

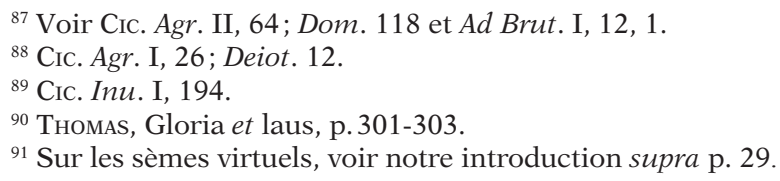


remarquer qu'ils ne lui ont pas fait l'honneur de l'hospitalité qui lui était due en sa qualité de magistrat:

Qui honos non homini solum habetur, sed primum populo Romano, cuius beneficio nos in hunc ordinem uenimus, deinde ordinis auctoritati, quae nisi grauis erit apud socios et exteras nationes, ubi erit imperi nomen et dignitas?

«Cet honneur n'est pas rendu seulement à la personne, mais avant tout au peuple romain dont les bienfaits nous ont placé dans le sénat, ensuite à l'autorité de l'ordre sénatorial; car si elle n'est puissante auprès des alliés et des peuples étrangers, où résidera le renom et la dignité de notre souveraineté ? »

(CIc. Verr.II, IV, 25 ; trad. Rabaud modifiée).

L'honos est ici appelé par l'auctoritas de l'ordre sénatorial, mais il est aussi ce qui contribue à rendre cet ordre grauis, à lui donner importance et sérieux. Il est grave que l'honos n'ait pas été octroyé à un sénateur, car ce manquement compromet l'auctoritas sénatoriale qui aurait dû être renforcée par la marque d'honneur ${ }^{92}$. Ce rapport de cause à effet entre honos et auctoritas réapparaît dans le Pro rege Deiotaro, quand Cicéron demande à César de pardonner à Déjotarus d'avoir suivi Pompée: le roi a cédé, de façon compréhensible, à l'auctoritas de Pompée, fondée sur les ornamenta et les honores dont il était chargé93. L'honos peut donc constituer un élément de prestige et d'influence. On comprend dès lors qu'il soit recherché par l'ambitiosus ${ }^{94}$ et puisse être associé à la gratia et à la potentia ${ }^{95}$. Ce sème virtuel peut être formalisé de la façon suivante: (/position éminente/) /susceptible d'être / assortie d'influence/. Il est actualisé dans environ $50 \%$ des occurrences.

\subsection{Conclusion}

Nous pouvons à présent présenter le sémème complet d'honos au sens « marque d'honneur » : /bienfait / signe / d'estime, / octroyé en reconnaissance / de certains mérites, / qui confère une position éminente dans la société, / susceptible d'être assortie / d'influence/.

Ces éléments vont nous permettre d'éclairer le rapport d'honos à d'autres termes de sens proche. Nous avons pu constater certaines convergences entre honos et praemium. L'honos est même défini comme un praemium uirtutis par Cicéron qui se plaît par ailleurs à associer les deux termes ${ }^{96}$. Le sens principal de praemium, «récompense», présente

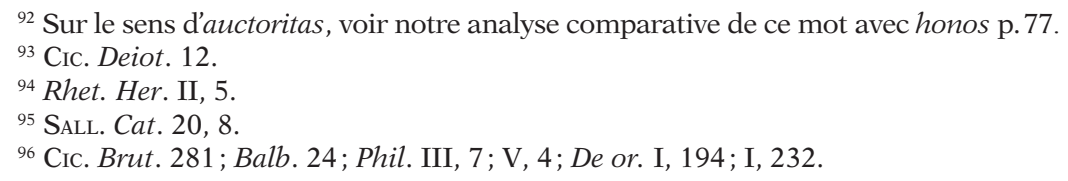


de fait plusieurs similitudes avec honos. Il implique un donateur qui confère à un tiers un bénéfice matériel qui peut prendre différentes formes: somme d'argent, droit de cité, notoriété étendue, triomphe, applaudissements,... ${ }^{97}$ Le praemium récompense des beneficia de nature variée, ceux que Cicéron recommande par exemple d'examiner dans les causes qui traitent de la récompense $\mathrm{e}^{98}$. Il a, comme l'honos, une fonction compensatoire: c'est un geste de reconnaissance qui permet de répondre à un bienfait reçu par un autre bienfait ${ }^{99}$. Cependant, des différences sont mises en lumière par les contextes où praemium est utilisé. Praemium suppose une rétribution matérielle qui n'a pas la nature d'un signe complexe comme honos : praemium ne signifie pas l'estime, ce n'est qu'une simple compensation concrète. Honos apparaît en outre comme un terme plus prestigieux que praemium. La raison en est que praemium n'implique pas l'obtention d'une position sociale élevée: il ne modifie pas le statut de la personne qui le reçoit et ne lui confère aucun prestige particulier, alors qu'honos procure une position éminente. Concernant les motifs impliqués par les deux termes, praemium n'est pas toujours fondé sur des actes glorieux: il peut récompenser une dénonciation, une trahison ou un complot, ce qui n'est pas le cas d'honos ${ }^{100}$. Et même quand l'action récompensée par un praemium est positive, elle n'est souvent pas aussi méritoire que celle qui vaut l'honos ${ }^{101}$. La divergence entre les deux mots est aussi sensible quand on observe l'étymologie de praemium: issu de *prai-emion, *prae-emium, le terme désigne initialement la part d'un butin de guerre consacrée au dieu ou donnée au général vainqueur ${ }^{102}$. Un des sens de praemium est d'ailleurs celui de "butin ${ }^{103}$, ce qui rapproche le mot de praeda plutôt que d'honos: praemium est plus ancré du côté de la rétribution que de celui de l'honneur.

Le terme pretium, qui a des sens variés, peut lui aussi signifier la « récompense » intervenant en retour d'un service rendu ${ }^{104}$. Il a de ce fait, comme praemium, un certain nombre de traits communs avec honos avec qui il est parfois associé ${ }^{105}$. Il renvoie à la rétribution de mérites, comme le courage ou des qualités morales plus générales ${ }^{106}$. Il est une réponse à des bienfaits ou à la peine prise par quelqu'un, comme on le

${ }^{97}$ Respectivement, CIc. Inu. II, 111 ; Balb. 43 ; Mil. 97 ; Inu. II, 111 ; PL. Cap. 1036.

98 CIC. Inu. II, 113.

${ }^{99}$ Ce mécanisme est explicité par Cic. Balb. 22.

${ }^{100}$ Cic. Sull. 51 ; Vat. 11 ; SAll. Cat. 17, 1.

${ }^{101}$ Cic. Phil.V, 4 distingue le praemium octroyé aux soldats de l'honos conféré au général en chef.

${ }^{102}$ DELL: «part de butin prise à l'ennemi et prélevée pour être offerte à la divinité qui a donné la victoire, ou au général vainqueur» (p. 531).

${ }^{103}$ Pl. Pseud. 1225; CAEs. BC III, 82, 1 ; Ov.Met. VI, 518.

${ }^{104}$ Pretium peut aussi rentrer en relation de synonymie avec honos quand ce dernier a le sens de "considération».

${ }^{105}$ LucIL. frg. XXX, 85 Charpin = 1040 Marx.

${ }^{106}$ PL. Trin. 274 : hoc probis pretiumst. Pl. As. 128; TER. Andr. 29; CIc. Leg. I, 48. 
voit dans le sens initial de la formule, ensuite figée, operae pretium est ${ }^{107}$. Cependant, le sémantisme de pretium s'écarte de celui d'honos, notamment parce que le mot reste fortement centré sur un paradigme financier: pretium désigne fondamentalement la dépense, le prix versé pour quelque chose, et peut prendre la forme d'une rançon, d'un pot-de-vin ou d'un salaire ${ }^{108}$. Comme praemium, pretium ne signifie pas l'estime: c'est une rétribution plus qu'un hommage car celui qui la reçoit n'en est pas socialement transformé. Le terme est en outre moins valorisant que ne l'est honos.

Decus est également proche d'honos sur le plan sémantique. Les deux mots partagent plusieurs sens, mais nous nous limiterons à observer le sens «ornement» que détient decus et qui le rapproche de la «marque d'honneur" signifiée par honos. Decus peut renvoyer à un ornement lié au prestige ou à la gloire, qui provoque l'illustration de celui qui le détient, comme honos confère un rang éminent au sein de la société: le triomphe est un decus, de même que la cuirasse donnée comme trophée militaire ${ }^{109}$. Une personne peut même être qualifiée de decus, au sens où elle fait honneur au groupe auquel elle appartient: on peut être ainsi le decus populi ${ }^{110}$. Mais les textes où le mot apparaît montrent qu'il implique une action et un bénéfice différents de ceux de l'honos: le decus est prestigieux parce qu'il orne et embellit celui qui le reçoit. Un decus modifie positivement l'aspect extérieur d'une personne, ce que n'implique pas toujours honos. Decus signale l'octroi d'une splendeur brillante: le mot est souvent repris par lumen ou parflos, ce qui suggère un apport esthétique et non seulement un bénéfice de prestige ${ }^{111}$. Le mot peut d'ailleurs signaler un ornement matériel sans rapport avec la distinction sociale: la lune est qualifiée de noctis decus, et le bonnet de Lucumon est son capitis decus ${ }^{112}$. Decus est un substantif neutre formé sur decet, qui préserve dans son sémantisme l'idée que c'est une chose qui sied, un ornement adapté. Les effets dénotés par honos et decus divergent donc: le premier relève de l'autorité et du prestige social alors que le second renvoie à une illustration et une distinction proches de la beauté.

On peut enfin rapprocher le sens d'honos «marque d'honneur» de laus quand le mot signifie «éloge, louange ${ }^{113}$. Le terme désigne alors

${ }^{107}$ PL. Amp. 151.

108 Rançon: Cic. Off. III, 107. Pot-de-vin: Ter. Ad. 349; Sall. Cat. 49, 1. Salaire: PL. Vid.30; Liv. VIII, 38, 1.

${ }^{109}$ Cic. Prou. 28; Verg. Aen. V, 262.

110 PL. As. 655.

${ }^{111}$ Lumen: Cic. Phil. II, 54 ; XI, 14. Flos : Cic. Flac. 75

112 Apul. Soc. 1, 15 ; Liv. I, 34.

113 Voir l'analyse sémantique qu'en donne Thomas, Gloria et laus, p. 236-255. Voir aussi Hellegouarc' H, Vocabulaire, p. 365-369 et L. Pernot, La Rhétorique de l'éloge dans le monde gréco-romain, Paris, Brepols, 1993. 
un acte concret, l'éloge, qui peut être adressé à un dieu, un général victorieux, à un défunt ou à des particuliers dans diverses circonstances moins codifiées ${ }^{114}$. Le mot implique l'appréciation favorable de la personne qui le donne, tout comme honos renvoie à un signe d'estime: il s'oppose à uituperatio et acrimonia qui indiquent le blâme et l'hostilité115. Comme honos, laus suppose aussi que la personne visée est fortement valorisée et que la louange se fonde sur des mérites remarquables ${ }^{116}$. Malgré ces points communs, laus se distingue d'honos car son référent est plus précis: l'éloge est un type particulier d'hommage, prenant une forme orale ${ }^{117}$. L'honos valorise la personne par le truchement d'objets et de gestes plus variés. Laus ne confère pas en outre à celui qui le reçoit d'autorité, mais simplement une position valorisée qui n'implique pas de pouvoir sur les autres.

\section{4. «CONSIDÉRATION » (S2)}

Honos est également apte à désigner la "considération", l' "estime» dont quelqu'un jouit auprès des autres. Le terme dénote l'appréciation favorable dont bénéficie une personne au sein de la collectivité, la situation de faveur dans laquelle elle se trouve. Honos ne renvoie plus ici à une marque concrète d'honneur mais à la position de prestige dont jouit l'individu; ce n'est plus un acte ou un objet, mais une situation. Honos peut alors être traduit par "considération », "estime», "prestige»; " honneur» est également adéquat, dans la mesure où honos se rapproche ici du mot français quand ce terme désigne l'estime dont bénéficie une personne pour ses qualités morales ou ses actions, comme dans l'expression "être à l'honneur». L'honos se rapproche alors d'autres notions essentielles de la culture romaine, telles que gloria, laus, fama, decus, dignitas, auctoritas ou gratia. Ce sens est aussi ancien que le précédent puisqu'on le rencontre chez Plaute et Ennius $^{118}$. Il est cependant moins fréquent et n'apparaît que dans une occurrence sur quatre environ.

${ }^{114}$ Voir par exemple PL. Mil. 411-414 ; Liv. VII, 7, 3 ; Cic. De or. III, 117. J. Hellegouarc'h insiste justement sur la valeur active du mot: "laus implique [...] la volonté consciente d'élever et d'exalter»(Hellegouarc'H, Vocabulaire, p. 366).

115 Thomas, Gloria et laus, p. 251. Voir Cic. Prou. 44 ; Rhet. Her. IV, 50.

${ }^{116}$ Ibid., p. 252-254.

${ }^{117}$ L'étymologie de laus est problématique mais on retient en général l'hypothèse qui rapproche le mot d'un radical *leu-t, attesté dans got. liupōn «chanter, louer» et vx. nor. ljopa (même sens), ang. sax.léopian (même sens). Voir DELL s.v.laus: "le sens ancien de laus devait être 'fait de nommer, de citer'; le mot s'est spécialisé dans une acception favorable. »

${ }^{118}$ PL. Cap. 277 ; Epid. 35 ; EnN. Evh. frg. X Vahlen. 


\subsection{Acception active et acception passive}

Parmi les différents sens d'honos présentés par les ouvrages de lexicographie, celui d' "estime», "considération» est souvent séparé en deux acceptions. On lit ainsi au début de l'article de l'OLD: «High esteem or respect accorded to superior worth or rank, honour. B.As enjoyed by the recipient»(p.801). L'OLD oppose ainsi ce qu'on peut nommer l'estime "active» ou "subjective», la considération qu'on nourrit pour quelqu'un, à l'estime " passive» ou « objective », la considération que l'on possède, dont on jouit. On retrouve cette distinction dans le TLL où deux sens sont disjoints: honos comme "actus positus in intellectu (fere i.q. 'aestimatio')»; honos comme "res distinguens sua ipsius uirtute, inhaerens, i. q. gloria, laus, dignitas, maiestas sim. ». Il faut souligner, de plus, que le sens d' "estime active» est présenté par les deux dictionnaires comme premier. Cette primauté chronologique est également ressentie par H. Quellet:

"Comme fauor 'disposition favorable, sympathie', puis 'marque de sympathie, faveur', honos paraît désigner d'abord un état, une disposition intérieure visà-vis de quelqu'un, 'le fait d'avoir de la considération pour quelqu'un' (cf.aliquem in honorem habere), puis, concrètement, le 'témoignage' de cette considération, 'estime, hommage, honneur(s), charge honorifique', etc. (cf.aliquem honore afficere, honorem habere alicui, honoris causa)». ${ }^{119}$

La confrontation de ces différentes définitions avec les textes appelle une réserve importante car l'acception active, "l'estime que je nourris pour quelqu'un", nous paraît pour ainsi dire inexistante. Plusieurs éléments nous ont mené à cette constatation. D’abord, la faiblesse numérique et qualitative des exemples convoqués à l'appui de l'acception subjective. Le TLL avance quelques textes, comme ce fragment de Plaute:

Honos syncerasto periit, pernis, glandio.

«L'honneur a péri à cause du ragoût, des jambons, du ris de porc.»

(PL.frg. 101 Ernout).

Le vers est d'interprétation difficile étant donné son caractère isolé ; mais on peut mettre en doute que syncerasto, pernis, et glandio soient des datifs d'intérêt, désignant les destinataires de l'honos, ainsi que semble le suggérer le TLL. Il s'agit plutôt d'ablatifs de cause. Ce n'est pas l'honos "pour le ragoût, le jambon et les ris de porc» qui a péri, mais plutôt l'honos qui a péri «à cause du ragoût» et des autres mets. L'honos n'est pas l'estime qu'on accorde à la nourriture, mais plutôt l'estime dont quelqu'un jouit (le personnage du goinfre probablement, 
qui est évoqué par le titre de la comédie, Phago), et qui a disparu à cause de ses excès de table. Le sens actif d'honos est donc loin de s'imposer de manière indiscutable. Il faut ensuite souligner que, à la différence de ce que l'on observe pour le sens «marque d'honneur", honos avec le sens " estime» est presque toujours référé à la personne qui en bénéficie, et jamais à un sujet qui la ressentirait comme un sentiment. On ne trouve par exemple jamais l'expression *honos meus erga te au sens de «l'estime que j'ai pour toi ». En revanche, un possessif ou un complément au génitif marque souvent la personne qui bénéficie de ce bien qu'est l'honos. C'est le cas dans ce passage de Cicéron:

Putaui, speraui, etiam si honos noster uobis uilior fuisset, salutem certe caram futuram.

«J'ai pensé, j’ai esperé que même si notre prestige vous avait été assez indifférent, notre salut, lui, vous serait cher.»

(CIC.Flac. 103).

En outre, des métaphores telles que honorem tollere, honorem demere ou honorem depeculari'120 invitent à comprendre l'honos "estime» comme un objet qu'on détient. La tournure in honore indique également que l'honos est une situation dans laquelle on se trouve $^{121}$. Quand un auteur veut évoquer la personne qui ressent de la considération, il le fait par le tour apud aliquem, et l'honos reste donc un bien appartenant au destinataire, comme on le voit dans ce passage de Cicéron, où il est question des marchands romains maltraités par Verrès:

[...] ut qui usque ex ultima Syria atque Aegypto nauigarent, qui apud barbaros propter togae nomen in honore aliquo fuissent, qui ex praedonum insidiis, qui ex tempestatum periculis profugissent, in Sicilia securi ferirentur, cum se iam domum uenisse arbitrarentur?

«[...] au point que ceux qui débarquaient du fin fond de la Syrie et de l'Égypte, qui avaient joui de quelque honneur chez les barbares en raison du renom de la toge, qui avaient échappé aux embuscades des pirates et aux dangers des tempêtes, étaient frappés de la hache en Sicile, alors qu'ils pensaient être enfin rentrés chez eux?»

(Cic. Verr. II, V, 157).

L'honos appartient bel et bien aux Romains, et la préposition apud n'introduit les barbares que de manière périphérique.

Laspect passif ou objectif d'honos nous paraît donc largement prépondérant. En conséquence, honos diffère d'un mot comme fama, car ce dernier a un versant actif et un versant passif bien définis; c'est la "voix publique» d'une part, et la «renommée» d'autre part. Honos n'a pas cette bipolarité ${ }^{122}$.

\footnotetext{
${ }^{120}$ Respectivement, CIc. Verr. II, IV, 79 et II, V, 84; Lucr. DRN V, 1114.

${ }^{121}$ Cic.Rosc. Amer 77 ; Verr. II, V, 157 ; De or. I, 235 ; Brut. 30.

${ }^{122} \mathrm{Ce}$ n'est donc pas exactement une notion « à double face », comme le dit R. Heinze
} 


\subsection{Une situation d'estime}

Honos désigne une situation particulière au sein de la collectivité. Nous avons un premier aperçu de sa nature avec un passage du Trinummus où Lysitélès renonce à l'amour et déclare vouloir se consacrer à la sagesse et à la vie publique:

Boni sibi haec expetunt, rem, fidem, honorem,

Gloriam et gratiam: hoc probis pretiumst.

«Les gens de bien, voilà ce qu'ils recherchent: la fortune, le crédit, l'honneur, La gloire et l'influence: voilà le salaire de la probité.»

(PL.Trin. 272-273).

Honos est ici associé à fides, gloria et gratia, qui renvoient tous à une position de faveur. Ces associations de termes sont courantes, et plus particulièrement celles d'honos avec laus et gloria ${ }^{123}$. Chaque terme possède cependant des particularités: fides, c'est le crédit, jouir de la confiance des autres. Gloria, c'est la gloire, une notoriété éclatante. Gratia renvoie à la popularité, à l'influence, notamment politique. L'honos suppose, quant à lui, une appréciation et un jugement positifs de la part de l'entourage. C'est perceptible avec ce passage du livre V du De rerum natura où il est question de l'origine de la royauté et de la richesse:

Condere coeperunt urbis arcemque locare

Praesidium reges ipsi sibi perfugiumque,

Et pecus atque agros diuisere atque dedere

Pro facie cuiusque et uiribus ingenioque;

Nam facies multum ualuit uiresque uigebant.

Posterius res inuentast aurumque repertum,

Quod facile et ualidis et pulchris dempsit honorem.

«Les rois commencèrent à fonder des villes et à placer leur citadelle

Pour qu'elle leur serve de défense et de refuge,

Et ils divisèrent puis distribuèrent le bétail et les champs

Selon la beauté, la force et l'esprit de chacun;

La beauté en effet avait du prix et la force était très estimée.

Plus tard on inventa la richesse et on découvrit l'or,

Qui ravirent facilement leur prestige à la force et à la beauté. »

(LuCR. DRN V, 1108-1114).

Les qualités personnelles telles que la beauté, la force, l'intelligence bénéficiaient initialement d'un grand honos qui leur a été ensuite ravi

qui évoque les doppelseitige Begriffe du latin, des notions ayant un versant subjectif et objectif. Voir R. HeInze, «Fides», Hermes, 64, 1929, p. 140-166.

${ }^{123}$ Pour laus, voir CIc.Inu. I, 5; Verr. II, III, 43; Catil.III, 26; Cael.46; Part.91. Pour gloria, voir Cat. frg. inc. 252 ORF ; Cic. Rep. III, 36; Leg. III, 31-32; Sall. Cat. 11, 1-2. 
par la richesse. Avoir l'honos, c'est donc être prisé, avoir de la valeur. Une chose est in honore quand elle est « estimée » au sens quasi économique du terme ${ }^{124}$. Soulignant les bienfaits de la famille de Marcellus à son égard, Cicéron écrit:

Patris tui beneficia in me sunt amplissima; neque enim saluti meae neque honori amicior quisquam dici potest; frater tuus quanti me faciat semperque fecerit esse hominem, qui ignoret arbitror neminem.

«Les bienfaits de ton père à mon égard sont immenses; personne n'a jamais été plus attaché à mon salut et à mon honneur; en quelle estime me tient et m’a toujours tenu ton cousin, aucun homme ne l'ignore, je pense.»

(Cic. Fam. XV, 10, 2).

Cicéron bénéficie de l'honos parce que le cousin de Marcellus fait grand cas de lui (quanti me faciat), l'évalue à haut prix: l'honos est une situation d'estime. Il entre d'ailleurs parfois en relation de synonymie avec existimatio, quand ce terme a une acception objective ${ }^{125}$. Honos se rapproche ici de la bonne réputation, désignée par nomen ou fama, termes avec lesquels il est parfois coordonné, comme lorsque Cicéron réplique à ceux qui le traitent de peregrinus qu'à Rome et nomen et honos inueterauit, "sa réputation et son honneur se sont fixés depuis longtemps » ${ }^{126}$. La iunctura sert ici à renforcer l'expression, notamment parce qu'honos porte une valeur légèrement plus forte que nomen ${ }^{127}$. Honos suppose un jugement de la part des autres et la circulation de propos favorables. Mais il comporte aussi une importante dimension visuelle, qui fait que la personne in honore est regardée, "considérée» au sens premier du terme. Cet aspect visuel d'honos l'écarte de nomen et fama qui sont de l'ordre de la réputation " auditive». Parlant de Caecilia auprès de qui Roscius a trouvé refuge, Cicéron dit d'elle que c'est une femina spectatissima, qui bénéficie d'un grand honos ${ }^{128}$. Décrivant l'envie qui ronge les hommes, Lucrèce insiste sur le fait que celui qui incedit honore attire les regards et excite les passions:

Consimili ratione ab eodem saepe timore

Macerat inuidia: ante oculos illum esse potentem,

${ }^{124}$ Voir le parallélisme de esse honore avec in pretio dans Lucr. DRN V, 1273. Sur le paradigme économique de l'honos, voir infra p. 223 sqq.

${ }^{125}$ CIc. Quinct. 72. Le parallèle sémantique d'honos et d'existimatio sert ici à souligner la structure syntaxique de la phrase. Voir J.-F. Thомаs, « Les fonctions linguistiques de la synonymie lexicale en latin", in Moussy, C. (éd.), De lingua latina nouae quaestiones. Actes du $x^{e}$ colloque international de linguistique latine, Paris-Sèvres, 19-23 avril 1999, Louvain, Peeters, 2001, p. 875-890, notamment p. 878-879.

${ }^{126}$ Cic. Sull.24. Voir aussi Verr. II, II, 87.

${ }^{127}$ Sur cette fonction linguistique de la iunctura de deux synonymes, voir THOMAs, «Les fonctions linguistiques de la synonymie lexicale en latin », p. 887.

${ }^{128}$ Cic. Rosc. Amer. 147. 
Illum aspectari, claro qui incedit honore, Ipsi se in tenebris uolui caenoque queruntur. Intereunt partim statuarum et nominis ergo.

«Par un procédé très semblable, l'envie, naissant souvent de la même peur Les tourmente: celui-ci affiche sous leurs yeux sa puissance, gémissent-ils, Celui-là attire les regards et s'avance dans l'éclat de l'honneur, Alors qu'eux-mêmes se roulent dans les ténèbres et la fange. Certains périssent pour des statues et pour un nom.»

(LucR. DRN III, 74-78).

Ces éléments nous amènent à distinguer un sème générique pour le sens "considération», qui est celui de /situation d'estime/. Se dessine ainsi une antonymie entre ce sens d'honos et des termes dont certains ont déjà été reconnus comme étant de sens contraire, tels qu'ignominia. L'ignominia désigne en effet l'affront, l'humiliation, mais peut aussi dénoter le "déshonneur ${ }^{129}$, la situation où l'on est privé de toute possibilité de considération, comme dans ce passage où se révèle l'antonymie avec honos:

Ibit igitur in exilium miser? Quo? Ad Orientisne partis in quibus annos multos legatus fuit, exercitus duxit, res maximas gessit? At habet magnum dolorem, unde cum honore decesseris, eodem cum ignominia reuerti.

«Il ira donc en exil, le malheureux? Mais où? Dans ces contrées de l'Orient où il fut légat pendant plusieurs années, où il a mené des armées, où il a accompli de grandes choses? Mais c'est une grande douleur de revenir couvert d'opprobre à l'endroit d'où l'on est parti couvert d'honneur. »

(CIc.Mur. 89).

Cicéron déplore le sort qui paraît réservé à Muréna, qui s'est autrefois distingué par ses hauts faits militaires qui lui valurent la considération de son entourage. Il risque aujourd'hui le déshonneur qui naîtrait d'une sentence d'exil. L'ignominia est la position du sujet privé de l'estime de la collectivité et dans l'impossibilité d'y prétendre, et s'oppose à honos qui désigne la situation où la personne jouit pleinement de cette considération publique. Honos s'oppose aussi aux autres termes relevant du même champ lexical qu'ignominia, comme infamia ${ }^{130}$ ou encore dedecus ${ }^{131}$.

\subsection{Un bénéfice social connexe}

Honos possède une autre particularité sémantique dans le lexique de la faveur publique: le mot implique l'existence d'un bénéfice de

${ }^{129}$ Thомаs, Déshonneur et honte p. 306-312.

${ }^{130}$ Voir par exemple Cic. Part. 91.

${ }^{131}$ Rhet.Her.IV, 57. Voir le sémème de dedecus établi par Thomas, Déshonneur et honte, p. 94. 
statut social qui vient se greffer à la situation d'estime dont jouit l'individu. Évoquant le risque qu'il y a pour une cité à avoir de mauvais chefs, Cicéron conclut:

Pauci enim atque admodum pauci honore et gloria amplificati uel corrumpere mores ciuitatis uel corrigere possunt.

"Il suffit de quelques gens peu nombreux et même très peu nombreux, qui soient grandis par l'honneur et la gloire, pour corrompre ou corriger les mœurs d'une cité.»

(Cıc. Leg. III, 32 ; trad. De Plinval modifiée).

L'honos confère à une personne un rôle primordial au sein de la cité puisqu'il l'établit comme modèle aux yeux des autres et lui donne une grandeur distinctive ${ }^{132}$. Il permet à un individu de gagner une supériorité sociale sur ses semblables comme le montre la définition que donne Cicéron du respect dans le De inuentione:

Obseruantiam, per quam aetate aut sapientia aut honore aut aliqua dignitate antecedentes ueremur et colimus.

«Le respect est ce qui nous porte à montrer de la vénération et des égards envers ceux qui l'emportent sur nous par l'âge, la sagesse, l'honneur, ou quelque dignité. »

(CIc. Inu. II, 66; trad. Achard modifiée).

L'honos est ce par quoi un individu précède les autres (antecedentes) et ce qui impose à son entourage de le traiter avec respect. Il permet de se distinguer au sein de sa famille et de l'emporter sur les autres citoyens ${ }^{133}$. Cette supériorité peut même devenir absolue quand, par l'honos, un homme devient le princeps de sa cité134. On retrouve en outre pour ce sens d'honos des images que nous avions identifiées à propos du sens «marque d'honneur» car le terme implique une splendeur brillante qui s'ajoute à l'idée de supériorité, comme dans ce passage du Trinummus:

Et postremo, nisi mi auscultas atque hoc ut dico facis,

Tute pone te latebis facile, ne inueniat honor;

In occulto iacebis, cum te maxume clarum uoles.

«Et enfin si tu ne m'écoutes pas et si tu ne fais pas comme je dis,

Tu seras si bien caché derrière toi-même, qu'il ne te trouvera pas, l'honneur; Tu stagneras dans l'ombre, alors que tu voulais briller plus que tout. »

(PL. Trin. 662-664).

${ }^{132}$ L'idée d'ampleur est récurrente: voir Cic. Parad. V, 40. Plusieurs syntagmes associent honos à amplitudo (CIc. Verr. II, II, 157; Clu. 150).

${ }^{133}$ Voir CIL I², 10 et Cic. Sull. 24.

${ }^{134}$ CIc. Verr. II, I, 64 ; Flac. 79. ; Rep. II, 34. 
Honos, ici personnifié, apporte à celui qui l'obtient une aura lumineuse qui l'arrache à l'obscurité ${ }^{135}$. Selon une autre métaphore, on peut aussi être florens honore ${ }^{136}$, ce qui indique ici encore le prestige émanant de la personne in honore. La supériorité sociale et la distinction associées à la situation de faveur que désigne honos font que le terme tend à se rapprocher à nouveau de dignitas quand ce mot désigne le rang et la dignité sociale du Romain. Crassus conclut son éloge de l'éloquence dans le De oratore en ces termes:

Ac ne plura, quae sunt paene innumerabilia, consecter, comprendam breui: sic enim statuo, perfecti oratoris moderatione et sapientia non solum ipsius dignitatem, sed et priuatorum plurimorum et uniuersae rei publicae salutem maxime contineri. Quam ob rem pergite ut facitis, adulescentes, atque in id studium in quo estis incumbite, ut et uobis honori et amicis utilitati et rei publicae emolumento esse possitis.

«Et pour ne pas m'étendre sur des détails qui seraient presque infinis, je résumerai brièvement: je considère que de la modération et de la sagesse de l'orateur parfait dépendent non seulement son propre prestige, mais aussi et surtout le salut de très nombreux citoyens et de la république tout entière. C'est pourquoi, jeunes gens, continuez comme vous le faites, appliquez-vous à cette pratique que vous étudiez, pour pouvoir être à vous-mêmes source d'honneur, à vos amis source d'utilité, et à la république source de profit. »

(CIc. De or. I, 34).

Le bénéfice de l'art oratoire est double: il sert l'orateur en lui apportant de la dignitas, idée reprise par l'exhortation à être à soi-même source d'honos, et il profite à la salus de la République, idée elle aussi reformulée par les notions d'utilitas et de commodum. Honos apparaît ainsi en relation de synonymie avec dignitas pour désigner l'estime associée à un rang social distinctif ${ }^{137}$. Nous retrouvons donc un sème déjà identifié pour le sens «marque d'honneur», celui de la/position éminente dans la société/.

\subsection{Les fondements de la considération}

Comme pour le sens "marque d'honneur », les contextes où apparaît honos "considération" actualisent fortement la notion d'un mérite à la racine de l'estime. En revanche, le trait de sens de la /reconnaissance/ disparaît ici pratiquement. Les qualités ou actions qui donnent lieu à l'honos sont proches de ce que nous avons observé précédemment. Le dévouement pour la patrie est ainsi une occasion privilégiée pour obtenir

${ }^{135}$ L'image se rencontrait déjà dans le texte de Lucrèce cité supra (DRN, III, 74). Sur cet aspect, voir BARTON, Roman Honor, p. 34: l'homme d'honneur est souvent splendidus, illustris ou clarus. Sur la dimension physique et visible de l'honos, voir aussi Lendon, Empire of Honour, p. 47.

${ }^{136}$ CIc. Quinct. 72 ; Sest. 136.

${ }^{137}$ L'emploi des deux synonymes relève ici d'un souci stylistique apparenté à la uariatio. Cf. Cic. Sull. 5. Sur cet usage, voir Thомаs, «Les fonctions linguistiques de la synonymie lexicale en latin », p. 883. 
la considération de l'entourage. Au début de la troisième Catilinaire, Cicéron se réjouit d'avoir sauvé la patrie et de mériter ainsi l'honos:

[...] esse apud uos posterosque uestros in honore debebit is qui eandem hanc urbem conditam amplificatamque seruauit.

«[...] il devra être à l'honneur chez vous et chez vos descendants celui qui a sauvé cette même ville qui avait autrefois été fondée et agrandie.»

(CIc. Catil. III, 2).

La pratique de l'éloquence est pour Cicéron une source d'honos, de même que l'excellence dans le domaine militaire ${ }^{138}$. L'honos peut à l'inverse se perdre quand l'individu se rend coupable de méfaits ou d'actions honteuses. Les iuuenes de la palliata mettent ainsi souvent en péril leur image publique par la fréquentation des courtisanes, comme l'explique l'esclave Cyame à propos de son maître Diniarque:

Velut haec meretrix meum erum miserum sua blanditia

Intulit in pauperiem,

Prinauit bonis, luce, honore atque amicis.

«C'est comme cette courtisane qui, par ses caresses, a réduit mon pauvre maître À la misère,

L'a privé de ses biens, de la lumière, de l'honneur, de ses amis. »

(PL. Truc. 572-574).

Le jeune homme a perdu tout ce qui fait son identité sociale, richesse, honneur, amis, en raison de sa fatale passion pour une meretrix. Ces différents éléments nous permettent d'isoler un sème: la situation d'estime qu'est honos est/fondée sur certains mérites/.

\subsection{Les effets de la situation d'estime}

Afin de parachever la description sémique d'honos "considération", il nous faut encore relever deux traits de sens qui concernent les effets de la situation de faveur que désigne honos. Le premier d'entre eux, actualisé dans environ $50 \%$ des occurrences, est identique à celui, également virtuel, repéré pour le sens «marque d'honneur»: il s'agit de l'autorité et de l'influence du bénéficiaire de l'honos. L'honos des anciens est ainsi un des éléments constitutifs de leur autorité et participe à la perpétuation du mos maiorum ${ }^{139}$. Si Crassus parle de l'honos que le droit civil apporte à celui qui le maîtrise parfaitement, c'est parce que le juriste qui a cette connaissance est estimé mais constitue aussi une figure de référence: il

${ }^{138}$ Cic. Inu. I, 5 et Mur. 12.

${ }^{139}$ Cic. Brut. 69. Sur cette fonction de l'honos, voir le chapitre 8. 
est consulté sur des points de droit par les Romains ${ }^{140}$. L'honos désigne ainsi un prestige qui se mêle d'autorité. Il est donc susceptible de déboucher sur un véritable pouvoir politique. La puissance que donne l'honos est ainsi selon Lucrèce la raison pour laquelle les hommes conçoivent à son endroit un désir qui n'est en réalité que folie:

\author{
At claros homines uoluerunt se atque potentes, \\ $V t$ fundamento stabili fortuna maneret \\ Et placidam possent opulenti degere uitam, \\ Nequiquam, quoniam ad summum succedere honorem \\ Certantes iter infestum fecere uiai, \\ Et tamen e summo, quasi fulmen, deicit ictos \\ Inuidia interdum contemptim in Tartare taetra. \\ «Mais les hommes ont voulu être illustres et puissants \\ Pour que leur destin fût fondé sur des bases solides \\ Et pour pouvoir mener une vie paisible grâce à l'opulence; \\ En vain, car pour parvenir au sommet de l'honneur \\ Ils luttent et se rendent le chemin dangereux, \\ Et même s'ils arrivent au sommet, ils tombent, souvent, frappés par \\ L'envie, telle la foudre, qui les précipite honteusement dans l'horrible Tartare. »
}

(LUCR. DRN V, 1120-1130).

L'honos est prisé pour le pouvoir (potentes) qu'il apporte; il séduit car les hommes croient y voir la sécurité qui les protégera de la mort. La protection que l'honos apporte contre les dangers est une idée qu'on retrouve dans d'autres textes, chez Cicéron et Salluste ${ }^{141}$. Dans la mesure où le pouvoir procuré par l'honos n'est pas toujours de l'ordre d'une puissance politique clairement définie, nous retiendrons le sème, assez général, de /l'influence/.

L'autre trait de sens virtuel relevant des effets de l'estime permet d'identifier le lien qui unit le sens de «considération» à celui de «marque d'honneur » et, du coup, de prendre la mesure de l'originalité d'honos par rapport à des notions proches comme celle de dignitas. Ce sème n'est pas systématiquement actualisé, mais il est plus fréquent que le précédent puisqu'on le retrouve dans environ $60 \%$ des cas. Honos a la singularité de dénoter le prestige d'un individu, mais en mettant l'accent sur la réaction collective de la société visà-vis de ce dernier. Les contextes mettent en exergue le fait que celui qui jouit de l'estime publique reçoit également des bienfaits qui signifient cette estime. On le perçoit dans un passage de Térence. Gnathon,

${ }^{140}$ CIc. De or. I, 198.

${ }^{141}$ Cic. Flac. 103; Dom. 46; Sall. Iug. 31, 1. La proximité de l'honos et de la potestas reste sensible au-delà de l'époque républicaine, notamment quand il est question du prince: voir GorI, «Le nozioni di honos e munus in Plinio il Giovane». 
parasite de son état, raconte ce qui lui est arrivé au marché alors qu'il s'y promenait avec un pauvre hère qui souhaitera bientôt devenir son émule:

Dum haec loquimur, interea loci ad macellum ubi aduentamus,

Concurrunt laeti mihi obuiam cuppedinarii omnes,

Cetarii, lanii, coqui, fartores, piscatores,

Quibus et re salua et perdita profueram et prosum saepe;

Salutant, ad cenam uocant, aduentum gratulantur.

Ille ubi miser famelicus uidet me esse tanto honore et

Tam facile uictum quaerere, ibi homo coepit me obsecrare

$V t$ sibi liceret discere id de me.

«Pendant que nous causons, nous arrivons au marché et à cet instant

Accourrent à ma rencontre, le sourire aux lèvres, tous les marchands de bonnes choses,

Les mareyeurs, les bouchers, les charcutiers, les rôtisseurs, les poissonniers, À qui, dans la richesse comme dans la misère, j'avais rendu et rends encore souvent des services;

Ils me saluent, m'invitent à dîner, me félicitent de ma venue.

Lorsqu'il voit, ce pauvre famélique, que je suis autant à l'honneur

Et que je gagne mon pain si facilement, il commence à me supplier

De lui permettre de devenir mon élève. »

(TER. Eun. 255-262).

Dans la leçon retenue par J. Marouzeau, qui est celle de la majorité des manuscrits ${ }^{142}$, honore désigne la considération dont jouit le parasite auprès des marchands. Et ce qui permet à Gnathon de juger qu'il est à l'honneur, c'est qu'il bénéficie d'une multitude d'égards et de prévenances de la part des bouchers et poissonniers. Les salutations, les invitations, sont autant de marques d'honneur qui signifient à Gnathon l'estime que les marchands ont pour lui et qui étayent son prestige. De même, les druides que décrit César jouissent d'un grand honos parce qu'ils sont entourés d'égards dans la société gauloise ${ }^{143}$. Honos renvoie donc à une situation d'estime, en tant qu'elle est /signifiée / par des bienfaits/.

\subsection{Conclusion}

Le sémème complet d'honos «considération» est le suivant: /situation d'estime / associée à une position éminente dans la société, / fondée sur certains mérites, / et susceptible / d'être assortie d'influence / et d'être signifiée / par des bienfaits/. Nous pouvons maintenant établir la relation de ce sémème (S2) avec celui de «marque d'honneur» (S1).

${ }^{142}$ L'apparat critique mentionne: me esse tanto honore DGPCE Don. Bentl. Fleck. : mihi esse tantum honorem $A^{1} U m p f$. DZ. Linds.-K. La différence est minime pour nous, car, si la construction diffère, le sens d'honos reste le même.

${ }^{143}$ CAES. BG VI, 13, 1 et 5. 


\begin{tabular}{|l|l|}
\hline \multicolumn{1}{|c|}{$\mathrm{S} 1:$ : Marque d'honneur» } & \multicolumn{1}{c|}{$\mathrm{S} 2:$ "Considération » } \\
/bienfait/ & /situation d'estime/ \\
/signe/ & /associée à une position éminente \\
/d'estime/ & dans la société,/ \\
/octroyé en reconnaissance/ & /fondée sur certains mérites,/ \\
/de certains mérites// & /et susceptible/ \\
/qui confère une position éminente & /dans la société,/ \\
dassortie d'influence/ & /et d'être signifiée/ \\
/susceptible/ & /par des bienfaits/. \\
/d'être assortie d'influence/. & \\
\hline
\end{tabular}

À l'exception du sème de la /reconnaissance/, la totalité des sèmes de S1 se retrouve dans S2 (les sèmes communs sont en gras). S2 a un sème générique (/situation d'estime/) différent de celui de S1 (/bienfait/), et l'on est donc très proche, selon la typologie établie par R. Martin, d'une relation de métonymie par pluralité d'acceptions ${ }^{144}$. Honos peut en effet désigner la "marque d'honneur», mais aussi la «situation de faveur où l'on jouit de marques d'honneur». Le sémantisme d'honos fonctionne ainsi d'une manière assez similaire à celui d'ignominia, son antonyme privilégié, qui peut désigner l'«humiliation» (l'affront) ainsi que le «déshonneur» (la privation de l'estime qui peut se manifester par un affront) ${ }^{145}$. La relation entre les deux sens présente cependant deux singularités qui l'écartent de la simple métonymie. Il y a d'abord, de S1 à S2, disparition du sème de la /reconnaissance/. Ensuite et surtout, le sémème de S2 présente une particularité importante: son sème générique, /situation d'estime/, n'est pas inédit puisqu'il est presque identique à un sème spécifique contenu dans S1, celui d'/estime/. D'une part honos renvoie au bienfait qui signifie l'estime et donne une position éminente, d'autre part il désigne la position éminente associée à l'estime qui est signifiée par des bienfaits. En outre, les sèmes de «marque d'honneur » et ceux de "considération" sont très semblables, mais leur ordre est changé. Il s'agit donc là d'une relation de métonymie complexe, selon la formule utilisée par J.-F. Thomas pour ce type de relation sémantique ${ }^{146}$.

Ce sens d'honos peut être confronté avec des termes ayant trait à la notoriété, comme gloria, laus, fama et existimatio, ainsi qu'avec des mots du lexique de la dignité et de l'influence sociale comme decus, dignitas, auctoritas et gratia. Ce réseau lexical étant riche et très

${ }^{144}$ Martin, Pour une logique du sens, p. 75-95.

${ }^{145}$ Voir les sémèmes établis par Thomas, Déshonneur et honte, p. 321.

${ }^{146}$ Voir les compléments apportés par J.-F. Thomas à la typologie de R. Martin, (Thомаs, Ibid., p.442-444). Le cas des deux sens d'honos est légèrement différent de celui décrit par J.-F. Thomas, puisqu'il n'y a pas ajout, mais effacement d'un sème entre S1 et S2, mais cela ne nous semble pas justifier la création d'une nouvelle catégorie, l'essentiel étant la relation de bijection et la modification de l'ordre des sèmes. 
complexe, nous nous limiterons à poser quelques jalons. Nous nous intéresserons, pour la première catégorie, à gloria et, pour la seconde, à dignitas et auctoritas. Ce sont en effet les notions les plus riches et les plus présentes dans les textes ${ }^{147}$.

Honos au sens de "considération » entre fréquemment en relation de synonymie avec gloria quand ce terme désigne la "gloire ${ }^{148}$. Les deux termes sont d'ailleurs fréquemment coordonnés pour former une paire qui renforce l'expression ou crée un effet d'abondance oratoire ${ }^{149}$. Ils renvoient de fait tous deux à une forme de prestige brillant au sein de la cité et partagent plusieurs traits de sens communs. Gloria désigne une large notoriété, qui s'accompagne d'un vif attachement de la part de l'entourage et d'une admiration pour l'individu à qui elle est rapportée, qui n'est pas sans rappeler l'estime liée à l'honos ${ }^{150}$. Le sujet jouit en outre, comme pour l'honos, d'égards et de marques de considération diverses, comme le montre la définition que donne Cicéron:

Gloria est frequens de aliquo fama cum laude.

«La gloire est une réputation largement répandue concernant une personne, et qui s'accompagne d'éloges.»

(CIc. Inu. II, 166).

La gloria suppose la présence de la laus, de l'éloge, qui est un témoignage de considération. Les contextes précisent d'ailleurs parfois que celui qui bénéficie de la gloria est entouré d'honores, au sens de "marques d'honneur», ou est honoratus ${ }^{151}$. Cette notoriété qu'est la gloria repose en outre sur des fondements proches de ceux de l'honos. Elle procède de qualités remarquables et méritoires, et notamment de la uirtus ${ }^{152}$. On rencontre à sa source l'excellence à la guerre et dans les activités civiles, mais aussi dans les arts, ce qui est déjà moins

${ }^{147}$ Sur existimatio et fama, voir Hellegouarc'H, Vocabulaire, p. 365-366 et Z. Yavetz, "Existimatio, Fama, and the Ides of March», HSCPh, 78, 1974, p. 35-65. Sur laus, voir Thomas, Gloria et laus. Sur gratia, voir Moussy, Gratia et sa famille.

${ }^{148}$ C'est le sens le plus fréquent du mot, que l'on rencontre dans environ $85 \%$ des occurrences. Voir Thomas, Gloria et laus, p. 18. Sur le sémantisme de gloria, voir, outre l'ouvrage de J.-F.Thomas, Hellegouarc'H, Vocabulaire, p. 369-383; U. Knoche, «Der römische Ruhmesgedanke», in OpPERmann, H. (éd.), Römische Wertbegriffe, Darmstadt, Wissenschaftliche Buchgesellschaft, 1967, p. 420-445; Drexler, Politische Grundbegriffe der Römer, au chapitre "Gloria».

${ }^{149}$ CAT. frg. inc. 252 ORF; Cic. Mur. 12; Sest. 136; Cael. 72; Leg. III, 32; Off. II, 31 et 42.

${ }^{150}$ Voir par exemple Cic. Off. II, 48. Knoche souligne le rôle important joué par la collectivité dans la création de la gloria, ce qui la distingue de la notion grecque de gloire (KNoche, «Der römische Ruhmesgedanke»).

${ }^{151}$ Cic. Prou. 29; Leg. I, 31. Voir Thomas, Gloria et laus, p. 64-65.

152 Sall. Iug. 1, 3 considère que la uirtus est la route vers la gloire (ad gloriam uia uirtutis). Sur les mérites à l'origine de la gloria, Ibid., p.28-36 et Hellegouarc'H, Vocabulaire, p. 371. 
fréquent à propos d'honos ${ }^{153}$. La gloria implique également une supériorité dans la cité: l'individu peut gloria excellere ou gloria praestare ${ }^{154}$. La gloria assure une prépondérance sur les autres citoyens et confère une prééminence qui fait qu'elle peut être mise sur le même plan que le pouvoir politique, militaire ou financier ${ }^{155}$. Elle se rapproche donc d'honos qui assure distinction et influence dans la société. Elle est d'ailleurs, comme ce mot et même plus encore, employée dans des métaphores qui la dépeignent comme un objet brillant et éclatant ${ }^{156}$. Par ses manifestations, ses fondements et ses effets, gloria semble donc très proche d'honos. Un certain nombre de divergences sémantiques apparaissent cependant quand on examine plus précisément les contextes des occurrences. On remarque, en premier lieu, que la gloria est fondamentalement une notoriété157 : elle désigne le fait d'être connu en bonne partie, d'avoir, comme le dit Cicéron dans le De inuentione, une large fama. La gloria est quelque chose qui dure dans le temps et a une grande extension dans l'espace ${ }^{158}$. Honos, en revanche, n'implique pas cette célébrité. Il renvoie à une situation où le sujet est estimé et respecté; l'homme in honore n'est pas nécessairement réputé au-delà des frontières de sa communauté et ne laisse pas toujours un souvenir immortel. L'honos est un prestige d'ordre plus visuel qu'auditif. La gloria renvoie en outre à une notoriété qui naît de manière spontanée. L'honos est une situation qui repose sur un choix plus réfléchi de la part de l'entourage, après un jugement sur la valeur de la personne que l'on décide de mettre à l'honneur. Le rôle des marques d'honneur octroyées délibérément par la collectivité est plus important dans la constitution de la "considération" que dans celle de la "gloire» ${ }^{159}$. Enfin, les motifs qui sont à la source de la gloria sont moins souvent des qualités morales que des réalisations remarquables: les vertus occupent dans le sémantisme d'honos une place plus importante.

Le sens d'honos "considération» rapproche également le terme de dignitas. Cette dernière possède une riche polysémie et l'un de ses sens principaux recoupe celui d'honos ${ }^{160}$. Le mot peut en effet désigner le

${ }^{153}$ Guerre: Sall. Cat. 2, 2; Cic. Imp. Pomp. 53. Éloquence: Cic. Brut. 314. Activité politique: Sall. Iug. 70. Activité littéraire: Sall. Cat. 3, 1-2.

${ }^{154}$ CIC. Phil. XI, 18; CAES. BG VIII, 6, 2.

${ }^{155}$ Cic. Agr. II, 54. Sur cette prééminence, Thomas, Gloria et laus, p. 70 sqq.

${ }^{156}$ Cic. Balb. 16; De or. I, 1. Ibid., p. 82 sqq.

${ }^{157}$ C’est le sème générique retenu par J.-F. Thomas (Ibid., p. 88).

158 Voir la fréquence du syntagme gloria immortalis ou immortalitas gloriae (Pl.Amp.1140; Cic. Pis. 63 et Balb. 40). Ibid., p. 23.

${ }^{159}$ Gloria est une notion qui est totalement attachée à la personne glorieuse alors qu'honos, parce qu'il possède un sens actif, celui de «marque d'honneur», présente dans son sémantisme l'idée d'une participation plus forte de la collectivité (KLose, Bedeutung, p. 44-45).

${ }^{160}$ Sur le sémantisme de dignitas, voir le TLL s.v.dignitas; H.Wegehaupt, Die Bedeutung und Anwendung von dignitas in den Schriften der republikanischen Zeit, Diss., 
rang élevé occupé par un individu dans la société, la posture de prestige dans la vie publique. Il s'oppose alors à humilitas qui implique la bassesse sociale ${ }^{161}$. Elle s'appuie fréquemment sur la naissance, la fortune ou le pouvoir et appartient notamment à celui qui a exercé des charges publiques. C'est pourquoi elle est volontiers attachée aux sénateurs, anciens magistrats ${ }^{162}$. La dignitas est la qualité de ceux qui sont situés au sommet de la société et de la cité: c'est par sa dignitas que Pompée l'emporte sur les autres grands hommes politiques de Rome et c'est pour elle que César prend le risque de déclencher une guerre civile contre Pompée ${ }^{163}$. C'est donc le «statut», le «rang » d'une personne. Ce sens de dignitas possède plusieurs traits communs avec la «considération » désignée par honos. Les deux mots désignent une situation favorable au sein de la société et s'appliquent notamment aux hommes publics ${ }^{164}$. Ils impliquent un rayonnement particulier et une distinction visible ${ }^{165}$. La dignitas est, comme l'honos, étayée sur des mérites et notamment sur la valeur personnelle et la uirtus ${ }^{166}$; elle procure elle aussi une autorité et une influence au sein de la cité. La définition qu'en donne Cicéron dans le De inuentione est explicite à ce sujet car elle identifie la dignitas à une forme d'auctoritas :

Dignitas est alicuius honesta et cultu et honore et uerecundia digna auctoritas.

«La dignité est une autorité honnête, digne de respect, d'honneur et de déférence. »

(CIc. Inu. II, 166; trad. Achard modifiée).

Breslau, 1932; KLose, «Altrömische Wertbegriffe (honos und dignitas) » Hellegouarc'H, Vocabulaire; H.DreXler, "Dignitas», in KLeIn, R. (éd.), Das Staatsdenken der Römer, Darmstadt, Wissenschaftliche Buchgesellschaft, 1966, p. 231-244; T. Piscitelli Carpino, "Dignitas in Cicerone», BStudLat, 9, 1979, p. 253-267; Pöschl, " Politische Wertbegriffe in Rom»; Lind, "The Tradition of Roman Moral Conservatism»; N. A. FËdorov, «La genèse de la composante esthétique dans la sémantique du groupe lexical decusdecorum-decere-dignitas (d'après les textes de Cicéron)", VMUfilol, 1, 1981, p.49-61; Thome, Zentrale Wertvorstellungen der Römer, vol.2, p. 117-134 ; R. RILINGER, "Ordo und dignitas als soziale Kategorien der römischen Republik» Ordo und dignitas. Beiträge zur römischen Verfassungs- und Sozialgeschichte, Stuttgart, F. Steiner, 2007, p. 95-104.

${ }^{161}$ CaEs. BG VII, 54, 4; Cic. Rosc. Amer. 136.

162 Cic. Verr. II, II, 95; Sull.5; SAll.Hist.frg. I, 55, 26. Voir Drexler, "Dignitas», p. 235 et Wegehaupt, Die Bedeutung und Anwendung von dignitas, p. 21 sqq.

${ }_{163}$ Cic. Imp. Pomp. 41 ; CAEs. BC I, 7, 1.

164 Thоме, Zentrale Wertvorstellungen der Römer, vol. 2, p. 118.

${ }^{165}$ La dignitas est souvent liée à des notions d'éclat et de splendeur (Cic.Cael.3; Fin. II, 107).

${ }^{166}$ Cic.Imp. Pomp. 42 ; Sall. Cat. 50, 7.Piscitelli Carpino, «Dignitas in Cicerone», p. 259. 
Ladignitas suppose une capacité d'agir dans les affaires publiques ${ }^{167}$. Le passage insiste également sur ce que l'individu qui possède cette dignité est en droit d'attendre des autres: il mérite (dignus) de recevoir des marques d'honneur et de respect. La dignitas permet de réclamer légitimement à l'entourage une attitude déférente et des honores au sens premier du mot ${ }^{168}$. C'est d'ailleurs avec cet aspect que commence à se faire sentir la divergence avec honos. Dignitas insiste plus qu'honos sur la prétention fondée du sujet à la reconnaissance des autres et à leur estime. Il ne marque pas simplement le rang dans la cité mais aussi le droit à recevoir des distinctions et des égards ${ }^{169}$. On retrouve ici la trace du sens étymologique de dignitas, qui désigne le fait d'être dignus, adjectif qui procède lui-même de decet ${ }^{170}$ : c'est donc le «fait de convenir », le «caractère approprié » d'une personne ou d'une chose ${ }^{171}$. De ce sens premier dérive celui de «mérite», "valeur» : la personne est digna non plus au sens où elle convient, mais au sens où cette convenance lui permet d'avoir des prétentions légitimes ${ }^{172}$. Avec ce sens, la dignitas ne se situe plus alors sur le même plan que l'honos: elle peut désigner la situation préalable à l'honos, les mérites créant la "dignité», cette dernière donnant lieu à l'honneur ${ }^{173}$. Le mot exprime moins le jugement positif de l'entourage qu'un haut statut social; il est plus spécifiquement politique qu'honos et reçoit fréquemment une coloration aristocratique alors qu'honos peut désigner différents types de prestige ${ }^{174}$. En raison de ces divergences sémantiques, les coordinations honos et dignitas qui reviennent fréquemment ne constituent pas que des procédés stylistiques d'insistance; l'association des deux

${ }^{167}$ Voir aussi la définition de Cic.Fam.IV, 14, 1 et le pouvoir qu'implique la dignitas dans Caes. BG VII, 12, 7 et VII, 77, 6. Hellegouarc'H, Vocabulaire, p.405-406; DreXler, "Dignitas», p. 242.

168 Cic. Rosc. Amer. 54; Liv.XXVI, 49, 15. Voir Wegenhaupt, Die Bedeutung und Anwendung von dignitas, p. 77 ; Lind, "The Tradition of Roman Moral Conservatism ", p. 25 ; Тноме, Zentrale Wertvorstellungen der Römer, p. 88.

${ }^{169}$ Hellegouarc' H, Vocabulaire p. 401.

${ }^{170}$ Voir DELL s.v.decet. La parenté de dignitas avec dico «montrer du doigt » est à récuser (Ibid., p. 389 sqq.). Le rapport entre dignus et decet est transparent dans les v. 52-53 de la Mostellaria: dignissimumst. / Decet me amare et te bubulcitarier ("C'est parfaitement convenable. Il convient à moi de faire l'amour et à toi de conduire les bœufs»).

${ }^{171}$ On parlera ainsi d'un sacrifice réalisé cum dignitate (Liv.XLIX, 49, 2), d'une accusation portée dignitate, de façon appropriée (CIc. Verr. II, II, 168).

${ }^{172}$ Sur ce sens de «mérite», voir Wegenaupt, Die Bedeutung und Anwendung von dignitas, p.5-9. Dignitas désigne notamment le «mérite» du candidat qui prétend exercer une fonction publique (Cic. Mur. 43).

${ }^{173}$ Voir la succession établie par KLOSE, "Altrömische Wertbegriffe (honos und dignitas)», p. 273: «uirtus - res gestae (merita) - honor(es) - dignitas - Verpflichtung (officium) - neue res gestae (merita) - honor(es) - höhere dignitas.»

${ }^{174}$ Sur l'association de dignitas à la noblesse, Cic.Rosc.Amer.16; Sall.Iug. 41, 5. Voir Hellegouarc'H, Vocabulaire, p. 549-550. 
mots peut aussi posséder une réelle richesse sémantique et dessiner l'excellence sociale et civique de l'individu à qui ils sont attribués ${ }^{175}$.

Le terme d'auctoritas possède avec honos plusieurs points communs. Le mot possède des sens nombreux, notamment dans le domaine juridique ("droit de possession», "garantie» d'un tuteur, d'un vendeur) et politique (la «volonté» du peuple, une «décision» prise par le sénat); nous nous limiterons au sens plus général de "prestige, influence, autorité» qui rapproche les deux notions ${ }^{176}$. Auctoritas désigne alors le pouvoir non institutionnel d'un individu. Cicéron parle ainsi du "prestige » du maître de son fils, Cratippe, et de la ville d'Athènes ${ }^{177}$, qui rayonne par son glorieux passé et son rôle intellectuel. L'influence puissante que désigne auctoritas se perçoit dans l'abondance des formules du type aliquid agere mea auctoritate; c'est l'auctoritas de César qui lui permet de tenir en respect Arioviste et ses troupes ${ }^{178}$. L'auctoritas d'un individu peut aussi le désigner aux yeux des autres comme un exemple à suivre. On comprend ainsi que les Romains en soient venus à évoquer l'auctoritas maiorum ${ }^{179}$. Auctoritas et honos désignent tous deux l'ascendant d'une personne sur ses semblables.

${ }^{175}$ Voir Cic. Verr. II, I, 37, 4 ; Clu. 119; Agr.I, 27 ; Sull. 5 ; Sest. 137 ; Pis. 57 ; Phil.XIII, 50 ; Off. I, 38; Fam. III, 7, 5; Q.fr. I, 1, 10. CAES. BC I, 7, 1 ; I, 32, 4. Sur la manière dont un couple de synonymes est employé pour rendre une notion complexe, grâce à la présence latente des autres sens de chacun des termes, voir THOмAs, «Les fonctions linguistiques de la synonymie lexicale en latin», p. 888.

${ }^{176}$ La notion d'auctoritas a surtout été étudiée sous trois angles: comme notion juridique (l'auctoritas des vendeurs, des témoins, etc.), comme notion politique, avec l'auctoritas patrum, et enfin comme élément du pouvoir impérial, notamment parce qu'elle occupe une place importante dans les Res Gestae. Sur cette notion, voir R. HeInZE, «Auctoritas », Hermes, 60, 1925, p. 348-366 ; F. Fürst, Die Bedeutung der auctoritas im privaten und öffentlichen Leben der römischen Republik, Diss., Marburg, 1934; L. Amirante, "Il concetto unitario dell'auctoritas » in Studi in onore di S. Solazzi, Naples, Jovene, 1948, p.375-390 ; J.P.V.D.BALSDON, "Auctoritas, dignitas, otium », CQ, 10, 1960, p.43-50; J. Collart, "À propos du mot auctoritas », Helikon, 1, 1961, p. 211-216; Pöschl, "Politische Wertbegriffe in Rom»; H. RaBE, Autorität, Elemente einer Begriffsgeschichte, Konstanz, Universitätsverlag, 1972. Pour l'aspect juridique voir, entre autres, A. D’Ors, "Aduersus hostem aeterna auctoritate esto », Eclás, 5, 1959, p. 174 et A. SolAzzI, « La forma della tutoris auctoritas e della patris auctoritas », Jura, 2, 1951, p. 133-139; sur l'auctoritas d'Auguste et des empereurs, A. Magdelain, Auctoritas principi, Paris, Les Belles Lettres, 1947; M. RiccA-BARBERIs, "Auctoritas e potestas», AG, 16, 1954, p.129-131; J.-L. FERRARY, "Res publica restituta et les pouvoirs d'Auguste», in Franchet D'EsPÈrEY, S. (éd.), Fondements et crises du pouvoir, Bordeaux, Ausonius, 2003, p. 419-428; S. GÉLY, Le Pouvoir et l'autorité. Avatars italiens de la notion d'auctoritas d'Auguste à Domitien (27 av.J.-C. - 96 ap. J.-C.), Louvain, Peeters, 1995.

177 Cic. Off. I, 1. Sur le prestige désigné par auctoritas, HeInze, "Auctoritas», p. 354-355.

${ }^{178}$ CAES. $B G$ I, 31, 16.

179 Hellegouarc'H, Vocabulaire, p. 303: «les exemples que propose pour une situation déterminée la conduite des ancêtres dans une même situation. » Voir J.C. Plumpe, Wesen und Wirkung der Auctoritas Maiorum bei Cicero, Diss., Munich, 1932. 
Mais les deux termes ne renvoient pas au même type de prestige. L'auctoritas désigne en effet le prestige de celui qui pèse spontanément de tout son poids sur la société, alors que l'honos renvoie au prestige de celui qui est estimé de ses semblables, et donc hissé par eux à une position supérieure ${ }^{180}$. L'honos est lié à des marques de considération concrètes, à des hommages adressés à une personne; l'auctoritas ne suppose rien de tel. On n'octroie pas l'auctoritas à quelqu'un, alors qu'on confère bien l'honos. En outre, l'auctoritas n'implique pas nécessairement un jugement ni une appréciation favorable de la part de ses concitoyens; la notion de bonne réputation en est absente, alors que l'existence de la faveur publique est essentielle à honos. Ce sont donc, en somme, les notions d'estime publique et de marque d'honneur qui font la singularité d'honos. En outre, l'auctoritas implique, ce qui n'est pas le cas d'honos, un pouvoir de garantie possédé par le sujet. Les emplois juridiques d'auctoritas ont ce trait en commun, qu'il s'agisse de l'auctoritas uenditoris, de la "garantie» qu'un vendeur est capable d'apporter lorsqu'il procède à une vente ${ }^{181}$, de l'auctoritas d'un tuteur, qui vient donner sa garantie aux actes de son pupille ${ }^{182}$, de l'auctoritas d'un témoin lors d'un procès ${ }^{183}$. Cette notion, originellement juridique, se ressent souvent dans les emplois non spécifiquement juridiques du mot: l'auctoritas est ce qu'une personne met en jeu pour cautionner ses actes ou ceux d'un autre individu ${ }^{184}$.

\subsection{Deux emplois lexicalisés: honoris gratia et honoris causa}

Ces deux tournures sont fréquentes et signifient le plus souvent "pour honorer», "pour rendre un hommage», ce qui est conforme à la valeur finale, à l'origine, des deux mots-outils ${ }^{185}$. Ce sens apparaît sans ambiguïté dans un texte de Cicéron:

Quod consuetudine patres faciunt, id quasi nouum reprehendis; quod beneuolentia fit, id odio factum criminaris; quod honoris causa pater filio suo concessit, id eum supplici causa fecisse dicis.

${ }^{180}$ Sur la notion d' «accroissement» propre à l'auctoritas et absente d'honos, voir COLlaRT, «À propos du mot auctoritas».

${ }^{181}$ Ainsi dans le Curculio, le personnage de Curculio qui souhaite acheter une courtisane au leno, lui refuse la qualité d'auctor, conteste son auctoritas, car le proxénète est l'homme de mauvaise foi par excellence (PL.Curc. 498).

${ }^{182}$ Une veuve, par exemple, ne peut agir sua auctoritate; il lui faut un garant. $C f$. le cas de Clodia dans Cic. Cael. 68.

${ }^{183}$ Voir Cic. Flac. 9 et 53 par exemple.

${ }^{184}$ Hellegouarc' H, Vocabulaire, p. 296-297.

185 C. Moussy, Gratia et sa famille, Paris, P.U.F., 1966, p.308-309; P.-J. Miniconi, Causa et ses dérivés. Contribution à l'étude du vocabulaire latin, Paris, Les Belles Lettres, 1951, p. 31 ; A.Ernout et F. Thomas, Syntaxe latine, 2e éd., Paris, C.Klincksieck, 1953, p. 117-8, § 139. 
«Ce que les pères font, conformément à la coutume, tu le réprouves comme une nouveauté; ce qui est un acte de bienveillance, tu l'incrimines comme étant une preuve de haine; la concession dont un père honore son fils, tu prétends que ce père l'a faite pour châtier ce fils. »

(Cic. Rosc. Amer. 44 ; trad. De La Ville de Mirmont).

Le parallélisme de honoris causa et supplici causa impose de comprendre la première formule comme «en vue de l'hommage » puisque la seconde signifie nécessairement «en vue du châtiment». On trouve de même, nous l'avons vu, une opposition entre contumeliae causa et honoris causa ${ }^{186}$, expressions qui ont toutes deux un sens final et impliquent un acte concret. Cependant, honos n'a pas toujours, dans cette expression, son sens concret de «marque d'estime» et peut, bien que cela soit moins fréquent, posséder le sens de «considération ». C'est sensible dès l'époque de Plaute, comme dans ce passage de l'Amphitryon où Mercure parle du comportement de Jupiter vis-à-vis d'Alcmène:

\footnotetext{
Sed Alcumenae huius honoris gratia

Pater curauit uno ut fetu fieret:

Vno ut labore absoluat aerumnas duas,

Et ne in suspicione ponatur stupri,

Et clandestina ut celetur consuetio.

«Mais pour l'honneur d'Alcmène,

Mon père a pris soin qu'elle accouchât en une seule fois,

Afin qu'elle se délivre de deux épreuves par un seul travail,

Qu'elle ne puisse être soupçonnée d'adultère,

Et que sa liaison clandestine demeure cachée.»
}

(PL. Amp. 486-490).

Jupiter veut faire accoucher Alcmène d'un fils qu'elle a de lui et, en même temps, de l'autre enfant qu'elle a de son mari. Ladultère commis passerait ainsi inaperçu puisqu'Alcmène enfanterait des jumeaux dont la paternité serait imputée à son époux. On peut comprendre Alcumenae honoris gratia de deux façons: "pour l'honneur d'Alcmène» (honos est la considération dont elle jouit) ou "pour honorer Alcmène» (honos est la marque d'honneur que recevrait Alcmène). Il s'agit pour Jupiter, selon la manière dont on interprète le vers, de préserver l'honos qu'elle a déjà, ou de lui en accorder un supplémentaire. La première lecture nous semble ici nécessaire: le stratagème de Jupiter ne vise pas à honorer Alcmène mais à éviter le soupçon de stuprum, qui serait une menace pour la réputation de cette digne épouse, donc pour son honos compris comme "considération». C'est ce que dit Mercure au vers 489: ne in suscipione ponatur stupri; il faut 
éviter à Alcmène l'accusation d'adultère, donc la perte de sa bonne réputation. Honoris gratia signifie «dans l'intérêt de sa bonne réputation », "pour son honneur ${ }^{187}$. Dans un autre passage de l'Amphitryon, Jupiter s'adresse directement aux spectateurs:

Nunc huc honoris uestri uenio gratia,

Ne hanc incohatam transigam comoediam.

Simul Alcumenae, quam uir insontem probri

Amphitruo accusat, ueni ut auxilium feram.

«Maintenant, en raison de votre prestige, je viens ici

Pour ne pas arrêter la comédie en cours de route;

Et aussi pour Alcmène, que son mari Amphitryon accuse injustement d'adultère,

Pour lui prêter mon aide.»

(PL.Amp. 867-870)

Ici encore il est plus satisfaisant de rendre honoris uestri gratia par «pour l'amour de votre prestige». Jupiter n'agit pas "pour honorer» les spectateurs; on ne voit pas en quoi mener à son terme la comédie est quelque chose d'honorifique. Honos désigne plutôt la considération dont jouissent les spectateurs (honoris uestri), et qu'il s'agit de ménager ${ }^{188}$. Or, dans ce cas, gratia prend une valeur causale et non finale. La formule honoris causa / gratia possède donc une certaine souplesse sémantique puisqu'elle peut signifier "pour honorer» mais aussi «à cause de son prestige».

Plusieurs philologues considèrent, cependant, qu'il s'agit d'une formule figée, dans laquelle honos serait dépourvu d'un sens plein. C. Moussy rapproche mei honoris gratia de mea gratia. Mea gratia, note C.Moussy, est une expression utilisée couramment par Plaute, mais bien moins fréquente à l'époque classique; son sens est "par bienveillance pour moi», "par égard pour moi». Puis il remarque que «Plaute se sert volontiers aussi du tour mei, tui... honoris gratia,

${ }^{187}$ Cela est confirmé par une autre parole de Mercure un peu plus loin: Jupiter a agi nemo id probro / profecto ducet Alcumenae (v.492-493). Le probrum se situe dans le même champ lexical que stuprum: il désigne la disgrâce, une situation de mépris, c'est-à-dire l'inverse de l'honos, de la considération. Voir aussi F.Klose: «Die aktivverbale Möglichkeit versagt hier, denn Juppiter hat natürlich der Alcumena durch seine Maßnahmen keine 'Ehre erweisen' wollen» (KLose, Bedeutung, p. 62).

${ }^{188}$ On peut remarquer que, dans cet exemple et dans le précédent, gratia peut recevoir son sens premier de "en faveur de", "dans l'intérêt de», tout autant que le sens moins marqué "pour», "en vue de». Mais gratia et causa peuvent aussi alors avoir un sens plus précisément causal: «à cause de leur honneur, en conséquence de leur honneur». On trouve d'autres cas chez Plaute où causa garde sa valeur initiale. Par exemple dans ce vers cité par P.-J. Miniconi: Tuin uentris causa filiam uendas tuam?: «Peux-tu bien, par amour pour ton ventre, vendre ta propre fille?» (PL.Pers. 338). Sur le sens causal de causa avec honos, Fest.73, 6. 
qu'il utilise avec une valeur identique ${ }^{189}$. Il nous semble cependant difficile de penser que cette formule a, dès l'époque de Plaute, évacué tout le sémantisme propre à honos. La construction de gratiā avec le génitif du nom est une formule différente de gratiā accompagné d'un déterminant possessif. Comme le dit lui-même C. Moussy, « recevant un nom de chose pour complément, gratiā a pris aussi le sens de 'en vue de' ${ }^{190}$. Et on ne voit pas pourquoi il y aurait à l'origine une différence (pour le sens de gratia), que marque pourtant C. Moussy, entre une expression comme deridiculi gratia et une autre comme honoris gratia: deridiculi et honoris sont sur le même plan et ont la même importance sémantique. Dans le texte le plus ancien qui présente cette formule, la Médée d'Ennius, on voit qu'honoris gratia ne signifie pas «pour moi », mais «pour m'honorer»:

Tu me amoris magis quam honoris seruauisti gratia.

«Toi, tu m’as sauvé plus par amour que pour me faire honneur. »

(ENN. Trag. frg. CVII Jocelyn).

Si honoris gratia signifiait "pour moi» ou "par bienveillance», la distinction faite par Jason perdrait toute sa force; ce que Jason reproche à Médée c'est d'avoir agi parce qu'elle était poussée par l'amour, et non pour lui conférer un honneur, c'est-à-dire afin que sa uirtus de guerrier soit reconnue et consacrée.

Si honoris gratia/causa nous paraît avoir ici un sens plein, cela ne signifie pas, néanmoins, que l'expression l'ait toujours conservé; il est exact que le sens originel s'est affaibli avec le temps. Nous en avons une première trace au $\mathrm{II}^{\mathrm{e}}$ siècle, où l'expression peut prendre le sens, moins marqué, de "pour vous », "dans votre intérêt » et évacuer la notion de "considération» ou d' "hommage». C'est le cas dans le Phormion de Térence. Le parasite Phormion s'est rendu en justice et a prétendu qu'Antiphon était le plus proche parent de la jeune Phanium. Comme la jeune fille est épiclère, Antiphon l'a épousée, conformément au droit athénien. Démiphon, le père d'Antiphon, revenu de l'étranger, découvre le mariage et veut l'annuler; il pousse alors Phormion à prendre la jeune femme comme épouse. Puis Démiphon revient sur sa décision, mais Phormion refuse de se laisser convaincre:

Nam non est aequom me propter uos decipi, Cum ego uestri honoris causa repudium alterae Remiserim, quae dotis tantumdem dabat.

${ }^{189}$ Moussy, Gratia et sa famille, p. 312.

${ }^{190}$ Ibid., p. 309. 
«Car il n'est pas juste que je sois, à cause de vous, bien attrapé, Parce que moi, dans votre intérêt, j'ai annoncé à l'autre Qu'elle était répudiée, elle qui m’offrait autant pour dot.»

(Ter. Phorm. 927-929).

Quand Phormion dit qu'il a accepté d'épouser Phanium uostri honoris causa, il ne prétend pas l'avoir fait "pour rendre hommage» à Démiphon. Il est plus simple et plus cohérent de comprendre uostri honoris gratia par "dans ton intérêt", "pour toi », dans la mesure où le mariage de Phormion et Phanium était un arrangement proposé par Démiphon pour annuler la décision irréfléchie de son fils et réaffirmer son autorité de père. L'affaiblissement du sens de la formule se poursuit au $\mathrm{I}^{\mathrm{er}}$ siècle $^{191}$.

\section{5. «Charge publique » (S3)}

Le troisième sens majeur d'honos est celui de "charge publique», employé de façon privilégiée pour renvoyer à une magistrature. Le terme s'oriente ainsi vers le vocabulaire de la vie civique et politique pour désigner une fonction à haute responsabilité. Ce sens est aussi ancien que les deux précédents, puisqu'on le rencontre chez Plaute et dans les discours de Caton ${ }^{192}$. Il est cependant peu employé avant le I ${ }^{\text {er }}$ siècle où sa fréquence devient alors aussi importante que celle du sens «considération ${ }^{193}$. On le rencontre souvent avec des tournures spécifiques comme gradus honorum, decursus honorum, cursus honorum ${ }^{194}$. Les honores en tant que "charges publiques » sont "exercés », "employés » (defungo honores, utor honoribus, gero honorem) ${ }^{195}$. On les recherche activement (adipiscor honores, adsequor honores, peto honores) ${ }^{196}$ et on se bat pour eux (contentio honoris, certamen honoris) ${ }^{197}$. Ils sont en outre octroyés de façon formelle, en général par le peuple (defero honores, mandare honores, committo honores) ${ }^{198}$.

${ }^{191}$ Voir par exemple Cic. Rosc. Amer. 98 et 132 et Fam. XIII, 26, 2

${ }^{192}$ Pl. Bac. 438; CAT. frg. XVIII, 93 ORF.

${ }^{193} \mathrm{~F}$. Klose note que c'est surtout Cicéron qui a développé ce sens du mot (KLosE, Bedeutung, p. 25). Sur cette acception, voir aussi STutz, Honos. De vocabuli significatione Romana, qui identifie magistratus et honos publicus.

${ }^{194}$ Gradus honorum: Cic. Catil. I, 28; Planc. 60; Brut. 156; Fam. II, 18, 2. Decursus honorum: Cic. De or. I, 1. Cursus honorum: CIc. Cato mai. 60; Fam. III, 11, 2.

${ }^{195}$ Defungo honores: Cic. Planc. 52. Vtor honoribus: Cic. Flac. 45; Att. VIII, 3, 2; SaLl. Iug. 25, 4. Gero honorem: Cic. Verr. II, II, 112.

196 Adipiscor honores: CIc. De or. III, 136. Adsequor honores: Cic. Red. Pop. 5. Peto honores: Cic. Font. 37. Voir aussi Hellegouarc'H, Vocabulaire, p. 385.

${ }^{197}$ Contentio honoris: Cic. Mur. 8 et 56; Sull. 90; Mil. 42. Certamen honoris: Cic. Sull. 49.

198 Defero honores: Cic. Vat. 10. Mandare honores: Cic. Imp. Pomp. 2; Pis. 2. Committo honores: CIc. Verr. II, V, 35. 


\subsection{La fonction publique}

Ce sens d'honos renvoie à une fonction de la res publica pourvue d'un pouvoir officiel de décision. Dans la grande majorité des cas, la fonction est une magistrature, une charge élective et temporaire dotée d'un pouvoir de nature variable. Il en est ainsi question à propos de la questure dans cette invective de Cicéron contre Pison:

Is mihi etiam gloriabatur se omnis magistratus sine repulsa adsecutum! Mihi ista licet de me uera cum gloria praedicare; omnis enim honores populus Romanus mihi ipsi homini detulit. Nam tu cum quaestor es factus, etiam qui te numquam uiderant, tamen illum honorem nomini mandabant tuo.

«Et il se glorifiait devant moi d'avoir obtenu toutes les magistratures sans essuyer de revers! C'est à moi qu'il est permis de dire cela, et d'en tirer une gloire véritable; car tous les honneurs, le peuple romain me les a décernés, à ma propre personne. Toi, lorsque tu as été élu questeur, même ceux qui ne t'avaient jamais vu décernèrent cet honneur à ton nom. »

(CIc. Pis. 2).

Cicéron se vante ici d'avoir obtenu la totalité des honores, c'est-àdire d'avoir rempli toutes les charges du cursus honorum. Le terme honos entre en relation de synonymie avec magistratus. Chez César, il désigne le consulat:

Docet se nullum extraordinarium honorem appetisse, sed exspectato legitimo tempore consulatus eo fuisse contentum, quod omnibus ciuibus pateret.

«Il montre qu'il n'a pas brigué une charge extraordinaire mais que, après avoir attendu la durée légale pour le consulat, il s'est contenté d'y être candidat, ce qui était permis à tous les citoyens. »

(CAES. BC I, 32, 2).

Honos ne se limite pas cependant à désigner des magistratures et doit donc être rattaché au genre plus large des fonctions publiques. Il peut en effet aussi renvoyer à une prêtrise, de rang municipal ${ }^{199}$ ou de plus grande importance, comme l'augurat; Cicéron juge ainsi insoutenable l'idée que Vatinius ait pu devenir augure parce qu'un tel honos ne peut revenir à un homme turpissimus ${ }^{200}$. D'autres fonctions plus ponctuelles sont également qualifiées d'honores, comme un décemvirat agraire ${ }^{201}$ ou une legatio, telle que celle confiée à Caton pour l'éloigner de Rome ${ }^{202}$. Des fonctions militaires sont aussi qualifiées d'honores ${ }^{203}$.

199 CIC. Verr. II, IV, 137: Héraclius possède à Syracuse l'honos de prêtre de Jupiter. Voir aussi la façon dont Verrès vend les sacerdoces, qualifiés encore d'honores (CIc. Verr. II, II, 128).

${ }^{200}$ Cic. Vat. 19.

${ }^{201}$ Cic. Agr. II, 60. Le texte parle de l'honos decemuiratus.

${ }^{202}$ Cic. Dom. 22. Voir aussi un autre exemple en Cic. Flac. 45.

${ }^{203}$ Cat. frg I, 18 ORF ; CaEs. BC I, 77, 2. 
Ces fonctions sont généralement publiques, au sens où elles relèvent des institutions de la res publica, mais aussi parce qu'elles sont en général conférées par le peuple. Nous avons vu avec le texte de l'In Pisonem cité supra que Cicéron se glorifiait des honores politiques reçus parce que le peuple en était l'auteur. Il ne manque jamais de rappeler que c'est le iudicium populaire qui octroie l'honos ${ }^{204}$. De fait, la charge politique est souvent qualifiée d'honos populi ou d'honos popularis au sens d' "honneur donné par le peuple» ${ }^{205}$. Le rôle important joué par le populus apparaît dans un passage du Pro Cluentio qui évoque l'opposition des chevaliers au projet de loi de M. Livius Drusus en 91 sur l'institution d'une quaestio pour les juges coupables de corruption:

Tum C. Flauius Pusio, Cn. Titinius, C. Maecenas, illa robora populi Romani, ceterique eiusdem ordinis, non fecerunt idem quod nunc Cluentius, ut aliquid culpae suscipere se putarent recusando, sed apertissime repugnarunt, cum haec recusarent et palam fortissime atque honestissime dicerent se potuisse iudicio populi Romani in amplissimum locum peruenire, si sua studia ad honores petendos conferre uoluissent.

«Alors Gaius Flavius Pusio, Gnaeus Titinius, Gaius Maecenas, l'élite du peuple romain, et d'autres membres du même ordre, n'agirent pas de la même façon que Cluentius aujourd'hui en pensant qu'en rejetant la loi ils commettaient quelque faute, mais ils ont lutté ouvertement, en protestant et en disant au grand jour, de façon très courageuse et très digne, qu'ils auraient pu parvenir grâce à la décision du peuple romain au rang le plus élevé, s'ils avaient voulu placer leurs efforts dans la recherche des honneurs.»

(Cic. Clu. 153).

Les chevaliers, à la différence des sénateurs, ont renoncé à briguer les honores et ne veulent donc pas encourir les risques de procès propres à ceux qui font une carrière politique. Ils ne manquent pas d'affirmer que, s'ils l'avaient voulu, ils auraient obtenu ces honores, forts du iudicium populi Romani qui leur était favorable. Ici encore le populus est présenté comme la source de l'honos. Les différentes charges publiques sont, comme les honores "marques d'honneur», hiérarchisées les unes par rapport aux autres. Nous avons vu qu'il est souvent question de parcourir le "chemin» des honores (cursus honorum, decursus honorum, gradus honorum), ce qui implique que les fonctions exercées au terme de la carrière, le consulat ou la censure, sont les plus prestigieuses. Les textes recourent très fréquemment à l'expression summus honos ou amplissimus honos pour désigner le consulat ${ }^{206}$. Ces différents éléments nous amènent à retenir le sème,

${ }^{204}$ Voir par exemple Cic. Agr. II, 2.

${ }^{205}$ Voir par exemple PL. Bac. 438 et Cic. Dom. 46. Voir aussi la tournure ab populo honores accipere (Ps.-CAEs. B. Afr. 57, 3).

${ }^{206}$ Summus honos: Volc.-Sed. frg. 4 FPL; Cic. Clu. 118; Agr. II, 2 ; Sest. 17 ; Brut. 96 ; SAll.Iug. 85, 28-30. Amplissimus honos: Cic. Diu. Caec. 70; Sull. 49 et 83; Rep. I, 10. 
générique, de /fonction publique/; nous parlerons plus exactement de /fonction publique attribuée/ pour rappeler que cette dernière est conférée par une élection ou une cooptation et marquer la proximité de ce sens avec celui de "marque d'honneur», la charge publique étant un type particulier de marque d'honneur.

\subsection{Le pouvoir apporté par la fonction}

Si l'honos comme "marque d'honneur» implique parfois la détention d'une autorité ou d'une influence au sein de la collectivité, l'honos au sens de "charge publique» suppose de manière systématique la possession d'un véritable pouvoir officiel. Certains textes évoquent la potentia qui se trouve associée à l'honos politique ${ }^{207}$ mais c'est surtout l'imperium qui apparaît associé à l'honos. Un fragment d'un discours de Scipion Emilien le montre sans ambiguïté:

Ex innocentia nascitur dignitas, ex dignitate honor, ex honore imperium, ex imperio libertas.

«De l'intégrité naît le mérite, du mérite l'honneur, de l’honneur le pouvoir, du pouvoir la liberté.»

(SCIP. Aem. frg. inc. 32 ORF).

Cette maxime construite sur une frappante concaténation montre quels sont, dans l'esprit d'un aristocrate romain comme Scipion Émilien, les tenants et les aboutissants de l'exercice d'une charge publique. L'honos se fonde sur le mérite, la dignitas, et confère un pouvoir, l'imperium. Il s'agit là du pouvoir suprême, symbolisé par les faisceaux des licteurs, qui permet de commander les armées et de faire appliquer les lois. Ce rapport de l'imperium et de l'honos est important, car il montre que le pouvoir lié à l'honos est élevé: c'est le pouvoir suprême des magistrats cum imperio. Cette importance du pouvoir conféré par l'honos est confirmée par l'usage privilégié qu'en font les sources pour désigner certains référents. En effet, si honos peut renvoyer en principe à tout type de magistrature, il est employé très majoritairement pour désigner les magistratures situées au sommet du cursus honorum. Le terme est très peu utilisé pour désigner la questure ou bien l'édilité, qui est qualifiée par Cicéron de "premier degré d'honneur » ${ }^{208}$. On le rencontre plus fréquemment pour la préture ${ }^{209}$, et encore plus souvent pour le consulat ${ }^{210}$. Un trait sémantique nouveau se dégage donc: la fonction publique est /dotée d'un pouvoir officiel important/.

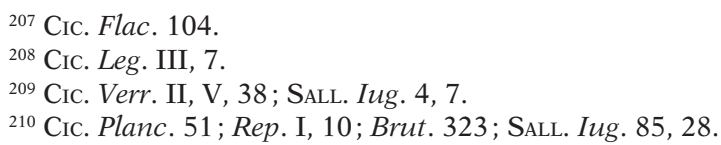




\subsection{Le bénéfice social de la charge}

Jusqu'à présent, la différence de sens entre honos et magistratus est inexistante. Mais la divergence apparaît dès l'instant où l'on observe, à l'aide des contextes où apparaît honos, les conséquences sociales qu'implique ce terme. En effet, honos désigne une charge publique en tant qu'elle est source de prestige social, qu'elle confère à son détenteur un rayonnement qui va au-delà du pouvoir institutionnel. Le $D e$ legibus est instructif sur ce point puisque Cicéron y recourt très rarement à honos pour désigner une magistrature alors que magistratus est récurrent; la raison en est que le texte est un traité et qu'il emploie donc plutôt le terme technique, neutre, qu'est magistratus. Honos est plus appréciatif car il implique une élévation du statut de l'individu ${ }^{211}$. Cet aspect d'honos est sensible également quand on observe les termes qui lui sont le plus volontiers associés: magistratus constitue moins souvent avec lui une paire que ne peut le faire dignitas. Comme honos, dignitas peut désigner une fonction publique. Et le mot renferme, tout comme honos, la notion d'un rang social élevé, ce que magistratus ne dénote pas $^{212}$. Honos renvoie à une charge qui confère de l'éclat: il comporte un splendor éblouissant ${ }^{213}$, il fait partie des choses clara et magnifica si la uirtus préside à sa conquête ${ }^{214}$, et permet de sortir de l'obscurité ${ }^{215}$. L'élévation sociale occasionnée par l'honos est aussi suggérée de manière imagée: l'honos est ce qui rehausse son détenteur (extulit $)^{216}$ ou lui donne de l'amplitudo ${ }^{217}$. Le Commentariolum petitionis énonce clairement le bénéfice de la réussite lors d'une élection:

Noli putare eos qui sunt eo honore usi non uidere, tu cum idem sis adeptus, quid dignitatis habiturus sis.

« Ne va pas croire que ceux qui ont exercé cette charge ne voient pas de quel prestige tu jouiras quand tu l'auras obtenue à ton tour. »

(Q. Cic. Comm. 13; trad. Constans modifiée).

Le bénéfice de prestige qu'apporte l'honos est bien réel puisqu'il permet, lorsque la magistrature est suffisamment élevée, de rejoindre

${ }^{211}$ La définition que donne le Digeste (L, 4, 14) de l'honos municipal ménage une place au prestige lié à l'exercice de la charge: Honor municipalis est administratio rei publicae cum dignitatis gradu [...]; "Un honneur municipal est une charge de gestion publique qui confère un rang dans la dignité. »

${ }^{212}$ Sur les liens établis entre honos et dignitas dans leurs sens politiques, voir Cic.Agr. I, 27 ; Sull. 1 et 24.

213 Cic. Red. Sen. 2

${ }^{214}$ SALL. Iug. 4, 8.

${ }^{215}$ Cic. Verr. II, V, 181.

216 Cic. Catil. I, 28.

${ }^{217}$ Cic. Mur. 8. 
les rangs de la nobilitas ${ }^{218}$. On peut donc dégager un sème supplémentaire: la fonction publique désignée par honos /confère une position éminente dans la société/.

\subsection{Les fondements de la charge}

Les mérites en reconnaissance desquels l'honos est attribué sont un trait de sens essentiel d'honos quand le terme désigne la «marque $\mathrm{d}^{\prime}$ honneur ${ }^{219}$. Le sème se retrouve pour le sens de "charge publique " mais n'occupe pas une place aussi importante puisqu'il n'est actualisé que dans $40 \%$ des occurrences environ ${ }^{220}$. On ne peut cependant ignorer les passages où la notion de mérite entre dans le sémantisme du mot. Nous l'avons déjà vu avec le fragment du discours de Scipion Émilien, où la dignitas, l'excellence personnelle, donne naissance à l'honos. L'idée réapparaît dans le Pro Plancio, lors de la prosopopée du peuple:

[...] sed amplissimos honores ut pro dignitate tua consequare, condiscas censeo mihi paulo diligentius supplicare.

«[...] mais, pour obtenir des fonctions plus hautes, comme il convient à tes mérites, je pense qu'il te faut apprendre à me supplier avec un peu plus de zèle. »

(Cic. Planc. 13; trad. Grimal).

Afin d'obtenir l'honos, le candidat doit savoir s'adresser au peuple, mais cet effort n'a aucun sens s'il n'est pas pourvu préalablement d'une dignitas qui permet de le briguer en toute légitimité. Outre la dignitas, une place importante est ménagée à la uirtus comme source d'honos, comme c'était le cas avec le sens «marque d'honneur»:

Deinde ista praeclara nobilitas desinat queri populum Romanum hominibus nouis, industriis, libenter honores mandare semperque mandasse. Non est querendum in hac ciuitate, quae propter uirtutem omnibus nationibus imperat, uirtutem plurimum posse.

«Après cela, que cette brillante noblesse cesse de se plaindre que le peuple romain confie et ait toujours confié volontiers les honneurs à des hommes nouveaux pleins de zèle. Il ne faut pas se plaindre, dans notre cité qui commande à tous les peuples grâce à son mérite, que le mérite puisse beaucoup. »

(CIc. Verr. II, IV, 81).

${ }^{218}$ Voir sur ce point infra p. 364-365.

${ }^{219}$ Supra p. 51-53.

${ }^{220} \mathrm{Il}$ faut donc relativiser la manière dont $\mathrm{F}$. Klose assoit systématiquement l'honos politique sur des merita (KLose, Bedeutung, p. 27). 
Cicéron défend les homines noui et affirme que les honores politiques ne doivent être appelés que par le mérite personnel, la uirtus, car c'est sur cette même uirtus que Rome s'est construite. La nature de ces mérites est encore très variable et il est difficile d'en donner une définition univoque. Les res gestae militaires, l'éloquence, les bonnes mœurs, le talent personnel, mais aussi la haute naissance, et parfois l'argent, sont autant de moyens d'accéder à l'honos ${ }^{221}$. La fonction publique est donc /susceptible / de se fonder sur certains mérites/.

\subsection{L'influence procurée par la charge}

Un dernier sème, lui aussi virtuel, et assez peu fréquent puisqu'il est actualisé dans environ $20 \%$ des occurrences, permet de creuser la différence avec magistratus. Honos est en effet apte à désigner une fonction qui donne à son détenteur une influence allant au-delà des pouvoirs officiels qui lui sont conférés. Celui qui a l'honos gagne aussi une autorité plus diffuse que l'imperium. Dans le cadre d'un procès, il parvient à recueillir l'attention des juges, comme on le voit dans le Pro Cluentio, où un homme qui assiste à la torture d'un esclave comprend qu'on cherche à lui arracher de faux aveux:

Quidam ex aduocatis, homo et honoribus populi ornatus et summa uirtute praeditus, intellegere se dixit non id agi ut uerum inueniretur sed ut aliquid falsi dicere cogerentur.

"Alors un des amis convoqués, personnage distingué par les honneurs du peuple et doué du plus haut mérite, déclara bien comprendre qu'il ne s'agissait pas de découvrir la vérité mais d'extorquer une fausse déclaration.»

(Cic. Clu. 177; trad. Boyancé).

Le fait que cet homme soit ornatus honoribus apporte du poids à son témoignage et le rend digne de foi. De même, au début du discours sur la lex Manilia, Cicéron affirme sa légitimité à parler en rappelant qu'il a obtenu les honores du peuple $\mathrm{e}^{22}$. Ces honores confèrent au témoin ou à l'orateur une auctoritas, distincte de l'imperium parce que non formalisée, mais susceptible de s'exercer dans tous les moments de la vie civile. Cicéron lui-même a théorisé dans les Topiques l'autorité que confère, dans le domaine juridique, l'exercice d'une charge publique: à propos des preuves extra-techniques que sont les témoignages, il reconnaît que ceux qui proviennent des hommes qui in honoribus populi reque publica uersantur ont une grande valeur ${ }^{223}$. La charge publique peut donc être /assortie d'influence/.

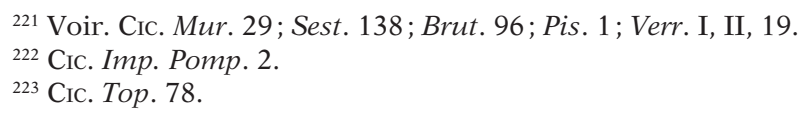




\subsection{Conclusion}

Le sémème complet d'honos « charge publique » (S3) est le suivant: /fonction publique attribuée, / dotée d'un pouvoir officiel important, / qui confère une position éminente dans la société / et est susceptible / de se fonder sur certains mérites / et d'être assortie d'influence/. On peut le rapprocher de celui de «marque d'honneur» $(\mathrm{S} 1)$ :

\section{/bienfait/}

S1: «Marque d'honneur»

/signe/

/d'estime/

/octroyé en reconnaissance/

/de certains mérites/

/qui confère une position éminente dans la société,/

/susceptible/

/d'être assortie d'influence/.
S3 : "Charge publique»

/fonction publique attribuée,/

/dotée d'un pouvoir officiel important,/

/qui confère une position éminente dans la société,/

/et est susceptible/

/de se fonder sur certains mérites,/ /et d'être assortie d'influence/.

Le sème générique de S3 (/fonction publique attribuée/) est différent de celui de S1 (/bienfait/) mais un certain lien persiste entre eux: le fait que la charge soit /attribuée/ rappelle qu'elle est régulièrement conçue comme un type particulier de "marque d'honneur» et donc de /bienfait/, bien que l'autonomie des deux sens soit acquise; il s'opère de $\mathrm{S} 1$ à $\mathrm{S} 3$ une adjonction de sèmes ainsi qu'un effacement de certains d'entre eux. La persistance de trois traits de sens communs et la proximité relative des deux sèmes génériques font que ces deux sens sont unis par une pluralité d'acceptions par déplacement de sens, pour reprendre l'un des types relevés par J.-F. Thomas ${ }^{224}$. Au-delà de ce constat purement sémique, le lien qui unit la "charge publique » à la «marque d'honneur» se dessine en effet assez bien. L'honos "charge publique» est une évolution et une spécialisation dans un sens politique de l'honos "marque d'honneur». Le rapport entre la charge et le signe d'estime est réel, ainsi que le souligne J.Hellegouarc'h: l'honos est selon lui essentiellement un "acte de reconnaissance», et

«le plus fréquent de ces 'actes', c'est celui par lequel le peuple conférait les magistratures. C'est un caractère essentiel de la manière dont les anciens concevaient les fonctions administratives: elles ne sont pas une charge à proprement parler [...], mais une récompense accordée par le peuple en raison des services rendus. Toutes les magistratures sont donc des honores ou honores populi. $»^{225}$

224 Thomas, Déshonneur et honte, p. 415 et 443.

${ }^{225}$ Hellegouarc' H, Vocabulaire, p. 384-385. Cette analyse rejoint en grande partie ce qu'écrit F. Klose sur ce point: la charge n'est qu'un des vecteurs par lesquels se manifeste la «öffentliche Anerkennung » du peuple pour les hommes de mérite (KLose, Bedeutung, p. 20). Voir aussi Milhous, Honos and Virtus in Roman Art, p. 84 et Hölkeskamp, Die Entstehung der Nobilität, p. 211. 
Il nous reste à analyser la différence entre magistratus et honos. Notons préalablement que le terme magistratus est connu et employé dès l'époque où honos est utilisé226. Ce dernier n'est donc pas employé à défaut de l'existence d'un terme spécifique et est donc apte à recevoir des particularités sémantiques. L'analyse sémique le confirme: honos renvoie à une magistrature en tant qu'elle confère à son détenteur un prestige social et une large influence au sein de la collectivité. L'existence de mérites singuliers à la source de l'honos est une autre particularité qui fait que le terme n'est pas totalement synonyme de magistratus. Magistratus, enfin, est une notion de droit public, dotée d'une technicité qu'honos n'a pas. On comprend ainsi que la traduction par «honneur», qui peut en français aussi désigner une fonction publique prestigieuse à responsabilité, soit, ici encore, la plus adaptée. Cependant, la métaphore de la magistrature comme honneur connaît une certaine érosion dans le temps ${ }^{227}$. Un texte capital à cet égard se trouve dans le Brutus, quand Cicéron parle à Brutus de Gaius Curion, jeune orateur qui a péri pendant les guerres civiles:

Qui si me audire uoluisset, ut coeperat, honores quam opes consequi maluisset.

- Quidnam est, inquit, istuc? et quemadmodum distinguis?

- [...]Qui autem occasione aliqua, etiam inuitis suis ciuibus, nactus est imperium, ut ille cupiebat, hunc nomen honoris adeptum, non honorem puto.

«Et s'il avait bien voulu continuer à m'écouter, il aurait recherché les honneurs plutôt que le pouvoir.

- Que veux-tu dire par là, dit Brutus, et quelle est cette distinction?

- [...] Celui qui, profitant de quelque circonstance, s'empare de l'autorité contre le gré de ses concitoyens, comme Curion désirait le faire, j'estime qu'il n'a obtenu de l'honneur que le nom et pas l'honneur lui-même. »

(CIc. Brut. 280-281).

Cicéron établit au début du passage une distinction entre honores, les honneurs politiques, et opes, le pouvoir dans la cité. Cette distinction provoque la surprise de Brutus, qui ne voit pas véritablement de différence entre les deux mots. Cette réaction est le signe qu'à cette date les termes d' "honneurs » et de "puissance, pouvoir» tendent à s'assimiler dans les esprits, jusqu'à se fondre dans une seule notion, celle de l'autorité politique. La dimension prestigieuse de l'honos comme charge et les mérites

${ }^{226}$ Les premières occurrences s'observent dans PL.Amp. 74 et CAT. frg. VII, 127 ORF.

${ }^{227}$ Il nous paraît nécessaire de relativiser l'affirmation de F. Klose selon laquelle honos ne peut jamais être traduit par «charge publique», car alors la notion de «reconnaissance publique» s'efface (Ibid., p.31). Il faut de même nuancer la position de J.E.Lendon pour qui honor et dignitas employés pour désigner une magistrature "are not dead metaphors, technical expressions devoid of their original flavour: honour, prestige, lies absolutely at the heart of the Graeco-Roman perceptions of office holding" (LENDON, Empire of Honour, p. 176). 
sur lesquels il s'appuie tendent à s'effacer. C'est contre cet effacement que réagit Cicéron: l'honos n'est pas l'imperium, le pouvoir; ce n'est là que le nomen honoris. L'honos est le pouvoir prestigieux, fondé sur la uirtus. Le fait que l'honos persiste à être analysé par Cicéron comme un «honneur» authentique, source de responsabilités et de distinction, relève alors plus d’une idéologie politique personnelle que du sémantisme du mot.

\section{6. «Dignité, Honorabilité » (S4)}

Nous abordons avec la signification «dignité, honorabilité » des sens d'honos bien moins fréquents que les trois qui ont été jusqu'alors observés et recouvrent plus de $90 \%$ des occurrences du mot. Honos peut désigner la «dignité», l' «honorabilité», autrement dit la prétention légitime d'une personne, fondée sur ses qualités morales, à l'estime de son entourage. Il s'agit d'une qualité individuelle qui implique l'observation de normes de conduite collectives; c'est le caractère de celui qui a, en somme, le «sens de l'honneur» et mérite à ce titre l'estime publique. On peut donc observer, pour la première fois, une réelle proximité entre le sens moral du mot français «honneur» et honos, alors que jusqu'à présent cet aspect éthique n'était pas très sensible en latin. Ce sens est ancien puisqu'il apparaît chez Plaute ${ }^{228}$. Il n'est pas relevé par les ouvrages de lexicographie mais nous paraît doté de particularités qui justifient d'en faire un sens autonome. L'observation des synonymes partiels d'honos montre en outre que l'existence de ce sens est bien réelle. Les grammairiens et glossateurs antiques proposent comme équivalents d'honos des termes à la coloration morale prononcée. Les Glossae Vergilianae indiquent ainsi honos: uerecundia ${ }^{229}$. La mention de uerecundia, qui signifie généralement le sentiment de l'honneur ou la honte ${ }^{230}$, souligne l'aspect moral et intériorisé que peut avoir honos.

\subsection{Un droit à la considération}

Avec ce sens d'honos, le jugement de la collectivité est toujours présent, mais sur un mode plus hypothétique, puisqu'on envisage le droit de la personne à l'estime publique, et non la situation où elle en bénéficie ou le bienfait qui la signifie. L'accent se porte sur ce qui légitime la prétention de la personne à la considération de son entourage. Dans les Bacchides, le jeune Mnésiloque se juge ainsi dépouillé de tout honos:

Petulans, proteruo, iracundo animo, indomito, incogitato,

Sine modo et modestia sum, sine bono iure atque honore.

${ }^{228}$ PL. Bac. 613 ; Trin. 697.

${ }^{229}$ Glossaria Latina (Lindsay) I, 282.

${ }^{230}$ Thomas, Déshonneur et honte, p. 401-439. 
«Imprudent, effronté, irascible, indomptable, irréfléchi,

Sans mesure ni modération, voilà ce que je suis; j'ignore le bon droit et l'honneur.»

(PL. Bac. 612-613).

Ces deux vers sont issus d'un monologue de désespoir dans lequel Mnésiloque regrette amèrement d'avoir restitué à son père l'argent que l'esclave Chrysale avait réussi à extorquer au senex. Sur la scène de la comédie où les valeurs sont inversées, le jeune homme se dit sine honore parce qu'il n'a pas dépouillé son père comme il se doit. L'honos ne désigne pas ici la considération dont il jouit et qu'il aurait perdue car Mnésiloque incarne le type du iuuenis mollis qui mène une vie dissolue et dont le prestige social est très faible. Le terme renvoie plutôt à sa dignité, à son honneur de jeune homme de comédie qui, pour mériter l'estime, doit se comporter comme son rôle l'impose, c'est-à-dire flouer son père. Une autre occurrence de ce sens se rencontre dans un elogium du tombeau des Scipions ${ }^{231}$ :

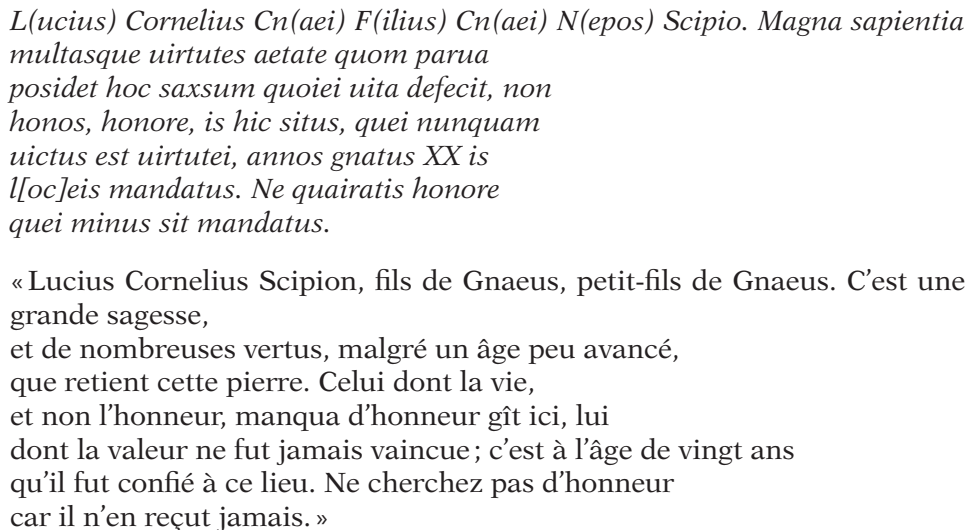
$\left(C I L \mathrm{I}^{2}, 11=I L L R P 312\right)$.

Le texte joue de manière intéressante sur la polysémie d'honos. On y trouve le sens de "dignité» avec honos au nominatif (1. 4); comme le dit A. Ernout, le mot renvoie ici à l'honestas morum du défunt qui le rend digne de recevoir une "marque d'honneur» (honore au datif archaïque 1.4) ${ }^{232}$. L'inscription déclare que Lucius Scipion n'a pas reçu d' «hommage » non pas parce qu'il ne possédait pas de « dignité » mais

${ }^{231}$ Pour la datation de l'inscription et l'identification du personnage, voir notre étude de ce texte p. 603 sqq.

${ }^{232}$ A. Ernout, Recueil de textes latins archaïques, 4e éd., Paris, C. Klincksieck, 1973, p. 20. Sur le problème de l'identification du cas de honore, voir P. KRuschwitz, Carmina Saturnia Epigraphica, Stuttgart, F. Steiner, 2002, p. 98. 
parce que sa vie a été trop courte ${ }^{233}$. Lucius Scipion était tout à fait digne d'être honoré mais il est mort trop jeune. L'honos au nominatif de la ligne 4 désigne donc la qualité de celui qui mérite la considération en vertu de son excellence morale. Le mot suppose bien ici un droit à l'estime et à ses marques car, dans l'idéologie aristocratique, la prétention du nobilis à obtenir des honores est toujours légitime en raison de sa haute naissance. Quant à l'honore de la ligne 7, il s'agit de la «charge publique». Les épitaphes mentionnent en effet habituellement le cursus honorum du défunt, les charges qu'il a exercées au cours de sa vie; ici la tombe s'adresse au passant en lui disant de ne pas "chercher l'honneur », c'est-à-dire la mention d'une charge, puisque L.Scipion est mort trop jeune pour en exercer une. On peut ainsi dégager les sèmes suivants: /droit légitime à / l'estime / et aux bienfaits / qui en sont le signe/.

\subsection{Les fondements moraux de l'honorabilité}

Les contextes où apparaît le sens «dignité » actualisent l'idée d'un mérite moral du sujet. On retrouve, ici encore, la notion de uirtus, comme on le voit dans l'épitaphe que nous venons de citer, mais aussi d'autres qualités, comme dans ce texte de Plaute:

Is est honos homini pudico meminisse officium suom.

«C'est cela l'honneur, pour un homme vertueux: se souvenir de son devoir. »

(PL. Trin. 697).

Lesbonicus, qui s'est ruiné par sa fréquentation des courtisanes, refuse cependant obstinément de laisser sa sœur se marier sans dot et justifie ce refus par la mention de son honos. C'est bien la dignité qui l'empêche d'agir ainsi, la volonté de ne pas se déshonorer. Cette dignité est comprise par Lesbonicus comme le propre de l'homme pudicus, de celui qui sait faire preuve de pudor, mélange de modération et de sens de la retenue qui permet d'éviter la honte. Le fondement moral de l'honos transparaît aussi dans le Pro Flacco quand Cicéron s'en prend à Méandrius, l'individu chargé par la cité de Tralles de transmettre ses plaintes contre Flaccus:

Quae si ciuitas per uiros bonos grauisque homines querelas ad uos detulisset, paulo commouerer magis. Nunc uero quid putem? Trallianos Maeandrio causam publicam commisisse, homini egenti, sordido, sine honore, sine existumatione, sine censu?

"Si cette cité vous avait transmis ses doléances par l'intermédiaire d'hommes de bien et de gens de poids, je serais un peu plus ému. Mais en réalité

${ }^{233}$ Littéralement: «Sa vie a fait défaut, non son honneur, pour l'obtention de l’honneur. » 
que penser? Que les Tralliens ont confié la défense de leur cité à Méandrius, un homme indigent, vil, sans honneur, sans considération, sans argent? »

(Cic. Flac. 52).

Honos pourrait ici se comprendre comme la "considération", mais l'expression sine honore, sine existumatione serait alors redondante. Cicéron insiste en outre beaucoup dans la suite du texte sur les tares morales de Méandrius, ce qui oriente honos vers le sens de "dignité». Le fait d'être sine honore s'oppose à la définition de l'homme digne de confiance donnée au début du texte: celui qui n'a pas l'honos n'est ni bonus ni grauis, ce qui implique que l'homme plein de «dignité » possède ces qualités éthiques. Nous pouvons donc indiquer des sèmes complémentaires: le droit à l'estime est/fondé sur des mérites / moraux/.

\subsection{Réguler sa conduite}

La dignité désignée par honos se fonde sur des qualités morales mais implique aussi une relation particulière du sujet à ces qualités. Celui qui a l'honos s'impose en effet une conduite en accord avec ces dernières, afin de conserver l'estime de l'entourage. Honos suppose donc que le sujet sache réguler sa conduite conformément à des principes supérieurs, qu'il ait conscience des exigences de l'honneur. Cette conscience l'amène à respecter les normes morales de la collectivité dans laquelle il se trouve. La régulation de la conduite qu'implique l'honos apparaît bien dans le texte des Bacchides cité supra qu'il est utile de réexaminer:

Petulans, proteruo, iracundo animo, indomito, incogitato,

Sine modo et modestia sum, sine bono iure atque honore.

«Imprudent, effronté, irascible, indomptable, irréfléchi,

Sans mesure ni modération, voilà ce que je suis; j'ignore le bon droit et l'honneur. »

(PL. Bac. 612-613).

Mnésiloque associe de façon significative l'honos au ius, qui désigne ici le «bon droit», l'équité, la conscience des principes de la loi. Honos suppose comme ius le respect de règles, mais de nature morale et non pas juridique. Être sine honore, c'est être incapable de respecter les contraintes imposées par la dignité, ce que dit bien le v. 612: Mnésiloque a un animus indomptable, qui ne sait se plier à des règles. L'autre texte de Plaute que nous citions, tiré du Trinummus, reprend cette idée d'une conformité à un code moral impliquée par honos puisqu'il est dit que l'honos consiste à meminisse officium suom, se souvenir de son devoir, autrement dit avoir conscience des règles qu'impose la position dans la 
société ${ }^{234}$. Dès lors, l'honos peut devenir un objet moral et intellectuel qui oriente le comportement. Critiquant la malhonnêteté du triumuir capitalis Manilius, Cicéron le présente en ces termes:

Manilium plerique noratis: non ille honorem a pueritia, non studia uirtutis, non ullum existimationis bonae fructum umquam cogitarat, sed ex petulanti atque improbo scurra in discordiis ciuitatis ad eam columnam ad quam multorum saepe conuiciis perductus erat tum suffragiis populi peruenerat.

«Vous avez connu pour la plupart Manilius. Dès son enfance, il n'avait jamais eu une pensée pour l'honneur, pour la pratique de la vertu, ni pour aucun des fruits qui naissent d'une bonne réputation. Mais de plaisantin effronté et impudent qu'il était, à la faveur des discordes civiles il était arrivé, grâce aux suffrages populaires, à siéger près de cette colonne où l'avaient conduit souvent les cris insultants de la multitude.»

(Cic. Clu. 39; trad. Boyancé modifiée).

Le contexte psychologisant, et le passage progressif de l'intériorité à l'extériorité (honos, puis uirtus et enfin existimatio) indiquent qu'honos désigne la «dignité » plutôt que le «prestige». L'honos est quelque chose à quoi il faut réfléchir (cogitare), et c'est cette pensée de la dignité qui conduit à faire preuve de uirtus et, ultimement, à obtenir l'estime (existimatio) de l'entourage. Manilius est dépourvu de cet honos, ce qui le conduit à se comporter comme un scurra, un bouffon, incapable de se maîtriser: on retrouve le terme de petulans qui apparaissait déjà dans les Bacchides. L'honos, constitué par le sujet en objet de conscience, guide le comportement. Cela nous permet de faire émerger un dernier sème: honos désigne un /guide pour la conduite/.

\subsection{Conclusion}

Le sémème complet d'honos "dignité» (S4) est le suivant: /droit légitime à / l'estime / et aux bienfaits / qui en sont le signe / fondé sur des mérites / moraux / et constituant un guide pour la conduite/. On peut le rapprocher utilement du sémème de «considération». La «dignité » apparaît en effet comme le droit à la «considération » pour celui qui est doté de mérites moraux. C'est la qualité de l'individu qui érige ces mérites en principes de conduite.

${ }^{234}$ PL. Trin. 688. 


\begin{tabular}{|c|c|}
\hline $\begin{array}{l}\qquad \mathrm{S} 1: \text { "Considération» } \\
\text { /situation d'estime/ } \\
\text { /associée à une position éminente dans } \\
\quad \text { la société,/ } \\
\text { /fondée sur certains mérites,/ } \\
\text { /et susceptible/ } \\
\text { /d'être assortie d'influence/ } \\
\text { /et d'être signifiée/ } \\
\text { /par des bienfaits/. }\end{array}$ & $\begin{array}{l}\quad \text { S4: «Dignité, honneur" } \\
\text { /droit légitime à/ } \\
\text { /l'estime/ } \\
\text { /et aux bienfaits/ } \\
\text { /qui en sont le signe/ } \\
\text { /fondé sur des mérites/ } \\
\text { /moraux/ } \\
\text { /et constituant un guide pour la conduite/ }\end{array}$ \\
\hline
\end{tabular}

Ce sens d'honos se révèle extrêmement proche de l'un des sens les plus importants d'honestas. Il nous appartiendra donc, lorsque nous examinerons ce dernier, de faire la comparaison entre les deux termes. Nous reportons aussi à cette occasion l'examen de la proximité du sens S4 d'honos avec le sens moral de dignitas et avec pudor et uerecundia ${ }^{235}$.

\section{7. «RÉCOMPENSE » (S5)}

Honos peut perdre tout rapport avec la notion d'estime et désigner une simple "récompense », un avantage octroyé en retour d'un service ou d'un bienfait reçu. Ce sens, peu fréquent, se rencontre pour la première fois chez Térence. L'OLD le rattache à celui de «marque d'estime " considérant que la marque est "given as a reward ${ }^{236}$; le dictionnaire de F. Gaffiot ${ }^{237}$, tout comme F. Klose ${ }^{238}$, le rapproche du sens "salaire» que peut avoir honos à une époque ultérieure. Ce signifié nous paraît cependant devoir être isolé en raison de l'effacement de plusieurs sèmes qui sont essentiels dans les autres acceptions du mot.

\subsection{Un bienfait}

Il existe une proximité entre honos «marque d'honneur» et le terme praemium, comme nous l'avons vu, proximité qui est naturellement accentuée quand honos désigne la "récompense » ${ }^{239}$. Au début de la seconde action contre Verrès, Cicéron évoque le comportement de Sylla avec Verrès après que ce dernier eut rallié sa cause: il le récompense, mais le tient à distance et se méfie de lui.

Ei postea praemia tamen liberaliter tribuit, bona quaedam proscriptorum in agro Beneuentano diripienda concessit, habuit honorem ut proditori, non ut amico fidem.

${ }^{235}$ Voir infra p. 173.

${ }^{236} O L D$, p. 802.

${ }^{237}$ Voir p. 753, «récompense, prix», sens relevé chez Virgile et Ovide.

${ }^{238}$ KLose, Bedeutung, p. 54.

${ }^{239}$ Sur le rapport entre honos et praemium, voir l'entrée du Glossarium Ansileubi (Glossaria latina p. 282, 72): "honorem: praemium» et supra p. 59. 
«Par la suite, il lui octroya généreusement de faire du butin, il lui permis de piller quelques biens de proscrits sur le territoire de Bénévent, il lui donna une récompense, comme on fait à un traître, et non sa confiance, comme on fait à un ami. »

(CIc. Verr. II, I, 38).

Sylla a permis à Verrès d'accumuler des praemia, qui sont une forme de butin, à titre d'honos. Le terme ne peut désigner ici une «marque d'honneur » car le sens de la phrase est péjoratif et Cicéron ne présenterait pas l'image d'un Sylla honorant un proditor. L'honos donné à Verrès n'est qu'une récompense, un dû dont il faut s'acquitter et qui ne signifie nullement l'estime ni ne confère une position sociale distinctive. Mais il s'agit bien d'un avantage matériel, opposé à la punition et au châtiment ${ }^{240}$. Honos implique un bienfait concret, comme on le voit quand Cicéron accuse les Roscii d'avoir demandé à Chrysogonus d'acheter les biens de Roscius aux enchères pour leur profit:

Si nihil aliud fecerunt nisi rem detulerunt, nonne satis fuit iis gratias agi, denique, ut perliberaliter ageretur, honoris aliquid haberi?

«S'ils n'ont accompli d'autre acte que leur dénonciation, ne suffisait-il pas de les remercier? tout au plus, pour agir avec la plus grande libéralité, de leur donner quelque récompense?»

(Cic. Rosc. Amer. 108; trad. De La Ville de Mirmont modifiée).

L'honos se situe juste au-dessus du remerciement (gratias agere) dans les gestes de reconnaissance, mais ne s'élève pas au niveau de l'hommage: il s'agit bien d'une récompense, ce qui donne à honos le sème générique de /bienfait/.

\subsection{La reconnaissance de certains mérites}

Le bienfait concret désigné par honos a des fondements précis: il ne s'agit pas d'un acte de générosité spontanée car il intervient en retour d'un service rendu, comme dans cette scène de l'Eunuque:

PY.: Tu iam pendebis qui stultum adulescentulum nobilitas

Flagitiis et eumdem indicas; uterque in te exempla edent.

$P_{\text {A. : Nullus sum. }}$

PY. :

Hic pro illo munere tibi honos est habitus. Abeo.

«Pythias: Tu vas être pendu immédiatement, toi qui rends un jeune imbé cile célèbre

Par des scandales, et le dénonces en même temps; ils feront tous deux de toi un exemple.

PARménon: Je suis anéanti. - Py.: Voilà la récompense qui t'attend pour tes services. Je m'en vais. »

(Ter. Eun. 1021-1023).

${ }^{240}$ Voir l'opposition entre honos et animaduersio dans Cic. Rosc. Amer. 137. 
La servante Pythias menace l'esclave Parménon, responsable de l'introduction de Chéréa dans la maison de la meretrix où il a violé une jeune fille. Pour ce méfait, Parménon va recevoir un honos, employé ici par antiphrase ${ }^{241}$. Le sens de "marque d'honneur», même ironique, est mal adapté au contexte: c'est bien d'un salaire en retour d'un "service rendu » (pro munere), dont parle Pythias ${ }^{242}$, d'une "récompense » sous la forme de la pendaison, sans que l'estime soit signifiée. De même, dans le De inuentione, l'accusateur doit s'en prendre à celui qui avoue en disant

cum beneficiis honos habitus sit, pro maleficio poenam sumi oportere.

"qu'il doit être châtié pour ses méfaits, puisqu'il a été récompensé pour ses services. »

(CIc. Inu. II, 108).

Dans ce contexte juridique, l'honos est plus une récompense qu'un honneur; il s'oppose d'ailleurs à la poena, la punition. Et il se fonde sur de bonnes actions (beneficiis). Nous pouvons donc retenir deux sèmes supplémentaires: /en reconnaissance / de certains mérites/.

\subsection{Conclusion}

Le sémème complet du sens «récompense» est le suivant: /bienfait/ octroyé en reconnaissance / de certains mérites/. Ce sens procède de celui de «marque d'honneur»:

\begin{tabular}{|l|l|}
\hline \multicolumn{1}{|c|}{$\mathrm{S} 1:$ «Marque d'honneur» } & \multicolumn{1}{c|}{$\mathrm{S} 5:$ «Récompense » } \\
/bienfait/ & /bienfait/ \\
/signe/ & \\
/d'estime/ & /octroyé en reconnaissance/ \\
/octroyé en reconnaissance// & /de certains mérites/. \\
/qui confère une position éminente dans la société,/ & \\
/susceptible/ & \\
/d'être assortie d'influence/. & \\
\hline
\end{tabular}

Plusieurs sèmes spécifiques de S1 disparaissent dans S5, mais le sème générique reste identique. Nous avons donc affaire à une relation d'extension de sens. Quand il désigne la "récompense », honos ne signifie plus l'estime comme quand il renvoie à la "marque d'honneur» et ne suppose pas non plus de bénéfices en termes de prestige social ni d'autorité sur l'entourage. Dès lors, le rapprochement sémantique avec praemium et pretium s'accentue.

${ }^{241}$ Le manuscrit A donne honus, issu d'une confusion avec honos, et $\mathrm{G}^{2}$ donne honor, qui ne peut être retenu pour des raisons métriques.

${ }^{242}$ Le mot ne peut en aucun cas avoir le sens de "charge politique», comme le suggère D.C. EARL, «Terence and Roman Politics », Historia, 11, 1962, p.469-485. 
8. «BeAuté, maJesté » (S6)

Ce sens d'honos, bien repéré par tous les ouvrages de lexicographie, constitue une évolution importante puisqu'il écarte le mot des sphères de l'honneur et de la vie politique où il était jusque-là employé. Honos désigne la «beauté » physique d'une personne, mais une beauté d'un type particulier, noble et impressionnante, si bien que "majesté» ou "noblesse», au sens où ces mots caractérisent l'apparence extérieure, peuvent constituer de bonnes traductions ${ }^{243}$. Ce sens apparaît quatre fois dans notre corpus, chez Lucrèce et Varron d'Atax. C'est donc le plus récent de tous les sens d'honos considérés.

\subsection{Analyse sémique}

Dans le courant du livre IV du De rerum natura, Lucrèce dépeint la passion amoureuse comme une folie nuisible et décrit notamment la manière dont les hommes s'aveuglent sur les défauts des femmes qu'ils aiment. Chaque vice est en effet transmué par eux en qualité:

\footnotetext{
Nigra melichrus est, inmunda et foetida acosmos,

Caesia Palladium, neruosa et lignea dorcas,

Paruula, pumilio, chariton mia, tota merum sal,

Magna atque immanis, cataplexis, plenaque honoris.

«Noire, elle est couleur de miel; sale et puante, elle est sans fard;

A-t-elle les yeux pers, c'est Pallas; nerveuse et sèche comme le bois, c'est une gazelle;

Une naine est une Pygmée, une des Grâces, un grain de sel pur;

Une monstrueuse géante est une merveille, pleine de majesté. »
}

(Lucr. DRN IV, 1160-1163).

Le passage oppose un à un des traits physiques négatifs aux qualités correspondantes. La femme qui est magna atque immanis devient, à travers les yeux de l'amoureux, plena honoris. L'honos est un trait de l'apparence physique qui provoque l'admiration de l'amoureux comme le suggère cataplexis qui dénote l'étonnement. Honos désigne donc la beauté, la qualité de l'apparence qui suscite une admiration de nature esthétique. À ces traits sémantiques s'ajoute un autre aspect important, que met en évidence le parallélisme avec magna atque immanis: honos comporte, comme ces deux termes qui en constituent le versant négatif, l'idée d'une grandeur qui force le respect, d'une apparence extérieure qui donne à son détenteur une importance de nature à impressionner. Honos est une beauté majestueuse, grandiose, connotée de manière très posi-

${ }^{243}$ Voir la traduction suggestive de l'OLD: «A quality of appearance that inspires esteem; dignity, grace»(p.802). Le TLL note qu'au sein de cette beauté désignée par honos "praeualet uis maiestatis, dignitatis» (VI, 3, col. 2930, 1. 17). 
tive. Un autre texte de Lucrèce, situé quelques vers après, présente des traits de sens similaires:

Sed tamen esto iam quantouis oris honore,

Cui Veneris membris uis omnibus exoriatur:

Nempe aliae quoque sunt; nempe hac sine uiximus ante

Nempe eadem facit, et scimus facere, omnia turpi,

[...]

«Mais soit: son visage a toute la beauté possible,

Et le charme de Vénus émane de tous ses membres.

Mais il y en a d'autres qu'elles! Mais nous vivions avant sans elle!

Mais elle a exactement les mêmes défauts qu'une laide, nous le savons bien!»

(LuCR. DRN IV, 1171-1174).

Honos désigne ici encore une qualité de l'apparence physique, qui siège plus spécifiquement sur le visage, ce qui est l'indice que cette beauté est plus noble que celle qui se répand sur le corps et se trouve associée au désir. Honos est lié à os, mais c'est Veneris uis qui est rapprochée de membris. La "force de Vénus» (charme érotique du corps) est distincte de la noblesse qui empreint le visage. Cette beauté est ici aussi source d'une intense admiration: l'amoureux est aveuglé par elle, ce qui lui fait négliger toutes les autres femmes. À cette femme pleine d'honos s'oppose celle qui est turpis, c'est-à-dire qui possède une laideur qui suscite le dégoût et la répulsion ${ }^{244}$. Se trouvent donc actualisés, comme dans le texte précédent, les sèmes de la /qualité physique/ et de /l’estime / admirative / d'ordre esthétique/. On ne retrouve pas ici l'idée de la grandeur mais l'effacement des autres personnes aux yeux de celui qui contemple la beauté de la femme suggère que c'est une beauté qui distingue son détenteur. Honos peut aussi qualifier la beauté d'objets dotés d'un statut particulier, comme les statues divines: pour prouver que la foudre n'est pas l'œuvre des dieux, Lucrèce montre qu'un être divin ne détruirait pas ses propres images; or il arrive que les temples et les statues divines soient foudroyés:

\footnotetext{
Postremo cur sancta deum delubra suasque

Discutit infesto praeclaras fulmine sedes

Et bene facta deum frangit simulacra suisque

Demit imaginibus uiolento uolnere honorem?

«Enfin pourquoi Jupiter renverse-t-il les temples sacrés des dieux

Et ses demeures superbes de sa foudre hostile,

Et pourquoi brise-t-il les belles statues divines

Et défigure-t-il ses propres images par d'horribles blessures?»
}

(LuCR. DRN VI, 417-420).

${ }^{244}$ Sur ce sens esthétique de turpis, voir P. MonTeI,, Beau et laid. Contribution à une étude historique du vocabulaire esthétique en latin, Paris, C. Klincksieck, 1964, p. 261-306. 
L'honos nous paraît ici renvoyer à la beauté des statues, car il est dit qu'elles sont bene facta $^{245}$ : la foudre enlève l'honos des statues parce qu'elle les brise et les défigure. L'honos est ici aussi une beauté distinctive, car propre aux objets sacrés, qui impose le respect à l'entourage et interdit toute atteinte. On retrouve donc un sème déjà identifié pour d'autres sens: la qualité de l'apparence extérieure /confère une position éminente/.

\subsection{Conclusion}

Le sémème complet d'honos au sens « beauté, majesté » est le suivant: /Qualité physique / qui suscite une estime / admirative / et confère une position éminente dans la société/. L'honos désigne l'apparence extérieure qui attire l'estime de l'entourage, mais une estime de nature esthétique, provoquée par des traits physiques. Ce sens peut donc être relié à celui de "considération », dans la mesure où la «beauté» est un trait qui apporte de la «considération».

\begin{tabular}{|l|l|}
\hline \multicolumn{1}{|c|}{ S2: «Considération » } & \multicolumn{1}{c|}{$\begin{array}{c}\text { S6: «Beauté, majesté» } \\
\text { /situation d'estime/ }\end{array}$} \\
$\begin{array}{l}\text { /associée à une position éminente dans phique/ } \\
\text { la société,/ } \\
\text { /qui suscite une estime / admirative/ } \\
\text { /d'ordre esthétique/ } \\
\text { /fondée sur certains mérites,/ } \\
\text { /et susceptible/ } \\
\text { /d'être assortie d'influence/ } \\
\text { let d'être signifiée/ } \\
\text { /par des bienfaits/. }\end{array}$ & \\
\hline
\end{tabular}

Il s'opère de S2 à S6 un changement de sème générique, avec l'apparition pour "beauté » de celui de la /qualité physique/. Plusieurs sèmes contenus dans S2 disparaissent, mais on retrouve dans S6 celui de la /position éminente/ ainsi que celui de /l'estime/, quelque peu modifié puisque l'estime se teinte d'une vive admiration. Il s'agit d'une relation de polysémie lâche de sens. On observe donc ici un passage d'honos dans le domaine de l'esthétique. Un tel déplacement de sens, s'il peut nous paraître surprenant, s'explique par la persistance des notions d'estime et de distinction sociale qui servent de maillons. On en trouve d'ailleurs d'autres exemples dans le lexique latin: dedecus, qui désigne le «déshonneur» et la «conduite déshonorante» en est venu à signifier,

${ }^{245}$ On trouve en outre une formulation assez semblable chez Varron d'Atax: Frigidus et siluis aquilo decussit honorem; «Et le glacial Aquilon a dépouillé les forêts de leur parure. » (VARR. ATAC. frg. 6 FPL). Tous les traducteurs ne s'accordent pas cependant sur ce point. C. Bailey et A. Ernout retiennent le sens de «beauté», mais J. Kany-Turpin et H. Clouard lui donnent le sens de "prestige». 
par une semblable polysémie lâche de sens, la «laideur physique» chez Ovide $^{246}$. Selon un mécanisme semblable, gloria a pris le sens esthétique d' "éclat», "parure», qui partage avec le sens "gloire» le trait de sens $\mathrm{du} /$ prestige reconnu et intense/ qui suit la notoriété ou la beautée ${ }^{247}$. Si le sens «beauté» d'honos procède bien du fonctionnement sémantique interne d'honos, il n'est pas impossible qu'ait pu jouer pour son émergence l'influence d'honestus, adjectif dérivé d'honos qui hérite donc de son sémantisme mais est aussi susceptible d'avoir réciproquement enrichi honos: l'adjectif possède en effet, dès l'époque de Térence, le sens esthétique de «beau » ${ }^{248}$.

Par rapport à pulchritudo, les traits sémantiques spécifiques d'honos sont assez nets: pulchritudo est un terme générique pour désigner la beauté, même si le mot a pu porter à l'origine une coloration religieuse ${ }^{249}$. C'est le terme le plus employé pour y renvoyer. Honos, qui est bien plus rare, dénote une beauté admirable, qui est liée à la notion d'estime et de position distinctive. L'évolution esthétique d'honos rappelle celle que connaissent d'autres mots du lexique social; dignitas peut ainsi avoir le sens de «beauté», comme l'atteste Cicéron, et renvoyer à une beauté virile, imposante, noble ${ }^{250}$. C'est aussi le cas de decus qui dénote, dans la lignée du sémantisme du mot, une splendeur qui orne le sujet de façon gracieuse ${ }^{251}$. On constate ainsi que dignitas et decus ont un fonctionnement sémantique parallèle, en plusieurs points, à celui d'honos puisqu'ils ont divers sens en partage. Chacun d'eux conserve cependant à chaque fois des nuances propres: l'estime et la marque distinctive pour honos, l'ornement et l'illustration pour decus, la dignité et le mérite pour dignitas.

\section{La Divinité Honos (S7)}

Honos est aussi à Rome une divinité qui fait l'objet d'un culte, au même titre que d'autres notions divines, comme Virtus ou Fides. Il s'agit là, du point de vue sémantique, d'un emploi particulier du mot, qui devient un nom propre et possède donc une désignation référentielle unique. Nous n'en donnons donc pas d'analyse sémique et renvoyons sur ce sujet au chapitre consacré à la divinité Honos ${ }^{252}$.

${ }^{246}$ Thомаs, Déshonneur et honte, p. 87-88.

${ }^{247}$ Thомаs, Gloria et laus, p. 208-211.

${ }^{248}$ Voir infra p. 143.

${ }^{249}$ Monteil, Beau et laid, p. 105-108.

${ }^{250}$ CIC. Off. I, 130. Voir FËDorov, «La genèse de la composante esthétique ».

${ }^{251}$ Verg. Aen. I, 592. Decus subit cependant alors la concurrence de decor, plus fréquent dans un sens esthétique.

${ }^{252}$ Infra chapitre 11. 


\section{CONCLUSION GÉNÉRALE SUR LE SÉMANTISME D’HONOS}

\subsection{La question du sens premier}

Les quatre sens les plus anciens d'honos sont «marque d'honneur», «considération», «charge publique», «dignité ». Les deux derniers ne peuvent constituer le sens premier du mot, puisque leur sémantisme procède respectivement de "marque d'honneur» et de «considération». C'est donc l'un de ces deux sens qui est premier. La mise en avant des différents traits de sens paraît impliquer que "marque d'honneur» soit antérieur à "considération", mais la relation de métonymie complexe qui les unit ne pourrait-elle pas fonctionner dans un sens aussi bien que dans l'autre? Il est à première vue naturel de penser que le sens de «considération " précède celui de «marque d'honneur», l'estime préexistant à la marque concrète qui la signifie. Deux ouvrages de lexicographie font de "considération» le sens premier: le TLL commence son article par une entrée honos au sens d'aestimatio compris comme actus positus in intellectu; l'OLD adopte un raisonnement similaire et donne d'abord le sens de "high esteem or respect accorded to superior worth or rank, honour ${ }^{253}$. Une telle hypothèse ne nous paraît cependant pas défendable. D'abord parce que l'existence pour honos d'une signification «estime » au sens de «opinion favorable» nous paraît difficile à soutenir ${ }^{254}$. Ensuite parce que l'établissement des sèmes de la «considération » montre que le sémème procède de celui de «marque d'honneur»: la "considération » désignée par honos est la situation de prestige qui repose, entre autres, sur les marques d'honneur. Cette préséance logique indique une préséance chronologique, comme le rappelle C. Nicolas:

"Chaque innovation sémantique, à l'intérieur d'un sémème donné, ne peut surgir qu'à partir d'un sémème déjà entériné (par voie de restriction de sens, extension, etc.), en sorte que, [...] il va de soi que le sommet de la pyramide est premier autant logiquement parlant que chronologiquement. »255

C'est donc selon nous la «marque d'honneur» qui est le sens premier. Cela est conforme à une certaine répugnance du latin envers l'abstrait. J. Marouzeau a montré combien le latin a une propension naturelle au concret et présente au début de son histoire un certain déficit de termes abstraits ${ }^{256}$. Il s'agit certes là d'une représentation du lexique qui a ses limites, qui se fonde sur le thème de la patrii sermonis egestas développé par les anciens eux-mêmes et qu'il faut relativiser

${ }^{253}$ TLL VI, 3, col. 2916, 1. 84; OLD p. 801.

${ }^{254}$ Voir supra p. 62 sqq.

${ }^{255}$ Nicolas, Calque, p. 87.

${ }^{256}$ Sur ces points, J. Marouzeau, Quelques aspects de la formation du latin littéraire, Paris, C. Klincksieck, 1949, chapitre «La conquête de l'abstrait». 
car le latin archaïque possédait déjà des termes abstraits ${ }^{257}$. Mais il est incontestable que les auteurs de l'époque classique, Cicéron en tête, ont largement employé les dérivations abstraites pour enrichir une langue qui en était assez peu pourvue initialement. Si des réserves ont été émises, à juste titre, sur la volonté de tout expliquer, dans la langue latine, par un sens premier concret ${ }^{258}$, il nous semble tout de même justifié de considérer que c'est là un trait d'honos, d'autant plus vraisemblable que le terme appartient au fonds le plus ancien du vocabulaire. Les realia le confirment. Estimer que la considération précède, dans les faits, les marques de considération, et que cet ordre logique se reflète dans le langage, revient à adopter un point de vue moderne qui n'est pas en accord avec la réalité romaine. La «considération » qu'est l'honos n'existe véritablement dans les esprits qu'en tant qu'on en a des marques visibles: l'honos concret produit l'honos abstrait tout autant qu'il en procède ${ }^{259}$.

L'identification du sens premier d'honos permet d'apporter un éclairage sur la question complexe de l'étymologie du mot. Le sens "marque d'honneur» semble pouvoir donner une certaine solidité à l'hypothèse qui paraissait la moins difficultueuse, celle qui faisait provenir honos de la racine indo-européenne * $g^{\widehat{h}} e n$ - ("se comporter amicalement»). Le lien entre la «marque d'honneur» et la notion de «comportement amical» est en effet perceptible et indique peut-être une filiation étymologique, sans que cet argument ne soit tout à fait décisif.

${ }^{257}$ Le thème de la patrii sermonis egestas est inauguré par Lucrèce (DRN I, 139 et 832 ; III, 260) et repris par Cicéron, Sénèque puis Pline le Jeune (E. VALETTE-CAGNAC, «Vtraque lingua. Critique de la notion de bilinguisme», in Dupont, F. et Valette-Cagnac, E. (éds.), Façons de parler grec à Rome, Paris, Belin, 2005, p. 7-35; T.FöGEN, Patrii sermonis egestas. Einstellungen lateinischer Autoren zu ihrer Muttersprache: ein Beitrag zum Sprachbewußtsein in der römischen Antike, Munich, K. G.Saur, 2000, passim). Sur la capacité d'abstraction du latin, J.DAUDE, «Les substantifs abstraits de qualité», in KIRCHER-DuRAND, C. (éd.), Grammaire fondamentale du latin, tome IX. Création lexicale: la formation des noms par dérivation suffixale, Louvain, Peeters, 2002, p. 225-305: «Le latin archaïque possédait déjà un large contingent de termes abstraits, beaucoup du type des noms-racines (uis, ius, ops, etc.)» (p.226). Voir aussi H.J.Molsberger, Abstrakter Ausdruck im Altlatein, Frankfurt am Main, Athenäum, 1989, notamment les p. 16 et suivantes, qui discutent les conceptions de J. Marouzeau.

${ }^{258}$ É. Gavoille met en garde contre «cette habitude qui, chez la plupart des philologues, consiste à partir du sens réputé 'concret' pour rendre compte d'une évolution sémantique» (GAvoILlE, Ars, p.29). É. Gavoille reprend un avertissement formulé par É. Benveniste, Problèmes de linguistique générale, Paris, Gallimard, 1966, vol.1, p. 298-301.

${ }^{259}$ Sur cet aspect, voir infra p. 367. 


\subsection{Honos, terme du vocabulaire religieux?}

Au cours de son étude du vocabulaire politique de la République, J. Hellegouarc'h considère qu'honos appartient initialement au lexique de la religion:

"À l'origine, honos est, selon toute vraisemblance, un mot du vocabulaire religieux: c'est 'l'hommage' rendu aux dieux, le témoignage de la pietas que l'on éprouve à leur endroit, témoignage qui leur est dû en raison des bienfaits qu'ils apportent aux hommes. $»^{260}$

C’est aussi la thèse que soutient Z. Hoffmann: honos désignerait au départ l'acte concret de rendre hommage aux dieux ${ }^{261}$. S'il arrive en effet que l'honos désigne, dès l'époque ancienne, la marque d'honneur adressée à une divinité, rien ne nous permet en réalité d'affirmer que c'est là le domaine où est né le terme. Les occurrences de ce terme dans son emploi religieux sont très peu nombreuses à l'époque la plus ancienne. On en trouve un exemple dans l'Évhémère d'Ennius, deux dans l'Aulularia et un dans un discours de Caton ${ }^{262}$. Il ne s'agit donc pas de l'emploi le plus fréquent. Par ailleurs, ces occurrences montrent qu'honos est un mot générique, employé incidemment dans un contexte religieux. Dans l'Évhémère, en parlant de Jupiter à qui on élève des autels, Ennius dit du dieu qu'il jouit d'un honorem diuinum ${ }^{263}$; l'expression montre bien que le terme a initialement un sens non marqué car la précision apportée par l'adjectif serait superflue si le mot était déjà connoté religieusement. De même, quand Caton parle du culte domestique: Domi cum auspicamus, honorem me dium immortalium uelim habuisse ${ }^{264}$. Ici encore, le génitif dium immortalium ne serait pas nécessaire si honos était un mot du lexique sacré. Mais c'est surtout le passage d'Ennius que nous venons de mentionner qui permet de mesurer combien le terme n'est pas perçu comme spécifiquement sacré. Le contexte apporte en effet un élément important: il y est dit que Jupiter obtient un honorem diuinum auprès des peuples à qui il a rendu visite; or, pour que ce terme d'honos soit cohérent, dans le cadre de la doctrine évhémériste développée par Ennius, il faut qu'il ne soit pas connoté religieusement à l'origine, sans quoi le raisonnement perdrait de sa valeur: Jupiter est censé n'être encore qu'un homme. L'honos qu'il reçoit n'est pas compris, dans ce texte, comme un acte de piété; il le deviendra par la suite, mais il ne s'agit pour l'instant que d'un hommage au sens général du terme.

${ }^{260}$ Hellegouarc'H, Vocabulaire, p. 383.

${ }^{261}$ HoffmanN, "Der Wertbegriff honos in den Komödien von Plautus ».

${ }^{262}$ EnN. Evh. frg. X Vahlen; PL. Aul. 17 et 19; CAt. frg XV, 60 ORF.

${ }^{263}$ ENN. Evh. frg. X Vahlen.

264 CAT.frg.XII, 73 ORF. Voir aussi, chez Cicéron, honos deorum immortalium (CIC.ND III, 50). 


\subsection{Le fonctionnement sémantique d'honos}

Une synthèse de la structure sémantique du mot apparaît dans le tableau ci-dessous. Majoritairement centré sur l'expression de l'honneur, sous la forme de l'hommage, de la considération publique et de la dignité, honos présente un glissement de sens principal vers la sphère du politique, puisqu'il peut désigner la «charge publique». D'autres évolutions se dessinent aussi dont l'une, avec le sens de «récompense», reste assez proche du sens initial tandis que l'autre fait passer honos dans le domaine de l'esthétique, avec le sens de «beauté». Honos apparaît donc comme un terme à la polysémie assez variée mais il n'est pas pour autant sémantiquement centrifuge. Tous les sens possèdent au moins un sème qui les rattache aux autres emplois. Les sèmes du /bienfait/, de l'/estime/, de la /position sociale éminente/ et des /mérites/ sont les plus fréquents et confèrent à honos une réelle unité.

Relations sémantiques entre les différents sens d'honos

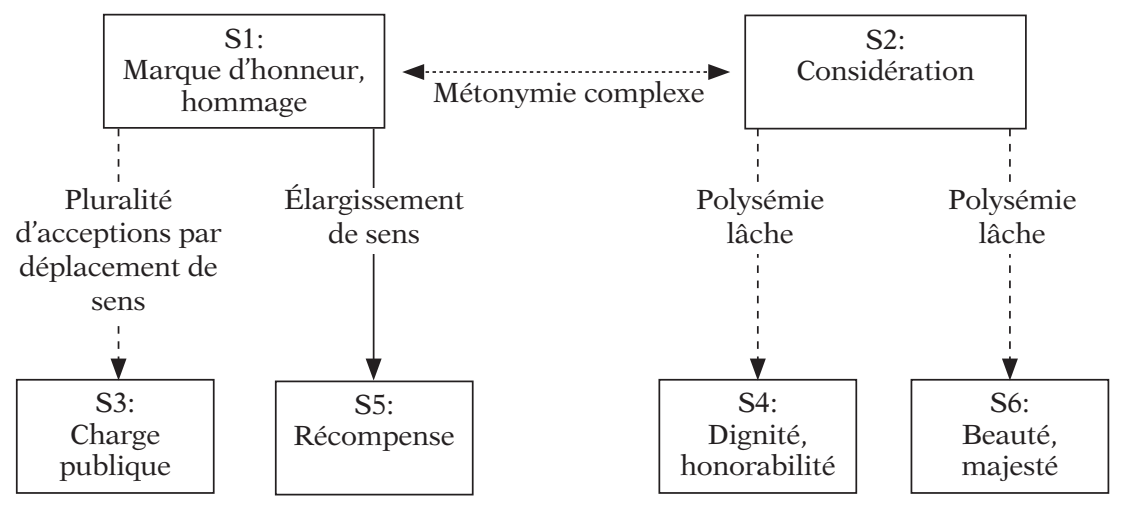

11. APPENDICE: HONOS ET LE LEXIQUE GREC

La comparaison d'honos avec d'autres termes du lexique latin nous a permis de dégager quelques singularités de ce mot dans le vocabulaire du prestige et de la dignité. Il nous paraît utile de mener également ce type de rapprochement avec le vocabulaire grec. Les travaux de glossographie réalisés au début du Moyen-Âge nous permettent d'avoir une idée des termes grecs perçus comme équivalents d'honos. Ils sont

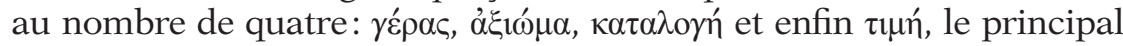
d'entre eux. 


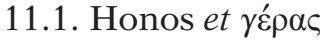

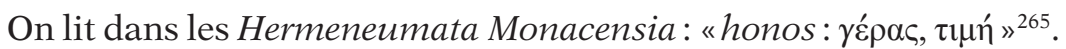

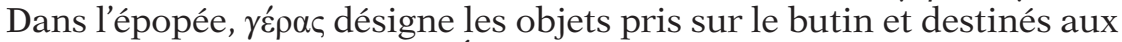
chefs, la «part d’honneur». É. Benveniste définit ainsi le terme:

«Un avantage en nature, conféré par l'ensemble des membres d'un groupe social en vertu d'un partage, lors d'une prise de dépouilles (sac d'une ville) au moyen d'une mise préalable en commun de tout ce butin sur lequel précisément est prélevé ce géras, part du chef. »266

Dans l'Odyssée, Ulysse décrit Néoptolème en ces termes à l'ombre de son père Achille:

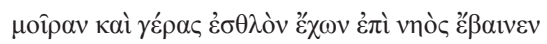

«avec son butin et sa magnifique part d'honneur, il remonta dans son navire»

(Od. XI, 534).

Par la suite, le terme désigne un don, un cadeau, compris comme

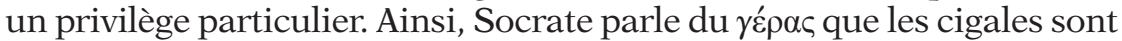
susceptibles d'accorder aux hommes qui, à l'heure la plus chaude de la journée, ne font pas la sieste mais conversent sans se laisser bercer

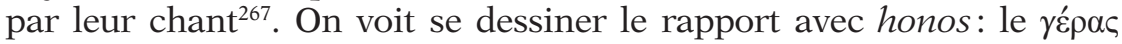
est, comme l'honos, une "marque d'honneur», qui prend la forme d'un

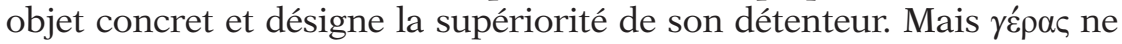
recouvre pas le terme d'honos dans sa complexité: il ne renvoie qu'à un seul sens du mot, la "marque d'honneur», sans suggérer les notions de "considération", de "charge» ou d' "honneur»; par ailleurs, il laisse dans l'ombre la dimension civique de l'honos: le y'́pas est essentiellement un terme du monde militaire et héroïque, alors que l'honos est un mot-clef de la res publica: le répas appartient au guerrier du monde épique et au roi, alors que l'honos appartient au citoyen et au magistrat.

\subsection{Honos et $\dot{\alpha} \xi 1 \omega ́ \mu \alpha$}

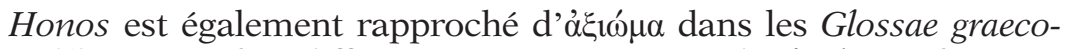
latinae $^{268}$. Parmi les différents sens que possède $\alpha \dot{\xi}, \omega ́ \mu \alpha$, plusieurs peuvent être comparés à ceux d'honos. Le mot désigne la "considération » dont on jouit. On lit chez Thucydide, à propos de Périclès:

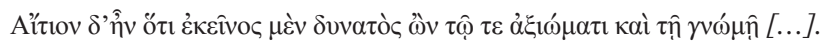

${ }^{265}$ CGL III, 131, 29.

${ }^{266}$ Benveniste, Le Vocabulaire des institutions indo-européennes, vol. 2, p. 44.

${ }^{267}$ Plat. Phaedr. 259b.

${ }^{268}$ CGL II, 232, 3. 
«La raison était la suivante: il avait, lui, de la puissance grâce à la considération dont il jouissait et à son esprit [...].»

(Thuc. II, 55, 8).

On trouve aussi, avec ce même sens de "considération », la tournure $\varepsilon^{\prime} v \grave{\alpha} \xi \mid \omega ́ \mu \alpha \tau$, très proche de la formule latine in honore ${ }^{269}$. Le terme grec désigne aussi la «marque d'honneur». On le voit dans ce vers de l'Ion d'Euripide où est évoqué le mariage de Xouthos avec Créuse. Xouthos, grâce à sa victoire militaire contre les Eubéens, a reçu un témoignage d'estime de la part des Athéniens qui lui ont permis de se marier avec Créuse:

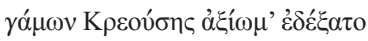

$$
\begin{aligned}
& \text { «Il eut l'honneur de recevoir Créuse en mariage» }
\end{aligned}
$$

(EuR. Ion 62).

D'où proviennent ces deux sens d' $\grave{\xi} \xi \omega \mu \alpha \alpha$ que le mot grec partage avec le mot latin? Le grec $\grave{\alpha} \xi \iota_{\mu} \mu \alpha$ dérive du verbe $\alpha \dot{\xi} \xi$ เó, «juger digne; juger convenable, agréer»; une des significations du substantif est donc, littéralement, « ce dont on est jugé digne », c'est-à-dire, de manière plus explicite, la «considération » ou l' " honneur ». Le rapprochement

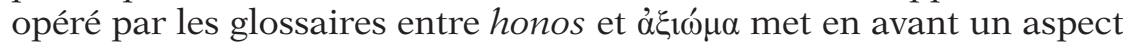
important d'honos que nous avions déjà repéré: l'honos est quelque chose qui s'obtient grâce à des mérites. Cette notion de "dignité", cruciale dans le sémantisme d'à $\xi ı \omega ́ \mu \alpha$ est aussi cependant ce qui trace la limite avec honos car la notion de mérite et de valeur ne se trouve pas à la racine du terme latin. De ce point de vue, dignitas serait un équivalent plus proche d'à́ı neur », qui est le noyau sémantique d'honos, n'est pas essentielle dans $\dot{\alpha} \xi ı \omega \mu \alpha$. Le terme grec ne rend pas compte, en outre, d'un sens important d'honos, celui de «charge publique».

\subsection{Honos et $\tau \iota \mu n$}

Dans les différents glossaires bilingues que nous possédons, $\tau 1 \mu$ ́ apparaît de loin comme le principal équivalent d'honos ${ }^{270}$. En outre, les différents dérivés d'honos sont le plus souvent eux-mêmes rendus par des dérivés de $\tau$ нй. On peut lire ainsi, par exemple, «honoratus:

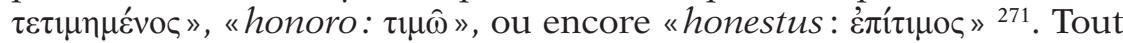
semble indiquer que le terme était ressenti comme le plus proche équivalent grec d'honos. Un texte du De republica nous permet de voir

${ }^{269}$ Voir par exemple Thuc. IV, 76, 6.

${ }^{270}$ On le trouve par exemple dans les Idiomata Codicis Harleiani (CGL II, 490, 4 et 29) ou les Hermeneuta Einsidlensia (CGL III, 240, 17 et 277, 19).

${ }^{271}$ Respectivement, CGL II, 453, 52 ; CGL II, 456, 6 ; CGL II, 312, 10. 
cette équivalence au plus près. Décrivant la manière dont le peuple renverse un régime en place, Scipion déclare:

Eos autem qui in magistratu priuatorum similes esse uelint eosque priuatos qui efficiant ne quid inter priuatum et magistratum differat, ferunt laudibus et mactant honoribus.

«Au contraire, les magistrats qui acceptent de devenir semblables aux simples citoyens, et les simples citoyens qui travaillent à supprimer toute distinction entre homme privé et magistrat, il [i. e. le peuple] les porte aux nues et les comble d'honneurs.»

(Cic. Rep. I, 67 ; trad. Bréguet).

Or Scipion dit explicitement quelques lignes plus haut (Rep. I, 65) qu'il s'inspire d'un passage de la République de Platon. Le texte latin est de fait une quasi-traduction du livre VIII :

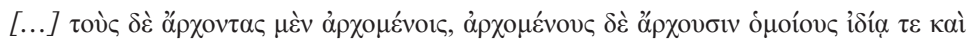

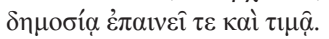

«[...] les gouvernants qui ressemblent aux gouvernés, et les gouvernés qui ressemblent aux gouvernants, on les loue et on les honore en privé et en public. »

(Plat. Resp. VIII, 562d).

Honos a été utilisé par Cicéron pour rendre le verbe $\tau \mu \omega \hat{\omega}$, de même

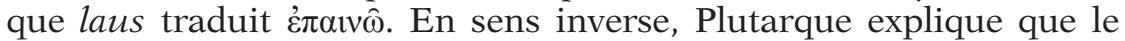
nom latin du dieu Honos peut être interprété en grec par $\tau \mu^{\prime 272}$. La

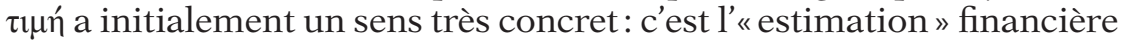
que l'on fait d'un bien et, par suite, le "prix», la "valeur». De cette notion de prix découlent deux aires de signification: celle du "prix à payer ", c'est-à-dire de la peine juridique, du châtiment; et celle du «prix qu'on attache à autrui » c'est-à-dire de la "valeur que l'on a », et donc de la "considération », de l' «honneur ${ }^{273}$. Trois sens de $\tau \mu \mu n$ peuvent être rapprochés d'honos:

1) Tıй́ peut signifier la «marque d'honneur». Dans le discours prononcé par Phèdre dans le Banquet, il est dit que l'amour est la seule chose qui doit guider les hommes:

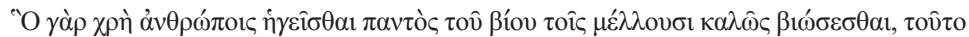

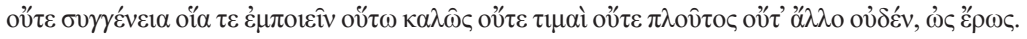

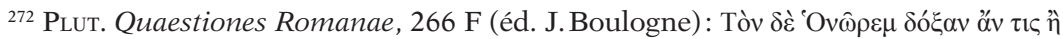

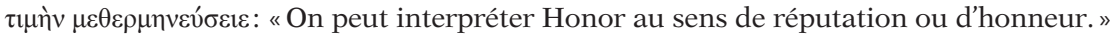

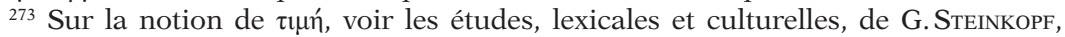
Untersuchungen zur Geschichte des Ruhmes bei den Griechen, Diss., Halle, 1937; J.De Romilly, "Le thème du prestige dans l'œuvre de Thucydide», Ancient Society, 4, 1973, p. 39-58; J.-C.RIEDINGeR, "Remarques sur la timè chez Homère", REG, 89, 1976, p. 244-264; H.Lloyd-Jones, "Ehre und Schande in der griechischen Kultur», A\&A, 33, 1987, p. 1-28; E. Alexiou, Ruhm und Ehre: Studien zu Begriffen, Werten und Motivierungen bei Isokrates, Heidelberg, C. Winter, 1995, p. 40-54. 
«En effet ce qui doit guider toute leur vie les hommes destinés à vivre de belle façon ne peut être inspiré ni par la parenté, ni par les honneurs, ni par la richesse, ni par rien d'autre d'aussi belle façon que par l'amour.»

(Plat. Conv. 178c).

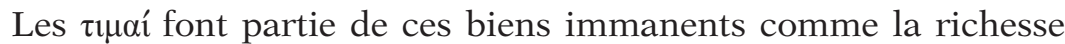
( $\pi \lambda$ ov̂ $\varsigma)$ que l'homme de bien ne saurait poursuivre. Il s'agit des marques de considération que l'on peut obtenir de ses semblables. Le même sens concret de $\tau \iota \mu$ ń apparaît chez Thucydide, dans le discours de Périclès qui exhorte les Athéniens à préserver l'empire:

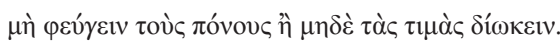

«Ne vous dérobez pas aux épreuves, si vous ne renoncez pas aussi à poursuivre les honneurs.»

(Thuc. II, 63, 1; trad. De Romilly).

Périclès met en garde ses concitoyens: s'ils renoncent à prendre des risques et à affronter le danger, ils doivent aussi renoncer à gagner

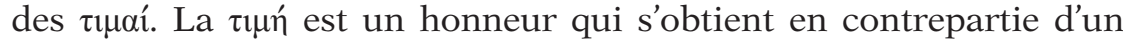
haut fait. On retrouve là un trait important du sémantisme d'honos: la marque d'honneur s'obtient en reconnaissance de certains mérites ${ }^{274}$. La «marque d'honneur» désignée par $\tau \mu$ ń existe aussi dans le contexte sacré: les Grecs doivent octroyer la $\tau$ ıń aux dieux et aux défunts ${ }^{275}$.

2) Le mot $\tau \mu$ ń peut aussi signifier la «considération» dont on jouit. Dans l'Apologie de Socrate, Socrate dit aux juges qu'il ne cessera jamais de philosopher et de réprimander les citoyens d'Athènes, et qu'il les exhortera en ces termes:

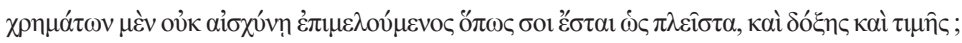

«Tu ne rougis pas de donner tes soins à ta fortune, pour l'accroître le plus possible, ainsi qu'à ta réputation et tes honneurs? »

(Plat. Apol. 29d-e; trad. Croiset).

Socrate fustige les Athéniens qui ne pensent qu'à leur argent et à leur statut au lieu de prendre soin de leur âme. La $\tau \mu$ ń désigne ici quelque chose qui est, selon Socrate, superflu et vain, au même titre que la richesse; c'est le prestige, l'importance sociale dans la cité. Isocrate affirme que la culture intellectuelle qu'il entend enseigner aux jeunes gens ne corrompt pas ces derniers. Car s'il en était ainsi, dit-il,

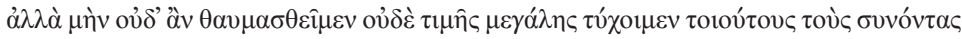
$\dot{\alpha} \pi \circ \pi \varepsilon \dot{\varepsilon} \mu \pi \mathrm{\sigma} \tau \varepsilon \varsigma[\ldots]$.

${ }^{274}$ Il est d'ailleurs remarquable qu'honos soit rendu dans un des glossaires bilin-

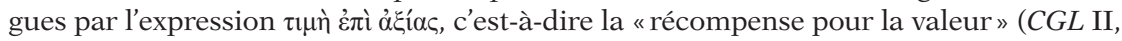
$455,38)$.

${ }^{275}$ Voir Plat. Euthyph. 15a; Crat. 398b; Thuc. II, 35, 1. 
«Nous ne serions pas non plus l'objet d'une grande admiration ni d'un grand honneur si c'étaient de pareils disciples qui sortaient de notre école [...]

(Isoc. Ant. 219; trad. Mathieu).

On voit que la $\tau$ пń a partie liée avec l'admiration $(\theta \alpha v \mu \alpha \sigma \theta \varepsilon i ̂ \mu \varepsilon v)$ : c'est la considération dont un individu jouit auprès des autres. Il s'agit donc là d'un sens proche d'honos. On rencontre d'ailleurs l'expression

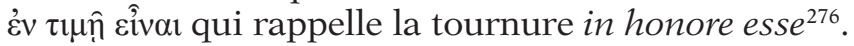

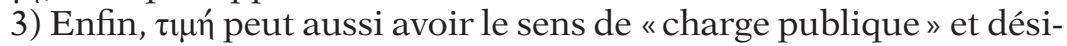
gner couramment une magistrature. Hérodote évoque ainsi l'action de Pisistrate après la prise de l'Acropole:

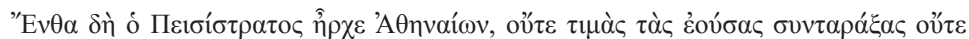
$\theta \varepsilon \dot{\sigma} \sigma \mu 1 \alpha \mu \varepsilon \tau \alpha \lambda \lambda \alpha \alpha^{\prime} \alpha \varsigma$ [...].

«Pisistrate, dès lors, régna sur les Athéniens, sans troubler l'exercice des magistratures existantes, sans changer les lois [...].»
}

(Hér. I, 59; trad. Legrand).

Après que Pisistrate fut devenu tyran, il laissa subsister les magistratures existantes. Thucydide utilise $\tau$ tuń de la même manière, pour désigner une charge publique ${ }^{277}$. Le mot semble donc être un équivalent d'ápxń. Mais, de même qu'honos en dit plus que le mot technique

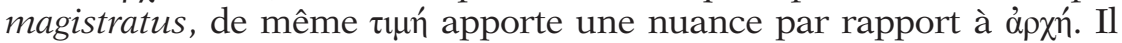
s'agit, comme en latin, d'évoquer une magistrature en tant qu'elle est une marque honorifique que l'on reçoit. On le ressent dans l'Apologie de Socrate; Socrate y évoque en ces termes les gens que les Athéniens choisissent pour être magistrats:

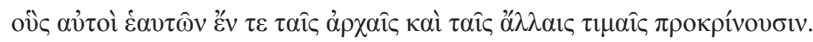

«ceux que les citoyens choisissent parmi eux pour leur confier magistratures et autres honneurs.»
}

(Plat. Apol. 35b).

Les magistratures ( $\tau \alpha \hat{\imath} \varsigma$ $\dot{\rho} \rho \chi \alpha \hat{\varsigma} \varsigma)$ sont considérées comme un élément

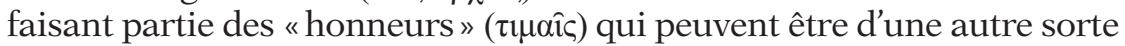
( $\alpha^{\prime} \lambda \lambda \alpha$ ac): une charge publique est un honneur parmi d'autres. Nous rencontrons donc ici une conception des fonctions publiques proche de celle qu'on a pu observer à Rome.

Dans l'ensemble, les sens les plus courants d'honos trouvent donc tous des équivalents dans le grec $\tau \mu \eta$. La proximité entre les deux mots se dessine nettement et l'on comprend que les grammairiens aient rapproché les deux termes. Néanmoins, ces deux mots conservent des différences réelles de sens. En premier lieu, si les deux mots ont des

${ }^{276} \mathrm{XEN}$. An. II, 5, 38.

${ }^{277}$ Voir par exemple Thuc. V, 20, 2. 
sens communs, les connotations et les contextes de ces sens diffèrent d'une langue à l'autre. On peut prendre, à titre d'exemple, le sens de «charge publique» que possède $\tau$ «ń. Le mot est employé pour désigner une fonction dotée d'un pouvoir politique, mais il peut s'agir d'un pouvoir de nature royale et pas seulement d'une magistrature. On le constate dans le Philippe d'Isocrate, où l'orateur parle en ces termes des Macédoniens qui ont brigué le pouvoir suprême et oppose leur attitude à celle de Caranos, ancêtre de la famille royale de Macédoine:

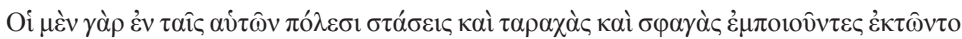

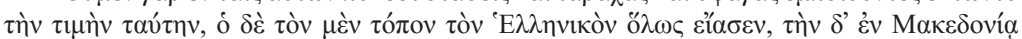

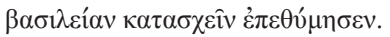

«Ils acquéraient en effet cet honneur en provoquant dans leurs villes des révoltes, des troubles et des massacres, mais lui laissa totalement de côté la région grecque et désira établir la royauté en Macédoine. »

(Isoc. Phil. 107; trad. Brémond modifiée).

La $\tau \mu$ ń désigne ici la fonction de roi en Macédoine. À Rome, un tel usage d'honos ne se rencontre pas; la fonction politique que désigne le terme s'inscrit dans les institutions de la res publica libera. L'association

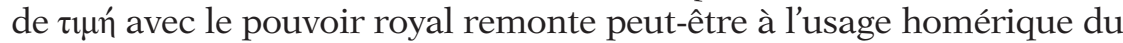

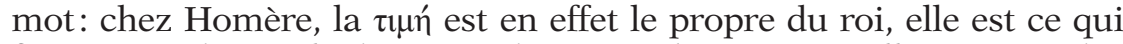
fait sa grandeur et le distingue des autres hommes, et elle est accordée par Zeus ${ }^{278}$. Honos, à l'inverse, appartient au domaine de l'immanent: il est toujours octroyé par les hommes. En second lieu, honos ne possède pas le sens juridique de $\tau \mu$, celui de "prix à payer». Ce sens singulier, absent d'honos, s'explique par un autre sens, essentiel en grec, qui fait

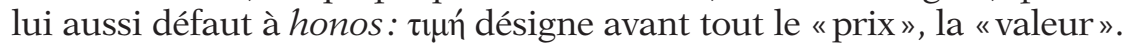
Ce sens paraît bien être la signification fondamentale du terme: $\tau$ ¡n c'est d'abord le prix strictement financier, la valeur marchande; puis le "prix à payer» dans le domaine juridique; et enfin le "prix social», la valeur dont on jouit. C'est la conclusion de P. Chantraine:

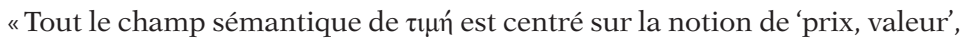
d'où les significations divergentes d' 'honneur', et de 'prix, ce que l'on paie, amende, réparation', ce dernier sens apparaissant déjà clairement chez Homère (Il. 3, 286). $)^{279}$

Cette notion de "prix » ou de "valeur», si elle peut s'insinuer dans honos quand le mot est rapproché de pretium ou emolumentum, n'est en revanche pas essentielle dans son sémantisme. Mais c'est surtout le fonctionnement sémantique d'honos et de $\tau \iota \mu n$ qui les différencie.

${ }^{278}$ Benveniste, Le Vocabulaire des institutions indo-européennes, vol.2, p. 50. Voir aussi RIEDINGER, " Remarques sur la timè chez Homère ». Voir par exemple Il. II, 196-197.

${ }^{279}$ P. Chantraine, Dictionnaire étymologique de la langue grecque, Paris, C. Klincksieck, 1968, p. 1120. 
Il faut souligner que $\tau \uparrow \mu$ n'entre dans l'aire sémantique de la «considération » que par métaphore: le mot désigne en effet à l'origine le «prix », la «valeur» financière puis, par analogie, le "prix d'une personne», l' «estime» dont elle jouit. Honos ne désigne pas la «marque d'honneur » ou la "considération » par évolution depuis un autre sens concret mais porte cette signification dès l'origine.

Malgré ces différences, il n'en reste pas moins que la proximité sémantique entre les deux mots est frappante. C'est ce qui a conduit certains philologues à envisager entre eux l'existence d'une filiation. Comme nous l'avons vu, honos n'est pas un mot emprunté à une autre langue: c'est un terme ancien, qui appartient au plus vieux fonds du vocabulaire latin; son étymologie est difficile à établir mais sa morphologie ne laisse transparaître aucun signe d'emprunt. Honos ne saurait donc, d'un point de vue morpho-linguistique, être issu de $\tau \mu \eta$. Mais cela n'exclut pas un emprunt d'un autre type, sémantique cette fois. On sait en effet qu'un mot latin peut s'enrichir du sens d'un mot d'une autre langue tout en conservant sa morphologie propre. Ce procédé a été observé par plusieurs linguistes. J. Marouzeau donne de cet emprunt de sens la définition suivante:

«Le processus consiste à charger tel mot latin en usage d'un contenu grec qui le renouvelle, et le recrée pour ainsi dire. Soit un mot ars, qui ne signifie pas autre chose que 'procédé'; on l'enrichira des sens de teknè, 'art'; un mot causa, 'sujet, motif': il prendra les divers contenus de aitia [...]. La langue s'enrichit ainsi d'un apport invisible, par transfusion de sens. ${ }^{280}$

Ce moyen a beaucoup été employé, notamment par Cicéron, pour créer à Rome une langue philosophique propre au latin; mais d'autres auteurs plus anciens y ont recouru. Ennius, par exemple, emprunte les sens du mot grec oopía pour les injecter dans le latin sapientia, ce qui rend ce dernier apte à désigner la sagesse de nature philosophique ${ }^{281}$. C. Nicolas a défini et décrit de façon systématique ce procédé, qu'il nomme «calque sémantique»:

«Le calque sémantique [...] est une transposition bilingue qui fait passer, dans des circonstances déterminées (traduction, recherche d'équivalences sémantiques...), d'un mot étranger à un mot autochtone, avec qui il se croise dans une ou plusieurs acceptions de base, une notion nouvelle, inédite à cette heure dans la langue emprunteuse. $»^{282}$

${ }^{280}$ Marouzeau, Quelques aspects de la formation du latin littéraire, p. 140.

${ }^{281}$ L'exemple est cité par A. MeILlet, Esquisse d'une histoire de la langue latine, $7^{\mathrm{e}}$ éd., Paris, C.Klincksieck, 1966, p.194; A. Meillet parle d'un "procédé plus ingénieux que l'emprunt brut » et remarque que Cicéron a beaucoup recouru à «ces emprunts de sens, plus discrets que les emprunts de mots, et par là même plus efficaces ». Sur l'évolution sémantique de sapientia, G. GaRBARINO, "Evoluzione semantica dei termini sapiens e sapientia nei secoli III e II a. C. », AAT, 100, 1965-1966, p. 253-284.

${ }^{282}$ Nicolas, Calque, p. 19. 
Le calque sémantique se distingue des autres procédés de création lexicale parce qu'il ne s'accompagne pas d'un néologisme, et parce que seule une fraction de sens est transférée. Il s'agit donc d'une technique de création plus discrète que l'emprunt direct. L'existence d'un calque sémantique d'honos d'après le grec $\tau$ lú est soutenue par le dictionnaire étymologique d' A. Walde et J.B.Hofmann ${ }^{283}$. L'idée est séduisante: elle permettrait d'expliquer l'abondance des traits sémantiques qu'honos a en commun avec $\tau \mu$. Il est bien établi, par ailleurs, que les premiers auteurs à utiliser honos, Plaute, Ennius et Caton, étaient familiers de la langue grecque ${ }^{284}$. Mais plusieurs éléments rendent cette hypothèse difficile à soutenir. Pour que calque il y ait, il faut qu'un ou plusieurs sens d'honos que l'on retrouve dans $\tau \mu \mu$ ' aient été absents dans les emplois anciens du mot et soient apparus sous l'influence du terme grec ${ }^{285}$. Or il est clair que les sens qu'honos partage avec $\tau \mu$ ń sont tous anciens: on les observe chez Plaute. Quant aux sens plus récents d'honos, comme celui de «beauté», ils n'ont manifestement rien à voir avec $\tau \mu \mu$. En outre, il faut voir si l'acception soupçonnée d'être un calque n'est pas plutôt une évolution naturelle du mot, préparée par les sens antérieurs. Or, dans le cas d'honos, les sens sont étroitement articulés les uns aux autres et apparaissent par des évolutions internes. Le sens de "charge publique», qu'on pourrait soupçonner d'être calqué, est préparé par celui de "marque d'honneur », la magistrature étant perçue comme un honneur. L'hypothèse d'un calque sémantique nous paraît donc devoir être écartée.

${ }^{283}$ LEW s.v. honos.

${ }^{284}$ Sur le bilinguisme grec et latin à Rome, voir le bilan bibliographique établi par B. Rochetтe, « Le bilinguisme gréco-latin et la question des langues dans le monde grécoromain », RBPh, 76 (1), 1998, p.177-196 et VALETTE-CAGNAC, «Vtraque lingua. Critique de la notion de bilinguisme».

${ }^{285}$ Par exemple, le mot ars ne prend, sous l'influence du grec $\tau \dot{\varepsilon} \chi v \eta$, les sens de "science», «technique» ou "théorie d'un art, traité» qu'au ${ }^{\text {er }}$ siècle avant notre ère (GAVoIlle, Ars, p. 324). 
CHAPITRE 2

\section{ANALYSE SÉMANTIQUE D'HONESTUS}

\section{INTRODUCTION}

Honestus est le principal dérivé d'honos. Nous en donnerons une analyse conjointe avec l'adverbe honeste. Par commodité, toute référence faite à honestus s'entendra aussi comme une référence à la forme adverbiale. Honestus est issu de la flexion non attestée *honos, -eris, un ancien neutre qui aurait existé en parallèle à honos, -oris. Il est formé à l'aide d'une suffixation en *-to. Ce suffixe, d'après Benveniste, exprime "l'accomplissement de la notion dans l'objet» ${ }^{1}$. Dans les adjectifs en -tus dérivés de noms, l'accomplissement de la notion prend une valeur possessive: honestus, funestus, uenustus, signifient «qui a de l'honneur (honos), du deuil (funus), de la séduction (uenus) »². Cependant, cela ne signifie pas que les sens d'honestus recouvrent entièrement ceux d'honos: les dérivés ont leurs développements sémantiques propres ${ }^{3}$. Le mot est aussi ancien qu'honos puisqu'on le rencontre chez Plaute et chez Ennius et il est légèrement plus fréquent que le substantif dont il est issu. Nous avons retenu sept sens d'honestus, dont deux sont étroitement liés et ne constituent pas à proprement parler des sens autonomes, mais plutôt des acceptions:

S1 : "Considéré, estimé.»

S2: «Honorable, source de considération » (pour une chose, une action). S2bis: «Honorable, digne de considération» (pour une personne). S3: "Honorifique.»

S4: «Honnête, probe.»

1 É. Benveniste, Noms d'agent et noms d'action en indo-européen, Paris, A. Maisonneuve, 1948, p.167. S. Mellet, M.-D. Joffre et G.Serbat, Grammaire fondamentale du Latin. Le signifié du verbe, Louvain, Peeters, 1994 en donne une analyse semblable: le suffixe exprime «l'accompli de la notion»(p.315).

${ }^{2}$ Voir A. Christol, «De l'accent phonologique à la suffixation: les thèmes en *-sen latin", in Bammesberger, A. et Heberlein, F. (éds.), Akten des VIII internationalen Kolloquiums zur lateinischen Linguistik, Heidelberg, C. Winter, 1996, p. 78-93: «le sens de l'adjectif $X$-to est 'qui est pourvu de X'» (p. 84).

3 F.Cusin-Berche, "Le lexique en mouvement: création lexicale et production sémantique », Langages, 136, 1999, p.5-26: «Dès qu'une forme nouvelle est intégrée au lexique, son sens évolue, se délie de la prescription morphologique» (p.21). 
S5: «Beau, admirable.»

S6: «Moralement beau, honnête, vertueux. »

Le nombre des significations isolées peut paraître important mais les disparités sémantiques sont réelles et, dans la mesure où elles sont en rapport avec la morale romaine et son évolution, constituent des données trop importantes pour qu'on les néglige. Le court passage que consacre J. Hellegouarc'h à honestus fait pressentir la diversité des sens du mot:

«Le plus souvent, sa valeur est très générale et il se rapporte à tous ceux qui appartiennent aux classes dirigeantes, et, de ce fait, exercent les honores ou sont susceptibles de les exercer. Il est l'équivalent du français 'honorable' et, comme lui, il se charge même d'une certaine valeur morale ce qui explique son large emploi dans le vocabulaire philosophique comme

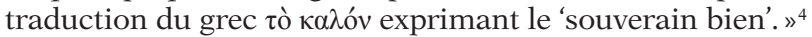

Le mélange dans cette définition d'aspects politiques, sociaux, moraux et philosophiques est un indice de la richesse d'honestus mais montre aussi qu'un effort d'analyse et de classement est nécessaire. La même exigence apparaît quand on consulte des ouvrages de lexicographie. L'OLD propose quatre entrées principales: 1. «Regarded with honour or respect, of good repute»; 2. "Well-born, of high rank»; 3. "Morally worthy of respect, honourable»; 4. "Having a fine appearance, handsome». Cependant, la distinction entre les sens 1 et 2 demande à être réexaminée et la polysémie du mot "honourable » en anglais occulte certaines singularités d'honestus. L'article du TLL est plus riche, mais recourt à des critères de classement qui ne nous paraissent pas pertinents: aucune distinction n'est faite, notamment, entre honestus désignant l'état de celui qui détient le prestige par opposition à celui qui le mérite en raison de ses qualités. Certaines subtilités sémantiques sont en revanche bien isolées, telles que la différence entre celui qui est «honorable» pour sa «décence», sa «chasteté», sa "probité » ou bien sa "droiture " ${ }^{5}$, mais il faudra interroger la capacité de ces distinctions à constituer des sens autonomes. Le tableau qui suit présente l'emploi des différents sens d'honestus dans la chronologie.

\footnotetext{
${ }^{4}$ Hellegouarc' h, Vocabulaire, p. 463.

${ }^{5}$ TLL VI, 3, col. 2906-2908.
} 


\begin{tabular}{|c|c|c|c|c|c|c|c|c|}
\hline \begin{tabular}{|l} 
HONESTUS \\
HONESTE
\end{tabular} & $\begin{array}{c}\text { S1: } \\
\text { Considéré, } \\
\text { estimé }\end{array}$ & $\begin{array}{c}\text { S2: } \\
\text { Honorable, } \\
\text { source de } \\
\text { considération }\end{array}$ & \begin{tabular}{|c|} 
S2bis: \\
Honorable, \\
digne de \\
considération
\end{tabular} & $\begin{array}{l}\text { S3: } \\
\text { Honori- } \\
\text { fique }\end{array}$ & $\begin{array}{c}\text { S4: } \\
\text { Honnête, } \\
\text { probe }\end{array}$ & $\begin{array}{c}\text { S5: } \\
\text { Beau, } \\
\text { admirable }\end{array}$ & \begin{tabular}{|c|} 
S6: \\
Moralement \\
beau, \\
vertueux
\end{tabular} & Total \\
\hline Plaute & 2 & 5 & & 2 & 1 & & & 10 \\
\hline Ennius & & 1 & & & & & & 1 \\
\hline Caton & & 2 & & 1 & & 1 & & 4 \\
\hline $\begin{array}{l}\text { Total } 1^{\text {er }} \\
\underline{I I}^{\underline{e}} \text { siècle }\end{array}$ & $\underline{2}$ & $\underline{8}$ & & $\underline{3}$ & 1 & 1 & & $\underline{15}$ \\
\hline Térence & & 4 & & & 2 & 5 & & 11 \\
\hline Lucilius & 1 & & & & 2 & 4 & 1 & 8 \\
\hline Scip. Émil. & & 1 & & & & & & 1 \\
\hline Afranius & & & & & 1 & & & 1 \\
\hline $\begin{array}{l}\text { Total } 2^{\underline{d}}- \\
\underline{I I}^{\mathrm{e}} \text { siècle }\end{array}$ & 1 & $\underline{5}$ & & & $\underline{5}$ & $\underline{9}$ & 1 & $\underline{21}$ \\
\hline Q. Scaevola & & 1 & & & & & & 1 \\
\hline Rhet. Her. & 1 & 11 & 4 & & 3 & & 8 & 27 \\
\hline Lucrèce & & 1 & & & & & & 1 \\
\hline Cicéron & 40 & 213 & 126 & 8 & 94 & 6 & 307 & 794 \\
\hline Oratoria & 32 & 74 & 110 & 4 & 45 & 1 & & 266 \\
\hline Rhetorica & & 36 & 4 & 3 & 9 & 1 & 35 & 88 \\
\hline Philosophica & 4 & 24 & 3 & & 21 & 2 & 266 & 320 \\
\hline Epistulae & 4 & 79 & 9 & 1 & 19 & 2 & 6 & 120 \\
\hline Corr. de Cic. & 2 & 4 & 1 & & & & & 7 \\
\hline Q. Cicéron & & 2 & & 2 & & & & 4 \\
\hline César & 1 & 2 & 3 & & & & & 6 \\
\hline Ps.-César & & 3 & & & & & & 3 \\
\hline M. Brutus & & 1 & & & 1 & & & 2 \\
\hline Publ. Syrus & & 3 & 1 & & 2 & & & 6 \\
\hline Salluste & 1 & 16 & 2 & 2 & 4 & & & 25 \\
\hline Varron & 1 & & 1 & & & 3 & & 5 \\
\hline Inscriptions & & 4 & & & & 2 & & 6 \\
\hline $\begin{array}{l}\frac{\text { Total I }}{\text { siè }^{\text {siele }}} \\
\end{array}$ & $\underline{46}$ & $\underline{261}$ & $\underline{138}$ & $\underline{12}$ & $\underline{104}$ & $\underline{11}$ & $\underline{315}$ & $\underline{887}$ \\
\hline Total général & 49 & 274 & 138 & 15 & 110 & 21 & 316 & 923 \\
\hline
\end{tabular}


L'adjectif et l'adverbe apparaissent dans tous les genres littéraires mais sont surtout employés dans les œuvres oratoires, historiques et techniques (philosophie et rhétorique). Comme honos, honestus est très rare en poésie: on ne le rencontre qu'une seule fois, chez Lucrèce, et jamais chez Catulle. Le sens le plus fréquent est celui d' "honorable», qui représente environ $45 \%$ des occurrences avec ses deux acceptions. Honestus est donc principalement tourné vers la sphère de l'honneur et de la dignité. Le second sens le plus récurrent est celui de " moralement beau » avec environ un tiers des occurrences, qui amène honestus dans la sphère de l'éthique. C'est aussi à ce domaine qu'appartient le troisième sens le plus représenté, "honnête », avec environ $12 \%$ des occurrences. Les autres sens sont moins employés mais aucun ne l'est de manière extrêmement réduite, ce qui témoigne de la diversité du sémantisme d'honestus. L'adjectif et l'adverbe voient leur usage croître considérablement au premier siècle, mais cette augmentation est causée en grande partie par l'état de notre documentation: Cicéron concentre à lui seul plus de $80 \%$ des occurrences. Les évolutions sémantiques les plus frappantes consistent dans le développement au second $\mathrm{II}^{\mathrm{e}}$ siècle des sens "honnête» et "beau», très peu représentés auparavant, et dans l'importance considérable prise au $\mathrm{I}^{\mathrm{er}}$ siècle, dans la Rhétorique à Herennius et l'œuvre de Cicéron, par le sens «moralement beau ". Le déplacement d'honestus vers l'esthétique et l'éthique intervient donc dans un second temps de l'histoire du mot. Honestus est centré initialement sur l'expression du prestige et de l'honneur.

\section{1. «ConsidÉRÉ, ESTIMÉ » (S1)}

Honestus désigne d'abord la personne qui bénéficie de la considération de son entourage ainsi que des marques d'honneur qui en sont le signe. Il s'agit d'une qualité purement sociale. Honestus signifie alors "considéré», «estimé» ou plus précisément «honoré», "distingué». Il s'agit d’un sens peu fréquent (environ $5 \%$ des occurrences) mais ancien et dont la position dans le sémantisme d'honestus est fondamentale. Le lien d'honestus avec honos est ici très fort, puisque l'adjectif désigne celui qui bénéficie de l'honos au sens "considération", ainsi que l'analyse morphologique nous l'a indiqué. Il s'agit donc probablement du sens premier d'honestus.

\subsection{Bénéficier de la considération et de ses marques}

Est honestus l'individu qui fait l'objet d'un jugement positif de la part de la collectivité. Cicéron, pour souligner la loyauté et l'honnêteté de Roscius, fait remarquer que même Saturius, l'avocat de la partie adverse, a de la considération pour lui:

Quid? Tu, Saturi, qui contra hunc uenis, existimas aliter? nonne, quotienscumque in causa in nomen huius incidisti, totiens hunc et uirum bonum esse dixisti et honoris causa appellasti? Quod nemo nisi aut honestissimo aut amicissimo facere consueuit. 
«Eh quoi? Toi-même, Saturius, toi qui te présentes ici contre lui, as-tu de lui une autre opinion? Chaque fois que dans cette cause tu as eu l'occasion de prononcer son nom, ne l'as-tu pas traité d'homme de bien, ne t'es-tu pas adressé à lui pour lui rendre hommage? Et cela, personne n'a pour habitude de le faire si ce n'est pour quelqu'un de très estimé ou pour un ami très cher.»

(Cic. Rosc. Com. 18; trad. De La Ville de Mirmont modifiée).

Cicéron présente Roscius comme une personne dont tous ont une bonne opinion: Saturius lui-même ne juge pas Roscius différemment (existimas aliter). C'est cette bonne opinion, rendue sensible par la marque d'honneur qui consiste à s'adresser à lui convenablement, pour l'honorer (honoris causa), qui justifie le qualificatif d'honestissimus décerné à Roscius. Celui qui est honestus est connu en bonne part: il n'est ni ignotus ni obscurus ${ }^{6}$. Ce sens d'honestus apparaît fréquemment associé à d'autres adjectifs qui suggèrent la faveur sociale, tels que gratiosus ou spectatus ${ }^{7}$. Dans la mesure où honestus qualifie celui qui bénéficie de l'honos, l'estime dont le sujet jouit peut s'accompagner de marques d'honneur concrètes qui signifient cette estime, puisque c'est là un des sèmes d'honos au sens «considération". Nous le voyons dans le passage du Pro Roscio Comoedo cité supra, mais aussi dans des textes plus anciens comme les Captifs de Plaute:

Me hic ualere et seruitutem seruire huic homini optumo Qui me honore honestiorem semper fecit et facit.

«Je vais bien et je suis en servitude ici, au service de cet excellent homme Qui, par les honneurs qu'il m'accorde, a fait et continue de faire de moi un homme plus honoré.»

(PL. Cap. 391-392).

Tyndare évoque ici la servitude dans laquelle il se trouve chez Hégion. L'adjectif honestus, au comparatif, signifie, sans ambiguïté possible, "honoré»: il désigne la situation de celui qui a bénéficié d'un honos au sens "marque d'honneur»; le texte dit bien que honore, à l'ablatif instrumental, est le moyen par lequel Tyndare est devenu honestiorem. Ce sème n'est cependant pas systématiquement actualisé, et nous pouvons donc donner comme premiers éléments d'analyse sémique les traits suivants: /Qui bénéficie / de l'estime / susceptible d'être / signifiée / par des bienfaits/.

${ }^{6}$ CIc. Tull. 19; Mur. 53; Verr. II, III, 60.

${ }^{7}$ Cic. Verr. II, III, 61 et II, IV, 44; Mur. 47. 


\subsection{Les avantages sociaux associés à l'estime}

L'individu honestus jouit de l'estime de l'entourage mais aussi d'une position distinctive au sein de la collectivité à laquelle il appartient. L'adjectif peut qualifier un individu ou une famille entière. Il apparaît ainsi à plusieurs reprises dans l'expression honesto loco natus. Un des protagonistes du Pro Flacco est décrit en ces termes:

Adulescens bonus, honesto loco natus, disertus cum maximo ornatissimoque comitatu uenit in oppidum Graecum [...].

«Un jeune homme de bien, né d'une famille estimée, s'exprimant aisément, arriva dans une ville grecque avec des compagnons nombreux et distingués [...]. »

(Cic. Flac. 18).

Le locus désigne le milieu dont l'adulescens est originaire, la famille dont il est issu; et ce locus est honestus, c'est-à-dire qu'il est estimé et possède aussi une supériorité sur les autres dans la société. On le voit bien dans un autre passage du Pro Flacco où, glosant l'expression infimo loco natus, Cicéron écrit nullo splendore uitae, nulla commendatione famae: celui qui n'est pas issu d'un locus honestus n'a ni éclat distinctif ni bonne réputation ${ }^{8}$. Il s'agit là d'un trait de sens essentiel au sémantisme d'honestus, que nous pouvons présenter de la façon suivante: /qui bénéficie d'une position éminente dans la société/.

À ce sème s'en adjoint un autre, relevant également des bénéfices sociaux impliqués par honestus et déjà observé à propos de plusieurs sens d'honos: celui de l'autorité sur l'entourage. Dans les Verrines, Cicéron souligne combien les témoignages contre Verrès sont accablants car ils sont portés par des hommes qui bénéficient d'un haut statut civique ou qui sont honestissimi ${ }^{9}$. L'honestus est une personne digne de foi, qui détient un réel pouvoir car son témoignage fait pencher la décision des juges dans le sens qu'il indique. Un sème virtuel se dégage, actualisé dans environ $25 \%$ des cas, où l'estime est /propre à / être assortie d'influence/.

${ }^{8}$ Cic. Flac. 24. Pour d'autres occurrences d'honesto loco natus, voir Cic. Verr. II, V, 31 ; Balb. 6; Tusc. V, 58 et CAEs. BG V, 45, 2; BC III, 61, 1. Il ne nous semble pas légitime d'isoler pour honestus, comme le fait l'OLD (p.801) notamment pour l'expression honesto loco natus, un sens "noble, de haut rang»: l'idée d'une distinction sociale est toujours associée à celle d'estime, qui est prévalente. On le voit bien quand on observe les tournures de sens contraire à honesto loco natus: on trouve d'une part l'idée de bassesse (infimo loco natus Cic. Flac. 24; Brut. 243; Tusc. III, 77) et d'autre part celle d'obscurité (ignobili loco natus Cic. Clu. 111 ; obscuro loco natus Cic. Verr. II, V, 167 et 181). Honestus unit la supériorité sociale et l'estime avec le sens "considéré», même si l'équivalent français restitue mal ce double aspect.

${ }^{9}$ Voir par exemple Cic. Verr. II, I, 10 et II, 149 où honestus est associé à grauis. 


\subsection{Conclusion}

Le sémème complet d'honestus "considéré» est le suivant: /Qui bénéficie / de l'estime, / susceptible d'être / signifiée / par des bienfaits, / et d'une position éminente dans la société / propre à / être assortie d'influence/. Ce sens d'honestus est étroitement lié à honos, dont il reprend plusieurs sèmes. Il apparaît comme exclusivement social puisqu'il qualifie l'individu ou le groupe jouissant de la faveur visible de l'entourage et d'une position distinctive et prestigieuse.

Sa singularité apparaît encore davantage quand on le compare à des adjectifs de sens proche. Honestus ne comporte pas de manière aussi forte que spectatus l'idée, attachée à la racine *spic-, que le sujet attire les regards de l'entourage et fait l'objet d'une intense admiration $^{10}$. Honestus est celui qui se distingue par les marques d'estime et par une position influente dans la société. On peut de la même façon le différencier d'ornatus, adjectif tourné vers l'expression d'un prestige visuel lié à une parure, qui ne suppose pas de hiérarchie sociale ${ }^{11}$. Honestus se distingue enfin de gratiosus tout comme honos s'écarte de gratia: la notion d'un crédit politique et d'une faveur populaire ${ }^{12}$ est nettement moins prégnante dans honestus.

\section{2. «HONORABLE, SOURCE DE CONSIDÉRATION»}

Ce sens d'honestus qualifie un objet, une action ou une qualité qui suscite la considération de l'entourage. Il désigne la conduite qui vaut à son auteur de l'honneur ou lui permet de conserver celui qu'il possédait déjà. On peut le traduire par «honorable», "source de considération", "source d'honneur». Il se distingue du sens précédent car il ne désigne pas la situation où l'on jouit de l'estime, mais le stade préalable à cette situation, la capacité à obtenir une estime fondée sur l'excellence morale ou sociale. Honestus désigne la qualité de ce qui vaut de l'honos, de ce qui suscite la «considération»(S2 de honos).

\subsection{Une source d'estime et de marques d'honneur}

Est honestum ce qui procure à son auteur la considération de son entourage. Il s'agit là d'un trait de sens essentiel, qui différencie honestus d'autres termes du vocabulaire moral tels que bonus ou probus: ces derniers, qui peuvent comme honestus renvoyer à un comportement jugé bon ou moral, n’impliquent jamais de bénéfice en

\footnotetext{
${ }^{10}$ PL. Merc. 318 ; Cic. Verr. I, 137 ; Phil. II, 69.

${ }^{11}$ Voir dans Rhet. Her. IV, 11 ; Cic. Font. 16; Mil. 18.

${ }^{12}$ Sensible dans Cic. Quinct. 2 ; Flac. 88.
} 
termes d'estime publique. Cicéron raconte comment les Crotoniates ont montré à Zeuxis les beaux jeunes gens de leur cité:

Illi autem statim hominem deduxerunt in palaestram atque ei pueros ostenderunt multos, magna praeditos dignitate. Etenim quodam tempore Crotoniatae multum omnibus corporum uiribus et dignitatibus antesterunt atque honestissimas ex gymnico certamine uictorias domum cum laude maxima retulerunt.

«Ils conduisirent l'homme à la palestre et lui montrèrent de nombreux jeunes hommes, dotés d'une grande beauté. En effet, il y eut un temps où les Crotoniates étaient de loin les premiers en force et en beauté physiques et ils remportèrent dans des combats gymniques de très honorables et glorieuses victoires. »

(CIc. Inu. II, 2 ; trad. Achard).

Dans le monde hellénisé de la Grande Grèce, les succès gymniques sont extrêmement valorisés et suscitent l'estime; les victoires remportées par les Crotoniates sont honestissimae. Le fait de s'attacher à un comportement honestus permet de gagner de l'estime et de ne pas tomber dans le déshonneur; c'est un des arguments que l'orateur qui veut parler en faveur du courage doit développer:

Item ab nulla re honesta periculi aut laboris magnitudine deduci oportere; antiquiorem mortem turpitudine haberi.

«De même il ne faut se laisser détourner d'aucune action honorable par l'importance du péril ou des épreuves; il faut préférer la mort au déshonneur. »

(Rhet. Her. III, 5 ; trad. Achard modifiée).

Faire preuve de courage au point de braver la mort écarte la turpitudo, c'est-à-dire la perte de l'estime collective par une action abjecte. L'action honesta, a contrario, permet de gagner la considération publique: le courage face au danger provoque en effet l'admiration. On retrouve avec ce sens d'honestus la notion d'estime observée au cœur du sémantisme d'honos. Cicéron expose en ces termes la raison qui l'a poussé à défendre les Siciliens:

Non enim spolia C.Verris, sed existimationem populi Romani concupiui. Meum fuit cum causa accedere ad accusandum: quae causa fuit honestior, quam a tam inlustri prouincia defensorem constitui et deligi?

«Car ce ne sont pas les dépouilles de Gaius Verrès que je désirai, mais l'estime du peuple romain. Il me fallait entreprendre mon accusation pourvu d'une cause légitime: quelle cause fut plus honorable que d'être choisi et constitué défenseur d'une si illustre province?»

(CIc. Verr. II, I, 21).

L'orateur a choisi de soutenir la cause des Siciliens, parce qu'elle est honesta, c'est-à-dire qu'elle permet d'attirer l'existimatio populi 
Romani, l'estime du peuple romain que Cicéron désire si fort ${ }^{13}$. Est honestum ce qui provoque une appréciation favorable et écarte le mépris ${ }^{14}$. C'est pourquoi honestus est régulièrement opposé à turpis ${ }^{15}$. Est turpe ce qui abaisse la considération et provoque une ségrégation sociale négative ${ }^{16}$. Honestus entre également dans des relations d'antonymie avec d'autres mots du vocabulaire du déshonneur et de l'infamie; on voit ainsi chez Cicéron que l'acte honestus est celui qui n'est jamais suivi de probrum et permet d'éviter l'infamia ${ }^{17}$. Cette capacité d'honestus à désigner l'estime qui va être suscitée explique que le mot ait été employé avec un sens technique dans le domaine de la rhétorique, pour évoquer un type de genus causae. Il ne s'agit cependant pas d'un sens nouveau, mais bien d'un emploi localisé car tous les traits de sens d'honestus "honorable» sont conservés ${ }^{18}$. Il est question du genus honestum dans la Rhétorique à Herennius et le De inuentione, lorsque ces textes dressent une typologie des genres de cause possibles. La cause relève du genus honestum lorsqu'elle suscite de manière spontanée la faveur du public et la bienveillance des juges:

Genera causarum quinque sunt: honestum, admirabile, humile, anceps, obscurum. Honestum causae genus est cui statim sine oratione nostra fauet auditoris animus.

«Il y a cinq genres de cause: l'honorable, l'extraordinaire, l'insignifiant, le douteux, l'obscur. La cause est du genre honorable quand l'esprit de l'auditeur est immédiatement favorable, sans que nous prenions la parole.»

(Cic. Inu. I, 20; trad. Achard modifiée).

La cause honesta est celle qui suscite la faveur de l'auditoire (fauet auditoris animus) qui est une forme d'estime. Le contenu social et moral d'honestus se trouve donc transposé dans le domaine technique de la rhétorique sans que son sens soit altéré ${ }^{19}$. C'est donc surtout l'es-

${ }^{13}$ Voir aussi Cic. Att. I, 12 où agir honeste permet de s'attacher l'existimatio de la collectivité.

${ }^{14}$ Voir SALL. Iug. 14, 24 qui oppose l'acte honestus et celui qui est iure contemptus.

${ }^{15}$ Voir parmi de nombreux exemples Ter. Phorm. 912-913; Cic. Verr. II, II, 142; Dom. 65 ; Cael. 78 ; Lig. 4 ; Phil. II, 32; CAES. BC III, 32, 4.

${ }^{16}$ Sur les valeurs morales de turpis, voir MonTeIL, Beau et laid, p. 280 sqq.

${ }^{17}$ Respectivement, Cic. Rosc. Amer. 48; Diu.Caec. 23.

${ }^{18} \mathrm{~F}$. Klose note de même que cet usage d'honestus n'a pas un sens éthique et reste très lié à la notion d'assentiment de la part des auditeurs de l'orateur (KLose, Bedeutung, p. 119).

19 Voir aussi Cic.Inu.I, 21 et Rhet.Her.I, 5.Le genus honestum correspond au

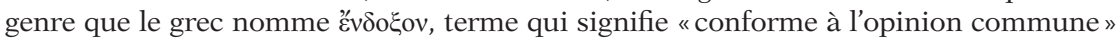
(voir par exemple Arstr. Top.I, 1, 13) et surtout «renommé, célèbre, glorieux ». Mais si honestus «honorable» possède un équivalent grec dans la langue de la rhétorique, il n'a pas subi l'influence de ce dernier par calque sémantique: son sens se situe parfaitement dans la lignée du sémantisme général du mot. 
time que la conduite honesta assure à son détenteur mais on voit aussi dans quelques textes que vivre honeste permet d'obtenir des bienfaits qui sont la marque tangible de cette estime. On lit ainsi chez Salluste, dans le discours prononcé par Marius devant l'assemblée du peuple, que se conduire honeste permet de recevoir un honos:

Verum homines corrupti superbia ita aetatem agunt quasi uostros honores contemnant; ita hos petunt, quasi honeste uixerint. Ne illi falsi sunt, qui diuorsissumas res pariter expectant, ignauiae uoluptatem et praemia uirtutis.

«Mais ces hommes corrompus par leur orgueil vivent comme s'ils méprisaient vos honneurs; et ils les briguent comme s'ils vivaient honorablement. Ils sont totalement dans l'erreur en voulant obtenir simultanément ces choses incompatibles, le plaisir de la paresse et les récompenses dues au mérite. »

(SALL. Iug. 85, 19-20; trad. Ernout modifiée).

Marius reproche aux nobles de rechercher des honores sans vivre honeste, c'est-à-dire sans se conduire d'une manière qui permette de les obtenir. Lassociation des deux termes montre qu'est honestus le comportement digne d'honos. Mais ce dernier trait de sens n'est pas systématiquement actualisé et constitue donc un sème virtuel. Les différents éléments de sens repérés peuvent être synthétisés par les sèmes suivants: /Qui permet de / bénéficier de / l'estime / susceptible d'être / signifiée / par des bienfaits/.

\subsection{La préservation du rang social}

Agir honeste permet de bénéficier pleinement de l'estime de la collectivité mais autorise également la préservation de son rang, de son appartenance à un groupe éminent. On voit ici resurgir un des traits du sémantisme d'honos qui associe la bonne réputation à la détention d'une position prestigieuse dans la société. L'acte honestus permet non seulement d'obtenir l'estime des autres mais aussi de préserver sa dignité sociale. Cet élément apparaît dans une tragédie d’Ennius. Agamemnon vient d'apprendre que sa fille Iphigénie est arrivée à Aulis et il sait qu'il va devoir la tromper pour la conduire au sacrifice, ce qui provoque en lui une intense affliction qu'il a cependant le devoir de réprimer:

Plebes in hoc regi antistat loco: licet

Lacrumare plebi, regi honeste non licet.

«La plèbe l'emporte sur le roi en ceci: il est permis

À la plèbe de pleurer, il n'est pas permis au roi de le faire sans se déshonorer. »

(ENN. Trag. inc. frg. CCXV Jocelyn).

Agamemnon est gagné par le chagrin mais se trouve dans l'impossibilité de laisser couler ses larmes. Montrer son émotion et pleurer 
en public est inconcevable pour un roi: ce ne serait pas agir honeste, c'est-à-dire d'une manière qui lui permette de garder son rang de monarque et d'avoir la considération de ses sujets. Le fait d'être haut placé dans la cité, parce qu'on exerce le pouvoir, interdit un certain type de conduite. L'orateur Antoine le confirme quand il souligne qu'il est des activités inconcevables pour un ancien censeur tel que lui: il ne peut honeste se faire accusateur dans un procès ${ }^{20}$. Trois sèmes se dégagent: est honestus ce /qui permet / de bénéficier / d'une position éminente dans la société/.

\subsection{Les fondements de l'estime suscitée: convenances sociales et règles morales}

L'adjectif honestus actualise de manière systématique l'idée que l'estime suscitée est fondée sur certaines qualités. Honestus évolue donc depuis un sens social, celui de "considéré », vers une coloration plus morale avec le sens "honorable». Cependant, le rapport avec la collectivité, déjà sensible dans le trait de sens de /l'estime/, est encore ici bien réel: l'acte honestus est conforme à des règles qui sont celles du groupe et en adéquation avec une morale sociale et non une éthique personnelle. Si Antoine ne peut se livrer à l'accusation dans les procès, c'est parce que les convenances sociales interdisent à des hommes de son rang de le faire. Les actions honestae sont mentionnées dans des contextes qui évoquent l'idée d'une bienséance sociale. C'est le cas dans les Captifs où le prisonnier Tyndare conseille à Hégion de ne pas réclamer une rançon trop importante à celui qu'il fait passer pour son père car ce dernier pourrait bien préférer pour son fils la captivité:

\footnotetext{
Ne tuum animum auariorem faxint diuitiae meae:

Ne patri, tametsi unicus sum, decere uideatur magis, Me saturum seruire apud te sumptu et uestitu tuo

Potius quam illi, ubi minime honestumst, mendicantem uiuere.

«Que mes richesses ne rendent pas ton cœur plus avide,

De peur qu'à mon père, bien que je sois son seul fils, il ne paraisse plus convenable

Que je sois esclave chez toi, bien nourri et vêtu à tes frais,

Plutôt que de vivre en mendiant chez nous, où c'est très peu honorable.»
}

(PL. Cap. 320-323).

La vie en captivité est préférable, pour autant que l'on soit bien traité, à une vie dans le dénuement le plus total car la misère impose de mendier, ce qui est très peu honestum. Aux yeux du père, cela n'est pas conforme aux convenances sociales du decet (decere uideatur).

${ }^{20}$ Cic. De or. II, 198. 
Le sémantisme d'honestus prend donc en compte l'obéissance à des règles sociales, mais qui se doublent toujours de normes morales: l'adjectif implique la détention de vertus individuelles. À ce titre, l'acte honestus est un acte "honorable», mais aussi "conforme à l'honneur», aux règles de comportement les plus prestigieuses et les plus hautes. Le courage, notamment face à la mort, et la dévotion de l'individu à la res publica sont des traits récurrents d'une vie honesta ${ }^{21}$. D'autres qualités apparaissent dans le Pro Caelio:

At uero in M. Caelio (dicam enim iam confidentius de studiis eius honestis, quoniam audeo quaedam fretus uestra sapientia libere confiteri) nulla luxuries reperietur, nulli sumptus, nullum aes alienum, nulla conuiuiorum ac lustrorum lubido.

«Pour revenir à Caelius - j’aurai plus d'assurance désormais pour parler de ses penchants honorables, puisque l'appui de votre sagesse me fait oser quelques libres confidences - l'on ne trouvera chez lui ni luxe ni dépenses ni dettes ni passion pour la table ou les mauvais lieux.»

(Cic. Cael. 44 ; trad. Cousin).

Les studia honesta de Caelius désignent son austérité et sa modération, son refus des plaisirs et du luxe, toutes qualités qui sont valorisées dans la morale romaine. Sont aussi qualifiées d'honestae des qualités comme la parsimonia, le pudor, la générosité ou encore le mépris de son intérêt personnel ${ }^{22}$. Nous pouvons donc isoler les sèmes suivants: le comportement honestus mérite l'estime /par sa conformité / aux normes sociales et morales collectives/.

\subsection{Un guide pour la conduite}

Il reste à expliciter un dernier trait de sens d'honestus: l'adjectif implique que l'action qu'il qualifie fait l'objet d'une inclination de la part des individus, que c'est une chose que l'on sélectionne de préférence quand il faut choisir telle conduite plutôt que telle autre. De ce fait, est qualifié d'honestum ce qui est propre à orienter le comportement du sujet: la conformité aux normes morales et sociales n'est pas vécue de manière passive mais active et les actes honesti constituent autant d'éléments d'un code de conduite. Il ne s'agit pas d'un trait de sens systématique, l'action honesta n'étant pas toujours érigée au rang de principe de comportement, mais on le retrouve tout de même dans environ $50 \%$ des occurrences du mot. L'objet honestus apparaît souvent dans les moments où une décision doit être prise et il sert alors de critère de choix. Dans le Poenulus, Hannon s'adresse aux deux jeunes filles de la pièce et fait semblant de les assigner en justice:

In ius uos uoco, nisi honestiust prehendi.

\footnotetext{
${ }^{21}$ Voir entre autres Rhet. Her. III, 5 et III, 9; SALl. Hist. frg. I, 12 et II, 47 (Reynolds).
}

${ }^{22}$ Voir respectivement CIc. Inu. II, 164; Sall. Cat. 13, 2; Cic. Verr.II, IV, 124; Diu. Caec. 64. 
«Je vous appelle en justice, à moins que vous ne jugiez plus honorable qu'on vous appréhende.»

(PL. Poen. 1232; trad. Ernout).

Il n'est pas honestus de subir une contrainte par corps pour être traîné devant le préteur (prehendi). Il est plus honorable de se plier à la procédure de mise en accusation classique devant le magistrat, que désigne la formule codifiée in ius uoco ${ }^{23}$. Hannon donne le choix aux jeunes filles entre une conduite honesta et une autre qui ne l'est pas et sa supposition ironique laisse clairement entendre que l'on choisit spontanément celle qui est honesta. Quand on hésite sur le mot à employer pour désigner une chose, on utilisera de préférence celui qui est honestus : le mot de consilium, pour désigner un dessein habile, est ainsi plus honorable que dolus qui est péjoratif ${ }^{24}$. Est donc honestum ce qui s'impose quand le sujet est placé face à un choix. À l'inverse, tout ce qui n'est pas honestum doit être rejeté et évité. L'adjectif turpis sert ici encore d'antonyme à honestus car il désigne une conduite mauvaise en insistant sur le fait qu'elle suscite la répulsion: est turpe ce dont on s'écarte en raison de l'aversion que l'on ressent ${ }^{25}$. À l'inverse, est honestum ce qui provoque une attraction et dirige l'action. Ce trait de sens devient particulièrement important quand honestus est utilisé comme substantif au neutre singulier; il est alors apte à désigner «l'honneur» compris comme principe d'action. Celui qui s'y attache fait preuve de "sens de l'honneur». C'est le cas chez Salluste quand ce dernier remarque que le consul Calpurnius, envoyé en Afrique avec des légions pour contrer Jugurtha, se laisse acheter par le roi Numide, tout comme Scaurus qui l'accompagne:

Qui, tametsi a principio, plerisque ex factione eius conruptis, acerrume regem inpugnauerat, tamen magnitudine pecuniae a bono honestoque in prauom abstractus est.

«Scaurus qui au début, bien que presque tous les gens de son parti se fussent laissé gagner, s'était déclaré l'adversaire acharné du roi, mais qui, devant les sommes énormes qu'on lui offrait, avait abandonné pour la voie du mal la voie du bien et de l'honneur. »

(SALL. Iug. 29, 2).

L'honestum renvoie à un comportement «honorable» en tant qu'il est érigé en principe de conduite propre à orienter l'action du sujet. Scaurus écoute d'abord ce principe supérieur, qui lui permet de ne pas céder à la corruption, mais l'oublie devant l'importance des

${ }^{23}$ Sur l'usage plautinien de cette formule, M. A. SuÁrez, et M. B. Álvarez, «La 'in ius uocatio' en Plauto: entre lo griego y lo romano", Faventia, 29 (2), 2007, p. 9-19.

${ }^{24}$ Rhet. Her. III, 8. Voir aussi Cic. Planc. 37 où sodalitas est préféré à consensio, bien que son sens soit plus éloigné du référent désigné.

${ }^{25}$ Voir MonteIL, Beau et laid, p. 283-287. 
cadeaux qui lui sont faits. Il est alors «arraché » (abstractus est) à l'honestum, image qui suggère bien que ce dernier est un guide auquel il faut s'attacher. Il est ici associé à un autre principe, bonum, mais s'en distingue néanmoins ${ }^{26}$ : le bonum indique lui aussi une conduite morale réglée, mais ne suppose pas comme honestum la conformité à une dignité sociale ni l'obtention consécutive de l'estime publique. Il apparaît donc qu'est honestum ce qui est /propre à / guider la conduite de l'individu/.

\subsection{Conclusion}

Le sémème complet d'honestus au sens «honorable, source de considération » est le suivant: /Qui permet de / bénéficier de / l'estime / susceptible d'être / signifiée / par des bienfaits / et d'une position éminente dans la société / par sa conformité / aux normes sociales et morales collectives / et qui est propre à / guider la conduite de l'individu/. Le nombre des sèmes retenu peut paraître important mais il nous paraît justifié par la complexité même de ce sens d'honestus. Ce sémème peut être comparé à celui de «considéré, estimé» (S1):

\begin{tabular}{|c|c|}
\hline $\begin{array}{l}\qquad \text { S1: «Considéré, estimé» } \\
\text { /Qui bénéficie/ } \\
\text { /de l'estime,/ } \\
\text { /susceptible d'être/ } \\
\text { /signifiée / par des bienfaits,/ } \\
\text { /et d'une position éminente dans la société// } \\
\text { /propre à// } \\
\text { /être assortie d'influence/. }\end{array}$ & $\begin{array}{l}\text { S2: «Honorable, source de consid. » } \\
\text { /Qui permet de/ } \\
\text { /bénéficier de/ } \\
\text { l'estime,/ } \\
\text { /susceptible d'être/ } \\
\text { /signifiée / par des bienfaits,/ } \\
\text { /et d'une position éminente dans la société// } \\
\text { /par sa conformité/ } \\
\text { /aux normes sociales et morales collectives/ } \\
\text { let qui est propre à/ } \\
\text { /guider la conduite de l'individu/. }\end{array}$ \\
\hline
\end{tabular}

La totalité des sèmes de S1 se retrouve dans S2, à l'exception du sème de /l'influence/, mais ce dernier est secondaire car faiblement actualisé. Le sème générique de $\mathrm{S} 2$ est nouveau par rapport à S1. Il s'agit donc d'une relation de métonymie: est "honorable» ce qui permet d'être "honoré» par ses qualités sociales et morales conformes à un code de conduite. L'innovation sémantique majeure de l'acception «honorable» consiste à faire une place importante aux fondements moraux de la considération.

Ces traits de sens permettent de mesurer la singularité d'honestus par rapport aux autres termes de son champ lexical. Laudabilis implique l'obtention d'un bienfait précis, l'éloge (laus), et gloriosus la détention d'une large notoriété qui n'est pas identique à l'estime

${ }^{26}$ Même association en Iug. 8, 1 et 82, 2. D'après KLose, Bedeutung, p.126, l'expression bonum atque honestum désigne «die sittliche Norm, die für das Handeln der Menschen maßgebend sein soll». 
et au respect des concitoyens suggérés par honestus: la gloria n'est pas l'honos. Honestus s'écarte encore davantage des adjectifs qui désignent la qualité morale comme bonus, probus ou rectus. D'abord parce que ces derniers n'envisagent pas les retombées sociales de la bonne conduite que sont l'estime et les marques d'honneur; ensuite parce qu'ils supposent une conformité à des normes surtout morales tandis qu'honestus implique aussi le respect de règles sociales imposées par le rang dans la société. Bonus peut certes porter lui aussi cette signification, mais son sens est beaucoup plus large que celui d'honestus et sa connotation n'est pas aussi laudative.

\section{3. «Honorable, DIGNE DE CONSIDÉRATION» (S2BIS)}

Ce sens d'honestus est très proche de celui que nous avons considéré précédemment. Il désigne le sujet qui mérite la considération et les marques d'honneur de son entourage pour ses qualités particulières. La traduction qu'en donne le français est d'ailleurs la même pour chacun des deux sens: est «honorable» l'acte qui apporte du prestige aussi bien que la personne qui est digne de le recevoir. Il faut cependant les distinguer, sinon en deux sens, du moins en deux acceptions. En effet, ce sens d'honestus diffère du précédent car des sèmes nouveaux apparaissent; il a en outre la singularité de ne pas apparaître avant la Rhétorique à Herennius, ce qui est un indice supplémentaire de son indépendance par rapport au sens "source de considération » qui est ancien. Le lien avec honos est assez net: est honestus le sujet qui mérite l'honos «considération ». À l'époque républicaine, l'adjectif n'est pas encore un titre, ce qu'il deviendra au $\mathrm{III}^{\mathrm{e}}$ siècle après J.-C., où sera faite une distinction juridique entre honestiores et humiliores ${ }^{27}$. Il est fréquemment utilisé au superlatif pour qualifier des personnes. La forme honestissimus semble même parfois perdre un peu de sa force tant elle est employée de manière systématique au lieu d'honestus; c'est le cas notamment dans les discours de Cicéron, où ce dernier qualifie facilement son client ou un témoin favorable d'honestissimus ou d'in primis honestus ${ }^{28}$. L'analyse sémique de ce sens sera plus rapide que celle opérée précédemment car les deux acceptions ont de nombreux sèmes en commun. Nous placerons l'accent sur leurs divergences.

${ }^{27}$ KLOSE, Bedeutung, p. 122. Sur cette distinction, G. CARDAScIA, «L'apparition dans le droit des classes d'honestiores et d'humiliores », RD, 1950, p.305-337 et 461-485 et R. RILINGER, Humiliores - Honestiores. Zu einer sozialen Dichotomie im Strafrecht der römischen Kaiserzeit, Munich, R. Oldenbourg, 1988.

${ }^{28}$ Voir, pour ne citer que quelques exemples, Cic. Quinct. 43 ; Rosc. Amer. 24 ; Verr. II, III, 56 ; Font. 41 ; Clu. 53. 


\subsection{Le droit à l'estime et à ses marques}

Avec ce sens, l'adjectif désigne non pas celui qui bénéficie de l'estime mais qui a droit à en bénéficier, qui la mérite. On le perçoit dans le passage des Verrines que Cicéron consacre à la cité d'Herbita, dépouillée par Verrès:

Etenim deinceps uideamus Herbitensis ciuitas honesta et antea copiosa quem ad modum spoliata ab isto ac uexata sit. At quorum hominum! summorum aratorum, remotissimorum a foro, iudiciis, controuersiis, quibus parcere et consulere, homo impurissime, et quod genus hominum studiosissime conseruare debuisti.

«Ensuite voyons donc comment l'honorable cité d'Herbita, qui était riche autrefois, a été dépouillée et persécutée par cet homme. Pourtant ces gens d'Herbita, quels hommes! les meilleurs cultivateurs, tout à fait étrangers aux affaires du forum, aux procès, aux chicanes; des gens que tu aurais dû épargner, sur qui tu aurais dû veiller, toi le plus impur des hommes, et dont tu aurais dû prendre le plus grand soin.»

(CIc. Verr. II, III, 75).

Herbita est une ciuitas honesta qui a été accablée de malheurs par la faute de Verrès et que Cicéron s'attache à montrer comme digne de considération et de soins: en tant qu'honesta, la cité aurait dû être protégée (conseruare debuisti), ce qui est le degré zéro de la marque d'honneur. On voit qu'est qualifié d'honestus celui envers qui s'exerce un devoir d'estime et d'égards. On le voit aussi dans la distinction faite par Cicéron de l'honestus et de l'honoratus dans un texte du Brutus que nous citions à propos d'honos et qui mérite un nouvel examen:

Cum honos sit praemium uirtutis iudicio studioque ciuium delatum ad aliquem, qui eum sententiis, qui suffragiis adeptus est, is mihi et honestus et honoratus uidetur.

«Puisque l'honneur est une récompense de la vertu accordée à quelqu'un par le jugement et l'affection des concitoyens, celui qui l'obtient par leurs décisions et leurs suffrages me semble à la fois honorable et honoré.»

(Cic. Brut. 281).

L'honoratus bénéficie pleinement de l'honos et de ses avantages mais n'est pas pour autant toujours honestus : pour pouvoir prétendre à cette qualité, il faut prouver que l'on est digne de l'honos, par ses qualités personnelles (la uirtus) et par la régularité des moyens avec lesquels on l'a obtenu. Honestus s'oppose aux termes qui impliquent l'impossibilité de mériter l'estime publique, comme turpitudo ou dedecus ${ }^{29}$. Les sèmes suivants peuvent donc être dégagés: /Qui mérite / de bénéficier / de l'estime / susceptible d'être / signifiée / par des bien 
faits/. Le sème des /bienfaits/ n'est pas systématiquement actualisé : on le rencontre dans environ $35 \%$ des cas.

\subsection{Les fondements du droit à l'estime: qualités morales et convenances sociales}

L'adjectif honestus désigne un droit à la considération fondé, essentiellement mais non exclusivement, sur des qualités morales. Cicéron évoque en ces termes Sextus Pompeius Chlorus, qui a défendu une victime de Verrès:

Quid ego hic nunc Sex. Pompei Chlori testimonium recitem, [...] hominis honestissimi, tametsi ciuis Romanus uirtutis causa iam diu est, tamen omnium Siculorum primi ac nobilissimi?

«Dois-je faire ici et maintenant la lecture du témoignage de Sextus Pompeius Chlorus, [...] cet homme très honorable qui, bien qu'il soit depuis longtemps devenu citoyen romain grâce à sa valeur, est cependant le premier et le plus noble de tous les Siciliens? ”

(CIc. Verr. II, II, 23).

Pompeius Chlorus est honestissimus, tout à fait digne de considération, et il a d'ailleurs reçu une marque d'honneur, l'octroi de la citoyenneté romaine. Ce bénéfice se fonde sur sa valeur générale, uirtutis causa. Est honestus celui qui se conforme à des règles de comportement strictes qui écartent toute indignité et respecte donc un code de l'honneur. Cela apparaît dans le passage du De suppliciis où, après une défaite navale des Siciliens face aux pirates, les capitaines de vaisseaux sont mis aux arrêts, à l'exception de Cléomène, nommé par Verrès à la tête de la flotte de Sicile:

Tum uero omnibus indignissimum uisum est homines honestissimos electos ex suis ciuitatibus in ferrum atque in uincla coniectos, Cleomenem propter flagitiorum ac turpitudinum societatem familiarissimum esse praetori.

«Alors tous jugent tout à fait révoltant que des hommes très honorables, choisis parmi leurs concitoyens, soient mis aux fers et enchaînés et que Cléomène, à cause de sa complicité de scandales et d'infamies, soit dans la plus grande familiarité avec le préteur.»

(CIc. Verr. II, V, 107 ; trad. Rabaud).

Les hommes honesti sont ceux qui ne sont entachés d'aucun flagitium ni d'aucune turpitudo, qui désignent respectivement une action scandaleuse et une conduite déshonorante et ignoble ${ }^{30}$. À l'inverse, faire preuve de courage, être fortis, est un trait de caractère de l'homme honestus, au même titre que le respect de la fides, de l'équité, que l'ab-

${ }^{30}$ Voir le sémème que donne Thomas, Déshonneur et honte pour chacun de ces termes (p. 158 et 212). Cf. la définition donnée par IsID. Orig X, 116: honestus, quod nihil habeat turpitudinis. 
sence d'esprit de chicane ou que la générosité désintéressée ${ }^{31}$. Outre ces qualités morales, le sens «honorable, digne de considération» d'honestus indique, comme S2, le respect des convenances sociales ${ }^{32}$. Se dégagent ainsi les sèmes de la /conformité / aux normes sociales et morales collectives/.

\subsection{Les bases sociales du droit à l'estime}

La singularité du sens d'honestus «digne de considération » par rapport à "source de considération » apparaît dans le second pilier du droit à l'estime désigné par l'adjectif. Cette acception garde en effet un aspect social prononcé: dans environ la moitié des textes, elle renvoie à un mérite qui ne se fonde pas seulement sur le respect de convenances mais aussi sur la détention d'une position socialement élevée, qu'il s'agisse de la noblesse de la naissance ou de la richesse personnelle. Le droit à l'estime de la personne honesta repose aussi sur son prestige social. Ce double fondement du droit à la considération apparaît bien dans le texte des Catilinaires qui détaille la composition de l'entourage de Catilina et envisage d'abord le cas des riches Romains:

Horum hominum species est honestissima (sunt enim locupletes), uoluntas uero et causa impudentissima.

«Ces gens sont d'apparence très honorable (car ce sont des riches), mais leurs intentions et leur cause manquent totalement de décence.»

(CIc. Catil. II, 18).

Les gens riches sont qualifiés d'honesti à cause de leur fortune (sunt enim locupletes). Mais elle n'est pas suffisante pour faire d'eux des personnes pleinement honestae: elles n'ont que l'apparence de l'honorabilité, c'est leur species qui est honestissima, il leur manque les fondements moraux qui créent la véritable dignité. Le caractère honestus de l'individu repose sur l'association de ces deux éléments, moral et social, comme en témoigne un texte des Verrines:

Eubulida est Grospus Centuripinus, homo cum uirtute et nobilitate domi suae, tum etiam pecunia princeps. Huic homini, iudices, honestissimae ciuitatis honestissimo non modo frumenti scitote sed etiam uitae et sanguinis tantum relictum esse quantum Aproni libido tulit.

«Eubulidas Grospus est un habitant de Centuripe, un citoyen, par sa valeur et la noblesse de sa famille ainsi que par sa fortune, de premier ordre. Cet III, 149 .

${ }^{31}$ Respectivement, Sall. Iug. 85, 49; Cic. Rosc. Amer. 113; Verr. I, 20; II, III, 67; II,

${ }^{32}$ L'honestus ne peut se comporter comme les déclassés que sont les gladiateurs ou les prostitués (Cic. Mur. 83 et Quinct. 95). 
homme, juges, le plus honorable d'une cité très honorable, sachez qu'on ne lui a laissé qu'autant de froment mais aussi de vie et de sang que le désir d'Apronius l'a permis.»

(CIc. Verr. II, III, 56).

Si Eubulidas est honestissimus, c'est par sa uirtus, sa valeur personnelle, mais aussi par la nobilitas de sa famille et par sa fortune (pecunia $)^{33}$. Il est par ailleurs significatif qu'honestus soit utilisé pour désigner un ordo: l'ordre équestre est très souvent qualifié d'honestus, par Cicéron, qui en était un membre éminent et pouvait donc avoir intérêt à souligner la grandeur de son extraction, mais aussi par César ou par la Rhétorique à Herennius, ce qui montre qu'il ne s'agit pas d'un emploi spécifique à l'Arpinate ${ }^{34}$. Que tout un ordo puisse être honestus indique que l'appartenance à ce dernier est un gage d'honorabilité, et que cette même honorabilité a donc un fondement social. On voit ainsi se dégager un sème dans environ $40 \%$ des occurrences: est honestus l'individu qui mérite l'estime par sa /position éminente dans la société/.

\subsection{Savoir guider sa conduite}

Être honestus implique aussi la conscience d'un certain nombre de règles et la capacité à orienter sa conduite conformément à ces règles. L'homme honestus obéit à un code d'honneur qui dirige son action:

Atque huic eidem nuper tres equites Romani honesti et graues, cum in causa liberali eum qui adserebatur cognatum suum esse diceret, non crediderunt.

"C'est ce même homme que récemment trois chevaliers romains honorables et dignes de foi ont refusé de croire, dans un procès de liberté où il affirmait que celui dont il revendiquait la liberté était son parent. »

(Cic. Flac. 40; trad. Boulanger).

Il est ici question d'un menteur qui essaie d'abuser les juges dans un procès. Les chevaliers qui entendent le discours mensonger et savent qu'il l'est n'y ajoutent pas foi (non crediderunt). C'est précisément le fait qu'ils soient honesti qui les contraint à ne pas croire un affabulateur mal intentionné car une telle attitude mettrait en péril

${ }^{33}$ Le qualificatif d'honestus est à plusieurs reprises associé à celui de locuples (Cic. Verr. II, IV, 45; II, V, 154).

${ }^{34}$ Voir, parmi de très nombreux exemples, Cic. Verr. II, I, 137 ; II, III, 36; Imp. Pomp. 17; Rab. Perd. 27. Et Rhet. Her. IV, 47; CAEs. BG VII, 3, 1. Sur l'usage d'honestus pour l'ordre équestre, C. Nicolet, L'Ordre équestre à l'époque républicaine (312-43 av.J.-C.),

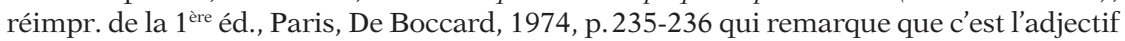
mélioratif le plus utilisé à son sujet, avec splendidus, et qu'il implique la détention d'un certain rang social, mais non nécessairement d'une grande fortune. L'adjectif honestus est aussi employé, quoique de manière moins fréquente, pour d'autres ordines, comme celui des scribes (Rhet. Her. III, 7; Cic. Catil. I, 28; Verr. II, III, 183; Phil. VII, 24). 
leur dignité. Un homme d'honneur ne peut, de la même façon, reconnaître publiquement qu'il va aux thermes avec son fils, car l'aveu d'une telle promiscuité dans la nudité est déshonorant ${ }^{35}$ : l'honestus doit écarter l'indécence sexuelle. Il doit écouter ce principe d'action qu'est l'honneur comme l'explicite Salluste au début du Bellum Iuguthinum:

Ea tempestate in exercitu nostro fuere conplures noui atque nobiles, quibus diuitiae bono honestoque potiores erant, factiosi domi, potentes apud socios, clari magis quam honesti, qui Iugurthae non mediocrem animum pollicitando accendebant, si Micipsa rex occidisset, fore uti solus imperi Numidiae potiretur: in ipso maxumam uirtutem, Romae omnia uenalia esse.

«À cette époque il y avait dans notre armée nombre d'hommes nouveaux et de nobles, qui préféraient la richesse au bien et à l'honneur, influents à Rome, puissants auprès des alliés, plus célèbres qu'honorables, qui enflammaient l'ambition déjà vive de Jugurtha à force de lui promettre que, si le roi Micipsa venait à disparaître, il deviendrait seul maître du royaume de Numidie: il avait pour lui sa grande valeur personnelle et à Rome tout se vendait. »

(SALL. Iug. 8, 1; trad. Ernout).

Ladjectif substantivé honestum désigne l'honneur en tant que principe imposant une conduite honorable ${ }^{36}$. Or Salluste associe cet honestum à la qualité de personne honesta: ceux qui préfèrent la richesse à l'honestum sont ceux qui sont clari magis quam honesti, "plus célèbres qu'honorables»: honestus ne désigne pas ici une notoriété mais le droit à cette notoriété, l'honorabilité. Et ce droit à l'estime implique d'écouter attentivement l'honestum. Est donc honestus celui qui sait /guider sa conduite/.

\subsection{Conclusion}

Le sémème complet d'honestus "honorable, digne de considération » (S2bis) est le suivant: /Qui mérite / de bénéficier / de l'estime / susceptible d'être / signifiée / par des bienfaits / pour sa conformité / aux normes sociales et morales / susceptible d'être / renforcée par sa position éminente dans la société /, et qui sait guider sa conduite/. Ici encore, le nombre de sèmes retenus peut paraître excessif mais il se justifie par la richesse des nuances sociales, morales et psychologiques. Il peut être rapproché du sémème de "honorable, source de considération » (S2):

\footnotetext{
${ }^{35}$ Cic. Clu. 141.

${ }^{36}$ Voir supra p. 127.
} 


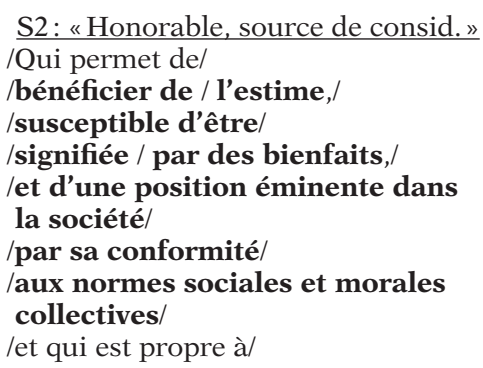

/guider la conduite de l'individu/.
S2bis: "Honorable, digne de consid." /Qui mérite de/ /bénéficier de / l'estime,/ /susceptible d'être/ /signifiée / par des bienfaits,/

/pour sa conformité/

/aux normes sociales et morales collectives/

/susceptible d'être/

/renforcée par sa position éminente

dans la société/,

/et qui sait guider sa conduite/.

Les deux sémèmes sont très proches: mis à part le changement du sème générique, la totalité des sèmes de $\mathrm{S} 2$ se retrouve dans $\mathrm{S} 2$ bis. Il faut cependant noter un changement de l'articulation logique: la /position sociale éminente/ est un bénéfice social de l'action honesta dans le premier cas alors qu'elle devient un fondement de l'honorabilité dans le second. Ce cas de figure n'est pas envisagé par R. Martin dans sa typologie, mais se rapproche de la relation de "pluralité d'acceptions par amincissement» décrite par J.-F. Thomas à propos de turpitudo et de flagitium: seul le sème générique change, les autres sèmes se maintiennent mais sont distribués différemment ${ }^{37}$. On ne passe pas réellement avec honestus d'une acception concrète à une acception abstraite, comme dans la description que donne J.-F. Thomas de ce phénomène, mais il y a tout de même évolution depuis une acception qui désigne une source tangible et concrète d'honneur à une autre où cet honneur est envisagé sur un mode plus conditionnel.

\section{4. «HONORIFIQUe » (S3)}

Il s'agit là d'un sens d'honestus assez peu fréquent mais qui témoigne de la souplesse sémantique de l'adjectif et de sa capacité à envisager l'honos sous différents points de vue. L'action honesta est alors celle par laquelle une marque d'honneur est conférée à un tiers, marque qui procure à celui qui la reçoit du prestige. À la différence du sens «honorable» (S2), les mérites de la personne honorée passent au second plan et, surtout, ce n'est pas l'auteur de l'action qui bénéficie de l'estime et du prestige mais celui qui est visé par l'action. Est honestus l'acte qui donne un honos à un tiers, qui lui procure une "marque d'honneur» ainsi que la "considération » qui en découle. Le sens est attesté dès Plaute. Il n'est pas isolé par les ouvrages de lexicographie

\footnotetext{
${ }^{37}$ Thomas, Déshonneur et honte, p. 152-153.
} 
moderne mais nous paraît constituer un sens autonome en raison de la singularité du point de vue qu'il suppose.

\subsection{Analyse sémique}

Ce sens apparaît dans un passage du Rudens:

Neque digniorem censeo uidisse anum me quemquam, Cui deos atque homines censeam bene facere magis decere. Vt lepide, ut liberaliter, ut honeste atque haud grauate Timidas, egentes, uuidas, eiectas, exanimatas Accepit ad sese, haud secus quam si ex se simus natae!

«Je n'ai jamais vu, je crois, de vieille femme plus digne, Personne ne mériterait plus de recevoir les bienfaits des dieux et des hommes.

Avec quelle attention, quelle générosité, quels égards, quelle spontanéité Elle nous a accueillies, nous qui étions terrifiées, dépouillées, trempées, abandonnées, épuisées,

Tout comme si nous étions ses propres filles!»

(PL. Rud. 406-410).

Ampélisque parle ici de la prêtresse de Vénus qui l'a recueillie, elle et sa compagne, après leur naufrage. Honeste qualifie la façon dont la prêtresse a traité les jeunes femmes: ce pourrait être «honorablement" mais l'adverbe aurait alors un sens un peu faible. Étant donné les termes qui accompagnent honeste (lepide, liberaliter, haud grauate), on peut plutôt penser que l'adverbe exprime la générosité et l'affabilité de la prêtresse; il indique qu'elle a accordé aux naufragées des honores. Elle a agi "d'une manière qui confère des égards », de façon "honorifique ${ }^{38}$. De même, quand Caton parle de son attitude lorsqu'il était à la tête de l'armée en Espagne:

Interea unamquamque turmam manipulum cohortem temptabam quid facere possent; proeliis leuibus spectabam cuiusmodi quisque esset; si quis strenue fecerat, donabam honeste, ut alii idem uellent facere, atque in contione uerbis multis laudabam.

«Pendant ce temps je mettais à l'épreuve chaque escadron, chaque manipule, chaque cohorte, pour voir ce qu'ils étaient capables de faire; en les engageant dans des escarmouches, j'essayais de voir de quelle trempe était chacun d'eux; si l'un s'était comporté vaillamment, je le récompensais généreusement, pour que les autres veuillent l'imiter, et pendant l'assemblée des soldats je le louais dans un long discours.»

(CAT. frg. IV, 35 ORF).

${ }^{38}$ C'est ainsi que F. Klose comprend le passage: "honeste entspricht etwa einem honorifice (...): 'wie annerkennend, wie ehrend' oder schon ein wenig abgeschliffen 'wie zuvorkommend, wie freundlich'» (Ibid., p. 100). Et il le rapproche, à juste titre, d'un autre passage du Rudens, v.464, où honeste a le même sens. 
Caton montre qu'il a bien traité ses troupes, qu'il les a récompensées honeste, en leur conférant des honneurs qui donnaient une position prestigieuse au sein de l'armée, propre à exciter l'émulation (ut alii idem uellent facere). On comprend dès lors qu'un honos soit qualifié d'honestus car il est bien, par essence, "honorifique», porteur de prestige pour un tiers. C'est ce qui apparaît quand Cicéron compare la façon dont Caton d’Utique et lui-même ont été écartés de Rome par leurs adversaires:

Eiciuntur duo quos uidere improbi non poterant, alter per honorem turpissimum, alter per honestissimam calamitatem.

«Les deux hommes que les méchants ne pouvaient voir sont chassés, l'un par un honneur très dégradant, l'autre par un malheur très honorable.»

(Cic. Dom. 65).

Par une alliance de mots suggestive, Cicéron note combien la mission qui a été confiée à Caton à Chypre était dégradante car elle ne visait qu'à l'éloigner: il s'agissait d'un honos qui n'en avait que le nom. À l'inverse, la calamitas qu'est l'exil infligé à Cicéron est honesta, elle lui apporte de l'honneur, car elle lui a permis un retour triomphal à Rome. En règle générale, c'est l'honos qui honore et l'affront qui déshonore, mais ce processus a été inversé.

\subsection{Conclusion}

Nous pouvons proposer pour le sens «honorifique» le sémème suivant: /Qui permet / à un tiers / de bénéficier / de l'estime, / par des bienfaits / qui en sont le signe, / ainsi que d'une position éminente dans la société/. Il peut être comparé sens «estimé, considéré»(S1):

\begin{tabular}{|l|l|}
\hline \multicolumn{1}{|c|}{$\mathrm{S} 1:$ "Considéré, estimé » } & \multicolumn{1}{c|}{$\mathrm{S} 3:$ «Honorifique» } \\
& $\begin{array}{l}\text { /Qui permet / } \\
\text { à un tiers/ } \\
\text { /de bénéficier/ } \\
\text { /de l'estime/, }\end{array}$ \\
$\begin{array}{l}\text { /Qui bénéficie/ } \\
\text { /de l'estime,/ } \\
\text { /susceptible d'être/ } \\
\text { /signifiée/ } \\
\text { /par des bienfaits,/ } \\
\text { /et d'une position éminente dans la société// } \\
\text { /propre à/ } \\
\text { /être assortie d'influence/. }\end{array}$ & $\begin{array}{l}\text { /par des bienfaits/ } \\
\text { /qui en sont le signe/, } \\
\text { /ainsie d'une position éminente } \\
\text { dans la société/. }\end{array}$ \\
\hline
\end{tabular}

Si l'on écarte le sème de /l'influence/, qui est de toute façon peu actualisé pour le sens "considéré", on observe que le sémème de S1 se retrouve intégralement dans S3. Il y a adjonction dans S3 de deux sèmes, dont un nouveau sème générique. Il s'agit donc d'une relation de métonymie entre les sens. Est en effet «honorifique» l'acte qui permet à un tiers d'être "considéré». 


\section{5. « HONNÊTE, PROBE » (S4)}

Avec ce sens d'honestus l'adjectif continue d'évoluer vers le lexique moral et de s'éloigner de la dimension sociale originelle. Honestus désigne en effet l'acte ou la personne "honnête», c'est-à-dire faisant preuve de qualités morales conformes aux normes de son temps, mais sans que cela apporte un quelconque bénéfice en termes d'estime ou de prestige social. Il ne s'agit plus, en outre, d'obéissance à un code d'honneur mais simplement d'adéquation aux bonnes mœurs. La chose ou l'individu ${ }^{39}$ honestus est "honnête», "probe», "moral». L'adjectif se rapproche donc de bonus, rectus et probus ${ }^{40}$. Du même coup, le lien avec le sémantisme d'honos se distend. Ce sens apparaît dès Plaute ${ }^{41}$ mais il est en réalité très peu utilisé avant la seconde moitié du $\mathrm{II}^{\mathrm{e}}$ siècle.

\subsection{La conformité à la morale collective}

Quand honestus porte le sens d' "honnête", il indique une conformité aux bonnes mœurs, sans impliquer que le sujet mérite pour cela l'estime de son entourage. C'est apparent dans la définition que donne Cicéron de la dignitas dans le De inuentione:

Dignitas est alicuius honesta et cultu et honore et uerecundia digna auctoritas.

«La dignité est une autorité honnête, digne de respect, d'honneur et de déférence.»

(Cic. Inu. II, 166; trad. Achard modifiée).

Honesta, qui qualifie auctoritas, ne peut ici signifier «honorable» car ce sens est porté par dignus honore. Ce qu'indique honestus, à propos de la dignitas, c'est qu'il s'agit d'une autorité qui s'accompagne d'une conduite moralement irréprochable, conforme aux bonnes mœurs. Cette conduite est susceptible de procurer de l'honos mais ce trait de sens n'appartient plus au sémantisme d'honestus. L'adjectif en vient essentiellement à désigner une personne ou une conduite qui témoigne de vertus diverses: modération, piété, pudeur dans la vie intime, par exemple ${ }^{42}$. Un texte de Cicéron permet de prendre la mesure des divers comportements que suppose une vie honesta:

Defensor autem primum, si poterit, debebit uitam eius qui insimulabitur quam honestissimam demonstrare. Id faciet, si ostendet aliqua eius nota et

${ }^{39}$ Aucune divergence sémantique ne permet ici de séparer deux acceptions d'honestus pour qualifier une personne ou une chose, comme nous l'avions fait pour honestus au sens «honorable».

${ }^{40}$ Voir le rapprochement fait par Cicéron entre innocentes, honesti et boni (CIc. Phil. VIII, 16).

${ }^{41}$ PL. Trin. 731.

${ }^{42}$ Respectivement, Cic. Dom. 54; Verr. II, IV, 11; SAll. Iug. 95, 3. 
communia officia; quod genus in parentes, cognatos, amicos, affines, necessarios; etiam quae magis rara et eximia sunt, si ab eo cum magno aliquid labore aut periculo aut utraque re, cum necesse non esset, officii causa aut in rem publicam aut in parentes aut in aliquos eorum qui modo expositi sunt factum esse dicet; denique si nihil deliquisse, nulla cupiditate inpeditum ab officio recessisse.

«Le défenseur, quant à lui, devra, s'il le peut, montrer que la vie de l'accusé a été la plus honnête possible. Il y parviendra en évoquant des services connus et ordinaires rendus par lui, par exemple à ses père et mère, à ses proches, à ses amis, à ses parents par alliance, à ses relations; en disant aussi - ce qui est plus rare et plus remarquable - qu'il a exécuté pour l'État, ou pour ses père et mère, ou pour certains de ceux que nous venons d'évoquer, une chose qui l'a exposé à bien des efforts ou à bien des dangers ou aux deux à la fois, et qu'il l'a faite pour rendre service alors qu'elle n'était pas obligatoire; en disant enfin qu'il n'a commis aucune faute; qu'aucune passion ne l'a empêché de remplir son devoir. »

(CIc. Inu. II, 35 ; trad. Achard).

Vivre de manière "honnête» suppose de remplir ses obligations envers sa famille et ses relations sociales, rendre un service qui n'est pas obligatoire, s'abstenir de commettre des fautes et s'en tenir, plus généralement, à l'officium. Le sujet peut être honestissimus quand il va jusqu'à se soucier de la res publica. Il n'est plus question avec ce sens d'un respect de la dignité sociale et des convenances imposées par le statut dans la société mais seulement de l'adéquation à des normes morales. Ladjectif peut alors entrer en relation de synonymie avec bonus dont le sens est encore plus général. Est donc honestum ce qui est /conforme / aux normes morales collectives/.

\subsection{La droiture}

Cette conformité générale aux règles morales doit être précisée par un sème virtuel, actualisé dans environ $35 \%$ des occurrences du sens «honnête». Honestus recouvre plusieurs qualités de nature diverse mais parmi ces dernières émerge une caractéristique récurrente, bien mieux représentée que les autres. Il s'agit de la droiture, du trait de caractère qui fait récuser toute fourberie ou toute fraude. Est honestus celui qui ne cherche pas à tromper les autres ni à les léser ${ }^{43}$. Dans le Trinummus, Calliclès éprouve des scrupules à laisser la fille de son ami, sur laquelle il doit veiller, se marier sans dot alors qu'il sait que son père a caché de l'argent qui se trouve maintenant dans sa maison:

Namque hercule honeste fieri non potest

Vt eam perpetiar ire in matrimonium

Sine dote, quom eius rem penes me habeam domi.

${ }^{43}$ Voir H.BARDON, "L'honnêteté à Rome: du De officiis à La Rochefoucauld", in Gareau, E.(éd.), Valeurs antiques et temps modernes, Ottawa, Éditions de l'Université d'Ottawa, 1972, p. 128-140: "L'honestus est essentiellement un homme droit, aux principes moraux bien assurés » (p. 129). 
«Et en effet, par Hercule, on ne peut honnêtement admettre que je la laisse se marier sans dot, alors que son bien est entre mes mains, chez moi. »

(PL. Trin. 731-733; trad. Ernout).

Il n'est pas honnête, pour Calliclès, de laisser la jeune fille faire un mariage peu glorieux, alors qu'il a chez lui de l'argent qui revient de droit à cette dernière. Ce n'est pas agir conformément à l'équité et à la probité. L'honestus évite tout autant la duplicité et la corruption ${ }^{44}$. Il ne se livre à aucune manigance ni aucune tricherie. Le terme honestus est de ce fait souvent employé dans le contexte judiciaire: ce n'est pas agir honeste que de dissimuler des preuves ou de faire du profit au détriment des autres ${ }^{45}$. Le mot est souvent employé par les avocats qui cherchent à innocenter leur client mis en accusation. Il s'oppose alors à l'illégalité et au crime, comme c'est le cas à propos de la mort de M. Papirius, chevalier romain tué sur la via Appia lors d'une rixe entre Clodius et les partisans de Pompée en 58 avant notre ère:

Quae cruentata antea caede honesti atque innocentis uiri silebatur, eadem nunc crebro usurpatur, postea quam latronis et parricidae sanguine imbuta est.

"Quand elle avait été ensanglantée par le meurtre d'un honnête homme, d'un innocent, on n'en parlait pas; on la mentionne constamment aujourd'hui qu'elle a été imprégnée du sang d'un brigand, d'un assassin. »

(CIc. Mil. 18; trad. Boulanger).

Honestus est associé à innocens, et s'oppose à la figure du latro et parricida, qui est un criminel hors-la-loi. Nous pouvons donc isoler un sème virtuel supplémentaire: est honestus l'action ou la personne qui se conforme aux normes morales et /notamment à la droiture/.

\subsection{Guider la conduite}

Quand honestus est utilisé avec son sens d'«honnête», l'adjectif implique que le sujet oriente son comportement, qu'il fait des choix et vise des buts précis. Ce trait de sens, déjà repéré pour le sens «honorable », reparaît ici mais il est moins prégnant puisqu'on ne le rencontre que dans $25 \%$ des cas où honestus signifie «honnête ». Quand la considération de l'honestum échoue à orienter correctement la conduite, cela est suffisamment exceptionnel pour être noté, comme dans cet exemple fourni par la Rhétorique à Herennius où il est question d'une femme soupçonnée de nombreux crimes:

[...] nulla potest honesta ratio retinere eam quam magnitudo peccati facit timidam, intemperantia audacem, natura mulieris inconsideratam.

${ }^{44}$ SAll. Iug. 5, 5 ; Cic. Verr. I, 9.

${ }^{45}$ Cic. Verr. II, II, 186. 
"Aucun raisonnement honnête ne peut retenir une femme que la gravité de sa faute emplit de crainte, l'excès de sa passion d'audace et sa nature féminine d'irréflexion. »

(Rhet. Her. IV, 23; trad. Achard modifiée).

La ratio honesta, le raisonnement honnête, est ce qui permet d'orienter la conduite et de s'écarter du peccatum; mais la femme en question dans le texte ne se plie pas à ce dernier, elle ne sait pas réguler son action et fait preuve d'intemperantia. L'individu véritablement honestus sait, lui, se tenir à des principes de comportement: il est inaccessible à toute forme de corruption. Ce qui n'est pas honestum suscite la répulsion. Dans l'Hécyre, l'esclave Parménon rapporte les paroles de Pamphile, qui s'est marié contre son gré à une jeune fille qu'il n'aime pas et dont il veut se séparer:

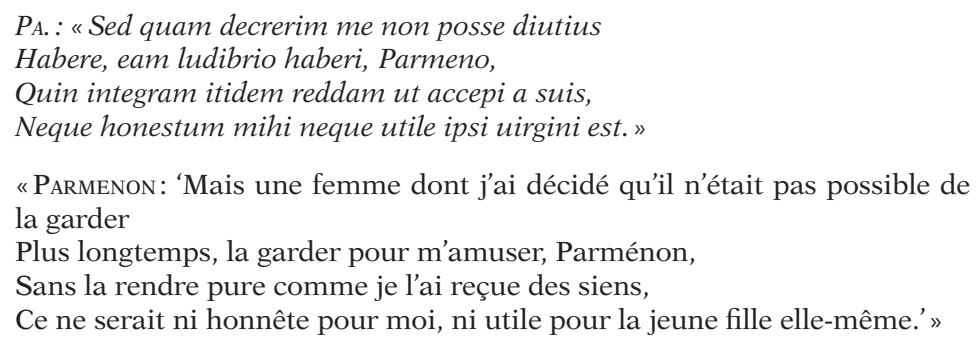

«Parmenon: 'Mais une femme dont j'ai décidé qu'il n'était pas possible de la garder

Plus longtemps, la garder pour m’amuser, Parménon,

Sans la rendre pure comme je l'ai reçue des siens,

Ce ne serait ni honnête pour moi, ni utile pour la jeune fille elle-même.' »

(TER. Hec. 148-151).

La considération de ce qui est honestum rejoint ici celle de l'utile pour orienter le choix du comportement à adopter. Se trouve donc actualisé un sème virtuel: /qui est propre à / guider la conduite/.

\subsection{Conclusion}

Le sémème complet d'honestus au sens «honnête» peut être établi de la manière suivante: / Qui est conforme / aux normes morales collectives / et parfois / notamment à la droiture / et qui est propre à / guider la conduite/. Ce sens paraît procéder du sens «honorable»:

\begin{tabular}{|l|l|}
\hline \multicolumn{1}{|c|}{$\mathrm{S} 2:$ «Honorable, source de consid.» } & \multicolumn{1}{c|}{$\mathrm{S} 4:$ «Honnête, probe» } \\
/Qui permet de/ \\
/bénéficier de/ \\
/l'estime,/ \\
/susceptible d'être/ \\
/signifiée/ \\
/par des bienfaits,/ \\
/et d'une position éminente dans la société/ \\
/par sa conformité/ \\
/aux normes sociales et morales collectives/ \\
/et qui est propre à/ \\
/guider la conduite de l'individu/. & $\begin{array}{l}\text { /Qui est conforme// } \\
\text { /aux normes morales collectives/ } \\
\text { /et parfois / notamment à la droiture/ } \\
\text { /et qui est propre à/ } \\
\text { /guider la conduite/. }\end{array}$ \\
\hline
\end{tabular}


De S2 à S4 s'opère un effacement de nombreux sèmes, l'ajout du sème de la /droiture/, et un changement du sème générique, qui était spécifique dans S2. Il s'agit donc d'une relation de polysémie lâche de sens, ce qui confirme notre impression initiale: le sens " honnête» s'écarte plus nettement du sémantisme initial d'honestus. Le plus frappant reste la disparition de tous les sèmes qui concernent l'estime et ses bénéfices sociaux que sont les bienfaits et la position éminente dans la société. Le sens «honnête» se concentre sur les motifs de l'honorabilité et évacue ses retombées en termes d'honos. Il faut en outre remarquer que les normes que le sujet respecte ne sont plus qu'exclusivement morales: la conformité aux convenances imposées par le rang est écartée du sémème. Est «honnête » ce qui respecte les bonnes mœurs et les coutumes du peuple auquel on appartient, mais pas les bienséances du groupe social précis auquel on est agrégé. Honestus n'implique plus le respect d'un code d'honneur mais d'une honnêteté plus générale.

Par rapport à bonus, honestus au sens "honnête» indique une qualité des mœurs, avec un accent porté plus particulièrement sur la probité et l'équité, alors que le sens de bonus est plus large. Honestus se rapproche davantage de rectus, mais ne comporte pas de manière aussi nette que ce dernier l'idée d'une rectitude morale: rectus possède dans ses différents sens le sème central de la droiture, hérité de son sens premier concret de "droit», et sensible dans l'opposition récurrente à prauus, qui désigne aussi bien ce qui est «courbe » que ce qui est moralement déviant ${ }^{46}$. La proximité sémantique d'honestus avec probus est grande elle aussi et les deux termes apparaissent parfois comme d'excellents synonymes; si l'emploi de l'un plutôt que de l'autre semble obéir à des préférences stylistiques, on peut toutefois déceler dans probus la notion d'une qualité globale, d'une excellence générale, alors qu'honestus est orienté vers le domaine plus précis de la morale et du respect des normes ${ }^{47}$. Probus tend aussi à qualifier une personne en se référant à son caractère, alors qu'honestus envisage plutôt l'individu du point de vue de son action concrète ${ }^{48}$.

46 Sur cette antinomie, voir Ter. Heaut. 485. Est rectum ce qui est droit au sens concret, «direct» dans sa façon de parler, «droit» dans sa conduite (PL. Men. 382; TER. Andr. 309; Cic. Att. VI, 4, 1). artifex.

${ }^{47}$ PL. Bac. 759 parle de l'excellence d'un général; Ter. Phorm. 259 de celle d'un

${ }^{48}$ Voir par exemple Ter. Ad. 504 ; Cic. Att. X, 7, 1. 


\section{6. «BEAU, ADMIRABLE» $(\mathrm{S} 5)$}

Avec ce sens, honestus s'écarte de la sphère sémantique de l'honneur et de celle de la morale pour rejoindre le lexique esthétique ${ }^{49}$. Honestus désigne en effet la belle apparence physique qui provoque l'admiration; il signifie "beau», "admirable», et se trouve de ce fait rapproché d'adjectifs comme pulcher, uenustus, speciosus ${ }^{50}$. L'adjectif commence d'être employé en ce sens par Caton, Térence et Lucilius ${ }^{51}$. Le sens est isolé par les ouvrages de lexicographie bien qu'il ne soit pas très répandu puisqu'on n'en trouve qu'une vingtaine d'occurrences dans notre corpus ${ }^{52}$.

\subsection{Une source d'estime et d'admiration}

L'adjectif peut désigner une chose concrète, comme dans le texte du De Agricultura où le mot apparaît pour la première fois :

Encytum ad eundem modum facito uti globos, nisi calicem pertusum cauum habeat: ita in unguen caldum fundito; honestum quasi spiram facito idque duabus rudibus uorsato praestatoque.

«Faites l'encytum de la même façon que les boules, sauf que l'on prenne un récipient creux à fond percé: ainsi, faites couler dans la graisse chaude; faites-le beau comme une spira, et retournez et dressez avec deux baguettes. »

(CAт. Agr. 80, 3 ; trad. Goujard).

L'auteur explique comment faire l'encytum, une sorte de gâteau au fromage cuit dans la friture. Honestus désigne l'aspect extérieur du gâteau, qui a une forme de spirale, comme le gâteau appelé spira décrit plus haut dans le texte. Peut aussi être honestus un vêtement ou bien encore une œuvre d'art, comme un uestibulum ou un ouvrage

${ }^{49}$ L'usage d'un vocabulaire moral dans un sens esthétique apparaît aussi pour des termes comme bonus et malus (PL. Merc. 414; Ter. Andr. 119). Voir le début de l'article d'A. Setaioli, "La notion éthique de kalós / kalón en latin», Prometheus, 34 (2), 2008, p. 160-180, qui montre que, dans la langue grecque, l'évolution du lexique se fait plutôt en sens inverse, de l'esthétique vers l'éthique. p. 262).

${ }^{50}$ Le glossaire $A A$ indique: Honesta facies: speciosa facies (Glossaria latina, vol. 5,

${ }^{51}$ Krostenko, Cicero, Catullus and the Language of Social Performance, p. 32-33, note que l'émergence d'un sens esthétique d'honestus est concomittante des débuts de la valorisation des arts grecs à Rome et de l'adoption par les élites du goût pour l'esthétisme hellénistique. Un tel changement culturel a pu conférer à un adjectif appréciatif un sens esthétique inédit.

${ }^{52}$ TLL VI, 3, col.2912, 42; OLD p. 801. Quelques-unes sont rapidement commentées par A. EsPigares PinILLA, «Claves para la historia de un cultismo : 'honesto'. 1, Antigüedad y Edad Media ». 
littéraire ${ }^{53}$. Mais l'adjectif tend plutôt à être utilisé pour qualifier une personne, comme dans ce passage de Térence où l'esclave Parménon aperçoit une jeune fille:

Facie honesta! Mirum ni ego me turpiter hodie hic dabo

Cum meo decrepito hoc eunucho. Haec superat ipsam Thaidem.

«Quel bel aspect! Pas étonnant si je donne aujourd'hui un vilain spectacle Avec mon eunuque décrépit que j’ai là. Celle-ci dépasse Thaïs elle-même! »

(TER. Eun. 230-231).

On remarque qu'honestus s'oppose encore à la racine turp-, non plus au sens où "honorable» s'oppose à "déshonorant», mais où «beau» s'oppose à «laid». Parménon s'émerveille de la beauté de la jeune fille qui se présente à ses yeux, et la laideur de l'eunuque qu'il doit offrir à l'amante de son maître n'est que plus manifeste. Turpis et honestus apparaissent ainsi comme une véritable paire de contraires dans le domaine moral aussi bien qu'esthétique. Sur le plan physique, est turpis une difformité qui provoque la répulsion, le dégoût $t^{54}$. À l'inverse, est honestus ce qui induit l'admiration. L'un repousse et l'autre attire. La beauté désignée par honestus est en effet une beauté qui provoque l'estime, d'ordre esthétique, de ceux qui la contemplent. C'est d'ailleurs ce trait de sens qui permet de comprendre comment honestus en est venu à signifier «beau». Un autre passage de l'Eunuque nous éclaire à ce sujet. Les personnages parlent de Chéréa, beau jeune homme qui se fait passer pour l'eunuque que Phédria a acheté pour son amica:
PA.: Vbi tu es, Dore? Accede huc. Em eunuchum tibi!
Quam liberali facie! Quam aetate integra!
TH.: Ita me di ament, honestust!
$P_{\text {A. : }}$
Quid tu ais, Gnatho?
Numquid habes quod contemnas? Quid tu autem, Thraso?
Tacent: satis laudant.
«PARMÉNON: Où es-tu Dorus? Viens par ici. Voilà ton eunuque!
Thails: Pour l'amour des dieux, il est beau! - Pa.: Et toi, qu'en dis-tu, Gnathon?
As-tu quelque chose à critiquer? Et toi, Thrason?
Ils se taisent: cela suffit comme louange.»

(TER. Eun. 472-476).

Parménon questionne de manière rhétorique Gnathon et Thrason, en leur demandant s'ils ont quelque chose à mépriser (contemnas),

${ }^{53}$ Respectivement, LucIL. frg. inc. 111 Charpin = 1161 Marx; CIc. Orat. 50; Cael. 40.

${ }^{54}$ Sur cet aspect de turpis dans son sens esthétique, voir Monterl, Beau et laid, p. 270 . 
chez cet eunuque; mais ils n'ont rien à dire, ils ne peuvent que louer (laudant). On voit ici se dessiner un lien entre le sens «beau» et le sens "honorable» d'honestus: l'eunuque est "beau» au sens où il est «esthétiquement digne d'estime». Mais c'est une estime particulière, proche de l'admiration car Gnathon et Thrason restent bouche bée. On le voit aussi dans le premier texte de l'Eunuque que nous citions: quand il voit la jeune fille honesta, l'esclave pousse des cris d'admiration $^{55}$. Les sèmes suivants se dégagent de ces analyses: est honestus ce qui /suscite / une estime / admirative / d'ordre esthétique/.

\subsection{Les qualités de l'aspect extérieur}

Les fondements de l'estime sont ici de nature exclusivement formelle: c'est l'aspect extérieur qui provoque l'admiration. Honestus qualifie, chez une personne, le corps ou une partie du corps comme dans ce fragment de Lucilius:

Cernuus extemplo plantas conuestit honestas

«Se penchant en avant, aussitôt il chausse ses nobles pieds.»

(LuCIL. frg. III, 33 Charpin = 129 Marx).

Il s'agit d'un fragment tiré du livre III qui raconte un voyage du poète vers la Sicile. Il évoque peut-être un personnage rencontré pendant le trajet. Il n'est pas improbable qu'il s'agisse d'un vers humoristique et moqueur, car il paraît curieux d'employer honestus, qui indique une beauté admirable, pour qualifier des pieds. Les qualités formelles de l'objet honestus se trouvent aussi dans les ouvrages littéraires; Cicéron évoque en ces termes la façon dont les Grecs parlent des travaux intellectuels et physiques:

[...] etiam apud Graecos, doctissimos homines, quibus, cum facere non possent, loqui tamen et scribere honeste et magnifice licebat, alia quaedam mutatis Graeciae temporibus praecepta extiterunt.

«[...] même chez les Grecs, qui étaient de grands savants, et qui, même s'ils n'étaient pas capables de les pratiquer, avaient du moins la possibilité d'en parler et d'en écrire avec noblesse et avec élévation. »

(CIc. Cael. 40 ; trad. Cousin).

C'est ici dans le loqui et le scribere que réside la «beauté», dans la tournure des phrases et le style des auteurs. L'adjectif honestus peut aussi s'appliquer à des bâtiments pour indiquer leur beauté architec-

${ }^{55}$ Voir aussi Ter. Andr. 121 où c'est le fait qu'une jeune femme soit honesta qui fait qu'elle est repérée par Simon. 
turale extérieure ${ }^{56}$. Une personne ou un objet est donc honestus /en raison de ses qualités formelles/.

\subsection{Une beauté distinctive et éminente}

La beauté de la personne honesta a ceci de spécial qu'elle donne une position éminente et différencie nettement celui qui la détient. On lit ainsi dans l'Andrienne:

Quia tum mihi lamentari praeter ceteras
Visast, et quia erat forma praeter ceteras
Honesta ac liberali, accedo ad pedisequas,
Quae sit rogo: sororem esse aiunt Chrysidis.
"Comme elle semblait alors se lamenter plus que les autres,
Et qu'elle était plus que les autres d'une apparence
Noble et distinguée, je m'approche de ses suivantes,
Je demande qui elle est: elles me disent que c'est la sœur de Chrysis.»

(TER. Andr. 121-124).

Simon parle de l'amante de son fils et de sa beauté frappante. Puisqu'il a déjà été dit que la forma de la jeune femme est bona (v.119), honesta apporte une précision supplémentaire sur sa beauté physique. Sa forma honesta la distingue de son entourage: Simon a manifestement été impressionné par son apparence physique, et il insiste sur le fait qu'elle surpasse de ce fait les autres (praeter ceteras). Une telle connotation apparaît aussi dans une satire de Lucilius qui évoque la posture d'un coq:

Gallinaceus cum uictor se gallus honeste

Altius <in> digitos primoresque erigit unguis.

«Lorsque le coq vainqueur se dresse noblement, haut sur la pointe de ses doigts et de ses ongles.»

(LuCIL. frg. VIII, 7 Charpin = 300-301 Marx; trad. Charpin).

Le coq se dresse «de belle façon», parce qu'il se hausse (altius erigit), de manière fière. La beauté suggérée par honestus est donc une beauté qui permet à son possesseur d'avoir le dessus sur les autres; c'est une beauté noble, majestueuse, qui confère une position éminente. On retrouve là en négatif un trait propre à turpis, qui désigne une laideur provoquant une ségrégation dégradante ${ }^{57}$. Nous retrouvons ainsi un sème identifié pour le sens social d'honestus : la personne belle a des qualités qui /confèrent une position éminente dans la société/. Ce sème n'est cependant pas toujours actualisé puisqu'on le retrouve dans environ $40 \%$ des occurrences.

\footnotetext{
${ }^{56}$ Pour un monument funéraire (CIL I, $\left.1019=C L E \mathrm{I}, 68\right)$ ou un temple (dans la lex a uicanis Furfensibus templo dicta; CIL I $\left.{ }^{2}, 756,1.11\right)$. Voir aussi CIc.Q. fr. III, 1, 2 et 14.

${ }^{57}$ MonteIL, Beau et laid, p. 270.
} 


\subsection{Conclusion}

Le sémème d'honestus au sens «beau, admirable » est donc le suivant: /Qui suscite / une estime / admirative / d'ordre esthétique / en raison de ses qualités formelles / propres à / conférer une position éminente dans la société/. Ce sens possède des sèmes communs avec «considéré » :

\begin{tabular}{|l|l|}
\hline \multicolumn{1}{|c|}{$\mathrm{S} 1:$ "Considéré, estimé » } & \multicolumn{1}{c|}{$\mathrm{S} 5:$ "Beau, admirable » } \\
/Qui bénéficie/ & /Qui suscite/ \\
/de l'estime,/ & /une estime / admirative / \\
/susceptible d'être/ & /d'ordre esthétique/ \\
/signifiée/ & /en raison de ses qualités formelles/ \\
/par des bienfaits,/ & /propres à/ \\
/et d'une position éminente dans la société// & /conférer une position éminente dans \\
/propre à/ & $\begin{array}{l}\text { la société/. } \\
\text { /être assortie d'influence/. }\end{array}$ \\
\hline
\end{tabular}

Les deux sens possèdent seulement deux sèmes communs: celui de /l'estime/ et de la /position éminente dans la société/. Des sèmes disparaissent et d'autres font leur apparition; en outre le sème générique est différent. Il s'agit d'une polysémie lâche de sens. Un clivage se dessine entre ce sens esthétique et l'ensemble des autres, qui ont une dimension morale plus nette. Cette bipartition morale et physique d'honestus fait pendant à celle de son antonyme turpis ${ }^{58}$.

Ainsi que les commentateurs postérieurs à la disparition de la République l'ont remarqué, honestus se rapproche de pulcher et des autres mots du lexique de la beauté. Servius note ainsi: ueteres [...] honestum pro specioso ponebant et une scholie au v. 132 de l'Eunuque indique maiores nostri honestum dicebant pulchrum ${ }^{59}$. Honestus présente cependant des singularités. À la différence de pulcher, terme le plus fréquent pour signifier la beauté60, honestus n'est que peu utilisé dans son sens esthétique. Il ne porte pas comme uenustus la notion d'une beauté charmeuse, qui séduit de manière raffinée ${ }^{61}$ : honestus attire, mais en provoquant une noble admiration, pas une attraction à connotation érotique ${ }^{62}$. Deux singularités caractérisent donc surtout honestus: il désigne une beauté qui provoque l'estime admirative de l'entourage et confère à son détenteur une position distinctive.

${ }^{58}$ MonteIl, Beau et laid, p. 261-306.

${ }^{59}$ Serv.Aen.I, 289; Scholia Bembina in Terentium, Eun.132 (éd. J.F. Mountford, 1934).

${ }^{60}$ MonteIl, Beau et laid, p. 108.

${ }^{61}$ Ibid., p. 133.

${ }^{62}$ Venustus bénéficie de la proximité avec Vénus: PL. Mos. 161 ; Cic. Pis. 70. 


\section{7. «Moralement Beau, vertueux, honnête » (S6)}

Ce sens est à première vue proche des sens «honorable» et «honnête", mais il possède en réalité une pleine autonomie. En effet, si honestus est ici utilisé comme terme technique de la langue de la rhétorique et de la philosophie, il ne s'agit pas d'un simple emploi dans des domaines spécialisés d'un sens préexistant. Avec ce sens, honestus se charge d'une densité conceptuelle sans précédent et reçoit des sèmes nouveaux. En outre, le mot entre en contact, selon des modalités qu'il

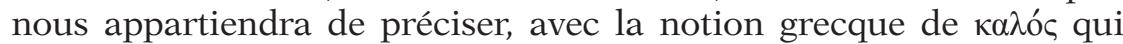
contribue à modifier son sémantisme. Ce sens d'honestus nous offre ainsi l'opportunité d'observer les procédés de constitution d'un vocabulaire philosophique et rhétorique en latin. Dans le domaine philosophique, honestus désigne ce qui est moralement beau, ce qui réalise pleinement la vertu et se conforme idéalement aux normes d'une éthique rationnellement établie. Il s'agit d'un concept employé notamment en contexte stoïcien. La forme substantivée honestum renvoie à la moralité qui représente pour les stoïciens le souverain bien et doit être recherchée pour elle-même. Dans le domaine rhétorique, honestus peut renvoyer à deux objets: la fin du genre délibératif ou un locus du discours. Mais ses traits sémantiques sont alors identiques à ceux de l'emploi philosophique, ce qui ne saurait étonner tant ces deux types de réflexion ont été associés à l'époque républicaine. Nous ne distinguerons donc ces deux emplois que par souci de clarté.

Ce sens apparaît pour la première fois, de manière très fugace, dans la seconde moitié du $\mathrm{II}^{\mathrm{e}}$ siècle, chez Lucilius, et il ne connaît un véritable développement qu'au $\mathrm{I}^{\mathrm{er}}$ siècle, dans les manuels latins de rhétorique et dans l'œuvre philosophique de Cicéron, à une époque où de nombreuses notions romaines reçoivent un nouveau fondement théorique par contact avec le grec ${ }^{63}$. Avant d'en venir à une analyse sémique, un épineux problème de traduction doit être abordé. De toute évidence, honestus prend ici un sens particulier, technique et pourvu d'une valeur doctrinale. Plusieurs traducteurs le restituent donc par "moralement beau», ce qui a l'avantage de faire ressortir le lien de la notion romaine avec le concept grec de $\kappa \alpha \lambda$ óc. Une telle traduction fait cependant problème car elle abolit la proximité, que les lettrés Romains qui ont forgé le concept perçoivent très bien, entre le sens technique d'honestus et son sens traditionnel. Elle survalorise en outre l'aspect esthétique de la notion, qui est de moindre importance

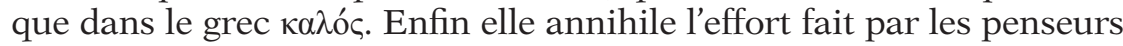

${ }^{63} \mathrm{Ni}$ le De inuentione de Cicéron ni la Rhétorique à Herennius ne présentent l'utilisation d'honestus au sens "moralement beau» comme un emploi inédit, ce qui laisse supposer que ce sens avait commencé à se répandre après Lucilius et avant le début du $\mathrm{I}^{\mathrm{er}}$ siècle. Sur l'approfondissement théorique des notions romaines à cette date, Тноме, Zentrale Wertvorstellungen der Römer, vol. 1, p. 32 et 50-51. 
latins pour intégrer de façon harmonieuse dans la langue latine, par le biais de soigneuses adaptations, un concept emprunté à la pensée grecque. Le sens philosophique d'honestus n'est pas en rupture avec les autres significations de l'adjectif et il ne manifeste nullement sa nouveauté avec brutalité64. C'est pour toutes ces raisons que nous le traduisons le plus souvent par «honnête» ou, moins fréquemment, «moral ». Il s'agit, à dessein, d'une traduction très proche du sens S4 ( «honnête, probe»), afin de rattacher cet emploi d'honestus au sémantisme général et de restituer l'effort fait par les Romains pour intégrer ce sens dans leur lexique, ce que ne peut faire une traduction par "moralement beau». Par souci de clarté, nous conserverons cependant cette dernière appellation au cours de notre analyse.

\subsection{Honestus en contexte philosophique}

\subsubsection{L’adéquation à la vertu éthique}

Ce sens d'honestus s'écarte des autres significations de l'adjectif que nous avons identifiées, ce que les textes eux-mêmes soulignent volontiers. Cela apparaît dans le Lucullus :

Audi contra illos qui nomen honestatis a se ne intellegi quidem dicant (nisi forte quod gloriosum sit in uolgus id honestum uelimus dicere), fontem omnium bonorum in corpore esse, hanc normam, hanc regulam, hanc praescriptionem esse naturae, a qua qui aberrauisset eum numquam quid in uita sequeretur habiturum.

"Écoute d'autre part ceux qui prétendent ne pas même comprendre le mot d' 'honnêteté' (à moins peut-être que ne nous ne voulions dire par 'honnête' ce qui est 'glorieux' pour la foule), qui disent que la source de tous les biens est dans le corps, que c'est là la norme, la règle, le précepte de la nature et que celui qui s'en écarte n'aura jamais de guide dans la vie.»

(CIc. Luc. 140).

Cicéron s'en prend ici aux épicuriens et notamment à la manière dont ils comprennent le terme honestus. Pour Cicéron, ce mot n'a pas le sens de gloriosus, "source de gloire», ce qui est une façon de le séparer de son sens traditionnel d' "honorable», source d'honos. Honestus tombe ici dans le domaine de l'éthique, sans considération d'une rétribution par le prestige ${ }^{65}$. Et il ne porte pas non plus le sens d'«honnête, probe» car Cicéron précise qu'il ne l'entend pas au sens du uolgus; il lui donne un sens philosophique, conceptuellement plus

${ }^{64}$ Voir la remarque que fait Antoine dans le De oratore (II, 61) à propos des livres écrits par les philosophes de honestate: le contenu, dit-il, est d'une grande complexité car il aborde un concept philosophique empêtré mais le titre est parfaitement clair, signe que la notion n'a pas un air étranger.

${ }^{65}$ Voir une semblable distinction entre gloriosus et honestus en Fin. II, 48. Le jugement de la foule est également écarté de l'honestum par Cic. Off. I, 64. 
riche. Cette évolution sémantique est déjà à l'œuvre dans le premier texte où apparaît le sens "moralement beau », le fragment sur la vertu de Lucilius, dont nous ne citons que deux vers:

Virtus, scire homini rectum, utile quid sit, honestum,

Quae bona, quae mala item, quid inutile, turpe, inhonestum.

"La vertu c'est savoir ce qui pour l'homme est droit, utile, honnête,

Quels sont les biens et de même quels sont les maux, ce qui est inutile, honteux, malhonnête. »

(LucIL. frg. hex. inc. 23 Charpin = frg. 1329-1330 Marx).

Dans ce passage, honestus apparaît, de manière alors inédite, dans le cadre d'une réflexion philosophique, d'orientation morale et de nature assez abstraite. Le mot gagne en densité conceptuelle; il est employé à côté d'utile et de rectum qui sont des notions de la pensée éthique. L'honestum est compris comme quelque chose d'un; Lucilius ne parle pas d'un acte ou d'un geste honestus, mais de ce qui est honestus en général. Ce sens désigne un ensemble de qualités morales, mais qui sont éthiquement fondées et philosophiquement valorisées. Cet usage d'honestus fait entrer dans le sémantisme du mot la notion de conformité à la uirtus, qui est ici la vertu éthique,

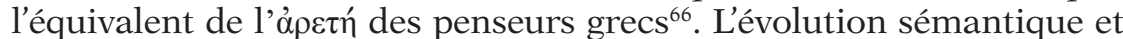
conceptuelle d'honestus va de pair avec celle de uirtus. Si honestus au sens «honorable» ou "honnête» indiquait la conformité à des normes morales collectives, l'adjectif, quand il a son sens «moralement beau », implique en revanche la conformité et l'accomplissement de règles éthiques différentes. Ces normes sont en effet réfléchies et rationnellement fondées. Voilà en quoi consiste une vie honesta pour les stoïciens:

[...] Stoicis consentire naturae, quod esse uolunt e uirtute, id est honeste, uiuere, quod ita interpretantur: uiuere cum intellegentia rerum earum quae natura euenirent, eligentem ea quae essent secundum naturam, reicientemque contraria.

«[...] Pour les Stoïciens c'est l'accord avec la nature, et ils entendent par là vivre suivant la vertu, c'est-à-dire moralement, ce qu'ils expliquent ainsi: vivre avec l'intelligence des événements qui sont produits par la nature, en choisissant ceux qui sont conformes à la nature et en rejetant ceux qui lui sont contraires. »

(CIc. Fin. II, 34; trad. Martha).

Vivre honeste implique d'avoir une compréhension (intellegentia) de la nature et de savoir choisir (eligentem) de manière réfléchie certains comportements. Le De officiis confirme cette intellectualisation de l'honestum puisque ce dernier « repose totalement dans le soin

${ }^{66}$ La uirtus n'est pas auparavant une qualité éthique mais l'adhésion à un code de conduite pratique. Sur l'évolution de la nature de la uirtus, voir infra p. 307 sqq. 
et la réflexion de l'âme ${ }^{67}$. L'honestum découle de la raison naturelle en l'homme ${ }^{68}$. On remarque en outre dans le passage du De finibus que la vie moralement belle est celle qui est guidée par la vertu (e uirtute uiuere). Les normes dont honestus dénote le respect ne sont donc plus celles, relatives, d'une collectivité, mais des normes absolues, indépendantes des circonstances, que l'individu s'impose seul à lui-même ${ }^{69}$. Les qualités morales recouvertes par l'adjectif honestus sont parfois précisées, ce qui permet de mesurer l'écart avec les autres sens du mot. $\mathrm{Au}$ cours de son exposé, Pupius Pison indique que la pratique de la vertu est une des plus nobles activités:

[...] tum prudens, temperata, fortis, iusta ratio reliquaeque uirtutes et actiones uirtutibus congruentes, quae uno uerbo complexi omnia honesta dicimus.

«[...] enfin la raison sous les formes de la prudence, de la tempérance, du courage et de la justice, ainsi que toutes les autres vertus et les actions qui répondent aux vertus; toutes choses que nous faisons tenir en un seul mot, en les appelant 'honnêtes'.»

(Cıc. Fin. V, 58; trad. Martha modifiée).

Honestus est un unum uerbum qui permet de recouvrir les quatre vertus cardinales, prudence, courage, justice et tempérance. L’adjectif est souvent associé à rectum ${ }^{70}$ mais aussi à laudabile ou, plus rarement, pulchrum. Ces termes ne sont jamais réellement synonymes et leur accumulation permet de mettre en relief certains aspects de la notion de beauté morale, comme l'explicite ce texte du De finibus:

Si una uirtus, unum istud quod honestum appellas rectum, laudabile, decorum (erit enim notius quale sit, pluribus notatum uocabulis idem declarantibus), id igitur, inquam, si solum est bonum, quid habebis praeterea, quod sequare? aut, si nihil malum, nisi quod turpe, inhonestum, indecorum, prauum, flagitiosum, foedum (ut hoc quoque pluribus nominibus insigne faciamus), quid praeterea dices esse fugiendum?

«Si seule la vertu, seul ce que tu appelles honnête, droit, louable, convenable (on saura mieux ce que c'est en le désignant par différents termes qui expriment la même chose), si cela seul, dis-je, est un bien, qu'y aura-t-il d'autre à rechercher? Et s'il n'y a pas d'autre mal que ce qui est immoral, malhonnête, inconvenant, corrompu, honteux, repoussant (ici encore, j'utilise plusieurs mots pour rendre cela bien remarquable), que diras-tu qu'il faut fuir, outre cela? »

(CIc. Fin. III, 14).

${ }^{67}$ Cic. Off. I, 79: Honestum autem id quod exquirimus, totum est positum in animi cura et cogitatione.

${ }^{68}$ Cic. Off. I, 107.

${ }^{69}$ KLose, Bedeutung, p. 107 : honestus au sens «honorable » suppose la conformité à un bien défini par le jugement de la collectivité; au sens «moralement beau », la conformité à un bien absolu.

${ }^{70}$ Cic. Parad. I, 9; Fin. II, 55; II, 117; IV, 58; V, 19; V, 66; Off. III, 82. 
Les différents adjectifs permettent de parcourir les diverses facettes de la moralité telle que les stoïciens la définissent: ils ne renvoient pas à des objets variés mais aux traits multiples d'une seule et même réalité (idem declarantibus) ${ }^{71}$. Il est à noter que l'on rencontre une nouvelle fois l'antagonisme honestus / turpis, plus fréquent que le couple honestus / inhonestus. Les deux termes s'opposent donc aussi

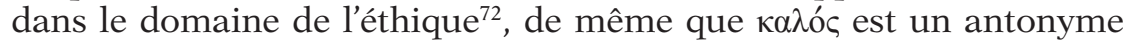
d'aíøxóc dans les textes grecs ${ }^{73}$. On peut dégager de ces différents éléments les sèmes suivants: est honestum ce /qui est conforme / aux normes éthiques de la vertu/.

\subsubsection{Un guide pour la conduite}

Comme pour les sens "honorable» et «honnête», honestus dénotant ce qui est "moralement beau» implique que l'objet considéré serve à orienter le comportement de l'individu. Il s'agit même là d'un trait de sens essentiel à cette signification d'honestus, plus important que pour S2 et S4. Dans le De legibus, Cicéron explique que les gens de bien sont poussés à bien agir par la conscience du bien moral et non par la recherche du profit; de même, la faute doit être évitée non par crainte du châtiment mais par aversion pour le mal:

Tum autem qui non ipso honesto mouemur ut boni uiri simus, sed utilitate aliqua atque fructu, callidi sumus, non boni. Nam quid faciet is homo in tenebris qui nihil timet nisi testem et iudicem?

"Mais alors, nous qui ne sommes pas poussés à être des gens de bien par l'honnêteté même, mais par quelque utilité ou bénéfice, nous sommes des habiles, non des gens de bien. Car que fera dans les ténèbres cet homme qui ne redoute qu'un témoin ou un juge? »

(CIc. Leg. I, 41).

L'honestum est ce qui pousse à agir: nous sommes mis en branle (mouemur) par cet honestum et non par la recherche d'un bénéfice. Cet aspect d'honestus est particulièrement sensible quand l'adjectif est, comme ici, substantivé au neutre: il désigne alors un principe de comportement qui permet de savoir ce qu'il faut faire ${ }^{74}$. Il ne s'agit

${ }^{71}$ Nous ne pouvons considérer, avec F. Klose, qu'honestum n'est que l'un des mots

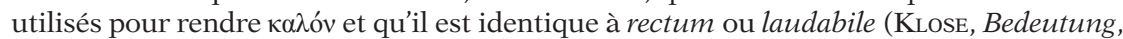
p. 104-105). Sur la fonction sémantique des synonymes, voir THOMAs, «Les fonctions linguistiques de la synonymie lexicale en latin», p. 876-878.

${ }^{72}$ Voir la remarque de MonteIL, Beau et laid, qui note à propos de turpis cette évolution éthique du mot: "la déchéance est subjectivement ressentie par l'individu qu'elle frappe; elle gagne aussi le plan moral et s'identifie au mal, à la bassesse» (p.293).

${ }^{73}$ Autres exemples de l'antagonisme honestus / turpis dans les textes philosophiques: Cic.Leg. I, 55; Fin. III, 11; III, 38; V, 93; Tusc. II, 30; V, 114.

${ }^{74}$ Cic. Fam. IV, 2, 2: quand on est sûr de l'honestum, non potest esse dubium quid faciendum nobis sit, "il ne peut y avoir aucune incertitude sur ce que nous devons faire». 
plus de «l'honneur» mais de la «beauté morale». Les gens de bien sont attirés par l'honestum, qualifié à plusieurs reprises de diligendus, expetendus ou optabilis ${ }^{75}$; l'opposition avec turpis fonctionne ici pleinement puisque le turpe est ce dont on se détourne. Dans la philosophie stoïcienne, l'honestum est propre à constituer le souverain bien, ce à quoi se rapportent toutes les actions de la vie et ce qui représente la fin suprême, comme on le voit dans la diuisio carneadia du livre $\mathrm{V}$ du De finibus:

At uero facere omnia, ut adipiscamur quae secundum naturam sunt, etiamsi ea non assequamur, id esse et honestum et solum per se expetendum et solum bonum Stoici dicunt.

«Par contre, on a dit que tout faire pour acquérir ce qui est selon la nature, quand même on ne l'obtiendrait pas, était une chose et morale et la seule méritant par elle-même d'être recherchée, la seule qui fût un bien; cela, les stoïciens le disent. »

(CIc. Fin. V, 20; trad. Martha).

L'honestum est présenté comme la seule chose qui soit à rechercher (expetendum) et la seule qui puisse porter le nom de bonum. La définition de l'honestum comme seul bien digne d'être recherché est une singularité de la pensée stoïcienne ${ }^{76}$ mais l'honestum entre parfois aussi, dans les autres écoles philosophiques hellénistiques, dans la composition d'un souverain bien de nature mixte ${ }^{77}$. L'inclination pour l'honestum et la capacité de ce dernier à diriger l'action humaine actualisent le sème suivant: /qui guide la conduite/.

\subsubsection{La valeur en soi}

L'attirance vers l'honestum au sens «moralement beau » opère en raison de sa valeur intrinsèque et non parce qu'un bénéfice d'estime peut en être retiré (sens «honorable») ou par conformité aux coutumes de la collectivité (sens «honnête»). Ce trait de sens est perceptible dans le texte cité précédemment, où l'honestum est per se expetendum, ou dans le discours de Cicéron contre Épicure dans le livre II du De finibus:

Ego autem existimo, si honestum esse aliquid ostendero, quod sit ipsum sua ui propter seque expetendum, iacere uestra omnia.

"Quant à moi, je pense que si je parviens à montrer que l'honnête est quelque chose qu'il faut rechercher en soi, pour son essence et pour lui-même, toutes vos théories sont par terre.»

(CIc. Fin. II, 44).

\footnotetext{
${ }^{75}$ Voir CIc. Leg. I, 48; Fin. III, 36; Fin. II, 99.

${ }^{76}$ Tusc. V, 33 réfère cette idée à Zénon et Ariston.

${ }^{77}$ Cic. Fin. II, 34-35.
} 
Cicéron s'apprête ici à démontrer que la moralité ne saurait être un moyen pour obtenir un autre objet. Elle est en elle-même sa propre fin, en raison de sa valeur intrinsèque, ce qui est glosé dans le texte par propter se et sua ui. Ce type de formulation redondante est récurrent dans les textes ${ }^{78}$. Dans le De officiis, l'honestum est défini comme ce qui est louable en soi, même s'il ne fait l'objet d'aucun éloge:

Quibus ex rebus conflatur et efficitur id quod quaerimus, honestum, quod etiamsi nobilitatum non sit, tamen honestum sit, quodque uere dicimus, etiamsi a nullo laudetur, natura esse laudabile.

"C'est de la fusion de ces éléments qu'est formé et créé ce que nous cherchons, l'honnête, qui, même s'il n'était pas renommé, serait cependant l'honnête, et nous avons dit en toute vérité que s'il n'était loué par personne, il serait quand même louable par nature.»

(CIC. Off. I, 14).

La rupture sémantique entre honestum et honos est donc totale, puisque l'honestum se passe de toute marque d'honneur. Est donc honestum ce qui guide la conduite/par sa valeur propre/.

\subsubsection{Une source d'estime admirative}

Si l'honestum ne débouche pas sur une estime d'ordre social ou sur une situation de prestige, cela ne signifie pas qu'il écarte toute évaluation de la part de l'entourage. L'honestum n'est pas recherché pour l'honneur qu'il apporterait mais les contextes actualisent parfois l'idée qu'il peut susciter l'admiration. Le terme honestus, dans la mesure où il est utilisé pour transposer le grec $\kappa \alpha \lambda o ́ \varsigma$ en contexte éthique, contient parfois la notion de beauté. On le perçoit dans ce texte du De finibus:

Non ob eam causam tamen illud dici esse honestum, quia laudetur a multis, sed quia tale sit, ut, uel si ignorarent id homines, uel si obmutuissent, sua tamen pulchritudine esset specieque laudabile.

«Je ne pense pas qu'il faille qualifier un comportement d'honnête pour la raison qu'il est loué par la foule, mais parce qu'il est tel que, même si les hommes l'ignoraient ou n'en parlaient pas, il serait néanmoins louable par sa beauté et son éclat.»

(CIc. Fin. II, 49).

L'honestum possède une beauté (pulchritudo) qui le rend digne d'une estime de nature intellectuelle et esthétique ${ }^{79}$. L'honestum est qualifié de laudabile, bien qu'il ne reçoive pas d'éloge. La notion

${ }^{78}$ CIc. Fin. II, 50 : per se, sua ui, sua sponte, sua natura. Voir aussi CIc. Fin. III, 36; Off. II, 32; III, 33.

${ }^{79}$ Voir aussi le lien entre la pulchritudo et les honesta en Fin. II, 47. 


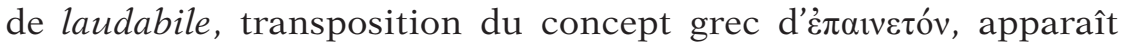
fréquemment comme composant ou équivalent d'honestum. On la retrouve dans ce syllogisme stoïcien:

Concluduntur igitur eorum argumenta sic: quod est bonum, omne laudabile est; quod autem laudabile est, omne est honestum; bonum igitur quod est, honestum est.

«Voici donc par quelles déductions ils prouvent la vérité de ce principe: 'Tout ce qui est bon est louable; or tout ce qui est louable est honnête; donc tout ce qui est bon est honnête'.»

(CIc. Fin. III, 27; trad. Martha modifiée).

Tout ce qui est laudabile est inclus dans l'honestum, mais l'inverse n'est pas nécessairement vrai. Torquatus note en outre que la mineure est accordée sans difficulté (conceditur). C'est donc une identification qui semble élémentaire. Est honestum ce qui est digne d'admiration et d'éloge. Ces éléments nous amènent à dégager un sème: /qui suscite / une estime / admirative/. Il s'agit d'un trait de sens virtuel, présent dans environ $20 \%$ des occurrences.

\subsection{Honestus en contexte rhétorique}

Ladjectif honestus connaît déjà un emploi en contexte rhétorique, quand il possède le sens "honorable » et sert à caractériser un type de cause, le genus honestum ${ }^{80}$. Mais honestus possède deux autres usages dans le domaine de l'éloquence, où il a le sens de "moralement beau, vertueux ». Honestus désigne d'abord une "fin » d'un genre rhétorique, l'objet que l'orateur a en vue. Dans le De inuentione, le terme est utilisé pour désigner la fin du genre démonstratif:

In iudiciis quid aequum sit quaeritur, in demonstrationibus, quid honestum, in deliberationibus, ut nos arbitramur, quid honestum sit et quid utile: nam ceteri utilitatis modo finem in suadendo et in dissuadendo exponi oportere arbitratisunt.

«Dans le genre judiciaire, on cherche ce qui est juste, dans le genre démonstratif, ce qui est honnête, dans le genre délibératif, ce qui est honnête et utile: c'est du moins mon avis, car tous les autres auteurs ont estimé que, lorsqu'on conseillait ou déconseillait quelque chose, il fallait seulement se proposer comme fin l'utilité.»

(CIc. Inu. II, 12; trad. Achard modifiée).

L'orateur qui fait l'éloge d'un individu vise ce qui est «moralement beau» par son discours. Cicéron reprend ici la doctrine aristotélicienne du $\tau \hat{\prime} \lambda$ oc rhétorique et utilise honestus pour rendre la notion grecque de $\kappa \alpha \lambda o_{o}{ }^{81}$. L'éloquence épidictique telle que l'envisage Aristote

${ }^{80}$ Supra p. 123.

${ }^{81}$ ARstT. Rhet. I, 3 


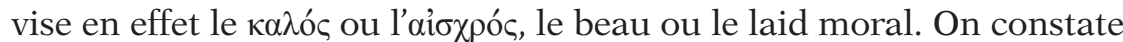
cependant une divergence car l'honestum apparaît aussi chez Cicéron

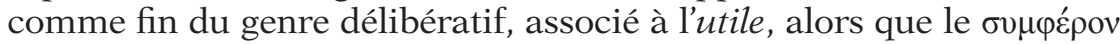
est le seul $\tau \hat{\varepsilon} \lambda$ oc de ce type d'éloquence chez Aristote ${ }^{82}$. Honestus dans un contexte rhétorique présente des traits semblables à ceux de l'adjectif dans le domaine éthique:

Quod aut totum aut aliqua ex parte propter se petitur, honestum nominabimus. [...] Est igitur in eo genere omnes res una ui atque uno nomine amplexa uirtus. Nam uirtus est animi habitus naturae modo atque rationi consentaneus. Quamobrem, omnibus eius partibus cognitis, tota uis erit simplicis honestatis considerata. Habet igitur partes quattuor: prudentiam, iustitiam, fortitudinem, temperantiam.

«Nous appellerons donc honnête ce que l'on recherche, totalement ou en partie, pour ses qualités propres. [...] Dans cette catégorie, tout est englobé sous un seul sens et sous un seul nom, la vertu. En effet la vertu est un comportement en accord avec la mesure et la raison naturelles. Aussi, lorsqu'on aura passé en revue toutes ses parties, on connaîtra le contenu complet de l'honnêteté à l'état pur. Or celle-ci contient quatre parties: la sagesse, la justice, le courage et la modération.»

(CIc. Inu. II, 159).

L'honestum que l'orateur doit viser quand son discours relève de l'éloquence délibérative est quelque chose que l'on recherche (petitur), pour sa valeur propre, propter se. On voit en outre, comme pour l'honestum éthique, apparaître le rapport avec la uirtus. On retrouve enfin, à propos du mot honestas, qui reprend ici honestum, les quatre vertus cardinales: prudence, justice, courage, modération. L'emploi rhétorique d'honestus n'implique donc pas de divergences sémantiques avec l'emploi philosophique. Le second usage de l'adjectif dans le domaine de la technique oratoire concerne les «lieux » du discours, les sources où l'utilisateur va puiser ses arguments ${ }^{83}$. L'honestum est un de ces lieux utilisables par l'orateur. Cicéron explique ainsi comment ruiner une définition formulée par la partie adverse dans un procès:

Item infirmabitur, si turpis aut inutilis esse ostendetur eius descriptionis adprobatio et quae incommoda consecutura sint, eo concesso, - id autem ex honestatis et ex utilitatis partibus sumetur de quibus in deliberationis praeceptis exponemus -; et si cum definitione nostra aduersariorum definitionem conferemus et nostram ueram, honestam, utilem esse demonstrabimus, illorum contra.

«De même on la ruinera en montrant qu'il est immoral ou inutile d'approuver cette définition et quels inconvénients s'ensuivront si on l'approuve cette démonstration sera empruntée aux considérations d'honnêteté et d'utilité que nous exposerons dans les règles concernant le genre délibératif; en compa-

82 ArstT. Rhet. I, 5.

${ }^{83}$ Sur les loci en rhétorique, L. Pernot, "Lieu et lieu commun dans la rhétorique antique », $B A G B, 1986$, p.253-284. 
rant d'autre part la définition donnée par nos adversaires avec la nôtre et en expliquant que la nôtre est exacte, honnête et utile, que la leur ne l'est pas. »

(Cic. Inu. II, 54 ; trad. Achard modifiée).

Dire que la définition que l'on soutient est uera, honesta, utilis revient à recourir à des loci, à employer des prédicats immédiatement utilisables dans différents contextes. Ces loci sont liés au genre délibératif mais peuvent être employés en d'autres endroits ${ }^{84}$. L'honestum est un locus communis, auquel on peut recourir quel que soit l'état de la cause que l'on défend: il peut être utilisé dans l'alternative, dans l'interprétation ${ }^{85}$, etc. Honestus entre ainsi dans une véritable topique. Les manuels de rhétorique du $\mathrm{I}^{\text {er }}$ siècle qui recommandent son usage se situent ici encore dans la lignée des ouvrages grecs et l'honestum

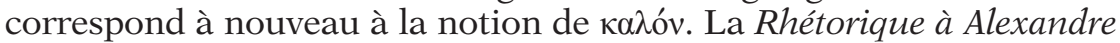
établit de fait une liste des prédicats que l'orateur peut appliquer à des

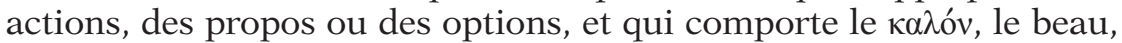
ainsi que le juste, le légal, l'utile, l'agréable, le facile, le possible, le

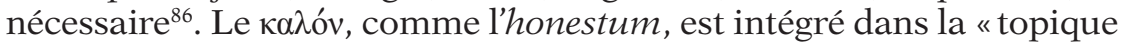

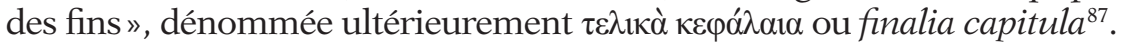

\subsection{Conclusion}

Ces différents traits de sens d'honestus peuvent être synthétisés de la façon suivante: /Qui est conforme / aux normes éthiques de la vertu / et guide la conduite / par sa valeur propre / susceptible / de susciter / une estime / admirative/. Ce sémème est proche de celui des sens «honnête» et «beau» mais nous le rapprocherons plutôt du premier car «honnête » et «moralement beau » ont une relation plus étroite et appartiennent au même champ lexical.

\begin{tabular}{|c|c|}
\hline $\begin{array}{l}\text { S4: «Honnête, probe» } \\
\text { /Qui est conforme/ } \\
\text { /aux normes morales collectives/ } \\
\text { /et parfois/ } \\
\text { /notamment à la droiture/ } \\
\text { /et qui est propre à/ } \\
\text { /guider la conduite/. }\end{array}$ & $\begin{array}{l}\quad \mathrm{S} 5: \text { : Moralement beau» } \\
\text { /Qui est conforme/ } \\
\text { /aux normes éthiques de la vertu / } \\
\text { /et guide la conduite/ } \\
\text { /par sa valeur propre/ } \\
\text { /susceptible/ } \\
\text { /de susciter/ } \\
\text { /une estime/ } \\
\text { /admirative/. }\end{array}$ \\
\hline
\end{tabular}

${ }^{84}$ C'est ce que montre la Rhet. Her. II, 16 et II, 21.

${ }^{85}$ CIc. Inu. II, 77; II, 119.

${ }^{86}$ Rhet. Alex. I, 4.

${ }^{87}$ Hermog., Progymnasmata 12, 10 et 25, 22; Sur les états, 52, 20. Voir Pernot, « Lieu et lieu commun dans la rhétorique antique», p. 261 sqq. 
Ces deux sens d'honestus possèdent le même sème générique, mais plusieurs sèmes spécifiques disparaissent quand d'autres apparaissent. Il s'agit donc d'une polysémie étroite de sens. Honestus arrive, au terme de son évolution, vers un sens exclusivement moral, conceptuellement dense, utilisé dans les langages techniques. Il ne comporte plus de référence à l'estime ou à une position sociale éminente, ce qui le sépare radicalement du sens «honorable». Il se différencie aussi du sens "honnête, probe», car les normes de comportement envisagées ne sont pas celles de la coutume et de la collectivité, mais de la raison et du sujet individuel. En outre, le mot implique l'attraction vers soi en raison d'une valeur propre, propter se, et il s'utilise dans des contextes

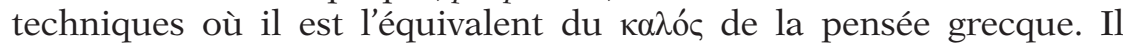
désigne souvent, au neutre substantivé, un principe, et non une simple qualité appliquée à une personne ou une chose. Ce sens d'honestus n'est pas, en outre, sans avoir de relations avec le sens «beau, admirable» puisque les deux partagent les sèmes de /l'estime / admirative/. Il s'agit là d'un développement sémantique spécifique de l'adjectif par rapport à honos: l'évolution d'honestus vers une acception éthique est singulière à ce dérivé, tout comme son utilisation dans des textes techniques, et contribue à l'éloigner de l'aire sémantique recouverte par honos qui appartient davantage au lexique social et politique.

Comme nous l'avons constaté, honestus est utilisé en philosophie et en rhétorique comme équivalent de $\kappa \alpha \lambda o ́ s$, qu'il s'agisse de la notion éthique des stoïciens ou bien de la catégorie rhétorique d'Aristote et des rhéteurs hellénistiques. L'usage d'honestus avec son sens de «beau moral" s'inscrit donc dans un travail de création d'un vocabulaire technique latin à travers la traduction du grec. On trouve, dans un

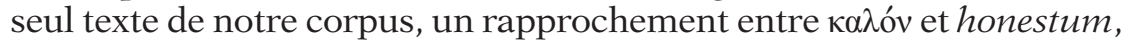
dans une lettre de Cicéron à Atticus, envoyée après que César a traversé le Rubicon:

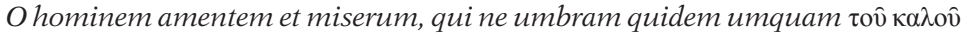
uiderit! Atque haec ait omnia facere se dignitatis causa. Vbi est autem dignitas nisi ubi honestas? honestum igitur habere exercitum nullo publico consilio, occupare urbis ciuium quo facilior sit aditus ad patriam?

«Ô insensé! malheureux! qui n'a jamais vu ne serait-ce que l'ombre du $\kappa \alpha \lambda o ́ v$ ! Et il prétend qu'il fait tout cela pour sa dignité. Où est la dignité si ce n'est dans la moralité ? Est-il donc moral de conserver une armée sans décision publique, d'occuper des villes de citoyens pour se ménager une entrée plus facile dans sa patrie? »

(CIc. Att. VII, 11, 1).

Cicéron reproche à César d'ignorer la moralité et évoque d'abord cette notion sous son aspect grec avant de la restituer en latin. L'usage du mot grec reste donc très strictement limité: il est immédiatement suivi de son équivalent latin et n'apparaît que dans le contexte privé de l'échange épistolaire. Cicéron ne recourt que très peu au mot grec quand il veut se référer au concept de beauté morale et utilise 
de manière presque systématique le terme latin ${ }^{88}$. Le contact entre

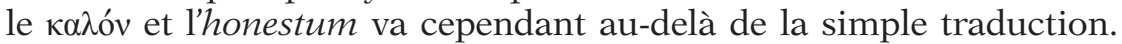
On le voit chez Lucilius, dans le fragment sur la vertu: il y a un véritable transfert de sens et une première tentative de calque séman-

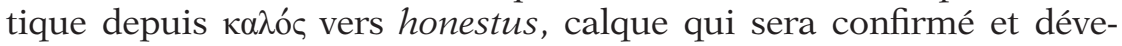
loppé par Cicéron ${ }^{89}$. Le sens de «beau moral» apparaît en effet dans un fragment qui porte la marque du stoïcisme de Panétius ${ }^{90}$, dans le cadre d'un vocabulaire technique, contexte où les calques sémantiques sont fréquents, et chez un auteur parfaitement bilingue, nourri de culture hellénique ${ }^{91}$, et faisant à plusieurs reprises allusion à des philosophes $^{92}$ et à des notions philosophiques grecques ${ }^{93}$. Lucilius et Cicéron se sont tous deux efforcés d'acclimater à Rome la pensée grecque, ce qui passe, entre autres innovations, par un enrichissement du vocabulaire. Honestus possédait en latin des sens bien établis, nous l'avons vu, et il s'enrichit, par le biais de ce contact culturel, d'une partie du sens de $\kappa \alpha \lambda$ ó qui lui a été transférée. Le sens «moralement beau» d'honestus trouve des racines dans le fonctionnement sémantique propre du mot latin mais son émergence en tant que sens autonome ne peut s'expliquer totalement sans le phénomène du calque. Il est donc issu d'une sorte de double paternité, latine et grecque.

Le calque de $\kappa \alpha \lambda o ́ s$ sur honestus a la singularité d'être discret et particulièrement réussi car plusieurs facteurs ont facilité le rapprochement des deux notions. L'évolution sémantique d'honestus dans un sens moral prédisposait le terme à recevoir une acception éthique de plus en plus marquée. Il faut aussi souligner l'existence, avant tout contact

${ }^{88}$ Sur le passage du latin au grec, G.E. DunKel, "Remarks on Code-switching in Cicero's Letters to Atticus ", $M H, 57$ (2), 2000, p.122-129. Il y a une autre occurrence

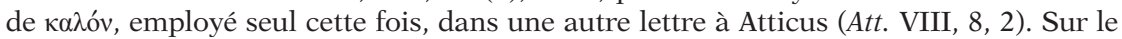
bilinguisme de Cicéron, notamment dans les lettres, M. Dubuisson, «Le grec à Rome à l'époque de Cicéron. Extension et qualité du bilinguisme», Annales ESC, 47 (1), 1992, p. 187-206; B. BALDwIN, «Greek in Cicero's Letters», Acta Classica, 35, 1992, p. 1-17. Sur le phénomène du bilinguisme gréco-latin en général, J. N. Adams, Bilingualism and the Latin Language, Cambridge, Cambridge University Press, 2003 et F. Dupont et E. ValetteCAGnac (éds.), Façons de parler grec à Rome, Paris, Belin, 2005.

${ }^{89}$ Sur le calque sémantique et son usage, voir supra p. 113-114.

${ }^{90}$ Sur cette influence, voir notre étude sur Lucilius au chapitre 16.

${ }^{91}$ Les technographes et ceux qui pratiquent régulièrement la traduction ont souvent recours à ce procédé (Nicolas, Calque, p. 23-24).

${ }^{92}$ Des allusions sont faites à Carnéade, Socrate, Aristippe,... Voir G. Garbarino, Roma e la filosofia greca dalle origini alla fine del II secolo a. C., Turin, Paravia, 1973, p. 487.

${ }^{93}$ Moquerie contre un paradoxe stoïcien (frg. 1284 M.); rapports entre l'âme et le corps (frg 635-643 M.); surtout, on trouve de nombreux éléments de philosophie morale, tels que la critique du luxe, des plaisirs de la table, de la colère,... Nombre de ces idées, cependant, relèvent aussi de la morale romaine traditionnelle, comme le remarque G. Garbarino: «sono spogliate del loro carattere propriamente filosofico, trasferite come sono sul piano della morale pratica, applicate a figure e situazioni della vita d'ogni giorno» (Ibid., p. 517). 
entre les termes, de plusieurs points communs dans leur sémantisme respectif, ce qui facilite le calque sémantique. Le plus évident, et certainement aussi le plus déterminant, est l'existence d'un sens esthétique d'honestus et de $\kappa \alpha \lambda o^{\prime} \varsigma^{94}$. La capacité d'honestus à désigner la beauté de l'apparence extérieure a dû jouer un rôle prépondérant dans le rappro-

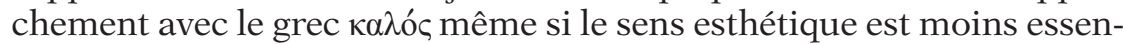
tiel en latin qu'en grec ${ }^{95}$. Chacun des termes possède également un sens moral non marqué philosophiquement: honestus peut qualifier une

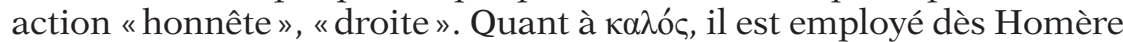
pour qualifier une action ou une personne moralement bonne ${ }^{96}$ et ce sens persiste à l'époque classique où le mot garde sa signification générale, non conceptuelle ${ }^{97}$. Un autre élément se retrouve en grec comme en latin, et a pu exercer une influence: il s'agit de la conception du

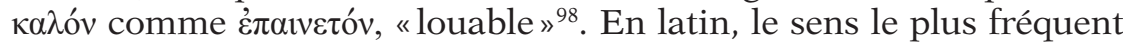
d'honestus est «honorable», "qui mérite l'honos», et la louange est une des formes que peut prendre l'honos ${ }^{99}$. Enfin, les deux termes présentent une dimension sociale qui a pu inciter à les rapprocher. C'est patent pour honestus, qui désigne la capacité à jouir de l'estime

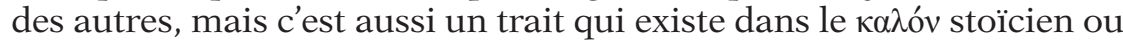
encore chez Aristote ${ }^{100}$. L'ensemble de ces traits communs font que le calque sémantique est très réussi et très discret: l'enrichissement du sens d'honestus est réel mais s'insère parfaitement dans la continuité sémantique du latin. Le choix d'honestum pour restituer к $\alpha \lambda$ óv repose, outre sur ces facteurs sémantiques, sur des motifs culturels et philosophiques qui seront abordés dans une autre partie de cette étude ${ }^{101}$.

${ }^{94}$ C'est ce qui fait du choix d'honestum pour rendre $\kappa \alpha \lambda$ óv un choix « heureux » selon les termes de M.O.Liscu (M.O. Liscu, Étude sur la langue de la philosophie morale chez Cicéron, Paris, Les Belles Lettres, 1930, p.151). Voir aussi A. EsPigares Pinilla, "Claves para la historia de un cultismo: 'honesto'. 1, Antigüedad y Edad Media», p.70 sur le travail de latinisation opéré par Cicéron.

${ }^{95} \mathrm{Il}$ est donc inexact de dire, comme le fait A. R. Dyck, A Commentary on Cicero, De Officiis, Ann Arbor, University of Michigan Press, 1996 (p.69) que Cicéron «sacrifie»

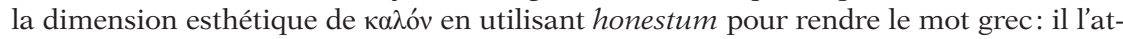
ténue sans l'effacer totalement.

${ }^{96}$ Od. XVII, 381; XVIII, 255.

${ }^{97}$ Voir par exemple Plat. Apol. 34e ou ARstT. EN 1115a.

${ }^{98}$ SVF II, 1003. Cette idée se rencontre notamment chez Chrysippe: SVF II, 296 et

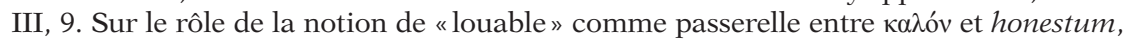
M. Pohlenz, Antikes Führertum. Cicero De Officiis und das Lebensideal des Panaitios,

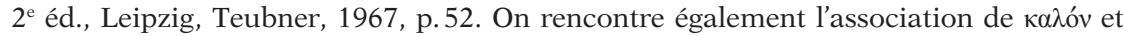
غ̇ $\pi$ alvetóv chez Aristote, EN 1109a, 1127a et 1169a. Sur le «louable» dans l'éthique aristo-

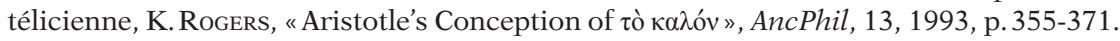

${ }^{99}$ Sur ces honores verbaux, voir infra p. 281-287.

${ }^{100}$ Setaioli, «La notion éthique de kalós / kalón en latin» et A. D. SMith, «Character and Intellect in Aristotle's Ethics », Phronesis, 41, 1996, p. 56-74: l'opinion publique, sans être le critère de l'action, est un indicateur de ce qui est beau (p. 72).

${ }^{101}$ Infra p. 631 sqq. et 659 sqq. 


\section{CONCLUSION GÉNÉRALE SUR HONESTUS}

La structure sémantique d'honestus peut être synthétisée sous forme d'un tableau:

Relations sémantiques entre les différents sens d'honestus

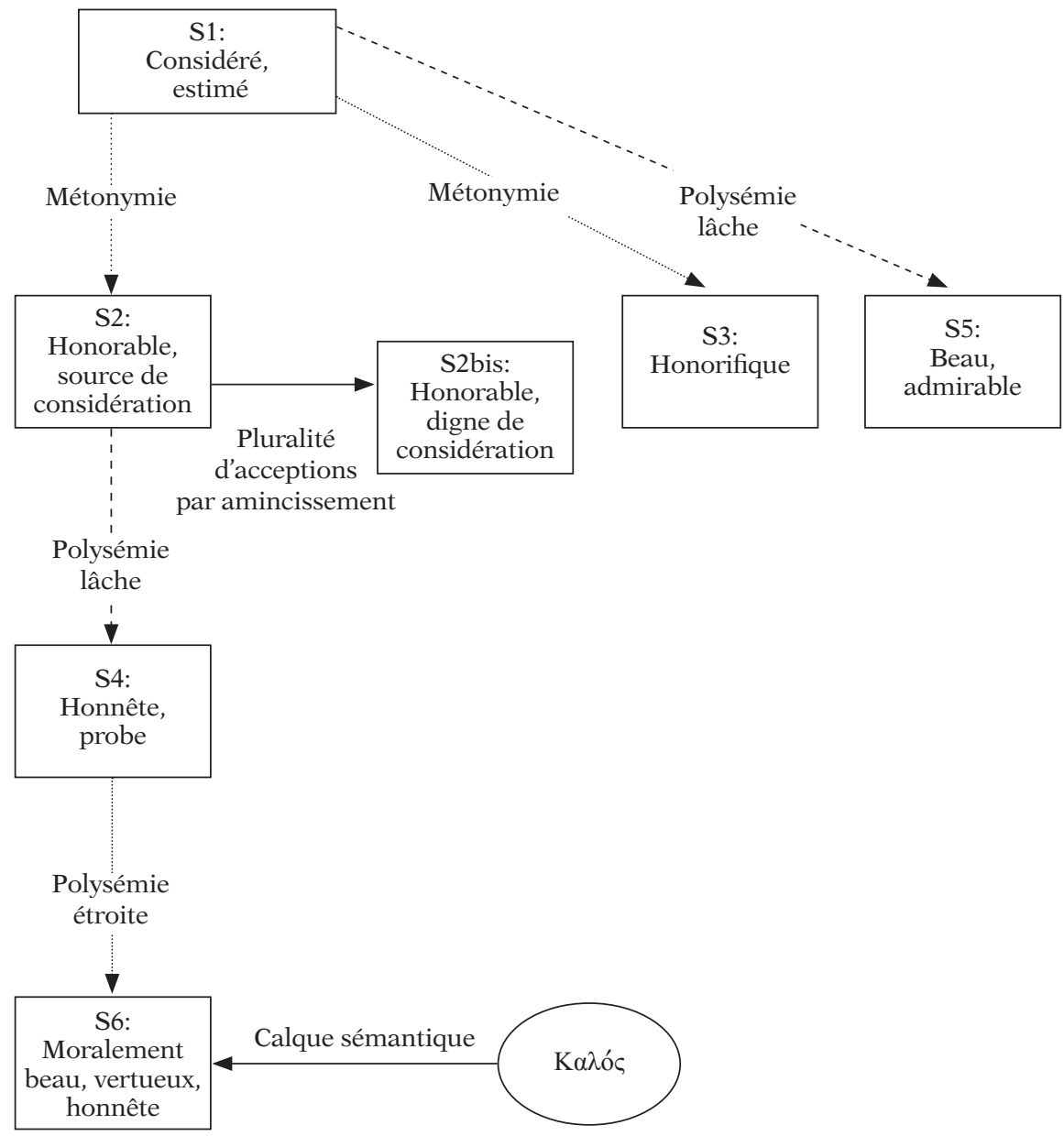

La partie gauche du schéma témoigne de la progressive moralisation d'honestus. Le terme renvoie initialement à une position exclusivement sociale, où le sujet bénéficie de la considération de son entourage et d'une position éminente au sein de la société. L'adjectif est 
alors très proche d'honos ${ }^{102}$. Puis il désigne rapidement le caractère «honorable» d'une personne ou d'une conduite. Ladjectif préserve un lien avec honos, puisqu'il dénote ce qui est source de prestige ou ce qui permet d'être digne de marques d'honneur. Mais il implique alors aussi le respect des normes morales et de la dignité sociale, ce que le sémantisme d'honos, qui indique la détention de mérites plus généraux, ne suppose que de manière partielle et non systématique. L'accent se déplace sur le respect de ces normes avec le sens "honnête", où l'on voit s'abolir l'aspect social et la référence à l'honos "considération". Le souci de l'estime publique n'est plus ce qui dicte le comportement. Enfin, le sens «moralement beau», utilisé en philosophie et en rhétorique, fait encore évoluer le terme vers le domaine de l'éthique, à la

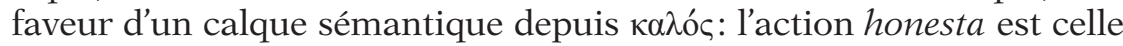
qui obéit à la vertu et vaut par elle-même. La beauté morale a remplacé l'honneur comme principe directeur. L'écart sémantique avec honos est maximal. Honestus passe ainsi d'un sens essentiellement social à un sens essentiellement moral. Le sémantisme d'honestus suit également deux autres lignes d'évolution, d'importance secondaire. La première, qui débouche sur le sens «honorifique», place l'accent sur l'octroi d'une marque d'honneur concrète, l'honos comme hommage. La seconde envisage la beauté comme qualité distinctive et admirable de l'apparence extérieure. Honestus apparaît donc comme un terme à la polysémie riche mais assez concentrée. Les différents sens sont bien reliés les uns aux autres et l'unité du sémantisme est assez nette.

${ }^{102}$ KLose, Bedeutung, p. 100: «Honestus in seinem ursprünglichen Sinn hat gemäß seiner Herkunft von honos keine sittlich-moralische Bedeutung. "Voir aussi les remarques d'H.Bardon sur l'estimation d'ordre social que suppose initialement honestus (BARDON, «L'honnêteté à Rome: du De officiis à La Rochefoucauld»). On ne souscrira pas cependant à l'idée de l'auteur selon laquelle l'adjectif désignait à l'origine «celui qui a exercé une charge officielle» (p. 128). Nous avons vu qu'est honestus celui qui bénéficie de l'honos comme "prestige», et non comme charge. 
CHAPITRE 3

\section{ANALYSE SÉMANTIQUE D'HONESTAS}

\section{INTRODUCTION}

Le substantif honestas est d'utilisation plus récente que les deux termes précédemment étudiés: il apparaît au début du $\mathrm{I}^{\mathrm{er}}$ siècle, dans la Rhétorique à Herennius et dans le De inuentione 1 . Il est possible que l'accroissement d'un écart sémantique entre honos et honestus ait pu conduire à la production d'un substantif plus proche du sens d'honestus. Il est issu de l'adjectif honestus, avec une formation en -tas, suffixe largement employé en latin pour générer des substantifs abstraits désignant une qualité ${ }^{2}$, peut-être par haplologie de *honestitat- $s^{3}$. On rencontre plus anciennement une substantivation d'honestus fondée sur l'emploi du suffixe -tudo (honestitudo) mais la forme ne s'est pas imposée, sans doute en raison de sa morphologie complexe et de son allure technique: les deux seules occurrences se trouvent chez le poète Accius ${ }^{4}$. Le suffixe en -tas est de sens très neutre, et tous les mots qui en sont pourvus désignent des notions assez générales, souvent abstraites et qui «constituent des données fondamentales, objectives et universelles de l'Vrbs, sur les plans juridique, social, économique et politique ${ }^{5}$. Nous avons isolé sept sens différents d'honestas pour l'ensemble de notre corpus. Nous évitons autant que possible, dans la présentation de ces sens, l'utilisation de la traduction «honneur»,

${ }^{1}$ Rhet. Her. I, 5 ; III, 7. Cic. Inu. I, 8; I, 20, etc.

${ }^{2}$ Daude, «Les substantifs abstraits de qualité », p. 246.

${ }^{3}$ C'est l'hypothèse du DELL p. 298. Mais J. Daude souligne, à propos des formations anciennes en -tas sur base consonnantique (libertas, egestas), que "pour tenter de les ramener à la norme: base adjectivale + -itas, on s'est acharné à y supposer des haplologies» (Ibid., p. 248).

${ }^{4}$ Acc. Trag. frg. 8 et 121 (Dangel). Sur cet usage chez Accius, voir J. Dangel, «Les mots suffixés en -tudo chez Accius: étude stylistico-linguistique», in LAVENCY, M. et Longrée, D. (éds.), Actes du ve colloque de linguistique latine, Louvain-la-Neuve / Borzée, 31 mars - 4 avril 1989, Louvain, Peeters, 1989, p.91-102; A. De Rosalia., "I sostantivi in -tūdō in L. Accio », ALGP, 11-13, 1974-1976, p. 255-271. Sur la différence entre le suffixe -tas et -tudo, voir DAUDE, "Les substantifs abstraits de qualité», p. 303: -tudo indique, à date ancienne, une qualité individuelle, subjective; -tas «devait d'abord désigner une qualité en soi, une notion pour elle-même».

${ }^{5}$ Daude, «Les substantifs abstraits de qualité », p. 251. 
même si elle est le plus souvent la plus adaptée, pour les raisons déjà exposées à propos d'honos ${ }^{6}$.

S1: «Considération.»

S2: «Honorabilité, dignité, honneur.»

S3: «Honnêteté, probité.»

S4: «Beauté admirable.»

S5: «Beauté morale, moralité, honnêteté.»

S6: «Marque d'honneur, source d'honneur.»

S7: «Notabilité, personne prestigieuse.»

Le sémantisme du substantif recoupe en bonne partie celui de l'adjectif honestus. Il nous appartiendra de voir quelles différences peuvent s'instaurer entre honestas et la forme substantivée de l'adjectif, honestum. Les sens S1, S2, S4 et S6 d'honestas sont par ailleurs très semblables à plusieurs sens d'honos. Il nous faudra donc aussi établir ce qui peut les différencier.

\begin{tabular}{|c|c|c|c|c|c|c|c|c|}
\hline HONESTAS & $\begin{array}{c}\text { S1: } \\
\text { Considéra- } \\
\text { tion }\end{array}$ & $\begin{array}{c}\text { S2: } \\
\text { Honorabilité } \\
\text { dignité, } \\
\text { honneur }\end{array}$ & $\begin{array}{c}\text { S3: } \\
\text { Honnêteté, } \\
\text { probité }\end{array}$ & $\begin{array}{c}\text { S4: } \\
\text { Beauté } \\
\text { admirable }\end{array}$ & $\begin{array}{c}\text { S5: } \\
\text { Beauté } \\
\text { morale, } \\
\text { moralité, } \\
\text { honnêteté }\end{array}$ & $\begin{array}{c}\text { S6: } \\
\text { Marque } \\
\text { d'honneur }\end{array}$ & \begin{tabular}{|c|} 
S7: \\
Notabilité, \\
personne \\
prestigieuse
\end{tabular} & Total \\
\hline Sisenna & 1 & & & & & & & 1 \\
\hline Rhet. Her. & & 2 & & & & & & 2 \\
\hline Cicéron & 12 & 16 & 6 & 1 & 164 & 2 & 1 & 202 \\
\hline Oratoria & 8 & 9 & 2 & & & 1 & 1 & 21 \\
\hline Rhetorica & & 4 & 1 & 1 & 45 & 1 & & 52 \\
\hline Philosophica & 1 & 2 & 3 & & 118 & & & 124 \\
\hline Epistulae & 3 & 1 & & & 1 & & & 5 \\
\hline Q. Cicéron & 1 & & & & & & & 1 \\
\hline Total général & 14 & 18 & 6 & 1 & 164 & 2 & 1 & 206 \\
\hline
\end{tabular}

Le mot est très majoritairement employé par Cicéron, qui rassemble 202 occurrences sur 206. Le terme fait une apparition tardive dans la langue et se trouve principalement dans les œuvres rhétoriques et philosophiques. On ne le rencontre jamais en poésie et qu'une seule fois dans un texte historique, chez Sisenna. Le sens le plus utilisé est de loin celui de «beauté morale». Mais il y a des occurrences significatives pour "considération» et «dignité». Il apparaît qu'honos et 
honestas ont des sens en commun, mais que les deux mots sont spécialisés dans un sens précis: honos vers l'expression de l'hommage et du prestige, honestas vers celle de la dignité et de la moralité.

\section{1. «CONSIDÉRATION » $(\mathrm{S} 1)$}

Honestas est propre à désigner la considération dont jouit une personne auprès des gens qui l'entourent, la situation d'estime dans laquelle elle se trouve au sein de la société. Ce sens fait pendant à celui de "considéré, estimé » qui est le sens premier d'honestus. Il y a tout lieu de penser qu'il s'agit également du sens premier d'honestas: on le rencontre dès le Pro Quinctio de Cicéron, discours le plus ancien de l'Arpinate qui ait été conservé. Le mot se rapproche ici grandement d'honos, qui peut lui aussi signifier "considération», et des autres termes du lexique de la notoriété7.

\subsection{Analyse sémique}

Honestas désigne la situation de la personne qui bénéficie de l'appréciation positive de son entourage. Évoquant les peines prévues pour infraction à la loi sur les mandats, Cicéron décrit le risque qu'il y a à les enfreindre:

Si hanc ei rem priuatim Sex. Roscius mandauisset ut cum Chrysogono transigeret atque decideret, inque eam rem fidem suam, si quid opus esse putaret, interponeret, ille qui sese facturum recepisset, nonne, si ex eo negotio tantulum in re suam conuertisset, damnatus per arbitrum et rem restitueret et honestatem omnem amitteret?

«Si Sex. Roscius lui avait donné à titre privé mandat de traiter et de s'arranger avec Chrysogonus et, au cas où il le jugerait à propos, d'engager sa parole pour cette transaction; si, après avoir accepté cette mission, Capito avait, à la suite de cette négociation, détourné à son profit la plus petite somme, n'aurait-il pas été condamné à la restitution par l'arbitre qui statue sur le mandat et n'aurait-il pas perdu toute considération?»

(Cic. Rosc. Amer. 114 ; trad. De La Ville de Mirmont).

L'honestas que Capito aurait perdue s'il avait détourné de l'argent désigne la bonne réputation qui aurait été endommagée par une condamnation. Tout le monde aurait connu son forfait et il aurait

${ }^{7}$ Ce sens d'honestas, qui n'est pas repéré par tous les lexicographes modernes, est cependant noté par les grammairiens anciens. Dans le chapitre de differentiis de son Ars, Charisius le rapproche ainsi de termes qui dénotent la notoriété ou l'importance sociale: auctoritas, amplitudo, claritas, claritudo (CHAR. 427, 2). 
perdu l'estime de son entourage. L'honestas est ici proche de la notoriété positive que dénote le mot gloria, comme le souligne Cicéron:

Propterque honestatis et gloriae similitudinem beati, qui honorati sunt, uidentur, miseri autem, qui sunt inglorii.

«Et en raison de la ressemblance entre honneur et gloire on trouve heureux ceux qui sont honorés, malheureux ceux qui ne connaissent pas la gloire. »

(Cic. Leg. I, 32 ; trad. De Plinval).

Le texte montre qu'une réelle similitudo est sentie entre les deux termes; cependant, l'honestas a cette singularité par rapport à la "gloire» de s'accompagner de marques d'honneur, comme le suggère la reprise du substantif par honorati sunt, «ils sont honorés, ils reçoivent des hommages ». En revanche, cette présence des signes d'estime n'est pas exprimée de manière aussi fréquente avec honestas qu'avec honos. Honestas paraît parfois plus proche de l'existimatio, qui ne suppose pas de tels bienfaits, que d'une position où l'on est honoré concrètement $^{8}$. Il s'agit d'un trait de sens virtuel, qui n'apparaît que dans environ $25 \%$ des occurrences. L'honestas est donc une /situation d'estime / susceptible / d'être signifiée / par des bienfaits/.

Les textes parlent d'honestas pour quelqu'un qui possède, outre la considération de ses contemporains, une position élevée au sein de la société, un statut social éminent. Ce statut est notamment lié à l'exercice du pouvoir, comme il apparaît dans un passage du Pro Sulla:

Honestatis enim et dignitatis habuisse nimis magnam iudicatus est cupiditatem; quam si nemo alius habuit in consulatu petendo, cupidior iudicatus est hic fuisse quam ceteri; sin etiam in aliis non nullis fuit iste consulatus amor, fortuna in hoc fuit fortasse grauior quam in ceteris.

"Car on a jugé qu'il avait trop désiré l'honneur et le statut; et si personne d'autre n'a eu cette envie en briguant le consulat, on a jugé qu'il l'avait désiré davantage que tous les autres; mais si quelques autres ont eu également cet amour du consulat, peut-être la fortune fut-elle pour lui plus sévère que pour les autres.»

(Cic. Sull. 73).

Cicéron évoque l'abattement de Sylla lors de son éviction du consulat, qu'il désirait fortement pour le rang qu'il pouvait lui conférer: l'obtention de cette charge suprême octroie de l'honestas, du prestige, qui donne un éclat particulier à Rome. Le terme est d'ailleurs associé à dignitas, qui désigne ici le haut rang. L'estime que désigne l'honestas est donc /associée à une position éminente dans la société/.

${ }^{8}$ Voir Cic. Quinct. 49 où honestas entre en synonymie avec l'expression existimatio integra. 
Cette estime est en outre étayée sur des qualités ${ }^{9}$. Honestas implique que l'excellence morale des individus justifie la faveur publique dont ils bénéficient. Lors de son proconsulat, Gabinius s'est comporté de manière injuste envers les publicains de Syrie, allant jusqu'à mettre en péril leur honestas. C'est pourquoi Cicéron demande au Trésor de leur venir en aide:

Etsi iam multis non potestis, qui propter illum hostem senatus, inimicissimum ordinis equestris bonorumque omnium, non solum bona, sed etiam honestatem miseri deperdiderunt, quos non parsimonia, non continentia, non uirtus, non labor, non splendor tueri potuit contra illius helluonis et praedonis audaciam.

«<Il faut les aider> bien que vous ne puissiez plus rien faire pour nombre d'entre eux, à qui cet ennemi du sénat, cet adversaire passionné de l'ordre équestre et de tous les gens de bien, a fait perdre tous leurs biens et même leur rang, les malheureux, que ni le goût de l'économie, ni leur retenue, ni leur valeur, ni leurs efforts, ni leur éclat n'ont pu protéger de l'audace de ce vorace et de ce brigand.»

(CIc. Prou. 11 ; trad. Cousin modifiée).

L'honestas des publicains, plus précieuse que tous les bona, a été détruite par Gabinius. C'est d'autant plus scandaleux que les chevaliers présentaient toutes les vertus nécessaires pour légitimer cette honestas: parsimonia, continentia, uirtus, labor. L’estime désignée par honestas est donc /fondée sur la conformité / aux normes morales collectives/.

\subsection{Conclusion}

Le sémème d'honestas "considération" (S1) est donc le suivant: /Situation d'estime / associée à une position éminente dans la société, / fondée sur la conformité / aux normes morales collectives /, et susceptible / d'être signifiée / par des bienfaits/.

Ce sens d'honestas est à l'évidence très proche de celui d'honos «considération» (S2), et il est possible que le choix de l'un ou de l'autre terme obéisse à des raisons stylistiques plus que sémantiques. Salluste et Lucrèce, par exemple, n'emploient jamais honestas, alors qu'ils utilisent tous les deux honos pour désigner l'honneur. Honestas est un mot plus récent qu'honos et a de ce fait une allure plus moderne. La terminaison en -tas lui confère aussi un aspect plus savant qu'honos qui relève d'un vocabulaire plus courant. On peut cependant déceler quelques légères divergences sémantiques entre les deux mots. La «considération» désignée par honestas repose moins sur des bienfaits concrets que celle désignée par honos; elle ne suppose pas la détention d'une autorité, sème que nous avions identifié pour honos; enfin, et

${ }^{9}$ Voir l'entrée d'un glossaire latin-grec: honestas: $\tau \mu$ Honestas est ainsi définie comme une considération accordée au mérite. 
surtout, l'honestas est un prestige qui repose sur des qualités morales, alors qu'honos a des fondements beaucoup plus divers ${ }^{10}$. Malgré tout, la proximité des deux mots reste grande. Honestas présente de ce fait les mêmes singularités qu'honos quand on le rapproche de gloria, auctoritas ou dignitas quand ces mots désignent la notoriété ou le rang social ${ }^{11}$.

\section{2. «HoNORABILITÉ, DIGNITÉ, HONNEUR » (S2)}

Ce sens émerge au début du Ir $^{\text {r }}$ siècle et constitue le deuxième sens le plus utilisé, après celui de «beauté morale». Il est à noter qu'avec cet emploi du mot, le lexique latin est très proche de la notion contemporaine d'honneur, qui désigne chez les modernes un droit à la considération de l'entourage ${ }^{12}$. Honestas renvoie en effet au caractère de la personne qui a une prétention légitime au respect et à l'estime des autres, prétention étayée sur des qualités morales. On peut le traduire par "honorabilité», ou, plus souvent, par "dignité», au sens de la dignité morale, ou «honneur». Ce sens d'honestas est lié au sens S2 d'honestus, "honorable», et notamment à son acception "qui a droit à la considération ». Il entre aussi en synonymie avec honos quand ce mot a le sens, peu courant, de «dignité». Honestas se rapproche également de dignitas, pudor et uerecundia.

\subsection{Analyse sémique}

Le mot désigne le caractère de celui qui mérite considération et égards. C'est l'attribut de la personne honesta, «honorable». On ne considère plus l'estime en tant que bien possédé, mais comme objet d'une légitime revendication, comme cela apparaît dans la péroraison du Pro Quinctio:

Itaque hoc te obsecrat, C. Aquili, ut, quam existimationem, quam honestatem in iudicium tuum prope acta iam aetate decursaque attulit, eam liceat ei secum

\footnotetext{
${ }^{10}$ Une autre différence est mise en avant par Lactance, mais elle n'est pas sensible dans les textes de notre corpus: quid est honestas nisi honor perpetuus ad aliquem secundo populi rumore delatus? "Qu'est-ce que le prestige si ce n'est un honneur permanent adressé à quelqu'un par la rumeur populaire? » (LACT. Inst. III, 8, 39). Voir aussi la définition d'Isidore de Séville: Nam quid est honestas nisi honor perpetuus, id est quasi honoris status? "Car qu'est-ce que le prestige si ce n'est un honneur permanent, c'està-dire, en quelque sorte, une solide situation d'honneur?» (IsID. Orig. X, 116). Les deux textes insistent sur le fait que l'honestas est un état de prestige plus durable que l'honos.

${ }^{11}$ On trouve honestas employé en juxtaposition ou coordination avec gloria (Cic.Lael. 84; Fam. V, 8, 4), laus (Cic. Phil. VII, 14), decus (Cic. Phil. VII, 14), auctoritas (Cıc. Inu. II, 33, 11; Flac. 49), dignitas (Cic. Sull. 73).

${ }^{12}$ Sur la conception de l'honneur comme droit à l'estime, voir la réflexion et les définitions de STEWART, Honor, p.12-29: l'honneur y est analysé comme un «claim-right».
} 
ex hoc loco efferre, ne is, de cuius officio nemo umquam dubitauit, sexagesimo denique anno, dedecore, macula, turpissimaque ignominia notetur [...].

"C'est pourquoi, C. Aquilius, il te supplie au nom des dieux de lui permettre d'emporter entière en sortant d'ici cette estime, cet honneur qu'il a apporté presqu'à la fin de sa vie et au terme de sa carrière devant ton tribunal. Que cet homme, dont personne n'a jamais mis en doute le sens du devoir, ne soit pas, alors qu'il est arrivé à sa soixantième année, déshonoré, souillé, marqué de la plus honteuse des flétrissures [...].»

(CIc. Quinct. 99; trad. De La Ville de Mirmont modifiée).

L'honestas de Quinctius n'est pas seulement la considération dont il bénéficie, que Cicéron désigne par existimatio : ce que Quinctius doit pouvoir emporter intact du tribunal n'est pas tant son image publique que son honneur, sa dignité. La fin du texte dit bien que Quinctius ne doit faire l'objet d'aucun affront (ignominia), d'aucune souillure (macula) qui provoqueraient pour lui le dedecus, le déshonneur, c'està-dire l'impossibilité radicale de pouvoir prétendre à l'estime collective $^{13}$. Il doit au contraire préserver la capacité de prétendre à la considération, ce que désigne honestas. Ce sens est visible aussi dans le passage du De inuentione consacré à la manière dont il faut supplier les juges quand l'accusé avoue sa faute:

Postea, si facultas erit, se aut consanguineum aut magnis uiris aut primis amicum esse et amplitudinem suae uoluntatis, nobilitatem generis, eorum qui se saluum uelint dignitatem ostendere, et cetera ea quae personis ad honestatem et amplitudinem sunt adtributa cum conquestione, sine arrogantia, in se esse, ut honore potius aliquo quam ullo supplicio dignus esse uideatur.

«Ensuite, si la possibilité s'offre, il évoquera ses liens de sang ou d'amitié avec des personnages importants ou de premier plan, l'étendue de son dévouement, la noblesse de sa race et le rang de ceux qui veulent son salut, et il dira sans arrogance, tout en suscitant la compassion, qu'il possède toutes les autres marques octroyées à l'honorabilité et au prestige, de manière à paraître plus digne d'être honoré que puni.»

(CIc. Inu. II, 107; trad. Achard).

L'accusé doit mettre en avant les bonnes relations sociales qu'il a établies avec différentes personnes de haut rang, et qui s'expliquent par son amplitudo et son honestas ${ }^{14}$. Or c'est la démonstration de son honestas qui le fera paraître dignus honore: l'honestas est la qualité de celui qui a droit à l'estime et à ses marques concrètes, qui interdit tout affront ou toute condamnation. Honestas désigne donc un /droit légitime à / l'estime / et parfois / aux bienfaits / qui en sont le signe/.

${ }^{13}$ Sur la valeur radicale et intensive de dedecus, Tномаs, Déshonneur et honte, p. 26-33.

${ }^{14}$ Le sens à donner à $a d$ dans l'expression ad honestatem et amplitudinem nous semble être «en retour de» plutôt que "en vue de». 
Notons qu'ici encore le sème des /bienfaits/ est moins prégnant que pour honos: il n'est actualisé que dans environ $50 \%$ des occurrences.

L' «honneur» que signifie honestas suppose la détention de qualités morales essentielles pour légitimer la prétention du sujet à la considération. Le juriste Sulpicius Rufus, qui a su donner des conseils utiles à ses concitoyens, tout comme Muréna, qui a fait preuve d'un courage exemplaire en Asie aux côtés de Lucullus, ont tous deux une summa honestas ${ }^{15}$. Le texte du Pro Quinctio cité supra fait état du remarquable officium de Quinctius, de son respect des obligations sociales et familiales. Et le De inuentione donne plusieurs exemples d'arguments utilisables pour affaiblir l'honestas de l'accusé que l'on veut faire condamner: l'orateur montrera qu'il est cupidus, avide de biens, petulans, incapable de se maîtriser, ou encore turpis, ignoble ${ }^{16}$. On voit resurgir ici un terme, relevant de la sphère du déshonneur et de la répulsion, qui était régulièrement opposé à honestus. De même, la turpitudo est l'inverse de l'honestas, comme le montre ce passage des Catilinaires:

Ex hac enim parte pudor pugnat, illinc petulantia; hinc pudicitia, illinc stuprum; hinc fides, illinc fraudatio; hinc pietas, illinc scelus; hinc constantia, illinc furor; hinc honestas, illinc turpitudo; hinc continentia, illinc lubido; denique aequitas, temperantia, fortitudo, prudentia, uirtutes omnes certant cum iniquitate, luxuria, ignauia, temeritate, cum uitiis omnibus.

«Car de notre côté combat la réserve, du leur la licence; ici la pudeur, là-bas la débauche; ici la loyauté, là-bas la fraude; ici la piété, là-bas le crime; ici la fermeté, là-bas la folie; ici l'honneur, là-bas la turpitude; ici la retenue, là-bas le désir déréglé; enfin la justice, la tempérance, le courage, la prudence, toutes les vertus combattent l'injustice, la débauche, la lâcheté, la témérité, tous les vices. »

(Cic. Catil. II, 25).

Cicéron oppose ici par paires les qualités des consuls (fides, pietas, ...) aux vices des conjurés (fraus, scelus, ...) L'honestas est la qualité morale valorisée, située du côté du bien, tandis que la turpitudo est le comportement blâmé, situé du côté du mal. Elle désigne l'action condamnable de Catilina, qui heurte les normes morales traditionnelles ${ }^{17}$. À l'inverse, l'honestas suppose le respect des règles de conduite fixées par la collectivité. Ces différents éléments actualisent les sèmes de la /conformité / aux normes morales collectives/.

L'opposition d'honestas à turpitudo suggère également que la «dignité» est quelque chose d'attirant et de valorisé, alors que la

${ }^{15}$ CIc. Mur. 21.

${ }^{16}$ CIC. Inu. II, 33.

${ }^{17}$ Sur cet aspect du sens de turpitudo, THomas, Déshonneur et honte, p. 128-129. Sur l'extrait des Catilinaires et sur sa valeur pour l'examen des vertus et des vices à Rome, voir Тноме, Zentrale Wertvorstellungen der Römer, vol. 1 p. 104. 
turpitudo provoque la répulsion et le dégoût. Les textes d'éloquence judiciaire cités précédemment montrent en effet que l'honestas est un bien précieux que l'on cherche à conserver. Lors de son exil, Cicéron regrette de n'avoir pas préféré la mort à la fuite, ce qui aurait préservé son honestas ${ }^{18}$. Les efforts faits pour conserver l'honestas font que cette dernière apparaît comme un but susceptible de guider toute la conduite de l'individu. Cela est confirmé par les textes où elle empêche le sujet de mal se conduire en lui interdisant certains comportements. Cicéron s'en prend en ces termes à Labiénus qui a dit que son oncle était sur le Capitole aux côtés du turbulent Saturninus lors du meurtre de ce dernier:

Equidem hoc adfirmo quod tu nunc de tuo patruo praedicas, neminem umquam adhuc de se esse confessum; nemo est, inquam, inuentus tam profligatus, tam perditus, tam ab omni non modo honestate sed etiam simulatione honestatis relictus, qui se in Capitolio fuisse cum Saturnino fateretur.

«Pour ma part, j'affirme que ce que tu avances à propos de ton oncle, personne ne l'a jamais avoué, jusqu'à aujourd'hui, à propos de lui-même; personne, dis-je, ne s'est trouvé assez avili, assez dépravé, assez abandonné par tout honneur mais aussi par tout semblant d'honneur, pour avouer avoir été sur le Capitole aux côtés de Saturninus.»

(CIc. Rab. Perd. 23).

C'est l'honestas qui doit empêcher quelqu'un d'avouer avoir été aux côtés de Saturninus, premier tribun de la plèbe visé par un senatus consultum ultimum. L'honestas est comparée à une entité qui habite le sujet, et qui peut l'abandonner (relictus). C'est quand elle le quitte que l'action n'est plus guidée de façon correcte et que des méfaits déshonorants sont accomplis. Les contextes actualisent donc l'idée que l'honestas /guide la conduite/. Mais ce sème ne se rencontre que dans un peu moins de la moitié des textes. Il nous faut enfin rappeler que, comme pour honestus au sens "honorable, source de considération", on rencontre pour honestas un emploi dans le domaine rhétorique pour renvoyer à un type de cause particulière: une causa se caractérise par son "honorabilité » quand elle suscite immédiatement la bienveillance de l'auditoire ${ }^{19}$.

\subsection{Conclusion}

Le sens «honorabilité, dignité, honneur» d'honestas peut être analysé de la façon suivante: /Droit légitime à / l'estime / et parfois / aux bienfaits / qui en sont le signe / qui se fonde sur la conformité / aux

${ }^{18}$ Cic. Q. fr. I, $4,4$.

${ }^{19}$ Rhet. Her. I, 5; Cic. Inu. I, 20 et I, 21. 
normes morales collectives / et qui est propre à / guider la conduite/. La relation au sémème de «considération » est la suivante:

\begin{tabular}{|c|c|}
\hline $\begin{array}{l}\qquad \text { S1: «Considération » } \\
\text { /Situation d'estime/ } \\
\text { /associée à une position éminente dans la société/, } \\
\text { /fondée sur la conformité/ } \\
\text { /aux normes morales collectives/, } \\
\text { /et susceptible/ } \\
\text { /d'être signifiée// } \\
\text { /par des bienfaits/. }\end{array}$ & $\begin{array}{l}\text { S2: «Honorabilité, dignité, honneur» } \\
\text { /Droit légitime à/ } \\
\text { l'estime/, } \\
\text { /et parfois/ } \\
\text { /aux bienfaits/ } \\
\text { /qui en sont le signe/, } \\
\text { /qui se fonde sur la conformité// } \\
\text { /aux normes morales collectives/ } \\
\text { /et qui est propre à/ } \\
\text { /guider la conduite/. }\end{array}$ \\
\hline
\end{tabular}

Les sèmes génériques diffèrent: $\mathrm{S} 1$ renvoie à une situation d'estime alors que $\mathrm{S} 2$ désigne un droit légitime à une telle situation. Il pourrait s'agir d'une relation de métonymie, où les sèmes de $\mathrm{S} 1$ seraient tous contenus dans S2, mais le trait de sens de la /position sociale éminente/ n'est pas actualisé avec le sens "dignité, honneur ». Il s'agit donc d'une relation de polysémie lâche de sens. Honestas désigne la conduite de celui qui manifeste un sens de l'honneur qui lui ouvre la considération de son entourage, tandis que S1 renvoie à la position sociale effective de celui qui bénéficie de l'estime et d'un rang élevé.

La différence sémantique est faible entre honestas et honestus quand ce dernier, employé au neutre substantivé, désigne un principe (honestum, «l'honneur»). Il s'agit dans les deux cas d'un guide que l'individu utilise pour orienter sa conduite. La nature d'adjectif substantivé d'honestum lui donne toutefois une capacité plus grande à renvoyer à un principe supérieur, détaché de la personne et relativement abstrait. Honestas peut désigner "l'honneur» en soi, mais est plus volontiers rapproché de l'individu dont il signifie la qualité et le mérite, la «dignité» personnelle. Si on compare honestas à honos avec son sens de "dignité, honneur», la différence sémantique est encore plus faible puisque nous retrouvons les mêmes traits de sens pour l'un et l'autre mot. On peut noter tout au plus que le sème des /bienfaits/ est virtualisé avec honestas alors qu'il est systématique avec honos, ce qui confère à ce dernier un ancrage plus matériel. Il faut en revanche souligner que le sens "dignité» est proportionnellement beaucoup plus fréquent avec honestas qu'avec honos, où il reste marginal. Cela semble indiquer que les deux mots se sont spécialisés vers la désignation d'une aire sémantique précise, pour l'un celle de l'honorabilité, pour l'autre celle du prestige et de ses marques. Les deux termes peuvent aussi être rapprochés de dignitas quand ce mot désigne la «dignité» morale. Dignitas peut en effet renvoyer à la prétention 
légitime d'un individu à un haut rang pour ses qualités morales ${ }^{20}$. La dignitas, comme l'honestas, impose des normes de comportement qui orientent la conduite de l'individu: elle empêche de prendre la fuite au combat ou de raconter des secrets intimes, par exemple ${ }^{21}$. C'est un principe dont il faut écouter la voix ${ }^{22}$. Malgré de nombreuses convergences sémantiques, la dignitas se distingue cependant de l'honestas par quelques aspects. La présence d'obligations contraignantes et absolument impératives est plus importante dans le sémantisme de dignitas que dans celui d'honestas; la dignitas morale consiste à faire ce qui est «digne» de son rang et de son statut plutôt qu'agir pour préserver l'estime et les hommages de l'entourage, ce que dénote honestas; les particularités sémantiques des deux termes paraissent en somme fondées sur leur lien respectif avec dignus / decet et honos. On peut enfin rapprocher honestas "honorabilité» de deux termes qui appartiennent au lexique de l'honneur, pudor et uerecundia. Les deux mots peuvent désigner la capacité d'un individu à guider son action en se conformant aux normes de la morale sociale, ce qui l'amène à contrôler son désir, sa colère ou sa violence, par exemple ${ }^{23}$. La coloration morale de ces termes et le trait sémantique de la normativité les rapprochent d'honestas. Ils désignent cependant un état psychologique particulier et non une situation de dignité comme honestas: pudor et uerecundia renvoient au "sens de l'honneur", à un sentiment qui oriente la conduite, et non à la posture de mérite moral que désigne honestas. En outre, la présence d'un trait de sens concernant l'estime de la collectivité est accessoire pour pudor et uerecundia alors qu'elle est essentielle pour honestas. La synonymie n'est donc pas si grande qu'il y paraît ${ }^{24}$.

\section{3. «HonNÊTETÉ, PROBITÉ » (S3)}

Ce sens d'honestas désigne la conformité d'un individu aux normes morales de son milieu, sans considération des retombées en termes de prestige. Ce sens correspond à celui d'honestus «honnête, probe» (S4) et se rapproche de termes comme probitas ou integritas ${ }^{25}$.

20 Sur l'aspect éthique de la dignitas, Wegenaupt, Die Bedeutung und Anwendung von dignitas, p.34-36; Hellegouarc'H, Vocabulaire, p.407; Piscitelli Carpino, "Dignitas in Cicerone», p.261.Sur la proximité des deux notions, DreXLER, "Dignitas», p.234. Cicéron en vient presque à les identifier l'une à l'autre en Att. VII, 11, 1: «ubi est dignitas nisi ubi honestas? "

${ }^{21}$ CAES. $B G$ VII, 66, 5; Ter. Heaut. 576.

${ }^{22}$ Cic. Verr. I, 27 et 28 : il faut consulere dignitati.

${ }^{23}$ Voir l'analyse de Thomas, Déshonneur et honte, p. 350 sqq. pour pudor et p. 409 sqq. pour uerecundia.

${ }^{24} \mathrm{~J}$.-F. Thomas relève aussi pour pudor et uerecundia un autre sens, celui de « honorabilité, honneur» dont la synonymie avec honestas est plus forte que pour le sens «sentiment de l'honneur», mais qui n'est pas attesté avant Sénèque le Rhéteur (Ibid., p. 330 et 403 ).

${ }^{25}$ Voir l'analyse que donne du terme BARDON, «L'honnêteté à Rome: du De officiis à La Rochefoucauld», p. 131. 


\subsection{Analyse sémique}

Les textes où ce sens apparaît nous permettent de dégager quelques lignes de force. Cicéron reconnaît ainsi à Caton d'Utique la détention de plusieurs qualités morales, parmi lesquelles figure l'honestas:

Finxit enim te ipsa natura ad honestatem, grauitatem, temperantiam, magnitudinem animi, iustitiam, ad omnis denique uirtutes magnum hominem et excelsum.

«La nature elle-même a fait de toi un homme important et éminent, excellemment disposé à l'honnêteté, au sérieux, à la tempérance, à la grandeur d'âme, à la justice, enfin, à toutes les vertus. »

(CIc. Mur. 60).

L'honestas apparaît aux côtés d'autres traits d'excellence, comme la grauitas ou la iustitia, et rejoint le domaine des uirtutes. Le contexte est peu explicite sur sa nature exacte, mais on remarquera qu'elle apparaît en tête de l'énumération, et que cette position inaugurale lui confère une certaine généralité. Elle est aussi un des éléments qui font de Caton un homme important et éminent, magnus et excelsus. Un texte du Pro Flacco permet de voir la nature des normes morales que l'honestas pousse à respecter. Cicéron vient de faire le récit d'une escroquerie à l'emprunt montée par Héraclide, témoin de l'accusation, contre Hermippus, un ami de l'orateur. Héraclide a été condamné, mais ne s'est pas soumis au jugement. Cicéron appelle l'attention des juges sur la malhonnêteté d'Héraclide:

Habetis et honestatem hominis et auctoritatem testimoni et causam omnem simultatis.

«Vous voyez l'honnêteté de cet individu, le poids de son témoignage et toute la raison de sa haine. »

(Cic. Flac. 49).

L'honestas désigne par antiphrase l'absence de probité de la personne considérée. Le terme suppose donc habituellement, à l'inverse, la loyauté.

\subsection{Conclusion}

L'honestas «honnêteté » désigne donc la /conformité / aux normes morales collectives / et parfois notamment / à la droiture / propre à / guider la conduite/. Ce sens paraît issu de celui d' "honorabilité ». 
S2: «Honorabilité, dignité, honneur»

/Droit légitime à/

/l'estime/,

/et parfois/

/aux bienfaits/

/qui en sont le signe/,

/qui se fonde sur la conformité/

/aux normes morales collectives/

/et qui est propre à/

/guider la conduite/.
S3: «Honnêteté, probité»

\section{/Conformité/}

/aux normes morales collectives/

/et parfois notamment/

/à la droiture/

/propre à/

guider la conduite/.

La référence à l'estime ou à ses marques s'efface. La notion évolue ainsi vers la sphère de la morale, coupée de tout lien avec celle du prestige social et donc de l'honos. Les sèmes génériques diffèrent, un sème apparaît, d'autres disparaissent. Il s'agit donc d'une relation de polysémie lâche, avec la particularité que le sème générique de S3 est présent dans S2 comme sème spécifique.

Ce sens est propre à honestas et ne se retrouve pas dans le sémantisme d'honos, ce qui est un indice supplémentaire de l'orientation plus spécifiquement morale d'honestas. Honos se tourne vers l'expression du prestige et des marques d'honneur, alors qu'honestas touche aux fondements de la considération publique, sous la forme de la dignité ou de l'honnêteté. La différence sémantique entre probitas et honestas est extrêmement faible. Les deux termes sont en effet propres à renvoyer à une bonté morale générale, liée à la $u i r t u s^{26}$, mais peuvent aussi se rapprocher plus précisément de la loyauté et de la droiture ${ }^{27}$.

\section{4. «BEAUTÉ ADMIRABLE » (S4)}

Ce sens esthétique d'honestas, désignant la beauté physique, ne se rencontre qu'une seule fois dans notre corpus. Il fait pendant au sens «beau, admirable» qu'on rencontre pour honestus.

\subsection{Analyse sémique}

C'est un texte du De oratore qui nous permet de constater son existence au $\mathrm{I}^{\mathrm{er}}$ siècle:

Rerum enim copia uerborum copiam gignit; et, si est honestas in rebus ipsis, de quibus dicitur, existit ex re naturalis quidam splendor in uerbis.

${ }^{26}$ CIC. Lael. 29.

${ }^{27}$ SALL. Iug. 14, 4. 
"L'abondance des choses donne naissance, en effet, à l'abondance des mots; et, s'il y a de la beauté dans les choses mêmes dont on parle, une sorte de splendeur naturelle s'en répand sur les mots.»

(CIC. De or. III, 125).

Le terme apparaît dans le livre III consacré à l'elocutio, dans le passage où Crassus montre qu'il est nécessaire pour l'orateur d'avoir une culture étendue même quand il ne s'agit que d'orner son discours. La copia des choses engendre la copia des mots et s'il y a de la beauté dans les choses (honestas), il y en aura aussi dans les mots (splendor). L'honestas désigne la beauté des objets évoqués par l'orateur, et le fait que le mot entre en relation de synonymie avec splendor indique qu'il s'agit d'une beauté éclatante, qui provoque l'admiration ${ }^{28}$.

\subsection{Conclusion}

Nous pouvons proposer le sémème suivant, qui est sujet à caution car il ne se fonde que sur une seule occurrence: / Qualité formelle / qui suscite une estime / admirative / d'ordre esthétique/. On le rapprochera du sens «prestige, considération»:

\begin{tabular}{|l|l|}
\hline \multicolumn{1}{|c|}{$\mathrm{S} 1:$ «Considération» } & \multicolumn{1}{|c|}{$\mathrm{S} 4:$ «Beauté admirable» } \\
/Situation d'estime/ & /Qualité formelle/ \\
/associée à une position éminente dans la société/, & $\begin{array}{l}\text { /qui suscite une estime/ } \\
\text { /fondée sur la conformité/ } \\
\text { /aux normes morales collectives/, } \\
\text { /et susceptible/ } \\
\text { /d'être signifiée/ } \\
\text { /par des bienfaits/. }\end{array}$ \\
\hline
\end{tabular}

Les deux sens sont à l'évidence éloignés l'un de l'autre puisqu'ils ne partagent que le sème de /l'estime/. Il s'agit d'une relation de polysémie lâche de sens.

Honestas a ici encore un sens en commun avec honos, qui peut lui aussi signifier "beauté», "majesté». Pour autant qu'il soit possible de différencier les deux termes avec le peu d'occurrences où il nous est donné de les observer, nous remarquons que la beauté désignée par honestas ne suppose pas, comme honos, l'obtention d'une position distinctive. En revanche, comme honos, honestas a la particularité, par rapport à d'autres termes du même lexique tels que pulchritudo, de renvoyer à une beauté qui provoque l'admiration de l'entourage.

${ }^{28}$ La synonymie crée ici un balancement syntaxique entre la protase et l'apodose. Sur cette fonction de la synonymie, voir THomas, «Les fonctions linguistiques de la synonymie lexicale en latin », p. 878-880. 


\section{5. «Beauté morale, Moralité, honNÊTETÉ » (S5)}

La polarisation d'honestas vers le domaine moral est surtout sensible quand le terme désigne la «beauté morale», la pleine réalisation de la vertu éthique, qui vaut en soi, et qui est propre à constituer le souverain bien. Le mot entre ici au contact de la notion grecque de $\kappa \alpha \lambda o^{\prime} v$ et s'enrichit de ce fait de traits inédits qui l'orientent vers l'expression d'une fin éthique et d'une adéquation à des normes morales absolues, détachées du groupe social dans lequel se trouve le sujet. Cicéron

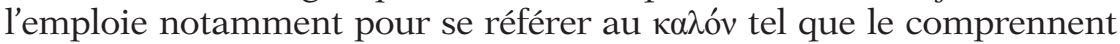
les stoïciens. Le mot est utilisé dans des contextes techniques, en philosophie et en rhétorique, où il vient enrichir la langue des spécialistes romains de ces disciplines. L'honestas ainsi comprise s'écarte radicalement du sémantisme d'honos, mais se rapproche grandement de la forme substantivée d'honestus, l'honestum, le «beau moral». Il nous appartiendra d'évaluer leurs points de convergence et de divergence.

\subsection{Analyse sémique}

\subsubsection{En contexte philosophique}

À la différence de "l'honneur», la «moralité» désignée par honestas renvoie à un ensemble de qualités morales qui ne débouchent sur aucun gain d'honos: l'honestas est une attitude qui se conforme à l'éthique pour elle-même, sans rétribution. Torquatus critique ainsi la manière dont Cicéron a montré que les hommes illustres du passé romain se sont bien conduits par amour de la moralité en elle-même, et non pour obtenir le plaisir; Cicéron, dit Torquatus, a parlé

claris et fortibus uiris commemorandis eorumque factis non emolumento aliquo, sed ipsius honestatis decore laudandis [...].

«en rappelant le souvenir des hommes illustres et vaillants et en faisant l'éloge de leur conduite, en y montrant non pas quelque gain obtenu par là, mais la beauté de la moralité elle-même [...].»

(Cic. Fin. I, 36; trad. Martha modifiée).

Par sa démonstration, Cicéron montre que l'honestas est une fin et non un moyen en vue du plaisir. L'absence de l'estime et de ses bénéfices sociaux est une des singularités de ce sens d'honestas, mais n'est pas suffisante pour le distinguer du sens "honnêteté, probité»(S3). Une première divergence réside dans la nature des normes qui sont observées: l'honnêteté suppose le respect des bonnes mœurs et des coutumes alors que la beauté morale implique une excellence selon les normes éthiques de la vertu. Ces normes sont au nombre de quatre, les vertus cardinales. Au terme d'un exposé à leur sujet, Cicéron peut déclarer:

Habes undique expletam et perfectam, Torquate, formam honestatis, quae tota quattuor his uirtutibus, quae a te quoque commemoratae sunt, continetur. 
«Tu as là, Torquatus, réalisée de toutes parts dans sa plénitude et son achèvement la forme de la moralité: elle tient tout entière dans l'ensemble des quatre vertus, dont, toi aussi, tu as rappelé les noms. »

(Cic. Fin. II, 48; trad. Martha modifiée).

La forma honestatis est tout entière résumée dans ces quatre qualités fondamentales de l'éthique, parfois qualifiées de partes ou fontes honestatis ${ }^{29}$. Cicéron oppose régulièrement cette honestas, faite d'excellence morale, à la uoluptas, qui désigne un plaisir coupable, incompatible avec les exigences de la moralité, au point que l'honestas peut consister précisément à mépriser la uoluptas, pour se tourner vers la vertu ${ }^{30}$. L'honestas peut d'ailleurs parfois devenir synonyme de uirtus quand ce mot a le même sens que l'ỏpetń éthique ${ }^{31}$. Plusieurs sèmes se dégagent de ces analyses: honestas désigne une /conformité / aux normes éthiques de la vertu/.

La qualité morale que désigne honestas a en outre la particularité d'être érigée en principe de conduite et de constituer de ce fait un guide qui oriente l'action de l'individu. Dans l'éthique stoïcienne, l'honestas est la fin de l'existence humaine, le seul terme à quoi tout doit être rapporté. C'est ce que l'homme, en tant qu'être rationnel, doit rechercher. L'honestas attire à soi, suscite l'approbation des hommes, et s'oppose donc à la turpitudo qui provoque le dégoût:

Quis est tam dissimilis homini, qui non moueatur et offensione turpitudinis et comprobatione honestatis?

"Qui est assez peu homme au point de ne pas être ému par l'aversion provoquée par l'immoralité et par l'approbation donnée à l'honnêteté? »

(CIc. Fin. V, 62).

Si la laideur morale repousse et suscite une offensio, l'honestas attire et reçoit la comprobatio. Elle provoque un mouvement au sein de l'individu (moueatur) et dirige de ce fait son action. Le pouvoir directeur de l'honestas apparaît parfois de manière encore plus explicite. Après avoir énuméré différentes figures illustres de l'histoire romaine, Cicéron écrit:

Quae quidem omnia et innumerabilia praeterea quis est quin intellegat et eos qui fecerint dignitatis splendore ductos immemores fuisse utilitatum suarum nosque, cum ea laudemus, nulla alia re nisi honestate duci?

«En voyant toutes ces actions, auxquelles s'en ajoutent une infinité d'autres, est-il possible de ne pas comprendre que ceux qui les ont accomplies, c'est la splendeur d'une chose très noble qui les a guidés et leur a fait oublier leur

${ }^{29}$ CIC. Off. III, 96.

${ }^{30}$ CIc. Luc. 139: cum honestas in uoluptate contemnenda consistat [...].

${ }^{31}$ Cic. Fin. II, 43. 
intérêt personnel; que nous, d'autre part, qui les célébrons, c'est le sentiment de la beauté morale, et pas autre chose, qui nous guide?»

(Cic. Fin. V, 64; trad. Martha).

Les uiri illustres du passé romain n'ont pas visé leur profit personnel ou leur plaisir. Le moteur de leur action réside dans l'honestas, dans la beauté morale par laquelle ils ont été guidés (ductos). C'est cette honestas qui pousse le sujet à faire preuve de vertu et oriente sa conduite. C'est pourquoi il est parfois question de sa force, bien plus grande que celle du plaisir ${ }^{32}$. D'autres images explicitent aussi cet aspect de l'honestas, comme quand elle est la règle (regula) qui dirige la vie et dont il ne faut pas s'écarter ${ }^{33}$. L'excellence morale désignée par honestas apparaît donc comme /ce qui oriente la conduite/.

Or cette valeur de l'honestas a la particularité de ne reposer que sur elle-même. On le voit dans ce texte du Lucullus :

Vnum igitur par quod depugnet relicuum est, uoluptas cum honestate; de quo Chrysippo fuit, quantum ego sentio, non magna contentio. Alteram si sequare, multa ruunt et maxime communitas cum hominum genere, caritas amicitia iustitia reliquae uirtutes, quarum esse nulla potest nisi erit gratuita; nam quae uoluptate quasi mercede aliqua ad officium inpellitur, ea non est uirtus sed fallax imitatio simulatioque uirtutis.

«Il ne reste donc qu'une paire de combattants, le plaisir et l'honnêteté. À ce sujet Chrysippe, autant que je le constate, ne connut pas de grand dilemme. Si l'on suit le premier, de nombreuses choses s'effondrent et surtout la communauté du genre humain, l'affection, l'amitié, la justice et les autres vertus dont aucune ne peut exister si elle n'est pas désintéressée. Car être poussé vers le devoir par le plaisir comme par une sorte de salaire, ce n'est pas la vertu mais une imitation trompeuse de la vertu, un semblant de vertu.»

(CIc. Luc. 140).

Cicéron souligne ici que la uoluptas ne peut constituer une fin de l'action morale, car elle en est alors un salaire, un merces. L'accomplissement des devoirs, l'officium, ne peut être réalisé qu'en raison de l'honestas même que comporte l'exercice de l'action droite. La moralité vaut par sa valeur propre, propter se, et n'implique aucune rétribution; elle doit être absolument gratuita. Il s'agit là d'un sème supplémentaire, celui de la /valeur propre/ que suppose l'honestas, mais qui n'est actualisé que dans un peu moins de la moitié des occurrences du sens «beauté morale».

Il faut enfin ménager une place à un autre sème virtuel qui accentue la singularité de ce sens par rapport à celui d' "honnêteté, probité", et que l'on trouve dans environ $40 \%$ des occurrences. Il est fait état

${ }^{32}$ CIC. Fin. II, 81.

${ }^{33}$ CIc. Luc. 140 hanc normam, hanc regulam, hanc praescriptionem esse naturae. Voir aussi Off. III, 74 où il y a identité entre l'utilitatis regula et l'honestatis regula. 
à plusieurs reprises du caractère admirable de l'honestas, voire de sa beauté, trait qui rapproche le mot de la notion grecque de $\kappa \alpha \lambda$ óv, plus nettement située sur un terrain esthétique. Les textes évoquent ainsi le splendor honestatis ou bien associent honestas et magnificentia pour créer l'idée d'une apparence brillante et remarquable ${ }^{34}$. Tout comme honestus, honestas est associée à la notion de laudabile, qui implique bien que c'est une qualité digne d'estime, même si elle ne nécessite aucune rétribution de ce genre ${ }^{35}$. L'honestas est la chose praeclarissima, plus brillante encore que la gloire qui est, à ses côtés, réduite à une ombre ${ }^{36}$. L'honestas est ainsi une excellence morale /propre à / susciter / une estime / admirative/.

\subsubsection{En contexte rhétorique}

Dans le domaine de la technique oratoire, honestas est un concept qui possède les mêmes traits de sens que ceux identifiés en contexte philosophique, mais connaît deux emplois particuliers. Tout comme l'adjectif honestus, il peut désigner la «fin» d'un genre rhétorique ou bien renvoyer à un locus emprunté au genre délibératif et employé dans divers types de causes. Le De inuentione fait de l'honestas la fin du genre démonstratif, retraçant la doctrine aristotélicienne du кaخóv comme fin du genre épidictique. Le terme apparaît ainsi dans les Topiques, ouvrage directement inspiré d'Aristote:

Laudationis finis honestas, de qua item est ante dictum.

«La fin de l'éloge est l’honnêteté, dont il a été question précédemment. »

(CIc. Top. 91).

Mais l'originalité cicéronienne dans la doctrine des fins du discours, déjà notée à propos de l'usage d'honestum comme but du genre délibératif, réapparaît avec le mot honestas, qui est associée à l'utilitas ${ }^{37}$. Avec ce sens, honestas continue d'être opposée à turpitudo ${ }^{38}$. Le second emploi d'honestas dans la langue technique de l'éloquence concerne la topique des fins et est exactement parallèle à l'usage qui est fait de l'adjectif honestus en ce sens. Quand l'orateur doit défendre une définition multiple, il peut recourir à des arguments propres à ce type de cause mais aussi à des lieux communs:

Deinde locus communis, per quem facti utilitas aut honestas adaugetur.

${ }^{34}$ Cic. Fin. V, 22.

${ }^{35}$ Voir Cic. Fin. I, 36; V, 64; V, 73.

${ }^{36}$ Cic. Fin. V, 69. Sur le lumen de l'honestas, voir aussi Cic. Tusc. II, 58. Un lien fort est aussi établi entre le pulcherrimum et l'honestas par Cic. Off. III, 19.

${ }^{37}$ Cic. Inu. II, 156.

${ }^{38}$ Cic. Inu. II, 157. 
«< Il faut enfin recourir > au lieu commun qui consiste à augmenter le caractère utile et honnête du fait. »

(CIc. Inu. II, 55).

L'honestas est, comme l'utilitas, un lieu commun que l'orateur utilisera pour qualifier l'acte qu'il défend. L'honestas en contexte rhétorique possède les mêmes traits de sens que dans les textes philosophiques. Elle désigne des qualités morales conformes à la vertu, propres à orienter la conduite de l'individu ${ }^{39}$. On retrouve aussi l'idée que l'honestas vaut pour sa valeur propre, comme dans ce passage des Partitions oratoires:

Horum partim, propter se honestate ipsa, partim commoditate aliqua expetuntur; honestate, ea quae proficiscuntur ab his uirtutibus, de quibus paullo ante est dictum, quae sunt laudabilia ipsa per sese; commoditate autem aliqua, quae sunt in corporis aut in fortunae bonis expetenda.

«Parmi ces biens, les uns sont recherchés pour eux-mêmes, en raison de leur honnêteté propre, les autres pour quelque avantage qu'ils procurent; on recherche pour leur honnêteté les biens qui relèvent de ces vertus dont j'ai parlé un peu avant et qui sont louables en eux-mêmes; pour un avantage qu'ils procurent, ceux des biens du corps ou de la fortune qui méritent d'être recherchés. »

(Cic. Part. 87).

La valeur propter se des objets distincts par leur honestas est nettement affirmée, tout comme le rapport de cette dernière aux uirtutes, le fait qu'elle est un objet digne d'être recherché, ou qu'elle possède un aspect admirable et louable.

\subsection{Conclusion}

De ces différents usages se dégage le sémème suivant: /Conformité / aux normes éthiques de la vertu / qui oriente la conduite / par sa valeur propre / susceptible de / susciter / une estime / admirative/. Le sémantisme d'honestas s'est donc orienté vers le domaine de l'éthique pour désigner un bien moral absolu. Le sens «beauté morale» peut être rapproché de celui d' "honnêteté» (S3).

\begin{tabular}{|l|l|}
\hline \multicolumn{1}{|c|}{ S3: «Honnêteté, probité» } & \multicolumn{1}{c|}{$\begin{array}{c}\text { S5: «Beauté morale, moralité, } \\
\text { honnêteté » } \\
\text { /Conformité/ }\end{array}$} \\
$\begin{array}{l}\text { /Conformité/ } \\
\text { /aux normes morales collectives/ } \\
\text { /et parfois notamment/ } \\
\text { /à la droiture/ } \\
\text { /propre à/ }\end{array}$ & $\begin{array}{l}\text { /qui oriente la conduite/ } \\
\text { /par sa valeur propre/ }\end{array}$ \\
/guider la conduite/. & $\begin{array}{l}\text { /susceptible de } \\
\text { /susciter/ } \\
\text { /une estime/ } \\
\text { /admirative/. }\end{array}$ \\
\hline
\end{tabular}

${ }^{39}$ CIc. Inu. II, 173-174. 
Les sèmes génériques sont identiques, ce qui crée une réelle proximité entre les deux sens. Cependant, des sèmes spécifiques s'effacent de S3 à S5 pendant que d'autres apparaissent. Il s'agit donc d'une polysémie étroite de sens. L'influence de la notion grecque de $\kappa \alpha \lambda o ́ v$ est réelle ici encore, et l'on peut soupçonner l'existence d'un calque sémantique, comme pour honestus au sens «moralement beau ». Cependant, il est aussi envisageable qu'honestas ait pris cette signification par contagion avec honestum, qui est d'usage plus ancien pour désigner le souverain bien des stoïciens. Honestas s'écarte ici nettement d'honos car ce dernier ne possède pas ce sens fortement éthique. L'existence d'une divergence sémantique entre honestas et honestum quand les deux mots renvoient à la beauté morale est difficile à établir, au point qu'ils apparaissent dans certains textes comme totalement interchangeables. C'est le cas par exemple dans ce passage du Lucullus :

Sapiensne non timeat ne patria deleatur, non doleat si deleta sit? Durum, sed Zenoni necessarium, cum praeter honestum nihil est in bonis, tibi uero Antioche minime, cui praeter honestatem multa bona, praeter turpitudinem multa mala uidentur, quae et uenientia metuat sapiens necesse est et uenisse doleat.

«Le sage ne craindrait pas la destruction de sa patrie, ne souffrirait pas si elle était détruite? Cela est dur, mais c'est nécessaire pour Zénon puisque il n'y a selon lui pas d'autre bien que l'honnête, mais pour toi Antiochus ce n'est pas vrai du tout, toi qui juges qu'il y a de nombreux biens outre l'honnêteté et de nombreux maux outre l'immoralité, dont il est nécessaire que le sage craigne la venue et souffre quand ils sont là.»

(CIC. Luc. 135).

Le sémantisme d'honestum et d'honestas est totalement similaire et les deux mots sont employés dans des structures identiques, praeter honestum et praeter honestatem. L'usage d'honestas à la place d'honestum ne semble dû qu'à la volonté d'éviter une répétition. C'est une raison stylistique, le souci de uariatio, qui gouverne ici le choix des mots $^{40}$. Cicéron semble aussi utiliser plus volontiers honestas qu'honestum quand il doit employer les cas obliques ${ }^{41}$. Il recourt par ailleurs plus souvent à honestum qu'à honestas pour signifier la «beauté morale ». Cet usage privilégié d'honestum est peut-être motivé par la volonté de restituer en latin ce qui est en grec un adjectif subs-

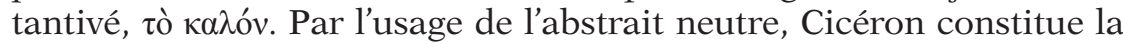
beauté morale en concept philosophique plus fermement qu'il ne le ferait avec honestas. La tendance de la langue à employer des adjectifs substantivés plutôt que les substantifs abstraits correspondants a dû

${ }^{40}$ Voir un semblable effet en Cic. Fin. II, 68; Tusc. II, 46. Cicéron recourt de même alternativement à decus et decorum. Sur cette alternance, voir R. Poncelet, Cicéron traducteur de Platon. L'expression de la pensée complexe en latin classique, Paris, De Boccard, 1953, p. 293.

${ }^{41}$ Ibid., p. 179. 
jouer également. Il est possible néanmoins d'observer quelques légères divergences sémantiques dans les emplois des deux mots, mais cela ne touche qu'à des nuances de sens très localisées. De façon générale, le terme honestas est utilisé dans des contextes variés, pour désigner la beauté morale comme qualité, lorsqu'elle est incarnée par des individus, alors qu'honestum a une dimension plus conceptuelle et plus technique. Il est par exemple question de l'honestas manifestée par le sénat quand ce dernier a refusé de racheter des prisonniers romains détenus par Hannibal, alors que Cicéron emploie honestum quand il s'agit de parler de la «beauté morale» en tant que souverain bien ou composant du souverain bien, comme cela apparaît dans la diuisio carneadia par exemple ${ }^{42}$.

\section{6. «MARQue D'HONNEUR» $(\mathrm{S} 6)$}

Ce sens d'honestas, dont il n'existe que deux occurrences, désigne l'objet par lequel est signifiée l'estime de la collectivité, autrement dit la «marque d'honneur». Le mot n'est utilisé qu'au pluriel, nombre qui facilite l'émergence d'un sens concret d'honestas. Honestas rejoint ici le sémantisme d'honos, au point de revêtir le sens premier de ce terme.

\subsection{Analyse sémique}

Ce sens d'honestas apparaît pour la première fois au moment de la miseratio du Pro Murena:

Nolite, per deos immortalis! iudices, hac eum cum re qua se honestiorem fore putauit etiam ceteris ante partis honestatibus atque omni dignitate fortunaque priuare.

«Ne permettez pas, juges, par les dieux immortels, qu'en plus de cette charge, par laquelle il pensait gagner en prestige, il soit privé aussi des autres honneurs acquis jadis, de toute dignité et de tout bien.»

(Cic. Mur. 87).

On retrouve le thème de l'honestas mise en péril par le procès, mais l'usage du mot au pluriel interdit de penser qu'il s'agit du "prestige» ou de la "dignité » de Muréna. L'expression ante partis va dans le sens d'un bien concret que l'accusé a obtenu autrefois et qu'il risque alors de perdre. Il s'agit des différentes marques d'honneur qu'il a accumulées dans le temps, signes de l'estime publique. L'autre texte où apparaît ce sens d'honestas est tiré des Partitions oratoires:

Nam et, si quid effici non potest, deliberatio tollitur, quamuis sit utile et, si quid necesse est [...] id est relicuis et honestatibus in ciuili ratione et commodis anteponendum.

${ }^{42}$ Comparer Cic. Off. III, 114 et Cic. Fin. V, 19-20. 
«En effet, si une chose ne peut être réalisée, quelque utile qu'elle soit, la délibération n'a pas lieu, et, si elle est nécessaire [...], il faut la préférer aux autres honneurs en politique et aux avantages. »

(Cic. Part. 83; trad. Bornecque modifiée).

Le texte fait état de la necessitudo qui oblige à choisir une chose quelles que soient les circonstances. Les honestates apparaissent comme des avantages matériels octroyés dans un cadre public et liés de ce fait à l'exercice d'un pouvoir ou au moins d'une influence. Le mot renvoie à un objet recherché et valorisé, propre à conférer un ascendant dans la société.

\subsection{Conclusion}

Nous pouvons proposer pour ce sens d'honestas le sémème suivant: /bienfait / signe d'estime / octroyé en reconnaissance / de certains mérites / qui confère une position éminente dans la société/. Ce sens paraît issu de celui de «considération» (S1):

\begin{tabular}{|c|c|}
\hline S1: «Considération» & S6: «Marque d'honneur» \\
\hline $\begin{array}{l}\text { /Situation d'estime/ } \\
\text { /associée à une position éminente dans la société/, } \\
\text { /fondée sur la conformité/ } \\
\text { /aux normes morales collectives/, } \\
\text { /et susceptible/ } \\
\text { /d'être signifiée/ } \\
\text { /par des bienfaits/. }\end{array}$ & $\begin{array}{l}\text { /bienfait/ } \\
\text { /signe/ } \\
\text { /d'estime/ } \\
\text { /fondé sur certains mérites/ } \\
\text { /qui confère une position éminente } \\
\text { dans la société/. }\end{array}$ \\
\hline
\end{tabular}

De S1 à S6 se produisent un effacement de certains sèmes et un changement de sème générique. Il s'agit donc, dans la typologie de R. Martin, d'une polysémie lâche de sens. Cependant, le sens «marque d'honneur » a la particularité d'être formé de sèmes qui sont pratiquement tous contenus dans S1. On note simplement une redistribution de l'ordre des sèmes à l'intérieur du sémème. Il s'agit en somme du cas inverse de la «métonymie complexe» que nous avions observée pour les sens $\mathrm{S} 1$ et $\mathrm{S} 2 \mathrm{~d}^{\prime}$ honos $^{43}$. Nous proposons de qualifier ce cas de figure inédit de "métonymie inverse complexe».

Ce sens d'honestas rejoint le sens premier d'honos, «marque d'honneur, hommage », ce qui indique que la sphère de la dignité et celle du signe d'estime finissent toujours par se rencontrer; honos possède en effet lui aussi un sens "dignité, honneur », très semblable au deuxième sens d'honestas. Cependant chacun de ces termes n'empiète que de manière très restreinte sur le sémantisme fondamental de l'autre: il n'y a que deux occurrences du sens «marque d'honneur» pour 
honestas, et six du sens "honorabilité, dignité» pour honos. Le petit nombre de textes où honestas signifie "marque d'honneur» rend difficile une comparaison sémantique avec honos; on peut noter tout au plus qu'honestas ne s'emploie en ce sens qu'au pluriel et ne paraît pas indiquer l'obtention d'une autorité ou d'une influence sur l'entourage comme c'est le cas d'honos.

\section{7. «NotABilité, PERSONNE CONSIDÉRÉE » S7}

Ce sens d'honestas ne se manifeste qu'une seule fois dans notre corpus mais il constitue bel et bien un sens autonome. Honestas ne renvoie pas à la situation ou à la qualité d'un individu, mais à l'individu lui-même, à une personne prestigieuse. Afin d'essayer de restituer son lien avec le sémantisme général d'honestas, on peut le traduire par "notabilité», mot qui possède en français ce sens de "personne notable, considérée».

\subsection{Analyse sémique}

Le terme apparaît dans le Pro Sestio, dans un passage où Cicéron précise le sens qu'il entend donner à l'adjectif popularis:

Vtra igitur causa popularis debet uideri: in qua omnes honestates ciuitatis, omnes aetates, omnes ordines una consentiunt, an in qua furiae concitatae tamquam ad funus rei publicae conuolant?

"Laquelle de ces deux causes doit être considérée comme la cause populaire, celle où toutes les notabilités de l'État, tous les âges, tous les ordres sont unanimes, ou bien celle où les furies surexcitées s'élancent à tire d'aile comme à l'enterrement de la République?»

(CIc. Sest. 109; trad. Cousin).

Cicéron montre ici que la causa popularis n'est pas celle des agitateurs, mais celle où se retrouvent les individus les plus sérieux ainsi que les différents ordres qui composent la ciuitas. Cicéron indique notamment que les honestates sont du côté de cette causa, et il renvoie par là aux personnages importants de la cité qui se distinguent par leur notoriété et leur rang élevé. Ces personnes sont connues, appréciées et ont un statut social important. En outre, elles s'opposent aux furiae révolutionnaires qui s'en prennent à la res publica et ne savent faire preuve de modération et de raison.

\subsection{Conclusion}

Ces quelques données nous amènent à dégager le sémème suivant: honestas désigne ici une /personne / qui bénéficie / d'une situation d'estime / associée à une position éminente dans la société / fondée sur la conformité aux normes morales collectives / et susceptible / d'être 
signifiée / par des bienfaits/. Ce sémème est lié à celui d'honestas signifiant « considération» :

\begin{tabular}{|l|l|}
\hline \multicolumn{1}{|c|}{$\mathrm{S} 1:$ «Considération» } & $\begin{array}{l}\mathrm{S} 7: \text { « Notabilité, personne prestigieuse » } \\
\text { /Personne/ qui bénéficie/ } \\
\text { /d'une situation d'estime/ } \\
\text { /associée à une position éminente dans } \\
\text { /Situation d'estime/ } \\
\text { /associée à une position éminente dansé/, } \\
\text { la société/, } \\
\text { /fondée sur la conformité/ } \\
\text { /aux normes morales collectives/, } \\
\begin{array}{l}\text { /fondée sur la conformité/ } \\
\text { /aux normes morales collectives/, } \\
\text { /d'être signifiée/ } \\
\text { /par des bienfaits/. }\end{array} \\
\text { /et susceptible/ } \\
\text { /d'être signifiée/ } \\
\text { /par des bienfaits/. }\end{array}$ \\
\hline
\end{tabular}

Les sèmes génériques différent, mais la totalité des sèmes de $\mathrm{S} 1$ se retrouve dans S7, avec le même ordre, ce qui indique une relation de métonymie simple. La "personne notable » est en effet la personne qui bénéficie de la «considération».

\section{CONCLUSION GÉNÉRALE SUR HONESTAS}

La structure sémantique d'honestas est assez semblable à celle d'honestus.

Relations sémantiques entre les différents sens d'honestas:

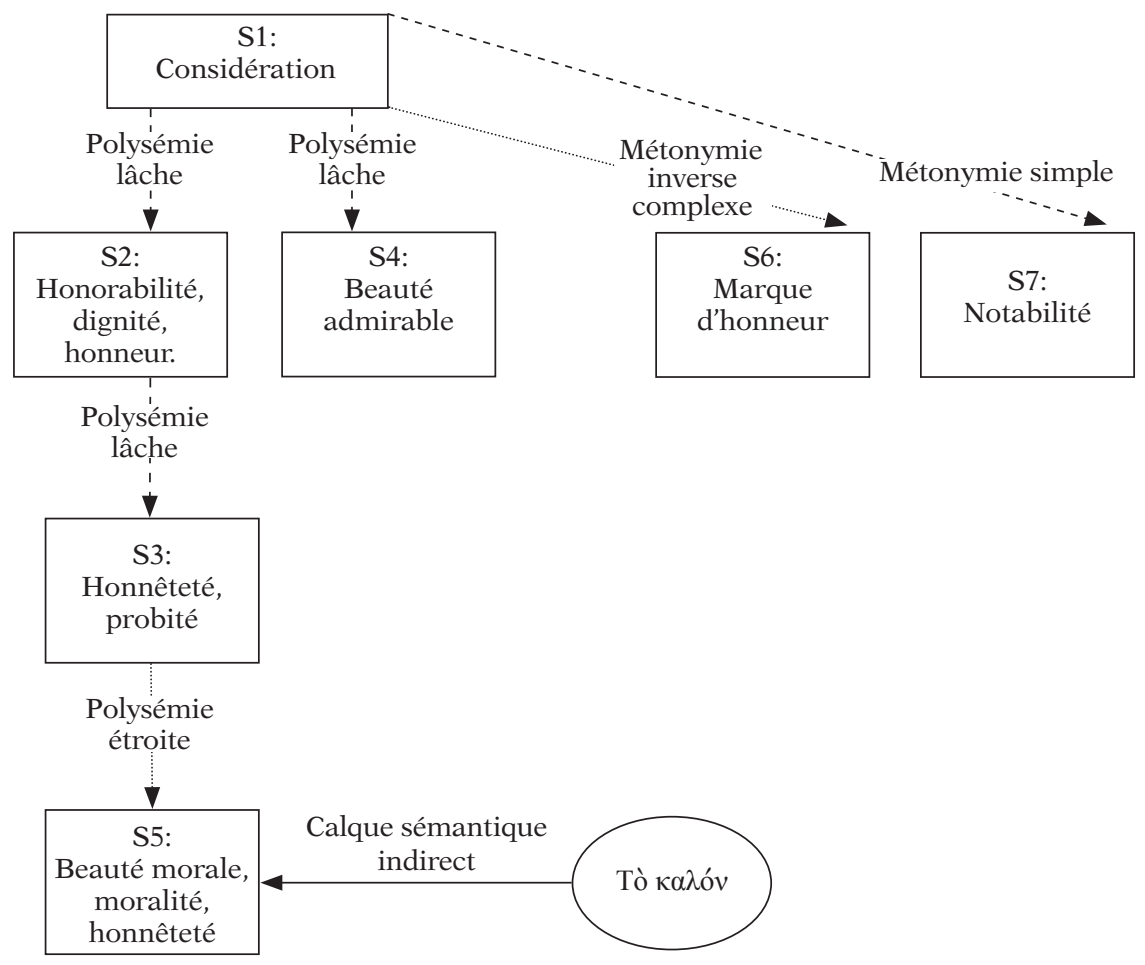


On remarque notamment, sur la gauche du schéma, l'évolution poussée du terme vers la sphère de l'éthique. À chaque étape, l'aspect social de la notion s'efface un peu plus au profit de la dimension morale. La désignation de la «beauté morale» par honestas apparaît ainsi comme un aboutissement et non comme une rupture avec les sens initiaux du mot. Si le terme a été enrichi d'un contact avec la notion

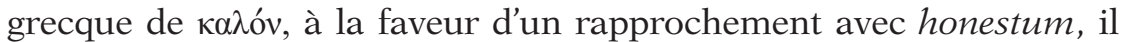
s'agit d'un calque sémantique discret et efficace, car parfaitement situé dans la lignée du sémantisme latin d'honestas. On perçoit ici toute l'habileté des cercles bilingues dans lesquels cet enrichissement s'est produit. Il faut aussi noter la capacité d'honestas à évoluer dans d'autres directions, même si ces sens restent secondaires. Honestas peut ainsi s'orienter vers un sens esthétique; il s'agit là d'une caractéristique de tout le vocabulaire de l'honneur, puisqu'une telle évolution est visible aussi avec honos et honestus. Enfin, la capacité d'honestas à désigner la «marque d'honneur» et une «notabilité » témoigne d'une connexion du mot avec la sphère sémantique d'honos et d'une capacité à évoluer vers la désignation d'objets concrets et de personnes, tout en conservant les traits de sens essentiels de l'estime, de la position sociale et du mérite moral.

\section{CONCLUSION DE LA PREMIÈRE PARTIE}

Au terme de ce parcours, il apparaît que les trois termes qui ont fait l'objet de notre étude ont une polysémie assez ample, avec neuf sens pour honos et sept pour honestus et honestas. Toutes les significations n'ont pas la même vitalité mais leur diversité témoigne de la plasticité du lexique en question; il concerne quatre grandes sphères sémantiques, celles du social, du politique, du moral et de l'esthétique. Une des orientations majeures des termes étudiés est la désignation du prestige vécu par l'individu dans la collectivité à laquelle il appartient, qu'il s'agisse plus précisément de la situation de considération dont il jouit auprès de son entourage ou bien des marques d'honneur qui en sont le signe. Cet aspect est prépondérant pour honos mais son importance est moins grande pour ses dérivés, dont le sémantisme se concentre plutôt sur les qualités morales de la personne qui ne sont suivies qu'à titre facultatif d'effets sociaux bénéfiques. On voit ainsi s'opérer une spécialisation d'honos dans le domaine social de l'estime et de l'hommage, et d'honestus / honestas dans celui de la bonne moralité. Nos trois termes s'organisent donc globalement autour de deux pôles, celui de la sphère socio-politique, d'une part, et celui de l'éthique, d'autre part.

Le sémantisme d'honos apparaît doté d'une assez forte cohérence car la très grande majorité des sens ont en commun un ou plusieurs sèmes. Ceux du /bienfait/, de l'/estime/, de la /position sociale éminente/ et des /mérites/ sont très fréquents et confèrent à honos 
une réelle unité. S'agissant d'honestus et d'honestas, on observe une récurrence de certains sèmes, tels que l'/estime/ ou la /conformité à des normes/, mais elle est moins massive que pour honos. Les sens s'organisent de manière cohérente mais ils sont plus étalés, certains d'entre eux apparaissant en cascade: dans honestas, «beauté morale» provient d' «honnêteté», qui provient d' "honorabilité » qui provient de « considération».

Notre analyse a aussi établi qu'honos, honestus et honestas ne sont pas isolés dans le système de la langue. En raison de leur polysémie, ils entrent chacun dans des relations d'antonymie ou de synonymie avec de nombreux autres termes. Parmi les différents rapports sémantiques observés, sont plus particulièrement significatives la synonymie d'honos avec dignitas, l'antonymie d'honos avec ignominia et celle d'honestus et honestas avec turpis et turpitudo.

L'étude lexicale, enfin, apporte une solide base pour l'étude de la pratique et de la pensée de l'honneur. Pour honos, les analyses contextuelles ont mis en évidence un trait de sens désignant la présence d'un "signe»; il nous faudra préciser la nature et le fonctionnement de ce signe et procéder à une herméneutique de l'honos. Il nous appartiendra aussi de préciser les formes concrètes prises par le «bienfait» qu'implique honos. Une place particulière devra être ménagée aux aspects politiques de l'honos et aux conséquences d'une définition des charges publiques comme marques d'honneur. Nous avons également constaté combien les mérites qui motivent l'honos occupaient une place importante dans les textes; nous tâcherons donc de préciser leur nature et leur rôle. Il faudra aussi s'intéresser aux effets de l'honneur, comme nous invite à le faire la présence récurrente de traits de sens concernant la position sociale éminente. Pour honestus et honestas, l'analyse sémique a permis de montrer un déplacement de l'accent sémantique depuis une valeur sociale vers une valeur morale; il faudra donc nous interroger sur la manière dont ces deux domaines s'articulent dans les faits. La présence de sèmes concernant la conformité à des normes et l'orientation de la conduite nous amènera à observer la capacité de l'honestum à agir comme un code d'honneur. L'évolution technique des termes nous conduira également à prêter une attention toute particulière à la conceptualisation de l'honestum et de l'honestas et à leur approfondissement théorique chez les auteurs de la République. 
DEUXIÈME PARTIE

LA PRATIQUE: FONCTIONNEMENTS ET USAGES 



\section{INTRODUCTION}

Les pistes ouvertes par notre étude sémantique nous incitent à envisager désormais l'honos, l'honestum et l'honestas comme des objets concrets. Il nous faut passer de l'étude du lexique de l'honneur à celle de la pratique de l'honneur. Nous nous intéresserons dans cette partie à l'honos, l'honestum et l'honestas dans la vie des Romains, en observant les fonctionnements de ces phénomènes et les usages qui en sont faits, dans le domaine politique, social, moral et religieux.

\section{Problèmes}

Une telle approche est cependant problématique. Les notions qui nous intéressent recouvrent en effet, comme l'a montré l'analyse sémantique, des objets très divers, les marques d'honneur - ellesmêmes hétérogènes -, le prestige social, les charges politiques, la dignité morale ou encore la beauté physique. Il faudra donc impérativement nous interroger sur l'unité et la cohérence de ces phénomènes. Nous nous demanderons ainsi s'il est possible de déceler des traits communs aux différents honores, ou encore s'il existe un lien concret entre l'honos et l'honestas.

Cette diversité pose aussi un autre problème: comment aborder cet ensemble complexe de pratiques et d'objets variés? Nous avons choisi de ne pas mener une étude historique détaillée des realia que recouvrent nos trois notions. Nous aurons à proposer une description des marques d'honneur, du prestige et des exigences du code de l'honestum, mais nous n'étudierons pas chacun de ces objets pour lui-même. Notre étude est une étude de notions, et non une histoire des charges publiques, des funérailles, ou des décorations militaires à Rome. Nous chercherons donc à voir en quoi ces objets sont tous, à leur manière, des honores ou des composantes de l'honestas.

\section{Méthode}

Pour mener à bien ce travail et nous conformer aux principes posés dans notre introduction générale, nous avons choisi d'aborder la pratique de l'honos et de l'honestas dans un esprit voisin de celui qui 
anime l'anthropologie et la sociologie historiques ${ }^{1}$. Nous centrerons donc notre investigation sur l'homme romain et sur son expérience de l'honos et de l'honestas. Nous nous intéresserons à des pratiques sociales, politiques et morales; les usages de l'honneur, les coutumes qui l'entourent, la place et le rôle de cet objet dans l'existence des Romains constitueront l'essentiel de cette partie ${ }^{2}$. Les évolutions chronologiques ne seront pas occultées mais elles ne se situeront pas au cœur de l'enquête. Nous pourrons aussi tenter d'approcher par ce biais les modes de pensée romains dans leur singularité, s'il est vrai que les actions et les œuvres humaines sont révélatrices de l'activité mentale ${ }^{3}$. Notre approche se propose non de décrire de façon exhaustive les pratiques de l'hommage et de l'honorabilité mais d'élucider leur fonction et leur signification pour l'individu et la collectivité: il s'agit de mener un travail plus interprétatif que descriptif.

${ }^{1}$ L'approche anthropologique des sociétés antiques n'est pas une nouveauté. Elle a même été pratiquée par un des pères fondateurs de l'anthropologie générale, James Frazer (Le Rameau d'or, Paris, R. Laffont, 1981). Elle s'est surtout développée à la fin $\mathrm{du} \mathrm{xx}^{\mathrm{e}}$ siècle, dans le domaine grec essentiellement. Voir par exemple les travaux de L. Gernet, Anthropologie de la Grèce antique, Paris, Flammarion, 1982; M. Detienne, Dionysos à ciel ouvert, Paris, Hachette, 1986; J.-P.Vernant, Mythe et pensée chez les Grecs. Études de psychologie historique, nouvelle éd., Paris, La Découverte, 1996; P. Vidal-Naquet, Le Chasseur noir, Paris, La Découverte, 1983; C. Calame, L'Eros dans la Grèce antique, Paris, Belin, 1996. Les recherches anthropologiques sur le monde romain ont été moins nombreuses: on peut citer celles de F.Dupont, L'Orateur sans visage. Essai sur l'acteur romain et son masque, Paris, P.U.F., 2000; P. MorEAU, Incestus et prohibitae nuptiae. L'inceste à Rome, Paris, Les Belles Lettres, 2002 ou P. Cordier, Nudités romaines. Un problème d'histoire et d'anthropologie, Paris, Les Belles Lettres, 2005. L'approche sociologique des sociétés disparues a été développée par l'École des Annales qui s'est intéressée, plutôt qu'à l'histoire événementielle, aux phénomènes sociaux profonds (la fête, la mort, la parenté, etc.). Voir par exemple l'étude d' E. Le Roy Ladurie sur le carnaval de Romans au Xvi ${ }^{\text {e }}$ siècle: il s'intéresse à la fête elle-même et à ses débordements, mais aussi à ce que le carnaval révèle sur les conflits d'ordres dans le Dauphiné de la Renaissance: «événement ponctuel, le Carnaval de Romans éclaire, reflète les cultures et les conflits d'une époque.» (E. Le Roy Ladurie, Le Carnaval de Romans, Paris, Gallimard, 1979, p. 407). Dans le domaine antique, l'ouvrage de P.VeYne, Le Pain et le cirque. Sociologie historique d'un pluralisme politique, Paris, Seuil, 1976 est, comme l'indique son sous-titre, un travail de sociologie historique.

${ }^{2} C f$. le projet de M. Meslin de faire « une analyse anthropologique, menée à un autre niveau que celui de l'histoire événementielle, institutionnelle, économique et sociale.» (M. Mesuin, L'Homme romain, Paris, Complexe, 1985, p.9).

${ }^{3}$ Voir les travaux de "psychologie historique» de J.-P.Vernant (Vernant, Mythe et pensée chez les Grecs) et le rapprochement entre «formes de société» et «formes de pensée» opéré par P.Vidal-Naquet (VIDAL-NAQUET, Le Chasseur noir). Ces travaux sont inspirés des recherches d'I. Meyerson qui a montré comment l'esprit se révèle en permanence dans le travail et les œuvres de l'homme, et comment on peut donc percevoir le fonctionnement de la pensée à travers les actions humaines (I. Meyerson, Les Fonctions psychologiques et les oeuvres, Paris, Vrin, 1948). 
Pour restituer avec justesse la pratique de l'honneur à Rome, nous recourrons à une méthode conjuguant analyse descriptive et interprétation théorique. Nous tâcherons, d'une part, d'observer les mécanismes de l'honneur romain à l'aide des catégories par lesquelles les Romains le pensaient eux-mêmes. Nous aurons donc recours à d'autres notions romaines aussi essentielles que la uirtus, la dignitas ou l'auctoritas. Nous prêterons attention aux discours et aux images décrivant le fonctionnement de l'honos. On ne peut, cependant, en rester à l'accumulation d'observations et à l'exploration de ce savoir indigène sans tomber dans la paraphrase. Notre investigation doit, d'autre part, recourir à des outils théoriques et à des catégories externes car c'est l'association de l'observation des pratiques romaines et d'un savoir théorique qui permettra de constituer l'honos, l'honestum et l'honestas en objets scientifiques. Nous emploierons donc avec profit des instruments d'analyse élaborés par les sciences sociales, comme les concepts de norme, de contrôle social, de modèle ou encore de fonction ${ }^{4}$. Nous pourrons aussi tenter d'éclairer des faits romains par le recours à la comparaison avec les pratiques d'honneur et de prestige analysées par les anthropologues spécialistes de la Méditerranée ou par les sociologues ou les historiens d'autres périodes. La comparaison de l'honos ou de l'honestas avec des éléments d'autres civilisations est un exercice périlleux car la découverte de ressemblances est souvent subjective. Mais c'est aussi une piste intéressante à suivre, pour peu que l'on cherche à comparer des structures plutôt que des contenus, des mécanismes de pensée plutôt que des thèmes ${ }^{5}$.

Notre usage des sources sera similaire à celui de la partie précédente. Afin de faire ressortir les traits communs, les fonctions essentielles et les traits profonds de l'honneur, nous devrons convoquer de manière rapprochée des textes appartenant à des périodes et des genres différents. Une telle juxtaposition, malgré ses inconvénients, nous semble nécessaire pour l'approche analytique et interprétative qui est la nôtre.

\footnotetext{
${ }^{4}$ Sur la norme, voir par exemple les réflexions d'E. Goffman, La Mise en scène de la vie quotidienne. 2. Les relations en public, Paris, Minuit, 1973; E. Goffman, Les Rites d'interaction, Paris, Minuit, 1974. Sur le contrôle social, J.-D. Reynaud, Les Règles du jeu. L'action collective et la régulation sociale, Paris, A. Colin, 1989. Sur le modèle, voir l'introduction de S. Bell et I. L. Hansen (éds.), Role Models in the Roman World. Identity and Assimilation, Ann Arbor, University of Michigan Press, 2008, qui utilise les outils de la sociologie pour l'étude des exempla. La notion de fonction a été développée par le fonctionnalisme anglais (A.R. RADCLIFFE-Brown, Structure et fonction dans la société primitive, Paris, Minuit, 1968) et français (É. DuRkheIm, Les Règles de la méthode sociologique, $13^{e}$ éd., Paris, PUF, 2007).

${ }^{5}$ Voir sur cette méthode M. Detienne, Comparer l'incomparable, Paris, Seuil, 2000, p. 51.
} 

CHAPITRE 4

\section{LES STRUCTURES DE L'HONNEUR}

\section{INTRODUCTION}

Afin de fournir un socle solide à notre analyse du phénomène de l'honneur, nous commencerons par dégager les dispositifs selon lesquels il fonctionne. Il s'agira de mettre au jour, par-delà la diversité des honneurs et des situations de prestige, un certain nombre de structures et de mécanismes essentiels. Létude ne portera donc pas, pour le moment, sur des aspects précis de l'honneur, tels que ses formes, ses fonctions ou ses fondements, mais sur les interactions qui animent l'honneur, sur le dynamisme situé en son cœur. L'étude de ces interactions doit nous permettre de voir selon quels paradigmes fondamentaux l'honos fonctionne et de dégager des structures interprétatives aptes à rendre compte de l'honos dans sa complexité. Ces paradigmes ne prétendent nullement fournir d'emblée la clef de l'honneur romain. Ils ne seront opératoires que pour expliquer un certain nombre de mécanismes et non le phénomène dans son ensemble. Ils devront donc être affinés et complétés au fur et à mesure.

\section{LES PROTAGONISTES DE L'HONOS: SOI-MÊME ET AUTRUI}

La première interaction fondamentale, située au cœur du phénomène de l'honos, qu'il s'agisse de l'hommage ou de la considération, est celle qui concerne les individus et les groupes. L'honneur met en rapport le sujet avec autrui, celui qui honore avec celui qui est honoré. C'est sur la place respective de ces acteurs que nous commencerons par faire porter l'analyse: qui possède l'honneur? Qui le donne?

\subsection{L'honos possédé: les détenteurs de l'honneur}

L'identification des bénéficiaires de l'honos est relativement aisée s'agissant de la "marque d'honneur», en raison de la forme concrète qu'elle revêt souvent; elle est en revanche plus délicate pour la «considération », objet beaucoup plus fluide et mouvant. Il importe cependant d'essayer de cerner avec précision le détenteur de l'honos car cela peut contribuer à mesurer la place de l'individu dans une culture réputée 
holistique, faisant la part belle aux groupes et à la collectivité plus qu'à la personne singulière ${ }^{1}$.

\subsubsection{Individu et collectivité}

L'honneur est un bien susceptible d'appropriation par des individus comme par des groupes de taille très diverse. On voit ainsi de façon régulière des personnes individuelles bénéficier de l'honos, qu'il s'agisse d'un hommage ou du prestige social: dans la Cistellaria, une jeune femme reçoit une marque d'honneur de la part de ses amis ${ }^{2}$; Cicéron conseille à son frère de se montrer digne, à l'occasion de son proconsulat, des honores qui se sont accumulés sur sa tête ${ }^{3}$; quelques années après, lors de son exil, il se lamente d'être privé du prestige qui était le sien autrefois ${ }^{4}$. Mais l'honneur peut aussi s'attacher à des groupes. Il est ainsi assez fréquemment question de celui d'une famille ${ }^{5}$. Cicéron évoque avec révérence la considération dont jouissaient en leur temps les Metelli, les Servilii et les Scipions, considération qui était le propre de la gens et s'attachait au nom de la famille, que Cicéron prononce avec respect ${ }^{6}$. L'honneur est ici un bien partagé par tous et transmis avec le nomen: chaque membre de la gens en jouit en vertu de la souche dont il est issu. C'est aussi cette idée qui apparaît dans les Verrines, quand Cicéron interpelle Q. Caecilius Metellus Pius Scipio, un des soutiens de Verrès, et lui reproche de protéger un homme qui a entaché l'honneur de sa famille en volant la statue de Diane à Ségeste, rapportée par Scipion l'Africain après sa victoire sur Carthage:

Cur pro isto, qui laudem honoremque familiae uestrae depeculatus est, pugnas, cur eum defensum esse uis [...]?

«Pourquoi combats-tu pour cet homme qui a fait main basse sur la gloire et l'honneur de votre famille? Pourquoi veux-tu qu'il soit défendu? »

(CIc. Verr. II, IV, 79; trad. Rabaud).

\footnotetext{
${ }^{1}$ Sur la représentation de Rome comme culture holistique et la discussion de cette vision, voir l'ouvrage de R. R. MARchese, La morale e il singolo. Individualismo, modelli etici e poesia romana. Lucilio, Orazio, Catullo, Lucrezio, Properzio, Ovidio, Palerme, Palumbo, 1998.

${ }^{2}$ PL. Cist. 4.

${ }^{3}$ CIC. Q. fr. I, 1, 30.

${ }^{4}$ Cic. Att. III, 10, 2.

${ }^{5}$ M. NAssiet, La Violence, une histoire sociale. France, $X V I^{e}-X V I I I^{e}$ siècles, Seyssel, Champ Vallon, 2011, distingue pour le XVI ${ }^{\mathrm{e}}$ siècle la «renommée », qui est individuelle, et «l'honneur», qui est collectif (p. 183).

${ }^{6}$ Cic. Rosc. Amer. 15.
} 
Il est insensé, aux yeux de Cicéron, de défendre quelqu'un qui a attaqué l'honos familiae. Cet honneur de la famille a deux caractéristiques importantes: il concerne surtout les hommes et il traverse les générations, de Scipion l'Africain jusqu'à Q.Caecilius Metellus Pius Scipion. Il y a donc une solidarité de prestige entre les individus mâles d'un même lignage ${ }^{7}$. L'honneur peut également être celui d'un cercle plus large de personnes qui ne possèdent pas de liens familiaux. Au sein de l'armée romaine, une unité peut recevoir, à titre collectif, des distinctions militaires qui augmentent le prestige de l'ensemble des soldats qui y appartiennent ${ }^{8}$. Cicéron fait état dans plusieurs discours de l'honos qui s'attache au groupe des publicains, qu'il considère comme digne de tous les égards: dans le De prouinciis consularibus, il dénonce ainsi l'attitude de Gabinius vis-à-vis des publicains lors de son proconsulat de Syrie et demande aux sénateurs de venir en aide aux chevaliers car leur honneur n'a pu les protéger de la voracité de Gabinius ${ }^{9}$. Mais c'est surtout la nobilitas qui est identifiée comme détentrice d'un prestige collectif, comme cela apparaît dans le Pro Roscio Amerino, quand Cicéron explique pourquoi Roscius a soutenu le parti de la noblesse lors de la guerre civile entre Marius et Sylla:

Etenim rectum putabat pro eorum honestate se pugnare propter quos ipse honestissimus inter suos numerabatur.

«Il estimait en effet que la droiture imposait de se battre pour l'honneur de ceux grâce auxquels il était, lui, compté parmi les siens comme l'homme le plus estimé.»

(Cic. Rosc. Amer. 16).

Il est question ici de l'honestas et non de l'honos des nobles, mais le sens est bien celui de "prestige»: c'est le statut des nobles qui a été menacé au cours des affrontements civils. C'est cet honneur que Roscius a jugé bon de défendre, par reconnaissance envers les bienfaits que la noblesse lui avait jadis octroyés. Ces différents exemples montrent que l'honneur du groupe n'est pas seulement constitué du

${ }^{7}$ L'aspect patrilinéaire de l'honneur a été repéré dans plusieurs cultures méditerranéennes, à différentes époques. C'est le cas par exemple de l'Espagne médiévale (BAROJA, «Honour and Shame: A Historical Account of Several Conflicts», à la p.89). Sur la transmission de l'honneur, voir infra p.451-458.

${ }^{8}$ Une légion, une flotte, une cohorte peuvent recevoir un honos dont l'obtention est souvent commémorée, à l'époque impériale surtout, par l'adjonction d'un surnom à l'unité ("victorieuse», "invincible», etc.) et par l'incorporation de la représentation iconographique de l'honos obtenu dans les signa officiels de l'unité comme les étendards. Voir A.BütTNER, "Untersuchungen über Ursprung und Entwicklung von Auszeichnungen im römischen Heer», Bonner Jahrbücher, 157, 1957, p.127-180 et V. MaXfIELd, The Military Decorations of the Roman Army, Londres, B. T. Batsford, 1981, p. 217-218.

${ }^{9}$ Cic. Prou. 11. 
prestige ou des honores concrets de chacun de ses membres additionnés à ceux des autres composants du groupe; il y a un honos spécifique à l'entité elle-même qui fait que celui qui lui appartient est d'emblée considéré comme un individu prestigieux ${ }^{10}$. Pour cela, les membres du groupe doivent posséder des liens qui les unissent les uns aux autres: liens de famille, mais aussi solidarité des membres d'une unité militaire, alliances sociales et politiques entre chevaliers ou entre nobles. Il peut aussi s'agir, et l'on touche alors au dernier cercle de l'honos, de l'appartenance à un même peuple: César a beau jeu de souligner que les Héduens, qui sont ses alliés, se distinguent par l'honos de leur nation, même s'ils doivent ce dernier à Rome ${ }^{11}$. L'honos paraît donc pouvoir s'attacher à un individu isolé aussi bien qu'à un groupe de taille importante: tous deux sont susceptibles d'être porteurs de l'honneur et donc de recevoir une existence sociale bien réelle. L'indépendance de l'individu par rapport au groupe, qui paraît donc bien réelle, doit cependant être nuancée par l'observation d'un phénomène qui rattache l'honos personnel à celui de tout le groupe: il s'agit de la capacité de propagation de l'honneur.

\subsubsection{La propagation de l'honos}

L'honos que détient un individu ne le singularise pas très nettement car il a un fort pouvoir d'extension à l'entourage. Quand un membre du groupe réalise une action remarquable, il augmente son prestige mais aussi, simultanément, celui de sa famille. C'est ce dont s'enorgueillit l'épitaphe de Scipion Hispanus:

Virtutes generis mieis moribus accumulaui, Progeniem genui, facta patris petiei.

Maiorum optenui laudem, ut sibei me esse creatum Laetentur: stirpem nobilitauit honor.

« J'ai augmenté grâce à mes mœurs les vertus de ma race,

J'ai fondé une descendance et essayé d'égaler les exploits de mon père.

${ }^{10}$ Voir sur l'honneur collectif des groupes sociaux PitT-Rivers, Anthropologie de l'honneur, p. 37: "Les groupes sociaux possèdent un honneur collectif auquel leurs membres participent, si bien que la conduite déshonorante d'un individu réagit sur l'honneur de tous et que, réciproquement, chaque membre bénéficie de l'honneur du groupe.»

${ }^{11}$ Populi Romani hanc esse consuetudinem, ut socios atque amicos non modo sui nihil deperdere, sed gratia, dignitate, honore auctiores uelit esse; quod uero ad amicitiam populi Romani attulissent, id iis eripi quis pati posset? "C'était une tradition des Romains de vouloir que leurs alliés et leurs amis, non seulement ne subissent aucune diminution, mais encore vissent s'accroître leur crédit, leur dignité, leur honneur: vraiment, ce qu'ils avaient apporté avec eux en devenant amis de Rome, qui pourrait souffrir qu'on le leur arrachât?»(CAES. BG I, 43, 6-8; trad. Constans modifiée). 
J'ai préservé la gloire de mes ancêtres, de sorte qu'ils se réjouissent de m'avoir engendré:

Mon honneur a ennobli ma lignée.»

$\left(C I L \mathrm{I}^{2}, 15=I L L R P 316\right)$.

Le défunt, issu de la famille aristocratique des Cornelii Scipiones, souligne qu'il a obtenu un honor, qui renvoie sans doute aux charges publiques qu'il a exercées ${ }^{12}$. Son honneur nobilitauit sa famille, expression qui peut être comprise de plusieurs manières. L'honos a d'abord "rendu notoire» la stirps: par l'exercice de hautes fonctions politiques, Hispanus a donné de la notoriété à son lignage. Mais il a aussi préservé la nobilitas des Scipions, leur haut rang socio-politique. La noblesse, pour ne pas s'user, doit en effet être régulièrement réactivée par l'obtention de marques d'honneur ${ }^{13}$. Le terme par lequel l'épitaphe désigne la famille sur laquelle rejaillit l'honneur n'est pas anodin: ce n'est pas la familia, mais la stirps, mot qui désigne la lignée familiale, par l'image de la souche. L'honneur se propage dans la famille par les voies de la filiation et peut remonter aux racines aussi bien que toucher la descendance ${ }^{14}$. L'individu est donc pris dans un réseau familial et son honneur se répercute sur tout son lignage. Il y a même des cas où la marque d'honneur adressée à une personne est perçue comme un hommage rendu à la famille dans son ensemble, comme dans la neuvième Philippique où Cicéron revient sur les statues offertes à d'illustres Romains. Il est ainsi question de Gnaeus Octavius, l'auteur de la capture de Persée:

Reddita est ei tum a maioribus statua pro uita, quae multos per annos progeniem eius honestaret, nunc ad tantae familiae memoriam sola restaret.

«Alors lui fut conférée par nos ancêtres, en compensation de la vie, une statue destinée à honorer sa descendance pendant de nombreuses années et à rester aujourd'hui le seul monument d'une telle famille.»

(Cıc. Phil. IX, 5 ; trad. Wuilleumier modifiée).

La statue, qui est un honos donné à Octavius, fait rejaillir le prestige sur sa descendance. Elle inscrit en effet les mérites du défunt dans

\footnotetext{
${ }^{12}$ Le début de l'inscription déclare que Scipion Hispanus a atteint la préture, ce que confirme VAL. MAX. I, 3, 3.

${ }^{13}$ Voir infra p.294 sur l'honos politique comme honneur par excellence et le chapitre 9 sur la gestion de l'honos.

${ }^{14}$ Sur le sens premier de stirps, "racine» d'arbre ou de plante, voir CAT. Agr. 44; Cic. Verr. II, V, 99; Plin. NH XVI, 163. Au sens figuré, la stirps désigne la «race» dont l'individu est issu (EnN. Ann. 178; Cic. Phil. I, 13; SALL. Iug. 14, 2) mais aussi la progéniture, la descendance (CATUL. 61, 68; Liv. I, 1, 11). L'épitaphe semble jouer sur ces deux derniers sens.
} 
l'espace public de la cité et apporte ainsi de la gloire à sa famille ${ }^{15}$. Ici encore, le texte convoque l'image de la filiation en recourant à la notion de progéniture (progeniem) pour dire que l'honos s'étend selon les voies du sang ${ }^{16}$. Par conséquent, l'individu qui reçoit l'honos n'est jamais isolé de son groupe: il y a transfusion immédiate entre son prestige et celui de l'entourage et son indépendance est donc limitée. De façon plus générale, la bonne ou la mauvaise conduite d'un individu a des répercussions sur la réputation de sa famille. Laction honorable est une source de considération pour son auteur mais aussi pour ses proches. Quand le jeune Lysitélès expose son projet de prendre une femme sans dot, il fait valoir à son père, navré par cette perspective, que cette action désintéressée augmentera la fama familiae ${ }^{17}$; à l'inverse, lorsque le iuuenis de la comédie mène une vie de débauche, un grand déshonneur rejaillit sur son père, son pédagogue et ses amis ${ }^{18}$.

La propagation de l'honos opère aussi dans un cercle plus large que celui de la famille, à l'échelle de la collectivité dans son ensemble. Quand une personne issue d'une région rurale de l'Italie parvient à obtenir à Rome l'honos d'une charge publique, c'est toute sa région d'origine qui se sent honorée. C'est le cas lors de l'accession de Cn. Plancius à l'édilité:

Tractus ille celeberrimus Venafranus, Allifanus, tota denique ea nostra ita aspera et montuosa et fidelis et simplex et fautrix suorum regio se huius honore ornari, se augeri dignitate arbitrabatur [...].

«Toute la région, si peuplée, de Vénafre et d'Allifes, bref toute cette contrée qui est la nôtre, si rude, montagneuse, loyale, sincère, dévouée aux siens, se jugeait distinguée par l'honneur fait à Plancius, élevée en dignité [...].»

(CIc. Planc. 22; trad. Grimal modifiée).

\footnotetext{
${ }^{15}$ Sur cet effet particulier des statues pour la famille, G. LaHusen, Untersuchungen zur Ehrenstatue in Rom, Rome, G. Bretschneider, 1983, p. 135.

${ }^{16}$ Ce point a été mis en évidence par Stutz, Honos. De vocabuli significatione Romana. La propagation de l'honos par le sang n'est pas une réalité propre à la culture romaine. On la retrouve, mutatis mutandis, dans la société bédouine étudiée par L. Abu-Lughod: les bédouins Awlad 'Ali, bergers transhumants, ont une conception de l'honneur liée au lignage agnatique: l'acte glorieux, source de prestige pour son auteur, apporte de l'honneur à toute la descendance, comme l'acte honteux déshonore tout le groupe familial (Aвu-LugHod, Veiled Sentiments).

${ }^{17}$ PL. Trin. 378-379.

${ }^{18}$ C'est le cas dans les Bacchides où les flagitia de Pistoclère provoquent la disgrâce de ses proches (PL. Bac. 375). Voir également Cic. Clu. 15 où un désir sexuel incontrôlé provoque un commune dedecus. Pour d'autres exemples, plus tardifs, de l'extension du déshonneur, voir Sen. Ben. V, 19, 5; Tac. Ann. XVI, 17; Plin. Ep. V, 11. Lendon, Empire of Honour, p. 45, note que dans le droit l'iniuria, l'attaque contre l'honneur, concerne ceux qui sont liés à la victime par la potestas ou des liens familiaux (Dig. XLVII, 10, 1, 3). L'expérience de la honte, du pudor, peut aussi naître de l'association à des individus qui ont commis une action honteuse (KASTER, Emotion, Restraint and Community in Ancient Rome, p. 38-42).
} 
L'honos provoque une augmentation de la dignitas de celui qui le reçoit, mais aussi de celle de sa région d'extraction: la zone de Vénafre et d'Allifes, près de la Campanie, est honorée par l'élection de Plancius, ce qui est révélateur du lien étroit des hommes politiques avec la «petite patrie». À plus grande échelle, c'est la res publica dans son ensemble qui peut bénéficier de l'honos fait à un individu. Les triomphes de Pompée sont une source d'honos pour tout l'imperium Romanum $^{19}$. Et quand Ennius adresse des éloges à Scipion l'Africain, c'est sur le peuple romain que retombe ce magnus honos ${ }^{20}$. L'individu est ici replacé au sein de la collectivité dont il fait partie et qui est indissociable de lui: l'honneur qu'il obtient se communique à tous. Cette extensibilité de l'honneur n'est pas sans rappeler d'autres représentations propres à la pensée antique. L'honneur est en effet envisagé sur un mode analogue à la théorie stoïcienne du mélange. On sait par Alexandre d'Aphrodise que Chrysippe distinguait trois types

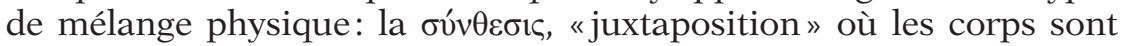
mélangés tout en conservant leurs propriétés particulières, comme

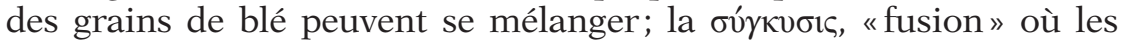
corps se fondent totalement l'un dans l'autre et perdent leurs caractéristiques propres, comme des drogues peuvent se mélanger; et, entre

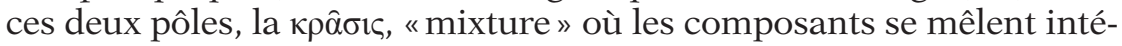
gralement l'un à l'autre mais conservent leur propriété initiale, comme une goutte de vin se propage dans la mer et parvient à avoir toute son étendue, sans cependant y être totalement fondue car elle conserve ses traits propres ${ }^{21}$. L'honos paraît fonctionner, dans les modes de pensée

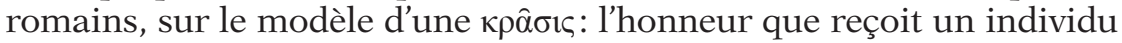
est, vis-à-vis de son entourage proche et lointain, comme la goutte de vin qui tombe dans l'étendue de l'océan. Il se propage à la totalité de l'entourage et parvient à atteindre des individus extrêmement éloignés, devenant coextensif à la collectivité dans laquelle vit la personne honorée. Mais il ne se fond pas totalement avec cette collectivité car il est adressé à un sujet qui en est le détenteur privilégié.

\subsection{L'honos conféré: le rôle d'autrui}

L'identification des détenteurs possibles de l'honos ne doit pas nous faire perdre de vue que ce dernier met en œuvre une relation intersubjective. Quelle que soit la forme de l'honos, autrui joue un rôle prépondérant dans son fonctionnement.

${ }^{19}$ Cic. Dom. 19.

${ }^{20}$ CIC. Arch. 22.

${ }^{21}$ SVF II, $473=L S$ 48C. Voir aussi $S V F$ II, $479=L S 48$ A. Sur cette théorie du mélange et sur l'application générale de ce modèle à d'autres domaines de la pensée stoïcienne, J. BRUnschwig, "Le modèle conjonctif» in Études sur les philosophies hellénistiques, Paris, P.U.F., 1995, p. 161-187. 


\subsubsection{Auteur de l'hommage}

L'honos est, à première vue, une relation à deux termes. L'indispensable présence de ces deux sujets est bien visible dans le Miles gloriosus quand Pyrgopolynice vient d'accepter de recevoir Acrotéleutie et s'adresse à sa servante:

Non edepol tu scis, mulier,

Quantum ego honorem nunc illi habeo.

«Par Pollux, tu ne sais pas, femme,

Quel honneur je lui fais, moi, en ce moment.»

(PL. Mil. 1074-1075).

L'existence de deux protagonistes est nettement soulignée par l'emploi des pronoms personnels ego et illi. Le soldat fanfaron est très attaché à marquer la différence entre les deux acteurs de l'honos: ego, c'est-à-dire lui-même, qui se pose en généreux dispensateur, et illi, Acrotéleutie, reléguée au rang de réceptrice reconnaissante de ces miettes d'honneur. L'honos implique ainsi un destinateur (le soldat) et un destinataire (la jeune femme). L'identité du donateur est très variable. Ce peut être un individu isolé mais aussi une communauté, comme quand une cité érige une statue à un de ses bienfaiteurs ${ }^{22}$. Le donateur peut aussi être une institution politique: c'est le cas du populus Romanus lorsqu'il est réuni en comices sur la convocation d'un magistrat et organisé en centuries pour voter et décerner l'honos d'une charge publique ${ }^{23}$. Le sénat est, avec le populus, l'autre institution majeure dispensatrice d'honores à Rome ${ }^{24}$.

Le rôle-clef joué par autrui apparaît de manière particulièrement sensible dans les commentaires que suscitent les honores qu'un individu s'octroie à lui-même et qui apparaissent comme une grave irrégu-

${ }^{22}$ Cic. Verr. II, II, 137. C'est le peuple qui a fait dresser la statue de Caton dans le temple du Salut, de même que la statue de Cornélie, la mère des Gracques (LaHusen, Untersuchungen zur Ehrenstatue in Rom, p. 107-110; F. CoARELli, « La statue de Cornélie, mère des Gracques, et la crise politique à Rome au temps de Saturninus », in CoArelLI, F. (éd.), Revixit ars. Arte e ideologia a Roma. Dai modelli ellenistici alla tradizione repubblicana, Rome, Quasar, 1996, p. 280-299).

${ }^{23}$ PL. Bac. 438; Cic. Planc. 11. Sur la réunion et le fonctionnement des comices, voir R.Develin, The Practice of Politics at Rome, 366-167 B. C., Bruxelles, Latomus, 1985, chap. 2, "The Constitution» et L. R. TAYLOR, Roman Voting Assemblies from the Hannibalic War to the Dictatorship of Caesar, Ann Arbor, University of Michigan Press, 1966. Voir aussi H. Mouritsen, Plebs and Politics in the Late Roman Republic, Cambridge, Cambridge University Press, 2001 pour des données sur le nombre des présents et l'organisation pratique des assemblées.

${ }^{24}$ L'accumulation sur une même personne des honores populi Romani et des honores senatus est un signe de prestige exceptionnel; ce fut le cas pour Pompée (Cic.Deiot. 12). 
larité. C'est du moins ainsi qu'en juge Caton l'Ancien, qui dénonce une pratique des riches matrones romaines:

Honorem emptitauere, malefacta benefactis non redemptitauere.

«Elles avaient pour coutume d'acheter l'honneur, mais non de racheter leurs méfaits par de bonnes actions.»

(CAT. frg. XIX, $94 O R F$ ).

Ce fragment, tiré du discours De uestitu et uehiculis, datant très probablement de la censure de Caton, en 184, est à replacer dans le cadre de son opposition virulente au luxe qui gagne les mœurs romaines. Un passage de Pline a conduit les commentateurs à penser que Caton s'attaquait ici aux femmes les plus riches qui se faisaient ériger des statues ${ }^{25}$. Il est intolérable pour Caton que les femmes agissent ainsi car l'honos ne peut être acheté (emptitauere): il doit en effet être étayé par des mérites, des actions de valeurs (benefactis), dont ces femmes sont dépourvues. L'honos doit, en outre, être décerné par un tiers autorisé, qui n'a pas d'intérêt à son obtention et peut garantir son objectivité. L'attitude de T. Albucius, propréteur de Sardaigne en 117, qui s'est octroyé de son propre chef un triomphe dans sa province, suscite de même la critique de Cicéron ${ }^{26}$.

La présence d'autrui revêt donc une importance toute particulière pour la légitimité de l'honos. Et c'est aussi cette présence qui permet de donner à l'honos une valeur plus ou moins importante. Il n'est pas indifférent, en effet, d'être honoré par un esclave ou par un aristocrate. L'identité du donateur est un enjeu essentiel de la relation d'honneur. On peut différencier un honneur de type horizontal, qui intervient entre personnes de même rang, et un honneur vertical, entre individus qui ne sont pas placés au même niveau dans la hiérarchie sociale ${ }^{27}$. Etre honoré par ses pairs ou ses concitoyens ne suscite pas en général de commentaire particulier: c'est une situation courante. Quant à la marque d'honneur reçue d'un inférieur, elle n'est pas méprisée: l'esclave peut apporter à son maître un honos que ce dernier sait appré$\operatorname{cier}^{28}$. Mais ce type de marque d'honneur se situe à la limite de l'honos et peut tomber dans le domaine de l'officium. L'égard est en effet motivé par le haut statut de la personne à qui on l'adresse et relève ainsi des devoirs sociaux de l'inférieur. Un passage du Pro Murena

${ }^{25}$ Plin. NH, XXXIV, 31 : Exstant Catonis in censura uociferationes mulieribus statuas Romanis in prouinciis poni: "Il reste des protestations de Caton prononcées pendant sa censure contre le fait que des statues étaient érigées dans les provinces en l'honneur de femmes romaines. "

${ }^{26}$ Cic. Prou. 15.

${ }^{27}$ Nous empruntons cette distinction à STEwart, Honor, p. 61.

${ }^{28}$ Voir par exemple PL. St. 338. 
permet d'en prendre la mesure. Il y est question des gens venus faire cortège à Muréna:

Neque enim fieri potest neque postulandum est a nobis aut ab equitibus Romanis ut suos necessarios [candidatos] adsectentur totos dies; a quibus si domus nostra celebratur, si interdum ad forum deducimur, si uno basilicae spatio honestamur, diligenter obseruari uidemur et coli; tenuiorum amicorum et non occupatorum est ista adsiduitas quorum copia bonis uiris et beneficis deesse non solet.

"Car c'est un service qu'en aucune manière on ne saurait demander ni à nous autres sénateurs ni aux chevaliers romains, d'escorter des amis candidats pendant des journées entières. S'ils fréquentent notre maison, s'il leur arrive de nous accompagner jusqu'au Forum, s'ils nous font l'honneur d'un seul tour de basilique, cela passe pour une grande marque de considération et d'égards. Seuls des amis d'humble condition et inoccupés sont capables de cette assiduité et leur affluence ne manque pas d'ordinaire aux hommes vertueux et bienfaisants. »

(Cic. Mur. 70; trad. Boulanger).

Il est rare que des sénateurs ou des chevaliers se joignent à ce type d'honos qu'est le cortège; ce dernier se compose plutôt d'amis d'humble condition, des clients en général. Le cortège formé par les clients est un officium, une obligation imposée par les liens sociaux ${ }^{29}$, alors que l'honos est un geste où entre davantage de liberté. Et cet honos est particulièrement apprécié quand il est octroyé par des personnages importants: lorsque des sénateurs se donnent la peine d'apparaître en compagnie d'un candidat, c'est une grande marque d'honneur. Le statut de celui qui octroie l'honos entre donc en bonne part dans la constitution de la valeur de cet honos. Il est également très précieux de recevoir une marque d'honneur de la part de quelqu'un qui jouit lui-même d'un honos important, comme si l'honneur du donateur se transmettait partiellement au destinataire. La Rhétorique à Herennius qui, en tant que traité de rhétorique, traite des formes orales de l'hommage, indique ainsi qu'un éloge a un poids particulier quand il est prononcé par des personnes qui appartiennent à un honestiori ordini, à un ordre honorable ${ }^{30}$. À l'inverse, il est déshonorant d'être honoré par un individu lui-même déshonoré: Cicéron considère que l'éloge qu'a fait de lui Pison l'a souillé plus qu'il n'a augmenté son prestige ${ }^{31}$.

\subsubsection{Garant et témoin de l'hommage}

Si l'honos établit une communication entre deux individus ou deux groupes, cette relation fait aussi intervenir un tiers. Quand une

\footnotetext{
${ }^{29}$ Voir Cic. Mur. 71.

${ }^{30}$ Rhet. Her. III, 7.

${ }^{31}$ Cic. Pis. 72: laudatio hominis turpissimi mihi ipsi erat paene turpis: "un éloge venu d'un homme totalement déshonoré était presque déshonorant pour moi.»
} 
personne en honore une autre, elle n'est pas seule dans l'octroi de la marque d'honneur: la collectivité est fréquemment impliquée dans l'hommage et transcende ce dernier. Il y a, au cours de l'honos, quelque chose qui dépasse les deux protagonistes directs: la collectivité dans son ensemble sert de garant à l'hommage. Cette garantie peut prendre la forme d'un consensus collectif autour de l'honneur fait par un donateur à un individu. Le donateur sert alors de médiateur avec la collectivité qui honore une personne. C'est le cas de l'honos dont a bénéficié le poète Stésichore dans sa cité d'Himère, en Sicile:

Erat etiam Stesichori poetae statua senilis incurua cum libro, summo, ut putant, artificio facta, qui fuit Himerae, sed et est et fuit tota Graecia summo propter ingenium honore et nomine.

"Il y avait aussi une statue du poète Stésichore représenté âgé, courbé avec un livre, statue qui passait pour un chef-d'œuvre. Ce poète vécut à Himère, mais il jouit et a toujours joui dans toute la Grèce du plus grand honneur et du plus grand renom à cause de son talent. »

(CIc. Verr. II, II, 87).

C'est la cité d'Himère qui a octroyé à Stésichore l'honos d'une statue mais elle n'a fait, par ce geste, que relayer l'estime du monde grec pour le poète. Il y a deux cercles de l'honos: Himerae et tota Graecia. L'honos fait par les habitants d'Himère met en relation le bénéficiaire avec la collectivité des Grecs et signifie, indirectement, leur estime à tous et non seulement celle de la cité de Sicile. Il en va de même pour l'honos du triomphe. Ce dernier est formellement octroyé par le sénat qui vote l'allocation de fonds publics et édicte un sénatus-consulte mais le triomphe n'a de sens que quand cet édit reflète l'estime de toute la collectivité ${ }^{32}$ :

Is enim demum est mea quidem sententia iustus triumphus ac uerus, cum bene de re publica meritis testimonium a consensu ciuitatis datur.

"Car, à mon avis, seul le triomphe donné par la décision unanime de la cité comme témoignage des mérites du général envers la république me semble être un triomphe juste et authentique.»

(CIc. Phil. XIV, 13).

L'honos fait intervenir un donateur et un bénéficiaire mais aussi un garant, la ciuitas, dont le consensus donne sa raison d'être et sa valeur à l'hommage ${ }^{33}$. La présence de la collectivité comme garant de

${ }^{32}$ Sur l'octroi du triomphe, voir p. 273-275.

${ }^{33}$ J.C.Plumpe, "Roman Elements in Cicero's Panegyric on the Legio Martia », CJ, 36, 1940-1941, p. 275-291 note que le panégyrique de la legio Martia dans la quatorzième Philippique parle de l'honos comme acte politique et civique, qui implique la reconnaissance de l'ensemble des ciues, du populus, ou du sénat (p. 280). La valeur de ce consensus de la cité apparaît bien au livre XXXIII de l'histoire livienne: Q. Cornelius demande et obtient un triomphe omnium consensu, alors que son collègue Minucius, qui fait la même demande, n'est pas exaucé, notamment à cause de l'opposition des tribuns de la 
l'honos est aussi impliquée dans tous les cas où l'honos a lieu entre deux individus sous les yeux d'un public. L'hommage fait à quelqu'un gagne à être fait devant un tiers, ne serait-ce que parce que le donateur peut ainsi faire valoir à tous sa générosité ou sa gratia ${ }^{34}$. Lors de l'honos funéraire rendu aux défunts des grandes familles, un héraut parcourait la ville pour annoncer les funérailles et inviter les citoyens à s'y rendre ${ }^{35}$; ce qui nous paraît relever aujourd'hui de la sphère intime était montré à tous et le prestige que retirait la gens de ces obsèques publiques dépendait en partie du nombre des spectateurs. La collectivité est le témoin de l'honos adressé à quelqu'un et amplifie le sens et la fonction de cet honos. Cicéron évoque en ces termes les marques d'honneur adressées au jeune Curion, qui s'oppose en 59 au pouvoir des «triumvirs»:

Vnus loquitur et palam aduersatur adulescens Curio. Huic plausus maximi, consalutatio forensis perhonorifica, signa praeterea beneuolentiae permulta a bonis impertiuntur.

«Un seul prend la parole et s'oppose ouvertement à eux: le jeune Curion. Il reçoit les plus vifs applaudissements, on le salue au forum d'une manière qui lui fait grand honneur, les gens de bien lui accordent, en outre, de très nombreux signes de bienveillance.»

(CIC. Att. II, 18).

Pour son attitude courageuse, Curion bénéficie d'une consalutatio perhonorifica, de saluts honorifiques adressés par d'autres citoyens. Mais il est crucial, pour le sens politique de ces marques d'honneur, qui visent à dire l'opposition au consulat de César et à l'alliance avec Crassus et Pompée, qu'il s'agisse d'une consalutatio forensis: l'hommage prend place au forum, au cœur de la vie publique de Rome. La ciuitas est le témoin de l'honos qui est fait à Curion et le vrai destinataire du message politique de cette consalutatio ${ }^{36}$. Dans son étude des mécanismes du bienfait, Sénèque, quand il s'intéresse à la manière dont il faut donner, distingue deux types de beneficia: ceux qui servent à remédier au dénuement ou au déshonneur doivent être dissimulés; en revanche, ceux qu'il est glorieux d'obtenir, bienfaits parmi lesquels se trouvent les honores, doivent être donnés en public car cela rehausse leur éclat ${ }^{37}$.

plèbe. Il triomphe donc à ses frais, sur le mont Albain; cette décision unilatérale rend son triomphe, dont l'apparence extérieure est pourtant brillante, inhonoratior, «moins prestigieux », car la collectivité ne l'a pas validé (Lıv. XXXIII, 23, 8).

${ }^{34}$ Sur le bénéfice de l'honos pour celui qui le donne, voir p. 420-427.

${ }^{35}$ Cic. Leg. II, 24; Suet. Caes. 84.

${ }^{36}$ Sur la fonction d'allégeance politique des honores, voir p. 419-420.

${ }^{37}$ SEN. Ben. II, 9, 1. 


\subsubsection{Fondement du prestige}

Autrui joue aussi un rôle décisif dans la constitution de l'honos comme "prestige». La situation de prestige qu'est l'honos a en effet ceci de particulier que celui qui le détient n'en est pas maître; c'est un bien qu'il possède mais qui n'existe que tant qu'autrui nourrit son existence. C'est en effet le regard d'autrui et son jugement qui donnent sa consistance au prestige qu'est l'honos. Nous en avons un exemple dans l'Amphitryon, lorsqu'il est question de la préservation de l'honos d'Alcmène qui a commis, à son insu, un adultère avec Jupiter. Mercure, dans une adresse aux spectateurs, explique comment le roi des dieux parviendra à sauvegarder l'honos de l'épouse d'Amphitryon:

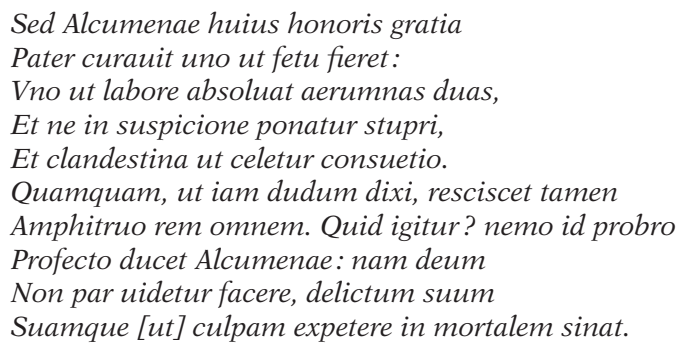

«Mais pour l'honneur d'Alcmène,

Mon père a pris soin qu'elle accouchât en une seule fois,

Afin qu'elle se délivre de deux épreuves par un seul travail,

Qu'elle ne puisse être soupçonnée d'adultère,

Et que sa liaison clandestine demeure cachée.

Pourtant, comme je l'ai dit tout-à-l'heure, il saura

Toute l'affaire, Amphitryon. Mais quoi? Personne assurément

Ne pensera qu'il y a pour Alcmène quelque cause d'opprobre: car pour un dieu Il paraît injuste de laisser retomber son délit

Et sa faute sur une mortelle. »

(PL. Amp. 486-495).

Le seul moyen pour Jupiter de dissimuler la faute consiste à faire naître son rejeton en même temps que l'enfant légitime d'Alcmène. Le fait d'avoir commis un stuprum met en effet en danger l'honos de la femme qui doit fidélité à son époux. Pour sauvegarder l'honos, il faut non pas annuler la faute mais la cacher (celetur). L'honos n'est donc pas ici la dignité morale, mais bien le prestige fondé sur la bonne réputation: ce qui importe, ce n'est pas de ne pas commettre de faute, mais de ne pas divulguer cette faute. L'honos dépend du jugement des autres et non de la conscience personnelle du sujet. Le discours social positif que suppose l'honos apparaît d'ailleurs clairement quand Mercure déclare que, par ce stratagème, nemo id probro / Profecto ducet Alcumenae: l'essentiel, c'est que personne ne raconte qu'il y a là un acte honteux; seule la réaction des autres est un objet d'inquié- 
tude $^{38}$. L'honos sera sauf dès l'instant où le geste honteux ne sera pas visible et où le discours négatif sera évité39. De la même façon, l'honos peut être mis en péril par une condamnation dans un procès, donc par une décision extérieure, ce qui montre que le prestige n'existe que par autrui : c'est la sanction reçue dans un iudicium, sous les yeux des concitoyens, qui menace l'honos ${ }^{40}$. L'honneur romain est un honneur public, animé par le regard des autres ${ }^{41}$.

\subsubsection{Du geste au discours fondamental}

La place prise par la collectivité dans la constitution du prestige permet de voir que ce dernier ne repose pas seulement sur l'obtention d'honores concrets. Il se compose aussi de discours positifs et suppose une bonne réputation dont la place doit être précisée. Un texte du Trinummus de Plaute nous servira de point de départ. Lysitélès, jeune homme rangé et sérieux, exhorte son ami Lesbonicus à renoncer à ses débauches et à mener une vie plus digne:

Itan tandem hanc maiiores famam tradiderunt tibi tui,
Vt uirtute eorum anteparta per flagitium perderes?
Atque honori posterorum tuorum ut uindex fieres,
Tibi paterque auosque facilem fecit et planam uiam
Ad quaerundum honorem; tu fecisti ut difficilis foret
Culpa maxime et desidia tuisque stultis moribus.
Praeoptauisti amorem tuum uti uirtuti praeponeres.

«Tes ancêtres t'ont-ils légué cette bonne réputation

Pour que tu ruines par ta débauche les biens acquis autrefois par leur vertu? Et pourtant, pour que tu puisses protéger l'honneur de tes descendants, Ton père et ton ancêtre t'avaient ménagé un chemin facile, tout plat,

${ }^{38}$ Le terme même de probrum, qui désigne ce qu'il faut éviter, est révélateur: le mot peut signifier la faute, l'acte infâme, mais son sens premier, qui est ici utilisé, est celui de «reproche, outrage». C'est par métonymie que probrum en est venu à désigner un «acte digne de reproche» (Thомаs, Déshonneur et honte, p. 230).

${ }^{39}$ Le déshonneur ne naît que lorsqu'autrui voit l'individu accomplir un geste déshonorant ou quand ce geste est confessé: BARTON, Roman Honor, p. 140 et 172; PITT-RIVERS, Anthropologie de l'honneur: "l'honneur n'est irrévocablement compromis que par des attitudes manifestées en présence de témoins, ceux-ci faisant office de représentants de la fonction publique» (p. 26).

${ }^{40}$ Sur le procès mettant en péril le prestige social, voir Cic. Quinct. 9 et Rosc. Amer. 114 et infra p. 448 sqq.

${ }^{41}$ "L'homme romain est incapable de se connaître par soi-même, il a besoin du regard des autres. Rome ignore l'intériorité psychologique et l'examen de conscience. L'homme romain n'est qu'extériorité. Il n'a d'autre miroir que ses semblables pour se voir dans son honneur... ou son indignité» (F. DuPonT, Le Citoyen romain sous la République. 509-27 avant J.-C., Paris, Hachette, 1994, p. 23). Une telle affirmation demande à être interrogée et nuancée, notamment à propos d'une hypothétique absence d'«intériorité psychologique » à Rome, mais elle fait ressortir la fonction constitutive du regard d'autrui pour l'honneur de l'individu. 
Vers l'honneur; tu l'as rendu difficile

Par ta conduite fautive, surtout, et par ta paresse et tes mœurs stupides.

Tu as choisi de faire primer ton amour sur la vertu.»

(PL. Trin. 642-648).

Pour ramener son ami sur le droit chemin, Lysitélès essaie de lui montrer qu'il met en péril l'excellente renommée de sa famille, progressivement constituée par ces ancêtres: ils lui ont légué (tradiderunt) une fama qu'il est chargé d'entretenir. Le terme de fama est repris par honos (v. 644) pour désigner le prestige que Lesbonicus doit transmettre à son tour à ses descendants (posterorum). Être le uindex honori, c'est être le protecteur, le garant ${ }^{42}$ de cette bonne réputation qui constitue un bien familial à préserver, un héritage précieux à transmettre. Lesbonicus, en faisant primer ses amours sur la vertu, met en danger cette bonne réputation impliquée par l'honos, puisque ses fredaines conduisent ses concitoyens à le blâmer. L'honos implique donc un jugement de la part d'autrui formulé verbalement. Les propos que Lesbonicus adresse un peu plus loin à Lysitélès permettent de mieux saisir le rapport entre rumeur publique et honos. Lysitélès, pour aider Lesbonicus, veut épouser sa sœur, mais sans réclamer de dot, pour ne pas grever davantage les finances de son ami, entamées par sa vie «à la grecque». Lesbonicus refuse cette largesse qui menace son honneur:

LE.: Nolo ego mihi te tam prospicere qui meam egestatem leues,

Sed ut inops infamis ne sim; ne mihi hanc famam differant

Me germanam meam sororem in concubinatum tibi,

Si sine dote $<$ dem $>$, dedisse magis quam in matrimonium.

Quis me inprobior perhibeatur esse? Haec famigeratio

Te honestet, me conlutulentet. Si sine dote duxeris,

Tibi sit emolumentum honoris; mihi quod obiectent siet.

«LESBONICUS: Je ne veux pas que tu veilles autant à soulager ma pauvreté;

Mais que tu t'occupes de ne pas me faire ajouter le déshonneur au dénue

${ }^{42}$ Dans son édition, Ritschl relie le v. 644 aux deux précédents, place le point d'interrogation après fieres et donne au sens de uindex le sens de «meurtrier, bourreau ». Nous préférons donner à uindex le sens de "protecteur, champion» (cf. Cic. Sest. 144; Phil. II, 30) et garder la ponctuation suggérée par E. H. RenKeMA, «Ad Plauti Trinummum », Mnemosyne, 58, 1930, p.114-120, qui est aussi celle retenue par A.Ernout. Cf. A. G. Hopkins, "On a Misunderstood Passage in the Trinummus of Plautus, v. 642-4», $C R, 9,1895$, p. 307-309, qui donne à uindex le sens de "protecteur» mais conserve la ponctuation de Ritschl, ce qui l'oblige à d'inutiles contorsions pour donner du sens à la phrase (le v. 644 serait alors ironique et atque possèderait un sens adversatif; "It is Lesbonicus' pretended regard for rumor that rouses the wrath of Lysiteles »; p. 309). Vindex se construit habituellement avec le génitif de l'objet protégé mais semble ici admettre un complément au datif qui indique le but de l'action (protéger les descendants pour leur honneur) ou son objet (protéger l'honneur des descendants): des noms d'agent (adiutor, comes,...) peuvent en effet se construire avec le datif (Cic. ND I, 17; Ernout et Thomas, Syntaxe latine, p. 65). 
ment; qu'on ne puisse pas colporter à mon sujet

Que je t'ai donné ma sœur comme concubine,

Si je te la donnais sans dot, plutôt que comme épouse légitime.

Qui passerait pour plus malhonnête que moi? La rumeur publique

T'honorerait, elle me traînerait dans la boue. Si tu l'épousais sans dot,

L’honneur serait ton bénéfice; moi je n'y gagnerais que reproches. »

(PL. Trin. 688-694).

Lesbonicus se montre très soucieux du qu'en-dira-t-on, sans doute parce qu'il en va de l'honneur de sa sœur et non plus seulement du sien. L'expression famigeratio honestet est particulièrement intéressante, car on voit que c'est la rumeur publique, presque personnifiée ici par le mot expressif de famigeratio, qui peut honestare, c'est-à-dire conférer l'honos. C'est le discours collectif des concitoyens, sous la forme de l'éloge, du blâme ou du racontar qui alimente l'honos ou, à l'inverse, recouvre de boue (conlutulentet). Cette place prise par la fama dans la constitution de l'honos montre que ce dernier ne repose pas seulement sur la vision et l'observation de signes d'estime: il implique aussi une notoriété orale. La comédie manifeste une anxiété particulière sur ce sujet mais la place prise par la fama apparaît également dans d'autres textes plus sérieux, comme le Pro Sulla, quand Cicéron répond au quolibet de peregrinus que lui a adressé son adversaire:

Ac si tibi nos peregrini uidemur quorum iam et nomen et honos inueterauit et urbi huic et hominum famae ac sermonibus, quam tibi illos competitores tuos peregrinos uideri necesse erit qui iam ex tota Italia delecti tecum de honore ac de omni dignitate contendent!

«Et si nous semblons des étrangers à tes yeux, nous dont la réputation et l'honneur se sont fixés depuis longtemps dans cette ville et dans l'opinion et les propos des hommes, comme ils devront te sembler étrangers ces concurrents qui, choisis parmi tous les peuples d'Italie, rivalisent désormais avec toi pour chaque magistrature et chaque dignité! »

(CIc. Sull. 24).

Le texte apporte une précision intéressante sur le rôle joué par la réputation dans le fonctionnement de l'honos: Cicéron y met en relation étroite le nomen, la renommée, et l'honos, l'honneur, et affirme que les propos de l'entourage sont ce par quoi l'honos inueterauit, arrive à maturité. L'honneur se propage donc au sein de la collectivité par le biais des discours évaluatifs de ses membres.

\section{LE PARADIGME SYMBOLIQUE: SIGNE ET REPRÉSENTATION}

Une fois posées les bases de l'interaction sociale propre à l'honos, il nous faut observer la manière dont interagissent ses composants essentiels. Le procès de l'honos met en jeu trois éléments fondamentaux, la marque d'honneur concrète, l'estime subjective que l'on nourrit 
pour quelqu'un, et la situation de prestige objective dont on jouit. Ce sont les rapports entre ces trois pôles qu'il faut éclairer. La marque d'honneur est-elle conçue par les Romains comme une émanation de l'estime? Sert-elle à concrétiser cette dernière aux yeux de celui à qui elle est donnée? Quelle est à Rome la nature et la place de ce que nous nommons «estime»? Quelle fonction jouent les marques d'honneur dans la constitution du prestige social? Les réponses à ces différentes questions feront apparaître que l'honos fonctionne au moyen de signes et de symboles, qu'il compose des images sociales, qu'il joue sur la visibilité et délivre des informations. L'honos nous paraît ainsi opérer selon un paradigme symbolique - "symbolique» étant entendu au sens large comme ce qui emploie des signes et se constitue dans leur domaine, sans se limiter aux symboles, qui sont un type particulier de signe.

\subsection{La marque d'honneur comme signe d'estime du donateur}

La première interaction qu'il nous faut éclairer est celle de l'estime et de la marque d'honneur. Comment s'articulent la considération que le sujet nourrit pour un tiers et l'action de lui rendre hommage?

\subsubsection{L'estime à l'origine de l'hommage}

Une première lecture des textes concernant l'honos fait apparaître que l'estime est ce qui donne son impulsion à la dynamique de l'honos. Lacte de rendre hommage trouve sa source dans la disposition d'esprit favorable de son auteur à l'égard de la personne honorée et matérialise cette opinion. Tel est le fonctionnement de l'honos dans le livre III du De republica, quand Philus imagine le destin d'un homme injuste qui réussirait à se faire honorer au sein de sa cité. Philus suppose que les citoyens se font une fausse opinion de sa nature réelle et que la collectivité existimet esse summa probitate ac fide, "estime qu'il est d'une honnêteté et d'une loyauté extrêmes ${ }^{43}$. La conséquence de cette estime est immédiate:

[...] contra autem ille inprobus laudetur, colatur, ab omnibus diligatur, omnes ad eum honores, omnia imperia, omnes opes, omnes undique copiae conferantur, uir denique optimus omnium existimatione et dignissimus omni fortuna iudicetur: quis tandem erit tam demens qui dubitet utrum se esse malit?

«<Suppose > au contraire que le gredin dont nous parlions soit loué, honoré, aimé de tous, que tous les honneurs, tous les commandements, tous les moyens d'agir et toutes les ressources matérielles lui soient offerts de tous côtés et qu'il soit jugé finalement, selon l'avis unanime, comme le meilleur et le plus digne de

${ }^{43}$ CIc. Rep. III, 58. 
toutes les faveurs du sort: qui donc sera assez fou pour hésiter à faire un choix entre ces deux destinées?»

(Cic. Rep. III, 28; trad. Bréguet modifiée).

L'évaluation positive de l'homme injuste débouche sur différents bienfaits, dont des honores. C'est parce qu'il y a initialement un jugement favorable porté sur lui (bien qu'il soit erroné) que des marques d'honneur lui sont octroyées. L'honos émerge de l'estime de la collectivité. Il importe cependant de bien cerner la nature de cette estime: il ne s'agit pas d'un sentiment ou d'une disposition affective mais d'un acte intellectuel et objectif d'évaluation. La cité existimet esse summa probitate, elle apprécie de façon neutre et collective sa valeur morale. La fin du texte le confirme et explicite le fonctionnement de cette évaluation. Si l'homme injuste est honoré, c'est parce que dignissimus omni fortuna iudicetur: il fait l'objet d'un «jugement » de nature axiologique, qui porte sur son mérite. La cité évalue les qualités de l'individu à l'aune des valeurs du groupe et, s'il apparaît en conformité avec elles, il reçoit un jugement favorable qui donne lieu ensuite à l'octroi de marques d'honneur. La première étape de l'honos est donc une évaluation et un jugement axiologiques. C'est ce qui apparaît aussi dans le De officiis:

Quaecumque igitur homines homini tribuunt ad eum augendum atque honestandum, aut beniuolentiae gratia faciunt cum aliqua de causa quempiam diligunt, aut honoris si cuius uirtutem suspiciunt quemque dignum fortuna quam amplissima putant [...].

«Ainsi donc, tout ce que les hommes accordent à l'homme pour le grandir ou l'honorer, ils le font soit par bienveillance lorsqu'ils ont une raison de l'aimer, soit pour lui rendre hommage s'ils admirent sa vertu et le jugent digne de la plus grande fortune $[\ldots]$..»

(CIc. Off. II, 21 ; trad. Testard modifiée).

Laction entreprise honoris gratia, pour rendre hommage, repose selon Cicéron sur une double condition. Il faut que les hommes aient pour celui qu'ils honorent une certaine admiration et qu'ils aient observé sa valeur (uirtutem suspiciunt): c'est l'évaluation morale. Et ils doivent aussi penser qu'il mérite, en raison de sa valeur, de recevoir des bienfaits (dignum putant): c'est le jugement axiologique du mérite. La conformité d'une personne aux normes éthiques de la cité, incarnées ici dans la uirtus, est appréciée par le groupe qui décide alors de lui octroyer un honos ${ }^{44}$. L'hommage procède de l'estime.

Il importe cependant de préciser que, de manière générale, cette estime ne reçoit pas de définition ni de contenu théorique fort dans les textes. L'origine de l'hommage n'est pas pensée au moyen d'une notion

${ }^{44} C f$. Cic. Vat. 2 où l'honos est donné à celui que l'on dignum putet, que l'on pense digne de le recevoir. 
unique bien délimitée. La seule qui semble relativement apte à jouer ce rôle est celle de uoluntas, et encore reste-t-elle assez floue. On la voit d'ailleurs intervenir en dehors des traités théoriques de Cicéron. On la rencontre par exemple dans une de ses lettres, datant d'octobre 54 avant J.-C.:

Caesaris amore quem ad me perscripsit unice delector; promissis iis quae ostendit non ualde pendeo, nec sitio honores nec desidero gloriam magisque eius uoluntatis perpetuitatem quam promissorum etiam exspecto.

«L'amitié de César, dont il me parle longuement, me cause une joie sans pareille; quant aux promesses qu'il fait luire à mes yeux, elles ne me donnent guère d'impatience: je n'ai pas soif d'honneurs, je ne regrette pas la gloire, je désire plus voir durer toujours ses sentiments que voir s'accomplir ses promesses.»

(Cic. Q. fr. III, 5, 3; trad. Constans).

Cicéron, plein d'amertume après les accords de Lucques et l'acquittement de son ennemi Gabinius dans un procès de maiestate, prend du recul vis-à-vis de la politique. Il déclare ne pas rechercher les honores que lui promet César et préférer voir durer sa uoluntas envers lui plutôt qu'obtenir les honores qui découlent de cette bienveillance. La uoluntas est invoquée mais rattachée de façon assez lâche au procès de l'honos. Elle apparaît ailleurs comme ce qui est mobilisé par le donateur lors de l'octroi de l'honos: les honores extorqués aux Siciliens par le préteur de Sicile étaient sans valeur car ils ne les avaient pas octroyés sua uoluntate ${ }^{45}$. Cette même uoluntas joue un rôle prépondérant pour le candidat à un honos politique: dans le Commentariolum petitionis, Quintus Cicéron signale que la petitio magistratuum doit s'efforcer d'obtenir deux choses, le dévouement des amici et la popularis uoluntas ${ }^{46}$. C'est de fait au moyen de la uoluntas du peuple, par son entremise, que l'honos est conféré à un candidat ${ }^{47}$. La notion de uoluntas ne fait donc pas l'objet d'une très nette théorisation, mais elle est perçue à plusieurs reprises comme le moyen par lequel l'honos se porte sur quelqu'un: l'absence de uoluntas conduit à l'absence d'honos ou alors à un honos contraint et par là-même dénaturé. Elle ne renvoie pas à un sentiment, mais à une disposition maîtrisée, proche de la "volonté " puisqu'elle conduit à l'expression d'un choix, par le biais de l'élection par exemple. Elle ne s'identifie pas cependant tout à fait à elle car ce n'est pas une pure faculté intellectuelle: elle implique une certaine bienveillance, voire une sympathie, pour la personne qui est honorée.

${ }^{45}$ CIC. Verr. II, II, 157. Voir aussi CIC. Verr. II, II, 143 où il apparaît nécessaire que celui qui confère un honos ne le fasse pas inuitus, ce qui ôterait tout son sens à la marque d'honneur.

${ }^{46}$ Q. Cic. Comm. 16, entre autres.

${ }^{47}$ Cic. Vat. 10. Sur la dimension politique de la uoluntas, Hellegouarc'H, Vocabulaire, p. 181 . 
Que l'estime à la source de l'honos soit perçue de manière un peu incertaine ne remet pas en cause son rôle opératoire. En revanche, un certain nombre de textes font passer au second plan l'estime par rapport à l'action de rendre hommage. Il s'agit certes de cas limites mais qui nous paraissent révélateurs du caractère potentiellement problématique de l'articulation entre honos et estime. Les dieux sont un des destinataires possibles de l'honos et l'on sait qu'à Rome l'accomplissement scrupuleux des gestes rituels possède beaucoup plus d'importance que l'existence d'une foi personnelle. Les actes du culte dont font partie les honores ne sont pas dictés par l'estime mais par la nécessité de respecter la coutume. La religion romaine se fonde, pour reprendre l'expression de J. Scheid, sur une « orthopraxie » et non sur une orthodoxie: l'honos sacré est une suite codifiée de gestes pour lesquels l'évaluation positive est secondaire ${ }^{48}$. Il peut aussi arriver que l'honos soit employé par quelqu'un pour parvenir à ses fins sans qu'une opinion favorable ne préside à son octroi. Cicéron indique ainsi que Verrès a fait au syracusain Cléomène un honos remarquable: il lui a confié le commandement de la flotte de Sicile, mais dans le seul but de l'éloigner pour courtiser son épouse ${ }^{49}$. L'honos repose sur un calcul et non sur l'estime. Les relations entre Rome et les peuples voisins fournissent bien d'autres exemples d'honores motivés par la stratégie diplomatique et non par une opinion positive ${ }^{50}$. On rencontre même, dans le contexte particulier de la comédie, des situations où l'honos procède d'un état d'esprit contraire à toute considération: dans le Poenulus des personnages confèrent un honos au leno, qu'ils n'estiment aucunement, pour le prendre au piège ${ }^{51}$.

\subsubsection{L'honos comme signe d'estime}

Ces quelques exemples problématiques nous amènent à penser que l'articulation entre l'estime et la marque d'honneur est plus complexe qu'un rapport de cause à effet. L'opinion favorable donne son impulsion à l'hommage mais elle est, simultanément, ce qui est signifié par cet hommage ${ }^{52}$. Cet aspect est même prépondérant et c'est le plus

\footnotetext{
${ }^{48}$ Voir l'analyse du sacrifice faite par J. ScHeId, La Religion des Romains, réimpr. de

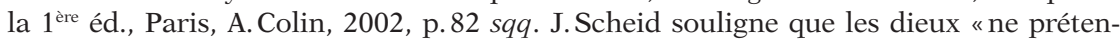
daient pas contrôler les consciences. Ils ne se préoccupaient guère des intentions de ceux qui les honoraient et se bornaient à réclamer et à recevoir leurs hommages » (p. 124).

${ }^{49}$ Cic. Verr. II, V, 82. Voir aussi l'honos fait par Clodius à Caton (qu'il hait) d'une mission à Chypre (Cıc. Dom. 21).

${ }^{50}$ Voir par exemple LIv. VII, 30, 4 pour les relations d'honos entre Romains et Samnites. L'honos fait par les Romains à leurs voisins repose sur un traité et ne se fonde sur aucune appréciation particulière; c'est un geste d'amicitia au sens politique du terme, une alliance d'intérêts.

${ }^{51}$ PL. Poen. 638-639.

${ }^{52}$ L'analyse sémantique a déjà montré la place que joue le sème du /signe/ dans le
} 
souvent selon le modèle du signifiant et du signifié que la marque d'honneur et l'estime sont appréhendées. La culture romaine produit un très grand nombre de signes: on sait l'importance de l'actio pour l'orateur qui doit veiller pendant son discours à ses gestes, qui sont autant de signes de ses sentiments ${ }^{53}$; l'acteur aussi porte des signes sur son corps quand il joue son rôle par ses mimiques et sa gestuelle. Il existe en outre de nombreux objets servant à signifier l'identité sociale ou la fonction politique: les affranchis portent le pileus, les chevaliers l'anneau d'or, les magistrats possèdent les faisceaux et la chaise curule. Le Romain est donc amené quotidiennement à pratiquer une lecture sémiotique de l'apparence extérieure ${ }^{54}$. C'est dans ce monde de signes que s'insère la marque d'honneur. C'est selon ce que nous nommerons un "paradigme symbolique» que les Romains eux-mêmes comprennent l'honos. La marque d'honneur, comme le signe linguistique défini par Saussure, est pourvue de deux faces: un signifiant, une action ou un objet, et un signifié, le «concept » abstrait, dans notre cas, l'estime ${ }^{55}$. Dans le Pro Caelio, Cicéron évoque les honores qu'a reçus son client:

Nam quod est obiectum municipibus esse adulescentem non probatum suis, nemini umquam praesenti Praetutiani maiores honores habuerunt, iudices, quam absenti M. Caelio; quem et absentem in amplissimum ordinem cooptarunt et ea non petenti detulerunt, quae multis petentibus denegarunt.

«On a reproché à Caelius de n'avoir point l'estime de ses compatriotes; or, jamais personne résidant à Praetutium n'y a reçu plus grands honneurs, juges, que M.Caelius, qui n'y résidait point; même absent, il est entré par cooptation dans l'ordre le plus élevé de la cité et, sans candidature, il s'est vu conférer des titres qu'on avait refusés à plus d'un candidat déclaré. »

(Cıc. Cael. 5 ; trad. Cousin).

Cicéron fait mention de ces honores car ils constituent le signe de l'estime que nourrit son entourage pour Caelius: les égards concrets accordés à Caelius sont le signifiant, et la considération des compa-

sémantisme d'honos (voir par exemple supra p. 49 sqq. pour le sens «marque d'honneur, hommage»).

${ }^{53}$ Voir le livre XI de l'Institution Oratoire que Quintilien consacre à la gestuelle de l'orateur, ainsi que U.MaIER-EichHorn, Die Gestikulation in Quintilians Rhetorik, Frankfurt am Main, P.Lang, 1989 et G. S. Aldrete, Gestures and Acclamations in Ancient Rome, Baltimore, Johns Hopkins University Press, 1999, p. 3-43.

${ }^{54} \mathrm{P}$. Cordier souligne que c'est de la fréquentation habituelle des signes extérieurs que naît l'angoisse liée à la nudité: le Romain nu est dépourvu de signes et n'est donc plus clairement identifié socialement (CoRDIER, Nudités romaines, chap. 10).

${ }_{55}$ F. De Saussure, Cours de linguistique générale, Paris, Payot, 1974, p.98-99. Saussure insiste à juste titre sur le fait que le signifiant du signe linguistique est l'image acoustique et non le son matériel: c'est l'empreinte psychique du son. Il en va de même, mutatis mutandis, du signe d'estime. Par commodité, nous serons cependant amenés à parler de signifiant «concret » et de signifié «abstrait », même si les deux ont une réalité psychique. 
triotes le signifié. Dans le contexte du procès, la nature de signe de l'honos apparaît de manière particulièrement éclatante car l'honos est invoqué comme la preuve indubitable que Caelius est probatus, qu'il est favorablement apprécié par la communauté; l'existence d'honores permet à l'orateur de balayer les doutes que l'accusation a émis sur la considération de Caelius. Le signe qu'est l'honos prend ici, pour Cicéron, la forme particulière de ce que C.S. Peirce désigne comme un "indice» car l'objet signifiant est lié de manière existentielle à ce qui est signifié: le signe est réellement affecté par ce à quoi il renvoie, sa présence est concomitante à celle de l'objet qu'il désigne, l'estime, comme le symptôme est lié à la maladie ${ }^{56}$. C'est sa nature indicielle qui permet à Cicéron de l'utiliser comme preuve. Mais l'honos n'est pas toujours l'indice de l'estime, il peut la signifier sans l'existence de cette dernière. Dans ses recommandations sur la façon de traiter les ouvriers agricoles, Varron prescrit de manifester des égards aux chefs des esclaves:

Inliciendam uoluntatem praefectorum honore aliquo habendo, et de operariis qui praestabunt alios, communicandum quoque cum his quae facienda sint opera, quod, ita cum fit, minus se putant despici atque aliquo numero haberi a domino.

«Il faut se concilier la bonne volonté des chefs en les traitant avec quelques égards, et parmi les ouvriers s'il y en a de supérieurs aux autres, il faut les mettre au courant du programme des travaux, car, à procéder ainsi, ils se sentent moins méprisés et tenus par le maître pour quantité non négligeable.»

(VARR. RR I, 17, 6; trad. Heurgon).

Les honores que le maître adresse aux ouvriers ne procèdent pas de son estime pour eux et ne visent qu'à accroître leur productivité en les ménageant. Mais cette efficacité n'est possible que parce que les honores signifient l'estime du maître pour les esclaves. Ils expriment de façon matérielle la considération du dominus puisque les ouvriers, une fois l'honos accordé, pensent qu'ils sont davantage estimés et se sentent moins méprisés (minus se putant despici). Le putant indique que l'estime est signifiée sans être réelle, mais cela n'engage nullement l'efficacité de l'honos: il suffit que le message de l'honos soit reçu, que le destinataire ait la représentation de l'estime du donateur, pour que sa disposition d'esprit devienne favorable à celui qui l'honore. Ici encore, l'honos conféré par le maître aux esclaves a une face concrète (les bons traitements) et une face abstraite (l'estime bienveillante). L'honos n'est pourtant pas fréquemment caractérisé par les textes comme signum: on en trouve un exemple chez Plaute et un autre chez

${ }^{56}$ L'indice est « un signe qui renvoie à l'objet qu'il dénote parce qu'il est réellement affecté par cet objet» (C.S. PEIRCE, Écrits sur le signe, Paris, Seuil, 1978 2, 247, p. 140). Il a nécessairement quelque qualité en commun avec l'objet. Un indice perd sa particularité d'indice quand son objet est supprimé (PEIrce, Écrits sur le signe 2, 304, p. 140). 
Cicéron ${ }^{57}$. C'est probablement parce que ce terme n'a pas en latin une grande profondeur abstraite ${ }^{58}$. On trouve en revanche à Rome d'autres signes en rapport avec l'honneur, comme les marques d'infamie qui sont le pendant négatif de l'honos. La faute morale est ainsi souvent perçue par les Romains comme une tache, une souillure visible qui dit le vice: Cicéron reproche ainsi à Pison et Gabinius d'avoir acquis des «marques éternelles d'ignoble turpitude ${ }^{59}$. Une autre nota, institutionnelle et encore plus concrète, est la nota censoria que peuvent infliger les censeurs lors du cens. Aux citoyens s'étant rendus coupables d'une faute morale les censeurs donnaient cette nota en inscrivant une marque sur les registres à côté du nom du citoyen ${ }^{60}$.

Si l'honos est un signe il possède une matérialité bien établie, un signifiant, mais aussi un signifié dont il faut préciser la nature. Il s'agit de l'«estime», comprise comme évaluation axiologique et jugement intellectuel, que nous avions identifiée à la source de l'hommage. Dans un passage de l'In Vatinium, Cicéron évoque incidemment les occasions qui sont données au peuple d'exprimer son jugement:

Duo sunt tempora, quibus nostrorum ciuium spectentur iudicia de nobis, unum honoris, alterum salutis. Honos tali populi Romani uoluntate paucis est delatus ac mihi, salus tanto studio ciuitatis nemini reddita. De te autem homines quid sentiant, in honore experti sumus, in salute expectamus.

«Il y a deux circonstances où l'on peut observer le jugement de nos concitoyens à notre égard: l'une concerne l'honneur, l'autre l'intégrité. Peu de gens ont obtenu comme moi un honneur avec une telle adhésion du peuple romain, et personne n'a recouvré son intégrité civile avec autant de marques d'affection. Quant à l'opinion que les gens ont de toi, nous l'avons constatée quand tu as brigué un honneur, et nous attendons de la voir quand ton intégrité civile sera en jeu.»

(CIc. Vat. 10).

${ }^{57}$ PL. Rud. 196 rapproche l'honos d'un signum envoyé par les dieux. Cic. Att. II, 18 rapproche les honores donnés à Curion de signa beneuolentia. Signalons cependant que le mot signum dans le texte de Plaute est issu d'une correction de Leo, qui nous paraît recevable.

${ }^{58} \mathrm{Il}$ est plutôt réservé à des objets appartenant à des domaines spécialisés: le signal de l'attaque ou les enseignes à l'armée (CAES. BG II, 20); les prodiges comme signes des dieux dans la religion (Cic. Diu. I, 15); les symptômes des maladies en médecine (PuIN. NH XXVI, 123); la statue dans le domaine de l'art (CIC. Verr. II, IV, 1); l'astre en astronomie (Ov. Fast. V, 113). Sur le mot signum, S. Dorothée, À l'origine du signe, le latin signum, Paris, L'Harmattan, 2006.

${ }^{59}$ CIc. Pis. 42: sempiternas foedissimae turpitudinis notas. Voir aussi LuciL. frg. XXXIX, 64.

${ }^{60}$ CIc. Clu. 120; Rep. IV, 13, frg. 1; LIv. XXIX, 42, 6; VAL. MAX. IV, 1, 10. À la nota censoria était adjointe une subscriptio qui décrivait la nature des fautes reprochées. Voir G. Pieri, L'Histoire du cens jusqu'à la fin de la République romaine, Paris, Sirey, 1968, p.113 et J.Suolahti, The Roman Censors, Helsinki, Suomalaien Tiedeakatemia, 1963, p. 59-61. Sur cette sanction censoriale, voir infra p. 449-451. 
Cicéron note ici que l'octroi d'un honos politique est un des moments où le iudicium du peuple est rendu manifeste (spectentur iudicia). Le fait que Vatinius ait échoué lors de sa candidature à l'édilité est le signe de ce que pensent de lui les électeurs: il montre parfaitement quid sentiant. L'honos exprime ainsi une évaluation intellectuelle. Habituellement, ce que dit l'honos est perçu de manière transparente par les personnes à qui il est destiné. Seuls des individus situés en marge de la collectivité romaine sont susceptibles de ne pas en comprendre le sens. C'est ce qui se produit avec les Allobroges que César a intégrés dans son armée et qu'il couvre de marques d'honneur. Les Gaulois, parce qu'ils sont des barbari, ne mesurent pas exactement le sens de ces honores et les interprètent comme le signe de l'amicitia aveugle et indéfectible de César à leur égard, ce qui les rend arrogants et méprisants vis-à-vis des autres soldats et finit par causer leur perte $^{61}$. Ne faisant pas partie de la cité et n'en partageant pas les codes, ils échouent à percevoir la signification, fondée sur une convention, des marques d'honneur ${ }^{62}$.

\subsection{Le prestige comme représentation}

Nous avons vu jusqu'à présent comment la marque d'honneur signifiait de manière concrète à un tiers l'estime qu'un individu nourrit à son endroit. Mais la relation entre hommage et estime est plus complexe car l'estime a deux faces: une subjective, l'opinion positive du donateur, et une objective, la considération dont jouit celui qui reçoit des marques d'honneur. Quelle est la relation entre l'honos considération et l'honos marque d'honneur?

\subsubsection{Un signe performatif}

Le signe qu'est la marque d'honneur signifie l'estime du donateur mais, simultanément, instaure une situation de prestige pour le destinataire. On retrouve ainsi dans l'honos une caractéristique de certains signes linguistiques qui délivrent une information mais agissent aussi sur les personnes à qui ils sont adressés. Il y a des actes de langage par lesquels le locuteur fait quelque chose en le disant ${ }^{63}$.

${ }^{61}$ CAES. $B C$ III, 59, 2-3.

${ }^{62}$ Euclion, l'avare de l'Aulularia rencontre la même difficulté. Il est persuadé que les honores qu'on lui fait constituent une manœuvre visant à le dépouiller et ne comprend pas qu'ils signifient l'estime (PL. Aul. 462-463). Sa monomanie rend toute communication avec lui impossible et empêche l'honos de délivrer son message. Sur l'imperméabilité de l'avare au monde qui l'entoure, D. Konstan, "The Social Themes in Plautus' Aulularia», Arethusa, 10, 1977, p.307-320.

${ }^{63} \mathrm{Ce}$ sont les actes illocutionnaires, qui possèdent des effets perlocutionnaires: F. Armengaud, La Pragmatique, 4e éd., Paris, P.U.F., 1999, p.77-79. Sur les actes de 
L'honos, comme ces signes linguistiques qui sont en même temps des actes, est un signe "performatif» qui réalise quelque chose en délivrant un message ${ }^{64}$. Dans une lettre de 46 avant J.-C. adressée à Sulpicius, Cicéron explique pourquoi il a soutenu l'honos que le sénat avait proposé de rendre à son ami :

[...] non existimaui me saluo iure nostrae ueteris amicitiae multorumque inter nos officiorum facere posse, ut honori tuo deessem; itaque affui supplicationemque tibi libenter decreui nec reliquo tempore ullo aut rei aut existimationi aut dignitati tuae deero.

«[...] j’ai pensé que je ne pouvais, sans trahir notre vieille amitié et les nombreux services que nous avons échangés, me dispenser de prendre part à l'hommage qui t'était rendu; aussi ai-je assisté à la séance et voté avec plaisir la supplication en ton honneur, et à l'avenir je ne manquerai en aucune circonstance de servir tes intérêts, ta réputation ou ton rang. »

(CIc. Fam. XIII, 77, 1; trad. Beaujeu).

Cicéron considère qu'en intervenant en faveur d'un honos pour Sulpicius il a travaillé à soutenir son existimatio et sa dignitas. La lettre suppose bien que c'est au moyen de l'honos que l'existimatio de Sulpicius, la considération publique dont il jouit, a été défendue et renforcée. La marque d'honneur instaure ici l'estime ${ }^{65}$. De la même façon, Cicéron déplore, à propos des statues que Verrès s'est fait octroyer, que l'on puisse ainsi se laisser gouverner earum honore aut gloria, "par l'honneur et la gloire qu'elles procurent»: les honores que sont les statues créent de toutes pièces le prestige et la célébrité66. C'est d'ailleurs une des raisons pour lesquelles Cicéron s'attarde sur cette affaire: il ne supporte pas que Verrès ait essayé, en forçant les Siciliens à lui élever des statues, de se créer un honneur factice et de dissimuler l'infamie de sa préture ${ }^{67}$. Cette capacité performative de l'honos explique qu'il soit particulièrement recherché par les hommes publics ${ }^{68}$.

langage, voir J.L.Austin, Quand dire, c'est faire, Paris, Seuil, 1962 et J.R. Searle, Les Actes de langage. Essai de philosophie du langage, Paris, Hermann, 1972.

${ }^{64}$ Austin, Quand dire, c'est faire, p. 47-48.

${ }^{65} \mathrm{Cf}$. une lettre avec un raisonnement semblable: CIc. Fam. XV, 10, 2.

${ }^{66}$ CIc. Verr. II, II, 143. Voir aussi Cic. Lael. 34 où l'honos est la source de la gloria.

${ }^{67}$ Voir notamment Cic. Verr. II, II, 168 où le nom honorable des Siciliens inscrit sur les statues que Verrès se fait construire lui sert à infamiam [...] exstinguere.

${ }^{68}$ Projetant sur les Numides une réalité bien romaine, Salluste fait état des conflits que génère cette recherche de l'honos après la mort de Micipsa parmi ses descendants. Hiempsal, fils cadet du roi, essaie d'empêcher Jugurtha d'occuper la place centrale parmi les sièges réservés aux princes: l'obtention de cet honneur établirait en effet le prestige supérieur de Jugurtha, lui conférant un élément de pouvoir décisif en cette période incertaine de succession (SALL. Iug. 11, 3). 
Dans le domaine politique, chaque succès à une élection, chaque honos obtenu, permet d'augmenter le prestige social ${ }^{69}$.

La puissance signifiante et créatrice de la marque d'estime est telle que l'honneur, la position supérieure de considération, ne se conçoit pas sans l'existence de ces signes. Le prestige semble même parfois entièrement fondé sur eux, plus que sur l'appréciation favorable du groupe. Dans le domaine de l'honneur, l'ordre du réel est en effet étroitement lié, voire identifié, à l'ordre du symbolique: l'honneur n'existe que parce qu'il y a des signes d'honneur, de même que le mépris n'a de réalité que par les signes de mépris ${ }^{70}$. Quand les Romains cherchent à mesurer l'honos d'un individu, l'intensité de son prestige, ils cherchent avant tout à voir de quelles marques d'honneur il bénéficie. Cela apparaît dans l'Eunuque:
Dum haec loquimur, interea loci ad macellum ubi aduentamus,
Concurrunt laeti mihi obuiam cuppedinarii omnes,
Cetarii, lanii, coqui, fartores, piscatores,
Quibus et re salua et perdita profueram et prosum saepe;
Salutant, ad cenam uocant, aduentum gratulantur.
Ille ubi miser famelicus uidet me esse tanto honore et
Tam facile uictum quaerere, ibi homo coepit me obsecrare
Vt sibi liceret discere id de me.

«Pendant que nous causons, nous arrivons au marché et à cet instant Accourent à ma rencontre, le sourire aux lèvres, tous les marchands de bonnes choses,

Les mareyeurs, les bouchers, les charcutiers, les rôtisseurs, les poissonniers, À qui, dans la richesse comme dans la misère, j'avais rendu et rends encore souvent des services;

Ils me saluent, m'invitent à dîner, me félicitent de ma venue.

Lorsqu'il voit, ce pauvre famélique, que je bénéficie de tant d'honneur et

Que je gagne mon pain si facilement, il commence à me supplier

De lui permettre de devenir mon élève.»

(TER. Eun. 255-262).

Le parasite Gnathon évoque ici plaisamment le prestige considérable dont il jouit auprès des marchands dont il fait fonctionner le commerce. Le personnage qui l'accompagne assiste à toutes les marques d'honneur qu'on adresse au parasite: les gens viennent à sa rencontre (obuiam), lui adressent diverses politesses, comme des saluts (salutant), l'invitent à dîner (ad cenam uocant), et se réjouissent de sa venue (aduentum gratulantur). Il s'agit donc d'un ensemble de prévenances qui, accumulées, font conclure que le parasite jouit

${ }^{69}$ H. ВесK, Karriere und Hierarchie: die Römische Aristokratie und die Anfänge des cursus honorum in der mittleren Republik, Berlin, Akademie Verlag, 2005, p.16. Et ce prestige social obtenu permet, à son tour, de faciliter le succès à une élection. Il y a donc une circularité positive de l'honos.

${ }^{70}$ Voir sur ce point les remarques de Veyne, Le Pain et le cirque, p. 87. 
d'un honneur très important. C'est de l'observation des égards que l'on conclut à l'existence d'une considération importante. Être à l'honneur, être in honore, c'est donc essentiellement recevoir des marques concrètes d'estime ${ }^{71}$. Il faut une sédimentation progressive des marques d'honneur au cours du temps pour pouvoir bénéficier du prestige. L'accumulation de ces signes compose une image prestigieuse, une image de marque: l'honos comme "prestige» fonctionne lui aussi selon un paradigme symbolique.

\subsubsection{L'insigne de prestige}

Ce paradigme symbolique peut encore être précisé. À la différence de l'énoncé linguistique, l'honos n'est pas un signe qui s'efface une fois délivré. C'est un signe «actif», qui exprime un sens au moment où il est octroyé, mais aussi un signe "passif», qui, une fois obtenu, signale la considération dont jouit celui qui le détient. C'est en ce sens que les Romains le considèrent comme un «insigne de prestige». Il marque que la personne qui le détient est quelqu'un d'important et de considéré. Cicéron montre dans le Pro Sulla que le grief de tyrannie qui lui est fait est une odieuse calomnie car il est l'auteur de bienfaits nombreux envers la république. Et cela lui donne le droit de prétendre à un repos mérité:

Ego, tantis a me beneficiis in re publica positis, si nullum aliud mihi praemium ab senatu populoque Romano nisi honestum otium postularem, quis non concederet? Sibi haberent honores, sibi imperia, sibi prouincias, sibi triumphos, sibi alia praeclarae laudis insignia; mihi liceret eius urbis quam conseruassem conspectu tranquillo animo et quieto frui.

«Pour ma part, après avoir donné tant de bienfaits à l'État, si je réclamais au sénat et au peuple romain pour seule récompense un loisir honorable, qui ne me le concéderait pas? Les autres garderaient pour eux les honneurs, pour eux les commandements, pour eux les provinces, pour eux les triomphes, pour eux les autres insignes d'une gloire éclatante; il me serait permis de jouir, l'esprit tranquille et serein, de la vue de cette ville que j’ai sauvée.»

(Cic. Sull. 26).

Après avoir sauvé Rome de la conjuration de Catilina, Cicéron se prend à imaginer qu'il pourrait renoncer aux honores et aux affaires

\footnotetext{
${ }^{71}$ Voir aussi Cic. Verr. II, II, 87 ; Lucr. DRN III, 74-78. Ce fonctionnement de l'estime s'observe aussi dans d'autres contextes historiques. F. CHAUvaUD, «Les experts judiciaires au XIX ${ }^{\mathrm{e}}$ siècle: un groupe social en quête de reconnaissance", in PonTET, J. (éd.), À la recherche de la considération sociale, Bordeaux, MSHA, 1999, p. 79-88, remarque qu'au $\mathrm{XIX}^{\mathrm{e}}$ siècle les experts judiciaires ne bénéficient pas de marques d'honneur concrètes et que leur prestige est de ce fait faible: «Les marques d'honneur ou les symboles qui attesteraient de leur particularité ne parviennent pas à se dessiner. À tel point que, pour les lexicographes du XIX ${ }^{\mathrm{e}}$ siècle, l'expert judiciaire n'existe pas vraiment» (p. 80).
} 
publiques. Ces honores, qui désignent le consulat mais aussi les différents honneurs obtenus après son action glorieuse de 63 , sont compris comme des praeclarae laudis insignia, des «insignes d'une gloire éclatante». Ils ont signifié à Cicéron l'estime du peuple romain quand il les a reçus et ils expriment à présent la laus extraordinaire dont il jouit. Le terme d'insigne montre que l'on reste avec ces honores dans le domaine du signe mais suggère que la marque est possédée et non octroyée. Un mode de pensée similaire est à l'œuvre dans les Catilinaires quand Cicéron déclare préférer, pour prix de son mérite, la gratitude de ses concitoyens à des récompenses concrètes:

Quibus pro tantis rebus, Quirites, nullum ego a uobis praemium uirtutis, nullum insigne honoris, nullum monumentum laudis postulo, praeterquam huius diei memoriam sempiternam. In animis ego uestris omnes triumphos meos, omnia ornamenta honoris, monumenta gloriae, laudis insignia condi et collocari uolo.

«Et pour de si grands services, Quirites, je ne vous réclame aucune récompense due à la vertu, aucune marque d'honneur, aucun monument de gloire si ce n'est le souvenir éternel de ce jour. C'est dans vos cœurs que je veux voir placés mes triomphes, tous les ornements de l'honneur, les monuments de la gloire, les marques de la célébrité.»

(CIc. Catil. III, 26).

On retrouve ici la mention des insignia laudis, des marques de notoriété que sont les honores comme le triomphe ou les monuments. Mais ce texte a en outre l'originalité d'appréhender l'honos, l'«hommage», comme insigne honoris, insigne de l'honos "estime». Les honores concrets marquent le prestige de celui qui les détient. Ils relèvent ainsi de ce qu'E. Goffman nomme des "symboles de prestige», des signes qui transmettent une signification en même temps qu'ils revendiquent une position d'honneur ${ }^{72}$. Le signe d'estime, parce qu'il peut persister dans sa matérialité une fois le message transmis et parce qu'il est visible de tous, se convertit aisément en insigne de prestige.

\subsection{Bilan: le paradigme symbolique}

Le fonctionnement de l'honneur est ainsi marqué par une abondance de processus de représentation et de signification. L'honos, comme marque d'honneur, signifie à celui qui le reçoit l'estime de celui qui le donne. L'honos, comme prestige, est une image de marque qui repose sur la détention de plusieurs insignes et symboles d'honneur. Il y a un fonctionnement symbolique de l'honos, animé d'une vraie dynamique: le signe d'honneur est performatif et instaure la considération du destinataire; il est en outre susceptible d'évoluer et de passer du signe à l'insigne de prestige. L'usage d'un paradigme symbolique pour

${ }^{72}$ E. Goffman, Stigmate. Les usages sociaux des handicaps, Paris, Minuit, 1975, p. 59. 
expliquer la nature de l'honneur romain nous paraît donc efficace, car apte à rendre compte de plusieurs aspects de l'honos, et légitime, car rencontrant un net écho dans les textes anciens. Il nous faudra, dans la suite de notre étude, essayer d'appliquer aux divers aspects de l'honneur ce paradigme afin, d'une part, de vérifier sa validité et, d'autre part, d'approfondir notre lecture de l'honos et de l'honestas. On entreprendra donc une herméneutique de l'honos pour comprendre le sens exact des signes mis en jeu par l'honneur. On s'interrogera également sur la polysémie de la marque d'honneur, apte à signifier l'estime mais aussi le lien social, l'allégeance politique ou l'excellence morale ${ }^{73}$. Utilisant avec profit les travaux de la linguistique saussurienne, on questionnera également le rapport entre le signifiant et le signifié: le signe d'honneur est-il arbitraire ou motivé ${ }^{74}$ ? Les outils théoriques mis au point par la sémiotique de C.S.Peirce, comme la distinction faite, au sein du monde des signes, entre icône, symbole et indice, nous permettront aussi de préciser le rapport de l'image et de l'idée ${ }^{75}$.

\section{LE PARADIGME ÉCONOMIQUE: RÉTRIBUTION ET CAPITAL}

L'évaluation axiologique menée par le donateur de l'honos nous amène à nous interroger sur la place des qualités évaluées dans l'émergence de l'honos. C'est en effet de la conjonction d'un jugement du donateur et d'un comportement du destinataire que naît l'honneur. Le lien du motif de l'honos et de sa réalisation constitue une autre de ces structures fondamentales de fonctionnement qu'il nous faut expliquer. Or cette entreprise fait apparaître un autre paradigme, parallèle à celui précédemment identifié. La marque d'honneur est un signe mais elle opère aussi, à un autre niveau, comme une rétribution, un salaire accordé pour un mérite reconnu. Et l'accumulation des honores permet à l'individu qui les reçoit de se constituer un capital de prestige. Ces deux aspects, qui retiendront maintenant notre attention, nous montrent que l'honos fonctionne selon un paradigme économique. Par «économique», nous n'entendons pas seulement ce qui relève des activités de production, de répartition, d'accumulation et du seul marché (éléments auxquels l'honos peut avoir trait), mais ce qui, plus largement, a un rapport avec des biens ou des services et implique "l'échange et l'usage de moyens matériels »"

${ }^{73}$ Voir chapitre 8 sur les fonctions de l'honos.

${ }^{74}$ Voir infra, chapitre 5 sur les formes de l'honos. De Saussure, Cours de linguistique générale, p. 100.

${ }^{75}$ Peirce, Écrits sur le signe, p. 140 sqq.

${ }^{76}$ M. Godelier, «Objet et méthodes de l'anthropologie économique», L'Homme, 5 (2), 1965, p. 32-91 souligne que l'économique est à la fois « un domaine d'activités particulières (production, répartition, consommation...) et un aspect particulier de toutes les activités humaines qui n'appartiennent pas en propre à ce domaine, mais dont le fonc- 


\title{
3.1. La marque d'honneur comme rétribution
}

La relation entre l'honos et le mérite de celui qui le reçoit est pensée par les Romains en termes économiques. La marque d'honneur est une rétribution car elle constitue le paiement d'un service ou l'acquittement d'une dette créée par les qualités de la personne à honorer.

\subsubsection{Récompense et salaire}

Une approche thématique du rapport entre l'honos et le mérite du bénéficiaire dans les textes de notre période permet de mettre au jour deux représentations récurrentes de l'honos, qui relèvent toutes deux de la rétribution: celle de la récompense et celle du salaire. Le terme même d'honos peut avoir le sens, comme on l'a vu, de "récompense » ${ }^{77}$. Et même quand il désigne la "marque d'honneur", il est appréhendé de façon répétée comme un praemium. C'est le cas dès le $\mathrm{II}^{\mathrm{e}}$ siècle, dans un fragment dramatique anonyme:

\begin{abstract}
Nam sapiens uirtuti honorem praemium, haud praedam petit.
Set quid uideo? ferro saeptus possidet sedis sacras.

«Car le sage recherche pour la vertu un honneur qui soit une récompense, et non un butin.

Mais que vois-je? Bardé de fer il envahit la demeure sacrée.»
\end{abstract}

(TRF inc. frg. 30-31).

Le premier vers associe étroitement honos à praemium et sa forme gnomique indique que ce rapprochement ne sort pas de l'ordinaire. L'honos doit être une rétribution concrète pour un mérite, ici la uirtus, qui désigne la valeur morale du sage. L'honos s'identifie au praemium, notion issue du domaine militaire où elle renvoie à la récompense octroyée au soldat ${ }^{78}$, mais ne doit pas être une praeda, un butin que l'on enlève de force: l'honos est une récompense dûment méritée, octroyée par un tiers. Cette approche est reprise par Cicéron, mais d'une manière plus réflexive et plus analytique, comme dans cette lettre à L. Plancus :

Is enim denique honos mihi uideri solet qui non propter spem futuri benefici, sed propter magna merita claris uiris defertur et datur. [...] Is autem, qui uere appellari potest honos non inuitamentum ad tempus, sed perpetuae uirtutis est praemium.

tionnement entraîne l'échange et l'usage de moyens matériels » (p. 38). Notre définition est proche du sens «matériel» et "final» que P.Veyne donne à «l'économique» dans Veyne, Le Pain et le cirque, p. 78-79.

${ }^{77}$ Voir l'analyse sémantique p. 96.

${ }^{78}$ Sur l'origine et les sens de praemium, voir notre première partie p. 58-59. 
«Car, en fin de compte, je considère comme un honneur celui qui est décerné et attribué à des hommes illustres non pas dans la perspective d'un bienfait futur, mais en raison de grands mérites. [...] L'honneur qui mérite vraiment ce nom n'est point un appât de circonstance, mais la récompense d'une valeur permanente.»

(Cic. Fam. X, 10, 1-2; trad. Beaujeu modifiée).

S'interrogeant sur ce qui fait l'honos authentique, Cicéron met en relief les motifs de ce dernier plutôt que ses effets. L'honneur véritable est amené par les mérites de celui à qui on le donne (propter magna merita) et non par la recherche d'un avantage de la part du donateur. De ce fait, il doit être un praemium uirtutis, une "récompense» pour l'excellence, et non pas un octroi intéressét9.

L'autre représentation rétributive de l'honos est celle du salaire: la marque d'honneur est assimilée à un paiement en argent pour des mérites ou des services précis. La dimension économique de l'honos est alors encore plus nette. Différents termes sont employés pour le suggérer, comme celui de pretium, "salaire ${ }^{80}$, ou celui d'emolumentum:

Si sine dote duxeris,

Tibi sit emolumentum honoris; mihi quod obiectent siet.

«Si tu l'épousais sans dot,

L'honneur serait ton bénéfice; moi je n'y gagnerais que reproches.»

(PL. Trin. 693-694).

Lesbonicus fait remarquer à son ami Lysitélès que s'il acceptait d'épouser sa sœur sans percevoir de dot, il serait, pour cette belle action, payé d'honneur. La largesse qui consiste à laisser l'argent de la dot dans la famille de la future épouse est rétribuée par l'honos qui sert ainsi d'emolumentum, de paiement ${ }^{81}$. Il est aussi question de l'honos comme remuneratio ou comme merces $^{82}$.

${ }^{79}$ Pour d'autres occurrences de l'honos comme praemium uirtutis, voir Cic. Catil. III, 26 et Brut. 280. Il est aussi compris comme praemium dignitatis (CIc. Balb. 1). Sur la proximité de l'honos et du praemium, voir Cic. Balb. 7 ; Phil. III, 7 et V, 4 . Sur la place de la uirtus comme motif d'honos, voir infra p. 307 et 311.

${ }^{80}$ Voir PL. Trin. 272-273 et CAT. frg I, 18 ORF.

${ }^{81}$ Le terme d'emolumentum est à rattacher à molo, "moudre». Il désigne initialement la somme payée au meunier pour son labeur (DELL p. 411; contra, voir É. Benveniste, «Le sens du mot emolumentum », Latomus, 8, 1949, p. 3-7).

${ }^{82}$ Cic. Dom. 27 ; Phil. V, 35 ; Rep. III, 36, frg. 1. L'image est encore celle de la rétribution, la merces étant à l'origine le prix payé pour une marchandise ou pour un travail (voir DELL p. 400 et BenvenISTE, Le Vocabulaire des institutions indo-européennes, vol. 1 p. 169-170). 


\subsubsection{La dette et l'échange}

Ces représentations de l'honos comme récompense et comme salaire ne constituent pas que des métaphores appréciées des auteurs. Il y a un véritable fonctionnement économique de l'honos car le mérite crée une dette auprès de l'entourage: les qualités morales ou civiques d'un individu ou les services rendus à ses proches le constituent comme créancier de ces derniers et l'honos sert à régler cette créance. De même que le travail fourni est rémunéré par un salaire financier, le mérite est rétribué par un salaire d'honneur. À propos de Sulpicius Rufus, dont il vient de louer les différentes qualités, Cicéron déclare:

Augeatur igitur isto honore etiam is uir cui nullus honos tribui non debitus potest; grati simus in eius morte decoranda cui nullam iam aliam gratiam referre possumus.

«Élevons donc aussi par cet honneur cet homme qui ne peut recevoir aucun honneur qui ne lui soit dû; soyons reconnaissants en illustrant la mort d'un individu à qui nous ne pouvons plus accorder aucun autre remerciement. »

(CIc. Phil. IX, 15).

Cicéron, qui demande dans la neuvième Philippique qu'un tombeau soit élevé à Sulpicius aux frais de l'État, considère que cet honneur est légitimé par son mérite: ce dernier est si grand qu'il n'y a aucun honos qui ne lui soit dû, debitus. Le sens premier du mot n'est ici nullement effacé: la res publica est débitrice de Sulpicius pour ses mérites et son action au sein de l'ambassade envoyée à Antoine ${ }^{83}$. L'excellence du défunt crée ainsi une dette pour son entourage qui doit s'en acquitter par une marque d'honneur ${ }^{84}$. L'honos s'inscrit donc dans un processus d'échange: la manifestation de qualités particulières doit être payée en retour par une marque d'honneur car le mérite est perçu comme une dépense consentie par l'individu au profit de la collectivité. La marque d'honneur est ainsi une rétribution mais aussi une compensation; elle instaure un échange de bienfaits entre les protagonistes de l'honos et rétablit un équilibre. Ce processus d'échange apparaît encore plus

${ }^{83}$ Debeo signifie initialement "avoir quelque chose en le tenant de quelqu'un", notamment à propos de l'argent; de là debitum, la dette (DELL p. 165).

${ }^{84}$ L'idée selon laquelle le mérite rend son auteur créancier de l'honos apparaît à plusieurs reprises chez Cicéron. L'honos est un dû pour celui qui a sauvé la patrie (Cic.Catil. III, 2); c'est aussi un dû que la marque d'honneur que l'on adresse aux dieux (CIc. Catil. III, 23). Si Cicéron a voté un honos à Munatius Plancus, c'est parce qu'il a pris en compte quantum a re publica debetur (Cıc. Fam. X, 13, 1). Sur le poids de la dette créée par le mérite, M. Lentano, «Il dono e il debito. Verso un'antropologia del beneficio nella cultura romana », in Haltenhoff, A., Heil, A. et Mutschler, F.-H.(éds.), Römische Werte als Gegenstand der Altertumswissenschaft, Munich, K. G.Saur, 2005, p. 125-142, notamment p. 131. 
nettement quand l'honos rétribue non pas une qualité mais un service rendu car dans ce cas la marque d'honneur, qui est un bienfait, répond à un autre bienfait. C'est pour le beneficium rendu par D. Brutus à la res publica que cette dernière doit l'honorer:

Huic tanto merito Bruti, patres conscripti, tantoque in rem publicam beneficio quis est tantus honos qui non debeatur?

«Ce si grand mérite de Brutus, sénateurs, ce si grand bienfait accordé à la république, quel honneur ne doit-il pas recevoir?»

(CIc. Phil. V, 37).

En prenant la tête de la révolte contre Antoine, Brutus sert les intérêts de la république qui doit le rétribuer en retour. L'honos rendu aux dieux pour les remercier de la victoire accordée à Rome est du même ordre: les divinités ont octroyé un avantage à la cité et cette dernière lui confère en échange un honos ${ }^{85}$. Toute action ayant permis le bien public doit être rétribuée par une marque d'honneur accordée à son auteur. Ce mécanisme de l'honos entre en résonance avec cette autre pratique d'échange, à la fois symbolique et économique, qu'est le don. M. Mauss, dans l'analyse célèbre qu'il en a donné, insiste sur les trois obligations qui président au don: il faut donner, recevoir et rendre $^{86}$. La dernière implique que celui qui reçoit un don est dans la nécessité de restituer un contre-don: il faut donner en échange et si possible donner plus, sous peine de perdre en prestige. Il y a donc une contrainte qui s'exerce sur le don. Cependant, bien souvent, le contredon ne peut être immédiat: du temps doit s'écouler entre le premier cadeau et celui qui lui répondra. Pendant ce temps, un «crédit» est fait à celui qui a donné et ce "crédit» doit être remboursé lorsque le terme arrive ${ }^{87}$. On voit que l'on se trouve ici proche de l'honos: on retrouve les structures de l'échange, de la compensation et de la dette à honorer. Les pratiques de don pourront constituer un intéressant parallèle pour l'étude des pratiques d'honneur ${ }^{88}$.

Il peut paraître incongru de rapprocher l'honos du don ou du salaire: une marque d'honneur n'est-elle pas, par essence, «honorifique » et placée hors de la sphère de l'intérêt et du profit? Il n'en est rien: il s'agit là d'une lecture moderne de l'honneur qui le détache de

${ }^{85}$ Voir par exemple l'honos rendu aux dieux après la victoire de Marcellus (Liv.XXVI, 21, 3).

${ }^{86}$ M. Mauss, Sociologie et anthropologie, $5^{e}$ éd., Paris, P.U.F., 1993, p. 206 sqq.

${ }^{87}$ Ibid., p. 199.

${ }^{88}$ É. BenVENISTE, «Don et échange dans le vocabulaire indo-européen», L'Année sociologique, 3, 1948-1949, p. 7-20 s'est aussi fondé sur les analyses de M. Mauss pour analyser, à partir du lexique, les notions de don réciproque et de rivalité agonistique dans la pensée indo-européenne ancienne. 
manière trompeuse de l'économique ${ }^{89}$. L'apparente incongruité disparaît quand on observe que l'honos suppose, dans de nombreux cas, une réelle dépense de la part de celui qui le donne: l'honos peut en effet prendre la forme d'une somme d'argent, de largesses ou d'autres prestations, comme le triomphe ou les couronnes d'or ${ }^{90}$. L'économique structure en profondeur l'honneur, autant que le symbolique. De même que le don appartient à l'économique, parce qu'il vise la satisfaction et le bénéfice de celui qui le reçoit, mais aussi au symbolique, parce qu'il exprime la relation sociale des protagonistes du don ${ }^{91}$, l'honos relève de l'ordre symbolique par l'estime qu'il signifie et de l'ordre économique par la rétribution qu'il concède et la dette qu'il acquitte. L'honos trouve sa place dans les rapports de don et de bienfaisance qui avaient une importance considérable dans l'Antiquité ${ }^{92}$.

\subsubsection{L'honos signe de gratia}

L'insertion de l'honos dans des procédures d'échange nous conduit à revenir sur la nature de ce qui est signifié par la marque d'honneur. Si l'honos constitue une réponse à un bienfait, il se charge en effet alors d'une autre signification: il manifeste l'estime mais aussi la reconnaissance du donateur, la gratia. C'est là une première manifestation de la polysémie de l'honos. Ce lien de la gratia et de l'honos apparaît bien dans le Commentariolum petitionis. Dans un passage consacré à la manière dont un candidat à une magistrature peut gagner en prestige, l'auteur évoque la pratique du cortège définie comme un honos ${ }^{93}$. Les clients peuvent, pour faire honneur à leur patron qui les a défendus en justice, l'escorter dans ses déplacements:

Praeterea magnam adfert laudem et summam dignitatem, si ii tecum erunt qui a te defensi et qui per te seruati ac iudiciis liberati sunt. Haec tu plane ab his postulato ut, quoniam nulla impensa per te alii rem, alii honestatem, alii salutem ac fortunas omnes optinuerint, nec aliud ullum tempus futurum sit ubi tibi referre gratiam possint, hoc te officio remunerentur.

«En outre, c'est une source de grande gloire et de haute considération si tu es accompagné par ceux que tu as défendus en justice et qui ont été grâce à toi sauvés par un acquittement. Demande-le leur directement; de la sorte, puisque, sans qu'il ne leur en coûte rien, ils ont les uns préservé leur honneur, les autres

\footnotetext{
${ }^{89}$ Le fonctionnement du prestige a été rapproché de manière nuancée de celui de l'économie de marché par Goode, The Celebration of Heroes, p. 41-65.

${ }^{90}$ Sur les formes de l'honos, voir le chapitre 5.

${ }^{91}$ Sur cette double appartenance du don, Veyne, Le Pain et le cirque, p. 88-89.

${ }^{92}$ Ibid., p. 18.

${ }_{93}$ Q. Cic. Comm. 34-38. Sur le cortège comme honos, voir aussi Cic. Cato mai. 63; Mur. 70; Sull. 81; Dom. 76. Voir aussi notre analyse infra p. 265.
} 
leur vie et tous leur fortune grâce à toi et qu'il n'y aura pas d'autre occasion de te témoigner leur reconnaissance, ils te rétribueront pour tes bons offices. »

(Q. CIc. Comm. 38).

L'honos qui consiste à faire cortège à un candidat est pour le client un moyen de referre gratiam à son patron, de lui marquer sa reconnaissance. C'est encore ici un salaire, puisqu'il sert à rétribuer les bons offices du patron (hoc te officio remunerentur). L’honos répond à un bienfait, l'assistance au procès, par un autre bienfait, l'escorte: il y a encore échange économique de bons offices. La notion de gratia elle-même le suggère, notamment dans ses emplois actifs ${ }^{94}$. Le terme peut désigner le sentiment de reconnaissance, défini selon Cicéron par deux traits principaux, le souvenir des bons offices et le règlement de ces derniers ${ }^{95}$. On retrouve ainsi dans cette notion le paradigme économique fonctionnant pour l'honos. La gratia suppose ainsi une relation étroite entre deux individus, placée sous le signe de l'échange et de l'honos ${ }^{96}$. L'importance prise par la gratia dans la société romaine et la nécessité de montrer sa reconnaissance expliquent partiellement l'usage de l'honos ${ }^{97}$ : ce dernier est un excellent moyen de signifier cette reconnaissance.

\subsection{La considération comme capital}

La fonction de rétribution assurée par la marque d'honneur nous amène à reconsidérer notre interprétation de la considération qu'est aussi l'honos. Si la marque d'honneur est un salaire ou une récompense, elle est susceptible d'être thésaurisée par celui qui la reçoit. Chaque honos "hommage» augmente alors l'honos "considération »: il y a accumulation des bienfaits reçus pour constituer un capital d'honneur ${ }^{98}$.

94 Sur la gratia, voir Hellegouarc'H, Vocabulaire, p. 202-208, Moussy, Gratia et sa famille et H. Drexler, "Gratia » in Politische Grundbegriffe der Römer, Darmstadt, Wissenschaftliche Buchgesellschaft, 1988, p. 159-187. L'aspect actif du terme semble premier (Moussy, Gratia et sa famille, p. 251 et Hellegouarc'H, Vocabulaire, p. 203).

${ }^{95}$ Gratiam, quae in memoria et remuneratione officiorum [...] teneat : "la reconnaissance, qui consiste dans le souvenir et la rétribution des bons offices [...]. »(Cic. Inu. II, 66). Voir aussi la définition de Inu. II, 161 qui fait de même intervenir la memoria et la remunerandi uoluntas.

${ }^{96}$ Sur le partenariat présupposé par la gratia, voir Pöschl, "Politische Wertbegriffe in Rom», p. 13. Sur le lien entre honos et gratia voir encore Cic. Mil. 81 et Ad Brut. I, 15,8 .

${ }^{97}$ Sur l'importance de la gratia à Rome, voir Cic. Off. I, 47 et Planc. 68 où une différence est faite entre la pecuniae debitio, la dette d'argent et la gratiae debitio, la dette de reconnaissance: celui qui règle une dette d'argent ne doit plus rien, alors que celui qui s'acquitte d'une dette de reconnaissance conserve en lui durablement la gratia pour son bienfaiteur.

98 Cette notion de capital est utilisée de façon convaincante par M. NAssiET, 


\subsubsection{L'accumulation et la gestion d'un capital d'honneur}

Quand l'honos désigne le "prestige », la "considération » dont jouit une personne, les modalités de sa constitution et de son fonctionnement sont également perçues selon un paradigme économique qui redouble le paradigme symbolique. Les Romains se le représentent en effet comme un bien extérieur: dans le Pro Quinctio, Cicéron suggère que ce pour quoi l'on fait les plus grands efforts est la conservation de sua res et honos, de sa fortune et de sa considération ${ }^{99}$. L'honos apparaît ainsi comme l'une des deux facettes essentielles du patrimoine de l'individu, mis en péril dans le cadre du procès: la res est le patrimoine financier de la personne, l'honos son patrimoine de prestige ${ }^{100}$. La dimension patrimoniale de l'honneur peut même être explicitement affirmée, comme dans ce vers de Publilius Syrus:

honestus rumor alterum est patrimonium

«Une réputation honorable est un second patrimoine. »

(P. Syr. frg. H 15 Meyer $=217 C R F)$.

La réputation honorable, la considération dont on jouit, est un second patrimoine, après celui de l'argent. C'est donc encore selon un paradigme économique que l'honneur est envisagé à Rome. Et de fait l'honos semble avoir les caractéristiques du capital. Il peut d'abord faire l'objet d'une évaluation: les Romains ont conscience que tous ne possèdent pas la même quantité d'honos ${ }^{101}$. Ce prestige, plus ou moins important, repose notamment sur l'accumulation de marques d'honneur: le Romain issu d'une famille honorée par l'obtention de nombreux consulats et de triomphes possède, au sein de l'aristocratie, une position particulièrement prisée. C'est pourquoi l'obtention du consulat, le summus honos, est perçue comme un avantage décisif. Dans la miseratio du Pro Murena, Cicéron indique l'importance de ces honores dans la constitution du prestige:

Nolite, per deos immortalis! iudices, hac eum cum re qua se honestiorem fore putauit etiam ceteris ante partis honestatibus atque omni dignitate fortunaque prinare.

«L'honneur au XVI ${ }^{\mathrm{e}}$ siècle: un capital collectif» in H. DréVILlon et D. VENTURINo (éds.), Vivre et penser l'honneur à l'époque moderne, Rennes, P.U.R., 2011, p.71-90.

${ }^{99}$ CIc. Quinct. 9.

${ }^{100}$ Ces deux facettes de la richesse apparaissent de façon récurrente dans le Pro Quinctio : voir Quinct. 49 et 50.

${ }^{101}$ Voir par exemple PL. 279 et Cic. Sest. 49. Sur ces différences de prestige, voir infra p. $244 s q q$. 
«Ne permettez pas, juges, par les dieux immortels, qu'en plus de cette charge, par laquelle il pensait gagner en prestige, il soit privé aussi des autres honneurs acquis jadis, de toute dignité et de tout bien.»

(CIc. Mur. 87).

C'est l'obtention par Muréna du consulat pour l'année 62 qui le rend honestior, qui accroît son prestige: le capital d'honneur est augmenté de cette marque d'honneur. Mais ce capital est menacé: Muréna est accusé de brigue par Sulpicius Rufus et il risque de perdre, outre l'honos du consulat, toutes les autres honestates, les «marques d'honneur» qu'il avait gagnées ${ }^{102}$. Cette perte des autres distinctions est grave car elle entraînerait une diminution considérable du capital de prestige. L'honos, comme le patrimoine, augmente et diminue; il peut aussi s'hériter et se transmettre. C'est un bien familial, que les ancêtres ont accumulé au fil du temps et qu'il faut préserver et faire passer à ses descendants. En revanche, et cela constitue une différence avec le capital de nature économique, quand l'honos a été totalement détruit, sa perte est le plus souvent irréversible et il est presque impossible de le reconstituer en repartant de zéro ${ }^{103}$.

\subsubsection{L'honos comme "capital symbolique»}

Ce fonctionnement de l'honneur rencontre l'analyse faite par P. Bourdieu du «capital symbolique ${ }^{104}$, concept par lequel le sociologue conceptualise la renommée et la considération, ce qu'est précisément l'honos ${ }^{105}$. P. Bourdieu a mis en évidence l'existence de différents "capitaux», de nature économique, culturelle, sociale et symbolique. Le capital économique est constitué des différents facteurs de production (travail, monnaie, terre, industries,...); le capital culturel recouvre aussi bien les goûts, les titres scolaires que les biens artistiques détenus; le capital social se compose des relations sociales qui peuvent être utilisées avec profit (parents, amis, connaissances, etc.). Quant au capital symbolique, deux textes permettent d'en donner un premier aperçu:

«La position d'un agent déterminé dans l'espace social peut ainsi être définie par la position qu'il occupe dans les différents champs, c'est-à-dire dans la distribution des pouvoirs qui sont agissants dans chacun d'eux, soit principa-

${ }^{102}$ Sur ce sens particulier d'honestas, voir p. 183.

${ }^{103}$ Sur la transmission et la destruction de l'honos, voir notre chapitre 9.

104 P. Bourdieu est revenu régulièrement sur ce concept. Voir notamment P.Bourdieu, Raisons pratiques, Paris, Seuil, 1994, p.116-123 et P.Bourdieu, Esquisse d'une théorie de la pratique, Paris, Seuil, 2000, p.348-376.

${ }^{105}$ Le concept a été utilisé de manière très convaincante dans deux ouvrages récents d'histoire romaine: DAVID, La République romaine, p. 30-31 et K.-J. HöLKESKAMP, Reconstruire une République. La "culture politique» de la Rome antique et la recherche des dernières décennies, Nantes, Les Éditions Maison, 2008, p. 97-111. 
lement le capital économique - sous ses différentes espèces -, le capital culturel et le capital social, ainsi que le capital symbolique, communément appelé prestige, réputation, renommée, etc., qui est la forme perçue et reconnue comme légitime de ces différentes espèces de capital. »106

«Le capital symbolique est une propriété quelconque, force physique, richesse, valeur guerrière, qui, perçue par des agents sociaux dotés des catégories de perception et d'appréciation permettant de la percevoir, de la connaître et de la reconnaître, devient efficiente symboliquement, telle une véritable force magique. »107

Plusieurs éléments de ces définitions peuvent rendre compte de l'honos dans sa complexité. Le terme de "capital symbolique", d'abord, renvoie aux deux paradigmes que nous avons identifiés: le prestige est un patrimoine (un capital) mais participe aussi de l'image de marque (symbolique): il est "efficien[t] symboliquement», ce qui renvoie au rayonnement apporté par les signes d'estime accumulés et au pouvoir qui en découle. Mais les textes de P. Bourdieu montrent surtout l'importance des motifs de l'honneur et le rôle joué par la collectivité dans son émergence. Pour P.Bourdieu, le capital symbolique a ceci de particulier par rapport aux autres capitaux qu'il n'a pas de constituant propre: c'est une sorte de méta-capital qui naît d'un autre capital (économique, social, culturel) quand ce dernier reçoit une reconnaissance publique. N'importe quelle qualité (une "propriété quelconque») peut se transmuer en capital symbolique pour peu qu'elle soit publiquement reconnue. On retrouve là le fonctionnement de l'honos: l'honneur repose sur des qualités comme la «valeur guerrière » évoquée par Bourdieu (la uirtus à Rome) qui accèdent à une reconnaissance supérieure parce qu'elles sont rétribuées par des marques d'honneur; et ces marques sont en même temps des signes qui entérinent la valeur de ce qui est ainsi récompensé. Les motifs de l'honos sont eux aussi des capitaux et il nous appartiendra d'en préciser ultérieurement la nature exacte. L'analyse de P. Bourdieu met en outre en exergue le rôle crucial de la collectivité: la constitution d'un capital symbolique nécessite l'intervention des agents sociaux. L'honneur, en effet, n'existe que par la représentation que les autres en ont, ce qui explique que les signes d'honos, qui manifestent le jugement d'autrui, aient une fonction si importante. Mais P. Bourdieu va plus loin dans l'analyse: il indique que les agents sociaux doivent détenir des «catégories de perception et d'appréciation » qui permettent la transmutation d'un capital en un autre; il s'agit là des croyances communes qui leur permettent de juger que certaines conduites sont honorables ou

${ }^{106}$ P. Bourdieu, Langage et pouvoir symbolique, Paris, Seuil, 2001, p. 295. La mise en gras est nôtre.

${ }^{107}$ Bourdieu, Raisons pratiques, p. 189. La mise en gras est nôtre. 
déshonorantes ${ }^{108}$. Cela correspond, à Rome, au sens de l'honestum, sur lequel nous reviendrons ultérieurement ${ }^{109}$.

L'application du concept de capital symbolique à l'honos nous permet également d'envisager d'une nouvelle manière le rapport entre la marque d'honneur et le prestige. Le capital peut être en effet, selon P. Bourdieu, "objectivé», sous forme de biens matériels, ou bien "incorporé », comme le capital culturel, par exemple, qui n'a pas de visibilité immédiate ${ }^{110}$. L'honos, capital symbolique, a ceci de particulier qu'il se situe dans l'entre-deux. La considération n'est pas en effet quelque chose d'immédiatement palpable: il s'agit d'un faisceau d'opinions favorables. Mais nous avons vu que la dimension performative des marques d'honneur fait d'elles des fondements prépondérants du prestige. Nous pourrions ainsi caractériser l'honos, le prestige, comme un capital incorporé, mais qui tend perpétuellement à s'objectiver. Cette analyse rejoint celle que fait P. Bourdieu du capital symbolique de la noblesse d'Ancien Régime ${ }^{111}$. La noblesse, initialement, repose sur une estime sociale tacite, c'est un prestige incorporé. Puis elle devient statutaire avec le développement des honneurs attribués par le roi et l'État:

«Bref, on passe d'un capital symbolique diffus, fondé sur la seule reconnaissance collective, à un capital symbolique objectivé, codifié, délégué et garanti par l'État, bureaucratisé. ${ }^{112}$

L'honos «prestige» est de même un «capital symbolique objectivé », rendu manifeste par les marques d'honneur mais il n'est pas, à Rome, bureaucratisé.

\subsection{Bilan: le paradigme économique}

L'ensemble de ces éléments nous paraît confirmer la validité du paradigme économique pour interpréter le fonctionnement de l'honos, notamment dans son rapport aux motifs qui déclenchent son octroi. Par la marque d'honneur, le donateur rétribue un mérite du destinataire; et ce salaire, une fois perçu, augmente le capital de prestige du destinataire $^{113}$. La suite de notre étude devra évaluer l'efficacité et les

${ }^{108}$ Sur ces «catégories », voir aussi Ibid., p. 117.

${ }^{109}$ Voir notre chapitre 10.

${ }^{110}$ Bourdieu, Langage et pouvoir symbolique, p. 294.

${ }^{111}$ Bourdieu, Raisons pratiques, p. 120-121.

${ }^{112}$ Ibid., p. 121.

${ }^{113}$ Benveniste remarque que, dans le vocabulaire indo-européen, la notion de «salaire » a émergé à partir de celle de "récompense» (Le Vocabulaire des institutions indo-européennes, vol. 1, p. 170). 
limites de ce paradigme économique ${ }^{114}$. Concernant la marque d'honneur, il faudra nous interroger sur les tenants et les aboutissants de la rétribution: quelles formes prend cette dernière? Quel profit apportet-elle au bénéficiaire et quelles contraintes? L'honos constitue un avantage pour celui qui le reçoit mais l'oblige également à une certaine conduite: c'est un signe de gratia mais, en tant que bienfait, il impose à nouveau l'expression de la gratia de la part de celui qui le reçoit; la logique du don et du contre-don continue de s'appliquer ${ }^{115}$. Si l'honos est un moyen de paiement, une monnaie, il faudra aussi interroger sa valeur: toute monnaie a un cours et peut subir des dévaluations ${ }^{116}$. La représentation du prestige comme capital symbolique nous conduira également à explorer certaines pistes. Comment ce capital est-il géré? Quelles sont les stratégies mises en place pour assurer sa protection ou sa transmission? Nous devrons aussi nous interroger sur le pouvoir qu'apporte ce capital: le patrimoine d'honneur est source d'un "crédit» dont la portée reste à déterminer ${ }^{117}$.

\subsection{Conclusion globale: le symbolique et l'économique}

L'honos présente donc deux structures fondamentales de fonctionnement, l'une symbolique et l'autre économique. On retrouve ainsi, au cœur de l'honos, un couple bien connu de la sociologie. Notre présentation distincte des deux paradigmes ne doit pas conduire à penser qu'ils fonctionnent de manière autonome: il n'y a pas, au sein de l'honos, de dualité structurelle. Le phénomène, s'il est complexe, n'en est pas moins unitaire, ce qui nous conduit à poser la question du rapport entre symbolique et économique. On ne peut répondre d'emblée à cette question: ce sera à l'étude de l'honos comme pratique de tenter de le faire progressivement. Mais on peut, pour conclure l'examen des deux paradigmes, donner les linéaments de la réflexion. Le symbolique et l'économique à l'œuvre dans l'honos possèdent d'abord un mode opératoire commun, une matrice: il s'agit de l'échange. L'honos se situe en effet au centre d'une relation d'échange entre individus ou groupes sociaux. L'échange est symbolique: il y a émission de signes et communication avec autrui. Un signe d'estime est octroyé à un tiers et se mue en insigne qui manifeste ensuite à l'entourage le prestige. L'échange est aussi économique: on délivre un paiement en retour d'un service ou d'une qualité, on règle une dette. Il y a prestation et

${ }^{114}$ M. Lentano a également fait usage d'un modèle économique, celui de l'échange, pour analyser des relations sociales non économiques comme le rapport père-fils (LENTANo, "Il dono e il debito »).

${ }^{115}$ Voir sur ce point infra p. 376 sqq.

${ }^{116}$ Nous y reviendrons plus spécifiquement dans notre $3^{\text {ème }}$ partie, où sera examinée l'évolution de la valeur de l'honos dans le temps.

${ }^{117}$ Sur ces effets de l'honos, voir le chapitre 7. 
compensation d'une dépense. En dernière analyse, la marque d'honneur apparaît comme une monnaie d'échange qui possède une valeur à la fois économique et symbolique.

Cette intégration du symbolique et de l'économique dans l'échange rencontre un écho important dans la pratique romaine où l'on s'aperçoit que ces deux ordres ne sont pas séparés l'un de l'autre. Comme l'a justement souligné Bourdieu, la distinction entre symbolique et économique est fallacieuse avant l'émergence du capitalisme. C'est ce dernier qui a défini "l'intérêt économique » de manière restreinte, au point de l'opposer à la culture ou à la spiritualité, qui sont de l'ordre du symbolique ${ }^{118}$. En réalité, ces pratiques

«ne cessent pas d'obéir au calcul économique lors même qu'elles donnent toutes les apparences du désintéressement parce qu'elles échappent à la logique du calcul intéressé (au sens restreint) et qu'elles s'orientent vers des enjeux non matériels et difficilement quantifiables. " ${ }^{119}$

P. Bourdieu a lui-même observé chez les Kabyles cette coïncidence étroite du symbolique et de l'économique ${ }^{120}$. M. Mauss l'avait fait avant lui: les objets échangés dans les conduites de don sont des richesses qui ont un prix, mais aussi les supports et les signes d'un prestige qui n'a de sens que dans la destruction somptuaire de ces richesses ${ }^{121}$. Dans un contexte romain, P. Veyne a souligné à son tour l'imbrication du symbolique et de l'économique. Son étude de l'évergétisme montre que la largesse faite à une communauté vaut par le bienfait accordé mais aussi par le lien social entre donateur et donataire qui est symbolisé par la dépense:

"Le don comprend en effet deux choses, la chose donnée et l'acte de donner. La chose donnée est un bien qui peut procurer une satisfaction à lui tout seul; l'acte de donner, de son côté, suppose l'existence d'une relation entre les deux individus, qu'il découle de cette relation, qu'il la crée ou qu'il la symbolise. »122

De même que le don a a priori un sens économique mais aussi, à bien y regarder, symbolique, l'honos possède a priori un sens symbolique mais aussi un sens économique: l'hommage recourt à un signe, mais ce signe a un signifiant matériel. Cette cohérence de l'économique et du symbolique devra nous amener à nous interroger sur la manière dont ils sont articulés: leur rapport est-il pensé sur le mode

${ }_{118}$ Bourdieu, Esquisse d'une théorie de la pratique, p. 361.

${ }^{119}$ Ibid., p. 362.

${ }^{120}$ Bourdieu, Trois études.

121 "Les vaygu'a des Trobriand, bracelets et colliers, tout comme les cuivres du Nord-Ouest américain ou les wanpun iroquois, sont à la fois des richesses, des signes de richesse, des moyens d'échange et de paiement, et aussi des choses qu'il faut donner, voire détruire» (Mauss, Sociologie et anthropologie, p. 268-269).

${ }^{122}$ Veyne, Le Pain et le cirque, p. 81-82. 
de la coïncidence? On pourrait envisager d'autres relations entre eux, comme une corrélation (plus la valeur symbolique augmente, plus la valeur économique baisse) ou une dissimulation (le symbolique cherchant à cacher l'économique aux yeux de ceux qui échangent).

\section{CONCLUSION ET MISE EN PERSPECTIVE HISTORIQUe}

L'honos est donc structuré, en profondeur, par plusieurs interactions essentielles. La première, qui est fondamentale, est celle du moi et d'autrui. Il y a deux protagonistes pour faire fonctionner l'honos: celui qui le donne, individu ou collectivité, et celui qui le reçoit, particulier, groupe social ou entité plus large. Cette interaction est dynamique car l'honneur se propage de l'individu qui le possède à ceux auxquels il est lié, notamment par le sang. Autrui joue un rôle-clef dans cette circulation de l'honneur car il donne la marque d'honos mais sert aussi de témoin et de garant à ce don ainsi que de fondement à la considération d'un Romain. La deuxième interaction essentielle à l'honos est celle de l'estime, de la marque d'honneur et du prestige, qui opère selon un paradigme symbolique: la marque d'honneur est un signe qui, en tant que tel, possède un signifiant (objet, geste, cérémonie, etc.) et un signifié, le jugement positif. La marque d'honneur, en outre, est un signe performatif: elle instaure le prestige de celui qui la reçoit. Corrélativement, l'honos comme «prestige» ne peut être envisagé sans marques concrètes d'honneur sur lesquelles il se fonde: ce dernier est alors appréhendé comme une "image de marque», une représentation étayée sur des signes. Un second paradigme, étroitement associé au premier, permet de rendre compte de l'interaction entre l'honos et son motif. La marque d'honneur est perçue à Rome comme une rétribution pour un acte remarquable ou un statut particulier. Le motif d'honos crée une dette qu'il convient d'acquitter. C'est l'accumulation de ces marques d'honneur (honores) qui permet à celui qui les reçoit de se constituer un capital, la considération (honos), qui augmente, diminue, se protège, se transmet. Ce prestige gagne à être analysé, avec les outils de la sociologie de P. Bourdieu, comme «capital symbolique». La comparaison de l'ordre du symbolique et de l'économique, qui ne sont pas exclusifs l'un de l'autre, nous amène à nous figurer l'honos comme inscrit dans une relation d'échange à plusieurs niveaux.

Pour terminer la description des structures de l'honos dans la Rome républicaine, on peut le replacer dans une perspective historique. Il ne s'agit pas de faire l'histoire de la pratique de l'hommage mais simplement de relever quelques lignes de force. Cela nous donnera l'occasion de constater que les mécanismes de l'honos ne fonctionnent pas de manière parfaite. Il y a des dysfonctionnements et des usages conflictuels de l'honneur: Rome est une société d'antagonismes et l'honos joue un rôle au sein de ces derniers. La première évolution qui touche l'honos concerne sa nature de signe. L'estime que la marque d'hon- 
neur est supposée signifier devient en effet de moins en moins perceptible. Dans la lettre adressée par Cicéron à L. Munatius Plancus en septembre 43 avant J.-C., il apparaît que ce dernier préfère le iudicium des gens, leur estime, aux honores, qui restent des marques d'honneur, mais dont le pouvoir signifiant est affaibli: l'estime s'écarte du signe qui est supposé la dire. Au $\mathrm{I}^{\mathrm{er}}$ siècle, on voit se multiplier les cas où les honores sont octroyés sans que le donateur n'ait d'estime pour le destinataire. Dans une lettre à Quintus à propos des honneurs qui lui sont rendus par les habitants de la province d'Asie, Cicéron écrit:

Equidem de isto genere honorum quid sentirem, scripsi ad te ante. Semper eos putaui, si uulgares essent, uiles, si temporis causa constituerentur, leues; si uero, id quod ita factum est, meritis tuis tribuerentur, existimabam multam tibi in iis honoribus tuendis operam esse ponendam.

«Ce que je pense, pour ma part, de ce genre d'honneurs, je te l'ai déjà écrit; mon opinion n'a jamais varié: si ce sont ceux qu'on donne à tout le monde, ils sont sans valeur; s'ils sont attribués en fonction des circonstances, leur valeur est mince; mais si - et c'est précisément le cas - ils sont la récompense de tes mérites, tu dois te donner beaucoup de peine pour les préserver.»

(Cic. Q. fr. I, 1, 31; trad. Constans modifiée).

Les honneurs reçus font encore partie de ceux, rares, qui ont de la valeur car ils sont donnés pour récompenser les mérites de Quintus. Mais Cicéron commence par souligner que de nombreux honores sont conférés de façon irréfléchie. Ce sont les avantages matériels qu'apporte l'honos qui passent au premier plan pendant que la signification s'efface: l'économique l'emporte sur le symbolique. La seconde évolution concerne la mainmise des puissants sur l'octroi des marques d'honneur. Avec le développement du pouvoir personnel au $\mathrm{I}^{\mathrm{er}}$ siècle et l'importance considérable prise par les grands imperatores au sein de la cité, les personnes à même de décerner l'honos ne sont plus aussi dispersées qu'autrefois. Le peuple et le sénat continuent de donner des marques d'honneur mais les distinctions les plus brillantes proviennent plutôt des puissants du jour. À la fin des années 80 et au début des années 70, Sylla est présenté comme celui qui a pu rendre à la noblesse l'honos qu'elle avait perdu en raison des lois passées par les populares: un homme seul est ainsi capable de conférer de l'honneur à tout un groupe social ${ }^{123}$. C'est un des aspects importants du pouvoir de ces grands généraux que d'être capable de décider du prestige ou de la disgrâce de larges groupes de personnes. Le même constat peut être fait pour César, qui fait et défait l'honneur de ses concitoyens ${ }^{124}$. Cicéron déplore ainsi que Curion se soit fait octroyer des honneurs illégalement par César plutôt que légalement par le peuple; avec la

${ }^{123}$ CIc. Rosc. Amer. 136 et Verr. II, I, 37.

${ }^{124}$ Sur l'usage que fait César de l'honos, voir notre chapitre 19 sur cet auteur. 
crise de la fin de la République, le peuple a été supplanté dans son rôle d'arbitre de l'honneur ${ }^{125}$. César devient aussi maître de l'octroi du triomphe, prérogative qui revenait jusqu'alors au sénat. La marque d'honneur n'est plus le signe de l'estime de la collectivité, mais la marque donnée par un puissant pour s'attirer l'allégeance d'un autre homme ${ }^{126}$. Enfin, les marques d'honneur sont de plus en plus concentrées entre les mains de quelques individus puissants. Au $\mathrm{II}^{\mathrm{e}}$ siècle on compte près de soixante-dix triomphateurs, dont sept ont triomphé deux fois et deux trois fois. Au $\mathrm{I}^{\text {er }}$ siècle, on relève une quarantaine de triomphateurs seulement et seuls trois ont triomphé deux fois. En revanche, on voit Pompée célébrer trois triomphes, César six et Octave cinq $^{127}$. Ces grands chefs militaires du $\mathrm{I}^{\mathrm{er}}$ siècle, à commencer par Marius, sont aussi ceux qui obtiennent les consulats, les supplications accomplies en leur nom, les statues et d'autres types d'honores ${ }^{128}$. Un passage du Pro rege Deiotaro témoigne de cette concentration d'honneurs sur un seul homme à propos de Pompée, que le roi Déjotarus a suivi en raison de l'éclat de ses distinctions:

Ignosce, ignosce, Caesar, si eius uiri auctoritati rex Deiotarus cessit quem nos omnes secuti sumus, ad quem cum di atque homines omnia ornamenta congessissent, tum tu ipse plurima et maxima. Nec enim si tuae res gestae ceterorum laudibus obscuritatem attulerunt, idcirco Cn. Pompei memoriam amisimus. Quantum nomen illius fuerit, quantae opes, quanta in omni genere bellorum gloria, quanti honores populi Romani, quanti senatus, quanti tui quis ignorat?

«Pardonne, pardonne, César, au roi Déjotarus d'avoir cédé au prestige de cet homme que nous avons tous suivi, sur qui dieux et hommes avaient accumulé toutes les distinctions, distinctions que toi aussi tu lui accordas en quantité et en qualité. Si tes exploits ont obscurci la gloire des autres hommes, nous n'avons pas pour autant oublié Pompée. La grandeur de son nom, de sa puissance, de sa gloire dans tout type d'affrontement, des honneurs que lui octroyèrent le peuple romain, le sénat et toi-même, qui l'ignore?»

(CIc. Deiot. 12).

Il n'est plus ici question de l'honneur d'une famille mais d'un seul homme qui a réussi à obtenir des marques d'estime de la part de tous les acteurs de la vie publique de Rome: le sénat, le peuple romain et César lui-même. L'honos n'est plus accessible à tout un chacun mais est monopolisé par quelques détenteurs. Cet état de fait rencontre de manière intéressante l'analyse faite par Polybe puis par Cicéron de la décadence et du cycle des régimes politiques. Polybe note que le

${ }^{125}$ CIc. Brut. 281.

${ }^{126}$ Voir les remarques de Cic. Att. IX, 2 b.

127 Nos données chiffrées se fondent sur l'index des triomphateurs établi par T. Itgenshorst depuis 340 av. J.-C. (Itgenshorst, Tota illa pompa).

${ }^{128}$ César, par exemple, obtint, entre autres honores, cinquante jours de supplications en 45 , le titre d'imperator et de nombreuses statues dont certaines furent placées dans les temples (David, La République romaine, p. 237-238). 
passage de la royauté à la tyrannie s'effectue quand le roi cherche à se distinguer de ses sujets, par son mode de vie et son apparat, quand il désire être servi avec plus de richesse et plus de pompe ${ }^{129}$. La concentration de l'argent et des marques distinctives, du capital économique et symbolique, dans les mains du monarque marque le début de la décadence du régime. Rome n'est pas une monarchie au dernier siècle de la République, mais on y voit que la montée du pouvoir personnel et la crise du régime vont de pair avec le monopole exercé par quelques puissants sur les marques d'honneur. Cicéron, pour sa part, place au centre de son analyse de la décadence la notion de surabondance. C'est quand un excès se manifeste en un certain domaine que le régime politique bascule: la liberté du régime démocratique, quand elle devient surabondante et incontrôlée, laisse place à la tyrannie ${ }^{130}$. Cette lecture politique pourrait s'appliquer, mutatis mutandis, à la réduction des détenteurs de l'honos à la fin de la République et à la surabondance de marques d'honneur concentrées entre leurs mains. L'amoncellement de l'honos sur quelques personnes va de pair avec la mise en danger de la res publica et prépare le passage à un nouveau régime. 

CHAPITRE 5

\section{LES FORMES DE L'HONOS}

\section{INTRODUCTION}

L'identification des mécanismes fondamentaux de l'honneur nous a donné le cadre général de fonctionnement de l'honos mais il reste à éclairer le contenu précis de ce cadre, les éléments matériels, objets, gestes et rituels, qui sont mobilisés par l'honos. Il faut voir quelles formes peut prendre, concrètement, la marque d'honneur et quels égards et bienfaits accompagnent la situation de prestige. L'honos peut revêtir des aspects extrêmement divers et il ne nous sera donc pas possible d'étudier chacune des marques d'honneur de façon étendue, d'autant que certaines d'entre elles, comme le triomphe ou les charges publiques, ont déjà fait l'objet de plusieurs monographies. Nous tenterons donc plutôt de donner de ces honores une typologie et de déceler une unité sous l'apparente diversité. Nous exploiterons aussi les paradigmes mis en avant précédemment: les marques d'honneur ont-elles une valeur économique ou symbolique? Le signifiant de l'honos a-t-il en lui-même un prix ou bien est-il destiné à s'effacer derrière le signifié?

\section{HONOS, INSIGNE, ORNAMENTUM}

Nous avons vu que l'honos est un signe parmi d'autres au sein d'une culture qui fait un large usage des marques symboliques. À ce titre, il peut être malaisé d'établir une différence profonde entre l'honos d'une décoration militaire et le signe qu'est l'anneau d'or des chevaliers, ou entre les marques d'honneur rendues à un consul et les insignes de sa charge comme la chaise curule ou les faisceaux. Tous appartiennent en effet à la catégorie des signes socio-politiques. Cependant, il convient de se déprendre d'une vision moderne de ces objets qui les engloberait tous dans la catégorie, à l'unité fallacieuse, des "signes d'honneur». Pour les Romains, les honores possèdent en effet au sein de cet univers symbolique une nature bien particulière, que reflète une distinction sémantique précise entre les termes d'honores, insignia et ornamenta.

Une première catégorie de signes politiques distincts des honores est celle des insignes des magistrats, faisceaux, chaise curule et toge 
prétexte $^{1}$. Tous ces attributs distinctifs possèdent un fort pouvoir symbolique mais ne sont jamais qualifiés d'honores. Ils ne sont cependant pas sans rapport avec l'honos, puisqu'ils sont qualifiés d'ornamenta honoris ou d'insignia honoris, honos portant le sens de "charge publique $»^{2}$. Il ne s'agit donc pas d'honores à part entière, mais d'objets d'apparat attachés à l'honos de la charge publique. Les prêtres obtiennent eux aussi des insignia liés à leur sacerdoce ${ }^{3}$. La situation est similaire pour le triomphe: ce dernier est bien un honos, et lors de la cérémonie le triomphateur arbore des objets symboliques mais ceux-ci ne sont jamais qualifiés d'honores. La tunica palmata, la couronne, le sceptre, le quadrige ne sont que des insignia honoris, ce qui explique que leur usage en dehors de la cérémonie du triomphe ait toujours suscité la désapprobation ${ }^{4}$.

Pourquoi ces divers insignia ne sont-ils pas des honores? D'abord parce qu'ils sont bien des signes, mais qu'ils ne disent pas l'estime de celui qui les donne mais le pouvoir de celui qui les possède. Les faisceaux sont l'insigne de la plus haute puissance publique et notamment de l'imperium du magistrat, les verges et la hache rappelant son pouvoir d'infliger des châtiments corporels allant jusqu'à la peine capi-

${ }^{1}$ Sur ces insignes, voir T. SCHÄFER, Imperii insignia, sella curulis und fasces: zur Repräsentation römischer Magistrate, Mainz, P.von Zabern, 1989. Les faisceaux sont des verges liées ensemble par une courroie, et fichées d'une hache quand le magistrat quitte la ville; ils sont portés par des licteurs qui se déplacent devant le magistrat en file indienne (Cic. Verr. II, V, 142; Rep. II, 55; LIv. XXIV, 44). Sur les licteurs et leurs faisceaux, voir T. Mommsen, Le Droit public romain, $2^{\mathrm{e}}$ éd., Paris, E. Thorin, 1892, vol 2, p. 2; P. KÜBleR, «Lictor», RE, XIII, 1, col. 507-518; E. SAMTER, «Fasces », RE VI, 2, col. 20022006; A. J. MarshalL, «Symbols and Showmanship in Roman Public Life: the Fasces», Phoenix, 38, 1984, p.120-141 et A. Goltz, "Maiestas sine uiribus - Die Bedeutung der Lictoren für die Konfliktbewältigungsstrategien römischer Magistrate », in LiNKE, B. et Stemmler, M. (éds.), Mos maiorum. Untersuchungen zu den Formen der Identitätsstiftung und Stabilisierung in der römischen Republik, Stuttgart, F. Steiner, 2000, p.237-267. La chaise curule est un siège pliable souvent fait d'ivoire, sans bras ni dossier, et dont les pieds sont généralement recourbés (MomMSEN, DPR, vol.2, p.33-34; O. Wanscher, Sella curulis: the Folding Stool: an Ancient Symbol of Dignity, Copenhague, Rosenkilde and Bagger, 1980). La toge prétexte est une toge blanche pourvue d'une large bande de pourpre (Mommsen, $D P R$, vol. 2 p. 55).

${ }^{2}$ Cic. Clu. 154 ; Sull. 50.

${ }^{3}$ Le flamine de Jupiter possède ainsi une chaise curule et revêt la toge prétexte (voir Mommsen, DPR, vol. 2, p. 38 et p. 59, ainsi que p. 101-102 de J. ScheID, "Le prêtre», in Giardina, A. (éd.), L'Homme romain, Paris, Seuil, 2002, p. 73-109). Il porte aussi l'apex et une toge de laine. Les augures ont une trabea de pourpre, les Vestales la robe matronale, un voile de mariée et une coiffure spéciale.

${ }^{4}$ On connaît des pratiques de ce genre depuis le milieu du II ${ }^{\mathrm{e}}$ siècle: Paul Émile aurait eu le droit de porter son costume triomphal lors des jeux et Marius a convoqué le sénat habillé en tenue triomphale en 104, par exemple. Voir M.BEard, The Roman Triumph, Cambridge (MA), Harvard University Press, 2007, p. 273. Sur les insignes du triomphateur, voir infra p. 274 sqq. 
tale ${ }^{5}$. Plusieurs textes montrent qu'ils sont, dans l'esprit des Romains, étroitement liés à l'imperium: César considère ainsi comme une illégalité qu'un priuatus dépourvu de l'imperium puisse avoir des licteurs ${ }^{6}$; lorsque les faisceaux sont brisés, c'est le signe que la puissance publique est bafouée ${ }^{7}$; des magistrats de même rang ne peuvent avoir simultanément les faisceaux pendant la durée de leur charge: les licteurs les accompagnent par roulement ${ }^{8}$. L'honos et les insignia imperii ne fonctionnent pas en outre de la même manière car, si l'honos doit être formellement octroyé par un tiers, l'insigne du pouvoir est attaché de manière automatique à l'obtention d'une charge et ne donne pas lieu à une décision autonome de la part du peuple. Parlant de l'édilité qu'il a remportée, Cicéron remarque que la toge prétexte, la chaise curule et les autres avantages sont des fructus de la charge, des bienfaits liés de manière indissoluble à cette dernière ${ }^{9}$. L'ensemble des insignia imperii se différencie donc des honores par leur mode d'octroi qui ne repose pas sur une décision autonome mais sur le lien indissoluble avec une charge publique ${ }^{10}$.

La seconde catégorie de signes socio-politiques à distinguer des honores est celle des marques du rang social ou de l'ordre auquel un citoyen appartient. Les imagines, l'anneau d'or ou encore le cheval public sont assurément honorifiques mais ne sont pas pour autant des honores. Les imagines, les masques de cire représentant les ancêtres ${ }^{11}$,

${ }^{5}$ Mommsen, $D P R$, vol.2, p.10. Sur l'imperium, possédé par le consul, le préteur, le dictateur, le magister equitum et certains promagistrats, voir A. Lintotr, The Constitution of the Roman Republic, Oxford, Clarendon Press, 1999, p.96. L'imperium implique notamment l'exercice du pouvoir de commandement militaire ainsi qu'une capacité judiciaire (iuris dictio et investigation des crimes).

${ }^{6}$ CAES. BC I, 6. Voir aussi l'indignation provoquée par les décemvirs qui, redevenus priuati à la sortie de leur charge, ne restituent pas les honoris insignia, ce qui est vu comme un signe de regnum (Liv. III, 38, 1).

${ }^{7}$ Liv. II, 55, 9 et III, 49, 4.

${ }^{8}$ Mommsen, $D P R$, vol. 1, p. 42.

${ }^{9}$ CIc. Verr. II, V, 36-37.

${ }^{10} \mathrm{C}$ 'est ce qui explique que le bisellium, un siège honorifique à première vue proche de la sella curulis, soit en réalité bien différent et constitue un véritable honos (voir CIL $\mathrm{X}, 1026$ ) ; cet objet est en effet conféré par les décurions des villes italiques pour récompenser la générosité envers la cité de particuliers qui n'ont pas encore exercé de charge. Ce n'est donc pas un insigne de pouvoir, mais bien un honos. Voir T. ScHÄFER, «Der Honor bisellii », MDAI(R), 97, 1990, p. 307-346.

${ }^{11}$ Les textes anciens les plus fournis sur la nature des imagines sont PoL. VI, 53-54 et Plin. NH XXXV, 4-14. Voir aussi les études modernes de H. I. Flower, Ancestor Masks and Aristocratic Power in Roman Culture, Oxford, Clarendon Press, 1996, p.32-52; F. Dupont, "Les morts et la mémoire: le masque funèbre" in La Mort, les morts et l'au-delà dans le monde romain, Caen, Centre de publications de l'Université de Caen, 1987, p.167-172; G. Lahusen, "Statuae et imagines », in Hausmann, U., Von Löringhoff, B., Mannsperger, D.et al. (éds.), Praestant interna. Festschrift für Ulrich Hausmann, Tübingen, E. Wasmuth, 1982, p.101-109. 
sont un des marqueurs de l'appartenance à la nobilitas romaine et servent à symboliser un statut socio-politique et non à marquer l'estime $^{12}$ : ils revêtent une fonction identitaire et idéologique ${ }^{13}$. Un constat similaire peut être fait pour l'anulus aureus ou pour le cheval public des chevaliers ${ }^{14}$. L'honos, lui, n'a pas pour fonction première de marquer l'appartenance à une communauté au statut élevé, même s'il peut, secondairement, être utilisé de la sorte. Il convient donc de ne pas mêler l'ensemble des signes sociaux et politiques sous la dénomination de "marques d'honneur", qui doit rester limitée aux honores tels que les Romains les conçoivent ${ }^{15}$.

\section{L'ÉCHELLE DE L'HONNEUR}

Si les Romains sont bien conscients de la variété des signes en général, ils sont aussi attentifs à la diversité interne des marques d'honneur. En effet, d'une part les honores ne se valent pas tous, d'autre part une personne in honore peut jouir d'un prestige plus ou moins important. Il peut y avoir une différence de hauteur (l'honneur est plus ou moins élevé) ou bien de taille (les honneurs sont plus ou moins grands).

Quand l'honos désigne la considération, elle est envisagée comme un gradus, une échelle pourvue de différents degrés. Nous en avons un exemple dans le Pro Sestio:

Neque enim in hoc me hominem esse infitiabor umquam, ut me optimo fratre, carissimis liberis, fidissima coniuge, uestro conspectu, patria, hoc honoris gradu sine dolore caruisse glorier.

${ }^{12}$ Sur l'adéquation partielle entre nobilitas et ius imaginis, voir C. BADEL, La Noblesse de l'Empire romain. Les masques et la vertu, Seyssel, Champ Vallon, 2005, p. 32. Sur le ius imaginum et sur la controverse historiographique depuis Mommsen à ce sujet, voir FLower, Ancestor Masks, p. 53-59.

${ }^{13}$ Badel, La Noblesse de l'Empire romain, p. 34-35; Flower, Ancestor Masks, p. 62 sqq.; HölKesKamp, Die Entstehung der Nobilität, p. 223.

${ }^{14}$ Sur les marques distinctives de l'ordre équestre, voir A. ALFÖLDI, Der frührömische Reiteradel und seine Ehrenabzeichen, Baden-Baden, Verlag für Kunst und Wissenschaft, 1952 et Nicolet, L'Ordre équestre. Le cheval public est cependant situé à la limite de l'insigne social et de la marque d'honneur: il est en effet octroyé par les censeurs, et devait bien être perçu initialement comme quelque chose d'honorifique (NICOLET, L'Ordre équestre vol. 1, p. 32).

${ }^{15}$ C'est aussi la raison pour laquelle nous n'agrégerons pas à notre étude des realia comme les trophées ou les arcs d'honneur dont la fonction et le sens sont différents des honores au sens strict, bien qu'en apparence ils soient eux aussi sources d'honneur. Sur la singularité du trophée, voir G.C.PICARD, Les Trophées romains, Paris, De Boccard, 1957. Sur l'arc d'honneur, voir A. WALLACE-HADRILL, « Roman Arches and Greek Honours: the Language of Power at Rome ", PCPhS, 36, 1990, p. 143-181 et Studi sull'arco onorario Romano, Rome, L’Erma di Bretschneider, 1979. 
«Je ne suis en cela qu'un homme comme les autres, j'en conviendrai toujours, et je ne me vanterai pas d'avoir été privé sans souffrir du meilleur des frères, d'enfants chéris, d'une épouse très dévouée, de votre vue, de ma patrie, du haut rang d'honneur que j'occupe ici. »

(CIc. Sest. 49; trad. Cousin).

Cicéron reconnaît que son exil lui a été douloureux, en particulier parce qu'il l'a privé de l'honoris gradus élevé qu'il occupait à Rome avant de quitter la ville. En tant que consulaire et père de la patrie, Cicéron se trouvait en effet au sommet de l'échelle du prestige; c'est l'exercice des charges publiques les plus importantes qui permet d'atteindre l'honos le plus élevé. Il est plusieurs fois question chez Cicéron du gradus honoris particulier que possèdent les consulaires ${ }^{16}$. Le plus haut degré du prestige a donc une coloration éminemment politique. On rencontre aussi d'autres représentations de l'honos en termes de hauteur, pour parler cette fois du plus bas degré. Dans une lettre à Cassius Longinus écrite à la fin de sa vie, Cicéron déplore le manque de courage de certains membres de la classe politique:

Quamquam egregios consules habemus, sed turpissimos consularis; senatum fortem, sed infimo quemque honore fortissimum.

"Il est vrai que nous avons des consuls extraordinaires, mais des consulaires tout à fait honteux; des sénateurs courageux, mais les plus courageux sont ceux qui ont le moins de prestige.»

(CIc. Fam. XII, 4, 1).

Parmi les sénateurs, ceux qui seraient le plus disposés à agir pour la défense de la république sont ceux qui ont le moins de prestige (infimo honore); il faut entendre par là ceux qui, au sein du sénat, ont le moins d'autorité en raison de leur jeune âge ou du caractère modeste des charges exercées ${ }^{17}$. Il y a donc bien des variations qualitatives de l'honos. Cependant, les Romains s'accordent plus facilement à reconnaître les degrés les plus hauts et les plus bas que les échelons intermédiaires. Il n'y a pas, à l'époque républicaine, de hiérarchie très détaillée de l'honneur. Le prestige demeure un bien social difficile à quantifier de manière précise.

${ }^{16}$ Dans le Pro Sulla, Cicéron affirme que les consulaires, qui ont un haut gradus honoris, n'ont pu tremper dans la conjuration de Catilina (Sull. 82). Dans une lettre à Appius Claudius Pulcher, il écrit que, pour avoir exercé les summa imperia, il a atteint le même honos que celui des plus nobles des Romains: superiorem quidem numquam, sed parem uobis me speraui esse factum: «j'eus l'espoir d'être devenu non point certes ni en aucun cas votre supérieur, mais votre égal» (CIc. Fam. III, 7, 5; trad. Constans et Bayet modifiée).

${ }^{17}$ Sur les modalités de décision du sénat et l'ordre de la prise de parole, voir Mommsen, $D P R$, vol. 6, 2, p.147-175 et M.Bonnefond-Coudry, Le Sénat de la République romaine de la guerre d'Hannibal à Auguste, Rome, E.F.R., 1989. 
Les marques d'honneur concrètes sont elles aussi hiérarchisées selon leur valeur. Mais l'image récurrente est celle de la taille et non plus celle du gradus. Cette représentation est utilisée dans le prologue de l'Aulularia, quand le lare de la maison se plaint de la médiocrité des honneurs que les précédents occupants lui ont accordés:
Vbi is obiit mortem qui mihi id aurum credidit,
Coepi obseruare, ecqui maiorem filius
Mihi honorem haberet quam eius habuisset pater.
Atque ille uero minus minusque impendio
Curare minusque me impertire honoribus.
«Lorsqu'il mourut, celui qui m'avait confié son or,
J'ai commencé à observer si son fils
Me ferait plus d'honneurs que son père.
Mais voilà qu'il se soucie encore moins - et beaucoup moins ! -
De m'octroyer des honneurs. »

(PL. Aul. 15-19).

Le lare déplore que le fils du premier occupant ne lui ait pas conféré un honos plus grand (maiorem honorem) que son père, mais qu'il y ait eu au contraire une incessante diminution (minus minusque), en nombre et en qualité. L'honos est donc une réalité qui se mesure, comme en témoigne le décompte scrupuleux que le lare en a fait. Les textes manifestent surtout une conscience des honneurs les plus importants, comme en témoigne la fréquence de l'expression maximi honores ${ }^{18}$. Cependant, la différence qualitative des marques d'honneur est plus finement ressentie que dans le cas de l'honos «considération». La corona ciuica, honos militaire octroyé à celui qui a sauvé la vie d'un citoyen romain en tuant un ennemi, est ainsi reconnue comme seconde en prix par rapport à la corona obsidionalis, conférée au soldat qui réussit à faire lever un siège ${ }^{19}$. Les cérémonies de victoire sont elles aussi des honores plus ou moins prestigieux. La salutation du titre d'imperator est un honos souvent considéré comme une première étape vers l'obtention d'une supplicatio, elle-même condition de l'octroi du triomphe ${ }^{20}$. Le triumphus est en effet un maximus honos, un des honneurs les plus précieux ${ }^{21}$. Si la hiérarchie des honores est assez étendue, il faut cependant noter qu'elle n'est pas extrêmement précise ni officiellement formalisée. Les distinctions faites parmi les différentes décorations militaires, par exemple, relèvent de la coutume, du mos, et non du droit. Ce n'est que bien après la République, à l'époque de Vespasien, qu'une échelle précise et officielle des honores,

${ }^{18}$ Voir par exemple PL. Pers. 510-512; Cic. Red. Pop. 16; Phil. V, 41 ; IX, 14 ; XIII, 9.

${ }^{19}$ Plin. NH XVI, 3 et XXII, 4, 6. Sur ces couronnes, voir infra p. 257.

${ }^{20}$ L. Halkin, La Supplication d'action de grâces chez les Romains, Paris, Les Belles Lettres, 1953, p. 79.

${ }^{21}$ Voir par exemple Cic. Phil. XIII, 9. 
adossée au rang militaire des soldats, sera établie ${ }^{22}$. Est-il possible de dégager, pour l'époque républicaine, le critère selon lequel les différentes marques d'honneur sont hiérarchisées? Ce n'est pas, semblet-il, la présence d'un trait unique qui rend un honos supérieur ou inférieur aux autres. Il s'agit plutôt d'un faisceau de caractéristiques qui, une fois combinées, permettent de différencier entre eux les honores. C'est d'abord la rareté d'une marque d'honneur qui fait son prix ${ }^{23}$. Cela explique qu'un honneur tel que le tombeau offert sur fonds publics, particulièrement rare, soit extrêmement prisé: Cicéron mentionne ce type d'honos une fois dans les Philippiques, et on en connaît un autre exemple grâce à l'inscription du monument funéraire de C. Poplicius Bibulus $^{24}$. La pérennité de l'honos est un autre critère de son prix, comme on le voit avec ces tombeaux, honneurs inscrits dans l'espace public de Rome, mais aussi avec les statues honorifiques ${ }^{25}$. Enfin, la magnificence plus ou moins importante de l'honos est aussi un indicateur de sa valeur: si le triomphe est l'un des maximi honores, c'est parce qu'il constitue un spectacle somptueux qui mobilise toute la cité.

Il faut ménager, dans la hiérarchie des marques d'honneur, une place particulière aux honores que sont les charges publiques. D'abord parce qu'elles constituent, avec le triomphe ou une statue sur les rostres, un de ces maximi honores ardemment recherchés par les Romains, ensuite parce que les honores politiques ont fait l'objet d'une organisation plus attentive et plus précoce que les autres signes d'estime. On lit ainsi, au $\mathrm{II}^{\mathrm{e}}$ siècle, chez Volcacius Sedigitus ${ }^{26}$ :

Hae quae < Terenti sex $>$ uocantur fabulae, cuiae sunt? non has iura qui populis [retentibus] dabat honore summo affectus fecit fabulas?

"Ces six comédies que l'on dit de Térence,

De qui sont-elles? ne les a-t-il pas écrites celui qui donnait des lois aux peuples,

Pourvu d'un honneur suprême? »

(VoLC.-SED. frg. 4 FPL).

\footnotetext{
${ }^{22}$ Maxfield, The Military Decorations, p. 157 et 206. Les honores sont alors organisés selon le rang de celui qui peut y prétendre: une distinction est opérée entre les marques d'honneur accessibles aux sénateurs, chevaliers, centurions ou soldats.

${ }^{23}$ Selon Sénèque, c'est aussi quand les bienfaits sont donnés de manière mesurée, et ont donc une certaine rareté, qu'ils font véritablement plaisir (SEN. Ben. I, 14, 1).

${ }^{24}$ Cic. Phil. IX, 14 et $C I L \mathrm{I}^{2}, 834$ (= ILLRP 357). L'honneur fait à Bibulus est d'autant plus surprenant qu'il s'adresse à une personne qui n'a été qu'édile de la plèbe et dont la famille n'est pas autrement connue de nous.

${ }^{25}$ Cic. Phil. XIII, 9 fait de la statue un maximus honos au même titre que le triomphe.

${ }^{26}$ Auteur du De Poetis, poème didactique en sénaires iambiques dont les quelques passages qui nous restent portent sur les auteurs comiques.
} 
On retrouve dans ce passage l'opinion, répandue dans l'Antiquité, selon laquelle Térence n'aurait pas composé tout seul certaines de ses pièces. L’auteur supposé des pièces est désigné comme honore summo affectus: il s'agit de Scipion Émilien, le vainqueur de Carthage et de Numance, et le summus honos n'est autre que le consulat ${ }^{27}$ qu'il revêtit à deux reprises, en 147 et 134 . Ce texte présente deux idées importantes: les honores politiques sont organisés suivant une échelle, en hauteur, puisqu'il est question d'un sommet (summo honore); c'est le consulat qui est perçu comme le point le plus haut de cette hiérarchie. De nombreux autres textes confirment ces deux éléments. Les magistratures y sont souvent représentées selon l'image du gradus, de l'échelle $^{28}$. Dans la prosopopée de la première Catilinaire, la patrie, parlant à Cicéron, lui rappelle que le peuple romain ad summum imperium per omnis honorum gradus extulit, "[1]'a porté par tous les degrés des honneurs jusqu'au pouvoir suprême ${ }^{29}$. Au sommet de cette échelle des honneurs se trouve le consulat: dans le Bellum Iugurthinum, Marius affirme ainsi que le consulat auquel il a été élu est pour lui summus honos et maximum negotium ${ }^{30}$. Les magistratures sont en effet hiérarchisées les unes par rapport aux autres, le consul ayant autorité sur les magistrats inférieurs ${ }^{31}$. Les honores politiques ont la particularité d'avoir été progressivement organisés. Jusqu'au début du $\mathrm{II}^{\mathrm{e}}$ siècle, il n'y a pas de législation précise car c'est le mos, la coutume, qui règle avec souplesse la hiérarchie ${ }^{32}$. Puis la loi de 180 du tribun L. Villius Annalis vient mettre de l'ordre ${ }^{33}$. Cette disposition

${ }^{27} M R R$, vol. 1 , p. 463 et 490.

${ }^{28}$ La notion de cursus honorum, couramment utilisée par les modernes, ne se rencontre pas avant les années 50 avant J.-C., et elle reste ensuite assez peu fréquente à l'époque républicaine. Cicéron est, semble-t-il, le premier à l'utiliser, deux fois seulement: Cato mai. 60 et Fam. III, 11, 2.

${ }^{29}$ Même image en Fam. II, 18, 2.

${ }^{30}$ SALL. Iug. 85, 28-30.

${ }^{31}$ C. Nicolet, Rome et la conquête du monde méditerranéen. Tome 1: Les structures de l'Italie romaine, 4e éd., Paris, P.U.F., 1991, p.397. Seul le dictateur peut exercer son pouvoir sur les consuls. Sur la hiérarchie des magistratures, voir LinTotT, The Constitution of the Roman Republic, p. 105-144.

${ }^{32} \mathrm{BECK}$, Karriere und Hierarchie, p. 33. Sur la question de l'existence d'une « constitution" à Rome et sur sa formation empirique, voir C. MEIER, Res publica amissa. Eine Studie zu Verfassung und Geschichte der späten römischen Republik, Wiesbaden, F. Steiner, 1966. Au III ${ }^{\mathrm{e}}$ siècle, l'accès au consulat sans exercice préalable de l'ensemble des autres magistratures est possible, tout comme l'itération de charges. Un ordre n'est pas fixé: on peut ainsi être consul puis préteur. Voir les exemples donnés par LiNTotT, The Constitution of the Roman Republic, p. 144. Sur l'organisation générale des magistratures au III siècle, BECK, Karriere und Hierarchie, p.62-113.

${ }^{33}$ Liv. XL, 44, 1. Sur cette loi, voir G. Rotond, Leges publicae populi Romani, réimpr. de l'éd. italienne, Hildesheim, G.Olms, 1962, p.278; G.V.Sumner, "The lex Annalis under Caesar», Phoenix, 25, 1971, p. 246-271; A. Afzelius, "Lex Annalis », Classica et Mediaevalia, 8, 1946 p. 263 sqq. et A.E.Astin, The Lex Annalis before Sulla, Bruxelles, 
est importante, car ce n'est plus la tradition qui régit la hiérarchie des honores mais le droit positif. La loi a cependant été bafouée dès les années 150 puis son application profondément perturbée par les guerres civiles. Sylla puis César ont dû légiférer à leur tour pour réorganiser le gradus honorum ${ }^{34}$.

\section{Typologie DES Formes DE L'HOMmage}

Nous proposons une typologie des marques d'honneur en prenant pour critère distinctif le moyen employé pour signifier l'estime.

\subsection{L'objet}

Plusieurs marques d'honneur consistent en l'octroi d'un objet concret qui sert de support matériel pour signifier l'estime.

\subsubsection{Formes}

L'honos comme objet peut prendre cinq formes différentes: il peut être un legs, une dépense édilitaire, une statue, un donum militarium ou encore une offrande religieuse.

Léguer de l'argent ou faire de quelqu'un son héritier est interprété par plusieurs textes comme un authentique honos. C'est le cas dans le Pro Quinctio où l'héritage de C. Quinctius doit revenir, après son décès, à son frère P. Quinctius :

Heredem testamento reliquit hunc P. Quinctium, ut, ad quem summus maeror morte sua neniebat, ad eundem summus honos quoque perueniret.

«Il fit par testament de notre P. Quinctius son héritier, de sorte que Publius recevait en raison de la mort de Gaius une immense douleur et qu'en même temps il obtenait aussi un immense honneur.»

(Cic. Quinct. 14).

L'honos consiste à léguer à un membre de sa famille une somme d'argent ou un ensemble de biens. Le legs d'une terre à un descendant est aussi perçu comme un honos ${ }^{35}$. L'honos de l'héritage a ceci de particulier qu'il est juridiquement défini et réglé, en général par

Latomus, 1958. La loi prévoit un ordre de succession obligatoire des magistratures (questure, édilité, préture puis consulat), un âge minimal pour accéder à la préture et au consulat, et impose un intervalle de deux ans (biennium) entre l'exercice de deux honores.

${ }^{34}$ Sur la lex annalis de Sylla de 81, voir Cic. Phil. V, 48; Agr. II, 3-4; App. Ciu. I, 100. Sur la loi de César, Sumner, "The lex Annalis under Caesar».

${ }^{35}$ Cic. Rosc. Amer. 44. 
un testament, disposition légale que le Digeste qualifie d'honos ${ }^{36}$. On rencontre un exemple assez détaillé de cette formalisation de l'honos à notre époque dans le Pro Caecina: Fulcinius a institué sa femme Césennia comme principale héritière de ses biens, lui faisant de ce fait un magnus honos qui prend la forme d'un testament prévoyant la légation de l'usus et du fructus de ses biens ${ }^{37}$.

Un autre type d'honos prend la forme d'un transfert de richesse à l'échelle publique. Il s'agit des dépenses édilitaires consenties par un particulier, souvent magistrat, au profit de sa cité. Deux textes épigraphiques du $\mathrm{I}^{\mathrm{er}}$ siècle avant J.-C. nous donnent un aperçu de ce type d'hommage. Le premier est une inscription trouvée à Pompéi:

C(aius) Quinctius C(aii) f(ilius) Valgus $\mid M$ (arcus) Porcius M(arci) f(ilius) duo uir(i)|quinq(uennales) coloniai honoris |caussa spectacula de sua | peq(unia) fac(ienda) coer(auerunt) et coloneis |locum in perpetuom deder(unt).

«Gaius Quinctius Valgus, fils de Gaius, et Marcus Porcius, fils de Marcus, duumvirs quinquennaux, se chargèrent d'organiser des spectacles à leurs frais pour honorer la colonie et donnèrent aux colons un lieu d'enterrement pour l'éternité. »

$\left(C I L, \mathrm{I}^{2}, 1632\right)$.

Les duumvirs C. Quinctius et M. Porcius ont donné un honos à la colonie en organisant à leurs frais (de sua pequnia) un spectacle, probablement dans l'amphithéâtre. L'honos est un geste de bienfaisance de la part des magistrats qui manifestent ainsi leur reconnaissance à leurs concitoyens pour la charge qu'ils ont obtenue. L'autre inscription provient de Nola:

C(aius) Catius M(arci) f(ilius) IIIIuir campum publice |aequandum curauit, maceriem | et scholas et solarium, semitam | de s(ua) p(ecunia) f(aciunda) c(urauit). | Genio coloniae et colonorum | honoris causa, | quod perpetuo feliciter utantur.

«Gaius Catius, fils de Marcus, quattuorvir, fit aplanir aux frais publics le campus et fit construire à ses frais un mur, des galeries, un solarium et un sentier. Au Génie de la colonie et des colons, pour les honorer; qu'ils l'utilisent pour toujours avec bonheur. »

$(C I L \mathrm{X}, 1236=I L L R P \mathrm{I}, 116)$.

Le quattuorvir C.Catius a fait réaliser divers travaux à ses frais pour honorer sa cité et ses concitoyens: l'honos prend la forme d'édifices publics. Ces bienfaits rendus par des particuliers à leur cité

${ }^{36}$ Dig. I, 2, 2, 45. Un testament est laissé in honorem alicuius. Voir aussi Dig. XXXII, 11,21 où il est prévu qu'un testator puisse vouloir honorem habere au profit de plusieurs héritiers. Sur le testament, voir M.Ducos, Rome et le droit, Paris, Le livre de poche, 1996, p. 83-90; A. WATson, The Law of Succession in the Later Roman Republic, Oxford, Clarendon Press, 1971.

${ }^{37}$ Cic. Caecin. 12. 
apparaissent aussi dans les textes de loi: le Digeste signale qu'il est possible de léguer de l'argent à une cité ad ornatum, pour l'édification de bâtiments, et ad honorem, pour organiser des jeux et des spectacles scéniques, des munera, des banquets, etc. ${ }^{38}$ Le fait que ces marques d'honneur soient conférées par un particulier à la cité dans laquelle il vit rapproche cette pratique de l'honos de l'évergétisme du monde hellénistique. L'acte d'évergétisme suppose en effet qu'un particulier fortuné, jouant un rôle important dans la vie de sa cité, contribue de ses deniers aux dépenses publiques et obtienne en retour la reconnaissance de ses concitoyens ${ }^{39}$. La pratique, qui existait déjà au $\mathrm{V}^{\mathrm{e}}$ et IV ${ }^{\mathrm{e}}$ siècles chez les hommes publics du monde grec qui assuraient de leur bourse la totalité ou une partie des dépenses de leurs fonctions ${ }^{40}$, est devenue un rouage essentiel de l'administration des cités hellénistiques au $\mathrm{III}^{\mathrm{e}}$ et $\mathrm{II}^{\mathrm{e}}$ siècles. Les aristocrates de la République romaine le pratiquèrent aussi, mais dans un contexte différent, notamment parce que les charges publiques n'étaient pas à Rome des fonctions honorifiques $^{41}$. Il est intéressant de voir que les actes d'évergétisme sont qualifiés d'honores car cela indique que les largesses des notables, gestes caractéristiques des cités hellénistiques, s'agglomèrent à une pratique proprement romaine, celle de l'honos ${ }^{42}$. L'évergétisme n'a cependant pas été totalement confondu avec l'honos car il possède une configuration plus rigide que ce dernier: l'acte d'évergétisme est le fait d'un individu isolé, appartenant à l'élite sociale et agissant au bénéfice d'une collectivité; l'honos, lui, fait intervenir des protagonistes plus variés. On le constate quand l'honos prend l'aspect d'une statue. Il n'est pas question, dans le cadre de ce travail, d'étudier en détail la statuaire romaine et son histoire mais il nous appartient de voir de quelle manière la statue peut consister en une marque d'honneur ${ }^{43}$.

${ }^{38}$ Dig. XXX, 122.

${ }^{39}$ Pour une définition de l'évergétisme, Veyne, Le Pain et le cirque, p. 21.

${ }^{40}$ Ibid., p. 215-218.

41 «L'évergétisme atteint son plein développement quand les fonctions publiques ne sont plus guère que des privilèges honorifiques et que la politique n'est plus une affaire sérieuse. Or rien n'était plus sérieux que la politique mondiale de Rome» (Ibid., p. 348).

${ }^{42}$ Les Romains reçoivent au $\mathrm{II}^{\mathrm{e}}$ siècle dans plusieurs cités grecques le titre d' "évergètes ", ce qui témoigne de l'assimilation de la pratique romaine à une tradition hellénique et de la capacité des Grecs à mettre en harmonie la notion d'évergétisme avec celle, romaine, de patronat. Sur les convergences de ces pratiques, voir J.-L. Ferrary, Philhellénisme et impérialisme, Rome, E.F.R., 1988, p.124-132 et J.-L. Ferrary, «The Hellenistic World and Roman Political Patronage», in Cartledge, P., Garnsey, P. et Gruen, E.S. (éds.), Hellenistic constructs, Berkeley, University of California Press, 1997, p. 105-119.

${ }^{43}$ La bibliographie critique sur le sujet est très abondante. Sont particulièrement utiles pour notre point de vue les ouvrages portant directement sur la pratique et l'idéologie de la statuaire durant la République: T. Hölscher, «Die Anfänge römischer Repräsentationskunst», MDAI(R), 85, 1978, p.315-357; LAHUSEN, Untersuchungen zur Ehrenstatue in Rom; M. B. Flory, "Livia and the History of Public Honorific Statues 
L'érection de statues est une pratique ancienne à Rome, que la tradition fait remonter, sans doute de façon anachronique, aux premiers temps de la République ${ }^{44}$. L'identification d'une statue comme honos dans un texte républicain commence avec l'inscription des Italiens de Sicile à L.C. Scipion, datée du premier tiers du $\mathrm{II}^{\mathrm{e}}$ siècle, qui figurait sur la base d'une statue représentant sans doute Scipion, le bénéficiaire de l'honos ${ }^{45}$. Mais c'est surtout pour le $\mathrm{I}^{\mathrm{er}}$ siècle que nous possédons de nombreux exemples de statues employées comme marques d'honneur. Dans son discours sur la préture urbaine de Verrès, Cicéron aborde l'affaire des statues extorquées par Verrès aux Siciliens:

Illae quid sibi statuae equestres inauratae uolunt, quae populi Romani oculos animosque maxime offendunt, propter aedem Volcani? nam inscriptum esse uideo quandam ex his statuis aratores dedisse. Si honoris causa statuam dederunt, inimici non sunt; credamus testibus.

"Que signifient ces statues équestres en or, près du temple de Vulcain, qui offensent grandement les yeux et l'esprit du peuple romain? Car je vois d'après l'inscription que l'une de ces statues a été donnée par les fermiers. S'ils te l'ont donnée pour t'honorer, ce ne sont pas tes ennemis; croyons-en les témoins. »

(CIc. Verr. II, II, 150-151).

Ces statues sont un honos particulièrement prestigieux en raison du matériau utilisé, l'or, et de la situation dans laquelle est représenté le bénéficiaire, à cheval ${ }^{46}$. Mais pour Cicéron, elles ne méritent qu'à peine le nom d'honos car Verrès a contraint les Siciliens à les lui octroyer. Le cas de Verrès est cependant exceptionnel: la statue sert bien, en général, à signifier au destinataire l'estime de celui qui la

for Women in Rome», TAPhA, 123, 1993, p.287-308; F. MARTIN, "The Importance of Honorific Statues : a Case-Study ", BICS, 41, 1996, p. 53-70; M. SEHLMEYER, Stadtrömische Ehrenstatuen der republikanischen Zeit, Stuttgart, F.Steiner, 1999; M.Sehlmeyer, "Die kommunikative Leistung römischer Ehrenstatuen», in Braun, M., HaltenhofF, A. et Mutschler, F.-H.(éds.), Moribus antiquis res stat Romana. Römische Werte und römische Literatur im 3. und 2. Jh. v. Chr., Munich, K. G. Saur, 2000, p. 271-284; P.STEWART, Statues in Roman Society. Representation and Response, Oxford, Oxford University Press, 2003. Sur l'aspect iconographique et artistique de la statuaire, voir les titres réunis par H. Inglebert, P. Gros et G.SAUron, Histoire de la civilisation romaine, Paris, P.U.F., 2005, p. L-LV.

${ }^{44}$ Clélie aurait été la première à recevoir une statue équestre pour sa bravoure lors de son évasion du camp de Porsenna (LIV. II, 13, 9-11). Sur les statues des héros de la guerre de Porsenna, Sehlmeyer, Stadtrömische Ehrenstatuen der republikanischen Zeit, p. 91-101.

${ }^{45}$ CIL I I $^{2}, 612$ = ILLRP 320. Sur les statues comme honores, SEHLMEYER, Stadtrömische Ehrenstatuen der republikanischen Zeit, p.274-278. Sur le vocabulaire utilisé pour désigner les statues, STEWART, Statues in Roman Society, p. 20-28.

${ }^{46}$ Cf. Cic. Phil. IX, 13 où Cicéron demande pour Ser. Sulpicius une statue en pied en bronze, et non une statue équestre dorée, honos qu'il juge démesuré. 
donne. C'est pourquoi Cicéron avait un temps plaidé en faveur d'une statue pour Lépide, avant que ce dernier ne se retourne contre le sénat:

At in Lepido reprehendimur, cui cum statuam in rostris statuissemus, idem illam euertimus; nos illum honore studuimus a furore reuocare: uicit amentia leuissimi hominis nostram prudentiam; nec tamen tantum in statuenda Lepidi statua factum est mali quantum in euertenda boni.

«Mais, dans le cas de Lépide, on nous critique, car, après lui avoir décerné une statue aux Rostres, nous l'avons ensuite abattue; c'est que nous nous sommes efforcés de le détourner de son égarement en l'honorant; la folie de cet homme, léger entre tous, a eu raison de notre sagesse; il a, d'ailleurs, été fait moins de mal en élevant une statue de Lépide que de bien en l'abattant. »

(Cic. Ad Brut. I, 15, 9; trad. Beaujeu).

La statue signifiait l'estime et le soutien du sénat; une fois cette opinion favorable disparue, l'ouvrage a été détruit.

L'observation de l'aspect matériel de ces statues permet de percevoir la dimension symbolique de l'honos. Les statues équestres, par exemple, ont un sens essentiellement symbolique: le cheval sur lequel la personne honorée est représentée devait initialement rappeler que l'individu appartenait aux prestigieuses centuries équestres et avait effectué son service militaire à cheval ${ }^{47}$. Il y avait donc un lien direct entre l'honos et le mérite récompensé, un exploit réalisé en contexte militaire. Cet honos est, à l'origine, un signe de type icône, pour employer la terminologie de Peirce: il «renvoie à l'objet qu'il dénote simplement en vertu des caractères qu'il possède, que cet objet existe réellement ou non ${ }^{48}$. Ce signe est une image de son objet: il lui ressemble et partage avec lui un certain nombre de caractéristiques. Mais le rapport d'analogie ne se situe pas entre le signe et l'estime, mais entre le signe et le mérite de son destinataire. C'est le motif de l'honos, l'exploit à cheval, qui est représenté. Le sens de cette figuration s'est néanmoins progressivement figé: la statue équestre a pu être octroyée pour des actions sans lien avec l'armée ou pour des personnes n'ayant pas effectué le service monté. Le signe s'est rapproché du symbole, renvoyant par convention à l'excellence et au prestige ${ }^{49}$. Le lien entre

${ }^{47}$ LAHusEn, Untersuchungen zur Ehrenstatue in Rom, p.56, n.84 et p.57-58. Sur les première statues équestres romaines, SEHLMEYER, Stadtrömische Ehrenstatuen der republikanischen Zeit, p.48 sqq. Sur le sens de la figuration à cheval, en rapport avec le service monté, SEHLMEYER, «Die kommunikative Leistung römischer Ehrenstatuen », p. $275-276$.

${ }^{48}$ PeIrce, Écrits sur le signe, 2, 247, p. 140. Peirce donne comme exemples d'icônes les plans et maquettes.

${ }^{49}$ Chez Peirce, le symbole est « un signe qui renvoie à l'objet qu'il dénote en vertu d'une loi, d'ordinaire une association d'idées générales» (Ibid., 2, 249 p. 140). On est également ici assez proche de la définition du symbole donnée par Saussure: il s'agit d'un signe où le lien entre signifiant et signifié n'est pas totalement arbitraire (DE 
la forme matérielle de l'honos et le mérite récompensé est alors beaucoup plus ténu.

La statue est une marque d'honneur aux effets particulièrement efficaces car elle se trouve sur la place publique. De nombreux ouvrages sont situés aux endroits fréquentés de Rome, tels que les temples: Caton avait sa statue dans le temple du Salut et Accius dans l'aedes Camenarum $^{50}$. Le forum a progressivement été rempli de statues, au point qu'un édit des censeurs de 158 a ordonné la suppression de toutes celles qui n'avaient pas été édifiées par une décision officielle ${ }^{51}$. Certains lieux à fort pouvoir symbolique en concentraient un grand nombre: c'est le cas des rostres où se trouvaient celles de Camille, Scipion l'Africain, Sylla, Pompée, César, Octavien, entre autres ${ }^{52}$. Le comitium accueillait également les statues de plusieurs héros légendaires, tels qu'Horatius Cocles ou Mucius Scaevola ${ }^{53}$ et le Capitole recevait celles des hommes les plus célèbres de l'histoire romaine, comme Romulus et Rémus, ou des membres des très grandes gentes ${ }^{54}$. L'honos de la statue inscrit donc celui qui en bénéficie dans l'espace public de Rome et lui confère un rayonnement particulier en l'associant aux lieux les plus illustres de l'Vrbs.

De ces statues, il faudrait rapprocher d'autres marques d'honneur, bien qu'elles ne soient pas explicitement qualifiées d'honores: il s'agit des peintures honorifiques. On peut en effet honorer un individu en le figurant dans une sculpture ou bien sur une surface peinte. Le portrait est employé comme moyen d'affirmation de soi, notamment par les aristocrates romains ${ }^{55}$ : on sait, par Pline l'Ancien, qu'à côté des imagines figurant dans les atriums des maisons de familles éminentes se trouvaient des arbres généalogiques dont les branches indiquaient les ancêtres les plus illustres de la gens et étaient ornées de représentations peintes de ces derniers (imagines pictae) ${ }^{56}$. Certains de ces portraits semblent même avoir figuré directement sur la façade

Saussure, Cours de linguistique générale, p. 100-101): la figuration équestre, si elle n'est plus une image fidèle, continue d'avoir un lien avec l'excellence signifiée.

${ }^{50}$ Plut. Cato mai. 19; Plin. NH XXXIV, 19.

51 Plin. NH XXXIV, 30; sur l'édit censorial, voir SEhLmeyer, Stadtrömische Ehrenstatuen der republikanischen Zeit, p. 152-163.

${ }^{52}$ Voir le relevé de Lahusen, Untersuchungen zur Ehrenstatue in Rom, p. 15-16.

${ }^{53}$ Liv. II, 10, 12 ; Plin. NH XXXIV, 22; Ps.-Aur. Vict. Vir. 12.

${ }^{54}$ LaHUSEN, Untersuchungen zur Ehrenstatue in Rom, p. 9-10.

${ }^{55}$ Sur cette pratique, voir H. DRERUP, «Totenmaske und Ahnenbild bei den Römern », MDAI, 87, 1980, p.81-129; R. RoBERT, "Quelques usages du portrait peint à l'époque médio-républicaine», in Auvray-Assayas, C. (éd.), Images romaines, Paris, Presses de l'E.N.S., 1998, p.73-89.

${ }^{56}$ Ces imagines pictae désignent bien des portraits peints, distincts des masques en cire, comme l'a montré R. ROBERT, «Quelques usages du portrait peint à l'époque médiorépublicaine», p. 75-79. 
des demeures, autour du seuil ${ }^{57}$. Le portrait peint inscrit ainsi dans le champ du visible, dans une zone publique ou semi-publique, celui que l'on souhaite honorer: il n'est pas aussi exposé que la statue située dans l'espace de la ville mais témoigne tout de même d'une volonté d'exposition de soi de la part des gentes aristocratiques ${ }^{58}$. Un fragment de fresque provenant d'une tombe de l'Esquilin revêt une fonction assez similaire, bien que l'interprétation en soit difficile ${ }^{59}$. Ce vestige datant du $\mathrm{III}^{\mathrm{e}}$ siècle ou du début du $\mathrm{II}^{\mathrm{e}}$ siècle se compose de quatre registres superposés qui représentent des scènes militaires, dans lesquelles figurent notamment deux personnages plus grands que les autres, identifiés par une inscription, M.Fannius et Q. Fabius. Les interprètes y voient soit un épisode de la deuxième guerre samnite, la conclusion d'un traité de paix entre le chef romain, Q. Fabius, et le chef ennemi, M.Fannius ${ }^{60}$, soit l'octroi par le général Q. Fabius d'une hasta pura, marque d'honneur militaire, au soldat M. Fannius ${ }^{61}$. On aurait dans ce dernier cas une peinture figurant l'octroi d'un honos. Quelle que soit l'inteprétation exacte de la scène représentée, il s'agit d'une peinture commémorative d'un événement passé, qui en donne une description assez minutieuse, mais vise simultanément à honorer un des protagonistes, ou un de ses descendants. La peinture est donc un signe, comme la statue, mais il est plus parlant que cette dernière car il permet une description plus abondante du fait rappelé, selon une certaine chronologie, comme semble l'indiquer la présence de registres superposés. La fresque de l'Esquilin est cependant un signe moins visible que les statues ou les portraits peints dans les maisons des aristocrates puisque seule la famille a accès à la sépulture dans laquelle figurait la fresque. On rapprochera de ce type de représentation figurée les peintures à caractère historique qui nous sont connues par les textes, telles que les peintures à sujet triomphal ou bien les

${ }^{57}$ Plin. NH XXXV, 2, 6.

${ }^{58}$ Sur cette conquête de l'espace visible par le portrait aristocratique, voir RoBERT, «Quelques usages du portrait peint à l'époque médio-républicaine», p. 85-86.

${ }^{59}$ Voir sur cette fresque les analyses de R. Bianchi Biandinelli, Rome, le centre du pouvoir, Paris, Gallimard, 1969, p.115; J.-M.CRoIsIlle, La peinture romaine, Paris, Picard, 2005, p. 24; F. CoArelli, "Frammento di affresco dall'Esquilino con scena storica", in Affreschi romani dalle raccolte dell'antiquarium comunale, Rome, 1976, p.13-21; E. La RoccA, «Fabio o Fannio. L'affresco medio-repubblicano dell'Esquilino come riflesso dell'arte rappresentativa e come espressione di mobilità sociale », DArch, 2, 1984, p. 31-53; HöLschER, «Die Anfänge römischer Repräsentationskunst ».

${ }^{60}$ C'est l'interprétation de CoARelli, «Frammento di affresco dall'Esquilino con scena storica » et HölSCHER, « Die Anfänge römischer Repräsentationskunst ». La fresque est également rattachée au conflit de Rome avec les Samnites par R. Bianchi BiandinelLi, Rome, le centre du pouvoir, p. 115 et J.-M. CROISILLE, La peinture romaine, p. 24.

${ }^{61}$ C'est l'interprétation de LA Rocca, «Fabio o Fannio», p.49, qui estime que M. Fannius est le possesseur de la sépulture. 
fresques du temple de Salus ${ }^{62}$. Ces dernières, dont la réalisation est attribuée à Fabius Pictor ${ }^{63}$, représentaient peut-être des épisodes des guerres samnites, dans la mesure où le temple a été consacré en 303 par C. Iunius Bubulcus, vainqueur des Samnites. On a aussi évoqué la possiblité d'une représentation des affrontements contre les Gaulois ${ }^{64}$. Ce type de figuration vise à honorer l'armée et le général représentés. Le temple de Salus devenait ainsi un moyen, pour le triomphateur, de célébrer sa réussite et de l'inscrire dans la mémoire de la ville ${ }^{65}$.

Les dona militaria présentent un pouvoir symbolique assez semblable à celui des peintures. À l'issue d'un combat victorieux, le général confère assez régulièrement des décorations militaires qualifiées d'honores ou de dona militaria. Elles sont attestées par quelques inscriptions de l'époque républicaine ${ }^{66}$ ainsi que par des textes littéraires, comme ce passage du Bellum Alexandrinum:

Ponto recepto, praeda omni regia militibus condonata, postero die cum expeditis equitibus ipse proficiscitur, legionem sextam decedere ad praemia atque honores accipiendos in Italiam iubet [...].

"Après avoir reconquis le Pont et distribué tout le butin royal à ses soldats, lui-même s'en va le lendemain avec ses cavaliers équipés à la légère, donne l'ordre à la sixième légion de rentrer en Italie pour y recevoir récompenses et honneurs $[\ldots]$.»

(Ps.-CAEs., B. Al. 77, 2; trad. Andrieu).

L'auteur évoque le retour en Italie de César et les suites de la victoire: les soldats de la sixième légion vont recevoir des praemia, des récompenses en argent tirées du butin, et des honores, des décorations militaires honorifiques ${ }^{67}$. L'étude de leur aspect à l'époque républicaine nous apporte plusieurs informations utiles sur l'impor-

${ }^{62}$ Sur les peintures triomphales, voir les cas évoqués par PLin. NH XXXV, 7. Sur Fabius Pictor et le temple de Salus, voir les évocations de Cic. Tusc. I, 4; Liv. IX, 43, 25 et X, 1, 9; Val. MaX. VIII, 14, 6 et Plin. NH XXXV, 7.

${ }^{63}$ Sur ce personnage, voir $R E$ col. 1835 s. v. Fabius (n $\left.{ }^{\circ} 122\right)$. Devant la distance, soulignée par plusieurs sources antiques, entre la noblesse de Fabius Pictor et la bassesse de l'art manuel qu'est la peinture, l'attribution des fresques à ce personnage a été mise en doute par R. RoBerT, «Le fragment de Denys A.R. 16 F et les peintures de Fabius Pictor. Histoire d'une interprétation» in S. PitTia (éd.), Fragments d'historiens grecs. Autour de Denys d'Halicarnasse, Rome, E.F.R., 2002, p. 307-328.

${ }^{64}$ J. H. Richardson, «Dorsuo and the Gauls», Phoenix, 58 (3-4), 2004, p. 284-297.

${ }^{65}$ Sur cet usage des temples pour l'exposition de portraits, ROBERT, "Quelques usages du portrait peint à l'époque médio-républicaine», p. 83-84.

${ }^{66}$ Voir par exemple celle qui concerne un soldat de l'armée césarienne: CIL X, 5713 $=I L L R P$ vol. $1,498 \mathrm{a}$.

${ }^{67}$ Pour un autre exemple d'honores donnés aux légions, voir Cic. Phil. III, 7. Sur ces deux catégories de récompenses militaires, bienfaits concrets et décorations symboliques, voir MAXFIELD, The Military Decorations, p. 56-57. 
tance de la matérialité de l'honos ${ }^{68}$. On peut distinguer deux catégories d'honores guerriers: les couronnes et les objets militaires. L'usage des couronnes comme signes honorifiques provient du monde grec, mais les Romains les emploient surtout en contexte martial; elles servent beaucoup moins pour récompenser la vertu civique ou les victoires dans les concours gymniques et artistiques ${ }^{69}$. Parmi les différentes couronnes, la corona obsidionalis est la plus prestigieuse: elle est donnée à celui qui a fait lever un siège et fabriquée à partir de la végétation qui pousse sur le $\operatorname{site}^{70}$. Cet honos a donc une valeur purement symbolique et aucunement économique. La corona ciuica, accordée à celui qui sauve la vie d'un citoyen romain, a elle aussi une valeur financière nulle puisqu'elle est faite de feuilles de chêne ${ }^{71}$. Ces deux couronnes fonctionnent comme des symboles, et ne possèdent qu'un rapport distant avec le mérite qu'elles récompensent. D’autres couronnes le rappellent en revanche de façon plus directe: la corona naualis, octroyée pour une victoire navale, est très rare, mais nous en connaissons une attestation pour M. Varron qui l'obtint de Pompée ${ }^{72}$; sa dénomination alternative de corona rostrata et un texte de Pline attestent qu'elle était composée de feuilles de laurier et ornée de proues miniatures de navire ${ }^{73}$. L'honos qui signifie l'estime représente donc aussi le mérite qui est à sa racine: le signe est ici icône. Il en est de même pour la corona muralis, donnée au soldat qui franchit le premier le mur d'une cité ennemie lors d'un assaut ${ }^{74}$, et pour la corona uallaris, donnée lors de la prise d'un camp ennemi pour celui qui l'a investi le premier ${ }^{75}$ : ces deux couronnes portaient une représentation stylisée d'une muraille. L'exploit est donc encore figuré directement sur l'honos. Il faut noter également que ces deux couronnes sont faites

${ }^{68}$ Sur les dona militaria, voir, outre l'ouvrage de MAXFIELD, J. NAudet, De la noblesse et des récompenses d'honneur chez les Romains, Paris, A. Durand, 1863; BütTner, «Untersuchungen » et J. Harmand, L'Armée et le soldat à Rome de 107 à 50 avant notre ère, Paris, Picard, 1967. Les dona militaria sont d'apparition ancienne, mais on connaît surtout leur emploi à partir du $\mathrm{I}^{\mathrm{er}}$ siècle avant notre ère (sur leur date d'apparition, voir BütTNER, «Untersuchungen », p. 127-128).

${ }^{69}$ Maxfield, The Military Decorations, p. 61.

${ }^{70}$ D'où son nom de corona graminea ou «couronne de gazon ». C'était autrefois le signe le plus solennel de défaite de la part d'un conquis que d'offrir au conquérant un morceau de sa terre (Gell. V, 6; Plin. NH XXII, 4, 6). Publius Decius eut l'honneur d'en recevoir deux (LIV. VII, 37, 2).

${ }^{71}$ Gell. V, 6, 13-14 et Plin. NH XVI, 12-13. Voir MaXfield, The Military Decorations p. 70. Plusieurs bas-reliefs permettent de se faire une bonne idée de son aspect (MAXFIELD, The Military Decorations, p. 72). C'est de là que vient son autre nom de corona iligna ou quercea.

${ }^{72}$ LiV. Epit. 129; VeLl. II, 81.

${ }^{73}$ PLIN. NH XVI, 4.

${ }^{74}$ Gell. V, 6, 16. Voir Maxfield, The Military Decorations, p. 77. Scipion Émilien en obtint une en Espagne.

${ }^{75}$ Gell. V, 6, 17; Fest. 49, 25. On l'appelle aussi corona castrensis. 
en or, et non en matériaux végétaux: leur valeur est donc à la fois symbolique et économique.

L'autre catégorie de dona militaria est composée d'objets militaires utilisés comme décorations. Un texte de Salluste en donne quelques exemples; il s'agit d'un passage du discours de Marius :

Non possum fidei causa imagines neque triumphos aut consulatus maiorum meorum ostentare; at, si res postulet, hastas, uexillum, phaleras, alia militaria dona, praeterea cicatrices aduorso corpore.

«Je ne puis, pour inspirer confiance, exhiber les portraits ni les triomphes ou les consulats de mes ancêtres, mais, s'il en était besoin, des lances, un étendard, des phalères et autres récompenses militaires, sans parler de mes blessures, toutes reçues par devant.»

(SALL. Iug. 85, 29-30; trad. Ernout).

Marius mentionne la hasta, une lance d'apparat donnée à un soldat qui tue un ennemi en combat singulier ${ }^{76}$. Le uexillum, honos rare à l'époque républicaine, est une exacte réplique de l'étendard porté par les légionnaires ${ }^{77}$. Les phalerae sont des disques de métal surtout utilisés pour le harnachement des chevaux ${ }^{78}$. L'honos prend donc la forme d'objets dont la nature première n'est pas honorifique; il s'agit d'accessoires militaires courants investis à titre secondaire d'un pouvoir honorifique ${ }^{79}$. Ces honores ne se distinguent donc pas par leur nature mais par l'intention qui préside à leur octroi et par le geste de donner, d'où leur dénomination générique de dona militaria. L'honos transforme ainsi l'usage et la destination d'un objet courant pour en faire un signe honorifique. Il en va de même pour deux autres types d'honores militaires qui sont d'origine barbare: les torques et les colliers. Ces deux objets figuraient probablement aux origines dans le butin de l'armée et devaient être arborés par les soldats comme prises de guerre. Puis ils sont progressivement passés dans le domaine des distinctions honorifiques ${ }^{80}$. L'honos est ainsi primitivement un trophée

${ }^{76}$ Pol. VI, 39, 3-4. La nature exacte de la hasta pura a fait débat car les textes sont contradictoires sur ce point, Varron indiquant, contre Polybe, que son nom de pura provient de l'absence d'un fer de lance (VArr. d'ap. Serv. Aen. VI, 760). Mais les représentations figurées témoignent de la présence de ce dernier; le qualificatif pura indique plutôt que la lance n'a jamais versé le sang (MAXFIELD, The Military Decorations, p. 86). Sur la hasta, voir BütTNER, "Untersuchungen», p.131 et p.142 sqq. Voir aussi sur la symbolique de la lance, régulièrement associée au pouvoir, A. ALFöLDI, "Hasta - Summa Imperii. The Spear as Embodiment of Sovereignity in Rome », AJA, 63 (1), 1959, p. 1-27.

${ }^{77}$ Maxfield, The Military Decorations, p. 82.

78 BütTner, «Untersuchungen», p. 123 et p.145-152. MAXFIELD, The Military Decorations, p. 92.

${ }^{79}$ Ces décorations ne sont d'ailleurs pas portées lors du combat: elles tombent bien dans le domaine de l'ornement (Maxfield, The Military Decorations, p. 142).

${ }^{80}$ Sur les torques et armillae comme honores, voir BüTTNER, "Untersuchungen », p. 133-135 (origine) et p. 152-154 (aspect et histoire). 
de guerre qui signifie que l'ennemi a été vaincu. Le lien de l'honos avec l'exploit au combat est donc ici encore rendu visible et le rapport entre signifiant et signifié est loin d'être arbitraire. La transformation, par la suite, de ces ornements en véritables honores est perceptible dans la façon dont ils sont portés: les torques ne sont pas placés autour du cou, là où les Celtes les mettent, mais attachés sur la cuirasse, par paires $^{81}$. Les armillae changent eux aussi de nature quand ils deviennent des honores; ce sont à l'origine des attributs féminins mais ils deviennent des récompenses de la vaillance virile ${ }^{82}$. L'honos peut ainsi altérer en profondeur les objets: ce qui est barbare devient romain, ce qui est féminin devient masculin.

Enfin, dans le domaine de l'honos religieux aussi la relation d'hommage recourt à des objets courants enrichis d'une portée honorifique. Nous avons vu, dans le prologue de l'Aulularia, que le lare se félicite que la jeune fille de la maison lui octroie des honores ${ }^{83}$. Leur nature est précisée quelques vers plus loin: il s'agit de vin, d'encens et de couronnes $^{84}$. Les coronae ont donc un autre usage honorifique, dans le domaine religieux; quant au vin et à l'encens, il s'agit de denrées qui ne sont qu'incidemment employées comme marques d'honneur. Les honores font partie intégrante du culte rendu aux dieux: ils relèvent à la fois du rituel du sacrifice, pour le cas du vin et de l'encens ${ }^{85}$, et de celui du don d'un objet à la divinité, pour les couronnes.

\subsubsection{Bilan}

L'objet utilisé par l'honos s'enrichit souvent d'une signification inédite en devenant un instrument qui sert à exprimer un jugement positif. Une somme d'argent, un bâtiment public, une lance, sont initialement des objets courants qui n'ont pas en soi de valeur honorifique. Mais quand ils sont conférés en récompense de certains mérites, ils peuvent se transformer en signes d'estime. Ce qui nous amène, pour affiner notre typologie, à opérer une distinction: les objets octroyés à titre d'honneur peuvent être déjà pourvus de cette signification honorifique ou bien ne la recevoir que parce qu'ils sont mobilisés dans une

${ }^{81}$ Maxfield, The Military Decorations, p. 88.

${ }^{82}$ Voir le texte d'Isidore de Séville (Orig. XIX, 31, 16): armillae autem proprie uirorum sunt, conlatae uictoriae causa militibus ab armorum uirtute: « et les bracelets sont des attributs proprement masculins, qui sont conférés aux soldats pour une victoire et en raison de leur vaillance au combat. »

${ }^{83}$ PL. Aul. 15-19.

${ }^{84}$ Voir aussi Aul. 325 sqq. où Euclion se décide à mettre de l'encens et des couronnes sur l'autel du lare pour que les noces de sa fille soient bénies.

${ }^{85}$ Lors de la praefatio du sacrifice, on offrait, sur un foyer portatif, de l'encens et du vin (J.ScHeID, Quand faire c'est croire. Les rites sacrificiels des Romains, Paris, Aubier, 2005, p. 44-50). 
relation d'honos. Les couronnes constituent ainsi des honneurs déjà codés comme tels: l'octroi à quelqu'un d'une couronne obsidionale dans un contexte autre que celui de l'hommage est impensable. Il est en revanche des cas où l'honos recourt à des objets qui ne sont nullement emprisonnés dans cet usage honorifique. Nous pouvons l'observer avec l'exemple du vin. Il est offert au lare de la maison, sous forme de libation, et c'est ce geste qui le transforme en honos.

Plusieurs marques d'honneur dessinent, par leur forme, un lien avec le mérite qu'elles récompensent. Il y a, de ce fait, un sens supplémentaire de la marque d'honneur: l'honos signifie l'estime ou la gratia mais aussi le mérite de celui qui le reçoit. L'honos dit quelque chose du donateur mais aussi du destinataire. La forme prise par les dona militaria est ainsi en rapport étroit avec ce qui fonde leur attribution: la muraille miniature présente sur la corona muralis ou uallaris rappelle que le soldat décoré a été le premier à franchir le mur de la cité ou du camp. Le signe figure, de manière analogique, l'exploit ou du moins le lieu de celui-ci. La statue peut également signaler le mérite de celui qui la reçoit mais elle est plus sujette à des conventions iconographiques: les statues équestres ne célèbrent pas toujours un individu qui s'est illustré dans le cadre du service monté. Ces exemples montrent que l'honos n'est pas toujours un signe aussi arbitraire que le signe linguistique défini par Saussure.

Tous les honores examinés précédemment possèdent une valeur symbolique car ils valent par l'estime qu'ils signifient. Cependant, même des honores à forte valeur symbolique ont une valeur économique: plusieurs couronnes, par exemple, sont faites en or et la nature du métal employé pour une statue n'est pas indifférente. Quant aux honores que sont les héritages et dépenses publiques, leur valeur repose précisément dans l'avantage matériel qui est conféré au destinataire. Le symbolique et l'économique ne sont donc pas deux ordres contradictoires. La coïncidence, cependant, n'est pas toujours systématique: certains honores, comme les couronnes faites de feuillage, n'ont pas de valeur économique. Le rapport entre l'économique et le symbolique est donc un rapport d'association et non pas de corrélation parfaite ${ }^{86}$. Cette association peut être encore précisée par trois observations. Les marques d'honneur examinées montrent d'abord que des actes relevant des échanges économiques, comme l'héritage ou la dépense publique, sont perçus comme des échanges symboliques: le donateur honore celui dont il fait son héritier et l'évergète honore la cité et ses concitoyens. Il s'opère ainsi une transfiguration de la relation économique en relation symbolique: la prestation devient un hommage ${ }^{87}$.

${ }^{86}$ Sur le détachement possible de l'économique et du symbolique, voir Bourdieu, Esquisse d'une théorie de la pratique, p. 374.

${ }^{87} \mathrm{La}$ situation est comparable à l'observation que fait P. Bourdieu de la pratique du don chez les Kabyles: travestissant des échanges de biens en conduites de don, ils font 
En second lieu, l'économique est associé au symbolique parce que l'économique dit l'estime et devient donc lui-même vecteur du symbolique. Les évergètes insistent sur le fait que l'honos est effectué de sua pecunia: c'est la dépense engagée qui est honorifique pour la cité et l'estime du bienfaiteur pour ses concitoyens se mesure à l'importance des largesses octroyées. En dernier lieu, la valeur économique est symbolique parce que la richesse s'accompagne à Rome, dans le cadre du régime censitaire, de prérogatives civiques. La matérialité de l'honos est cruciale car les biens permettent d'avoir un rang social et d'exercer un rôle politique dans la cité. L'honos augmente le prestige par ce qu'il dit, mais aussi par ce qu'il est. La valeur économique de l'hommage ne doit donc pas être opposée à sa valeur symbolique.

Cette double valeur de l'honos nous invite à le rapprocher du phénomène du don. Les deux pratiques se ressemblent en effet: elles recourent à des objets matériels, mettent en œuvre l'acte volontaire et personnel d'attribuer un objet, et opèrent une combinaison du symbolique et de l'économique. Les analyses du don faites par les ethnologues fournissent d'autres parallèles intéressants avec l'honos. Dans son étude du potlatch, qui est une forme extrême de don, M. Mauss insiste sur l'importance prise par la dépense matérielle. Au cours de cette cérémonie, il faut donner, et donner beaucoup. Les dons prennent en effet une tournure agonistique: les chefs s'affrontent pour savoir qui sera capable de donner le plus et d'atteindre ainsi le sommet de la hiérarchie. Le prestige se gagne par le biais de la dépense somptuaire, qui peut aller parfois jusqu'à la destruction de biens ${ }^{88}$. L'honos romain n'est pas une forme de potlatch: aucune rivalité ne s'y exprime. Mais la dépense et le coût de ce qui est donné revêtent une place très importante, comme on l'a vu: pour les Kwakiutl étudiés par M. Mauss comme pour les Romains, le don ou l'honneur accordé est d'autant plus significatif et prestigieux qu'il est coûteux. M. Mauss montre également que le don est source d'honneur pour celui qui le reçoit; l'homme déconsidéré retrouve son prestige quand des statues lui sont érigées et des fêtes organisées en son nom, notamment parce que ces célébrations occasionnent des dépenses significatives ${ }^{89}$. Malgré ces

en sorte que «le don cesse d'être un objet matériel pour devenir une sorte de message ou de symbole propre à créer un lien social » (Raisons pratiques, p. 189). Il y a un tabou de la vérité économique qui doit être dissimulée.

${ }^{88}$ Sur le potlatch, Mauss, Sociologie et anthropologie, p. 149 sqq. Voir aussi la lecture critique de Godelier, L'Énigme du don, Paris, Flammarion, 1996, p. 79-109. Sur les dons non agonistiques, voir cet ouvrage p.59-62.

${ }^{89}$ Voir le mythe des Indiens Haïda rapporté par MAuss, Sociologie et anthropologie, p. 103, n. 6. Un vieux chef de clan se rend à un potlatch mais il ne donne pas assez pour pouvoir conserver son rang; ses offrandes insuffisantes lui valent de ne plus être invité, ce qui le plonge dans une profonde détresse, au point qu'il en meurt. Ses descendants lui adressent alors des dons: ils lui érigent une statue et organisent des fêtes en son nom, ce qui a pour effet de faire renaître son prestige. 
parallèles, cependant, l'honos n'est pas totalement réductible à une conduite de don. L'honos est en effet une réponse à un mérite, la rétribution d'une qualité ou d'un service, sur le mode du paiement. Le don, lui, est consenti plus librement. Il y a, dans les sociétés étudiées par les anthropologues, une obligation de donner, mais elle n'est pas imposée par la dignité de celui qui reçoit le don. Le paradigme économique de l'honos, celui de la rétribution, n'est donc pas le même que celui du don.

\subsection{Le geste}

L'honos peut aussi prendre la forme d'un geste fait par une personne en direction d'une autre. Il s'agit alors d'un acte qui n'implique pas le recours à un instrument extérieur pour signifier l'estime. Ce geste peut être de deux types, les soins et services ou bien les égards et politesses.

\subsubsection{Formes}

Les honores peuvent d'abord consister en bons traitements ou services. C'est le cas dans le Stichus où Panégyris déclare à sa sœur, à propos de leurs maris partis en mer:

Nolo ego, soror, me credi esse immemorem uiri,

Neque ille eos honores mihi quos habuit perdidit.

Nam pol mihi grata acceptaque huiust benignitas.

«Je ne veux pas, ma sœur, qu'on pense que j’ai oublié mon mari, Ni que les honneurs qu'il m'a conférés ont été donnés en pure perte.

Car, par Pollux, j'accepte et je lui suis reconnaissante de sa bienveillance.»

(PL. St. 48-50).

Panégyris veut conserver le souvenir des honores que son mari lui a témoignés et qui consistent en un ensemble de bons traitements et de gestes d'attention. Ce sont des bienfaits matériels procédant de la benignitas de l'époux. Le maître peut aussi avoir ce type d'honores pour ses esclaves, en leur donnant plus de vivres, de vêtements ou de repos $^{90}$. Quand un sénateur se déplace à l'étranger, on lui fait généralement l'honos de lui offrir l'hospitalité91. C'est un honos que d'accéder à la demande de suppliants en leur offrant asile ${ }^{92}$ ou d'apporter son aide à un ami dans une affaire délicate ${ }^{93}$. L'honos consiste ainsi en un geste

${ }^{90}$ VARR. $R R$ I, 17, 6.

${ }^{91}$ CIC. Verr. II, IV, 25.

${ }^{92}$ PL. Rud. 284-289.

${ }^{93}$ Voir par exemple Cic. Att. XVI, 16a, où Cicéron demande l'aide de L.Plotius Plancus honoris gratia dans l'affaire de Buthrote, dans laquelle Atticus et César ont joué un rôle important. 
prévenant qui vise le bien-être de celui qui est honoré ${ }^{94}$. Il implique donc une activité plus grande de la part de celui qui honore que lorsqu'il s'agit d'un objet: le destinateur doit faire un effort pour rendre hommage à autrui. L'honos impose une dépense d'énergie et pas seulement une dépense matérielle. Le contact entre celui qui donne et celui qui reçoit l'honos est en outre plus direct car il se passe d'objet intermédiaire. L'honos d'un geste est cependant plus fugace et plus volatil que l'honos sous forme d'objet car il s'efface une fois accompli.

Une seconde catégorie de gestes honorifiques recouvre les égards et marques de politesse. Ces marques d'honneur n'augmentent pas le bien-être ni ne protègent la personne mais visent à dire le respect. Deux textes de notre époque en fournissent des exemples. Le premier est un passage de Térence:

Dum haec loquimur, interea loci ad macellum ubi aduentamus,
Concurrunt laeti mihi obuiam cuppedinarii omnes,
Cetarii, lanii, coqui, fartores, piscatores,
Quibus et re salua et perdita profueram et prosum saepe;
Salutant, ad cenam uocant, aduentum gratulantur.
Ille ubi miser famelicus uidet me esse tanto honore et
Tam facile uictum quaerere, ibi homo coepit me obsecrare
Vt sibi liceret discere id de me.

«Pendant que nous causons, nous arrivons au marché et à cet instant

Accourent à ma rencontre, le sourire aux lèvres, tous les marchands de bonnes choses,

Les mareyeurs, les bouchers, les charcutiers, les rôtisseurs, les poissonniers, À qui, dans la richesse comme dans la misère, j'avais rendu et rends encore souvent des services;

Ils me saluent, m'invitent à dîner, me félicitent de ma venue.

Lorsqu'il voit, ce pauvre famélique, que je suis autant à l'honneur

Et que je gagne mon pain si facilement, il commence à me supplier

De lui permettre de devenir mon élève.»

(TER. Eun. 255-262).

Il est ici question de la grande considération dont jouit le parasite Gnathon auprès des marchands et des marques d'honneur qui l'accompagnent. Il s'agit d'égards cordiaux: les gens viennent à sa rencontre (obuiam), le saluent (salutant), l'invitent à dîner (ad cenam uocant), et se réjouissent de sa venue (aduentum gratulantur). Ce sont des prévenances gestuelles ou orales. Aller à la rencontre de quelqu'un est un honos bien identifié comme tel, que l'on retrouve dans d'autres

${ }^{94}$ C'est pourquoi l'honos s'oppose à toutes les actions qui visent à endommager l'intégrité physique d'autrui: Cicéron oppose la façon dont les marchands romains ont été honorés en Syrie et en Égypte à l'attitude de Verrès en Sicile qui les a emprisonnés et décapités (Cic. Verr. II, V, 157). 
contextes ${ }^{95}$. Par cette marque d'honneur le donateur épargne à celui qu'il honore la peine de se déplacer et fait l'effort de se rapprocher de lui: il y a mouvement vers celui que l'on reconnaît comme supérieur pendant que ce dernier reste immobile. Le salut est également un honos relativement répandu; Cicéron estime que Pison est tellement ignoble qu'il ne mérite même pas une marque d'honneur aussi banale ${ }^{96}$. La salutatio consiste à se tourner vers un tiers et à lui adresser une parole de civilité, que ce soit dans la rue ou, plus spécifiquement, dans la maison d'un concitoyen. Les aristocrates romains recevaient tous les matins clients et visiteurs dans l'atrium de leur demeure pour la salutatio avant de vaquer à leurs affaires ${ }^{97}$.

Le second texte important pour la compréhension de ces honores à l'époque républicaine est un passage du Cato maior évoquant les marques d'honneur rendues aux personnes âgées ${ }^{98}$ :

Haec enim ipsa sunt honorabilia quae uidentur leuia atque communia, salutari, appeti, decedi, adsurgi, deduci, reduci, consuli; quae et apud nos et in aliis ciuitatibus, ut quaeque optime morata est, ita diligentissume obseruantur.

"Voici en effet des marques certaines d'honneur, bien que cela paraisse frivole et banal, saluer, aborder, céder le pas, se lever, escorter, reconduire, consulter, toutes coutumes qui s'observent chez nous et dans d'autres cités, avec d'autant plus de soin que les mœurs y sont plus honnêtes.»

(Cıc. Cato mai. 63; trad. Wuilleumier modifiée).

On retrouve parmi ces marques de respect le salut (salutari) et le fait de se porter au devant de quelqu'un (appeti). Trois autres honores sont relevés par l'auteur: céder le pas (decedi), se lever (adsurgi) et faire cortège (deduci, reduci). La demande de conseil (consuli) n'appartient pas quant à elle aux honores gestuels. Céder le pas à quelqu'un revient à lui laisser la place dans les rues et les lieux publics, à s'effacer en sa présence pour qu'il n'ait pas de peine à se donner en faisant un écart ${ }^{99}$. L'honos consiste donc à donner une place avantageuse et à laisser occuper librement l'espace. La personne honorée gagne ainsi en visibilité publique. Se lever devant quelqu'un est une marque d'estime octroyée en des occasions diverses : quand Cicéron paraît devant

\footnotetext{
${ }^{95}$ Quand le roi Bocchus, rallié aux Romains, tend un piège à Jugurtha pour le livrer à Sylla et Marius, il s'avance vers lui pour faire semblant de l'honorer (SALL. Iug. 113, 5).

${ }^{96}$ Cic. Pis. 96.

${ }^{97}$ Nous renseignent sur cette pratique Pol. XXXI, 29; Val. MaX. V, 8, 3 ; Sen. Ben. VI, 34, 2. Voir l'article de Hug dans la RE s. v. salutatio et Flower, Ancestor Masks, p. 217-219.

${ }^{98}$ Sur ce texte, voir l'étude de P. Moreau, «Positions du corps, gestes et hiérarchie à Rome», in Moreau, P. (éd.), Corps romains, Grenoble, J. Millon, 2002, p. 179-200.

${ }^{99}$ On donne à celui que l'on veut honorer la place éloignée du bord de la route quand on marche à ses côtés dans la rue (Hor. Sat. II, 5, 17): c'est l'endroit le moins boueux et le mieux protégé.
} 
le sénat de Syracuse, tous ses membres se lèvent honorifice ${ }^{100}$. Le public du théâtre se lève aussi lors de l'entrée dans les gradins d'un personnage décoré ${ }^{101}$. Quand un citoyen à cheval ou assis sur un siège se trouve en présence d'un magistrat, on attend de lui qu'il se mette debout ${ }^{102}$. La position assise est en effet celle du supérieur, notamment quand il exerce une charge publique; c'est assis sur la chaise curule que le magistrat administre la justice, prend les auspices ou lève les troupes ${ }^{103}$. C'est donc rendre une marque d'honneur toute particulière pour un personnage important que de se lever devant un inférieur: devant le jeune Pompée, Sylla se découvrait, se levait et le saluait du titre d'imperator ${ }^{104}$. Se lever, c'est reconnaître de façon manifeste la supériorité de celui devant qui on se trouve ${ }^{105}$. La position assise du supérieur lui confère, par rapport à ceux qui sont debout, une posture distinctive. C'est à la valorisation de cette posture assise que se rattachent les signes distinctifs relevant de la proédrie: il y a, dans les édifices de spectacle, dans les banquets, dans les camps militaires, des places réservées, qui ne sont pas perçues comme des honores, mais relèvent des insignes de prestige liés à une posture dans l'espace et à une ségrégation positive ${ }^{106}$. La dernière marque d'honneur gestuelle relevée dans le texte du Cato maior consiste à accompagner quelqu'un dans les endroits publics. Il s'agit là de la pratique romaine du cortège, que l'on rencontre en différentes occasions: les magistrats et les promagistrats qui entrent ou sortent de Rome pour l'exercice de leur charge sont traditionnellement accompagnés d'une foule qui les escorte pour leur faire honneur ${ }^{107}$. Des cortèges se forment aussi autour des généraux vainqueurs: en 201, Scipion l'Africain fut accueilli dans les villes qu'il traversait sur le chemin de son retour à Rome et les paysans le suivaient le long des chemins ${ }^{108}$. Mais c'est surtout pour les candidats

${ }^{100}$ Cic. Verr. II, IV, 138.

${ }^{101}$ Plin. NH XVI, 4, 13.

${ }^{102}$ Cic. Pis. 26 ; Liv. IX, 46.

${ }^{103}$ LiV. III, 11, 1. Mommsen, DPR, vol. 2, p. 31.

${ }^{104}$ Val. Max. VIII, 3, 4 ; Plut. Pomp. 8 et Crass. 6. Voir Moreau, " Positions du corps, gestes et hiérarchie à Rome», p. 183.

${ }^{105}$ C'est pourquoi Accius ne se levait pas devant J. Caesar Strabo car il considérait que ce dernier, qui lui était bien supérieur par le rang social, ne l'emportait pas sur lui par le talent poétique (VAL. MAX. III, 7, 11).

${ }^{106}$ Voir par exemple SALL. Iug. 65, 1-2 où la place honorifique est celle située près du siège de l'imperator, dans le praetorium, à peu près au milieu du camp militaire, au croisement des deux axes matérialisés par les quatre portes ( $c f$. les textes plus tardifs de Suet. Nero 13, 2 et Domit. 11, 1).

107 Voir C. Nicolet, Le Métier de citoyen dans la Rome républicaine, 2e éd., Paris, Gallimard, 1976, p.473. Caton, de retour de sa propréture de Chypre, remonta le Tibre jusqu'à Rome et fut accueilli par le peuple, les magistrats et le sénat sur les berges (Plut.Cato 39).

${ }^{108}$ Liv. XXX, 45, 2. À l'inverse, Cicéron raille Pison que personne n'est venu escorter lors de son piteux retour à Rome (CIC. Pis. 55). 
à une charge politique que les cortèges revêtent une importance particulière: ils leur permettent d'affirmer visiblement leur popularité aux yeux de l'électorat. Le Commentariolum petitionis consacre tout un passage riche d'enseignement à l'honos des cortèges ${ }^{109}$. Il distingue les gens qui viennent simplement pratiquer la salutatio dans la demeure, ceux qui escortent le candidat au forum, et enfin ceux qui le suivent partout en ville. On constate à nouveau dans ce passage l'existence d'une échelle des honores: suivre quelqu'un partout est un hommage plus grand que venir le saluer le matin. On voit également l'importance prise par le nombre des présents dans ces honores: plus la foule est dense, plus le prestige est accru ${ }^{110}$. L'honos se nourrit donc du capital humain mobilisé et de la visibilité conférée au candidat dans l'espace de la cité.

Peut-on déceler une matrice commune à ces différents honores ${ }^{111}$ ? Il s'agit à chaque fois de conduites gestuelles qui s'inscrivent dans l'espace: se lever, céder la place ou faire cortège implique de se déplacer au bénéfice de la personne honorée. Ce qui importe est le mouvement mais surtout l'abandon d'une posture occupée avant l'honos: celui qui marque son estime change de position alors que l'autre garde sa place ${ }^{112}$. L'effort fait par celui qui honore est lui aussi capital: on va à la rencontre d'autrui, on prend la peine de se lever ou de l'escorter pendant de longues heures. Il y a des gestes, de l'ordre du symbolique, mais aussi une dépense d'énergie, qui relève de l'économique.

\subsubsection{Bilan}

Ces honores gestuels signifient, comme les objets, l'estime de celui qui les accomplit mais ont la singularité de mobiliser pour ce faire le corps. L'octroi de bons traitements implique physiquement la personne qui les donne et la fait entrer en relation étroite avec l'individu honoré. Les gestes de salut et de respect utilisent directement le corps comme support de signes: ce sont le mouvement des membres et la posture physique qui signifient l'estime. L'honos rejoint ainsi d'autres pratiques romaines qui font du corps un objet parlant. Ce dernier joue un rôle signifiant dans le discours de l'orateur, au moment de l'actio, dans le sacrifice religieux, où les gestes sont performatifs, au

${ }^{109}$ Q. Cic. Comm. 34-38. Voir aussi d'autres textes importants: Cic. Mur. 70; Sull. 81; Dom.76.

${ }_{110}$ Q. Cic. Comm. 36. Le prestige est encore accru quand des individus de haut statut acceptent de prendre part au cortège (Cic. Sull. 81).

${ }^{111}$ Ces gestes honorifiques perdurent au-delà de l'époque républicaine et semblent alors avoir fait l'objet d'une progressive codification. Voir SERV. Aen. XI, 500 et SEN. Epist. LXIV, 10. Sur ces textes et sur l'élaboration d'une réflexion sur les modes de salutation, Moreau, «Positions du corps, gestes et hiérarchie à Rome», p. 186 sqq.

${ }^{112}$ Ibid., p. 199. 
cours des funérailles, où les larmes disent l'intensité du chagrin, ou bien au sénat où l'on vote en se déplaçant vers celui dont on soutient la proposition ${ }^{113}$. L'honos lui aussi mobilise gestes et postures pour délivrer une signification, le jugement favorable. L'expression corporelle de l'estime est rendue possible par la corrélation que posent les Romains de la République entre aspects du corps et aspects de l'âme. Cette correspondance a été par exemple théorisée à propos de l'actio de l'orateur dans le De oratore, où Cicéron explique comment le corps d'un homme et les expressions de son visage sont gouvernés par l'âme et ses mouvements, puis de manière plus générale dans le De officiis où l'apparence extérieure est considérée comme le reflet de la personnalité intérieure ${ }^{114}$.

À cette fonction symbolique des marques d'honneur gestuelles s'ajoute une dimension économique tout aussi importante. Il y a en effet, comme on l'a vu, une dépense engagée par le donateur, d'ordre physique: celui qui fait cortège prend de la peine pour honorer un candidat; l'hôte qui reçoit chez lui engage une dépense financière ${ }^{115}$. L'honos gestuel apporte en outre d'authentiques bienfaits à celui auquel il est destiné: son bien-être est augmenté par des attentions, son intégrité physique préservée par une intervention extérieure, sa situation sociale protégée par une assistance dans un procès, ses chances de succès à une candidature renforcées par les cortèges.

Pour que l'honos remplisse pleinement sa fonction, il doit être visible de tous. On se souvient en effet que la marque d'honneur est destinée à autrui mais prend son sens quand un public assiste à la relation d'hommage ${ }^{116}$. Or, le geste honorifique s'en assure parfaitement en se plaçant sous les yeux de tous et en conférant au bénéficiaire une visibilité remarquable. Faire cortège à un individu implique de placer en tête celui que l'on honore et d'occuper l'espace public dans la cité ${ }^{117}$.

${ }^{113}$ Sur ces gestes, voir A.P.CorbeILl, Nature Embodied. Gesture in Ancient Rome, Princeton, Princeton University Press, 2004. Sur les signes portés par le corps de l'orateur, voir le livre XI de l'Institution Oratoire de Quintilien, et les études de MaIEREIchHorn, Die Gestikulation in Quintilians Rhetorik; F. Graf, "The Gestures of Roman Actors and Orators", in Bremmer, J.et Roodenburg, H.(éds.), A Cultural History of Gesture, Oxford, Polity Press, 1991, p. 36-58 et Aldrete, Gestures and Acclamations in Ancient Rome.

${ }^{114}$ Cic. De or. III, 216; Off. II, 128-130. On retrouve ici les principes de la tradition physiognomonique, qui connut une vraie vogue entre le $\mathrm{III}^{\mathrm{e}}$ et le $\mathrm{I}^{\mathrm{er}}$ siècles avant notre ère (E.C.Evans, Physiognomonics in the Ancient World, Philadelphie, American Philosophical Society, 1969).

${ }^{115}$ Voir CIc. Verr. II, IV, 62 où un invité estime avoir été traité honorifice parce que la cena a été somptueuse.

${ }^{116}$ Supra p. 204 sqq.

${ }^{117}$ Voir les remarques de C. Nicolet à ce sujet sur Rome comme « civilisation ostentatoire où le fait d'être 'entouré d'hommes' est essentiel» (Nicolet, Rome et la conquête, p. 234). 
La personne honorée se trouve placée dans une posture distinctive: elle est assise quand son entourage est debout, elle demeure immobile alors que les autres viennent vers elle. Cette distinction spatiale est d'importance car l'honos gestuel, à la différence du don, n'est pas durable: sa faible extension temporelle est compensée par une inclusion dans l'espace. Le prestige repose sur le discours positif des autres mais aussi sur le regard des pairs: un aristocrate romain n'a pas de prestige quand il est seul dans sa uilla de campagne mais quand il se trouve à Rome, sous les yeux de tous ${ }^{118}$.

Ces différentes marques d'honneur nous paraissent, en dernière analyse, pouvoir être rapprochées des actes de bienfaisance, les beneficia $^{119}$. L'honos gestuel vise en effet l'utilité, ce qui est l'une des règles de la bienfaisance dans la définition qu'en donne Cicéron au premier livre du De officiis :

Videndum est enim, primum ne obsit benignitas et iis ipsis quibus benigne uidebitur fieri et ceteris, [...].

«Il faut veiller, en effet, d'abord à ce que cette bonté ne nuise pas à ceux-là mêmes en faveur de qui on paraîtra agir avec bonté, ni non plus aux autres [...].»

(CIc. Off. I, 42 ; trad. Testard).

La bienfaisance ne doit pas nuire en prétendant accorder un bienfait, ce qui reviendrait à ôter tout sens à ce bienfait. La même recommandation pourrait valoir pour l'honos tel que nous venons de l'analyser. Le beneficium comme l'honos apportent un avantage matériel, voire économique, et ont donc une utilité concrète. L'honos, en outre, vise le bien-être de ceux à qui il est destiné. Or c'est là une autre caractéristique du beneficium dans la définition qu'en donne Sénèque:

Quid est ergo beneficium? Beneuola actio tribuens gaudium capiensque tribuendo in id, quod facit prona et sponte sua parata.

«Qu'est-ce donc qu'un bienfait? Un acte de bienveillance qui procure de la joie et qui, par ce fait, s'accompagne de joie, en même temps qu'une inclination et une disposition spontanée à l'accomplir. »

(Sen. Ben. I, 6, 1; trad. Préchac).

Le beneficium produit de la joie comme l'honos contente celui auquel il est destiné. On remarque par ailleurs, dans cette définition,

${ }^{118}$ Sa situation est comparable à celle du courtisan qui, pour avoir du prestige et appartenir à l'élite, doit être à la cour et non en province (N. Elias, La Société de cour, Paris, Calmann-Lévy, 1974, p.91-92).

${ }^{119}$ Le beneficium est une réalité sociale et juridique qui a été enrichie de caractères moraux par Cicéron et Sénèque (R. MARINO, «Fra diritto e morale: il concetto metagiuridico di beneficium nel trattato senecano ", in Rocca, S. (éd.), Latina didaxis, 18, Gênes, Compagnia dai Librai, 2003, p. 79-118). 
la présence de la volonté bienveillante (beniuolentia actio) qui rappelle le rôle joué par la uoluntas dans l'octroi de l'honos ${ }^{120}$. Certains textes de notre époque indiquent d'ailleurs eux-mêmes combien l'honos est proche du beneficium. On le voit dans les Captifs, quand Tyndare remercie Hégion de lui ôter ses chaînes:

TYN.: $\quad$ Di tibi omnes omnia optata $<$ of $>$ ferant,

Cum me tanto honore honestas cumque ex uinclis eximis.

HE. : Quod bonis bene fit beneficium, gratia ea grauida est bonis.

«TYNDARE: Que les dieux t'apportent tout ce que tu désires

Pour te remercier de m'honorer d'un tel honneur et de m'enlever mes chaînes.

HÉGION: Quand on accorde un bienfait de bon cœur aux gens de bien, les gens de bien sont pleins de reconnaissance.»

(PL. Cap. 355-357).

L'honos fait à Tyndare est interprété par Hégion comme un beneficium, avec une insistance particulière sur le «bien» qui justifie l'hommage et l'instaure en même temps (bonis, bene, beneficium, bonis). Cette proximité de l'honos et du beneficium est confirmée par la présence de la gratia comme dénominateur commun: la reconnaissance de celui qui est honoré est aussi attendue de celui qui reçoit un bienfait ${ }^{121}$.

Malgré cette proximité entre les deux notions, certains éléments nous amènent à les distinguer. Il y a d'abord une faible valeur symbolique du beneficium: ce dernier n'a pas autant que l'honos vocation à être un signe. Il peut avoir un sens, mais ce n'est pas là l'essentiel de ce qu'il est: son aspect matériel est primordial. Le beneficium, ensuite, n'exige pas comme l'honos l'existence d'un mérite. Il s'ancre dans la générosité spontanée du bienfaiteur et rien ne l'impose hormis la décision personnelle de son auteur alors que l'honos doit être la récompense d'une qualité ou d'un exploit. Si Cicéron recommande d'octroyer un bienfait de préférence à ceux qui le méritent, il s'agit là seulement d'une prescription, qui vise un usage idéal ${ }^{122}$.

${ }^{120}$ Voir supra p. 213. Dans un autre texte de Sénèque, la uoluntas et l'estime (iudicium) occupent pour le beneficium une place assez similaire à celle qu'ils ont pour l'honos: Non est beneficium, cui deest pars optima, datum esse iudicio; alioqui pecunia ingens, si non ratione nec recta uoluntate donata est, non magis beneficium est quam thesaurus. "Un bienfait n'en est pas un quand il lui manque l'élément le plus important: d'être octroyé après jugement; sans cela une immense somme d'argent, si elle n'a pas été donnée en étant guidée par la raison et une volonté droite, ce n'est pas plus un bienfait qu'un trésor trouvé»(SEN. Ben. I, 15, 6).

${ }^{121}$ Voir les remarques de Cicéron sur le mépris que suscite l'ingrat (CIC. Off. II, 63). Sur la gratitude à laquelle est tenu le destinataire du beneficium, Hellegouarc'H, Vocabulaire, p. 164.

${ }^{122}$ Cic. Off. I, 42. Cicéron recommande que la bienfaisance pro dignitate cuique tribuatur, "soit donnée à chacun en fonction de son mérite. » 


\subsection{La cérémonie}

Il arrive que la marque d'honneur mette en jeu non pas un geste unique mais un ensemble de gestes ordonnés de façon rituelle qui porte en général une forte dimension religieuse. L’honos prend alors la forme d'une cérémonie.

\subsubsection{Formes}

Les honores de ce type sont surtout des cérémonies de victoire octroyées pour honorer un chef militaire. Trois sont reconnues comme des honores: la salutation du titre d'imperator, la supplication d'action de grâces et le triomphe. Un autre type d'honos cérémoniel n'est pas lié à la guerre: il s'agit des funérailles.

Aux $\mathrm{II}^{\mathrm{e}}$ et $\mathrm{I}^{\mathrm{er}}$ siècles avant notre ère, le terme d'imperator est utilisé pour désigner le détenteur de l'imperium militiae, qu'il s'agisse d'un général ou bien d'un promagistrat. Mais il peut aussi être employé comme titre honorifique au cours d'une cérémonie où les soldats le décernent de façon solennelle à leur général: il s'agit de la salutation impératoriale, que César lui-même qualifie d'honos ${ }^{123}$. Cette marque d'honneur se rapproche de l'honos du salut puisqu'elle consiste pour les soldats à se réunir autour du général et à lui octroyer un nomen particulier. Elle en diffère cependant car elle est beaucoup plus exceptionnelle ${ }^{124}$. Après une campagne victorieuse, les soldats de l'armée se réunissent au camp et, restant debout pendant que le général est assis, le désignent du nom d'imperator par une puissante acclamation. Ce dernier a ensuite le droit d'être salué de ce titre et de l'utiliser dans sa correspondance ${ }^{125}$. La première attestation de cet honos se rencontre avec Scipion l'Africain ${ }^{126}$. Cet honneur a été obtenu par la plupart des grands généraux romains, parfois à plusieurs reprises, et une étape supplémentaire fut franchie par Octave qui en fit son praenomen. Cette cérémonie procède à un grandissement de nature religieuse du général: le terme imperator est en effet

${ }^{123}$ CAEs. BC II, 32, 14. Sur ce rituel, voir l'article de RosenBerg dans la RE s. v. imperator et R. ComBÈs, Imperator. Recherches sur l'emploi et la signification du titre d'imperator dans la Rome républicaine, Thèse principale de doctorat, Université de Paris (Sorbonne), Paris, 1966.

${ }^{124} \mathrm{La}$ reconstitution exacte de la cérémonie est difficile en raison du manque d'explications données par les sources qui l'évoquent. Nous nous appuyons sur les données réunies par ComBÈs, Ibid., p. 87 sqq.

${ }^{125} \mathrm{Il}$ est alors mentionné à côté du nom et de la magistrature exercée. Voir par exemple CIc. Phil. XIX, 14.

${ }^{126}$ Liv. XXVII, 19, 4. Le texte de Tite Live est confirmé par une inscription de Sagonte (CIL II, 3836). R. Develin, «Scipio Africanus Imperator », Latomus, 36, 1977, p. 110-113, estime qu'il ne fut pas le premier à recevoir le titre car les sources ne présentent pas cet octroi comme une nouveauté. 
une épithète de Jupiter attestée dès le début du IV siècle ${ }^{127}$. Il est possible que, par l'usage de ce qualificatif, les soldats aient souhaité consacrer la supériorité du chef victorieux en l'associant à cette divinité128.

Un autre honos cérémoniel octroyé à l'issu d'une victoire militaire est la supplication d'action de grâces ${ }^{129}$. Dans une lettre adressée à Sulpicius Rufus, Cicéron explique pourquoi il a soutenu l'octroi de cet honos à son ami:

[...] non existimaui me saluo iure nostrae ueteris amicitiae multorumque inter nos officiorum facere posse, ut honori tuo deessem; itaque affui supplicationemque tibi libenter decreui nec reliquo tempore ullo aut rei aut existimationi aut dignitati tuae deero.

«[...] j’ai pensé que je ne pouvais, sans trahir notre vieille amitié et les nombreux services que nous avons échangés, me dispenser de prendre part à l'hommage qui t'était rendu; aussi ai-je assisté à la séance et voté avec plaisir la supplication en ton honneur, et à l'avenir je ne manquerai en aucune circonstance de servir tes intérêts, ta réputation ou ton rang. »

(Cic. Fam. XIII, 77, 1; trad. Beaujeu).

Le texte montre que la supplication a été discutée au sénat et a fait l'objet d'un vote. Ce n'est donc pas un honos spontané comme la salutation impératoriale: il fait l'objet de la consultation d'une institution centrale de Rome ${ }^{130}$. Un passage du De prouinciis consularibus montre, à propos d'une supplication octroyée à César, une autre singularité de cette cérémonie, qui est la complexité du rôle des différents protagonistes:

Ergo in illa supplicatione, quam ego decreui, res ipsa tributa est dis immortalibus et maiorum institutis et utilitati rei publicae, sed dignitas uerborum, honos et nouitas et numerus dierum Caesaris ipsius laudi gloriaeque concessus est.

"Ainsi, pour la supplication que j'ai votée, la cérémonie elle-même a été dédiée aux dieux immortels, aux institutions des ancêtres et au bien de la république, mais la grandeur du texte, l'honneur, son caractère nouveau ainsi que le nombre de jours décrété ont été concédés à César lui-même, à son mérite et à sa gloire.»

(Cic. Prou. 27; trad. Cousin modifiée).

${ }^{127}$ Combès, Imperator, p. 38-49.

${ }^{128}$ C'est d'autant plus probable que l'assimilation du vainqueur à Jupiter existait déjà dans la cérémonie, plus ancienne, du triomphe, et que le premier à recevoir la salutation impératoriale fut Scipion l'Africain dont les rapports privilégiés avec Jupiter sont bien connus. Combès, Imperator, p. 66. Voir, sur la relation entre Scipion et Jupiter, Pol.X, 5, 5; Liv. XXVI, 19, 3-9; Gell. VI, 1; et la synthèse de F.W.Walbank, "The Scipionic Legend », PCPhS, 13, 1967, p. 54-69.

${ }^{129}$ Sur la supplication d'action de grâces, voir HaLKIN, La Supplication. La procédure de demande et d'octroi de cette cérémonie est assez bien connue grâce aux supplications obtenues par Cicéron en 50 pour ses victoires sur des peuplades insoumises de Cilicie: sa correspondance de l'époque montre les différentes étapes du processus (voir notamment les lettres Fam. XV, 3 et 4).

${ }^{130}$ Ibid., p. 87-89. On connaît des cas où le sénat a refusé l'octroi d'une supplication demandée par le général (Ibid., p. 93-97). 
L'honos n'est pas adressé directement au général mais aux dieux et par-delà à la république. Cependant, il y a un destinataire secondaire, le général: l'honos est bien, dans le texte, défini comme la propriété de César (Caesaris). Comment le général, qui n’est pas celui qui reçoit les actions de grâces, peut-il bénéficier de l'honos? Un passage de la quatrième Catilinaire, qui évoque les récompenses pour ceux qui ont déjoué la conjuration, l'explique:

[...] maximeque quod meo nomine supplicationem decreuistis, qui honos togato habitus ante me est nemini.

«[...] et surtout parce que vous avez décrété en mon nom une supplication, honneur qui avant moi n’a été donné à aucun civil. »

(Cic. Catil. IV, 5).

L'homme est, autant que les dieux, honoré par la supplicatio car cette dernière est organisée en son nom (meo nomine, dit Cicéron). Le nom de Cicéron est donc associé aux gestes de piété de la collectivité. C'est aussi en invoquant le nomen de Marcellus que l'honos de la supplication aux dieux a été décidé après la prise de Syracuse ${ }^{131}$. La supplication est donc un honos qui implique un nombre élevé de protagonistes: le donateur de l'honos est le sénat qui décide de la cérémonie, mais aussi le peuple qui l'effectue; le destinataire est à la fois le général, au nom de qui l'honos est fait, mais aussi les dieux, bénéficiaires directs. La cérémonie se déroule de la façon suivante: une fois la supplication décidée par le sénat, les jours qui lui sont consacrés sont décrétés fériés puis tous les Romains sont invités à se rendre dans les temples de la ville pour accomplir différents rites dont le principal est la gratulatio, la récitation de la prière de remerciement aux dieux ${ }^{132}$. Il s'agit d'un rituel ancien, dont la première attestation remonte, si l'on en croit Tite Live, à 449, après les victoires de Valerius Publicola sur les Èques et d'Horatius Barbatus sur les Sabins ${ }^{133}$. De nombreuses grandes victoires militaires furent suivies de supplications: la prise de Véies par Camille, les succès de Marcellus en Sicile, la victoire de Paul Émile à Pydna ${ }^{134}$.

${ }^{131}$ Liv. XXVI, 21, 3. On voit aussi chez Tite Live un général victorieux, de retour à Rome, demander un honos pour les dieux, c'est-à-dire une supplication, et un triomphe pour lui-même. Voir par exemple Liv. XXVIII, 9, 7-8 après la victoire du Métaure et XXXVII, 59, 1 après la victoire sur Antiochus.

${ }^{132}$ Halkin, La Supplication, p. 101-102. Des offrandes et des sacrifices sont aussi réalisés.

${ }^{133}$ Liv. III, 63, 5.

${ }^{134}$ Respectivement, Liv. V, 23, 3 ; Liv. XXVI, 21, 3 ; Liv. XLV, $2,1$. 
Parmi les cérémonies liées à la victoire militaire, le triomphe est l'honos le plus prestigieux ${ }^{135}$. À propos de celui décerné à Lépide, Cicéron écrit qu'il relève des maximos honores ${ }^{136}$. Comme la supplicatio, le triomphe est une marque d'honneur qui fait intervenir plusieurs protagonistes. Le sénat joue un rôle capital car c'est lui qui donne au général l'autorisation de triompher et vote l'allocation de fonds ${ }^{137}$. Le peuple joue également un rôle: après le vote du sénat et l'édition du sénatus-consulte, une lex doit être passée devant le peuple ou la plèbe pour que le général puisse entrer en armes dans l'enceinte de Rome ${ }^{138}$. Quant au destinataire de l'honos, il est ici encore multiple. Il est incontestable que l'imperator qui triomphe bénéficie de cette cérémonie exceptionnelle: revêtu d'insignes de grand prestige, placé au centre d'une pompa fastueuse, il attire tous les regards. Le rituel sacré qu'est le triomphe a ménagé de plus en plus de place au cours du temps à la célébration du général ${ }^{139}$. Cependant, le triomphe reste une procession, une pompa, et son point culminant est le sacrifice à Jupiter au Capitole. C'est donc aussi un honneur rendu à un dieu et

${ }^{135}$ Le triomphe a donné lieu à de très nombreuses études critiques, portant sur la cérémonie en général ou sur des points plus précis tels que le terme triumphus, l'origine du rituel, la localisation de la porta triumphalis, la signification des insignes du triomphateur, etc. Se sont révélés utiles pour notre approche les travaux d'ensemble de W. Ehlers, «Triumphus », RE, vol. VII, A, 1, col.493-511; H.-S. Versnel, Triumphus. An Inquiry into the Origin, Development and Meaning of the Roman Triumph, Leiden, Brill, 1970 ; E. KünZL, Der römische Triumph. Siegesfeiern im antiken Rom, Munich, C. H. Beck, 1988; C. Auliard, Victoires et triomphes à Rome, Besançon, Presses universitaires franccomtoises, 2001; ITGENSHORST, Tota illa pompa; J.-L. BASTIEN, Le Triomphe romain et son utilisation politique à Rome aux trois derniers siècles de la République, Rome, E.F.R., 2007; BEARD, The Roman Triumph.

${ }^{136}$ CIc. Phil. XIII, 9.

${ }^{137}$ Liv. III, 63, 9-10 et PoL. VI, 15, 7. On connaît le cas extrême de Lucullus, qui aurait été contraint d'attendre trois ans aux portes de Rome pour pouvoir entrer en triomphe (Eutr. VI, 10; Vell. II, 34, 2 ; Plut. Luc. 37).

${ }^{138}$ Les amis du général ainsi que ses soldats font bien évidemment pression: Liv.XXXI, 48, 1 et XXXVIII, 50, 2. Sur la pression de l'armée, voir Auliard, Victoires et triomphes à Rome, p. 142-145. On connaît des cas où un général triomphe sans le sénatus-consulte ou sans le vote du peuple: c'est le cas de P.Servilius Priscus Structus, consul en 495, d'après DH. VI, 30, 2-3, par exemple. Il y a des cas où un général triomphe contre la décision du sénat, avec l'appui du peuple: le dictateur C. Marcilius Rutilius en 356 (Liv. VII, 17, 9) et C. Flaminius en 223 (Liv. XXI, 63, 2 et XXIII, 14, 4). Le triomphe est parfois même célébré contre l'avis du sénat et du peuple: L. Postumius Megellus, consul en 294 (Liv. X, 37, 6-12) et Appius Claudius Pulcher en 143 (BEard, The Roman Triumph, p. 204). Mais ces cas restent rares, et la majorité des triomphes connus a été octroyée par les instances publiques de Rome.

${ }^{139}$ Nicolet, Métier: ce qui est d'abord une célébration de la victoire de la cité va devenir avec le temps le triomphe d'un chef précis, qui procède d'une idéologie différente, celle du «Sauveur individuel» (p. 471). Sur la valorisation du général et pour une lecture du triomphe comme point culminant de la carrière d'un nobilis, voir HöLKESKAMP, Die Entstehung der Nobilität, p. 236. 
cette cérémonie n’a pas été complètement sécularisée malgré la diminution de sa dimension religieuse ${ }^{140}$. La cérémonie elle-même peut être reconstituée à l'aide de sources textuelles et iconographiques des $\mathrm{II}^{\mathrm{e}}$ et $\mathrm{I}^{\mathrm{er}}$ siècles ${ }^{141}$. Elle consiste en une procession, la pompa triumphalis, qui parcourt l'espace public de Rome ${ }^{142}$ : les participants commencent par se rassembler au Champ de Mars en dehors du pomerium, puis franchissent la porte Triomphale ${ }^{143}$, traversent le Cirque Maxime puis le forum jusqu'au Capitole où le triomphateur offre à Jupiter les lauriers figurant sur les faisceaux de ses licteurs et ceux qu'il tient en main. Puis les animaux figurant dans la procession sont sacrifiés. Le cortège qui traverse la ville peut être plus ou moins étendu. En tête figure le butin de la guerre et des tableaux ou des écriteaux qui signalent les villes prises, les batailles remportées et les chefs vaincus ${ }^{144}$. Comme dans le cas des dona militaria, une partie de la campagne militaire est donc représentée. Derrière le butin se trouvent les animaux pour le sacrifice, suivis de trompettes et de danseurs, puis des captifs. Viennent ensuite les licteurs qui précèdent l'imperator: ce dernier est placé avec ses enfants sur un quadrige de chevaux blancs. Il porte différents attributs: une tunica palmata de pourpre, la toga picta, le sceptre d'ivoire surmonté d'un aigle dans une main, un rameau de laurier dans l'autre et une couronne de laurier. Debout derrière lui,

${ }^{140}$ LrV. XLV, 39, 10: diis quoque [...] non solum hominibus debetur triumphus. «Le triomphe est dû aux dieux aussi, et non seulement aux hommes. » Sur la permanence de l'aspect religieux, voir ITGENSHORST, Tota illa pompa et KüNZL, Der römische Triumph, passim. L'origine du triomphe et sa fonction religieuse première ont suscité de nombreux travaux dont BASTIEN, Le Triomphe romain a proposé une récapitulation (p.122-132). La thèse de Versnel, Triumphus, selon laquelle le triomphe était aux origines une cérémonie orientale de renouvellement du temps et de régénération du pouvoir royal, transmise à Rome par le biais des Étrusques au VI ${ }^{\mathrm{e}}$ siècle, a notamment suscité de nombreux travaux critiques.

${ }^{141}$ Sur l'iconographie, voir BASTIEn, Le Triomphe romain, p. 259. BEARD, The Roman Triumph note justement que la description que l'on donne en général de la cérémonie est une image idéale du triomphe, faite d'éléments qui ne se trouvaient sans doute pas tous dans chaque pompa (p.82 et 105-106). Nous suivons principalement la description faite par W. EHLERs dans son article de la $R E$, qui s'appuie sur de nombreuses sources anciennes.

${ }^{142}$ Pour les différentes hypothèses sur l'itinéraire suivi par la pompa, voir KünzL, Der römische Triumph, p. 14-19.

${ }^{143}$ Le problème de sa localisation a été résolu par F. Coarelli qui l'identifie avec la porta Carmentalis (F. CoARELLI, "La porta trionfale e la via dei trionfi », DArch, 2, 1968, p. 55-103).

${ }^{144}$ Cléopâtre, qui s'était suicidée pour ne pas figurer dans le triomphe d'Octave, y fut représentée par un tableau. Sur ces tableaux peints, voir Plin. NH V, 36; DC. LI, 21, 8. Sur les écriteaux, voir LIV. XXVI, 21 ; Cic. Phil. VIII, 6; Pol. VI, 13. C'est ainsi que César, lors de son triomphe pontique, avait fait inscrire le fameux Veni uidi uici (SuET. Caes. 37). 
un esclave tient une couronne d'or au-dessus de sa tête ${ }^{145}$. Le général est suivi de son armée et ses soldats crient io triumpe! et chantent des chansons satiriques ${ }^{146}$. Figurent aussi parfois d'autres personnes derrière le général: des sénateurs, des magistrats, des citoyens libérés de la servitude, etc ${ }^{147}$. Cet honos du triomphe rassemble donc autour du général un grand nombre de personnes pour l'accompagner dans sa procession au cœur de la cité.

Il faut enfin mentionner trois autres cérémonies proches du triomphe mais qui possèdent une moindre valeur. La première est le «triomphe sur le mont Albain", attesté pour la première fois avec C. Papirius Maso, consul en 231, victorieux en Corse ${ }^{148}$. Il s'agit d'une procession vers le mont Albain, situé à $27 \mathrm{~km}$ au sud-est de Rome, où se trouvait le sanctuaire de Jupiter Latiaris ${ }^{149}$. Cette cérémonie est généralement organisée quand un triomphe a été refusé, comme dans le cas de Marcellus en 211 ; elle est conduite en vertu de l'imperium du général et financée par le butin ${ }^{150}$. Cet honos conserve une dimension religieuse mais a la singularité de ne pas être octroyé formellement par un tiers: le général triomphe à ses frais. Une autre cérémonie triomphale est l'ovation (ouatio) qui est, elle, conférée par le sénat. Elle semble avoir consisté en une entrée du général suivi par son armée dans la ville, à pied et non en quadrige, et vêtu seulement de la

${ }^{145}$ Liv. X, 7, 10; Plut. Aem. Paul. 34 ; DH. III, 61 ; Val. Max. IV, 4, 5 ; Plin. NH XV, 137. Voir KüNZL, Der römische Triumph, p. 85-88. La signification de ces attributs a été discutée. Certains semblent avoir été empruntés au temple de Jupiter Capitolin (Liv. X, 7, 10 parle de Iouis optimi maximi ornatu et Juv. Sat. 10, 38 de la tunica Iouis; voir Versnel, Triumphus, p. 73 sqq. et Ehlers, $R E$, col. 494) ce qui a conduit certains à penser que le triomphateur était mis en relation avec le dieu, mais les partisans de cette théorie ne sont pas d'accord sur la nature de cette relation: le triomphateur peut être le dieu, le représenter, être son double, représenter sa statue, etc. Voir Bastien, $L e$ Triomphe romain p. 128 sur ces différentes interprétations. Une autre lecture a reconnu dans ces insignes ceux du roi. Versnel, Triumphus, Künzl, Der römische Triumph et L. Bonfante-Warren, "Roman Triumphs and Etruscan Kings. The Changing Face of the Triumph », JRS, 60, 1970, p.49-66 ont tenté une intéressante synthèse de ces deux interprétations. L. Bonfante-Warren souligne de manière convaincante que ces différents attributs correspondent à des strates différentes de la cérémonie qui ont fini par se mélanger, les attributs du roi appartenant à la période étrusque et ceux de la divinité au $\mathrm{III}^{\mathrm{e}}$ siècle, introduits sous l'influence hellénistique.

${ }^{146}$ Liv. IV, 20; V, 49; XXXIX, 7; Plin. NH XIX, 144; Plut. Marc. 8; Suet. Caes. 49. Sur les soldats et leurs chants, voir BEARD, The Roman Triumph, p. 245-249.

${ }^{147}$ Ibid., p. 239-244.

${ }^{148}$ Il est recensé par les fastes triomphaux: de Corseis primus in monte Albano (A. Degrassi, Inscriptiones Italiae XIII, 1, 78-79). Le triumphus in monte Albano fut aussi célébré par d'autres généraux tels que Marcellus en 211 ou Q. Minucius Rufus en 197. Voir la liste de T.C.Brennan, "Triumphus in Monte Albano», in Wallace, R. W. et Harris, E.M.(éds.), Transitions to Empire. Essays in Greco-Roman History, 360-146 B. C., in honor of E. Badian, Norman, University of Oklahoma Press, 1996, p. 315-337.

${ }^{149}$ Bastien, Le Triomphe romain, p. 267-268.

${ }^{150}$ BRennan, «Triumphus in Monte Albano », p. 320. 
toge prétexte et couronné de myrte ${ }^{151}$. La dernière forme de triomphe, dont on ignore presque tout, est le triumphus naualis; il est lié à une victoire sur mer et a été célébré pour la première fois en 260 avant J.-C. par C. Duilius ${ }^{152}$.

Outre ces rites de victoire militaire, l'honos peut prendre la forme d'une autre cérémonie qui est celle des funérailles. Les auteurs latins qualifient d'honos le funus, c'est-à-dire les obsèques dans leur ensemble, avec rites préliminaires, pompa et ensevelissement ou crémation, comme dans ce passage de la neuvième Philippique où Cicéron montre que Ser. Sulpicius Rufus, membre de la députation envoyée à Antoine et mort pendant le voyage, mérite qu'on lui rende dignement hommage:

Quodsi cuiquam iustus honos habitus est in morte legato, in nullo iustior quam in Ser. Sulpicio reperietur.

"Si jamais un juste honneur fut rendu à la mort d'un légat, on verra qu'il n'est personne pour qui il serait plus juste que pour Servius Sulpicius. »

(CIc. Phil. IX, 2).

L'honos réclamé par Cicéron consiste en des funérailles nationales et en l'élévation d'un tombeau ${ }^{153}$. La nature de cette cérémonie est assez bien connue, notamment grâce à des textes de Polybe et de Pline ${ }^{154}$. Les obsèques commencent par des rites pratiqués dans la maison du défunt ${ }^{155}$ : ses proches lui font un dernier adieu, lui ferment les yeux et appellent plusieurs fois son nom. Puis le mort est lavé, habillé et pourvu des couronnes qu'il a reçues dans sa vie: l'honos ultime des funérailles inclut les honores obtenus de son vivant ${ }^{156}$. Les obsèques des Romains de condition moyenne comprennent une pompa où le

${ }^{151}$ Liv. XXXIX, 29, 4-5 ; Gell. V, 6, 21 et 27; DH. V, 47, 3-5. Voir KünZl, Der römische Triumph, p. 100-101.

${ }^{152}$ Liv. XLII, 20, 1 ; PLin. NH XXXIV, 20.

${ }^{153}$ Sur l'honos du tombeau, voir aussi Cic. Phil. IX, 14-15 ainsi que le fragment où Lucilius déplore l'absence d'honos funéraire pour Tib. Sempronius Gracchus (LucIL. frg. XXVII, 10 Charpin = 691 Marx).

${ }^{154}$ Pol. VI, 53-54 et PuIN. NH XXXV, 6. Sur le déroulement des funérailles, voir aussi l'article de E. Cue dans le DAGR; J. M.C. ToynBeE, Death and Burial in the Roman World, Londres, Thames \& Hudson, 1971, p. 43-72; L. Deschamps, «Rites funéraires de la Rome républicaine", in Hinard, F. (éd.), La Mort au quotidien dans le monde romain, Paris, De Boccard, 1995, p.171-180; E. FlaIG, «Die pompa funebris. Adlige Konkurrenz und annalistische Erinnerung in der römischen Republik», in OexLE, O.G. (éd.), Memoria als Kultur, Göttingen, Vandenhoeck und Ruprecht, 1995, p. 115-148 et Flower, Ancestor Masks, p. 93-126.

${ }^{155}$ ToynBEe, Death and Burial in the Roman World, p. 44-45 (qui exploite notamment le relief de la tombe dite des Haterii) et Flower, Ancestor Masks, p. 93-97.

${ }^{156} \mathrm{Il}$ s'agit là d'une prescription remontant aux XII Tables (CIc. Leg. II, 60; TerT. Cor. 10). 
corps est transporté depuis la demeure jusqu'au lieu de la sépulture. Il est placé dans une sorte de cercueil sans couvercle lui-même installé sur une litière, souvent portée par les descendants du mort. Devant le cercueil se trouvent des joueurs de trompette et de flûte et des praeficae, pleureuses professionnelles qui chantent la nénie, un chant de lamentation ${ }^{157}$. Derrière le cercueil, la famille et les amis forment le cortège $^{158}$. La pompa s'arrête sur le lieu de la sépulture, situé en dehors de la cité, conformément à une interdiction ancienne ${ }^{159}$. Le corps est alors inhumé dans un cercueil déposé en terre ou bien brûlé sur un bûcher; ses restes calcinés sont recueillis dans une urne ${ }^{160}$.

Quand le défunt est un aristocrate ou un homme public important, le funus s'enrichit de rites supplémentaires ${ }^{161}$. Un héraut parcourt la ville pour annoncer les obsèques ${ }^{162}$ et le cortège comprend davantage de musiciens, des chœurs d'hommes, des danseurs et des bouffons $^{163}$. Quand le mort est un nobilis, des acteurs portant les imagines des ancêtres, leur tenue et leurs insignes défilent en tête de la proces-

${ }^{157}$ Sur la praefica et la nénie, voir FEst. 155, 27 et 250, 5; VARR. LL VII, 70 et De uita pop. Rom. frg. 110 Riposati; SERV. Aen. VI, 216. Une parodie de nénie en anapestes se trouve dans Sen. Apoc. 12. Voir aussi Deschamps, "Rites funéraires de la Rome républicaine», p.175-176 et W. KIERDORF, Laudatio funebris. Interpretationen und Untersuchungen zur Entwicklung der römischen Leichenrede, Meisenheim am Glan, A. Hain, 1980, p. 96 sqq.

${ }^{158}$ Deschamps, «Rites funéraires de la Rome républicaine », p. 173-174.

${ }^{159}$ Cicéron indique que cette interdiction repose sur la crainte des incendies en cas de crémation (CIC. Leg. II, 58). Mais il est possible que la souillure que représente le cadavre et l'odeur putride aient joué un rôle dans l'institution de cette règle (IsID. Orig. $\mathrm{XV}, 11$; CuQ, DAGR, p. 1392). Le sépulcre est en effet un locus religiosus, un espace particulier qui doit être séparé du domaine des vivants (M.Ducos, «Le tombeau, locus religiosus ", in Hinard, F. (éd.), La Mort au quotidien dans le monde romain, Paris, De Boccard, 1995, p. 135-144). C'est par conséquent un grand privilège que de recevoir une sépulture dans l'enceinte de la ville, comme ce fut le cas pour certains grands hommes (Cic. Leg. II, 58). Des lois ou sénatus-consultes spéciaux ont par exemple accordé cet honneur à Sylla (Liv. Per. 90), Hirtius et Pansa (Liv. Per. 119).

${ }^{160}$ Aux origines de Rome, crémation et inhumation sont pratiquées concurremment. C'est à partir du IV ${ }^{\mathrm{e}}$ siècle que la crémation est de plus en plus utilisée, mais certaines familles restent attachées à l'inhumation (la gens Cornelia par exemple). Le règne d'Hadrien verra un retour à l'inhumation (ToynBeE, Death and Burial in the Roman World, p. 39-40).

${ }^{161}$ Sur le funus aristocratique, voir BADEL, La Noblesse de l'Empire romain, p. 35-37 et FLower, Ancestor Masks, p. 97-106.

162 Fest. 94, 17 ; Suet. Caes. 84 ; Cic. Leg. II, 61.

${ }^{163}$ DC. LXXIV, 4, 5 ; Suet. Caes. 84. La présence de danseurs grotesques suscitant le rire est attestée par Denys d'Halicarnasse (VII, 72, 10). Sur cette présence comique au sein des funérailles, voir M. Bettini, "Death and its Double. Imagines, Ridiculum and Honos in the Roman Aristocratic Funeral ", in Mustakallio, K., Hanska, J., Sainio, H.-L.et al. (éds.), Hoping for Continuity: Childhood, Education and Death in Antiquity and the Middle Ages, Rome, Institutum Romanum Finlandiae, 2005, p. 191-202. 
$\operatorname{sion}^{164}$. Le public voit ainsi revivre tous les ascendants du défunt au sommet de leur gloire politique: les funérailles constituent pour la gens une remarquable démonstration de pouvoir. Le prestige de la famille est encore renforcé quand le convoi funéraire s'arrête au forum pour que soit prononcé l'éloge funèbre du défunt; ce dernier étant un honos à part entière, il sera étudié en son lieu, avec les autres honores uerborum $^{165}$. L'honos des funérailles peut prendre un tour encore plus prestigieux quand un défunt reçoit un funus publicum, des obsèques officielles, financées par l'État ${ }^{166}$. Les retombées politiques de cet honos expliquent qu'il ait été l'un de ceux dont le déroulement fût le plus contrôlé ${ }^{167}$.

Le terme d'honos peut aussi désigner plus précisément un aspect seulement du funus, l'inhumation (ou la crémation) et le monument funéraire qui est édifié par la suite. Après la mort de Marcellus dans une embuscade tendue par les Carthaginois, ces derniers n'osèrent pas lui refuser l'honos sepulturae ${ }^{168}$. La sépulture permet d'éviter que le corps du défunt ne subisse des outrages et représente l'honos ultime rendu à un individu. Les tombes rendent hommage au mort, rappellent ses qualités par une inscription et préservent durablement le souvenir du défunt. Leur aspect pouvait être extrêmement varié en fonction de la richesse de la famille, allant de la simple fosse au grand monument richement décoré169. Un monument funéraire de la République se signale par sa nature particulière et son inscription mentionnant

${ }^{164}$ Pol. VI, 54, 3. Flower, Ancestor Masks, p. 99.

${ }^{165}$ Voir infra p. 283 sqq.

${ }^{166}$ Sur l'histoire et le déroulement des obsèques publiques, voir G. WESCH-KLEIN, Funus publicum. Eine Studie zur öffentlichen Beisetzung und Gewährung von Ehrengräbern in Rom und den Westprovinzen, Stuttgart, F. Steiner, 1993. Sylla obtint des funérailles de ce genre: son corps fut porté sur une litière d'or, accompagné par deux cents couronnes d'or et faisceaux, et suivi par une procession des Vestales, sénateurs, magistrats, soldats, cavaliers et citoyens (ApP. Сiu. I, 105-106).

${ }^{167}$ Les XII Tables imposaient déjà certaines restrictions comme la limitation du nombre de joueurs de flûte, des dépenses vestimentaires, du nombre et de la nature des offrandes qui pouvaient être inhumées ou brûlées avec le défunt, et du nombre des affranchissements par testament autorisés. Voir Cic. Leg. II, 58-62; GaI., Inst. I, 42. Ainsi que H.Von Hesberg, Römische Grabbauten, Darmstadt, Wissenschaftliche Buchgesellschaft, 1992, p.10-13 et E. Baltrusch, Regimen morum. Die Reglementierung des Privatlebens der Senatoren und Ritter in der römischen Republik und frühen Kaiserzeit, Munich, C.H.Beck, 1988, p.43. Cicéron estime que cette régulation est marquée par la législation de Solon. Cependant, il ne s'agit pas seulement, comme en Grèce, de limiter le luxe mais aussi d'éviter les ravages sur l'aristocratie d'une compétition débridée entre les grandes familles (Flower, Ancestor Masks, p.118; "The best model for understanding Roman sumptuary legislation is that of aristocratic self-preservation within a highly competitive society which valued overt display of prestige above all else»).

${ }^{168}$ Cic. Cato mai. 75. Voir aussi Cic. Inu. 108.

${ }^{169}$ Voir les typologies de ToynBeE, Death and Burial in the Roman World, p. 101-244 et Von Hesberg, Römische Grabbauten, p. 55-201. 
l'honos. Il s'agit du monument de C.Poplicius Bibulus. Le texte de l'inscription est le suivant:

C(aio) Poplicio L(ucii) F(ilio) Bibulo aed(ili) pl(ebis) honoris

uirtut[is]que caussa, senatus

consulto populique iussu locus

monumento quo ipse postereique

eius inferrentur publice datus est.

«À Gaius Poplicius Bibulus, fils de Lucius, édile de la plèbe, pour l'honorer, et en raison de sa valeur, par décision du sénat et par ordre du peuple, un lieu a été attribué aux frais de l'État pour l'édification d'un monument où lui-même et ses descendants seront ensevelis. »

$\left(C I L \mathrm{I}^{2}, 834=I L L R P 357\right)$.

Le personnage honoré semble être le tribun de la plèbe de 209 mentionné par Tite Live et Plutarque ${ }^{170}$. L'orthographe est ancienne (Poplicio, caussa, posterei), mais les lettres sont d'époque syllanienne ou césarienne. L'aspect et les matériaux du monument font également pencher pour une datation dans la première moitié du ${ }^{\text {er }}$ siècle ${ }^{171}$, mais il est possible qu'il s'agisse d'une restauration et que le texte et le monument soient un peu plus anciens. L'honos fait à Bibulus est très grand car il reçoit un emplacement sur une portion de l'ager publicus ${ }^{172}$, aux frais de l'État (publice), pour que lui-même et ses descendants $\mathrm{y}$ soient ensevelis ${ }^{173}$. Il s'agit là d'un honos rare à l'époque républi-

${ }^{170}$ Liv. XXVII, 20 et Plut. Marc. 27. Voir aussi Macr. Sat. I, 7, 33. Cette thèse est retenue par A. TOMASSETTI, «Un edificio antico lungo il cliuus Argentarius : il monumentum di Gaio Publicio Bibulo», BCAR, 101, 2000, p. 39-80 et B. FrIscher, "Monumenta et Arae Honoris Virtutisque Causa. Evidence of Memorials for Roman Civic Heroes », BCAR, 88, 1982-1983, p.51-86. L'identification avec Lucius Poplicius Bibulus, tribun militaire en 216 est plus difficile (hypothèse de Broughton, $M R R$, vol. 1, p. 251): l'inscription fait clairement état d'un praenomen qui est Gaius.

${ }^{171}$ Pour la date de l'inscription, A.E. Gordon, Album of Dated Latin Inscriptions, Berkeley, University of California Press, 1958 ; I. CALABI Limentani, Epigrafia latina, 4 e éd., Milan, Cisalpino, 1991. Sur les éléments archéologiques faisant pencher vers le courant du $\mathrm{I}^{\mathrm{er}}$ siècle, voir l'étude de ce monument par M.E. Blake et E.B. Van Deman, Ancient Roman Construction in Italy from the Prehistoric Period to Augustus, Washington, Carnegie Institution, 1947; M.EISNER, Zur Typologie der Grabbauten im Suburbium Roms, Mainz, P.von Zabern, 1986; TomassetTI, «Un edificio antico ».

172 C'est pourquoi il a fallu un vote du peuple, nécessaire pour qu'une partie de l'ager publicus puisse être aliénée. $C$. Cic. Dom. 127. Le monument se trouve au pied du Capitole mais la question de savoir s'il se situait à l'extérieur ou à l'intérieur du pomerium est débattue. Voir E.NASH, Bildlexikon zur Topographie des Antiken Rom, Tübingen, E. Wasmuth, 1962; EISNER, Zur Typologie der Grabbauten im Suburbium Roms; TomAssETTI, «Un edificio antico». La situation à l'intérieur du pomerium, peu courante pour un édifice funéraire, n'est pas improbable en raison de l'honos particulier, publice, fait à Bibulus.

${ }^{173}$ Le monument a parfois été identifié non comme une tombe mais comme un édifice commémoratif (Frischer, «Monumenta et Arae»; TomassetTI, "Un edificio antico »). Mais cette interprétation est contraire à ce que dit l'inscription elle-même: l'emplacement doit servir quo ipse postereique eius inferrentur. 
caine $^{174}$. L'aspect du tombeau, placé sur un haut podium, soigneusement décoré, et relevant du type du tombeau-temple, marqué par le style de l'herôon hellénistique, témoigne d'un souci de monumentalité qui amplifie encore la grandeur de l'honos rendu à Bibulus ${ }^{175}$.

\subsubsection{Bilan}

Ces différents honores consistent en une succession d'actions précises organisées en un ensemble relativement codifié: procession, sacrifice, discours, prière peuvent être utilisés conjointement. L'honos prend donc ici le visage du rituel et remplit, de ce fait, une fonction symbolique centrale: le rituel dit quelque chose par des gestes, qu'il s'agisse de remercier les dieux ou d'affirmer la supériorité du général vainqueur. Mais ici encore l'économique est conjoint au symbolique: l'aspect somptueux du triomphe rehausse encore le prestige du général, comme l'importance des dépenses consenties pour les funérailles, dépenses qui ont dû être limitées par la loi tant elles pouvaient prendre de l'ampleur. L'économique participe donc au symbolique. Laspect rituel de ces honores apparaît aussi dans la manière dont ils mettent en jeu des divinités: la salutation impératoriale utilise un titre de Jupiter, la supplication a lieu dans tous les temples de la ville, le triomphe culmine sur le sacrifice à Jupiter Capitolin, les funérailles font passer le défunt chez les dieux mânes. Il faut souligner que les honores liés à la victoire militaire sont plus spécifiquement associés à Jupiter, dieu qui exerce le pouvoir suprême. Il est associé aux cérémonies de victoire car ces dernières sont le lieu d'expression de la souveraineté dans le domaine de la guerre ${ }^{176}$.

Tous ces honores ont également pour particularité d'impliquer un très grand nombre d'individus dans leur exécution. Les rites de la supplicatio doivent être accomplis par les hommes et les femmes, adultes comme enfants. Le titre d'imperator est donné au général par l'ensemble de son armée. Quant aux triomphes et aux funérailles, ils réunissent un large public: le fait que la pompa triumphalis passait par le circus maximus, le plus grand édifice de spectacle de Rome, donne une idée du nombre possible de spectateurs présents ${ }^{177}$. Les funérailles des grands hommes de la cité attiraient de nombreuses personnes et

${ }^{174}$ Cf. Cic. Phil. IX, 6; IX, 14; IX, 7 et XIV, 33.

${ }^{175}$ Une description détaillée du monument se trouve dans R. DeLBRÜcK, Hellenistische Bauten in Latium, Strasbourg, Trübner, 1907 et ToмAsSETтI, "Un edificio antico ». Sur le podium, voir Nash, Bildlexikon zur Topographie des Antiken Rom, p. 319; A. Golfetto, «Das Grabmal des C. Publicius Bibulus », Raggi, 5 (2), 1963, p. 9-11.

${ }^{176}$ Voir l'article de J. SCHEID «Jupiter» dans l'OCD, p. 801-802; G. Wissowa, Religion und Kultus der Römer, Munich, C.H.Beck, 1902, p.113 sqq. et C.Косн, Der römische Iuppiter, 1937.

${ }^{177}$ Pour un calcul du nombre des spectateurs, voir KüNZL, Der römische Triumph, p. 70-71. 
Cicéron indique que rendre hommage au défunt consiste précisément à venir grossir les rangs du cortège pour lui donner un tour plus somptueux ${ }^{178}$. C'est donc une large part de la cité qui est mobilisée par ces différents honores. Ils sont aussi l'occasion, pour une communauté, de se retrouver et de prendre conscience de son unité: la salutation impératoriale réunit les soldats de l'armée, et les funérailles les différents membres de la famille, par exemple. Il nous faudra donc prêter attention aux fonctions sociales et identitaires de l'honos.

Cette mobilisation de la cité contribue à donner aux honores cérémoniels un éclat particulier et à en faire de véritables spectacles ${ }^{179}$. Comme les précédentes marques d'honneur, les cérémonies s'inscrivent dans l'espace public de l'Vrbs: la pompa triumphalis comme la pompa funebris parcourent Rome. La personne honorée doit être visible et tire son prestige de la dimension ostentatoire de l'honos: être à l'honneur, c'est être vu. Paraître en public est un des modes de communication les plus efficaces et les honores contribuent à magnifier ces apparitions. Le souci du spectaculaire apparaît dans la pompa triumphalis avec la présence d'animaux, de danseurs, de décorations et d'insignes, de personnes très diverses dans leur costume particulier ${ }^{180}$, mais aussi avec les musiciens, les chansons et les applaudissements; dans la pompa funebris, ce sont les lamentations, les cris et les éloges qui sollicitent l'ouïe. Il s'agit donc véritablement d'un spectacle total. Cette exhibition occasionne d'importantes dépenses. Il y a donc pour l'honos cérémoniel une corrélation inverse entre l'argent dépensé et le prestige gagné, entre la déperdition du capital économique et l'augmentation du capital symbolique.

\subsection{L'honos uerborum}

Certains honores peuvent être intégralement constitués de paroles. Nous les nommons honores uerborum, reprenant une formule de Cicéron qui les oppose à d'autres marques d'honneur plus concrètes comme les statues ${ }^{181}$.

${ }^{178}$ Cic. Quinct. 50.

${ }^{179}$ L'identification de ces rites comme de vrais spectacles a déjà été suggérée par Dupont, Le Citoyen romain et Nicolet, Métier, p. 461 sqq. à propos des funérailles et du triomphe.

${ }^{180}$ Sur l'aspect spectaculaire du triomphe, voir R. BrILLIANT, "Let the Trumpets roar!' The Roman Triumph ", in Bergmann, B. et Kondoleon, C. (éds.), The Art of Ancient Spectacle, New Haven, Yale University Press, 1999, p. 221-228 et G. Амготті, «Il trionfo come spettacolo ", in Sord, M. (éd.), Guerra e diritto nel mondo greco e romano, Milan, Vita e Pensiero, 2002, p. 201-206. Ce dernier souligne, d'après Plut. Aem. Paul. 32, que le peuple fait tout pour voir la procession: il se masse dans le cirque, autour du forum, et dans tout endroit de la cité qui offre un point de vue (p. 203).

${ }^{181}$ CIc. Att. V, 21, 7. Ce sont les honores que les Chypriotes veulent lui décerner mais qu'il refuse: Ob haec beneficia quibus illi obstupescunt nullos honores mihi nisi uerborum 


\subsubsection{Formes}

Les honneurs verbaux peuvent consister à citer le nom de quelqu'un, à lui donner un titre, à faire son éloge ou encore à rédiger un décret en son honneur. La première de ces formes d'honneur, prononcer en public le nom d'un individu, est la plus simple ${ }^{182}$. Dans la narration du Pro Quinctio, on voit Quinctius, dépouillé en son absence par Naevius, recourir à l'aide du propréteur de Gaule C. Flaccus:

Expulsus atque eiectus a praedio Quinctius accepta insigni inuria confugit ad C. Flaccum imperatorem, qui tunc erat in prouincia, quem, ut ipsius dignitas poscit, honoris gratia nomino.

«Expulsé, jeté hors de sa propriété, Quinctius, après avoir subi cette injustice insigne, a recours au gouverneur $\mathrm{C}$. Flaccus, qui était alors dans la province et que je nomme pour lui faire honneur, comme son rang l'exige».

(Cic. Quinct. 28; trad. De La Ville de Mirmont modifiée).

Cicéron aurait pu se contenter de mentionner que Quinctius en appelait au propréteur de la province sans donner le nom de ce dernier, cependant la dignitas du promagistrat pousse l'orateur à dire son nom. On se situe ici dans le cadre d'un procès public et le nom du propréteur retentit donc aux oreilles de nombreuses personnes. C'est une parole prestigieuse car le nom de C. Flaccus se trouve accolé à la fonction d'imperator, c'est-à-dire de promagistrat. La précision apportée par Cicéron, quem honoris gratia nomino, répond à une règle protocolaire: il faut préciser, quand on mentionne une personne extérieure à l'affaire, qu'on le fait sans lui porter offense ${ }^{183}$. La valeur surnaturelle du nomen explique que le prononcer puisse consister en un honos ${ }^{184}$. Il y a en effet une authentique puissance du nom et la nomination fait partie intégrante de certains rites religieux ou magiques ${ }^{185}$.

L'honos verbal peut aussi ajouter quelque chose au nomen de l'individu honoré. Il arrive en effet qu'une institution, généralement le sénat, octroie à une personne ou à un groupe un titre qui lui procure

decerni sino, statuas, fana, $\tau \hat{\theta} \theta \rho ı \pi \alpha$ prohibeo nec sum in ulla re alia molestus ciuitatibus; «Pour de pareils bienfaits, qui les laissent muets d'étonnement, je ne permets pas qu'on me décerne d'autres honneurs que verbaux; statues, sanctuaires, quadriges, je les interdis, et il n'est rien où je n'évite d'ennuyer les cités. »

${ }^{182}$ Sur cette pratique, Moreau, "Quem honoris causa appello».

${ }^{183}$ Ibid., p. 296.

${ }^{184}$ La dimension honorifique de l'ostentation du nom est visible dans d'autres cultures, comme la culture urbaine moderne où elle participe à la construction symbolique de soi (D. Lepoutre, Coeur de banlieue. Codes, rites et langages, Paris, Odile Jacob, 1997, p. 367).

${ }^{185}$ Voir K. Latte, Römische Religionsgeschichte, Munich, C.H.Beck, 1960, p. 62-63. Les incantations curatives doivent par exemple mentionner le nom du patient pour le guérir (PLIN. NH XXI, 176). 
de la considération. Cet usage n'est pas encore souvent repéré comme honos à l'époque républicaine mais il en existe quelques attestations dans le domaine diplomatique ${ }^{186}$. Cicéron écrit à propos de Ptolémée:

Rex Ptolemaeus, qui, si nondum erat ipse a senatu socius appellatus, erat tamen frater eius regis qui, cum esset in eadem causa, iam erat a senatu honorem istum consecutus [...].

"Le roi Ptolémée, qui, s'il n'avait pas encore été lui-même qualifié d'allié par le sénat, était cependant le frère de ce roi qui, dans une situation semblable, avait déjà reçu cet honneur du sénat [...].»

(CIc. Sest. 57).

L'honos consiste, pour un souverain étranger, à recevoir du sénat le titre de socius de Rome. C'est une appellation honorifique car le roi est, ici encore sur le mode de l'association, rapproché d'une entité prestigieuse sur la scène internationale: Rome. En 200, quand Vermina, le fils de Syphax, envoie des ambassadeurs à Rome pour réclamer les titres de "roi, allié, ami », il se voit répondre que cet honos n'est donné par le sénat qu'à ceux qui ont fait preuve de grands mérites à son égard ${ }^{187}$. Ce titre de rex, socius, amicus est bien un signe qui dit quelque chose. Mais il suppose aussi des avantages matériels non négligeables concrétisés par des traités; on retrouve ainsi la double valeur, symbolique et concrète, de l'honos.

Mais c'est sous la forme de l'éloge que l'honos verbal est le plus riche: il s'agit alors d'un discours entier, composé et orné. Deux types d'éloges sont perçus comme des honores, la laus prononcée pour un homme public et la laudatio funebris adressée à un défunt. Le premier type est assez peu fréquent: dans le Brutus, en dehors de la laudatio funebris, Cicéron ne cite pas un seul exemple de discours d'éloge pour un homme public; Varron résume lui aussi le genre démonstratif à l'éloge funèbre ${ }^{188}$. Cicéron indique tout de même qu'un discours honorifique fut adressé à Octave, à l'instigation de plusieurs sénateurs :

[...] quis honos ei non fuit decernendus? Quamquam ego illi tum uerborum laudem tribui eamque modicam, decreui etiam imperium; quod quamquam uidebatur illi aetati honorificum, tamen erat exercitum habenti necessarium.

${ }^{186}$ Il se répandra en revanche à l'époque impériale, au sein de l'armée où des titres honorifiques sont octroyés à des unités militaires, et dans la société où certains qualificatifs progressivement figés seront réservés aux individus d'un certain rang: "Très Grand » pour les anciens consuls, "Très Célèbre» pour les sénateurs, "Illustres » pour les chevaliers de premier ordre, etc. Sur ce point, voir R. MACMuLLEN, Les Rapports entre les classes sociales dans l'Empire romain, 50 av.J.-C.-284 ap. J.-C., Paris, Seuil, 1986 et Nicolet, L'Ordre équestre vol. 1, p. 256 sqq.

${ }^{187}$ Liv. XXXI, 11, 16.

${ }^{188}$ Cic. Brut. 62; VARr. Men. 370-383 (Cèbe). De façon générale, le genre épidictique a été bien moins représenté pendant la République romaine que l'éloquence délibérative ou judiciaire (PERnOt, La Rhétorique de l'éloge, p. 50-51, M. DurRy, "Laudatio funebris et rhétorique », Rph, 16, 1942, p. 105-114). 
«[...] y avait-il un honneur qu'on dût lui refuser? Pourtant, je ne lui accordai alors qu'une louange verbale, et encore modeste; je lui fis décerner aussi le pouvoir de commander en chef; ceci paraissait, il est vrai, un grand honneur pour son âge; mais c'était une nécessité pour qui avait une armée sous ses ordres. »

(Cic. Ad Brut. I, 15, 7 ; trad. Beaujeu).

Parmi différents honores, Octave a reçu une laus, un éloge que Cicéron ne considère pas manifestement comme une marque d'honneur extrêmement importante: elle est modica, sans doute parce qu'elle se compose de uerba. L'honos de l'éloge semble donc moins prisé que les autres parce qu'il n'implique pas d'avantages importants et ne s'inscrit pas dans la durée. Ces uerba font la singularité de ce type d'honos car ils situent l'hommage dans le domaine des signes verbaux et de l'oralité et non dans celui des marques visuelles.

L'éloge funèbre est, lui, plus répandu et apprécié. Il s'agit d'une pratique singulière, différente de l'êđı ce fait suscité l'intérêt de Polybe, entre autres ${ }^{189}$. Les premiers témoignages assurés de ce rituel datent du dernier quart du $\mathrm{III}^{\mathrm{e}}$ siècle avant notre ère ${ }^{190}$, mais les Romains font remonter cette tradition à Brutus, le premier consul de Rome, qui aurait été loué par son collègue Publicola $^{191}$; la pratique perdure ensuite pendant la République ${ }^{192}$. La laudatio constitue le point culminant des funérailles des aristocrates et des individus qui ont exercé une charge publique ${ }^{193}$ : la pompa funebris s'arrête au forum et un parent proche du défunt ${ }^{194}$, généralement son fils, prononce son éloge depuis les rostres, devant les ancêtres représentés par les acteurs portant les imagines et devant la cité assemblée. C'est de cet honos qu'il est question dans le De oratore:

Ita, inquit Antonius, et in eo quidem genere scio et me et omnis, qui adfuerunt delectatos esse uehementer, quom a te est Popilia mater uestra laudata, cui primum mulieri hunc honorem in nostra ciuitate tributum puto.

${ }^{189}$ Pol. VI, 53, 2. Voir aussi, comme source grecque, DH. V, 17. La laudatio n'est pas comme le discours funèbre grec une célébration civique, mais la mise en avant d'une famille à des fins de prestige. Sur le déroulement de la laudatio funebris, ses origines, son histoire et sa forme rhétorique, voir F. VolLmER, Laudationum funebrium Romanorum historia et reliquiarum editio, Leipzig, Teubner, 1891; O.C.CRAWFORD, «Laudatio funebris », CJ, 37, 1941, p. 17-27; DURRY, «Laudatio funebris et rhétorique»; KIERDORF, Laudatio funebris; Flower, Ancestor Masks, p. 129-150.

${ }^{190}$ Il s'agit de l'éloge de L. Caecilius Metellus (Plin. NH VII, 139-140) et de celui de Marcellus (Liv. XXVII, 27, 13). Voir KIERdorf, Laudatio funebris, p. 94.

${ }^{191}$ DH. V, 17, 1 ; Plut. Publ. 9.

192 Voir les listes établies par Vollmer, Laudationum funebrium Romanorum historia et KIERDORF, Laudatio funebris, p. 106 sqq.

${ }^{193} \mathrm{Il}$ est possible qu'un éloge funèbre ait aussi été prononcé pour des défunts plus modestes, près de la tombe (FLower, Ancestor Masks, p. 131).

${ }^{194} \mathrm{Il}$ y a quelques cas rares où l'éloge n'est pas prononcé par un membre de la gens du défunt (voir par exemple Liv. II, 47; VolLmer, Laudationum funebrium Romanorum historia, p. 457). 
«Oui, poursuivit Antoine; et je me rappelle le singulier plaisir que me causa un discours de ce genre, à moi et à tous ceux qui l'entendirent: ce fut lorsque tu prononças, Catulus, l'éloge funèbre de votre mère Popilia, la première femme, je crois, à qui l'on ait décerné dans notre cité cet honneur. »

(Cic. De or. II, 44 ; trad. Courbaud modifiée).

Antoine évoque l'éloge funèbre prononcé par Lutatius Catulus pour sa mère Popilia qui fut, selon ce texte, la première à recevoir ce type d'honneur ${ }^{195}$. Il apparaît dans le De oratore que le style des laudationes était considéré comme monotone et sec mais Kierdorf a montré que ces discours, qui ont certes un style particulier, suivaient les tendances oratoires de leur époque ${ }^{196}$. Leur contenu varie assez peu: après un exorde, l'orateur fait d'abord l'éloge de la famille et des ancêtres puis du défunt en parlant de son mode de vie, des honores qu'il a obtenus et de ses actions et vertus ${ }^{197}$. Le discours s'achève par une adresse parénétique aux auditeurs. L'orateur s'applique plus particulièrement à souligner l'excellence du défunt dans différents domaines et à donner de lui une image grandiose. La laudatio de Q. Caecilius Metellus indique ainsi que ce dernier avait réussi à primarium bellatorem esse, optimum oratorem, fortissimum imperatorem, «être le premier guerrier, le meilleur orateur, le général le plus courageux » ${ }^{198}$. Léloge prononcé par César pour sa tante Julie évoquait quant à lui les origines légendaires et glorieuses de la gens Iulia ${ }^{199}$. Ces éloges possèdent à l'évidence une importante fonction politique, sur laquelle il nous faudra revenir. Plusieurs auteurs ont d'ailleurs souligné que l'information qu'ils contenaient n'était pas fiable et les ont considérés comme des moyens de publicité familiale ou personnelle ${ }^{200}$.

Le dernier honos uerborum connu est de nature différente des précédents car il est matérialisé par un texte écrit: il s'agit du décret honorifique. On donne à lire les mérites de la personne honorée, on lui dit qu'on l'honore plutôt qu'on ne fait le geste de l'honorer. Il s'agit d'une marque d'honneur répandue à l'époque hellénistique et qui

${ }^{195}$ Contrairement à ce qu'affirme Tite Live qui rapporte que les matrones qui aidèrent à payer la rançon demandée par les Gaulois en 390 reçurent l'honos d'un éloge funèbre (Lrv. V, 50, 7). Sur cette contradiction, voir R. J. Evans, "Popillia, mater uestra: a Note on Cicero, de Orat. 2.11.44 », LCM, 17, 1992, p. 35 et T. W. Hillard, «Popilia and 'laudationes funebres' for Women", Antichthon, 35, 2001, p. 45-63. Des éloges funèbres de femmes sont bien attestés au début de l'Empire avec les deux laudationes inscrites de Turia et Murdia (ILS 8393 et 8394). Voir KIERDORF, Laudatio funebris, p. 111-126.

${ }^{196}$ Cic. De or. II, 341. KieRdorf, Laudatio funebris, p. 58 sqq.

${ }^{197}$ PoL. VI, 53, 2.

${ }^{198}$ Plin. NH VII, 139. Sur ce texte, voir KIERDorf, Laudatio funebris, p. 10-21 et Flower, Ancestor Masks, p. 139.

${ }^{199}$ Suet. Caes. 6, 1. Voir Flower, Ancestor Masks, p. 143.

${ }^{200}$ Cic. Brut. 62 et Liv. VIII, 40, 4 relèvent l'invention de consulats, de triomphes et de généalogies. 
perdure ensuite ${ }^{201}$. César rappelle en ces termes à Arioviste que les Héduens sont en bons termes avec les Romains:

Docebat etiam quam ueteres quamque iustae causae necessitudinis ipsis cum Haeduis intercederent, quae senatus consulta quotiens quamque honorifica in eos facta essent.

«Il lui apprit encore combien étaient anciennes et légitimes les raisons de l'amitié qui unissait les Héduens aux Romains, quels sénatus-consultes avaient été rendus en leur faveur, à mainte reprise et dans les termes les plus honorables. »

(CAEs. BG I, 43, 6-7; trad. Constans modifiée).

L'amitié entre Rome et les Héduens est visible dans les sénatusconsultes honorifiques rendus en leur faveur. Le sénat a voté et publié un texte qui est une marque d'honneur adressée aux Héduens par les dispositions qu'il prévoit et les mérites qu'il signale chez les Gaulois. Dans son discours de retour d'exil devant le sénat, Cicéron remercie cette assemblée a quo saepe magnificentissimis decretis sumus honestati, «qui nous a souvent honoré des plus magnifiques décrets ${ }^{202}$. Dans la cinquième Philippique, Cicéron demande aux sénateurs de décerner à D. Brutus ainsi qu'à Lépide l'honos d'un sénatus-consulte élogieux pour s'être opposé à Antoine ${ }^{203}$. L'honos prend donc le tour particulier d'une décision officielle, faisant l'objet d'un vote de la part du sénat. Il a aussi la particularité, partagée avec l'éloge, de signifier de façon directe et particulièrement efficace les mérites de la personne honorée: Cicéron veut mentionner dans le sénatus-consulte pour Lépide la uirtus, l'auctoritas et la felicitas de ce dernier pour montrer à tous ses mérites ${ }^{204}$.

\subsubsection{Bilan}

La puissance de signification de ces honores uerborum nous semble leur principale caractéristique: ces honores sont des signes mais leur capacité de signifier, pour l'éloge et le décret surtout, est considérablement enrichie par le moyen des uerba. Il ne s'agit plus ici de représenter de façon imagée une partie des mérites qui ont donné lieu à l'honos, comme pour les dona militaria ou le triomphe, mais de dire en détail

${ }^{201}$ Voir Veyne, Le Pain et le cirque, p. 275-278.

${ }^{202}$ Cic. Red. Sen. 2. Cicéron a peut-être notamment en tête le décret voté en juillet 57 qui indique qu'une proposition de loi pour le rappeler d'exil sera déposée et ajoute que toute tentative de s'opposer à la présentation de cette loi aux comices exposera le responsable à être déclaré ennemi public (Cic. Sest. 129-130).

${ }^{203}$ Cic. Phil. V, 35 et 40.

${ }^{204}$ Cic. Phil. V, 41. Pour d'autres exemples d'honos par sénatus-consultes, voir CIc.Fam. XV, 10, 1; Fam. XII, 25, 1; Fam. X, 13, 1. 
le mérite ${ }^{205}$. Les honneurs verbaux ont donc une puissance symbolique extrêmement forte. Cette dernière apparaît cette fois inversement proportionnelle à leur valeur économique: à la différence des autres marques d'honneur, la valeur d'échange de ces honores est très réduite.

Ces honores uerborum ont eux-mêmes une matérialité assez faible: ils se situent pour la plupart dans la sphère de l'oralité et non dans celle du geste. L'honos ne mobilise donc pas seulement la vision: il fait aussi appel à l'écoute de l'entourage. Cette oralité fait de ces honores des marques plus éphémères que les autres hommages, à moins qu'ils ne soient couchés par écrit. Mais elle confirme le lien que l'honos nourrit avec la réputation. Être à l'honneur, c'est bien faire l'objet d'un discours favorable. Par rapport à l'honneur gestuel, l'honneur verbal apparaît revêtu d'une moindre importance et comme en relation de dépendance par rapport à lui. La nomination ou l'éloge sont des hommages moins fréquents que ceux que nous avons précédemment examinés et ils ne se manifestent que rarement de façon autonome: l'éloge funèbre prend place au sein de l'honos des funérailles; le décret honorifique s'accompagne d'autres marques d'honneur. Tout se passe comme si l'absence de matérialité de l'honos verbal, son éloignement de la sphère de l'économique et sa très forte dimension symbolique restreignaient sa valeur propre. Pour que l'échange mis en place par l'honos fonctionne pleinement, la marque d'honneur verbale doit être articulée à un honos plus matériel.

\subsection{La responsabilité publique}

La dernière catégorie des honores est celle des fonctions et charges publiques. Leur importance dans la vie politique romaine et leur singularité par rapport aux autres honores nous a conduit à leur donner une place à part.

\subsubsection{Formes}

La responsabilité publique qu'est l'honos peut prendre la forme de la citoyenneté, d'une charge politique, militaire ou religieuse. La citoyenneté représente le premier degré de cette catégorie. Cette dernière est comprise comme un honos car c'est un statut particulier qui n'est pas donné à tous les habitants de Rome. On le voit dans le Pro Balbo, où Cicéron défend Balbus, originaire de Gadès, qui a obtenu de Pompée le droit de cité. Un accusateur, inconnu de nous, considère que cet octroi est illégal et intente une action en justice. Toute

205 «Le discours détaille précisément les mérites, donne une image globale de l'objet, au présent et au passé, et exprime les fondements moraux de la louange » (PERNOT, $\mathrm{La}$ Rhétorique de l'éloge, p. 621). 
l'argumentation du défenseur consiste à montrer que cette marque d'honneur est bien méritée et qu'elle respecte les formes légales. Dès le début du texte, la ciuitas est définie comme honos:

Vbi igitur est crimen? Quod eum Pompeius ciuitate donauit. Huius crimen? Minime, nisi honos ignominia putanda est. Cuius igitur? Re uera nullius, actione accusatoris eius unius qui donauit.

«Où est donc le crime? Pompée lui a offert le droit de cité. Est-ce le crime de Balbus? Pas du tout, à moins qu'un honneur ne doive être considéré comme une humiliation. De qui alors? En vérité, ce n'est le crime de personne, mais selon la plainte de l'accusateur, de celui-là seul qui a donné ce droit. »

(CIc. Balb. 7).

L'octroi du droit de cité est un honos authentique, pas une ignominia, ce qui fait que Balbus n'est pour rien dans le crimen que l'accusateur essaie d'établir. Pompée a conféré la ciuitas à Balbus pour le récompenser et lui signifier son estime, ce qui en fait bien un honos ${ }^{206}$. Que la citoyenneté soit une marque d'honneur apparaît également dans les avantages et le prestige dont elle s'accompagne. La ciuitas impose un certain nombre de devoirs, financiers et militaires notamment, mais procure aussi un ensemble de droits comme celui de contracter un mariage, d'accéder à la légion, de voter et de faire appel au peuple ${ }^{207}$. Elle s'accompagne du port d'un vêtement distinctif, la toge, marque du citoyen ${ }^{208}$. Cet honos consiste donc en un faisceau de pouvoirs et de droits au sein de la cité et en un statut rendu visible par des signes extérieurs.

Les autres honores publics sont différents de la citoyenneté car ils consistent en des fonctions officielles octroyées au moyen d'une désignation ou d'une élection. C'est par souci de clarté que nous distinguons des fonctions politiques, militaires et religieuses, car les responsabilités publiques relèvent souvent à Rome de ces trois domaines simultanément. La charge politique, c'est-à-dire la magistrature conférée par le peuple lors d'une élection, est la fonction publique la plus souvent qualifiée d'honos ${ }^{209}$. C'est de cet honos dont il est question

${ }^{206}$ C'est une pratique ancienne. Voir par exemple la ciuitas sine suffragio donnée aux chevaliers campaniens et aux habitants de Fundi et de Formies honoris causa parce qu'ils n'ont pas pris part aux révoltes des Latins contre Rome (LIv. VIII, 14, 10).

207 J. Gaudemet, Institutions de l'Antiquité, Paris, Sirey, 1967, p. 362-364; Nicolet, Métier, p.31-37.

${ }^{208}$ Sur le symbole de la toge, voir C. Vout, «The Myth of the Toga: Understanding the History of Roman Dress », G\&R, 43 (2), 1996, p. 204-220.

${ }^{209} \mathrm{Au}$ point que la différence entre magistratus et honos peut devenir très faible (voir supra p. 90). Pour Mommsen, DPR, vol. 1, p. 8, n. 1 et BЕск, Karriere und Hierarchie, p. 11, cette convergence n'est pas surprenante car la charge publique constitue le stade supérieur de l'honneur au sein de la collectivité. 
dans le Pro Flacco quand sont fustigés ceux qui essaient de l'obtenir de façon illégale:

Quotus enim quisque est qui hanc in re publica sectam sequatur, qui uobis, qui uestri similibus placere cupiat, qui optimi atque amplissimi cuiusque hominis atque ordinis auctoritatem magni putet, cum illam uiam sibi uideant expeditiorem ad honores et ad omnia quae concupiuerunt?

«Car combien y en a-t-il qui puissent s'attacher à notre parti politique, qui songent à vous complaire, à vous et à ceux qui vous ressemblent, qui attribuent un grand prix à l'autorité des premiers citoyens de l'État, quand ils voient qu'ils ont une autre route pour les mener plus aisément aux magistratures et à tout ce qu'ils ont désiré?»

(Cic. Flac. 104; trad. Boulanger).

L'honos est ici la charge politique qu'il convient de briguer en attirant à soi la faveur du peuple et ses suffrages. Cependant, dans l'esprit des Romains, toute magistrature ne constitue pas un honos. Les magistratures les plus élevées comme le consulat, la censure et la préture sont bien appréhendées de cette manière, mais l'usage de la notion d'honos est déjà moins fréquent pour l'édilité et la questure, bien que nous en possédions des exemples ${ }^{210}$. Le tribunat de la plèbe, en revanche, n'est jamais dans nos sources qualifié d'honos. La raison en est peut-être son caractère sulfureux dans l'histoire romaine. Quant aux magistratures inférieures, comme celles des tresuiri capitales ou des decemuiri stlitibus iudicandis, elles ne sont pas non plus perçues comme des honores ${ }^{211}$. L'honos d'une fonction politique implique donc la détention, sinon de l'imperium, du moins d'un pouvoir relativement important: l'honos est lié à l'autorité dans la cité mais aussi sur le champ de bataille et possède de ce fait une réelle coloration militaire ${ }^{212}$. En quoi ces charges sont-elles des marques d'honneur? Elles sont d'abord octroyées par un tiers, le populus réuni en comices ${ }^{213}$, au moyen du vote, comme le dit un passage de Plaute:

Nam olim populi prius honorem capiebat suffragio

Quam magistro desinebat esse dicto oboediens.

«Car autrefois on recherchait l'honneur et les suffrages du peuple

Alors qu'on n'avait pas cessé d'obéir aux ordres de son maître. »

(PL. Bac. 438-439).

${ }^{210}$ Respectivement, Cic. Planc. 26 et Cic. Verr. II, V, 35 ou Cic. Pis. 2.

${ }^{211}$ Sur ces magistratures, voir Lintott, The Constitution of the Roman Republic, p. 137-144.

${ }^{212}$ Sur l'aspect militaire de l'honos, voir aussi son lien à la uirtus martiale (p. 307) et le chapitre 11 sur la divinité Honos.

${ }^{213}$ Plus précisément, l'obtention définitive de l'honos doit passer par une loi d'investiture et implique aussi, d'une certaine façon, une approbation divine puisque le magistrat reçoit les auspices (Nicolet, Métier, p. 19-20). 
Lydus, le pédagogue acariâtre de la pièce, se plaint que son jeune maître ne respecte plus rien et qu'il soit en cela semblable à la jeunesse nouvelle qui enfreint toutes les autorités. On voit dans le passage que l'obtention de l'honos suppose de capter le suffragium du peuple ${ }^{214}$. Comme pour tout honos, le rôle du donateur est donc ici primordial ${ }^{215}$. La charge publique, comme les autres marques d'honneur, est en outre un signe d'estime:

Iam de C.Fannio quae sit existimatio uidemus; quod iudicium populi Romani in honoribus eius futurum sit, nemini dubium esse debet.

«Quant à Fannius, nous voyons l'estime dont il jouit; le jugement que le peuple romain portera sur lui, lors de futures candidatures, ne saurait faire de doute pour personne.»

(Cic. Sest. 113; trad. Cousin).

Cicéron parle ici d'un tribun de la plèbe, C. Fannius, qui sera sans doute prochainement élu préteur. Ce personnage jouit déjà d'une grande estime (existimatio), au point qu'il est possible de prédire quel sera, au moment de l'élection, le iudicium du peuple romain. Habituellement, pour des candidats moins notoires, c'est donc l'obtention de l'honos qui exprime au grand jour le jugement et l'estime du peuple ${ }^{216}$.

${ }^{214}$ Voir aussi l'honos populi dont il est question dans PL. Trin. 482.

${ }^{215}$ Le pouvoir réel du peuple au sein des institutions romaines a suscité ces dernières années un important débat, né des travaux de F. Millar. Pour ce dernier, le pouvoir réel du populus dans la vie politique romaine est bien plus important qu'on ne l'a dit, au point qu'il est possible de considérer Rome comme une démocratie et de la comparer à l'Athènes de l'époque classique (F. Millar, «The Political Character of the Classical Roman Republic, 200-151 B.C.», JRS, 74, 1984, p. 1-19; F. MilLaR, "Political Power in Mid-Republican Rome: Curia or Comitium?», JRS, 79, 1989, p.138-150; F. Millar, The Crowd in Rome in the Late Republic, Ann Arbor, University of Michigan Press, 1998). Une telle lecture, qui visait notamment à remettre en cause l'interprétation oligarchique de Rome faite par l'école historique allemande, a suscité de nombreuses critiques, justifiées selon nous. S'il est exact que le pouvoir du peuple, notamment lors des comices, ne doit pas être sous-estimé et que l'emprise des grandes familles sur la plèbe par le biais de la clientèle n'est pas aussi étendue qu'on a pu le dire, la cité romaine ne peut être définie comme une démocratie. Le peuple, à Rome, n'est amené à voter que lorsque le magistrat le convoque, et c'est toujours aussi un magistrat qui dirige les élections. Le vote à bulletin secret n'a en outre été introduit que tardivement dans l'histoire de la République. Pour l'ensemble des arguments allant contre l'interprétation de F. Millar, voir Beck, Karriere und Hierarchie, p. 22 sqq. et HöLKESKamp, Reconstruire une République, notamment p.13-43, qui souligne que le peuple joue le rôle de «tierce instance» de la compétition aristocratique, notion empruntée au sociologue allemand G. Simmel.

${ }^{216}$ Voir aussi Cıc. Clu. 153 sur le rôle décisif du iudicium populi dans l'élection et CIc. Vat. 10 où l'honos est considéré comme le moment crucial où nostrorum ciuium spectentur iudicia de nobis, "on peut observer le jugement de nos concitoyens à notre égard ». À l'époque impériale, l'honos politique reste un signe d'estime, mais de celle du 
L'honos sous forme de charge publique peut aussi être une fonction militaire. Caton en évoque deux de ce type dans son discours de 195:

Maiores seorsum atque diuorsum pretium parauere bonis atque strenuis, decurionatus, optionatus, hastas donaticas, aliosque honores.

"Les ancêtres ont établi des récompenses bien différenciées pour les soldats bons et valeureux: décurionats, optionats, lances de parade, et d'autres honneurs.»

(CAT. frg I, $18 O R F)$.

Les deux charges militaires, optionat et décurionat, sont des honores placés sur le même plan que les objets honorifiques. Le décurion est un officier de cavalerie, qui commandait à l'origine dix cavaliers; l'option est un sous-officier choisi par le centurion pour l'assister $^{217}$. L'honos consiste donc en une élévation du grade de simple légionnaire. Dans le Bellum ciuile, César évoque un autre honos militaire, le grade de tribun militaire octroyé à des chevaliers ${ }^{218}$.

L'honos peut aussi prendre la forme d'une prêtrise. Il en est question dans ce passage du discours de Memmius dans le Bellum Iugurthinum de Salluste:

Itaque postremo leges, maiestas uostra, diuina et humana omnia hostibus tradita sunt. Neque eos qui ea fecere pudet aut paenitet, sed incedunt per ora uostra magnifici, sacerdotia et consulatus, pars triumphos suos ostentantes, proinde quasi ea honori, non praedae habeant.

«Aussi ont-ils fini par livrer aux ennemis les lois, la majesté de votre nom, tous les droits des dieux et des hommes. Et les auteurs de ces excès n'ont ni honte, ni remords; ils défilent insolemment devant vos yeux, étalant leurs sacerdoces et leurs consulats, quelques-uns même leurs triomphes; comme s'ils avaient ces charges à titre d'honneur et non de butin. »

(SALL. Iug. 31, 9-10; trad. Ernout).

Memmius reproche aux nobles leur arrogance et leur mainmise sur les honores. Sont ici regroupés sous la notion générale d'honos les triomphes, les consulats et les sacerdoces, ce qui confirme la vision unitaire qu'ont de l'honos les Romains du I ${ }^{\text {er }}$ siècle. Il est difficile d'établir avec précision quels sacerdoces sont plus spécifiquement pensés comme des honores car le mot renvoie souvent à une prêtrise sans plus de précision mais on rencontre une fois chez César le grand pontificat

prince ou du puissant qui les octroie: «in a world where one was appointed to posts by high personages, the receipt of an office publicized the esteem of the great man who had given it. » (LENDON, Empire of Honour, p. 185).

217 K.R. Dixon et P.Southern, The Roman Cavalry, Londres, Batsford, 1992;

D. J. BreEze, «Pay Grades and Ranks below the Centurionate », JRS, 61, 1971, p. 130-135.

${ }^{218}$ CAES. BC I, 77, 2. 
qualifié d'honos, et une fois chez Cicéron l'augurat ${ }^{219}$. Le sacerdoce constitue, comme la magistrature, un authentique honos pour celui qui le reçoit, marquant l'estime du donateur et conférant des responsabilités au sein de la cité: les prêtres jouent un rôle dans l'exécution des rites et, ce qui fait leur singularité par rapport aux magistrats, sont les seuls à connaître le droit sacré et la manière dont il faut interagir avec les dieux ${ }^{220}$.

Enfin, quelques autres charges ne faisant pas partie des fonctions régulières de la cité sont aussi perçues comme des honores en raison de leur importance politique ou de leur dimension prestigieuse. Il en est ainsi du décemvirat dont la création est prévue par la loi agraire proposée par le tribun de la plèbe Servilius Rullus et que critique Cicéron, alors consul:

Denique, si qui est honos singularis, nihilne interest, utrum populus Romanus eum cui uelit deferat, an is impudenter populo Romano per legis fraudem surripiatur?

«Enfin, quand il s'agit d'un honneur exceptionnel, cela ne fait-il aucune différence, que le peuple romain l'octroie à qui il veut ou que cet honneur soit dérobé de manière impudente au peuple romain, par une loi frauduleuse?»

(Cic. Agr. II, 46).

Cicéron fustige notamment une disposition de la loi qui prévoit l'élection des décemvirs selon des modalités particulières. Le décemvirat agraire, qui ne fait pas partie des institutions courantes établies par la coutume, est un honos singularis. C'est de même un honos particulier qui est confié à Caton d'Utique lorsqu'on lui donne, pour l'éloigner de Rome, une mission à Chypre 221 .

\subsubsection{Bilan}

Les honores que nous venons d'examiner ne s'apparentent nullement à des "fonctions honorifiques» car ils impliquent l'obtention d'un réel pouvoir. Le citoyen, le magistrat, l'officier, le prêtre possèdent tous le droit d'intervenir dans la vie civique. Les pontifes établissent le droit sacré et le calendrier; les officiers de l'armée ont sous leurs ordres un nombre variable de légionnaires; les magistratures supérieures s'accompagnent de l'imperium. Un texte de Scipion Émilien fonde de façon explicite l'imperium sur l'honos:

Ex innocentia nascitur dignitas, ex dignitate honor, ex honore imperium, ex imperio libertas.

${ }^{219}$ CAES. BC III, 83, 4. CIC. Fam. XV, 4, 13. Chez Tite Live, l'honos peut renvoyer à d'autre charges comme le sacerdos des Vestales (Liv. I, 3, 11).

${ }^{220}$ ScHeID, «Le prêtre », p. 90-92.

${ }^{221}$ CIC. Dom. 22. 
«De l'intégrité naît le mérite, du mérite l'honneur, de l'honneur le pouvoir, du pouvoir la liberté.»

(ScIr. Aem. frg. inc. $32 O R F$ ).

Ce climax, qui nous est connu par Isidore de Séville ${ }^{222}$, est riche d'enseignements sur les conceptions politiques de Scipion Émilien mais nous ne retiendrons pour le moment que le troisième terme de cette gradation, ex honore imperium. Scipion rattache directement à l'obtention de l'honos l'exercice de l'imperium, qui permet de mener des opérations militaires, de conclure des traités, et d'exercer des pouvoirs administratifs et judiciaires au sein de la cité223. Mais l'honos consiste bien en une responsabilité, car ces pouvoirs sont assortis de devoirs, comme les officia liés à la charge ou bien la dignitas que l'on exige du magistrat ${ }^{224}$.

Les honores possèdent de ce fait une valeur pratique: ils sont prisés pour le pouvoir qu'ils apportent ainsi que pour les différents avantages auxquels ils donnent droit, tels que la détention de places réservées lors des spectacles ou bien le droit de se déplacer dans un véhicule en certaines circonstances ${ }^{225}$. Mais ils sont aussi perçus comme le moyen pour le populus d'exprimer son iudicium, comme on l'a vu: ce sont des signes d'estime pourvus d'une valeur symbolique. C'est ce qui explique que ces charges ne puissent être vénales, si l'on excepte celles des sous-officiers qui perçoivent une solde: aucune indemnité ne peut être octroyée pour l'exercice de ces responsabilités qui sont avant tout des marques d'honneur ${ }^{226}$. La loi municipale dite d'Urso (lex Vrsonenis ou lex coloniae genitiuae Iuliae), un document datant des années 40 avant notre ère ${ }^{227}$, interdit ainsi qu'un décret soit pris

quo cui pecunia publica a[liutue] | quid honoris habendi causa munerisue d[andi pol]|licendi [proue] statua danda ponenda detur do[netur]

«par lequel de l'argent public ou quoi que ce soit d'autre puisse être donné à quelqu'un pour avoir exercé une charge, offert un combat de gladiateurs ou donné ou érigé une statue»

$\left(C I L \mathrm{I}^{2}, 594\right)$.

Il est ainsi prohibé de verser de l'argent à un individu pour l'exercice d'un honos. Dans le cas précis de la magistrature, la rétribution

${ }^{222}$ Le terme de climax provient d'Isidore (Orig. II, 21, 4).

${ }^{223}$ Mommsen DPR, vol. 1, p. 136 sqq.; GaUdemet, Institutions de l'Antiquité, p. 331-332;

Lintott, The Constitution of the Roman Republic, p. 96 sqq.

${ }^{224}$ Voir infra p. 382 sqq.

${ }^{225}$ Mommsen, $D P R$, vol. 2, p. 27.

${ }^{226}$ Mommsen, $D P R$, vol. 1, p. 335.

${ }^{227}$ Sur cette loi, inscrite sur trois tables de bronze qui nous sont parvenues en plusieurs fragments, voir FIRA I, p. 77, n. 21 et M.H.CRAWFORD, Roman Statutes, Londres, Institute of classical studies, 1996, vol. 1, p. 393-454. 
fonctionne de manière symbolique et exclut, du moins dans les dispositions légales, tout profit économique. La puissance symbolique de ce type d'honos est rendue sensible, enfin, dans les insignia dont il s'accompagne régulièrement. La magistrature est inséparable d'un certain nombre de marques de pouvoir tels que la toge prétexte, la chaise curule et les faisceaux portés par les licteurs ${ }^{228}$. De même, l'exercice d'un sacerdoce implique le port d'insignes visibles: les augures étaient ainsi pourvus d'une trabea de pourpre et du bâton augural recourbé, le lituus. L'honos, s'il ne consiste pas ici dans l'octroi de signes concrets, s'accompagne cependant de marques qui manifestent le pouvoir et les particularités de la charge exercée.

Il reste à expliquer la grande fréquence avec laquelle la notion d'honos renvoie aux magistratures. Cela est partiellement dû à la nature des textes de l'époque étudiée, qui font la part belle à la prose oratoire et historique. Mais le fait que le consulat soit régulièrement qualifié de summus honos n'est pas lié au genre littéraire des textes où l'expression apparaît. Une telle polarisation de l'honos vers sa forme politique provient en réalité de la façon dont se définissent l'aristocratie romaine et sa frange la plus prestigieuse, la nobilitas. Appartiennent en effet à la noblesse, au $\mathrm{III}^{\mathrm{e}}$ siècle et au début du $\mathrm{II}^{\mathrm{e}}$, les descendants d'un magistrat curule, puis au ${ }^{\text {er }}$ siècle, ceux d'un consul ou d'un dictateur 229 . De ce point de vue, aucune marque d'honneur n'a donc autant de valeur que l'honos d'une magistrature de haut rang qui permet l'accès à ce cercle fermé. L'honos politique est l'honos par excellence car la noblesse romaine est une noblesse politique ${ }^{230}$. Et il est d'autant plus crucial que l'appartenance à la noblesse n'est pas acquise une fois pour toutes: la nobilitas est quelque chose qui s'use au point de pouvoir s'éteindre si elle n'est pas réactivée, à chaque génération, par l'obtention de nouveaux honores. Un noble issu de trois générations de consuls n'a pas le même statut qu'un noble qui compte

${ }^{228}$ Voir supra p. 241-242.

${ }^{229}$ C'est la leçon de l'étude prosopographique de Gelzer, dont les conclusions ont été précisées par Afzelius (M. Gelzer, Die Nobilität der römischen Republik. Die Nobilität der Kaiserzeit, 2e éd., Stuttgart, Teubner, 1983 et A. Afzelius, «Zur Definition der römischen Nobilität in der Zeit Ciceros ", $C \& M, 1,1938$, p. 40-94). Mais la question reste controversée. P. A. BRUNT, «Nobilitas and Nouitas», JRS, 72, 1982, p.1-17, a contesté une telle définition. Il a été à son tour contredit par D. R. SHAcKLeton Bailey, "Nobiles and Novi reconsidered", AJPh, 107, 1986, p. 255-260; L. BuRcKHARDT, "The Political Elite of the Roman Republic: Comments on Recent Discussion of the Concepts nobilitas and homo nouus ", Historia, 39, 1990, p. 77-99. Voir le bilan dressé par BADEL, La Noblesse de l'Empire romain.

${ }^{230}$ MeIer, Res publica amissa. Eine Studie zu Verfassung und Geschichte der späten römischen Republik, p.47; HölKesKamp, Die Entstehung der Nobilität, p.204-205 et HölKeskamp, Reconstruire une République, p. 80-81; Flower, Ancestor Masks, p. 62 sqq. 
un seul consul parmi ses lointains ancêtres ${ }^{231}$. Chaque honos politique de la famille augmente un peu plus son prestige ${ }^{232}$. Le fait que la nobilitas ne soit pas un statut juridiquement défini explique aussi l'importance de la dimension symbolique des honores et l'usage de différents «marqueurs sociaux» qui rendent visible cette noblesse ${ }^{233}$.

\section{CONCLUSION ET MISE EN PERSPECTIVE HISTORIQUE}

Les formes prises par l'honos nous paraissent donc pouvoir être ramenées à cinq catégories principales. La marque d'honneur peut être un objet, un geste, une cérémonie, un ensemble de mots ou une charge publique. L'existence de ces cinq types d'honores ne permet pas de définir de manière univoque les marques d'honneur mais, au-delà de cette hétérogénéité, un certain nombre de traits communs apparaissent. Tous ces honores, d'abord, sont octroyés en public: la statue, la décoration militaire, le service rendu, le triomphe, l'éloge ou la magistrature sont conférés sous les yeux des membres de la cité. À cette dimension publique des honores est liée leur grande visibilité: la plupart des marques d'honneur attirent le regard et possèdent, à des degrés divers, une dimension spectaculaire. Les objets offerts comme marques d'honneur sont les vecteurs visibles de l'estime, les gestes honorifiques n'ont de sens que parce qu'ils sont vus, le triomphe ou les funérailles sont une forme de spectacle, les décrets sont publiés et les charges publiques se parent d'insignes. Cet aspect visuel explique l'existence, pour chacun de ces honores, d'une fonction symbolique: par leur aspect, les marques d'honneur symbolisent l'estime et parfois le mérite qu'elles récompensent. L'ordre symbolique de l'honos est articulé à un aspect économique, confirmant l'importance des deux paradigmes que nous avons identifiés. L'honos est souvent précieux et utile. Mais le mode de relation de l'économique et du symbolique peut être de nature très variée. On voit le symbolique corrélé à l'économique: plus la valeur de l'objet donné est grande, plus l'estime signifiée est importante. Mais la corrélation peut être inverse: le triomphe ou les funérailles accroissent le prestige mais imposent des dépenses qui entament le capital économique. On rencontre aussi des cas où le

${ }^{231}$ L'impossibilité de satisfaire à l'obtention répétée de l'honos a obscurci la nobilitas de personnages comme Sylla (SAll. Iug. 95, 3), Servius Sulpicius (CIC. Mur. 16) ou Aemilius Scaurus (Cic. Mur. 16; Ascon. 23C). Voir HölKeskamp, Reconstruire une République, p. 102. Sur les échecs de la nobilitas à se perpétuer, voir K. Hopkins, Death and Renewal, Cambridge, Cambridge University Press, 1983.

${ }^{232}$ Sur l'augmentation du degré de dignitas par l'honos politique, ВЕск, Karriere und Hierarchie, p. 16 et infra p. 361-367.

${ }^{233}$ La notion sociologique de marqueurs sociaux est utilisée par BADEL, La Noblesse de l'Empire romain dans son introduction. 
symbolique et l'économique ne sont pas liés, comme pour l'éloge, ou peuvent même s'exclure, comme pour la magistrature qui ne doit pas être vénale.

Avant de passer à un autre moment de l'analyse, il faut dessiner à grands traits l'évolution des formes de l'honos au cours de notre période. Depuis les premières apparitions de la notion d'honos jusqu'à la fin de la République, les formes revêtues par l'honos sont relativement stables. On relève cependant quelques nouveaux types d'hommage, qui apparaissent pour l'essentiel au I ${ }^{\text {er }}$ siècle. Dans le Pro Archia, Cicéron qualifie d'honos les récits faits par les poètes des hauts faits des généraux romains ${ }^{234}$ : on se trouve ici proche de l'éloge, mais il est bien question d'une œuvre poétique et non d'un discours, puisque Cicéron pense à Archias et à Ennius. Cette orientation de la poésie vers la louange des grands hommes n'est pas nouvelle, mais elle n'était pas appréhendée comme honos auparavant. C'est également au premier siècle que l'on voit se développer des honores d'un nouveau genre, adressés aux grands généraux de l'époque. Pompée obtient par exemple des distinctions hors norme, en étant consul unique, en prenant le surnom de Magnus et en recevant le droit de porter une couronne d'or et la toge triomphale lors des jeux ${ }^{235}$. Mais c'est surtout César qui bénéficie de son vivant puis à sa mort d'honneurs exceptionnels dont quelques-uns peuvent être nommés ${ }^{236}$ : il préside tous les jeux et est interrogé en premier au sénat; en 45 le titre d'imperator devient une partie de son nom; il gagne le droit de porter la tenue triomphale en permanence; des statues le représentent pourvu de la couronne obsidionale et de la couronne civique sur les rostres. Il reçut également, et c'est là l'innovation centrale, des honneurs divins: sa maison est dotée d'un fastigium, comme si c'était celle d'un dieu; son effigie est portée avec celles des divinités lors des jeux; un jour de fête lui est consacré en 44 aux ludi Romani puis un collège de luperques juliens est créé et un temple dédié à sa clémence. Après sa mort, on projette de lui construire un temple sur le forum et il devient le diuus Iulius $^{237}$. Ces distinctions divines sont expressément qualifiées d'honores par Cicéron qui les fustige comme une aberration ${ }^{238}$.

${ }^{234}$ CIC. Arch. 22.

${ }^{235}$ DC. XXXVII, 21 ; Vell. II, 40, 4.

${ }^{236}$ Sur ces différents honneurs, S. Weinstock, Divus Julius, Oxford, Clarendon Press, 1971, passim, qui soutient que César a lui-même introduit, à la fin de sa vie, le culte divin de sa personne; G. Dobesch, Caesars Apotheose zu Lebzeiten und sein Ringen um den Königstitel. Untersuchungen über Caesars Alleinherrschaft, Vienne, Österreichisches Archäologisches Institut, 1966; C. CogrossI, «Gli onori a Cesare nella tradizione storiografica e nelle monete del 44 a. C. », CISA, 3, 1975, p. 136-156 et J.-L. Ferrary, "À propos des honneurs décernés à César entre 48 et 44 » in URso, G. (éd.), Cesare: precursore o visionario?, Pise, ETS, 2010, p. 9-30.

${ }^{237}$ Sur la divinisation de César et son culte, voir Weinstock, Divus Julius, p. 364-410.

${ }^{238}$ Cic. Phil. I, 5 ; II, 107 et 110. 
Les honores connaissent aussi une augmentation de leur faste et de leur nombre. Les funérailles aristocratiques sont ainsi de plus en plus somptueuses : celles de Sylla et de César sont restées célèbres pour leur splendeur extraordinaire ${ }^{239}$. Il en va de même pour les triomphes: la longueur de la procession augmente, tout comme la richesse du butin présenté. Se greffent à la pompa d'autres éléments de prestige tels que l'exposition de dépouilles et de peintures triomphales ${ }^{240}$. On voit surtout leur nombre augmenter: alors qu'une soixantaine de triomphateurs sont répertoriés au $\mathrm{III}^{\mathrm{e}}$ siècle, on en connaît une trentaine rien que dans le premier quart du $\mathrm{II}^{\mathrm{e}}$ siècle. Un contrôle plus rigoureux de leur octroi est alors établi par la loi ${ }^{241}$, ce qui conduit à une réduction des triomphes à partir des années 170 . On ne compte de ce fait qu'une dizaine de triomphateurs supplémentaires au $\mathrm{II}^{\mathrm{e}}$ siècle par rapport au ${ }{ }^{\mathrm{e}}{ }^{\mathrm{e}}$. Leur nombre décroît au premier siècle, mais ces données doivent être pondérées par la diminution, également, du nombre des conflits extérieurs où Rome est engagée. D’autres dispositions légales furent prises au $\mathrm{II}^{\mathrm{e}}$ et au $\mathrm{I}^{\mathrm{er}}$ siècle pour contrôler le développement exponentiel des marques d'honneur: en 158, les censeurs font enlever du forum les statues qui n'avaient pas été érigées par décision du peuple ou du sénat ${ }^{242}$; on trouve aussi des règles juridiques sur la façon dont un patronus peut être honoré ou dont un gouverneur de province peut recevoir des honneurs de ses administrés ${ }^{243}$.

L'augmentation des autres honores au $\mathrm{I}^{\mathrm{er}}$ siècle est malgré tout très sensible. La durée des supplications s'allonge régulièrement. Le nombre de jours qui leur est consacré va de un à trois, initialement, puis Paul Émile en obtient cinq ${ }^{244}$, Marius dix puis Pompée douze. César en obtient quinze en 57 , vingt en 55 et en 52 . Puis il en reçoit trente en 47 , et enfin cinquante en $45^{245}$. César semble avoir joué un rôle décisif dans l'augmentation considérable des honores, comme le montrent aussi les statues qu'on lui érigea. Sur son forum se trouvaient une statue équestre ainsi qu'une statua loricata qui fut peut-être

${ }^{239}$ Voir Flower, Ancestor Masks, p. 122-125 et Weinstock, Divus Julius, p. 346-355.

${ }^{240}$ Sur ces développements, voir BASTIEN, Le Triomphe romain, p. 158-165.

${ }^{241}$ Sur cette réglementation, voir Ibid., p. 287-309 et Auliard, Victoires et triomphes à Rome.

242 Plin. NH XXXIV, 30. Sehlmeyer, Stadtrömische Ehrenstatuen der republikanischen Zeit, p. 152-163.

${ }^{243}$ C'est le cas dans la lex municipale dite Vrsonenis et dans la lex Iulia repetendarum (voir J. Nicols, "Zur Verleihung öffentlicher Ehrungen in der römischen Welt », Chiron, 9, 1979, p. 243-260).

${ }^{244}$ Liv. XLV, 2, 1 (HaLKIN, La Supplication, p. 33-34).

245 Sur ces données, voir Ibid., p. 106 sqq. Cicéron (Prou. 25 et Pis. 45) et César lui-même ( $B G$ II, 35, 4) font état de cette augmentation. Sur les supplications reçues par César, Weinstock, Divus Julius, p.62-64. 
la première du genre ${ }^{246}$. Il avait aussi des statues à son effigie dans les temples de Rome, dans les maisons de certains particuliers, et on le voit chez Appien recevoir une statue «de la part de chaque tribu ${ }^{247}$. Parmi les différents facteurs responsables de cette surenchère, il faut faire une place à la situation politique créée par les guerres civiles: la lutte des généraux pour la suprématie se fait aussi en dehors du champ de bataille et l'obtention d'honores plus importants que ceux de l'adversaire permet d'affirmer symboliquement sa supériorité. L'extension du territoire de Rome et du nombre d'habitants sous domination romaine a pu également nécessiter l'utilisation de moyens de communication de masse. Or les honores, par leur éclat et leur visibilité, sont un de ces instruments de publicité: les marques d'honneur permettent, autant que la communication orale ou écrite, de s'imposer à un public toujours plus large ${ }^{248}$.

${ }^{246}$ Stat. Silu. I, 1, 84 et Plin. NH XXXIV, 5, 18. Voir Lahusen, Untersuchungen zur Ehrenstatue in Rom, p. 22.

${ }^{247}$ DC. XLIV, 4, 4; XLIV, 18, 2.

${ }^{248} C f$. DAvid, La République romaine, à propos des suites de la guerre sociale: "Cet élargissement de la sphère civique contribuait à promouvoir de nouveaux modes de communication et d'action qui allaient favoriser les hommes politiques qui seraient capables d'étendre leur influence au-delà de leurs relations personnelles directes" (p. 189). Sur ces modes de communication, voir G. AcHARd, La Communication à Rome, Paris, Payot, 1994. 
CHAPITRE 6

\section{L'ACCÈS À L'HONNEUR: CAUSES ET CONDITIONS}

\section{INTRODUCTION}

L'honos étant une rétribution, il ne peut que répondre à un travail, un service, une qualité. Il faut, pour recevoir l'honos, faire preuve de certains mérites. Ce sont ces différentes causes d'accès à l'honos dont il faut à présent éclairer la nature, pour l'honos comme "considération" et comme "hommage ${ }^{1}$. Pareille enquête nous conduira à poser différentes questions. La première d'entre elles porte sur la nature de ces mérites: l'honneur se gagne-t-il par des exploits guerriers, des vertus morales ou un statut social privilégié? Nous dresserons une typologie commentée de ces différentes sources. La détermination précise des motifs de l'honos permet d'appréhender les valeurs de la société romaine à l'époque qui nous intéresse: voir ce qui fait régulièrement l'objet de marques d'honneur, c'est percevoir ce qui est sanctionné positivement à Rome et donc comprendre quelles sont les conduites les plus valorisées. S'interroger sur les sources de l'honos nous impose en second lieu d'étudier son accessibilité. Les textes nous renseignent en effet sur les conduites d'excellence qui donnent lieu à l'honos mais insistent également sur la manière dont l'aristocratie romaine tend à monopoliser le prestige ou les marques d'honneur. L'accès à l'honos peut donc être conditionné par des facteurs sociaux ou politiques qu'il faut expliciter. Cela nous conduira à nous intéresser à deux autres notions romaines essentielles, celles de dignitas et de uirtus: il nous faudra mettre en évidence leur complexité propre, leur rapport à l'honos et la manière dont elles ont fait l'objet de définitions contradictoires et partisanes.

\section{LE MÉRITE AU FONDEMENT DE L'HONOS: DIGNITAS ET AEQUUM}

Nous avons vu que la uoluntas joue un rôle dans l'émergence de l'hommage, mais elle est elle-même mise en branle par l'identification

\footnotetext{
${ }^{1}$ Sur l'importance du sème du /mérite/ pour ces deux sens du mot, et sur son caractère assez imprécis, voir supra p. 51 sqq. et 68 sqq.
} 
d'un mérite particulier chez autrui. C'est perceptible dans ces vers du Truculentus:

Dic ob haec dona quae me miserit,

Me illum amare plurimum omnium hominum merito.

Meque honorem illi habere omnium maxumum.

«Dis-lui que pour ces cadeaux qu'il m'a envoyés,

Je l'aime, à juste titre, plus que tous les hommes du monde

Et que je lui rends le plus grand des honneurs.»

(PL. Truc. 589-591).

La courtisane Phronésie demande à Cyame, l'esclave du jeune Diniarque, de remercier son maître pour ses cadeaux; l'honos qui revient à Diniarque n'existe que parce qu'il a octroyé ces cadeaux ( $o b$ haec dona).

Comment ce mérite à la source de l'honos est-il pensé par les Romains eux-mêmes? Un texte éloquent sur ce sujet est le climax d'un discours de Scipion Émilien que nous citions précédemment ${ }^{2}$. La valeur personnelle y est en effet présentée comme la condition absolument nécessaire de l'hommage:

Ex innocentia nascitur dignitas, ex dignitate honor, ex honore imperium, ex imperio libertas.

«De l'intégrité naît le mérite, du mérite l'honneur, de l'honneur le pouvoir, du pouvoir la liberté.»

(ScIP. Aem. frg. inc. 32 ORF).

Le texte est particulièrement intéressant parce qu'il présente un degré d'abstraction qui permet de conceptualiser ce que nous avons qualifié jusqu'alors de «mérites». L’honneur, dit Émilien, procède de la dignitas. Le mot revêt ici le sens de "mérite », "caractère approprié » d'une personne. Dans notre texte, la dignitas procède d'une qualité, l'innocentia (l'intégrité), et conduit à l'honos. Ce lien entre dignitas et honos est confirmé par la définition que donne Cicéron de la dignitas dans le De inuentione:

dignitas est alicuius honesta et cultu et honore et uerecundia digna auctoritas.

«La dignité est une autorité honnête, digne de respect, d'honneur et de déférence.»

(Cic. Inu. II, 166; trad. Achard modifiée).

La dignitas est définie comme une autorité honorable, qui impose à l'entourage respect et égards. C'est un statut supérieur où l'on est, étymologiquement, "digne» de marques d'honneurs. La dignitas est donc ce qui appelle l'honos de façon légitime. À l'inverse, l'octroi 
d'honneurs à une personne qui n'a aucune dignitas suscite l'indignation. Il est intolérable à Cicéron que Verrès ait fait nommer Cléomène à la tête de la flotte de Sicile:

O di immortales! quid? si harum ipsarum ciuitatum militibus, nauibus, nauarchis Syracusanus Cleomenes iussus est imperare, non omnis honos ab isto dignitatis, aequitatis, officique sublatus est?

"Ô dieux immortels! quoi? si le Syracusain Cléomène a reçu l'ordre de commander aux soldats, aux navires et aux officiers de marine de ces cités, tout honneur n'a-t-il pas été enlevé par Verrès au mérite, à l'équité et aux bons offices?»

(CIC. Verr. II, V, 84).

Il est scandaleux aux yeux de Cicéron qu'un simple particulier, sans aucune compétence particulière, reçoive l'honos d'un commandement militaire aussi important. Cléomène est dépourvu de toute dignitas et il a malgré cela reçu une marque d'honneur; Verrès, l'auteur de cet hommage, est à blâmer pour avoir bouleversé le fonctionnement normal de l'honos.

La nécessité de fonder l'honos sur la dignitas repose sur l'attention que portent les Romains à une valeur centrale de leur culture, l'équité. On la rencontre dans le Pro Rhodiensibus de Caton ${ }^{3}$, prononcé en 167:

Sed si honorem non aequum est haberi ob eam rem, quod bene facere uoluisse quis dicit, neque fecit tamen, Rodiensibus oberit, quod non male fecerunt sed quia uoluisse dicuntur facere?

«Mais s'il n'est pas équitable de recevoir une marque d'honneur quand on a dit qu'on a désiré bien faire et qu'on ne l'a pas fait, les Rhodiens subiront-ils un préjudice de ne pas avoir mal fait, mais de passer pour avoir désiré le faire? »

(CAT. frg. XLII, 168 ORF).

La bienveillante neutralité que les Rhodiens ont témoignée au roi Persée pendant la troisième guerre menée par Rome contre la Macédoine leur vaut d'être mis en accusation par les vainqueurs. Un débat s'engage au sénat pour savoir s'il faut punir les Rhodiens (c'est l'avis du préteur Manlius Iuventius Thalna) ou leur pardonner (c'est l'avis de Caton, qui prévaudra). Caton invoque l'indispensable mérite qui doit présider à l'honos et s'en sert comme point de comparaison pour la conduite à tenir envers les Rhodiens. Selon lui, ce n'est pas la volonté d'agir qu'il faut juger, mais l'action elle-même: de même que l'on n'honore pas celui qui déclare vouloir faire le bien mais ne le fait pas, de même il ne faut pas châtier celui qui passe pour vouloir faire le mal mais ne passe pas à l'acte. Le passage est surtout intéressant pour la norme au nom de laquelle il convient, selon Caton, de donner

\footnotetext{
${ }^{3}$ Sur ce texte, voir l'édition commentée de Calboli, Catonis Pro Rhodiensibus.
} 
l'honos au mérite, l'aequum. Cette notion juridique est complexe car elle a fait l'objet d'une attention grandissante à partir du $\mathrm{II}^{\mathrm{e}}$ siècle et a été enrichie au $\mathrm{I}^{\mathrm{er}}$ siècle par Cicéron sous l'influence de la pensée grecque $^{4}$. L'aequum peut désigner l'égalité pure et simple, comme lorsqu'il est question du ius aequum ${ }^{5}$, mais le terme renvoie plus fréquemment à l'équité, notamment dans l'expression figée aequum et bonum $^{6}$. C'est aussi le cas dans le passage de Caton qui nous intéresse. En quoi consiste cet aequum ? À la fin du $\mathrm{III}^{\mathrm{e}}$ siècle et au début du II ${ }^{\mathrm{e}}$, il est mis en relation avec le ius auquel il est associé mais aussi parfois opposé ${ }^{7}$. On voit en effet apparaître l'idée que le respect de la loi n'est pas toujours conforme à la justice ${ }^{8}$. L'aequum sert à corriger la loi pour se rapprocher de l'idéal de justice: il va au-delà de la stricte égalité pour tenir compte des circonstances. La loi recouvre le cas général, l'aequum s'adresse aux situations particulières ${ }^{9}$. Cet aspect était déjà celui de l'équité chez Aristote: dans l'Éthique à Nicomaque, l'équité est une modification avantageuse de l'égalité parfaite, un correctif apporté au juste selon la loi pour améliorer la justice ${ }^{10}$. Cicéron a développé cet aspect de l'aequum en même temps qu'il a enrichi la notion en lui donnant le même fondement que le droit naturel et en l'associant en profondeur à la justice ${ }^{11}$. Dans le texte de Caton, donner l'honos au mérite consiste donc à respecter l'équité car c'est prendre en compte les circonstances particulières et la nature de la personne qu'on honore. Cela revient à donner à chacun ce qui lui est dû. Prendre en compte la dignitas, le mérite, est d'ailleurs un des aspects de l'aequum dans la définition qu'en donne le juriste Ulpien ${ }^{12}$. On retrouve une semblable exigence d'équité pour l'octroi de l'honos dans le De

${ }^{4}$ Voir M. Ducos, Les Romains et la loi, Paris, Les Belles Lettres, 1984, p. 303-338; F. CALlier, "Einige Bemerkungen über das ius und das aequum bei Terenz», in Blänsdorf, J.(éd.), Theater und Gesellschaft im Imperium Romanum, Tübingen, 1990, p. 81-92; G. CiuleI, L'Équité chez Cicéron, Amsterdam, A. M. Hakkert, 1972; P. Cerami, "Aequum iudicium e 'giusto processo': prospettive romane e moderne », ASGP, 46, 2000, p. 115-130.

${ }^{5}$ Cic. Off. I, 124 ; Rep. III, 16; Verr. II, III, 6. Voir Ducos, Les Romains et la loi, p. 50.

${ }^{6}$ Sur les actions in aequum et bonum conceptae, voir CiUleI, L'Équité chez Cicéron, p. 9 .

${ }^{7}$ Par exemple chez Plaute: PL. Curc. 64; Men. 580; Most. 682; Pers. 399; St. 423; Trin. 97. Voir Ducos, Les Romains et la loi, p. 325.

8 TER. Heaut. 796.

${ }^{9}$ Ducos, Les Romains et la loi, p. 307 et 328.

${ }^{10}$ Arstr. EN, livre V et notamment $1137 \mathrm{~b}$.

${ }^{11}$ Ducos, Les Romains et la loi, p.331-335. Pour Cicéron, l'équité est notamment liée à l'interprétation de la loi: elle consiste à s'attacher à l'esprit plutôt qu'à la lettre (Cic. Caecin. 65).

${ }^{12}$ Dig. XI, 7, 14, 6. 
republica. Scipion rapporte le discours des défenseurs de l'aristocratie qui critiquent l'égalité régnant dans une démocratie:

Cum enim par habetur honos summis et infimis, qui sint in omni populo necesse est, ipsa aequitas iniquissima est; quod in iis ciuitatibus quae ab optimis reguntur accidere non potest.

"Car quand on donne un honneur semblable à ceux qui sont de la plus haute valeur comme à ceux qui sont de la plus basse, gens qui existent toujours nécessairement dans toutes les cités, cette égalité même est extrêmement inique; mais cela ne peut arriver dans les cités gouvernées par les meilleurs. »

(Cic. Rep. I, 53).

Les enjeux de ce texte de philosophie politique sont différents de ceux du Pro Rhodiensibus mais on y retrouve le souci de l'aequitas. Ici encore, l'honos, pour respecter l'aequum et être juste, doit se fonder sur le mérite. La réflexion prend cependant une tournure nettement plus politique: selon Scipion, donner l'honos d'une charge à tout un chacun, de façon indifférenciée, c'est-à-dire sans prise en compte de la dignitas, constitue une violation de l'équité. L'égalité qui règne dans les démocraties, quand les charges sont obtenues par tirage au sort, comme à Athènes, est à rejeter car elle conduit à des catastrophes et ne récompense pas la valeur: elle n'a d'aequitas que le nom. Dans la conception aristocratique, cette égalité est en réalité inique car elle spolie ceux qui ont davantage de mérite, les summi évoqués dans le texte, en les plaçant sur le même plan que les infimi. Ce mode de pensée, qui est celui de Scipion ${ }^{13}$, est répandu à Rome, comme le montre l'importance attachée à la dignitas dans les textes. Il est admis par une large frange de la population que tous les citoyens ne sont pas égaux en mérite, mais que certains ont plus de dignitas que d'autres et doivent de ce fait obtenir plus d'honores. L'ancrage de l'honos sur la dignitas relève donc, d'une certaine façon, d'une représentation aristocratique de l'honneur, soucieuse d'aequum. Ce mode de pensée repose sur la logique de l'égalité géométrique que l'on observe dans d'autres mécanismes civiques et politiques tels que le $\operatorname{census}^{14}$. À la différence

${ }^{13}$ Scipion, parlant en son nom propre, développe un raisonnement similaire en Rep. I, 43 où l'aequabilitas est qualifiée d'iniqua.

${ }^{14}$ Sur l'égalité géométrique, voir Nicolet, Métier, p. 81 sqq; C. Nicolet, «L'idéologie du système centuriate et l'influence de la philosophie politique grecque» in La filosofia greca e il diritto romano, Rome, Accademia nazionale dei Lincei, 1976, p. 111-137; J.-L. FERRARY, "Le idee politiche a Roma nell'epoca repubblicana», in FIRPo, L. (éd.), Storia delle idee politiche, economiche e sociali, Turin, UTET, 1982, vol.1, p.723-804, aux p.738-739; Ducos, Les Romains et la loi, p. 327-331; M.Humm, Appius Claudius Caecus, Rome, E.F.R., 2005, p.584-600. Il s'agit d'un principe ancien, que l'on rencontre chez les Pythagoriciens (A.Delatte, Essai sur la politique pythagoricienne, Liège, Vaillant-Carmanne, 1922, p. 100-106), chez Platon (Gorg.508a; Lois VI, 757a-e) qui la préfère à l'égalité arithmétique et chez Aristote (EN 1131b-1133b) qui en fait le socle de la justice distributive. 
de l'égalité arithmétique qui donne à chacun de manière strictement équivalente, l'égalité géométrique consiste à procurer à chacun ce qui lui revient selon ses qualités: il doit y avoir proportionnalité entre ce que l'on obtient et ce que l'on mérite ainsi qu'entre les avantages que l'on gagne et les contraintes que l'on subit. Cette égalité géométrique est supérieurement juste parce qu'elle n'implique pas un traitement identique pour tous. C'est elle qui est au cœur de l'aequum et structure le fonctionnement de l'honos.

\section{TYPOLOGIE DES MOTIFS DE L'HONOS}

Notre étude sémantique a mis en avant l'importance du mérite dans les différents sens d'honos mais aussi la variété de ce mérite. C'est cette variété que nous voudrions maintenant appréhender. Une première distinction, fondamentale, peut être faite entre l'honos appelé par le comportement de celui qui le reçoit et l'honos motivé par son statut. La marque d'honneur ou le prestige d'un individu reposent soit sur une conduite manifestant certaines qualités, soit sur une position sociale occupée par la personne. Pour reprendre le paradigme du capital emprunté à Bourdieu, il nous faut identifier à partir de quel capital se forme le capital symbolique qu'est l'honos. Le prestige n'est en effet rien d'autre qu'une qualité ou propriété publiquement reconnue par les agents sociaux ${ }^{15}$.

\subsection{Comportements et qualités}

Il apparaît qu'à Rome le capital symbolique qu'est l'honos naît de la reconnaissance par la collectivité d'un type de capital qui n'est pas envisagé par Bourdieu dans ses études sur le prestige. L'honneur ne naît pas de la richesse ou de la clientèle, capitaux de type économique et social, mais de la détention de qualités morales valorisées par la tradition. Le capital symbolique provient ainsi de ce que l'on pourrait nommer un «capital moral».

${ }^{15}$ Sur le capital symbolique comme capital reconnu par les agents sociaux, voir supra p.231-232 et Bourdieu, Raisons pratiques, p.161: "J'appelle capital symbolique n'importe quelle espèce de capital (économique, culturel, scolaire ou social) lorsqu'elle est perçue selon des catégories de perception, des principes de vision et de division, des systèmes de classement, des schèmes classificatoires, des schèmes cognitifs, qui sont, au moins pour une part, le produit de l'incorporation des structures objectives du champ considéré, c'est-à-dire de la structure de la distribution du capital dans le champ considéré. » 


\subsubsection{Mérites militaires}

La guerre est, pour les Romains de la République, une réalité quotidienne: Rome a en effet été engagée dans des conflits de manière presque ininterrompue pendant les premiers siècles de son histoire. Elle n'apparaît cependant pas tant comme une source de contraintes ou de dangers que comme une occasion offerte au citoyen de prouver sa valeur et de gagner du prestige ${ }^{16}$. C'est en effet au milieu des combats que l'on peut gagner l'honos, comme en témoignent ces vers du Curculio:

Sibi sua habeant regna reges, sibi diuitias diuites, Sibi honores, sibi uirtutes, sibi pugnas, sibi proelia;

Dum mi abstineant inuidere, sibi quisque habeant quod suum est.

«Qu'ils gardent leurs royaumes, les rois, qu'ils gardent leurs richesses, les riches,

Qu'ils gardent leurs honneurs, leurs exploits, leurs combats, leurs batailles! Pourvu qu'ils s'abstiennent de me jalouser, qu'ils gardent tous ce qui leur appartient. »

(PL. Curc. 178-180).

Phédrome, qui vient de retrouver son amante Planésie, est transporté de joie, et son amour pour la jeune fille le conduit à rejeter tout ce qui est valorisé dans la tradition romaine. Il repousse ainsi, entre autres, les honores; ces derniers sont associés d'une part aux regna et diuitias, qui sont d'autres biens prestigieux mis sur le même plan que les honores; d'autre part aux uirtutes, pugnas, proelia, qui, invoqués dans le même vers que les honores, en apparaissent comme des sources possibles. Les honores trouvent donc ici leur origine dans les combats qui permettent d'accomplir des uirtutes, des «actes de bravoure ${ }^{17}$. C'est par la conduite de grandes opérations militaires que de nombreux personnages publics romains ont acquis de l'honneur. C'est le cas par exemple de Muréna, comme l'indique le passage où Cicéron se représente son client partir pour l'exil s'il venait à être condamné:

Ibit igitur in exilium miser? Quo? Ad Orientisne partis in quibus annos multos legatus fuit, exercitus duxit, res maximas gessit? At habet magnum dolorem, unde cum honore decesseris, eodem cum ignominia reuerti.

«Il ira donc en exil, le malheureux? Mais où? Dans ces contrées de l'Orient où il fut légat pendant plusieurs années, où il a mené des armées, où il a accompli

${ }^{16}$ Sur l'évolution de l'opinion du peuple romain face à la guerre, voir W.V.HARRIS, War and Imperialism in Republican Rome 327-70 B.C., Oxford, Clarendon Press, 1985, p. 43 sqq.

${ }^{17}$ Sur ce sens de uirtus, voir Eisenhut, Virtus romana, p. 28. 
de grandes choses? Mais c'est une grande douleur de revenir couvert d'opprobre à l'endroit d'où l'on est parti couvert d'honneur. »

(CIc. Mur. 89).

Muréna s'est acquis de l'honos en prenant part à la campagne d'Asie aux côtés de Lucullus. C'est pour avoir exercé les fonctions de légat et avoir conduit des armées qu'il s'est couvert de gloire. Son départ en exil pour l'Orient, couvert d'ignominia, contrasterait donc de façon pathétique avec son retour à Rome plein d'honos. L'obtention de l'honos en contexte militaire est conditionnée par l'accomplissement de grandes actions: la simple participation aux combats ne suffit pas. Nous avons vu avec l'étude des décorations militaires qu'un soldat doit avoir réalisé un exploit précis pour les obtenir, comme avoir fait lever un siège ou avoir été le premier à entrer dans une ville ennemie ${ }^{18}$. Pour le général, c'est le fait d'avoir remporté une victoire décisive sur l'ennemi qui est source d'honneur. Ce sont les succès militaires répétés de César en Gaule qui lui valent de nombreuses supplications accomplies en son nom $^{19}$; les vainqueurs de la guerre de Modène méritent quant à eux de grands honores pour avoir largement vaincu les troupes d'Antoine $^{20}$. La participation à la guerre constitue donc encore au ${ }^{\text {er }}$ siècle un moyen de prestige auquel les Romains sont sensibles, sans quoi Cicéron ne l'utiliserait pas comme argument pour convaincre ses auditeurs. Aux siècles précédents, la réussite militaire constitue pour les aristocrates un ingrédient essentiel de l'honos, qui leur permet ensuite de s'affirmer dans d'autres domaines de la vie civique ${ }^{21}$. L'excellence militaire est un élément identitaire central pour l'aristocratie des $\mathrm{III}^{\mathrm{e}}$ et $\mathrm{II}^{\mathrm{e}}$ siècles et l'honos est, de ce fait, teinté d'une forte coloration martiale ${ }^{22}$ : le succès au combat a constitué une source privilégiée de l'honos pendant toute l'histoire de la République.

La victoire du général et les exploits du soldat sont des sources d'honos car leur obtention est le signe d'une qualité particulière. Il faut en effet différencier, pour comprendre sur quelles bases repose l'honos, l'acte et la qualité manifestée par cet acte. Ce qui appelle l'honos, c'est, au moins autant que l'exploit militaire, ce qui a permis

${ }^{18}$ Voir supra p. 257.

${ }^{19}$ Cic. Prou. 25.

${ }^{20}$ CIc. Phil. XIV, 12.

${ }^{21}$ "Military success was not only highly advantageous to the Roman state, it was of vital importance to the personal aims and interests of many, probably most, Roman aristocrats » (HARRIS, War and Imperialism, p. 17).

${ }^{22}$ Voir par exemple la place occupée par les succès militaires dans les épitaphes des Scipions (chapitre 14). L'idéal de la pax ne devint réel qu'au milieu du Ir siècle, avec la génération de Cicéron, et parmi les Romains de condition élevée. Voir par exemple Lucr. DRN I, 29-40 et Cic. Att. I, 20, 5. Sur ce point, Ibid., p. 36. 
l'exploit, c'est-à-dire, pour les Romains, la uirtus, la vaillance. César le dit explicitement à propos des Allobroges intégrés dans son armée pendant la guerre civile:

Hi propter uirtutem non solum apud Caesarem in honore erant, sed etiam apud exercitum cari habebantur.

«Ces hommes, en raison de leur vaillance, étaient non seulement honorés par César mais aussi appréciés par l’armée.»

(CAES. BC III, 59, 2-3; trad. Fabre modifiée).

L'honos dont jouissent les Gaulois se fonde sur leur uirtus, qui renvoie à une qualité particulièrement appréciée au sein d'un corps militaire ${ }^{23}$; c'est aussi en raison de la uirtus montrée par les soldats qui ont combattu Antoine lors de la guerre de Modène que Cicéron veut leur faire élever un tombeau aux frais publics ${ }^{24}$. La notion de uirtus est complexe ${ }^{25}$. Son sémantisme est riche dès les textes les plus anciens et le devient encore plus aux deux derniers siècles de la République. Dans les deux textes précédents, le terme renvoie à la vaillance du soldat au combat. Il est alors sémantiquement proche de uir, mot dont il dérive par un suffixe *-tūt- ${ }^{26}$. La uirtus est, fondamentalement, la qualité du uir, de l'homme, et entretient donc un rapport de sens avec la virilité. Cet aspect de la notion, qui l'oriente vers l'expression de la bravoure et du courage physique, est ancien et fondamental ${ }^{27}$. Dans

${ }^{23}$ Le fait de prendre la fuite, de manquer de courage, constitue à l'inverse une action turpis, c'est-à-dire déshonorante (CAES. BC II, 31, 4).

${ }^{24}$ Cic. Phil. XIV, 33.

${ }^{25}$ La notion de uirtus a fait l'objet de plusieurs études, de nature surtout philologique. Voir E.W.Webster, Virtus and Libertas. The Ideals and Spirit of the Roman Senatorial Aristocracy from the Punic Wars through the Time of Augustus, Diss., University of Chicago, Chicago, 1934; VAN OMME, Virtus. Een semantiese studie; BüchNER, "Altrömische und horazische virtus»; EISENhut, Virtus romana; H.STEINMEYER, «Der virtus-Begriff bei Cicero und Seneca», $A U, 17,1974$, p. 50-59; J. SARSILA, "Some Notes on Virtus in Sallust and Cicero», Arctos, 12, 1978, p.135-143; Mutschler, "Virtus und kein Ende?»; MutschleR, «Virtus 2002: zur Rolle der 'römischen Werte' in der Altertumswissenschaft»; McDonnell, Roman Manliness; C. E. Balmaceda, «'Virtus Romana' en el siglo I a.C. », Gerión, 25 (1), 2007, p. 285-303.

${ }^{26}$ DELL p.739 s. v. uir; EIsEnhut, Virtus romana, p. 12 et McDonnell, Roman Manliness, p. 2.

${ }^{27}$ Sur le lien entre uir et uirtus, voir Cic. Tusc. II, 43. Contra EisEnHut, Virtus romana (p.23-24 et 219) considère que le sens premier est plus large et désigne l' "excellence» et la «capacité». Sur le rapport à la virilité et au courage, voir BücHNER, "Altrömische und horazische virtus », p.377 et Hellegouarc'H, Vocabulaire, p. 244. Voir surtout la démonstration de M. McDonnell sur l'importance de la virilité et du courage physique dans la uirtus des $\mathrm{III}^{\mathrm{e}}$ et $\mathrm{II}^{\mathrm{e}}$ siècles (McDonnell, Roman Manliness, p. 12-71). Le sens de "valeur », "capacité » se rencontre à l'époque de Plaute, mais il est moins fréquent que celui de «courage» ou «vaillance». C'est aussi de cette bravoure qu'il est question dans le tout premier texte où apparaît la notion, un fragment de la loi des XII Tables (= PLIN. 
l'œuvre philosophique cicéronienne, la notion a pris un sens éthique nouveau, sous l'influence de l'ảpetń grecque, mais ce sens inédit n'est pas en contradiction avec la nature première de la uirtus ${ }^{28}$. Il existe donc entre uirtus et honos un lien étroit de cause à effet, la bravoure étant la source privilégiée, si ce n'est exclusive, de l'honos dans un contexte militaire $^{29}$. Ce lien est confirmé par le fait que, dans le culte religieux, le dieu Honos est très régulièrement associé à la divinité Virtus, le premier incarnant le juste hommage rendu à la seconde ${ }^{30}$.

\subsubsection{Mérites moraux}

Il est aussi possible pour un Romain d'obtenir des marques d'honneur par ses qualités morales. Trois vertus apparaissent de manière récurrente comme des sources d'honneur, le pudor, la fides et la uirtus. Dans l'Asinaria, le vieux Déménète se réjouit que son fils lui ait confié ses soucis amoureux:

Praesertim quom is me dignum quoi concrederet

Habuit, me habere honorem eius ingenio decet.

Quom me adiit, ut pudentem gnatum aequomst patrem,

Cupio esse amicae quod det argentum suae.

«Surtout, comme il m’a jugé digne de lui servir de confident,

Il convient que je rende hommage à son bon caractère.

Puisqu'il est venu me voir, comme il est juste qu'un fils respectueux le fasse avec son père,

Je désire qu'il ait de l'argent à donner à sa maîtresse.»

(PL. As. 79-83).

Déménète souhaite conférer à son fils un honos parce qu'il s'est comporté en fils respectueux (pudentem): il a fait preuve de pudor, c'est-à-dire de retenue décente, et plus précisément de "respect» envers son père, il n'a pas essayé de le tromper et est venu spontanément vers lui pour se confier ${ }^{31}$. Le pudor implique, de façon plus

NH XXI, 7 ; Cic. Leg. II, 24, 60) qui règle l'usage des couronnes militaires lors des funérailles de celui qui les a obtenues. Le fait qu'il soit question d'une corona, décoration obtenue à l'armée, oriente la notion de uirtus vers la «bravoure» du soldat et montre son lien précoce avec les honores (McDonNell, Roman Manliness, p. 14 rejette avec raison, pour le texte des XII Tables, la traduction d'Eisenhut par «valeur, capacité»).

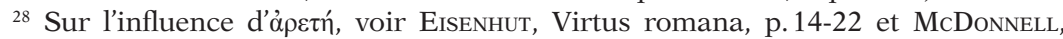
Roman Manliness, p. 72-141.

${ }^{29}$ Sur le lien entre uirtus et reconnaissance de la communauté, sous forme d'honos ou de fama, se reporter à BücHNER, "Altrömische und horazische virtus », p. 380.

${ }^{30}$ Sur le rapprochement des deux divinités et les temples communs qui leur sont consacrés voir infra chapitre 11.

${ }^{31}$ Sur ce sens de pudor, voir Thомаs, Déshonneur et honte, p. 337. Outre cet ouvrage, voir, sur la notion de pudor, E. VAuBeL, Pudor, verecundia, reverentia. Untersuchungen zur Psychologie von Scham und Ehrfurcht bei den Römern bis Augustin, Münster, 
générale, une réaction de la conscience morale et, par conséquent, une attitude retenue ${ }^{32}$ : le fils pudens s'abstient de commettre des actes vils et ne fait pas preuve d'audace ni d'effronterie. C'est en partie l'inexistence de tout pudor chez les acteurs qui explique qu'ils aient été dans l'impossibilité de prétendre à l'honos:

Cum artem ludicram scaenamque totam in probro ducerent, genus id hominum non modo honore ciuium reliquorum carere, sed etiam tribu moueri notatione censoria uoluerunt.

«Comme ils jugeaient déshonorant tout ce qui touche à l'art théâtral et à la scène, ils résolurent non seulement de priver ceux qui s'y adonnaient de toute distinction que pouvaient obtenir les autres citoyens, mais encore de les exclure de leur tribu, en vertu de la note censoriale.»

(CIc. Rep. IV, 13, frg. 1 ; trad. Bréguet).

Ce propos de Scipion éclaire l'infamie attachée au métier d'acteur. Leur profession était entourée de mépris et des dispositions juridiques les privaient, par conséquent, de certains droits ${ }^{33}$. Comme les gladiateurs, les lanistes, les prostituées, les proxénètes ainsi que les criminels condamnés selon certaines procédures, les acteurs étaient marqués d'infamia: ils étaient exclus, pour des raisons morales, de l'exercice de certaines fonctions publiques ${ }^{34}$ et ne pouvaient pas accéder aux magistratures ou au sénat, ni à Rome ni dans les municipes ${ }^{35}$.

1969; K. Hopkins, «From Shamelesness to Guilt. The Roman Moral Revolution », PCA, 81, 1984, p. 23-24; A. WLosoK, "Nihil nisi pudorem. Über die Rolle der Scham in der römischen Rechtskultur», in Heck, E. et Scнmidt, E. A. (éds.), Res humanae - res divinae. Kleine Schriften, Heidelberg, C. Winter, 1990, p. 84-100; KASTER, Emotion, Restraint and Community in Ancient Rome, p.28-65; R. AleXandre, C. Guérin et M. Jacotot (éds.), Rubor et pudor. Vivre et penser la honte à Rome, Paris, Éditions Rue d'Ulm, 2012.

32 Thomas, Déshonneur et honte, p. 398.

${ }_{33}$ Sur la condition juridique des acteurs, W. M. Green, "The Status of Actors at Rome», CPh, 28, 1983, p. 301-304; M. Ducos, "La condition des acteurs à Rome. Données juridiques et sociales", in BLäNSDORF, J. (éd.), Theater und Gesellschaft im Imperium Romanum, Tübingen, 1990, p. 19-33; C. EDWARDS, «Unspeakable Professions: Public Performance and Prostitution in Ancient Rome», in Hallett, J.P. et Skinner, M.B. (éds.), Roman Sexualities, Princeton, Princeton University Press, 1997, p.66-95; C. Hugoniot, «De l'infamie à la contrainte. Évolution de la condition sociale des comédiens sous l'Empire romain ", in Hugoniot, C., Hurlet, F. et Milanezi, S. (éds.), Le Statut de l'acteur dans l'Antiquité grecque et romaine, Tours, P.U.F.R., 2004, p. 213-240.

${ }^{34}$ L'édit du préteur déclare marqué d'infamie (infamia notatur) celui qui se produit sur une scène pour jouer ou déclamer (Dig. III, 2, 1 et 2, 2, 5). Sur l'infamia en général, A. H. J. Greenidge, Infamia. Its Place in Roman Public and Private Law, Oxford, Clarendon Press, 1894 ; L. Pommeray, Études sur l'infamie en droit romain, Paris, Sirey, 1937; KaSER, «Infamia und ignominia in den römischen Rechtsquellen».

${ }^{35}$ Liv. VII, 2, 12; Tertul. Spect. 22. La table d'Héraclée montre que les comédiens, comme les autres gens du spectacle, ne peuvent accéder aux magistratures municipales ni à l'ordre des décurions (CIL I², $593=$ FIRA I, n 13, l. 108 sqq.). Voir Ducos, « La condition des acteurs à Rome», p. 20-21. 
Ils n'étaient pas protégés des châtiments corporels et de la coercition des magistrats comme les autres citoyens ${ }^{36}$. Toutes ces limitations, et notamment l'impossibilité de prétendre à l'honos, s'imposent pour des raisons morales: les acteurs sont en effet souillés du probrum attaché à l'art scénique. Paraître sur scène en public constitue une conduite indigne d'un citoyen: l'acteur abandonne en effet toute retenue et gesticule de manière indécente, en s'exhibant devant un large public. En outre, comme le gladiateur et la prostituée, il vend son corps pour le plaisir des autres ${ }^{37}$. Il lui manque la décence et la réserve qui font le pudor et il ne peut de ce fait prétendre à l'honos.

Une deuxième qualité morale fréquemment invoquée comme source d'honos est la fides. Au moment de la révolte des Sénons contre Rome, seuls les Héduens et les Rèmes ne changent pas d'attitude visà-vis de l'Vrbs, comme l'explique César:

Tantum apud homines barbaros ualuit esse aliquos repertos principes inferendi belli tantamque omnibus uoluntatum commutationem attulit, ut praeter Haeduos et Remos, quos praecipuo semper honore Caesar habuit, alteros pro uetere ac perpetua erga populum Romanum fide, alteros pro recentibus Gallici belli officiis, nulla fere ciuitas fuerit non suspecta nobis.

"L'impression fut si forte sur ces esprits barbares quand on sut qu'il s'était trouvé quelques audacieux pour nous déclarer la guerre et il en résulta un tel changement dans les dispositions de tous les peuples que, sauf les Héduens et les Rèmes, à qui César témoigna toujours des honneurs particuliers, les uns en raison de leur ancienne et durable fidélité envers Rome, les autres à cause de leurs services récents dans la guerre contre les Gaulois, il n'y eut guère de cité qui ne nous donnât lieu de la soupçonner.»

(CAES. BG V, 54, 4; trad. Constans modifiée).

C'est la relation ancienne d'honos instituée entre Rome et les Héduens qui explique la permanence des bonnes dispositions de ces derniers. Cet honos lui-même est justifié par la fides des Héduens qui sont depuis longtemps attachés à Rome et ne se sont pas signalés par des révoltes ou des actes de perfidie. La fides qui leur vaut l'honneur est donc une loyauté, une bonne foi persistante. La notion suppose droiture et absence d'intention maligne: elle s'oppose à la fraus par laquelle on trompe les autres ${ }^{38}$. C'est une qualité de l'homme d'Etat

${ }^{36}$ TAC. Ann. I, 77.

${ }^{37}$ Sur le caractère déviant de l'acteur, F. Dupont, Le Théâtre latin, Paris, A.Colin, 1988, p.23, ainsi qu'Edwards, «Unspeakable Professions: Public Performance and Prostitution in Ancient Rome». Sur le lien entre pudeur et honneur, voir infra p. 476-479.

${ }^{38}$ Sur ces aspects de la fides, Freyburger, Fides. Étude sémantique et religieuse depuis les origines jusqu'à l'époque augustéenne, Paris, Les Belles Lettres, 1986, p. 49 $s q q$. et p. 85 sqq. Sur la notion en général, voir aussi Heinze, "Fides»; V.D’Agostino, «La Fides Romana», RSC, 9 (1), 1945, p. 73-86; Hellegouarc'H, Vocabulaire, p. 23-35; P.BoyancÉ, "Les Romains peuple de la Fides» in Études sur la religion romaine, 
que les inscriptions honorent ${ }^{39}$. C'est en raison de ce lien entre fides et honos que Cicéron estime que les meilleurs accusateurs, ceux qui causent le moins de tort à la république, sont ceux qui se soucient de leur honos: quand leur honneur est en jeu, en effet, ils veillent à ne pas porter d'accusation calomnieuse, à ne pas enfreindre la fides afin de ne pas mettre à mal leur réputation ${ }^{40}$.

Une dernière vertu motif d'honneur doit retenir notre attention: différents textes placent, à nouveau, la uirtus à l'origine de l'honos. Néanmoins, le terme ne désigne pas cette fois le courage viril. C'est une autre signification que l'on relève dans le passage du Trinummus où Lysitélès réprimande son ami Lesbonicus pour sa conduite débauchée:

Itan tandem hanc maiiores famam tradiderunt tibi tui,

Vt uirtute eorum anteparta per flagitium perderes?

Atque honori posterorum tuorum ut uindex fieres,

Tibi paterque auosque facilem fecit et planam uiam

Ad quaerundum honorem; tu fecisti ut difficilis foret

Culpa maxime et desidia tuisque stultis moribus.

Praeoptauisti amorem tuum uti uirtuti praeponeres.

«Tes ancêtres t'ont-ils légué cette bonne réputation

Pour que tu ruines par ta débauche les biens acquis autrefois par leur vertu? Et pourtant, pour que tu puisses protéger l'honneur de tes descendants, Ton père et ton ancêtre t'avaient ménagé un chemin facile, tout plat, Vers l'honneur; tu l'as rendu difficile

Par ta conduite fautive, surtout, et par ta paresse et tes mœurs stupides.

Tu as choisi de faire primer ton amour sur la vertu.»

(PL. Trin. 642-648).

La uirtus, à laquelle Lysitélès fait référence deux fois dans le passage est opposée d'abord au flagitium, au scandale causé par la débauche, puis à l'amor, c'est-à-dire ici à la fréquentation des courtisanes. La uirtus nous paraît donc renvoyer à une valeur spécifiquement morale, à l'excellence des mœurs, même s'il ne s'agit pas encore d'un vrai concept éthique ${ }^{41}$. Ce qu'entend précisément Lysitélès par uirtus apparaît quelques vers plus loin:

Cape sis uirtutem animo, et corde expelle desidiam tuo.

In foro operam amicis da, ne in lecto amicae, ut solitus es.

Paris, 1972, p.135-152; Pöschl, "Politische Wertbegriffe in Rom»; Tноме, Zentrale Wertvorstellungen der Römer, vol.2, p. 50-84.

39 E. ForBIS, Municipal Virtues in the Roman Empire. The Evidence of Italian Honorary Inscriptions, Stuttgart, Teubner, 1996, p. 62 sqq.

${ }^{40}$ Cic. Diu. Caec. 71.

${ }^{41}$ Sur cette évolution morale de la notion de uirtus, voir McDonnell, Roman Manliness, p. 105-141. 
«Accueille la vertu dans ton âme, et chasse la paresse de ton cœur. Consacre tes efforts à tes amis sur le forum, pas à ta maîtresse dans ton lit, comme tu en as l'habitude.»

(PL. Trin. 650-651).

La uirtus consiste donc non seulement à éviter le flagitium mais aussi à tenir dignement sa place dans la cité. C'est une vertu civique et sociale, dont le lieu d'exercice est le forum, et qui trouve son expression dans les services propres à l'amicitia. La conduite qu'impose la uirtus est étroitement liée au service de l'État dans la conception des aristocrates et des homines noui ${ }^{42}$. Le rapport entre l'honos et la uirtus apparaît à toutes les époques et dans des textes très différents. Une inscription d'un aristocrate, l'épitaphe de Cn. Cornelius Scipion Hispanus, en donne un autre exemple ${ }^{43}$ :

Cn(aeus) Cornelius Cn(aei) F(ilius) Scipio Hispanus

pr(aetor) aid(ilis) cur(ulis) q(uaestor) tr(ibunus) mil(itum) II Xuir s(t) l(itibus) iudik(andis) Xuir sacr(is) fac(iundis).

Virtutes generis mieis moribus accumulaui, Progeniem genui, facta patris petiei.

Maiorum optenui laudem, ut sibei me esse creatum Laetentur: stirpem nobilitauit honor.

«Gnaeus Cornelius Scipio Hispanus, fils de Gnaeus, préteur, édile curule, questeur, deux fois tribun militaire, décemvir chargé de juger les litiges, décemvir chargé des sacrifices.

J'ai augmenté grâce à mes mœurs les vertus de ma race,

J'ai fondé une descendance et essayé d'égaler les exploits de mon père.

J'ai préservé la gloire de mes ancêtres, de sorte qu'ils se réjouissent de m'avoir engendré:

Mon honneur a ennobli ma lignée.»

$\left(C I L \mathrm{I}^{2}, 15=I L L R P 316\right)$.

L'elogium commence par le terme de uirtutes et s'achève sur celui d'honos. Les uirtutes sont différentes qualités morales, dont un échantillon est donné dans les vers suivants avec la fondation d'une descendance et l'imitation des ancêtres. L'honos, quant à lui, apparaît comme la récompense qui couronne ces vertus. On retrouve cet ancrage de

${ }^{42}$ Cic. Rep. I, 1 et I, 7. Voir Earl, Tradition, p. 34; Webster, Virtus and Libertas, p. 29; Steinmeyer, «Der virtus-Begriff bei Cicero und Seneca » et SarSiLA, «Some Notes on Virtus in Sallust and Cicero ». Sur le rapport comparé de l'aristocrate et de l'homo nouus à la uirtus, voir p. 339-343.

${ }^{43}$ L'inscription ne mentionnant pas de charge supérieure à celle de préteur, Hispanus est sans doute mort peu après l'avoir exercée, en 139. Selon Coarelli, l'inscription daterait des années 130. (F. COARELLI, "Il sepolcro degli Scipioni », DArch, 6 (1), 1972, p. 36-106 et F. CoArelli, Guide archéologique de Rome, Paris, Hachette, 1998, p. 116). 
l'honos sur la uirtus quand cette dernière subit, à partir du II ${ }^{\mathrm{e}}$ siècle, l'influence de la philosophie grecque ${ }^{44}$. Un fragment dramatique anonyme déclare:

Nam sapiens uirtuti honorem praemium, haud praedam petit.

Set quid uideo? ferro saeptus possidet sedis sacras.

«Car le sage recherche pour la vertu un honneur qui soit une récompense, et non un butin.

Mais que vois-je? Bardé de fer il envahit la demeure sacrée.»

(TRF inc. frg. 30-31).

C'est encore ici sur la uirtus, qui désigne la «vertu» éthique, dans la mesure où elle est présentée comme le propre du sage, que repose la prétention à l'honos: l'excellence morale peut rechercher légitimement une récompense (praemium) sous forme d'honos. La uirtus, quand elle touche à l'éthique, conserve donc un lien avec l'honos.

Cette place importante prise par les qualités morales parmi les motifs d'honos appelle quelques remarques conclusives. L'honos nous est apparu jusqu'alors comme une réalité éminemment sociale, à la fois signe mettant en jeu des relations intersubjectives complexes et prestige accompagné d'une réputation positive. L'examen des motifs de l'honos fait ressortir l'aspect moral de la notion: c'est une sanction, positive, donnée par la collectivité, qui repose sur l'adéquation à des règles morales. Cette conjonction du moral et du social abolit, par conséquent, toute distinction trop tranchée entre sphère privée et sphère publique: les mores, ce que nous appellerions la "vie privée", sont placés sous le regard et le jugement des autres. Briguer un honos implique d'exposer à tous son mode de vie pour qu'il soit examiné: les mours du candidat sont évaluées par les électeurs ${ }^{45}$. Caton justifie l'obtention de sa charge de censeur par l'excellence de ses mores et Scipion Émilien fonde l'accès à l'honos et à l'imperium sur l'innocentia ${ }^{46}$. Ce n'est pas la détention de compétences particulières ni l'expérience dans les affaires publiques qui sont mises en avant par les candidats, encore moins qu'un programme politique, mais leurs qualités personnelles.

${ }^{44}$ L'assomption éthique de la uirtus est notamment sensible dans le célèbre fragment sur la vertu de Lucilius, marqué par la pensée stoïcienne. Sur ce passage, voir le chapitre 16. Sur l'aspect éthique de la uirtus et le rapprochement notamment avec les quatre vertus cardinales de la pensée grecque, voir McDonnell, Roman Manliness, p. 105-141.

${ }^{45}$ La notoriété des candidats et la professio faite avant le vote permettaient aux électeurs d'examiner leurs mérites (NicoLET, Métier, p. 328).

${ }^{46}$ Cat. frg. XVIII, 93 ORF; ScIP. Aem. frg. inc. 32 ORF. 


\subsubsection{Bienfaits et services}

Parmi les motifs d'honos, les mérites militaires et les mérites moraux sont sans doute les mieux représentés. Mais il arrive que l'honos soit une réponse à une action beaucoup plus ponctuelle comme un bienfait ou un service rendu. L'honos permet alors, de manière pragmatique, de remercier quelqu'un pour un geste généreux et utile. Dans le Trinummus, Lysitélès accepte de prendre pour femme la sœur de son ami Lesbonicus et de l'épouser sans dot, pour ne pas aggraver la situation financière de la famille; ce geste désintéressé lui vaudra un emolumentum honoris ${ }^{47}$. Mais ce sont surtout les marques d'honneur octroyées par une cité à un individu qui reposent sur des services rendus. Cicéron décrit en ces termes Sthenius, un Sicilien victime de Verrès:

Estne Sthenius is qui, omnis honores domi suae facillime cum adeptus esset, amplissime ac magnificentissime gessit, qui oppidum non maximum maximis ex pecunia sua locis communibus monumentisque decorauit, cuius de meritis in rem publicam Thermitanorum Siculosque uniuersos fuit aenea tabula fixa Thermis in curia, in qua publice erat de huius beneficiis scriptum et incisum?

«Est-ce ce Sthénius qui chez lui a facilement obtenu tous les honneurs, qu'il a exercés de la façon la plus noble et la plus généreuse qui soit? qui a orné à ses frais une ville qui n'était pourtant pas très grande de très grands édifices d'usage commun? est-ce lui qui a mérité par ses actions en faveur de la république de Thermes et de l'ensemble des Siciliens qu'une table de bronze fût fixée dans la curie de Thermes, sur laquelle on grava une inscription publique rappelant ses bienfaits?»

(CIc. Verr. II, II, 112).

Sthenius a reçu de ses concitoyens plusieurs honores, dont une inscription gravée sur une table de bronze et affichée dans un lieu prestigieux, la curie. Il les doit à des actes d'évergétisme: il a fait construire, à ses frais, des édifices publics dans sa cité. Ceux qui aident la cité de leur bourse ont droit, en retour, à des distinctions ${ }^{48}$. C'est peut-être également la raison véritable de l'honos qui a été fait à Bibulus dont nous évoquions précédemment le monument funéraire ${ }^{49}$. L'inscription indique que c'est la uirtus de Bibulus qui motive la marque d'honneur qu'il a reçue. Il n'est pas impossible que ce terme

${ }^{47}$ PL. Trin. 684.

${ }^{48}$ Voir les inscriptions qui honorent la générosité des bienfaiteurs d'une cité (ForBIs, Municipal Virtues, p. 29-43). Il faut donc relativiser l'affirmation de P.Veyne selon laquelle "Rome ne cultivera pas les honneurs aux évergètes comme faisait la Grèce » (VEYne, Le Pain et le cirque, p. 348). Il est exact que les hommes publics aspirent surtout à des honores politiques fondés sur leur mérite, mais les bienfaiteurs reçoivent également des distinctions concrètes. Sur les honores rendus aux évergètes dans le monde grec, voir VeYne, Le Pain et le cirque, p. 268-272.

${ }^{49}$ Voir supra p. 279-280. 
désigne la vaillance militaire, mais Bibulus paraît s'être illustré dans une carrière plutôt civile. A. Tomassetti, en se fondant sur la position topographique du monument, va plus loin: le monumentum offert à Poplicius Bibulus est situé le long du cliuus Argentarius, près de l'intersection avec la via Lata, à la base du Capitole, à l'extérieur du mur servien, à une centaine de mètres au-delà de l'antique porta Fontinalis $^{50}$. La position des édifices funéraires n’est en général pas laissée au hasard: les tombes sont placées le long des routes, pour être bien visibles, et auprès de voies de communication qui sont en elles-mêmes significatives ${ }^{51}$. La position de l'édifice de Bibulus le long du cliuus Argentarius et à proximité du Macellum n'est donc peut-être pas fortuite: l'édile qu'était Bibulus s'est en effet occupé des activités commerciales et il est possible que le monument ait été placé là pour l'honorer après ses interventions dans ce secteur d'activité52. Si l'hypothèse est exacte, c'est pour ces services publics que Bibulus a été honoré, et la uirtus dont parle l'inscription recouvre alors des actions qui ne sont ni du domaine militaire ni du domaine moral. Tout se passe comme si la uirtus était invoquée de manière irrésistible dès lors qu'il y a honos et devenait susceptible de renvoyer aux réalités les plus diverses, y compris des beneficia civiques. L'honos fonctionne ici comme un phénomène économique de rétribution: il constitue un salaire de prestige pour des services concrets.

\subsubsection{Bilan: la matrice de ces comportements}

Quand l'origine d'une marque d'honneur ou la source de la considération peuvent être identifiées, on y découvre donc souvent des mérites militaires, moraux ou civiques, qui reposent sur des qualités spécifiques. Mais à quel titre ces qualités sont-elles honorées? L'expliquer en les identifiant comme des valeurs partagées par tous ne fait que déplacer le problème: il faut essayer de voir pourquoi elles ont été érigées comme valeurs. Pour ce faire, nous allons tâcher de discerner la matrice de ces conduites jugées dignes d'honneur. Les motifs d'honos

50 Tomassetti, «Un edificio antico »: "l'area era fuori dalle cosiddette mura Serviane, nel fondo della sella tra Quirinale e Campidoglio» (p.39). Voir aussi S. B. PlatNer et T. Ashby, A Topographical Dictionary of Ancient Rome, Oxford, Oxford University Press, 1929, p. 477; NASH, Bildlexikon zur Topographie des Antiken Rom, p. 319; A. Golfetto, "Das Grabmal des C. Publicius Bibulus in Rom », AW, 10 (4), 1979, p. 56-57 et G. LugLI, $I$ monumenti antichi di Roma e suburbio, Rome, G. Bardi, 1930, au vol. 1, p. 262.

${ }^{51}$ Le tombeau des Scipions était ainsi placé auprès de la via Appia, la route vers le monde hellénique de l'Italie du Sud, localisation bien en accord avec l'ouverture de la famille à l'hellénisme. Voir F. ZEVI, "Considerazioni sull'elogio di Scipione Barbato", Studi Miscellanei, 15, 1969-1970, p.63-73 et J.VAN SickLE, «The Elogia of the Cornelii Scipiones and the Origin of Epigram at Rome», $A J P h, 108$ (1), 1987, p.41-55, à la page 41.

52 Tomassetti, «Un edificio antico », p. 70. 
nous paraissent partager deux caractéristiques communes: ils témoignent, en profondeur, d'un souci de la collectivité, d'une part; ils ont un référent commun, le mos maiorum, d'autre part. Leur "valeur » est donc à la fois intrinsèque, par l'existence d'une qualité fondamentale, et extrinsèque, par la conformité à des normes morales ancestrales qui servent d'étalon.

La uirtus est apparue, sous ses différents aspects, comme une source majeure de l'honos. Or elle consiste presque toujours à se mettre au service de la res publica. C'est patent quand il s'agit de la vaillance guerrière qui implique de défendre la patrie. C'est aussi le cas de la vertu morale qui suppose de ne pas être, pour reprendre l'image du Trinummus, dans son lit avec son amica, mais au forum avec ses amis. Le souci de la collectivité s'exprime aussi quand la uirtus conduit à octroyer des bienfaits à sa cité. Cette uirtus source d'honos est caractéristique d'un mode de pensée holistique où l'individu s'efface derrière la collectivité. Le service du groupe est situé au cœur des motifs de l'honos et apparaît de manière très vive dans certains textes. C'est le cas d'un passage de la Rhétorique à Herennius qui donne un exemple de raisonnement utilisant l'expolition:

Etenim uehementer est iniquum uitam, quam a natura acceptam propter patriam conseruaueris, naturae cum cogat reddere, patriae cum roget non dare; et, cum possis cum summa uirtute et honore pro patria interire, malle per dedecus et ignauiam niuere.

«En effet il est totalement injuste, alors que l'on a reçu la vie de la nature, qu'on l'a conservée grâce à la patrie, de la rendre à la nature quand elle l'exige et de ne pas la donner à la patrie quand elle le demande; injuste aussi, quand on peut mourir pour la patrie avec le plus grand courage et le plus grand honneur, de préférer vivre dans le déshonneur et la lâcheté. »

(Rhet. Her. IV, 57 ; trad. Achard).

Il s'agit là d'un passage fictif de discours employé à titre illustratif et dont on peut donc penser qu'il reflète des représentations courantes. Or on y voit que c'est le fait de mourir pro patria, de sacrifier sa personne à l'entité collective, qui est l'incarnation de la plus grande uirtus et, consécutivement, du plus grand honos: le sommet du service de la cité est aussi le sommet de la uirtus et de l'honneur. Plus un comportement est utile à la collectivité, plus il est honoré. On retrouve ici un fonctionnement économique proche de la loi de l'offre et de la demande: plus une conduite est demandée par la collectivité, plus elle est payée cher en terme d'honneur ${ }^{53}$. C'est ce qui explique que l'octroi

\footnotetext{
${ }^{53}$ Pour une application de la loi de l'offre et de la demande au phénomène du prestige social, Goode, The Celebration of Heroes, p. 46-48. Le cas du sacrifice pour la patrie montre aussi que l'honorabilité se situe là où est la dépense la plus grande, celle de sa propre vie. Il y a une analogie entre le coût d'une conduite et son potentiel de prestige.
} 
d'honneurs pour des exploits accomplis dans un contexte de guerre civile soit si problématique. La quatorzième Philippique montre bien la difficulté: est-il possible de voter des supplications pour Octave et les consuls alors qu'ils ont affronté Antoine, un concitoyen, ce qui va à l'encontre de la définition de la uirtus et des motifs de l'honos comme préservation de la cité et de ses membres ? Devant l'impossibilité d'une telle résolution, Cicéron s'évertue dans son discours à montrer qu'Antoine n'est plus, précisément, un ciuis mais un hostis, ce qui rend possible le vote d'honores pour ses vainqueurs ${ }^{54}$.

Il faut à présent nous intéresser à la matrice extrinsèque des motifs d'honos. Si les qualités militaires, morales, sociales valent de l'honos parce qu'elles incarnent l'idéal du service de la république, il nous faut voir comment cet idéal est défini. L'honos est donné pour une conduite jugée excellente, mais quel est le référent, l'étalon de cette excellence? La dignitas de l'individu est jugée à l'aune de son respect du code de conduite qui régit la communauté, le mos maiorum, la «coutume des ancêtres $»^{55}$. Il s'agit d'un ensemble de règles coutumières et non juridiques $^{56}$, dont le contenu est défini par les vertus des maiores, les

Pour une analogie comparable entre coût et beauté, voir T. Veblen, Théorie de la classe de loisir, Paris, Gallimard, 1970, p. 84 sqq.

${ }^{54}$ CIc. Phil. XIV, 12. Les triomphes et les supplications ne pouvaient être octroyés que lorsque la victoire avait été remportée sur des ennemis extérieurs. Sur cette règle régissant les supplications, voir HaLKIN, La Supplication, p. 93. On connaît cependant une exception: César a obtenu une supplication en son nom pour sa victoire sur les fils de Pompée à Munda. Pour le triomphe, la règle est la même: la guerre doit avoir été menée contre l'étranger (Künzl, Der römische Triumph, p.30; Mommsen, DPR, vol. 1, p. 152). Elle a cependant été contournée à plusieurs reprises: Sylla triomphe par exemple en 81, officiellement sur Mithridate et les Samnites, mais en fait sur les Italiens après la guerre sociale (AULIARD, Victoires et triomphes à Rome, p. 53).

${ }^{55}$ Sur le mos maiorum, voir H. RecH, Mos maiorum. Wesen und Wirkung der Tradition in Rom, Diss., Marburg, 1936; J. SснміDт, Ethos. Beiträge zum antiken Wertempfinden, Leipzig, R. Noske, 1941, p. 35-59; Lind, «The Tradition of Roman Moral Conservatism », p.48-56; M.BetTinI, «Mos, mores und mos maiorum: Die Erfindung der 'Sittlichkeit' in der römischen Kultur", in Braun, M., Haltenhoff, A.et Mutschler, F.-H. (éds.), Moribus antiquis res stat Romana. Römische Werte und römische Literatur im 3. und 2. Jh. v. Chr., Munich, K. G. Saur, 2000, p. 303-352; W. BLöseL, "Von der Familientradition zum Nobilitätsethos. Die Geschichte des Begriffes mos maiorum von den Anfängen bis zu Cicero", in Linke, B. et Stemmler, M. (éd.), Mos maiorum. Untersuchungen zu den Formen der Identitätsstiftung und Stabilisierung in der römischen Republik, Stuttgart, F. Steiner, 2000, p. 25-97.

${ }^{56}$ Le mos est distinct du ius car il n'est pas écrit et ne tire sa valeur contraignante que du poids de la tradition. Voir les définitions anciennes du mos comme coutume ancestrale: Fest. 146, 3-5 et Isid. Orig. V, 3, 2. Voir aussi Rech, Mos maiorum, p. 9-10 et Betrini, "Mos, mores und mos maiorum». Sur la distinction entre mos et ius, voir BLösel, «Von der Familientradition zum Nobilitätsethos »; W. KunKeL, « Gesetzesrecht und Gewohnheitsrecht in der Verfassung der römischen Republik », Romanitas, 9, 1971, p. 357-375 ; J.BLEICKEN, Lex publica. Gesetz und Recht in der römischen Republik, Berlin, W. De Gruyter, 1975. 
ancêtres, qui ont été érigées en normes de conduite et sont illustrées par les récits concernant les héros de l'histoire romaine, constitués en exempla à imiter ${ }^{57}$. Le mos maiorum est un code de conduite qui a cours dans le domaine militaire, religieux et politique et qui est l'étalon grâce auquel les comportements des contemporains sont évalués. Mais il régit aussi pendant longtemps une bonne partie du droit pénal et de la vie politique et institutionnelle ${ }^{58}$. Son existence est perçue, dès le début du $\mathrm{II}^{\mathrm{e}}$ siècle, comme essentielle à la stabilité de la république bien qu'il ait cours surtout pour la nobilitas au sein de laquelle se comptent les maiores les plus illustres ${ }^{59}$. La grande majorité des comportements à la source de l'honos appartient précisément au code moral qu'est le mos maiorum. La uirtus, source privilégiée de l'honos, occupe une importance particulière au sein du mos maiorum. La vaillance au combat et le courage face au danger sont caractéristiques des Romains de l'ancien temps, tels qu'on les voit par exemple dans le récit historique de Tite Live. Chacun des trois héros qui se sont illustrés lors de la guerre contre Porsenna a fait preuve d'une grande uirtus : à propos d'Horatius Cocles, il est dit que grata erga tantam uirtutem ciuitas fuit ${ }^{60}$; Porsenna déclare à Mucius Scaevola qu'il admire ista uirtus ${ }^{61}$; quant à Clélie, il est fait mention de sa nouam uirtutem ${ }^{62}$. Cette uirtus donne lieu, dans chacun des trois cas, à des honores: Horatius Cocles reçoit une statue, un champ et des vivres; Mucius Scaevola est libéré par Porsenna; Clélie obtient une statue équestre. C'est donc parce que la uirtus est un trait essentiel du mos maiorum qu'elle permet d'obtenir l'honneur.

Des remarques similaires peuvent être faites pour les autres qualités à l'origine de l'honos. La fides est également une vertu exemplaire des ancêtres, comme on le voit dans la geste de Régulus au cours de la première guerre punique: fait prisonnier par les Carthaginois, puis envoyé par eux à Rome pour négocier un échange de captifs, il retourna, une fois sa mission accomplie, chez les ennemis bien qu'il dût y subir les pires supplices; il avait en effet donné sa parole qu'il

\footnotetext{
${ }^{57}$ Sur les vertus des maiores, LIND, «The Tradition of Roman Moral Conservatism », p. 51. Le mos maiorum est un réservoir d'exemples mais possède aussi une force contraignante, comme le signalent les expressions telles que mos maiorum postulat, uetat, praescribit (RECH, Mos maiorum, p. 15). Sur les exempla, voir infra p. 410 sqq.

${ }^{58}$ MEIER, Res publica amissa. Eine Studie zu Verfassung und Geschichte der späten römischen Republik, p. 54-57; HöLKESKAmp, Reconstruire une République, p. 20.

${ }^{59}$ La stabilité politique qu'apporte le mos maiorum est reflétée par le célèbre vers d'Ennius moribus antiquis res stat Romana uirisque (Annales, V, 1 Skutsch). Sur l'importance du mos maiorum pour la nobilitas, BLÖSEL, "Von der Familientradition zum Nobilitätsethos », p. 35.

${ }^{60}$ «La cité fut reconnaissante d'une si grande vaillance» (LIv. II, 10, 12).

${ }^{61}$ Liv. II, 12, 14.

${ }^{62}$ LIV. II, 13, 11.
} 
reviendrait, il avait engagé sa fides et respecta donc son engagement ${ }^{63}$. Cicéron présente ainsi la fin de son histoire:

Cum retinetur a propinquis et ab amicis, ad supplicium redire maluit quam fidem hosti datam fallere.

«Alors que ses proches et ses amis le retenaient, il préféra retourner vers le supplice plutôt que de manquer à la parole donnée à l'ennemi. »

(Cic. Off. I, 39; trad. Testard).

Ce respect de la fides, au péril de sa vie, manifeste toute la grandeur de Régulus et fait de lui un personnage exemplaire, incarnation de la fides Romana. Un autre ancêtre illustre, Camille, a déjà eu, bien avant la première guerre punique, l'occasion de se distinguer par sa fides: lors de la guerre de Rome contre Faléries, il fit renvoyer et battre de verges le maître d'école de la ville qui, trahissant sa patrie, venait lui livrer des enfants en otages. Les Falisques sont les premiers à reconnaître la noblesse du geste de Camille et la grandeur de la fides Romana ${ }^{64}$.

Tous ces exemples montrent combien les motifs qui valent l'obtention de l'honos sont étroitement liés à la morale traditionnelle de Rome et à l'image que les Romains se font d'eux-mêmes. Il arrive même que l'imitation des ancêtres soit directement présentée, en tant que telle, comme un motif d'honos. On le constate dans le Trinummus, quand l'esclave Stasime se plaint de la dégradation des mœurs:

ST.: Utinam ueteres homin<um mor>es, ueteres parsimoniae

Potius <in> maiore honore hic essent quam mores mali.

$C_{H .}$ : Di inmortales, basilica hicquidem facinora inceptat loqui;

Vetera quaerit, uetera amare hunc more maiorum scias.

«STASImE: Si seulement les mœurs d'autrefois, les économies d'autrefois

Étaient ici plus à l'honneur que les mauvaises mœurs!

CHARMidÈs: Dieux immortels, voilà qu'il entame un discours rempli de paroles divines;

Il cherche à retrouver le temps d'autrefois; c'est la preuve qu'il aime le temps d'autrefois, à la manière de nos ancêtres.

(PL. Trin. 1028-1032).

${ }^{63}$ C'est la version de Cicéron et Tite Live (Cic. Pis. 43; Fin. V, 82; Off. III, 99; Liv. Per. XXVIII, 43, 1; XXX, 30, 23) qui sont suivis par plusieurs auteurs postérieurs. Mais il est possible que l'histoire de Régulus ait été embellie: Diodore mentionne qu'il mourut en prison et que sa veuve vengea cette mort sur deux Carthaginois (DS. XXIV, 12; voir aussi GeLL. VII, 4). Sur Régulus comme modèle moral, voir M. GendRe et C. Loutsch, «C. Duilius et M.Atilius Regulus», in Coudry, M.et Späth, T. (éds.), L'Invention des grands hommes de la Rome ancienne, Paris, De Boccard, 2001, p.131-172.

${ }^{64}$ Liv. V, 27, 11. 
Il est possible que ce discours soit quelque peu parodique, dans la mesure où c'est un esclave, personnage traditionnellement peu regardant des normes morales, qui fait l'éloge des mœurs à l'ancienne. Mais s'il y a moquerie de la part de Plaute, la raillerie, pour avoir son sens, doit renvoyer à une réalité romaine de l'époque. Stasime regrette que l'honos ne soit plus adressé aux ueteres hominum mores ${ }^{65}$, c'est-à-dire que la conformité au mos maiorum ne soit plus un motif d'honneur. Cette déploration reflète une vision du monde conservatrice qui fait de la fidélité aux coutumes ancestrales la clef de la morale et le socle de $l^{\prime} h o n o s^{66}$.

\subsection{Statut et identité}

Le mérite qui provoque l'honneur peut être attaché à la personne de manière plus intime, en étant lié à l'identité profonde ou à la place occupée dans la société. C'est alors ce que l'individu est, plutôt que ce qu'il fait, qui est à la source de l'honos. La chose est d'importance, car cela signifie que les marques d'honneur ou la considération dont jouit un Romain peuvent lui être attachées d'office, sans action particulière, et être légitimement revendiquées sur la simple foi de son identité et de son rang.

\subsubsection{Identité sociale distinctive}

Dans le cadre de l'honos privé, les marques d'honneur peuvent être conférées en raison de l'identité spécifique de celui qui les reçoit et pour l'existence de liens sociaux entre les individus concernés. Quand le mari confère des honores à sa femme, l'honos se fonde sur l'identité de l'épouse et, à travers elle, sur le lien social du mariage qui impose aux deux parties certaines obligations ${ }^{67}$. L'honos peut aussi être adressé au frère ou à la sœur, ou encore au père ou au fils, et procède dans ce cas des liens du sang ${ }^{68}$. C'est aussi l'existence de liens sociaux qui motivent l'honos conféré par un Romain à un ami. En septembre 44, Cicéron écrit à Munatius Plancus et justifie son absence au sénat:

Meum studium honori tuo pro necessitudine nostra non defuisset, si aut tuto in senatum aut honeste uenire potuissem.

${ }^{65}$ Nous suivons la correction proposée par Lindemann; elle est nécessaire pour que le septénaire trochaïque soit complet, et nous paraît vraisemblable car le terme de mores est un vrai leitmotiv comique du passage.

${ }^{66}$ Ce mode de pensée se retrouve chez Cicéron, quand il souligne, dans le Pro Roscio Amerino, l'honos de Caecilia, la fille du Baléarique, qui reste attachée aux obligations de l'officium ancestral (CIc. Rosc. Amer. 27).

${ }^{67}$ PL. St. 48-50.

${ }^{68}$ Voir par exemple PL. Cist. 1-7 ou Cic. Quinct. 14. 
«Pour t'honorer, mon dévouement ne t'aurait pas fait défaut, en raison des liens qui nous unissent, si j’avais pu me rendre au sénat en sécurité et dans l'honneur.»

(CIc. Fam. X, 2, 1 ; trad. Beaujeu).

Cicéron se serait volontiers rendu au sénat pour rendre honneur à Munatius Plancus mais les circonstances, après la mort de César, ont été défavorables à sa venue. Il était cependant bien décidé à travailler à l'honos de Plancus en raison des liens étroits qui les unissent (pro necessitudine). C'est le lien social d'amitié qui conduit à des manifestations symboliques d'estime ${ }^{69}$. Pour expliquer ce qui l'a poussé à voter l'honos d'une supplication en l'honneur de Sulpicius Rufus, Cicéron mentionne explicitement l'amicitia qui les unit ${ }^{70}$. Cette marque d'honneur, déclare-t-il, fait partie des officia attendus de deux amis. L'honos relève donc ici des "bons offices", des devoirs qui s'imposent au sujet à l'égard de son entourage et qui peuvent prendre la forme de bienfaits $^{71}$. L'amicitia ne saurait prendre tout son sens sans l'existence entre les amis de prestations réciproques; soutenir un ami candidat, lui prêter assistance en justice font partie de ces obligations essentielles dont l'honos peut relever ${ }^{72}$. L'amicitia entre peuples donne aussi lieu à des honores de part et d'autre. Il en est plusieurs fois question dans les textes qui évoquent les alliances nouées par Rome aux IV et

${ }^{69}$ Voir aussi Cic. Att. XVI, 16a où la coniunctio de Cicéron et Plancus est le motif de l'honos. Dans les lettres où Cicéron recommande quelqu'un à un de ses amis, il lui demande souvent de faire bon accueil à la personne recommandée honoris mei causa, "pour [lui] faire honneur»; l'honos est justifié par les liens qui l'unissent au destinataire de la lettre (voir par exemple Fam. XIII, 27, 1; XIII, 31, 1 et XIII, 69, 2). L'amicitia romaine n'est pas une amitié éthérée et désintéressée. Même dans le Laelius, qui en donne une image assez idéalisée, Cicéron reconnaît que l'un des devoirs des amis est de s'aider dans leur carrière politique (Cıc. Lael. 73). Sur l'utilité, notamment politique, de l'amicitia, voir P. A. BRUNT, «Amicitia in the Late Roman Republic», PCPhS, 11, 1965, p. 1-20 et B. Fiore, "The Theory and Practice of Friendship in Cicero », in Fitzgerald, J.T.(éd.), Greco-Roman Perspectives on Friendship, Atlanta, Scholars Press, 1997, p.59-76. Sur les services réciproques des amici et sur le fonctionnement de l'amicitia en général, voir aussi J.Powell, "Friendship and its Problems in Greek and Roman Thought », in Innes, D., Hine, H. et Pelling, C. (éds.), Ethics and Rhetoric: Classical Essays for Donald Russell on his Seventy-fifth Birthday, Oxford, Clarendon Press, 1995, p.31-45.

${ }^{70}$ Fam. XIII, 77, 1.

${ }^{71}$ Sur l'aspect social de l'officium, voir F. CANCELLI, « Saggio sul concetto di officium in diritto romano ", RISG, 1957-1958, p. 351-402 et B.F. SCHERER, "Metamorphosis of Officium. Late Roman Republic to Early empire», $C B, 41,1964$, p. 1-4. Sur la place des bienfaits dans l'officium, voir les passages que consacre Cicéron aux bienfaits dans le $D e$ officiis (Cic. Off. I, 14-17 et 42-60). Voir aussi CANCELLI, "Saggio sul concetto di officium in diritto romano ", p. 356 et Hellegouarc'H, Vocabulaire, p. 153 sqq.

${ }^{72}$ Sur les bons offices propres à l'amicitia, voir Cic. Brut. 245; Mur. 86; Cato mai. 49. Voir aussi sur ce point CANCELLI, «Saggio sul concetto di officium in diritto romano", p. 359-360; Тноме, Zentrale Wertvorstellungen der Römer, vol. 1, p. 108 sqq. 
III ${ }^{\mathrm{e}}$ siècles de la République, comme dans ce discours des Campaniens devant le sénat romain rapporté par Tite Live:

Neque hercule, quod Samnites priores amici sociique uobis facti sunt, ad id ualere arbitror ne nos in amicitiam accipiamur, sed ut ii uetustate et gradu honoris nos praestent; neque enim foedere Samnitium, ne qua noua iungeretis foedera, cautum est.

«Et, par Hercule, l'antériorité de l'amitié et de l'alliance que les Samnites ont nouées avec vous n'est pas, à mon avis, raison valable pour nous refuser votre amitié: elle leur donne seulement sur nous l'avantage de l'ancienneté et du degré d'honneur; et en effet le traité avec les Samnites ne stipule pas qu'il vous est interdit de conclure de nouvelles alliances. »

(Liv. VII, 30, 4 ; trad. Bloch).

Les Samnites ont attaqué les Sidicins puis les Campaniens qui viennent demander l'aide des Romains: ils souhaitent rentrer dans leur amicitia. Cette amicitia relève davantage de la diplomatie que de l'amitié telle que nous la comprenons: il s'agit d'une des formes d'alliance reconnues par le droit international romain. Elle donne cependant lieu, tout comme l'amitié entre particuliers, à des honneurs: les Samnites, qui sont déjà dans une relation d'amicitia avec les Romains, bénéficient de ce fait d'un plus important gradus honoris que les Campaniens: ils sont placés plus haut sur l'échelle romaine du prestige. L'honos est donc ici aussi en rapport avec l'amicitia, mais sur une modalité beaucoup plus pragmatique: plutôt qu'une position de prestige, il désigne une situation diplomatiquement privilégiée assurant un comportement neutre de la part des Romains ${ }^{73}$.

Après le membre de la famille et l'ami, l'hôte est la dernière des identités sociales à constituer en soi un motif d'honos: l'hospitium priuatum, intervenant entre un citoyen et un étranger contraint en effet à recevoir son hospes lorsqu'il voyage loin de sa demeure, à lui procurer logement et repas, à le protéger et éventuellement à l'assister juridiquement si quelqu'un lui intente un procès ${ }^{74}$. Comme dans le cas des époux ou des amis, c'est donc un lien social, l'hospitium, qui est à la source de l'honos. Pour les Romains, en effet, l'hospitium unit étroitement deux personnes et ce lien est symbolisé par l'échange des tesserae hospitales, un objet séparé en deux fragments qui se rejoi-

${ }^{73} \mathrm{Il}$ semblerait que l'amicitia n'obligeait pas les contractants à une assistance militaire mutuelle (Lrv. XLV, 25). Sur l'amicitia diplomatique, voir l'étude de P.J.Burton, Amicitia in Roman Social and International Relations (350-146 B.C.), Ph. D., University of Maryland, College Park, 2000. Pour un autre exemple d'une "amitié» de ce genre impliquant des honores de la part de Rome, voir Liv. XXVI, 24, 4 où M. Valerius Laevinus promet des honores aux Étoliens s'ils rentrent dans l'amicitia romaine.

${ }^{74}$ Sur ces aspects de l'hospitium, voir Pl. Pers. 512; Cic. Diu. Caec. 41 et 66; CaEs. BG. I, 47. 
gnent parfaitement ${ }^{75}$. Ce rôle joué par l'association des deux hospites dans l'émergence de l'honneur est également visible chez Ennius, à la faveur de l'explication qu'il donne, dans l'Évhémère, de l'apparition des temples consacrés à Jupiter:

Nam cum terras circumiret, ut in quamque regionem uenerat, reges principesue populorum hospitio sibi et amicitia copulabat et cum a quoque digrederetur iubebat sibi fanum creari hospitis sui nomine, quasi ut posset amicitiae ac foederis memoria conseruari. Sic constituta sunt templa Ioui Ataburio, Ioui Labryandio [...]. Quod ille astutissime excogitauit, ut et sibi honorem diuinum et hospitibus suis perpetuum nomen adquireret cum religione coniunctum.

\begin{abstract}
"Car lorsqu'il parcourait la terre, dans chaque pays où il était venu, il s'associait les rois ou les princes de ces peuples par des liens d'hospitalité et d'amitié et, chaque fois qu'il les quittait, il ordonnait qu'un sanctuaire lui fût élevé au nom de leurs liens d'hospitalité, comme s'il avait l'intention de conserver le souvenir de leur amitié et de leur alliance. C'est ainsi que furent édifiés des temples à Jupiter Ataburien, à Jupiter Labryandien [...]. Et ce procédé qu'il imagina était très astucieux car il procurait un honneur divin à lui-même et à ses hôtes un nom éternellement lié à la religion.»
\end{abstract}

(EnN. Evh. frg. X Vahlen; nous soulignons).

Ce texte, qui raconte comment Jupiter, à l'occasion de visites auprès de souverains, les a convaincus de construire des temples en son nom, montre sur quelles bases s'est développé l'honos divin. Ce prestige, rendu visible par des temples, procède de l'amicitia et de l'hospitium qui unissaient Jupiter aux peuples qu'il a fréquentés: c'est hospitis sui nomine, au nom de leurs liens d'hospitalité, que les édifices religieux, forme alors inédite d'honos, ont été bâtis. L'honos émerge donc d'un processus de singularisation sociale, établi à travers différents liens (familiaux, amicaux, d'hospitalité) entre des égaux.

\title{
2.2.2. Statut social supérieur
}

La nature fortement hiérarchisée de la société romaine nous invite cependant à interroger l'existence, au-delà des marques d'honneur échangées entre égaux, d'un prestige qui s'appuierait sur l'ascendant social qu'un individu peut avoir sur les autres. Il s'agit, ici encore, de conférer l'honos en vertu d'une identité sociale spécifique, mais dont la spécificité est liée au rang, à la position "verticale» dans la société, et non à une relation privilégiée et «horizontale» avec ses semblables. Trois statuts supérieurs donnent accès à l'honos: le fait d'être un dominus, un patronus ou un homme âgé.

Le dominus jouit d'une position supérieure et privilégiée dans la domus, consacrée par la coutume mais aussi par la loi: il détient la

${ }^{75} \mathrm{Il}$ en est question à plusieurs reprises chez Plaute dans le Poenulus, v. 958 et 1047. Sur ces tesserae, voir DAGR III, 1, p. 298. 
potestas qui lui permet d'exercer un pouvoir fort sur les habitants de sa demeure, épouse, enfants et esclaves ${ }^{76}$. Ces derniers apparaissent dans les textes comme les principaux donateurs de l'honos au dominus. Dans le Stichus, le seruus Pinacion déclare ainsi agir au profit de son maître honoris causa, pour lui faire honneur et lui montrer ainsi son dévouement ${ }^{77}$. Dans d'autres cas, on assiste à une inversion comique de ce rapport entre maître et esclave puisque le seruus s'emploie à flouer le vieux dominus qui devrait avoir autorité sur lui ${ }^{78}$. Ce jeu avec une convention est symptomatique d'une différence de position génératrice d'honos en temps habituel. Il arrive d'ailleurs, et cela dans les pièces de Plaute elles-mêmes, que l'honos de l'esclave à son maître soit pris très au sérieux, comme c'est le cas dans les Captifs. Philocrate, avant d'échanger son rôle avec celui de son serviteur Tyndare, lui adresse ces ultimes recommandations:

Per fortunam incertam et per mei te erga bonitatem patris,

Perque conseruitium commune quod hostica euenit manu

Ne me secus honore honestes quam quom seruibas mihi,

Atque ut qui fueris et qui nunc sis meminisse ut memineris.

«Par la fortune capricieuse et par la bonté que mon père t'a manifestée,

Par la servitude commune où le bras de l'ennemi nous a placés,

$\mathrm{Ne}$ va pas m'honorer par moins d'honneurs que lorsque tu étais à mon service,

Et qui tu as été et qui tu es à présent, fais en sorte de t'en souvenir, de ne pas l'oublier.»

(PL. Cap. 245-248).

Sur un ton solennel, Philocrate demande à Tyndare de continuer à l'honorer (honestare) malgré l'échange apparent de leurs positions sociales, de persister à respecter le statut du maître et de se souvenir qu'il n'est en réalité qu'un esclave. Le dernier vers où Philocrate demande à Tyndare de ne pas oublier qui il est suggère bien que l'identité est, ici encore, fondatrice. Ce qui motive et justifie l'honos, c'est ce qu'est le dominus pour l'esclave, c'est-à-dire un homme libre, supérieur en tant que tel au seruus. Il y a aussi à la source de cet honos un lien social, comme pour les époux ou les hôtes, mais qui est ici diffé-

76 Sur la patria potestas, voir l'article d'E.SACHERs, "Potestas patria» (RE XXII, 1, col. 1046-1175); W.K. Lacey, "Patria potestas", in Rawson, B. (éd.), The Family in Ancient Rome: New Perspectives, Londres, 1986, p.121-144; Y. Thomas, "Vitae necisque potestas. Le père, la cité, la mort "Du châtiment dans la cité. Supplices corporels et peine de mort dans le monde antique, Paris, De Boccard, 1984, p.499-548 et l'analyse nuancée de Saller, R.P., Patriarchy, Property and Death in the Roman Family, Cambridge, Cambridge University Press, 1994, p. 102-132.

77 PL. St. 337-338. Il est de même question, dans le Miles Gloriosus, d'un seruus inventant des stratagèmes au profit de son maître honoris gratia (Mil. 617).

${ }^{78}$ Sur l'inversion du fonctionnement de l'honos sur la scène de la comédie, voir le chapitre 12 . 
rent puisqu'il instaure une supériorité de l'un sur l'autre: c'est un lien de propriété d'abord, puisque l'esclave fait partie des res mancipi au même titre que les autres possessions; c'est un lien de pouvoir ensuite car le maître peut traiter l'esclave comme bon lui semble.

Le patronus, qui accorde sa protection ou des biens matériels à ses clients, bénéficie lui aussi par son statut de l'honos ${ }^{79}$. Dans sa défense de Roscius d'Amérie, Cicéron représente par une puissante hypotypose la scène du crime commis par Glaucia au profit de Roscius Magnus et Roscius Capito. Il souligne que l'empressement pris par Glaucia à commettre le meurtre et à venir le rapporter aux commanditaires s'explique par la volonté de Glaucia d'accorder un honos à ces derniers. Or Glaucia est le cliens de T. Roscius: l'honos apparaît ainsi motivé par le lien de clientèle entre ces hommes ${ }^{80}$. C'est aussi cette volonté d'honorer un patron que l'on décèle quand des collectivités locales décernent une statue à leur protecteur ${ }^{81}$. Il est notable que, dans ce cas de figure, comme quand une marque d'honneur est donnée par un esclave à son maître, l'honos est beaucoup moins libre que lorsqu'il est octroyé pour des mérites moraux ou militaires car celui qui le donne est dans une situation de dépendance et d'infériorité.

Une dernière caractéristique relevant du statut social permet de prétendre légitimement à l'honos de la part de son entourage: il s'agit de l'âge. Les personnes âgées font en effet à Rome l'objet d'un respect particulier $^{82}$. Nous avons vu à propos du Cato maior de Cicéron que différents gestes d'estime devaient être octroyés aux anciens ${ }^{83}$. Il n'est pas besoin d'ailleurs d'être un vieillard pour avoir droit à des honores: il suffit de l'emporter sur son entourage du point de vue de l'âge. Dans sa description du camp pompéien, César montre les chefs préoccupés, avant la bataille, de se partager les dépouilles de leur ennemi qu'ils imaginent déjà vaincu:

Iam de sacerdotio Caesaris Domitius, Scipio Spintherque Lentulus cotidianis contentionibus ad grauissimas uerborum contumelias palam descenderunt, cum Lentulus aetatis honorem ostentaret, [...].

\footnotetext{
${ }^{79}$ Sur les bienfaits et devoirs réciproques du patron et de ses clients, voir NicoLET, Rome et la conquête, p. 233 sqq.

${ }^{80}$ Cic. Rosc. Amer. 96.

${ }^{81}$ Voir par exemple la statue octroyée par les habitants de Thourioi à C. Aelius (PLIN. NH XXXIV, 32). Pour d'autres exemples, LaHusEN, Untersuchungen zur Ehrenstatue in Rom, p. 84 sqq.

${ }_{82}$ Sur le statut de la vieillesse à Rome, voir B. BAKноuche (éd.), L'Ancienneté chez les anciens, Montpellier, Université de Montpellier III, 2003 et U. Mattioli (éd.), Senectus. La vecchiaia nel mondo classico, Bologne, Pàtron, 1995.

${ }^{83}$ Voir supra p. 264 (Crc. Cato mai. 63). Cicéron précise cependant que ces derniers doivent se conformer au rôle social qui est le leur pour mériter pleinement les marques d'honneur (Cato mai. 38).
} 
«Bientôt, à propos du sacerdoce de César, Domitius, Scipion et Lentulus Spinther, dans des discussions journalières, en arrivèrent à échanger publiquement les plus graves insultes, Lentulus faisant valoir l'honneur dû à son âge, [...]. »

(CAES. BC III, 83, 1; trad. Fabre modifiée).

Les pompéiens espèrent chacun pouvoir obtenir, après leur victoire, le sacerdoce de César, c'est-à-dire le grand pontificat, et se disputent pour savoir lequel d'entre eux pourra l'exercer. Lentulus Spinther fait valoir qu'il est plus âgé que les autres, ce qui lui donne certaines prérogatives. On remarque d'ailleurs, plus généralement, que le prestige se constitue progressivement, au cours d'un processus temporel pouvant être très étendu. L'homme âgé a plus de prestige que le jeune car il a pu, au cours de sa vie, accumuler les marques d'honneur. Cette sédimentation temporelle des honores accroît la considération et donne droit à de nouvelles distinctions. Il existe cependant des cas de figure où des marques d'honneur sont octroyées par des personnes âgées à des jeunes. Il est ainsi question, dans une lettre de Cicéron, des honores que le propréteur P.Silius a octroyé à Ti. Claudius Nero qui est plus jeune que lui ${ }^{84}$. Une telle situation s'explique en réalité par la complexité des protagonistes de l'hommage: à travers Claudius Nero, c'est en fait Cicéron qui est visé par les hommages de P. Silius car c'est l'Arpinate qui a recommandé le jeune homme à P. Silius et en a fait son protégé. En outre, Nero est un nobilis et a de bonnes chances d'accéder à un statut élevé dans l'avenir; il possède donc une quantité virtuelle d'honos qui ne demande qu'à être actualisée par un tiers ${ }^{85}$. L'honos est ainsi donné à un jeune homme parce qu'il est protégé par un autre individu d'âge mûr et parce qu'il est fortement prometteur. Un second cas d'honos conféré par quelqu'un à plus jeune que lui concerne Cicéron et Octave. Cicéron a en effet œuvré en 43 à ce que des honores importants soient octroyés à Octave. À Brutus qui le blâme de ce manque de mesure, Cicéron répond en invoquant la nécessité de ces marques d'honneur pour essayer d'attacher Octave au camp du sénat et de stabiliser ainsi la res publica ${ }^{86}$. Octave est encore un puer, comme l'écrit Cicéron, et ces marques d'honneur sont donc exceptionnelles: elles sont un moyen de salut public en une période très troublée. L'octroi d'un honos à un tout jeune homme reste donc un geste très particulier, qui s'explique par la destruction des cadres traditionnels de la pratique politique romaine ${ }^{87}$.

${ }^{84}$ CIc. Fam. XIII, 64, 1.

${ }^{85}$ Cic. Fam. XIII, 64, 2 évoque les clientèles de ses ancêtres qui seront consolidées par ses soins.

${ }^{86}$ Cic. Ad Brut. I, 15, 3.

${ }^{87}$ Le dernier exemple d'un honos conféré par un homme âgé à plus jeune que lui se rencontre dans un contexte lui aussi très particulier, puisqu'il s'agit d'une comédie de Plaute où un père honore son fils (PL. As. 81). Ici encore, ce type d'honos est un cas limite, situé en dehors du quotidien, dans le temps du spectacle et des ludi. 


\subsubsection{Statut civique et politique supérieur}

La supériorité sociale qui donne droit à l'honos doit être distinguée de la supériorité civique qui confère aussi de la dignitas en raison de l'exercice de certaines fonctions au sein de la cité ou de l'appartenance à un ordo. Il y a en effet à Rome une hiérarchie civique qui redouble la hiérarchie sociale et peut se confondre avec elle. Le fait d'être citoyen donne ainsi droit à certains égards auxquels les non-citoyens ne peuvent prétendre. Parlant des marchands romains qui ont été maltraités puis exécutés à l'instigation de Verrès, Cicéron s'exclame:

[...] ut qui usque ex ultima Syria atque Aegypto nauigarent, qui apud barbaros propter togae nomen in honore aliquo fuissent, qui ex praedonum insidiis, qui ex tempestatum periculis profugissent, in Sicilia securi ferirentur, cum se iam domum uenisse arbitrarentur?

«[...] au point que ceux qui débarquaient du fin fond de la Syrie et de l'Égypte, qui avaient joui de quelque honneur chez les barbares en raison du renom de la toge, qui avaient échappé aux embuscades des pirates et aux dangers des tempêtes, étaient frappés de la hache en Sicile, alors qu'ils pensaient être enfin rentrés chez eux?»

(CIc. Verr. II, V, 157).

La citoyenneté, représentée symboliquement par la toge, permet à ceux qui la possèdent de bénéficier d'honos chez des peuples étrangers, les Syriens et les Égyptiens. La ciuitas impose le respect à ces barbari de même qu'elle donne droit à des égards particuliers à Rome, tels que la possibilité de participer à la vie politique, d'être candidat aux charges publiques ou de faire appel au peuple contre l'action coercitive d'un magistrat (prouocatio); la citoyenneté protège ainsi de l'arbitraire et offre des garanties judiciaires ${ }^{88}$. Ce sont ces garanties que Verrès n'a pas respectées en faisant emprisonner puis exécuter des citoyens romains, se montrant ainsi plus barbare que des barbari. La citoyenneté ne constitue cependant que la plus modeste des catégories politiques prestigieuses car le statut de magistrat donne droit à de plus grands honores. Lorsqu'un citoyen se trouvait en présence d'un magistrat, il lui fallait par exemple se lever ${ }^{89}$. L'appartenance au sénat est également un motif récurrent d'honos, fondé sur l'appartenance à un groupe au statut particulier au sein de la citég0.

${ }^{88}$ Selon la tradition, la prouocatio ad populum remonterait à l'époque royale (Liv. I, 26, 6). Ce droit a été régulièrement réaffirmé et précisé. Une lex Valeria de 300 interdisait notamment la mise à mort d'un citoyen romain s'il avait fait usage de son droit de prouocatio (LIv. III, 55, 4); une des leges Porciae du II siècle aurait interdit la flagellation des citoyens (Liv. X, 9, 6; Cic. Rab. Perd. 12). Voir Gaudemet, Institutions de l'Antiquité, p. 320-323; A. LintotT, "Prouocatio. From the Struggle of the Orders to the Principate», ANRW, I, 2, 1972, p. 226-267 et Ducos, Les Romains et la loi, p. 71-79.

${ }^{89}$ Liv. IX, 46, 9. Voir Mommsen, DPR vol. II, p. 31.

${ }^{90}$ Cicéron montre comment Verrès a bafoué l'honos dû au sénat (Cic. Verr. II, III, 


\subsubsection{Statut sacré}

Dans la religion romaine, les dieux vivent avec les hommes, et non dans un monde à part qui leur est propre, mais ils occupent les sommets de cette communauté. Et c'est cette supériorité qui leur donne le droit de recevoir les hommages des hommes:

Domi cum auspicamus, honorem me dium immortalium uelim habuisse. Serui, ancillae, si quis eorum sub centone crepuit, quod ego non sensi, nullum mihi uitium facit. Si cui ibidem seruo aut ancillae dormienti euenit, quod comitia prohibere solet, ne is quidem mihi uitium facit.

«Quand je prends les auspices domestiques, je voudrais honorer les dieux immortels. Si l'un des esclaves ou l'une des servantes laisse échapper un bruit sous sa tunique sans que je m'en aperçoive, il n'y a là pour moi nulle irrégularité. Et s'il arrive là-même à un esclave ou une servante pendant leur sommeil quelque chose qui, habituellement, interdit la tenue des comices, il n'y a pas là non plus d'irrégularité pour moi.»

(CAT. frg. XII, 73 ORF).

L'honos évoqué par Caton paraît être un rite d'auspicium nocturne où le silence est essentiel ${ }^{91}$. Cette prise d'auspices domestiques donne lieu à l'octroi aux dieux d'un honos, et ce dernier ne répond qu'à la nature des destinataires, les «dieux immortels ». Cet honos est récurrent car lié à un rituel qui rythme la vie de la domus, ce qui indique bien qu'il n'est pas appelé par une conduite précise de la part de celui qui le reçoit, mais par son rang de divinité.

Le statut des morts est, comme celui des dieux, spécifique, et appelle de ce fait des honneurs. À sa mort, le défunt rejoint en effet les rangs des Dieux Mânes, il n'appartient plus à la communauté des vivants mais revêt une nouvelle identité, sacrée. C'est ce nouveau statut qui justifie qu'on lui octroie des honneurs comme les funérailles puis les rites funéraires réguliers ${ }^{92}$. La mort appelle de façon particulièrement impérieuse l'honos de la sépulture afin que l'âme du défunt trouve le repos et ne connaisse pas l'errance ${ }^{93}$. Le simple fait de

96-97). Voir aussi Cic. Leg. III, 19 où Quintus Cicéron reproche aux tribuns de la plèbe d'avoir voulu arracher l'honneur des sénateurs.

${ }^{91}$ La prise des auspices n'est pas réservée aux magistrats: elle peut être faite par le paterfamilias, qui est lui aussi, à l'échelle de la domus, prêtre et chef de culte.

${ }^{92}$ Comme ceux de la fête des Parentalia, où la famille faisait un sacrifice auprès de la tombe du mort, sur le sol. Sur les rites funèbres autres que ceux des funérailles ellesmêmes, ScHeId, Quand faire c'est croire, p. 165-188.

${ }^{93}$ Les défunts qui n'étaient pas honorés par des funérailles appropriées devenaient des lémures, esprits errants dangereux pour les vivants. Il est remarquable que même ces défunts frustrés de l'honos suprême reçoivent tout de même une forme de marque d'honneur, montrant par là que leur identité de morts l'exige, puisqu'ils sont honorés et simultanément exorcisés lors de la fête des Lemuria; voir la description qu'en donne Ovide dans Fastes, V, 419 sqq. Sur la nécessité des rites funéraires, voir Cic. Inu. I, 108. 
quitter les rangs des vivants, d'avoir cette nouvelle identité de mort, est un motif suffisant de l'honos. Les inscriptions funéraires évoquent certes parfois les actions méritoires du mort mais ces motifs ne nous paraissent pas essentiels pour expliquer l'honos. Les qualités mentionnées par l'épitaphe de Bibulus ${ }^{94}$ n'expliquent que le caractère remarquable du monument qui lui est consacré; elles ne sont pas à l'origine de la décision de lui octroyer des funérailles. C'est donc sur la base d'un statut différencié et supérieur que l'honos est octroyé. Le cas de Bibulus montre cependant que des motifs de nature différente peuvent se combiner pour donner naissance à l'honos. Le monumentum offert à Bibulus découle ainsi de trois sources, une qualité (la uirtus), associée à un bienfait (envers les commerçants), et à un statut (celui de défunt).

\subsubsection{Bilan: la matrice de ces statuts}

Toutes ces sources d'honos possèdent deux caractéristiques: elles reposent sur des liens sociaux qui sont, d'une part, essentiels à la stabilité de la collectivité et, d'autre part, valorisés par la tradition. On retrouve ainsi, mutatis mutandis, deux traits identifiés à propos des comportements sources d'honneur, à savoir le souci de la communauté et l'adéquation au mos maiorum. En premier lieu, l'honos est octroyé en vertu de rapports d'égalité ou de supériorité qui sont au cœur de la structure civique et contribuent à son équilibre. L'honneur décerné aux dieux relève d'un lien contractuel entre hommes et divinités, ce qu'est proprement pour les Anciens la religio, substantif rattaché à religare, "relier ${ }^{95}$. Ce lien puissant entre hommes et dieux doit être cultivé par les rites et sa préservation permet la stabilité de la cité. Il en va de même pour l'honos décerné aux défunts: il serait dangereux pour la cité de ne pas honorer les morts car ces derniers pourraient devenir malfaisants. Les honores décernés à l'hôte ou au patronus procèdent aussi de l'observation de liens sociaux qui créent des solidarités au sein de la cité et unissent des individus de statut très différent.

En second lieu, l'honos accordé à ces statuts procède de l'observation scrupuleuse de valeurs du mos maiorum. Si le statut de dominus ou de père de famille provoque l'honos, c'est en vertu de la potestas détenue par ces derniers. Il en va de même pour l'honos des magistrats supérieurs fondé sur leur imperium, ou des égards dus au patron en

${ }^{94}$ Voir supra p. 279.

${ }^{95}$ Étymologie mise en avant par LACT. Inst. IV, 28, 2 et SERV. Aen. VIII, 349. D'autres auteurs rattachent le mot à relegere, "contrôler, reprendre" (CIC. ND II, 72). Voir DELL p. 569. Pour une analyse sémantique de religio, Тноме, Zentrale Wertvorstellungen der Römer, vol. 2, p. 4-28. 
vertu de la fides que le client doit lui témoigner. Quant aux honneurs octroyés aux dieux et aux défunts, c'est la pietas, caractéristique de l'excellence romaine aux yeux des Romains eux-mêmes, qui se situe en leur cœur. Quand l'honos s'appuie sur l'identité sociale ou le statut, il persiste à trouver sa source dans la conformité au mos maiorum. Mais il y a une différence de taille avec l'honos appelé par un comportement: c'est cette fois la conformité du destinateur à la coutume sociale et morale, et non plus celle du destinataire, qui explique l'honos. Le respect pour l'hospitium, l'amicitia, la fides, la pietas est à la source du geste de celui qui honore.

C'est ce qui explique que les contraintes qui s'exercent sur l'honos soient plus fortes que lorsqu'il repose sur un comportement valorisé. L'honos adressé aux défunts se fonde sur le respect d'une règle sacrée: tout mort doit être enterré conformément aux rites funèbres sans quoi il devient dangereux pour la communauté. Il en va de même pour l'honos aux dieux qui fait partie d'un rite qui doit être observé. Dans d'autres cas, l'honos est lié à des contraintes non seulement religieuses mais aussi juridiques. Ce peut être le cas des marques d'honneur accordées à un hôte par exemple: l'hospitium est un lien religieux, placé sous la protection de Jupiter hospitalis, et dont la violation est considérée comme un crime ${ }^{96}$. Mais l'hospitium tombe aussi dans le domaine du droit privé et des contraintes légales. On voit en effet chez Tite Live que l'hospitalité relève des priuata iura, que sa nature est contractuelle, et qu'il n'est possible de se défaire de ces engagements que par un acte précis, celui de la renuntiatio ${ }^{97}$. Le recours à la poignée de main ${ }^{98}$, qui scelle un accord tout en le plaçant sous le regard de la divinité Fides ${ }^{99}$, est également symptomatique de cette double nature juridique et religieuse de l'hospitium. Le mariage crée lui aussi des liens de nature juridique entre les époux: le matrimonium est régi par le droit privé, et l'une des étapes importantes de la cérémonie est la signature des tablettes de mariage, devant des témoins. Les implications juridiques et contractuelles du matrimonium imposent donc elles aussi des témoignages d'attention et d'estime entre les conjoints. Dans une certaine mesure, les honores de l'esclave à son maître, appelés par la potestas de ce dernier, répondent également à des contraintes juridiques, puisque le statut de l'esclave est réglé par le dominium, le droit de propriété du maître.

Les différentes sources d'honneurs liées au statut ne sont plus de l'ordre du «capital moral» que nous avions précédemment observé mais constituent un capital social, au sens large du terme: c'est le

${ }^{96}$ Voir Cic. Verr. II, 4, 22 et Ov. Met. X, 224.

${ }^{97}$ Tout ce vocabulaire apparaît dans Liv. XXV, 18.

${ }^{98}$ Attesté par Cic. Deiot. 8 et VERg. Aen. III, 83.

${ }^{99}$ Sur la valeur de la poignée de main et le rapport entre dextram dare et fidem dare, voir Freyburger, Fides, p. 136 sqq. 
statut social et identitaire qui provoque la reconnaissance de la collectivité et permet le développement d'un capital symbolique de prestige. Il faut noter, au terme de cette typologie des motifs d'honos, que la richesse, si elle peut faciliter, comme on va le voir, l'accès à l'honos, n'est pas en soi un motif de prestige. Le capital économique n'est pas, comme c'est le cas dans d'autres sociétés, un moyen direct de constitution d'un capital symbolique ${ }^{100}$.

\section{OUVERTURE OU FERMETURE DE L'ACCÈs À L'HONOS?}

Identifier les sources d'honos ne nous donne qu'une vision partielle de l'accès à l'honos: il nous reste à nous interroger sur les conditions pratiques de cet accès, sur les obstacles rencontrés, sur les privilèges existant en ce domaine. La présence d'un mérite ne suffit pas en effet à gagner immédiatement un honneur. Cela doit nous amener à reconsidérer la nature de la dignitas en rapport avec l'honos: la notion désigne bien le mérite, mais renvoie aussi à un rang social qui entre en ligne de compte dans l'obtention de l'honos. Il n'est pas certain, en effet, que tout Romain méritant puisse facilement se procurer l'honos. L'accès à ce dernier est-il ouvert à tous ou restreint?

\subsection{L'accès privilégié de l'aristocratie}

L'observation de l'identité des Romains qui parviennent à obtenir des honores ou à se distinguer par une situation de prestige montre une nette prééminence en ce domaine de l'aristocratie. Nous désignons de ce terme les membres des grandes familles romaines qui possèdent des moyens importants en termes d'argent et de clientèle et exercent souvent des charges publiques telles que les prêtrises ou les magistratures. La nobilitas, qui constitue l'élite de cette aristocratie, exerce une emprise particulière sur les différentes marques d'honneur ${ }^{101}$. Les études statistiques et prosopographiques fournissent des renseignements importants sur ce sujet mais nous nous intéresserons surtout à la représentation que se font les Romains de cette mainmise de l'aristocratie sur l'honos plutôt qu'à ses modalités concrètes.

${ }^{100}$ L'échelle du prestige n'est donc pas à Rome isomorphe de celle de la fortune, comme certains sociologues et anthropologues l'ont montré à propos d'autres sociétés. Sur les théories matérialistes du prestige, voir НАтсн, «Theories of Social Honor ». Sur les cultures où la fortune est un critère d'honneur important, voir CAMPBELL, Honour, Family and Patronage; A.A.M.ZEID, "Honour and Shame Among the Bedouins of Egypt », in Peristiany, J.G.(éd.), Honour and Shame. The Values of Mediterranean Society, Londres, Weidenfeld \& Nicolson, 1966, p. 243-259.

${ }^{101}$ Pour notre conception de la nobilitas, voir supra p. 294-295. 


\subsubsection{Le prestige comme bien propre de l'aristocratie}

L'honos comme «considération » est conçu comme un bien appartenant principalement à l'aristocratie. Si on peut gagner l'honos par différents moyens, comme l'excellence militaire, morale ou civique, cet honneur est, dans les faits, perçu comme attaché aux grandes familles de Rome. Dans le Pro Roscio Amerino, Cicéron se défend, à la fin de la «confirmation » de son discours, de s'en prendre à la noblesse en défendant Roscius contre un affranchi de Sylla. Il approuve au contraire la victoire passée de la nobilitas lors de la guerre civile:

Quo in certamine perditi ciuis erat non se ad eos iungere quibus incolumibus et domi dignitas et foris auctoritas retineretur. Quae perfecta esse et suum cuique honorem et gradum redditum gaudeo, iudices, uehementerque laetor, eaque omnia deorum uoluntate, studio populi Romani, consilio et imperio et felicitate L. Sullae gesta esse intellego.

«Dans ce combat, c'était faire acte de citoyen pervers que de ne pas se joindre à ceux dont le salut assurait la dignité de la république à l'intérieur et son autorité au dehors. C'est ce qui a été réalisé et chacun a retrouvé son honneur et son rang; je m'en réjouis, juges, j'en suis profondément heureux, et je me rends compte que tous ces résultats sont dus à la volonté des dieux, au zèle du peuple romain, à la sagesse, à l'autorité et au bonheur de L. Sylla.»

(Cic. Rosc. Amer. 136; trad. De La Ville de Mirmont modifiée).

Cicéron déclare avoir soutenu le parti de la noblesse parce que son succès permettait de rétablir la stabilité et la dignité de la république. Mais le texte montre aussi que le retour à l'ordre assuré par Sylla a permis de rendre à chacun suum honorem et gradum. Vu la restauration conservatrice mise en œuvre par Sylla, il faut sans doute comprendre ici que c'est la noblesse qui a retrouvé son honos et son gradus, mis à mal par les mesures d'inspiration popularis prises antérieurement. L'honneur et le rang sont donc des biens qui appartiennent surtout à la nobilitas. Un passage similaire des Verrines le confirme. Cicéron y dénonce les malversations de Verrès lors de sa questure et déclare que c'est pour truquer ses comptes qu'il s'est fait syllanien:

Vt hoc pacto rationem referre liceret, eo Sullanus repente factus est, non ut honos et dignitas nobilitati restitueretur.

"C'est pour qu'il lui fût permis de remettre ses comptes de cette façon qu'il s'est subitement transformé en soutien de Sylla; ce n'est pas pour que soient restitués à la noblesse son honneur et son rang. »

(CIc. Verr. II, I, 37).

Verrès a soutenu Sylla par intérêt personnel et non pas pour que la nobilitas retrouve son honos et sa dignitas. L'aristocratie bénéficie donc d'un authentique prestige que les Romains se représentent comme attaché de façon intime à ce groupe social. 


\subsubsection{La mainmise sur les marques d'honneur}

Les différentes marques d'honneur apparaissent de même comme un privilège de l'aristocratie. Deux facteurs expliquent cette emprise de l'élite romaine. Le premier réside dans le rôle de la fortune, le capital économique, dans l'accès à l'honneur. Les textes ne parlent qu'assez rarement de l'argent comme d'un motif d'honos mais ce dernier possède bien des fondements matériels: les sources tendent à occulter le rôle de la richesse derrière la mise en avant de qualités morales et sociales comme piliers de l'honneur. Certains éléments nous permettent de mesurer ce rôle du capital économique dans la constitution du capital symbolique. Quelques textes, d'abord, l'évoquent directement. C'est le cas du passage du Curculio que nous citions à propos des motifs militaires de l'honos:

Sibi sua habeant regna reges, sibi diuitias diuites,

Sibi honores, sibi uirtutes, sibi pugnas, sibi proelia;

Dum mi abstineant inuidere, sibi quisque habeant quod suum est.

«Qu'ils gardent leurs royaumes, les rois, qu'ils gardent leurs richesses, les riches,

Qu'ils gardent leurs honneurs, leurs exploits, leurs combats, leurs batailles! Pourvu qu'ils s'abstiennent de me jalouser, qu'ils gardent tous ce qui leur appartient. »

(PL. Curc. 178-180).

Le jeune homme rejette tous les biens, pourtant précieux, des rois et des riches, au profit de son seul amour. Le second vers, simplement juxtaposé au premier, en est l'expansion logique: les reges ont leurs regna et les diuites leur diuitias, et Phédrome énumère ensuite leurs autres privilèges que sont les succès militaires ainsi que les honneurs qui en découlent. Pour le jeune homme, les honores appartiennent en propre aux rois et aux riches. La richesse n'est pas présentée comme un motif d'honneur, puisque le riche doit encore accomplir des uirtutes, des "actions d'éclat», mais cette supériorité économique paraît conditionner l'accès à l'honos. Il est également significatif que, dans les comédies, le déshonneur du jeune homme soit causé par sa débauche sexuelle parce que cette dernière implique une dilapidation du patrimoine. C'est le déclassement économique qui mène à la disgrâce sociale ${ }^{102}$. La richesse, quand elle est bien acquise et constituée de biens valorisés par la tradition, comme les propriétés agricoles,

${ }^{102}$ Voir aussi PL. Trin. 257 où une corrélation est établie entre le pretium au sens économique (le prix, l'argent) et au sens figuré (la valeur de l'individu) et Trin. 272 où la res va de pair avec la gloria, le decus et l'honos. Cf. le rôle de la richesse comme composant de l'existimatio (Yavetz, "Existimatio, Fama, and the Ides of March»). 
permet d'accéder à l'honneur ${ }^{103}$. Ce rapport entre la fortune et l'accès à l'honneur s'explique par l'armature censitaire de la société romaine. Par le biais du census, l'ensemble des citoyens est recensé et hiérarchisé, à des fins fiscales, politiques et militaires ${ }^{104}$. C'est ce dernier aspect qui nous intéresse ici : lors du cens, les citoyens sont répartis, en fonction de la valeur de leur patrimoine déclaré, en adsidui, ceux qui ont une fortune suffisante pour servir dans la légion, et en capite censi (recensés pour leur "tête») et proletarii (qui n'ont que des enfants) qui ne sont pas aptes à être mobilisés. À l'intérieur des adsidui, les citoyens sont répartis en cinq classes à nouveau délimitées par des critères de fortune et à chacune desquelles correspond un armement spécial. Pour participer à la guerre, il faut donc être non seulement citoyen mais aussi posséder un certain niveau de fortune; on comprend dès lors que l'obtention des honores au combat dont parle le Curculio ne soit possible que pour les individus possédant une certaine richesse. En outre, les honores militaires prestigieux comme le triomphe ou la supplication d'action de grâces étaient réservés aux généraux, exerçant comme consul ou comme préteur, charges elles-mêmes difficilement accessibles à ceux qui n'appartenaient pas à l'aristocratie. L'examen des fastes triomphaux montre que la nobilitas exerce une très grande emprise sur l'honos du triomphe ${ }^{105}$.

\subsubsection{La mainmise sur les charges publiques}

L'emprise la plus nette et aussi la mieux connue de l'aristocratie dans le domaine des marques d'honneur concerne les charges publiques. Ici encore, la fortune conditionne en effet l'accès à l'honos. Un passage du Trinummus dresse ce constat sur un mode plaisant. Philton demande à l'esclave Stasime comment il se comporterait s'il était invité à un banquet public aux côtés d'un riche, et Stasime répond:

Decedam ego illi de uia, de semita,

De honore populi; uerum quod ad uentrem attinet,

Non hercle hoc longe, nisi me pugnis uicerit.

«Je lui céderais le pas sur la chaussée, sur le trottoir,

Je lui abandonne les honneurs publics; mais pour ce qui touche à mon ventre,

Je ne lui céderais pas de ça, sauf s'il triomphe de moi aux poings.»

(PL. Trin. 481-483; trad. Ernout modifiée).

${ }^{103}$ Sur la valeur positive de la richesse foncière et agricole, voir CAT. Agr. praef. 1-2; Cic. Cato mai. 51 et Off. I, 151. Sur l'honorabilité des différents métiers, voir infra p. 470-471 et 476 sqq.

${ }^{104}$ Sur le census et ses fonctions, voir Nicolet, Métier, chap. 2 et Pieri, L'Histoire du cens.

${ }^{105}$ Bastien, Le Triomphe romain, p. 207 sqq. 
L'esclave glouton ne pense qu'à satisfaire son estomac et laisse volontiers au riche ce qu'il considère comme des objets qui lui sont dus, la préséance sur le trottoir et l'honos populi, c'est-à-dire la magistrature. Comme pour l'accès à la légion, c'est la fortune qui détermine en effet la possibilité d'être candidat aux honores publics: pour pouvoir être questeur, la première des magistratures civiles du cursus honorum, il fallait posséder au moins le cens équestre, c'est-à-dire appartenir aux centuries les plus riches de la première classe, celles qui devaient, à l'origine, le service à cheval ${ }^{106}$. La richesse, le capital économique, est donc une condition indispensable pour l'accès aux honores. De nombreux textes font état, au premier siècle, de la mainmise de la nobilitas sur les charges publiques. Le thème est traité de manière particulièrement étendue par Cicéron, homo nouus qui s'est hissé jusqu'au consulat. Dans la prosopopée de la première Catilinaire, la patrie s'adresse en ces termes à Cicéron pour l'exhorter à agir contre les conjurés:

An inuidiam posteritatis times? Praeclaram uero populo Romano refers gratiam, qui te, hominem per te cognitum, nulla commendatione maiorum, tam mature ad summum imperium per omnis honorum gradus extulit, si propter inuidiam aut alicuius periculi metum salutem ciuium tuorum neglegis.

«Est-ce le blâme de l'avenir que tu redoutes? Admirable reconnaissance vraiment dont tu paies ce peuple romain qui, alors que tu n'étais connu que par toi-même, que tu ne te recommandais d'aucun aïeul, t'a porté si promptement, par tous les degrés des honneurs, jusqu'à la magistrature suprême, si la haine des partis, si la peur d'un danger te font mépriser le salut de tes concitoyens! »

(Cic. Catil. I, 28; trad. Bailly).

Le passage souligne le caractère exceptionnel de l'élection de Cicéron au consulat en 63: il a atteint le degré suprême de l'honneur nulla commendatione maiorum, sans bénéficier de la «recommandation» que constituent des ancêtres consulaires. Il apparaît tout à fait inhabituel qu'un homme qui ne soit pas descendant de consul, c'està-dire nobilis, parvienne lui-même au consulat. Cette idée réapparaît dans d'autres passages, modalisée selon des images révélatrices: les nobles sont «saturés d'honneurs » tant ils les monopolisent depuis des générations; ils représentent une "place forte» que Cicéron a prise

${ }^{106}$ Il a longtemps été dit, dans la lignée de T. Mommsen, qu'il n'y avait pas de conditions de fortune pour devenir magistrat, mais C. Nicolet a montré l'inexactitude de ce jugement: les sources ne sont pas très claires, mais un examen serré permet de dire qu'il faut appartenir à l'ordre équestre pour devenir magistrat. Or, l'accès à ce dernier est soumis, entre autres, à des conditions de fortune, fixées à 400.000 sesterces à la fin de la République (C. Nicolet, «Le cens sénatorial sous la République et sous Auguste», $J R S, 66,1976$, p. 20-38). 
d'assaut à l'aide du peuple en obtenant l'honos du consulat ${ }^{107}$. L'homo nouus apparaît ainsi comme celui qui introduit une brèche dans le monopole absolu des honores de la nobilitas représentée comme une caste qui fait circuler les honores en cercle fermé108. Des idées similaires apparaissent à plusieurs reprises dans l'œuvre historique de Salluste, qui utilise une image récurrente, celle de la pureté que croit détenir la noblesse et qui ne doit pas être entachée par l'accès au pouvoir suprême d'un homo nouus. Dans un passage du Bellum Iugurthinum, l'historien s'exprime en son nom propre:

Etiam tum alios magistratus plebes, consulatum nobilitas inter se per manus tradebat. Nouos nemo tam clarus neque tam egregiis factis erat, quin is indignus illo honore et quasi pollutus haberetur.

«C'était encore le temps où, si la plèbe avait accès aux autres magistratures, la noblesse se réservait le consulat qu'elle se passait de main en main. Il n'y avait pas d'homme nouveau, si grand fût-il par sa gloire et ses exploits, qui ne fût jugé indigne de cet honneur et comme entaché de quelque souillure.»

(SAll. Iug. 63, 6-7; trad. Ernout modifiée).

Salluste remarque que les mérites de Marius lui ont permis de gravir les échelons du cursus honorum mais que le consulat lui reste, encore pour un moment, inaccessible car la noblesse se le passe inter se per manus. La nobilitas considère que l'homme nouveau qu'est Marius porte une souillure (pollutus) qui ne lui ouvre pas la voie de l'honos ${ }^{109}$. Le cas de Marius montre que les mérites personnels, comme les qualités militaires, ne suffisent nullement pour accéder à certains honores.

Ces représentations littéraires correspondent-elles aux faits? Dans l'histoire de Rome, les charges publiques ont été effectivement accaparées périodiquement par un groupe de la population. Ce fut d'abord le

${ }^{107}$ Cic. Planc. 21 et Agr. II, 2-3. Voir aussi Cic. Mur. 17 où Cicéron dit avoir brisé les barrières posées par la noblesse pour empêcher l'accès au consulat.

${ }^{108}$ La définition précise de ce qu'est un homo nouus pose deux difficultés. Celle de l'origine des homines noui d'abord: on considère généralement que ce sont des fils de chevaliers ou de citoyens plébéiens (BRUNT, "Nobilitas and Nouitas ») mais Cicéron parle de la nouitas de personnages qui descendent de préteurs (Muréna dans le Pro Murena et $\mathrm{Cn}$. Octavius dans les Philippiques et le De officiis). La nouitas semble donc dès lors s'opposer exactement à la nobilitas. La seconde difficulté est celle de la délimitation de la nouitas: on considère tantôt (T.P. WisEMAN, "Competition and Co-operation ", in Wiseman, T.P.(éd.), Roman Political Life, $90 B C$ - AD 69, Exeter, University of Exeter Press, 1985, p.3-19) que tous ceux qui entrent au sénat sont des homines noui, tantôt (M.Dondin-Payre, "Homo novus: un slogan de Caton à César? ", Historia, 30, 1981, p. 22-81) que seuls les consulaires et prétoriens susceptibles de devenir consuls reçoivent cette dénomination. L'approche de M. Dondin-Payre, fondée sur un relevé systématique des occurrences du terme homo nouus, nous paraît la plus convaincante.

${ }^{109}$ L'image apparaît déjà en SALL. Cat. 23, 6. 
cas des patriciens ${ }^{110}$ qui ont graduellement développé un monopole sur les magistratures au cours du $\mathrm{V}^{\mathrm{e}}$ siècle ${ }^{111}$. Ce n'est que progressivement que la plèbe a ensuite réussi au cours des $\mathrm{V}^{\mathrm{e}}$ et $\mathrm{IV}^{\mathrm{e}}$ siècles à ouvrir des brèches dans ce contrôle, d'abord en obtenant des magistrats particuliers, les tribuns de la plèbe, et ensuite en parvenant à accéder aux autres honores. Les lois licinio-sextiennes de 367 ont joué de ce point de vue un rôle considérable en ouvrant l'accès au consulat et à certains grands collèges religieux aux plébéiens et en donnant ainsi naissance à une nouvelle noblesse, la nobilitas ${ }^{112}$. Les patriciens, après la fin de leur monopole sur les magistratures, ont continué de bénéficier d'un accès privilégié à certains honores : les flamines majeurs, les saliens et le rex sacrorum étaient toujours des patriciens, et la moitié des places des grands collèges de prêtres leur était réservée ${ }^{113}$. La nouvelle nobilitas parvint ensuite à son tour à se réserver l'accès aux magistratures les plus élevées et notamment au consulat. Plusieurs études prosopographiques et statistiques ont confirmé, en les nuançant, les données apportées sur ce point par les textes ${ }^{114}$ : entre 178 et 82, environ $75 \%$ des consuls viennent de familles consulaires. Entre 78 et 49, c'est le

${ }^{110}$ La nature et l'origine exactes du patriciat restent controversées. Pour un état de la question avec bibliographie, Nicolet, Rome et la conquête, p. 196 et HinARd (éd.), Histoire romaine, p.188. La tradition fait des patriciens les descendants du "sénat» créé par Romulus (Liv. I, 8, 7) et suggère que leur nombre a été augmenté de membres des clans aristocratiques. Un critère important de leur définition semble avoir été la détention du ius auspicii, la capacité de prendre les auspices majeurs. Voir P.-C. RANouIL, Recherches sur le patriciat (509-366 av. J.-C.), Paris, Les Belles Lettres, 1975; J.-C.RichaRD, Les Origines de la plèbe romaine: essai sur la formation du dualisme patricio-plébéien, Rome, E.F.R., 1978; R.E. Mrtchell, Patricians and Plebeians: the Origin of the Roman State, Ithaca, Cornell University Press, 1990.

${ }^{111}$ Ce n'est que progressivement que se sont installés le monopole des honneurs et la «fermeture du patriciat ». L'expression, due à G. de Sanctis, est reprise et développée par D. Briquel in Hinard (éd.), Histoire romaine (p.188 sqq.). Ce dernier insiste notamment sur la vision erronée des sources anciennes présentant la plèbe et le patriciat comme deux entités dont l'existence est consubstantielle à la République. Leur constitution, leur opposition et le monopole des honneurs du patriciat ne se sont établis que progressivement. Les patriciens n'ont donc pas eu, de tout temps, l'exclusivité des honores, comme l'indiquent d'ailleurs les fastes consulaires: on y trouve, de 509 à 486 avant notre ère, un nombre important de noms connus ultérieurement comme plébéiens; ce n'est qu'ensuite que s'accroît considérablement la présence de familles patriciennes; le patriciat n'est véritablement clos que dans les années 430.

112 Gelzer, Die Nobilität der römischen Republik et HöLKEsKamp, Die Entstehung der Nobilität.

${ }^{113}$ Pour un exemple d'affrontement entre plébéiens et patriciens au sujet de l'honos des prêtrises, voir LIV. X, 7, 9. Sur l'ouverture progressive, voir H.D. Jocelyn, «The Roman Nobility and the Religion of the Republican State ", JRH, 4 (2), 1966, p. 89-104.

${ }^{114}$ H.H.Scullard, Roman Politics, 220-150 B.C, $2^{\mathrm{e}}$ éd., Oxford, Clarendon Press, 1973; Hopkins, Death and Renewal; BECK, Karriere und Hierarchie, p.114 sqq. Voir aussi sur le monopole des charges publiques R. Develin, Patterns in Office-Holding 366-49 B.C, Bruxelles, Latomus, 1979 et Develin, The Practice of Politics at Rome, 366-167 B. C., chapitre 5. 
cas de $88,5 \%$ des consuls ${ }^{115}$. Il y a donc une réelle emprise de la noblesse sur les honores politiques, mais il ne s'agit pas d'un monopole, contrairement à l'image qu'en donnent Cicéron et Salluste ${ }^{116}$. L'accès des homines noui au consulat est certes difficile, mais pas impossible, comme le montrent les exemples célèbres de Caton, Marius ou Cicéron. Les magistratures inférieures au consulat sont encore plus accessibles: entre 78 et $49,51 \%$ des préteurs et $56 \%$ des édiles ne sont pas issus de familles consulaires ${ }^{117}$. Il convient donc de nuancer l'image d'une nobilitas totalement fermée aux hommes nouveaux et se passant les honores de main en main. Il faut distinguer dans la nobilitas un noyau restreint de familles qui parvient effectivement à garder pendant des générations les honores et un cercle plus large qui n'y parvient que de façon beaucoup plus irrégulière et dont l'appartenance à la noblesse est donc plus précaire ${ }^{118}$.

\subsubsection{L'honos source de l'honos}

L'accès privilégié de l'aristocratie à l'honos s'explique en partie par les modalités d'accès aux honores les plus grands, reposant sur l'exercice d'une charge publique élevée; c'est dans ce cas un premier honos qui ouvre la voie à un second. Cet aspect relève d'un mode de pensée fréquent qui tend à faire de l'honos lui-même une source d'honos, ce qui donne l'impression d'un système fermé119. Quand Salluste évoque les raisons qui ont poussé des hommes politiques à vouloir impliquer César dans la conjuration de Catilina, il écrit à propos de deux d'entre eux:

Nam uterque cum illo grauis inimicitias exercebat: Piso oppugnatus in iudicio pecuniarum repetundarum propter cuiusdam Transpadani supplicium iniustum, Catulus ex petitione pontificatus odio incensus quod extrema aetate, maxumis honoribus usus, ab adulescentulo Caesare uictus discesserat.

«Tous deux en effet avaient contre lui de graves motifs d'inimitié: Pison parce qu'il avait été, au cours d'un procès de concussion, attaqué par lui à propos du supplice injustement infligé à un habitant de la Gaule Transpadane;

${ }^{115}$ Lintott, The Constitution of the Roman Republic, p. 167.

${ }^{116}$ EARL, Tradition, p. 13. Sur la mobilité au sein de la nobilitas, voir Lintott, The Constitution of the Roman Republic, p. 168 et Hopkins, Death and Renewal, p. 32.

${ }^{117}$ E. S. Gruen, The Last Generation of the Roman Republic, Berkeley, University of California Press, 1974, p. 522-523.

118 Lintott, The Constitution of the Roman Republic, p. 167 sqq.; HölKesKamp, Reconstruire une République, p. 75-79.

${ }^{119}$ La sociologie a mis en avant ce phénomène où les honneurs sont adressés plus facilement à ceux qui en détiennent déjà. Voir la relecture du "Matthew Effect » par Goode, The Celebration of Heroes, p. 116 sqq. 
Catulus, depuis sa candidature au pontificat, brûlait de haine contre César pour avoir été, à la fin d'une carrière comblée des plus grands honneurs, battu par ce tout jeune homme, auquel il avait dû céder la place.»

(SAll. Cat. 49, 2; trad. Ernout).

L'inimitié de Catulus pour César vient de son échec lorsque tous deux briguèrent le grand honos du pontificat. Catulus n'a pas supporté d'être battu par César qui, outre qu'il était plus jeune, était surtout moins avancé dans sa carrière politique. Catulus, lui, avait déjà exercé de très grands honneurs (maxumis honoribus), ce qui légitimait sa prétention à un autre honos. C'est l'accumulation d'honores qui donne un droit supérieur à une marque d'honneur supplémentaire ${ }^{120}$. Il y a donc une circularité de tous les honores, circularité vertueuse pour le détenteur: plus il accumule les marques d'honneur, plus d'autres honores sont susceptibles de lui échoir. C'est la même logique qui apparaît pour la magistrature et l'éloge funèbre: il s'agit d'un honos exceptionnel, mais qui n'est octroyé que lorsque le défunt a lui-même déjà obtenu l'honos d'une magistrature ${ }^{121}$. Il en va de même pour le triomphe et le consulat: entre 227 et 79, on voit que parmi les 19 préteurs qui ont triomphé, 15 ont ensuite atteint le summus honos du consulat ${ }^{122}$.

\subsection{La controverse sur la nature du mérite}

Les luttes entre aristocrates et non-aristocrates pour l'accès à l'honos ne sont pas seulement politiques mais aussi idéologiques puisque chacun a tenté de définir à son avantage la nature de la dignitas, le mérite donnant droit à l'honos. Ce dernier a fait l'objet de caractérisations rivales, qui se résument en général à un clivage majeur: l'honneur est fondé tantôt sur l'appartenance à une famille prestigieuse, tantôt sur le mérite personnel ${ }^{123}$. Ce clivage entre l'honneur conçu comme possession héritée ou comme bien mérité se retrouve dans d'autres sociétés où l'honneur occupe une place importante ${ }^{124}$.

${ }^{120}$ C'est aussi ce qui transparaît dans le discours de Marius tel que le recompose Salluste dans le Bellum Iugurthinum: la prétention de la nobilitas à l'exercice des plus grandes charges repose sur une accumulation ancienne de magistratures et de triomphes, c'est-à-dire d'honores (SALL. Iug. 85, 28-30).

${ }^{121}$ Voir les remarques de Cicéron sur ce sujet (Cic. Leg. II, 62). L'honos de l'éloge funèbre mentionne d'ailleurs les honores politiques obtenus par le défunt. Voir par exemple la laudatio de L. Caecilius Metellus qui mentionne que ce dernier a obtenu le maximus honos (PLIN. NH VII, 139-140). Sur les avantages liés à l'exercice d'une magistrature, voir Mommsen, $D P R$, vol. 2, p. 76-98.

${ }_{122}$ HARRIS, War and Imperialism, p. 32.

${ }^{123}$ Voir sur ce point FERRARY, «Le idee politiche a Roma nell'epoca repubblicana », p. 741. L'auteur souligne aussi que la philosophie politique a notamment interrogé la part respective de la richesse et du mérite (ARSTT. EN 1131a; Pol. 1280a et 1294a). Sur la justification du fondement économique de l'honos politique à Rome, voir Cic. Rep. II, 39-40 et SALL. Cat. 37, 3.

${ }^{124}$ Pitt-Rivers, Anthropologie de l'honneur, p. 20. Les ethnologues ont observé, plus 


\subsubsection{Genus contre uirtus}

Pour les aristocrates, c'est l'appartenance à une grande famille au riche passé politique qui justifie la prétention aux honores. L'honneur se fonde ainsi sur la naissance et l'extraction, c'est-à-dire le genus. Les nobles, utilisant à leur profit le fonctionnement circulaire des honores, soulignent qu'avoir des ancêtres prestigieux, ayant exercé des charges publiques, constitue un moyen privilégié d'atteindre les honneurs. Dans une lettre adressée à Cicéron, Brutus, issu d'une haute lignée, tient un raisonnement caractéristique de l'aristocratie. Parlant à Cicéron de son fils Marcus en termes élogieux, il lui écrit

\section{[...] tibi persuadeas non fore illi abutendum gloria tua ut adipiscatur honores paternos. \\ «[...] sois persuadé qu'il n'aura pas à utiliser ta gloire pour atteindre les honneurs de son père.»}

(BRUT. = Cic. Ad Brut. II, 3, 6).

Pour Brutus, le jeune Marcus, dont le père est ancien consul et père de la patrie, pourrait parfaitement s'appuyer sur la gloria paternelle pour atteindre les honneurs: sa prétention est légitimée par la lignée dont il est issu. Brutus remarque que cela ne sera pas nécessaire, tant Marcus montre de talents, mais cette remarque flatteuse ne change pas le fond de sa pensée. De façon significative, Brutus parle, à propos des marques d'honneur que pourrait obtenir Marcus, d'honores paternos: les honneurs du père sont susceptibles de devenir ceux du fils. Pour l'aristocratie, l'honos des ancêtres se retrouve dans l'honos des descendants ${ }^{125}$. Les exploits et les charges publiques exercées par les ascendants sont pour un jeune noble un solide moyen d'accès à l'honos: c'est ce que Cicéron appelle la commendatio maiorum ${ }^{126}$. Les ancêtres d'un noble, rendus présents dans sa demeure par les imagines, constituent une «recommandation » qu'il est possible de faire valoir, notamment pendant les élections : c'est l'excellence des ancêtres et leur importance politique qui sont au cœur de la dignitas de la noblesse. L'aristocratie romaine tend plus généralement à considérer qu'elle bénéficie, de par son statut, d'un authentique droit à l'honos. Marius

généralement, que le prestige dans une société pouvait être hérité ou mérité. Voir par exemple l'étude de M.Godelier sur les Baruya de Nouvelle-Guinée, (M. Godelier, La Production des grands hommes. Pouvoir et domination masculine chez les Baruya de Nouvelle-Guinée, Paris, Flammarion, 1996, p. 11 et 261). Voir aussi, en Espagne, à partir de la Renaissance, la manière dont se heurtent la valeur militaire et la richesse financière comme sources d'honneur (BAROJA, «Honour and Shame: A Historical Account of Several Conflicts», p. 106).

${ }^{125}$ Sur la transmission de l'honos, voir infra p. 451-458.

${ }^{126}$ Cic. Catil. I, 28; Brut. 96. Sur cette notion, voir HöLKESKAmP, Die Entstehung der Nobilität, p. 205-206 et Flower, Ancestor Masks, p. 65 et 90. 
reproche ainsi aux nobles d'exiger du peuple tous les honneurs quasi debitos ${ }^{127}$, "comme s'ils leur étaient dus ». Catilina, après son échec au consulat, se sent, dans la représentation qu'en donne Salluste, injustement écarté de l'honos dont il est, dit-il, alienatus, "tenu à l'écart» alors qu'il estime, en patricien qu'il est, y avoir droit ${ }^{128}$ : il s'en prend à Cicéron, homo nouus, devenu consul, et à Silanus, plébéien, qui est consul désigné. Ces deux hommes, selon lui, ne sont pas digni honore.

À cette définition du mérite par l'appartenance à une grande famille et le prestige des ancêtres, s'oppose une conception reposant sur l'excellence personnelle et les réalisations individuelles. C'est notamment le point de vue des homines noui. L'impossibilité de faire appel à la commendatio maiorum amène ces derniers à mettre en avant d'autres mérites pour justifier leur prétention à l'honos, parmi lesquels se rencontre surtout la uirtus ${ }^{129}$. Cela apparaît bien chez Cicéron. À la fin du dernier discours des Verrines, il explique que toutes les peines qu'il a prises pour défendre la cause des Siciliens viennent de sa volonté de gagner l'honos: n'étant pas issu d'une famille aristocratique, il ne peut compter que sur ses efforts, ses labores, et sa valeur personnelle, sa uirtus. Il n'est pas d'ailleurs en cela le seul:

Q. Pompeius, humili atque obscuro loco natus, nonne plurimis inimicitiis maximisque suis periculis ac laboribus amplissimos honores est adeptus? Modo C.Fimbriam, C.Marium, C.Caelium uidimus non mediocribus inimicitiis ac laboribus contendere ut ad istos honores peruenirent ad quos uos per ludum et per neglegentiam peruenistis.

"Quintus Pompéius, né dans une famille humble et obscure, n'a-t-il pas, au prix de nombreuses inimitiés et de très grands dangers et efforts, obtenu les honneurs les plus importants? Nous avons vu il y a peu Gaius Fimbria, Gaius Marius, Gaius Caelius aux prises avec des inimitiés et des peines qui étaient tout sauf minimes, pour parvenir à ces honneurs auxquels vous êtes parvenus en vous amusant et en négligeant tout. »

(CIC. Verr. II, V, 181).

Cicéron oppose la situation des nobles, qui parviennent aux honneurs grâce à leur naissance, à celle des Romains d'extraction obscure qui obtiennent les honneurs periculis et laboribus: c'est par des exploits personnels que l'honos se gagne quand on n'est pas noble. À propos de Caton, Cicéron écrit quelques lignes plus haut: uirtute,

127 SALL. Iug. 85, 37.

${ }^{128}$ SALL. Cat. 35, 3-4. Catilina est patricien mais sa famille ne s'est pas distinguée dans la vie publique depuis longtemps. Voir l'article de la $R E$ par F. Münzer, «Sergius » $\mathrm{n}^{\circ} 1$ (vol. II, A).

${ }^{129}$ Les homines noui ne constituent pas un groupe cohérent à l'image de la nobilitas (Dondin-PAYre, "Homo novus: un slogan de Caton à César?", p. 52), mais on relève cependant chez eux quelques constantes idéologiques (T.P. WisEman, New Men in the Roman Senate 139 B.C. - 14 A.D., Oxford, Oxford University Press, 1971, p. 107-116). Sur leur revendication de uirtus, McDonnell, Roman Manliness, p. 320-332. 
non genere populo Romano commendari putaret, «il pensait que c'était son mérite et non sa naissance qui le recommandait au peuple romain $»^{130}$. Cicéron reprend, à propos de l'homo nouus qu'est Caton l'Ancien, la notion aristocratique de commendatio mais remplace les ancêtres par la uirtus: c'est l'excellence personnelle, au service de la république, qui sert de «recommandation » auprès du peuple pour accéder à l'honos ${ }^{131}$. Plusieurs années après son élection, dans son discours contre Pison, Cicéron rejette avec une mordante raillerie la définition nobiliaire du mérite:

Numquam erat audita uox in foro, numquam periculum factum consili, nullum non modo inlustre sed ne notum quidem factum aut militiae aut domi. Obrepsisti ad honores errore hominum, commendatione fumosarum imaginum, quarum simile habes nihil praeter colorem.

«Jamais l'on n'avait entendu ta voix sur le forum, jamais l'on n'avait fait l'épreuve de ton jugement, aucune action, je ne dis pas d'éclat, mais même connue, n'avait été accomplie, ni à l'armée, ni à l'intérieur. Tu t'es glissé jusqu'aux honneurs grâce à l'erreur générale, grâce à l'appui d'images enfumées, auxquelles, en toi, rien ne ressemble que le teint.»

(Cic. Pis. 1 ; trad. Grimal).

Pison n'a dû son élection, dit Cicéron, qu'à l'appui d' «images enfumées ", c'est-à-dire les imagines situées dans l'atrium de la maison, insignes de la nobilitas. Cicéron oppose l'accès à l'honos par la naissance à un accès par l'action méritante, à l'armée et au forum, militiae aut domi. Le mérite ne peut se définir par la naissance car cette dernière ne garantit en rien l'excellence personnelle: même si les ancêtres de Pison sont des hommes de valeur, cette valeur ne se transmet pas et Pison ne leur ressemble nullement. Seul son teint, altéré par la fréquentation des lieux de débauche, est semblable aux imagines des ancêtres ${ }^{132}$.

Une conception semblable apparaît dans le discours hostile à la noblesse que Salluste fait tenir à Marius dans le Bellum Iugurthinum. Un passage est particulièrement révélateur de la place prise par la uirtus dans la définition du mérite ${ }^{133}$ :

Quod si iure me despiciunt, faciant item maioribus suis quibus, uti mihi, ex uirtute nobilitas coepit. Inuident honori meo; ergo inuideant labori, innocen-

${ }^{130}$ CIC. Verr. II, V, 180.

${ }^{131}$ L'importance de la uirtus pour la définition de la dignitas apparaît également dans le Commentariolum petitionis: Quintus est bien conscient du problème posé par la nouitas de son frère lors de sa candidature au consulat mais considère qu'il peut la compenser de trois façons, par sa gloire d'orateur, par l'appui de ses amis, et surtout par sa uirtus (Q. CIc. Comm. 2; 3 et surtout 7: nemo sit qui audeat dicere plus illis nobilitatem quam tibi uirtutem prodesse oportere: «Personne n'oserait dire que leur noblesse leur est plus utile à eux [i.e. les nobles] que ta valeur personnelle à toi »).

${ }^{132}$ Voir aussi Cic. Pis. 2 qui oppose homo et genus, mores et maiores, uirtus et nobilitas. Sur la définition cicéronienne des motifs de l'honos, voir EARL, Tradition, p. 47 sqq.

${ }^{133}$ Sur la uirtus chez Salluste, McDonnell, Roman Manliness, p. 356-384. 
tiae, periculis etiam meis, quoniam per haec illum cepi. Verum homines corrupti superbia ita aetatem agunt quasi uostros honores contemnant; ita hos petunt, quasi honeste uixerint. Ne illi falsi sunt, qui diuorsissumas res pariter expectant, ignauiae noluptatem et praemia uirtutis.

«Si les nobles ont le droit de me mépriser, qu'ils en fassent autant pour leurs ancêtres qui n'ont dû, comme moi, leur noblesse qu'à leur mérite. Ils m'envient l'honneur qui m'est fait; qu'ils m'envient donc mon labeur, mon intégrité, les dangers même que j'ai courus, puisque c'est à ce prix que je l'ai obtenu. Mais ces hommes corrompus par leur orgueil vivent comme s'ils méprisaient vos honneurs; et ils les briguent comme s'ils vivaient honorablement. Ils sont totalement dans l'erreur en voulant obtenir simultanément ces choses incompatibles, le plaisir de la paresse et les récompenses dues au mérite.»

(SALL. Iug. 85, 17-20; trad. Ernout modifiée).

Marius, après avoir obtenu le consulat, fustige la noblesse à laquelle il reproche de ne rien faire pour mériter les honneurs qu'elle brigue. Pour l'homo nouus qu'est Marius, seule l'action peut valoir de l'honos: ce dernier s'obtient à force de peine et l'on retrouve le labor et les pericula déjà mentionnés par Cicéron. L’image que se fait Marius de la recherche de l'honos est celle d'une quête: rien n'est donné, il faut prendre (cepi). C'est donc l'action et la peine, le labor, qui permettent d'accéder à l'honos. Le mérite de Marius se concentre, ici encore de manière parallèle à la pensée cicéronienne, dans la uirtus. Celle-ci concerne la vaillance militaire, dont Marius est un des meilleurs représentants, mais aussi les qualités morales telles que l'innocentia et une vie menée honeste. Ce sont aussi des vertus qui constituent le mérite, vertus qui s'opposent à la conduite des nobles qui sombrent dans la corruption et la paresse, se rendant ainsi indignes de l'honos ${ }^{134}$. Marius oppose une dignitas de l'action et de la droiture morale à une prétention à l'honos fondée sur la naissance et le prestige familial ${ }^{135}$. Les homines noui comme la nobilitas tentent donc de donner du mérite une définition en adéquation avec leur statut ainsi qu'avec l'idéologie du groupe auquel ils appartiennent, en ramenant la dignitas du côté de la uirtus ou du genus ${ }^{136}$.

${ }^{134}$ Sur l'opposition entre noblesse sociale et noblesse morale chez Salluste, voir BADEL, La Noblesse de l'Empire romain, p. 182.

${ }^{135}$ Cette idée est récurrente dans le discours de Marius (voir Iug. 85, 14 et 37-38). Sur le rapport de Marius à la uirtus, voir McDonnell, Roman Manliness, p. 266-267. Sur la figure d'homo nouus que représente Marius dans l'œuvre de Salluste, voir EARL, Tradition, p.49 sqq. (notamment sur l'authenticité de cette prise de position par le Marius historique).

${ }^{136}$ Cette définition des qualités à la source de l'honneur en accord avec l'idéologie du groupe se retrouve à l'époque contemporaine (voir STEWART, Honor, p. 32 sqq). Cf. les définitions des fondements de l'honneur données par les nazis (M.BREzina, Ehre und Ehrenschutz, im nationalsozialistischen Recht, Augsburg, AV, 1987) ou par les communistes soviétiques après la seconde guerre mondiale (S. TACKMANN, "Die moralische 


\subsubsection{Les limites de cette opposition idéologique}

Cependant, il ne faut pas opposer de manière trop tranchée ces deux conceptions des sources de l'honos car chacune d'elles n'est pas aussi fermement attachée qu'il y paraît au groupe qui s'en réclame. Il $\mathrm{y}$ a bien eu, notamment au $\mathrm{I}^{\mathrm{er}}$ siècle, une controverse sur la nature du mérite, mais la ligne de partage entre genus et uirtus, ainsi qu'entre nobles et hommes nouveaux, est en réalité difficile à dessiner. Du côté des nobles, d'abord, la place accordée aux maiores et à la naissance ne doit pas occulter l'importance de la notion de uirtus au sein de l'aristocratie et son rôle dans la prétention à l'honos. C'est principalement sous l'égide de la nobilitas que la uirtus est devenue à Rome une valeur prisée; elle a été mobilisée par cette noblesse pour se constituer une image d'elle-même cohérente parallèlement à la consolidation des critères objectifs d'appartenance à l'aristocratie: la uirtus est une de ces qualités morales qui donnent une stabilité à la nouvelle élite patricio-plébéienne émergeant à partir du IVe siècle ${ }^{137}$. La place prépondérante de la uirtus et du service de la cité comme sources de l'honos est une trace de cette idéologie nobiliaire, encore bien perceptible au $\mathrm{I}^{\text {er }}$ siècle. Les deux notions jouent en effet un rôle crucial pour l'aristocratie nouvelle qui naît après les lois licinio-sextiennes: la première parce qu'elle permet à la nobilitas de se différencier du patriciat, l'ancienne noblesse, la seconde parce qu'elle est le socle sur lequel la nobilitas, noblesse de charge publique, s'édifie. Plusieurs textes mettent d'ailleurs en avant les vertus de la nobilitas pour montrer que cette dernière a droit à l'honos: Marius soulignait son innocentia dans le texte précédent, mais c'est aussi de cette innocentia que naît, selon Scipion Émilien, la dignitas qui ouvre sur l'honos ${ }^{138}$. Dans l'épitaphe de Scipion Hispanus, l'honor dont le défunt s'enorgueillit est la conséquence logique des uirtutes dont la mention inaugure l'elogium ${ }^{139}$. La uirtus apparaît donc comme une valeur attachée initialement à la nobilitas puis étendue aux milieux non aristocratiques: elle devient alors,

Begriffe Ehre und Würde in der sowjetischen Ethikliteratur», Deutsche Zeitschrift für Philosophie, 23, 1975, p.172-177).

${ }^{137}$ HöLKESKAMP, Die Entstehung der Nobilität, p. 204-240. Il est possible que ce soient surtout les plébéiens intégrés à la nouvelle noblesse qui aient fait usage de cette notion de uirtus, dépourvus qu'ils étaient de prestige familial, mais elle est devenue ensuite une valeur du groupe dans son entier. Sur le rôle des plébéiens dans la constitution idéologique de la nouvelle nobilitas, voir K.-J. HöLKESKAMP, « Krieg, Konkurrenz und Konsens: die Expansion in Italien und die Entstehung der Nobilität» in Senatus Populusque Romanus. Die politische Kultur der Republik, Stuttgart, F. Steiner, 2004, p. 11-48.

${ }_{138}$ Comme nous l'avons vu avec le fragment Ex innocentia nascitur dignitas, ex dignitate honor, ex honore imperium, ex imperio libertas. "De l'intégrité naît le mérite, du mérite l'honneur, de l'honneur le pouvoir, du pouvoir la liberté» (ScIP. AEm. frg. inc. $32 O R F)$.

${ }^{139} \mathrm{CIL} \mathrm{I}^{2}, 15=I L L R P 316$. 
pour les uns et les autres, un fondement de l'honos ${ }^{140}$. Cependant, dans la conception des homines noui, la noblesse du $\mathrm{I}^{\mathrm{er}}$ siècle ne peut plus utiliser la uirtus pour prétendre à la dignitas car elle a déchu moralement: Marius reconnaît dans son discours qu'autrefois la nobilitas était étayée sur la uirtus mais que ce n'est plus le cas à son époque ${ }^{141}$. C'est dès lors sur le genus que les nobles se sont rabattus, pervertissant la seule définition légitime, aux yeux des hommes nouveaux, du mérite ${ }^{142}$. Ce sont ainsi, paradoxalement, les homines noui qui se considèrent comme les héritiers des ancêtres de la nobilitas car ils ont perpétué l'idéal de uirtus. Ils n'ont donc pas fait que s'emparer de la uirtus, ils l'ont aussi retournée contre les nobles qui en étaient à l'origine et ont pu prétendre incarner alors la véritable noblesse, comme le fait le Marius de Salluste ${ }^{143}$.

L'opposition entre uirtus et genus doit aussi être relativisée en raison de la nature particulière de l'homo nouus. Ce dernier possède en effet un statut ambigu: il parvient, par sa uirtus et son labor, à conquérir l'honos et à briser les barrières posées par la noblesse. Mais en atteignant l'honneur suprême du consulat, il devient à son tour créateur de noblesse pour ses descendants. Et ces derniers pourront dès lors se prévaloir de leur genus pour briguer d'autres honores. Cette position charnière de l'homo nouus apparaît avec éclat quand Cicéron parle de son fils, comme dans ce passage du Pro Plancio:

Quaesisti utrum mihi putarem, equitis Romani filio, faciliorem fuisse ad adipiscendos honores uiam an futuram esse filio meo, quia esset familia consulari. Ego uero quamquam illi omnia malo quam mihi, tamen honorum aditus numquam illi faciliores optaui quam mihi fuerunt.

«Tu as demandé si je pensais que le chemin m’avait été plus facile, pour parvenir aux magistratures, à moi, fils d'un chevalier romain, qu'il ne le serait à mon fils, parce qu'il était d'une famille consulaire. Eh bien, vois-tu, j'ai beau préférer en tout son bien au mien, je n'ai jamais pourtant souhaité que l'accès aux honneurs lui fût plus facile qu'il ne le fut pour moi. »

(Cic. Planc. 59; trad. Grimal modifiée).

Cicéron a eu du mal à se ménager un accès aux honneurs car il n'appartenait pas à la noblesse. Mais maintenant qu'il est consulaire, il ouvre à son fils une voie bien plus facile pour obtenir les charges publiques: son fils, devenu nobilis, pourra bénéficier du prestige de

${ }^{140}$ C'est pourquoi l'autonomie idéologique des hommes nouveaux n'est pas totale (BAdel, La Noblesse de l'Empire romain, p. 42; McDonnell, Roman Manliness, p. 329).

${ }^{141}$ SALl. Iug. 85, 17.

${ }^{142}$ Pour Cicéron, c'est la définition même de la nobilitas sur la naissance qui est une perversion de l'ancienne conception unissant nobilitas et uirtus : Cic. Sest. 136; Balb. 51; Mur. 17.

143 «Le modèle idéologique de la nobilitas pouvait sans cesse être retourné contre le groupe social des nobiles»(BADEL, La Noblesse de l'Empire romain, p. 42). 
son père. Cicéron reste cependant marqué par les valeurs de l'homo nouus et souhaite que son fils parvienne comme lui aux honores par l'effort personne.

\subsection{La réglementation de l'accès à l'honos}

Si la délimitation des statuts à l'origine de l'honos est assez simple, puisque le fait d'être citoyen, sénateur ou patronus répond à des critères précis, bien des qualités reconnues comme motifs d'honneur, telles que la vaillance militaire ou le pudor, ne sont pas définies de manière objective. C'est pourquoi s'est développée progressivement une réglementation concernant les modalités d'accès à certains honores. Une autre raison de ce souci de normativité réside dans la grande valeur attachée à certains honores militaires et politiques et dans l'augmentation consécutive du nombre de prétendants: il est dès lors devenu nécessaire de contrôler l'accès à certains honores par des dispositions contraignantes.

Deux types de marques d'honneur ont fait l'objet de réglementations bien connues: les honores militaires et les charges publiques. Certaines décorations honorant la bravoure au combat ne pouvaient être octroyées que si le soldat répondait à des exigences très précises. La couronne civique, donnée à celui qui a sauvé la vie d'un citoyen romain, n'était conférée que si le soldat avait tué l'adversaire qui menaçait le citoyen en question et s'il occupait pendant un jour entier l'endroit où le combat avait eu lieu ${ }^{144}$. L'obtention d'une supplicatio était contrôlée par le sénat ${ }^{145}$ : le général devait jouir de l'imperium et du droit d'auspices majeurs, et avoir vaincu des ennemis en grand nombre au cours d'un affrontement régulier, dans le cadre d'un bellum iustum. La réglementation du triomphe est celle qui nous est la mieux connue, grâce aux passages de l'histoire livienne où des débats s'élèvent sur son octroi et à des textes d'Aulu Gelle et de Valère Maxime ${ }^{146}$. Pour triompher, il faut avant tout détenir l'imperium et avoir mené la guerre suis auspiciis ${ }^{147}$. Comme pour la supplicatio, la guerre doit

${ }^{144}$ Gell. V, 6, 13-14 et Plin. NH XVI, 12. Voir MaXfield, The Military Decorations, p. 70 .

${ }^{145}$ Voir HaLkin, La Supplication, p. 90-93 sur les conditions requises.

${ }^{146}$ GeLL. V, 6, 21 évoque la différence entre ouatio et triomphe. VAL. MAX. II, 8 traite de iure triumphandi. Sur ces règles, voir J.S. Richardson, "The Triumph, the Praetors and the Senate in the Early Second Century B.C. ", JRS, 65, 1975, p.50-63; BRENNAN, "Triumphus in Monte Albano", à la p. 317 surtout, et Auliard, Victoires et triomphes à Rome.

${ }^{147}$ VAL. MAX. II, 8, 2. Un débat s'est élevé parmi les historiens sur l'importance relative de l'auspicium et de l'imperium pour l'obtention du triomphe. R. LAQueUR, «Über das Wesen des römischen Triumphs », Hermes, 44, 1909, p. 215-236 considérait que l'auspicium était primordial, mais Versnel a réhabilité la lecture traditionnelle de Mommsen qui accordait la part la plus importante à l'imperium (VERSNEL, Triumphus, p. 164-195). Voir le résumé historiographique de BASTIEN, Le Triomphe romain, p. 129. 
avoir été un bellum iustum conforme au droit fétial ${ }^{148}$; une victoire dans une guerre civile ne donne pas droit, en principe, au triomphe ${ }^{149}$. Le général devait aussi avoir fait au moins 5000 morts du côté ennemi, et la victoire devait être décisive et avoir étendu l'empire de Rome ${ }^{150}$.

L'accès à l'honos des magistratures a lui aussi été progressivement régulé. Nous avons déjà eu l'occasion d'évoquer la lex Villia Annalis qui prévoyait un âge minimal pour accéder à la préture et au consulat, imposait un intervalle de deux ans entre l'exercice de deux honores et fixait l'ordre de leur succession ${ }^{151}$. D'autres dispositions légales visaient à interdire l'accès aux charges politiques à certaines catégories de personnes. La table d'Héraclée, qui contient le texte d'une loi du Ir siècle avant notre ère ${ }^{152}$, définit, entre autres dispositions, les conditions d'accès au duumvirat et au quattuorvirat en interdisant leur exercice, sauf exception, à ceux qui ont moins de trente ans et à ceux qui sont crieurs publics ou entrepreneurs de pompes funèbres. L'honos municipal était aussi interdit aux soldats dégradés pour lâcheté, aux lanistes, aux comédiens et aux proxénètes ${ }^{153}$. Le Digeste présente aussi plusieurs dispositions légales réglant l'accès à l'honos: il y avait, par exemple, un âge minimal et maximal pour être décurion et il n'était pas possible d'exercer en même temps deux honores dans deux cités différentes ${ }^{154}$.

Les modalités de désignation des prêtres ont également été plus nettement contrôlées avec le temps. Jusqu'au $\mathrm{III}^{\mathrm{e}}$ siècle, les membres des collèges et des sodalités sont renouvelés, à quelques exceptions près, par cooptation ${ }^{155}$. Puis, depuis le milieu du III ${ }^{\mathrm{e}}$ siècle, le grand

${ }^{148}$ Liv. XXXVII, 47, 5; VAL. MAX. II, 8, 7; Gell. V, 6, 21.

${ }^{149}$ Cette disposition a cependant été contournée (voir supra p. 317 n. 54).

${ }^{150}$ Liv. XXVI, 21, 1-3 et XXXIX, 29, 4-5; Gell. V, 6, 21; VAl. MaX. II, 8, 1 et 5; Brennan, "Triumphus in Monte Albano», p.318; Richardson, "The Triumph, the Praetors and the Senate in the Early Second Century B.C.», p. 61.

${ }^{151}$ Voir supra p. 248-249.

${ }^{152}$ CIL I$^{2}$, 593. La nature et la date exactes de cette loi, dite aussi, sans doute de manière erronée, lex Iulia municipalis, font encore débat. Sur ce texte, voir FIRA I, p. 140, n. 13 et CRAWFord, Roman Statutes, vol. 1, p. 355-391, n. 24.

${ }^{153} C I L \mathrm{I}^{2}, 593,1.121-123$. Voir Mommsen, $D P R$, vol. 2, p. 144. Sur l'infamia attachée à certaines professions, KASER, «Infamia und ignominia in den römischen Rechtsquellen » et Edwards, «Unspeakable Professions: Public Performance and Prostitution in Ancient Rome». Sur les acteurs en particulier, $c f$. p.362-363.

${ }^{154}$ Dig. L, 2, 2, 8 et L, 4, 8; Dig. L, 1, 17. Voir tout le Dig. L, 4 sur la législation de muneribus et honoribus.

${ }^{155}$ DH. II, 73; LIv. III, 32, 3; XXXIII, 44, 3. Voir Mommsen, DPR, vol. 3, p. 26-27; SCHEID, «Le prêtre » et JocelYN, «The Roman Nobility and the Religion of the Republican State», p. 94. Exceptions: le rex sacrorum, les flamines et les Vestales étaient choisis par le grand pontife (G. J.Szemler, The Priests of the Roman Republic, Bruxelles, Latomus, 1972, p. 30; M. BEARD, «Priesthood in the Roman Republic», in BEARD, M. et North, J.(éds.), Pagan Priests: Religion and Power in the Ancient World, Ithaca, Cornell University Press, 1990, p. 17-48). 
pontife est élu parmi trois candidats désignés par les pontifes, par une assemblée spéciale réunissant dix-sept tribus, tirées au sort parmi les trente-cinq ${ }^{156}$. Ce processus électoral est étendu à la fin du $\mathrm{II}^{\mathrm{e}}$ siècle par la lex Domitia aux prêtres des collèges pontifical, augural, décemviral et septemviral, les sodalités continuant de pratiquer la cooptation ${ }^{157}$. La loi sera brièvement abolie à l'époque de Sylla puis remise en place en 63.

Plusieurs règles délimitent donc les conditions dans lesquelles l'honos peut être octroyé. Mais cette réglementation n'est que très partielle: les conditions d'obtention des services, éloges, dons et d'autres marques d'honneur ne font l'objet d'aucune définition ${ }^{158}$. En outre, les règles que nous avons observées ont été, pour la plupart, élaborées progressivement pour faire face à des situations problématiques. Les conditions d'obtention du triomphe, par exemple, se sont empiriquement ajoutées les unes aux autres et ne forment pas un système concerté de régulations ${ }^{159}$. Il faut également garder à l'esprit que, à l'exception des dispositions concernant les magistratures, les conditions posées pour accéder aux honores ne sont pas des règles juridiques très précises. Le sénat peut faire preuve de flexibilité dans l'octroi du triomphe et l'accorder quand certaines exigences ne sont pas satisfaites ${ }^{160}$. Les règles qui contrôlent l'honos relèvent plus de la coutume, du mos, que du droit, du ius. On le perçoit dans un texte de Tite Live qui fait état du retour du proconsul d'Espagne Lucius Manlius, en 185. Ce dernier demande le triomphe mais il lui est refusé car il n'a pas mené l'assaut final lors de la bataille et a été obligé de rentrer à Rome sans ses troupes ${ }^{161}$ :

L. Manlius proconsul ex Hispania redierat; cui postulanti ab senatu in aede Bellonae triumphum rerum gestarum magnitudo impetrabilem faciebat, exemplum obstabat quod ita comparatum more maiorum erat ne quis qui exercitum non deportasset triumpharet nisi perdomitam pacatamque prouinciam tradidisset successori. Medius tamen honos Manlio habitus ut ouans Vrbem iniret.

«Le proconsul Lucius Manlius était revenu d'Espagne; il demandait le triomphe au sénat réuni dans le temple de Bellone, demande que rendait légitime l'ampleur de son œuvre accomplie, mais les exemples précédents s'y oppo-

${ }^{156}$ Mommsen DPR, vol. 3, p. 28-31; SzemLer, The Priests of the Roman Republic, p. 30; SCHEID, «Le prêtre», p. 82.

${ }^{157}$ Rotondi, Leges publicae populi Romani, p. 329.

158 À la notable exception de l'honos dû par le client à son patron: l'édit du préteur a limité la nature de ce qui pouvait être exigé du client (Dig. XXXVIII, 2, 1).

${ }^{159}$ Le tableau qu'en donne Valère Maxime ne doit pas, à cet égard, nous abuser: il s'agit d'une récapitulation, réalisée au début de l'époque impériale, de différentes dispositions, comme le montre la diversité des exemples cités par l'auteur (VAL. MAX. II, 8).

${ }^{160}$ Sur ce point, voir BeARD, The Roman Triumph, p. 207-210.

${ }^{161}$ Pour le détail des opérations de L. Manlius en Espagne, voir Liv. XXXIX, 21, 6-10. 
saient parce qu'il avait été établi dans la coutume ancestrale que celui qui ne ramenait pas son armée ne pouvait triompher à moins d'avoir transmis à son successeur une province totalement soumise et pacifiée. On octroya cependant à Manlius un honneur intermédiaire, le droit d'entrer dans la Ville avec l'ovation. »

(Liv. XXXIX, 29, 4-5).

L. Manlius ne remplit pas l'une des conditions du triomphe et ne peut de ce fait recevoir l'honos. L'historien indique que cette condition n'est pas une règle de droit mais une norme établie more maiorum, par la coutume ancestrale. On ne connaît de fait aucun texte juridique, mis à part la lex Marcia Porcia de 62, qui réglemente l'octroi du triomphe ${ }^{162}$. Comme l'indique le texte de Tite Live, ce sont les exempla anciens qui établissent les normes de fonctionnement. Cela explique que ces normes puissent faire l'objet d'ajustements: le mos maiorum est un code ancestral qui régule la conduite des contemporains mais est susceptible de variations et d'enrichissements progressifs ${ }^{163}$. Les magistratures elles-mêmes ne sont, avant la lex Villia Annalis, régulées par aucun droit constitutionnel: c'est la coutume ancestrale qui sert ici encore de guide ${ }^{164}$.

\section{CONCLUSION ET MISE EN PERSPECTIVE HISTORIQUE}

L'étude des sources de l'honos et de ses conditions d'accès a permis de préciser le fonctionnement de ce dernier ainsi que la représentation que s'en font les Romains. Le prestige et les marques d'honneur reposent sur des mérites particuliers, pensés sous le terme générique de dignitas. Cette dernière est à la fois l'origine et le fondement de l'honos: elle motive son octroi tout en le légitimant car l'honos qui répond à la dignitas se conforme ainsi à la norme de l'aequum. On ne rencontre pas à Rome de définition officielle et objective des motifs d'honos ${ }^{165}$ mais l'observation des textes permet de dégager deux catégories principales. L'honos peut d'abord reposer sur des comportements et des qualités, tels que la valeur militaire, l'excellence morale ou les bienfaits aux concitoyens. Tous ont en commun de prendre en compte l'intérêt de la collectivité et d'incarner la uirtus, sous des

162 Val. Max. II, 8, 1. Sur la lex Marcia Porcia, voir Rotondi, Leges publicae populi Romani, p. 382 et Auliard, Victoires et triomphes à Rome, p. 10. Il n'est pas certain que la lex dont parle Valère Maxime à propos de la règle des 5000 morts ait été une vraie loi. Sur l'absence de lois et le rôle du mos, voir NAUDET, De la noblesse et des récompenses d'honneur chez les Romains, p. 185-188 et Auliard, Victoires et triomphes à Rome, passim.

${ }^{163}$ Voir BetTini, «Mos, mores und mos maiorum», p. 329-330.

${ }^{164}$ BEсK, Karriere und Hierarchie, p. 33.

${ }^{165}$ La situation est parallèle pour l'ignominia censoriale, marque de déshonneur inverse de l'honos. On connaît les motifs pour lesquels les censeurs infligeaient cette punition, mais ils ne sont pas constitués en un code officiel ou légal de comportements répréhensibles (voir PIERI, L'Histoire du cens, p. 99 sqq.). 
aspects différents. Ces qualités sont aussi toutes conformes au mos maiorum, le code de conduite ancestral qui régit la vie des Romains de la République. L'autre catégorie de motifs d'honos concerne le statut ou l'identité: avoir une position familiale, sociale, civique ou sacrée distincte est une source de prestige et d'hommages. Il en est ainsi car toutes ces situations impliquent l'existence de liens sociaux qui contribuent à la cohérence de la collectivité romaine. Ces liens familiaux, amicaux, sacrés,... reposent en outre sur le respect de valeurs essentielles, issues elles aussi du mos maiorum, telles que la fides ou la pietas. Le capital symbolique qu'est l'honos provient ainsi de la reconnaissance publique de deux types de capitaux, le capital moral et le capital social. Ces différentes sources d'honos ne suffisent cependant pas à rendre compte de l'accès des Romains à l'honneur: il y a en ce domaine des prérogatives et des obstacles particuliers. L'aristocratie se procure en effet plus facilement l'honos et tend à établir dessus un monopole régulièrement contesté au cours de l'histoire. Si tous estiment que la dignitas est à l'origine de l'honos, cette notion de mérite a fait l'objet d'appropriations rivales, la noblesse la tirant vers le genus alors que ceux qui n'appartenaient pas à l'aristocratie la rapprochaient de la uirtus. Cet antagonisme idéologique doit cependant être nuancé par l'origine aristocratique de la notion de uirtus et par la proximité sociale des homines noui et de la nobilitas. L'accès à l'honos, enfin, a fait l'objet de différentes réglementations. Mais ces dernières, de toute manière peu étendues, restent du domaine de la coutume et non du droit.

Pour terminer l'étude des sources et conditions de l'honos, nous proposons un rapide aperçu de l'évolution historique de l'accès à l'honneur. On constate d'abord qu'à partir du milieu du II ${ }^{\mathrm{e}}$ siècle de nouvelles sources d'honos font leur apparition. Des activités plus intellectuelles donnent un nouvel accès à l'honneur. On le voit par exemple avec la place faite à la poésie, dans le Pro Archia notamment. Cicéron a naturellement intérêt à insister sur l'honorabilité de cette pratique puisqu'il défend un poète mais son argumentation témoigne aussi de la dignité nouvelle de la poésie aux yeux des juges de son époque: la valeur de la poésie et des lettres en général est affirmée dans l'excursus sur les litterae, où Cicéron déclare qu'il ne faut pas rougir de s'adonner à ce type d'activités ${ }^{166}$, et avant cela quand l'orateur souligne qu'Archias bénéficie d'un réel honos dans la société romaine ${ }^{167}$. La philosophie bénéficie elle aussi au I ${ }^{\text {er }}$ siècle d'une certaine considération: au début du De natura deorum, il est question de l'honos dont jouissent les principales écoles philosophiques, épicurienne, stoïcienne, académicienne et antiochéenne, au milieu du ${ }^{\text {er }}$ siècle. Le dialogue

${ }^{166}$ CIC. Arch. 12-16.

${ }^{167}$ CIC. Arch. 6. 
met d'ailleurs en scène des hommes politiques romains tels que Cotta, Velleius et Balbus, qui s'y intéressent vivement ${ }^{168}$. La poésie et la philosophie sont ainsi intégrées parmi les motifs d'honos à côté des qualités militaires, morales et civiques. Il faut reconnaître là la marque de l'hellénisme et les conséquences de l'ouverture croissante de l'aristocratie romaine à la culture grecque au cours des $\mathrm{II}^{\mathrm{e}}$ et $\mathrm{I}^{\mathrm{er}}$ siècles: la place prise par la poésie et la philosophie comme moyen d'accès à l'honos correspond à la dernière phase d'hellénisation, choisie, des couches supérieures de la société romaine ${ }^{169}$. Cette ouverture à des valeurs culturelles grecques offrait à la nobilitas un nouveau terrain de compétition, par la recherche de l'excellence dans des activités et des modes de vie innovants par rapport à l'antique mos maiorum; cela a conduit, corrélativement, les sources d'honos à évoluer depuis la pratique politique et militaire traditionnelle vers des activités plus intellectuelles ${ }^{170}$.

Ces nouveaux motifs d'honos ne doivent pourtant pas nous amener à considérer que les fondements de ce dernier ont radicalement changé à partir du milieu du $\mathrm{II}^{\mathrm{e}}$ siècle. On remarque, d'abord, une persistance d'éléments traditionnels de prestige. Le développement, après les Gracques, d'une nouvelle figure politique centrale, celle de l'imperator, en témoigne. Les victoires remportées par Marius, Sylla, Pompée et César constituent un élément essentiel de leur notoriété et de leur suprématie politique. Le cas de Marius est exemplaire: son élévation à l'honos suprême du consulat, qu'il exerça sept fois, repose non pas sur la maîtrise d'une culture raffinée, mais sur son éclatante carrière militaire: sa uirtus reste martiale, sans entrer en contact avec l'hellénisme ${ }^{171}$. Même Cicéron, parvenu aux honores par une carrière civile, a recherché à augmenter son prestige par des victoires militaires. Lors de son proconsulat de Cilicie, à l'occasion de luttes victorieuses menées contre les ennemis de Rome dans la zone frontière du mont Amanus, entre Syrie et Cilicie, il fut salué imperator par ses troupes et rechercha ensuite à obtenir les honores d'une supplication, qui lui fut octroyée, puis d'un triomphe qu'il n'obtint jamais, entre autres à

${ }^{168}$ Cic. ND I, 16.

${ }^{169}$ Sur cette acculturation, voir P. Grimal, Le Siècle des Scipions. Rome et l'hellénisme au temps des guerres puniques, 2e éd., Paris, Aubier, 1975, p. 250 sqq. et E.S. Gruen, Culture and National Identity in Republican Rome, Ithaca, Cornell University Press, 1992, chap. 6 "The appeal of Hellas».

${ }^{170}$ Les aristocrates se sont livrés à « une nouvelle compétition pour la légitimation de traits culturels et de valeurs dont la possession ouvrait un champ nouveau à la définition de la vertu aristocratique»(DAvId, La République romaine, p. 77). Sur l'investissement de la nobilitas dans des valeurs nouvelles, voir BADEL, La Noblesse de l'Empire romain, p.170-175. Les sources identifiées de la gloria ont évolué dans le même sens (voir KNOCHE, «Der römische Ruhmesgedanke » et ThomAs, Gloria et laus, p. 47-48).

${ }^{171}$ Sur la distance, réelle ou affectée, prise par Marius vis-à-vis de l'hellénisme, voir Sall. Iug. 63, 3 et 85; Plut. Mar. 2, 2; Cic. Arch. 19; Val. Max. II, 2, 3. Voir aussi Gruen, Culture and National Identity, p. 268-269 et McDonnell, Roman Manliness, p. 273-274. 
cause du début de la guerre civile ${ }^{172}$. L'honos reste donc étroitement lié à l'excellence militaire. La continuité des sources de l'honos apparaît également quand on observe ce qui fait, en profondeur, l'honorabilité de la poésie et de la philosophie. Cette dernière, par exemple, est devenue honorable en tant que discipline, contenu intellectuel, mais la posture du philosophe reste problématique: se présenter comme un philosophe qui tient école est encore à la fin de la République une conduite très originale; c'est ce qui fait toute la particularité de l'attitude de Cicéron dans les Tusculanes, lorsqu'il se met à dispenser des leçons de philosophie ${ }^{173}$. La philosophie est parfaitement honorable, en revanche, quand ceux qui s'y intéressent restent des hommes d'État et assument principalement des fonctions civiques et politiques. On retrouve donc ici la matrice des motifs traditionnels d'honos, c'est-àdire le service de la cité ${ }^{174}$. L'otium litteratum vanté par Cicéron dans le Pro Archia est du même ordre: les poètes méritent l'honos car leur œuvre exalte la grandeur de Rome et attise chez les lecteurs l'amour de la uirtus au bénéfice de la cité entière ${ }^{175}$.

Une seconde évolution historique remarquable des motifs d'honos consiste dans l'accroissement des honores donnés sans mérite manifeste ou contrairement aux réglementations. Un des aspects de la crise qui touche la République romaine au dernier siècle de son existence est la multiplication des infractions au fonctionnement traditionnel de l'honos ou l'indignité manifeste des individus qui en bénéficient. Cette dernière caractéristique est isolée par Polybe, dans son analyse des cycles des régimes politiques, comme la cause de la décadence d'une aristocratie ${ }^{176}$ : les gouvernants de l'aristocratie se montrent initialement dignes des honneurs qui leur sont faits après la chute de la royauté mais leurs descendants, qui bénéficient aussi de ces honneurs, n'ont pas une conduite en accord. L'honneur ne repose plus sur le mérite, ce qui précipite la chute du régime. Cette analyse ne peut pas être transposée telle quelle dans la Rome tardo-républicaine mais elle a l'intérêt de replacer l'effacement des motifs à la source de l'honos dans un processus historique de décadence qui n'est pas totalement étranger à la situation romaine. Nous en avons un exemple avec l'affaire de Plancius, accusé de fraude lors de son élection à l'édilité:

172 Sur les opérations menées par Cicéron, voir Cic. Att. V, 20 et Fam. XV, 4.

${ }^{173}$ Sur la singularité de cette posture, voir C.LÉvy, "L'âme et le moi dans les Tusculanes ", REL, 80, 2002, p. 78-94 et I. GiLdenhard, Paideia Romana. Cicero's Tusculan Disputations, Cambridge, Cambridge Philological Society, 2007, p. 21-34.

${ }^{174}$ L'utilité de l'éloquence pour la cité et le prestige qui en résulte pour l'orateur apparaît ailleurs dans le De oratore (I, 117) et dans le Brutus (voir M. ЈАсотот, «De re publica esset silentium. Pensée politique et histoire de l'éloquence dans le Brutus ", in Aubert, S. (éd.), Prosopographie et rhétorique: le Brutus, paradigme de l'histoire culturelle, Louvain, Peeters, à paraître).

${ }^{175}$ Cic. Arch. 14 et 22.

${ }^{176}$ PoL. VI, 8, 4-6. 
dans son plaidoyer pour Plancius, Cicéron essaie de contrecarrer les accusations des adversaires qui mettent en avant l'indignité morale de son client ${ }^{177}$. La vie et les mœurs de Plancius font l'objet d'une grande attention car si l'accusation parvient à établir leur indignité, elle délégitimera du même coup l'octroi de l'honos. Cicéron met donc en avant la fides, la uirtus et la misericordia de celui qu'il défend ${ }^{178}$. Cependant, nous savons que c'est plus vraisemblablement le soutien des triumvirs, et notamment de Crassus, ainsi que l'appui des chevaliers qui avaient valu à Plancius son élection ${ }^{179}$. Cicéron essaie d'étayer l'honos sur des motifs moraux mais il est probable que leur invocation soit purement oratoire; ils continuent à fonder l'honos, mais dans les représentations, de manière conventionnelle. À cette fossilisation des motifs de l'honos s'ajoute le développement d'honores extraordinarii, octroyés contrairement aux règles que nous avons identifiées ${ }^{180}$. Brutus reproche ainsi à Cicéron d'avoir fait accorder des honneurs démesurés à Octave et redoute que cela ne l'encourage à convoiter de grands pouvoirs ${ }^{181}$. De façon clairvoyante, Brutus relie le dysfonctionnement des honores à la décadence de la République. Cicéron reconnaît qu'octroyer l'imperium à Octave malgré son jeune âge est un honos très inhabituel mais le justifie par la nécessité pour lui d'avoir ce pouvoir puisqu'une armée est sous ses ordres ${ }^{182}$. D’autres anomalies touchent l'octroi du triomphe et constituent encore un exemple du délabrement des institutions républicaines ${ }^{183}$. Ces perturbations affectant l'honos ne datent pas cependant du $\mathrm{I}^{\mathrm{er}}$ siècle. Scipion l'Africain semble avoir été un des premiers à se singulariser par l'obtention ou l'octroi d'honores extraordinarii: il reçut en 210 avant notre ère l'imperium, alors qu'il n'avait été qu'édile curule, pour commander les opérations en Espagne ${ }^{184}$. Tite Live le représente, après la victoire sur Syphax, donnant des distinctions considérables à Massinissa: il lui octroie une chaise curule, insigne réservé aux magistrats supérieurs,

${ }^{177}$ Voir notamment Cic. Planc. 30-31.

${ }^{178}$ Cic. Planc. 26.

179 Plancius était le fils d'un publicain important et Cicéron évoque lui-même l'appui des chevaliers (Planc. 23 et 24). Sur les liens de Plancius avec les triumvirs, voir P. Grimal (éd.), Cicéron. Discours (tome XVI, $2^{e}$ partie). Pour Cn. Plancius. Pour M. Aemilius Scaurus, p. 16-18.

${ }^{180}$ L'expression d'honores extraordinarii est utilisée à plusieurs reprises par Cicéron et ses correspondants en 43 (Cic. Ad Brut. I, 4a et I, 10, 3 par exemple).

${ }^{181}$ Cic. Ad Brut. I, 4a, 2-3. Brutus appelle Cicéron à plus de modus dans l'octroi des honneurs.

${ }^{182}$ Cic. Ad Brut. I, 15, 7.

${ }^{183}$ Voir Auliard, Victoires et triomphes à Rome, p. 39 sqq. On va jusqu'à rencontrer des triomphes octroyés sans qu'un combat ait été livré.

${ }^{184} M R R$ vol. 1, p. 301. Sur ces irrégularités et les innovations propres à Scipion dans différents domaines, voir M. A. LEvI, «Inizi di Scipione Africano e di una età di cambiamento » DHA, 23 (1), 1997, p. 145-153 et $C A H$ vol. 8, p. 174-176. 
ainsi que les distinctions des triomphateurs ${ }^{185}$. Ces innovations dans l'usage des marques d'honneur confèrent à Scipion un prestige exceptionnel et signent l'émergence de la figure nouvelle de l'imperator; elles sont également à mettre en rapport avec le développement de la «légende de Scipion » qui le présente comme un favori des dieux ${ }^{186}$. Ici encore, le dysfonctionnement de l'honos va de pair avec la montée en puissance d'un individu dont l'affirmation met en péril l'équilibre de la res publica et les règles de la compétition aristocratique.

${ }^{185}$ Liv. XXX, 15, 12-14.

${ }^{186}$ WaLBanK, "The Scipionic Legend». J.R. Fears, "The Theology of Victory at Rome: Approaches and Problems», ANRW, II, 17, 2, 1981, p.736-826 voit en lui la première étape dans la personnalisation de la théologie de la victoire (p. 780). 
CHAPITRE 7

\section{LES EFFETS DE L'HONNEUR}

\section{INTRODUCTION}

Létude des motifs et critères de l'honos nous a permis d'établir ce que l'honos servait à rétribuer. Mais si l'honos est rétribution, il reste à déterminer quel profit il apporte à celui qui le reçoit. Il nous faut donc déplacer le regard depuis les fondements de l'honneur vers ses effets: quel est le bénéfice pour le destinataire de la marque d'honneur? De quels bienfaits s'accompagne le prestige? Notre analyse sémantique a mis en avant la place que les contextes attachaient aux effets de l'honos et il faut approfondir cet aspect ${ }^{1}$. Un texte de Cicéron nous apporte en la matière quelques pistes de réflexion. À propos de la réaction des equites romains à la législation de M. Livius Drusus, hostile aux chevaliers, Cicéron rapporte les paroles de membres éminents de l'ordre équestre. Il est question de la loi prévoyant l'institution d'une quaestio pour les juges coupables de corruption, disposition à laquelle les chevaliers sont opposés :

Iniquum esse eos qui honorum ornamenta propter periculorum multitudinem praetermisissent populi beneficiis esse priuatos, iudiciorum nouorum periculis non carere. Senatorem hoc queri non posse, propterea quod ea condicione proposita petere coepisset quodque permulta essent ornamenta quibus eam mitigare molestiam posset, locus, auctoritas, domi splendor, apud exteras nationes nomen et gratia, toga praetexta, sella curulis, insignia, fasces, exercitus, imperia, prouinciae; quibus in rebus cum summa recte factis maiores nostri praemia tum plura peccatis pericula proposita esse noluerunt.

"Il était injuste que ceux qui avaient renoncé aux distinctions que valent les honneurs, en raison du grand nombre de dangers qu'ils comportent, fussent privés des bienfaits du peuple mais ne le fussent pas des dangers de nouveaux tribunaux. Un sénateur ne pouvait s'en plaindre, parce que c'est à cette condition qu'il avait commencé à se porter candidat et parce que les distinctions qui adoucissent cet aspect pénible sont innombrables: le rang, l'autorité, l'éclat à Rome, la réputation et la faveur chez les peuples étrangers, la toge prétexte, la chaise curule, les insignes, les faisceaux, les armées, les gouvernements, les provinces;

\footnotetext{
${ }^{1}$ Voir supra p. 54-58.
} 
dans ce domaine, nos ancêtres ont voulu qu'il y ait les plus hautes récompenses pour les bonnes actions, et de nombreux dangers pour ceux qui commettent des fautes.»

(CIc. Clu. 154).

L'argument des chevaliers est le suivant: il n'est pas équitable (iniquum) que les chevaliers, qui ont renoncé aux honores, subissent des contraintes qui n'ont de sens que pour les sénateurs. Ces derniers, en effet, ont choisi, eux, la voie des honneurs politiques, en tirent des bénéfices et il est donc normal qu'ils doivent, en contrepartie, obéir à certaines obligations et courir des risques. Ce texte présente plusieurs éléments intéressants qui feront l'objet d'une analyse approfondie dans ce chapitre. On voit d'abord que l'obtention de l'honos s'accompagne de divers avantages que Cicéron qualifie par deux fois d'ornamenta, de «distinctions, qui contribuent à l'illustration de la personne. L'individu honoré gagne en splendor, en prestige: il reçoit un éclat brillant qui attire le regard de ses contemporains. Il acquiert aussi une position élevée dans la société: il est question, juste avant ce texte, du haut locus gagné par celui qui reçoit l'honos et de sa dignitas sociale $^{2}$. Il obtient également un pouvoir, sous forme d'autorité officielle (exercitus, imperia, prouinciae) et d'influence plus diffuse (auctoritas, gratia). Ce pouvoir s'accompagne, enfin, de marques concrètes (sella curulis, fasces). Ce sont à ces avantages de l'honos que nous nous intéresserons d'abord. Mais le passage du Pro Cluentio souligne que ces avantages ont une contrepartie: l'honos provoque la molestia et fait courir des pericula à celui qui l'obtient. Il nous faudra donc nous pencher ensuite sur les contraintes imposées par l'honos. Enfin, nous nous intéresserons à l'articulation de ces avantages et contraintes: Cicéron indique en effet que les périls sont adoucis (mitigare) par les avantages, image qui demande à être interrogée pour voir quel phénomène exact de compensation est à l'œuvre.

\section{Les aVANTAges}

L'honos procure à celui qui en jouit un certain nombre de bénéfices personnels ${ }^{3}$. Nous retiendrons trois avantages en particulier: l'image de splendeur, la dignitas sociale et le pouvoir dans la cité. Nous ne reviendrons pas sur un quatrième élément, important, qui est l'honos lui-même: nous avons déjà vu que l'honos donnait naissance à l'honos ${ }^{4}$.

${ }^{2}$ Cic. Clu. 153.

${ }^{3}$ C'est ce qu'É. Terraillon nomme les «éléments égoïstes de l'honneur»: l'estime est recherchée en partie pour les bénéfices qu'elle apporte (E.TERRAILlon, L'Honneur, sentiment et principe moral, Paris, F. Alcan, 1912, p. 27). L'analyse sémantique a montré l'importance du sème du /bienfait/ dans le sémantisme d'honos (voir p.47-49 pour le sens «hommage » et p. 70-71 pour le sens «considération»).

${ }^{4}$ Voir supra p. $70-71$. 


\subsection{Une image de splendeur}

Nous avons pu constater que les marques d'honneur concrètes étaient ancrées dans le domaine du visible et, pour certaines d'entre elles, détenaient un aspect véritablement spectaculaire ${ }^{5}$. Ce dernier n'est pas sans effet sur le détenteur de l'honos: l'honneur place celui qui le reçoit sous les yeux de la collectivité et le fait passer de l'obscurité à la lumière. Les décorations militaires ou les insignes de la magistrature, d'une part, marquent visiblement leur possesseur en ornant sa personne; le triomphe et les funérailles, d'autre part, attirent sur l'honoratus les regards de ses concitoyens. Quant aux statues et aux tombeaux, placés à des endroits très fréquentés, les places et les routes, ils captent également l'œil du passant. L'honos fait ainsi d'un individu une figure publique: il l'inscrit dans l'espace de la cité et lui donne une visibilité exceptionnelle. L'image de l'éclat, du brillant et de la splendeur est associée de manière récurrente à l'honos, comme nous l'avons montré dans notre analyse sémantique ${ }^{6}$.

L'élaboration de cette image passe par l'octroi d'une visibilité mais aussi d'une distinction particulière: l'honos singularise celui qui le reçoit, le fait sortir de la masse de la communauté. Les dona militaria différencient les soldats qui les ont obtenus de ceux qui ne les ont pas; les triomphes consignés dans les fastes séparent les consuls triomphateurs des autres. Un texte de Salluste est particulièrement révélateur de ce fonctionnement, bien qu'il concerne les Numides. Après la mort de Micipsa, ses fils se réunissent:

Sed Hiempsal, qui minimus ex illis erat, natura ferox, et iam antea ignobilitatem Iugurthae, quia materno genere impar erat, despiciens, dextra Adherbalem adsedit ne medius ex tribus, quod apud Numidas honori ducitur, Iugurtha foret.

"Mais le plus jeune d'entre eux, Hiempsal, nature orgueilleuse, et qui depuis longtemps méprisait Jugurtha pour l'infériorité de sa naissance du côté maternel, s'assit à la droite d'Adherbal, afin d'empêcher Jugurtha d'occuper le siège du milieu, qui est la place d'honneur chez les Numides. »

(SALL. Iug. 11, 3; trad. Ernout).

Dans la lecture que fait Salluste de la disposition des princes numides, le siège du milieu est la place source d'honos ${ }^{7}$. Mettre quelqu'un au centre, c'est en effet le distinguer de ceux qui restent autour. L'honos singularise parce qu'il donne une position par rapport

${ }^{5}$ Supra p. 281 et 295.

${ }^{6}$ Supra p. 57.

${ }^{7}$ C'est aussi le cas à Rome (Cic. Rep. I, 18; Plut. Sull. 5). 
aux autres $^{8}$. Cet effet propre à l'honos relève de son mode opératoire symbolique: il amène l'individu à se distinguer des autres parce qu'il est un signe. Il appose une marque sur celui qui le reçoit et signale de ce fait à tous le mérite particulier de son détenteur par rapport aux autres personnes. On comprend dès lors pourquoi Cicéron, dans le passage que nous citions en introduction, concevait les avantages de l'honos comme des ornamenta: l'honos a pour effet de créer une image embellie de celui qui l'obtient. Un vers de Publilius Syrus confirme le lien entre signe, ornement et honos:

honos honestum decorat, inhonestum notat

«L'hommage embellit l'homme d'honneur mais stigmatise l'infâme.»

(P. Syr. frg. H 24 Meyer $=226 C R F)$.

L'honos embellit celui qui est honorable: il lui donne un decus qui augmente sa beauté. Quand il est octroyé à un inhonestus, à une personne qui ne le mérite pas, sa nature de signe ne disparaît pas pour autant, non plus que son effet distinctif: il continue d'apposer une marque, mais qui est de l'ordre de la nota, c'est-à-dire de la marque d'ignominie infligée par les censeurs à celui dont la conduite est immorale. L'honos signale et singularise, mais de façon cette fois négative.

La construction par l'honos d'une image publique peut encore être précisée. Outre la mise en lumière et la singularisation opérées par l'honneur, on voit apparaître dans les textes un réseau de représentations décrivant l'élévation opérée par l'honos. L'honneur donne à l'individu une supériorité sur ses semblables. C'est ce qui transparaît dans un fragment des Didascalica d'Accius, ouvrage de critique et d'histoire littéraire ${ }^{9}$ :

et magnificissimei excelsissimeique honore

«au plus haut point et magnifiques et sublimes grâce à l'honneur»

(Acc. Didasc. frg. X Dangel; trad. Dangel).

L'honos est le moyen d'un embellissement mais aussi d'une élévation remarquable: c'est par l'honos que l'on atteint une hauteur élevée, que l'on est excelsissimus. Il y a donc une distinction d'avec autrui,

${ }^{8}$ L'honos rendu aux défunts permet de même de les distinguer des vivants en les plaçant dans un lieu à part, religiosus, en dehors de la cité et en leur faisant rejoindre les rangs des dieux mânes (Toynbee, Death and Burial in the Roman World, p. 35-36; Ducos, «Le tombeau, locus religiosus »).

${ }^{9}$ Sur l'œuvre, A. PociÑa, El tragediógrafo latino Lucio Acio, Grenade, Universidad de Granada, 1984, p. 34-38. Selon R. Degl'Innocenti Pierini, Studi su Accio, Florence, CLUSF, 1977, p.66-67, le fragment que nous citons est issu d'un discours tenu par Accius devant le collegium poetarum. 
mais selon une échelle verticale. C'est avec une intention critique très différente de l'esprit du vers d'Accius, mais reposant sur la même imagerie, que Lucrèce note, dans sa critique de l'ambition, que l'envie fait bien souvent tomber les hommes du sommet où l'honos les a placés pour les précipiter directement dans le Tartare ${ }^{10}$. Ces métaphores de la supériorité procurée par l'honos font écho à la grandeur effective que donnent les marques d'honneur. Une statue équestre, par exemple, figure son destinataire dans une posture symboliquement prestigieuse puisqu'elle l'élève au rang de ce qui était à l'origine l'élite de l'armée romaine. La statue peut également grandir son destinataire quand elle le représente sous des traits héroïques et divins, l'élevant alors au-dessus de l'humanité ${ }^{11}$. Le triomphe établit lui aussi la supériorité du général, sur ses ennemis d'abord, sur les hommes ensuite, en rapprochant le triomphateur de la divinité puisqu'il arbore pendant la cérémonie les attributs de Jupiter ${ }^{12}$. L'éloge funèbre se livre également à une entreprise d'élévation du destinataire par le procédé de l'amplification dont la place centrale dans le genre démonstratif est reconnue par tous les ouvrages de rhétorique ${ }^{13}$. Léloge funèbre de L. Caecilius Metellus en donne un bon exemple avec la cascade de superlatifs employés à propos du défunt:

Voluisse enim primarium bellatorem esse, optimum oratorem, fortissimum imperatorem, auspicio suo maximas res geri, maximo honore uti, summa sapientia esse, summum senatorem haberi, pecuniam magnam bono modo inuenire, multos liberos relinquere et clarissimum in ciuitate esse; haec contigisse ei nec ulli alii post Romam conditam.

«Il avait voulu en effet être le premier guerrier, le meilleur orateur, le général le plus courageux, conduire de grandes entreprises sous ses auspices, bénéficier du plus grand honneur, être de la plus haute sagesse, être considéré comme le sénateur le plus important, faire fortune de manière honnête, laisser de nombreux enfants et être l'homme le plus brillant dans la cité; tout cela lui était échu à lui et à lui seul depuis la fondation de Rome.»

(PLIN. NH VII, 140).

Léloge crée ainsi chez les auditeurs une représentation grandiose de la personne honorée et l'on sait que certains panégyristes ont cédé

${ }^{10}$ LuCr. DRN V, 1124-1126.

${ }^{11}$ Voir par exemple les statues de ce type octroyées à César (LAHUSEN, Untersuchungen zur Ehrenstatue in Rom, p. 53).

${ }^{12}$ Voir supra p. 274 sqq. sur l'interprétation des insignes du triomphateur. Même si l'on estime que les insignes du triomphateur sont ceux du roi, il y a tout de même une élévation considérable au-dessus de la foule des spectateurs.

13 «Cette association de l'éloge et de l'amplification a constitué dans la théorie rhétorique antique une sorte de dogme, réaffirmé à toutes les époques, depuis la Rhétorique à Alexandre jusqu'aux auteurs de la fin de l'Antiquité »(PERNOT, La Rhétorique de l'éloge, p. 676-677). 
à la tentation d'amplifier les mérites de la personne louée au point de lui inventer des exploits ${ }^{14}$. Il est important de noter que, dans les exemples que nous avons donnés, l'effet d'élévation de l'honos opère à chaque fois dans le domaine de la figuration: l'honneur crée pour la collectivité qui en est le témoin une image de la supériorité du détenteur de l'honos. La statue est une représentation matérielle du sujet, le triomphe une mise en scène spectaculaire ${ }^{15}$ et l'éloge une représentation verbale. La personne qui bénéficie de l'honos connaît donc une élévation d'ordre symbolique.

Cette image de splendeur, enfin, rencontre un écho particulier à Rome parce qu'elle trouve une place dans le temps en plus d'être située dans l'espace de la cité. L'honos a pour effet de préserver le souvenir de l'individu honoré. Il confère ainsi un éclat particulièrement apprécié parce que durable. C'est évidemment le cas des honores funèbres et notamment des tombeaux. Ces honores constituent des monumenta dans tous les sens du terme: ce sont des édifices mais aussi des objets qui permettent de se souvenir ${ }^{16}$. L'épitaphe qui accompagne la sépulture, en donnant le nom du défunt et en rappelant l'essentiel de ce que fut sa vie, participe à cet effet mémoriel de l'honos ${ }^{17}$. Dans le Cato maior, au cours de la démonstration sur la survie de l'âme après la mort, il apparaît que les honores accordés aux défunts permettent à ceux qui viennent après eux de conserver leur memoria et que ce souvenir est facilité par l'action de leur âme qui survit après le trépas:

Nec uero clarorum uirorum post mortem honores permanerent, si nihil eorum ipsorum animi efficerent, quo diutius memoriam sui teneremus.

${ }^{14}$ Cic. Brut. 62 ; Liv. VIII, 40, 4. Sur ce point, voir R. T. Ridley, «Falsi triumphi, plures consulatus ", Latomus, 42, 1983, p.372-382.

${ }^{15}$ Dans l'interprétation donnée par J. Scheid du triomphe, il y a une figuration à double niveau car le général représente, plutôt que le dieu, la statue cultuelle du dieu (J.ScheID, "Le flamine de Jupiter, les Vestales et le général triomphant. Variations romaines sur le thème de la figuration des dieux», Le temps de la réflexion, 7, 1986, p. 213-230).

${ }^{16}$ Sur ce sens de monumentum et le rapport du mot avec moneo, voir DELL p. 412. Sur le rôle mémoriel du tombeau, voir H. Lavagne, "Le tombeau, mémoire du mort» in La Mort, les morts et l'au-delà dans le monde romain, Caen, Centre de publications de l'Université de Caen, 1987, p. 159-165 et Ducos, «Le tombeau, locus religiosus » qui renvoie à la définition du Digeste, XI, 7, 2, 6: Monumentum est quod memoriae seruandae gratia existat. On trouve chez CIc. Verr. II, II, 157 un honos sous forme de monumentum où le terme renvoie simultanément à un objet matériel érigé et à un moyen de commémoration.

${ }^{17}$ Voir par exemple notre étude des épitaphes des Scipions, chapitre 14. L. Lamoine, «Les lecteurs de l'elogium de Scipion Barbatus», ArchClass, 51 (N.S. 1), 1999-2000, p. 361-368 note à propos du premier occupant du tombeau de la famille des Scipions que "par la composition de l'elogium, sa gravure dans la pierre et sa lecture, les Scipions du $\mathrm{II}^{\mathrm{e}}$ siècle offrent à Barbatus 'quelques instants de vie', annulent le passé donc l'oubli » (p.363). 
«Et les honneurs octroyés aux hommes célèbres après leur mort ne perdureraient certainement pas si leurs propres âmes n'agissaient pas pour que nous préservions plus longtemps leur souvenir. »

(CIc. Cato mai. 80).

L'honos octroyé aux défunts contribue à les rendre clari, illustres, c'est à dire à leur donner une splendeur visible mais aussi à faire durer cette splendeur dans le temps, à faire entrer ces hommes parmi les personnages célèbres dont on se souvient. D'autres honores que les tombeaux sont aptes à inscrire la personne honorée dans le souvenir des hommes. C'est le cas notamment des portraits peints ou encore des statues, dont certaines sont d'ailleurs octroyées à titre posthume, pour honorer un défunt dont la mort a été particulièrement illustre. Les délégués du peuple romain qui ont péri à Fidènes par la faute de Lar Tolumnius ont reçu l'honos de statues sur les rostres que Cicéron pouvait encore voir. Il remarque qu'elles ont donné à ces victimes une diuturna memoria, un souvenir durable ${ }^{18}$. C'est aussi par souci d'éviter l'obliuio que Cicéron demande aux sénateurs une statue pour Ser.Sulpicius mort en mission ${ }^{19}$. L'oubli est connoté négativement dans une société dont les normes reposent en grande partie sur l'imitation des ancêtres et la perpétuation des coutumes.

\subsection{La dignitas}

L'honos met en avant celui qui le détient mais le transforme aussi profondément, en modifiant son être social. Exilé à Thessalonique, Cicéron écrit à Atticus:

Possum obliuisci qui fuerim, non sentire qui sim, quo caream honore, qua gloria, quibus liberis, quibus fortunis, quo fratre?

«Puis-je oublier qui je fus, ne pas voir qui je suis, de quel honneur je suis privé, de quelle gloire, de quels enfants, de quels biens, de quel frère? »

(CIC. Att. III, 10, 2).

La perte de l'honneur et des autres biens a provoqué chez Cicéron un changement d'être: il y a une nette divergence entre ce qu'il fut (qui fuerim) quand il avait l'honos et ce qu'il est (qui sim) à présent qu'il en est privé. L'honos confère en effet à celui qui le gagne statut, importance et respectabilité. Il y a là une rétribution qui ne relève plus du seul ordre symbolique mais se compose d'avantages sociaux concrets

18 Cic. Phil. IX, 4. Sur la dimension commémorative des statues, LahuSEn, Untersuchungen zur Ehrenstatue in Rom, p. 135.

${ }^{19}$ Cic. Phil. IX, 10. Sur l'honos pour empêcher l'oubli, voir aussi Cic. Phil. XIV, 33. 
que les Romains subsument sous la notion de $\operatorname{dignitas}^{20}$. Cette dernière recouvre trois éléments que nous allons passer en revue, l'obtention d'un haut rang dans la cité, l'intégration à l'aristocratie, et le droit au respect de la part de l'entourage.

La dignitas procurée par l'honos désigne d'abord le rang au sein de la cité. Félicitant le sénat d'avoir couvert César de distinctions pour mieux le contrôler, Cicéron déclare:

Neminem umquam est hic ordo complexus honoribus et beneficiis suis, qui ullam dignitatem praestabiliorem ea, quam per uos esset adeptus, putarit.

«Aucun de ceux que notre ordre a entourés d'honneurs et de bienfaits n'a jamais préféré une autre distinction à celle qu'il vous devait. »

(Cic. Prou. 38; trad. Cousin modifiée).

Les honores donnés par le sénat procurent à César une dignitas qui est un rang élevé dans la hiérarchie des hommes publics, accompagné de différentes prérogatives ${ }^{21}$. Ces aspects de la dignitas s'observent aussi chez celui qui reçoit une corona ciuica: l'individu pourvu de cet honos a, par conséquent, le droit de s'asseoir parmi les sénateurs lors des jeux et ces derniers se lèvent à son entrée; il est exempté de certains devoirs civiques et Tite Live fait état d'une occasion où, pour combler les trous du sénat, on considère sérieusement, parmi les candidats possibles, ceux qui ont obtenu une couronne civique ${ }^{22}$. Dans les municipes, l'obtention d'un honos est un moyen d'ascension sociale au même titre que l'enrichissement économique ${ }^{23}$. La promotion civique et sociale assurée par l'honneur nous amène à préciser le fonctionnement de l'honos comme capital symbolique. On voit que le symbolisme propre à l'honos et sa capacité à signifier l'estime n'excluent nullement une efficacité concrète. L'expression symbolique de la considération débouche au contraire sur une ascension dans la hiérarchie de la cité. Ce capital symbolique qu'est l'honneur est donc

${ }^{20}$ Cette notion peut donc désigner le « mérite » à la source de l'honos (voir p. 76) mais aussi, par une sorte de circularité, différents avantages sociaux qui résultent de l'honos. Sur la dignitas comme avantage social, voir WegeHaupt, Die Bedeutung und Anwendung von dignitas; Hellegouarc'H, Vocabulaire, p. 389 sqq.; DreXler, "Dignitas »; Piscitelli CARPINo, "Dignitas in Cicerone»; LIND, «The Tradition of Roman Moral Conservatism»; Pöschl, "Politische Wertbegriffe in Rom»; FËDorov, "La genèse de la composante esthétique»; Thомe, Zentrale Wertvorstellungen der Römer, vol. 2, p. 117-134.

${ }^{21}$ Sur cet aspect de la dignitas, HöLKesKamp, Die Entstehung der Nobilität, p. 212. Sur le rapport privilégié de la notion de dignitas au rang social, RILINGER, "Ordo und dignitas als soziale Kategorien der römischen Republik ».

${ }^{22}$ Sur ces points, voir LIV. XXXIII, 23, 6 et le commentaire de MAXFIELD, The Military Decorations, p. 70.

${ }^{23}$ Nicols, "Zur Verleihung öffentlicher Ehrungen in der römischen Welt», p. 244. Sur le rôle respectif des honneurs et de l'argent dans l'élévation sociale, voir MAcMuLLEN, Rapports, p. 102. 
particulièrement précieux car il est susceptible d'être converti en un autre type de capital: la considération, capital d'estime, peut se muer en rang social élevé, en capital social ${ }^{24}$.

La dignitas procurée par l'honos provoque en outre un changement d'appartenance sociale par l'intégration à l'aristocratie ${ }^{25}$. Obtenir l'honos, c'est commencer à s'agréger à l'élite romaine. On le constate même à des échelons modestes, en dehors de Rome. Cicéron parle en ces termes de Philodamus de Lampsaque:

Is ad eum rem istam defert, Philodamum esse quendam, genere, honore, copiis, existimatione facile principem Lampsacenorum.

"Il lui rapporte la chose suivante: il y avait à Lampsaque un certain Philodamus, et la naissance, l'honneur, la richesse, la considération dont il jouissait faisaient de lui facilement le premier des citoyens de la ville.»

(Cic. Verr. II, I, 64).

L'honneur, sous la forme de l'honos et de l'existimatio, ajouté à la haute naissance (genus) et à la fortune (copiae) fait de Philodamus le princeps des habitants de Lampsaque, le citoyen le plus important de la ville. Ces mêmes catégories réapparaissent dans le Pro Flacco:

Amyntas est genere, honore, existimatione, pecunia princeps illius ciuitatis.

«Amyntas est, de par sa naissance, son prestige, sa considération, sa fortune, le premier des habitants de cette cité.»

(CIc. Flac. 72).

Appartenir aux principes, autrement dit à l'aristocratie, suppose une certaine fortune et une haute naissance. Cela n'est pas surprenant: tout le système civique romain est organisé de façon censitaire et l'appartenance au patriciat ou à la nobilitas génère d'importants privilèges. Mais on voit aussi que cela n'est pas suffisant pour rejoindre l'élite: il faut aussi bénéficier de la considération de l'entourage et d'un réel prestige social ${ }^{26}$. Le sujet qui veut s'élever dans la cité a besoin du

${ }^{24}$ Bourdieu a donné un exemple de la conversion du capital symbolique à propos des Kabyles (Bourdieu, Esquisse d'une théorie de la pratique, p. 367): le prestige d'une famille peut être converti en capital économique car il lui sert à obtenir des crédits ou à participer avantageusement à des échanges marchands. Voir aussi l'analyse de Goode, The Celebration of Heroes sur la manière dont le prestige peut être utilisé comme «risk capital» (p.42).

${ }^{25}$ La notion est associée de manière privilégiée à la nobilitas, frange supérieure de l'aristocratie: Sall. Iug. 41, 5; Cic. Rosc. Amer. 16. Voir Wegehaupt, Die Bedeutung und Anwendung von dignitas, p.12-14; Hellegouarc'H, Vocabulaire, p. 549-550; Piscitelli CARPINO, «Dignitas in Cicerone», p. 258-259.

${ }^{26}$ Sur ce point, Веск, Karriere und Hierarchie, p. 11. 
regard et de l'approbation des autres et de marques concrètes d'honneur qui créent une ségrégation positive, nécessaire à l'intégration dans l'élite ${ }^{27}$.

Cette importance de l'honos pour l'accès à l'aristocratie est réelle quand il est question du "prestige » mais elle est d'autant plus cruciale s'agissant de la "charge publique» car c'est surtout cet honos qui agrège l'individu aux principes de la cité. L'aristocratie romaine est une aristocratie politique: le fait même qu'honos puisse désigner le prestige et la charge publique en est un indice ${ }^{28}$. L'honos permet en premier lieu de rejoindre les rangs du sénat et la dignitas procurée par l'honos politique est donc une dignité sénatoriale, ainsi que l'indique Cicéron quand il remercie le peuple

cuius honoribus in amplissimo consilio et in altissimo gradu dignitatis [...] collocati sumus.

«dont les honneurs nous ont élevé dans la plus auguste assemblée, au plus haut degré de dignité. »

(CIc. Red. Sen. 2 ; trad. Wuilleumier modifiée).

Les honores politiques qu'il a exercés ont amené Cicéron, en le faisant entrer au sénat, à la plus haute dignitas possible. Recrutant d'abord les anciens magistrats curules, la prestigieuse assemblée s'est progressivement ouverte aux édiles puis aux tribuns de la plèbe et aux questeurs ${ }^{29}$. L'honos permettait aussi d'occuper une place précise dans la hiérarchie de l'assemblée: les consulaires avaient bien plus d'influence que les anciens questeurs ${ }^{30}$. En second lieu, si l'honos agrège à l'aristocratie, c'est aussi parce qu'il a pour effet d'ouvrir l'accès à la nobilitas. La charge politique est, on l'a vu, l'honos par excellence parce qu'elle permet, quand sa position dans le cursus est suffisamment élevée, de préserver la nobilitas de ses ancêtres ou bien d'y faire

${ }^{27}$ Sur l'importance de la ségrégation visible dans la constitution des élites, voir Elias, La Société de cour, p. 85. Voir aussi Veyne, Le Pain et le cirque, p. 278-279 pour qui les honneurs servent, dans le monde grec, à créer une « inégalité de prestige ».

${ }^{28}$ Sur ce sens d'honos, voir supra p. 82 sqq. Sur l'honos et l'Amtsorientierheit de l'aristocratie, HöLKESKamp, Die Entstehung der Nobilität, p. 210.

${ }^{29}$ Lintott, The Constitution of the Roman Republic, p. 68-69 et Nicolet, Rome et la conquête, p. 198 sqq. et 367 . On connaît quelques cas de particuliers intégrés au sénat sans avoir été magistrats au préalable, en 216 et en 80 notamment (Ibid. p. 199). Cependant l'exercice d'une magistrature n'était pas suffisant: il fallait posséder une qualification censitaire minimale et faire preuve de bonne moralité pour être inscrit par les censeurs sur l'album du sénat (Ibid. p. 200 et 365-367). L'exercice de professions infamantes comme celles de gladiateur, laniste, marchand d'esclave, entrepreneur de pompes funèbres, etc. interdisait l'accès au sénat.

${ }^{30}$ Sur le rang des sénateurs et l'ordre dans lequel ils sont interrogés, voir BonNEFONDCoudry, Le Sénat de la République romaine et F.X. Ryan, Rank and Participation in the Republican Senate, Stuttgart, F. Steiner, 1998. 
accéder ses descendants lorsque l'on est un homo nouus ${ }^{31}$. L'honos est ainsi un ingrédient essentiel de l'appartenance à l'élite suprême de Rome. C'est lui qui permet à la commendatio maiorum de s'exercer efficacement: un noble peut se recommander de ses ancêtres car ils ont obtenu des honores, signes de l'estime de la collectivité. L'honos exercé par les ancêtres autorise les descendants à exhiber leurs imagines, à montrer la gloire de leur famille et à assurer ainsi leur propre succès politique $^{32}$. Au sein même de la nobilitas s'opère pour chaque membre un décompte des honores (charges publiques, triomphes, etc.) qui le situe sur une échelle de dignitas au sommet de laquelle se trouvent les consuls et triomphateurs ${ }^{33}$ : les honores sont aussi un facteur de différenciation dans la hiérarchie interne de l'élite.

Le haut rang assuré par l'honos s'accompagne, enfin, d'un droit au respect de la part de l'entourage. En plein cour de la lutte contre Catilina et les conjurés de 63, Cicéron est amené à défendre Muréna, consul désigné pour 62, accusé de brigue. Il justifie en ces termes son intervention en sa faveur:

Mihi autem cum Murena, iudices, et magna et uetus amicitia est, quae in capitis dimicatione a Ser. Sulpicio non idcirco obruetur quod ab eodem in honoris contentione superata est. Quae si causa non esset, tamen uel dignitas hominis uel honoris eius quem adeptus est amplitudo summam mihi superbiae crudelitatisque infamiam inussisset, si hominis et suis et populi Romani ornamentis amplissimi causam tanti periculi repudiassem.

«Or je suis lié, juges, à Muréna par une amitié forte et ancienne qui ne sera pas ensevelie par Servius Sulpicius parce qu'il l'a emporté sur elle lors d'une compétition pour l'honneur. Et même si cette raison n'existait pas, la dignité de Muréna ou la grandeur de l'honneur qu'il a obtenu feraient peser sur moi une réputation d'orgueil et de cruauté si je rejetais la cause extrêmement périlleuse d'un homme tout à fait important par ses propres distinctions et par celles que lui a données le peuple romain.»

(Cic. Mur. 8).

Cicéron prend en considération l'amicitia ancienne qui l'attache à l'accusé mais relève qu'une autre raison, encore plus impérieuse, le pousse à le défendre: c'est la dignitas de Muréna et de l'honos qu'il a obtenu (uel dignitas hominis uel honoris). Il est encore question de la dignitas qui s'attache à l'honos mais on voit apparaître un aspect resté jusqu'ici dans l'ombre: la dignitas générée par l'honneur est un statut supérieur qui impose des contraintes à l'entourage de l'honoratus. Il est impensable, pour Cicéron, de ne pas répondre à l'appel

${ }^{31}$ Voir supra p.294-295 pour la définition de la nobilitas et le rôle essentiel de l'honos politique. et 90 .

${ }^{32}$ Sur la commendatio maiorum et les imagines, voir Flower, Ancestor Masks, p. 65

${ }^{33}$ Sur ce gradus dignitatis, voir BЕсK, Karriere und Hierarchie, p. 12; HöLKesKamp, Reconstruire une République, p. 83. 
d'un consul désigné; ne pas venir en aide à une personne dotée, par sa charge, d'une si haute dignitas serait se condamner soi-même à l'infamia: on se déshonore si on ne répond pas à la demande de celui qui est à l'honneur. Caton et Sulpicius, les accusateurs, intentent certes une action en justice contre Muréna; mais ils se permettent de le faire précisément parce qu'ils contestent la validité de l'honos obtenu par Muréna et lui refusent donc la dignitas honoris. La dignitas impose à la collectivité une attitude de déférence vis-à-vis du dignus : c'est un droit au respect ${ }^{34}$. Ce dernier est appréhendé par Cicéron dans la définition théorique qu'il donne de l'obseruantia:

Obseruantiam, per quam aetate aut sapientia aut honore aut aliqua dignitate antecedentes ueremur et colimus.

«Respect, ce qui nous porte à montrer de la vénération et des égards envers ceux qui l'emportent sur nous par l'âge, la sagesse, l'honneur, ou quelque dignité.»

(Cic. Inu. II, 66; trad. Achard modififée).

L'honos, le prestige, est un des traits qui imposent l'obseruantia, le respect. Deux obligations concrètes sont réunies sous ce qualificatif: colere, c'est-à-dire donner des marques de vénération, protéger soigneusement, voire rendre un culte quand il s'agit d'une divinité; uereri, révérer profondément, non sans une certaine crainte.

Bénéficier de l'honos a donc des répercussions extrêmement concrètes: la situation d'estime va de pair avec la détention d'une aura protectrice qui permet d'écarter les iniuriae par la création d'une zone sanctuarisée. L'image d'une citadelle sacrée bâtie par les honores apparaît dans un discours de T. Sempronius Gracchus, le père des Gracques, qui s'en prend aux tribuns de la plèbe qui s'acharnent contre Scipion l'Africain:

Nullisne meritis suis, nullis uestris honoribus, umquam in arcem tutam et uelut sanctam clari uiri peruenient, ubi si non uenerabilis, inuiolata saltem senectus eorum considat?

«Jamais les hommes illustres, grâce à leurs propres mérites et aux honneurs que vous leur décernez, n'atteindront donc une citadelle sûre et inviolable où leur vieillesse puisse se reposer, sinon entourée de vénération, du moins préservée des attaques?»

(Lrv. XXXVIII, 53, 4; trad. Adam modifiée).

Les multiples honores obtenus par l'Africain devraient lui permettre de se retirer dans une citadelle sûre, religieusement garantie. Cette garantie supérieure consécutive aux honores rend toute attaque intolérable et presque sacrilège. Porter atteinte physiquement à une personne

${ }^{34}$ Sur les obligations qui s'imposent à l'entourage de celui qui détient la dignitas, voir par exemple Cic. Rosc. Amer. 54 et Liv. XXVI, 49, 15. 
in honore constitue en effet un crime particulièrement scélérat: le $D e$ inuentione range cette agression au second rang des plus abominables, après le crime commis contre un membre de sa famille ou contre un suppliant ${ }^{35}$. Si l'on prend l'ensemble des discours de Cicéron comme corpus de référence, on s'aperçoit que ce sont les personnages représentés par lui comme les plus ignobles qui s'en prennent à des honesti, des individus considérés. Verrès agit de la sorte en faisant violence à des Siciliens distingués par leur honos ${ }^{36}$. Clodius ignore également toutes les règles que l'honos impose:

Ac si hoc de me potuit, quem honos, quem dignitas, quem causa, quem res publica tuebatur [...], quid tandem futurum est iis quorum uita remota ab honore populari et ab hac inlustri gratia est [...]?

«Et s'il a pu me faire cela, à moi qui étais protégé par mon honneur, mon rang, ma cause, la république [...], qu'arrivera-t-il enfin à ceux dont la vie ne connaît ni l'honneur que donne le peuple ni l'éclat que donne la faveur?»

(CIc. Dom. 46).

La loi sur l'exil de Cicéron votée à l'instigation de Clodius est une grave atteinte à l'honos et à la dignitas de l'Arpinate qui n'aurait jamais dû subir pareil assaut étant donné son statut. Pour bien prendre la mesure de la singularité de cette garantie associée à l'honos, il convient de garder à l'esprit que l'honos est octroyé par un tiers ou par une collectivité. Conférer l'honos à quelqu'un revient donc, pour le donateur, à s'imposer à lui-même une règle de conduite vis-à-vis de la personne qu'il honore. Le groupe qui donne l'honneur consent ainsi volontairement à son infériorité et crée lui-même les règles du respect dont il devra entourer l'honoratus.

Nous voyons ainsi se dessiner plus nettement la relation de l'honos à la dignitas et la nature de cette dernière. Générée par l'octroi de marques d'honneur ou issue d'une conversion du capital symbolique de prestige, elle consiste en un rang social et civique élevé, est la caractéristique distinctive de l'aristocratie et impose à l'entourage une attitude de respect. La dignitas, que nous avions repérée à la source de l'honos, en est aussi un effet. Il y a donc une relation dialectique entre honos et dignitas, qui peut se muer en enchaînement sans fin: la dignitas acquise au moyen d'honores provoque à son tour l'obtention de nouveaux honores. La dignitas appelle l'honos qui renforce à son tour la dignitas. Ce cercle vertueux explique pourquoi l'honos tend à déclencher l'honos, comment l'aristocratie parvient à monopoliser certains honneurs et pourquoi il est si difficile aux homines noui de parvenir à les acquérir.

${ }^{35}$ CIc. Inu. I, 103. Voir aussi Inu. I, 107.

${ }^{36}$ CIc. Verr. II, I, 67 ; II, II, 16 et II, II, 112. 


\subsection{Le pouvoir}

L'analyse par les ethnologues des sociétés non occidentales a permis de mettre en évidence, pour certaines d'entre elles, la manière dont le prestige gagné par un individu grâce à des talents bien précis, de nature guerrière par exemple, pouvait s'étendre au-delà de la sphère dont il était issu et lui permettre d'agir dans la gestion des relations au sein du groupe social ou d'exercer une autorité de nature politique ${ }^{37}$. Quel est, à Rome, le rapport de l'honos avec le pouvoir, notamment politique? Le symbolique peut-il avoir un usage politique? Lanalyse faite par Bourdieu du capital symbolique nous incite à en faire l'hypothèse, tout capital étant un "pouvoir sur un champ », sur un ensemble de revenus et de profits ${ }^{38}$. Il convient cependant de tester cette hypothèse et, surtout, d'identifier avec précision la nature du pouvoir apporté par l'honneur ${ }^{39}$.

L'analyse des textes montre, en premier lieu, que l'honos confère une capacité d'agir sur le cours des affaires publiques et de gouverner l'État. C'est bien évidemment le cas des honores que sont les charges: l'obtention d'une magistrature confère la potestas et, pour les plus importantes d'entre elles, l'imperium ${ }^{40}$. Mais les autres aspects de l'honos, la considération et les marques d'honneur non politiques, procurent aussi un pouvoir. Le prestige qu'est l'honos constitue d'abord un atout pour accéder aux charges publiques: avoir fait ses preuves comme chef militaire, comme jurisconsulte expert du droit ou comme patronus éloquent ne suffit pas; il faut en outre disposer d'un capital symbolique qui justifie la prétention au gouvernement de la cité ${ }^{41}$. Lors de l'élection, le candidat qui l'emporte n'est pas élu pour un programme ou pour son appartenance à un parti mais pour sa personne et il est donc essentiel qu'il soit connu et estimé ${ }^{42}$. C'est une des raisons pour lesquelles les nobiles parviennent plus facilement au

${ }^{37}$ Voir par exemple l'analyse faite par M. Godelier de l'aoulatta, le « Grand guerrier » des Baruya de Nouvelle-Guinée: sa bravoure guerrière lui confère un grand prestige militaire, qui peut devenir un pouvoir dans la tribu en temps de paix. Il est écouté et règle des conflits: "Son autorité prenait donc source dans sa bravoure et dans la crainte que celle-ci inspirait, et par-là son prestige se transformait en pouvoir social »(GodELIER, La Production des grands hommes, p. 174).

38 "Les espèces du capital, à la façon des atouts dans un jeu, sont des pouvoirs qui définissent les chances de profit dans un champ déterminé » (Bourdieu, Langage et pouvoir symbolique, p. 294).

${ }^{39}$ L'analyse donnée par Lendon de l'autorité conférée par le prestige reste très générale et ne fait pas ressortir assez les particularités de l'ascendant donné par l'honos (p. 55-60).

${ }^{40}$ Sur la nature de la potestas et de l'imperium, voir supra p. 293.

${ }^{41}$ David, La République romaine, p. 30.

${ }^{42}$ Sur l'importance de la notoriété du candidat dans l'élection, voir Gruen, The Last Generation of the Roman Republic, p.121-122. 
consulat: le prestige de leur famille leur permet, plus que leur richesse et au moins autant que leur clientèle, d'attirer des électeurs traditionnellement enclins à confier le pouvoir à des individus au nom connu et aux ancêtres respectables ${ }^{43}$.

Une fois passée l'étape des comices, l'honos confère d'importants moyens d'action. Plus un homme politique détient de prestige, plus il pourra influer sur les affaires publiques. En février 43, au cœur de sa lutte contre Antoine, Cicéron déplore l'état des forces du sénat:

Quamquam egregios consules habemus, sed turpissimos consularis; senatum fortem, sed infimo quemque honore fortissimum.

«Il est vrai que nous avons des consuls extraordinaires, mais des consulaires tout à fait honteux; des sénateurs courageux, mais les plus courageux sont ceux qui ont le moins de prestige.»

(CIc. Fam. XII, 4, 1).

Cicéron regrette que les sénateurs les plus courageux ne soient pas les consulaires, situés au sommet de la hiérarchie interne du sénat, mais ceux qui ont le moins d'honos, c'est-à-dire les magistrats de rang inférieur. Pour pouvoir passer à l'action et orienter les décisions du sénat, il faut en effet détenir un honos important; être courageux ne suffit pas, encore faut-il pouvoir convaincre les autres, par son prestige, de se montrer courageux également. Dans une société structurée par des hiérarchies internes et attentive aux préséances, l'honos est une source de pouvoir politique. L'honneur n'est pas à Rome l'aura glorieuse de l'homme de pouvoir qui s'ajoute par surcroît à son autorité; il est ce qui fait d'un homme public un homme de pouvoir. L'honos confère une légitimité supérieure qui facilite l'acceptation par les administrés de l'autorité. Verrès a commis une erreur capitale en emmenant avec lui en Sicile, pour l'assister dans son activité, un ramassis de truands: un promagistrat doit veiller à s'entourer de gens honnêtes et compétents afin de rester considéré, pour que son pouvoir ne soit pas ressenti comme une oppression mais comme une autorité légitime ${ }^{44}$. Le magistrat doté d'un fort capital symbolique, reposant sur

${ }^{43}$ Voir sur ce point Nicolet, Métier, p. 419. La confiance accordée aux nobles en matière politique apparaît dans l'anecdote rapportée par Valère Maxime au sujet de Scipion Nasica Serapio. Un tribun avait proposé des mesures pour faire face à l'augmentation du prix des denrées alimentaires, mesures auxquelles Nasica s'opposa publiquement, suscitant immédiatement des récriminations de la plèbe. Il la fit taire par ces paroles: 'Tacete, quaeso, Quirites, inquit, plus ego enim quam uos quid rei publicae expediat intellego.' Qua uoce audita omnes pleno uenerationis silentio maiorem auctoritatis eius quam suorum alimentorum respectum egerunt. "'Taisez-vous Citoyens, je vous le demande, dit-il: je sais mieux que vous ce qui est utile à la république'. À ces paroles, tous marquèrent un silence plein de respect, montrant plus de considération pour son autorité que pour leur ravitaillement»(VAL. MAX. III, 7, 3).

${ }^{44}$ Voir l'analyse de Cic. Verr. II, II, 28-29. 
des mérites réels, transforme la relation d'obéissance des administrés en une relation de respect pour son honneur qui rend la contrainte du pouvoir plus acceptable ${ }^{45}$. Dans une société dotée de forces de police limitées, le pouvoir doit s'imposer par le respect plus que par la contrainte et le prestige est un élément essentiel pour susciter ce respect ${ }^{46}$. Les marques concrètes d'honneur jouent aussi de ce point de vue une grande importance car elles matérialisent l'estime, renforcent le prestige de l'homme public et donc son pouvoir. Elles participent directement à ce double processus de renforcement et de légitimation de l'autorité publique. C'est la raison pour laquelle Cicéron s'indigne que, lors de sa visite chez les Mamertins, on ne lui ait pas offert l'hospitalité alors qu'il est sénateur de Rome:

Qui honos non homini solum habetur, sed primum populo Romano, cuius beneficio nos in hunc ordinem uenimus, deinde ordinis auctoritati, quae nisi grauis erit apud socios et exteras nationes, ubi erit imperi nomen et dignitas?

"Cet honneur n'est pas rendu seulement à la personne, mais avant tout au peuple romain dont les bienfaits nous ont placé dans le sénat, ensuite à l'autorité de l'ordre sénatorial; car si elle n'est puissante auprès des alliés et des peuples étrangers, où résidera le renom et la dignité de notre souveraineté ? »

(CIc. Verr. II, IV, 25 ; trad. Rabaud modifiée).

L'hospitalité dans une cité de l'empire est un honos attendu pour un sénateur, une marque d'honneur presque protocolaire. Pour autant, son oubli représente une grave omission car cet honos met en jeu la stabilité de l'imperium Romanum. La marque d'honneur est en effet perçue comme ce qui rend grauis celui qui la reçoit, ce qui lui donne poids et sérieux. C'est de cette accumulation de marques d'honneur que proviennent le renom et la dignité de l'empire de Rome. La négligence des Mamertins, si elle était imitée des autres peuples, serait compromettante pour le pouvoir de Rome car ce dernier repose en partie sur des symboles qui manifestent la soumission des cités, tels que les honores octroyés aux hommes d'État romains. Les marques d'honneur sont l'une des clefs de la suprématie romaine car elles montrent la respectabilité de Rome, sa dignitas, à un large cercle de spectateurs étrangers ${ }^{47}$.

\footnotetext{
${ }^{45}$ Sur la «rhetoric of concealment» mise en œuvre par l'honneur, qui requalifie des relations de pouvoir en relations d'honneur, voir LENDON, Empire of Honour, p. 24. On se rapproche ici de la notion de "violence symbolique» analysée par Bourdieu. Le capital symbolique parvient à obtenir «des soumissions qui ne sont même pas perçues comme telles en s'appuyant sur des 'attentes collectives', des croyances socialement inculquées » (Bourdieu, Raisons pratiques, p. 190).

${ }^{46}$ Pour C. Nicolet, «la majesté du pouvoir réside en fait dans le respect qu'il doit imposer, c'est-à-dire dans le consensus, plus que dans la force» (Nicolet, Métier, p. 435).

${ }^{47} \mathrm{Cf}$. l'importance, à l'échelle de la ville de Rome, des insignia honoris que sont les licteurs ou la chaise curule. Privés de ces symboles, le magistrat voit son pouvoir considérablement affaibli (CoRdier, Nudités romaines, p. 97 sqq.).
} 
Ce fort pouvoir symbolique des marques d'honneur, dont la nature de signe est ici pleinement mobilisée, explique qu'elles aient fait l'objet d'une attention particulière dans les périodes de guerre civile: quand le pouvoir au sommet de l'État n'est pas précisément repérable, il devient crucial de détenir les honores qui permettent de le symboliser. Le symbole est alors aussi important que ce qu'il représente et détenir des marques d'honneur revient à détenir le pouvoir véritable. C'est pourquoi les imperatores du $\mathrm{I}^{\mathrm{er}}$ siècle ont redoublé d'efforts pour obtenir des statues ou faire détruire celles de leurs adversaires ${ }^{48}$. On le voit très bien dans les années 44-43, où le conflit opposant Antoine aux sénateurs qui lui sont hostiles donne lieu à une lutte pour l'obtention d'honores. Cicéron plaide ainsi dans la troisième Philippique pour l'octroi d'honores à la légion de Mars et à la 4 e légion qui ont abandonné Antoine et dans la cinquième Philippique pour des honneurs à D. Brutus, Lépide, Octave et Egnatuleius qui ont pris la tête de la rébellion contre Antoine ${ }^{49}$. À la même époque, Antoine se fait décerner une statue équestre dorée au nom des trente-cinq tribus de Rome et une autre statue lui est élevée, à lui et à $\mathrm{Q}$. Tremulus, sur le forum ${ }^{50}$. Le conflit se joue donc aussi sur le terrain symbolique.

Le pouvoir conféré et légitimé par l'honos n'est cependant pas toujours un pouvoir politique s'exerçant au plus haut niveau de l'État. L'honos permet aussi à son détenteur d'avoir dans les autres espaces de la vie civile une influence plus diffuse qu'un pouvoir officiel mais bien réelle. C'est à cela que les textes font allusion quand ils évoquent l'auctoritas qui découle de l'honos ${ }^{51}$. Au début de son discours Sur les pouvoirs de Pompée, Cicéron justifie en ces termes son droit à prendre la parole:

[...] cum et auctoritatis in me tantum sit, quantum uos honoribus mandandis esse uoluistis.

«[...] fort de l'autorité qu'il vous a plu de m'accorder en m'élevant aux honneurs. »

(Cic. Imp. Pomp. 2; trad. Boulanger).

Pour son premier discours à la tribune aux harangues, Cicéron souligne qu'il peut prendre la parole en public grâce à son auctoritas . Cette dernière résulte des honores, et notamment de la préture, que le peuple a bien voulu lui accorder. En conférant à Cicéron un honos, le peuple lui a simultanément donné le droit d'intervenir dans différents

${ }^{48} \mathrm{P} . \mathrm{J}_{\mathrm{AL}}$, La Guerre civile à Rome. Étude littéraire et morale de Cicéron à Tacite, Paris, P.U.F., 1963, p. 169-170.

${ }^{49}$ Cic. Phil. III, 7 et V, 35-38.

${ }^{50}$ Cic. Phil. VI, 12 et 13 . Voir aussi les honores évoqués en Phil. VI, 14.

${ }^{51}$ Sur la notion d'auctoritas, voir supra notre comparaison entre honos et auctoritas avec la note bibliographique p. 77. 
champs de la vie publique et d'exercer une influence sur les autres citoyens ${ }^{52}$. Cette dernière est un pouvoir non institutionnel qui s'exprime notamment par des avis et des conseils. L'auctoritas permet de donner son opinion et d'être écouté quand on le fait ${ }^{53}$. On le voit très bien dans le texte cité ci-dessus: l'autorité donnée par l'honos permet de prendre la parole en public et d'exposer son avis. C'est valable aussi dans un contexte non politique, comme dans les Res rusticae de Varron. Quand Agrasius demande à ce qu'on l'instruise sur ce qu'un agriculteur doit savoir et se demande si ce savoir constitue une ars, Stolon réagit ainsi :

Stolo cum aspexisset Scrofam: Tu, inquit, et aetate et honore et scientia quod praestas, dicere debes.

«Stolon regarda Scrofa: C'est toi, dit-il, puisque tu l'emportes par l'âge, l'honneur et le savoir, qui dois parler.»

(VARR. RR I, 3, 1).

L'honos, associé à l'âge et à la science, fait que l'on est consulté avant les autres: c'est parce que $\mathrm{Cn}$. Tremelius Scrofa a été préteur puis a participé à la commission chargée par César de l'allocation des terres de Campanie qu'il est interrogé en premier ${ }^{54}$. L'autorité repose ainsi sur des qualités traditionnelles plutôt que sur un savoir scientifique $^{55}$. Mais l'auctoritas va au-delà de ce droit à la parole: c'est une véritable influence sur les autres. Le détenteur de l'honos a une autorité qui fait que son avis s'impose aux autres. C'est un atout pour Cicéron dans le De Imperio Pompei mais c'est aussi ce qui fait la difficulté de sa tâche car ses adversaires aussi jouissent de l'honos et, par conséquent, de l'auctoritas: Hortensius et Catulus, hostiles à la lex Manilia, ont tous deux des ornamenta honoris ${ }^{56}$ et opposent ainsi leur propre autorité à celle de Cicéron ${ }^{57}$. Ce poids de l'auctoritas apporté par l'honos explique qu'il faille prêter attention à la personne que l'on choisit pour porte-parole: un individu dépourvu d'honos ne sera pas écouté ou ne

${ }^{52}$ Sur le lien entre honos et auctoritas, voir aussi Cic. Rep. II, 59.

53 Voir J.Béranger, Recherches sur l'aspect idéologique du principat, Bâle, F. Reinhardt, 1953, chap. 2 et Hellegouarc'H, Vocabulaire, p. 295 sqq.

${ }^{54}$ Sur ce personnage, J.Heurgon (éd.), Varron. L'Économie rurale, Paris, Les Belles Lettres, 1978, vol. 1, p. 110, n. 30.

${ }^{55}$ Sur cette assise de l'autorité et sa critique au Ir siècle, C. Moatti, La Raison de Rome. Naissance de l'esprit critique à la fin de la République (II ${ }^{e}-I^{e r}$ siècle avant JésusChrist), Paris, Seuil, 1997, p. 183 sqq.

${ }_{56}^{5}$ Cic. Imp. Pomp. 51.

${ }^{57}$ Auctoritatem apud uos multis locis plurimum ualuisse: «Leur autorité, en maintes circonstances, a exercé une influence considérable sur vos décisions» (Imp. Pomp. 51). Sur l'honos d'Hortensius et l'influence qui en découle, voir aussi Cıc. Quinct. 72. 
parviendra pas à emporter l'adhésion des auditeurs ${ }^{58}$. L'auctoritas que donne l'honos permet d'agir sur les décisions et les actions d'autrui: plus qu'un pouvoir pratique, c'est un pouvoir moral ${ }^{59}$.

L'influence procurée par l'honos possède une seconde caractéristique qui l'identifie encore à l'auctoritas. L'honneur sert de garantie à ses propres actions ou à celles d'un tiers que l'on soutient. On retrouve ici le paradigme économique de l'honneur: ce dernier sert de "caution", dans tous les sens du terme, et permet, par la mise en jeu de cette caution, d'obtenir en retour des bénéfices. Salluste nous renseigne en ces termes sur les députés envoyés en Afrique pour porter secours à Adherbal attaqué par Jugurtha:

Legantur tamen in Africam maiores natu nobiles, amplis honoribus usi; in quis fuit M. Scaurus, de quo supra memorauimus, consularis et tum senatus princeps.

"On envoie cependant en Afrique des personnages d'âge et de naissance, ayant rempli les plus hautes charges; de ce nombre était M. Scaurus dont nous avons parlé plus haut, personnage consulaire et pour lors prince du Sénat. »

(SALL. Iug. 25, 4 ; trad. Ernout).

L'exercice des plus hauts honores par les députés est perçu comme la garantie de leur sérieux. Or cette garantie apportée par l'honos est précisément un aspect de la notion d'auctoritas, terme que Salluste utilise quelques lignes plus loin au sujet des émissaires ${ }^{60}$. Dans ses emplois juridiques, l'auctoritas est une garantie, un supplément de validité qui permet à son détenteur de s'attirer la fides des autres ${ }^{61}$. Il en va de même de l'influence apportée par l'honos. Pour preuve que son client Roscius est innocent de ce dont on l'accuse, Cicéron rappelle qu'il est hébergé et aidé par Caecilia, la fille de Q. Caecilius Metellus Balearicus, qui est pourvue d'un grand honos en raison de l'excellence de sa famille. L'honos de Caecilia sert de garantie à l'innocence de Roscius ${ }^{62}$. Dans un contexte plus politique, l'honos des grands hommes est aussi utilisé au bénéfice d'un tiers qui se porte candidat à

${ }^{58}$ C'est le cas de Méandrius, choisi par la cité de Tralles pour transmettre ses plaintes contre Flaccus: sa moralité douteuse et son absence de prestige en font un bien piètre orateur (Cic. Flac. 52). C’est aussi le cas d'Héraclide (Cic. Flac. 45).

${ }^{59}$ Sur cette définition de l'auctoritas, Heinze, "Auctoritas ».

${ }^{60}$ SALL. Iug. 25, 6. Sur la garantie que constitue l'auctoritas, voir supra p. 78.

${ }^{61}$ Hellegouarc'H, Vocabulaire, p. 296-297. L'auctoritas est, dans le droit, un pouvoir issu d'un tiers qui permet de mener à bien l'action d'un agent (RICCA-BARBERIS, «Auctoritas e potestas »). L'auctoritas du vendeur, par exemple, est la garantie qu'il apporte lors d'une vente (PL. Curc. 498).

${ }^{62}$ Cic. Rosc. Amer. 147. 
une charge. Le Commentariolum petitionis souligne l'importance des amis illustres:

Deinde sunt instituendi cuiusque generis amici: ad speciem homines inlustres honore ac nomine, qui etiam si suffragandi studia non nauant tamen adferunt petitori aliquid dignitatis.

«Puis il faut se créer des amis de différentes sortes: pour l'apparence, des hommes illustres par leur honneur et leur renommée, qui, même s'ils ne font rien pour le recommander, apportent cependant au candidat un supplément de considération. »

(Q. CIc. Comm. 18; trad. Constans modifiée).

Le fait d'avoir dans ses relations des personnages inlustres honore ac nomine augmente la dignitas du candidat car le prestige de ces grands hommes rejaillit sur leur entourage et constitue un gage supplémentaire de la valeur du petitor. L'honos n'est pas ici la source d'un pouvoir légal mais d'un rayonnement, d'une aura puissante, dont on peut faire bénéficier ses amis. Ce fonctionnement de l'honos comme garantie, outre qu'il confirme la prégnance du modèle économique de l'honneur, rapproche encore l'honos du concept de capital symbolique. Bourdieu observe en effet que, lors de la négociation d'un mariage kabyle, les deux familles font intervenir des alliés de grand prestige, pourvus d'un capital symbolique élevé, qui représentent "une arme dans la négociation et une garantie de l'accord conclu ${ }^{63}$ ". L'individu qui mobilise son honos pour cautionner les actes d'un ami agit selon le même modèle, en utilisant son prestige comme garantie pour autrui.

C'est encore selon un paradigme économique qu'est appréhendé un dernier aspect du pouvoir procuré par l'honos, le crédit. La personne in honore inspire en effet confiance aux autres: on se fie à elle plus facilement qu'à quelqu'un qui ne possède aucun honos et l'on a aisément foi en sa parole. La collectivité lui « fait crédit » de ses dires sans exiger leur vérification immédiate, à la manière d'un vendeur qui n'exige pas de paiement sur-le-champ. L'individu qui possède l'honos a ainsi le pouvoir d'accumuler un certain nombre de créances, symboliques ou réelles, et son seul honos suffit à assurer qu'elles seront acquittées. C'est pourquoi il y a, dans les discours judiciaires, un usage stratégique de l'honos. Si l'orateur montre que lui-même ou les témoins favorables à son client sont pourvus du plus grand honos c'est parce que cela inspire la confiance des juges et donne du crédit aux propos tenus. Dans le Pro Fonteio, où Cicéron défend le préteur Fonteius accusé de concussion par ses anciens administrés, les Gaulois, l'orateur souligne combien le témoignage de ces gens, des barbari brutaux et sans honneur, est dépourvu de valeur et ne saurait provoquer la fides

${ }^{63}$ Bourdieu, Esquisse d'une théorie de la pratique, p. 355. 
des juges ${ }^{64}$. À l'inverse, dans les Verrines, dans une affaire de concussion assez semblable, Cicéron indique que les témoignages contre Verrès sont accablants:

His ego iudicibus non probabo C. Verrem contra leges pecuniam cepisse? Sustinebunt tales uiri se tot senatoribus, tot equitibus Romanis, tot ciuitatibus, tot hominibus honestissimis ex tam inlustri prouincia, tot populorum priuatorumque litteris non credidisse [...]?

«Ne pourrai-je pas prouver, moi, à ces juges, que Gaius Verrès a pris de l'argent de manière illégale? Des hommes comme eux auront-il le courage de ne pas croire tant de sénateurs, tant de chevaliers romains, tant de cités, tant d'hommes très estimés d'une si illustre province, tant de preuves écrites issues de peuples entiers ou de particuliers $[\ldots]$ ? »

(CIc. Verr. II, I, 10).

Le témoignage des sénateurs, des chevaliers et des habitants de Sicile, qui sont tous des honestissimi, des personnes bénéficiant d'un très grand honos, ne peut être récusé: il est impossible de ne pas les croire (non credidisse) ${ }^{65}$. Avoir du prestige permet de situer la vérité de son côté et d'emporter l'adhésion. La confiance que suscite l'homme in honore apparaît aussi dans les textes juridiques, où l'on voit par exemple qu'un testament doit être confié en dépôt à un individu amplioris honoris plutôt qu'à un inferiori ${ }^{66}$ : l'homme de prestige est plus digne de foi que les autres. Ces différents cas de figure révèlent que l'honos confère de la fides à son détenteur, du «crédit » qui inspire confiance à l'entourage ${ }^{67}$. La collectivité prête plus volontiers, des biens ou de la confiance, à celui qui est in honore. Ici encore, l'honos fonctionne comme un capital symbolique que son possesseur peut utiliser à des fins de pouvoir:

«Si l'on sait que le capital symbolique est un crédit, mais au sens le plus large du terme, c'est-à-dire une espèce d'avance, d'escompte, de créance, que la croyance du groupe peut seule accorder à ceux qui lui donnent le plus de garanties matérielles et symboliques, on voit que l'exhibition du capital symbolique (toujours fort coûteuse sur le plan économique) est un des mécanismes qui font que le capital va au capital. ${ }^{68}$

À Rome aussi l'honos fonctionne comme un crédit et le «capital va au capital » car c'est par la mobilisation du capital symbolique, du

${ }^{64}$ CIC. Font. $4 ; 23 ; 31$.

${ }^{65}$ Même idée en Cic. Verr. II, I, 128 et 156 et en Tull. 24. Sur les effets positifs de la considération en contexte judiciaire, voir aussi Pommeray, Études sur l'infamie en droit romain, p. 77 sqq.

${ }^{66}$ Dig. XXII, 4, 6 (commentaire d'Ulpien à l'édit du préteur).

${ }^{67}$ Fides possède un double sens, actif et passif: c'est la confiance qu'on donne et aussi celle qu'on obtient, donc le crédit (FrEYBURGER, Fides, p. 37 sqq.).

${ }^{68}$ P. Bourdieu, Le Sens pratique, Paris, Minuit, 1980, p. 203-204. 
prestige, que l'homme à l'honneur peut accumuler d'autres bienfaits, de nature politique, sociale et parfois matérielle ${ }^{69}$.

L'honos apporte donc un pouvoir qui peut prendre trois aspects: une capacité légitime d'action politique, une garantie mobilisable pour cautionner ses propres actions ou celles d'un proche (auctoritas), un crédit qui permet de s'attirer la confiance d'autrui (fides). Celui qui détient l'honos possède ainsi bien plus que l'estime de son entourage. Le pouvoir procuré par les marques d'honneur et le prestige est d'autant plus efficace qu'il ne prend pas directement la forme de la contrainte: l'honos reste un capital symbolique qui peut être converti en pouvoir mais n'est pas par lui-même un pouvoir coercitif.

\section{LES CONTRAINTES}

L'éclat, le rang social et le pouvoir conférés par l'honos peuvent apparaître comme des avantages démesurés, conférant à la personne in honore une supériorité écrasante sur les autres individus. Il n'en est rien en réalité car la distinction de l'homme de prestige est aussi avantageuse que contraignante: l'honos confère des privilèges qui sont indissociables d'une série d'obligations.

\subsection{La reconnaissance (gratia)}

L'honos, nous l'avons vu, peut répondre à un service rendu et signifier ainsi la reconnaissance, la gratia, de celui qui a été aidé ${ }^{70}$. Mais la relation de l'honos à la gratia est complexe car la reconnaissance peut aussi être un effet de l'honos: on attend de celui qui reçoit une marque d'honneur qu'il témoigne sa gratitude pour l'hommage qui lui est fait. Dans son analyse des mécanismes de la bienfaisance, Sénèque accorde une grande place à la gratia et en montre toute l'importance. Il distingue dans son étude deux aspects de la reconnaissance: le fait de ressentir un sentiment de gratitude, d'une part, et le fait de rendre des bienfaits concrets en retour de ceux obtenus, d'autre part. Sénèque commence par soutenir le paradoxe stoïcien selon lequel «recevoir de bon cœur, c'est avoir rendu le bienfait $»^{71}$ : le vrai beneficium se passe de rétribution concrète. Cependant, cette conception, concède-t-il, heurte

${ }^{69}$ Cf. l'analyse faite par A. Jouanna de l'honneur au XVI ${ }^{\mathrm{e}}$ siècle (A. JouAnnA, "Recherches sur la notion d'honneur au XVI ${ }^{\mathrm{e}}$ siècle", Revue d'histoire moderne et contemporaine, 15, 1968, p.597-623): les avantages matériels et le pouvoir que procure le prestige permettent de "canaliser vers les qualités socialement approuvées les biens matériels et les richesses et de transformer la hiérarchie d'estime en hiérarchie de pouvoir, de dignité et de richesse» (p.620).

${ }^{70}$ Voir l'étude sémantique p. 53-54.

${ }^{71}$ SEN. Ben. II, 31, 1 : qui libenter accipit, beneficium reddidisse. 
le sens commun qui estime qu'il faut répondre au bienfait par un autre bienfait $^{72}$; Sénèque précise alors qu'une telle façon de penser ne doit pas être totalement écartée, mais que le retour concret ne doit être qu'une conséquence accessoire du bienfait reçu. On retrouve dans les textes concernant l'honos les deux formes de la réponse au bienfait, la reconnaissance spirituelle et la réponse par un autre bienfait, qui sont ressenties comme des obligations. Le sentiment de gratitude suscité par l'honos apparaît dans le passage du Stichus que nous citions concernant les honores conjugaux. Â propos de son mari disparu en mer, Panégyris déclare à sa sœur:
Nolo ego, soror, me credi esse immemorem uiri,
Neque ille eos honores mihi quos habuit perdidit.
Nam pol mihi grata acceptaque huiust benignitas.
«Je ne veux pas, ma sœur, qu'on pense que j'ai oublié mon mari,
Ni que les honneurs qu'il m'a conférés ont été donnés en pure perte.
Car, par Pollux, j'accepte et je lui suis reconnaissante de sa bienveillance.»

(PL. St. 48-50).

Panégyris ne veut pas se montrer ingrate pour les honores que son mari lui a accordés: elle souhaite en préserver le souvenir et rester fidèle à son époux, même si son absence se prolonge indéfiniment. La bienveillance de l'époux, sa benignitas, marquée par les honores, doit être grata, reçue avec reconnaissance. On retrouve dans ces vers les deux éléments essentiels de la gratia qui figurent dans la définition qu'en donne le De inuentione, à savoir la memoria et la remuneratio $^{73}$; Panégyris veut se souvenir des honores, ne pas être immemor, et elle souhaite payer en retour les hommages reçus en restant fidèle au disparu. La reconnaissance suppose, d'une part, de préserver dans son esprit le souvenir des hommages, et, d'autre part, d'y répondre par des actes précis qui signifient visiblement la gratia. La gratia, en somme, fonctionne ici comme l'honos qui la génère: des marques concrètes, visibles (remerciements) servent à signifier un sentiment (reconnaissance). Les différents honores appellent tous la gratia de celui qui les reçoit. Le patronus qui a défendu avec succès un client en justice, lui conférant un authentique honos, attend de lui de la gratia, seul type de rétribution qu'il puisse exiger ${ }^{74}$. L'obtention d'une magistrature contraint également à manifester sa reconnaissance au peuple qui l'a conférée: les électeurs attendent ainsi des édiles élus

${ }^{72}$ SEN. Ben. II, 32, 1.

${ }^{73}$ Cic. Inu. II, 66. Voir le texte supra p. 229 n. 95.

${ }^{74}$ Toute rétribution financière du patronus est interdite par la lex Cincia (J.-M. DAvID, Le Patronat judiciaire au dernier siècle de la République romaine, Rome, E.F.R., p. 121). 
qu'ils organisent des jeux publics somptueux ${ }^{75}$. L'obligation de manifester sa gratia se ressent particulièrement quand on n'y satisfait pas et que cela provoque le dépit. Cicéron se dit ainsi très peiné que Lépide n'ait pas rendu grâce au sénat pour les grands honores qui lui ont été décernés ${ }^{76}$. Comment expliquer cette réaction? Il nous semble que c'est la nature de l'obligation de gratia qui rend son omission particulièrement dommageable. Une lettre de L. Munatius Plancus à Cicéron nous laisse entrevoir la manière dont est envisagée cette obligation. Plancus a obtenu, à l'instigation de Cicéron, plusieurs marques d'honneur et il souhaite manifester sa gratitude pour ces bienfaits ${ }^{77}$. On lit dans un de ses courriers à Cicéron:

Opto ut mihi liceat iam praesenti pietate meorum officiorum tua beneficia tibi facere iucundiora.

«Je souhaite qu'il me soit possible de te rendre tes bienfaits plus agréables, en m'acquittant dès à présent avec respect de mes propres devoirs. »

(CIc. Fam. X, 23, 7; trad. Beaujeu).

Plancus souhaite répondre aux honneurs et aux bienfaits qui lui ont été accordés en s'acquittant de ses officia. Cela lui permettrait d'agir avec pietas et de ne pas passer pour un ingrat. L'obligation de rendre grâce pour des bienfaits relève donc des officia, c'est-à-dire des devoirs attachés aux liens sociaux comme ceux de l'amicitia ${ }^{78}$. Témoigner sa reconnaissance est un impératif social dont l'observation est importante pour le maintien des relations entre individus. La nécessité de témoigner de la gratia et de répondre à l'honos par un bienfait dessine entre l'honos et la gratia une interaction qui rappelle celle qui existe entre le motif d'honneur et l'honneur lui-même. Comme nous l'avons vu, la qualité morale d'un individu, l'exploit qu'il a accompli ou le service qu'il a rendu créent, selon un paradigme économique, une dette en sa faveur auprès de son entourage, dette dont il faut s'acquitter en octroyant un honos. L'obligation de répondre à l'honos par la gratia fonctionne de manière très similaire: celui qui reçoit un honos se retrouve, à son tour, endetté vis-à-vis de celui qui l'a honoré

\footnotetext{
${ }^{75}$ Il n'y a pas en revanche, autant que dans le monde grec, d'évergétisme ob honorem à Rome à l'époque républicaine (VEYNE, Le Pain et le cirque, p. 348). C'est à partir du II ${ }^{\mathrm{e}}$ siècle après J.-C. que se développe ce type de dépense des magistrats (N. HAYASHI, «Die pecunia in der pollicitatio ob honorem », Klio, 71, 1989, p. 383-398).

${ }^{76}$ Cic. Fam. X, 27, 1.

${ }^{77}$ Cic. Fam. X, 13, 1.

${ }^{78}$ Hellegouarc'H, Vocabulaire, p. 154. Sur l'officium dans la tradition romaine, voir supra n. 71 p. 321. Sur l'officium qu'il y a à rendre un bienfait reçu, Cic. Off. I, 47 et LENTANO, «Il dono e il debito», p.132-133. Sur l'obligation de rendre théorisée dans le De officiis, voir C. Feuvrier-Prévotat, «'Donner et recevoir': remarques sur les pratiques d'échanges dans le De officiis de Cicéron", DHA, 11 (1), 1985, p. 256-290.
} 
et doit régler cette dette en manifestant sa gratia. S'il ne le fait pas, il ne répond pas aux obligations sociales de l'officium et se déconsidère. La lecture spirituelle que fait Sénèque de l'échange de bienfaits et de la reconnaissance ne correspond pas au paradigme économique sur lequel fonctionne l'honos à l'époque républicaine car l'honos impose une contrepartie concrète ${ }^{79}$. L'analogie entre honos et acte d'évergétisme réapparaît ici $^{80}$ : le bienfaiteur d'une cité qui dépense de sa bourse pour l'embellir est en effet en droit d'attendre de la reconnaissance de la part des citoyens qui bénéficient de ses largesses. En échange de leurs bienfaits, les évergètes attendent des distinctions, des remerciements, des décrets, des statues ${ }^{81}$. Les citoyens sont contraints de manifester leur gratitude envers les notables pour leurs bienfaits: comme pour l'honos, l'action d'un individu impose un retour de la part de celui qui profite de cette action ${ }^{82}$. L'interaction de l'hommage et de la reconnaissance rapproche également le fonctionnement de l'honos de celui du don. Mauss a consacré une bonne partie de ses travaux sur la question à l'étude de l'obligation faite, à celui qui reçoit un don, de le rendre. Tout don appelle un contre-don et l'absence de contre-don conduit à la disgrâce sociale ${ }^{83}$. Ce contre-don repose, comme la gratia appelée par l'honos, sur une relation de crédit car il n'est pas accordé dès la réception du premier cadeau: le premier donateur, pendant un certain temps "fait crédit» à son obligé et n'exige le contre-don

${ }^{79} C f$. SEN. Ep. 81, 18. Sénèque note ailleurs dans cette lettre qu'en latin on parle souvent du beneficium en utilisant le vocabulaire relatif à l'aes alienum, à la dette (Ep. 81 , 9). Sur cet aspect, Lentano, «Il dono e il debito», p. 132-133.

${ }^{80}$ Sur cette analogie, voir supra p. 251.

${ }^{81}$ VeYne, Le Pain et le cirque, p. 269.

${ }^{82}$ Cette situation n'est pas propre à l'Antiquité. Au Mexique et dans les Andes, certaines communautés pratiquent le système des cargos par lequel un individu reçoit un statut honorifique qui l'élève au-dessus des autres mais le charge aussi de l'organisation des fêtes de la Vierge et des saints (A. Métraux, Religion et magie indiennes, Paris, Gallimard, 1967 et F. CANCIAN, Economics and Prestige in a Maya Community, Stanford, Stanford University Press, 1965). En Mélanésie, les membres de certaines tribus, grâce à leurs qualités personnelles (talent oratoire, capacité à accumuler des richesses agricoles, passage de certains rituels, etc.) gagnent le statut prestigieux de Big Men mais se voient du même coup dans l'obligation de distribuer leurs biens et d'accomplir certains travaux (M.D.SAHLins, "Poor Man, Rich Man, Big Man, Chief: Political Types in Melanesia and Polynesia », Comparative Studies in Society and History, 5, 1963, p. 285-303; Godelier, La Production des grands hommes, p. 253-290).

${ }^{83}$ Les conséquences de l'absence de contre-don peuvent même être beaucoup plus sérieuses: chez les Maori, le cadeau possède une force spirituelle, un hau, qui occupe l'esprit du destinataire et devient dangereuse si on ne répond pas à ce cadeau par un autre cadeau (MAuss, Sociologie et anthropologie, p.160). Cette interprétation faite par Mauss de la force magique de l'objet donné a été critiquée par Lévi-Strauss ( "Introduction à l'œuvre de Mauss» in Mauss, Sociologie et anthropologie, p.xxxvIII) et M. Godelier (Godelier, L'Énigme du don, p. 26 sqq. et 69 sqq.). 
que lorsque le terme du crédit échoit ${ }^{84}$. Le même paradigme financier structure la relation de don et celle d'honos.

Ce parallèle doit nous inciter à prêter une attention particulière à l'échange instauré par l'honos et la gratia. Le bienfait donné pour signifier la gratia sert de rétribution pour l'honos obtenu. Or ce dernier est déjà lui-même une rétribution pour un mérite; c'est patent quand l'honos est donné en retour d'un service. Il y a ainsi entre celui qui honore et celui qui est honoré un échange réciproque de bienfaits, sous forme d'honos dans un sens, et de marques de gratia dans l'autre sens. Et cet échange est susceptible de se prolonger durablement, lorsque la marque de gratia reçue en retour de l'honos est à son tour perçue comme un honos et oblige à rendre un nouveau bienfait. Il se crée ainsi, entre les deux protagonistes, un endettement mutuel persistant qui provoque une circulation potentiellement infinie des marques d'honneur. Nous en avons un exemple au début de l'Aulularia, lors du prologue prononcé par le lare. Ce dernier se réjouit d'avoir été bien traité par la fille d'Euclion:

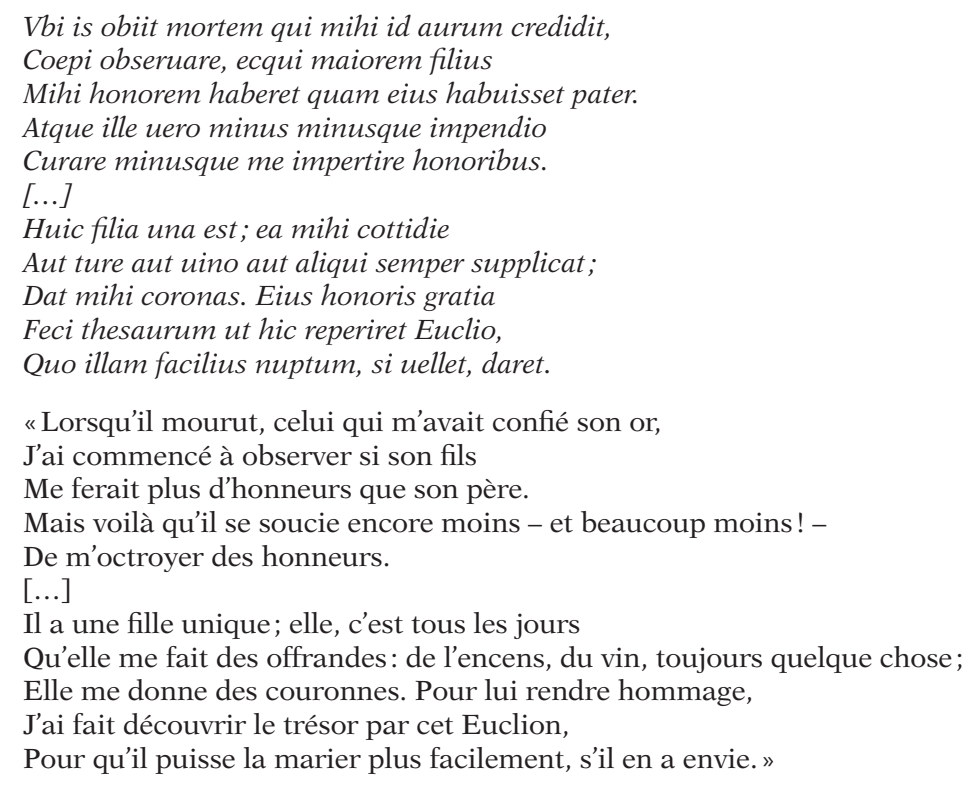

(PL. Aul. 15-19 et 23-27).

À la différence de son père et de son grand-père, la fille d'Euclion a octroyé au lare les honneurs qui lui sont dus en tant que dieu. C'est parce que le lare a reçu des honores de la jeune fille (encens, 
vin, couronnes) qu'il va, à son tour, lui conférer un honos: le trésor a été mis au jour eius honoris gratia (v.25), pour l'honorer. Cet argent devrait en effet permettre de lui constituer une dot et donc de réaliser un bon mariage. Attribuer un honos revient à s'attirer à son tour un honos, pour son propre bénéfice: l'honos passe d'une main à l'autre. Cette circulation est caractéristique des beneficia dans l'analyse qu'en donne Sénèque. Dans le commentaire qu'il fait du mythe des Trois Grâces, il estime en effet que la manière dont elles sont figurées, c'està-dire formant une chaîne ininterrompue en se donnant la main, est analogue du fonctionnement des beneficia: la chaîne des Gratiae représente la manière dont les bienfaits passent de main en main de manière continue ${ }^{85}$. L'honos se trouve, de manière similaire, au cœur d'une relation d'échange.

Cet échange est symbolique, puisqu'il est chargé de signifier l'estime et la reconnaissance mais il ne faut pas en méconnaître la dimension économique. La gratia mobilise des objets qui sont des signes mais aussi des biens de valeur ou des services et l'on peut se demander si l'invocation de la gratia et de l'honos ne sert pas en réalité à masquer une relation somme toute assez prosaïque de donnant-donnant dans des contextes où il n'est pas approprié que cette relation économique apparaisse. C'est le cas des marques d'honneur échangées par des hôtes, par exemple. Dans le Persa de Plaute, Timarchide donne des recommandations pour l'arrivée à Athènes d'un de ses hôtes, un Perse:

Operam atque hospitium ego isti praehiberi uolo

Qui tibi tabellas adfert. Cura quae is uolet,

Nam is mihi honores suae domi habuit maxumos.

"Que l'on donne assistance et hospitalité, je le veux,

À celui qui t'apporte ces tablettes. Prends soin de faire tout ce qu'il veut,

Car il m’a gratifié de très grands honneurs dans sa demeure. »

(PL. Pers. 510-512).

Timarchide est très soucieux du bien-être du Perse et recommande que l'on prenne soin de lui. Toutes ces prévenances sont justifiées et expliquées (nam) par les grands honneurs reçus par Timarchide quand il était chez son hôte en Perse. Il lui faut compenser les dépenses fastueuses engagées par le Perse en le recevant à son tour de manière somptueuse. Il y a donc un échange de biens entre les deux hommes, mais cet échange économique prend la forme d'une relation d'hommage et de gratitude: le contexte de l'hospitium occulte la nature de transaction de l'échange. De la même façon, les services rendus par un client à son patron, quoique très concrets, ne prennent pas la forme d'un paiement financier, ce qui est interdit, mais d'un acte de gratia qui

${ }^{85}$ SEn. Ben. I, 3, 3-4. 
répond à un honos. De même, la dimension économique des dépenses personnelles engagées par l'édile pour le peuple reste au second plan car ces frais sont présentés comme des gestes de gratitude pour l'honos obtenu. Tout se passe comme si l'aspect financier de l'échange d'honos et de gratia était refoulé sous l'aspect symbolique de ce dernier. Le rapport objectif de donnant-donnant est supplanté par un rapport non marchand d'hommage et de gratitude ${ }^{86}$.

\subsection{La dignité et l'honorabilité (dignitas et honestas)}

La deuxième obligation créée par la détention de l'honos est de nature morale. L'honneur singularise son détenteur et l'élève au-dessus des autres mais, en attirant ainsi sur lui le regard de la collectivité, il lui impose également de se conformer de manière plus stricte aux règles de conduite de la société et peut, en outre, lui imposer le respect d'autres normes de comportement plus exigeantes ${ }^{87}$. La première exigence morale à laquelle doit se soumettre celui qui reçoit l'honos consiste à se montrer digne de l'honneur qui lui est fait. C'est la raison pour laquelle Cicéron s'en prend aux consulaires qui favorisent Antoine, perçu par l'Arpinate comme un ennemi de la république:

Et quidem dicuntur uel potius se ipsi dicunt consulares. Quo nomine dignus est nemo, nisi qui tanti honoris nomen potest sustinere.

«Et cependant, on les nomme ou plutôt ils se nomment consulaires. De ce titre n'est digne que celui qui est capable de le soutenir, quand il s'agit du titre d'un tel honneur.»

(Cıc. Phil. VII, 5 ; trad. Wuilleumier modifiée).

Dans l'optique cicéronienne, un ancien consul doit en permanence se rendre digne de l'honos qui lui a été fait. Il est inacceptable que des consulaires transigent avec Antoine car ils contribuent ainsi à la ruine de la res publica, ce qui est en totale contradiction avec les fonctions que le peuple leur a autrefois accordées ${ }^{88}$. Il est aussi nécessaire, une fois que l'on est à l'honneur, de ne pas renoncer aux mérites qui fondent son acquisition. Il convient de persister dans l'excellence morale qui a permis de gagner l'honos: puisque la marque d'honneur signifie l'es-

${ }^{86}$ Le don aussi peut en venir à masquer, sous des dehors symboliques, un échange économique plus prosaïque. Voir Bourdiue, Raisons pratiques, p.180: le fait que le contre-don soit différé joue alors un rôle essentiel dans la dissimulation du principe de donnant-donnant.

${ }^{87}$ Voir la remarque de Salluste: Qui magno imperio praediti in excelso aetatem agunt, eorum facta cuncti mortales nouere. "Ceux qui, revêtus d'un grand pouvoir, vivent au faîte des grandeurs, ne peuvent rien faire dont tout le monde ne soit informé » (SALL.Cat. 51, 12; trad. Ernout). L’idée se trouve déjà chez Xénophon (Xen. Ages. 5, 6).

${ }^{88}$ Le reproche fait aux consulaires de trahir leur titre est récurrent dans les Philippiques (Phil. I, 10; VIII, 20-22 et 29-32; XIV, 13-19). 
time, ce serait trahir son sens que de ne plus faire preuve des qualités qui sont à la racine de cette estime. C'est pourquoi Cicéron recommande à son frère de veiller à préserver les merita qui lui ont permis de recevoir des honneurs: la prolongation de la bonne conduite permet de conserver les honores acquis ${ }^{89}$. Les règles de comportement existent indépendamment de l'honos mais deviennent plus rigoureuses une fois ce dernier obtenu. Leur contrainte se fait sentir plus fortement car un manquement entraîne, outre les sanctions sociales ou juridiques habituelles, une mise en péril de l'honneur. L'existence de cette obligation morale nous ramène à la notion de dignitas. Nous avons vu qu'elle constituait un effet positif de l'honos sous la forme d'une supériorité de rang et d'une respectabilité. Cependant cette dignitas a un statut mêlé car c'est à la fois une supériorité avantageuse et un état moralement contraignant. La dignitas recouvre de façon indissociable des prérogatives et des obligations. Elle est "dignité » au sens de "prestige », mais aussi "dignité » au sens de "conduite digne» voire "devoir " ${ }^{90}$. C'est au nom de la dignitas que des individus haut placés se jugent tenus de venir en aide à leurs compatriotes, que des sénateurs orientent leurs décisions, que des soldats s'interdisent de fuir, qu'un jeune homme fait preuve de discrétion sur sa vie privée ${ }^{91}$. La dignitas consiste à faire ce qui est digne de soi et de son statut.

Outre cette obligation de dignité, l'honos impose un second faisceau de contraintes morales qui sont de l'ordre d'une «honorabilité », c'est-à-dire d'un code de conduite issu précisément de cet honos et propre aux gens à l'honneur. Le passage de Cicéron que nous citions au début de notre ouvrage nous permet de cerner plus précisément le fonctionnement de ces normes:

Ego autem Varro (dicam enim ut res est), dum me ambitio dum honores dum causae, dum rei publicae non solum cura sed quaedam etiam procuratio multis officiis implicatum et constrictum tenebat, animo haec inclusa habebam et ne obsolescerent renouabam cum licebat legendo; nunc uero et fortunae grauissimo percussus uulnere et administratione rei publicae liberatus doloris medicinam a philosophia peto et otii oblectationem hanc honestissimam iudico.

${ }^{89}$ Cic. Q. fr. I, 1, 30-31. Caton l'Ancien considérait déjà comme periniurium de changer son mode de vie une fois l'honos obtenu car cet honos se fonde sur les mores (CAT. frg. XVIII, 93 ORF).

${ }^{90}$ Sur la proximité de la dignitas et du devoir, voir KLOSE, "Altrömische Wertbegriffe (honos und dignitas)» et Hellegouarc'H, Vocabulaire, p. 393. Sur les devoirs liés à la dignitas, voir Wegehaupt, Die Bedeutung und Anwendung von dignitas, p.24-29; DreXler, «Dignitas», p.238. La dignitas oblige à prouver continuellement qu'on la mérite (HöLKESKAMP, Die Entstehung der Nobilität, p. 212).

${ }^{91}$ Respectivement, Cic. Clu. 49; Liv. XXIII, 4, 2; CaEs. BG VII, 66, 5; Ter. Heaut. 576. Avec Cicéron, la dignitas reçoit un sens philosophique plus marqué et est apte à désigner une des qualités du sage (Tusc. II, 31 et 33; Off. I, 67 et 69). 
"Quant à moi, Varron (je dirai les choses comme elles sont), tant que l'ambition, les honneurs, les affaires judiciaires, le souci de la république et plus encore son administration me tenaient enfermé et enserré par de nombreuses obligations, je conservais ces connaissances philosophiques en moi et, pour ne pas qu'elles dépérissent, je les ravivais quand je le pouvais par des lectures. Mais à présent que je suis atteint par la fortune d'une très grave blessure et que je suis libéré de la gestion des affaires publiques, je cherche dans la philosophie un remède à ma douleur et je considère ce doux loisir comme tout à fait honorable.»

(Cic. Ac. Post. I, 11).

Cicéron montre dans ce texte qu'il est libéré des obligations qui pesaient autrefois sur lui et l'empêchaient de se consacrer à la philosophie. Dans le contexte des Seconds Académiques, écrits en 45, la domination de César sur la vie publique le prive en effet de toute possibilité d'activité politique ou rhétorique, ce qui lui permet de se tourner légitimement vers d'autres occupations. Mais le loisir intellectuel n'est rendu acceptable que par ces circonstances exceptionnelles; un tel otium est inconvenant pour celui que l'ambitio et les honores maintiennent dans la vie politique. L'exercice des honores s'accompagne en effet de nombreux devoirs. Mais le texte va plus loin. La fin du passage indique en effet que la philosophie est désormais pour Cicéron honestissima, "parfaitement honorable», ce qui n'était pas le cas quand il était engagé en politique. Cicéron articule ainsi l'honos et l'honestas, la marque d'honneur et l'honorabilité. Seule la détention de l'honos empêche le loisir intellectuel d'être honestus: dès l'instant où les honores ne pèsent plus sur l'individu, cet otium peut entrer dans le champ des conduites honestae. La définition de ce qui est honorable, honestum, dépend ainsi de l'honos de l'individu. De la sorte, le "code de l'honneur» romain est d'abord, si l'on peut dire, un code de l'honos, un ensemble de règles de conduite définies par le prestige et les marques d'honneur que détient le sujet. Ce code de comportement n'est donc ni universel ni inné92.

Nous aurons l'occasion de revenir sur la nature de ce code d'honneur et sur les règles de l'honestas ${ }^{93}$ mais nous pouvons d'ores et déjà noter que l'honorabilité définie et imposée par l'honos touche fréquemment aux convenances sociales et à l'activité publique. Dans les Académiques, l'exercice des honores interdit de se livrer à la philosophie, qui est du domaine de l'otium, et fait coïncider l'honestas avec l'intérêt pour les affaires publiques et le mépris du loisir et des plaisirs.

${ }^{92}$ On voit même, à travers la correspondance de Cicéron, que le souci de l'honestas se fait plus aigu dès l'instant où il devient consul (Cic. Att. I, 12 et Q. fr. I, 1, 19).

${ }^{93} \mathrm{Au}$ chapitre 10. 
À Atticus qui regrettait que, dans le De oratore, Scaevola n'apparaisse plus après le livre I, Cicéron explique ainsi cette absence:

Multo ego magis hoc mihi cauendum putaui in Scaeuola, qui et aetate et ualetudine erat ea qua eum esse meministi et iis honoribus ut uix satis decorum uideretur eum pluris dies esse in Crassi Tusculano.

«J'ai pensé qu'il fallait encore plus faire attention à cela avec Scaevola qui, tu t'en souviens, était âgé et de santé fragile, et couvert d'honneurs tels qu'il paraissait tout juste convenable pour lui de rester plusieurs jours dans le Tusculanum de Crassus. »

(CIc. Att. IV, 16, 3).

C'est d'abord par souci de vraisemblance que Cicéron n'a pas voulu faire figurer trop longtemps dans son dialogue un homme faible et âgé. Mais c'est aussi pour respecter le decorum, les convenances. Il n'est pas approprié, en effet, pour un homme couvert d'honores, de passer plusieurs jours à converser sur la rhétorique. Q. Mucius Scaevola, consul en 117, s'était distingué par son courage, en prenant part à la répression contre Saturninus et surtout en refusant de décréter Marius ennemi public comme le souhaitait Sylla en 88. Il ne serait pas convenable que ce personnage digne et respecté soit figuré dans une situation d'otium litteratum prolongé94. Les honores interdisent que l'on consacre trop de temps à une activité qui ne bénéficie pas directement à la res publica. Dans le même ordre d'idées, parler d'activités qui passent pour frivoles, comme la poésie ou l'art dramatique, n'est pas convenable pour un individu in honore: dans le Pro Sestio, Cicéron s'excuse d'évoquer, pour les besoins de sa démonstration, le jeu d'un acteur qui s'en est pris à Clodius en lui criant à la figure un vers à double sens; il sait que cela n'est pas en accord avec la grauitas des juges, avec la dignitas de Sestius ni avec son propre honos mais fait une exception dans l'intérêt de son client ${ }^{95}$. Ici encore, s'intéresser au domaine de l'otium est une conduite suspecte pour celui qui jouit d'un grand prestige.

\subsection{Le poids des responsabilités (onus)}

Le dernier type de contrainte qui s'impose à qui bénéficie de l'honos est l'obligation d'exécuter plusieurs tâches, souvent pénibles ou périlleuses. Le pouvoir que l'honneur apporte doit en effet être employé pour mener des actions d'importance. Celui qui fait à son frère l'honos de lui léguer par testament des terres et des fermes 265).

${ }^{94}$ Il prend congé des protagonistes du dialogue au terme du livre I (CIC. De or. I,

${ }^{95}$ Cic. Sest. 119. Cicéron déclare savoir quid [... ] meus honos postulet, « ce que mon honneur exige». 
l'oblige à se charger de la gestion de ces biens ${ }^{96}$. Le donateur impose ainsi, indirectement, des contraintes à celui qu'il honore. Mais c'est surtout avec l'honos politique qu'échoient d'importantes responsabilités: quand le peuple décerne une magistrature, il donne à l'homme d'État la charge du gouvernement de la res publica. Cicéron, après son élection au consulat, le souligne dans ses discours sur la loi agraire, comme lorsqu'il évoque une disposition de la loi prévoyant l'envoi de colons à Capoue:

Si est omnibus uobis maioriue uestrum parti, quamquam me uester honos uigilare dies atque noctes et intentis oculis omnis rei publicae partis intueri iubet, tamen paulisper, si ita commodum uestrum fert, coniuebo.

«Si vous devez en être tous - ou du moins la majeure partie d'entre vous-, bien que l'honneur que vous m'ayez décerné m'oblige à veiller jour et nuit et à tenir les yeux ouverts sur toutes les affaires publiques, je veux bien, si vous y trouvez votre avantage, fermer les yeux un instant.»

(CIc. Agr. II, 77 ; trad. Boulanger).

Cicéron se déclare prêt à accepter cette disposition si la majorité des citoyens en est d'accord. Mais ce sera tout à fait exceptionnel car l'honos qu'il a reçu l'oblige à veiller sur l'intérêt de la res publica et à préserver le bien commun. Il s'agit là, pour Cicéron, d'une contrainte très puissante: l'honos ordonne (iubet) de surveiller les affaires publiques. Il confère du pouvoir mais ce pouvoir est assorti d'un impératif qui oriente son exercice dans un sens bien précis, l'intérêt de la collectivité. L'honos donne ainsi au magistrat une grande responsabilité, parfois perçue comme très pesante. Conférer l'honos, c'est donner, dans tous les sens du terme, une "charge», ce qu'exprime parfaitement ce fragment d'une comédie anonyme:

Onus est honos qui sustinet rem publicam.

"C'est un poids que la charge de celui qui soutient la république.»

(CRF inc. frg. 63).

La paronomase du vers est révélatrice. La fonction publique est perçue comme une "charge» dans tous les sens du terme car elle suppose d'exercer des responsabilités publiques et de "prendre en charge » la république, de la porter sur ses épaules ${ }^{97}$. Cicéron, lui, est

${ }^{96}$ Cic. Quinct. 14.

${ }^{97}$ On retrouve ce rapprochement entre honos et onus quand Cicéron reproche à Verrès de ne pas avoir mesuré l'importance des obligations attachées à la magistrature que le peuple romain lui a confiée (Cic. Verr. II, V, 38). 
conscient des responsabilités qui sont les siennes et déclare à propos de l'édilité qu'il a obtenue:

Tametsi mihi iucundissimus est honos populi, tamen nequaquam capio tantum uoluptatis quantum et sollicitudinis et laboris [...]

«Bien que l'honneur que m'a fait le peuple me soit très agréable, je n'en reçois nullement autant de plaisir que de souci et de peine [...].»

(CIc. Verr. II, V, 37).

L'honos procure du plaisir à celui qui le reçoit mais il reste inférieur au labor qui attend le magistrat, au travail pénible qu'il doit effectuer, et à la sollicitudo, aux soucis qui accompagnent l'exercice de l'autorité. On voit ainsi se construire aux $\mathrm{II}^{\mathrm{e}}$ et $\mathrm{I}^{\mathrm{er}}$ siècles avant notre ère un thème promis à un bel avenir, celui du fardeau du pouvoir et des honneurs. Salluste, qui a été plus malheureux que Cicéron dans son expérience politique, le développe plus particulièrement. Les préfaces de la Conjuration de Catilina et de la Guerre de Jugurtha soulignent les périls qui accompagnent l'exercice des honores et les tourments générés par l'ambition ${ }^{98}$. Dans les Histoires, le début du discours de Lepidus, prononcé contre Sylla à la fin du règne du dictateur, évoque de manière dramatique les labores associés à l'honos:

Itaque illa quies et otium cum libertate, quae multi probi potius quam laborem cum honoribus capessebant, nulla sunt: hac tempestate seruiendum aut imperitandum, habendus metus est aut faciendus, Quirites.

«C'est pourquoi ce repos, ce loisir dans la liberté, que beaucoup d'honnêtes gens préféraient à la peine qui accompagne les honneurs, sont réduits à néant: maintenant, il faut servir ou commander, avoir peur ou faire peur, citoyens. »

(SALL. Hist. frg. I, 55, 7-10 Reynolds).

Dans le contexte de la dictature de Sylla, il n'est plus possible, selon Lepidus, de continuer à vivre dans l'otium. Il faut, même si cela est pénible, renouer avec les honores et le labor. Accepter ces honneurs, c'est renoncer à son indépendance personnelle, à sa libertas, pour s'enchaîner aux affaires publiques mais cet engagement est nécessaire pour ne pas vivre dans la servilité. L'honos impose ainsi des contraintes qui ne sont pas dépourvues de grandeur.

${ }_{98}^{9}$ Respectivement, SALL. Iug. 3, 1-4 et Cat. 3, 5. Sur ce thème sallustéen, voir chapitre 20 . 


\section{L'ARTICULATION DES AVANTAGES ET DES CONTRAINTES}

La présentation successive des avantages et des contraintes propres à l'honneur a permis d'isoler les différents effets de l'honos pour celui qui en bénéficie. La distinction que nous avons établie entre effets positifs et effets négatifs ne doit cependant pas nous amener à considérer qu'il s'agit de deux conséquences de l'honos indépendantes l'une de l'autre. Les privilèges et les obligations apportés par l'honneur sont étroitement liés et il nous appartient de préciser la manière dont ils s'articulent.

Il est frappant de constater, en premier lieu, que les avantages sont indissociables des contraintes. Les impératifs qui s'imposent à l'homme in honore ne viennent pas s'ajouter dans un second temps aux bienfaits qu'il reçoit: ils sont l'autre face de ces bienfaits. En conférant de la visibilité, l'honos octroie une splendeur source de légitime fierté mais place aussi sous la stricte surveillance de la collectivité. La dignitas agrège à une élite et impose le respect à l'entourage mais provoque par là-même l'obligation de tenir son rang et de surveiller sa conduite. De même, le pouvoir apporté par l'honos confère une capacité d'action mais expose du même coup aux peines et aux dangers; il est contrainte sur les autres mais aussi contrainte sur soi.

Cette étroite conjonction nous paraît s'expliquer par deux facteurs: d'une part, les avantages sont légitimés par les contraintes et, d'autre part, les avantages compensent les contraintes. Concernant le premier facteur, c'est parce que le sujet jouissant de l'honos se soumet aux contraintes propres à ce prestige qu'il peut, en retour, bénéficier de certaines prérogatives sans qu'elles n'apparaissent comme des privilèges outranciers. L'acceptation des obligations liées à l'honos fonde l'acquisition des avantages. On le perçoit dans le récit que fait Scipion Émilien des débuts de la République au livre II du De republica. Après la sécession de la plèbe, note-t-il, le prestige des sénateurs n'a pas faibli :

Quorum auctoritas maxime florebat, quod, cum honore longe antecellerent ceteris, uoluptatibus erant inferiores nec pecuniis ferme superiores.

"Ils disposaient d'une très grande influence car, tout en étant supérieurs à tous les autres par l'honneur, ils vivaient moins dans les plaisirs et n'étaient guère supérieurs par les richesses. »

(Cic. Rep. II, 59; trad. Bréguet modifiée).

Les sénateurs, par leur honos, l'emportent sur les autres citoyens et cet honneur leur confère notamment de l'auctoritas. Or Scipion assigne à cette auctoritas un fondement précis: c'est parce que (quod) ils méprisaient l'argent et les plaisirs qu'ils pouvaient bénéficier, par 
le truchement de leur honos, de l'auctoritas. Leur autorité est incontestable parce qu'ils adoptent un mode de vie exemplaire. Les sénateurs acceptent de bon gré la contrainte morale imposée par l'honos et peuvent donc à bon droit exercer le pouvoir lié à l'honos ${ }^{99}$.

Le second facteur de cette réunion réside dans la compensation des contraintes par les avantages. Les contraintes sont nécessaires pour légitimer les avantages aux yeux de celui qui octroie l'honos mais les avantages, réciproquement, sont nécessaires pour corriger l'effet néfaste des contraintes aux yeux de celui qui les subit. Les périls encourus du fait de l'exercice des honores, l'interdiction faite aux hommes de prestige d'avoir certaines conduites jugées inconvenantes, l'obligation de témoigner sa gratitude en échange de l'honos, sont contrebalancés par la détention du pouvoir, d'une supériorité sociale et d'une distinction enviable. Dans le texte du Pro Cluentio que nous citions en introduction, Cicéron déclare que ces avantages permettent de mitigare molestiam, d'adoucir la pénibilité de l'honos, comme on ameublit une terre dure ou on adoucit un vin âpre ${ }^{100}$. Mais l'image à nos yeux la plus caractéristique apparaît quelques lignes auparavant:

Quam multa sunt commoda quibus caremus, quam multa molesta et difficilia quae subimus! atque haec omnia tamen honoris et amplitudinis commodo compensantur. Conuerte nunc ad equestrem ordinem atque in ceteros ordines easdem uitae condiciones: non perferent.

«De combien d'avantages ne sommes-nous pas privés! À combien de désagréments et d'embarras sommes-nous exposés! Et tout cela cependant est compensé par les avantages de l'honneur et de l'importance sociale. Impose maintenant à l'ordre équestre et aux gens des autres classes de l'État les mêmes conditions de vie: ils ne les supporteront pas.»

(Cic. Clu. 150; trad. Boyancé modifiée).

L'honos s'accompagne de désagréments qui sont compensés (compensantur) par des avantages. Les prérogatives pondèrent les peines et rééquilibrent la situation de l'homme in honore. Compensare, c'est rétablir un équilibre perturbé, contrebalancer un poids par un autre ${ }^{101}$. Le mot est ici employé dans un sens abstrait mais il connaît un usage concret, notamment dans la langue juridique où il désigne la compensation accordée pour régler une dette ou un autre type de déficit ${ }^{102}$. On retrouve donc ici le paradigme économique qui structure

${ }^{99}$ L'auctoritas se fonde ainsi indirectement sur l'excellence morale. J. E. GoodwIN, "Cicero's Authority», Ph\&Rh, 34 (1), 2001, p.38-60 montre comment l'auctoritas de Cicéron dans le Pro Sulla est assise sur sa dignitas.

${ }^{100}$ Sur cet usage de mitigare, voir Cic. ND II, 130; Plin. NH XIV, 149.

${ }^{101}$ Compenso se rattache à pendo, "suspendre» et donc "peser» (DELL, p. 494).

${ }^{102}$ Val. MaX. IX, 1, 4; GaI. Inst. IV, 66; Dig. XXIV, 1, 32, 9; XXIV, 3, 22, 3 ; XXXII, $11,19$. 
en profondeur l'honos: les obligations de l'honneur créent une dette qu'il faut régler par l'octroi d'avantages. C'est pourquoi, dans l'argumentation de Cicéron, les chevaliers ne peuvent être soumis aux mêmes contraintes juridiques que les sénateurs: ayant renoncé aux bénéfices de l'honos, ils ne peuvent en voir peser sur eux les impératifs car ils seraient créanciers d'une dette dont le paiement ne serait pas prévu. Ce système de compensation fonctionne d'ailleurs aussi dans l'autre sens: l'obtention de privilèges contraint la personne honorée à accepter de bon gré les contraintes de l'honos car elle crée une dette dont il faut s'acquitter: on reçoit (de la distinction, du rang social, du pouvoir) donc il faut donner (de la gratia, des preuves d'excellence morale, des efforts) ${ }^{103}$.

Cette obligation de compenser l'avantage ou la contrainte par son contraire relève d'un mode de pensée romain caractéristique. Dans le Pro Cluentio, Cicéron déclare qu'il est iniquum pour les chevaliers d'obéir aux contraintes de l'honos sans recevoir les avantages qui y sont attachés ${ }^{104}$. Seul ce phénomène de compensation garantit que le fonctionnement de l'honos est aequum, autrement dit conforme à l'équité. Cet aequum n'est pas une stricte égalité, où tout citoyen reçoit autant que les autres, mais une égalité perfectionnée, proportionnelle, où celui qui s'investit davantage reçoit davantage. La compensation mise en œuvre par l'honos est, autrement dit, en phase avec le principe de l'égalité géométrique ${ }^{105}$. L'organisation du census repose sur cet idéal: celui qui possède plus de biens a davantage de droits, notamment politiques, mais aussi davantage de devoirs, notamment fiscaux et militaires ${ }^{106}$. Cette égalité proportionnelle est aussi à l'œuvre dans le domaine de la guerre; la militia est un devoir pesant et dangereux, mais c'est aussi un moyen d'acquérir des avantages matériels par le biais du butin et d'augmenter son prestige ${ }^{107}$.

\section{CONCLUSION}

La marque d'honneur étant envisagée dans bien des cas comme une rétribution et le prestige comme un capital, il importait de voir quel profit l'honos pouvait générer pour son détenteur. Trois avantages majeurs issus de l'honneur ont ainsi été isolés: l'honos permet en premier

${ }^{103}$ L'obligation de rendre s'étend donc au-delà de la gratia pour concerner l'ensemble des avantages et contraintes de l'honos. $C f$. la nécessité pour l'oligarchie du monde hellénistique de "compense[r] par les largesses son monopole du pouvoir» (Veyne, Le Pain et le cirque, p. 218).

${ }^{104}$ Cic. Clu. 154.

${ }^{105}$ Sur l'aequum et l'égalité géométrique, voir supra p. 302-304.

${ }^{106}$ Sur l'organisation censitaire, voir DH. IV, 19; LIV. I, 43; XXVI, 36, 2. Voir aussi Nicolet, Métier, p. 82-83. Sur le rôle des centuries équestres dans les élections, Nicolet, L'Ordre équestre, p. 126-138.

${ }^{107}$ Nicolet, Métier, p. 127. 
lieu de construire une image sociale éclatante en donnant une supériorité et en préservant la memoria dans le temps. En second lieu, l'honos procure de la dignitas, c'est-à-dire un statut élevé au sein de la cité, statut qui intègre à l'aristocratie et impose le respect. Enfin, l'honos est une source de pouvoir. Ce dernier, cependant, ne relève pas fréquemment de l'autorité officielle dotée de moyens de coercition. Le pouvoir de l'honos est plus diffus et moins direct, ce qui ne veut pas dire moins efficace. Il s'exerce notamment par la mobilisation du capital de prestige pour servir de "garantie» aux actions (auctoritas) et pour augmenter le "crédit» de son détenteur (fides). Ces différents avantages sont compensés par des contraintes qui leur sont étroitement liées. L'obtention d'un honos oblige celui qui le reçoit à témoigner sa reconnaissance aux donateurs et à rendre un bienfait contre l'honos. Témoigner sa gratia est un offcium et le respect de ce devoir instaure une relation d'échange durable entre les protagonistes de l'hommage, amenés à rivaliser de gratitude. L'honos oblige aussi celui qui l'obtient à en être digne, en faisant preuve de dignitas dans sa conduite, et à adopter le code de comportement propre à ceux qui jouissent de l'honos, à savoir l'honestas, qui est une forme de code d'honneur. Enfin, l'honos donne des responsabilités qui peuvent être ressenties comme un vrai fardeau. Toutes ces obligations sont cependant inséparables des avantages liés à l'honos: elles en sont le revers nécessaire. En effet, d'une part, l'acceptation des contraintes légitime l'exercice des prérogatives de l'honos aux yeux de ceux qui le donnent. D'autre part, aux yeux de ceux qui le reçoivent, les privilèges compensent les efforts consentis et les impératifs à suivre. L'honos fonctionne donc selon la logique de l'égalité géométrique: celui qui a davantage de droits a aussi davantage de devoirs.

L'étude des effets de l'honos met ainsi en lumière le rôle structurant de l'échange au sein de l'honneur. L'octroi d'un pouvoir s'accompagne nécessairement de contreparties pesant sur celui qui l'exerce: le pouvoir est ainsi une contrainte sur les autres mais il est aussi contrainte sur soi. Il procure une autorité sur l'entourage mais donne aussi prise à cet entourage sur soi. En recevant des avantages, l'homme in honore doit donner en retour et le peuple qui donne l'honos attend de recevoir en échange. Se développe ainsi une perpétuelle recherche de compensation et d'équilibre qui rend l'usage de l'honos particulièrement délicat et explique, rétrospectivement, les règles qui ont progressivement été fixées. Notre examen des effets de l'honneur a enfin permis de voir combien l'honos était étroitement lié à d'autres notions romaines essentielles. Il procure de la dignitas (comme statut) de l'auctoritas et de la fides et contraint, par là-même, à la dignitas (comme conduite digne), à la gratia, à l'honestas et au respect de l'officium. Notre objet n'est pas isolé dans les représentations qu'en ont les Romains mais situé dans un réseau de notions qu'il contribue à rendre dynamiques. Ce dynamisme et cette efficacité de l'honos sur celui qui le reçoit en font un instrument susceptible d'être employé à des fins diverses par le donateur. Ce sont ces fonctions de l'honos qui vont à présent nous intéresser. 

CHAPITRE 8

\title{
LES FONCTIONS DE L'HONNEUR
}

\author{
INTRODUCTION
}

L'analyse précédente a mis au jour les avantages et les contraintes apportés par l'honos mais il nous faut pousser l'analyse au-delà. On peut en effet supposer que ces effets de l'honos sont utilisés à dessein par le donateur pour parvenir à certaines fins : avantages et contraintes sont des conséquences de l'honos mais peuvent aussi devenir à leur tour des instruments, dotés de fonctions sociales qui dépassent le cadre de la relation individuelle d'honneur. Il faut donc prendre en compte, au-delà des effets localisés de l'honneur, ses fonctions à l'échelle de la collectivité, fonctions peut-être moins explicites mais essentielles. Comment les processus de symbolisation et de rétribution au cœur de l'honneur contribuent-ils au fonctionnement de la cité et de la vie sociale? Nous avons choisi de porter notre attention sur les trois fonctions les plus importantes de l'honos. La première est de nature morale: l'honos est utilisé pour régler le comportement des individus. C'est la fonction prépondérante et c'est donc elle qui retiendra le plus notre attention. La seconde est de nature sociale: l'honos sert à structurer la société. La troisième est politique au sens large du terme: l'honos permet à celui qui l'octroie de gagner du pouvoir dans la cité.

\section{RÉGLER LES COMPORTEMENTS}

Dans la représentation que s'en font les Romains, l'honos apparaît comme un moyen utilisé par les instances qui le confèrent pour régler le comportement des individus, de ceux qui le reçoivent et de la collectivité dans son ensemble qui, en tant que témoin, est également concernée par l'honneur. La capacité de l'honneur à régler les mœurs s'exerce de deux manières complémentaires qui seront examinées successivement: l'honos sert à la fois de guide de conduite pratique et d'instrument de définition axiologique. D'une part, il amène celui qui le reçoit et son entourage à s'adonner préférentiellement à certaines activités en exerçant une influence directe sur le comportement, notamment au moyen de la rétribution qu'il procure (fonction liée au paradigme économique). D'autre part, il sert à définir les valeurs et les normes de conduite et exerce ainsi une influence indirecte en agis- 
sant sur les représentations et en délivrant des signes (fonction liée au paradigme symbolique). L'honos règle ainsi les attitudes au niveau pratique et au niveau idéologique, en orientant l'action et les représentations morales.

\subsection{L'orientation pratique des conduites}

L'honos permet en premier lieu d'orienter de façon pratique et directe l'action des individus. Octroyer une marque d'honneur et donner du prestige à quelqu'un est un moyen d'amener, sans coercition, à accomplir certaines actions.

\subsection{1. «Honos alit artes »: stimuler des pratiques}

Dans le proøemium de la première Tusculane, Cicéron concède que, dans le domaine des arts, les Grecs l'emportaient jadis sur les Romains car la pratique artistique n'a été introduite que tardivement à Rome. Ce fut le cas de la poésie:

Quo minus igitur honoris erat poetis, eo minora studia fuerunt, nec tamen si qui magnis ingeniis in eo genere extiterunt, non satis Graecorum gloriae responderunt. An censemus, si Fabio, nobilissimo homini, laudi datum esset quod pingeret, non multos etiam apud nos futuros Polyclitos et Parrhasios fuisse? Honos alit artes, omnesque incenduntur ad studia gloria, iacentque ea semper, quae apud quosque improbantur.

«Donc, moins la poésie était à l'honneur, moins on s'y consacrait, mais tous ceux qui montrèrent un grand talent pour cette pratique, ne manquèrent pas d'égaler la gloire des Grecs. Pensons-nous par hasard que si ses talents de peintre avaient valu à Fabius, cet homme extrêmement noble, des éloges, nous n'aurions pas été entourés de nombreux Polyclète et Parrhasius? L'honneur nourrit les arts, et la gloire enflamme tous les esprits pour les études, et, chez tous les peuples, ce qui ne reçoit pas l'approbation gît à terre. »

(CIc. Tusc. I, 3-4).

Le nombre réduit d'honneurs adressés à la poésie autrefois a eu un effet négatif sur la pratique de cet art: peu de gens s'y sont adonnés. De même, Fabius Pictor n'a pas reçu d'éloges, honores verbaux, pour son œuvre picturale et par conséquent peu de Romains l'ont suivi dans cette voie et Rome n'a pas excellé en ce domaine. L'honos, déclare Cicéron, alit artes, est l' " aliment » des arts, il les nourrit et leur permet de se développer. Il cite ici librement un passage des Annales d'Ennius, que nous ne connaissons que de manière fragmentaire: laus alit artis, «l'éloge nourrit les arts $»^{1}$. L'hommage détermine le développement de

${ }^{1}$ EnN. Ann. frg. inc. 113 Skutsch. Sur ce fragment, voir G. MazzolI, «Il frammento enniano Laus alit artis e il proemio al XVI libro degli Annales", Athenaeum, 42, 1964, 
certaines activités et notamment des pratiques culturelles. La rétribution qu'est la marque d'honneur encourage la collectivité à reproduire l'action honorée. Les bienfaits associés à l'honos rendent en effet son obtention enviable et encouragent à s'adonner aux pratiques récompensées. C'est la raison pour laquelle Caton regrette que la poésie jouisse à son époque de l'honos et ne soit plus méprisée, comme c'était autrefois le cas:

Poeticae artis honos non erat: siquis in ea re studebat aut sese ad conuiuia adplicabat, grassator nocabatur.

«La pratique de la poésie n'était pas en honneur: si quelqu'un s'y consacrait ou s'attachait aux banquets, ils l'appelaient traînard. »

(Cат. Carmen frg. 2 Sblendorio-Cugusi).

Le passage est issu du Carmen de moribus qui semble avoir été un recueil de préceptes moraux à visée didactique. Il confirme les dires de Cicéron sur le peu d'intérêt suscité autrefois par la poésie. Caton déplore que la poésie soit à l'honneur car cela en fait une activité attractive, drainant le studium de ses contemporains et les détournant des activités sérieuses et utiles à la république, comme l'exercice physique ou la présence sur le forum². L'honos a ainsi pour fonction d'orienter la conduite des individus vers certaines pratiques.

Reste à savoir comment il y parvient. Il faut pour cela opérer une distinction entre la fonction de l'honos pour celui qui le reçoit et pour celui qui en est seulement le témoin. Celui qui reçoit une marque d'honneur se voit confirmé dans sa conduite: l'honos agit à la manière d'un stimulant qui l'incite à poursuivre dans le même sens. Les honneurs votés par le sénat aux légions opposées à Antoine sont un excellent moyen de confirmare animos, "d'affermir leurs dispositions " contre ce dernier et de ne pas debilitare uirtutem, "affaiblir leur courage ${ }^{3}$. L'honos a pour fonction de rétribuer une action jugée positive et, par là-même, de la prolonger en consolidant les intentions de son auteur. Un passage de la Rhétorique à Herennius donne une présentation plus formalisée de cette fonction de la marque d'honneur à propos des discours délibératifs. L'une des "fins» du genre délibératif, ce dont

p. 307-333. Le vers est commenté par Sénèque (Epist. 102, 16) qui considère qu'Ennius parle de l'estime des cœurs et non d'éloges verbaux. Une idée similaire au passage cicéronien figure chez Velleius Paterculus I, 16-17 (L. ALFONSI, «La dottrina dell'aemulatio in Velleio Patercolo », Aevum, 40, 1966, p. 375-378).

${ }^{2}$ La volonté de ne pas octroyer trop d'honos à la poésie n'a pas disparu avec Caton. On voit indirectement dans le Pro Archia combien la pratique poétique peut susciter de réprobations: Cicéron y exhorte les juges à ne pas a Musarum honore et a poetarum salute abhorrere, "avoir en horreur l'honneur des Muses et le salut des poètes" (Cic. Arch. 27).

${ }^{3}$ CIc. Phil. V, 4. 
l'orateur doit convaincre l'auditoire, est l'honestum, qui se subdivise en rectum et en laudabile: l'orateur doit souligner le caractère honnête de la décision en faveur de laquelle il se prononce en montrant qu'elle est droite et louable 4 . La dimension louable d'une conduite ne suffit pas en soi à la faire accepter mais accroît le prix que lui donne sa rectitude:

Neque enim solum laudis causa rectum sequi conuenit, sed si laus consequitur, duplicatur recti adpetendi uoluntas.

«Et il ne convient pas en effet d'agir avec rectitude pour mériter des éloges, mais si ceux-ci viennent de surcroît, la volonté d'atteindre la rectitude est doublée.»

(Rhet. Her. III, 7 ; trad. Achard).

Laction droite vaut par elle-même, mais les honores verbaux que sont les éloges permettent de renforcer la uoluntas qui mène à agir droitement. La marque d'honneur stimule donc la conduite de celui qui la reçoit en agissant sur sa uoluntas ${ }^{5}$. Le donateur de l'honos peut de la sorte orienter en sa faveur le comportement de celui qu'il honore. Varron indique ainsi, lors de ses recommandations sur la façon de traiter les esclaves, qu'on doit accorder de l'honos aux ouvriers agricoles les plus importants pour "se concilier leur bonne volonté» (inliciendam uoluntatem), et les rendre "plus attachés à travailler" (studiores ad opus $)^{6}$. L'honos est présenté à nouveau comme un moyen d'agir sur la uoluntas de la personne honorée et d'orienter son studium d'une manière utile à l'auteur de l'honos. Ce dernier emploie donc à son profit la fonction stimulante de l'honos.

Cette fonction de l'honneur concerne un cercle plus large que celui des personnes honorées. La collectivité, on l'a vu, est témoin de l'honos et, à ce titre, peut indirectement être la cible des fonctions qu'il remplit. L'honneur joue, pour l'entourage, un rôle protreptique: il incite ceux qui n'ont pas encore adopté les conduites qui valent de l'honos à se tourner vers elles ${ }^{7}$. Les avantages visibles apportés par l'honneur amènent ceux qui en sont les témoins à désirer en bénéficier à leur tour et désignent les conduites à la racine de l'honos comme le moyen d'obtenir ces avantages. Les portraits peints honorifiques des ancêtres prestigieux dans les atriums des maisons aristocratiques incitent les occupants suivants à bien se conduire: ces peintures servent, pour

\footnotetext{
${ }^{4}$ Sur la place de l'honestum dans la Rhétorique à Herennius, voir le chapitre 17.

${ }^{5}$ Sur la fonction du prestige comme moyen de pousser un individu à se surpasser, voir Goode, The Celebration of Heroes, p. 80-81.

${ }^{6}$ VARr. RR I, 17, 6-7.

${ }^{7}$ W.J.Goode a analysé la manière dont, aux États-Unis, les individus modifient régulièrement leur "allocation d'activité» en abandonnant leur métier au profit d'un autre plus prestigieux (Goode, The Celebration of Heroes, p. 1-93).
} 
reprendre le terme de Pline l'Ancien, de stimulatio $^{8}$. Si Caton évoque, dans sa contio adressée aux chevaliers avant le combat à Numance, les honores octroyés aux soldats valeureux, c'est pour que cette remémoration des honneurs donnés à la vaillance excite leur courage pour le combat à venir'. Les récompenses que promet César avant l'assaut contre Avaricum aux soldats qui seront les premiers à escalader le rempart ont de même pour fonction de les inciter à la bravoure ${ }^{10}$. Comme le résume bien une phrase de Tite Live, «les grands honneurs font les grandes âmes ${ }^{11}$. L'honos parvient à diriger efficacement le comportement parce qu'il rétribue la valeur, selon un paradigme économique: les individus voient que les efforts sont compensés par l'honos et qu'il vaut la peine de se faire créancier d'une communauté qui sait acquitter ses dettes.

Cette fonction d' "aliment» remplie par l'honos explique l'importance du phénomène à l'échelle de la cité entière. Puisque l'honneur guide la conduite des individus, il est crucial pour les autorités de prendre en main l'octroi des marques d'honneur et de choisir avec discernement les personnes et les mérites récompensés. Il y a de ce fait un authentique usage politique de l'honos. C'est ce que nous apprend Cicéron dans le De natura deorum, où il opère un retour réflexif sur l'usage des marques d'honneur:

Atque in plerisque ciuitatibus intellegi potest augendae uirtutis gratia, quo libentius rei publicae causa periculum adiret optimus quisque, uirorum fortium memoriam honore deorum immortalium consecratam. Ob eam enim ipsam causam Erectheus Athenis filiaeque eius in numero deorum sunt, itemque Leo

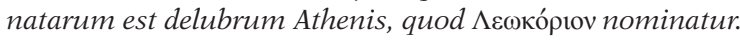

«Et dans la plupart des cités on peut voir que, pour stimuler la vertu et encourager les meilleurs citoyens à affronter plus volontiers les dangers dans l'intérêt de l'État, le souvenir des hommes courageux a été consacré par l'octroi d'honneurs réservés aux dieux immortels. C'est pour cette même raison qu'à Athènes Érechtée et ses filles sont au nombre des dieux, et que, dans la même ville, il y a un sanctuaire des filles de Leos, appelé Léocorion. »

(CIC. ND III, 50).

\footnotetext{
${ }^{8}$ PLIN. NH XXXV, $2,7$.
}

${ }^{9}$ CAT. frg I, 18 ORF. Selon Marmorale, Caton essaie avec un certain opportunisme de se concilier les equites réputés indisciplinés au sein de son armée (E.V. Marmorale, Cato maior, $2^{\mathrm{e}}$ éd., Bari, Laterza, 1949, p.57-58).

${ }^{10}$ CAEs. BG VII, 27, 2. Il s'agit sans doute de coronae murales. Voir aussi BG III, 26, 1 où Crassus invite les préfets de la cavalerie à exciter l'ardeur de leurs hommes magnis praemiis pollicitationibusque. D'après Polybe, les décorations militaires sont un excellent moyen de pousser les soldats à braver le danger et leur importance au sein de l'armée explique le succès des Romains à la guerre (PoL. VI, 39, 8-9).

${ }^{11}$ Liv. IV, 35, 7-9 (discours attribué aux tribuns de la plèbe en 424). 
L'octroi d'honneurs exceptionnels, de nature divine, obéit à une stratégie de gouvernement de la part des instances supérieures de nombreuses cités (in plerisque ciuitatibus). La construction de sanctuaires, qui fait l'objet d'une décision publique, préserve la memoria des individus honorés, effet de l'honos déjà observé. Mais Cicéron remarque surtout que ces honneurs publics sont là augendae virtutis gratia, "pour stimuler la vertu »: leur fonction est morale et vise l'ensemble des citoyens. C'est la cité elle-même qui prend en charge ces honores pour orienter le comportement de ses membres rei publicae causa, «dans l'intérêt de l'État ». L'État dépense pour honorer certains citoyens mais cette dépense est un investissement avisé car elle finit par lui être bénéfique: par l'honos, l'État incite au courage pour pouvoir renforcer sa sécurité. Sur un autre terrain, il honore les évergètes pour perpétuer l'investissement des particuliers dans la cité12. L'honos est le moyen pour une société de promouvoir ce qui paraît utile à son fonctionnement et à sa pérennité ${ }^{13}$. Il assure en outre le perfectionnement des citoyens dans les pratiques qui sont mises à l'honneur par l'émulation qu'il suscite entre eux: le désir d'honos, s'il peut avoir des conséquences néfastes, est aussi un facteur d'excellence ${ }^{14}$.

\subsubsection{Contrôler le corps social}

L'honos est utilisé par la société pour amener à des conduites utiles à son développement mais on va voir qu'il sert aussi à éviter des comportements déviants et nuisibles et constitue donc également un instrument de contrôle et de stabilité du corps social ${ }^{15}$. La Rome républicaine possédait des moyens de police assez peu importants rapportés au nombre élevé de ses habitants et les historiens n'ont pas

\footnotetext{
${ }^{12}$ VeYne, Le Pain et le cirque, p. 273: «en acclamant un évergète, le peuple encourage et même contraint les autres à l'imiter.»

${ }^{13}$ Les Encyclopédistes faisaient une analyse assez similaire du rôle de l'honneur à l'échelle de la société au XVIII e siècle (TerRaILlon, L'Honneur, p. 59).

${ }^{14}$ Sur ce rôle positif du désir d'honos, voir p.462 de DrexLer, "Honos». Pour un exemple de l'honos comme facteur d'excellence, dans le domaine rhétorique, voir K. Heldmann, Antike Theorien über Entwicklung und Verfall der Redekunst, Munich,

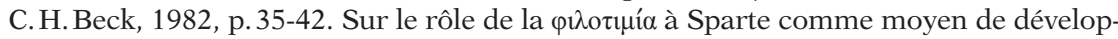
pement des qualités morales, voir J. E. Lendon, «Spartan Honor», in Hamilton, C. D. et Krentz, P. (éds.), Polis and Polemos. Essays on Politics, War, and History in Ancient Greece in Honor of Donald Kagan, Claremont, Regina, 1997, p. 105-126.

${ }^{15} \mathrm{Il}$ renforce ainsi le rôle des lois dont l'une des fonctions est de maintenir la concorde dans la cité (Ducos, Les Romains et la loi, p.194-202). Il est aussi le pendant positif du châtiment qui sert à sauvegarder la cohésion sociale (CIc. Off. III, 23; voir Ducos, Les Romains et la loi, p.357-358). Cette fonction de l'honneur a été observée, dans la société du XVI ${ }^{\mathrm{e}}$ siècle, par M.NASsIET, "L'honneur au XVI ${ }^{\mathrm{e}}$ siècle: un capital collectif »: «Le devoir de se conformer à un modèle de comportement propre à sa condition est un trait élémentaire de contrôle social; l'honneur contribuait à la régulation sociale puisqu'il suscitait la conformité des comportements aux normes » (p.77).
} 
manqué de s'interroger sur la façon dont l'ordre y était maintenu ${ }^{16}$. Les magistrats avaient un rôle à jouer dans ce domaine mais leurs moyens étaient assez limités ${ }^{17}$. W. Nippel a montré que l'action des particuliers contribuait autant que celle des institutions à préserver l'ordre dans la Ville ${ }^{18}$. Les citoyens, en effet, sont d'une part pris dans des réseaux sociaux qui contraignent leur comportement: les enfants sont soumis à la patria potestas du chef de famille et les clients à l'autorité de leur patron, par exemple. D'autre part, ils peuvent agir directement pour maintenir l'ordre, en constituant des corps de garde ou en se livrant à des formes de justice populaire spontanée ${ }^{19}$. À ces moyens de contrôle extra-institutionnels du corps social identifiés par W. Nippel, il faut ajouter, nous semble-t-il, l'honos. L'hommage fonctionne en effet comme une sanction sociale. Une sanction, au sens non marqué du terme, est une mesure consécutive à une action qui entérine son rapport, de conformité ou de discordance, vis-à-vis d'une norme $^{20}$. Dans le domaine extra-institutionnel et non juridique qui nous intéresse, c'est l'affront (ou ignominia) qui est la sanction négative qui punit la transgression de la norme ${ }^{21}$, alors que l'honos est la sanction positive qui récompense la conformité exemplaire à cette même norme. Il assure par là-même la pérennité de cette dernière et de sa valeur contraignante. Évoquant les conditions du prestige chez les vieillards, le Caton du De senectute s'exprime en ces termes:

Ita enim senectus honesta est, si se ipsa defendit, si ius suum retinet, si nemini emancipata est, si usque ad ultimum spiritum dominatur in suos.

${ }^{16}$ Voir notamment W. NipPEL, Public Order in Ancient Rome, Cambridge, Cambridge University Press, 1995 et H. MénARD, Maintenir l'ordre à Rome (II -IVe siècles ap.J.-C.), Seyssel, Champ Vallon, 2004.

${ }^{17}$ Les magistrats à imperium pouvaient infliger des amendes, mettre aux arrêts, faire battre de verges et exécuter des contrevenants, mais ces pouvoirs ont été limités une fois le ius prouocationis établi. Les censeurs possédaient des pouvoirs de contrôle s'exerçant surtout sur les classes dirigeantes. Les édiles et les tresuiri capitales avaient quelques moyens de surveiller l'ordre mais pas de pouvoirs de police au sens moderne du mot. Voir NipPel, Public Order in Ancient Rome, p. 5-6.

18 "The magistrates' role in maintaining order can be understood as complementary to the mechanisms of social control underlying the authority of both the magistrates and the Senate» (Ibid., p. 30).

${ }^{19}$ Sur ces cas de figure, Ibid., p. 30-46. Sur le fonctionnement du contrôle social en général, Reynaud, Les Règles du jeu, p. 30-31.

${ }^{20}$ Sur la sanction comme instrument de contrôle, Reynaud, Les Règles du jeu, p. 37 sqq. qui montre qu'elle peut être institutionnelle ou coutumière, organisée ou spontanée. Voir aussi Goffman, La Mise en scène de la vie quotidienne, p. 101: «Une norme est une sorte de guide pour l'action soutenue par des sanctions sociales; les sanctions négatives pénalisent l'infraction; les sanctions positives récompensent la conformité exemplaire. »

${ }^{21}$ Plusieurs pratiques collectives tapageuses comme les «charivaris » (flagitia), les libelles injurieux, les chansons diffamatoires, les vers obscènes, agissent comme des sanctions endommageant le prestige. Sur ces pratiques, voir infra p. 445 sqq. 
"Car la vieillesse est estimée si elle se défend elle-même, si elle conserve ses droits, si elle ne s'aliène à personne, si elle commande aux siens jusqu'à son dernier souffle. »

(CIc. Cato mai. 38).

Caton déclare qu'un homme âgé doit, pour être honestus, c'està-dire pour bénéficier de l'estime de son entourage, préserver une certaine vigueur et se conduire avec dignité. On attend notamment de lui qu'il conserve l'autorité sur les siens, que sa patria potestas ne s'efface pas avec l'âge. L'octroi de l'honneur est conditionné par la satisfaction d'un certain nombre d'obligations nées des représentations que la collectivité a du rôle social des hommes âgés. L'honos vient sanctionner le respect de deux règles de comportement que la collectivité impose aux senes, la dignitas et la potestas; il récompense la conformité à ces règles et, du même coup pérennise ces normes puisque, selon le fonctionnement que nous avons précédemment observé, la récompense amène à la reproduction des attitudes récompensées. L'honos entérine la norme et assure sa perpétuation. Dans l'exorde de son plaidoyer pour C. Rabirius, Cicéron affirme que le rôle des bons citoyens est de soutenir l'État et ses institutions et de barrer la route à la sédition. indicare.

Ea qui secutus sit, laude potius et honore quam poena et supplicio dignum

«Celui qui a suivi ces principes, <il faut> le juger digne de louange et d'honneur plutôt que de châtiment et de supplice. »

(CIc. Rab. Perd. 3).

Celui qui, comme Rabirius, a assuré la sauvegarde de la res publica a observé les règles de conduite qui s'imposent à tout citoyen, les principes républicains rappelés par Cicéron. Rabirius les a pleinement suivis (secutus) et l'honos doit venir sanctionner cette adhésion et la valider. Cicéron réclame que le châtiment soit écarté de Rabirius car il discréditerait les principes qui ont guidé son action et remettrait en cause les règles essentielles au bon fonctionnement de l'État. L'honos, à l'inverse, viendrait confirmer la validité de ces règles et rappeler leur importance ${ }^{22}$.

L'honos constitue de la sorte le versant positif des pratiques d'ignominia légales ou spontanées. Son efficacité en la matière est même

${ }^{22}$ Voir aussi Cic. Ad Brut. I, 15 où Cicéron se réfère sans le commenter à un mot de Solon déclarant qu'une république se fonde sur deux pratiques, la récompense et la punition. Le renforcement des normes est également une des fonctions attribuées à l'honos verbal, l'éloge. Ce dernier possède un rôle protreptique, car il incite les auditeurs à imiter les qualités de la personne louée et sert ainsi souvent à « renforcer l'adhésion du public à des valeurs admises et reconnues »(РеRNot, La Rhétorique de l'éloge, p. 720). Sur le contenu moral de l'éloge, voir KIERDORF, Laudatio funebris, p. 80-82. 
double car l'honos impose à celui qui le reçoit un code de conduite tatillon, ce «code de l'honos » que nous avions identifié comme une des contraintes liées à l'honneur ${ }^{23}$. Ce qu'il faut remarquer, pour compléter notre analyse de ce code de l'honos, c'est qu'il fonde, pour les auteurs qui l'évoquent, la bonne marche de la res publica dans sa totalité et contribue à introduire de la stabilité dans l'ordre social. Un passage de l'In Caecilium le rappelle opportunément:

Nulla salus rei publicae maior est quam eos qui alterum accusant non minus de laude, de honore, de fama sua quam illos qui accusantur de capite ac fortunis suis pertimescere. Itaque semper ii diligentissime laboriosissimeque accusarunt qui se ipsos in discrimen existimationis uenire arbitrati sunt.

«La république n'est jamais plus assurée de son salut que lorsque les accusateurs ne craignent pas moins pour leur gloire, leur honneur, leur réputation que les accusés pour leur personne et leurs biens. C'est pourquoi les accusateurs les plus soigneux et les plus laborieux ont toujours été ceux qui considéraient qu'ils mettaient en péril l'estime dont ils jouissaient. »

(CIc. Diu. Caec. 71).

Cicéron, qui souhaite pouvoir mener l'accusation contre Verrès, répond ici à une objection qu'on pourrait lui faire: pourquoi veut-il se faire accusateur alors même qu'il jouit d'un certain prestige et brigue un honos, l'édilité? Pour Cicéron, c'est précisément l'honneur qu'il détient qui fait de lui un accusateur de qualité car ceux qui risquent leur prestige personnel dans une affaire constituent des accusateurs scrupuleux et honnêtes: ils sont en effet obligés de se conformer, au cours de la procédure judiciaire, au code de conduite que leur honos leur impose pour ne pas perdre l'estime de leur entourage. De ce fait, laisser les hommes in honore jouer un rôle dans les affaires publiques ou privées est la garantie de la salus rei publicae car ces personnes respectent les normes collectives pour ne pas se discréditer. En donnant de l'honos à un individu, cette même collectivité contribue indirectement à son bon fonctionnement car cet octroi impose un code d'honneur qui amène au respect des lois ${ }^{24}$.

De manière plus générale, la crainte du déshonneur et le souci d'éviter le discrédit constituent à Rome des piliers efficaces du maintien de l'ordre ${ }^{25}$. Dans une société qui prise autant le prestige et l'honneur, la peur de l'infamie est régulatrice. Caecilius ne constitue pas aux yeux de Cicéron un bon accusateur car il ne fait aucun cas de sa fama, de sa réputation, ce qui le conduira nécessairement à mal

${ }^{23}$ Voir supra p. 383-385.

${ }^{24}$ Sur le rapport du code d'honneur et de l'observation des lois, voir Ducos, Les Romains et la loi, p. 396-397.

${ }^{25}$ M. Ducos, «La crainte de l'infamie et l'obéissance à la loi (Cicéron, De republica, V,4,6)», REL, 57, 1979, p. 145-165; Ducos, Les Romains et la loi, p.397-399; Pöschl, "Politische Wertbegriffe in Rom », p. 14. 
agir $^{26}$. Quand des individus dotés d'un rôle social clef ne se soucient plus de leur honneur, c'est l'État tout entier qui est en péril. Dans un de ses discours, Scipion Émilien s'indigne ainsi que de jeunes enfants nobles, qui sont l'avenir de Rome, fréquentent les écoles d'histrions où ils compromettent leur honneur en apprenant des praestigias inhonestas, "des tours déshonorants»; cette absence de souci pour l'honneur désole Scipion: me rei publicae maxime miseritum est, "cela me fait grandement pitié pour la république ${ }^{27}$. La crainte du déshonneur doit donc conduire l'individu à se conformer aux règles de conduite propres à son statut et permettre à la res publica de perpétuer la structure sociale et morale sur laquelle elle est fondée.

L'honos semble donc susceptible d'agir en complémentarité avec les moyens légaux du maintien de l'ordre: une pratique coutumière, relevant du mos, fonctionne ainsi de concert avec les punitions légales, relevant du ius ${ }^{28}$. Cependant, l'honos diffère de la sanction juridique. Les châtiments légaux sanctionnent des infractions aux lois et orientent négativement la conduite par la punition. L'honos sanctionne une conformité à des normes sociales et morales et oriente positivement le comportement, par la rétribution. En outre, la contrainte exercée par l'honos n'est pas aussi directe que celle des lois et ne provient pas d'un organe spécialisé chargé de son application: l'honos peut être issu de foyers multiples, individuels ou collectifs. L'honos, enfin, ne s'applique pas selon des règles explicites et écrites mais fonctionne de manière bien plus souple. En dernière analyse, la société romaine utilise conjointement l'honos et les lois pour orienter l'action des agents sociaux car ces instruments n'ont pas exactement la même visée: l'honneur et la crainte de l'infamie permettent d'amener à des conduites jugées bonnes par l'opinion mais dont la législation n'exige pas nécessairement l'accomplissement, telles que la dignité ou le dévouement à la res publica.

\subsection{L'orientation axiologique des modes de pensée}

L'honos est également employé, à un niveau supérieur à celui de la pratique, pour définir des normes morales. Il continue ainsi d'orienter l'action, non plus en agissant directement sur cette dernière mais en

${ }^{26}$ Cic. Diu. Caec. 71.

${ }^{27}$ ScIP. AEm. frg. IX, 30 ORF.

${ }^{28}$ Sur la complémentarité du mos et du ius et de l'honneur et de la loi, voir LinTotT, The Constitution of the Roman Republic, p. 4 sqq.; BLEICKEN, Lex publica. Gesetz und Recht in der römischen Republik, p. 368 sqq.; Ducos, Les Romains et la loi, p. 384-399 et A. RuElle, "Le citoyen face aux pratiques collectives de la honte à Rome: le droit et les dieux, ou deux poids, deux mesures », in Alexandre, R., Guérin, C. et Jacotot, M. (éds.), Rubor et pudor. Vivre et penser la honte à Rome, Paris, Éditions Rue d’Ulm, 2012, p.61-82. 
modelant les représentations morales qui motivent les agissements des individus. Il agit dans ce domaine de deux façons, en établissant des valeurs et en définissant des modèles. Les valeurs servent de soubassement aux normes et motivent la conduite; les modèles incarnent et illustrent les normes. L'honneur permet ainsi de produire des règles nécessaires à l'orientation de l'action individuelle ${ }^{29}$.

\subsubsection{Définir des valeurs}

L'honos ne crée pas directement les normes de conduite mais formule des valeurs qui sous-tendent les normes. Nous entendons par «valeurs» les éléments de référence idéaux d'un groupe qui servent à orienter l'action des individus de ce groupe en guidant leur choix parmi les moyens et les fins possibles. Ce sont, pour reprendre l'expression de C. Kluckhohn, des "conceptions du désirable» qui servent à maintenir les systèmes culturels ${ }^{30}$. Ces valeurs sont, par nature, difficiles à saisir et l'honos, qui les précise, joue de ce point de vue un rôle capital pour la société en lui permettant de cerner ces éléments essentiels à son fonctionnement. L'honos contribue de la sorte à l'instauration du mos maiorum, cet ensemble de règles coutumières qui orientent le comportement des individus. S’ajoutant aux œuvres littéraires, au culte des ancêtres, aux temples consacrés à des qualités divinisées, il définit les valeurs de la «coutume ancestrale ${ }^{31}$. Comment cette définition fonctionne-t-elle?

${ }^{29}$ Cette fonction normative est aussi présente dans le fonctionnement de la gloria qui fixe ce que doit être la conduite des individus (J.-F. Thomas, "Gloria maiorum, gloria antiqua. La conscience du passé dans la conception de la gloire à Rome », in BAKHOUCHE, B. (éd.), L'Ancienneté chez, les Anciens, Montpellier, Université de Montpellier III, 2003, vol. 1, p. 133-153). De façon générale, le contrôle social en vigueur dans une société ne se borne pas à éviter la déviance et à maintenir les règles mais agit aussi sur ces dernières et peut les modifier (REYNAUd, Les Règles du jeu, p. 31).

30 C. Kluckhonn, "Values and Value-Orientations in the Theory of Action", in Parsons, T.et ShILs, E.(éds.), Toward a General Theory of Action, Cambridge (MA), Harvard University Press, 1951, p.388-433. Pour une définition plus pragmatique de la valeur, en tant qu'objet sur lequel une action collective peut se fonder, voir REYNAUD, Les Règles $d u$ jeu, p.234. Sur le rapport des valeurs et des normes à Rome, E. FlaIG, « Keine Performanz ohne Norm - keine Norm ohne Wert. Das Problem der zwingenden Gesten in der römischen Politik ", in Haltenhoff, A., HeIl, A. et Mutschler, F.-H. (éds.), Römische Werte als Gegenstand der Altertumswissenschaft, Munich, K. G. Saur, 2005, p. 209-221.

${ }^{31}$ On ne peut donc dire, avec M. Bettini (BEtTinI, "Mos, mores und mos maiorum ", p.324), que la façon dont se définit le mos maiorum est floue. Il est exact que cette définition ne procède pas par l'édiction systématique de normes explicites, mais il y a tout de même, par l'honos, désignation de valeurs essentielles. Sur la manière dont sont établies les normes du mos maiorum, voir F.-H. Mutschler, «Norm und Erinnerung: Anmerkungen zur sozialen Funktion von historischem Epos und Geschichtsschreibung im 2. Jh. v. Chr. ", in Braun, M., Haltenhoff, A. et Mutschler, F.-H. (éds.), Moribus antiquis res stat Romana. Römische Werte und römische Literatur im 3. und 2. Jh. v. Chr., Munich, K.G.Saur, 2000, p.87-124, notamment p. 88 et B. LinKe et M.STEMmLer, 
L'honos permet de définir des valeurs car il confère du prix aux personnes qui le reçoivent ainsi qu'à leurs qualités. Nous retrouvons ici le paradigme économique de l'honneur: c'est parce que la marque d'honneur est une rétribution qu'elle "enrichit» son destinataire et en fait une personne "prisée» dans tous les sens du terme. C'est là que se situe, selon Salluste, l'effet pervers du très grand honos conféré à la richesse après la dictature de Sylla:

Postquam diuitiae honori esse coepere et eas gloria, imperium, potentia sequebatur, hebescere uirtus, paupertas probro haberi, innocentia pro maliuolentia duci coepit.

«Lorsque la richesse fut en honneur, qu'elle s'accompagna de la gloire, du commandement, de la puissance, bientôt le mérite personnel perdit de sa valeur, la pauvreté devint une honte, l'intégrité, de la malveillance.»

(SALL. Cat. 12, 1; trad. Ernout modifiée).

Salluste élucide dans ce texte le mode opératoire de l'honos et en débusque les conséquences morales sur le long terme. Selon son analyse de la décadence à Rome, le moment où l'honos fut décerné à la richesse et non plus à la virtus précipita la chute de la république. Honorer les riches, c'est en effet faire de l'argent une valeur supérieure aux autres et notamment à la uirtus qui, du coup, s'émousse (hebescere) car elle n'est plus un désirable et n'est plus pratiquée. Déplacer l'honos d'un objet à un autre revient à altérer les représentations morales dans leur ensemble: la pauvreté devient honteuse, l'intégrité est perçue comme de la malveillance. Donner de l'honos à une pratique, c'est donc modifier en profondeur l'axiologie des membres de la société et, partant, leur comportement. L'analyse de Salluste est particulièrement pénétrante car il évoque les raisons pour lesquelles l'honos est apte à définir les valeurs: il donne du prix, étant une rétribution, mais il s'accompagne aussi de pouvoir (potentia sequebatur) qui est un des avantages de l'honos, comme nous l'avons vu ${ }^{32}$. C'est cette puissance apportée par l'honos qui rend les objets sur lesquels il se porte "désirables ». L'honneur contribue à façonner les représentations morales et provoque

"une entorse au dogme philosophique de la séparation des jugements de valeur et de réalité; ce qui 'est', quel qu'il soit, devient ce qui 'est bien'. ${ }^{33}$

«Institutionalität und Geschichtlichkeit in der römischen Republik», in LinKE, B. et STEMmLER, M. (éds.), Mos maiorum. Untersuchungen zu den Formen der Identitätsstiftung und Stabilisierung in der römischen Republik, Stuttgart, F. Steiner, 2000, p. 1-23.

${ }^{32}$ Supra p. 368 sqq.

${ }^{33}$ Pitt-Rivers, Anthropologie de l'honneur, p. 40. 
L'hommage rendu à un individu et à ses mérites confère une plusvalue morale à ces derniers, les extrait du champ du réel pour les instituer dans le champ du devoir et des idéaux. C'est la raison pour laquelle l'octroi de l'honos apparaît à Salluste comme une pratique cruciale pour le bon fonctionnement de la collectivité. Donner l'honneur à des vices conduit à un bouleversement profond des comportements. Dans le discours que Salluste place dans la bouche de Caton quand ce dernier plaide en faveur de la peine de mort pour les conjurés de 63, il relève les effets dévastateurs d'hommages mal orientés: les qualités des ancêtres ont cédé la place au luxe et à la paresse parce que

Laudamus diuitias, sequimur inertiam; inter bonos et malos discrimen nullum; omnia uirtutis praemia ambitio possidet.

«Nous louons les richesses, nous suivons la paresse; entre les bons et les méchants, aucune distinction; l'ambition détient toutes les récompenses dues à la vertu. »

(SAlL. Cat. 52, 22).

Le mauvais usage des marques d'honneur, qu'il s'agisse des éloges (laudamus) ou des autres récompenses de la vertu (uirtutis praemia), a modifié les représentations morales des Romains. Le fait d'avoir octroyé des honneurs au vice a perturbé la définition du bien et du mal: il n'y a plus, selon Caton, de discrimen, de distinction, entre bons et méchants. L'honos doit servir à établir cette distinction dans les esprits en montrant à tous la différence entre bien et mal par la récompense des actions jugées bonnes.

Le fonctionnement économique de l'honos participe de la sorte à l'établissement des «désirables » qui motivent l'action individuelle; mais son fonctionnement symbolique concourt à cette fonction d'orientation axiologique. En signifiant l'estime du donateur, l'honos reconnaît en effet également le mérite du destinataire. Le triomphe, par exemple, constitue une élévation des qualités militaires du triomphateur qui sont montrées au peuple. La présence des captifs, du butin, l'exhibition de tableaux représentant les territoires conquis servent à rendre sensible, au cœur de Rome, une excellence militaire qui ne peut autrement y être vue ${ }^{34}$. Le triomphe sublime la bravoure guerrière et la violence martiale pour les élever au rang de qualités désirables propres à constituer un mode de conduite idéal. C'est pourquoi la visibilité des honores est cruciale: ils doivent pouvoir représenter à tous les mérites récompensés et signifier ce qu'est la uirtus. L'honos verbal remplit lui aussi parfaitement cette fonction: il dit l'estime du locuteur mais signale aussi le mérite de celui qui le reçoit et propose ainsi une définition de l'excellence. C'est pourquoi le texte du sénatus-consulte

${ }^{34}$ Sur ces éléments du triomphe, voir supra p. 274-275. 
honorifique demandé par Cicéron pour D. Brutus contient une énumération des services qu'il a rendus à la république ${ }^{35}$.

Le rappel des res gestae et des uirtutes dans les éloges funèbres ou sur les tombeaux contribue de même à la définition des qualités morales ${ }^{36}$.

C'est parce que l'honos est un signe polysémique qu'il permet cette exhibition des mérites. La riche signification de l'honos est perceptible dans un passage du Rudens de Plaute. Palestra, qui vient de faire naufrage sur une côte inhospitalière, adresse une plainte aux dieux; ce malheur qu'ils lui ont envoyé est immérité, car elle a toujours fait preuve de pietas à leur endroit, et il a des conséquences funestes:
Nam quid habebunt sibi $<$ s>igni impii posthac
Si ad hunc modum est innoxiis honor apud uos?
"Car quel signe les impies recevront-ils après cela
Si c'est de cette façon que vous honorez les innocents?»

(PL. Rud. 195-196).

Le texte ici reproduit est celui retenu par Leo et Ernout dans leurs éditions, mais une correction a été apportée: les manuscrits présentent en effet la leçon «sibigni » $(B T)$ ou encore «sibi igni » $(C D)$, corrigée en $s i b i<s>i g n i^{37}$. La restitution du $s$ nous paraît vraisemblable car elle donne au texte une cohérence: Palestra se plaint auprès des dieux qu'en lui infligeant un naufrage, ils ne récompensent pas sa piété et adressent par là-même un signe désastreux aux impies qui seront confirmés dans leur comportement. Sous réserve que la correction faite par Leo et Ernout soit bonne, le raisonnement de Palestra montre que l'honos tient le rôle de signum. Et l'on peut effectivement penser que, si Palestra avait échappé au naufrage, cet honos aurait signifié l'estime des dieux, estime elle-même fondée sur la piété de la jeune femme. Manquer d'honorer les gens pieux est une faute aux conséquences sérieuses car cela revient à signifier que la piété est sans valeur. Conférer un honos, c'est donc, à l'inverse, signifier que la personne honorée est dotée de qualités valables. Ce rapport signifiant de l'honos au mérite apparaît de manière plus directe dans une lettre de Cicéron à Munatius Plancus:

Crede igitur mihi, Plance, omnis quos adhuc gradus dignitatis consecutus sis - es autem adeptus amplissimos -, eos honorum uocabula habituros, non 40-41)

${ }^{35}$ Cic. Phil. V, 36. Il en va de même du décret en l'honneur de Lépide (Cic. Phil. V,

${ }^{36}$ Sur la présence des mérites du défunt dans l'éloge funèbre, voir PoL. VI, 53, 2 et KIERDORF, Laudatio funebris, p. 75-80. Sur les qualités mentionnées sur les tombeaux, voir Von Hesberg, Römische Grabbauten, p. 208.

${ }^{37}$ L'éditeur allemand Marx juge la correction irrecevable, considère que le passage est irrécupérable et place igni entre cruces desperationis (F. MARX, Plautus Rudens. Text und Kommentar, Amsterdam, A. M. Hakkert, 1959). 
dignitatis insignia, nisi te cum libertate populi Romani et cum senatus auctoritate coniunxeris.

«Eh bien! crois-moi, Plancus, tous les échelons de la dignité que tu as gravis jusqu'à présent - et tu as atteint les plus élevés -, on considérera qu'ils n'ont d'honneurs que le nom et ne sont pas des marques de ton mérite si tu ne fais pas cause commune avec la liberté du peuple romain et l'autorité du sénat. »

(Cic. Fam. X, 6, 2).

Les honores que Plancus a obtenus sont considérés comme des dignitatis insignia, comme des "marques de son mérite", à condition que son action en reste digne. Ils sont la preuve de l'excellence de Plancus, qu'ils servent à manifester, exhibant du même coup à tous ce qu'est la dignitas. Les honores apposent une marque distinctive sur des individus aux qualités reconnues. C'est la raison pour laquelle la personne honorée doit ensuite perpétuer les mérites qui lui ont valu l'honneur, sans quoi le signe voit ses effets pervertis car il ne renvoie plus à un mérite valable et utile à la collectivité. Sans le mérite, l'honos n'est qu'un mot creux ${ }^{38}$.

Cette fonction de définition axiologique remplie par l'honos montre que la détermination des conduites morales à Rome peut être faite par la pratique et non par la théorie. Les normes du mos maiorum ne sont pas établies par l'élaboration théorique de lois morales mais par la rétribution concrète des mérites et la désignation explicite des valeurs. Cette manière de se doter de règles de comportement offre l'avantage de la souplesse: l'orientation des honores en direction de conduites nouvelles permet de les intégrer avec facilité au sein du mos maiorum, qui n'est pas un code fermé à l'innovation ${ }^{39}$. Cette définition des normes par la pratique est aussi très efficace. Dans son éloge du droit civil, Crassus affirme que cette discipline est supérieure à la philosophie quand il s'agit de fournir des règles de conduite et donne une place, au sein de ce droit, aux honores:

Ex his enim et dignitatem maxime expetendam uidemus, quoniam uirtus atque honestus labor honoribus, praemiis, splendore decoratur, uitia autem hominum atque fraudes damnis, ignominiis, uinclis, uerberibus, exsiliis, morte multantur; et docemur non infinitis concertationumque plenis disputationibus, sed auctoritate nutuque legum domitas habere libidines, coercere omnis cupiditates, nostra tueri, ab alienis mentes, oculos, manus abstinere.

${ }^{38}$ Cicéron se représente aussi la manière dont l'honos exprime le mérite selon une autre image que le signe: il s'agit du testimonium, du témoignage en justice. L'obtention d'un honos est un témoignage de la dignitas ou de la uirtus de celui qui le reçoit et manifeste ainsi publiquement sa valeur (CIc. Planc. 50; Phil. IX, 11 et 15).

${ }^{39}$ Sur cet aspect du mos maiorum, voir Lind, "The Tradition of Roman Moral Conservatism», p. 53. 
"C'est à partir des lois, en effet, que nous considérons qu'il faut surtout viser à la dignité, parce que c'est à la vertu et à une honnêteté sans faiblesse que l'on décerne des honneurs, des récompenses, la gloire, alors que les vices humains et les crimes sont punis par des amendes, par des flétrissures, par l'emprisonnement, par des coups, par l'exil, par la mort; et leur enseignement ne s'appuie pas sur des dissertations sans fin, remplies de controverses, mais sur l'autorité décidée des lois qui nous apprend à dompter nos passions, à contrôler tous les désirs, à veiller sur nos biens et à tenir éloignés de ceux d'autrui nos esprits, nos regards et nos mains.»

(Cic. De or. I, 194).

Pour Crassus, la philosophie échoue à délivrer un enseignement moral car elle se perd dans des arguties sans fin, contradictoires et peu claires (infinitis concertationumque plenis disputationibus). Les lois, en revanche, sont un maître particulièrement efficace parce qu'elles recourent, entre autres, aux honores et aux ignominiae pour amener à la vertu: les honores ne sont plus ici un moyen complémentaire à l'action régulatrice des lois mais un instrument de ces dernières ${ }^{40}$. Mais Crassus va plus loin dans son analyse: c'est par l'usage des honores que les hommes apprennent (docemur) la valeur de la maîtrise de soi et de la propriété. L'honneur délivre un enseignement sur ces objets que la philosophie revendique habituellement comme siens. Crassus met en relation les honores et l'honestus labor, c'est-à-dire les marques d'honneur et l'honnêteté dans l'effort. Par leur immédiateté, les hommages et les affronts mènent directement à la moralité: l'honos est le meilleur chemin vers l'honestas.

\subsubsection{Définir des modèles}

L'honneur agit sur les représentations morales des individus en établissant des valeurs qui permettent de motiver leur action. Il est donc facteur de normativité. Mais cette dernière s'exerce aussi d'une autre manière. Toute norme s'appuie en effet sur des modèles qui l'incarnent et auxquels les individus sont supposés se conformer. Or l'honos contribue à définir ces modèles et ainsi à orienter la conduite des membres de la société. L'honneur constitue celui qui le reçoit en individu exemplaire, propre à être imité. Il fait ainsi le lien entre les normes abstraites et leur mise en application pratique. À Rome, les valeurs ne sont pas définies de manière théorique mais par la mise en avant d'occurrences significatives: elles sont incarnées dans des personnes remarquables et explicitées dans des rituels symboliques ${ }^{41}$.

${ }^{40}$ Sur le rôle de l'ignominie et des récompenses prévues par les lois pour guider la conduite, voir Ducos, Les Romains et la loi, p. 395-396.

${ }^{41}$ Sur ce mode de définition romain des normes de comportement, A. Haltenhoff, "Wertbegriff und Wertbegriffe», in Braun, M., Haltenhoff, A. et Mutschler, F.-H. (éds.), Moribus antiquis res stat Romana. Römische Werte und römische Literatur im 3. und 
Pour les Anciens, la pratique de l'hommage et celle de l'imitation sont étroitement liées. Honorer quelqu'un suppose de reconnaître la valeur de sa conduite et, par conséquent, de chercher à la reproduire. Le rapport de l'imitation et de l'hommage apparaît par exemple dans le Trinummus, quand le vieux Philton, se faisant l'écho de l'opinion commune, déplore que ses contemporains fassent l'éloge des ancêtres et se conduisent en même temps de manière immorale: rendre hommage aux maiores doit aller de pair avec l'imitation de leur comportement; c'est faire preuve d'une incohérence totale que de ne pas associer honos et reproduction de la conduite ${ }^{42}$. Ce lien étroit de l'honos et de l'imitation fait que la marque d'honneur est utilisée pour constituer quelqu'un en individu à imiter. Elle place en effet sur lui un signe distinctif qui lui donne le statut de modèle visible. L'effet de distinction de l'honos est utilisé pour remplir une fonction morale de définition. On le voit dans un texte contemporain des comédies de Plaute, mais d'un genre très différent. Il s'agit d'un discours de Caton l'Ancien où ce dernier évoque la manière dont il entraînait ses troupes armées:

Si quis strenue fecerat, donabam honeste, ut alii idem uellent facere, atque in contione uerbis multis laudabam.

«Si l'un s'était comporté vaillamment, je le récompensais généreusement, pour que les autres veuillent l'imiter, et pendant l'assemblée des soldats je le louais dans un long discours. »

(CAT. frg. IV, 35 ORF).

Le fait de les récompenser honeste, c'est-à-dire, littéralement, «en conférant des honneurs », de manière "honorifique» et donc "généreuse ${ }^{43}$, a un but précis: Caton souhaite que les autres soldats, témoins de l'honneur, idem uellent facere, "veuillent faire la même chose». L'honos oriente la conduite par l'attrait que suscite la rétribution mais aussi, à un niveau supérieur, par la définition de personnages de référence: usant de la dimension symbolique de l'honos, Caton signifie à l'armée que le soldat qui s'est comporté strenue est un modèle de conduite ${ }^{44}$. La rétribution économique et la désignation symbolique sont ici associées pour élaborer la norme morale. Les règles de conduite ne sont pas tacites: elles sont constamment extériorisées par l'institution de modèles visibles. Et si la constitution de ces modèles est efficace pour orienter l'action, c'est parce que, notamment dans le cadre militaire, l'imitation se fait sur le mode de l'émulation:

2. Jh. v. Chr, Munich, K. G. Saur, 2000, p.15-29, notamment p. 24; Linke et StemmLer, «Institutionalität und Geschichtlichkeit in der römischen Republik », p. 8.

${ }^{42}$ PL. Trin. 291-292.

${ }^{43}$ Sur ce sens d'honeste, voir supra p. 136-137.

${ }^{44}$ Cf. Cic. Font. 42 où il apparaît que l'honos doit être octroyé aux généraux valeureux car cela les pose en figures de référence pour tous, dans l'intérêt de la république. 
on imite pour essayer de se hausser au même niveau, voire tenter de faire mieux que la personne honorée. Certains honores semblent plus propres que d'autres à constituer l'individu en modèle. C'est le cas des statues qui placent dans l'espace public, de façon durable, des figures de référence bien identifiables ${ }^{45}$. L’honos ultime des funérailles, où apparaît une autre représentation physique des personnes, les imagines, constitue aussi un moyen particulièrement efficace d'inciter à l'imitation. Dans la description que Polybe donne des funérailles aristocratiques, il souligne que la présence figurée des ancêtres ainsi que l'éloge funèbre adressé au défunt sont des moyens d'inciter les jeunes gens qui assistent à cet honos à tout faire pour obtenir la gloire qui a été celle de ces grands hommes ${ }^{46}$. Les marques d'honneur que sont les funérailles, les éloges, les triomphes, sur lesquels l'aristocratie jouit d'un certain monopole, servent à orienter la conduite des jeunes générations en suscitant l'émulation avec les ancêtres ${ }^{47}$.

Le statut de modèle conféré par l'honos nous amène à nous interroger sur l'exemplarité des figures bénéficiant de l'honneur. Le "modèle» est en effet celui que l'on imite, mais c'est aussi celui qui illustre de manière exemplaire un trait particulier, au point de pouvoir en constituer l'archétype. L'honos donne-t-il ce statut archétypal? Pour répondre à cette question, il est utile de rapprocher l'honos de la notion d'exemplum ${ }^{48}$. Ce terme possède des sens nombreux qui procè-

${ }^{45}$ Voir par exemple Cic. Phil. IX, 4. Sur cet aspect, LaHusen, Untersuchungen zur Ehrenstatue in Rom, p.136; T. SРÄтH, «Faits de mots et d'images. Les grands hommes dans la Rome ancienne», Traverse, 5 (1), 1998, p.35-56; SEHLMEYER, Stadtrömische Ehrenstatuen der republikanischen Zeit, p. 103-108.

${ }^{46}$ Pol. VI, 54, 3. Voir Flower, Ancestor Masks, p. 220-221 et Badel, La Noblesse de l'Empire romain, p. 39.

${ }^{47}$ Sur ce rôle de définition morale joué par les rituels sociaux aristocratiques, voir Hölkeskamp, Die Entstehung der Nobilität, p. 204 sqq. Sur le rôle plus spécifiquement identitaire des honores voir infra p.415-418.

${ }^{48}$ La notion a fait l'objet de nombreuses études critiques. Pour notre approche, se sont révélés utiles les travaux généraux sur la notion (H.KorNHARDT, Exemplum. Eine bedeutungsgeschichtliche Studie, Diss., Göttingen, 1936; A.LumPE, "Exemplum», $R L A C, 6,1966$, p. 1229-1257), ceux consacrés à l'exemplum comme procédé rhétorique (M. Fuhrmann, "Das Exemplum in der antiken Rhetorik», in Koselleck, R. et Stempel, W.D.(éds.), Geschichte, Ereignis und Erzählung, Munich, Fink, 1973, p.449-452; J. GAILLARD, "Auctoritas exempli: pratique rhétorique et idéologie au ${ }^{\mathrm{er}}$ s. av. J-C. », REL, 56,1978 , p. 30-34; N. ZoRZETTI, «Dimostrare et convincere: l'exemplum nel ragionamento induttivo e nella communicazione ", in DAVID, J.-M. et BerLIOz, J. (éds.), Rhétorique et histoire. L'exemplum et le modèle de comportement dans le discours antique et médiéval, Rome, E.F.R., 1980, p.33-65; J.-M.DAvID, "Maiorum exempla sequi: l'exemplum historique dans les discours judiciaires de Cicéron", in DAvID, J.-M.et BerLIOz, J. (éds.), Rhétorique et histoire. L'exemplum et le modèle de comportement dans le discours antique et médiéval, Rome, E.F.R., 1980, p.67-86; J.-M.DAVID, "Les enjeux de l'exemplarité à la fin de la République et au début du principat », in DAVID, J.-M. (éd.), Valeurs et mémoire à Rome. Valère Maxime ou la vertu recomposée, Paris, De Boccard, 1998, p. 9-17; R. GAzIcH, "Teoria e pratica dell'exemplum in Quintiliano», in Vincenzo, C.V.(éd.), Aspetti della 
dent d'une image centrale, celle de l'objet que l'on distingue de ceux de sa catégorie ${ }^{49}$. L'objet peut être employé à des fins illustratives et représentatives (comme "échantillon», " exemple typique», " exemplaire») ou dans une visée didactique, pour susciter l'imitation ou la répulsion (comme "précédent», "modèle», «exemple», "punition»...) ${ }^{50}$. Ces notions de "distinction" et de "modèle» contenues dans le mot nous invitent à le rapprocher de l'honos qui les possède aussi. Nous retiendrons pour notre comparaison deux aspects de la notion fréquemment invoqués. L'exemplum peut désigner un personnage illustre grâce à ses qualités saillantes. On se demandera si l'honos ne contribue pas à la création de ces figures remarquables. L'exemplum peut aussi être un procédé rhétorique par lequel on évoque dans un discours une figure illustre à des fins argumentatives et morales. On se demandera si l'honos, comme procédé, peut fonctionner d'une manière analogue à l'exemplum. L'exemplum, au sens large du terme, est un grand homme du passé qui s'est illustré par ses qualités, morales notamment ${ }^{51}$. C'est à la fois un exemple illustratif d'une vertu et un exemple normatif, qui, par le souvenir qu'il laisse de lui dans les mémoires, dicte la conduite à suivre: M. Atilius Régulus est ainsi un exemplum de fides et de pietas envers la patrie; M.' Curius Dentatus de seueritas et de paupertas $^{52}$.

paideia di Quintiliano, Milan, Vita e Pensiero, 1990, p.61-141); les études sur l'idéologie des exempla (H.W. LitchField, "National Exempla Virtutis in Roman Literature», HSCPh, 25, 1914, p.1-71; M.StemmLER, "Auctoritas exempli. Zur Wechselwirkung von kanonisierten Vergangenheitsbildern und gesellschaftlicher Gegenwart in der spätrepublikanischen Rhetorik», in LinKe, B. et StemmleR, M.(éds.), Mos maiorum. Untersuchungen zu den Formen der Identitätsstiftung und Stabilisierung in der römischen Republik, Stuttgart, F. Steiner, 2000, p.141-205; K.-J. HöLKeSKAMP, «Exempla und mos maiorum: Überlegungen zum kollektiven Gedächtnis der Nobilität» in Senatus Populusque Romanus. Die politische Kultur der Republik, Stuttgart, F. Steiner, 2004, p. 169-198); les travaux sur les recueils d'exempla et notamment celui de Valère Maxime (G. Maslakov, "Valerius Maximus and Roman Historiography: a Study of the Exempla Tradition", ANRW, II, 32, 1, 1984, p.437-496; J.-M.DAVID (éd.), Valeurs et mémoire à Rome. Valère Maxime ou la vertu recomposée, Paris, De Boccard, 1998; U. LucARelli, Exemplarische Vergangenheit. Valerius Maximus und die Konstruktion des sozialen Raumes in der frühen Kaiserzeit, Göttingen, Vandenhoeck \& Ruprecht, 2007). Voir aussi les études sur les «grands hommes» (Орётн, «Faits de mots et d'images. Les grands hommes dans la Rome ancienne»; M. Coudry et T. SPÄth (éds.), L'Invention des grands hommes de la Rome antique, Paris, De Boccard, 2001).

${ }^{49}$ Voir le rapport établi entre emo, eximo, eximius et exemplum par le DELL, p. 195. «Exemplum est proprement l'objet séparé des autres pour servir de modèle» (DELL, p. 205).

${ }^{50}$ Sur les sens d'exemplum et sur cette organisation du sémantisme voir KoRNHARDT, Exemplum. Eine bedeutungsgeschichtliche Studie qui isole deux sens fondamentaux, celui d" «échantillon» et celui de «modèle».

${ }^{51}$ Ce sont les exempla uirtutis étudiés par LitchFIELD, «National Exempla Virtutis in Roman Literature».

${ }^{52}$ Sur les vertus qu'illustrent les exempla uirtutis, voir Ibid., p. 28-35. 
Quel rôle l'honos peut-il jouer dans la constitution de ces exempla? Un passage du De legibus nous renseigne à ce sujet:

Quaecumque mutatio morum in principibus extiterit, eandem in populo secutam. [...] Quo perniciosius de re publica merentur uitiosi principes, quod non solum uitia concipiunt ipsi, sed ea infundunt in ciuitatem, neque solum obsunt quod ipsi corrumpuntur, sed etiam quod corrumpunt, plusque exemplo quam peccato nocent. Atque haec lex, dilatata in ordinem cunctum, coangustari etiam potest: pauci enim atque admodum pauci honore et gloria amplificati uel corrumpere mores ciuitatis uel corrigere possunt.

«Tout changement moral qui se produit chez les chefs se poursuit dans le reste du peuple. [...] C'est pourquoi des dirigeants dépravés font d'autant plus de mal à l'État que, non seulement eux-mêmes contractent des vices, mais encore les introduisent dans la cité; ils ne sont pas nuisibles seulement parce qu'ils sont corrompus, mais parce que, de plus, ils corrompent les autres, et ils font plus de mal par leur exemple que par leur propre faute. D'ailleurs cette loi, étendue à un ordre tout entier, peut aussi se restreindre: il suffit de quelques gens peu nombreux et même très peu nombreux, qui soient grandis par l'honneur et la gloire, pour corrompre ou corriger les mœurs d'une cité.»

(CIc. Leg. III, 31-32; trad. De Plinval modifiée).

Cicéron explique pourquoi le fait d'avoir des dirigeants corrompus conduit une cité à la ruine morale. L'amplification assurée par l'honneur procure à l'individu un statut d'exemplum et explique que son attitude, si elle est déviante, ait des répercussions négatives sur la cité. Ce ne sont pas les mauvaises mœurs de l'homme in honore qui sont par elles-mêmes nuisibles mais "l'exemple» désastreux qu'elles donnent. L'honos donne un statut d'exemplum qui provoque ensuite l'imitation de l'entourage. Celui qui le reçoit obtient non seulement une image de supériorité mais aussi une posture de référent exemplaire. Le choix du destinataire de l'honos est donc, à l'échelle de la cité, crucial pour orienter les mœurs des habitants car c'est un moyen de créer des images de référence morale qui incarnent les normes de conduite. Cette exemplarité procurée par l'honos réapparaît dans le Pro Flacco, quand Cicéron remarque que la considération et les ornamenta uirtutis dont jouit Flaccus font de lui un «exemple de l'antique gravité» (exemplar pristinae grauitatis): celui qui jouit de l'estime et des marques d'estime de son entourage est constitué en représentant de l'excellence des ancêtres et devient un exemple à suivre ${ }^{53}$. L'honneur joue ainsi un rôle important dans la constitution des "grands hommes " de la cité. M. Coudry note que Camille apparaît en tant que figure de référence chez Claudius Quadrigarius et Cicéron mais que son image de grand homme est plus ancienne et a pu se structurer par d'autres moyens que l'écrit; on connaît par exemple une statue honorifique de

${ }^{53}$ Cic. Flac. frg. 17 du manuscrit de Cues. Sur la distinction entre exemplum et exemplar, voir KoRNHARDT, Exemplum. Eine bedeutungsgeschichtliche Studie, p. 52-55. 
Camille sur les rostres, qui date sans doute de la fin du IVe ou du début du III siècle $^{54}$ : l'honos contribue donc à l'élaboration de la figure d'un grand homme. J.-M. David fait une remarque similaire pour Coriolan:

«L'histoire culturelle de Rome n'est pas seulement celle de sa littérature. Elle est aussi celle des modes de représentation du passé et de son utilisation par des hommes qui grâce à lui déterminaient leur identité et légitimaient leurs conduites. [...] Avant même que l'histoire n'apparût à la fin du III ${ }^{\mathrm{e}}$ siècle, d'autres formes de célébration des grands hommes des temps anciens avaient leur place et trouvaient leur efficacité. $»^{55}$

L'honos nous paraît pouvoir contribuer à la création de modèles de référence dans la cité. Il n'est cependant pas suffisant pour créer un grand homme. Il est en effet possible d'accumuler les honores sans être pour autant une figure exemplaire. Plus d'un Romain a obtenu les honneurs du consulat, du triomphe et de funérailles publiques sans rejoindre les rangs des grands exempla. C. Duilius, par exemple, consul de 260, vainqueur des Carthaginois sur mer à Mylae lors de la première guerre punique a célébré un triomphe naval, a obtenu une statue sur les rostres et la columna rostrata qui rappelait ses mérites. Il avait aussi le droit de se faire raccompagner après les banquets publics par un porteur de torche et un joueur de flûte ${ }^{56}$. Cependant, il n'a jamais eu la même stature que son contemporain M.Atilius Régulus $^{57}$. Ce dernier, lui aussi consul et vainqueur des Carthaginois à Ecnome, eut finalement moins de succès que Duilius puisqu'il fut battu par les troupes puniques menées par Xanthippe et réduit en captivité. Cependant, les récits qui se sont développés sur son compte et l'épisode de son retour héroïque à Rome, du sacrifice de sa personne et de sa mort sous la torture à Carthage ont fait de lui une figure exemplaire. Régulus a été confronté à un choix difficile et a fait primer le devoir sur sa survie; il a fait montre de loyauté, de courage face à la mort et de dévouement à la patrie ${ }^{58}$. Pour devenir un véritable grand homme, l'individu doit remplir trois conditions: faire l'objet d'une

${ }^{54}$ M.Coudry, "Camille: construction et fluctuations de la figure d'un grand homme», in COUdrY, M. et SPÄTH, T. (éds.), L'Invention des grands hommes de la Rome ancienne, Paris, De Boccard, 2001, p.47-81, aux p.50-51. Sur la statue de Camille, voir Ascon. In Scaur. 29C.

${ }^{55}$ À la p. 17 de J.-M. DAVID, « Les étapes de la construction de la figure de Coriolan », in Coudry, M. et Späth, T. (éds.), L'Invention des grands hommes de la Rome ancienne, Paris, De Boccard, 2001, p. 17-25.

${ }^{56}$ Sur la columna rostrata, PLIN. NH XXXIV, 20;CIL I'2, $25=I L L R P$ 319. Sur le porteur de torche et le joueur de flûte, Cic. Cato mai. 44; Liv. Per. 17; Val. Max. III, 6 , 4; SIL. VI, 663-669.

${ }^{57}$ Nous nous appuyons sur la comparaison des deux personnages faite par GeNDRE et Loutsch, «C. Duilius et M. Atilius Regulus».

${ }^{58}$ Ibid., p. 164. Sur les sources historiques concernant Régulus, voir supra p. 319 n. 63. 
élaboration littéraire assez importante ${ }^{59}$; être situé dans le passé, car l'exemplum est le plus souvent un personnage historique ou légendaire que le décalage temporel avec le présent contribue à grandir; avoir montré ses grandes qualités morales ${ }^{60}$. L'honos ne vient en quelque sorte que par surcroît.

On peut dès lors se demander si ce n'est pas plutôt avec l'exemplum rhétorique que l'honos a le plus de rapports. Ce procédé, connu comme instrument de persuasion depuis Aristote ${ }^{61}$, est défini ainsi par la Rhétorique à Herennius: exemplum est alicuius facti aut dicti praeteriti cum certi auctoris nomine propositio ${ }^{62}$. C'est la mention d'une action ou d'un fait passé qui permet au locuteur de garantir, par le prestige de son auteur, un autre fait. Par exemple, pour justifier la vie à la campagne menée par Roscius, Cicéron utilise l'exemplum d'Atilius qui montre l'honorabilité de ce mode de vie ${ }^{63}$. L'honos et l'exemplum ont des similitudes. Tous deux, d'abord, réduisent la personnalité des individus à quelques traits saillants, parfois à un seul, ce qui permet de transformer la personne en une figure univoque et puissante ${ }^{64}$. L’honos donné pour un mérite moral fige celui qui le reçoit en mettant en valeur la qualité qui fonde son octroi: le triomphe, par exemple, consacre la uirtus militaire et réduit l'individu honoré à l'image d'un imperator vainqueur. Ensuite, l'exemplum vaut par l'auctoritas de la personne invoquée, comme l'indique la définition de la Rhétorique à Herennius; l'honos confère de même une auctoritas qui permet ensuite d'influencer le comportement de l'entourage ${ }^{65}$. Enfin, exemplum et honos ont une même fonction morale: les exempla constituent un système de références éthiques et politiques et permettent d'établir des normes tout en les énonçant ${ }^{66}$. L'honos, nous l'avons vu, fonctionne de

59 Sur l'importance de la littérature dans la construction d'un modèle de référence, LitchField, «National Exempla Virtutis in Roman Literature », p. 62-63; T. SpäтH, "Erzählt, erfunden: Camillus. Literarische Konstruktion und soziale Normen», in COUdRY, M. et SpÄth, T. (éds.), L'Invention des grands hommes de la Rome ancienne, Paris, De Boccard, 2001, p. 341-412; HöLKESKAMP, «Exempla und mos maiorum : Überlegungen zum kollektiven Gedächtnis der Nobilität ».

${ }^{60}$ C'est la manifestation de uirtutes à travers les actions réussies qui rend exemplaire et non la réussite de ces actions elle-même. Sur la cohérence des uirtutes d'une figure à l'autre, LitchField, « National Exempla Virtutis in Roman Literature», p. 421-437.

${ }^{61}$ ARstT. Rhet. 1356 a-b.

62 «L'exemple consiste à citer un fait ou un propos du passé dont on peut nommer l'auteur avec précision» (Rhet. Her. IV, 62; trad. Achard). Voir aussi la définition de Cic. Inu. I, 49; De or. III, 204-205; Top. 41-45; Part. 44 et 55. Sur ces définitions, David, «Les enjeux de l'exemplarité», p.9; David, "Maiorum exempla sequi», p.68-69; LuCARELLI, Exemplarische Vergangenheit, p. 31.

${ }^{63}$ Cic. Rosc. Amer. 50.

${ }^{64}$ DAVID, «Les enjeux de l'exemplarité », p. 10; SPÄTH, «Erzählt, erfunden ».

${ }^{65}$ Sur l'auctoritas exempli, voir GAILLARD, «Auctoritas exempli: pratique rhétorique et idéologie au $\mathrm{I}^{\mathrm{er}}$ s. av. J-C. » et STEMmLER, "Auctoritas exempli».

${ }^{66}$ David, «Les enjeux de l'exemplarité », p. 10. 
façon similaire: il illustre et énonce des valeurs. Honos et exemplum servent à orienter la conduite en donnant, par un procédé pragmatique ou rhétorique, une stature supérieure à des personnages présentés dès lors comme objets d'imitation ${ }^{67}$. Honos et exemplum, s'ils divergent par leurs moyens, l'un utilisant l'action et l'autre le discours, l'un consacrant des contemporains et l'autre exhumant des héros du passé, ont cependant des fonctions morales similaires.

L'honos apparaît, au terme de l'analyse de sa fonction morale, comme un facteur de normativité. Nous pensons que l'honneur entretient en effet un triple rapport aux normes: comme sanction, il entérine la conformité exemplaire aux normes et participe ainsi à leur stabilité; comme rétribution symbolique, il donne du prix à certains objets, signifie où se situe le mérite et définit ainsi les valeurs qui sous-tendent les normes et motivent l'action; comme facteur d'émulation et d'imitation, il participe à la constitution de modèles de référence qui explicitent les normes et les énoncent simultanément. L'honos fait ainsi constamment le lien entre les règles de la société et leur mise en application.

\section{STRUCTURER LA SOCIÉTÉ}

À ce rôle normatif et moral de l'honos s'ajoute une fonction sociale. Comme nous l'avons vu, l'honos met en relation des individus ou des groupes: ses protagonistes sont associés par des rapports d'observation, de bienfaisance, de reconnaissance, d'échange, etc. Il ne faudrait pas cependant concevoir ces relations sociales comme de simples préalables nécessaires à son fonctionnement. L'honos se fonde sur ces relations mais peut aussi avoir pour fonction de les exprimer symboliquement, voire de les instaurer. L'honos joue à Rome un rôle de structuration sociale: il établit des liens entre les individus et participe à la formation de groupes sociaux homogènes. Cette fonction est remplie de deux façons complémentaires, que nous aborderons successivement. D'une part, l'hommage suscite, entre les donateurs de l'honos, une cohésion et un sentiment d'appartenance à une communauté. D'autre part, il permet d'exprimer l'existence d'un lien social entre le donateur de l'honos et le destinataire.

\subsection{Contribuer à la cohésion du groupe}

L'honos procure à celui qui le reçoit une supériorité sur les autres, sous forme de dignitas et de pouvoir, qui le distingue de la communauté. Il peut donc paraître paradoxal de déclarer que l'honos est

67 Kornhardt, Exemplum. Eine bedeutungsgeschichtliche Studie, p. 57; DAvID, "Maiorum exempla sequi », p. 76; Sрӓтн, «Erzählt, erfunden », p. 343. 
facteur de cohésion sociale. Le paradoxe n'est cependant qu'apparent, car l'octroi d'un signe d'honneur, s'il isole un membre du groupe, permet simultanément à ce groupe de se réunir autour de celui à qui l'hommage est rendu. Quand des soldats octroient à leur général le titre d'imperator, ils le font en se retrouvant tous ensemble au camp et en poussant à l'unisson une acclamation solennelle ${ }^{68}$. L'honos reconnaît la supériorité du chef et permet à son armée de se représenter comme un corps uni dans l'estime du général; il réunit les différents éléments du groupe militaire autour de la figure de l'imperator. Lors de l'honos suprême des funérailles, c'est toute une gens qui se retrouve et reprend conscience de son unité autour de la célébration d'un défunt et de la présence symbolique, par les imagines, de tous les ancêtres communs. La procession funéraire a pour fonction de représenter la communauté des membres de la famille, passés et présents, et de montrer leurs liens ${ }^{69}$. Après l'inhumation, la sépulture et le culte rendu au défunt rassemblent les membres épars de la famille ${ }^{70}$. Ces rites funéraires ont une importance fonctionnelle au sein de la société en permettant de renforcer les liens entre les vivants et la cohésion du groupe familial. La contemplation de portraits honorifiques figurant dans les atria ou dans les tombes des aristocrates est elle aussi l'occasion pour les proches de ressentir l'appartenance à un groupe ${ }^{71}$. D'autres honores religieux servent aussi à rassembler les membres d'une communauté. Les fêtes en l'honneur de Marcellus permettent ainsi aux Syracusains de se retrouver et d'afficher leur appartenance à une même cité, dans la célébration du souvenir d'un de leurs bienfaiteurs ${ }^{72}$. Quand l'honos religieux prend une certaine ampleur, il implique la participation de plusieurs personnes qui se retrouvent associées dans une même succession d'actes rituels, tendus vers un même but: la supplication d'action de grâces exige ainsi la collaboration de tous les membres de la cité pour rendre hommage aux dieux ${ }^{73}$. L'octroi de l'honos d'une charge publique revêt également un aspect rituel important et suscite un rassemblement de la collectivité. Le populus est réuni dans un lieu précis et organisé selon son appartenance à un groupe civique, classe, tribu ou centurie ${ }^{74}$. Le vote est une procédure technique mais aussi une des formes de l'expression symbolique de l'appartenance à la res publica dans son ensemble et à ses unités plus réduites. L'octroi de l'honos réunit une large communauté civique tout en l'ordonnant

${ }^{68}$ CombÈs, Imperator, p. 93.

${ }^{69}$ Flower, Ancestor Masks, p. 99-100.

${ }^{70}$ Von Hesberg, Römische Grabbauten, p. 14.

${ }^{71}$ RoBert, "Quelques usages du portrait peint à l'époque médio-républicaine», p. 85 .

${ }^{72}$ CIC. Verr. II, II, 51.

${ }^{73}$ Halkin, La Supplication, p. 101-102. Voir par exemple Cic. Catil. III, 23.

${ }^{74}$ Voir Nicolet, Métier, p. 333-341 et 347-348. 
selon les catégories qui la subdivisent. Allant parfois au-delà de cette fonction de réunion sociale, l'honos permet de renforcer la concorde des membres d'un groupe. On voit à plusieurs reprises, dans l'histoire livienne, le peuple romain oublier ses dissensions à l'occasion d'un honos ou exprimer son estime avec une ferveur unitaire ${ }^{75}$. Cette concorde instaurée par l'honos provient de la répercussion positive sur la communauté des marques d'honneur accordées à certains de ses membres. Le triomphe, en mettant en avant le général victorieux, célèbre en même temps la grandeur de Rome. L'imperator se trouve au cœur de la pompa triumphalis, mais il est accompagné de son armée ainsi, semble-t-il, que de sénateurs et magistrats, sous les yeux de la communauté ${ }^{76}$. Le triomphe rassemble tous les membres de la cité dans la célébration de la victoire ${ }^{77}$.

Si l'honos produit efficacement de la cohésion sociale, c'est parce que l'unité du groupe des donateurs ne repose pas sur la seule réunion physique de ces derniers. La concorde permise par l'octroi de l'honos procède en effet également du partage constamment renouvelé de représentations collectives. L'honos est l'occasion de réunir des individus mais aussi d'expliciter ce qu'ils ont en commun et de définir les principes qui régissent leur rapprochement. Il a de ce fait une fonction identitaire: c'est un moyen pour une communauté de célébrer des qualités spécifiques à cette dernière, sources de l'honos, et de reformuler ainsi les valeurs sur lesquelles elle s'est bâtie. La fonction morale rejoint ici la fonction sociale: l'honos permet de définir des valeurs qui orientent le comportement mais servent aussi à donner une identité à un groupe. Les marques d'honneur sont ainsi pour l'aristocratie un moyen d'affirmer les qualités et les valeurs qu'elle considère comme

${ }^{75}$ Voir le consensus universel qui préside à l'honos rendu à Horatius Coclès (LrV. II, 10, 12-13) ou à Manlius Capitolinus (Liv. V, 47, 8). Après la victoire du Métaure, c'est tout Rome qui honore les vainqueurs (Liv. XXVII, 51, 1-10).

${ }^{76}$ BEARD, The Roman Triumph, p. 239-244.

${ }^{77}$ Le triomphe fonctionne ici comme un rituel qui renforce les liens des membres de la communauté. Cette interprétation traditionnelle du rituel, qui est celle de V. W. Turner et É. Durkheim, a été contestée par T. Itgenshorst et M. Beard. Pour T. Itgenshorst, la pompa triumphalis, si elle est bien un rituel, a plutôt pour fonction de laisser s'exprimer des conflits qui agitent la société, entre le général et le sénat, ou le général et le peuple (Itgenshorst, Tota illa pompa, p. 189). Pour M. Beard, le rituel du triomphe permet de mettre en cause les valeurs traditionnelles (BEARD, The Roman Triumph, p. 59). Ces deux lectures ne nous paraissent pas recevables. L'octroi du triomphe donne bien lieu à des rivalités et des dissensions, mais elles se produisent avant la cérémonie où elles sont ensuite occultées. La subversion que M. Beard décèle à l'œuvre dans le triomphe repose sur un argument qui nous paraît bien mince: ce serait la splendeur de certains vaincus, susceptibles de concurrencer le général, qui inverserait le rapport vainqueur-vaincu. Mais cette splendeur, qui ne se manifeste que dans quelques triomphes et non systématiquement, ne change rien au destin des vaincus, étranglés dans le carcer et à l'assomption du vainqueur, l'imperator, assimilé à Jupiter. 
centrales et de se définir sur le terrain moral ${ }^{78}$. La pompa funebris et les éloges funèbres mettent par exemple en valeur les activités politiques, les succès militaires et les qualités morales du défunt; ce rituel rend ainsi hommage à ce dernier mais énonce simultanément quelles sont les valeurs prisées et établit du même coup les caractéristiques de l'appartenance à la nobilitas ${ }^{79}$. La mise en avant de ces mérites essentiels est une manière d'établir des critères subjectifs, moraux, de l'appartenance à l'élite patricio-plébéienne qui s'ajoutent au critère plus objectif, politique, qu'est l'exercice d'une charge élevée dans le cursus honorum.

\subsection{Symboliser le lien social}

La structuration sociale des groupes opérée par l'honos fonctionne aussi à l'échelle des individus. Il ne s'agit plus alors de la cohésion instaurée entre donateurs de l'honos mais des rapports établis entre donateur et destinataire. La marque d'honneur permet en effet de symboliser les liens sociaux existant entre eux et de les entretenir. L'honos peut par exemple se fonder sur un lien d'amicitia et servir alors à signifier l'estime d'un individu à son ami mais aussi à symboliser leur relation d'amitié ${ }^{80}$. Dans une lettre adressée à L. Plotius Plancus où il lui demande d'intervenir dans l'affaire de Buthrote ${ }^{81}$, Cicéron écrit:

[...] tamen hoc pro coniunctione et beneuolentia nostra mihi sumpsi ut id a te peterem quod tua singularis humanitas suauissimique mores a te essent impetraturi; id autem est ut hoc quod te tua sponte facturum esse certo scio, honoris nostri causa libenter, prolixe, celeriter facias.

«Cependant, étant donné nos relations et notre bienveillance mutuelle, je me permets de te demander ce que te dicteraient ta bonté sans égale et la douceur de ton caractère, c'est-à-dire d'accomplir avec plaisir, empressement, célérité, par considération pour moi, l’acte que, j'en ai la certitude, tu accomplirais de toi-même.»

(CIc. Att. XVI, 16a, 4 ; trad. Beaujeu).

Cicéron demande à Plotius Plancus d'agir au nom de leur coniunctio et de leur beneuolentia, c'est-à-dire au nom des liens qui les unissent et de leurs bonnes relations. Aux yeux de Cicéron, ce serait lui

78 Voir Hölkeskamp, Die Entstehung der Nobilität, p. 204 et Blösel, "Von der Familientradition zum Nobilitätsethos », p.46-53.

${ }^{79}$ HölKesKamp, Die Entstehung der Nobilität, p. 222. Voir par exemple l'éloge funèbre de Caecilius Metellus (Plin. NH VII, 139-140).

${ }^{80}$ Dans la typologie que donne P. Veyne des échanges, l' «hommage» vise non pas la satisfaction des protagonistes de l'échange mais la figuration métaphorique de leur relation (VeYne, Le Pain et le cirque, p. 82).

${ }^{81}$ Sur cette affaire où un territoire est frappé de confiscation et où sont impliqués, de façon plus ou moins directe, Atticus et César, voir J.Beaujeu (éd.), Cicéron. Correspondance. Tome IX, Paris, Les Belles Lettres, p. 289-294. 
faire honneur (honoris nostri causa) que de lui venir en aide dans cette affaire. L'invocation de l'honos est habile de la part de Cicéron car un refus serait le signe que la beneuolentia et la coniunctio précédemment évoquées n'ont pas de réelle existence. L'honos que Cicéron réclame servirait à manifester clairement leur relation d'amitié et un refus entraînerait une détérioration de leurs rapports. Les honores rendus entre amis permettent de visualiser l'amitié et de la renforcer car cette dernière se nourrit de services concrets ${ }^{82}$. L'économique connait ainsi un usage symbolique: la dépense d'argent ou d'énergie consentie par l'ami sert à représenter l'existence d'une relation sociale.

La notion d'amicitia possédant à Rome une coloration politique toujours plus ou moins marquée, on peut s'interroger sur la fonction de communication politique que peut avoir l'honos qui exprime cette amitié. Manifester l'amicitia par des marques d'honneur peut revenir à signifier également son allégeance à un homme ou au parti qu'il représente. Le jour de supplication supplémentaire que Marc Antoine veut faire consacrer à César après sa mort est une façon de se positionner comme héritier politique du dictateur défunt et de marquer son opposition irréductible aux césaricides ${ }^{83}$. Les personnes qui font à un candidat à une magistrature l'honos de l'escorter le soutiennent dans la perspective des élections et signifient de manière très visible leur appui ${ }^{84}$. L'honos sert ici de media: il fait passer de manière efficace et rapide un message de nature politique à la population urbaine de Rome. L'honos est également un moyen d'expression de l'alliance entre deux cités ou deux États. Les honores échangés par des peuples servent à manifester une bonne entente diplomatique et à prolonger cette dernière. Un passage de César, que nous avons cité précédemment à propos des décrets honorifiques, témoigne de cette fonction de l'honos. En voici à nouveau le texte:

Docebat etiam quam ueteres quamque iustae causae necessitudinis ipsis cum Haeduis intercederent, quae senatus consulta quotiens quamque honorifica in eos facta essent.

«Il lui apprit encore combien étaient anciennes et légitimes les raisons de l'amitié qui unissait les Héduens aux Romains, quels sénatus-consultes avaient été rendus en leur faveur, à mainte reprise et dans les termes les plus honorables.»

(CAES. BG I, 43, 6-7; trad. Constans modifiée).

César explique à Arioviste que des liens étroits unissent les Romains aux Héduens et qu'il ne saurait donc tolérer qu'on s'en prenne à eux. Les sénatus-consultes honorifiques rendus en faveur des Héduens

${ }^{82}$ Sur cet aspect de l'amicitia, voir supra p. 321-322.

83 Cic. Phil. I, 12. Sur cet épisode, Ferrary, "À propos de deux passages des Philippiques $(1,11-13$ et 2,110$)$ ».

${ }^{84}$ Cic. Mur. 70. 
sont l'expression de la necessitudo qui rapproche les deux peuples, le signe tangible de leur alliance. La répétition des senatus consulta honorifica permet de symboliser et d'entretenir cette necessitudo dans le temps. C'est aussi par l'honos que Rome renforce ses liens avec les cités grecques d'Asie après la victoire sur Antiochus ou, quelques années après, avec Eumène, placé à la tête du royaume de Pergame ${ }^{85}$. Les marques d'honneur sont ainsi les éléments d'un langage diplomatique: elles constituent des informations publiques sur la teneur des relations de Rome avec les autres cités de Méditerranée et symbolisent, pour les bénéficiaires mais aussi pour tous les autres États qui en sont les témoins, le degré d'amicitia entre l'Vrbs et ces peuples.

\section{OBTENIR DU POUVOIR}

Nous avons vu au chapitre précédent que l'honos procurait à son détenteur un ascendant sur son entourage et que cet ascendant était indissociable de certaines contraintes ${ }^{86}$. L'existence de ces dernières nous amène à reconsidérer la nature de la relation de pouvoir créée par l'honneur. Les obligations liées à l'honos sont en effet une forme d'emprise du donateur sur la personne qui reçoit l'honos. On peut dès lors se demander si les honores n'ont pas pour fonction de donner du pouvoir à celui qui les octroie.

\subsection{Gagner en prestige}

L'acte de rendre hommage n'est pas un geste totalement désintéressé. Le donateur de l'honos peut bénéficier, de manière indirecte, de l'hommage qu'il rend à un tiers. Il peut d'abord être lui-même un destinataire secondaire de l'honos conféré à autrui. C'est patent lorsqu'une famille aristocratique rend honneur à l'un des siens à son décès. $\mathrm{La}$ procession, qui met en scène les ancêtres du trépassé, souligne en effet le prestige de toute la gens et non du seul mort; cette démonstration de grandeur profite aux derniers descendants encore vivants de la famille. L'éloge funèbre rappelle de même les mérites du défunt mais commence par glorifier les ancêtres et la famille, et donc les personnes mêmes qui organisent le funus ${ }^{87}$. La fonction politique de la laudatio

${ }^{85}$ Liv. XXXVIII, 39, 12 pour Smyrne, Chios et Erythrées; XLII, 11, 2 et 14, 10 pour Pergame.

${ }^{86}$ Supra p. 355 sqq.

${ }^{87}$ L'éloge de la famille a lieu juste après le préambule et constitue une constante de la laudatio funebris (KIERDORF, Laudatio funebris, p. 64-69). Sur la glorification des autres personnes que le défunt par les funérailles, voir FlaIG, «Die pompa funebris », p. 130. 
est nette: cet honos sert le prestige de la famille en commémorant sa valeur passée et en mettant en avant un de ses jeunes rejetons, celui qui prononce le discours ${ }^{88}$. Les portraits peints des aristocrates triomphateurs figurant dans les temples ou les tombes visent de même à imposer le souvenir d'une gens tout entière dans des espaces semipublics ${ }^{89}$.

La marque d'honneur permet à celui qui la reçoit de se singulariser et de se construire une image publique positive. Mais cet effet particulier est également recherché par le donateur pour son propre compte: donner un honos constitue un moyen de publicité efficace. La statue honorifique décernée à un individu est pourvue d'une inscription qui mentionne en général le nom de celui qui l'octroie ${ }^{90}$. L'honos ne bénéficie pas alors seulement à celui qui le reçoit mais aussi à celui qui le confère. Une inscription retrouvée en Sicile sur un piédestal qui supportait vraisemblablement une statue dédiée au frère de Scipion l'Africain déclare:

Italicei

L. Cornelium Sc[ip]i[one]m

honoris caussa

«Les Italiens, à Lucius Cornelius Scipion, pour l'honorer.»

$\left(C I L \mathrm{I}^{2}, 612=I L L R P 320\right)$.

Le texte rappelle l'identité de la personne figurée sous forme de statue mais indique aussi, en premier lieu, l'auteur de cet honos, les Italiens de Sicile. Par cet honos, les Italicei remercient sans doute L.Scipion pour son action en Sicile lorsqu'il y était préteur mais rappellent aussi à tous l'hommage qu'ils ont pris la peine de décerner à un magistrat du peuple romain ${ }^{91}$. L'honos montre que le donateur est reconnaissant et donne de lui une image sociale positive. Il en va de même des peintures historiques qui célèbrent des grands hommes de l'histoire de Rome mais mettent simultanément en valeur le peintre: à en croire Valère Maxime, Fabius Pictor a cherché à s'attirer la gloire par les fresques qu'il réalisa dans le temple de Salus, alors même que sa famille était déjà extrêmement célèbre ${ }^{92}$.

Enfin, sur un plan plus concret, le donateur de l'honos peut augmenter son propre prestige en engageant des dépenses impor-

${ }^{88}$ FLower, Ancestor Masks, note que par la laudatio « an office holding family set itself apart from ordinary citizens by virtue of past political function and made an exhibition of its history in the most public way available» (p.132).

${ }^{89}$ ROBERT, «Quelques usages du portrait peint à l'époque médio-républicaine», p. 86.

${ }^{90}$ Sur les inscriptions sur la base des statues, LaHusen, Untersuchungen zur Ehrenstatue in Rom, p. 142.

${ }^{91}$ Liv. XXXIV, 44 ; Cic. De or. II, 280.

${ }^{92}$ VAL. MAX. VIII, 14, 6. 
tantes. La forme matérielle de l'honos est en effet loin d'être secondaire: la valeur économique soutient la valeur symbolique. Mauss a souligné dans son analyse du don combien le prestige se gagnait par la dépense somptuaire, voire, dans les sociétés où le don est un échange agonistique, par la destruction de ses biens ${ }^{93}$. Vu la publicité qui entoure l'octroi d'honores, le don de marques d'estime coûteuses est un moyen de prouver sa richesse et d'en tirer une supériorité: c'est une forme de la consommation ostentatoire théorisée par Veblen ${ }^{94}$. L'homme public qui octroie des honores à sa cité retire de l'estime de son geste généreux: les inscriptions qui commémorent les largesses rappellent avec précision les investissements réalisés et soulignent que les donateurs les ont fait de sua pecunia. C'est le cas de Gaius Quinctius et Marcus Porcius à Pompéi:

C(aius) Quinctius C(aii) f(ilius) Valgus $\mid M$ (arcus) Porcius M(arci) f(ilius) duo uir(i) $\mid$ quinq(uennales) coloniai honoris $\mid$ caussa spectacula de sua $\mid$ peq(unia) fac(ienda) coer(auerunt) et coloneis $\mid$ locum in perpetuom deder(unt).

«Gaius Quinctius Valgus, fils de Gaius, et Marcus Porcius, fils de Marcus, duumvirs quinquennaux, se chargèrent d'organiser des spectacles à leurs frais pour honorer la colonie et donnèrent aux colons un lieu d'enterrement pour l'éternité. »

$\left(C I L \mathrm{I}^{2}, 1632\right)$.

Les deux magistrats locaux ont investi leur argent personnel dans un honos à leur cité, en organisant un spectacle et en offrant un lieu d'ensevelissement aux colons. L'inscription commémore, à leur profit, cette largesse et leur donne une image durable d'hommes généreux ${ }^{95}$. L'honos intègre ici les effets particuliers de la pratique hellénistique de l'évergétisme, par laquelle un notable s'attire la reconnaissance du peuple, affirme son appartenance à la classe dirigeante et augmente son prestige ${ }^{96}$. Les funérailles sont un autre type d'honos où la dépense économique engagée sert le prestige de celui qui la fait. L'exhibition, lors de la pompa funebris aristocratique, de nombreux musiciens, chanteurs, danseurs, mimes, les affranchissements testamentaires à l'occasion du décès et la destruction dans le feu du bûcher d'objets précieux relèvent de ces dépenses ostentatoires, dont certaines sont

${ }^{93}$ Lors du potlatch, donner est une obligation si l'on veut conserver son rang (MAUss, Sociologie et anthropologie, p. 101).

${ }^{94}$ Veblen, Théorie de la classe de loisir, p. 48-68 notamment. Pour Veblen, montrer les dépenses élevées que l'on consent est un moyen d'acquérir du prestige car cela revient à exhiber sa puissance pécuniaire. Pour une application nuancée de cette théorie à l'Antiquité, voir Veyne, Le Pain et le cirque, p. 104 sqq.

${ }^{95} \mathrm{Cf}$. l'inscription commémorant les actes d'évergétisme de C. Catius (ILLRP I, 116 = CIL X, 1236).

96 Sur l'image de magnificence procurée par l'évergétisme, VEYNE, Le Pain et le cirque, p. 31 sqq. 
ici réalisées en pure perte, à des seules fins de prestige social ${ }^{97}$. Le nombre parfois très élevé de ces sacrifices matériels, qui ne sont pas sans rappeler les destructions de biens intervenant lors des potlatchs décrits par Mauss, ont conduit à des limitations légales, pour éviter de mettre en péril l'ordre public par l'excès de luxe et la ruine des familles ${ }^{98}$.

\section{2. "Do ut des» : s'attirer bienfaits et partisans}

L'honos contribue également à l'augmentation du pouvoir de la personne qui en est à l'origine en lui permettant d'obtenir des avantages concrets et des alliés qui lui sont soumis. L'honos procure à son donateur un pouvoir de nature symbolique, le prestige, mais aussi une influence directe sur la personne honorée. Cet ascendant est rendu possible par le fonctionnement économique de l'honneur et plus précisément par la dette qu'il crée et la gratia qu'il impose. La rétribution honorifique conférée à autrui sous forme d'honos l'oblige en effet à rendre en retour un autre bienfait pour acquitter sa dette ${ }^{99}$. Ce mécanisme d'échange explique que l'honos puisse avoir comme fonction délibérée de s'attirer des bienfaits de la part de celui qu'on honore: c'est le principe du do ut des ${ }^{100}$. C'est cet usage de l'honos que Cicéron dénonce chez Marc Antoine: il l'accuse d'avoir honoré César non pas en raison de sa dignitas mais par intérêt personnel, avec l'espoir d'être gratifié pour ces honneurs ${ }^{101}$. Cette critique est étayée de manière théorique par la réflexion à laquelle se livre Cicéron au livre II du De officiis; il s'interroge sur les manières de s'attirer la faveur de son entourage et les évalue d'un point de vue moral. Or, accorder l'honos dans le seul but de recevoir en retour un bienfait est une conduite méprisable à ses yeux:

Quaecumque igitur homines homini tribuunt ad eum augendum atque honestandum, aut beniuolentiae gratia faciunt cum aliqua de causa quempiam diligunt, aut honoris si cuius uirtutem suspiciunt quemque dignum fortuna quam amplissima putant [...] aut postremo pretio ac mercede ducuntur, quae sordidissima est illa quidem ratio et inquinatissima et iis, qui ea tenentur, et illis, qui ad eam confugere conantur.

«Ainsi donc, tout ce que les hommes accordent à l'homme pour le grandir ou l'honorer, ils le font soit par bienveillance lorsqu'ils ont une raison de l'aimer,

${ }^{97}$ Pour T. Veblen, la dépense ostentatoire prestigieuse est celle qui va à des superfluités et non à des biens indispensables (VeBLen, Théorie de la classe de loisir, p.65). L'important lors du funus n'est pas de dépenser pour les funérailles elles-mêmes mais pour leur somptuosité.

${ }^{98}$ Supra p. 278 n. 167.

${ }^{99}$ Supra p. 376-382.

${ }^{100}$ Ce principe est formulé par le juriste Paul (Dig. XIX, 5, 5).

${ }^{101}$ CIC. Phil. II, 110 et 111. 
soit pour lui rendre hommage s'ils admirent sa vertu et le jugent digne de la plus grande fortune $[\ldots]$ ou s'ils sont menés par la récompense d'un salaire, ce qui est assurément le motif le plus vil et le plus ignoble, à la fois pour ceux qu'il retient et pour ceux qui entreprennent de recourir à lui. »

(Cic. Off. II, 21 ; trad. Testard modifiée).

L'octroi d'une marque d'honneur peut répondre, entre autres raisons, à la volonté d'honorer une grande uirtus mais aussi au désir de s'attirer, par ce signe de respect, la bienveillance de celui qui est honoré et des récompenses de sa part, pretium ou merces. On retrouve ici le paradigme économique de l'honos, qui vise encore le profit, mais de celui qui le donne cette fois. La critique est reprise par Sénèque dans le De beneficiis où il expose que la bienfaisance doit être désintéressée: selon le point de vue stoïcien de Sénèque, la vertu, manifestée dans le beneficium, ne peut rechercher une récompense car elle vaut par elle-même et constitue le souverain bien ${ }^{102}$. Ces diverses répréhensions morales montrent indirectement que l'utilisation de l'honos pour obtenir des bienfaits en retour ne devait pas être une pratique rare à Rome. Ce principe du do ut des est également à l'œuvre dans les marques d'honneur adressées aux dieux: les signes d'estime sont donnés aux divinités par les hommes dans l'espoir d'obtenir en retour la faveur des dieux. C'est ce qu'indique un passage du De natura deorum où est récusée l'idée épicurienne selon laquelle les dieux ne se préoccupent pas des affaires humaines:

Sin autem dei neque possunt nos iuuare nec uolunt nec omnino curant nec quid agamus animaduertunt nec est quod ab is ad hominum uitam permanare possit, quid est quod ullos deis immortalibus cultus honores preces adhibeamus?

"Mais si les dieux ne peuvent et ne veulent nous aider et ne s'en soucient pas du tout, s'ils ne font pas attention à nos actions et si rien de ce qui est issu d'eux ne peut toucher la vie humaine, pourquoi adresser aux dieux immortels un culte, des honneurs ou des prières?»

(CIc. ND I, 3).

Si les dieux n'ont pas part aux activités humaines, comme le soutiennent les épicuriens, alors les marques d'honneur que les hommes leur adressent perdent tout leur sens car elles ne peuvent infléchir favorablement leur attitude ${ }^{103}$. Mais, avance Cicéron, comme ces rites ont bien, dans la tradition religieuse romaine, une signification, c'est la preuve que les divinités ne sont pas indifférentes. Les

${ }^{102}$ SEn. Ben. IV, 1, 2 sqq.

${ }^{103}$ Malgré ces affirmations sur l'inefficacité des honores sur les dieux, les épicuriens ont entouré d'honneurs et d'un culte de type quasi religieux le fondateur de leur secte, Épicure, qui, par sa réalisation parfaite de la sagesse, avait égalé les dieux. Sur le culte rendu à Épicure par les adeptes du Jardin, voir R. KocH, Comment peut-on être Dieu? La secte d'Épicure, Paris, Belin, 2005. 
gestes rituels honorifiques sont accomplis parce qu'ils permettent d'obtenir en retour des avantages. Les dieux romains peuvent faire l'objet d'un certain contrôle et les hommes peuvent instaurer avec eux un lien de nature contractuelle: les honores servent à orienter dans leur intérêt les puissances divines ${ }^{104}$.

L'influence que l'honos permet à son auteur d'exercer sur la personne honorée va cependant au-delà de l'obtention de bienfaits. La dette que crée l'honos n'instaure pas seulement une relation d'échange mais aussi une inégalité car le donateur prend un véritable ascendant sur le destinataire: l'honneur «oblige» celui qui le reçoit car le donataire est placé dans une posture de débiteur vis-à-vis du donateur tant qu'il n'a pas rétribué l'hommage reçu ${ }^{105}$. L'honos permet à l'honorans de prendre l'avantage sur l'honoratus en lui imposant une conduite et constitue donc un instrument de pouvoir. On le voit dans l'usage qu'en fait César. Lors de la révolte des Gaulois rapportée dans le livre V du Bellum Gallicum, César raconte comment l'honos accordé aux Héduens a permis de préserver leur fidélité envers Rome:

Tantum apud homines barbaros ualuit esse aliquos repertos principes inferendi belli tantamque omnibus uoluntatum commutationem attulit, ut praeter Haeduos et Remos, quos praecipuo semper honore Caesar habuit, alteros pro uetere ac perpetua erga populum Romanum fide, alteros pro recentibus Gallici belli officiis, nulla fere ciuitas fuerit non suspecta nobis.

«L'impression fut si forte sur ces esprits barbares quand on sut qu'il s'était trouvé quelques audacieux pour nous déclarer la guerre, il en résulta un tel changement dans les dispositions de tous les peuples que, sauf les Héduens et les Rèmes, à qui César témoigna toujours des honneurs particuliers, les uns en raison de leur ancienne et durable fidélité envers Rome, les autres à cause de leurs services récents dans la guerre contre les Gaulois, il n'y eut guère de cité qui ne nous donnât lieu de la soupçonner. »

(CAES. BG V, 54, 4 ; trad. Constans modifiée).

César présente la fides des Héduens comme la source des honores qu'il leur a accordés mais il est fort possible que ce soit, à l'inverse, l'octroi de marques d'honneur qui ait amené les Gaulois à la fides. L'honos est ici un instrument de contrainte dont César fait un usage stratégique pour maintenir chez les Héduens et les Rèmes des dispositions qui

104 "The purpose of most Roman sacrificers was to make the divine power more capable of carrying out their wishes. Purely honorific sacrifice seems to have been unknown" (JocelYn, "The Roman Nobility and the Religion of the Republican State», p. 100).

${ }^{105}$ Le mécanisme de l'honos est similaire à celui du don: «Donner semble instituer immédiatement un double rapport entre celui qui donne et celui qui reçoit. Un rapport de solidarité, puisque celui qui donne partage ce qu'il a, voire ce qu'il est, avec celui à qui il donne, et un rapport de supériorité, puisque celui qui reçoit le don et l'accepte se met en dette vis-à-vis de celui qui lui a donné. » (Godelier, L'Énigme du don, p. 21). 
lui sont favorables et faire d'eux ses obligés ${ }^{106}$. Il s'agit d'une pratique fréquente chez les grands chefs de guerre: Scipion avait agi de même en octroyant des honores à des Espagnols afin de pouvoir gagner une emprise sur eux ${ }^{107}$. L'honos crée un lien de dépendance de l'honoré visà-vis de celui qui l'a honoré, lien qui est assorti de plusieurs devoirs. C'est ainsi un moyen d'exercer un pouvoir de manière plus discrète et peut-être plus efficace que par la coercition directe car les avantages liés à l'honos en dissimulent les contraintes. L'honos apparaît également dans nos sources comme un excellent moyen de se rallier des partisans fidèles dans les luttes politiques. César a offert, à plusieurs reprises, des honores à Cicéron, dans l'espoir de s'attacher son soutien. Nous en avons la trace dans le De prouinciis consularibus:

Consul ille egit eas res, quarum me participem esse uoluit; quibus ego si minus adsentiebar, tamen illius mihi iudicium gratum esse debebat. Me ille ut quinqueuiratum acciperem rogauit; me in tribus sibi coniunctissimis consularibus esse uoluit; mihi legationem, quam uellem, quanto cum honore uellem, detulit.

«Pendant son consulat, il a pris des mesures auxquelles il désirait me voir m'associer. Si je ne les approuvais guère, son jugement à mon égard ne devait pas moins m'être agréable. Il m'a prié d'accepter d'être l'un des Cinq; il a voulu que je fusse l'un des trois consulaires étroitement associés à sa politique; il m'a offert la mission de légat que je voudrais, avec tous les honneurs que je pouvais souhaiter. »

(CIc. Prou. 41 ; trad. Cousin modifiée).

Les charges publiques offertes par César à Cicéron lui auraient donné du pouvoir mais elles auraient aussi eu pour effet de le soumettre indirectement à la volonté de César, ce qui a contribué au refus de Cicéron ${ }^{108}$. La réception d'un honos de la part d'un homme puissant lie en effet celui qui le reçoit à son bienfaiteur et amenuise son indépendance. C'est pourquoi Cicéron félicite les sénateurs d'avoir couvert César d'honneurs:

Ego uos intellego, Patres conscripti, multos decreuisse eximios honores C. Caesari et prope singularis. Si, quod ita meritus erat, grati, sin etiam, ut quam coniunctissimus huic ordini esset, sapientes ac diuini fuistis.

${ }^{106}$ Voir aussi la manière dont César, avant de quitter l'Espagne après sa victoire sur Varron, distribue des honores à des particuliers ou à des cités afin de s'assurer de leur soutien futur dans la guerre civile et au-delà (CAES. BC II, 21, 5).

${ }^{107}$ Voir par exemple la manière dont il adresse un honos à Allucius en lui restituant une captive (Lrv. XXVI, 50, 13). Cette marque d'honneur produit rapidement l'effet escompté: Allucius repart chez lui et revient auprès de Scipion avec 1400 cavaliers d'élite (Liv. XXVI, 50, 14).

${ }^{108}$ Voir l'explication donnée en Cic. Prou. 41. Il est question à plusieurs reprises dans l'œuvre de Cicéron des honneurs que César lui a fait miroiter: Cic. Pis. 79; Fam. VII, 17, 2; Q. fr. III, 5, 3. 
«Je vois, sénateurs, que vous avez conféré à César beaucoup d'honneurs, des honneurs magnifiques et presque uniques. Si c'est en raison de ses mérites, c'est un acte de reconnaissance, mais si vous l'avez fait aussi pour l'attacher le plus étroitement possible à notre ordre, c'est un acte de sagesse divine. »

(Cic. Prou. 38; trad. Cousin modifiée).

Les honores octroyés à César par le sénat lui ont procuré du prestige mais ont aussi servi à se l'attacher (coniunctissimus) et d'une certaine façon à se le soumettre. L'honos fait de César l'obligé du sénat et sert de moyen de pression sur le chef des populares, en essayant de le détacher de ses amitiés politiques ${ }^{109}$.

\section{ConClusion}

L'honos semble donc jouer plusieurs rôles essentiels au fonctionnement de la collectivité. C'est tout d'abord un moyen de régulation des comportements. Il oriente, dans la pratique, l'action des membres du corps social en stimulant leur volonté et en leur assignant des buts désirables qui gravitent autour de l'utilité publique. Il permet ainsi d'exercer un contrôle social et de stabiliser les normes collectives. Cette fonction d'orientation opère aussi dans le domaine axiologique: l'honos façonne les représentations morales en définissant les valeurs prisées et en constituant des modèles de conduite à imiter. S’il se fonde sur les qualités du mos maiorum qu'il vient récompenser, il est aussi ce qui fonde, réciproquement, ces normes morales traditionnelles. En second lieu, l'honos contribue à la structuration de la société romaine. Il rassemble en effet les individus dans des rituels d'hommage communs et permet au groupe d'affirmer son identité. Il symbolise également les liens sociaux existant entre les personnes. En dernier lieu, l'honos remplit une fonction politique au sens large du terme: il permet à celui qui le donne de bâtir des rapports de pouvoir, d'une part en bénéficiant lui-même de l'honos qu'il donne, par le prestige qui rejaillit sur lui, d'autre part en créant chez autrui un lien de dépendance en sa faveur. Ces fonctions assurées par l'honos sont indissociables des effets de l'honneur sur le destinataire: ils en sont l'utilisation stratégique et parfois polémique, dans le contexte des antagonismes qui agitent la cité. L'honos peut instituer des modèles exemplaires grâce à la visibilité qu'il procure et à l'inscription dans la mémoire collective qu'il réalise, par exemple. Il énonce les valeurs morales parce qu'il signale,

${ }^{109}$ C'est pour la même raison que Cicéron justifie les honores qu'il a voulu faire octroyer à Octave en 43 : ils ont servi, dit-il, à rapprocher Octave du sénat et des partisans de la res publica et à l'écarter d'Antoine (Cic. Ad Brut. I, 15, 9). Voir aussi Cic. Fam. X, 2, 1 où Cicéron essaie de s'attacher L. Munatius Plancus en s'intéressant à lui, en lui écrivant, et en veillant à son honos. 
par les avantages qu'il donne, quelles sont les qualités prisées. Il donne du pouvoir au donateur parce qu'il oblige le destinataire à faire preuve de gratia. Sont ainsi mobilisés le fonctionnement symbolique aussi bien que le fonctionnement économique de l'honos. Le paradigme symbolique réapparaît dans l'utilisation de l'honos comme signe de ce qu'est le bien, comme désignation des modèles à imiter et comme symbolisation des liens sociaux. Le paradigme économique structure le rapport de pouvoir créé par l'honos: on donne un hommage pour créer une dette et devenir créancier de bienfaits et de soutiens. 
CHAPITRE 9

\section{LA GESTION DE L'HONNEUR}

\section{INTRODUCTION}

Létude des fonctions de l'honos a permis de mettre au jour les différents usages qui pouvaient être faits de l'honneur par celui qui le donne. Déplaçant le regard vers celui qui le reçoit, nous voudrions examiner l'attitude de ce dernier vis-à-vis de l'honos. Une importante activité est en effet déployée pour obtenir puis conserver l'honneur. L'analyse de l'honos comme capital symbolique impose d'élucider la manière dont les Romains gèrent ce capital de prestige, l'augmentent, le détériorent, le préservent, le transmettent. Se déploient autour de ce capital différentes stratégies, comme l'explique P. Bourdieu:

«Il [i. e. le capital symbolique] est attaché à des groupes - ou à des noms de groupes, familles, clans, tribus - et il est à la fois l'instrument et l'enjeu de stratégies collectives visant à le conserver ou à l'augmenter et de stratégies individuelles visant à l'acquérir ou à le conserver, en s'agrégeant aux groupes qui en sont pourvus (par l'échange de dons, la commensalité, le mariage, etc.) et en se distinguant des groupes qui en sont peu pourvus ou dépourvus. $»^{1}$

Comment l'individu préserve-t-il l'honos? Comment le capital symbolique évolue-t-il dans le temps? Comment est-il mis en péril? Pour répondre à ces questions, nous observerons trois aspects de la gestion de l'honos: la recherche active de l'honos et sa constitution en capital; la préservation de ce capital par l'individu; les modalités de transmission de ce capital au sein de la famille.

\section{LA RECHERCHE DE L'HONNEUR}

L'honneur est avant tout objet de désir: il apparaît de façon récurrente dans les textes comme un bien précieux dont il faut entreprendre la recherche ${ }^{2}$. L'individu cherche à se constituer un capital d'honneur

${ }^{1}$ Bourdieu, Raisons pratiques, p. 191.

${ }^{2}$ L'importance du "prestige seeking " dans les sociétés où l'honneur est valorisé a été mise en valeur par Goode, The Celebration of Heroes, qui a analysé la manière dont les individus calculent la conduite à adopter pour obtenir le plus de distinction possible. 
ou à augmenter celui qu'il possède déjà et se place dès lors avec les autres dans un rapport de compétition.

\subsection{La valeur de l'honos}

Au cœur de la volonté des agents sociaux d'obtenir l'honos se situe le prix attaché à cet objet. Nous avons vu que la marque d'honneur contribuait à définir les valeurs de la collectivité par la distinction et la rétribution accordées à des qualités comme la uirtus ou la fides ${ }^{3}$. Mais l'honos a la singularité d'être lui-même une de ces valeurs. Il donne du prix à des qualités mais est lui-même prisé, au même titre que d'autres biens non matériels comme la gloria. Pour reprendre la définition de la valeur proposée par C.Kluckhohn, l'honos est une de ces «conceptions du désirable» qui orientent le comportement des individus ${ }^{4}$. Il est significatif que l'honos soit, dans la rhétorique de l'éloge, un «lieu» du discours, un de ces gisements où l'orateur puise des arguments ${ }^{5}$. Cela montre qu'il constitue, d'une part, un trait prisé qui contribue à l' "amplification » de l'individu que le discours démonstratif doit opérer et qu'il représente, d'autre part, une valeur consensuelle susceptible de recueillir l'adhésion des auditeurs ${ }^{6}$. L'importance attachée par les Romains à l'honneur transparaît également dans un thème fréquent des discours et des récits historiques, celui du caractère préférable de l'honneur à la vie. L'idée est en général la suivante: une vie dépourvue d'honos ne vaut pas la peine d'être vécue et il faut tout risquer pour obtenir l'honneur plutôt que continuer à mener une existence tranquille mais obscure. C'est cette idée que Salluste place dans la bouche de Catilina dans le discours qu'il adresse à ses complices:

Itaque omnis gratia, potentia, honos, diuitiae apud illos sunt aut ubi illi uolunt; nobis reliquere repulsas, pericula, iudicia, egestatem. Quae quousque tandem patiemini, o fortissumi uiri? Nonne emori per uirtutem praestat quam uitam miseram atque inhonestam, ubi alienae superbiae ludibrio fueris, per dedecus amittere?

«Aussi toute influence, tout pouvoir, tout honneur, toute richesse sont à eux, ou aux gens qu'ils veulent; ils nous ont laissé les échecs, les périls, les condamnations, la misère. Jusques à quand enfin, mes braves, le supporterez-vous? $\mathrm{Ne}$

Pour une lecture critique de cette analyse sociologique, voir НАTcH, «Theories of Social Honor», p. 346 sqq.

${ }^{3}$ Voir p. 403 sqq.

${ }^{4}$ Sur cette définition, voir p. 403.

${ }^{5}$ Sur les lieux de l'éloge et la topique encomiastique, voir Pernot, La Rhétorique de l'éloge, p.129-131 ainsi que PERNOT, «Lieu et lieu commun dans la rhétorique antique».

${ }^{6}$ Sur la nature consensuelle des qualités louées dans l'éloge et la fonction parénétique de ce genre oratoire, Pernot, La Rhétorique de l'éloge, p. 718-720. 
vaut-il pas mieux mourir courageusement que de perdre honteusement une vie misérable et sans honneur, après avoir servi de jouet à l'insolence d'autrui ? »

(SALL. Cat. 20, 8-9; trad. Ernout modifiée).

Catilina dénonce la manière dont les nobles ont le monopole du pouvoir, de l'argent et de l'honos. Cette confiscation est insupportable car l'honneur est un bien extrêmement précieux. Il vaut mieux donc mourir les armes à la main (emori per uirtutem) que de passer une vie inhonesta, dépourvue d'honneur: l'honos est préférable à la vie. C'est la raison pour laquelle ne pas rechercher l'honos quand on est un homme public apparaît comme un comportement aberrant. Cicéron reproche très vivement à Pison de ne pas avoir désiré l'honos du triomphe quand il était dans sa province de Macédoine: une telle conduite, peut-être en accord avec l'épicurisme de Pison, ne peut qu'être le fait d'un esprit étroit et bas ${ }^{7}$. Il est aussi honteux de rechercher une gloire imméritée que de fuir le prestige d'un honos légitime.

L'observation diachronique des textes dont nous disposons montre que l'honos est plus particulièrement prisé par l'aristocratie romaine et par sa frange la plus haute, la nobilitas. Cette valorisation de l'honos est ancienne puisqu'on la rencontre dès le dernier tiers du $\mathrm{III}^{\mathrm{e}}$ siècle dans un texte représentatif de l'idéologie nobiliaire, l'éloge funèbre de L. Caecilius Metellus prononcé par son fils Quintus ${ }^{8}$. Nous avons déjà eu l'occasion de faire quelques observations sur ce texte mais il nous paraît utile d'y revenir pour examiner la place qu'y occupe l'honos:

Q. Metellus in ea oratione quam habuit supremis laudibus patris sui L. Metelli [...] scriptum reliquit decem maximas res optimasque, in quibus quaerendis sapientes aetatem exigerent, consummasse eum: uoluisse enim primarium bellatorem esse, optimum oratorem, fortissimum imperatorem, auspicio suo maximas res geri, maximo honore uti, summa sapientia esse, summum senatorem haberi, pecuniam magnam bono modo inuenire, multos liberos relinquere et clarissimum in ciuitate esse; haec contigisse ei nec ulli alii post Romam conditam.

«Quintus Metellus, dans le discours qu'il prononça pour faire l'éloge funèbre de son père Lucius Metellus [...] écrivit que son père avait accompli les dix objectifs suprêmes que les hommes avisés passent leur vie à rechercher: il avait voulu en effet être le premier guerrier, le meilleur orateur, le général le plus courageux, conduire de grandes entreprises sous ses auspices, bénéficier du plus grand honneur, être de la plus haute sagesse, être considéré comme le sénateur le plus important, faire fortune de manière honnête, laisser de nombreux enfants et être l'homme le plus brillant dans la cité; tout cela lui était échu à lui et à lui seul depuis la fondation de Rome.»

(PLIN. NH VII, 139-140).

${ }^{7}$ Cic. Pis. 57

8 Sur cet éloge funèbre, voir Vollmer, Laudationum funebrium Romanorum historia; KIERdorf, Laudatio funebris, p.10-21 et EARL, Tradition, p.21-27. Selon ce dernier, "the earliest expression of the aristocratic ideal is well summarized in the eulogy that Q. Metellus delivered at the funeral of his father» (p.24). 
L'éloge célèbre l'excellence du défunt en montrant qu'il a atteint la perfection dans les dix domaines les plus importants. On y trouve des activités au service de la cité, comme la réussite militaire (primarium bellatorem; fortissimum imperatorem), oratoire (optimum oratorem) et politique (maximas res geri; maximo honore; summum senatorem), mais aussi l'accomplissement des devoirs de père de famille (pecuniam magnam bono modo inuenire; multos liberos relinquere) et l'obtention d'un large prestige (clarissimum in ciuitate). L'éloge dessine l'image d'une excellence militaire, politique et sociale conforme aux idéaux de l'aristocratie de l'époque. L'honos maximus, qui est certainement le consulat, exercé deux fois par le défunt en 251 et en $247^{9}$, est un de ces dix objectifs suprêmes qu'il est particulièrement glorieux d'avoir atteint: l'honneur politique est donc bien, aux yeux des nobiles, un but particulièrement valorisé. La laudatio indique en outre que ces decem maximas res sont l'objectif des sapientes. Le terme ne renvoie pas ici à la sagesse philosophique et à la oopía grecque mais à la sagesse pratique du uir bonus romain, à un bon sens qui s'exprime notamment en matière politique ${ }^{10}$. Ces sapientes ne sont pas des "sages" mais les grands hommes avisés de la tradition, devenus exemplaires par leurs mérites et pris comme modèles par l'aristocratie ${ }^{11}$. L'honos est donc un objectif dont la réalisation est un devoir pour les membres des grandes familles qui veulent imiter les Romains les plus glorieux du passé. Semblable valorisation de l'honos, comme considération sociale et comme charge politique, se retrouve dans les épitaphes des Scipions, autres textes où s'expriment les modes de pensée aristocratiques. On y observe la fierté que suscite l'exercice d'honores et l'affliction que provoque leur absence lorsque le défunt n'a pas pu les obtenir en raison de sa mort prématurée ${ }^{12}$. L'honos est donc un titre de gloire particulier pour la noblesse et un «désirable» qui oriente vers lui l'activité des individus.

Pourquoi la nobilitas valorise-t-elle autant l'honos? L'explication réside dans la fonction constitutive de cet honos pour la noblesse. L'honos politique est en effet au cœur de la définition du nobilis. Au

${ }^{9} M R R$, p. 213 et 216 .

${ }^{10}$ Sur l'évolution de la notion de sapientia, voir GARBARINo, «Evoluzione semantica dei termini sapiens e sapientia nei secoli III e II a. C. » et U. KLIMA, Untersuchungen zu dem Begriff Sapientia von der republikanischen Zeit bis Tacitus, Bonn, R. Habelt, 1971.

${ }^{11}$ Cicéron rapporte que les maiores qualifiaient de sapientes des gens comme C. Fabricius, M. Dentatus et Tib. Coruncanius (Cic. Lael. 18). Le terme sapientes n'a donc pas ici, comme le veut KIERDORF, Laudatio funebris (p. 12), le sens de nobiles qui n'est jamais attesté ailleurs (voir les remarques de GARBARINO, "Evoluzione semantica dei termini sapiens e sapientia nei secoli III e II a. C. », p. 259, n. 2).

${ }^{12}$ Voir notre étude détaillée de ces textes au chapitre 14. Ces inscriptions mettent particulièrement en valeur la notion d'honos: c'est le premier des biens mentionnés dans le texte $C I L \mathrm{I}^{2}, 10$. Le terme d'honos apparaît trois fois, avec des sens différents, dans le texte $C I L \mathrm{I}^{2}, 11$. C'est le dernier mot de l'inscription $C I L \mathrm{I}^{2}, 15$. 
$\mathrm{III}^{\mathrm{e}}$ siècle et au début du $\mathrm{II}^{\mathrm{e}}$, c'est par l'exercice d'une magistrature curule puis, à la fin de la République, par l'obtention du consulat ou de la dictature qu'un homme public peut ouvrir à ses descendants les portes de la nobilitas ${ }^{13}$. L'honos est activement recherché parce qu'il constitue un critère de noblesse, bien plus que la fortune: la nobilitas est une noblesse politique ${ }^{14}$. L'honos comme "prestige » est quant à lui un trait identitaire de la noblesse, aux côtés d'autres qualités comme la uirtus. Après les lois licinio-sextiennes, la disparition du critère de la naissance, propre au patriciat, comme moyen de définir la noblesse amène l'aristocratie à recourir à d'autres éléments de référence parmi lesquels l'honos joue un rôle essentiel. Comme "charge publique», l'honos ouvre les portes de la nouvelle nobilitas patricio-plébéienne; comme "prestige", il appartient à ces valeurs autour desquelles la nobilitas se regroupe et consolide idéologiquement son existence ${ }^{15}$.

L'importance de l'honos pour l'aristocratie romaine est bien réelle mais nos textes, qui sont souvent écrits par des membres de cette noblesse ou, quand ils ne le sont pas, la prennent fréquemment pour objet, tendent à donner l'impression que seule la nobilitas s'y intéresse. Il s'agit là d'une image faussée: le caractère essentiel de l'honos pour l'aristocratie n'implique pas que d'autres groupes sociaux n'en aient pas fait eux aussi un objet prisé. Plusieurs moyens peuvent être employés pour le montrer. Les travaux prosopographiques de C. Nicolet sur les chevaliers fournissent ainsi des données intéressantes. L'on sait que la vraie différence entre les chevaliers et les sénateurs n'était pas l'origine sociale ou la fortune mais l'absence d'exercice des honores populi Romani $^{16}$. L'on sait aussi que certains d'entre eux, comme le célèbre Atticus, refusaient délibérément d'entrer dans la carrière des honneurs pour vivre dans l'otium ${ }^{17}$. Cependant, une telle attitude n'implique pas un désintérêt général de l'ordre équestre pour l'honos. Il n'y a, d'abord, de vrai refus de l'honos qu'à partir du $\mathrm{II}^{e}$ siècle et encore doit-il être relativisé: tous les chevaliers qui se détournent alors des honores ne le font pas par goût de l'ataraxie. Nombre d'entre eux préfèrent en effet se spécialiser dans la judicature ou les publica, qui sont des activités aux implications politiques ${ }^{18}$. La prosopographie montre en outre que l'absence d'honores est plus souvent subie que choisie: nombre de

${ }^{13}$ Sur cette définition, voir supra p. 294-295.

${ }^{14}$ HöLKeSKamp, Die Entstehung der Nobilität, p. 204-205.

${ }^{15}$ Ibid., p. 210 sqq.; Blösel, "Von der Familientradition zum Nobilitätsethos», p.46-53, montre que le mos maiorum dans son ensemble est une éthique de la nobilitas.

${ }^{16}$ Nicolet, L'Ordre équestre, vol. 1, p. 700.

${ }^{17}$ Sur ce refus d'Atticus, voir Y.Benferhat, Ciues Epicurei. Les Épicuriens et l'idée de monarchie à Rome et en Italie de Sylla à Octave, Bruxelles, Latomus, 2005, p. 121-123. Atticus est le plus célèbre mais on connaît bien aussi le cas de L. Oppius et de Q. Sextius Niger (Nicolet, L'Ordre équestre, vol. 1, p. 706-707). Voir aussi dans notre chapitre 16 la situation de Lucilius.

${ }^{18}$ Ibid., vol. 1, p. 704. 
chevaliers ont cherché à faire carrière et à s'attirer la considération publique sans y parvenir ${ }^{19}$. Il y a donc bien une attirance pour l'honos en dehors de la noblesse. On le constate aussi dans d'autres catégories de la population, comme cela apparaît dans les comédies de Plaute ${ }^{20}$. Rejetant les séductions de l'amour, le personnage de Lysitélès déclare:

Boni sibi haec expetunt, rem, fidem, honorem,

Gloriam et gratiam: hoc probis pretiumst.

«Les gens de bien, voilà ce qu'ils recherchent: la fortune, le crédit, l'honneur, La gloire et l'influence: voilà le salaire de la probité.»

(PL. Trin. 272-273).

L'honos, envisagé ici selon le paradigme économique de la rétribution, apparaît comme ce que visent les boni, les gens de bien, c'està-dire ceux qui ont une vie rangée et ne succombent pas aux tentations de la vie de plaisir. La recherche de l'honos dépend donc d'une qualité morale et non sociale et la volonté d'être honoré peut dès lors se retrouver dans toutes les catégories de la population. Dans le Persa, Toxile souligne que bien des affranchis pensent qu'ils ne seront pas assez considérés, qu'ils ne bénéficieront pas de suffisamment d'honos, s'ils ne s'en prennent pas à leur ancien maître devenu leur patron ${ }^{21}$. Le groupe social des affranchis, situé entre deux mondes, celui des esclaves et des ingénus, tient particulièrement à l'obtention de l'honos et la comédie raille leur ambition. Ces différents indices nous conduisent à penser que la recherche de l'honos et l'élévation de ce dernier au rang de valeur ne sont pas seulement le fait de la nobilitas: la quête de l'honos se retrouve bel et bien aux différents niveaux de la société. Il est possible en revanche que la noblesse ait donné l'impulsion première à la valorisation de l'honos et ait été ensuite imitée par les autres catégories sociales.

\subsection{La compétition pour l'honos}

Comme les marques d'honneur sont en nombre limité et que le prestige n'a de sens que par la distinction qu'il opère entre un individu élevé en dignité et les autres, la recherche de l'honos provoque une compétition qui voit s'opposer les membres de la société les plus actifs. Les stratégies de constitution et d'accumulation du capital symbolique passent à Rome par l'antagonisme entre des concurrents. L'honos est envisagé comme un bien précieux dont l'acquisition permet d'assouvir un désir qui enflamme les esprits. Ce désir devait être largement

${ }^{19}$ Ibid., vol. 1, p. 701.

${ }^{20}$ Malgré la fiction qui situe le lieu de l'action dans le monde grec, plusieurs traits bien romains sont observables dans ces pièces (voir infra p. 547 sqq.).

${ }^{21}$ PL. Pers. 838-839. 
répandu car plusieurs textes du $\mathrm{I}^{\mathrm{er}}$ siècle, période où se développe une approche réflexive de l'honos, en rendent compte. Il figure comme exemple illustratif dans la Rhétorique à Herennius:

Hic, tametsi uidetur esse honoris cupidus, tamen non tantum curiam diligit quantum Curiam.

«Celui-ci, bien qu'il semble avide d'honneur, n'aime pas cependant la curie autant que Curie.»

(Rhet. Her. IV, 29).

Pour illustrer le procédé de la paronomase entre curiam (la curie) et Curiam (Curie, prénom d'un personnage féminin), l'auteur convoque la figure manifestement connue du cupidus honoris, de l'ambitieux qui cherche à obtenir une charge publique pour entrer dans la curie, c'està-dire au sénat. L'honos fait l'objet d'un véritable désir (cupidus) qui est rapproché du désir amoureux ${ }^{22}$. Un fragment du De uita populi Romani de Varron témoigne, dans le contexte cette fois d'une analyse historique, de l'emprise de cette cupiditas:

Tanta porro inuasit cupiditas honorum plerisque, ut uel caelum ruere, dummodo magistratum adipiscatur, exoptent.

«Ils ont pour la plupart été gagnés d'un tel désir d'honneurs qu'ils vont jusqu'à souhaiter que le ciel s'écroule pourvu qu'ils obtiennent une magistrature.»

(VARR. Vita Pop. Rom. frg. 121 Riposati = 434 Salvadore).

Le désir d'honneurs des Romains apparaît comme une cupiditas irrépressible, qui envahit les esprits (inuasit) et mène à une conduite déraisonnable. On voit aussi, chez ceux qui ne parviennent pas à se procurer ces honores, le désir se muer en inuidia pour ceux qui ont réussi en ce domaine. Cicéron déplore que Plancius, qui a obtenu l'honos de l'édilité, suscite autour de lui l'inuidia, jalousie mêlée de haine, parce qu'il n'est pas nobilis ${ }^{23}$. Le désir se fait envie et suscite l'irritation contre celui qui a obtenu l'honos ${ }^{24}$. Si l'on quitte le terrain de l'art oratoire pour rejoindre celui de la réflexion philosophique, on trouve de semblables représentations de l'honos comme source d'envie. Dans son analyse critique de l'ambition, Lucrèce, se fondant sur la doctrine épicurienne, décrit en des termes terrifiants la manière dont l'inuidia, comparée à la foudre, frappe ceux qui atteignent le sommet de l'honos et les précipite dans le Tartare ${ }^{25}$. Ces réflexions des

\footnotetext{
${ }^{22}$ Voir aussi Rhet. Her. III, 5 où le désir d'honos est à nouveau utilisé à titre d'exemple pour illustrer les loci relatifs à la modération: critiquer les nimias libidines honoris, les « désirs d'honneur excessifs » est une des façons d'utiliser ces lieux.

${ }^{23}$ Cic. Planc. 60.

${ }^{24}$ Voir aussi Cic. Balb. 19 sur l'honos donnant naissance à l'inuidia.

${ }^{25}$ LUCR. DRN V, 1123-1126.
} 
auteurs du I ${ }^{\mathrm{er}}$ siècle n'ont d'existence que parce que le désir d'honos prend alors une ampleur inégalée.

L'existence de ce puissant désir conduit ceux qui recherchent l'honos à entrer en lutte les uns avec les autres. La stratégie à mettre en œuvre pour obtenir l'honneur est pensée sur le modèle d'un plan de guerre: il faut livrer des batailles pour remporter la victoire. C'est patent dans la description que fait le Pro Sulla de la manière dont P. Sylla a été démis du consulat pour brigue et dont L. Manlius Torquatus a été élu à sa place:

Tum adflicto P. Sulla consulatus uobis pariebatur, sicuti partus est; honoris erat certamen; ereptum repetere uos clamitabatis, ut uicti in campo in foro uinceretis; tum qui contra uos pro huius salute pugnabant, amicissimi uestri, quibus non irascebamini consulatum uobis eripiebant, honori uestro repugnabant, et tamen id inuiolata uestra amicitia, integro officio, uetere exemplo atque instituto optimi cuiusque faciebant.

"Alors la défaite de Sylla vous assurait le consulat, comme cela est arrivé en effet. L'honneur suprême était en jeu. Vous ne faisiez que revendiquer un bien qu'on vous avait ravi, répétiez-vous à grands cris; vaincus au Champ de Mars, vous vouliez triompher au Forum. Alors ceux qui combattaient contre vous en faveur de Sylla, vos meilleurs amis, à qui pourtant vous ne témoigniez aucun ressentiment, cherchaient à vous arracher le consulat. Ils combattaient votre élévation à l'honneur suprême et cependant ils le faisaient sans trahir l'amitié, ni négliger leur devoir, conformément à l'antique exemple et à la tradition de tous les meilleurs citoyens.»

(CIc. Sull. 49; trad. Boulanger).

Tout le passage file la métaphore militaire de la guerre pour l'honneur. L'honos qu'est le consulat fait l'objet d'un certamen, d'une lutte entre des partis adverses pour son obtention ${ }^{26}$. Après l'éviction de P. Sylla, Torquatus, dont le camp avait d'abord été vaincu (uicti in campo), a cherché à prendre sa revanche et à l'emporter à son tour (in foro uinceretis). Il a dû pour cela affronter d'autres adversaires (pugnabant; repugnabant). Cette transposition dans le domaine politique du lexique militaire témoigne de la virulence des affrontements suscités par l'honos. Ces antagonismes ne sont pas propres au cas un peu particulier de l'élection de Sylla au consulat et de son éviction car on les retrouve à propos de nombreuses autres affaires. Muréna a ainsi obtenu le consulat pour 62, emportant la victoire dans la contentio honoris qui l'opposait notamment à Sulpicius Rufus ${ }^{27}$. Les charges publiques ne sont pas les seuls honores à provoquer des antagonismes entre ceux qui y prétendent. On observe, à la fin de la République, une concurrence entre les grandes familles pour donner à leurs défunts

\footnotetext{
${ }^{26}$ L'image du certamen honoris réapparaît en Cic. Off. I, 38 et en Lael. 34.

${ }^{27}$ Cic. Mur. 8.
} 
des honores particulièrement prestigieux et édifier des monuments funéraires encore plus magnifiques que ceux de leurs rivaux ${ }^{28}$.

La compétition pour l'honos montre toute la dimension agonistique de la culture politique romaine. Les membres de l'aristocratie n'entrent pas en compétition, comme ce pouvait être le cas en Grèce, dans le domaine athlétique, lors des Jeux, mais seulement dans la sphère politique $^{29}$ : l'idéal agonistique grec est déplacé sur le terrain civique. Cette logique compétitive s'explique par deux facteurs. D'abord, le nombre restreint des marques d'honneur prestigieuses pouvant être obtenues: dans le domaine politique, par exemple, il n'y a au $\mathrm{II}^{\mathrm{e}}$ siècle qu'environ soixante-dix postes politiques importants à pourvoir, pour un nombre beaucoup plus élevé de prétendants, ce qui attise l'ardeur de la lutte. Ensuite, l'honos est par nature un objet qui ne peut être octroyé à tous et n'a de sens que par l'exclusion qu'il opère. Le prestige n'a de réalité que lorsqu'il est réservé à quelques-uns, de même que la marque d'honneur qui sert à distinguer les individus. Il ne peut y avoir d'honos pour tous car cela reviendrait à diluer la force de cet honneur. Une société comme Rome qui valorise tant l'honos ne peut donc qu'être compétitive ${ }^{30}$.

Le grand prix attaché à l'honos et l'intensité de la compétition pour y parvenir ne sont pas sans conséquence sur le fonctionnement de la res publica. La stratégie employée pour atteindre l'honneur peut en effet recourir à des moyens déviants qui rendent la compétition pour l'honos néfaste pour la cité. Cette concurrence a cependant ceci de singulier qu'elle apparaît simultanément aux auteurs anciens comme un mécanisme essentiel à l'excellence de la vie politique et au bon fonctionnement de l'État. La recherche de l'honos, à la fois positive et nuisible, recèle donc une profonde ambivalence. La compétition pour l'honos peut d'abord pousser les individus à différentes malversations. Le désir de conquérir l'honos politique conduit par exemple certains candidats à s'attirer la faveur des électeurs par la corruption, plus ou moins dissimulée sous l'octroi de gratifications et bienfaits divers. Ces procédés ont néanmoins été de plus en plus rigoureusement encadrés par la législation de ambitu ${ }^{31}$. La compétition pour l'honos

${ }^{28}$ Von Hesberg, Römische Grabbauten, p. 26-37.

29 Sur la culture de la compétition en politique, WiSEMAN, "Competition and Co-operation » et HöLKESKAMP, Reconstruire une République, p. 81.

${ }^{30}$ Voir sur ce point Wiseman, "Competition and Co-operation », p. 12. La compétition à laquelle donne lieu l'honos n'apparaît pas cependant comme une fin en soi : c'est bien le prestige et les honneurs qui sont l'essentiel. Pour une approche différente de la recherche du prestige où la lutte a en elle-même une valeur essentielle, voir J. HuIzINGA, Homo ludens: essai sur la fonction sociale du jeu, Paris, Gallimard, 1951 et la lecture critique qu'en fait HAтcH, «Theories of Social Honor», p. 350-351.

${ }^{31}$ Cic. Planc. 50. Sur l'ambitus et les manœuvres frauduleuses destinées à attirer le vote des électeurs, voir L. FAscione, Crimen e quaestio ambitus nell'età repubblicana, Milan, A. Giuffrè, 1984 ; J. LindersKI, "Buying the Vote. Electoral Corruption in the Late Republic», AncW, 11, 1985, p.87-94; E. Deniaux, "De l'ambitio à l'ambitus: les lieux 
peut aussi provoquer des dissensions entre les membres de la cité. Cicéron remarque dans le Laelius que la concurrence politique est la pire menace de l'amitié:

Quod si qui longius in amicitia prouecti essent, tamen saepe labefactari, si in honoris contentionem incidissent; pestem enim nullam maiorem esse amicitiis, quam in plerisque pecuniae cupiditatem, in optimis quibusque honoris certamen et gloriae; ex quo inimicitias maximas saepe inter amicissimos exstitisse.

"Quant à ceux qui persistent plus longtemps encore dans leur amitié, ils la voient souvent chanceler quand ils se trouvent en compétition pour quelque magistrature. Car il n'est pire fléau de l'amitié que le désir de s'enrichir, chez la plupart des hommes, que la lutte pour les magistratures et pour la gloire chez les meilleurs; elle engendre souvent les plus vives inimitiés entre les amis les plus intimes.»

(CIc. Lael. 34 ; trad. Combès).

La contentio honoris qu'implique la recherche des magistratures va à l'encontre du fonctionnement de l'amicitia: elle place les individus en concurrence et suscite des inimicitiae. On retrouve l'image de la lutte, du certamen, dont les effets négatifs sur le lien social sont soulignés. Dans la lignée de cette réflexion, Cicéron remarque dans le De officiis que le désir des honores provoque une telle contentio entre les membres de la société que la justice est mise en péril et qu'il devient impossible de préserver la societas des hommes ${ }^{32}$. La compétition pour l'honos possède une force centrifuge qui rompt les liens unissant les membres d'une collectivité. Si l'on passe du terrain de l'analyse philosophique à celui de la description historique, on voit de fait à plusieurs reprises des affrontements internes à la cité naître de la recherche de l'honos. À propos de Q. Marcius Rex et de Q. Metellus Creticus, Salluste remarque qu'ils ont été empêchés de triompher à cause d'une cabale organisée par «quelques hommes » derrière lesquels il faut sans doute reconnaître Pompée et ses proches, opposés à ce qu'un honos soit octroyé à des personnages qui sont leurs adversaires ${ }^{33}$. Pompée cherche ainsi à se réserver l'honos prestigieux du triomphe et à affaiblir symboliquement ses ennemis. On rencontre également plusieurs fois dans l'histoire livienne de semblables dissensions à propos du triomphe ${ }^{34}$. Dans le pire des cas, les discordes générées par la compétition pour l'honos peuvent aller jusqu'aux affrontements civils. Dans le

de la propagande et de la corruption électorale à la fin de la République ", in Gros, P. et Nicolet, C. (éds.), L'Vrbs. Espace urbain et histoire, Rome, E.F.R., 1987, p. 279-304; A. LinTotT, «Electoral Bribery in the Roman Republic», JRS, 80, 1990, p.1-16.

${ }^{32}$ CIC. Off. I, 26.

${ }^{33}$ Sall. Cat. 30, 4. Voir le commentaire sur ce passage de K. VRetska (éd.), Sallust. De Catilinae coniuratione, Heidelberg, C. Winter, 1976. Pompée pouvait empêcher ces deux généraux de triompher car ils se trouvaient sous ses ordres en vertu de la lex Manilia et de la lex Gabinia.

${ }^{34}$ Voir par exemple Liv. XXXIII, 22, 2-6 et Liv. XXXVIII, 47, 2. 
tableau que fait Salluste de la situation à Rome avant que Marius ne se présente au consulat, on voit la plèbe, agitée par des tribuns séditieux, quitter son travail, escorter Marius et susciter le trouble dans l'Vrbs pour que Marius puisse obtenir l'honos auquel il prétend ${ }^{35}$. Le prix attaché à l'honos conduit à des perturbations de l'ordre public.

Pourtant, malgré les troubles suscités par la compétition pour l'honos, cette dernière n'est pas analysée de manière totalement négative. Elle recèle aussi des effets positifs bien réels car elle peut susciter entre ceux qui prétendent à l'honos une émulation bénéfique pour la collectivité. Les évergètes font assaut de générosité pour s'attirer la considération de leurs concitoyens et les soldats sont amenés à faire preuve de la plus grande uirtus pour remporter les honores, en nombre limité, que le général décerne à l'issue de la bataille. En ce qui concerne les honores politiques, la compétition pour leur obtention est pensée à Rome comme un ferment nécessaire à la vie publique. C'est elle qui donne son impulsion au fonctionnement des institutions et au jeu politique $^{36}$. Un passage important du second discours de Cicéron sur la loi agraire nous permet d'en prendre la mesure à travers l'exemple de Capoue. Après sa trahison pendant la deuxième guerre punique, Capoue n'a pas été détruite mais elle a été laissée sans force par des dispositions qui y paralysent la vie politique ${ }^{37}$ :

Neque enim contionandi potestas erat cuiquam nec consili capiundi publici; non gloriae cupiditate efferebantur, propterea quod, ubi honos publice non est, ibi gloriae cupiditas esse non potest; non contentione, non ambitione discordes. Nihil enim supererat de quo certarent, nihil quod contra peterent, nihil ubi dissiderent.

«Car personne n'avait le pouvoir de prononcer des discours, ni de prendre l'avis du peuple; les gens n'étaient pas agités par le désir de gloire pour la raison que, là où il n'y a pas d'honneur public, le désir de gloire ne peut exister; pas de discordes provoquées par la compétition et l'ambition. Il ne restait rien, en effet, sur quoi s'affronter, rien pour quoi lutter, rien pour donner lieu à des dissensions.»

$$
\text { (CIC. Agr. II, 91). }
$$

La suppression de toute possibilité d'atteindre l'honos a éteint à Capoue le désir de gloire et a également supprimé les discordes. Le passage fait en apparence écho aux textes qui soulignent les effets

${ }^{35}$ SALL. Iug. 73, 6. Sur la place que Salluste assigne à l'honos dans la naissance des troubles civils, voir infra p. 733-736.

${ }^{36}$ R. Syme, La Révolution romaine, Paris, Gallimard, 1967, p. 25: «La vie politique de la République romaine reçut l'empreinte et l'impulsion, non pas de partis et de programmes d'un caractère moderne et parlementaire, non pas de l'opposition prétendue entre le Sénat et le Peuple, optimates et populares, nobiles et novi homines, mais de la lutte pour le pouvoir, la richesse et la gloire. »

${ }^{37}$ Elle a été, à l'issue de la guerre, privée de son territoire et de ses droits politiques par Rome; elle était administrée directement par un préteur romain. Sur la reddition de la ville en 211, Liv. XXVI, 6. 
néfastes de la compétition: Cicéron souligne que l'absence d'honos a induit une absence de contentio et, partant, une absence de discordes. Cependant, la suppression des honores et la mise au pas des institutions ont aussi fait tomber la cité dans un état de léthargie qui lui fait perdre toute souveraineté et toute grandeur ${ }^{38}$. Les luttes pour l'honos sont au cœur de l'activité publique et leur disparition signe la mort de toute indépendance et de toute vitalité politique. Une image suggestive montre les effets de cette suppression des antagonismes liés aux honneurs:

\begin{abstract}
[...] neruis urbis omnibus exsectis urbem ipsam solutam ac debilitatam reliquerunt.

«[...] après avoir tranché tous les nerfs de la ville, ils la laissèrent amollie et paralysée.»
\end{abstract}

(CIc. Agr. II, 91).

Capoue est assimilée à un corps humain auquel on a tranché tous les nerfs et qui se retrouve totalement inerte. La compétition pour les honneurs est donc l'élément qui donne vie à une cité et lui permet d'être vigoureuse. K.-J.Hölkeskamp va jusqu'à affirmer, en s'appuyant sur les analyses du sociologue G. Simmel, que cette compétition est un ferment de consensus pour la res publica et non de dissension ${ }^{39}$ : ceux qui s'affrontent pour l'obtention des honores ne s'opposent pas en effet directement les uns aux autres. Ils sont en concurrence auprès d'une "tierce instance», le peuple qui octroie les charges publiques. Cela leur impose de se rapprocher de ce dernier, de tisser des liens avec lui, de chercher ses faveurs. La classe politique est contrainte à des compromis et à la proximité avec le populus. La recherche de l'honos peut donc avoir un effet socialisant et contribuer à générer des solidarités au sein de la collectivité. La relation de l'individu au groupe mise en jeu par les stratégies d'honos est ainsi plus complexe qu'il n'y paraît car elle associe compétition et consensus.

\title{
2. LA PRÉSERVATION DE L'HONNEUR
}

Une fois que l'honos a été obtenu, un autre enjeu se dessine pour son détenteur, celui de sa préservation. Si certaines marques d'honneur paraissent acquises de façon définitive ou sont au contraire, par nature, éphémères, comme les charges publiques, il n'en va pas de même de la «considération » qu'est l'honos. Il s'agit en effet d'un capital

\footnotetext{
${ }^{38}$ "Cicéron résume la vie de Capoue par un otium indolent et amorphe, et ramène la tranquillité publique à une somme de paresses individuelles» (J.-M.ANDRé, L'Otium dans la vie morale et intellectuelle romaine des origines à l'époque augustéenne, Paris, P.U.F., 1966, p. 244).

${ }^{39}$ HöLKESKAMP, Reconstruire une République, p. 87-90.
} 
de prestige que les Romains veulent durable mais qui est susceptible d'être perdu. Au fil du temps, l'honneur peut être mis en péril et subir des attaques et il est donc essentiel de le protéger.

\subsection{La vulnérabilité de l'honneur personnel}

Le prestige qu'est l'honos, puisqu'il repose sur l'estime de l'entourage, dépend de ce dernier qui peut cesser de l'alimenter et le faire donc disparaître: il est possible de passer rapidement du prestige au déshonneur. Même un individu bénéficiant d'une grande considération n'est pas à l'abri du déshonneur. Quelqu'un comme Muréna, qui s'est couvert d'honneur au cours des campagnes militaires d'Orient, risque de perdre totalement cet honos s'il est convaincu de brigue et condamné à l'exil:

Ibit igitur in exilium miser? Quo? Ad Orientisne partis in quibus annos multos legatus fuit, exercitus duxit, res maximas gessit? At habet magnum dolorem, unde cum honore decesseris, eodem cum ignominia reuerti.

«Il ira donc en exil, le malheureux? Mais où? Dans ces contrées de l'Orient où il fut légat pendant plusieurs années, où il a mené des armées, où il a accompli de grandes choses? Mais c'est une grande douleur de revenir couvert d'opprobre à l'endroit d'où l'on est parti couvert d'honneur.»

(CIc. Mur. 89).

Muréna court le risque de passer sans transition de l'honos à l'ignominia, de l'honneur au déshonneur ${ }^{40}$. Ce texte témoigne de la façon dont l'honos est mis en péril: il n'est pas progressivement entamé mais détruit subitement et de manière irréversible. Les anthropologues ont eu le loisir d'observer, dans différentes cultures, les moyens mis à la disposition des agents sociaux pour tenter de récupérer leur prestige; ils ont notamment mis en évidence le rôle de la vengeance ${ }^{41}$. Or, si les assauts contre l'honneur suscitent bien à Rome des réactions, aucun texte de l'époque républicaine ne fait état, à notre connaissance, d'une possibilité de récupérer ainsi son honos perdu. Des ripostes à un attentat contre le prestige d'un individu sont prévues par le droit, notamment quand il s'agit d'insultes, mais à l'époque qui nous intéresse on ne leur assigne pas pour fonction de restaurer un honos endommagét2 . Il peut aussi y avoir des formes de vengeance plus spontanées, mais elles ne débouchent pas nécessairement sur la reconsti-

${ }^{40}$ Sur l'antonymie de ces deux termes, voir p. 55.

${ }^{41}$ Voir Losada-Goya, L'Honneur au théâtre; Lepoutre, Coeur de banlieue. Codes, rites et langages, p. 380 ; NAssiet, La Violence, une histoire sociale, p. 133 sqq. Sur la dialectique du défi et de la riposte au cœur de l'honneur, voir Bourdieu, Trois études, p.29-32. Sur la nécessité de répondre aux attaques visant l'honneur, voir Stewart, Honor, p. 64 sqq.

${ }^{42}$ Sur les réactions à l'iniuria et à la contumelia, Lendon, Empire of Honour, p. 50 $s q q$. 
tution d'un honos détruit. On le voit dans l'épisode qui fait intervenir M. Aurelius Cotta: C. Carbo avait fait condamner son père en 67 pour des déprédations et lui avait ainsi fait perdre son titre de sénateur, qui est une forme d'honos. M. Aurelius Cotta se vengea dès qu'il fut en âge de prendre la toge virile en accusant à son tour C. Carbo ${ }^{43}$. Cependant les textes n'indiquent pas que l'honneur du père fut pour autant récupéré par son fils. Si l'on peut parler de vengeance, elle ne débouche pas sur une restauration de l'honos. Il n'y a pas non plus à Rome de recours à la violence physique pour racheter l'honos endommagé, alors que l'usage de la force brutale, sous la forme du duel par exemple, sera un moyen essentiel de préservation du prestige en réaction à une avanie dans les milieux nobles des $\mathrm{XVI}^{\mathrm{e}}$ et $\mathrm{XVII}{ }^{\mathrm{e}}$ siècles, et un rouage essentiel de l'honneur nobiliaire ${ }^{44}$. Il peut y avoir à Rome des réactions violentes au déshonneur, comme le suicide de Lucrèce ou le meurtre de Virginie ${ }^{45}$, mais les auteurs qui évoquent ces épisodes célèbres ne parlent pas à leur sujet de la récupération d'un honos perdu: chez Tite Live, par exemple, Lucrèce se tue parce qu'elle est aegra, "affligée ", de son nouveau statut, bien involontaire, d'impudica; Virginie est tuée par son père parce que c'est pour lui le seul moyen de la préserver de l'esclavage qu'elle encourt et de sauvegarder sa libertas ${ }^{46}$. Il n'est pas question ici de regagner un honos. Quand elle intervient, la perte de l'honos paraît donc définitive. On voit ainsi se dessiner les limites de la notion de capital pour la compréhension du fonctionnement de l'honneur car le capital économique, quand il est détruit, est susceptible d'être ensuite reconstitué progressivement. Or il n'en est pas ainsi de l'honos qui apparaît comme un bien absolu ${ }^{47}$.

Le caractère irréversible de la destruction de l'honos explique que le sujet soit très soucieux de le préserver dès qu'il est menacé. Une remarque incidente de Cicéron dans l'In Caecilium permet de le mesurer. L'orateur fait observer que Verrès et ses amis ont tout fait pour que l'accusation ne lui soit pas confiée:

Ecquis umquam tam palam de honore, tam uehementer de salute sua contendit quam ille atque illius amici ne haec mihi delatio detur?

${ }^{43}$ DC. XXXVI, 440 et VaL. MAX. V, 4, 4. Voir RE II, 2, col. 2489, s. v. Aurelius Cotta $\left(n^{\circ} 107\right)$.

${ }^{44}$ Sur le lien entre violence et honneur à cette époque, voir, entre autres, NASSIET, La Violence, une histoire sociale.

${ }^{45}$ Sur le déshonneur lavé par le sang, voir BARTON, « Savage Miracles : the Redemption of Lost Honor in Roman Society and the Sacrament of the Gladiator and the Martyr ».

${ }^{46}$ Liv. I, 48 et III, 48.

${ }^{47}$ NASSIET, La Violence, une histoire sociale souligne de même qu'il y a au XVI ${ }^{\text {e }}$ siècle une échelle de la dignité mais pas de l'honneur qui est soit présent soit absent: «la moindre atteinte suffisait à le faire perdre» (p.181). 
"Quelqu'un a-t-il jamais lutté aussi ouvertement pour son honneur, aussi violemment pour son salut que ne l'ont fait cet homme et ses amis pour que cette accusation ne me soit pas confiée?»

(Cic. Diu. Caec. 22).

Pour éviter que Cicéron ne soit constitué comme accusateur dans le procès intenté à Verrès, le camp de l'intéressé a fait de très grands efforts, comme s'il en allait, dit Cicéron, de leur salut (de salute) ou de leur honneur (de honore). Le parallèle montre la très grande valeur attachée à l'honos, bien aussi précieux que la vie, et dont la perte est aussi irrémédiable ${ }^{48}$. On retrouve également dans le texte, à propos de la préservation de l'honneur, une image employée au sujet de son acquisition, celle de la lutte: personne, dit Cicéron, ne s'est battu (contendit) de façon aussi intense pour son honneur. Il est donc nécessaire de mener une contentio non seulement pour obtenir l'honos mais aussi pour le préserver.

Cette vulnérabilité de l'honos impose à l'homme in honore de suivre une certaine conduite afin de le préserver car si l'honneur dépend largement d'autrui, cela ne signifie pas que le détenteur de l'honos n'ait aucun rôle à jouer dans sa conservation. Il lui revient en effet d'adopter un comportement conforme aux normes morales et sociales de la collectivité et en accord avec le statut privilégié que l'honos lui a conféré. Nous avons vu précédemment que l'honos imposait à son détenteur de suivre un code de comportement, un «code de l'honos». Nous voudrions voir à présent les effets sur l'honos des infractions à ces règles de conduite ${ }^{49}$. Les comédies de Plaute nous permettent d'observer les conséquences désastreuses que peuvent avoir pour la considération un certain nombre de comportements jugés déviants, notamment dans le domaine de la vie intime. La débauche sexuelle du personnage de l'amoureux entraîne très fréquemment chez lui une destruction de son honos. La fréquentation assidue des courtisanes n'est pas en effet considérée comme convenable car elle détourne des devoirs civiques et sociaux que doit remplir le Romain. Dans le Truculentus, Diniarque, amoureux transi et esclave de sa passion, oublie tout pour se consacrer à son amour pour la meretrix Phronésie. Une telle conduite a entraîné la perte de son honos, comme le remarque son esclave Cyame:

Velut haec meretrix meum erum miserum sua blanditia

Intulit in pauperiem,

Prinauit bonis, luce, honore atque amicis.

${ }^{48}$ Même parallèle dans le Pro Quinctio où Cicéron évoque le zèle extraordinaire avec lequel des hommes puissants soutiennent Naevius, l'accusateur de son client, quasi sua res aut honos agatur, "comme s'il s'agissait de leur fortune ou de leur honneur» (Cic. Quinct.9).

${ }^{49}$ Sur le code de conduite imposé par l'honos, voir p.383-385. Nous aurons l'occasion de revenir plus en détails sur le contenu et le fonctionnement du code de l'honneur à Rome dans le chapitre 10. 
«C'est comme cette courtisane qui, par ses caresses, a réduit mon pauvre maître

À la misère,

L'a privé de ses biens, de la lumière, de l'honneur, de ses amis.»

(PL. Truc. 572-574).

La courtisane, comparée à la mer qui engloutit tout, a fait perdre à Diniarque sa fortune, ses amis et son honneur. Dans les Bacchides, Pistoclère, le jeune homme rangé de la pièce, refuse de céder aux avances des courtisanes qui tentent de le séduire car il sait trop bien qu'elles «blessent la conduite et la réputation» (facta et fama sauciant ${ }^{50}$ : leur fréquentation dérègle le comportement et engendre une destruction de la bonne renommée. On voit ainsi apparaître, en négatif, les conditions de préservation de l'honos: elles résident dans l'adoption d'une conduite rangée, qui évite la débauche et les excès. Le contrôle du comportement et du corps, notamment dans la vie intime, permet de maintenir l'honos intact. C'est aussi ce qui apparaît dans un fragment d'une autre comédie de Plaute, le Phago («Le Dévoreur»):

Honos syncerasto periit, pernis, glandio.

"L'honneur a péri à cause du ragoût, des jambons, du ris de porc. »

(PL. frg. 101 Ernout).

Par une métaphore, l'honos est assimilé à un être vivant dont on pleure le décès. La cause de cette mort réside dans la consommation excessive de mets variés, ragoût, jambons, ris de porc. Il est sans doute question du personnage éponyme de la pièce, le goinfre, qui a perdu tout prestige social en raison de sa passion déréglée pour la nourriture. Ici encore, la préservation de l'honos impose de faire preuve de modération et de frugalité. Il convient donc, d'une manière générale, d'être capable de régler sa conduite pour conserver son honneur.

\subsection{Les menaces d'autrui sur l'honos}

Le sujet met en péril son honneur quand il se comporte de façon indigne mais la destruction de son honos n'intervient pas toute seule: elle suppose le regard d'autrui et parfois même sa participation active. L'entourage peut être impliqué de deux manières dans l'annihilation de l'honneur d'un individu: il peut provoquer sa disparition en réagissant à un comportement jugé déshonorant, par la critique, la moquerie ou l'indignation. Il peut aussi s'en prendre à l'honneur d'une personne alors même qu'elle adopte une conduite en accord avec les normes morales. Que l'assaut contre l'honneur soit une réponse à une attitude 
déshonorante ou ne possède pas de fondement assignable chez celui qu'il vise, il revêt en général deux formes. L'honneur d'un tiers peut d'abord être atteint par des pratiques populaires hostiles, licites ou illicites (insulte, texte diffamatoire, etc.) qui provoquent l'infamia ${ }^{51}$. De manière plus institutionnelle et réfléchie, la considération peut également être mise à mal par des procédures légales menées par un individu ou par des magistrats (condamnation, blâme, etc.). Nous ne pouvons, sans excéder les limites de notre travail, nous intéresser à tous les procédés d'attaque contre la considération et nous nous limiterons donc à l'étude de ceux où les notions d'honos et d'honestas sont directement impliquées. C'est le cas dans trois procédures infamantes, le flagitium, la condamnation en justice et la nota censoriale.

\subsubsection{Le flagitium}

Plusieurs pratiques populaires d'infamie permettaient à un individu ou un groupe de porter atteinte à l'honneur d'un tiers ${ }^{52}$. Une des plus répandues de ces pratiques est la diffamation, sous la forme d'une insulte verbale, de vers obscènes ou de libelles injurieux ${ }^{53}$. Elle a été assez tôt réprimée à Rome, dès la loi des XII Tables semble-t-il ${ }^{54}$. Un

${ }^{51}$ L'infamia n'est pas à l'origine une institution légale et judiciaire mais un moyen populaire de faire respecter le mos maiorum (Pommeray, Études sur l'infamie en droit romain, p. 11 sqq.).

52 Sur ces pratiques d'infamie romaines voir, pour une approche générale, H. Usener, «Italische Volksjustiz», RhM , 56, 1901, p. 2-28; P. Veyne, La Société romaine, Paris, Seuil, 1991, p. 58 sqq.; Ruelle, «Le citoyen face aux pratiques collectives de la honte à Rome: le droit et les dieux, ou deux poids, deux mesures » et les analyses sur la "popular justice» de Lintott (A. Lintott, Violence in Republican Rome, Oxford, Oxford University Press, 1999, p. 8 sqq.) et de Nippel (NIPPel, Public Order in Ancient Rome, p.39-46). Ces pratiques existent dans de nombreuses autres cultures; voir par exemple le vito andalou étudié par Pitt-Rivers qui sert à donner une publicité tapageuse à une faute morale (PITT-Rivers, Anthropologie de l'honneur, p. 53).

${ }^{53}$ Voir par exemple le libelle injurieux visant les sénateurs créés par César (SuET. Caes. 80). Sur ces pratiques de diffamation, voir l'ensemble du Digeste XLVII, 10 De iniuriis et famosis libellis. Voir aussi A. D. MANFrEDINI, La diffamazione verbale nel diritto romano, Milan, A. Giuffrè, 1979 ainsi que M. Ducos, "Le droit romain et la polémique », in Declerce, G., Murat, M. et Dangel, J. (éds.), La Parole polémique, Paris, H. Champion, 2003, p. 283-296.

${ }^{54}$ Cic. Rep. IV, 12 ; Hor. Sat. II, 1, 82-83. Voir G. ComercI, «Carmen, occentatio ed altre voci magico-diffamatorie delle XII Tavole a Cicerone », BStudLat, 7, 1977, p. 287-306 et Ducos, «Le droit romain et la polémique». Des édits prétoriens ont également sanctionné la diffamation: voir notamment les édits De conuicio, De adtemptata pudicitia et Ne quid infamandi causa fiat (O. LENEL, Essai de reconstitution de l'édit perpétuel, Paris, L. Larose, 1901, § 191, 192 et 193; PommerAY, Études sur l'infamie en droit romain, p. 114 sqq.; D. Daube, "Ne quid infamandi causa fiat. The Roman Law of Defamation», in Moschetti, G. (éd.), Atti del congresso internazionale di diritto romano e di storia del diritto, Milan, 1951, p.411-450; E. Pólay, «Der Schutz der Ehre und des guten Rufes im römischen Recht», ZRG, 106, 1989, p. 502-534). Selon Ulpien, l'iniuria, qui désigne 
certain nombre d'actions collectives tapageuses visaient également à attirer la réprobation sur un individu. L'occentatio et le conuicium consistaient en un rassemblement bruyant de personnes qui poursuivaient quelqu'un ou s'attroupaient devant sa maison, pour pousser des clameurs de réprobation et attirer sur lui le mauvais œeil et l'infamie $^{55}$. L'obuagulatio était une sorte de charivari fait devant la porte d'un témoin défaillant: il servait à publier la faute de l'individu en question et à porter réclamation pour sa défaillance ${ }^{56}$. Un dernier type de pratique collective infamante est le flagitium, et c'est à son sujet qu'il est question d' «honorabilité», dans une comédie de Plaute. Dans le Mercator, Charinus a ramené de l'étranger son amoureuse et tente de la faire passer pour une servante. Son père Démiphon, qui s'en est épris et entend se la réserver, s'oppose à ce que la jeune femme soit confiée à son épouse comme domestique:
DE.: [...] Verum quod praeterii dicere,
Neque illa matrem satis honeste tuam sequi poterit comes
Neque sinam.
CHA.: Qui uero?
DE.: $\quad$ Quia illa forma matrem familias
Flagitium sit si sequatur, quando incedat per uias.
Contemplent, conspiciant omnes, nutent, nictent, sibilent, Vellicent, uocent, molesti sint, occentent ostium;
Impleantur elegeorum meae fores carbonibus.
Atque ut nunc sunt maledicentes homines, uxori meae
Mihique obiectent lenocinium facere. Nam quid eost opus?

dans un sens général quod non iure fit, peut aussi, dans un sens précis, renvoyer à la contumelia punie par la loi; elle concerne tantôt le corps tantôt la dignitas et l'infamia (Dig. XLVII, 10, 1, pr. et 2). Une action pour injure fut par exemple intentée contre un mime qui avait insulté Accius et une autre contre un acteur qui s'en était pris au poète Lucilius (Rhet. Her. I, 24 et II, 19). Sur cet aspect de l'iniuria, voir F. RABER, Grundlagen klassischer Injurienansprüche, Vienne, Böhlau, 1969; A.D. MANFrEdinI, Contributi allo studio della iniuria in età repubblicana, Milan, A. Giuffrè, 1977 et E. Pólay, Iniuria Types in Roman Law, Budapest, Akademiai Kiadó, 1985.

${ }^{55}$ Occentatio: Pl. Pers. 569; Cic. Rep. IV, frg. 11 ; voir G. Lepointe, «L'occentatio de la loi des XII Tables d'après saint Augustin et Cicéron », RIDA, 2, 1955, p. 287-302 et Ducos, «Le droit romain et la polémique», p. 285 sqq. Conuicium: Dig. XLVII, 10, 15, 4 et 5; voir A. Ruelle, "L'anathème en chantant. Scandale, fascinatio et fatalité", in KLimis, S. et VAn Eynde, L. (éds.), Littérature et savoir(s), Bruxelles, Publications des Facultés universitaires Saint-Louis, 2002, p.127-173, notamment p.132-135. Ulpien note que seul le conuicium dirigé contre les bonos mores et provoquant l'infamia est illicite. Pour Festus, le conuicium est la forme moderne de l'occentatio (Fest. 190, 32). Le sens du conuicium s'est progressivement élargi pour désigner l'insulte et les comportements sanctionnés par l'actio iniuriarum (CIc. Cael. 6; GaI. Inst. III, 220).

${ }^{56}$ Fest. 262, 19 = XII Tables, II, 3 (FIRA). Voir J. A. ArIAS Bonet, « Prueba testifical y obvagulatio en el antico diritto romano", Studi in onore di Pietro di Francisci, I, Milan, 1956, p. 283-301; G. MACCORMACK, "Witnesses in the Law of the Twelve Tables », BIDR, 76,1973, p. $225-243$. 
«Demiphon: Mais, j'ai oublié de te dire:

Elle ne pourra pas honorablement accompagner ta mère comme suivante, Je ne le permettrai pas. - Charinus: Pourquoi donc? - DE. : Parce que si une beauté comme elle

Accompagnait une mère de famille, il y aurait du scandale quand elle passe rait dans les rues.

Tous l'observeraient, la dévisageraient, il y aurait des signes de tête, des œillades, des sifflements,

On la bécoterait, on l'appellerait, on serait désagréable, il y aurait du chari vari devant la porte;

Les battants seraient charbonnés de vers licencieux.

Et vu comme les gens sont médisants de nos jours, on m'accuserait,

Ma femme et moi, de faire les maquereaux. En quoi ai-je besoin de tout cela?»

(PL. Merc. 403-411).

Le refus de Démiphon s'appuie sur les conséquences de la présence de la jeune fille aux côtés de son épouse: cela provoquerait, dit-il, un flagitium, un «scandale». Il s'agit là du sens premier du mot qui désigne la protestation tapageuse faite devant la maison de quelqu'un qu'on juge coupable d'une faute, pour attirer sur lui l'attention de manière négative $\mathrm{e}^{57}$. Le texte du Mercator permet d'observer les caractéristiques de ce flagitium: on y retrouve l'occentatio (occentent ostium) et les vers obscènes (elegeorum), procédés déshonorants déjà observés, auxquels s'ajoutent des regards inquisiteurs (conspiciant omnes), des comportements grossiers et moqueurs comme les clins d'œil (nictent) ou les sifflements (sibilent) ainsi que des cris et des dénigrements plus violents (uocent, maledicentes). Le flagitium implique une émotion collective qui donne naissance à un tollé bruyant et accusateur. Ce scandale, note Démiphon, met en péril l'honneur de la famille car il empêche de se conduire honeste, d'une manière qui préserve l'honos. Le flagitium menace l'honos pour deux raisons principales: d'abord parce qu'il s'accompagne d'un tapage agressif et fort peu discret, ensuite parce qu'il donne lieu à des calomnies dégradantes (Démiphon et sa femme seraient accusés de faire le métier de leno). La préservation de l'honos consiste ainsi, à l'inverse, à bénéficier du respect d'autrui et d'un discours positif, signes d'une opinion favorable. D'autres espaces que celui de la rue donnaient lieu à des tapages visant à déshonorer un individu; c'est le cas du théâtre et des jeux qui représentent, avec les comices et les réunions publiques, l'une des trois occasions où, selon Cicéron, le peuple peut manifester son opinion ${ }^{58}$. La foule a

57 Autres occurrences: PL. Epid. 516; Curc. 198. Sur ce sens, UsENER, "Italische Volksjustiz», p. 9; DELL, p. 238 s. v. flagito et Thomas, Déshonneur et honte, p. 181-185. Le terme est formé sur le fréquentatif-intensif flagito, qui se ramène à la racine *flag"faire du bruit», de *bhlāg-, ce qui implique l'idée d'une réclamation tapageuse.

${ }^{58}$ Cic. Sest. 106. Sur les manifestations populaires au théâtre, voir NicolET, Métier, p. $482 s q q$. 
en effet alors l'occasion de rencontrer dirigeants et hommes d'État et peut en profiter pour exprimer son mépris: au lendemain de l'acquittement de Valerius Messala, accusé de brigue, Hortensius, son avocat, se rendit au théâtre et fut accueilli par des sifflets et des hurlements ${ }^{59}$. On peut aussi, à l'inverse, être honoré et acclamé, ce qui fut le cas de Cicéron, comme il se plaît à le rappeler ${ }^{60}$. Le théâtre est un des lieux où le prestige d'un homme public est mesuré et éventuellement attaqué.

\subsubsection{La condamnation en justice}

Le second type d'attaque contre l'honos émanant d'autrui prend la forme de la condamnation en justice. L'honos de l'individu n'est plus alors en proie à la justice populaire mais à un châtiment infligé conformément à la loi. Le procès est un procédé par lequel on peut tenter de priver quelqu'un de son honneur, notamment quand la punition encourue est dégradante. Dans la péroraison du Pro Sulla, l'orateur explique que P.Sylla cherche à éviter la condamnation pour ne pas tomber dans le déshonneur:

Omnia, iudices, haec amissa sunt, omnia generis, nominis, honoris insignia atque ornamenta unius iudici calamitate occiderunt. Sed ne extinctor patriae, ne proditor, ne hostis appelletur, ne hanc labem tanti sceleris in familia relinquat, id laborat, id metuit ne denique hic miser coniurati et conscelerati et proditoris filius nominetur; huic puero qui est ei uita sua multo carior metuit, cui honoris integros fructus non sit traditurus, ne aeternam memoriam dedecoris relinquat.

«Il a perdu tout cela juges, tous les insignes et les distinctions de sa famille, de sa réputation, de son honneur, par le désastre d'une seule décision de justice. Mais être appelé destructeur de sa patrie, traître, ennemi, laisser à sa famille la souillure d'un tel crime, voilà ce qui l'inquiète; ce qu'il craint, c'est que ce malheureux jeune homme que voici soit nommé fils de conjuré, de criminel, de traître; il craint de laisser à cet enfant, qui lui est bien plus cher que la vie et à qui il ne pourra transmettre intact les avantages de son honneur, le souvenir éternel du déshonneur.»

(CIC. Sull. 88).

Sylla a déjà perdu l'honos du consulat lors du procès qui lui a été intenté pour brigue mais il risque dans cette affaire de perdre tout son honos, tout son prestige. Si P.Sylla est convaincu d'avoir participé aux conjurations contre l'État, il sera entaché d'un déshonneur éternel pour avoir pris les armes contre sa patrie. Son fils ne recevra dès lors aucun des avantages associés à l'honos de son père puisque ce dernier aura été totalement détruit. Sylla risque ce que Cicéron appelle en d'autres endroits un turpe iudicium, une condamnation

\footnotetext{
${ }^{59}$ Cic. Fam. VIII, 2, 1.

${ }^{60}$ Cic. Sest. 121.
} 
infamante ${ }^{61}$. Le procès est donc un moment critique où l'on met en péril sa considération ${ }^{62}$. C'est d'autant plus vrai que l'accusé y risque toujours son honos, même quand la condamnation encourue n'est pas en soi déshonorante. Cicéron répète à l'envi dans le Pro Quinctio qu'en défendant Quinctius il protège ses biens mais aussi sa fama et que Naevius tente de dépouiller Quinctius de sa fortune ainsi que de sa réputation $^{63}$. La partie condamnée par les juges encourt, outre la peine prévue, le dedecus, c'est-à-dire la disparition radicale et irréversible de la bonne renommée ${ }^{64}$. L'acquittement, à l'inverse, est quelque chose $\mathrm{d}^{\prime} h o n o r a b l e^{65}$. Le procès est un lieu où l'honneur est mis en péril et le tribunal est donc une des instances capables d'agir sur le prestige d'un individu, de manière positive ou destructrice. Il assume ainsi une fonction supplémentaire à celle qui lui est officiellement dévolue en sanctionnant une action répréhensible par le déshonneur, et non seulement par un châtiment légalement défini. Le procès peut dès lors servir d'instrument pour discréditer un adversaire en le faisant tomber dans l'ignominie.

\subsubsection{Le blâme des censeurs}

Un dernier type d'attaque contre le prestige social est opéré par la cité elle-même en la personne des censeurs. Lors des opérations du census, ces derniers ont pour charge de recenser les citoyens, d'évaluer leur fortune et de les classer à des fins militaires, financières et politiques ${ }^{66}$. Mais ils doivent aussi, avant de confectionner les listes de citoyens, examiner les mœurs et sanctionner l'immoralité67. Un certain nombre de comportements étaient répréhensibles: l'insubordination militaire, le défaut de comparution au recrutement, les faux serments,

${ }^{61}$ Cic. Rosc. Amer. 113 ; Clu. 119.

${ }^{62}$ Sur le risque d'infamie lié au procès, voir Pommeray, Études sur l'infamie en droit romain, p. 52 sqq. et 106 sqq. et J. M. Kelly, Studies in the Civil Judicature of the Roman Republic, Oxford, Clarendon Press, 1976, p. 96 sqq.

${ }^{63}$ Cic. Quinct. 8; 26; 27; 33. Cf. Cic. Caecin. 7 où le procès est un existimationis periculum.

${ }^{64}$ Cic. Quinct. 46. Voir aussi Cic. Rab. Perd. 27 où la condamnation pour perduellio est une ignominia. Sur la perte irréversible de l'honneur impliquée par dedecus, THomas, Déshonneur et honte, p. 26. Le procès met aussi en péril l'honos en permettant à l'accusation de tenir un discours très défavorable à l'endroit de l'accusé et parfois insultant, la reprehensio uitae (CIC. Mur. 11; Kelly, Studies in the Civil Judicature of the Roman Republic, p. 98-99).

${ }^{65}$ Cic. Rosc. Amer. 113 et Clu. 104.

${ }^{66}$ Sur les opérations du census, voir Nicolet, Métier, p. 71-121.

${ }^{67}$ Sur l'examen des mœurs pratiqué par les censeurs, voir PIERI, L'Histoire du cens, p. 100 sqq. et Nicolet, Métier, p. 103 sqq. Sur le regimen morum des censeurs en général, voir aussi A.E. Astin, «Regimen morum », JRS, 78, 1988, p. 14-34 et BALTRUsch, Regimen morum, p. 12-29. 
les faux témoignages, la mauvaise gestion des biens, etc. ${ }^{68}$ Le blâme infligé par les censeurs prend la forme d'une note placée à côté du nom du coupable sur les registres du cens, la nota censoria. Elle pouvait s'accompagner d'un changement de tribu, ce qui avait des conséquences néfastes pour la participation à la vie politique, ou de l'obligation de rejoindre les aerarii, contribuables qui ne bénéficiaient plus des droits liés à leur fortune ${ }^{69}$. Le regimen morum des censeurs s'exerce aussi lors de la lectio du sénat, dont certains membres peuvent être exclus, et de la recognitio equitum, pendant laquelle un chevalier peut être privé de son cheval public ${ }^{70}$. La sanction de la nota censoria est liée à l'honos de plusieurs manières. Le blâme en lequel elle consiste est désigné par le terme d'ignominia, l'antonyme récurrent d'honos ${ }^{71}$. Les deux notions sont donc, dans les esprits, exclusives l'une de l'autre. En second lieu, deux passages de Cicéron mettent en relation le blâme censorial avec l'honneur. Dans le De republica, l'Arpinate fait état, par la bouche de Scipion, des dispositions prises par les ancêtres à l'encontre des acteurs qui furent privés d'honos et changés de tribu en vertu de la notatio censoria ${ }^{72}$. Le second passage, qui figure dans le Pro Cluentio, est plus problématique. Cicéron y compare les effets sur l'honos d'un turpe iudicium et du blâme des censeurs:

Quod si illud iudicium putaretur, ut ceteri turpi iudicio damnati in perpetuum omni honore ac dignitate priuantur, sic hominibus ignominia notatis neque ad honorem aditus neque in curiam reditus esset. Nunc si quem Cn. Lentuli aut L. Gelli libertus furti condemnarit, is omnibus ornamentis amissis numquam ullam honestatis suae partem recuperabit; quos autem ipse L. Gellius et Cn.Lentulus, duo censores, clarissimi uiri sapientissimique homines, furti et captarum pecuniarum nomine notauerunt, ei non modo in senatum redierunt sed etiam illarum ipsarum rerum iudiciis absoluti sunt.

«Si on avait vu là un jugement, pareils à ceux qui frappés par une condamnation infamante sont à jamais privés de tout honneur et de toute charge, les hommes atteints d'ignominie n'auraient eu ni accès aux honneurs ni retour dans la curie. Mais en réalité, qu'un affranchi de Gnaeus Lentulus et de Lucius Gellius ait condamné quelqu'un pour vol, ce dernier perdra tous ses titres et jamais ne recouvrera la moindre part de son honorabilité, mais ceux que Lucius Gellius

${ }^{68}$ Sur les causes de sanction censoriale, voir la liste établie par Mommsen, $D P R$, vol. 4, p. 55-60 et PIERI, L'Histoire du cens, p. 99.

${ }^{69}$ Nicolet, Métier, p. 114-118.

${ }^{70}$ Nicolet, L'Ordre équestre, p. 69-101.

${ }^{71}$ Parce que, selon Cic. Rep. IV, 7, frg. 5, cette sanction frappe le nomen. Voir Pommeray, Études sur l'infamie en droit romain, p. 26-32 qui distingue l'infamia de source populaire et l'ignominia censoriale, ainsi que Ducos, Les Romains et la loi, p. 385. Sur le rapport entre nomen et ignominia, Tномаs, Déshonneur et honte, p. 303.

${ }^{72}$ Cic. Rep. IV, 13, frg. 1. 
lui-même et que Gnaeus Lentulus, tous deux censeurs, personnages illustres et très éclairés ont flétris pour vol et pour corruption judiciaire, non seulement sont rentrés dans le sénat, mais ont été acquittés par des jugements qui visaient précisément ces points-là.»

(Cic. Clu. 119-120; trad. Boyancé).

Cicéron cite le cas de Gaius Geta, exclu du sénat par les censeurs, qui devint plus tard lui-même censeur. Il remarque à son sujet que l'effet produit par la sanction censoriale sur l'honos est moindre que celui d'une condamnation infamante dans le cadre d'un procès. Un châtiment judiciaire détruit irrémédiablement l'honestas, l'honorabilité, et empêche donc de prétendre à quelque honos que ce soit, alors que le blâme des censeurs n'empêche pas de rejoindre les rangs du sénat. Cicéron paraît donc indiquer que la nota censoria n'a qu'un effet limité sur l'honos: elle induit une disqualification sociale partielle, qui ne se propage pas à l'activité politique. La lecture de Cicéron doit cependant être nuancée. L’Arpinate, d'abord, fait état de la situation au I ${ }^{\text {er }}$ siècle, ce qui ne présage pas de l'efficacité de la nota avant cette date $^{73}$. Il ne faut pas perdre de vue, en outre, que Cicéron défend un client qui a précisément fait l'objet d'une nota censoria et qu'il a donc tout intérêt à en minimiser les effets.

Le fait qu'un individu puisse voir son honneur mis en péril par son entourage et sa cité montre que le rapport du sujet à autrui est encore ici un rapport d'antagonisme: il importe de ne pas donner prise au scandale, aux accusations et au blâme pour pouvoir préserver son honos. Le groupe est à la racine du prestige de l'individu mais il est aussi à l'origine de sa destruction quand le sujet ne se comporte pas d'une manière conforme à ses normes.

\section{LA TRANSMISSION DE L'HONNEUR FAMILIAL}

La volonté de sauvegarder l'honos prend tout son sens quand on la rapporte au désir qu'ont les Romains de le transmettre à leurs descendants. Il importe de conserver son prestige pour ne pas déchoir soimême mais aussi pour pouvoir le léguer à ses héritiers et les faire bénéficier des prérogatives qui y sont attachées. L'honos apparaît ici encore dans nos textes comme un capital car il y a un patrimoine d'honneur que les générations successives essaient de se transmettre et d'augmenter au cours du temps. La transmission de ce patrimoine d'honneur contribue à la reproduction sociale ${ }^{74}$ des élites romaines, c'est-à-dire au maintien de leur position différenciée de génération

${ }^{73}$ Sur l'affaiblissement des effets de l'ignominia censoriale à la fin de la République, Pommeray, Études sur l'infamie en droit romain, p. 35-36.

${ }^{74}$ Sur cette notion, voir P.Bourdieu et J.-C.PAsSERon, La Reproduction. Éléments pour une théorie du système d'enseignement, Paris, Minuit, 1970. 
en génération, par un phénomène de tri entre les individus possédant l'honneur et ceux ne le possédant pas. C'est à l'un des mécanismes de cette reproduction, les stratégies de cession et d'héritage du capital symbolique, que l'on s'intéressera à présent. Avec ce mode de gestion de l'honos, l'individu n'est plus placé en conflit avec autrui mais travaille en collaboration avec son groupe familial à la conservation de l'honos. Comment faire pour assurer la pérennité de l'honneur dans le temps? Comment un objet aussi fuyant que le prestige peut-il se passer de main en main?

\subsection{Nécessité et difficulté de la transmission}

L'honneur familial possède une histoire. Il est appréhendé à Rome comme un patrimoine progressivement constitué, au fil du temps : l'héritier d'une famille prestigieuse reçoit un legs d'honneur à préserver. C'est le cas de Muréna:

Qui primum, dum ex honoribus continuis familiae maiorumque suorum unum ascendere gradum dignitatis conatus est, uenit in periculum ne et ea quae relicta et haec quae ab ipso parta sunt amittat, deinde propter studium nouae laudis etiam in ueteris fortunae discrimen adducitur.

«D'abord, en voulant ajouter aux honneurs perpétués dans sa famille et chez ses ancêtres un nouveau degré de dignité, il court le risque de perdre à la fois ce qui lui a été légué et ce qu'il a acquis lui-même; ensuite l'ambition d'une gloire nouvelle met en péril jusqu'à son ancienne fortune.»

(Cic. Mur. 55; trad. Boulanger).

Les ancêtres de Muréna ont réussi à accumuler au cours du temps un stock prestigieux d'honores familiae. Ils ont pour particularité d'être continus (continuis), de former une chaîne ininterrompue au fil des générations et de se stratifier dans le temps. Muréna est l'héritier de cet honneur familial et des avantages qui vont avec: tout cela lui a été relicta, "légué ». La transmission du prestige dans la lignée a été jusqu'alors assurée, mais elle est mise en péril par la situation de Muréna. Lors de sa candidature au consulat, Muréna a été accusé de brigue et risque une condamnation en vertu de la loi de ambitu. Il risque donc de perdre (amittat) la considération et les honneurs patiemment accumulés par ses ascendants et d'échouer à transmettre, à son tour, l'honneur à ses descendants. C'est, de façon paradoxale, en voulant perpétuer les honores dont il est l'héritier qu'il les a mis en péril: c'est sa candidature à l'honos du consulat qui l'a amené à être traîné en justice. On retrouve donc le thème de la préservation de l'honos, augmenté d'une problématique temporelle et familiale: il faut conserver son prestige mais aussi celui de ses ancêtres et être capable de le transmettre à ses enfants. C'est cette nécessité de la transmission qui amène Cicéron à critiquer, dans les Verrines, le comportement de Caecilius Metellus Pius Scipion. Ce dernier défend en effet Verrès qui 
s'en est pourtant pris à l'honos de sa famille en faisant main basse sur des statues rapportées de Carthage en Sicile par Scipion l'Africain. Cicéron fait montre de son incompréhension devant cette attitude et rappelle que c'est un devoir (officium) envers la famille que de s'opposer à ceux qui attaquent l'honos de la gens ${ }^{75}$.

Cette transmission directe de l'honos aux descendants est cependant difficile. S'agissant du "prestige» qu'est l'honos, d'abord, le fait qu'il puisse être hérité ne va pas de soi. À la différence du capital économique, fondé sur la fortune, et du capital social, composé de la clientèle et des amis, le capital symbolique ne peut s'hériter directement car l'estime des concitoyens ne se reporte pas automatiquement d'une personne à ses descendants: nous avons vu combien Cicéron était réservé à l'égard de Caecilius Metellus Pius Scipion malgré l'admiration qu'il voue à Scipion l'Africain et à Scipion Émilien. Il paraît donc difficile de contrôler le transfert de la considération publique. En ce qui concerne les marques d'honneur, ensuite, il faut souligner qu'elles ne sont pas décernées à une famille en général mais à un de ses membres en particulier et qu'elles ne peuvent pas être transférées à un proche sans perdre leur sens. Il est essentiel, en premier lieu, que celui qui reçoit un hommage ait fait la preuve de son mérite pour que l'honos soit conforme à l'aequum ${ }^{76}$ et, en second lieu, qu'un tiers extérieur soit intervenu dans l'octroi de l'honos ${ }^{77}$. Le bénéfice d'un éloge, d'une supplication ou d'une statue ne sont donc pas transférables. Mais comment expliquer, alors, que certaines familles aristocratiques aient pu exercer un quasi-monopole sur certaines marques d'honneur? Cet état de fait ne s'explique pas, quoiqu'en disent certaines sources, par la faculté qu'a la nobilitas de se passer l'honos de main en main mais plutôt par la «recommandation » qu'est la présence, au sein d'une famille, d'ancêtres ayant déjà obtenu ces honores: la commendatio maiorum facilite l'accès aux honneurs ${ }^{78}$. Pour rendre compte de ce phénomène, les textes utilisent une image révélatrice: les ancêtres qui détiennent l'honos " ouvrent la voie " à leurs descendants pour que ces derniers y accèdent à leur tour. Un personnage de Plaute déclare de la sorte à son ami que son père et son grand-père lui ont préparé une planam uiam / Ad quaerundum honorem, " une route dégagée pour briguer l'honneur » et Cicéron, dans un passage où l'honos est envisagé de manière plus réflexive que chez Plaute, se souvient d'avoir déclaré à Publius Crassus que la meilleure uia vers la gloire et l'honneur était celle quam maiores eius ei tritam reliquissent, "que ses ancêtres lui avaient ouverte ${ }^{79}$. Les ancêtres ne peuvent pas donner directement

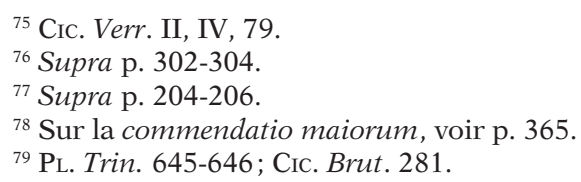


l'honos à leur descendants mais ils peuvent leur en faciliter l'accès. Cela n'est pas propre d'ailleurs à l'honos des magistratures. On voit aussi les triomphateurs recourir à certains artifices pour permettre à leur fils de prétendre ultérieurement à l'honos du triomphe. Les enfants de l'imperator étaient par exemple associés au cortège et montaient parfois les chevaux tirant le quadrige du général ${ }^{80}$. Ce type de procédé ne réalise cependant pas, lui non plus, la transmission: il ne fait que la faciliter. Comment se résout donc la tension entre la nécessité de transmettre l'honos et la difficulté qu'il y a à le faire?

\subsection{Reproduire l'honneur ancestral}

Devant l'impossibilité d'hériter directement de l'honos, les descendants se trouvent contraints, pour préserver le prestige de leur famille, d'œuvrer personnellement pour obtenir à leur tour l'honos. Il y a donc bien une forme de transmission de l'honos mais elle est en quelque sorte indirecte: l'honos ne se transmet du père au fils que lorsque le fils parvient à reproduire l'honos de son père. C'est en obtenant soimême l'honos qu'un individu réussit à préserver celui de sa gens. La reproduction sociale implique un réel effort de la part des héritiers des grandes familles honorables.

On comprend mieux, dès lors, l'attitude de Muréna: ce dernier a pris le risque de mettre en péril les honores familiae lors de sa candidature parce que l'obtention du consulat était nécessaire à leur conservation. L'obtention d'honores permet la préservation du capital symbolique. Un passage du Trinummus que nous avons déjà exploité permet d'en prendre la mesure. Lysitélès, jeune homme rangé, réprimande son ami Lesbonicus qui mène une vie de plaisir ruineuse et dangereuse pour son prestige:

Itan tandem hanc maiiores famam tradiderunt tibi tui,
Vt uirtute eorum anteparta per flagitium perderes?
Atque honori posterorum tuorum ut uindex fieres,
Tibi paterque auosque facilem fecit et planam uiam
Ad quaerundum honorem; tu fecisti ut difficilis foret
Culpa maxime et desidia tuisque stultis moribus.
Praeoptauisti amorem tuum uti uirtuti praepo

"Tes ancêtres t'ont-ils légué cette bonne réputation

Pour que tu ruines par ta débauche les biens acquis autrefois par leur vertu? Et pourtant, pour que tu puisses protéger l'honneur de tes descendants, Ton père et ton ancêtre t'avaient ménagé un chemin facile, tout plat, Vers l'honneur; tu l'as rendu difficile Par ta conduite fautive, surtout, et par ta paresse et tes mœurs stupides. Tu as choisi de faire primer ton amour sur la vertu. »

(PL. Trin. 642-648). 
Les ancêtres de Lesbonicus ont réussi à lui transmettre (tradiderunt) une bonne réputation, une fama favorable. Le jeune homme a dès lors pour charge de préserver la considération publique qui s'attache à sa famille et de la donner à son tour à ses enfants: il doit se faire le uindex, le protecteur, de l'honos posterorum, de l'honneur de ses descendants, en évitant toute conduite indigne qui ruinerait la possibilité de leur léguer cet honos. Ce qui fait tout l'intérêt de ce passage, c'est que Lysitélès y définit les conditions d'une transmission efficace du prestige et articule pour cela deux aspects différents de l'honos. C'est par l'obtention d'un honos concret, qui semble désigner ici une charge publique, que le jeune homme pourra préserver le prestige, l'honos familial. L'acquisition d'une marque d'honneur a pour but (ut) le maintien de l'honneur ancestral. L'estime d'une famille doit être non seulement préservée par une attitude morale convenable mais aussi actualisée et transmise par l'obtention de marques d'honneur. Il s'agit d'une exigence essentielle dans l'idéologie de la nobilitas dont le Trinummus pastiche peut-être le discours. On la retrouve, de fait, dans un contexte beaucoup plus sérieux, dans l'épitaphe de Scipion Hispanus, où le défunt déclare que, par l'honor obtenu, maiorum optenui laudem, "j’ai préservé la gloire de mes ancêtres " ${ }^{81}$. La conservation de la notoriété publique de la famille passe par l'acquisition de l'honos, notamment sous la forme des magistratures ${ }^{82}$. Le capital symbolique ne peut se perpétuer que s'il est nourri de façon régulière. D'autres honores permettent d'entretenir le prestige de la lignée, notamment l'honos des funérailles. Cette cérémonie bénéficie autant au défunt qu'à la gens dans son ensemble car elle est l'occasion de faire figurer au cœur de la cité toute la lignée des ancêtres du défunt, représentés par des acteurs portant les imagines et les insignes de la charge exercée $^{83}$. La pompa funebris et l'éloge funèbre rappellent l'apport de chaque membre de la famille au capital symbolique collectif, inscrivent leur honneur dans une succession familiale, et exhibent à tous le prestige du groupe. C'est ainsi, pour l'aristocratie, un excellent moyen de perpétuation de l'honos.

S'il importe de conquérir des honores pour alimenter le prestige gentilice, ce qui anime cette conquête semble être la volonté d'imiter les honores ancestraux et de les égaler. La transmission de l'honos s'opère par la reproduction des marques d'honneur obtenues jadis, afin de provoquer l'impression d'une continuité parfaite à travers le temps. Il n'y a pas de propagation des honores par le sang mais par l'imitation.

${ }^{81} C I L \mathrm{I}^{2}, 15=I L L R P 316$.

${ }^{82}$ Voir EARL, Tradition, p. 27: "The noble who refused to take his proper place in public life disgraced not merely himself but his whole family and not only those members who were alive but his ancestors who had won glory and his posterity who would receive from him a diminished prestige.»

${ }^{83}$ Supra p. 276 sqq. 
Scipion Hispanus, qui a obtenu l'honos et a donc maintenu la gloire de sa famille, précise aussi qu'il a essayé d'égaler les exploits de son père $^{84}$. À propos de Q. Aelius Tubero, le stoïcien, Cicéron indique qu'il ne fut pas un grand orateur:

[...] ut uita sic oratione durus, incultus, horridus; itaque honoribus maiorum respondere non potuit.

"Comme sa vie, son éloquence était dure, négligée, âpre; c’est pourquoi il ne put égaler les honneurs obtenus par ses ancêtres. »

(Cic. Brut. 117).

Lâpreté de son éloquence, caractéristique de la rhétorique stoïcienne, l'a empêché d'atteindre les mêmes honores que ses ancêtres, de leur respondere, ce qui est perçu comme une défaillance. Il est nécessaire, pour assurer la transmission de l'honos, de suivre le même parcours d'honneur que ses ascendants.

La nécessité d'égaler les honores des ancêtres a une conséquence directe sur les membres des grandes familles de Rome. Elle met sur eux une pression importante car ils sont les dépositaires du prestige de leur lignée et seule leur réussite dans la conquête des honores permet de l'entretenir ${ }^{85}$. On en perçoit le poids dans le dialogue du jeune Scipion Émilien avec Polybe, à qui il confie son inquiétude de ne pas être à la hauteur de ce qu'on attend de lui ${ }^{86}$. Cette pression apparaît aussi indirectement dans l'épitaphe de Scipion Hispanus quand ce dernier indique que ses ancêtres se réjouissent de l'avoir engendré car il a réussi à préserver le prestige de la famille: voir s'éloigner l'échec en ce domaine constitue manifestement un soulagement ${ }^{87}$. Cette attente et les incitations répétées à l'imitation des honores ne doivent cependant pas occulter le fait que la reproduction effective des honores paternels ou ancestraux n'est pas une réalité courante. Dans la pratique, il est très difficile pour une famille de voir chaque génération obtenir un consulat, un triomphe ou un autre honos prestigieux. Concernant le consulat, qui est l'honos pour lequel on trouve le plus de données, on a remarqué qu'il n'était pas fréquent qu'un fils soit consul comme son père et que, lorsque cela arrivait, on ne voyait pas le phénomène s'étendre sur de nombreuses générations ${ }^{88}$. On observe au contraire que même des gentes célèbres et puissantes comme les Fabii disparaissent des fastes consulaires pendant plusieurs dizaines d'années ${ }^{89}$. L'accumulation

${ }^{84}$ facta patris petiei $\left(C I L \mathrm{I}^{2}, 15,1.4\right)$.

${ }^{85}$ Sur la pression s'exerçant sur les descendants de l'aristocratie romaine, FLower, Ancestor Masks, p. 62.

${ }^{86}$ Pol. XXXI, 23, 12. Voir HölKesKamp, Die Entstehung der Nobilität, p. 206 et 211 sqq.

${ }^{87}$ Maiorum optenui laudem, ut sibei me esse creatum $\left(C I L \mathrm{I}^{2}, 15,1.5\right)$.

${ }^{88}$ Develin, Patterns in Office-Holding 366-49 B.C, p. 99.

${ }^{89}$ Plus de cinquante ans pour les Fabii, entre la fin de la deuxième guerre punique et 145 (HölKeskamp, Reconstruire une République, p. 76-77). 
régulière des honores et leur transmission constante relève donc d'un idéal aristocratique plutôt que de la réalité. Le monopole absolu de la nobilitas sur les honores apparaît, ici encore, comme un fantasme.

\subsection{Dépasser l'honos des ancêtres}

Les modes de pensée aristocratiques n'en continuent pas moins à se caractériser par l'importance accordée à la reproduction des honores à chaque génération. Et il apparaît même parfois que l'honos est un véritable terrain d'émulation avec les ancêtres: il est essentiel d'imiter les honneurs des ascendants et il est encore plus prestigieux de les dépasser. Le capital symbolique doit être préservé mais aussi, si possible, augmenté au fil du temps ${ }^{90}$. L'individu n'entretient donc pas seulement avec ses ancêtres une relation d'imitation mais aussi d'émulation $^{91}$. Il y a une compétition pour l'excellence à l'intérieur même de la gens, dans la diachronie, et non seulement entre les grandes familles, dans la synchronie. C'est une source de fierté que d'avoir égalé ou, mieux, dépassé ses ascendants, comme on le voit dans une autre épitaphe du tombeau des Scipions ${ }^{92}$ :

Quei apice insigne Dial[is fl]aminis gesistei,
mors perfe[cit] tua ut essent omnia
breuia, honos, fama, uirtusque,
gloria atque ingenium, quibus sei
in longa licu[i]set tibi utier uita,
facile facteis superases gloriam
maiorum. Qua re lubens tua in gremiu,
Scipio, rec[i]pit Terra, Publi,
prognatum Publio Corneli.

«Toi qui as porté l’apex, insigne du flamine de Jupiter,

La mort a mis un terme prématuré à toutes tes qualités:

Honneur, réputation et valeur,

gloire et talent, s'il t'avait été permis

d'en jouir au cours d'une longue vie,

tu aurais facilement surpassé par tes actes la gloire

de tes ancêtres. C'est pourquoi la Terre te reçoit volontiers en son sein,

Publius Cornelius Scipion,

fils de Publius Cornelius. »

$\left(C I L \mathrm{I}^{2}, 10=I L L R P 311\right)$.

90 Sur l'importance de cette augmentation du prestige ancestral, Rech, Mos maiorum, p.29. Le rapport à l'honos des ancêtres est ainsi proche de celui à la gloria maiorum qui est conçue comme un bien à égaler ou à dépasser (THомAs, "Gloria maiorum», p. 137-138).

${ }^{91}$ Develin, The Practice of Politics at Rome, 366-167 B. C., p. $203:$ "The ethos of aristocracy demanded that individuals of established family uphold and, if possible, advance the family's standing by achievement. »

${ }^{92}$ Sur ce texte et l'identification du défunt concerné, voir p. 605 sqq. 
L'honos, la considération, apparaît comme l'un des domaines dans lesquels s'exerce l'émulation avec les ancêtres: c'est en l'utilisant (utier) que l'on peut dépasser les ancêtres. Scipion aurait pu surpasser (superare) la gloire de ses ancêtres s'il n'était pas mort trop tôt. Chaque génération doit augmenter les exploits, la gloria et l'honos de la famille. Un passage de Tite Live fait état, à propos d'une autre gens aristocratique célèbre, celle des Fabii, de l'existence d'une même idéologie de l'émulation gentilice par les honneurs. Au moment du récit de la mort de Fabius Maximus, l'historien écrit, dans un style proche de celui des elogia Scipionum et peut-être influencé par le texte de l'éloge funèbre réel adressé au défunt,

Superauit paternos honores, auitos aequauit. Pluribus uictoriis et maioribus proeliis auus insignis Rullus; sed omnia aequare unus hostis Hannibal potest.

«Il surpassa les honneurs de son père et égala ceux de son grand-père. Son ancêtre Rullus était remarquable par ses nombreuses victoires et les combats plus importants qu'il avait menés; mais d'avoir eu Hannibal lui seul comme ennemi suffit à égaler toutes ses actions. »

(Liv. XXX, 26, 8).

Fabius Maximus Cunctator a réussi à dépasser (superauit) les trois consulats exercés par son père et à égaler (aequauit) les cinq consulats de son grand-père, ce qui apparaît comme un titre de gloire. L'honos se situe donc au cœur d'une dynamique d'amplification constante. La gestion de l'honneur fait intervenir ici encore une forme d'antagonisme, quoiqu'il ne soit pas hostile ni destructeur, entre l'individu et le groupe familial.

\section{CONCLUSION}

Au terme de cette étude du rapport de l'individu à l'honos, différentes stratégies pour obtenir et conserver l'honneur apparaissent. L'honneur fait en premier lieu l'objet d'une recherche assidue qui témoigne de sa valeur dans les mentalités. Elle prend la forme d'une véritable conquête car elle implique de lutter avec d'autres individus pour pouvoir atteindre des marques d'honneur et un prestige qui ne sont pas disponibles pour tous. En second lieu, une fois obtenu, l'honos doit être préservé. Il possède en effet une réelle vulnérabilité et ne saurait être acquis une fois pour toutes. Cette fragilité impose à son détenteur de suivre une conduite exemplaire pour ne pas le mettre en péril. Elle le contraint également à protéger son honos des atteintes venues de l'extérieur, pratiques populaires infamantes, condamnations en justice ou blâme infligé par les censeurs. Enfin, il est essentiel de transmettre l'honneur reçu. Mais devant l'impossibilité d'hériter directement de l'honos, les descendants de l'homme de prestige se doivent d'obtenir à leur tour des honores afin de préserver le prestige de la 
famille dans le temps et, éventuellement, l'augmenter; ils s'efforcent pour cela d'imiter leurs ancêtres, voire de les dépasser, notamment en accumulant par strates successives les marques d'honneur. L'honos nous apparaît donc ici encore comme un capital car il doit être acquis, entretenu et accru. Et sa bonne gestion est un des facteurs de la bonne reproduction sociale des élites.

En dernière analyse, trois aspects de l'attitude des Romains vis-àvis de l'honos doivent être soulignés. Leur rapport à l'honneur s'inscrit, d'abord, dans la temporalité: sa recherche prend du temps, et une fois acquis il importe de le faire durer puis de le transmettre dans sa famille. Ensuite, la relation à l'honneur apparaît, à chaque stade, comme un désir puissant: la conquête de l'honos est sous-tendue par une vigoureuse envie de l'atteindre, sa conservation provoque une réelle anxiété et la nécessité de sa transmission exerce une grande pression sur les descendants des familles prestigieuses. Enfin, les stratégies de gestion de l'honos donnent fréquemment naissance à des antagonismes qui créent une dynamique: la conquête de l'honneur est perçue comme un certamen honoris, sa préservation impose de se protéger des attaques d'autrui et sa transmission donne lieu à une émulation avec les ascendants. 

CHAPITRE 10

\section{LE CODE DE L'HONNEUR}

\section{INTRODUCTION}

Notre étude de la pratique de l'honneur à Rome a jusqu'ici porté essentiellement sur le prestige et les marques d'honneur, autrement dit sur une forme socio-politique de l'honneur. Or notre étude sémantique a montré qu'il existe aussi une facette morale de l'honneur qui a jusqu'ici été laissée dans l'ombre: honos peut en effet désigner l' " honorabilité », la "dignité », une situation d'excellence éthique qui permet de prétendre à l'estime de son entourage ${ }^{1}$. Cet aspect, certes assez peu sensible dans la notion d'honos, est en revanche prépondérant s'agissant d'honestum et d'honestas. Il semblerait donc, à première vue, que l'honneur romain puisse être appréhendé de manière bipartite, comme le font les anthropologues qui distinguent l'honneur comme réputation et l'honneur comme intégrité ${ }^{2}$. Nous avons mis en évidence l'importance du premier aspect, qui est surtout social, concernant honos; nous voudrions voir si le second, qui est surtout moral, peut s'appliquer à l'honestas. Nous tâcherons de voir dans ce chapitre si l'honestas peut être envisagée comme un code d'honneur qui guide la conduite des individus. Peut-on parler d'un sentiment intérieur de l'honneur? Quels sont les impératifs moraux de l'honestas? Sont-ils universels ou relatifs? Quel est le rapport de la dignité morale avec l'autre facette de l'honneur, le prestige? Telles sont les questions qui orienteront notre étude de l'honorabilité ${ }^{3}$.

${ }^{1}$ Sur ce sens, voir supra p.91-96.

${ }^{2}$ Sur cette bipartition, voir Stewart, Honor, p. 18. Voir aussi Bourdieu, Trois études, p. 47, qui relève l'existence de nombreuses distinctions au sein de la notion kabyle d'honneur, parmi lesquelles celle entre essar (considération) et nif (point d'honneur). Cette distinction entre honneur-prestige et honneur-dignité est nécessaire car elle permet une analyse beaucoup plus fine de l'honneur: elle permet par exemple de comprendre que l'on puisse perdre son prestige sans perdre son honorabilité ou l'inverse (U. WIKAN, "Shame and Honour: a Contestable Pair», Man, 19, 1984, p.635-652). Il est également possible que, dans une société, l'honneur-prestige ait de l'importance mais que l'honneur-honorabilité en ait moins (voir l'analyse de L. Febvre, Honneur et patrie, Paris, Perrin, 1996 sur le Moyen-Âge).

${ }^{3}$ Nous laissons ici de côté l'étude de l'honestum et de l'honestas comme honnêteté et beauté morale: elle sera menée dans la troisième partie car des variations importantes 


\section{LE SENS DE L'HONNEUR}

Une première condition doit être remplie pour parler d'un code d'honneur à propos de l'honestas et de l'honestum: il faut que les individus aient conscience de l'existence de règles de l'honorabilité. On doit interroger, en somme, l'existence d'un "sens de l'honneur ». Selon F. Stewart, le sens de l'honneur se compose de deux éléments: une appréhension de ce qui constitue une conduite honorable et un attachement à une telle conduite ${ }^{4}$.

\subsection{La conscience de l'honestum: le pudor}

Plusieurs textes montrent que les Romains ont une notion de ce qui constitue une conduite honorable et distinguent de façon assez claire ce qui est honestum et ce qui ne l'est pas. Dans une scène du Poenulus, Hannon porte une accusation contre les deux jeunes filles de la pièce et déclare vouloir les traîner en justice:

\section{[...] In ius uos uoco, nisi honestiust prehendi.}

«Je vous appelle en justice, à moins que vous ne jugiez plus honorable qu'on vous appréhende.»

$$
\text { (PL. Poen. 1232; trad. Ernout). }
$$

L'alternative qu'Hannon propose aux jeunes filles est la suivante: être citées en justice ou bien subir une contrainte par corps. Mais la tournure hypothétique nisi honestiust écarte implicitement la possibilité d'accepter la prehensio, qui serait déshonorante, et montre que les personnages de la scène sont tous parfaitement conscients du choix le plus honestus. Les individus partagent une définition de l'honestum et ont à l'esprit les normes qui lui sont attachées. Grâce à cette connaissance, ils sont aptes à juger rapidement du meilleur parti à prendre pour conserver l'estime de leur entourage. Un texte plus récent et de nature plus analytique que celui de Plaute confirme ce statut de l'honestum comme notion dont on a conscience. Il s'agit d'un passage des Verrines où il est question de Chelidon, une courtisane proche de Verrès, et du jeune L. Domitius Ahenobarbus que Cicéron a interrogé à son sujet:

Tantus in adulescente clarissimo ac principe iuuentutis pudor fuit ut aliquandiu, cum a me premeretur, omnia potius responderet quam Chelidonem nominaret; primo necessarios istius ad eum allegatos esse dicebat, deinde

apparaissent d'un auteur à l'autre. Nous aurons également l'occasion de revenir dans cette troisième partie sur certains aspects du code de l'honneur qui sont spécifiques à tel ou tel auteur. Ne sont ici envisagés que les traits généraux et récurrents de l'honestas, du III $^{\mathrm{e}}$ au I ${ }^{\mathrm{er}}$ siècle.

${ }^{4}$ STEWART, Honor, p. 47. 
aliquando coactus Chelidonem nominauit. Non te pudet, Verres, eius mulieris arbitratu gessisse praeturam quam L. Domitius ab se nominari uix sibi honestum esse arbitrabatur?

«Tel était le sens de l'honneur de ce très noble jeune homme, le premier parmi les jeunes gens de son âge, que, pendant assez longtemps, malgré mes instances, il me faisait toutes les réponses possibles plutôt que de prononcer le nom de Chelidon; d'abord, il déclarait que c'étaient des amis de Verrès qu'on avait délégués auprès de lui; et puis enfin, contraint et forcé, il a nommé Chelidon. N'as-tu pas honte, Verrès, d'avoir exercé tes fonctions de préteur suivant le bon plaisir d'une femme dont L. Domitius croyait pouvoir à peine prononcer le nom sans déshonneur? »

(CIC. Verr. II, I, 139-140; trad. De la Ville de Mirmont modifiée).

Le texte n'est pas exempt d'exagérations d'avocat, visant à mettre en valeur l'opprobre de la partie adverse, mais on peut apercevoir, à travers l'hyperbole, le fonctionnement de l'honestum. L'argumentation de Cicéron, pour être recevable par son auditoire, doit en effet recourir à un mode de pensée commun. Si Domitius hésite à donner le nom de Chelidon, c'est parce qu'il a une nette conscience de ce qui est honestum, d'une part, et du caractère honteux du métier de Chélidon, d'autre part. Par son jugement, il estime (arbitrabatur) que l'honorabilité n'est pas compatible avec l'obscénité du terme même de courtisane. Domitius est un jeune homme qui a le sens de l'honneur car il a une forte conscience des impératifs de l'honorabilité. Le texte est particulièrement intéressant car il éclaire le rapport entre l'honestum et une autre notion morale, le pudor. C'est en effet parce qu'il a du pudor que Domitius refuse d'évoquer le nom de Chelidon. Le pudor est donc la qualité de celui qui connaît l'honestum et agit en conséquence: il s'agit du «sens de l'honneur $»^{5}$. Cicéron dessine un habile contraste entre Domitius et Verrès qu'il apostrophe d'un non te pudet? Verrès, lui, n'a plus de pudor, ce qui le conduit à accomplir des actions déshonorantes: sa conscience de l'honestum est obscurcie par son désir pour Chelidon et ne lui permet plus de régler sa conduite ${ }^{6}$.

\subsection{L'attachement à l'honestas}

La définition du «sens de l'honneur» proposée par F. Stewart implique, outre la compréhension de ce qu'est la conduite honorable, l'attachement à cette conduite. Le sujet, pour être un homme d'honneur, doit savoir ce qu'est l'honestum et désirer mettre en œuvre ce principe de comportement. Cet aspect est bien représenté dans les

\footnotetext{
${ }^{5}$ Sur ce sens de pudor, Thomas, Déshonneur et honte, p. 350: «c'est ce 'sentiment de l'honneur' propre à celui qui a la sagesse pour accomplir son devoir. »

${ }^{6}$ Le lien entre pudor et honestum se retrouve dans l'Hécyre, où il est dit que Pamphile se soucie de l'honestum et agit ainsi en individu pius ac pudicus (Ter.Hec. 151-152).
} 
textes latins. Dans les Captifs, comédie qui se distingue par son aspect relativement sérieux et son fort contenu moral, Tyndare, qui est retenu prisonnier, se fait passer pour son maître Philocrate et recommande à Hégion, qui le tient captif, de ne pas demander une rançon trop élevée pour sa libération:

Ne tuum animum auariorem faxint diuitiae meae:

Ne patri, tametsi unicus sum, decere uideatur magis,

Me saturum seruire apud te sumptu et uestitu tuo

Potius quam illi, ubi minime honestumst, mendicantem uiuere.

«Que mes richesses ne rendent pas ton cœur plus avide,

De peur qu'à mon père, bien que je sois son seul fils, il ne paraisse plus convenable

Que je sois esclave chez toi, bien nourri et vêtu à tes frais,

Plutôt que de vivre en mendiant chez nous, où c'est très peu honorable.»

(PL. Cap. 320-323).

Tyndare fait valoir à Hégion que son père pourrait refuser de payer la rançon si cela devait le ruiner. Il serait en effet fort peu honorable d'être conduit à mendier pour vivre. Tyndare affirme ainsi - et c'est un argument qui porte - qu'un père préfère voir son fils rester dans l'esclavage que se ruiner pour l'en tirer car cela l'amènerait à mener une vie déshonorante. Le souci de l'honneur est plus fort que l'amour paternel et l'honorabilité vaut mieux que la liberté. L'attachement à la dignité apparaît aussi dans les cas où une mort honesta est préférée à une vie dépourvue d'honneur: la conformation aux normes de l'honorabilité prime sur la préservation de soi $^{7}$. L'observation des règles d'honneur est valorisée, et lorsque le sujet y manque, il ressent une vive douleur. On le voit très bien dans la correspondance d'exil de Cicéron. Après l'affichage par Clodius en 58 du projet de loi de capite ciuis Romani, Cicéron, directement visé, en raison de son action contre Catilina et ses complices, par cette disposition qui prévoit l'exil et la confiscation des biens pour quiconque aurait fait exécuter sans jugement un citoyen romain, quitte de lui-même Rome. Mais sa décision le tourmente et, une fois en exil, il regrette amèrement de ne pas avoir choisi de lutter, comme il l'écrit à son frère Quintus:

Scio fuisse et honestius moriendi tempus et utilius; sed non hoc solum, multa alia praetermisi, quae si queri uelim praeterita, nihil agam nisi ut augeam dolorem tuum, indicem stultitiam meam. Illud quidem nec faciendum est nec fieri potest, me diutius, quam aut tuum tempus aut firma spes postulabit, in tam misera tamque turpi uita commorari [...].

«Je sais qu'il y eut un temps où ma mort aurait été plus honorable et plus utile; mais si j'ai raté cette occasion-là, j'en ai aussi raté beaucoup d'autres; si je

${ }^{7}$ Sall. Cat. 20, 8-9 et Hist. frg. II, 47, 9-11 Reynolds. 
voulais déplorer le passé, je ne ferais qu'augmenter ton chagrin et montrer ma stupidité. Mais ce qu'il ne faut pas faire, ce qu'il est impossible de faire, c'est que je continue une vie si malheureuse et si honteuse plus longtemps que ton intérêt ou qu'un ferme espoir ne le commandera [...].»

(CIc. Q. fr. I, 3, 6).

Le départ de Cicéron prend pour lui le visage d'une fuite devant le danger et lui paraît donc déshonorant. Il aurait été plus honorable (honestius) et plus utile de rester à Rome et de risquer sa vie plutôt que de partir pour la sauvegarder: il aurait mieux valu se conformer à l'honestum que faire primer sa sécurité. La douleur que suscite le manquement à l'honneur et la velléité de suicide qui s'ensuit montrent que Cicéron a une nette conscience de l'honestum et est très attaché à mener une vie honorable; son sens de l'honneur est donc bien réel. C'est la conscience d'une non-adéquation de sa conduite aux règles de l'honestum qui provoque son désespoir et sa souffrance ${ }^{8}$.

Son attachement à l'honestas reparaît quelques années plus tard. En 49, alors que la guerre civile entre Pompée et César a commencé et que Pompée a abandonné Rome et se prépare à quitter l'Italie, Cicéron s'interroge sur la conduite qu'il convient d'adopter. Faut-il rester et se livrer à l'ennemi, qui a montré lors de la prise de Corfinium qu'il pouvait faire preuve de clémence, ou bien suivre Pompée et risquer sa vie dans un affrontement avec César ${ }^{9}$ ? Ces questions tourmentent Cicéron: il ne serait pas honorable de rester en Italie alors que Pompée est parti mais suivre ce dernier reviendrait à renoncer à toute tentative de faire la paix avec César et à s'engager dans une guerre dangereuse. Le dilemme que génère la comparaison de ce qui est honorable et de ce qui est sûr et la manière dont Cicéron tranche ce dilemme montrent son attachement à la dignité. Il choisit cette fois de faire primer l'honestas bien que cela implique de renoncer à sa sécurité:

Officii me deliberatio cruciat cruciauitque adhuc. Cautior certe est mansio, honestior existimatur traiectio. Malo interdum multi me non caute quam pauci non honeste fecisse existiment.

"La décision sur ce qu'il convient de faire m'a torturé jusqu'ici et continue de me torturer. Il est certes plus prudent de rester, mais on estime qu'il est plus honorable de prendre la mer. Je préfère parfois avoir manqué à la prudence aux yeux de la foule que manquer à l'honneur aux yeux d'un petit nombre.»

(CIc. Att. VIII, 15, 2).

Cicéron montre son sens de l'honneur en choisissant le parti de l'honestum plutôt que celui du cautum, en sacrifiant la prudence à

${ }^{8}$ Il ne cesse de répéter dans ses lettres de l'année 58 combien la mort face à Clodius aurait été plus honorable que l'exil volontaire: Cic. Q. fr. I, 4, 4 et Att. III, 7, 2.

${ }^{9}$ Sur ce dilemme, voir Cic. Att. VII, 22, 2 et Att. VIII, 14, 2. 
$l^{\prime} h o n n e u r^{10}$. On retrouve donc ici les deux éléments qui composent un «sens de l'honneur»: l'appréhension de ce qu'est une conduite honorable et l'attachement à cette dernière.

\section{LES NORMES DE L'HONNEUR}

Un code d'honneur est un ensemble de règles de conduite socialement définies dont l'adoption permet de conserver la considération de l'entourage. Il se caractérise par sa normativité contraignante. Il faut donc interroger de ce point de vue les notions d'honestum et d'honestas: l'honestum peut-il constituer une norme de conduite? Si c'est le cas, quels sont ses impératifs moraux?

\subsection{La normativité de l'honneur}

D’après la définition d'E. Goffman, une norme est

«une sorte de guide pour l'action soutenu par des sanctions sociales; les sanctions négatives pénalisent l'infraction; les sanctions positives récompensent la conformité exemplaire. $»^{11}$

Or nous avons vu que l'honos servait de sanction positive et contribuait à l'orientation des comportements. On peut donc faire l'hypothèse que la conduite qu'il sanctionne est précisément l'honestas, la conformité à un principe normatif (l'honestum) qui guide l'action. L'hypothèse est d'autant plus légitime que l'analyse sémantique des termes honestus et honestas a montré que les contextes actualisaient de manière fréquente un trait de sens concernant la normativité: est qualifié d'honestum ce qui est propre à orienter la conduite de l'individu $^{12}$. Et de fait, la manière dont les Romains se servent de l'honestum confirme son rôle de régulateur. Cela apparaît en négatif dans le Pro Cluentio, lorsque Cicéron évoque le triumuir capitalis Manilius, personnage malhonnête dont il dit qu'il n'a jamais eu de sa vie de pensée pour l'honneur ${ }^{13}$. Ce mépris pour l'honneur en fait, selon les termes mêmes de l'orateur, un petulans scurra, un «bouffon effronté». Manilius, dépourvu d'honneur, ne possède du même coup aucune règle de conduite et mène sa vie de manière désordonnée et incohérente,

\footnotetext{
${ }^{10}$ Voir aussi Cic. Att. IX, 10 et IX, 12. Dans une lettre jetant un regard rétrospectif sur cette période, Cicéron affirmera avoir préféré le pudor à la salus (CIc. Fam. VII, 3).

${ }^{11}$ Goffman, La Mise en scène de la vie quotidienne, p. 101.

${ }^{12}$ Supra p. 140-141.

${ }^{13}$ Cic. Clu. 39. Le terme d'honos est ici employé dans son sens, rare, d' «honorabilité», « dignité ».
} 
sans pouvoir imposer de limite à ses actes. L'absence d'honneur le rapproche des jeunes gens de la comédie qui agissent sans respecter les normes sociales et font preuve d'impudence ou d'immoralité ${ }^{14}$.

Cette régulation assurée par l'honneur se fait de manière contraignante car la norme s'exprime en imposant au sujet ses commandements. Cela apparaît dans le rapport que l'honestas entretient avec l'officium, le devoir, qui prescrit de façon impérative des actes à accomplir en fonction de son rôle social ${ }^{15}$. Le lien entre les deux notions apparaît dans la Rhétorique à Herennius, quand le texte propose à l'orateur qui doit parler en invoquant la nécessité d'être courageux d'avancer les arguments suivants:

Item ab nulla re honesta periculi aut laboris magnitudine deduci oportere; antiquiorem mortem turpitudine haberi; nullo dolore cogi ut ab officio recedatur.

«De même il ne faut se laisser détourner d'aucune action honorable par l'importance du péril ou des épreuves; il faut préférer la mort au déshonneur; nulle douleur ne doit détourner du devoir.»

(Rhet. Her. III, 5 ; trad. Achard modifiée).

Le texte place sur le même plan l'adoption d'une conduite honorable et l'attachement à l'officium: ignorer le danger et risquer sa vie est conforme à l'honneur qui s'incarne dans le refus de s'écarter du devoir ( $a b$ officio recedatur). L'honneur est donc obéissance à des injonctions. Cette idée est ancienne et parcourt des textes de nature très différente. Il en est ainsi question dans des passages de comédie, moins théoriques que les textes techniques comme la Rhétorique à Herennius mais non moins révélateurs de la pratique de l'honneur. Dans le Trinummus, Lesbonicus refuse de laisser sa sœur se marier sans dot et invoque l'officium:

LE. : Neque uolo neque postulo neque censeo; uerum tamen Is est honos homini pudico meminisse officium suom.

${ }^{14}$ La description de Manilius par Cicéron rappelle d'ailleurs, par son vocabulaire, un passage des Bacchides où le jeune homme débauché se décrit lui-même: Petulans, proteruo, iracundo animo, indomito, incogitato, / Sine modo et modestia sum, sine bono iure atque honore; "Imprudent, effronté, irascible, indomptable, irréfléchi, / Sans mesure ni modération, voilà ce que je suis; j'ignore le bon droit et l'honneur» (PL. Bac. 612-613). L'absence de dignité va de pair avec une absence de contrôle de soi et une attitude effrontée. Sur le repoussoir que représente pour Cicéron le scurra, C. GuÉRIN, Persona. L'Élaboration d'une notion rhétorique au Ier siècle av.J.-C., Paris, Vrin, 20092011, vol. 2, p. 273-288.

${ }^{15}$ Sur l'officium, voir supra n.71 p. 321. Le lien de l'honneur et du devoir existe également dans d'autres cultures: leur rapport intime dans la France de la Renaissance est étudié par JouAnNa, «Recherches sur la notion d'honneur au XVI e siècle», p. 604. 
«LESBOnicus: Je ne le veux pas, je ne réclame rien de tel, je n'y pense pas; mais cependant,

C'est cela l'honneur, pour un homme vertueux: se souvenir de son devoir.»

(PL. Trin. 695-697).

Lesbonicus définit explicitement l'honos, qui a ici le sens d' "honorabilité», comme le fait de se souvenir de son devoir, c'est-à-dire d'obéir à des impératifs qui s'imposent en vertu du rôle social que l'on joue. L'officium réclame que le jeune homme veille à la dignité de sa sœur et vienne à son secours matériellement. L'homme d'honneur ne peut occulter les exigences propres à l'officium mais doit, au contraire, accepter ces contraintes et adopter la conduite que l'on attend de lui, même si cela l'amène à changer radicalement sa façon de vivre, ce qui est le cas de Lesbonicus qui s'est ruiné par ses débauches et se doit d'adopter un mode de vie plus sage afin de reconstituer sa fortune pour doter sa sœur ${ }^{16}$. Les impératifs de l'honneur ne s'identifient pas cependant exactement à l'officium car ils sont essentiellement négatifs. L'honestas ne commande pas tant d'accomplir des actions précises qu'elle n'interdit certaines conduites ${ }^{17}$. Être honestus, c'est s'interdire d'agir de façon vile. Dans une autre comédie, l'Hécyre, Pamphile, de retour de voyage, vient d'apprendre que sa femme est sur le point d'accoucher et pense qu'il n'est pas le père. Il estime qu'il ne peut continuer à vivre avec elle:

Nam de redducenda, id uero ne utiquam honestum esse arbitror, Nec faciam, etsi amor me grauiter consuetudoque eius tenet.

"Quant à la reprendre, elle, je crois vraiment que ce ne serait nullement honorable

Et je ne le ferai pas, en dépit de l'amour et des liens qui m'attachent sérieu sement à elle. »

(Ter. Hec. 403-404; trad. Marouzeau modifiée).

La considération de l'honestum amène Pamphile à s'interdire de mener une vie maritale avec une épouse suspectée d'infidélité. Il s'agit d'une véritable contrainte car Pamphile aime toujours sa femme: l'honestas entrave donc ses sentiments et contrecarre son désir de rester auprès d'elle. Aux deux derniers siècles de la République, la normati-

${ }^{16}$ Sur le lien entre honorabilité et officium, voir aussi CIc. Quinct. 99 et Att. VIII, $15,2$.

${ }^{17}$ La normativité de l'honneur est donc différente de celle de la honte qui implique la réorientation d'un comportement mauvais vers une conduite acceptable, une conversion du mal vers le bien (Thomas, Déshonneur et honte, p. 366 et J. Elfassi, « De la honte classique à la honte chrétienne? Quelques réflexions d'après l'œuvre d'Isidore de Séville », in AleXandre, R., Guérin, C. et Jacotot, M. (éds.), Rubor et pudor. Vivre et penser la honte à Rome, Paris, Éditions rue d'Ulm, 2012, p.119-126, qui montre comment la honte induit la conversion au christianisme). 
vité de l'honneur est de nature contraignante: elle circonscrit les possibilités de l'action en interdisant certains choix.

Cependant, son poids ne doit pas être surestimé. On observe, d'une part, que la force contraignante du code d'honneur a eu tendance à perdre de sa puissance à la fin de la République où les sources se font de plus en plus l'écho des dérèglements moraux des individus et de leur mépris pour les normes de conduite. D'autre part, l'honestas n'est pas un code totalement rigide qui corsète tout comportement déviant. Des personnages très prestigieux ont pu, sans que cela nuise véritablement à leur honneur, se conduire d'une manière non conforme aux idéaux moraux de la société. Ce fut par exemple le cas de Scipion l'Africain, qui fut surpris par son père dans la maison d'une femme et fut contraint de s'enfuir vêtu de son seul manteau, si l'on en croit l'anecdote $^{18}$. On sait aussi que la manière dont Marcellus pilla les œuvres d'art de Tarente après la prise de la ville fut jugée sévèrement, sans entamer pour autant la considération qui était la sienne ${ }^{19}$. Tout se passe comme si la grandeur des actions militaires de ces hommes et la noblesse de leur famille étayaient suffisamment leur prestige pour qu'ils puissent, de temps à autre, contrevenir à l'excellence morale. L'excentricité ou les défauts dans le comportement ne compromettent pas systématiquement l'honorabilité: il peut y avoir un certain jeu dans les obligations imposées par l'honestum.

\subsection{Les commandements du code d'honneur}

Si l'honestas consiste à se conformer à des impératifs, il reste à établir la nature de ces derniers. Nous avons déjà eu l'occasion d'étudier les motifs de l'honos, c'est-à-dire les actions et les statuts qui permettent d'atteindre le prestige ${ }^{20}$. Ces derniers sont liés au code d'honneur puisqu'en ouvrant la voie vers le prestige social ils définissent aussi les traits de l'honorabilité qui en est la condition. Cependant, ils ne constituent qu'une partie des règles du code d'honneur: il faut en effet différencier les conduites qui sont honorables parce qu'elles sont valorisées par l'honos de celles qui sont honorables parce qu'elles sont indispensables pour ne pas encourir le déshonneur. Des comportements peuvent valoir un prestige faible, voire inexistant, et donc ne pas être source d'honos, tout en étant nécessaires pour ne pas tomber dans l'infamie: ne pas prendre la fuite au combat est conforme à l'honestum sans que cela soit un moyen de se couvrir de gloire. Les commandements de l'honestum sont des normes minimales qui prohibent certaines conduites pour éviter le déshonneur ${ }^{21}$. Il faut donc

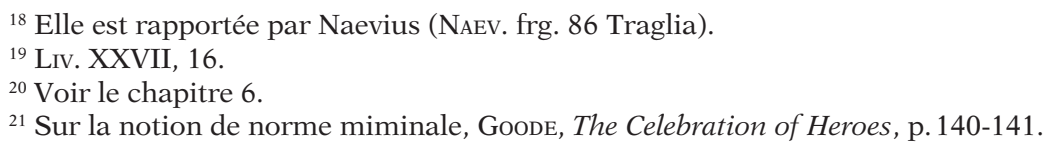


différencier les sources du prestige et les impératifs de l'honestum, qui peuvent se recouper mais ont des objectifs différents. Nous donnons ici un aperçu général des exigences de l'honestum, en insistant sur les règles récurrentes aux $\mathrm{II}^{\mathrm{e}}$ et $\mathrm{I}^{\mathrm{er}}$ siècles.

\subsubsection{Conduites honorables et motifs d'honneur}

Plusieurs traits qui composent le code de l'honestas recoupent les motifs d'honos que nous avons précédemment étudiés et nous ne les analyserons donc pas à nouveau en profondeur. Il nous paraît cependant utile de signaler leur existence pour montrer l'importance de certains traits de caractère au sein de la culture morale romaine. La uirtus, qui est une source essentielle d'honos, constitue également une exigence importante de l'honestas ${ }^{22}$. L'homme d'honneur se doit de faire preuve de uirtus, de courage viril, notamment au combat ${ }^{23}$. L'honneur impose de ne pas avoir peur de la mort et de refuser catégoriquement de prendre la fuite devant le danger, ce qui est une conduite extrêmement déshonorante ${ }^{24}$. Ici encore, l'honneur romain est étroitement lié à l'excellence militaire et à la vertu martiale. Une autre qualité exigée de l'homme d'honneur est la fides, le fait d'être digne de confiance mais aussi de faire preuve de loyauté en général ${ }^{25}$. Il n'est pas conforme à l'honorabilité de revenir sur la parole donnée ${ }^{26} \mathrm{ni}$ de se livrer à des malversations alors que l'on bénéficie de la confiance de la collectivité27. L'homme honestus fait preuve de droiture et s'acquitte de la tâche qui lui est confiée: les registres publics sont confiés aux scribes parce que ce sont des honesti qui ne cherchent pas à tromper ${ }^{28}$. Les Romains sont également attentifs à respecter l'honestum dans la manière de gagner leur vie; l'argent gagné honeste provient essentiellement du travail et des revenus de la terre et ne doit en aucun cas être issu d'une fraus, d'une action déloyale ${ }^{29}$. Le caractère honestus des métiers de l'agriculture est, plus généralement, lié à un idéal moral et socio-politique qui ménage une place essentielle au citoyen

${ }^{22}$ Sur la uirtus, voir p. 307 sqq.

${ }^{23}$ Cic. Verr. II, V, 5; Ps.-Caes. B. Al. 24, 1. Dans Rhet. Her. III, 9, la uirtus est au premier plan des qualités recouvertes par l'honestas.

${ }^{24}$ CIc. Phil. VIII, 29: la fuite est quelque chose de turpis et de pire que la mort ellemême.

${ }^{25}$ Sur la fides, voir p. 310-311.

${ }^{26}$ PL. Mil. 1369-1372: le soldat fanfaron, qui a donné son esclave en cadeau à un autre personnage, songe à le reprendre auprès de lui mais le seruus l'en dissuade en lui faisant valoir que ce ne serait pas agir honeste que de revenir sur sa décision et de se démentir soi-même.

${ }^{27}$ Cic. Phil. III, 26: aux trafics d'Antoine s'oppose l'intégrité de L.Cinna qui est honestissimus.

${ }^{28}$ CIC. Verr. II, III, 183.

${ }^{29}$ Cат. Agr. praef. 1-2; Cic. Quinct. 74 et Rosc. Com. 23. 
paysan et regarde avec méfiance des activités comme l'artisanat ou le commerce $^{30}$.

Un dernier impératif de l'honestas, faisant écho à un motif d'honos, est l'obligation d'apporter aide et bienfaits à autrui ${ }^{31}$. Ainsi, il est considéré comme honestum de défendre et protéger ses parents, ses hôtes et ses amis, surtout quand cela implique de sacrifier son intérêt personnel ${ }^{32}$. Il est contraire à l'honneur d'attaquer ses proches en justice ${ }^{33}$. Mais c'est surtout la dévotion de l'individu à la collectivité qui est conforme au code de l'honestum. On retrouve ici l'un des traits caractéristiques de la morale aristocratique qui ménage une grande place au service de l'État, que ce soit en temps de guerre, où l'honneur commande de défendre la patrie, ou en temps de paix, où il convient d'œuvrer politiquement dans la cité. Agir honeste, pour Salluste, c'est travailler au bonum publicum, en soutenant les droits de ses concitoyens ou en défendant l'autorité du sénat ${ }^{34}$. L'homme d'honneur se soucie du salut de la res publica. Cotta, le consul de 75, incarne parfaitement cet idéal dans le discours que Salluste lui attribue. Dans l'exorde, il affirme son total dévouement à la cité:

Atque ego, quoius aetati mors propior est, non deprecor, si quid ea uobis incommodi demitur; neque mox ingenio corporis honestius quam pro uostra salute finem uitae fecerim. Adsum en C. Cotta consul, facio quod saepe maiores asperis bellis fecere: иoueo dedoque me pro re publica.

${ }^{30}$ Sur la valeur de l'agriculture, Cic. Cato mai. 51-60 et Off. I, 151. Cicéron se fait aussi l'écho du dédain des Romains pour les artisans (Cic. Off. I, 150, avec le commentaire de J.-P. Morel, "L'artisan», in Giardina, A. (éd.), L'Homme romain, Paris, Seuil, 2002, p.277-314). Son évaluation des activités commerciales est plus nuancée: les spéculateurs, les usuriers et les petits commerçants sont méprisés (CIc. Off. I, 151; voir A. Giardina, «Le marchand », in Giardina, A. (éd.), L'Homme romain, Paris, Seuil, 2002, p.315-347). Le commerce à grande échelle, en revanche, n'est pas incompatible avec l'honorabilité pour des personnes n'appartenant pas à l'aristocratie: des marchands siciliens sont qualifiés d'honesti par Cic. Verr. II, V, 154. La lex Claudia interdisait la pratique du gros commerce maritime aux sénateurs (Liv. XXI, 63, 3-4; J.H. D'ARms, Commerce and Social Standing in Ancient Rome, Cambridge (MA), Harvard University Press, 1981, p.31-39; Baltrusch, Regimen morum, p. 30-40) mais elle ne repose pas, comme le dit Tite Live, sur le fait que toute forme de profit était inconvenante: gagner de l'argent est valorisé par la laudatio de Caecilius Metellus (PLIN. NH VII, 140) comme par Caton (Plut. Cato mai. 21, 8) et par Salluste quand il parle des ancêtres (Sall. Cat. 7, 6). Le gros commerce est critiqué lorsqu'il exprime la cupidité ou recourt à des méthodes douteuses (D'ARms, Commerce and Social Standing in Ancient Rome, p. 20-21; E. GaBBA, «Ricchezza e classe dirigente romana fra III e I sec. a C. », RSI, 93 (3), 1981, p. 541-548). La lex Claudia a des buts surtout politiques et procède du poids moral de la culture de la terre ainsi que de la volonté d'assurer une stabilité économique aux sénateurs (Baltrusch, Regimen morum, p. 34-35).

${ }^{31}$ Sur les bienfaits sources d'honos, voir p. 314 sqq.; sur la place du souci de la collectivité, voir p.316-317.

${ }^{32}$ Rhet. Her. III, 5.

${ }^{33}$ CIc. Quinct. 44.

${ }^{34}$ Sall. Cat. 38, 3. 
«Et moi, qui suis par mon âge assez proche de la mort, je ne refuse pas cette mort si par elle je peux vous ôter un peu de vos malheurs; et, étant donné mon état physique, je ne pourrais voir ma vie s'achever plus honorablement qu'en la perdant pour vous sauver. Me voici, C. Cotta, votre consul; je fais ce que souvent nos ancêtres ont fait dans des guerres difficiles: je me dévoue, je me sacrifie pour la république.»

(SALL. Hist. frg. II, 47, 9-11 Reynolds).

Pour Cotta, le sommet de l'honestas consiste à offrir sa vie dans l'intérêt de la collectivité. On retrouve ainsi le thème de la mors honesta: l'acte le plus prestigieux, et celui qui témoigne de la plus parfaite obéissance à l'honneur, est le sacrifice de soi pour le salut des autres. L'honestas consiste à se rendre utile à la cité par son abnégation. Cotta, par l'expression иоиео dedoque me, rapproche son action de la deuotio, rituel par lequel un général faisait le sacrifice de sa vie en se jetant seul sur l'armée ennemie et liait sa mort à celle des opposants en les vouant aux dieux des enfers ${ }^{35}$.

\subsubsection{Modération}

D'autres conduites honestae ne constituent pas des sources d'honos mais permettent de conserver le degré zéro de l'estime de son entourage et de ne pas tomber dans la disgrâce. Plusieurs impératifs de l'honestum ont ainsi en commun d'interdire l'excès et d'imposer la modération. Nous avons vu, à propos du scurra Manilius, que l'homme honestus se caractérise par sa capacité de ne pas agir en petulans et de se contrôler ${ }^{36}$. L'honneur impose également de modérer ses dépenses. Le crieur public Gallonius, qui s'était rendu célèbre par sa gourmandise, apparaît à Cicéron opposé en tous points aux honesti en raison de l'argent qu'il engloutit dans sa passion ${ }^{37}$ : il consacre toute sa fortune à des achats de mets raffinés et coûteux et est incapable de contrôler ses dépenses. Ce n'est pas la possession de richesses qui est déshonorante mais l'usage déréglé qui en est fait. L'analyse historique et morale d'un Salluste ne se prive pas de critiquer ceux qui gaspillent leur argent de manière inconsidérée:

Nam quid ea memorem quae nisi eis qui uidere nemini credibilia sunt, a priuatis conpluribus subuorsos montis, maria constrata esse? Quibus mihi uidentur ludibrio fuisse diuitiae; quippe quas honeste habere licebat abuti per turpitudinem properabant.

${ }^{35}$ Liv. VIII, 9. Sur ce rituel, G. Stievano, "La supposta deuotio di P.Decio Mure nel 279 a.C.», Epigraphica, 13, 1951, p.3-13; H.-S. Versnel, "Two Types of Roman devotio», Mnemosyne, 29, 1976, p.365-410 et L.SAcco, «Deuotio», StudRom, 52 (3-4), 2004, p. 312-352.

${ }^{36}$ Supra p. 466.

${ }^{37}$ CIc. Quinct. 94. Sur Gallonius, voir aussi CIc. Fin. II, 8, 24 et Hor. Sat. II, 2, 47. Sur la nécessité de mesurer le sumptus pour se conformer à l'honestum, voir aussi la recommandation formulée par Lucilius (p.653). 
«À quoi bon rappeler d'autre part ces faits incroyables pour qui ne les a vus: montagnes aplanies, mers converties en chaussées par de simples particuliers? Ne semble-t-il pas qu'ils aient voulu seulement se railler de leurs richesses, en se hâtant d'épuiser par de honteuses profusions des biens dont ils pouvaient faire un usage honorable?»

(SAlL. Cat. 13, 1-2; trad. Ernout).

L'usage dispendieux de la richesse est non seulement inutile mais aussi honteux: c'est agir per turpitudinem, et donc ruiner sa considération, que de l'employer pour montrer sa puissance.

Pour ne pas se déshonorer, il convient aussi de mesurer son désir et de limiter la recherche des plaisirs. L'honneur n'interdit pas formellement tout type de uoluptas mais il proscrit la débauche. Les commandements de l'honestum s'exercent dans deux domaines où la volupté a sa place, les plaisirs de la table et la sexualité. Il est possible, en premier lieu, de se déshonorer par la façon que l'on a de prendre ses repas, quand ces derniers se transforment en banquets interminables, composés de mets luxueux et raffinés. L'honorabilité consiste à modérer sa consommation. Il faut noter cependant que le festin n'est pas en soi proscrit par l'honneur: tout comme la richesse n'est pas déshonorante mais seulement l'usage qui en est fait, le conuiuium n'est dégradant que lorsqu'il dépasse certaines bornes. C'est ce qu'indique le Pro Murena:

Nemo enim fere saltat sobrius, nisi forte insanit, neque in solitudine neque in conuiuio moderato atque honesto. Tempestiui conuiui, amoeni loci, multarum deliciarum comes est extrema saltatio.

«En effet, si l'on n'est pas ivre, on ne danse guère, à moins d'avoir perdu la raison, ni quand on est seul, ni dans un festin modeste et honnête. C'est à un festin prolongé, à un lieu de plaisir, c'est à toutes sortes de voluptés que vient en dernier lieu s'associer la danse.»

(CIc. Mur. 13; trad. Boulanger).

Cicéron s'interroge ici sur les facteurs qui peuvent pousser un Romain à danser, attitude jugée particulièrement inconvenante ${ }^{38}$. La saltatio ne peut qu'être le fait d'un homme fou ou ivre, et cette ivresse ne se rencontre que dans certains types de conuiuium. L'orateur distingue le banquet honorable et le banquet de débauche. Tandis que le premier se caractérise par la mesure (moderatum), parce qu'il est restreint dans le temps et ne donne pas lieu à des excès de boisson ni donc à des comportements inconvenants comme la danse, le second ne connaît pas de limites: il est tempestiuum, il dure longtemps, et s'accompagne de plaisirs raffinés et nombreux (multarum deliciarum). L'honneur proscrit l'absence de mesure et les quantités indéfinies; il exige des bornes précises et un contrôle de soi, de son corps et de

\footnotetext{
${ }^{38}$ Voir p. 476-477.
} 
ses plaisirs. Le banquet n'est donc pas interdit aux individus honorables, car c'est un lieu de convivialité et de sociabilitée ${ }^{39}$, mais il doit être contrôlé: c'est en effet un moment périlleux pour la dignité car il peut loger des vices, tels que la gloutonnerie, l'ivresse, la danse ou les relations sexuelles déviantes ${ }^{40}$.

Le second type de plaisir qui doit être limité est le plaisir sexuel ${ }^{41}$. Il apparaît régulièrement contraire à l'honneur, lorsqu'on est un homme, de ne pas tempérer son désir. Il est ainsi particulièrement indigne de séduire des personnes comme les femmes mariées, les très jeunes filles et les jeunes garçons de naissance libre: toute relation sexuelle avec ces derniers leur fait perdre leur propre honneur et déconsidère celui qui l'a engagée ${ }^{42}$. Le désir sexuel doit être contenu et orienté vers les individus qui ne sont pas tabous, c'est-à-dire l'épouse légitime, les esclaves ou les courtisanes. Ici encore, c'est l'incapacité de se conformer à des règles de conduite qui est déshonorante. L'ignominie provient aussi d'une activité sexuelle s'exerçant dans des cadres acceptés mais de manière débridée. Dans l'Hécyre, Parménon rapporte les paroles de

${ }^{39}$ Sur la pratique du banquet à Rome et ses fonctions sociales, voir J.H. D'ARMs, "Control, Companionship, and Clientela. Some Social Functions of the Roman Communal Meal », EMC, 28, 1984, p. 327-348; J. H. D'ARms, "The Roman Conuiuium and the Idea of Equality », in Murray, O. (éd.), Sympotica: a Symposium on the Symposion, Oxford, Clarendon Press, 1990, p.308-320. Voir aussi sur le conuiuium les contributions rassemblées dans N.W. Slater (éd.), Dining in a Classical Context, Ann Arbor, University of Michigan Press, 1991.

${ }^{40}$ Ce sont des thèmes favoris de la satire (Hor. Sat. II, 8 ; Iuv. Sat. 5) et de l'invective (Cic. Pis. 22). Sur ces vices, A.P. Corbeill, "Dining Deviants in Roman Political Invective", in Hallett, J.P. et Skinner, M. B. (éds.), Roman Sexualities, Princeton, Princeton University Press, 1997, p.99-128, qui souligne que le banquet est surtout une menace pour la virilité des hommes. Sur le vin et les dangers de l'ivresse, O. MurRay et M. Tecusan (éds.), In vino veritas, Londres, British School at Rome, 1995.

${ }^{41}$ Les travaux sur la morale sexuelle des Romains se sont multipliés ces dernières décennies. Pour un bilan, voir S. Boehringer, "Sexe, genre, sexualité: mode d'emploi (dans l'Antiquité)", Kentron, 21, 2005, p.83-110 et T.ÉLoI, "La sexualité de l'homme romain antique: actualité bibliographique», in CHAPERon, S. et Fine, A. (éds.), Utopies sexuelles, Toulouse, Presses Universitaires du Mirail, 2005, p.167-184. Parmi de très nombreux titres, les normes de la sexualité sont abordées dans C. EDwards, The Politics of Immorality in Ancient Rome, Cambridge, Cambridge University Press, 1993 (chapitre 2); D. M. Halperin (éd.), Before Sexuality. The Construction of Erotic Experience in the Ancient World, Princeton, Princeton University Press, 1990; T. A. McGINn, Prostitution, Sexuality, and the Law in Ancient Rome, Oxford, Oxford University Press, 1998; R. Langlands, Sexual Morality in Ancient Rome, Cambridge, Cambridge University Press, 2006 ; G. Puccini-Delbey, La Vie sexuelle à Rome, Paris, Tallandier, 2007.

${ }^{42}$ Pl. Curc. 37-38. Voir J. Walters, "Invading the Roman Body: Manliness and Impenetrability in Roman Thought", in Hallett, J.P. et Skinner, M.B. (éds.), Roman Sexualities, Princeton, Princeton University Press, 1997, p.29-43 pour les interdits pesant sur le jeune homme praetextatus et la femme mariée. L'auteur montre que ce sont surtout avec des personnes de statut social élevé que les relations sexuelles sont répréhensibles. 
Pamphile qui s'est marié contre son gré à une femme qu'il n'aime pas et dont il projette de se séparer:

Sed quam decrerim me non posse diutius
Habere, eam ludibrio haberi, Parmeno,
Quin integram itidem reddam ut accepi a suis,
Neque honestum mihi neque utile ipsi uirgini est.
"Mais une femme dont j’ai décidé qu'il n'était pas possible de la garder
Plus longtemps, la garder pour m'amuser, Parménon,
Sans la rendre pure comme je l'ai reçue des siens,
Ce ne serait ni honnête pour moi, ni utile pour la jeune fille elle-même.»

(TER. Hec. 148-151).

Pamphile considère qu'il ne serait pas conforme à l'honneur de conserver auprès de lui son épouse pour le plaisir, dans le simple but d'assouvir ses désirs. Ce serait faire passer l'amusement, ludibrium, avant les obligations que l'on peut avoir envers une jeune femme encore vierge. Ce qui est honestum, c'est de contrôler son désir, sans céder à la frivolité. Une anecdote rapporte que Caton avait félicité un jeune homme sortant d'une maison close parce qu'il ne portait pas son désir vers les femmes mariées, mais l'avait ensuite réprimandé parce qu'il l'avait vu plusieurs fois sortir de cet endroit ${ }^{43}$. L'honestas d'un individu s'évalue donc aussi à la nature de sa vie sexuelle ${ }^{44}$. Les interdits pesant sur l'excès des jouissances de la table et du sexe montrent que l'honorabilité tend à occuper une position antagoniste au plaisir. Honestas et uoluptas ne sont pas exclusives l'une de l'autre, puisque l'honneur ne proscrit pas tout plaisir, mais l'un des rôles de l'honestas est de circonscrire la uoluptas, de poser des limites à son exercice. Le citoyen peut détendre son corps et son esprit dans le plaisir à condition qu'il ne se laisse pas dominer par lui et puisse retourner à la vie civique. Il est déshonorant de ne pas mesurer son désir car cela implique une absence de liberté: l'individu débauché est asservi à son propre plaisir, ce qui le rapproche de la figure honnie du tyran asujetti à la voluptét5.

${ }^{43}$ Hor. Sat. I, 2, 31-35 et la glose de Porphyrion ad loc. Voir F. Dupont et T. Éloi, L'Érotisme masculin dans la Rome antique, Paris, Belin, 2001, p.140. Au début des Origines (I, 1), Caton évoque la nécessité pour les grands hommes de rendre compte de leurs occupations publiques mais aussi de leurs loisirs et de leur vie intime.

${ }^{44}$ Nous laissons de côté l'indignité de la passivité sexuelle des hommes, qui, si elle est importante dans les textes, n'est pas directement reliée à l'honestas. Voir WaLTERS, «Invading the Roman Body: Manliness and Impenetrability in Roman Thought» et Dupont et ÉloI, L'Érotisme masculin dans la Rome antique.

${ }^{45}$ Dupont et ÉLoI, L'Érotisme masculin dans la Rome antique, p. 92. 


\subsubsection{Décence et pudeur}

Outre cette modération dans les désirs et les plaisirs, l'honestas impose de respecter, dans sa personne physique, les convenances sociales. L'homme d'honneur est contraint de faire preuve de ce que l'on peut qualifier de "décence»: il évite de prendre des postures inconvenantes et de mettre en avant certaines parties de son corps ou bien de les évoquer dans ses propos. Cette décence prend souvent la forme de la pudeur car ce sont principalement les objets sexuels, mots du vocabulaire ou parties de l'anatomie, qu'il s'agit de taire ou de cacher. L'honestum commande, ici encore, de contrôler son corps, non pas en modérant son désir mais en évitant l'obscénité propre à déclencher la disgrâce sociale. Deux types d'indécence sont proscrits par l'honestum, la gesticulation et la nudité. Ce sont en premier lieu les mouvements du corps exubérants et ostentatoires qui sont une source de déshonneur. La danse, la saltatio pratiquée par les acteurs, pantomimes et danseurs professionnels, apparaît ainsi comme une pratique dégradante ${ }^{46}$. Nous avons vu dans le passage du Pro Murena cité supra à propos des festins que dans un conuiuium honestum personne ne saurait s'y livrer, à moins d'être ivre ou fou. Le saltator pratique un métier tout à fait vil aux yeux des Romains de l'aristocratie, au point que le mot est utilisé comme insulte dans les invectives ${ }^{47}$. L'infamie liée à cette pratique la rend incompatible avec l'honestum, comme le montre un fragment d'un discours de Scipion Émilien qui s'indigne que de jeunes nobiles fréquentent les écoles d'histrions:

Docentur praestigias inhonestas, cum cinaedulis et sambuca psalterioque eunt in ludum histrionum, discunt cantare, quae maiores nostri ingenuis probro ducier uoluerunt; [...] plus [...] in eo ludo uidi pueris uirginibus quingentis, in his unum (quos me rei publicae maxime miseritum est) puerum bullatum [...], cum crotalis saltare, quam saltationem impudicus seruulus honeste saltare non posset.

«On leur enseigne des tours indécents, c'est en compagnie de misérables invertis, la harpe et la cithare à la main, qu'ils se rendent à l'école des histrions, où ils apprennent à chanter, alors que nos ancêtres ont voulu que cela fût considéré comme une honte pour des gens bien nés; [...] j’ai vu dans cette école plus de cinq cents jeunes filles, parmi lesquelles (et cela me fait grandement pitié

${ }^{46}$ Sur la danse et les critiques des Romains sur cette pratique, M.-H. FrançoIsGARELLI, «Le danseur dans la cité: quelques remarques sur la danse à Rome », $R E L, 73$, 1995, p. 29-43. L'article souligne que la danse est considérée par les sources, à quelques exceptions près, comme une activité efféminée risquant de conduire à tous les vices mais que cela ne l'a pas empêchée de jouir d'une réelle faveur.

${ }^{47}$ Insulte prononcée par Caton contre Muréna (Cic. Mur. 13) et par Cicéron contre Gabinius (Cic. Red Sen. 13; Dom. 60; Planc. 87). Cicéron attribue en partie le déclin moral de l'État aux séductions de la danse et de la musique (Leg. II, 39). La seule danse acceptable est la danse en armes ou celle pratiquée par certaines confréries religieuses (FrançoIs-Garelli, Ibid., p. 39). 
pour la république) dansait, des castagnettes à la main, un jeune garçon portant la bulle [...], et sa danse, un misérable débauché d'esclave n'aurait pu l'exécuter sans se déshonorer.»

(ScIP. Aem. frg. IX, 30 ORF).

Scipion déplore que les jeunes gens apprennent au ludus histrionus à pratiquer des danses totalement déshonorantes. L'indignité de la saltatio repose sur plusieurs motifs. Elle implique d'abord l'adoption de postures dégradantes qui consistent en des pitreries et des gesticulations en tous sens (praestigias inhonestas); le nobilis se doit, au contraire, d'avoir une attitude réservée et digne, des gestes mesurés et une posture droite ${ }^{48}$. L'honneur proscrit l'agitation du corps et le désordre des mouvements. La danse déshonore ensuite parce qu'elle suppose d'exhiber son corps en public et de risquer d'en rendre visibles les parties intimes. Elle comporte ainsi une impudicité qui heurte la décence sexuelle exigée par l'honestum ${ }^{49}$. Elle est également honteuse parce que le danseur abandonne sa masculinité et adopte des postures efféminées, indignes du uir romain, pour séduire les spectateurs ${ }^{50}$. Enfin, comme l'explique Cicéron, les saltatores font un métier ignoble parce qu'ils sont au service du plaisir et non de l'utilité, ce qui les range aux côtés des marchands de mets raffinés et des parfumeurs ${ }^{51}$. On voit ainsi, en négatif, que l'honestum réclame d'adopter une posture digne, de faire preuve de discrétion dans les mouvements de son corps et de ne pas s'asservir au plaisir d'autrui. Il faut cependant souligner que dans le De finibus, la danse est devenue, pour le personnage de Caton, la métaphore de la sagesse ${ }^{52}$. La valeur de la danse est alors radicalement inversée puisque cette pratique conçue comme déshonorante devient l'image de la perfection morale. Cela témoigne de la capacité d'évolution de l'honestum, notamment lorsque le concept est convoqué dans des espaces de réflexion qui peuvent s'éloigner des représentations morales traditionnelles, comme dans le De finibus.

Le second type d'indécence heurtant le sens de l'honneur est la dénudation en public ${ }^{53}$. La nudité n'est pas systématiquement vue à Rome comme un état dégradant mais elle est tout de même considérée avec beaucoup plus de suspicion que dans le monde grec. Le citoyen est en effet l'homme qui porte la toge, habit qui le distingue

${ }^{48}$ La seule danse acceptable, celle des guerriers et des prêtres, contraste par son «rituel digne et figé » avec celle des acteurs qui «se donnent toute liberté » (Ibid., p. 39).

${ }^{49}$ Sur la possible visibilité des parties génitales des acteurs, Cic. Off. I, 129. Sur le caractère dégradant de la performance en public, voir EDWARDS, "Unspeakable Professions: Public Performance and Prostitution in Ancient Rome».

${ }^{50}$ Sur le caractère efféminé de la danse, CoRBeill, «Dining Deviants in Roman Political Invective» et Dupont et ÉLoI, L'Érotisme masculin dans la Rome antique, p. 105.

${ }^{51}$ CIc. Off. I, 150.

${ }^{52}$ Cic. Fin. III, 24.

${ }^{53}$ Sur la nudité à Rome, voir l'étude d'ensemble de CoRDIER, Nudités romaines. 
des sauvages qui vont nus et dont la perte paralyse l'action publique ${ }^{54}$. Le gymnase à la grecque, où les athlètes sont nus, est pour les Romains un lieu de débauche associé à l'homosexualité masculine ${ }^{55}$. À Rome, la dénudation du corps est périlleuse pour la dignité et risque en permanence l'obscénité. Aller aux bains avec son père ou son beau-père, ce qui implique de se dénuder en présence de membres de sa famille, ne peut se faire honeste ${ }^{56}$. La nudité visible des proches crée un malaise et heurte les exigences de l'honorabilité. Les femmes aussi doivent veiller à ne pas porter de vêtements transparents ${ }^{57}$. L'honneur recèle ainsi un commandement de pudeur qui conduit à dissimuler les parties intimes du $\operatorname{corps}^{58}$. Cette obligation a été théorisée par Cicéron dans le premier livre du De officiis et dans une lettre adressée à Papirius Paetus, où il expose la théorie cynico-stoïcienne sur l'obscène et en donne une réfutation. Il y oppose précisément l'honestum à l'obscenum ${ }^{59}$. Dans la lettre à Paetus, Cicéron soutient que la pudeur, qu'il nomme uerecundia, est nécessaire et que l'on doit éviter dans ses actes aussi bien que dans ses propos l'obscénité contraire à l'honneur. Pour les cyniques, rien n'est obscène car l'obscénité, si elle existe, réside dans la chose ou dans le mot. Or elle n'est pas dans la chose puisqu'elle peut être désignée sans choquer, comme le font bien des œuvres littéraires, dont les tragédies, textes particulièrement nobles. Et elle n'est pas non plus dans le mot qui n'est qu'un support de la pensée dépourvu de toute faculté d'impudicité ${ }^{0}$. Pour les stoïciens et les cyniques, un terme désignant une chose naturelle ne peut lui-même être obscène et le sage parlera sans détour, selon le précepte communément attribué à Zénon: ó бọò

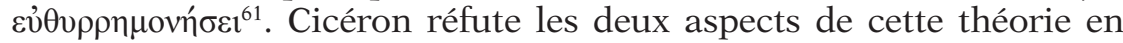

${ }^{54}$ Ibid., p. 97 et le chapitre $\mathrm{V}$ dans son ensemble.

${ }_{55}$ Cic. Rep. IV, 4, 4. Dupont et Élor, L'Érotisme masculin dans la Rome antique, p. 35; Cordier, Nudités romaines, p. 320; J.-P. Thuillier, «Le corps du sportif romain», in Moreau, P. (éd.), Corps romains, Grenoble, J. Millon, 2002, p. 251-266. Ce dernier note cependant que la nudité athlétique a fini par être acceptée partiellement sous l'Empire.

${ }^{56}$ CIc. Clu. 141; Off. I, 129.

${ }^{57}$ Sen. Ben. VII, 9, 5; Hor. Sat. I, 2, 94-100. Voir Puccini-Delbey, La Vie sexuelle à Rome, p. 73-75.

${ }^{58}$ Cf. la honte ressentie par les malades contraints de montrer ces parties au médecin (S. ARNAUD-LeSot, «Les aspects médicaux de la honte dans le De medicina de Celse ", in AleXandre, R., Guérin, C. et Jacotot, M. (éds.), Rubor et pudor. Vivre et penser la honte à Rome, Paris, Éditions rue d'Ulm, 2012, p. 45-59).

${ }^{59}$ L'opposition apparaît en Cic. Off. I, 128. La réfutation est menée par Cicéron dans le De officiis I, 127-129 et dans la lettre Fam. IX, 22. Le traité polémique contre les cynici et quelques stoici paene cynici tandis que la lettre réfute nommément Zénon. Sur la théorie cynico-stoïcienne de l'obscénité, liée au rapport entre les mots et les choses, G. Romeyer-DHerbeY, "Zénon appelle les choses par leur nom. La chasteté de la langue d'après les stoïciens », Mesure, 3, 1990, p.47-59. Sur le traitement de l'obscénité dans le De officiis, voir CoRDIER, Nudités romaines, p. 253-254.

${ }^{60}$ Voir l'exposé fait par Cicéron de la théorie de Zénon (Fam. IX, 22, 1-3).

${ }^{61}$ Cic. Fam. IX, 22, 5; RomeYer-Dherbey, «Zénon appelle les choses par leur nom », p. 49. 
s'appuyant sur le sens commun et sur la nature. Les hommes cachent spontanément, dit-il, les parties intimes de leur anatomie et assouvissent en secret leurs besoins naturels: ils tendent donc spontanément à dissimuler certaines réalités qui sont bien obscènes ${ }^{62}$. Concernant le langage, ils utilisent des périphrases pour désigner les actes bas ou sexuels, telles que liberis dare operam, "mettre en chantier des enfants ${ }^{63}$ : il y a donc bien une grossièreté localisée dans les mots eux-mêmes, grossièreté que l'honneur impose d'éviter. Les expressions périphrastiques peuvent, elles, s'employer honeste, note Cicéron, sans choquer la décence: l'être obscène de la chose ne retentit pas sur le mot. L'obscénité est donc bien une réalité, dans les actes et dans le langage, et il importe à l'homme d'honneur de l'éviter. Il doit pour cela adopter deux règles: dissimuler les parties intimes de son corps, qui ne sont pas honteuses en soi mais seulement quand elles sont exhibées, et ne pas employer de termes obscènes ${ }^{64}$. Il faut suivre la natura pour accomplir ce qu'exige l'honestum en matière de décence: la uerecundia doit imiter la nature qui a caché les parties hideuses servant à satisfaire les besoins naturels ${ }^{65}$. L'honestum consiste donc à se comporter sans heurter ni le regard ni les oreilles, à contrôler son corps et ses propos.

\subsubsection{Impassibilité et sérieux}

Un dernier ensemble de règles propres à l'honestas s'organise autour d'un impératif de gravité dans l'attitude. Il est essentiel, pour éviter le discrédit, de faire preuve d'une dignité sérieuse qui ne donne pas prise à la critique et de montrer une constance d'âme face aux événements, fussent-ils désagréables. Deux conduites sont exigées par l'honestum: ne pas tomber dans la sensiblerie et éviter le ridicule. Une émotivité excessive est, en premier lieu, un signe de faiblesse inacceptable pour l'homme d'honneur et compromet l'estime que les autres ont de lui. On le voit notamment dans l'interdit qui pèse sur les pleurs. Cela apparaît chez Ennius, dans des paroles d'Agamemnon:

Plebes in hoc regi antistat loco: licet

Lacrumare plebi, regi honeste non licet.

${ }^{62}$ CIC. Off. I, 126.

${ }^{63}$ Cic. Off. I, 128 et Fam. IX, 22, 3.

${ }^{64}$ Doivent être évités les termes directement grossiers mais aussi ceux dont seul l'un des sens est obscène. Cicéron donne l'exemple de mentula, qui peut désigner un petit pied de menthe ou un pénis (Cic. Fam. IX, 22, 3). Sur ces exigences cicéroniennes touchant l'emploi des mots et leur importance pour l'orateur, voir Guérin, Persona. L'Élaboration d'une notion rhétorique au I Ier siècle av. J.-C., vol. 2, p. 264 et 289-294.

${ }^{65}$ Cic. Off. I, 126. 
«La plèbe l'emporte sur le roi en ceci: il est permis

À la plèbe de pleurer, il n'est pas permis au roi de le faire sans se désho norer.»

(ENN. Trag. inc. frg. CCXV Jocelyn).

Il s'agit ici vraisemblablement d'une méditation du roi qui apprend l'arrivée de sa fille à Aulis et sait qu'il va devoir la conduire au sacrifice pour permettre le départ de la flotte grecque. Il n'est pas possible pour un souverain comme Agamemnon de pleurer honeste; son statut le lui interdit. L'honneur impose de ne pas montrer son émotivité ni sa douleur mais de faire preuve de force d'âme dans des circonstances particulièrement pénibles. Un passage d'une tragédie de Pacuvius permet de voir d'où procède cet interdit:

Conqueri fortunam aduorsam, non lamentari decet; Id uiri est officium, fletus muliebri ingenio additust.

«Se plaindre de l'adversité de la fortune est convenable, pas de se lamenter; Tel est le devoir de l'homme, les pleurs sont donnés à la nature de la femme. »

(PACUV. frg. 268-269 TRF).

Les pleurs sont caractéristiques des femmes ${ }^{66}$; il est déshonorant pour un homme de le faire car cela entre en contradiction avec son ingenium viril: c'est être efféminé que de pleurer sur son sort. Dans les textes de la République, ce sont de fait surtout les femmes que l'on représente en train de verser des larmes ${ }^{67}$. Les règles de l'honneur ne se fondent pas sur la nécessité de l'impassibilité, comme chez Ennius, mais sur les devoirs de la virilité, le uiri officium évoqué par Pacuvius ${ }^{68}$. Il y a un clivage sexué des commandements de l'honneur puisqu'une conduite acceptable pour une femme est déshonorante pour un homme ${ }^{69}$. Ces obligations persistent au $\mathrm{I}^{\text {er }}$ siècle avant J.-C.: quand Metellus apprend que les opérations de Numidie ont été confiées à Marius, il se comporte, écrit Salluste, supra honestum, il dépasse les bornes fixées par l'honneur, car il se laisse aller à pleurer,

${ }^{66}$ Voir le commentaire que donne Cicéron de ces vers en Tusc. II, 50 et la critique qu'il fait de l'Ulysse de Sophocle, représenté en pleurs à cause de la douleur qu'il ressent.

${ }^{67}$ Voir par exemple Rhet. Her. IV, 65 ; CAES. BC, II, 4, 3 ; CIC. Verr. II, IV, 47 et II, IV, 52; Clu. 16 ; Dom. 59.

${ }^{68}$ Cicéron fait dans les Tusculanes le rapprochement entre larmes, féminité et déshonneur pour l'homme: Quid est enim fletu muliebri uiro turpius? "Qu'y a-t-il de plus déshonorant pour un homme que des pleurs de femme? (Cic. Tusc. II, 57).

${ }^{69}$ Sur ce point, infra p. 501-504. Sur le clivage hommes / femmes à propos des larmes, voir H.VAN WEES, «A Brief History of Tears: Gender Differentiation in Archaic Greece", in Foxhall, L. et Salmon, J. (éds.), When Men were Men. Masculinity, Power and Identity in Classical Antiquity, Londres, Routledge, 1998, p. 10-53. 
ce qui est indigne d'un général romain ${ }^{70}$. Cependant, les larmes ne sont pas inacceptables en toutes circonstances: Cicéron parle à plusieurs reprises des pleurs qu'il verse sur la situation du client qu'il défend et l'orateur peut tout à fait chercher à susciter ce type de réaction physique chez son public ${ }^{71}$. On connaît aussi les larmes que versèrent Marcellus après la prise de Syracuse et Scipion Émilien devant les ruines de Carthage ${ }^{72}$. Ces attitudes ont pour point commun d'être une réponse à la situation de détresse d'un tiers: on pleure pour d'autres que soi et notamment pour ses proches et ses amis ${ }^{73}$. Les larmes ne sont donc déshonorantes que lorsqu'elles sont suscitées par l'apitoiement de l'individu sur son propre sort et non pas lorsqu'elles proviennent du malheur qui touche autrui ${ }^{74}$.

Il est aussi considéré comme déshonorant de prêter à rire: le comportement ridicule est contraire à la gravité et au sérieux qu'implique la conformité au code de l'honestum. Le rire qui s'exerce aux dépens de quelqu'un n'est en effet pas compatible avec l'évaluation positive de cette personne: le rire, à l'inverse de la marque d'honneur, manifeste l'exclusion et rabaisse la valeur de celui qu'il vise. On le constate dans les comédies, quand un personnage est ludificatus, victime d'une ruse qui le ridiculise ${ }^{75}$. Dans l'Eunuque, le jeune Phédria comprend aux deux tiers de la pièce que son eunuque a été utilisé par son frère Chéréa dans une machination: Phédria a été berné par son frère qui s'est fait passer pour l'eunuque afin de s'introduire auprès de la femme qu'il aime et de la violer. Phédria a une part de responsabilité dans cette affaire et se retrouve donc dans une position fort délicate. Une fois la supercherie découverte, il cherche à ne pas perdre la face et quitte la scène en malmenant son eunuque:

Alio pacto honeste quo modo hinc abeam nescio. Actumst, si quidem tu me hic etiam, nebulo, ludificabere!

${ }^{70}$ SALL. Iug. 82, 2. Metellus enfreint également l'honestum car il est incapable de se modérer et invective Marius de manière inconsidérée.

${ }^{71}$ Sur les larmes versées sur le sort d'un client, Cic. Verr. II, I, 153; Planc. 76; Mil. 92. Sur les larmes suscitées par l'orateur, Cic. De or. I, 228 et II, 189.

72 A.F. Rossi, "The Tears of Marcellus: History of a Literary Motif in Livy ", G\&R, 47 (1), 2000, p.56-66; A.E. Astin, Scipio Aemilianus, Oxford, Clarendon Press, 1967, p. 283 sqq. Sur les larmes autorisées au sein de l'aristocratie, R. MACMullen, "Romans in Tears ", CPh, 75, 1980, p. 254-255.

${ }^{73}$ CIC. Att. III, 15, 4 et Lael. 41.

${ }^{74}$ Cic. Tusc. II, 57. Cicéron reconnaît parfois qu'il pleure sur son sort, notamment lors de son exil, mais ne le fait que dans des lettres privées (CIC. Att. III, 10, 2; Fam. XIV, 1, 5). Le fait de s'abstenir totalement des larmes reste la conduite idéale du sage (CIc. Tusc. II, 51).

${ }^{75}$ Sur les termes ludificatio et ludificari, voir PL. Amp. 565; Epid. 373; Poen. 1097; TER. Eun. 645. Sur le rôle de la ludificatio et de la ruse dans la comédie, Dupont, Le Théâtre latin, p. 105 sqq. 
« Je ne sais pas d'autres moyens de me tirer de là honorablement.

Ton affaire est faite, vaurien, si tu te joues encore de moi ici! »

(Ter. Eun. 716-717; trad. Marouzeau).

Le fait que Phédria ait été dupé le rend ridicule, d'autant plus que la tromperie a été partiellement mise en œuvre par l'esclave sur lequel il est censé avoir autorité. Phédria cherche à sauvegarder son honneur en montrant publiquement son indignation, en corrigeant l'eunuque, mais aussi en quittant la scène pour échapper au regard du public: c'est le seul moyen pour lui de s'en tirer honeste. Avoir été berné et susciter le rire va à l'encontre de la conduite attendue de l'homme d'honneur. Le rapport entre ridicule et déshonneur est approfondi théoriquement au I ${ }^{\text {er }}$ siècle par Cicéron, dans les propos qu'il prête à César Strabon dans le De oratore, au cours de son exposé sur la plaisanterie et son usage rhétorique ${ }^{76}$. Les notions de prestige et d'honneur sont convoquées de deux manières dans ce passage, à propos de l'auteur de la plaisanterie et de la cible de cette dernière. César Strabon montre en premier lieu que l'orateur doit faire un bon usage des moqueries afin de ne pas passer pour un bouffon: il doit savoir les modérer et les utiliser à bon escient ${ }^{77}$. Sa maîtrise des mots d'esprit lui permet de conserver toute sa dignitas, essentielle à l'exercice de son art. La dignité de l'orateur n'est donc pas incompatible avec la plaisanterie si cette dernière est contrôlée. S'interrogeant en second lieu sur les moyens d'exciter le rire, César Strabon montre que l'honorabilité est en revanche inconciliable avec le ridicule. Être constitué en objet de rire, c'est se déconsidérer socialement: faire rire aux dépens de son adversaire est, pour l'orateur, un moyen de le briser ${ }^{78}$. La destruction de l'estime opérée par la moquerie naît de la saillie de l'orateur, de la fulgurance de son trait d'esprit, mais aussi de la mise en avant, par la plaisanterie, de traits de la victime qui sont à l'opposé de l'honestum:

[...] grauitas honestis in rebus seuerisque, iocus in turpiculis et quasi deformibus ponitur.

«[...] la pensée grave s'applique aux choses honorables et sérieuses, la plaisanterie à celles qui sont viles et laides.»

(CIc. De or. II, 248).

\footnotetext{
${ }^{76}$ Cic. De or. II, 216-290. César Strabon est considéré comme un maître en matière de iocus (Cic. Brut. 177; Off. I, 133). Sur l'ensemble de ce passage, voir le commentaire au De Oratore de A.D.Leeman, vol.3, p.172-183; A. Michel, Les Rapports de la rhétorique et de la philosophie dans l'auvre de Cicéron. Recherches sur les fondements philosophiques de l'art de persuader, $2^{\mathrm{e}}$ éd., Louvain, Peeters, 2003, p. 271-283; Guérin, Persona. L'Élaboration d'une notion rhétorique au Ier siècle av.J.-C., vol. 2, p. 145-169.

${ }^{77}$ L'orateur doit se distinguer du scurra qui ne sait pas modérer ses saillies ni prendre garde aux circonstances dans lesquelles elles peuvent être faites (Cic. De or. II, 247). On retrouve ici l'idéal de mesure propre à l'honneur et la figure repoussoir du bouffon, employée par Cicéron à propos de Manilius (Clu. 39).

${ }^{78}$ Cic. De or. II, 236: le rire frangit aduersarium.
} 
César Strabon donne du ridicule une définition qui conjoint la turpitude morale et la difformité physique dans la notion de laideur ${ }^{79}$. Ce sont les objets honteux ou hideux qui donnent lieu à la plaisanterie et suscitent donc le rire. Les difformités physiques, les conduites obscènes et les vices moraux forment en effet un sujet de choix du rire romain ${ }^{80}$. À l'inverse, ce qui est honestum ne provoque nullement le iocus mais l'interdit et amène à la grauitas. Le propos de César Strabon formalise ainsi l'exclusion mutuelle de l'honestas et du ridicule et confirme le lien entre sérieux et honneur.

\section{L'EXTÉRIORITÉ DU CODE D'HONNEUR}

Après avoir établi les exigences du code de l'honneur, il nous reste à voir comment ces dernières sont fondées. L'observation des textes fait apparaître que l'obéissance des Romains aux règles de l'honneur ne procède pas d'une intuition de principes absolus indépendants du corps social. Les normes de l'honneur ne sont pas intérieures à chaque individu: elles sont fondées et mises en œuvre de façon extérieure, par une action de la collectivité sur le sujet. L'honestas est une morale hétéronome parce qu'elle est structurée par la présence d'autrui. Trois aspects lui confèrent cette extériorité: son critère, sa motivation et son archétype. Le critère de l'honestas consiste dans l'approbation de la collectivité, ce qui fait que ses normes sont collectivement définies. La motivation de l'honestas, ensuite, réside dans le regard et la présence d'autrui, qui participe donc à la normativité de l'honneur. L'archétype de l'honestas, enfin, s'incarne dans les ancêtres, ce qui fait de la morale de l'honneur une morale mimétique, concentrée sur un modèle extérieur. Ce sont ces trois aspects que nous allons développer.

${ }^{79}$ Sur le sens moral et physique de turpe, voir supra p. 123 et 152 . Cette définition du ridicule a des antécédents aristotéliciens (ARstr. Poet. 1449a où le ridicule est une partie du laid) et sera reprise par Quintilien dans son exposé général sur le rire (QuiNT. IO VI, 3: les causes du rire se situent dans le corps, l'âme ou les caractéristiques extérieures). Sur cette définition, A.P.Conberll, Controlling Laughter: Political Humor in the Late Roman Republic, Princeton, Princeton University Press, 1996, p. 20 sqq. La moquerie contre la laideur physique est socialement acceptable car une difformité signale pour les anciens une faute morale (Ibid., p. 55-57). Sur la difformité comme objet du rire dans l'Antiquité, R. GARLAND, «The Mockery of the Deformed and Disabled in Graeco-Roman Culture», in JäKeL, S. et Timonen, A. (éds.), Laughter down the centuries, vol.I, Turku, Turun Yliopisto, 1994, p.71-84.

${ }^{80}$ On les retrouve de manière récurrente dans l'invective rhétorique et dans la satire. Voir CorbeILl, Controlling Laughter: Political Humor in the Late Roman Republic, p.128-173; Dupont et ÉLoI, L'Érotisme masculin dans la Rome antique, p. 86-87. 


\subsection{Un critère extérieur: la définition de l'honorabilité par la collectivité}

L'extériorité du code d'honneur qu'est l'honestas apparaît de manière particulièrement nette quand on observe le critère fondamental à l'aide duquel un comportement est identifié comme honestus: est ainsi qualifié l'acte qui suscite le jugement approbateur de la collectivité. Ce qui est honestum n'est pas ce qui est conforme à une norme absolue et universelle, comme le bien, mais ce qui est socialement considéré et approuvé ${ }^{81}$. Enfreindre l'honestum, quand ce terme désigne «l'honneur », c'est aller à l'encontre de la dignité sociale et heurter l'opinion publique et non briser les règles d'une éthique rationnellement fondée. C'est provoquer le scandale et détruire son image sociale. Les commandements de l'honestum, comme la décence ou la modération, ne s'imposent que parce qu'ils sont jugés positivement par la société et non en vertu de leur valeur intrinsèque. Dans le Phormion, le vieux Démiphon rapporte des paroles de son frère qui l'a conseillé sur la conduite à tenir vis-à-vis de Phanium, jeune fille que son fils a épousée en cachette. Démiphon avait projeté de briser ce mariage et de remettre Phanium au parasite Phormion mais il est revenu sur cette décision comme il l'explique à Phormion:

DE. : At hic dehortatus est me ne illam tibi darem:

"Nam qui erit rumor populi, inquit, si id feceris?

Olim cum honeste potuit, tum non est data;

Nunc uiduam extrudi turpest.»

"Demiphon: Mais celui-ci m'a dissuadé de te la donner:

'Car quelle sera la rumeur publique, dit-il, si tu fais cela?

Autrefois, quand on pouvait le faire honorablement, on ne la lui a pas donnée;

Ce serait honteux de la pousser dehors à présent sans mari.»

(TER. Phorm. 910-913).

Le frère de Démiphon lui a fait valoir qu'il serait turpe, contraire à l'honneur, de rompre le mariage et de laisser une femme sans mari. Elle aurait pu autrefois vivre honeste aux côtés de Phormion mais cela est désormais impossible. Si Démiphon casse l'union de son fils avec Phanium, cela ne sera pas approuvé par le rumor populi. Ce qui est inhonestum, c'est ce qui suscite la désapprobation de la collectivité. À l'inverse, l'honestas consiste à adopter le comportement que la cité approuve, c'est-à-dire, ici, conserver une épouse légitime. L'honestum

\footnotetext{
${ }^{81}$ L'honneur a été compris ainsi à d'autres époques que celle qui nous intéresse ici. Drévillon et VentuRino (éds.), Vivre et penser l'honneur à l'époque moderne, soulignent qu'au XVII ${ }^{e}$ siècle l'honneur est «l'adéquation du comportement individuel aux règles de la société chrétienne en général, et avec celles de son propre rang social, de sa propre vacation, de son propre sexe, en particulier» (p.12).
} 
n'implique pas d'exécuter un devoir moral mais de respecter les exigences de la collectivité ${ }^{82}$. L'honestas, la conformité au code d'honneur, est un «impératif hérité » qui résulte d'une pression du groupe sur l'individu ${ }^{83}$. Il n'y a de ce fait de véritable action inhonesta, et donc de réel déshonneur, que lorsque les fautes d'un individu sont publiques: l'action déshonorante ne l'est que sous les yeux de la collectivité, seule apte à juger de la conformité à l'honestum ou de la déviance.

\subsection{Une motivation extérieure: le rôle d'autrui dans l'adoption du code d'honneur}

La collectivité exerce également une autre pression sur l'individu car elle est à l'origine de l'adoption de ce code, de deux manières : l'honestas du sujet est mise en branle par le regard d'autrui, d'une part; elle vise l'estime de la collectivité, d'autre part. En premier lieu, autrui joue un rôle déterminant dans l'adoption des règles de l'honneur en raison du regard qu'il porte sur le sujet. L'observation par la collectivité informe la conduite de l'individu avant même qu'une sanction, positive ou négative, ne soit donnée par le groupe. Caton indique dans son Carmen de moribus que l'on peut s'habiller avec le strict nécessaire lorsque l'on se trouve chez soi, à l'abri du regard des autres, mais qu'il faut absolument se vêtir honeste lorsqu'on est au forum, lieu par excellence de la vie publique ${ }^{84}$. De même, un mari se préoccupe plus particulièrement de la conduite de sa femme quand elle se rend dans la rue et qu'elle est visible de tous: c'est dans ces conditions qu'elle doit se comporter honeste ${ }^{85}$. La fréquentation d'un espace socialisé fait peser une contrainte forte sur les individus car c'est là que se joue la disgrâce ou le gain de prestige. Le souci du code de l'honneur se manifeste donc sous le regard du groupe qui joue ainsi un rôle moral important ${ }^{86}$.

En second lieu, si les commandements de l'honestum sont observés par les individus, c'est parce que ces derniers se soucient de préserver leur réputation. Nous avons déjà eu l'occasion de voir que la détention

${ }^{82}$ Comme le dit le frère de Démiphon un peu avant, non satis est tuom te officium fecisse, id si non fama approbat, "il ne suffit pas que tu aies fait ton devoir si la rumeur publique ne t'approuve pas » (Ter. Phorm. 724; trad. Marouzeau).

${ }^{83}$ L'expression est de L. Febvre (FEBvre, Honneur et patrie, p. 71).

${ }^{84}$ CAт. Carmen frg. 2 Sblendorio-Cugusi: Vestiri in foro honeste mos erat, domi quod satis erat; "c'était la coutume de s'habiller de manière décente au forum, et de ne porter à la maison que le nécessaire.»

${ }^{85}$ PL. Merc. 403-406.

${ }^{86}$ Cf. Bourdieu, Trois études, p. 40: «Le point d'honneur est le fondement de la morale propre à un individu qui se saisit toujours sous le regard des autres, qui a besoin du regard des autres pour exister, parce que l'image qu'il forme de lui-même ne saurait être distincte de l'image de soi qui lui est renvoyée par les autres. » L'importance du regard d'autrui se manifeste aussi dans le fonctionnement du pudor (KaSTER, Emotion, Restraint and Community in Ancient Rome, p. 56-61). 
de l'honos contraignait à l'honestas ${ }^{87}$ mais on peut encore préciser le rapport entre les notions de considération et d'honorabilité: la volonté de préserver le prestige et la renommée est à la racine du comportement honorable. Dans la péroraison du Pro C. Rabirio perduellionis reo, Cicéron demande aux juges de permettre à l'accusé de mourir honeste, c'est-à-dire dans sa patrie, près des siens. Une condamnation à l'exil serait en effet, pour reprendre la métaphore de l'orateur, un terrible uolnus famae, une blessure fatale à sa réputation ${ }^{88}$. Mourir honeste consiste à trépasser en préservant son prestige social. Celui qui ne se soucie nullement de sa réputation ne se contraint pas à obéir aux règles de la dignité. Caton déclare à propos de Q. Minucius Thermus:

\footnotetext{
Rumorem, famam flocci fecit intercutibus stupris obstinatus, insignibus flagitiis.

«Il se moque de la rumeur, de l'opinion publique, constant dans ses vilenies cachées, dans ses turpitudes remarquables.»
}

(CAT. frg. VI, 60 ORF).

L'infâme Minucius Thermus plonge dans le vice et la cruauté parce qu'il ne fait aucun cas de la fama. Il ne se soucie pas de sa réputation et donc ne cherche pas à respecter le code qui s'impose à ceux qui veulent la conserver. C'est la recherche du prestige qui motive l'observation du code de l'honneur. Ce dernier ne s'impose pas en raison de la conscience du bien mais par souci de la réaction d'autrui ${ }^{89}$. Comme l'a montré l'analyse sémantique, l'honorabilité est, à Rome, une attitude qui donne droit à l'honos: l'honestas est le chemin de l'honos et perdre la première revient à se voir interdire l'accès au second ${ }^{90}$.

Le rôle joué par le regard d'autrui dans l'adoption de règles de conduite et le fait que l'honestas soit suivie par souci du prestige social semblent caractériser Rome comme une "shame culture», une culture de la honte ${ }^{91}$. Ce concept sociologique, qui va de pair avec celui de "guilt culture», culture de la culpabilité, permet de caractériser la morale qui régit une société. Les deux notions ont été rendues célèbres par R. Benedict, dans son étude du Japon du milieu du $\mathrm{XX}^{\mathrm{e}}$ siècle, et par E.R.Dodds, qui les a appliquées à la Grèce homérique

\footnotetext{
${ }^{87}$ Voir p. 383-385.
}

${ }^{88}$ Cic. Rab. Perd. 36-37.

${ }^{89}$ Le fonctionnement du code d'honneur est comparable à celui de l'étiquette dans les sociétés de cour. Le respect de l'étiquette par les courtisans s'explique par la volonté de s'assurer "dans la compétition et sous une pression permanente, des chances de statut et de prestige par un comportement approprié» (Elias, La Société de cour, p. 82).

${ }^{90}$ Voir supra p. 169 sqq.

${ }^{91}$ J. E. Lendon applique ce qualificatif à Rome (LENDon, Empire of Honour, p. 41). 
et archaïque ${ }^{92}$. Pour R. Benedict, le Japon est une culture de la honte, ce qui le différencie des sociétés occidentales qui sont des cultures de la culpabilité, car l'action y est gouvernée par le souci de l'estime de l'entourage et par des sanctions extérieures: la collectivité joue un rôle normatif essentiel. Dans un tout autre contexte, E. R. Dodds a avancé que la Grèce homérique était une culture de la honte et se distinguait de la Grèce archaïque, culture de la culpabilité. Les héros vivent dans un monde qui ignore le remords et règlent leur comportement à l'aide de l'aỉôsc, leur sens de l'honneur: ils redoutent de perdre la face devant leurs pairs. Le fait que l'adoption d'une conduite morale soit motivée par la peur du déshonneur et que l'honestas soit définie en outre par le groupe semble tirer la morale romaine du côté de la shame culture. L'application du qualificatif de "culture de la honte» à Rome est-elle cependant véritablement appropriée? La notion permet de synthétiser certains éléments de l'honestas et suggère d'intéressants rapprochements avec d'autres cultures mais son intérêt épistémologique nous paraît limité ${ }^{93}$. Partir de l'importance que jouent dans une civilisation la honte et le sens de l'honneur pour labelliser cette dernière dans sa totalité comme "culture de la honte» nous paraît pour le moins réducteur. La normativité, d'abord, s'exprime dans d'autres espaces que celui de l'honneur: elle est assurée par différentes contraintes, juridiques et civiques, entre autres, et non par la seule pression du groupe social ${ }^{94}$. Ensuite, la distinction trop tranchée entre "culture de la honte» et "culture de la culpabilité » peine à rendre compte de la façon dont contrainte de la collectivité et conscience du sujet se mêlent pour orienter la conduite. Il y a, en premier lieu, intériorisation des normes extérieures: il est significatif qu'avant la bataille de Lutèce Labiénus exhorte les soldats à se conduire comme si César lui-même était présent et les observait ${ }^{95}$. Le regard du chef a une fonction régulatrice mais il est intériorisé par les légionnaires et opère alors même que César est absent. La distinction établie par les concepts de R. Benedict et E. R. Dodds entre honte extérieure et culpabilité intérieure est donc trop tranchée pour nous. En second lieu, on voit apparaître, au dernier siècle de la République, une morale qui se passe de l'extériorité et de la collectivité et trouve son fondement dans l'intériorité: l'honestas est directement affectée par cette évolution

${ }^{92}$ R. Benedict, Le Chrysanthème et le sabre, Arles, Picquier, 1995, notamment p. 253 sqq. ; E. R. DodDs, Les Grecs et l'irrationnel, Paris, Flammarion, 1977, p. 11-70.

${ }^{93}$ L'usage que fait Dodds de ces catégories pour le monde grec a été critiqué par CAIRns, Aidôs (p.27 sqq.) et par J.T.Hooker, "Homeric Society: A Shame-Culture?", $G \& R, 34$ (2), 1987, p. 121-125.

${ }^{94}$ Voir Ducos, Les Romains et la loi, p. 383-425 sur les différentes manières d'amener les citoyens à l'obéissance (crainte de l'infamie, sens de l'honneur, éducation, persuasion et obéissance spontanée).

${ }^{95}$ CAEs. BG VII, 62, 2. 
dont les débuts sont visibles chez Lucilius ${ }^{96}$. Cela ne signifie pas pour autant que la honte disparaisse et perde toute fonction régulatrice: il y a coexistence des deux systèmes de contrôle, intérieur et extérieur ${ }^{97}$. La notion sociologique de R. Benedict, si elle était appliquée à Rome, écraserait le travail réflexif et philosophique menée sur l'honestas par les Romains. Caractériser Rome comme shame culture nous paraît donc charrier plus d'inconvénients que d'avantages.

\subsection{Un archétype extérieur: les ancêtres}

L'extériorité de l'honneur réside enfin dans la manière dont les normes de l'honestum sont incarnées et mises en pratique. L'honestas est en effet une morale dont les exigences sont illustrées par un archétype qui sert de point de référence. Par conséquent, la satisfaction des exigences de l'honneur passe par l'imitation de ce modèle extérieur, ce qui fait de l'honestas une morale mimétique. Les règles de l'honorabilité sont présentées par le recours à des exempla et non à des préceptes généraux et abstraits.

\subsubsection{L'archétype de l'honestas}

Les historiens et anthropologues ont observé que les cultures au sein desquelles existe un code d'honneur se dotent d'une figure de référence qui en rassemble tous les traits. Le gentleman, le samurai ou l'hidalgo sont de ces archétypes qui cristallisent, dans la culture à laquelle ils appartiennent, les idéaux de l'honneur ${ }^{98}$. On rencontre aussi à Rome un archétype de l'honneur, incarné dans les maiores, les ancêtres. Il s'agit d'un modèle un peu différent des types employés par les autres cultures car il a la particularité d'être collectif: les ancêtres ne sont pas une figure individuelle mais un ensemble de personnages historiques. Il s'agit cependant bien d'un archétype unique car, malgré leur nombre, les maiores détiennent des qualités récurrentes et forment un tout. La manière dont ils incarnent l'honestas apparaît dans le Pro Roscio Amerino, lorsque Cicéron défend le fait que son

${ }^{96}$ Voir le chapitre 16.

97 On retrouve, même à l'ère chrétienne, le poids du regard d'autrui sur l'action de l'individu, alors que les notions de culpabilité et de faute ont été considérablement développées par le christianisme (L.Ciccolini, "Honte et conversion chez Tertullien et Cyprien », in Alexandre, R., Guérin, C. et Jасотот, M. (éds.), Rubor et pudor. Vivre et penser la honte à Rome, Paris, Éditions rue d'Ulm, 2012 et ELFASsI, «De la honte classique à la honte chrétienne? Quelques réflexions d'après l'œuvre d'Isidore de Séville », p. 99-117).

${ }^{98}$ Tolosana, «The Ever-Changing Faces of Honour» ; PERISTIAny (éd.), Honour and Shame, p. 10. 
client vive à la campagne en rappelant que ce genre de vie était celui d'illustres Romains:

Etenim qui praeesse agro colendo flagitium putes, profecto illum Atilium, quem sua manu spargentem semen qui missi erant conuenerunt, hominem turpissimum et inhonestissimum iudicares.

«En effet, puisque tu penses que c'est un crime déshonorant de diriger une exploitation agricole, tu aurais sans doute jugé totalement infâme et méprisable l'illustre Atilius, que des légats trouvèrent occupé à semer de sa propre main. »

(Cic. Rosc. Amer. 50).

Atilius, qui fait partie des maiores, est à l'opposé d'un inhonestissimus: ses remarquables qualités morales font de lui un modèle d'honneur. Par conséquent, on ne peut blâmer Roscius d'imiter par son mode de vie rustique une figure idéale et admirée.

Les différents impératifs de l'honestas sont tous des traits typiques des ancêtres. La modération, par exemple, qui est un commandement de l'honestum, notamment en matière de dépenses, est une caractéristique des mœurs ancestrales. Les textes décrivant les maiores comme des ennemis du luxe, vivant humblement, mangeant dans de la vaisselle de terre et couchant à la dure, sont légion. On le voit par exemple dans une controverse de Sénèque le Rhéteur:

Hoc animo scio nostros fuisse maiores, hoc illum Aelium Tuberonem, cuius paupertas uirtus fuit, hoc Fabricium Samnitium non accipientem munera, hoc ceteros patres nostros, quos apud aratra ipsa mirantes pecora sua circumstetere lictores.

«Je sais que tels étaient les sentiments de nos ancêtres, de l'illustre Aelius Tubéron, dont la pauvreté fut une vertu, de Fabricius qui refusa les cadeaux des Samnites, de tous nos autres ancêtres qui étaient à la charrue en train de surveiller leur bétail lorsqu'ils furent entourés de licteurs. »

(Sen. Rhet. Contr. II, 1, 8).

Le texte, qui développe le thème de l'inanité des richesses, convoque plusieurs maiores dont la simplicité et la frugalité étaient proverbiales: Aelius Tubéron, stoïcien, ami de Tibérius Gracchus, était connu pour son modeste mobilier et Cicéron déclare que son discours était aussi durus, incultus et horridus que sa personne ${ }^{99}$; Fabricius, consul en 282 et 278, vainqueur des Samnites, des Bruttiens et des Lucaniens, était célèbre par sa pauvreté et son austérité ${ }^{100}$; enfin, Cincinnatus, le

${ }^{99}$ SEn. Epist. 98, 13; Cic. Brut. 117.

${ }^{100}$ Censeur, il avait exclu un ancien consul du sénat pour avoir possédé une quantité excessive de vaisselle d'argent; il avait également refusé les cadeaux de Pyrrhus. Sur C. Fabricius Luscinus, C. Berrendonner, «La formation de la tradition sur M'. Curius Dentatus et C. Fabricius Luscinus: un homme nouveau peut-il être un grand homme? », 
dictator ab aratro, symbole de la rusticité et de l'humble labeur, qui n'est pas nommé tant suffit à l'évoquer l'image des licteurs se présentant alors qu'il laboure son champ pour lui annoncer qu'il est nommé dictateur. La figure des ancêtres est évoquée spontanément pour illustrer ces vertus que sont la frugalité et l'humilité et, bien qu'elle soit devenue un lieu commun rhétorique, elle sert encore d'argument d'autorité. Les autres commandements de l'honestum recoupent aussi des qualités ancestrales: la fides est illustrée de manière remarquable par Régulus, la décence et la pudeur par M.Claudius Marcellus ou des figures féminines comme Lucrèce et Virginie, l'impassibilité et le sérieux par la rigueur d'un T. Manlius Torquatus ${ }^{101}$. Vivre honeste, c'est donc vivre dans la tradition morale romaine. Le mos maiorum, par sa fonction régulatrice, sous-tend la normativité de l'honestas ${ }^{102}$.

\subsubsection{Une morale mimétique}

Si les ancêtres constituent un archétype de l'honestum, cela ne signifie pas seulement qu'ils servent d'illustrations aux commandements de l'honneur. Les maiores sont également des modèles qu'il convient d'imiter pour être soi-même honestus. L'honestas consiste donc, dans son fonctionnement idéal, à reproduire des types de conduite ancestraux. Un texte de Plaute nous permet d'observer le fonctionnement attendu de ce procédé et de voir, simultanément, qu'il peut être tourné en dérision. Pleusiclès vient de se déguiser afin de se faire passer pour le capitaine du bateau sur lequel doit embarquer Philocomasie, jeune femme dont il est épris:

\footnotetext{
Alium alio pacto propter amorem ni sciam

Fecisse multa nequiter, uerear magis

Me amoris causa $<$ huc $>$ hoc ornatu incedere.

Verum quom multos multa admisse acceperim

Inhonesta propter amorem atque aliena a bonis -

Mitto iam, ut occidi Achilles ciuis passus est...
}

«Si je ne savais toutes les fourberies que d'autres, chacun à leur manière,
Ont faites à cause de l'amour, j'aurais plus de scrupules
À me présenter dans cette tenue que l'amour me fait endosser.
Mais puisque j'ai entendu dire que bien des gens s'étaient permis bien des choses

in Coudry, M.et Späth, T.(éds.), L'Invention des grands hommes de la Rome ancienne, Paris, De Boccard, 2001, p.97-116 et A.VIgourT, "M'. Curius Dentatus et C.Fabricius Luscinus: les grands hommes ne sont pas exceptionnels», in CoudrY, M. et Späth, T. (éds.), L'Invention des grands hommes de la Rome ancienne, Paris, De Boccard, 2001, p. 117-129.

${ }^{101}$ Sur ces différents personnages et la qualité morale qu'ils illustrent, LitchFIELD, «National Exempla Virtutis in Roman Literature».

${ }^{102}$ Sur l'aspect contraignant du mos maiorum, Rech, Mos maiorum, p. 12 et BetTinI, «Mos, mores und mos maiorum», p. 322. 
Contraires à l'honneur et étrangères à la vertu à cause de l'amour -

Sans parler de la manière dont Achille a laissé tuer ses concitoyens... »

(PL. Mil. 1284-1289).

Sur le point de mettre en œuvre la supercherie qui a été préparée, Pleusiclès ressent des scrupules: il est très peu convenable, en effet, de porter une tenue ridicule et de tromper les autres pour arriver à ses fins. Son hésitation est cependant levée par la considération des actions inhonestae que d'autres, et non des moindres, ont accomplies avant lui. Achille, notamment, s'est comporté de manière contraire à l'honneur à cause de son amour puisqu'il a laissé massacrer les Grecs en se retirant sous sa tente après avoir été frustré de Briséis par Agamemnon. Pleusiclès oriente donc sa conduite en se référant à des précédents exemplaires qu'il choisit d'imiter. Le comique vient du fait qu'il utilise comme modèles des auteurs d'inhonesta, et non pas des exemples d'honorabilité, comme cela devrait être le cas. Le jeune homme se réfère à un individu remarquable, Achille, mais pour imiter son comportement le moins prestigieux. Le texte montre en négatif que l'honestas consiste à prendre comme modèles des individus qui se distinguent par leur excellence morale. Ce mimétisme moral est à la base du système d'éducation de Déméa, le senex traditionnel et rigoureux des Adelphes de Térence: Déméa préconise d'agir en regardant les autres tanquam in speculum, "comme dans un miroir ${ }^{103}$. Un tel mimétisme de l'honneur prend une importance toute particulière à Rome, pour deux raisons. D'abord parce que l'archétype de l'honneur, le groupe des maiores, est, indépendamment du fonctionnement du code d'honneur, un point traditionnel de référence. La prédication morale, l'invective politique, l'éloge ou d'autres genres littéraires prennent régulièrement pour modèle les ancêtres dès qu'il est question des mours au sens large du terme ${ }^{104}$. Les rituels religieux, la pratique politique, l'exercice militaire gagnent tous à être menés more maiorum. La tradition romaine recourt plus volontiers aux exempla qu'aux praecepta, à l'image frappante plutôt qu'à la formulation discursive de normes. Ensuite, la morale de l'honneur est fortement mimétique en raison du rôle culturel de l'imitation à Rome. Dans le domaine des mœurs comme dans celui de l'éducation, avec la pratique du tirocinium fori, de la littérature, marquée par l'intertextualité avec les auteurs hellènes, ou de la philosophie, où s'opèrent des transferts conceptuels entre les mondes grec et romain, les Romains ont en effet largement recouru au mimétisme pour élaborer leur culture et leur

${ }^{103}$ Ter. $A d$. 415. Le père d'Horace usait de la même pédagogie de l'exemple moral que Déméa, si l'on en croit le poète (Hor. Sat. I, 4, 105-114).

${ }^{104}$ Edwards, The Politics of Immorality, p. 1-4. 
pensée propres ${ }^{105}$. La critique est à présent sortie du débat sans issue, initié par la Quellenforschung, entre ceux qui tenaient les Romains pour de serviles imitateurs et ceux qui cherchaient à toute force leur originalité, notamment en matière littéraire, et l'importance du phénomène a été évaluée avec plus de justesse ${ }^{106}$. L'imitation romaine, qu'elle porte sur les ancêtres ou sur les Grecs, ne consiste jamais à copier mais à recourir à des modèles qui contribuent à la formation de l'individu, de son goût et de son esprit. Le Romain cherche à égaler un illustre prédécesseur et non à le singer. C'est cette émulation mimétique que l'on retrouve au sein de l'honestas. Il y a donc une pression du modèle ancestral sur les individus, qui sont amenés à s'y conformer pour ne pas se déshonorer. Ce n'est pas l'éclat particulier de l'honestas qui pousse les Romains à obéir à ses commandements mais le poids des ancêtres qui l'incarnent.

\subsubsection{Une morale traditionnelle et identitaire}

Le fait que le mos maiorum joue un rôle dans le fonctionnement du code de l'honneur a deux conséquences sur la nature de l'honestas. En premier lieu, la morale de l'honestas est fondamentalement traditionnelle. Elle intègre et élève au rang de normes des comportements qui relèvent du mos, c'est-à-dire de la coutume, dont l'origine n'est pas nettement perçue. Les règles de ce code d'honneur valent en somme par leur ancienneté et par le consensus qui les entoure. Ce traditionalisme de l'honestas ne va pas également sans un certain conservatisme. Les modèles de l'honorabilité sont en effet localisés dans le passé. L'observation des mœurs ancestrales et leur reproduction sont donc valorisées au détriment des pratiques nouvelles, regardées avec suspicion: l'usage et l'habitude sont honorables, et non l'innovation. Cela ne signifie pas que tous les Romains se soient abîmés dans une contemplation des temps révolus et aient méprisé leur époque, mais qu'ils règlent leur conduite présente à l'aide du passé.

En second lieu, l'ancrage de l'honestas sur le mos maiorum fait de la morale de l'honneur un code de conduite identitaire, perçu comme singulièrement romain. Les maiores sont des modèles dont l'une des fonctions est d'établir l'identité romaine et de construire un sentiment

${ }^{105}$ Sur le tirocinium fori, DAVID, Le Patronat judiciaire, p. 321 sqq. Sur l'imitation littéraire, la bibliographie est immense; voir en dernier lieu A.THILL, Alter ab illo. Recherches sur l'imitation dans la poésie personnelle à l'époque augustéenne, Paris, Les Belles lettres, 1979.

${ }^{106}$ Pour un bilan de ce débat et des travaux érudits menés dans un sens ou dans l'autre, THILL, Alter ab illo, notamment p.30-35 et M. PIERRE, «Rome dans la balance. La poésie augustéenne imite-t-elle la poésie grecque? », in Dupont, F. et Valette-Cagnac, E. (éds.), Façons de parler grec à Rome, Paris, Belin, 2005, p.229-254 pour une lecture critique de la notion, à visée synthétique, d' «imitation créatrice». 
d'appartenance à une communauté: Fabricius, Cincinnatus, Caton sont des types moraux autour desquels la cité se rassemble ${ }^{107}$. Le fait de les mobiliser dans la définition de l'honestas confère donc à cette dernière un rôle identitaire: faire preuve de fides, c'est reproduire la conduite ancestrale et imiter, entre autres, Régulus; mais c'est aussi répondre à une exigence constitutive de l'appartenance à la romanité. La uirtus, le pudor, la grauitas imposés par l'honestum sont autant de traits que les Romains se représentent comme caractéristiques d'euxmêmes. Une pratique honesta est conforme aux attentes de la collectivité et signale aussi l'appartenance à cette dernière. Pour défendre Caelius, Cicéron évoque dans son plaidoyer les honestae artes auxquels il s'est formé dans sa jeunesse; ces artes, mentionnées également dans le Brutus, comprennent la lecture des poètes, des orateurs et l'étude du droit ${ }^{108}$. Or s'exercer à l'éloquence et travailler le droit sont des activités perçues comme singulièrement romaines, comme une composante essentielle du tirocinium fori. Ce sont des activités honorables parce qu'elles ne heurtent pas la représentation que les Romains se font d'eux-mêmes. Suivre les exigences de l'honestum, c'est donc se présenter comme romain, d'autant plus que les comportements déviants rejetés par l'homme d'honneur, comme la débauche dans les festins ou l'intempérance dans les plaisirs, sont constitutifs de la mollitia perçue comme une tare proprement grecque ${ }^{109}$.

\section{LA RELATIVITÉ DU CODE D’HONNEUR}

La mise en avant de la coïncidence entre les exigences de l'honestas et les normes du mos maiorum nous amène à une nouvelle interrogation. Comme les règles du mos maiorum ont surtout une importance pour les grandes familles romaines qui comptent d'illustres ancêtres parmi leurs ascendants ${ }^{110}$, on peut se demander si les exigences de l'honestas ne s'appliquent pas surtout, voire exclusivement, à ces dernières. L'honestas n'est-elle pas, comme bien des codes d'honneur, particulière à un groupe de la société, à savoir l'aristocratie? Nous interrogerons dans ce chapitre la relativité des exigences de l'honestas et leur capacité à s'étendre à l'ensemble de la population. L'investigation doit porter

${ }^{107}$ Voir par exemple M. JАсотот, «La représentation de Cincinnatus chez Tite-Live: figure morale et mythe républicain ", in Blandenet, M., Chillet, C. et Courrier, C. (éds.), Figures de l'identité. Naissance et destin des modèles communautaires dans le monde romain, Lyon, ENS Éditions, 2011, p. 71-85.

${ }^{108}$ Cic. Cael. 9 ; Brut. 213-214.

${ }^{109}$ Sur les atours grecs de la vie de plaisir, Edwards, The Politics of Immorality, p. 92-93; P. Cordier, «Les habits grecs du baigneur romain », in Dupont, F. et ValetteCagnac, E. (éds.), Façons de parler grec à Rome, Paris, Belin, 2005, p. 81-102.

${ }^{110}$ Blösel, "Von der Familientradition zum Nobilitätsethos », p. 35. 
sur deux aspects. L'honestas peut être relative quant à son existence: s'agit-il d'un code qui ne vaut que pour une élite et n'est mis en œuvre que par elle ou bien ses exigences s'appliquent-elles à tous? L'honestas peut aussi être relative du point de vue de ses commandements: à supposer qu'elles valent pour tous, les obligations de l'honneur sontelles identiques pour chacun ou variables selon l'identité sociale? Y a-t-il un seul ou plusieurs codes d'honneur?

\subsection{La relativité de l'existence de l'honestas}

Nous tâcherons de voir en premier lieu si l'honestas est un code de comportement propre à un groupe restreint ou bien s'il est partagé par tous.

\subsubsection{La nature aristocratique de l'honestas}

Plusieurs éléments semblent faire de l'honestas une morale proprement aristocratique. Ses règles, d'abord, reflètent des exigences propres à l'aristocratie romaine, ce qui laisse à penser qu'elles ont été constituées par et pour elle. Le courage militaire et le service de la collectivité, par exemple, sont des attitudes valorisées par la noblesse. Il en va de même de la gravité ou du pudor, qualités morales illustrées surtout par des maiores qui appartenaient à l'aristocratie. Ces qualités, nous l'avons vu, ont une valeur identitaire, mais on peut se demander si cette dernière ne vaut pas davantage pour l'élite que pour la cité dans son ensemble. La nouvelle noblesse patricio-plébéienne qui émerge à partir de la fin du $\mathrm{IV}^{\mathrm{e}}$ siècle avant J.-C. a ressenti le besoin de se définir à partir d'autres critères que celui de la naissance: elle a mis en avant la prépondérance des honores et le service de la res publica mais aussi diverses qualités morales (uirtus, fides, etc.) incarnées dans des modèles ancestraux exemplaires et organisées au sein d'un code de conduite dont l'honestum est la colonne vertébrale ${ }^{111}$. Les diverses règles de l'honestas et leur élévation au rang de principes se fondent sur ce processus de légitimation de la nouvelle noblesse et lui sont donc plus particulièrement liées. L'obéissance aux règles de l'honneur justifie sur le terrain moral l'appartenance à la noblesse.

En outre, l'obligation de se conformer aux règles de l'honneur dépend d'un facteur important, le statut social. Le code d'honneur est en effet contraignant pour ceux qui bénéficient d'un rang élevé au sein de la société: il vaut, ici encore, surtout pour l'élite romaine. Nous avons déjà observé que l'honestas était suscitée par la possession de l'honos: le prestige s'accompagne de contraintes morales strictes qui

111 HölKeskamp, Die Entstehung der Nobilität, p. 208 sqq.; BlöSEL, "Von der Familientradition zum Nobilitätsethos », p.46-53. 
orientent la conduite des individus in honore ${ }^{112}$. De manière plus générale, avoir un statut social élevé impose, même si l'on ne jouit pas de l'honos, de suivre les règles de l'honestas. Les chevaliers ou les sénateurs, parce qu'ils appartiennent à un ordo éminent, ne peuvent chercher à gagner de l'argent par tous les moyens et doivent écarter les gains déshonorants pour se conformer à l'honestum et ne pas déchoir moralement et socialement ${ }^{113}$. C'est pour des personnages d'un certain rang social que l'on s'interroge sur les exigences de l'honorabilité. En 49, Cicéron a suivi Pompée lors de son départ de Rome mais sa femme et sa fille sont restées dans l'Vrbs. Il écrit à Atticus:

De mulieribus nostris, in quibus est tua soror, quaeso uideas ut satis honestum nobis sit eas Romae esse cum ceterae illa dignitate discesserint.

«À propos de nos femmes, parmi lesquelles se trouve ta sœur, je te prie de considérer la situation: comment serait-il honorable pour nous qu'elles restassent à Rome alors que sont parties toutes les autres femmes de leur rang? »

(CIc. Att. VII, 14, 3).

Cicéron se demande s'il est conforme à l'honneur, et notamment au sien (honestum nobis), que son épouse et sa fille soient restées à Rome. Il se trouve en effet que les autres femmes d'une dignitas semblable, c'est-à-dire appartenant à des familles consulaires, ont quitté la ville. Le fait d'avoir un rang social élevé impose donc des exigences de l'honestum qui ne s'appliquent pas à ceux qui sont plus humbles. La dignitas, dont nous avons observé à plusieurs reprises le lien avec l'honos ${ }^{114}$, est donc aussi connectée à l'honestas : elle conduit à faire preuve d'une attention particulière aux règles de l'honneur. De la dignitas à l'honestas la conséquence est directe car la conduite honorable permet, comme le montre l'allusion de Cicéron aux autres femmes de sénateurs, l'intégration dans le groupe social des aristocrates, dont il faut partager les normes pour être membre. C'est l'appartenance à une catégorie privilégiée de la cité qui suscite une sensibilité aux règles de l'honneur et leur donne une force contraignante ${ }^{115}$.

L'association entre le haut statut social et l'honorabilité est si forte qu'il est très difficile d'amener des membres de l'élite à des pratiques jugées peu honorables. Cicéron en a fait l'expérience à propos de l'enseignement de la rhétorique. L'éloquence n'est pas une activité déshonorante, bien au contraire, mais vouloir enseigner la technique

112 Sur les contraintes morales de l'honos, voir supra p. 383-385.

113 Cic. Parad. VI, 43.

${ }^{114}$ Supra p. 302 sqq. et p. 361 sqq.

${ }^{115}$ Cf. dans la comédie l'inquiétude que manifestent les personnages féminins qui mènent une vie indigna genere, indignes de leur extraction familiale et sociale, par exemple quand des jeunes filles de bonne naissance sont contraintes de faire le métier de courtisanes (PL. Poen. 1140 et 1186). 
oratoire à ses contemporains n'est pas compatible avec la dignitas des hommes publics. Dans le De oratore, Crassus fustige les professeurs d'éloquence trop confiants en leur savoir et ignorants des réalités romaines, tout comme leurs écoles qualifiées de ludus impudentiae ${ }^{116}$. Quelques années après, dans l'Orator, Cicéron adopte pourtant la posture d'un enseignant de rhétorique mais il est obligé de récuser l'idée qu'il est honteux pour une personne de sa dignitas d'agir ainsi:

Nam si uitiosum est dicere ornate, pellatur omnino e ciuitate eloquentia; sin ea non modo eos ornat penes quos est, sed etiam iuuat uniuersam rem publicam, cur aut discere turpe est quod scire honestum est aut quod nosse pulcherrimum est id non gloriosum est docere?

«Si c'est un vice de parler avec ornement, qu'on chasse complètement l'éloquence de la cité; mais si elle est non seulement un ornement pour ceux chez qui on la trouve, mais une assistance pour la cité tout entière, pourquoi serait-il honteux d'apprendre ce qu'il est honorable de savoir ou pourquoi ce qu'il est très beau de connaître n'est-il pas glorieux de l'enseigner?»

(Cic. Orat. 142 ; trad. Yon).

L'opinion commune considère qu'il est acceptable de connaître l'art de parler mais qu'il n'est pas honestum de l'enseigner. La raison de ce rejet est explicitée quelques lignes plus loin: dignitatem docere non habet, "l'enseignement n'a pas de dignité » ${ }^{117}$. Les interdits de l'honestum s'appliquent donc ici encore pour des raisons de dignitas. Cicéron sait qu'en tant que consulaire on n'attend pas de lui qu'il prenne la posture, moralement suspecte, d'un maître d'éloquence. Cicéron conteste un tel état de fait et met en avant les contradictions de ce mode de pensée traditionnel: comment serait-il honorable de connaître une discipline mais honteux de l'enseigner? Cicéron prend la tradition à contrepied et tâche de refonder rationnellement les critères de l'honestas en la détachant du statut social. On observe donc également, avec cet exemple de la rhétorique, qu'il y a une plasticité de l'honestas car des comportements jugés moralement répréhensibles peuvent parvenir à y être intégrés progressivement.

\subsubsection{Le souci partagé de l'honestum}

La signification particulière de l'honestas pour l'aristocratie romaine ne nous paraît pas cependant impliquer l'inexistence d'une attention aux normes de l'honorabilité dans des catégories sociales plus modestes. Ce qui différencie l'élite romaine des autres individus dans le domaine de l'honneur n'est pas l'existence du code mais son prix à leurs yeux. L'honos et la dignitas qui caractérisent l'aristocratie

${ }^{116}$ Cic. De or. III, 94.

${ }^{117}$ Cic. Orat. 144. 
ne sont pas des conditions à l'existence de la conduite honorable mais des facteurs de contrainte supplémentaires qui rendent encore plus impérieuse l'adoption des normes de l'honestum. La singularité de l'honneur des Romains de haut rang réside dans sa grande force d'obligation mais ne préjuge pas de l'existence ou de l'absence de l'honestas chez des personnes plus modestes; ces dernières, en revanche, subissent une pression beaucoup moins importante et sont moins sujettes à l'observation de la collectivité. La situation est assez similaire à ce qui se passe lors de l'examen des mœurs mené par les censeurs: les sénateurs et les chevaliers font l'objet d'une surveillance toute particulière et nos sources s'attardent sur les sanctions qui leur sont infligées mais tous les citoyens subissaient cet examen moral. Le contrôle des mœurs s'exerce sur l'ensemble de la cité, en s’appliquant de façon plus pointilleuse aux ordres les plus élevés de l'État ${ }^{118}$. Mais on peut être honestus sans appartenir à l'aristocratie: les honesti ne forment pas encore à la période qui nous intéresse un groupe au statut juridique précis. Ce n'est que vers la fin du $\mathrm{II}^{\mathrm{e}}$ siècle après J.-C. que se constitue la catégorie des honestiores dans laquelle sont inclus sénateurs, chevaliers, décurions et certains vétérans ${ }^{119}$. À faute égale, ces personnes subissent alors, lorsqu'elles sont condamnées en justice, une punition moins sévère que les humiliores.

La détention de l'honos n'est pas non plus une condition sine qua non de la conscience de l'honestum et de ses exigences. Les commandements de l'honneur sont également perçus par des personnes dépourvues de tout prestige social et la crainte de l'ignominie est répandue au-delà des individus in honore. Un personnage aussi peu considéré que le parasite de comédie est tout à fait à même de juger du caractère honestus des individus qui l'entourent ${ }^{120}$. La conscience de ce qui est honorable n'est donc pas réservée à l'élite. Les textes de l'époque républicaine qui évoquent l'honestas le font certes le plus souvent à propos des aristocrates, mais c'est parce que ces derniers constituent l'objet le plus fréquent du regard des orateurs, historiens et philosophes qui constituent l'essentiel de notre corpus. Les épitaphes nous permettent en revanche d'observer autre chose que l'élite romaine. Or le souci de l'honorabilité apparaît aussi dans ces textes épigraphiques, même quand ils concernent des Romains de condition modeste. Le thème de la mort honorable, la mors honesta, abondamment développé par les

118 Astin, «Regimen morum».

${ }^{119}$ CARDAScIA, "L'apparition dans le droit des classes d'honestiores et d'humiliores »; RILINGER, Humiliores - Honestiores. Zu einer sozialen Dichotomie im Strafrecht der römischen Kaiserzeit.

${ }^{120}$ PL. Cap. 99. 
nobiles ${ }^{121}$, est présent également dans une épitaphe datée du ${ }^{\text {er }}$ siècle avant J.-C.:

C(aius) Numitorius | Asclepiades | Mummia L(ucii) l(iberta) | Zosima. | Heis sunt duo $\mid$ concordes $\mid$ famaque bona | exsituq(ue) hones(to). | Felixs.

"Gaius Numitorius Asclepiades et Mummia Zosima, affranchie de Lucius. Ils sont en harmonie, ont bonne réputation et connurent une fin honorable. Heureux. »

$\left(C I L \mathrm{I}^{2}, 1347\right)$.

Le cognomen porté par Numitorius Asclepiades trahit une origine grecque servile: il s'agit sans doute d'un affranchi, ce qui est aussi le statut de sa compagne. Or ce couple d'affranchis a pris soin de souligner sa bonne réputation et son honneur: ils ont bénéficié de leur vivant d'une fama bona et leur fin a été honesta. D'autres épitaphes du I ${ }^{\text {er }}$ siècle mentionnent que le défunt, de condition modeste, a vécu honeste $^{122}$. L'importance attachée à la renommée et à la dignité dans la conduite traverse donc les différentes couches de la population. Néanmoins, cet attachement à l'honneur provient probablement, par contagion, des représentations aristocratiques, surtout dans le cas des affranchis qui ont pu être influencés en la matière par leurs anciens maîtres. Les règles de l'honneur se retrouvent hors de l'élite, dans des catégories sociales qui en imitent les représentations morales ${ }^{123}$.

\subsection{La relativité des commandements de l'honestas}

Ces différents éléments nous permettent de conclure à la présence d'une conscience partagée de l'honestum. En revanche, le fait que la conscience de l'honneur ait une certaine universalité n'implique pas l'uniformité des commandements de l'honneur: ce qui est honorable pour une catégorie sociale peut l'être moins pour une autre. Il y a une fluctuation des obligations de l'honestas.

${ }^{121}$ Voir supra p. 472.

${ }^{122}$ Épitaphe de C. Utius $\left(C I L \mathrm{I}^{2}, 1761\right)$ et inscription de Massa d'Albe $\left(C I L \mathrm{I}^{2}, 1822\right)$.

${ }^{123}$ Flaig, « Keine Performanz ohne Norm - keine Norm ohne Wert. Das Problem der zwingenden Gesten in der römischen Politik», p. 219. Ce procédé est sensible également dans l'iconographie des affranchis et des nouveaux citoyens: ces derniers choisissent, quand ils se font représenter, des portraits réalistes qui soulignent leur âge et leur sérieux, signe qu'ils ont adopté les valeurs de l'aristocratie comme la grauitas: ils se conforment au mode de représentation de l'élite romaine pour montrer leur intégration dans la romanité (P.ZANKER, "Grabreliefs römischer Freigelassener», JDAI, 90, 1975, p. 267-315). 


\subsubsection{Le clivage du statut social}

La principale variation des exigences de l'honneur est liée au statut social des individus. L'imitation des règles de l'honneur de l'aristocratie par les autres membres de la société n'est en effet que partielle. Un comportement honorable pour un individu modeste, et donc conforme à sa représentation de l'honestum, peut être inapproprié pour un membre de l'élite. Le code d'honneur de l'aristocratie se révèle donc plus exigeant que celui des autres acteurs sociaux. Cela est patent dans le texte d'Ennius que nous citions à propos de l'interdit pesant sur les larmes. Agamemnon y observe qu'un roi ne peut en aucun cas pleurer honeste mais que cela est permis à la plèbe ${ }^{124}$. Plus on descend dans la hiérarchie sociale, moins le code d'honneur est contraignant. Il en va de même dans le contexte de la fin du $\mathrm{II}^{\mathrm{e}}$ siècle, si l'on en croit Salluste. L'historien rapporte que Marius a engagé, chose sans précédent, des citoyens qui ne possédaient pas la qualification censitaire requise pour servir dans la légion, ouvrant ainsi l'armée aux proletarii. D'aucuns jugent que cette réforme ne vise qu'à attirer des partisans dévoués:

[...] homini potentiam quaerenti egentissumus quisque opportunissumus, cui neque sua cara, quippe quae nulla sunt, et omnia cum pretio honesta uidentur.

«[...] pour un homme en quête du pouvoir, les meilleurs partisans sont les plus besogneux: car n'ayant rien, ils n'ont rien à ménager, et tout ce qui rapporte est honorable à leurs yeux. »

(SALL. Iug. 86, 3 ; trad. Ernout).

Les citoyens situés au bas de l'échelle sociale, parce qu'ils ne possèdent pas suffisamment pour figurer dans l'une des « classes » de citoyens lors des opérations du cens, sont particulièrement dévoués à qui sait se les attacher. Leur très faible fortune va en effet de pair avec un code d'honneur assez peu contraignant: ils ont bien une conscience de l'honestum, mais peuvent faire entrer facilement dans cette catégorie des comportements que d'autres jugeraient moralement répréhensibles. Les impératifs de l’honneur sont donc relatifs à l'identité sociale.

\subsubsection{Le clivage de l'ethnie}

Les Romains sont conscients que le code d'honneur qu'ils suivent ne vaut pas pour tous les peuples. Ils ont eu l'occasion d'observer, lors de leurs contacts avec l'étranger, que des actions jugées chez eux parfaitement honorables pouvaient être perçues de manière très négative dans d'autres contrées, et inversement. Le code d'honneur paraît donc relatif à l'appartenance ethnique: faire partie d'un peuple impose

${ }^{124}$ EnN. Trag. inc. frg. CCXV Jocelyn. 
des règles d'honneur qui valent pour ce peuple mais ne s'appliquent pas nécessairement à l'étranger. Le code d'honneur qui vaut à Rome, dans l'Italie romaine ou dans les zones les plus romanisées des provinces ne s'applique pas chez des peuples étrangers. César en fait le constat dans le Bellum Gallicum à propos des Germains. Il souligne ainsi que chez eux, rien n'est plus contraire à l'honneur que de monter à cheval en utilisant une selle, alors que cela ne l'est pas pour un Romain ${ }^{125}$. C'est, précise-t-il, la singularité des mœurs des Germains qui explique cette divergence. La relativité des règles de l'honneur est donc ramenée par César à la diversité culturelle et morale des peuples: les traits de l'honestas sont ancrés sur les mores. Dans les développements ethnographiques consacrés aux Gaulois, César relève plusieurs traits particuliers dans leur conception de l'honorabilité. Il est ainsi turpe qu'un fils qui n'est pas en âge de porter les armes se présente devant son père dans un lieu public ${ }^{126}$. La divergence des normes de l'honneur participe ainsi à la conscience d'une distance culturelle avec l'étranger. La relativité ethnique des injonctions de l'honestum apparaît aussi dans les propos que Cicéron fait tenir à Philus dans le De republica. Les présupposés et les intentions du discours de Philus, marqué par celui de Carnéade lors de l'ambassade des philosophes athéniens à Rome en 155 avant J.-C., diffèrent naturellement beaucoup de ceux de César, mais le raisonnement de Philus rencontre celui de l'historien. Dans son discours contre la justice, Philus utilise comme argument contre l'existence d'un droit naturel la diversité des lois et des coutumes à travers le monde. S'il existait un droit naturel, dit-il, tous les hommes obéiraient aux mêmes règles, ce qui est loin d'être le cas:

Vitae uero instituta sic distant ut Cretes et Aetoli latrocinari honestum putent, Lacedaemonii suos omnis agros esse dictitarint quos spiculo possent attingere.

«Quant aux mœurs établies, elles diffèrent tellement qu'aux yeux des Crétois et des Étoliens la piraterie est honnête, et que les Lacédémoniens déclarèrent à mainte reprise comme leur propriété toutes les terres qu'ils pouvaient atteindre de leur lance.»

(CIc. Rep. III, 15; trad. Bréguet modifiée).

Ce qui est honestum chez les Crétois et les Étoliens ne l'est pas à Rome et il n'y a donc pas d'universalité de l'honestum. Ce dernier repose sur les uitae instituta, sur les coutumes et les mœurs établies, c'est-à-dire sur la tradition, et il est donc relatif à cette dernière, éminemment sujette à variation ${ }^{127}$. L'absence de fondement rationnel et objectif à l'honestum a pour conséquence nécessaire son caractère variable.

${ }^{125}$ CAES. $B G$ IV, $2,4$.

${ }^{126}$ CAES. $B G$ VI, $18,3$.

${ }^{127}$ Cette thèse de la relativité des coutumes est à rapporter au discours de Carnéade sur l'injustice (Ferrary, Philhellénisme, p.356-357). Il s'agit aussi d'une réminiscence de Protagoras (Plat. Prot. 309-329b). La relativité des coutumes et du droit naturel a également été soutenue par les épicuriens (voir, pour le domaine latin, Lucr. DRN V, 1019 et 1023) 


\subsubsection{Le clivage du genre}

Le dernier clivage entraînant des disparités dans les commandements de l'honestum est celui du genre: les règles de l'honneur ne sont pas les mêmes pour les hommes et les femmes. Il est difficile d'établir quelles sont pour les femmes les exigences de l'honestas car les textes qui en parlent directement sont très rares. Elles étaient pourtant attentives à la préservation de leur bonne réputation: les matrones de la comédie cherchent à se distinguer des courtisanes, les épouses des grands hommes politiques doivent adopter un comportement en accord avec leur dignitas et les descendantes des grandes familles se montrer dignes de leurs ancêtres ${ }^{128}$. Quelques textes nous permettent d'entrevoir en quoi résidait, dans les représentations sinon dans la réalité, l'honneur propre aux femmes. Le plus révélateur d'entre eux est un extrait des commentaires de Sextus Pomponius sur Q. Mucius Scaevola qui nous fait connaître une réponse apportée par le juriste sur une question concernant l'origine des biens:

Quintus Mucius ait, cum in controuersiam uenit, unde ad mulierem quid peruenerit, et uerius et honestius est quod non demonstratur unde habeat existimari a uiro aut qui in potestate eius esset ad eam peruenisse.

"Quintus Mucius dit que quand une controverse naît à propos de la source d'un bien venu entre les mains d'une femme, quand il n'est pas clair d'où vient le bien, il est plus correct et plus honorable de considérer qu'elle le tient de son mari ou de quelqu'un qui est placé sous son autorité.»

(Dig. XXIV, 1, 51 = Pomp. V ad Q. Muc.)

Quand une femme détient un bien dont l'origine n'est pas assurée, il est plus honorable (honestius) de considérer que ce dernier lui vient de son mari. Il serait contraire à l'honneur de juger qu'il provient de quelqu'un d'extérieur à la famille, car ce serait considérer qu'elle a reçu un cadeau d'un étranger, ce qui ferait soupçonner l'existence d'une relation extra-conjugale. L'honneur féminin implique ainsi de faire preuve de fidélité à son mari ${ }^{129}$. Même si, dans la réalité, cette règle est de moins en moins observée au fil du temps, puisque les épouses romaines bénéficiaient d'une certaine indépendance à la fin de la République, elle reste une exigence dans les mentalités romaines. Or cette exigence n'existe pas pour les hommes : fréquenter d'autres parte-

${ }^{128}$ Voir par exemple l'anxiété d'Alcmène pour sa réputation tout au long de l'Amphitryon, le souci de Cicéron pour la dignité de sa femme et de sa fille pendant la guerre civile (CIC. Att. VII, 14, 3) ou les reproches adressés à Clodia dans le Pro Caelio (Cael. $35 ; 47$; etc.).

129 Sur cette exigence de fidélité, Puccini-Delbey, La Vie sexuelle à Rome, p.75-78. D'autres passages du Digeste signalent ce qu'il est honestum de faire pour une femme, mais ce sont des textes qui regardent l'époque impériale (voir par exemple Dig. VII, 8, 7). 
naires, tant que cela est fait avec modération, n'est pas déshonorant ${ }^{130}$. À la racine de cet interdit de l'infidélité se situe une autre exigence qui concerne les mœurs sexuelles: il est attendu des femmes qu'elles fassent preuve de chasteté. Au début de notre période, leur honneur est essentiellement sexuel: c'est en manquant de chasteté qu'elles se déshonorent ${ }^{131}$. Chez les jeunes filles, l'exigence d'ordre sexuel prend la forme d'un impératif de virginité, jusqu'à la date de leur mariage. Une uirgo qui subit un viol est donc gravement déshonorée. On le voit à plusieurs reprises dans les comédies, où la violence exercée sur une jeune femme est un des ressorts de l'intrigue et suscite l'inquiétude des autres personnages. Un fragment d'une pièce de Caecilius Statius met en relation le viol et l'atteinte à l'honneur:

Per mysteria hic inhoneste [honestam] grauidauit probro. affront. »

«Lors des Mystères, il l'a engrossée de manière déshonorante, en lui faisant

(CAECIL. frg. $224 C R F)$.

Le fragment est issu d'une comédie qui imite la Tithè de Ménandre: une jeune femme a été violée et l'enfant né de cette violence est confié en secret à une nourrice jusqu'au jour où le père de la jeune fille s'en aperçoit. Le vers conservé fait référence à l'acte du viol et indique que ce geste revient à agir inhoneste, d'une manière qui offense l'honneur de la jeune fille ${ }^{132}$. L'avoir forcée à un acte sexuel a détruit sa virginité et mis gravement en péril son honorabilité. La jeune femme doit, pour se conformer à l'honneur, préserver une parfaite chasteté. Il s'agit ici encore d'un impératif spécifique, qui n'a pas lieu d'être pour les jeunes gens.

D'autres exigences ne sont en revanche pas valables pour les femmes mais seulement pour les hommes. La plus évidente est celle de la uirtus: le courage est une composante du code de l'honneur masculin. La uirtus reste en effet, fondamentalement, la qualité du uir, ce qui la rend spécifique aux hommes et étrangère aux femmes ${ }^{133}$. L'impassibilité devant les épreuves est de même une qualité masculine: les pleurs sont inconvenants pour un homme mais pas pour une

${ }^{130}$ Sur l'exigence de modération, voir supra p. 472-475.

${ }^{131}$ Cette exigence de chasteté se maintient à l'époque impériale (LENDON, Empire of Honour, p.46). Elle est aussi répandue dans les sociétés méditerranéennes modernes. Voir J. K. Campbell, «Honour and the Devil », in Peristiany, J. G. (éd.), Honour and Shame. The Values of Mediterranean Society, Londres, Weidenfeld \& Nicolson, 1966, p. 139-170; A. BцoK, «Rams and Billy-goats: a Key to the Mediterranean Code of Honour », Man, 16, 1981, p. 427-440; Bourdieu, Trois études; PItT-Rivers, Anthropologie de l'honneur, p. 50.

${ }^{132}$ Honestam est un ajout de l'éditeur Bothe qui comble un manque dans les manuscrits mais il est purement conjectural. Le sens d'inhoneste correspond au sens d'honestus "honorifique», "qui fait honneur».

${ }^{133}$ Sur l'inexistence de la uirtus chez les femmes, McDonNelL, Roman Manliness, p. 159-180. 
femme car son émotivité est une caractéristique du genre qui est le sien $^{134}$. D'autres commandements de l'honneur, enfin, sont communs aux hommes et aux femmes: l'interdit pesant sur la nudité, par exemple, vaut pour les deux.

Il n'y a donc pas deux codes d'honneur différents, mais un ensemble de commandements communs auquel s'ajoutent des règles spécifiques en fonction du genre: l'honneur masculin est globalement orienté vers le courage, l'activité publique et le sérieux, tandis que l'honneur féminin se structure autour d'exigences de pudeur et de chasteté. Le clivage n'est donc pas total. Il l'est d'autant moins que les deux honneurs possèdent une forme d'interdépendance car l'honorabilité de la femme sert à protéger l'honneur de l'homme. L'observation des règles de l'honestum par une femme permet de conserver son prestige mais aussi celui des individus masculins de sa famille ${ }^{135}$. Quand Amphitryon comprend que son épouse a commis un adultère, cette faille dans la pudicitia d'Alcmène porte un coup à sa propre considération et provoque sa colère ${ }^{136}$. Cette relation croisée fonctionne également pour une jeune femme avec les hommes qui lui sont liés par le sang. Cela apparaît en dehors de la comédie, dans les grandes familles évoquées par certains discours de Cicéron. L'Arpinate fait ainsi l'éloge de Caecilia auprès de qui son client Roscius a trouvé refuge:

Quasi uero nescias hunc et ali et uestiri a Caecilia Balearici filia, Nepotis sorore, spectatissima femina, quae cum patrem clarissimum, amplissimos patruos, ornatissimum fratrem haberet, tamen cum esset mulier, uirtute perfecit ut, quanto honore ipsa ex illorum dignitate adficeretur, non minora illis ornamenta ex sua laude redderet.

"Comme si tu ignorais qu'il est nourri et habillé par Caecilia, la fille du Baléarique, la sœur de Nepos, cette femme si considérée, qui, alors qu'elle avait un père très illustre, des oncles très importants, un frère très distingué, a réussi par sa vertu, alors qu'elle était une femme, à donner aux hommes de sa famille des distinctions aussi grandes, grâce à sa conduite louable, que l'honneur qui lui venait à elle-même en raison de leur rang. »

(CIc. Rosc. Amer. 147).

Ce passage constitue un bon exemple de la manière dont l'honorabilité des uns protège l'honneur des autres. Cicéron remarque que la conduite exemplaire de cette femme profite essentiellement à ses proches puisqu'elle leur procure des ornamenta remarquables. Elle

${ }^{134}$ Sur le caractère acceptable des pleurs féminins, PAcuv. frg. 268-269 TRF et Cic. Tusc. II, 50.

${ }^{135}$ C'est encore ici une caractéristique des systèmes de prestige méditerranéens: tout manquement des femmes à la pudeur y met en péril l'honneur des hommes qui lui sont liés par le sang et le mariage (CAmpBell, Honour, Family and Patronage, p. 271; Bourdieu, Trois études, p. 51).

${ }^{136}$ PL. Amp. 808-819. 
contribue ainsi au prestige de la famille tout entière. Cette extension de la réputation au sein d'un groupe restreint a déjà été observée ${ }^{137}$; ce qui est ici remarquable, c'est le mode de fonctionnement de cette extension. Deux caractéristiques doivent être soulignées. La relation croisée, d'une part: l'action louable de la femme suscite le prestige des hommes. L'aspect bijectif de la protection de l'honneur d'autre part: la femme maintient la dignité des hommes de la famille, mais, en sens inverse, les hommes font bénéficier Caecilia de leur prestige; Cicéron précise en effet que c'est la dignitas des mâles, appartenant à la descendance de Caecilius Metellus Balearicus, conquérant des Baléares, triomphateur et ancien censeur, qui procure de l'honneur à la femme ${ }^{138}$. La dignitas des hommes provoque l'honos de la femme; la uirtus de la femme provoque les ornamenta des hommes.

\section{CONCLUSION}

Au terme de ce parcours, il apparaît que la distinction faite par l'anthropologie entre l'honneur social, c'est-à-dire la réputation et le prestige, et l'honneur éthique, l'intégrité et la dignité morale, possède une pertinence pour notre objet. Les chapitres précédents avaient mis en évidence les aspects et les usages sociaux et politiques de l'honneur; nous venons de voir se dessiner sa dimension proprement morale à travers sa capacité à orienter la conduite des individus. Il faut noter, cependant, qu'à la différence de la notion d' " honneur », qui est unitaire, il y a à Rome une bipartition, dans le vocabulaire et les représentations mentales, entre l'honos d'une part, pratique sociale et politique, et l'honestas et l'honestum d'autre part, qui concentrent l'aspect éthique de l'honneur, sa normativité et ses règles de conduite. Il est en outre nécessaire, quand on cherche à formaliser le fonctionnement de l'honorabilité, de prendre en compte d'autres notions, le pudor, qui est à Rome le sens de l'honneur, et le mos maiorum, qui constitue le soubassement de tout code de conduite. Il serait donc réducteur d'établir une identité entre l' "honneur» éthique et l'honestas. Cependant, il nous apparaît fructueux d'analyser l'honestas comme un code d'honneur. L'honestum apparaît en effet doté d'un important pouvoir normatif, qui s'exerce surtout de manière négative en posant des interdits. L'honestas est un comportement qui consiste à observer des exigences morales diverses, notamment en faisant preuve de uirtus, de fides, de modération, de décence et de sérieux. L'honestum est le principe directeur, l'image idéale de ce comportement, qui, lorsqu'on en a conscience et qu'on y attache de l'importance, autrement dit lorsqu'on a du pudor, oriente

${ }^{137}$ Voir p. 198-201.

${ }^{138}$ Sur le Baléarique, voir l'article de F. Münzer dans la RE s.v. Caecilius nº 82. 
les mœurs. L'existence de ce faisceau de normes attachées à l'honestas pourrait n'en faire qu'un code de conduite et non un code d'honneur si elle ne possédait deux caractéristiques essentielles. En premier lieu, le code de conduite de l'honestas est hétéronome: c'est la collectivité et non le sujet qui définit ce qui est honestum; c'est le regard d'autrui et la crainte de perdre son estime qui motivent l'observation des règles de comportement; c'est par l'imitation de la conduite des ancêtres, archétypes de l'honneur, que l'on atteint l'honestas. En second lieu, les exigences de l'honestas sont relatives. Il s'agit d'un code d'honneur qui a une existence pour diverses catégories de la population mais qui vaut principalement pour l'aristocratie. Ce que commande l'honestum, en outre, n'est pas identique pour tous: plus le statut de l'individu est élevé, plus les règles sont contraignantes, et les Romains sont conscients que ce qui est honorable chez un peuple peut ne pas l'être chez un autre ou que ce qui est socialement acceptable pour un homme ne l'est pas nécessairement pour une femme. Cette hétéronomie et cette relativité de l'honestas en font un code de conduite traditionnel. L'analyse anthropologique permet de mettre en avant ses caractéristiques mais elle est cependant insuffisante pour en comprendre tous les enjeux et en percevoir l'évolution. L'honestas est en effet une réalité dynamique, dont les contours évoluent. Elle est aussi pour les Romains un objet problématique, sur lequel se sont exercées réflexions et évaluations, notamment à partir de la fin du $\mathrm{II}^{\mathrm{e}}$ siècle. Ses normes ne sont pas figées, ni son mode de fonctionnement, et l'enjeu consistera donc, ultérieurement, à en appréhender l'évolution ${ }^{139}$.

${ }^{139}$ Voir l'ensemble de notre troisième partie. 



\title{
CHAPITRE 11
}

\section{LE DIEU HONOS}

\author{
INTRODUCTION
}

Les chapitres précédents ont surtout abordé la pratique de l'honos et de l'honestas. Mais l'honos a la particularité d'avoir à Rome un aspect divin car Honos est aussi un dieu du panthéon. Comme la libertas, la concordia ou la uirtus, l'honos est à la fois une pratique humaine et une divinité, et la frontière qui sépare ces deux aspects n'est pas parfaitement étanche ${ }^{1}$. Notre travail ne peut donc faire l'économie d'une approche théologique, d'autant que l'honos est, parmi les nombreuses notions qui touchent au prestige et à la renommée, la seule à faire l'objet d'un culte à l'époque républicaine ${ }^{2}$. L'étude du dieu Honos nous permettra de compléter et d'affiner notre analyse de la notion d'honos dans son ensemble en essayant de voir si son aspect divin possède des traits originaux laissés jusqu'ici dans l'ombre. Elle sera aussi l'occasion de nous intéresser à l'une de ces «abstractions divinisées » qui peuplent le panthéon romain. D’un point de vue méthodologique, l'étude de ce dieu nous imposera d'analyser des sources situées hors du cadre chronologique que nous nous sommes fixé car peu de textes de l'époque républicaine l'évoquent. Notre objectif n'est pas de donner une analyse exhaustive du dieu Honos mais de nous

${ }^{1}$ Sur la difficulté qu'il y a à différencier objet concret et divinité, voir J.R. FEARs, «The Cult of Virtues and Roman Imperial Ideology », ANRW, II, 17, 2, 1981, p. 827-946, à la p.944. Voir aussi le refus d'A. J. Clark d'utiliser une majuscule pour la divinité et une minuscule pour l'objet humain, ce qui aurait pour effet de trop les distinguer (A. J. CLARK, Divine Qualities. Cult and Community in Republican Rome, Oxford, Oxford University Press, 2007, p.21). L'auteur préfère employer les petites capitales pour renvoyer à la divinité sans effacer la référence à l'aspect pratique de la notion: "Once LIBERTAS was worshipped, for example, any reference to LIBERTAS, however mundane, was theological, in the strict sense of the word. " (p. 18). Nous utiliserons quant à nous les termes d'honos et d'Honos car les textes d'époque républicaine où il est totalement impossible de trancher entre l'objet humain et le dieu sont rares. Un seul texte laisse véritablement planer le doute: il s'agit d'un passage de Plaute (Trin. 663): Tute pone te latebis facile, ne inueniat honor; «Tu seras si bien caché derrière toi-même qu'il ne te trouvera pas, l'honneur. »

${ }^{2}$ On ne voit apparaître dans la liste établie par Clark jusqu'en 44 avant J.-C. nidignitas, ni gratia, ni gloria, ni laus, ni decus, qui sont pourtant par ailleurs des concepts essentiels dans la pratique et la pensée romaines (CLARK, Divine Qualities, p.11). 
intéresser à un certain nombre de problèmes. Nous commencerons par nous interroger sur la nature de cette divinité: quel est son statut au sein du panthéon romain? Sur quel domaine Honos exerce-t-il sa souveraineté? Puis nous donnerons une description de son culte en nous intéressant notamment aux temples qui lui ont été élevés. Comme ces derniers ont été bâtis à l'initiative de grands hommes de la République, il faudra étudier l'usage politique et idéologique qu'ils ont fait de ce dieu.

\section{LA NATURE D'HoNOS}

Déterminer la nature exacte de ce dieu n'est pas une tâche facile car cela impose de répondre à trois questions qui ont suscité des réponses contradictoires: quel est son statut parmi les différentes divinités du panthéon? De quoi est-il le dieu? Quelle est son origine?

\subsection{Le statut d'Honos dans le panthéon}

Honos ne possède ni la richesse ni l'importance des grandes divinités romaines comme Jupiter ou Mars et on ne le rencontre pas fréquemment dans les sources. Il n'est pas non plus individualisé: on ne connaît pas de mythe à son sujet et son nom ne fait que refléter la réalité à laquelle il préside, l'honos. L’anthropomorphisme des dieux romains est en général assez faible, mais dans le cas d'Honos il semble extrêmement réduit ${ }^{3}$. Cependant, Honos fait l'objet d'un culte dès le $\mathrm{III}^{\mathrm{e}}$ siècle: il possède plusieurs temples à Rome, on lui adresse vœux et sacrifices et il a des fêtes et des prêtres ${ }^{4}$. On ne peut donc pas non plus l'assimiler aux indigitamenta, ces divinités mineures qui ne reçoivent pas de culte et président à un moment très limité et très précis de la vie biologique, agricole ou sociale ${ }^{5}$, comme Vaticanus, dieu du vagisse-

${ }^{3}$ Sur la question de l'individualité des dieux romains, voir J.BAYET, Histoire politique et psychologique de la religion romaine, Paris, Payot, 1957, p. 109 et CAH, vol. 7, 2, p. 578 .

${ }^{4}$ Sur le culte, voir p. 517 sqq.

${ }^{5}$ Selon G. Wissowa, le terme d'indigitamenta renvoie à des listes de phrases secrètes utilisées par les prêtres pour contraindre les dieux à certaines actions (WIssowA, Religion und Kultus der Römer, p.397 et 513). Mais on considère aussi que ce sont des divinités mineures regroupées dans des listes, connues indirectement par la polémique antipaïenne des auteurs chrétiens, et notamment d'Augustin. Ces derniers nous ont transmis de manière indirecte des fragments des Antiquitates rerum diuinarum de Varron sur le sujet (notamment le livre XIV sur les di certi). Voir Y. LehmanN, Varron théologien et philosophe romain, Bruxelles, Latomus, 1997, p.171-172. M. Perfigli juge cette dénomination d'indigitamenta impropre (M. PERfIGLI, Indigitamenta. Divinità funzionali e funzionalità divina nella religione romana, Pise, ETS, 2004, p. 183-184). Sur le sens du mot, R. Schilling, "Le culte de l'Indiges à Lauinium », REL, 57, 1979, p. 49-68. 
ment des enfants, ou Mena qui préside au cycle menstruel des femmes. Honos occupe une place plus importante dans la religion civique.

Honos appartient à cette catégorie de dieux nommés d'après des notions riches de sens, à l'aspect souvent moral, psychologique ou politique, comme Pudicitia, Virtus, Concordia, Victoria, Libertas ${ }^{6}$. Ces divinités sont en relation étroite avec un objet humain qui a été considéré comme contrôlé par une puissance divine particulière à laquelle a été donné le nom de l'objet qu'elle gouverne: Pudicitia est souveraine sur la pudeur, Gloria sur la gloire, Concordia sur la concorde ${ }^{7}$. Elles ont été généralement désignées de deux manières. Une première dénomination est celle d' "abstractions divinisées » ou de "personnifications de notions abstraites ${ }^{8}$. Ces expressions sont cependant trompeuses. Il s'agit bien, d'abord, de vraies divinités et non seulement de "personnifications ${ }^{9}$; ensuite, la plupart de ces notions divines n'ont rien d'abstrait: la concorde, la pudeur ou la victoire ont un solide ancrage concret, tout comme l'honneur dont nous avons montré l'importance pratique, et leur divinisation ne les tire pas vers l'abstrait, au contraire: elle les incarne dans le culte et l'espace de la cité par les temples qui leur sont érigés. Ces divinités ne sont donc pas plus abstraites que les autres dieux du panthéon ${ }^{10}$. Une autre dénomination, adoptée notamment par J.R. Fears, est celle de «vertu divine ${ }^{11}:$ J.R. Fears indique qu'il faut entendre "vertu» en son sens ancien de "power or operative influence inherent in a supernatural being». Mais cette désignation a le défaut d'utiliser un terme qui prête à confusion car son sens le plus

Sur ces divinités mineures en général, voir H. UsEner, Götternamen, Bonn, F. Cohen, 1896, p. 301 sqq., et Perfigli, Indigitamenta. Pour les divinités que nous citons, voir Aug.Ciu. IV, 8 et 11 ; VII, 3 et Perfigli, Indigitamenta, p. 55.

${ }^{6}$ Les notions divinisées ayant reçu un culte avant 43 avant J.-C. sont Bonus Euentus, Clementia, Concordia, Felicitas, Fides, Fortuna, Honos, Iuventas, Libertas, Moneta, Ops, Pavor, Pallor, Pietas, Pudicitia, Quies, Salus, Spes, Valetudo, Victoria, Virtus (WIssowa, Religion und Kultus der Römer, p. 271 ; CLARK, Divine Qualities, p. 11). Voir aussi les listes établies par L. Deubner dans W. H. Roscher, Ausführliches Lexikon der griechischen und römischen Mythologie, Leipzig, Teubner, 1884 s. v. Honos et par H. J. Axtell, The Deification of Abstract Ideas in Roman Literature and Inscriptions, Diss., University of Chicago, Chicago, 1907.

${ }^{7}$ FEARs, «The Cult of Virtues », p. 828. Ces notions divinisées existent dans plusieurs religions anciennes du monde indo-européen (J.HANI, "Aidôs personnifiée et sa portée réelle chez les Grecs », in Duchemin, J. (éd.), Mythe et personnification, Paris, Les Belles Lettres, 1980, p. 103-112). On connaît en Grèce Thèmis, Phobos, Tychè, Nikè, etc.

${ }^{8}$ Deubner et Wissowa parlent de "Personifikationen abstrakter Begriffe», Usener d' "Abstrakte Gottesbegriffe », Axtell de «deified abstracts», Bayet d' "abstractions divinisées ».

${ }^{9}$ Comme le remarque justement J.R. Fears, la personnification de Fama existe, mais il n'y a pas de culte de Fama à Rome (FEARs, «The Cult of Virtues », p. 830).

${ }^{10}$ Ibid., p. 831-832 et CLARK, Divine Qualities, p. 26.

${ }^{11}$ FEARs, "The Cult of Virtues», p. 832 et CLARK, Divine Qualities, p. 27 "faute de mieux». 
fréquent est celui de "qualité morale». G. Dumézil retient le terme de «forces puissantes » qui nous paraît plus adapté ${ }^{12}$ car il se situe dans la lignée de l'importante analyse que Cicéron consacre à ces dieux dans un passage du De natura deorum: Balbus remarque que bien des réalités humaines ont été divinisées parce qu'elles renfermaient uis aliqua maior, "une assez grande puissance» que seul un dieu pouvait gouverner ${ }^{13}$. Nous parlerons donc plutôt de «forces divines ».

\subsection{Les attributions d'Honos}

Il faut à présent déterminer les attributions d'Honos et l'aspect de l'honos pratique auquel le dieu est lié.

\subsubsection{Le dieu de l'hommage}

Une réponse à ces questions a été apportée par le New Pauly et par un article de Z. Hoffmann: ils estiment qu'Honos est le dieu de l'honneur au sens d' «honorabilité», de "dignité». Honos représenterait dans le panthéon le sens de l'honneur, la qualité qui consiste à suivre une conduite digne et qui donne droit à l'estime des autres. Il serait, comme par exemple Pudicitia (Pudeur), une qualité morale divinisée ${ }^{14}$. Cette thèse nous paraît cependant difficile à soutenir. Notre analyse sémantique a montré que le sens "honorabilité», "dignité » d'honos était très peu fréquent et que cette idée était bien plus incarnée par honestas, qui n'a pas d'équivalent divin. Il serait surprenant que la facette divine de l'honos mette en relief un aspect de la notion qui est très marginal dans la pratique humaine. Plusieurs textes, en outre, montrent qu'Honos n'est pas une divinité qui préside à une vertu ou une qualité. On le voit dans un passage du De legibus:

Bene uero quod Mens, Pietas, Virtus, Fides consecrantur humanae, quarum omnium Romae dedicata publice templa sunt, ut illas qui habeant (habent autem omnes boni) deos ipsos in animis suis conlocatos putent. [...] Quodsi fingenda nomina sint, adsciscenda potius Vicae Potae et Statae, cognominaque Statoris et Inuicti Iouis, rerumque expetendarum nomina, Salutis, Honoris, Opis, Victoriae.

"Il est bon de diviniser des qualités humaines, Esprit, Piété, Vertu, Bonne Foi, qui ont toutes à Rome des temples qui leur sont dédiés pour que ceux qui les possèdent (et tous les gens de bien les possèdent) pensent que des dieux en personne se sont logés dans leur âme. [...] Mais s'il faut forger des noms, il faut plutôt adopter ceux de Vica Pota, de Stata, les dénominations de Stator et Invincible pour Jupiter, et les noms de choses qu'il faut rechercher, Salut, Honneur, Prospérité, Victoire.»

(Cic. Leg. II, 28).

${ }^{12}$ G. DuméziL, La Religion romaine archä̈que, 2e éd., Paris, Payot, 1974, p. 399.

${ }^{13}$ CIc. ND II, 61. Voir infra p. 511-512.

${ }^{14} N P$ vol. 5, col. 478; Hoffmann, "Der Wertbegriff honos in den Komödien von Plautus ». Sur Pudicitia, Clark, Divine Qualities, p. 39-46. 
Cicéron se livre ici à une interprétation du culte et il faut donc être prudent quand on utilise ses affirmations comme documents sur la pratique religieuse. L'Arpinate distingue deux types d'éléments divinisés. Les premiers sont des qualités, l’Esprit, la Piété, la Vertu, la Bonne Foi, et les seconds sont des res expetendae, des choses désirables dont il faut entreprendre la recherche, le Salut, l'Honneur, la Prospérité, la Victoire. Honos appartient à la seconde catégorie: l'aspect divin de la notion d'honos n'est pas la «dignité», le "sens de l'honneur», qui est une qualité qui relèverait de la première catégorie si elle était divinisée, mais la «marque d'honneur» ou le "prestige» qui peuvent être l'un et l'autre des res dont on entreprend la conquête ${ }^{15}$. Honos est une de ces divinités souveraines sur des biens précieux: il préside à l'honneur, c'est-à-dire au prestige et à ses marques, comme Salus préside au salut, Ops à l'abondance agricole et Victoria à la victoire.

Un passage d'Augustin, que Cardauns considère comme une citation de Varron, permet de préciser le rapport du dieu Honos à l'aspect humain de la notion d'honos: il rapporte que les anciens considéraient certains bienfaits précieux comme d'origine divine. Ne sachant cependant identifier avec certitude l'identité du dieu qui les leur octroyait, ils ont donné à ce dernier le nom du bienfait lui-même:

Ita Virtus, quae dat uirtutem, Honor, qui honorem, Concordia, quae concordiam, Victoria, quae dat uictoriam.

«Ainsi, Vaillance est la divinité qui donne la vaillance, Honneur celle qui donne l'honneur, Concorde celle qui donne la concorde, Victoire celle qui donne la victoire.»

(VARR. RD XIV, frg. 189 Cardauns = Aug. Ciu. IV, 24).

La souveraineté qu'Honos exerce sur l'honos est ainsi de nature dispensatrice: Honos est le dieu qui donne les marques d'honneur et le prestige, comme Victoria apporte la victoire ${ }^{16}$. La valeur particulière que les Romains attachent à l'honos les amène à considérer qu'une divinité est impliquée dans son octroi. Cette représentation de la divinité est confirmée par le discours du stoïcien Balbus dans le De natura deorum auquel nous faisions précédemment allusion. Après avoir donné différentes preuves de l'existence des dieux, Balbus se penche sur leur identité. Il montre que le monde lui-même est divin, tout comme les corps célestes, et s'intéresse ensuite à la nature divine des bienfaits accordés aux hommes:

Vides Virtutis templum uides Honoris a M. Marcello renouatum, quod multis ante annis erat bello Ligustico a Q. Maxumo dedicatum. Quid Opis quid Salutis quid Concordiae Libertatis Victoriae; quarum omnium rerum quia uis erat tanta

${ }_{15}$ C'est l'interprétation que donne du dieu F. Klose, que nous rejoignons (KLose, Bedeutung, p. 91 sqq.).

${ }^{16}$ Sur cet aspect de Victoria, Fears, «The Theology of Victory », à la p. 745. 
ut sine deo regi non posset, ipsa res deorum nomen optinuit [...]. Vtilitatum igitur magnitudine constituti sunt ei di qui utilitates quasque gignebant, atque is quidem nominibus quae paulo ante dicta sunt quae uis sit in quoque declaratur deo.

«Tu vois le temple de Vertu, celui d'Honneur restauré par Marcellus, qui avait été dédié il y a de nombreuses années par Quintus Maximus, lors de la guerre contre les Ligures. Et que dire du temple d'Abondance, de Salut, de Concorde, de Liberté, de Victoire? C'est parce que ces notions recelaient une puissance si grande qu'elle ne pouvait être gouvernée que par un dieu qu'elles ont elles-mêmes obtenu le nom de dieux [...]. C'est donc en raison de leur grande utilité qu'ils ont été divinisés, ceux qui donnaient naissance à chacun de ces avantages, et c'est au moyen des noms que j'ai donnés plus haut que l'on signifie quelle puissance réside dans chacun de ces dieux.»

(CIC. ND II, 61-62).

On retrouve dans ce passage la conception varronienne des bienfaits divinisés, formulée en des termes plus précis. Balbus remarque que certain biens possèdent une telle uis, c'est-à-dire une telle importance et une telle puissance, que les hommes ont estimé que seule une divinité pouvait les octroyer. Ce sont des dieux ( $d i)$ qui dispensent ces bienfaits, et ces dieux sont désignés par le nom du bienfait, ce qui donne l'impression que l'objet bénéfique lui-même est divinisé. L'honos est un bien utile et le dieu Honos préside à son octroi, ce qui explique que des généraux comme Fabius Maximus, à qui Cicéron fait allusion, se soient adressés à lui: ils invoquaient Honos lorsqu'ils espéraient recevoir des marques d'honneur comme le triomphe ${ }^{17}$. Cette attribution de l'honos à Honos témoigne d'une conception fonctionnaliste de la divinité: chaque dieu remplit à Rome un rôle bien déterminé dans le champ des activités humaines et la connaissance du pouvoir divin dérive de l'évidence des bienfaits qu'il apporte ${ }^{18}$.

Il faut souligner enfin que le dieu Honos paraît surtout lié à l'honos comme «marque d'honneur» plutôt que comme «considération». Dans une de ses élégies, Properce l'évoque en ces termes:

Mollia, Pegasides, date uestro serta poetae: non faciet capiti dura corona meo.

At mihi quod uiuo detraxerit inuida turba, post obitum duplici faenore reddet Honos.

«Ô vous qui montez Pégase, donnez à votre poète de tendres guirlandes: une dure couronne ne conviendrait pas à ma tête.

Ce qu'une foule envieuse m'aura ôté de mon vivant, après ma mort l'Honneur me le rendra au double, comme un usurier. »

(Prop. III, 1, 16-19).

${ }^{17}$ Sur la dévotion de Fabius Maximus et son vœu à Honos, voir infra p. 520 sqq.

${ }^{18}$ FeARs, "The Cult of Virtues», p. 837 et DumÉzIL, La Religion romaine archaïque, p. 32-46. 
Les distinctions que la foule pourrait arracher au poète de son vivant lui seront restituées après sa mort par Honneur: ce dernier lui octroiera deux fois plus de mollia serta. La divinité est ainsi associée aux marques d'honneur concrètes conférées aux poètes. Les représentations iconographiques d'Honos vont aussi dans ce sens ${ }^{19}$. Honos est représenté comme un homme jeune, aux cheveux courts, torse nu ou drapé d'une toge ${ }^{20}$. Il revêt souvent une couronne de feuilles de laurier et quelquefois de chêne ${ }^{21}$, objet qui est en contexte militaire une marque d'honneur décernée pour un exploit ${ }^{22}$. Il tient fréquemment une corne d'abondance, ce qui est un moyen d'évoquer la générosité avec laquelle il dispense les bienfaits que sont les honores ${ }^{23}$. Il a aussi dans son autre main une lance, un sceptre ou un rameau ${ }^{24}$. Honos est associé dans quelques représentations à des marques d'honneur: sur une monnaie de Lollius Palikanus figure au droit une tête d'Honos et au revers une chaise curule ${ }^{25}$. Sur le pylône nord de l'arc de Titus, Honos accompagne le triomphe de l'empereur ${ }^{26}$.

\subsubsection{Le dieu de la juste rétribution du mérite; Honos et Virtus}

Certains textes nous permettent de formuler une hypothèse qui préciserait la nature de l'hommage auquel Honos préside. Il semble, à lire notamment les poètes, que le dieu octroie les marques d'honneur quand elles répondent à un mérite qui les légitime. Chez Properce, Honos donne au poète les distinctions que la foule inuida lui a arrachées: il corrige cette irrégularité en rétribuant le mérite à sa juste valeur. Dans la théogonie qui ouvre le livre V des Fastes d'Ovide, on voit Honor s'unir à Reuerentia pour enfanter Maiestas. Maiestas s'installe ensuite dans l'Olympe, avec Pudor et Metus, ce qui permet de rétablir l’ordre, troublé par les divinités inférieures qui usurpaient la

19 Sur l'iconographie d'Honos, LIMC, vol.5, 2 s. v. Honos; EAA vol.4, p. 55; M. Bieber, "Honos and Virtus », AJA, 49, 1945, p. 25-34 et surtout Milhous, Honos and Virtus in Roman Art, qui dresse un catalogue complet.

${ }^{20}{ }^{2 I M C} \mathrm{n}^{\circ} 6$ ou $L I M C \mathrm{n}^{\circ}$ 9a et 10.

${ }^{21}$ Couronne de laurier: RRC $482 \mathrm{n}^{\circ} 473$; $\operatorname{LIMC}^{\circ}{ }^{\circ}$; couronne de chêne: $L I M C \mathrm{n}^{\circ} 2$.

${ }^{22}$ Voir supra p. 246-247.

${ }^{23}$ La cornucopia apparaît souvent à Rome entre les mains de forces divines qui renvoient à l'abondance, à la fertilité et au bonheur des hommes (Fortuna, Ops, Pax, Felicitas, Concordia). C'est un attribut très en vogue dans les représentations divines de l'époque des Flaviens et des Antonins (DAGR vol. I, 2, p. 1514 sqq.; EAA s. v. cornucopia).

${ }^{24} L I M C \mathrm{n}^{\circ}$ 4, 6, 9a. L'ensemble de ses attributs le rapproche du type iconographique du Genius Populi Romani (L. J. Richardson, "Honos et Virtus and the Sacra Via », AJA, 82 (2), 1978, p. 240-246). Le Genius, cependant, tient une patère, ce qui n'est pas le cas d'Honos.

${ }^{25}$ RRC $482 \mathrm{n}^{\circ} 473$.

${ }^{26}$ LIMC 14a. Il est aussi associé à des scènes de triomphe sur des sardoines du III ${ }^{\mathrm{e}}$ et IV ${ }^{\mathrm{e}} \mathrm{s}$ après J.-C. (LIMC 15-18). 
place des dieux les plus nobles ${ }^{27}$. C'est grâce à l'union de l'Honneur et du Respect que chaque dieu retrouve la place qui doit être la sienne. Honos contribue ainsi à donner à chacun ce qui lui revient. Mais c'est surtout l'association récurrente d'Honos avec Virtus qui montre qu'Honos préside à l'hommage légitime rendu au mérite ${ }^{28}$. Les deux dieux sont en effet fréquemment conjoints: ils sont invoqués ensemble, représentés côte à côte sur des monnaies ${ }^{29}$, et plusieurs temples leur sont consacrés à tous deux ${ }^{30}$. La raison de leur association est éclairée par Symmaque:

Bene ac sapienter maiores nostri, ut sunt alia aetatis illius, aedes Honori atque Virtuti gemella facie iunctim locarunt conmenti, quod in te uidimus, ibi esse praemia honoris, ubi sunt merita uirtutis.

«En cela comme en d'autres mesures de jadis, nos ancêtres ont agi avec raison et sagesse, quand ils ont placé côté à côte en couplant leurs façades les temples d'Honneur et de Vertu. Ils avaient en effet pensé - et c'est ce que nous avons vu chez nous - que les récompenses honorifiques sont là où sont les actions vertueuses. »

(Symm. Ep. I, 20, 1 ; trad. Callu).

Symmaque évoque les deux aedes contigus consacrés à Honos et Virtus par Marcellus ${ }^{31}$ et remarque que l'association de ces deux divinités est pleine de bon sens car les merita uirtutis, les actions vertueuses et méritoires, reçoivent régulièrement des praemia honoris, des récompenses sous forme d'honneur. Nous retrouvons chez Symmaque la conception, répandue à l'époque républicaine, de l'honos comme rétribution de la uirtus. Létroite conjonction des deux divinités dans le culte est donc en parfaite harmonie avec le lien qui rapproche dans la pratique l'honos et la uirtus. Honos est le dieu de l'honneur rendu à la "vaillance», à la "vertu» ou, plus généralement, à la «valeur » ${ }^{32}$. Cet aspect apparaît encore dans un passage du Pro Sestio où Cicéron

${ }^{27}$ Ov. Fast. V, 23-24.

${ }^{28}$ Sur la divinité Virtus, Axtell, The Deification of Abstract Ideas, p. 25-27; MiLhous, Honos and Virtus in Roman Art, p. 35-43 et McDonnell, Roman Manliness, p. 142-158 et p. 206-240.

${ }^{29}$ Voir le denier d'argent de Kalenus et Cordus où leurs têtes sont côte à côte (RRC $\left.413 \mathrm{n}^{\circ} 403\right)$ et des sesterces d'époque flavienne (LIMC $\mathrm{n}^{\circ} 9$ et 10). Virtus est en général casquée, armée d'une lance et revêtue d'une tunique. Sur sa figuration, McDonNELL, Roman Manliness, p. 142-158.

${ }^{30}$ On ne connaît qu'un seul temple consacré à Virtus seule, celui de Scipion Émilien (Plut. De fortuna Romanorum 318 d-e), et un seul dédié à Honos seul, celui de la porte Colline. Trois autres lieux de culte abritent Honos et Virtus (voir infra p. 524 sqq.).

${ }^{31}$ Sur cette consécration et les problèmes qu'elle a posés, voir infra p. 524 sqq.

${ }^{32}$ Sur ces différents aspects de la uirtus, voir supra p. 307 sqq. Sur le lien de l'honos et de la uirtus, voir p. 307 sqq. 
évoque la séance où le sénat, réuni dans le temple consacré par Marius à Honos et Virtus, a décidé son rappel:

[...] in templo Virtutis honos habitus esset uirtuti, Gaique Mari, conseruatoris huius imperii, monumentum municipi eius et rei publicae defensori sedem ad salutem praebuisset.

«[...] dans le temple de la Vertu, on rendait honneur à la vertu et ce monument de Gaius Marius, le sauveur de notre empire, permit d'assurer le salut d'un de ses compatriotes, un défenseur de la république.»

(CIc. Sest. 116).

Le lieu où son rappel a été décidé est très significatif pour Cicéron : il a été voté dans le temple d'Honneur et de Vertu car c'était un moyen de rendre honneur à sa vertu (honos habitus esset uirtuti). Les hommages accordés par Honos sont toujours légitimes et mérités: c'est le dieu de la juste rétribution de la valeur ${ }^{33}$.

\subsubsection{Une divinité militaire}

Le lien étroit existant entre Honos et Virtus est à rapprocher du fait qu'Honos possède une forte coloration militaire: il incarne fréquemment l'honneur gagné à la guerre grâce à la vaillance ${ }^{34}$. Dans des documents de l'époque impériale, le dieu apparaît en effet dans des inscriptions faites par des soldats: les légionnaires ont adressé des consécrations à "l'Honneur de l'Aigle de la légion», ou encore à «l'Honneur de l'étendard ${ }^{35}$. Qui plus est, dans l'iconographie, le dieu

${ }^{33}$ Cet aspect d'Honos nous permet de reconnaître sa présence dans un denarius datant des alentours de 100 av. J.-C. dont l'iconographie a été discutée $\left(R R C \mathrm{n}^{\circ} 329,1 \mathrm{a}\right)$. Au droit se trouve une figure féminine debout avec casque, tunique courte, bottes et lance dans la main droite. Elle est couronnée par une figure masculine, torse nu, pourvue d'une cornucopia. Une légende indique LENT. MAR. F., ce qui permet d'identifier le monétaire, P.Cornelius Lentulus Marcellinus, un descendant du célèbre Marcellus, le vainqueur de Syracuse. Pour Crawford, la monnaie représente une figure masculine d'identité incertaine qui couronne Roma. Mais cette interprétation a été mise en doute et on a proposé de voir ici Honos et Virtus (Richardson, «Honos et Virtus and the Sacra Via», p. 245; Milhous, Honos and Virtus in Roman Art, p. 119). Les attributs des deux personnages de la monnaie coïncident en effet avec l'apparence traditionnelle de ces deux divinités. En outre, le monétaire est un descendant de Marcellus, qui avait consacré un temple à Honos et Virtus, et il est possible qu'il ait ainsi voulu rappeler son illustre ascendance. Le fait qu'Honos soit une divinité qui rétribue le mérite nous paraît en outre expliquer qu'il soit représenté en train de couronner Virtus.

${ }^{34}$ Wissowa, Religion und Kultus der Römer, p. 135 ; Axtell, The Deification of Abstract Ideas, p. 21 ; LATTE, Römische Religionsgeschichte, p. 236.

${ }^{35}$ Voir par exemple CIL XIII, 6708, 6679, 6752, 6762, 7591. Sur le culte d'Honos dans la légion, A. Von Domaszewski, "Die Religion des römischen Heeres », Westdeutsche Zeitschrift für Geschichte und Kunst, 14, 1895, p.1-121; LATTE, Römische Religionsgeschichte, p. 236 sqq. Pour les inscriptions dues à des soldats, voir CIL III, 3307 et 10285 (Pannonie), VIII, 6951 et 15665 (Afrique), V, 4449, 5869, 5892, 7468 (Gaule cisalpine), etc. 
apparaît dans des scènes martiales, comme le triomphe de Titus, ou aux côtés de divinités guerrières comme Mars et Victoria ${ }^{36}$. Avant même l'époque impériale, le fait que les temples qui lui sont consacrés aient été voués pour la plupart pendant des guerres confirme l'aspect militaire important d'Honos ${ }^{37}$. L'emplacement du temple de Fabius Maximus puis de Marcellus, en dehors du pomerium et près de la via Appia, est également révélateur: il s'agit d'un espace situé en dehors du cœur civique de Rome et marqué par les activités militaires: c'est là que s'effectuaient souvent les départs des généraux pour la guerre ou leur retour des opérations. Un temple consacré à Mars se trouvait d'ailleurs à peu de distance de celui d'Honos ${ }^{38}$. Pompée a, quant à lui, associé le culte d'Honos à celui de Venus Victrix, Felicitas et Virtus, déesses associées à la guerre et au prestige militaire ${ }^{39}$.

Honos peut néanmoins parfois être invoqué en contexte civil. L'inscription de l'affranchi M. Bicoleius nous l'indique:

M(arcus) Bicoleio V(ibii) l(ibertus) Honore donom dedet mereto.

«Marcus Bicoleius, affranchi de Vibius, a offert ce don à Honos qui le méritait bien. »

$\left(C I L \mathrm{I}^{2}, 31=I L L R P\right.$ 157).

L'inscription, retrouvée à une trentaine de mètres de l'antique porte Colline ${ }^{40}$, est ancienne: sa brièveté, le datif Honore avec réduction de la diphtongue ei à $e$, les formes donom, dedet, et mereto permettent de la dater du III ${ }^{\mathrm{e}}$ siècle avant J.-C. ${ }^{41}$. Il s'agit d'un texte de dédicace, utilisant un formulaire habituel, pour remercier d'un bienfait reçu. L'élément intéressant réside dans le fait que le dédicant est un affranchi. À la date de l'inscription, les affranchis peuvent figurer dans l'armée mais

${ }^{36}$ Sur un trophée en pierre de 73-74 ap. J.-C. (LIMC n ${ }^{\circ}$; ; PICARD, Les Trophées romains, p. 348-349).

${ }^{37}$ Fabius Maximus, on l'a vu, a voué un temple à Honos lors de la guerre contre les Ligures. Marcellus, lui, a voué un temple à Honos et Virtus à Clastidium et a renouvelé ce vœu lors de la prise de Syracuse (Liv. XXVII, 25, 7 et XXIX, 11, 13; Cic. Verr. II, IV, 123). Le temple édifié à Honos et Virtus par Marius a été construit avec l'argent du butin de la guerre contre les Cimbres (CIL I ${ }^{2}$ p. 195, XVIII), après la victoire de Verceil en 101.

${ }^{38}$ Sur la localisation du temple, voir infra p. 521. Sur le temple de Mars, voir l'article de F. Coarelli, «Aedes Marti», LTUR Sub. IV, p. 44-45.

${ }^{39}$ Sur le complexe de Pompée, voir infra p. 534-535.

${ }^{40}$ D. PalombI, «Honos, aedes », LTUR III, p. 30.

${ }_{41}$ R.WACHTER, Altlateinische Inschriften. Sprachliche und epigraphische Untersuchungen zu den Dokumenten bis etwa 150 v. Chr., Bern, P.Lang, 1987, p.345; PalombI, «Honos, aedes », LTUR III, p. 30; CoARelli, «Il sepolcro degli Scipioni », p. 56 n. 1. 
cela reste rare et ils sont exclus du service régulier ${ }^{42}$. Ce n'est donc pas comme divinité militaire qu'Honos est honoré. L'affranchi semble bien plutôt remercier le dieu de lui avoir octroyé un bienfait qui est peut-être l'affranchissement car la citoyenneté était perçue comme un honos $^{43}$. Le texte montre aussi qu'Honos faisait l'objet d'une dévotion populaire. Une épigramme de Martial indique qu'Honos était invoqué dans le monde des spectacles puisque le poète s'adresse à lui après la mort d'un conducteur de char:

Frangat Idumaeas tristis Victoria palmas, plange, Fauor, saeua pectora nuda manu;

Mutet Honor cultus, et iniquis munera flammis mitte coronatas, Gloria maesta, comas.

«Que Victoire affligée brise les palmes iduméennes, Frappe, Faveur, d'une main cruelle ta poitrine mise à nu;

Qu'Honneur prenne le deuil et toi, Gloire désolée, jette en offrande Aux flammes iniques les couronnes qui parent les cheveux.»

(MART. Ep. X, 50, 1-4).

Maintenant qu'est décédé Scorpus, un agitator qui avait manifestement remporté de nombreux succès, Victoire n'aura plus usage des palmes qui récompensent le vainqueur, Gloire ne le décorera plus de ses couronnes, et Honneur prend le deuil. Honos préside ici aux distinctions honorifiques gagnées lors des ludi. Même si l'on ne se trouve pas ici en contexte militaire, on remarque cependant que c'est dans un contexte agonistique que l'on recherche les faveurs d'Honos.

\section{Le CUlte d’Honos et SA SIgNification idéologiQue ET POLITIQUe}

Ce n'est pas parce qu'Honos est un dieu secondaire et impersonnel, qu'il ne fait pas l'objet d'un culte et ne suscite pas l'intérêt des Romains: le fait qu'il soit dispensateur de marques d'honneur a attiré vers lui bien des dévotions. Honos possédait ainsi à Rome pas moins de quatre sanctuaires différents. Trois d'entre eux ont été édifiés ou modifiés par les Romains les plus éminents de leur temps, Fabius Maximus, Marcellus, Marius et Pompée. La religion et la politique

${ }^{42}$ On ne connaît que quelques rares cas de recrutement d'affranchis, lors de circonstances très difficiles pour Rome, pendant les guerres puniques et la guerre sociale (Liv. XXII, 11, 8; LIv. Per. 74). Les affranchis rejoignent la flotte ou des cohortes auxiliaires de volontaires (Mommsen, DPR, vol. 6, 2, p. 35-36).

${ }^{43}$ Voir supra p. 56. 
étant à Rome inextricables, nous aurons à évaluer l'usage politique fait par ces hommes du culte d'Honos et la signification idéologique de leur dévotion ${ }^{44}$.

\subsection{Les rites attestés}

Il faut souligner, en premier lieu, que si Honos était surtout honoré à Rome, le dieu faisait aussi l'objet d'un culte hors de l'Vrbs. On sait par la lex parieti faciendo de Pouzzoles qu'il existait dans cette ville un aedes Honoris au moins depuis 105 avant notre ère ${ }^{45}$. En outre, le nom officiel de la colonie de Cirta était, depuis César, Colonia Iulia Iuuenalis Honoris et Virtutis $\mathrm{Cirta}^{46}$. On trouve également la trace du dieu, grâce à l'épigraphie, à Terracina, Narbo et Visentium à l'époque impériale ${ }^{47}$. Nous avons plusieurs informations sur les actes de culte adressés à Honos. Sont attestés des sacrifices qui semblent de rite grec: si l'indication de Plutarque selon laquelle on sacrifiait à Honos tête nue n'est pas une trace assurée de ritus graecus, les actes des arvales font tout de même état de l'offrande d'une vache, à l'époque néronienne, ce qui est caractéristique ${ }^{48}$. On connaît aussi par les fastes des fêtes

${ }^{44}$ Pour d'autres exemples de mobilisation des dieux à des fins politiques, voir FEARs, "The Theology of Victory». Nous laissons de côté le sens politique d'Honos quand le dieu est figuré sur des monnaies; l'interprétation de son iconographie pose en effet des difficultés propres à la numismatique. Sur cette question, A. AlföLDI, «The Main Aspects of Political Propaganda on the Coinage of the Roman Republic » in Essays in Roman Coinage Presented to H.Mattingly, Oxford, Oxford University Press, 1956, p.63-95; T.J.Luce, "Political Propaganda on Roman Republican Coins (92-82 B.C.)», AJA, 72, 1968, p. 25-39; C. T.H.R. EhrhardT, «Roman Coin Types and the Roman Public», JNG, 34, 1984, p.41-54; H.ZEHNACKER, Moneta. Recherches sur l'organisation et l'art des émissions monétaires de la République romaine (289 - 31 av. J.-C.), Rome, E.F.R., 1973; M.H. CRAWford, "Roman Imperial Coin Types and the Formation of Public Opinion», in Brooker, C. N. L., Stewart, B. H.I. H., Pollard, J. G. et al. (éds.), Studies in Numismatic Method Presented to P. Grierson, Cambridge, Cambridge University Press, 1983, p. 47-64. Les deux monnaies qui représentent Honos de manière assurée $\left(R R C \mathrm{n}^{\circ} 403,1\right.$ et $\mathrm{n}^{\circ}$ 473, 2a) ont été étudiées par ZEHNACKer ( $I$ bid. vol. 1, p. 580-581 et 590), B. ManNSPERGER, «Libertas - Honos - Felicitas. Zur Prägung des Münzmeisters Palikanus », Chiron, 4, 1974, p. 327-342 et C.J. Classen, «Virtutes Romanorum nach dem Zeugnis der Münzen republikanischer Zeit », $M D A I(R), 93,1986$, p. 257-279.

${ }^{45} C I L \mathrm{I}^{2}, 698,2,1.11$ = FIRA III, p. 472, n. 153. La lex est le texte d'un marché passé en 105 par Pouzzoles pour la construction d'une porte dans le rempart qui longe la ville côté mer.

${ }^{46}$ CIL VIII, 7041.

${ }^{47}$ Respectivement, CIL X, 8266; X, 4371; XI, 2910 et 2911.

${ }^{48}$ Plut. Aet. $266 \mathrm{f}$ (= Moralia IV, 18, éd. Boulogne). Mars était honoré tête nue sans qu'il soit question de rite grec à son sujet. On se découvrait aussi pour honorer Saturne, mais cela correspondait au fait que le dieu présidait au phénomène général de la dissolution (J.ScHEID, "Graeco ritu: A Typically Roman Way of Honoring the Gods », HSCPh, 97, 1995, p. 15-31). Sur la vacca, CIL VI, 2044. Selon Milhous, Honos and Virtus in Roman Art, p. 44, ce serait un remerciement adressé par Néron à Honos après l'échec de la conjuration de Pison, pour avoir sauvegardé son prestige. 
en l'honneur d'Honos et Virtus. D'après les Fasti Antiates Maiores, les dieux étaient fêtés ensemble le 17 juillet, puis, à partir d'Auguste, le 29 mai $^{49}$. Les fastes d'Amiternum indiquent qu'Honos, Virtus, Felicitas, Venus Victrix et une autre divinité, dont la lettre initiale est un V. et dont l'identité est controversée, étaient célébrés le 12 août in theatro Marmoreo, c'est-à-dire dans le temple situé au sommet de la cauea du théâtre de Pompée, dans le complexe du Champ de Mars ${ }^{50}$. Il est également possible que la transuectio equitum, qui a lieu le 15 juillet, deux jours après la fête d'Honos, ait été associée d'une certaine manière à Honos: s'il n'est pas certain que le temple construit pour Honos par Fabius Maximus à la porte Capène en constituait le point de départ, il se trouvait au moins sur l'itinéraire de la procession, dont le déroulement avait été profondément modifié par l'ancêtre de Fabius Maximus, Fabius Rullianus ${ }^{51}$. Enfin, à l'époque impériale, des ludi pour Honos et Virtus sont attestés à Terracina et on connaît un collegium qui leur est dédié 52 .

\subsection{Le temple de la porte Colline}

Ce temple, le plus vieux des sanctuaires connus d'Honos, est mentionné par un passage du De Legibus à propos des sépultures situées sur des terrains publics:

Nostis extra portam Collinam aedem Honoris. Aram in eo loco fuisse memoriae proditum est. Ad eam cum lamina esset inuenta, et in ea scriptum 'Honoris', ea causa fuit ut aedis haec dedicaretur. Sed quom multa in eo loco sepulcra fuissent, exarata sunt. Statuit enim collegium locum publicum non potuisse priuata religione obligari.

«Vous connaissez le temple d'Honneur situé après la porte Colline. On raconte qu'il y avait en ce lieu un autel. Comme on avait trouvé près de ce dernier une plaque sur laquelle était inscrit 'd'Honneur', ce fut la raison pour laquelle on dédia ce temple. Mais comme il y avait de nombreux tombeaux en cet endroit, ils furent rasés, car le Collège décida qu'un lieu appartenant à l'État ne pouvait être assujetti à des obligations religieuses privées. »

(Cic. Leg. II, 58; trad. De Plinval modifiée).

Le temple devait se trouver à proximité directe de la porte Colline mais à l'extérieur de l'enceinte puisque sa construction a nécessité le déplacement de tombes qui ne pouvaient être à l'intérieur du

${ }^{49}$ CIL I I $^{2}$, p. 319; DC. LIV, 18.

${ }^{50} C I L \mathrm{I}^{2}$, p. 244. Sur les divinités du complexe de Pompée, voir infra p. 535 sqq.

${ }^{51}$ Voir la démonstration de McDonnell, Roman Manliness, p. 215-216.

${ }^{52}$ CIL X, 8266 et XII, 4371. 
pomerium $^{53}$. Vu la façon dont Cicéron l'évoque (nostis [...] aedem Honoris) il est possible qu'il n'ait pas été extrêmement bien connu de ses contemporains et n'ait donc plus été au $\mathrm{I}^{\mathrm{er}}$ siècle un sanctuaire majeur. À la différence de tous les autres temples d'Honos, le choix de son emplacement repose sur une raison sacrée. D'après Cicéron, c'est suite à la découverte d'un autel ainsi que d'un fragment inscrit portant le terme "Honoris » que les pontifes ont estimé avoir retrouvé un sanctuaire primitif d'Honos tombé à l'abandon qu'il fallait restaurer. Des facteurs historiques ont pu contribuer à la volonté de faire renaître le culte d'Honos. Le temple de la porte Colline a pu être édifié entre 300 et 240 environ $^{54}$. Or il a été souligné que les forces divines étaient très souvent introduites dans des périodes de crise ${ }^{55}$. Il n'y a pas en effet à Rome de «révélation » des dieux: ce sont les magistrats et les prêtres de la cité qui décident de leur installation ${ }^{56}$. Plusieurs épisodes difficiles pour Rome pourraient avoir donné lieu à l'introduction d'Honos entre 300 et 250, mais c'est la première guerre punique qui nous paraît constituer le contexte le plus vraisemblable. D'autres phénomènes de scrupule religieux se sont en effet manifestés à cette époque, comme l'introduction du culte de Dis et Proserpine en 248, prescrite par les livres sibyllins, ou la condamnation qui frappe la Vestale Claudia, sœur de Publius Claudius Pulcher, pour le vœu incivique qu'elle avait formulé en 246. C'est aussi à cette époque que le grand pontife interdit solennellement à Aulus Postumius Albinus, consul, de quitter Rome parce qu'il est aussi flamine de Mars ${ }^{57}$. On peut faire l'hypothèse que la dédicace d'un temple à Honos est une manifestation de ce souci des rites et du droit sacré à une période où Rome est menacée. Honos a pu bénéficier en outre d'un intérêt particulier car il était à même, dans le contexte d'une guerre, de contribuer au succès de Rome en lui assurant la victoire et les honneurs qui s'ensuivent.

\subsection{Le temple de la porte Capène (1): la dévotion de Fabius Maximus}

Les circonstances de l'édification du temple dédié à Honos par Fabius Maximus sont différentes, tout comme les fonctions assurées

\footnotetext{
${ }^{53}$ Sur sa localisation, A.ZıоLкоwsкi, The Temples of Mid-Republican Rome and Their Historical and Topographical Context, Rome, L'Erma, 1992, p. 57 et Richardson, «Honos et Virtus and the Sacra Via», p. 243.

${ }^{54}$ Sur la date du temple, voir Platner et Ashby, A Topographical Dictionary of Ancient Rome; L.J.Richardson, A New Topographical Dictionary of Ancient Rome, Baltimore, The Johns Hopkins University Press, 1992, p. 190.

${ }^{55}$ Concordia a été introduite après la crise civile de 367 et Salus après les guerres samnites (FEARS, "The Theology of Victory», p. 741 et FEARS, "The Cult of Virtues», p. 833). Voir aussi Clark, Divine Qualities, p. 58 sur l'introduction des notions divines dans des circonstances difficiles pour Rome.

${ }^{56}$ J. Scheid, Religion et piété à Rome, 2e éd., Paris, A. Michel, 2001, p. 70.

${ }^{57}$ Sur ces épisodes, HinARD (éd.), Histoire romaine, p. 372.
} 
par le bâtiment. À partir de la fin du III ${ }^{\mathrm{e}}$ siècle, les édifices religieux sont de plus en plus liés à celui qui les réalise. Ils sont pour le commanditaire un moyen de rendre hommage à une divinité mais aussi de s'affirmer sur la scène publique. Ce temple est évoqué notamment par Cicéron, dans le passage du De natura deorum dont il a déjà été question et que nous citons à nouveau partiellement:

Vides Virtutis templum uides Honoris a M. Marcello renouatum, quod multis ante annis erat bello Ligustico a Q. Maxumo dedicatum.

«Tu vois le temple de Vertu, celui d'Honneur restauré par Marcellus, qui avait été dédié il y a de nombreuses années par Quintus Maximus, lors de la guerre contre les Ligures. »

(CIC. ND II, 61).

Fabius est à l'origine de la construction du temple et c'est lui qui l'a dédié ; puis Marcellus l'a restauré et a adjoint à Honos, qui était honoré seul à l'origine, la divinité Virtus. L'identité du Q. Fabius Maximus évoqué par Cicéron a fait l'objet de discussions. Alors qu'on s'accordait traditionnellement à l'identifier à Fabius Maximus Verrucosus, le «Cunctator» de la deuxième guerre punique, L. Richardson et D. Palombi ont considéré qu'il s'agissait de son grand-père, Fabius Maximus Rullianus ${ }^{58}$. Cicéron indique en effet qu'entre la dédicace de Fabius et la restauration par Marcellus s'est écoulé un intervalle de multis annis, expression qui convient mieux à la distance temporelle séparant Rullianus et Marcellus qu’à celle, plus réduite, entre Verrucosus et Marcellus. En outre, Rullianus a joué un rôle important dans la réorganisation en 304 de la transuectio equitum qui partait selon le ps.-Aurelius Victor de ce temple d'Honos. La remarque du De uiris illustribus serait anachronique si Verrucosus était à l'origine de la construction du temple ${ }^{59}$. Cependant, ces arguments ne nous paraissent pas convaincants et l'attribution à Verrucosus doit être maintenue. L'expression multis annis, d'abord, peut parfaitement convenir pour désigner l'intervalle d'environ vingt-cinq ans qui sépare la dédicace de Fabius et celle de Marcellus qui ne fut opérée que tardivement. Quant à la transuectio equitum, le De uiris illustribus peut commettre un anachronisme en lui assignant comme point de départ le temple d'Honos dès l'époque de Rullianus; il est vraisemblable que le temple de Mars, qui n'est pas très loin, ait joué ce rôle avant l'existence du sanctuaire d'Honos, ce qui expliquerait que Denys d'Halicarnasse situe le départ de la procession au temple de $\operatorname{Mars}^{60}$. Il est possible que la procession soit partie ensuite seulement du nouveau temple d'Honos.

${ }^{58}$ Richardson, «Honos et Virtus and the Sacra Via», p. 244 et D. Palombi, «Honos, aedes », LTUR III, p. 30-31.

${ }^{59}$ Ps.-Aur. Vict. Vir. 32.

${ }^{60} \mathrm{DH}$. VI, 13, 4-5. 
Il est fréquent que les auteurs anciens projettent sur Rullianus des faits qui concernent son descendant ${ }^{61}$. Enfin, Cicéron parle clairement de la guerre ligure, qui a été menée par Verrucosus ${ }^{62}$. Ce dernier nous paraît donc à l'origine de ce temple. Cela n'aurait rien de surprenant chez un homme aussi averti en matière de religion: à partir de 216, il fut pontife et augure, cas unique à Rome jusqu'à Sylla, et il joua un grand rôle pendant la deuxième guerre punique dans l'institution du culte d'une autre force divine, Mens ${ }^{63}$.

Il est assez vraisemblable que ce temple soit issu d'un vœu fait par Fabius lors des opérations menées contre les Ligures, en 233, lors de son premier consulat. Environ $60 \%$ des nouveaux temples bâtis à Rome procèdent de vœux, réalisés lors de périodes difficiles et surtout pendant des guerres. Le général peut vouer un temple à un dieu pour s'attirer la victoire avant une bataille ou à son issue, quand elle est favorable, pour remercier une divinité de son aide ${ }^{64}$. Celui qui fait la dédicace d'un temple est aussi, en général, celui qui a fait le uotum, et l'on sait par le texte de Cicéron cité supra que c'est Fabius qui a dédié le temple. C'est donc sans doute lui qui est à l'origine du uotum. Cette dédicace est liée aux activités guerrières: c'est parce que Fabius a obtenu une victoire qui fut suivie d'un triomphe, très grand honos, qu'il a édifié le temple. Cette dédicace va cependant plus loin car elle remplit pour Fabius une fonction politique ${ }^{65}$. En 233, ce descendant d'une des plus grandes familles de Rome exerce son premier consulat et cherche probablement, par cette dévotion personnelle à Honos, à

${ }^{61}$ Voir l'article de F. Münzer dans la RE s. v. Fabius $n^{\circ} 114$. Sur l'anachronisme probable du De Viris illustribus, Platner et AshBy, A Topographical Dictionary of Ancient Rome, p. 259; H.H. Scullard, Festivals and Ceremonies of the Roman Republic, Londres, Thames and Hudson, 1981, p. 165.

${ }^{62}$ F. Münzer dans la RE s. v. Fabius n ${ }^{\circ}$ 116. Sur la campagne ligure, Plut. Fab. 2.

${ }^{63}$ Sur ses charges religieuses, Liv. XXIII, 21, 7 et J.RüPKE, Fasti sacerdotum, Stuttgart, F.Steiner, 2005, vol.2, p. 971. Sur le culte de Mens, Fears, "The Cult of Virtues », p. 855-857 et CLARK, Divine Qualities, p. 66.

${ }^{64}$ Sur le fonctionnement du uotum en général, OrLin, Temples, Religion and Politics in the Roman Republic, Leiden, Brill, 1997, p.35 sqq. et Ziolkowski, The Temples of Mid-Republican Rome, p.195-203. Pour les données chiffrées, Orun, Temples, Religion and Politics in the Roman Republic, p. 48. Les cultes adressés aux notions divines sont fréquemment introduits à la suite de vœux en contexte militaire. $C f$. le temple à Fors Fortuna édifié par Sp. Carvilius avec le butin de ses campagnes à Cominium et en Étrurie (Liv. X, 46, 14) et le temple à Iuventas voué par M. Livius Salinator lors de la bataille du Métaure (Liv. XXXVI, 36, 5). Pour un exemple de formule de vœu, voir Liv. $\mathrm{X}, 19,17$ : Bellona, si hodie nobis uictoriam duis, ast ego tibi templum uoueo; "Bellone, si tu nous donnes la victoire aujourd'hui, moi, je te voue un temple. »

${ }^{65}$ La construction d'un temple à Mens aura elle aussi un sens politique et idéologique puisqu'elle sera en phase avec sa stratégie de temporisation sage et réfléchie qui lui vaudra le surnom de Cunctator pendant la deuxième guerre punique. Sur l'usage politique fait par Fabius de la religion, R. Develin, "Religion and Politics at Rome during the Third Century B.C. », JRH, 10, 1978, p. 3-19. 
lancer sa carrière publique. La dédicace du temple sert à associer son nom à la divinité qu'il honore dans un édifice visible et durable et à se placer, de manière propitiatoire, sous la protection du dieu qui délivre les honores. Fabius affirme ainsi sa volonté de se montrer digne de son ancêtre Rullianus en accumulant les honores comme ce dernier le fit ${ }^{66}$. L'édifice, d'abord, rappelle indirectement le souvenir de sa victoire et de son triomphe. Il occupe ensuite un emplacement stratégique. Le choix de ce dernier ne répond pas, comme pour le sanctuaire de la porte Colline, à une exigence religieuse mais à une décision personnelle du dédicant. On sait par Tite Live qu'il se trouvait ad portam Capenam, c'est-à-dire dans les environs de la porte Capène, à l'extérieur de l'enceinte ${ }^{67}$. Le temple était ainsi localisé dans un des lieux de Rome les plus prestigieux. Il se trouvait en effet le long de la uia Appia qui menait vers la Campanie et que l'on appelait la «reine des voies ${ }^{68}$. L'axe était très fréquenté et symbolisait, par sa rectitude, l'autorité romaine dans le Latium ${ }^{69}$. De très grandes gentes de Rome y installaient leur tombeau familial et il s'agissait donc d'un lieu où s'exprimait par l'architecture la compétition des aristocrates romains pour la gloire $^{70}$. Le prestige de la porte Capène venait aussi du fait que c'était à cet endroit que, depuis le $\mathrm{IV}^{\mathrm{e}}$ siècle, les généraux étaient accompagnés lors de leur départ en campagne et accueillis lors de leur retour ${ }^{71}$. Les délégations étrangères venant de l'est et du sud de Rome y passaient également ${ }^{72}$. La localisation du sanctuaire à cet endroit relève donc chez Fabius Verrucosus d'une volonté manifeste de prestige dans le contexte de l'antagonisme aristocratique.

Fabius, cependant, n'est pas Marius ou Pompée. Il n'y a pas encore, au III siècle, d'appropriation personnelle de la divinité. La construction du temple à Honos a aussi un sens idéologique pour la cité tout

${ }^{66}$ Rullianus fut cinq fois consul (en 322, 310, 308, 297 et 295) et triompha trois fois (en 322, 309 et 295).

${ }^{67}$ Liv. XXV, 40 et XXIX, 11, 13. Platner et Ashby, A Topographical Dictionary of Ancient Rome, p. 259; Ziolkowski, The Temples of Mid-Republican Rome, p. 59; PalomBI, "Honos, aedes", LTUR III, p. 32. L'expression ad portam Capenam indique bien que le temple est à l'extérieur du pomerium: on la retrouve à propos du tombeau des Scipions qui est assurément hors de l'enceinte. D'autres éléments rendent cette localisation très plausible, et notamment la proximité de la tombe des Marcelli, dont l'un des membres sera à l'origine de la modification de l'édifice (COARELl, Guide archéologique de Rome, p. 112), et du temple de Mars, autre divinité militaire.

${ }^{68}$ L'expression est de Stat. Silu. II, 1, 12.

${ }^{69}$ Voir Ziolkowski, The Temples of Mid-Republican Rome, p. 298; J. R. Patterson, "Via Appia », LTUR V, p. 130-133.

${ }^{70}$ Y avaient leur tombeau les Scipions, Marcelli, Seruilii et Calatini (CIc. Tusc. I, 13). Voir Coarelli, Guide archéologique de Rome, p. 112 et F. ZeVI, "Sepulcrum Scipionum », LTUR IV, p. 281-285. Celui des Scipions paraît le plus ancien et semble à l'origine d'une convergence des monuments funéraires de la nobilitas vers cette zone.

${ }^{71}$ Coarelli, "Porta Capena », LTUR III, p. 325.

${ }^{72}$ Ziolkowski, The Temples of Mid-Republican Rome, p. 292. 
entière car elle exalte la puissance de Rome. La dédicace a lieu en effet à un moment où son rayonnement est à un très haut niveau: quelques années auparavant, l'Vrbs a vaincu Carthage, s'est emparé de la Sardaigne et a pu ajouter au traité de paix conclu avec les Puniques des clauses supplémentaires humiliantes pour les vaincus. En 235, deux ans avant la dédicace à Honos, le temple de Janus a été fermé, pour la deuxième fois de l'histoire de Rome ${ }^{73}$. Le vœu fait à Honos, divinité proprement romaine d'une part et veillant sur les honneurs et le prestige d'autre part, participe à cette exaltation par la cité de sa propre puissance dans le prolongement de la fin victorieuse de la première guerre punique.

\subsection{Le temple de la porte Capène (2): la transformation de M. Claudius Marcellus}

Le temple édifié par Fabius Maximus a fait l'objet d'une transformation importante de la part d'un autre grand général romain, M. Claudius Marcellus, contemporain du premier. Plusieurs sources nous apprennent qu'à Clastidium, en 222, Marcellus avait fait le vœu d'édifier un temple à Honos et Virtus. Cependant, il ne semble pas s'être exécuté, malgré le succès remporté contre les Gaulois, puisqu'il réitéra le même vœu onze ans après, en 211 , lors de l'attaque décisive contre Syracuse ${ }^{74}$. Le projet de temple dédié à Honos et Virtus repose ici encore sur un uotum fait dans un contexte militaire. On sait qu'à Syracuse il fut formulé avant la bataille et visait donc à se rendre propice les divinités invoquées pour le combat à venir:

Et Marcellus qui, si Syracusas cepisset, duo templa se Romae dedicaturum uouerat, is id quod erat aedificaturus iis rebus ornare quas ceperat noluit.

«Et Marcellus, qui avait fait le vœu, s'il prenait Syracuse, de dédier à Rome deux temples, ne voulut pas que l'on ornât le bâtiment qui allait être construit des objets qu'il avait pris.»

(CIc. Verr. II, IV, 123).

Malgré ce nouveau vœu, aucun temple n'est encore construit et ce n'est que trois ans plus tard, en 208, que Marcellus s'acquitte de sa promesse. Mais le projet de Marcellus a subi des modifications: le texte cité ci-dessus évoque la construction d'un nouvel édifice (aedificaturus) mais il n'y eut finalement que «rénovation», comme le dit le $D e$ natura deorum, du sanctuaire construit par Fabius à la porte Capène ${ }^{75}$,

${ }^{73}$ Sur ce contexte historique, HinaRd (éd.), Histoire romaine, p. 380-381.

${ }^{74}$ Liv. XXVII, 25, 7 ; XXIX, 11, 13; Val. MaX. I, 1, 8; Eum. VII, 1-2.

${ }^{75}$ Sur cette rénovation et la nouvelle dédicace qui s'ensuivit, CIc. ND II, 61 ; CIL VI, 449; Lact. Inst. I, 20, 12. Voir Platner et Ashby, A Topographical Dictionary of Ancient Rome, p. 259. 
rénovation qui posa des problèmes, ainsi que l'explique Valère Maxime :

In qua cum Marcellus quintum consulatum gerens templum Honori et Virtuti, Clastidio prius, deinde Syracusis potitus, nuncupatis debitum uotis consecrare uellet, a collegio pontificum impeditus est negante unam cellam duobus diis recte dicari; futurum enim, si quid prodigii in ea accidisset, ne dinosceretur utri rem diuinam fieri oporteret; nec duobus nisi certis diis una sacrificari solere. Ea pontificum admonitione effectum est ut Marcellus separatis aedibus Honoris ac Virtutis simulacra statueret neque aut collegio pontificum auctoritas amplissimi uiri aut Marcello adiecto impensae impedimento fuit quominus religionibus suus tenor suasque obseruatio redderetur.

"C'est chez elle que Marcellus, au cours de son cinquième consulat, quand il voulait consacrer un temple à Honneur et à Valeur, à la suite de la prise de Clastidium d'abord, puis de Syracuse, pour s'acquitter des vœux faits alors, s'en trouva empêché par le collège des pontifes qui déclarait qu'une seule chapelle ne pouvait pas normalement être dédiée à deux divinités. Car il serait impossible, si quelque prodige s'y produisait, de décider à laquelle adresser la cérémonie qui serait accomplie alors, et il n'y a que certaines divinités qui peuvent recevoir un sacrifice à deux, selon la coutume. Cet avertissement des pontifes fit que Marcellus plaça dans deux sanctuaires indépendants les statues d'Honneur et de Valeur; ainsi ni le collège des pontifes ne trouva dans l'autorité d'un homme si éminent ni Marcellus dans ce surcroît de dépense un obstacle à la continuité qu'ils devaient assurer dans la pratique religieuse ni au respect qu'ils devaient y apporter.»

(VAL. MAX., I, 1, 8; trad. Combès).

La volonté de Marcellus de consacrer un temple à Honos et Virtus pose un problème de droit sacré qui amène les pontifes à s'opposer à sa dédicace: une même cella ne peut être consacrée à deux divinités car si un prodige s'y produisait on ne saurait auquel des dieux l'expiation devrait être adressée ${ }^{76}$. Pour contourner le problème, Marcellus fait ajouter au temple de Fabius consacré à Honos une aedes spécifique pour Virtus:

Ita addita Virtutis aedes adproperato opere; neque tamen ab ispo aedes eae dedicatae sunt. Tum demum ad exercitum quem priore anno Venusiae reliquerat cum supplemento proficiscitur.

«Aussi ajouta-t-on en hâte un temple pour Virtus; et d'ailleurs ces temples ne furent pas dédiés par lui-même. C'est seulement à ce moment qu'il part avec des renforts pour l'armée qu'il avait laissée l'année précédente à Venouse. »

(Liv. XXVII, 25, 10 ; trad. Jal).

${ }^{76}$ L'opposition des pontifes est aussi évoquée par Liv. XXVII, 25, 6-10 et Plut. Marc. 28. Sur le problème de droit sacré, A.Von Domaszewski, Abhandlungen zur römischen Religion, Leipzig, Teubner, 1909, p.168-169 et DumézIL, La Religion romaine archaïque, p. 401-402. 
Comme l'indique Tite Live, Marcellus ne fit pas lui-même la dédicace du temple: il dut partir pour Venouse où il mourut dans une embuscade. C'est son fils qui assura la dédicace, en 205, dix-sept ans après le vœu initial de son père à Clastidium ${ }^{77}$. Laspect du temple de Fabius en était donc modifié: il comprenait désormais deux aedes dont les façades se rejoignaient ${ }^{78}$. Le temple comprenait des statues cultuelles et fut orné des dépouilles prises à Syracuse ${ }^{79}$.

À première vue, la dévotion de Marcellus pour Honos et Virtus ressemble à celle de Fabius. Comme son contemporain, Marcellus a fait un vœu au cours d'une guerre pour se concilier des divinités. Le premier vœu, à Clastidium, eut lieu lors de son premier consulat et Marcellus, qui appartient à une famille prestigieuse, semble avoir voulu lui aussi affirmer son intention de se montrer digne de ses ancêtres en matière d'honos ${ }^{80}$. La volonté de dédier un temple à Honos et Virtus est également guidée, comme pour Fabius, par le souci du prestige. Le choix d'Honos s'explique par le désir de donner dans l'Vrbs un écho architectural durable à l'honos exceptionnel que Marcellus a obtenu à Clastidium, les dépouilles opimes remportées sur le chef gaulois ${ }^{81}$, et le renouvellement du vœu est une façon de rappeler les autres marques d'honneur régulières obtenues, comme le triomphe ou le consulat ${ }^{82}$. Marcellus va cependant plus loin que Fabius dans l'établissement de liens entre sa personne et le dieu. La rénovation du temple de la porte

${ }^{77}$ Liv. XXIX, 11, 13. La dédicace est faite par le fils de Marcellus, ce qui est normal car il hérite des obligations religieuses de son père. Mais il a la particularité de le faire en tant que priuatus. On ne connaît qu'un seul autre exemple de cet état de fait, celui de Caton l'Ancien pour la dédicace du sanctuaire de Victoria Virgo en 193 (OrLin, Temples, Religion and Politics in the Roman Republic, p.170-171). Sur ce retard de dédicace, M. Aberson, Temples votifs et butin de guerre dans la Rome républicaine, Genève, Institut suisse de Rome, 1994, p. 120-121. Sur la procédure de dédicace en général, Zıolkowski, The Temples of Mid-Republican Rome, p. 219-234.

${ }^{78}$ Une lettre de Symmaque à Ausone précise que les deux aedes étaient placées iunctim et gemella facie. (Symm. Ep. I, 20,1). Plutarque parle également de la solidarité des deux aedes (Plut. Marc. 28).

${ }^{79}$ Cic. Verr. II, IV, 121 et Rep. I, 21; Liv. XXV, 20, 3. À l'époque de Tite Live, il ne reste pas grand'chose de ces ornamenta. Le bâtiment semble avoir été édifié grâce au butin de la prise de Syracuse (Plut. Marc. 28; voir Aberson, Temples votifs et butin de guerre dans la Rome républicaine, p. 32-33).

${ }^{80}$ Eumène note que l'édification d'un temple à Honos et Virtus procède de la passion pour les honores et pour la uirtus d'un individu qui en est le sectator et le fautor (Eum. VI, 4).

${ }^{81}$ Liv. Per. 20 ; Plut. Marc. 7-8; Val. Max. III, 2, 5. Voir H. I. Flower, «The Tradition of the Spolia Opima: M. Claudius Marcellus and Augustus », ClAnt, 19, 2000, p. 34-64.

${ }^{82}$ Marcellus a triomphé en 222 et a célébré deux cérémonies triomphales mineures en 211 (Itgenshorst, Tota illa pompa ${ }^{\circ} 155$ et 158-159). Il fut consul en 222, 214, 210 et 208 ( $M R R$ vol. 1, p. 232). Sur le lien entre ses honores et le choix du dieu Honos, voir SpanNagel, «Zur Vergegenwärtigung abstrakter Wertbegriffe in Kult und Kunst der römischen Republik», p. 246. 
Capène prend en effet pour lui un tour particulier car le sanctuaire est localisé près de la tombe des Marcelli ${ }^{83}$ : l'endroit devient ainsi le lieu de l'exaltation de la grandeur de la gens et de ses honores, d'autant que le petit-fils de Marcellus fit ajouter des statues des membres illustres de la famille dans le tombeau ainsi qu'une inscription rappelant les neufs consulats, maximi honores, obtenus au total par trois d'entre $e^{84}{ }^{84}$. On a vu aussi que furent mises dans le temple des œuvres d'art prises à Syracuse par Marcellus: le temple n'est plus alors seulement un édifice du peuple romain mais aussi le réceptacle des exploits du général $^{85}$. Ces éléments renforcent l'impression d'un lien organique entre les Marcelli et Honos, première étape de l'appropriation des divinités par les grands imperatores du $\mathrm{I}^{\mathrm{er}}$ siècle puis par les empereurs ${ }^{86}$. Une dernière particularité montre que les intentions de Marcellus sont différentes de celles de Fabius: Marcellus est le premier à unir le culte d'Honos à celui de Virtus au sein d'un temple. Ce choix nous paraît reposer précisément sur le désir de se démarquer de son contemporain Fabius Maximus: la consécration d'un temple à Vaillance vise à donner un écho à sa conduite très active lors de la deuxième guerre punique, différente de la stratégie dilatoire incarnée par Fabius. Marcellus, pour reprendre une image traditionnelle, a été pendant la guerre l'épée de Rome quand Fabius en était le bouclier ${ }^{87}$ : il a pris à plusieurs reprises des initiatives audacieuses pour affronter directement Hannibal et c'est, selon Tite Live, en raison de sa témérité qu'il a

${ }^{83}$ CoArelli, Guide archéologique de Rome, p. 325 ; PAtTerson, «Via Appia », LTUR V, p. 131.

${ }^{84}$ Idem cum statuas sibi ac patri itemque auo poneret in monumentis aui sui ad Honoris et Virtutis, decore subscripsit: TRES MARCELLI NOVIES COSS. <Fuit enim ter consul, > auus quinquies, pater semel. "Ce même Marcellus fit placer des statues de lui, de son père et de son grand-père dans le monument de son grand-père, près du temple d'Honneur et Vertu, et ajouta une belle inscription: 'trois Marcellus, neuf fois consuls'. Car il fut trois fois consul, son grand-père cinq fois et son père une fois. " (Ascon. In Pis. p. 11, 15). CLARK, Divine Qualities, p. 180-181.

${ }^{85}$ L'introduction des dépouilles de Syracuse dans le temple d'Honos et Virtus revêt une portée idéologique particulière car elles étaient composées d'œuvres d'art et d'objets scientifiques (CIc. Rep. I, 21 parle d'une sphère, œuvre d'Archimède); se trouvaient donc unies dans un même lieu la culture grecque et des notions traditionnelles romaines comme l'honos et la uirtus. Sur ce point, P. Gros, «Les statues de Syracuse et les 'dieux' de Tarente», REL, 57, 1979, p.85-114; K. MeIster, "Die Tugenden der Römer», in Oppermann, H.(éd.), Römische Wertbegriffe, Darmstadt, Wissenschaftliche Buchgesellschaft, 1967, p. 1-22.

${ }^{86}$ Le lien entre Marcellus et le dieu s'accentue encore si l'on suit l'hypothèse d'A. J. Clark selon laquelle la pièce de Naevius, Clastidium, aurait été représentée à l'occasion de la dédicace du temple et non lors des funérailles de Marcellus (CLARK, Divine Qualities, p.111-113). Plusieurs forces divines de l'époque républicaine deviennent à l'époque impériale des vertus divines du prince (FEARs, "The Cult of Virtues», p. 875 sqq.).

${ }^{87}$ Plut. Marc. 12. 
trouvé la mort à Venouse dans une embuscade ${ }^{88}$. On comprend ainsi qu'à Honneur il ait voulu associer Vaillance pour afficher sa singularité et transposer dans le domaine divin deux traits dont il pensait qu'ils le caractérisaient. L'affirmation par Marcellus de son prestige et de celui de sa gens n'a pas été sans susciter des oppositions qui expliquent les anomalies qui émaillent l'histoire de la dédicace du temple: le premier vœu n'est pas acquitté; le second ne l'est que trois ans après avoir été formulé; Marcellus choisit finalement d'ajouter à la hâte une aedes pour Virtus à un temple déjà existant avant de partir en campagne. Ces retards accumulés ne peuvent avoir été le fait d'un manque de moyens ou d'une négligence de la part de Marcellus. Ils témoignent plutôt de l'opposition d'une partie suffisamment puissante de la classe politique. Il en va de même pour l'impossibilité de la dédicace à Honos et Virtus mise en avant par les pontifes. Valère Maxime déforme la réalité en indiquant que cet épisode témoigne, par son heureuse résolution, de la concorde au sein de la cité. Ce problème de droit sacré signale une tension au sein de l'aristocratie romaine et a dû être soulevé, à travers les pontifes, par le même groupe hostile à Marcellus. Il s'agit

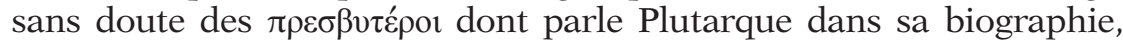
les sénateurs traditionalistes ${ }^{89}$. Marcellus a en effet déjà été en butte à leur hostilité: élu consul en 215 , il a été contraint d'abdiquer sous le prétexte d'un coup de tonnerre entendu au moment de l'élection ${ }^{90}$; à son retour de Syracuse en 211, le sénat lui a refusé le triomphe, ne lui octroyant qu'une ouatio, ce qui l'a amené à triompher à ses frais in monte Albano ${ }^{91}$. Marcellus a donc été, par deux fois, privé d'un honos prestigieux, ce qui donne à son entêtement à vouloir dédier un temple à Honos et Virtus un nouveau relief: il s'agit pour lui d'affirmer la légitimité de sa prétention à l'honos en raison de sa uirtus. L'hostilité de la nobilitas traditionaliste à Marcellus s'explique par plusieurs facteurs. Il n'appartient pas, d'abord, à la plus haute noblesse de Rome puisque les Marcelli sont une branche plébéienne de la gens Claudia; il est en outre vu comme le responsable de l'introduction à Rome de l'art grec, ce dont plusieurs sénateurs lui tiennent rigueur ${ }^{92}$. Enfin, sa volonté de dédier un temple à Honos et Virtus interfère nécessairement avec la dévotion, préexistante, de Fabius Maximus à Honos. La reconstruction du temple de la porte Capène avec l'ajout d'une aedes à Virtus constitue

${ }^{88}$ LIV. XXVII, 27.

${ }^{89}$ Plut. Marc. 21. P. Gros l'a parfaitement mis en lumière dans son article, que nous utilisons ici (Gros, «Les statues de Syracuse et les 'dieux' de Tarente»). Sur l'opposition sénatoriale à Marcellus dans cet épisode, voir aussi ABERSON, Temples votifs et butin de guerre dans la Rome républicaine, p. 148.

${ }^{90}$ Liv. XXIII, 31, 13. Voir MRR, vol. 1, p. 254.

${ }^{91}$ Liv. XXVI, 21, 1-14; Plut. Marc. 22 ; voir Brennan, « Triumphus in Monte Albano », p. 323-324.

${ }^{92}$ Gros, «Les statues de Syracuse et les 'dieux' de Tarente», p. 103. 
une remarquable captation par les Marcelli d'un édifice associé à la gens Fabia $^{93}$. On comprend mieux, du même coup, l'opposition des pontifes à la dédicace du temple, car Fabius Maximus appartenait lui-même au collège ${ }^{94}$. Le problème de droit sacré est un épisode de la rivalité entre les deux hommes, qui n'ont pas toujours collaboré politiquement, et révèle les tensions qui parcourent l'aristocratie romaine ${ }^{95}$.

\subsection{Le sanctuaire de Marius}

Un peu plus d'un siècle après la dédicace du temple de la porte Capène sous sa forme remaniée par Marcellus, un nouveau sanctuaire consacré à Honos et Virtus fait son apparition à Rome à l'initiative de Marius. Ce nouvel édifice présente des points communs avec le sanctuaire de la porte Capène, mais son sens global est différent, en raison du contexte historique d'une part, qui voit la montée des affrontements au sein de la cité, et de la personne du dédicant d'autre part, un homo nouus parvenu au sommet du pouvoir. Comme nous l'apprend l'elogium inscrit de Marius au forum d'Auguste, le temple a été édifié avec le butin de la guerre contre les Cimbres:

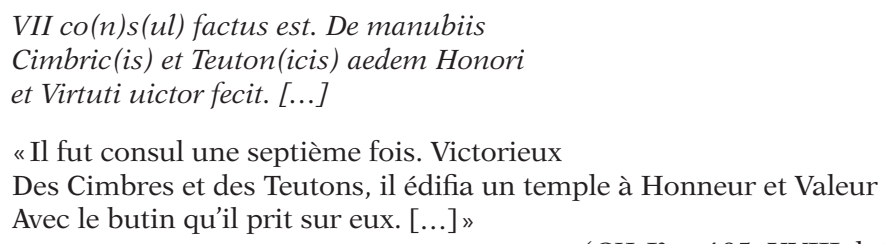

(CIL I² p. 195, XVIII, 1. 16-18).

Le sanctuaire a donc été construit après la victoire remportée par Marius et Q. Lutatius Catulus sur les Cimbres à Verceil en 101. Il est vraisemblable que, comme les dédicaces de Fabius et Marcellus, celle de Marius soit issue d'un uotum fait à Verceil ${ }^{96}$. La particularité de l'édifice est qu'il a été bâti ex manubiis, c'est-à-dire que la construction en a

93 Sur cette stratégie de Marcellus, voir McDonnell, Roman Manliness, p. 219. Sur la compétition aristocratique à travers les temples, voir l'analyse de Curti sur les temples du Quirinal aux IV e et Ve siècles (E. CuRTI, "From Concordia to the Quirinal ", in Bispham, E. et Sмiтн, C. (éds.), Religion in Archaic and Republican Rome and Italy, Londres, Routledge, 2000, p. 77-91).

${ }^{94}$ Fabius Maximus est pontife depuis 216 (RÜPKE, Fasti sacerdotum, vol. 2, p. 971).

${ }^{95}$ Sur l'opposition entre Fabius et Marcellus, Plut. Marc. 24. Voir aussi Gros, « Les statues de Syracuse et les 'dieux' de Tarente», p. 110 et McDonnell, Roman Manliness, p. 223-228.

${ }^{96}$ Plut. Mar. 26 reste très vague à ce sujet, mais c'est une source hostile à Marius (A. PAsserini, "Caio Mario come uomo politico», Athenaeum, 12, 1934, p. 10-44). Sur le lien entre le temple et la bataille, voir G. Brizzi, "Honos et Virtus, Fortuna Huiusce Diei. Idéologies et propagande au dernier siècle de la République» in LE BoHEc, Y. (éd.), État et société aux deux derniers siècles de la République romaine. Hommage à François Hinard, Paris, De Boccard, 2010, p. 13-22. 
été financée par le butin de la guerre et non par l'État ${ }^{97}$. Plusieurs hypothèses ont été faites sur son emplacement ${ }^{98}$; elles s'appuient toutes sur un texte essentiel de Festus qui indique que Marius a évité de bâtir un édifice trop élevé pour ne pas gêner la prise des auspices ${ }^{99}$. Cette indication révèle que le temple se situait dans le champ de l'auguration. On l'a ainsi localisé d'abord sur le Capitole, sous l'auguraculum situé sur l'arx ${ }^{100}$. Mais cette localisation sur un flanc escarpé ne coïncide pas avec un texte de Valère Maxime parlant de l'area Marianorum monumentorum, qui indique une zone plane, ni avec le fait qu'on ne parle plus jamais dans les sources du temple d'Honos et Virtus alors que la zone du Capitole a été beaucoup remaniée dans le temps ${ }^{101}$. F. Coarelli a proposé de le situer plutôt sur la Velia, à la hauteur du futur arc de Titus ${ }^{102}$. L. Richardson, au terme d'une minutieuse démonstration, arrive à une conclusion proche: le temple se situe nécessairement sur l'axe de la spectio augurale reliant l'arx au Mont Albain, axe qui suit en partie le trajet de la Via Sacra. Il ne peut se situer sur l'arx, lieu trop abrupt, ni sur le Caelius, trop éloigné du forum et trop proche du temple de Fabius et Marcellus. La Velia est donc l'emplacement le plus probable, d'autant que le temple est alors proche de la maison de Marius située sur la Via Sacra ${ }^{103}$. Le temple devait être assez grand car Vitruve le cite comme exemple de temple périptère, avec six colonnes de face et onze de côté ${ }^{104}$, et il pouvait accueillir le sénat ${ }^{105}$. Vu l'attention portée par Marius aux questions de droit sacré à propos de la spectio augurale, il est probable que la cella ait été divisée en deux pour se conformer aux recommandations que les pontifes avaient faites au sujet du temple de Marcellus. Il est possible, enfin, que le temple édifié par Marius se soit inscrit dans un plus grand ensemble architectural car plusieurs textes parlent de monumenta Mariana ${ }^{106}$.

\footnotetext{
${ }^{97}$ Sur les temples ex manubiis, voir ABERSON, Temples votifs et butin de guerre dans la Rome républicaine et ORLIN, Temples, Religion and Politics in the Roman Republic, p.116-139. Ils sont moins nombreux à l'époque républicaine qu'on ne l'a dit autrefois car on confondait les temples décorés par les manubiae, qui sont nombreux, avec ceux bâtis à l'aide de l'argent rapporté par les manubiae, qui sont bien moins répandus.

${ }^{98}$ Voir le résumé donné par PaLombi, «Honos et Virtus, aedes », LTUR III, p. 35 et Clark, Divine Qualities, p. 125.

${ }^{99}$ FEST. 466-468.

${ }^{100}$ Roscher, Ausführliches Lexikon der griechischen und römischen Mythologie, vol. 1, 2 col. 2708; G. Lugli, Roma antica. Il centro monumentale, Rome, G. Bardi, 1946, p. 38.

${ }^{101}$ VAL. MaX. II, 5, 6.

${ }^{102}$ F. Coarelli, Il foro romano, 3e éd., Rome, Quasar, 1992, vol. 1, p. 100-103.

${ }^{103}$ Richardson, "Honos et Virtus and the Sacra Via ». Sur la maison de Marius, Plut.

Mar. 32; CLARK, Divine Qualities, p. 126.

${ }^{104}$ VITR. III, 2, 5.

105 Cic. Sest. 116; Bonnefond-Coudry, Le Sénat de la République romaine, p. 125-132.

${ }^{106}$ Val. MaX. II, 5, 6 et VItr. III, 2, 5. Voir Clark, Divine Qualities, p. 126.
} 
Lédification du temple à Honos et Virtus s'inscrit dans le contexte de la victoire remportée à Verceil et constitue pour Marius un moyen de remercier les divinités ayant contribué à ce succès et de le commémorer de manière prestigieuse. De ce point de vue, le projet de Marius n'est pas très différent de celui de Fabius ou Marcellus: son temple est étroitement lié à une victoire militaire et inscrit dans l'espace urbain la faveur divine dont il a bénéficié. Cependant il possède une réelle singularité en raison de deux éléments: d'abord la personne même de Marius et le sens qu'il donne aux notions d'honos et de uirtus; ensuite le fait que Q. Lutatius Catulus, qui a remporté la victoire de Verceil aux côtés de Marius, ait dédié lui aussi un temple, mais à Fortuna Huiusce Diei, «Fortune de ce Jour ». Ces deux aspects, que nous allons examiner successivement, donnent à l'édifice de Marius un sens particulier en exaltant sa valeur personnelle et en manifestant son opposition à la nobilitas. Concernant la personne de Marius, d'abord, plusieurs traits le distinguent nettement de Fabius et de Marcellus et donnent à sa dévotion un sens original. Marius n'est pas au début de sa carrière quand il formule le vœu à Verceil: en 101, il s'est déjà couvert de gloire en terminant la guerre contre Jugurtha et il est parvenu à plusieurs reprises à l'honos suprême du consulat. La dédicace d'un temple à Honos et Virtus n'est donc pas un moyen de lancer sa carrière politique et d'affirmer ses prétentions aux honores mais d'entériner ses succès passés et de leur donner une ampleur inédite. Le culte d'Honos n'est plus seulement lié à la victoire militaire mais aussi à la réussite politique ${ }^{107}$. C'est d'autant plus important que Marius n'appartient pas comme Fabius et Marcellus à la nobilitas: c'est un homo nouus et ce statut est l'une des clefs de sa dédicace à Honos et Virtus. Le culte que leur rend Marius est en effet en accord profond avec l'idéologie des homines noui du Ir siècle. Nous avons vu que pour le Marius que représente Salluste, comme pour Cicéron, l'honos doit être la récompense de la uirtus et non pas du genus $^{108}$. La dévotion à Honos et Virtus constitue le pendant religieux et l'expression architecturale de ce mode de pensée. L'association des deux dieux exprime l'unité de la valeur personnelle, caractéristique de l'homo nouus, et de l'honneur. Par cette dédicace, Marius s'en prend à la nobilitas car il s'attache des divinités traditionnellement révérées par les nobiles, comme le montrent le temple de Fabius et Marcellus ainsi que le sanctuaire dédié à Virtus par Scipion Émilien ${ }^{109}$, et il conteste plus généralement aux nobles la détention exclusive du prestige et de la valeur ${ }^{110}$.

107 Sur le rapport de la dédicace à Honos et des succès politiques de Marius, Bonnefond-Coudry, Le Sénat de la République romaine, p. 126. Sur le double sens, politique et militaire, du choix d'Honos par Marius, CLARK, Divine Qualities, p. 127.

${ }^{108}$ Voir par exemple SALl. Iug. 85 et Cic. Sest. 116.

${ }^{109}$ Sur le sanctuaire à Virtus de Scipion Émilien, voir n. 30 p. 514 et Astin, Scipio Aemilianus, p. 79.

${ }^{110}$ Nous ne pensons pas que par cette dédicace Marius ait voulu se concilier l'aris- 
Mais la dédicace réalisée par Marius ne prend tout son sens que lorsqu'on la compare à celle effectuée, à la même époque, par Q. Lutatius Catulus à Fortuna Huiusce Diei ${ }^{111}$. Les deux édifices, celui de Catulus et celui de Marius, révèlent l'antagonisme social, politique et culturel qui oppose les deux hommes ayant combattu ensemble à Verceil ${ }^{12}$. Le choix des divinités fait par chaque général est en lui-même révélateur: Catulus souligne que le sort favorable a présidé à la victoire et remercie la Fortune bienfaisante pour son heureux succès. Marius choisit, avec Honos et Virtus, de valoriser son courage et sa valeur personnelle qui sont la source unique de sa réussite ${ }^{113}$. Valère Maxime indique par ailleurs que Marius a beaucoup lutté au cours de sa carrière contre la fortuna pour atteindre les honores: on sait en effet que, jugé indigne des honores à Arpinum, il osa briguer la questure à Rome; ultérieurement, il ne s'est pas laissé rebuter par ses échecs à l'édilité mais a persévéré ${ }^{114}$. Marius a ainsi toujours résisté aux déboires de la fortuna et a gardé confiance en sa uirtus pour atteindre les honores. La localisation des deux temples témoigne aussi de l'antagonisme social des deux hommes. Le sanctuaire de Catulus, qui a été identifié comme étant le temple B de la zone sacrée du Largo Argentina ${ }^{115}$, se situe à proximité d'autres édifices en rapport avec des aristocrates comme lui, le temple de Juturne, construit par un autre Lutatius Catulus, et le sanctuaire des Lares Permaniri dû aux Aemiliii ${ }^{116}$. L'édifice de Marius,

tocratie romaine en adoptant leurs divinités de prédilection, comme le pense J.VAN Ooteghem, Caius Marius, Bruxelles, Académie Royale de Belgique, 1964 (p.229). En 101, Marius ne collabore plus avec la nobilitas mais s'y oppose, même s'il faut sans doute relativiser le discours très virulent que Salluste lui fait tenir dans le Bellum Iugurthinum. La rivalité de Marius et d'autres grands personnages publics s'est exprimée à plusieurs reprises à propos de divinités. Voir les dissensions entre Marius et les Metelli à propos de Magna Mater (M.G. Morgan, "Villa Publica and Magna Mater», Klio, 55, 1973, p. 215-245) et entre Marius et Sylla à propos de Victoria (S. Weinstock, «Victor and Inuictus », HTR, 50, 1957, p. 211-247).

${ }^{111}$ Plut. Mar. 26.

${ }^{112}$ Si leurs relations étaient bonnes avant Verceil, le prestige retiré par Marius de la victoire contre les Cimbres lui valut rapidement l'animosité de Catulus, et ce dès le débat qui s'éleva concernant le triomphe qui devait être célébré à l'issue de la guerre (J.-C. RichARD, « La victoire de Marius », MEFRA, 77, 1965, p. 69-86).

${ }^{113}$ L'opposition entre honos et fortuna apparaît déjà chez Lucilius (LucIL. frg. XIII, 8 Charpin $=450-451$ Marx). Sur l'antagonisme des divinités honorées par Marius et Catulus, McDonnell, Roman Manliness, p.96-114 ; Richard, "La victoire de Marius», p. 281 ; F. HinARD, "Sur une autre forme de l'opposition entre uirtus et fortuna », Kentron, 3, 1987, p. 17-20 ; G. BrIzzI, «Honos et Virtus, Fortuna Huiusce Diei. Idéologies et propagande au dernier siècle de la République».

${ }^{114}$ Val. Max. VI, 9, 14; Cic. Planc. 51; Van Ooteghem, Caius Marius, p. 87.

115 P. Boyancé, «Aedes Catuli», MEFRA, 57, 1940, p.64-71; F. Coarelli, «L'identificazione dell'Area Sacra dell'Argentina», Palatino, 12 (4), 1968, p.365-373; G. SAURON, Quis deum? L'expression plastique des idéologies politiques et religieuses à Rome à la fin de la République et au début du principat, Rome, E.F.R., 1994, p. 135.

${ }^{116}$ HinARD, «Sur une autre forme de l'opposition entre uirtus et fortuna». 
on l'a vu, se situe dans un endroit moins connoté socialement et à proximité de sa maison: la solidarité aristocratique s'oppose ainsi symboliquement à l'isolement de l'homo nouus. La dévotion à Fortuna et à Honos et Virtus relève, enfin, d'un antagonisme culturel profond. Les divinités honorées et les deux temples sont pourvus de traits qui marquent pour les uns l'ouverture à l'hellénisme et pour les autres la fidélité à la tradition romaine. Catulus est en effet un homme très cultivé, intéressé par la philosophie et les arts grecs. Il a adapté en latin des poésies de Callimaque, s'est lié avec Roscius et Archias et a été en contact avec l'entourage de Scipion Émilien ${ }^{117}$. La tradition nous a en revanche laissé l'image d'un Marius rebelle aux lettres et dédaigneux des raffinements de l'hellénisme ${ }^{118}$. Cette divergence transparaît dans les particularités architecturales de chaque temple ${ }^{119}$. Celui de Catulus est une tholos sur le modèle grec, pourvue de colonnes stuquées coiffées de chapiteaux corinthiens ${ }^{120}$. Il avait été décoré d'œuvres d'art grecques $^{121}$. Celui de Marius évite au contraire les schémas helléniques qui ont la faveur des nobles depuis le milieu du $\mathrm{II}^{\mathrm{e}}$ siècle: il n'emploie pas de marbre et ne possède pas de colonnade postérieure ${ }^{122}$. Son architecte, Mucius, ne vient pas d'Orient comme c'est le cas des bâtisseurs des édifices sacrés de la nobilitas ; c'est un Romain qui a su adapter les modèles grecs aux vieux schémas italiques ${ }^{123}$. Le temple élevé par Marius, en outre, est consacré à des forces divines proprement romaines, ancrées dans la tradition nationale, alors que Fortuna, sous l'aspect de Fortuna Huiusce Diei, est marquée par le Kairos grec

${ }^{117}$ H. Bardon, «Q. Lutatius Catulus et son 'cercle littéraire' », Études classiques, 18, 1950, p. $145-164$.

${ }^{118}$ Marius avait accepté un temps que le poète Archias chantât sa gloire mais la relation des deux hommes fut de courte durée (Cic. Arch. 19-20). Sur le rapport de Marius à la culture et l'hellénisme, Van Ooteghem, Caius Marius, p. 231 et A. La Penna, «Aspetti e conflitti della cultura latina dai Gracchi a Silla », DArch, 4-5, 1970-1971, p. 193-211.

${ }^{119}$ Sur ce point, HINARD, "Sur une autre forme de l'opposition entre uirtus et fortuna »; M. Royo, "Catulus et les infortunes de la Virtus », Kentron, 5, 1989, p. 151-160; Clark, Divine Qualities, p. 129-130; McDonnell, Roman Manliness, p. 129-130.

${ }^{120}$ Varr. RR III, 5, 12. Boyancé, "Aedes Catuli»; P. Gros, "Fortuna Huiusce Diei », LTUR II, p. 269-270; McDonnell, Roman Manliness, p. 282. Le modèle grec de la tholos est tout de même adapté à Rome puisque le temple possède un podium élevé avec un escalier d'accès caractéristique de l'axialité romaine.

${ }^{121}$ CIc. Verr. II, IV, 126; PLIn. NH XXXIV, 54.

${ }^{122}$ VITr. III, 2, 5 et VII, praef. 17. PaLOMBI, «Honos et Virtus, aedes », LTUR III, p. 33; Clark, Divine Qualities, p. 125.

${ }^{123}$ VITR. VII, praef. 17. Voir P. GRos, «Les premières générations d'architectes hellénistiques à Rome" in L'Italie préromaine et la Rome républicaine. Mélanges offerts à Jacques Heurgon, Paris, De Boccard, 1976, p. 387-410, à la p.407. D'après F. Münzer (RE XVI, 1, col.414), il appartenait peut-être à la clientèle de Q. Mucius Scaevola l'Augure, opposé au philhellénisme. L. J. Richardson cherche à le rapprocher d'un Mucius dans l'entourage de Marius (Richardson, «Honos et Virtus and the Sacra Via», p. 245). 
et l'astrologie orientale ${ }^{124}$. Marius situe donc son temple dans la tradition romaine et marque par sa dévotion à Honos et Virtus son opposition politique, idéologique et culturelle à la nobilitas .

Pour terminer notre analyse, il faut souligner que l'on voit s'affermir avec Marius le lien entre Honos et la personne d'un imperator en particulier. Marcellus avait dédié un temple à côté du tombeau des Marcelli; Marius en fait construire un à proximité de sa propre maison. Le sanctuaire a en outre été édifié de manubiis, à partir du butin constitué par Marius pendant la guerre, sans l'intervention de fonds publics. Il apparaît donc plus comme un monument à la gloire de Marius que comme un temple du peuple romain. Marius a souvent prétendu avoir été guidé et aidé par les dieux et la construction d'un temple à Honos et Virtus sert à signifier à tout le peuple de Rome le rapport privilégié qu'il entretient avec ces dieux en particulier ${ }^{125}$.

\subsection{Honos dans le complexe de Pompée}

Le dernier sanctuaire d'Honos construit à l'époque républicaine figurait dans le grand complexe architectural réalisé par Pompée au Champ de Mars. Cet ensemble d'une richesse et d'une ampleur exceptionnelles fut inauguré en deux temps, en 55, au cours du deuxième consulat de Pompée, puis en 52, lors de son troisième consulat. La seconde dédicace concerne le temple situé au sommet de la cauea du théâtre, qui nous intéressera plus particulièrement ${ }^{126}$. Le complexe se composait, d'ouest en est, d'une uilla destinée à Pompée, d'un théâtre en dur qui supportait, au sommet de sa cauea, un temple consacré à Vénus Victrix et à d'autres divinités, dont Honos et Virtus, d'un parc séparé du théâtre par le frons scaenae, entouré de portiques et orné de statues et de tableaux, et enfin d'une curie où figurait une statue monumentale de Pompée ${ }^{127}$. Le sanctuaire situé au sommet de la cauea jouait un

${ }^{124}$ Le sens exact de l'épithète Huiusce Diei fait débat (CLARK, Divine Qualities, p. 130). Il est probable que cette dénomination ait un sens astral et fasse référence aux rythmes cosmiques et aux mouvements des astres qui amènent les dies (BoyancÉ, «Aedes Catuli »; SAURON, Quis deum?, p.135-136). Cela serait bien en accord avec le choix d'une tholos, possédant une forme circulaire qui est assimilée en architecture à la sphère cosmique. La volière de Varron à Casinum, qui imite le temple de Catulus, avait la même forme et était surmontée d'une coupole indiquant les heures et d'une rose des vents (SAURON, Quis deum?, p. 92-93).

${ }^{125}$ Sur la relation entre Marius et les dieux: Cic. Diu. I, 106; Leg. I, 1; VAL. MAx. I, 3 , 4 et I, 5, 5; Plut. Mar. 36.

${ }^{126}$ Sur cette datation, Gell. X, 1, 6 sqq.; F. Coarelli, «Il complesso pompeiano di Campo Marzio e la sua decorazione scultorea", in CoARelli, F. (éd.), Revixit ars. Arte e ideologia a Roma. Dai modelli ellenistici alla tradizione repubblicana, Rome, Quasar, 1996, p. 360-381; SAURON, Quis deum?, p. 249, n. 3.

${ }_{127}$ Sur l'aspect du complexe, Sauron, Quis deum?, p.250-253; Coarelli, Guide archéologique de Rome, p.201-202 et P.Gros, Architecture et société à Rome et en Italie 
rôle essentiel dans l'ensemble: Pompée, pour contourner l'interdit qui pesait à Rome sur la construction d'un théâtre en dur, déclarait que la cauea de son théâtre n'était qu'un immense escalier menant au temple situé à son sommet ${ }^{128}$. Le sanctuaire se composait de plusieurs aedes et différentes divinités y étaient honorées ${ }^{129}$. Les Fasti Amiternini indiquent que le 12 août une fête était consacrée Veneri Victrici, Hon(ori), Virt(uti), Felicitati in theatro marmoreo ${ }^{130}$. Les Fasti Allifani confirment la présence de Vénus, Honos, Virtus et Felicitas mais mentionnent un autre dieu: V.V.HONOS V.V.FELICITA ${ }^{131}$. Les deux premiers V sont pour Vénus Victrix, le troisième pour Virtus, mais à quel dieu renvoie le quatrième? Deux interprétations sont possibles. Soit c'est une erreur du calendrier ${ }^{132}$, et dans ce cas il faut imaginer que figurait au sommet de la cauea un temple principal dédié à Vénus Victrix, entouré de deux chapelles, l'une consacrée à Honos et Virtus, l'autre à Felicitas. Soit le V. est correct et fait référence à un autre dieu ${ }^{133}$; on aurait ainsi un temple central et quatre chapelles latérales, accolées deux par deux de chaque côté du temple de Vénus. Cette dernière solution nous paraît plus probable: Marcellus a rencontré bien des difficultés quand il voulut consacrer une seule aedes à Honos et Virtus et Pompée aurait donc difficilement pu les réunir dans une chapelle unique; de l'autre côté du temple de Vénus devaient donc figurer également deux chapelles, l'une pour Felicitas, l'autre pour une autre divinité, peut-être Victoria: une lettre de Tiron mentionne une aedes Victoriae à propos du théâtre de Pompée ${ }^{134}$.

centro-méridionale aux deux derniers siècles de la République, Bruxelles, Latomus, 1978, p. 67-70. Sur le programme décoratif, voir COARELLI, «Il complesso pompeiano »; SAURON, Quis deum? p. 253-266.

${ }^{128}$ Gell. X, 1, 7; Plin. NH VIII, 20: Tertul. Spect. 10. L'implantation d'un temple au-dessus de la cauea porte la marque de l'architecture hellénistique d'Asie Mineure (SAURON, Quis deum? p.252).

${ }^{129}$ Suétone mentionne un sacrifice fait par Claude ad superiores aedes du théâtre de Pompée (Suet. Claud. 21). Sur ces édifices, voir Wissowa, Religion und Kultus der Römer, p. 136; Milhous, Honos and Virtus in Roman Art, p. 31.

${ }^{130}$ CIL I ${ }^{2}$ p. 244. Wissowa, Religion und Kultus der Römer, p. 136.

${ }^{131}$ CIL I ${ }^{2}$, p. 417.

${ }^{132}$ R. Schilling considère que c'est une dittographie (R. Schilling, La Religion romaine de Vénus, depuis les origines jusqu'au temps d'Auguste, Paris, De Boccard, 1954, p. 298, n.4).

${ }^{133}$ L. J. Richardson, "A Note on the Architecture of the Theatrum Pompei in Rome", AJA, 91, 1987, p. 123-126; J. ScHEID, « Nouveaux éléments concernant les Fastes des frères arvales » in Epigrafia. Actes du Colloque international d'épigraphie latine en mémoire d'Attilio Degrassi, Rome, E.F.R., 1991, p.75-92 a apporté un argument décisif en ce sens en comparant l'inscription avec les fastes des frères arvales où figure de manière assurée le deuxième « $V »($ p. 79).

${ }^{134}$ Gell. X, 1, 7 cite ou paraphrase une lettre de Tiron qui parle du «temple de la Victoire». Voir cependant sur cette identification les réserves de ScHEID, "Nouveaux éléments concernant les Fastes des frères arvales », p. 80. 
La construction de cette chapelle à Honos répond chez Pompée à des préoccupations politiques et spirituelles complexes. La dévotion de Pompée d'abord, proche en cela de celle de Marius, vise à consacrer son prestige de général. Comme Marius, la dédicace du temple n'intervient pas au début de sa carrière mais au moment de son apogée et donne une publicité remarquable aux honores obtenus jusqu'alors. Pompée a obtenu trois fois le maximus honos du consulat, ce que rappelait une inscription située dans le complexe ${ }^{135}$. Il a également triomphé trois fois et ce dans des conditions très particulières puisqu'il n'était pas consul lors de ses deux premiers triomphes ${ }^{136}$. En construisant une aedes pour Honos il entérine les faveurs que ce dieu lui a régulièrement octroyées. Le culte adressé par Pompée à Honos contribue également à faire de lui l'héritier des plus grands généraux romains. La construction d'un sanctuaire à Honos et Virtus au sein du complexe constitue une sorte de citation architecturale des édifices sacrés du même type réalisés avant lui par trois des généraux romains les plus prestigieux de l'histoire, Fabius Maximus, Marcellus et Marius. Pompée se place ainsi dans leur glorieuse lignée en répétant leur dévotion. Mais il va au-delà en construisant un édifice sacré bien plus somptueux, extrêmement élevé et fait de marbre, et en le situant dans un complexe architectural tout à sa gloire. Qui plus est, il se livre à une audacieuse synthèse en rapprochant Honos et Virtus d'autres divinités comme Vénus Victrix, Felicitas et peut-être Victoria. Le choix de Felicitas est particulièrement révélateur car la divinité avait été associée à Sylla, ennemi juré de Marius dont les divinités favorites figurent elles aussi au sommet de la cauea. Pompée réunit ainsi des cultes politiquement antagonistes autour de sa divinité tutélaire, Vénus ${ }^{137}$. Il constitue une synthèse originale et affirme sa supériorité sur tous les généraux de l'histoire romaine, affirmation qui prend un sens particulier en 52, après la mort de Crassus en Orient, et alors que ses relations avec César ont commencé à se tendre.

Il faut également prendre en compte, pour comprendre la portée exacte de la présence d'Honos au sommet de la cauea du théâtre, le sens idéologique et spirituel global du complexe pompéien ${ }^{138}$. L'aedes, en effet, se situe dans un ensemble plus vaste et n'est plus isolée comme les temples précédemment consacrés à Honos et Virtus. Le choix de la divinité Honos est en accord profond avec le programme statuaire qui décorait le théâtre

135 Gell. X, 1, 7.

${ }^{136}$ Pompée a triomphé en 79, 71 et 61 (Itgenshorst, Tota illa pompa, n 246, 253 et 258). Plutarque souligne qu'il a triomphé à chaque fois sur un continent différent (Afrique, Europe, et enfin Asie - Plut. Pomp. 45).

137 «Ignorant volontairement l'hérédité de la guerre civile, il tend à assumer un rôle super partes, à travers l'appropriation personnelle d'une série de mots d'ordre, traduits en culte» (F. CoArelli, "Le théâtre de Pompée», DHA, 23 (2), 1997, p. 105-124, à la p. 116).

${ }^{138}$ La signification spirituelle en a été étudiée en détails par SAURON, Quis deum? p. 253-266. Sur les statues, voir aussi COARELLI, «Il complesso pompeiano». 
et les portiques. Au niveau inférieur de l'enceinte du théâtre se trouvait un groupe représentant les quatorze nations vaincues par Pompée qui rappelait les triomphes obtenus par le général, son honos militaire, et faisait écho à la divinité située au sommet des gradins ${ }^{139}$. Les trois séries de statues féminines localisées dans l'ambulatio et les exèdres du portique sont aussi en rapport avec les dieux du sanctuaire: le groupe des hétaïres est en rapport avec Vénus (déesse de l'amour), celui des poétesses avec Honos (qui octroie des honneurs aux poètes) et celui des femmes à la fécondité extraordinaire avec Felicitas (déesse, entre autres, de la fertilité $)^{140}$. Cependant de tels rapprochements, comme l'a noté G. Sauron, sont problématiques. L'association d'Honos aux poétesses n'est pas immédiate dans les modes de pensée, ni celle de Felicitas aux femmes fécondes: ces groupes sont habituellement patronnés par Minerve et Junon. En outre, l'association de Vénus aux hétaïres est sulfureuse. Ces deux particularités, en réalité, s'expliquent l'une l'autre. La mise en place de forces divines autour de Vénus rappelle le sens des statues féminines du portique mais permet aussi de dépouiller Vénus de son aspect érotique: la présence d'Honos et Virtus l'amène du côté de l'excellence morale en l'éloignant des hétaïres, dont elle est déjà physiquement séparée par le frons scaenae du théâtre $^{141}$. Vénus est en outre, par les dieux qui l'entourent, solidement ancrée dans la tradition romaine, ce qui confère au sanctuaire un aspect national assez fort par rapport à la zone du portique plus marquée par la culture hellénistique ${ }^{142}$.

La présence d'Honos dans le complexe confère donc au dieu une fonction culturelle et spirituelle inédite. Sur le plan des liens dessinés entre Honos et la personne de Pompée, l'innovation est moindre mais on note tout de même une accentuation, par rapport à Marius, de l'appropriation personnelle du dieu. Le plus frappant est le fait que la chapelle consacrée à Honos ne se situe pas dans un espace civique traditionnel comme c'était le cas des autres temples. Elle est incluse dans un complexe étroitement associé à Pompée. Le sanctuaire se trouve au sommet de la cauea et surplombe du même coup la uilla de Pompée, qui se trouvait à l'ouest du théâtre: il y a ainsi une grande proximité spatiale entre la demeure des divinités et celle de Pompée, et ce dernier a peut-être imité le rapprochement que Marius avait essayé d'établir entre sa maison et le temple qu'il avait dédié à Honos et Virtus. Enfin, le sanctuaire de Vénus Victrix et des autres dieux fait face à la statue colossale de Pompée, représenté en kosmokrator, qui se situait à l'autre extrémité du complexe, dans la curie ${ }^{143}$. Il s'établit ainsi une connivence symbolique entre les dieux et Pompée, les premiers envoyant la victoire au second.

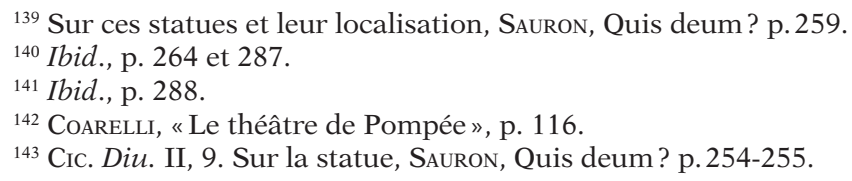




\section{CONCLUSION}

Honos est donc l'une de ces «forces divines", de ces transpositions dans le domaine divin de notions essentielles du mos maiorum. Le dieu ne représente pas une qualité, comme c'est le cas de Pietas ou de Virtus, mais une res expetenda, comme le dit Cicéron dans le De natura deorum, un bien précieux activement recherché. C'est la valeur attachée par les Romains à l'honos qui les a amenés à considérer qu'il s'agissait d'un bienfait d'origine divine et à donner au dieu qui le dispense le nom de ce bienfait. Létude d'Honos permet de confirmer certains éléments que nous avions observés à propos de l'honos comme pratique humaine. Honos, d'abord, préside aux marques d'honneur de toutes sortes, militaires, politiques et sociales. Il est honoré par des personnes de statuts divers et aux fonctions variées. L'association récurrente d'Honos et de Virtus confirme le lien intime de ces deux notions et fait écho à la conception de l'honneur comme praemium uirtutis. L'importance de son culte, enfin, confirme que l'honos est un bien recherché et valorisé. Honos n'est pas en effet une divinité de tout premier plan mais il ne faut pas sous-estimer sa prégnance: pas moins de quatre temples lui ont été dédiés à l'époque républicaine à Rome. Le dieu a suscité l'intérêt de plusieurs grands hommes qui ont donné à leur dévotion un sens idéologique et politique de plus en plus marqué. Fabius Maximus s'attache le dieu qui lui apportera les honores nécessaires à une carrière brillante et à la conservation de son rang de nobilis dans un contexte de compétition aristocratique. Marcellus, lui, fait un usage plus offensif du culte d'Honos en captant au bénéfice de sa famille l'édifice de Fabius et en faisant du temple un moyen d'exaltation de ses exploits militaires et de son ouverture à l'hellénisme, ce qui l'oppose aux sénateurs traditionalistes. Marius utilise de manière encore plus polémique les dieux Honos et Virtus en en faisant les porteurs de son idéologie d'homo nouus hostile à la noblesse et en donnant à son culte des traits qui l'opposent presque en tous points à celui rendu par Q. Lutatius Catulus à Fortuna Huiusce Diei. Pompée, lui, se pose en héritier synthétique de ces grands généraux et les dépasse en même temps en inscrivant sa dévotion à Honos au sein du remarquable complexe du Champ de Mars qui donne au dieu une portée spirituelle nouvelle en même temps qu'il l'associe de manière très étroite à sa personne d'imperator victorieux. L'étude du dieu Honos confirme ainsi un autre aspect de la notion d'honos en général, sa mobilisation idéologique par les grands hommes politiques romains, qui se poursuivra à l'époque impériale ${ }^{144}$. Elle montre enfin la forte coloration romaine de la notion, puisque le dieu est utilisé par Marius pour contrer l'hellénisme de Catulus et par Pompée pour romaniser Vénus.

${ }^{144}$ Le dieu Honos semble notamment avoir suscité l'intérêt d'Auguste, qui déplaça sa fête et le fit figurer sur l'Ara Pacis (DC. LIV, 18; LIMC s. v. Honos n 19). Sur le rôle joué par Auguste dans le devenir des forces divines, Clark, Divine Qualities, p. 263 sqq. 


\section{CONCLUSION DE LA DEUXIÈME PARTIE}

Nous soulignions au début de cette partie l'apparente hétérogénéité des realia que recouvrent les notions d'honos et d'honestas et la nécessité de nous interroger sur leur unité. Au terme de notre étude, il apparaît que cette diversité est réelle: l'hommage peut prendre des formes concrètes variées en étant objet, geste, cérémonie, parole ou charge publique. Cependant, la variété des formes de l'honos et des situations où il apparaît ne doit pas occulter ses mécanismes profonds, qui sont en nombre réduit. L'honneur fonctionne en effet à Rome selon deux paradigmes essentiels. Le premier est de nature symbolique: l'auteur de l'hommage confère un signe d'estime à la personne honorée. Ce signe dit la considération mais il est aussi performatif: il instaure le prestige de celui qui le reçoit et lui constitue une image de marque prestigieuse. Un second paradigme, de nature économique, permet de rendre compte de l'interaction entre l'honos et son motif: la marque d'honneur est perçue à Rome comme un salaire pour un mérite particulier. C'est l'accumulation dans le temps de ces marques d'honneur (honores) qui permet à celui qui les reçoit de se constituer un capital de prestige (honos).

Les moyens d'obtenir l'honos sont également divers et ont en outre évolué dans le temps: la vaillance militaire, la fides, la bienfaisance publique, l'appartenance à l'élite sociale sont autant de voies, parmi d'autres, vers l'honos. Cependant, il s'agit là encore de diversité et non de foncière hétérogénéité car les différents motifs d'honos procèdent d'une même matrice, qui est le souci de la collectivité et l'observation des principes du mos maiorum. On remarque également que l'aristocratie se procure plus facilement l'honos et tend à en avoir le monopole. Il a cependant été régulièrement contesté: la nature du mérite a fait l'objet de définitions antagonistes, la noblesse la tirant vers le genus alors que ses rivaux la rapprochaient de la uirtus.

Une fois que l'individu a acquis l'honos, il peut bénéficier de ses effets. L'honneur confère à son détenteur une image sociale supérieure et l'inscrit dans l'espace public et dans la mémoire de la cité. Il lui procure également une dignitas, qui le rapproche de l'aristocratie et impose le respect à son entourage. Il lui assure enfin une autorité, forme de pouvoir diffuse mais efficace. Ces différents avantages s'accompagnent de contraintes qui les contrebalancent selon la logique de l'égalité géométrique: l'honos oblige à la reconnaissance (gratia), à la dignité (dignitas), et à l'honorabilité (honestas).

Il y a donc un rapport étroit entre honos et honestas. De ce fait, cette dernière n'est pas un simple code de conduite. C'est un code d'honneur car l'observation des règles de l'honestas vise la préservation du prestige: c'est le regard d'autrui et la crainte de perdre son estime qui motivent le respect des règles de comportement. Cet aspect, ajouté au fait que l'imitation de la conduite des ancêtres, archétypes de l'honneur, est le meilleur chemin vers l'honestas, fait de cette dernière une morale d'hétéronomie. Le rapport entre honos et honestas implique, en outre, 
que les exigences de l'honestum s'appliquent surtout aux détenteurs de l'honos, c'est-à-dire, le plus souvent, aux aristocrates. Il y a une relativité des commandements de l'honneur, de nature sociale principalement, mais aussi générique et ethnique.

Si l'honestas parvient à imposer ses règles contraignantes, c'est parce que l'honos est un objet prisé, pour la détention duquel différentes stratégies sont élaborées. Quand les Romains en sont dépourvus, ils mettent tout en œuvre pour l'acquérir, ce qui donne lieu à une compétition entre les membres de la cité car ni les marques d'honneur ni le prestige ne sont disponibles pour tous. Une fois obtenu, l'honos doit être préservé car c'est un bien vulnérable aux attaques de l'extérieur, pratiques populaires infamantes, condamnations en justice ou blâme censorial. Il faut aussi s'efforcer de le transmettre à ses descendants pour créer une chaîne d'honores à travers le temps et grossir le prestige de la famille à chaque génération. Pour ce faire, les Romains s'efforcent d'imiter leurs ancêtres et de les dépasser.

Notre étude a permis de voir également l'importance de l'honneur à l'échelle de la collectivité. Par ses effets particuliers, à la fois bénéfiques et contraignants, l'honos est en effet utilisé pour remplir différentes fonctions qui concernent les Romains dans leurs relations les uns avec les autres. L'honos sert ainsi de moyen de régulation des comportements. Il oriente, dans la pratique, l'action des membres du corps social en stimulant leur volonté et en leur assignant des buts désirables qui gravitent autour de l'utilité publique. Il façonne également les représentations axiologiques des Romains en définissant les valeurs prisées et les modèles de conduite. L'honos permet aussi de structurer la société romaine: les rituels d'hommage rassemblent les acteurs sociaux dans une même célébration et revêtent une fonction identitaire. L'honos est également utilisé pour symboliser les liens entre individus. Enfin, l'honos sert à constituer des rapports de pouvoir. Celui qui le reçoit gagne en autorité et celui qui le donne en influence: le don est prestigieux pour le donateur et «oblige» son destinataire.

Notre enquête, enfin, a montré la place de la notion d'honos au niveau théologique avec l'étude de cette force divine qu'est Honos. L'importance attachée par les Romains à l'honos les a en effet amenés à considérer qu'il s'agissait d'un bienfait d'origine divine et à donner au dieu qui le dispense le nom de ce bienfait. Le dieu Honos préside aux marques d'honneur et à leur octroi. De ce fait, il a fait l'objet d'un véritable culte et a suscité l'intérêt de plusieurs grands hommes, de Fabius Maximus à Pompée, qui ont donné à leur dévotion un sens politique. Le dieu Honos, comme certains aspects de la notion, a ainsi fait l'objet d'appropriations antagonistes. Il y a, tout au long des deux derniers siècles de la République, une pratique de l'honneur, mais aussi des usages de plus en plus réfléchis de cet objet et des inflexions partisanes de cette notion. C'est à cette approche intellectuelle et idéologique de l'honos, de l'honestum et de l'honestas, menée par les Romains eux-mêmes, que nous devons à présent nous intéresser. 
TROISIÈME PARTIE

LA PENSÉE: APPROCHES INTELLECTUELLES ET REPRÉSENTATIONS 



\section{INTRODUCTION}

L'étude du fonctionnement concret de l'honos et de l'honestas a permis de faire surgir les spécificités de l'honneur romain. Notre objet a été envisagé comme une pratique à la fois sociale, politique et morale, dont nous avons tâché de donner une description et une interprétation, en recourant à des outils empruntés à l'anthropologie et à la sociologie. Une telle approche a cependant l'inconvénient de donner une vision peut-être trop cohérente et trop systématique de l'honneur en le constituant en un objet clos, fonctionnant sans accroc selon des mécanismes bien rodés. La pratique de l'honneur n'est pourtant pas à Rome quelque chose qui va de soi; l'honos et l'honestas sont vécus mais aussi constamment interrogés, évalués, voire contestés. Les auteurs de la période républicaine ont opéré sur ces objets un retour réflexif et un approfondissement théorique. Il est donc nécessaire de nous intéresser, au-delà de la pratique de l'honneur, à la pensée de l'honneur, en envisageant notre objet comme donnée intellectuelle et représentation mentale. On abordera les textes non plus comme des documents mais comme des acteurs d'une construction intellectuelle et axiologique de l'honneur ${ }^{1}$.

\section{Objets d'étude}

L'honos, l'honestum et l'honestas peuvent être, dans les textes qui nous intéressent, pensés de trois manières. Ils sont abordés comme des concepts, en philosophie ou en rhétorique, comme des valeurs, dans la réflexion morale et dans l'idéologie politique, et comme des images, quand ils font l'objet du travail littéraire des auteurs. Telles sont les trois formes de l'idée d'honneur qui feront l'objet de cette partie.

Certains aspects nous intéresseront plus particulièrement. Nous interrogerons ainsi l'élaboration théorique de l'honneur: il y a au

${ }^{1}$ L'honneur est aussi envisagé comme objet intellectuel de réflexion par des historiens d'autres époques que la nôtre. Voir par exemple dans le volume collectif H. Drévillon et D. Venturino (éds.), Vivre et penser l'honneur à l'époque moderne, Rennes, P.U.R., 2011, les contributions de R.HALÉVI, «La pensée politique de l'honneur» (p.109-126) et D.A. BeLL, «La critique de l'honneur à la fin du siècle des Lumières: ses origines et ses conséquences» (p.143-149). 
cours de la période républicaine une progressive conceptualisation de la notion dont il faut apprécier les étapes et les méthodes. L'honos et l'honestum sont au début de notre période des notions, c'est-à-dire des objets intellectuels définis d'une manière assez lâche et pourvus d'un faible degré d'abstraction. Au premier siècle avant notre ère, cependant, l'honos fait l'objet de définitions et reçoit des normes de fonctionnement. L'honestum, lui, devient un concept philosophique important et doté d'une profondeur théorique inédite, puisqu'il désigne le beau moral et est identifié au souverain bien dans la pensée stoïcienne. Il nous faudra déterminer selon quels procédés l'honneur est passé de la notion au concept. Il nous appartiendra aussi de préciser les effets de cette théorisation, par exemple sur l'écart entre l'honos et l'honestum et sur l'évolution de l'honestum hors de la sphère de l'honneur, vers celle du bien moral; nous nous pencherons aussi sur ses causes, en observant entre autres le rôle joué par l'influence de l'hellénisme, prépondérante à l'époque qui nous intéresse.

On étudiera également les jugements de valeur formulés par les auteurs sur l'honneur. Quel prix accordent-ils à l'honos? Quelle appréciation les Romains, en fonction de leurs affinités intellectuelles et $\mathrm{du}$ contexte historique dans lequel ils vivent, portent-ils sur l'honneur? Comment considèrent-ils l'ambition et la recherche de l'honos? Il faudra ici encore évaluer le poids respectif de l'hellénisme et du mos maiorum sur leurs représentations.

On s'intéressera tout autant à l'utilisation littéraire de l'honneur et à sa place dans l'imaginaire des œuvres de l'époque républicaine. Il faudra notamment prêter attention à l'usage singulier qu'en font les différents genres littéraires: quelle modalisation les pièces comiques de Plaute ou de Térence font-elles du thème de l'honneur? Quel discours la satire tient-elle à son sujet? Quelle est la place de l'honneur dans les récits historiques d'un Salluste ou d'un César?

\section{Méthode}

Pour répondre à ces différentes questions, il nous faudra, à l'inverse de ce que nous avons fait jusqu'alors, suivre un fil chronologique. Il importe en effet de faire ressortir les progrès de la théorisation de l'honneur, l'évolution du jugement des Romains sur cette notion et les variations littéraires auxquelles elle donne lieu. Nous procéderons en étudiant les auteurs les uns après les autres; si cette méthode risque de donner lieu à quelques redites, elle a cependant l'avantage de mettre en valeur la singularité de chaque écrivain et de constituer une approche différente de celle que nous avons suivie jusqu'alors, qui procédait par recoupements et étude des points communs. Elle nous permettra de revenir sur la diversité des représentations de l'honneur et sur les particularités laissées jusqu'à présent de côté. Nous nous efforcerons aussi de souligner les points de convergence entre les auteurs. Nous commencerons par Plaute, premier auteur chez qui apparaît la 
notion d'honneur, pour finir avec Salluste, dont les œuvres ont été écrites autour de l'époque qui voit la disparition de la République avec la formation du triumvirat et la défaite à Philippes des derniers républicains. Plutôt que d'étudier en détails chez un seul auteur le traitement des notions qui nous intéressent, nous avons fait le choix de n'aborder que certaines questions, mais de les envisager dans la diachronie, chez chacun des écrivains de l'époque républicaine, pour dégager des lignes de force dans l'histoire intellectuelle de l'honos et de l'honestum. Létude de Cicéron, qui requiert de longs développements, n'a pas pu trouver sa place dans cet ouvrage et devrait faire l'objet d'une publication ultérieure de notre part².

${ }^{2}$ Nous avons commencé l'étude de l'honneur et du bien moral chez Cicéron dans notre thèse de doctorat et poursuivons actuellement nos recherches sur cet auteur. 



\section{PLAUTE: L'HONNEUR À L'ÉPREUVE DE LA COMÉDIE}

\section{INTRODUCTION}

L'étude de l'image littéraire et intellectuelle que Plaute donne de l'honneur est importante car ses œuvres bénéficient d'un grand écho au sein de la cité puisqu'elles sont représentées lors des ludi qui rassemblent en masse des Romains de toutes origines ${ }^{1}$. Mener une investigation sur le jugement que la comédie de Plaute formule sur l'honneur n'est cependant pas une tâche facile car cela revient, plus largement, à s'interroger sur le sens, la portée et la fonction des passages à teneur morale de la comédie, qu'ils soient moralisateurs ou subversifs. Or cette question de la "morale de Plaute " n'a cessé de faire débat et de diviser la critique ${ }^{2}$. Nous voudrions, à titre préalable, réévaluer les termes de ce débat, et essayer de définir une méthode de travail pour notre objet. Certains problèmes nous semblent en effet avoir été mal posés, ce qui a eu pour effet de déboucher sur des apories interprétatives.

Deux exigences méthodologiques nous paraissent nécessaires. La première consiste à renoncer à vouloir à tout prix identifier dans les comédies, et notamment dans les passages à teneur morale, l'opinion de leur auteur. L'accès à la subjectivité d'un écrivain à travers ses œuvres est toujours problématique mais l'appréhension des représentations auctoriales se révèle particulièrement délicate s'agissant d'un auteur de théâtre qui n'emploie jamais la première personne mais ne fait que mettre en scène des personnages derrière lesquels il tend à disparaître. Plusieurs critiques ont essayé de définir la morale de Plaute, en le clas-

${ }^{1}$ Il est difficile, en raison de l'absence d'édifice de théâtre en dur aux $\mathrm{III}^{\mathrm{e}}$ et $\mathrm{II}^{\mathrm{e}}$ siècles, de connaître avec précision le nombre des spectateurs pouvant assister à une représentation. Une étude est cependant parvenue à calculer qu'à l'époque de Plaute, aux jeux mégalésiens, le public se composait d'environ 2000 personnes (voir S. M. GoldBeRg, "Plautus on the Palatine», JRS, 88, 1998, p.1-20; voir aussi les remarques, concluant à un nombre d'environ 3000 spectateurs au maximum, de C. W. Marshall, The Stagecraft and Performance of Roman Comedy, Cambridge, Cambridge University Press, 2006, p.80). La diversité sociale des spectateurs est attestée par les sources anciennes (Pl.Poen. 17-35; Cic. Har. 24).

${ }^{2}$ C'est le titre d'un article de P. Grimal, «Existe-t-il une morale de Plaute? », BAGB, 4 (4), 1975, p. 485-498. Les notes qui suivent mentionnent les différentes contributions scientifiques à ce débat. 
sant comme un écrivain conservateur ou au contraire subversif, ou même en le rattachant à un "parti » contemporain, celui de Caton ou des Scipions ${ }^{3}$. Or cette démarche, outre qu'elle repose sur une conception trop tranchée de l'opposition entre les «catoniens » et les Scipions, se fonde souvent sur le repérage d'allusions à l'actualité dont la réalité n'est pas fermement établie 4 . Mais elle perd surtout de vue le fait que Plaute n'est pas un poète-client ni un partisan engagé, mais un auteur comique qui se moque de tous les excès de ses contemporains, quels qu'ils soient ${ }^{5}$. Cette façon de faire est en outre impuissante à rendre compte des contradictions qui apparaissent, parfois au sein d'une même pièce, entre des passages édifiants et des scènes scabreuses: des pièces comme le Trinummus et la Mostellaria dépeignent les ravages de la débauche amoureuse alors que le Miles gloriosus ou le Mercator en célèbrent le triomphe. Il importe, en réalité, de ne pas se tromper d'objectif: plutôt que de chercher le message moral de Plaute sur l'honneur, ce qui est très aléatoire, il faut interroger, de manière plus modeste mais aussi plus efficace, le rôle dramatique que joue la mise en scène de l'honneur et la portée comique des discours que les

${ }^{3}$ F. Della Corte distingue deux périodes dans les comédies de Plaute: jusqu'au début du II ${ }^{\mathrm{e}}$ siècle, l'auteur soutiendrait la politique du groupe philhellène des Scipions, puis ses sympathies iraient à Caton et aux conservateurs (F. Della Corte, Da Sarsina a Roma. Ricerche plautine, $2^{\mathrm{e}}$ éd., Florence, La Nuova Italia, 1967). Plusieurs travaux ont cherché à relever des concordances entre des passages de Plaute et la pensée du Censeur, ce qui n'est pas en soi illégitime, mais certains en concluent à une adhésion de Plaute au "catonisme» et à une défense de ces idéaux à travers ces pièces, ce qui nous paraît une conclusion abusive (voir P.Cugusi, "Plauto e Catone», BStudLat, 21, 1991, p. 291-305). Selon E. Flores, Letteratura latina e ideologia del III-II a. C., Naples, Loffredo, 1974, Plaute serait le représentant de la «tendance démocratique » romaine hostile aux Scipions.

${ }^{4}$ Les allusions à l'actualité repérées sont toujours rares et peu claires; elles ne sont pas en outre nécessairement polémiques (voir D. GAGLIARDI, «Aspetti del teatro comico latino: la 'politica' di Plauto ", Le Parole e le Idee, 5, 1963, p. 167-174, à la p. 173; R. PernA, L'originalità di Plauto, Bari, Leonardo da Vinci, 1955, p. 321 sqq. et C. PAnsiéri, Plaute et Rome ou les ambiguïtés d'un marginal, Bruxelles, Latomus, 1997, p. 346-390).

${ }^{5}$ Cela a été souligné à plusieurs reprises: Gruen, Studies in Greek Culture and Roman Policy, remarque que Plaute a choisi comme modèle la Néa, et non la comédie ancienne, donc un genre délibérément apolitique (p.129). G. MonAco, "Qualche considerazione sullo sfondo politico e sociale del Teatro di Plauto ", Dioniso, 43, 1969, p. 301-307 montre qu'il y a de la satire sociale chez Plaute, mais qu'elle ne vise que des personnages typiques et non individualisés (les banquiers, les usuriers, les femmes, etc.). On ne rencontre pas d'attaques ad hominem comme c'est le cas chez Aristophane. Sur l'anonymat des cibles, J.-P. CÈBE, La Caricature et la parodie dans le monde romain antique des origines à Juvénal, Paris, De Boccard, 1966, p.61. C. GIzewsKi, «Mores maiorum, regimen morum, licentia. Zur Koexistenz catonischer und plautinischer Sittlichkeitsvorstellungen", Xenia, 22, 1989, p. 81-105 fait une analyse beaucoup plus nuancée - et plus juste - des rapports entre Plaute et le conservatisme moral contemporain. 
personnages tiennent sur lui ${ }^{6}$. Il faut renoncer à étudier Plaute comme un moraliste qui exprimerait des jugements sur ses contemporains: la coloration morale de certaines scènes ne doit pas nous amener à considérer systématiquement qu'elles sont porteuses d'un message moral; elle doit nous conduire en premier lieu à en élucider le rôle proprement théâtral et l'effet sur le public.

Ce qui implique une deuxième exigence méthodologique, celle d'une étude spécifiquement littéraire et dramaturgique des comédies, avec la prise en compte du genre auquel elles appartiennent et du spectacle particulier qu'elles représentent. P. Grimal a eu raison de souligner les contradictions des comédies sur le plan moral et de renoncer, du même coup, à en chercher la «leçon» unitaire. Mais l'article qu'il consacre à la question a selon nous l'inconvénient de rabattre ces contradictions sur une question de sources, sans prendre en compte leur valeur dramatique. Les divergences morales du théâtre de Plaute proviennent, selon P. Grimal, des différents modèles utilisés par Plaute:

«Plaute se trouvait en présence d'un théâtre où l'on débattait de questions morales [...] et il n'a pas jugé utile de simplifier les réflexions et les théories qu'il rencontrait dans ses modèles [...]. Il en a transposé la substance, à peu près telle quelle, dans ses propres pièces. $»^{7}$

À supposer que Plaute ne fasse que transposer l'aspect moral des comédies grecques qu'il imite, ce qui est contestable quand on sait le travail d'adaptation au public romain accompli par le dramaturge, il reste encore à expliquer pourquoi Plaute a choisi telle comédie, à l'intrigue moralement conformiste ou contestataire, plutôt que telle autre. Il faut préciser l'intérêt dramatique et comique des passages traitant de questions morales, observer leur emplacement dans l'intrigue, la nature du personnage qui les prend en poids et leur charge comique. On ne s'en tiendra donc pas à des interprétations subjectives, comme celles qui identifient le ton «ironique» ou "parodique»d'un passage sans se fonder sur des analyses littéraires rigoureuses ou des définitions théoriques précises ${ }^{8}$. On ne pourra pas non plus, comme le

${ }^{6}$ C'est ce que fait T. J. Moore en s'interrogeant sur le rapport de la métathéâtralité et du discours moral mais ses conclusions, qui vont dans le sens d'une parodie généralisée des propos moraux, nous paraissent trop tranchées (T. J. Moore, The Theater of Plautus, Austin, University of Texas Press, 1998, p. 67 sqq.).

${ }^{7}$ Ibid., p. 488.

${ }^{8}$ C'est ce que fait Z. Hoffmann, "The Parody of the Idea of the Mos Maiorum in Plautus », Oikumene, 3, 1982, p.217-233, qui voit de la parodie dans presque toutes les allusions au mos maiorum; c'est aussi, dans une moindre mesure, ce qui rend problématique les analyses de T.J. Moore, The Theater of Plautus, Austin, University of Texas Press, 1998, p. 67 sqq. Ce dernier considère par exemple que Mégaronide, un des senes du Trinummus, est un moralisateur ridicule par ses excès de réprimande; il est cependant nettement plus mesuré que bien des personnages, et en tout cas moins moqué 
font plusieurs critiques, s'en tenir à une analyse des palliatae comme de purs objets textuels, supports d'un blâme ou d'un éloge. La comédie est une performance, un spectacle total fondé sur le texte mais aussi sur la danse, le chant et la musique ${ }^{9}$; c'est également un événement rituel qui prend place dans le cadre des ludi et remplit une fonction religieuse. L'image de l'honneur est construite par la comédie dans des conditions de représentation particulières, qui agissent sur son sens et sa portée.

En résumé, nous étudierons les représentations de l'honneur en insistant sur le dispositif comique et dramatique dans lequel elles s'insèrent et sur leur dimension spectaculaire, ce qui nous permettra de mieux comprendre in fine leur portée morale pour le public.

\section{L'INVERSION DE L'HONOS SUR LA SCÈNE DE LA COMÉDIE}

Notre étude de la pratique de l'honos a mis au jour les mécanismes essentiels de son fonctionnement. Or la comédie de Plaute fait entrer du jeu dans ces mécanismes et donne de ces derniers une image extrêmement perturbée: elle renverse les dispositifs les plus fondamentaux de l'hommage et du prestige et représente sur scène un honneur à l'envers. Tout l'enjeu consiste à apprécier la portée de ce renversement radical selon les principes posés dans notre introduction. L'inversion est-elle moralement subversive? Quelles en sont les fonctions autres que morales?

\subsection{Des règles de fonctionnement inversées}

Deux aspects de l'honos se retrouvent totalement renversés sur la scène de la comédie, l'identité des protagonistes de l'hommage et les motifs pour lesquels des individus sont honorés. On voit en effet, en premier lieu, des personnages recevoir des marques d'honneur de la part d'individus qui sont habituellement, en raison de leur statut, les destinataires et non les auteurs de l'honos. Ainsi, dans l'Asinaria, le vieux Déménète déclare vouloir honorer son fils :

\footnotetext{
Praesertim quom is me dignum quoi concrederet

Habuit, me habere honorem eius ingenio decet.

Quom me adiit, ut pudentem gnatum aequomst patrem,

Cupio esse amicae quod det argentum suae.
}

(et moins drôle) que d'autres vieux de comédie comme Euclion, l'avare de l'Aulularia. Lorsque Plaute cherche à ridiculiser un personnage, il emploie des moyens autrement plus dévastateurs que l'ironie ou la moquerie sous-jacente.

${ }^{9}$ N. W. Slater, Plautus in Performance. The Theatre of the Mind, Princeton, Princeton University Press, 1985; F. DuPont, L'Acteur-roi, Paris, Les Belles Lettres, 1986, p. 114, ont bien mis en valeur le fait que les comédies sont des performances. L'étude récente de Marshall, The Stagecraft and Performance of Roman Comedy insiste sur l'importance de l'action scénique, de la musique, du chant et des costumes dans la comédie. 
«Surtout, comme il m’a jugé digne de lui servir de confident,

Il convient que je rende hommage à son bon caractère.

Puisqu'il est venu me voir, comme il est juste qu'un fils respectueux le fasse avec son père,

Je désire qu'il ait de l'argent à donner à sa maîtresse. »

(PL. As. 80-83)

Nous avons vu qu'il est rare qu'un homme âgé octroie des honneurs à quelqu'un de plus jeune que lui ${ }^{10}$. En règle générale, ce sont les jeunes qui honorent les personnes plus âgées. Ce n'est pas le cas ici puisque le senex est l'auteur de l'honos. En outre, c'est un père qui honore son fils, au rebours de ce que le spectateur romain pourrait attendre, habitué qu'il est aux normes de la pietas qui veut que les enfants honorent leur père. La comédie renverse ici la situation commune et prend ses distances avec le réel. Cette inversion va de pair avec le comportement inattendu de Déménète qui, plutôt que de s'opposer aux projets amoureux de son fils, choisit de les favoriser en lui procurant de l'argent. Dans une nouvelle inversion des rôles, c'est la mère du jeune homme qui surveille rigoureusement ce dernier et prend la place du père ${ }^{11}$. Une autre inversion des protagonistes ordinaires de l'honos a lieu dans l'Amphitryon où Jupiter, s'adressant aux spectateurs, leur déclare qu'il intervient dans l'action afin de mener la comédie à son terme en raison de l'honos du public ${ }^{12}$. On voit ainsi un dieu accorder des égards à des hommes alors que, dans la pratique religieuse, ce sont les hommes qui honorent les divinités en leur rendant un culte. La différence de statut qui existe entre les deux protagonistes est inversée le temps du spectacle.

La seconde inversion de l'honos est encore plus inattendue que la précédente. Les spectateurs voient dans la comédie des personnages honorés pour des raisons opposées à celles qui suscitent l'honos en temps normal. On y observe notamment que le manquement aux règles de la morale sociale et du mos maiorum peut donner lieu à des distinctions honorifiques. C'est ce qui arrive au début de l'Épidique, quand Thesprion, l'écuyer de Stratippoclès, de retour de la guerre, raconte à l'esclave Épidique comment leur maître a lâchement fui devant l'ennemi:

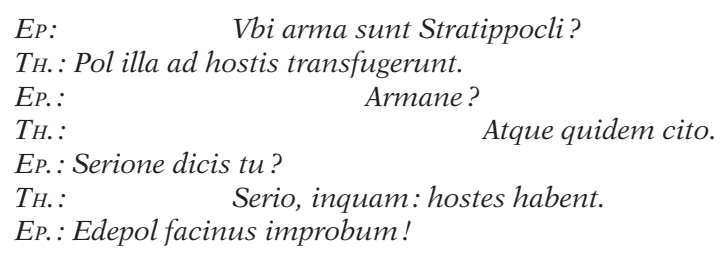

${ }^{10}$ Supra p. 326.

${ }^{11}$ PL. As. 78-79.

${ }^{12}$ PL. Amp. 867. 
TH.: $\quad$ At iam ante alii fecerunt idem.

Erit illi illa res honori.

EP.:

Qui?

TH. :

Quia ante aliis fuit.

«EPIDIQue: Où sont les armes de Stratippoclès?

Thesprion: Par Pollux, elles ont déserté et sont passées à l'ennemi! - Ep.:

Ses armes? - TH. : Et plutôt vite.

Ep.: Tu parles sérieusement?

Тн.: Sérieusement, je te dis: les ennemis les détiennent.

Ep.: Quel méfait honteux, par Pollux! - TH.: Pourtant il y en a d'autres qui ont fait pareil avant lui.

Tout cela lui vaudra de l'honneur - Ep.: Comment cela? - Тн.: Parce que cela en a valu à d'autres avant lui.»

(PL. Epid. 29-35).

Stratippoclès, face à l'ennemi, a fait preuve de couardise et ce comportement provoque une réaction attendue de la part d'Épidique qui le qualifie de "méfait honteux» (facinus improbum). Thesprion prend néanmoins le contre-pied de ce jugement conforme aux modes de pensée courants: ce facinus lui vaudra de l'honos, dit-il. La lâcheté est diamétralement opposée à l'exigence de uirtus imposée par le code d'honneur mais, dans la comédie, elle peut être récompensée par un honos $^{13}$. À l'inverse, la conduite conforme aux normes morales est désignée à plusieurs reprises comme dégradante et scandaleuse. C'est le cas par exemple dans les Bacchides: Mnésiloque, un des adulescentes de la pièce, croit par erreur que son ami Pistoclère a séduit la courtisane dont il est épris et décide donc, par dépit, de rendre à son père l'argent que l'esclave Chrysale avait réussi à escroquer pour servir les amours des jeunes gens. Détrompé par Pistoclère, il regrette amèrement d'avoir restitué la somme volée à son père:

Petulans, proteruo, iracundo animo, indomito, incogitato,

Sine modo et modestia sum, sine bono iure atque honore

«Imprudent, effronté, irascible, indomptable, irréfléchi,

Sans mesure ni modération, voilà ce que je suis; j'ignore le bon droit et l'honneur.»

(PL. Bac. 612-613).

Dans ce chant de désespoir, Mnésiloque déplore le geste qu'il a eu et le considère comme la marque de son manque de modération, de décence et d'honneur. Or la restitution à son père de l'argent qui lui a été dérobé est, du point de vue de la morale romaine, une action qui n'est pas répréhensible, mais témoigne au contraire de la droiture et de la pietas filiale. De manière totalement paradoxale, c'est donc l'ac-

${ }^{13}$ Dans l'Amphitryon, Sosie évoque sans nulle honte la manière dont il a pris la fuite lors de la bataille menée par Amphitryon contre les Téléboens (Amp. 199). 
tion honnête qui a coûté son honneur à Mnésiloque. L'honos du jeune homme de comédie impose en effet d'escroquer le senex et de tout faire pour satisfaire ses amours. La comédie étaye la dignité et le prestige sur les méfaits et la satisfaction du désir à tout prix. On y voit également des personnages recevoir des éloges pour les bassesses qu'ils ont commises: dans l'Asinaria, l'esclave Léonide est loué par Liban pour s'être parjuré, avoir volé et avoir causé le déshonneur de son maître; dans le Pseudolus, l'esclave déclare à Singe qu'il l'estime grandement pour sa perfidie ${ }^{14}$. L'honneur est donc accordé à celui qui enfreint les règles morales de l'honestas.

\subsection{La question de la subversion morale}

L'image que la comédie donne de l'honos est de toute évidence en opposition flagrante avec le fonctionnement habituel de l'honneur. Faut-il considérer que cette inversion radicale est moralement subversive et vise à remettre en cause l'honos comme valeur et rouage civique et à critiquer la conformité aux normes collectives? Il est impératif, pour répondre à cette question, de prendre en compte les particularités dramatiques des comédies, c'est-à-dire les conditions internes dans lesquelles l'inversion est présentée, et le contexte de leur représentation spectaculaire, les conditions externes dans lesquelles s'inscrit l'inversion.

D'un point de vue interne à la comédie, d'abord, les inversions de l'honneur sont précisément délimitées. Quand une inversion se produit, elle est localisée à un moment précis de l'action et ne se répand pas dans toute la pièce. Dans l'Épidique, par exemple, la lâcheté n'est traitée comme une source d'honos qu'au début de la pièce et cet aspect paradoxal est occulté dans la suite de l'intrigue. Le personnage du miles ne cesse au contraire de répéter qu'il doit sa gloire à son courage et ses prouesses au combat ${ }^{15}$. Il est certes comique, mais c'est sa vantardise et ses prétentions excessives qui le sont, pas le fait qu'il ait de la uirtus et réclame pour cela de la considération. La palliata représente une distorsion des normes morales mais cette dernière ne débouche pas sur leur destruction: l'honneur est mis à l'envers mais l'irrégularité n'est que temporaire et annulée par la situation finale où chacun retrouve sa place. Le happy-end des comédies, où les méchants sont punis et les bons récompensés, fait que l'inversion ne mène pas au chaos ${ }^{16}$. À

${ }^{14}$ Pl. As. 569-575. Pl. Pseud. 944.

${ }^{15}$ Voir par exemple PL. Epid. 442-452.

${ }^{16}$ Sur cette fonction de la scène finale, J. Blänsdorf, «Plautus », in LefÈvre, E. (éd.), Das römische Drama, Darmstadt, Wissenschaftliche Buchgesellschaft, 1978, p. 135-222 et M. Fuhrmann, «Lizenzen und Tabus der Lachen. Zur sozialen Grammatik der hellenistisch-römischen Komödie », in Preisendanz, W. et Warning, R. (éds.), Das Kömische, Munich, Fink, 1976, p.65-101, à la p. 90. 
l'échelle de l'œuvre globale de Plaute, il apparaît bien en outre que l'inversion de l'honneur n'est nullement systématique puisque d'autres pièces présentent un fonctionnement parfaitement conventionnel des mécanismes de l'honos et sont en adéquation avec les représentations traditionnelles de la dignité. Dans l'Aulularia, le lare de la maison souligne combien la jeune fille de la pièce lui adresse des honores réguliers ${ }^{17}$. Dans le Rudens, les règles de l'honos sont parfaitement respectées:

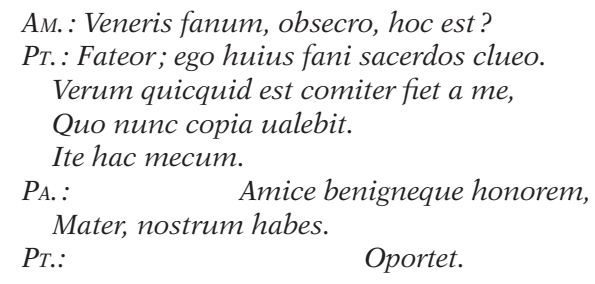

«Ampélisoue: Est-ce là, je te prie, le temple de Vénus?

Ptolémocratie: Absolument; je suis connue ici comme la prêtresse de ce temple.

Mais quoi qu'il en soit, je vous recevrai en toute bienveillance,

Autant que ma richesse me le permettra.

Venez par ici avec moi. - Palestra: Tu nous fais honneur,

Mère, avec amitié et bienveillance - Рт. : C'est mon devoir.»

(PL. Rud. 284-289).

Ampélisque et sa sœur Palestra ont fait naufrage et elles sont recueillies par Ptolémocratie, la prêtresse du temple de Vénus, à qui elles viennent d'adresser une supplication. La prêtresse leur accorde l'honos de l'hospitalité car, dit-elle, il est conforme aux obligations morales et religieuses (oportet) de protéger des suppliants. La scène, qui ne présente aucune forme de comique, est empreinte d'un pathétique touchant et montre que l'honos peut fonctionner normalement dans la palliata. Le fait que l'inversion de l'honos soit circonscrite et non systématique nous incite à penser qu'elle remplit des fonctions non pas morales mais dramatiques, liées à l'évolution de l'action, sur lesquelles il nous faudra revenir.

Un autre élément, essentiel à la palliata, limite également la portée du renversement de l'honneur: il s'agit de l'implantation de l'intrigue dans le monde grec. Plaute imite en effet les œuvres de la Néa, la nouvelle comédie attique dont Ménandre est le plus célèbre représentant, et importe sur la scène romaine plusieurs éléments de son modèle. Le décor grec des comédies est cependant loin de dessiner une image 
parfaitement cohérente de l'hellénisme. On rencontre fréquemment dans l'intrigue des éléments romains: la présence du lare au début de l'Aulularia, de la bulla dans les bijoux d'une jeune fille, l'allusion à l'atrium d'une maison ou à des éléments de religion et de droit romains jurent avec le contexte grec des pièces et montrent que ce dernier n'est qu'un alibi qui remplit des fonctions précises ${ }^{18}$. L'allure grecque ne trompe probablement pas les spectateurs mais permet de représenter des comportements indécents ou inacceptables selon les normes romaines en les tenant à distance puisqu'ils sont attribués à des Grecs. Il est ainsi significatif que la débauche et les excès soient désignés dans les pièces par des verbes comme pergraecari ou congraecare: vivre dans le plaisir, c'est vivre à la grecque ${ }^{19}$. La dégradation des mœurs et de l'honneur que présente la comédie est donc bien en contradiction avec les idéaux romains mais l'attribution de telles conduites à des Grecs, même de pacotille, atténue la portée critique ou subversive de cette représentation ${ }^{20}$. Ici encore, la portée potentiellement subversive de l'inversion de l'honos est donc fortement circonscrite.

Un troisième facteur, étranger cette fois au contenu des pièces, limite encore leur dimension corrosive. Il s'agit des conditions de représentation des comédies dans la cité: à Rome, les représentations théâtrales ont lieu dans le cadre des $l u d i^{21}$ et font donc partie intégrante d'un rituel religieux qui se déroule en une période particulière, où les autres activités de la vie civique sont en suspens. Le spectacle est luimême un moment singulier, qui possède un début et une fin nettement délimités; ces bornes temporelles sont visibles dans le texte des pièces puisqu'au début de celles-ci un personnage, le prologue, demande aux spectateurs de s'asseoir et de se taire ${ }^{22}$. À cette ouverture rituelle de la comédie correspond une clôture, celle de l'adieu aux spectateurs et de la demande d'applaudissements ${ }^{23}$. L'action de la comédie est

${ }^{18}$ Sur ces aspects et sur le mélange des éléments grecs et romains dans les pièces de Plaute, E. Frankel, Plautinisches im Plautus, Berlin, Weidmann, 1922, p. 26 sqq.; L. Deschamps, "Épidaure ou Rome? À propos du Curculio de Plaute», Platon, 32-33, 1980-1981, p.144-177; PANsIÉRI, Plaute et Rome, p. 296 sqq.; Moore, The Theater of Plautus, p. 52 sqq.; F. Dupont, "Plaute 'fils du bouffeur de bouillie': la palliata est-elle une comédie grecque en latin? ", in Dupont, F. et Valette-Cagnac, E. (éds.), Façons de parler grec à Rome, Paris, Belin, 2005, p. 175-209.

${ }^{19}$ Pl. Most. 22; Truc. 87 ; Bac. 743. Voir E. Segal, Roman Laughter. The Comedy of Plautus, Cambridge (MA), Harvard University Press, 1968, p. 36 sqq.

${ }^{20}$ Moore, The Theater of Plautus remarque que les références au contexte grec augmentent en même temps que le degré d'immoralité des scènes de comédie (p.61) et que les personnages les plus roués sont souvent «heavily hellenized» (p.64; c'est le cas de Pseudolus, par exemple, interpellé comme serue Athenis pessume en Pl. Pseud. 270).

${ }^{21}$ Sur les ludi, Wissowa, Religion und Kultus der Römer, p. 449-467.

${ }^{22}$ Pl. As. 4-5; Poen. 11-15, par exemple.

${ }^{23}$ PL. Most. 1181 ; Truc. 968, entre autres. Sur l'ouverture et la fermeture rituelle de la comédie, Dupont, "Plaute 'fils du bouffeur de bouillie'». 
donc enclose dans la durée festive et rituelle de la pièce de théâtre qui constitue un moment à part. Ce cadre contribue à circonscrire davantage les inversions de l'honos et les manquements aux règles morales ${ }^{24}$.

\subsection{La fonction régénératrice}

L'inversion de l'honos par la comédie n'a pas une visée destructrice: elle ne cherche pas à annihiler la pratique sociale de l'hommage ou la valeur qu'est l'honneur. Il s'agit, en effet, d'une inversion ludique et non d'une désarticulation chaotique. L'honos est très précisément mis sens dessus dessous: c'est le dieu qui honore l'homme et non l'homme qui honore le dieu; la source de l'honos n'est plus le courage, mais la lâcheté. La comédie ne rend donc pas illisible le fonctionnement normal de l'honos; elle en donne simplement une image en négatif à des fins d'amusement. Le jeu avec l'honneur est un jeu bienfaisant qui contribue à la fonction psychologique remplie par la comédie, le relâchement des tensions, fonction mise en avant par E. Segal ${ }^{25}$. La palliata permet aux spectateurs d'assister à une action où des individus ne se soucient plus des règles habituelles de l'honneur. Les idéaux moraux de l'honorabilité, dont le poids peut être très pesant, sont temporairement rejetés, d'une manière qui en atténue la nature contraignante. Létrangeté temporelle et spatiale du spectacle comique joue de ce point de vue un rôle essentiel: le décor grec de la pièce autorise cet abandon des normes romaines et l'inscription de l'action dans un rituel festif temporairement délimité permet aux spectateurs de tirer bénéfice, sans culpabilité, de cette inversion des règles habituelles $^{26}$. On retrouve ici un mode de fonctionnement proche de celui des Saturnales. Cette fête, où les codes sociaux et vestimentaires des citoyens et des esclaves sont inversés ${ }^{27}$, ne vise pas à détruire l'ordre social mais à abolir temporairement son fonctionnement pour le rendre plus acceptable en temps normal. Il en va de même pour la comédie: si son objectif est de soulager les tensions et si l'honos n'y est pas totalement déstructuré mais seulement présenté en négatif, l'inversion de l'honneur, loin de jouer un rôle subversif, peut au contraire

${ }^{24}$ Sur ce rôle du cadre festif, G. Petrone, Morale e antimorale nelle commedie di Plauto, Palerme, Palumbo, 1977, p. 27 et GIZEWSKI, «Mores maiorum, regimen morum, licentia», p.93. Le fait que les pièces aient été commandées par des magistrats induit également une limitation de leur dimension subversive.

${ }^{25}$ Segal, Roman Laughter. Voir aussi Della Corte, Da Sarsina a Roma. Ricerche plautine, p. 274 sqq. et PANsiéri, Plaute et Rome, p. 598 sqq.

${ }^{26}$ SEgAL, Roman Laughter, p. 41

${ }^{27}$ Sur les Saturnales, H.-S. Versnel, "Saturn and the Saturnalia: the Question of Origin ", in SAncisi-Weerdenburg, H. (éd.), De agricultura: in memoriam Pieter Willem De Neeve (1945-1990), Amsterdam, Gieben, 1993, p.98-120. Sur le rapport entre la comédie et les Saturnales, E. LefÈvre, "Saturnalien und Palliata », Poetica, 20, 1988, p. 32-46. 
servir de stabilisateur. Le fait que les pères honorent leur fils et que la lâcheté prime sur le courage suscite chez les spectateurs non pas l'indignation ni l'exaltation mais un rire régénérateur devant un honos mis à l'envers le temps du spectacle et qui sera, pour avoir été transformé en objet ludique, mieux accepté par la suite ${ }^{28}$.

\subsection{La fonction comique}

Pour que le relâchement psychologique de la comédie puisse opérer sur le spectateur, il est impératif que le dramaturge déclenche chez lui le rire. Or l'inversion de l'honneur constitue un moyen privilégié pour ce faire. Elle amuse en premier lieu parce qu'elle repose sur un jeu de para prosdokian: elle déjoue un attendu du public. Les règles de l'honneur sont en effet bien connues des spectateurs. Il est donc inhabituel et amusant de voir un personnage se comporter de façon diamétralement opposée à ces règles. C'est le cas dans les textes que nous citions au début de ce chapitre: dans son monologue de désespoir, Mnésiloque va plaisamment à l'encontre de la définition de l'honneur en se déclarant déshonoré parce qu'il s'est refusé à escroquer son père ${ }^{29}$. C'est également un effet comique que produit l'attitude de Jupiter dans l'Amphitryon quand il déclare vouloir rendre honneur aux spectateurs: inversant les rôles traditionnels, Jupiter se place dans une position inférieure à celle du public et tient un discours qui contraste singulièrement avec sa nature divine; Plaute crée ainsi un effet comique de type burlesque ${ }^{30}$.

L'inversion de l'honneur remplit donc une fonction ludique et comique prépondérante. Cette fonction vient éclairer le problème du mélange, au sein d'une même comédie, de passages qui présentent, les uns, un honos à l'envers, les autres, un fonctionnement habituel. Cette non-systématicité de la représentation de l'honneur, de même que la juxtaposition de scènes en accord avec la morale traditionnelle et de moments où les règles sont violées, est incompréhensible si l'on cherche à les expliquer du seul point de vue de leur portée éthique. Elle est en revanche plus claire si l'on se souvient de leur rôle dramatique: les inversions servent à créer la surprise et à déclencher le rire, ce qui ne saurait avoir lieu à chaque moment de l'action ${ }^{31}$.

\footnotetext{
${ }^{28}$ Sur l' « indirekte Stabilisierung » opérée par certains genres littéraires, MUTSCHLER, «Virtus und kein Ende?», p. 36.

${ }^{29}$ PL. Bac. 612-613.

${ }^{30}$ Sur le burlesque divin dans la comédie, CÈBE, La Caricature et la parodie dans le monde romain, p. 67-73.

${ }^{31}$ Sur le mélange des moments sérieux et immoraux et la fonction dramatique de cette alternance, Petrone, Morale e antimorale nelle commedie di Plauto, p. 67 sqq.
} 
2. L'ÉvALUATION DE L'HONNEUR PAR LES PERSONNAGES DE COMÉDIE

Pour approfondir les modifications que subit l'honneur à l'épreuve de la scène, il faut également prendre en compte les différentes scènes où des personnages évaluent l'honos et les comportements honesti. L'honneur n'est en effet pas seulement un mécanisme dont les rouages sont l'occasion d'un spectacle ludique mais aussi une valeur sur laquelle différents discours sont tenus. Le théâtre de Plaute paraît, ici encore, parcouru de contradictions: on y rencontre aussi bien des discours moralisateurs qui valorisent l'honneur que des propos contestataires qui le méprisent. Il semble donc à nouveau difficile de dégager une «morale de Plaute» cohérente. Pour évaluer la portée de ces différentes évaluations de l'honneur, il faut continuer de nous appuyer sur les éléments internes à la comédie. Nous tâcherons aussi de cerner les fonctions non morales de l'évaluation de l'honneur.

\subsection{Le mépris de l'honneur}

Quatre textes de notre corpus présentent, de manière plus ou moins frappante, un personnage qui rejette l'honneur au profit d'un autre objet jugé plus précieux, mais dont le statut est problématique au regard des normes morales romaines.

\subsubsection{L'amoureux et le glouton}

Les discours qui rejettent l'honneur sont pris en charge par des personnages typiques de la comédie: deux d'entre eux sont tenus par un jeune homme amoureux, deux autres par un glouton. Le début du Curculio met en scène devant la maison d'un leno l'esclave Palinure et son jeune maître Phédrome, amoureux d'une des jeunes filles retenues par le proxénète. Phédrome parvient à obtenir une entrevue avec son amante. Transporté de joie à ces retrouvailles, il la serre dans ses bras puis s'écrie:

Sibi sua habeant regna reges, sibi diuitias diuites, Sibi honores, sibi uirtutes, sibi pugnas, sibi proelia;

Dum mi abstineant inuidere, sibi quisque habeant quod suum est.

«Qu’ils gardent leurs royaumes, les rois, qu'ils gardent leurs richesses, les riches,

Qu'ils gardent leurs honneurs, leurs exploits, leurs combats, leurs batailles! Pourvu qu'ils s'abstiennent de me jalouser, qu'ils gardent tous ce qui leur appartient. »

(PL. Curc. 178-180).

Le jeune homme, tout entier à son amour, se considère comme le plus heureux des hommes et rejette avec dédain tout ce qui est habituellement prisé, richesse, pouvoir et honores. Il apprécie plus que tout 
la réunion avec son amante et la satisfaction de son désir amoureux ${ }^{32}$. Il en va un peu de même dans le Miles gloriosus, où c'est cette fois l'honestas, le comportement conforme à l'honneur, qui est rejeté par un personnage de iuuenis amoureux. Il s'agit du passage que nous avons étudié à propos des modèles de l'honneur, où le jeune Pleusiclès se déguise en capitaine de navire pour pouvoir se rapprocher de Philocomasie, jeune femme dont il est épris:

Alium alio pacto propter amorem ni sciam
Fecisse multa nequiter, uerear magis
Me amoris causa $<$ huc $>$ hoc ornatu incedere.
Verum quom multos multa admisse acceperim
Inhonesta propter amorem atque aliena a bonis-
Mitto iam, ut occidi Achilles ciuis passus est...

«Si je ne savais toutes les fourberies que d'autres, chacun à leur manière,

Ont faites à cause de l'amour, j'aurais plus de scrupules

À me présenter dans cette tenue que l'amour me fait endosser.

Mais puisque j'ai entendu dire que bien des gens s'étaient permis bien des choses

Contraires à l'honneur et étrangères à la vertu à cause de l'amour -

Sans parler de la manière dont Achille a laissé tuer ses concitoyens... »

(PL. Mil. 1284-1289).

Pleusiclès éprouve quelques scrupules à se grimer de manière ridicule pour satisfaire sa passion mais balaie toute hésitation quand il se souvient que bien des gens ont mal agi par amour: il fait passer son amour avant l'observation de l'honneur et se risque à mener une action inhonesta pour pouvoir être aux côtés de celle qu'il aime. La scène présente donc un personnage qui renonce à observer les règles de l'honneur pour obéir à ce que lui dicte son désir.

Les deux autres textes où un personnage rejette explicitement l'honneur et l'honorabilité mettent en scène un glouton. Dans le Trinummus, le vieux Philton demande aux autres personnages de s'imaginer assis dans un banquet public aux côtés d'un riche devant qui s'entasseraient des plats appétissants; quelle serait alors, demande-t-il, leur attitude? L'esclave Stasime réagit vivement:

Decedam ego illi de uia, de semita,

De honore populi; uerum quod ad uentrem attinet,

Non hercle hoc longe, nisi me pugnis uicerit.

32 Voir aussi Curc. 284-287 où la gloire est une valeur rejetée. Sur ce point, J.-F. Thомаs, «Les genres nobles dans les comédies de Plaute et de Térence: l'exemple du thème de la gloire », CGITA, 14, 2001, p. 115-137. 
« Je lui céderais le pas sur la chaussée, sur le trottoir,

Je lui abandonne les honneurs publics; mais pour ce qui touche à mon ventre,

Je ne lui céderais pas de ça, sauf s'il triomphe de moi aux poings.»

(PL. Trin. 481-483; trad. Ernout modifiée).

S'il avait cette possibilité, Stasime ferait tout son possible pour s'emparer des plats et manger autant que possible. La satisfaction de son appétit est pour lui essentielle, au point qu'il est prêt à en venir aux mains s'il le faut. En revanche, aucune des préséances ou des marques d'honneur du riche n'intéresse Stasime. La gourmandise est bien plus forte que le souci de l'honneur et ce choix de l'esclave glouton prend le contre-pied des valeurs romaines. Il en va probablement de même dans un passage du Phago que nous ne connaissons que de manière fragmentaire mais qui mettait en scène un personnage de goinfre, comme l'indique le titre de la pièce, «Le Dévoreur»:

Honos syncerasto periit, pernis, glandio.

«L'honneur a péri à cause du ragoût, des jambons, du ris de porc. »

(PL. frg. 101 Ernout).

Il est ici question de la manière dont un personnage, sans doute le glouton de la pièce, a perdu son honos en raison des festins auxquels il s'est livré. La gourmandise dispendieuse et immodérée est en effet en contradiction avec les règles de l'honneur ${ }^{33}$. Le phago a préféré la satisfaction de son désir à la préservation de son honos. Ces différents textes constituent donc chacun une sorte de spectacle du déshonneur où triomphent des anti-valeurs comme l'amour ou la gourmandise. Les personnages y tiennent des propos en contradiction flagrante avec les normes de l'honorabilité. S'agit-il donc là d'une attaque contre la tradition morale romaine?

\subsubsection{La portée morale de ce mépris}

La comédie représente assurément le mépris de l'honneur mais elle ne nous paraît pas constituer pour autant une défense iconoclaste de la débauche ou une critique virulente de l'honos. Il convient en effet, pour mesurer la portée de ces discours, de les rapporter à l'identité du personnage qui en est l'auteur. Or ceux qui affichent un mépris pour l'honneur, l'amoureux et le glouton, peuvent susciter la sympathie mais n'apparaissent nullement comme des exemples à suivre. Le glouton est un personnage entièrement dominé par sa passion de la nourriture, ce qui le rend ridicule. Son discours ne peut donc pas être

\footnotetext{
${ }^{33}$ Voir supra p. 472.
} 
pris au sérieux. Il en est de même de l'amoureux, qui se caractérise par son absence de retenue: Phédrome est totalement transporté par l'amour dans le passage où il rejette les honores, comme le montre le ton exalté de sa tirade: il ne connaît pas la mesure et ne peut donc être le support d'un discours moral valide. Quant aux scrupules de Pleusiclès, ils sont bien rapidement balayés; ils ne conviennent en effet nullement au type comique de l'amator. Comme le lui dit son esclave Palestrion:

Nouo modo tu homo amas, siquidem te quicquam quod faxis pudet.

«Tu es un amoureux d'une espèce nouvelle si vraiment quelque honte peut te retenir.»

(PL. Mil. 624; trad. Ernout modifiée).

L'amoureux n'a pas de pudor, pas de sens de l'honneur, et son discours sur l'honorabilité est donc sans valeur morale. En outre, son écart par rapport aux normes morales collectives est toujours entouré d'un discours critique: Pleusiclès ressent quelque hésitation avant d'enfreindre les règles de l'honneur, et sa déviance n'est donc pas totalement ignorante des règles de conduite. Dans le passage du Curculio, l'esclave Palinure ne cesse de rappeler à son maître Phédrome le caractère inconvenant de sa conduite:

Flagitium probrumque magnum, Phedrome, expergefacis.

"Tu éveilles, Phédrome, un grand scandale et une grande débauche.»

(PL. Curc. 198).

Le mépris de l'honos n'est donc pas présenté par la comédie comme une alternative sérieuse à sa valorisation car elle est le fait de personnages socialement et moralement dégradés, en proie à la passion. Le spectateur entend des propos paradoxaux mais dont la portée est limitée par le statut de ceux qui les prononcent et par le discours critique qui les environne. Plaute n'incarne pas la rébellion contre un ordre moral oppressant: il n'y a pas de leçon de Plaute sur la valeur de l'honos ${ }^{34}$.

L'absence d'une leçon critique sérieuse ne signifie pas néanmoins que ces jugements de valeur inhabituels sont sans effet sur le public. Le mépris des honneurs affiché par Phédrome ne peut être pris comme une exhortation de l'auteur à renoncer à l'honos, mais il n'en reste pas moins qu'il incarne un choix possible. Son attitude est comique mais c'est cela même qui la rend représentable sur la scène romaine. De même, Stasime, l'esclave glouton, est un personnage amusant, au

${ }^{34}$ Comme le souligne justement P.Lejay, Plaute, Paris, Boivin, 1925, «rien n'est plus éloigné de son tempérament que la prédication» (p.212). Sur la neutralité morale de Plaute, voir aussi Gizewski, «Mores maiorum, regimen morum, licentia», p.99-100. 
statut social très faible, ce qui discrédite son dédain de l'honneur mais permet simultanément à ce rejet paradoxal d'être montré. La comédie rend la présence de la déviance acceptable dans le cadre du spectacle; elle donne, malgré tout, une consistance au négatif, à ce qui ne peut être représenté dans la vie courante. La palliata, jouant de sa temporalité singulière et de son décor exotique, est le lieu de l'exhibition de conduites répréhensibles qui ne peuvent autrement être montrées: elle ouvre le champ des possibles. L'honos n'est pas réellement dévalorisé par la comédie mais il apparaît comme une valeur relative et non plus absolue. C'est une valeur préférée à d'autres et non plus la seule valeur envisageable. Le mépris affiché du glouton et de l'amoureux pour l'honneur n'est pas présenté comme une conduite à suivre mais ouvre la voie à une pensée évaluative de l'honneur, qui peine sans cela à trouver sa place. Plaute ne mène pas lui-même l'évaluation de l'honos mais la rend possible en représentant l'impensable déshonneur.

\subsubsection{L'amorce d'une réflexion sur l'honneur}

La comédie place donc l'honneur face à d'autres objets, comme l'amour ou le plaisir, qui sont évalués de manière diverse par les personnages au sein des pièces. Un tel procédé constitue l'embryon d'une approche plus réflexive de l'honos car on trouve, sur un mode comique et encore peu élaboré théoriquement, une confrontation entre deux types de conduite qui n'est pas sans rappeler les développements de la philosophie grecque sur les genres de vie ${ }^{35}$. Plusieurs traces d'une pensée philosophique ont déjà été repérées dans les comédies de Plaute, lorsque sont abordés des thèmes comme la vertu, le plaisir ou le rôle des dieux. Le modèle de la palliata est en effet un genre grec, la Néa, qui était lui-même imprégné de la réflexion spéculative de son temps et dont Plaute transpose plusieurs passages ${ }^{36}$. Le fait même qu'il procède ainsi révèle que le public était réceptif à ces aspects: Plaute ne les aurait pas conservés par pur souci de fidélité à ses modèles s'ils avaient été incompréhensibles pour les spectateurs ${ }^{37}$. Il a d'ailleurs été bien établi, à partir du contenu des pièces de Plaute, que le public de la comédie, parfois présenté comme indigent intellectuellement, est en

${ }^{35}$ Sur la question philosophique des genres de vie, voir A. GRILLI, Il problema della vita contemplativa nel mondo greco-romano, Milan, Fratelli Bocca, 1953; R. JoLy, Le Thème philosophique des genres de vie dans l'Antiquité classique, Bruxelles, Académie royale de Belgique, 1956 et S. GASTALDI, Bios hairetotatos: generi di vita e felicità in Aristotele, Naples, Bibliopolis, 2003.

${ }^{36}$ Sur les éléments philosophiques dans les pièces de Plaute, Garbarino, Roma e la filosofia greca, vol.2, p. 544-560; P. R. COLEMAN-NorTon, «Philosophical Aspects of Early Roman Drama », $C P h, 31,1936$, p. 320-337 et K. STAWECKA, «Spuren der philosophischen uirtus in den Komödien von Plautus ", Eos, 57, 1967-1968, p.211-218.

${ }^{37}$ Voir les remarques de Garbarino, Roma e la filosofia greca, vol. 2, p. 539. 
réalité cultivé ${ }^{38}$. Une interrogation réflexive sur l'honneur n'a donc rien de déplacé sur la scène de la comédie. Le thème philosophique des genres de vie est abordé par les présocratiques puis les sophistes, avant que Platon et ensuite Aristote ne lui donnent une nouvelle ampleur ${ }^{39}$. C'est surtout ce dernier qui retiendra notre attention car sa philosophie imprègne fortement Ménandre et ses contemporains, c'est-à-dire les modèles de Plaute ${ }^{40}$. Il ne serait donc pas surprenant de retrouver, sous un aspect transformé, une problématique aristotélicienne dans son théâtre. Au premier livre de l'Éthique à Nicomaque est présentée une classification des genres de vie: la vie de plaisir est choisie par la foule et les gens grossiers qui placent le bonheur dans la jouissance; la vie dite "politique» est celle de l'élite et des hommes d'action qui

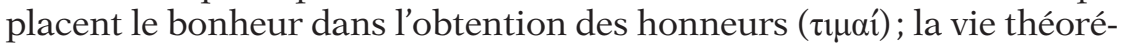
tique est celle des philosophes qui placent le bonheur dans la contemplation ${ }^{41}$. L'attitude et les propos des personnages de Plaute sur l'honneur reflètent certaines de ces distinctions: il faut en effet garder en mémoire le fait qu'honos, qui apparaît dans nos textes, est ressenti comme l'équivalent latin de $\tau \mu \mu n ́$, terme qu'emploie Aristote pour désigner la fin que vise la vie politique ${ }^{42}$. Le fait que les personnages de Plaute méprisent l'honos au profit de l'amour ou de la gourmandise, qui sont deux types de plaisir, remobilise la distinction entre vie politique et vie hédoniste dans la comédie. On voit notamment apparaître les catégories aristotéliciennes dans le Curculio: Phédrome y rejette les honores, équivalents des $\tau \mu \alpha i ́$ définies par Aristote comme la fin de la vie politique, mais aussi les batailles (pugnas, proelia) et le pouvoir (regna), qui sont dans l'Éthique à Nicomaque propres aux hommes qui

${ }^{38}$ Les articles de J.-P. CÈBE, "Le niveau culturel du public plautinien », REL, 38, 1960, p. 101-106 et de W.R.Chalmers, "Plautus and his Audience», in Dudley, D. R. et Dorey, T.A.(éds.), Roman Drama, Londres, Routledge, 1965, p.21-50, ont montré que l'emploi par Plaute de procédés comme la paratragédie, les jeux de mots, les allusions à la mythologie et à l'histoire grecques impliquent que le public était à même de les apprécier.

${ }^{39}$ Sur l'évolution de ce thème, des présocratiques à Aristote, Joly, Le Thème philosophique des genres de vie, p. 19-127 et GASTALDI, Bios hairetotatos: generi di vita e felicità in Aristotele.

${ }^{40}$ Ménandre aurait été l'élève de Théophraste, disciple d'Aristote. Sur cette influence, M. TIERnEY, "Aristotle and Menander », Proceedings of the Royal Irish Academy, 43, 1936, p. 241-254 et A. BARIgAzzI, La formazione spirituale di Menandro, Turin, Bottega d'Erasmo, 1965. Sur la marque de l'aristotélisme chez Plaute, GrimaL, «Existe-t-il une morale de Plaute? » et P. GRIMAL, "Analyse du Trinummus et les débuts de la philosophie à Rome? ", in Grimal, P. (éd.), Rome. La littérature et l'histoire, Rome, E.F.R., 1986, vol. 1, p. 283-293.

${ }^{41}$ ARstT. EN I, 5. Sur ce passage, GASTALDI, Bios hairetotatos: generi di vita e felicità in Aristotele, p.89-93. Ce ne sont pas les seuls genres de vie qui existent, mais les principaux.

${ }^{42}$ Sur l'équivalence d'honos et de $\tau$ tú, voir supra p. 108 sqq. 
se consacrent à ce genre de vie ${ }^{43}$. Le Curculio représente un individu qui a fait le choix d'une vie de plaisir, consacrée à l'amour, et a délaissé la vie pragmatique qui vise l'honneur dans la cité. L'élaboration théorique de la question des genres de vie reste cependant limitée: il n'y est pas question de la vie contemplative mais seulement d'une alternative entre plaisir et honneur; nulle part n'est évoqué le concept de bonheur qui est essentiel chez Aristote; Plaute ne parle pas non plus du moment précis du choix de vie, qui revêt une grande importance pour Aristote, mais seulement du résultat de ce choix. Enfin et surtout, Phédrome valorise la vie de plaisir qui est irrémédiablement rejetée par Aristote pour la bassesse qu'elle implique. Il y a donc une présence indirecte et peu formalisée de la question philosophique des genres de vie, mais qui a le mérite d'amorcer la réflexion en dessinant une antinomie entre honneur et volupté ${ }^{44}$.

\subsubsection{Les fonctions dramatiques}

Ces propos paradoxaux tenus sur l'honneur, s'ils ont un contenu moral, n'ont pas nécessairement une fonction morale. Il ne faut pas perdre de vue qu'ils prennent place au sein d'une comédie, un spectacle total, qui obéit à d'autres impératifs que la satire ou la prédication. Ils ont un rôle du point de vue de la technique dramatique ${ }^{45}$. Ces développements permettent d'abord de caractériser les personnages. Dans le Curculio, le discours exalté de Phédrome prend place lors de l'exposition de la pièce. Son rejet des honores et sa valorisation de l'amour permettent aux spectateurs de reconnaître en lui le type de l'amator transi; avant ce passage, il n'est qu'un iuuenis qui peut remplir différents rôles-types et ce sont ses déclarations moralement paradoxales qui le caractérisent comme le jeune homme amoureux et incapable de mesure. Les propos exaltés de l'esclave Stasime sur le prix de la bonne chère et le dédain des honneurs ont également un intérêt sur le plan dramatique: ils dessinent un contraste saisissant entre l'attitude violemment passionnée de l'esclave et la résignation bougonne de son maître Lesbonicus, qui constituent deux réactions opposées aux propos du vieux Philton. Le contraste s'accentuera encore quand

${ }^{43}$ ArstT. EN X, 6-7.

${ }^{44}$ Le plaisir est également abordé de manière réflexive dans un passage du Mercator marqué par la philosophie, où il est question de la valeur comparée de la souffrance et du plaisir (Merc. 138 sqq.). Voir H.ZehNacker, «Plaute et la philosophie grecque. À propos du Mercator» in Mélanges P. Boyancé, Rome, E.F.R., 1974, p. 769-785.

${ }_{45}$ Sur les particularités de la technique dramatique romaine, notamment par rapport à la Néa, GrimaL, « Jeu et vérité dans les comédies de Plaute», Dioniso, 46, 1975, p. $137-152$. 
Lesbonicus se désespérera d'avoir perdu son honos, objet que Stasime, de son côté, avait rejeté depuis longtemps ${ }^{46}$.

Le rejet de l'honneur est également un moyen pour le dramaturge de susciter le rire du public. Il ne s'agit pas cependant cette fois d'inversion burlesque mais d'un comique plus subtil. Dans le Miles gloriosus, l'infraction de Pleusiclès aux exigences de l'honneur prend en effet un tour plaisant par le double sens de son discours. Son évocation de la honte qu'il ressent à se présenter devant les autres grimé en capitaine de navire et du déshonneur lié à un tel déguisement provoque un amusant effet de métathéâtre car la description donnée par l'acteur vaut aussi bien pour le personnage qu'il incarne, Pleusiclès, que pour l'histrion lui-même ${ }^{47}$. Pleusiclès joue en effet, au sein de la pièce, une comédie en se déguisant en capitaine de navire, ce que fait également l'acteur qui revêt le costume du personnage qu'il doit figurer. Lorsque l'histrion déclare qu'il est honteux de s'avancer ainsi déguisé (hoc ornatu incedere), il incarne la honte du personnage de Pleusiclès mais fait aussi référence au déshonneur qui le touche en tant qu'acteur puisqu'à Rome ceux qui s'exhibent sur scène pour le plaisir des autres sont frappés d'infamie ${ }^{48}$. La référence de Pleusiclès aux nombreuses personnes qui ont accompli des actions ignominieuses par amour possède un sens au sein de la comédie, puisque d'autres individus, comme Achille, cité par Pleusiclès, se sont déshonorés en raison de leur passion. Mais elle a aussi un sens sur le plan métathéâtral: l'acteur fait référence au fait que, dans les autres comédies que le public a pu voir, bien des personnages se comportent de manière contraire à l'honneur. Tout le discours de Pleusiclès sur le déshonneur est donc l'occasion d'un jeu de doubles sens humoristiques.

\subsection{L'attachement à l'honneur}

Les propos iconoclastes tenus sur l'honneur par les personnages de la comédie ne sont donc pas le support d'une critique de l'honos ou de l'honorabilité. Plaute ne formule pas à travers eux de leçon morale. Qu'en est-il des passages où, à l'inverse, les acteurs manifestent leur attachement à l'honneur ou prennent en charge un discours moralisateur? Ces discours sont-ils édifiants ou parodiques et donc subversifs?

\subsubsection{La valorisation de l'honneur par les personnages}

Plusieurs pièces de Plaute mettent en scène des personnages qui montrent leur attachement à l'honneur ou leur souhait de l'obtenir.

\footnotetext{
${ }^{46}$ PL. Trin. 612.

${ }^{47}$ Nous entendons par métathéâtre tous les effets par lesquels le théâtre se montre conscient de sa propre théâtralité (SLater, Plautus in Performance, p. 14).

${ }^{48}$ Sur la condition de l'acteur, voir supra p. 309.
} 
Parmi ces comédies, le Trinummus est plus particulièrement intéressant car il présente trois passages où un personnage prononce un discours moralisateur favorable à l'honneur et à la vertu. Nous concentrerons donc le regard sur cette œuvre ${ }^{49}$. La forte teneur morale de cette palliata a suscité plusieurs études, qui ont abouti à des résultats contradictoires. Pour les uns, la comédie est une pièce édifiante, où Plaute manifeste son attachement à la politique catonienne ${ }^{50}$. D'autres critiques ont tenté de montrer que les propos moralisateurs étaient parodiques et se moquaient, précisément, de Caton ${ }^{51}$. Nous avons donné dans notre introduction les raisons pour lesquelles ce type de lecture nous paraît peu heuristique. Pour comprendre la portée des passages moraux, il faut, ici encore, les replacer dans le spectacle comique ${ }^{52}$. L'honos apparaît dans le Trinummus dans la bouche de Lysitélès, un des jeunes gens de la pièce, qui s'interroge au début de la comédie sur la conduite à tenir: se consacrera-t-il à l'amour et ses plaisirs ou à une vie rangée et sérieuse? L'examen du mépris dans lequel est tenu l'amoureux le conduit à rejeter la première branche de l'alternative:

\author{
Amor, mihi amicus ne fuas umquam. \\ Sunt tamen quos miseros maleque habeas, \\ Quos tibi obnoxios fecisti. \\ Certas est res ad frugem applicare animum, \\ Quamquam ibi animo labos grandis capitur. \\ Boni sibi haec expetunt, rem, fidem, honorem, \\ Gloriam et gratiam: hoc probis pretiumst. \\ «Amour, ne sois jamais mon ami. \\ Il y a des malheureux que tu maltraites \\ Et que tu t'es soumis. \\ La chose est décidée, je me consacre au bien,
}

\footnotetext{
${ }^{49}$ Nous aurions pu également tirer parti de la valorisation de l'honos faite par l'Amphitryon (486 sqq.) ou par les Captifs (245-248).

${ }^{50}$ Voir O. JuRewicz, "Plautus, Cato der Aeltere und die römische Gesellschaft», in Irmscher, J.et Kumaniecki, K. (éds.), Aus der Altertumswissenschaftlichen Arbeit Volkspolens, Berlin, Akademie Verlag, 1959, p. 52-72; D.C. EARL, «Political Terminology in Plautus", Historia, 9, 1960, p.235-243 et Della Corte, Da Sarsina a Roma. Ricerche plautine, p. 79 sqq.

${ }^{51}$ Voir J.P.Stein, "Morality in Plautus' Trinummus», CB, 47, 1970, p.7-13; W.S. Anderson, "Plautus' Trinummus: the Absurdity of Officious Morality», Traditio, 35, 1979, p. 333-345; L. BENZ, «Megaronides Censorius - Eine anticatonische Konzeption im plautinischen Trinummus?", in BLänsDorf, J.(éd.), Theater und Gesellschaft im Imperium Romanum, Tübingen, Francke, 1990, p.55-68; E.LeFÈVRE, «Politics and Society in Plautus' Trinummus ", in Scodel, R. (éd.), Theater and Society in the Classical World, Ann Arbor, University of Michigan Press, 1993, p. 177-190.

${ }^{52}$ C'est ce que fait, en partie, M. BRaun, «Moribus vivito antiquis! Bemerkungen zur Moral in Plautus' Trinummus », in Braun, M., Haltenhoff, A. et Mutschler, F.-H. (éds.), Moribus antiquis res stat Romana. Römische Werte und römische Literatur im 3. und 2. Jh. v. Chr, Munich, K.G. Saur, 2000, p. 185-203, qui donne une interprétation plus nuancée du sens moral de la comédie.
} 
Bien que cela revienne à s'imposer une lourde tâche.

Les gens de bien, voilà ce qu'ils recherchent: la fortune, le crédit, l'honneur, La gloire et l'influence: voilà le salaire de la probité. »

(PL. Trin. 267-273).

Lysitélès adopte ici une attitude opposée à celle de Phédrome dans le Curculio: il renonce à l'amour et préfère se consacrer aux biens que la tradition romaine valorise, parmi lesquels se trouvent l'argent, l'honneur et l'influence. Il se voue, pour ce faire, à une vie austère et morale, conforme aux idéaux en vigueur dans la société. Lysitélès parvient à se tenir à ce programme au cours de la pièce et réprimande quelques scènes plus loin son ami Lesbonicus qui s'est, lui, consacré à l'amour et aux plaisirs:

Itan tandem hanc maiiores famam tradiderunt tibi tui,
Vt uirtute eorum anteparta per flagitium perderes?
Atque honori posterorum tuorum ut uindex fieres,
Tibi paterque auosque facilem fecit et planam uiam
Ad quaerundum honorem; tu fecisti ut difficilis foret
Culpa maxime et desidia tuisque stultis moribus.
Praeoptauisti amorem tuum uti uirtuti praeponeres.

«Tes ancêtres t'ont-ils légué cette bonne réputation

Pour que tu ruines par ta débauche les biens acquis autrefois par leur vertu?

Et pourtant, pour que tu puisses protéger l'honneur de tes descendants,

Ton père et ton ancêtre t'avaient ménagé un chemin facile, tout plat,

Vers l'honneur; tu l'as rendu difficile

Par ta conduite fautive, surtout, et par ta paresse et tes mœurs stupides.

Tu as choisi de faire primer ton amour sur la vertu.»

(PL. Trin. 642-648).

Lysitélès reproche à Lesbonicus d'avoir, par sa débauche dispendieuse, mis à mal l'honos de sa famille. Le jeune homme sérieux sermonne son ami dans un discours qui valorise l'honos et rejette l'amour et ses plaisirs. Le dernier texte qui constitue une exhortation aux bonnes mœurs et à l'honorabilité est une déploration portant sur la dégradation des mœurs, prononcée par l'esclave Stasime et soutenue par le vieux Charmidès:

ST. : Vtinam ueteres homin<um mor $>$ es, ueteres parsimoniae

Potius <in> maiore honore hic essent quam mores mali.

$C_{H}$. : Di inmortales, basilica hicquidem facinora inceptat loqui;

Vetera quaerit, uetera amare hunc more maiorum scias.

ST. : Nam nunc mores nihili faciunt quod licet nisi quod lubet.

Ambitio iam more sanctast, liberast a legibus;

Scuta iacere fugereque hostis more habeant licentiam;

Petere honorem pro flagitio more fit.

CH:

Morem improbum!

«STASImE: Si seulement les mœurs d'autrefois, les économies d'autrefois Étaient ici plus à l'honneur que les mauvaises mœurs !

CHARMIDÈs: Dieux immortels, voilà qu'il entame un discours rempli de paroles divines; 
Il cherche à retrouver le temps d'autrefois; c'est la preuve qu'il aime le temps d'autrefois, à la manière de nos ancêtres.

Sт.: Car les mœurs d'aujourd'hui ne font nul cas des interdits, mais seule ment du bon plaisir.

L'ambition est désormais consacrée par les mœurs, libérée des lois;

Il est permis dans nos mœurs d'abandonner son bouclier et de s'enfuir devant l'ennemi;

Rechercher l'honneur pour prix de sa turpitude est passé dans les mœurs. $\mathrm{CH}_{\text {H. : }}$ Ah les mauvaises mœurs!

(PL. Trin. 1028-1035).

Stasime se désole que l'honos ne soit plus donné à la vertu mais aux mauvaises mœurs, autrement dit que l'honorabilité ne coïncide plus avec le prestige. Il souligne également l'ambition effrénée de ses contemporains et le recours à des moyens moralement répréhensibles pour l'obtention de l'honos. Stasime s'en prend donc ici à ce que la comédie représente parfois, à savoir l'inversion de l'honneur, puisqu'il critique le fait que le flagitium soit source de distinction ${ }^{53}$. Soutenu par Charmidès, il vante les mœurs d'autrefois et se montre attaché à un honos fondé sur des qualités morales traditionnelles ${ }^{54}$.

\subsubsection{La portée morale de cette valorisation}

Il nous appartient à présent d'apprécier la portée de ces discours moralisateurs. Pour ce faire, il convient de distinguer le discours de Lysitélès de celui de Stasime. Ce dernier, en effet, comporte certains aspects qui nous empêchent de le considérer comme un développement sérieux. Il est surprenant, en premier lieu, que ce soit un esclave, personnage habitué aux ruses, qui fasse l'éloge de la bonne moralité. Les caractéristiques du seruus sont en contradiction avec le fond de son propos et rendent ce dernier suspect. L'emphase des vers de Stasime, ses exclamations indignées et la répétition incessante du terme mos font soupçonner un pastiche. Le commentaire béat de Charmidès sur les paroles «royales» (basilica) débitées par Stasime contribue à rendre comique l'ensemble de son discours. Le passage ne nous semble donc pas avoir une visée édifiante; il est possible, dans ce cas précis, d'y voir une parodie. Pour autant, il ne nous paraît pas légitime de considérer que Plaute critique ici les normes du mos maiorum et de l'éthique aristocratique en les plaçant, de manière dérisoire, dans la bouche d'un esclave ${ }^{55}$. S'il y a moquerie, c'est contre les moralisa-

\footnotetext{
${ }^{53}$ On retrouve d'ailleurs, présentée sous un jour critique, l'image de l'abandon des armes que mentionnait l'Épidique (voir supra p. 551-552).

${ }^{54}$ Sur les sources du discours de Stasime, Frankel, Plautinisches im Plautus, p. 157 et R. Hunter, "Philemon, Plautus and the Trinummus », MH, 37, 1980, p. 216-230.

55 C'est l'opinion de Hoffmann, "The Parody of the Idea of the Mos Maiorum in Plautus » (p. 221) et de BLÖSEL, «Von der Familientradition zum Nobilitätsethos » (p. 37).
} 
teurs intempestifs, pas contre la morale instituée. Les propos ridicules de Stasime ne subvertissent pas les bonnes mœurs mais moquent ceux qui se piquent de donner des leçons ${ }^{56}$.

Les propos tenus par Lysitélès ont un statut différent. Le personnage n'est pas un jeune homme débauché. Il incarne au contraire le type du iuuenis rangé qui respecte les bonnes mœurs. Lysitélès ne fait pas non plus figure de moralisateur ridicule: on rencontre sur la scène plautinienne des personnages acariâtres, qui débitent des sermons et finissent par se ridiculiser parce qu'ils sont bernés ou se retrouvent dans des situations inconvenantes, mais rien de tel n'advient au jeune homme ${ }^{57}$. Son discours moral peut donc être pris au sérieux. Faut-il alors considérer qu'il s'agit d'une leçon édifiante adressée aux spectateurs? Cela n'est pas impossible. La valorisation de l'honos menée par Lysitélès est manifestement présentée sous un jour plus favorable que ne l'étaient les propos iconoclastes des amatores ou des gloutons et aucun élément dramatique ne vient la discréditer. En outre, dans une autre comédie au fort contenu moral, les Captifs, le chef de troupe dit lui-même à la fin du spectacle que la pièce représentée se voulait édifiante ${ }^{58}$ :

Spectatores, ad pudicos mores facta haec fabula est.

«Spectateurs, cette pièce a été montée pour conduire aux mœurs honnêtes. »

(Pl. Cap. 1029).

Certaines comédies peuvent donc avoir pour but explicite de donner un spectacle moral. On ne peut donc écarter l'idée que le discours de Lysitélès ait une visée édifiante ${ }^{59}$. Il reste cependant à évaluer son impact réel sur le public. Force est de constater, en premier lieu, que le rejet de la volupté amoureuse opéré par Lysitélès et son choix d'une vie consacrée à l'honneur, la fortune et l'honnêteté ne relèvent pas d'une morale très originale: ce sont des propos conformistes. Le spectacle

${ }^{56}$ C'est aussi le sens que donnent Braun, "Moribus vivito antiquis! » et AndERson, "Plautus' Trinummus: the Absurdity of Officious Morality » au passage. Sur la critique des moralisateurs chez Plaute, Moore, The Theater of Plautus, p.90: "Plautus seldom suggests that the high moral principles sometimes espoused in his plays are wrong: it is moralizing rather than morality that Plautus mocks. " Il nous paraît en revanche aventureux de considérer, avec T. Frank, "Some Political Allusions in Plautus' Trinummus ", $A J P h, 53,1932$, p. 152-156 et Pansiéri, Plaute et Rome (p. 373), que le discours de Stasime cible précisément les catoniens qui lui sont contemporains.

${ }^{57}$ Voir par exemple le personnage du pédagogue dans les Bacchides, qui se retrouve au milieu d'un festin de débauchés (Pl. Bac. 368-384).

${ }^{58}$ Sur le caractère moral des Captifs, P. GrimaL, "Le modèle et la date des Captiui de Plaute », in Grimal, P.(éd.), Rome. La littérature et l'histoire, Rome, E.F.R., 1986, vol. 1, p.297-314.

${ }^{59}$ Nous n'irons cependant pas jusqu'à penser, avec E. SEGAL, "The Purpose of the Trinummus », AJPh, 95, 1974, p.252-264, que l'éloge de la vertu contenu dans le Trinummus est une commande des édiles qui financent la pièce. Toutes les comédies, même les plus immorales, impliquent en effet l'intervention de ces magistrats. 
n'assure donc pas la promotion de valeurs nouvelles mais vise plutôt à réaffirmer le prix de celles qui ont cours. Or les spectateurs sont concernés au premier chef par une telle réassertion des normes en vigueur; la suite des propos du chef de troupe des Captifs le montre:

[...] Nunc uos, si uobis placet,

Et si placuimus neque odio fuimus, signum hoc mittite:

Qui pudicitiae esse uoltis praemium, plausum date.

«[...] Vous maintenant, si vous le voulez bien,

Et si nous vous avons plu et ne vous avons pas ennuyés, adressez-nous ce signe:

Vous qui voulez que la pudeur soit récompensée, applaudissez.»

(PL. Cap. 1034-1036).

L'appel aux applaudissements, traditionnel à la fin d'une comédie, prend ici un sens particulier. Le personnage incite le public à manifester que le spectacle lui a plu mais il fait aussi de leurs acclamations le signe d'un assentiment donné à la pudicitia. Ce passage éclaire la portée des propos moralisateurs de Lysitélès: la fonction morale de ces derniers n'est pas réellement protreptique. La leçon délivrée sert à représenter positivement les normes morales de la société et à renouveler leur approbation par la collectivité. La valorisation de l'honos, associée au rejet de l'amour et des plaisirs, renforce les structures morales romaines: elle reformule la doxa éthique de la cité et réclame l'adhésion du public à cette dernière sous la forme, propre au spectacle, des applaudissements. Un passage d'une autre comédie de Plaute, le Rudens, le confirme. Il s'agit des paroles que Gripus adresse à Démonès qui vient de lui déclarer de manière sentencieuse qu'il faut s'abstenir des mauvaises actions. Gripus se moque de cette leçon qu'on lui donne:

Spectaui ego pridem comicos ad istunc modum

Sapienter dicta dicere atque is plaudier,

Cum illos sapientis mores monstrabant poplo.

Sed cum inde suam quisque ibant diuorsi domum,

Nullus erat illo pacto ut illi iusserant.

«Moi, j’ai déjà vu des poètes comiques débiter

De sages maximes de ce genre et le public applaudir

Quand ils donnaient des leçons de sage morale.

Mais quand chacun retournait ensuite chez soi de son côté,

Personne ne se comportait de la manière qu'on lui avait recommandée. »

(PL. Rud. 1249-1253).

Gripus indique sans ambages que les leçons de morale délivrées par les comédies n'ont pas d'effet sur les mœurs du public une fois le spectacle fini: les discours moralisateurs ne servent donc pas à réorienter le comportement des Romains dans leur vie quotidienne. Ils remplis- 
sent une autre fonction. Gripus signale en effet que ces développements moraux sont appréciés du public qui les applaudit. Ils servent à reformuler l'adhésion aux normes morales collectives et le sentiment de cohésion sociale. L'allusion de Gripus aux spectateurs qui oublient tout en rentrant chez eux est significative: les discours moraux n'ont pas d'application en dehors du moment de la comédie. Ils sont inutiles lorsque les Romains quittent le cadre rituel du spectacle et que les spectateurs ne sont plus des spectateurs. Les pièces de Plaute sont contemporaines des dernières années de la deuxième guerre punique et des affrontements qui opposent Rome à la Macédoine et la Syrie ${ }^{60}$, période agitée où s'entrechoquent le traumatisme causé par le conflit avec Carthage, l'euphorie des victoires en Orient et des affrontements intérieurs à la cité. La mobilisation permanente de Rome, les importantes pertes humaines et économiques causées par les combats et l'approfondissement du contact avec des cultures étrangères et notamment helléniques suscitent une certaine agitation morale à Rome, qui ressent le besoin de se recentrer autour de valeurs qui lui sont propres. Les discours moralisateurs valorisant l'honos, notion ressentie comme profondément romaine, contribuent à renforcer le sentiment d'appartenance à une communauté structurée par une éthique singulière. Les propos sur l'excellence morale concentrent ainsi l'expression d'une axiologie romaine qui remplit des fonctions de cohésion identitaire.

\subsubsection{L’aspect réflexif de la leçon morale}

Les propos sur l'honneur, comme les paroles iconoclastes tenues par les personnages, jouent également d'autres rôles. Ils sont l'occasion d'introduire une approche réflexive des valeurs qu'ils évoquent, comme nous l'avions noté à propos de la vie pragmatique et de la vie de plaisir dans le Curculio. La même problématique apparaît dans le Trinummus avec les propos de Lysitélès sur l'honneur, mais de manière cette fois plus maîtrisée et plus approfondie ${ }^{61}$. Le modèle utilisé par Plaute pour le Trinummus a sans doute joué un rôle dans la présence de ces éléments réflexifs: il s'agit du Trésor, une œuvre de Philémon, auteur de la Néa qui s'était intéressé à la philosophie ${ }^{62}$. L'influence de Philémon n'explique cependant pas tout: la présence de ces passages à teneur réflexive dans le Trinummus repose sur un choix

${ }^{60}$ Grimal, Le Siècle des Scipions, p. 167; sur le rapport des Romains à la Macédoine, FERrary, Philhellénisme, p. 45-132.

${ }^{61} \mathrm{P}$. Grimal a d'ailleurs avancé l'idée selon laquelle le personnage de Lysitélès tient dans la pièce des propos qui portent l'empreinte des théories péripatéticiennes (GRIMAL, "Analyse du Trinummus »). Sur la présence de thèmes péripatéticiens chez Plaute, voir aussi GARBARINo, Roma e la filosofia greca, vol.2, p. 557.

${ }^{62}$ Voir Zehnacker, "Plaute et la philosophie grecque. À propos du Mercator», n. 1, p. 771 . 
délibéré de Plaute qui a décidé de ne pas les évacuer. La question des genres de vie est abordée de manière plus étendue dans le Trinummus que dans le Curculio car elle passe par l'opposition, de nature dramatique, entre deux personnages, Lysitélès et Lesbonicus, qui ont chacun choisi un genre de vie, la vie pragmatique pour le premier, la vie de plaisir pour le second. On voit l'opposition se dessiner rien qu'à leur nom: Lesbonicus, comme le suggère A. Ernout, est «le vainqueur à Lesbos », c'est-à-dire le vainqueur des jeunes femmes de l'île, connues dès l'époque d'Anacréon pour leur homosexualité, ou le vainqueur dans une île liée à la poésie, notamment amoureuse, avec Alcée et Sappho. Dans les deux cas, son nom indique qu'il s'agit d'un personnage tourné vers les plaisirs de l'amour. Lysitélès est un nom formé sur l'adjectif $\lambda v \sigma \imath \tau \varepsilon \lambda \hat{n} \varsigma$, littéralement "qui paye les frais» et donc «utile, avantageux ». C'est celui qui est tourné vers l'utilité et l'efficacité $^{63}$. Lesbonicus apparaît de fait comme un iuuenis traditionnel de comédie: il fréquente les courtisanes et dilapide l'argent de la famille. Contrastant avec ce portrait, Lysitélès, dans le monologue que nous citions, rejette vigoureusement l'amour et la vie de plaisir au profit de la vie pragmatique. On voit en effet apparaître, dans ce texte, les caractéristiques aristotéliciennes de la vie "politique", l'honos, équivalent de la тин́ définie par Aristote comme la fin de ce genre de vie, mais aussi la res, la fortune, à laquelle Aristote assigne une place dans la recherche du bonheur ${ }^{64}$. Lesbonicus, lui, incarne la vie de plaisir: dans la réprimande qu'il lui adresse, Lysitélès fustige les mœurs dissolues de son ami et critique le fait que toute sa vie soit placée sous le signe de l'amor et qu'il ait pour cela négligé l'honos. Les deux personnages incarnent donc chacun un genre de vie différent. On comprend mieux ainsi les discours contradictoires des personnages de comédie qui valorisent tantôt les bonnes mœurs, tantôt la volupté: l'incohérence de leurs propos sur le plan moral se résorbe sur le plan philosophique puisqu'il s'agit d'illustrer deux types de conduite possibles et non de prendre parti pour l'une d'elles. L'intérêt du Trinummus pour l'histoire du traitement de la question des genres de vie à Rome ne réside cependant pas tant dans cette mise en scène de deux types de vie que dans la représentation, nouvelle et singulière, de la question

${ }^{63}$ L'opposition entre l'amoureux et l'utile se rencontre chez Platon (Phaedr. 239c):

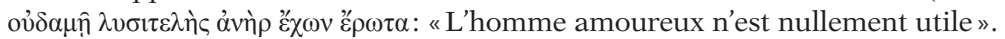

${ }_{64}$ «Ce sont là presque les termes dont se sert Aristote pour évoquer le bonheur de l'homme d'action, qui se proposera comme fin d'obtenir les honneurs dans sa cité, et pour cela ne dédaignera pas d'acquérir la richesse »(GRImaL, "Analyse du Trinummus »). $C f$. Arstt. EN I, 5, 4 et I, 8, 15. 
du choix d'un type de vie. Quelques vers avant ceux que nous citions, Lysitélès déclare:

Multas res simitu in meo corde uorso,

Multum in cogitando dolorem indipiscor.

Egomet me coquo, et macero et defetigo;

Magister mihi exercitor animus nunc est.

Sed hoc non liquet, nec satis cogitatumst,

Vtram potius harum mihi artem expetessam,

Vtram aetati agundae arbitrer firmiorem:

amorin med an rei opsequi potius par sit.

[...]

De hac re mihi satis hau liquet: nisi hoc sic faciam, opinor,

Vt utramque rem simul exputem, iudex sim reusque ad eam rem.

"Que de pensées roulent en même temps dans mon cœur, que de douleur ces réflexions m'inspirent! Je me consume et je me mine et je m'épuise; et dans ces épreuves c'est mon propre esprit qui est mon maitre d'exercice. Mais il est un point qui pour moi n'est encore ni assez clair, ni assez mûrement délibéré: de ces deux règles de conduite, laquelle me faut-il adopter? Laquelle dois-je considérer comme la plus sûre dans la vie? Est-ce l'amour, est-ce l'intérêt qu'il vaut mieux écouter? [...] La chose reste encore pour moi bien obscure; mais voici, je pense, la méthode à suivre: je vais confronter dans un même examen l'une et l'autre façon de vivre, et dans cette affaire être à la fois juge et partie.»

(PL. Trin. 223-234; trad. Ernout).

Pour sa première apparition sur scène, Lysitélès apparaît comme un jeune homme indécis, qui se demande quel genre de vie choisir. La comédie présente donc ici le premier stade du choix de vie, celui de l'hésitation. Dans la suite du texte, Lysitélès confronte, dans une sorte de disputatio in utramque partem, les mérites respectifs de la vie consacrée à l'amour et de celle dédiée à l'honos et à la res. Les avanies subies par les amoureux ont vite fait d'orienter son choix vers l'honos, et c'est le résultat de cette réflexion qui s'exprime dans le texte que nous citions au début de notre analyse du Trinummus ${ }^{65}$. Plaute met donc ici en scène non seulement la conduite d'un personnage ayant choisi la vie pragmatique mais aussi le moment de ce choix, qui repose sur la sélection d'une fin, qui est l'honos associé à la $\operatorname{res}^{66}$. La translation de la réflexion péripatéticienne n'est cependant pas complète. On remarque en effet que, comme dans le Curculio, il n'est jamais question du troisième genre de vie, la vie théorétique. En outre, une divergence importante apparaît vis-à-vis de la tradition aristotélicienne car le Trinummus valorise, comme on l'a vu, l'honos et la vie pragmatique

${ }^{65}$ Pl. Trin. 267-273, supra p. 566-567.

${ }^{66}$ Le passage ressemble aussi, par certains aspects, au calcul des plaisirs et des peines que prône l'épicurisme, ce qui montre qu'il n'y a pas chez Plaute la marque d'une philosophie unique (voir GARBARINo, Roma e la filosofia greca, vol. 2, p. 558). 
à travers le personnage de Lysitélès alors que, pour Aristote, la $\tau \mu n$ ́ constitue une fin problématique: elle est dépendante d'autrui, ce qui constitue un obstacle pour l'associer au bonheur ${ }^{67}$. Enfin, la formulation de la question des genres de vie et du statut de l'honos comme fin demeure imprécise et imagée, comme il est normal dans une comédie. On ne retrouve pas exactement dans le Trinummus les catégories que sont la vie de plaisir et la vie politique et le moment du choix n'est pas pensé de manière réflexive mais représenté à l'aide de métaphores instables. Plaute emploie une image judiciaire d'abord, puisque Lysitélès se fait iudex (v. 234) des possibilités qui s'offrent à lui ; puis il rapproche l'acte de choisir un genre de vie de celui de prendre une épouse puisque Lysitélès déclare à l'Amour, qu'il rejette, tuas res tibi habeto (v. 266) selon la formule rituelle du divorce. La comédie traite donc cette question des genres de vie selon des modalités qui lui sont propres mais n'en reste pas moins un laboratoire de la réflexion sur l'honos comme fin possible de l'action. Plaute contribue de la sorte à familiariser les Romains avec la philosophie, bien avant la venue de l'ambassade athénienne de 155 ou l'arrivée à Rome de philosophes épicuriens ${ }^{68}$.

\subsubsection{Les fonctions dramatiques}

Comme les propos iconoclastes d'un Phédrome sur l'honneur, les discours moralisateurs des personnages ont aussi des fonctions internes au spectacle. Le fait que les développements sur l'honneur et les bonnes mœurs suscitent les applaudissements, comme nous l'apprend la remarque amusée de Gripus dans le Rudens, témoigne de leur valeur proprement dramatique et de leur contribution au succès de la représentation ${ }^{69}$. Ces discours servent d'abord, comme les propos paradoxaux de Phédrome, à caractériser le personnage qui les tient. Le choix que fait Lysitélès de l'honos a lieu lors de sa première apparition sur scène et permet donc de le caractériser comme le personnage du iuuenis sérieux. Il s'agit d'un rôle que Lysitélès se crée progressivement, sous les yeux du spectateur, puisqu'il envisage un temps de se consacrer à l'amour, donc de prendre le rôle de l'adulescens débauché, avant d'y renoncer pour jouer celui du jeune homme rangé. Ce personnage permet à Plaute de dresser un intéressant contraste avec Lesbonicus,

${ }^{67}$ Arstt. EN I, 5, 4. GaStaldi, Bios hairetotatos: generi di vita e felicità in Aristotele, p. $90-91$.

${ }^{68}$ Pour d'autres aspects philosophiques du Trinummus, Garbarino, Roma e la filosofia greca, vol.2, p. 557-558.

${ }^{69}$ Les discours moralisateurs devaient plaire à la frange la plus traditionaliste du public, tandis que les scènes iconoclastes pouvaient avoir du succès auprès d'autres catégories de spectateurs. Voir L. Perelli, «Società romana e problematica sociale nel teatro plautino », StudRom, 26, 1978, p.307-327. 
son double dégradé, et de créer des scènes de confrontation, comme celle où Lysitélès réprimande son ami au sujet de l'honos, qui donnent du relief à la comédie.

Le discours moralisateur sur l'honneur et les bonnes mœurs permet aussi de créer des effets comiques jouant, comme dans le Miles gloriosus, sur la métathéâtralité. Il faut, pour percevoir ce comique, situer la réprimande que Lysitélès adresse à Lesbonicus dans son contexte, qui est celui d'une confrontation. Lysitélès critique la manière dont son ami a négligé l'honos et s'est consacré à l'amour. Lesbonicus, lui, reconnaît sa faute mais refuse de laisser pour autant sa sœur se marier sans dot avec Lysitélès, comme ce dernier le lui propose pour ne pas le ruiner davantage. Chacun des deux personnages fait donc valoir ses arguments, jusqu'à ce que l'esclave Stasime les interrompe de la façon suivante:

Non enim possum ut exclamem: euge, euge, Lysiteles, $\pi \alpha ́ \lambda ı$ !

Facile palmam habes: hic uictust; uicit tua comoedia.

Hic agit magis ex argumento et uersus melioris facit.

«En vérité je n'y tiens plus, il faut que je crie: bravo, bravo Lysitélès; bis! À toi la palme sans conteste, il est battu, ta comédie triomphe. C'est lui qui traite le mieux le sujet et fait les meilleurs vers.»

(PL. Trin. 705-707; trad. Ernout).

Ces commentaires rompent l'illusion théâtrale et ramènent la dispute à une confrontation entre deux acteurs où chacun cherche à prendre le dessus sur l'autre et à s'attirer la faveur du public. Dans l'image qu'en donne Stasime, Lysitélès et Lesbonicus ont chacun monté une comoedia et s'affrontent pour l'obtention de la palme. Les genres de vie représentés par les deux jeunes gens ne sont donc pas posés comme des thèses morales qui s'affrontent mais comme des exercices de comédiens sur un thème préétabli: ils ne visent pas l'édification mais ont un enjeu dramatique et comique.

\section{CONCLUSION}

Au terme de ce parcours, il apparaît que les comédies de Plaute donnent de l'honneur une représentation complexe dont il est impossible de rendre compte par une explication unique. La complexité de l'approche plautinienne réside d'abord dans la pluralité des images qui sont données de ces notions: on voit se mêler sur la scène de la palliata des pratiques d'honneur paradoxales jusqu'à l'inversion et des usages ou des discours beaucoup plus conventionnels. La recherche d'un sens moral cohérent dans ces représentations contradictoires est dès lors rendue difficile. Plutôt que de tenter d'élucider les intentions du dramaturge et la "morale de Plaute », il nous a paru plus fécond de nous interroger sur la portée et les fonctions de cette image de l'hon- 
neur au sein du spectacle. Il est apparu que les inversions de l'honneur et les discours rejetant ce dernier n'étaient pas si subversifs qu'il y semblait et remplissaient, de concert avec les scènes où des personnages affirment leur attachement à l'honos, un rôle psychologique de relâchement des tensions et une fonction de cohésion autour de valeurs identitaires. La mise en question de l'honneur par les personnages ou les discours valorisants qu'ils tiennent à son sujet ne relèvent donc pas d'une intention critique ou édifiante. Ils ouvrent en revanche la voie à une première approche réflexive de l'honneur: le renversement de son fonctionnement habituel permet d'en appréhender les mécanismes de manière plus consciente, le mépris que témoignent à son endroit certains personnages laisse apparaître sur scène, dans un cadre circonscrit et contrôlé, l'image de la déviance, et les développements moralisateurs introduisent de façon subreptice à Rome la question philosophique des genres de vie. Il est néanmoins essentiel de ne pas perdre de vue la singularité de la palliata qui constitue l'honneur en objet comique et ludique: la représentation de l'honneur caractérise les personnages, sert le jeu métathéâtral des acteurs et déclenche le rire des spectateurs, ce qui permet à la comédie, en tant que spectacle et rituel, d'être réussie. 


\section{CATON : L'HONNEUR DU CENSEUR}

\section{INTRODUCTION}

Caton constitue, pour différentes raisons, un auteur de choix pour l'étude de la notion d'honneur. Il s'agit en effet, d'abord, d'un homme politique de premier plan, parvenu au sommet du cursus honorum alors qu'il est un homo nouus, ce qui le rend particulièrement attentif à la valeur de l'honos. Son activité en tant qu'orateur l'a également amené à développer une réflexion politique dans ses discours, dont plusieurs abordent le fonctionnement de l'honos au sein de la cité. L'image de Caton, enfin, reste dans l'histoire celle d'un moraliste rigoureux: ses prises de position sur l'évolution des mœurs romaines, notamment pendant sa célèbre censure de 184 , révèlent une réflexion morale singulière et vigoureuse. Or cette dernière s'est exercée, entre autres, sur les notions d'honos et d'honestas. Il nous faut donc nous intéresser à la spécificité de la posture intellectuelle de Caton sur l'honneur. Son œuvre sera aussi l'occasion de mesurer la manière dont cette notion est représentée dans des textes oratoires et historiques, moins liés à la fiction que ne l'était la production dramatique de Plaute. Nous distinguerons au sein de ce chapitre trois facettes de la notion d'honneur, qui seront abordées successivement. Nous commencerons par étudier la manière singulière dont Caton appréhende l'honos quand il s'agit de l'hommage: le Censeur le conçoit comme un phénomène qui nécessite des normes de fonctionnement et se propose de les édicter lui-même. Nous ferons ensuite porter l'accent sur l'honneur proprement politique, en observant la place assignée par Caton dans son idéologie à l'honos de la magistrature et au prestige de l'homme d'État. Nous verrons enfin comment la pensée morale du Censeur envisage l'honorabilité, c'est-à-dire l'honestas.

\section{UNE APPROCHE NORMATIVE DE L'HOMMAGE}

Tout au long de sa vie d'homme public, Caton n'a cessé d'intervenir énergiquement pour réglementer l'évolution des mœurs. Dès son gouvernement de Sardaigne, il a lutté contre l'usure et y sera toujours 
hostile pendant sa carrière d'homme d'État ${ }^{1}$; consul, il s'opposa, sans succès, à l'abrogation de la loi Oppia, manifestant par là son désir de limiter le luxe, un autre de ses chevaux de bataille favoris ${ }^{2}$. Quant à sa censure de 184, elle est le point d'orgue d'une action consacrée à la défense de certains idéaux et à la lutte contre des pratiques jugées non conformes au mode de vie romain. Caton s'est donc toujours montré soucieux de codifier les conduites morales de ses contemporains. Les pratiques d'honneur, qui sont un rouage essentiel de la cité, ne pouvaient manquer d'échapper à sa vigilance. De fait, Caton s'y intéresse à plusieurs reprises et le fait avec un certain recul puisqu'il cherche à définir à leur propos les normes d'un bon usage. Cette réflexion normative du Censeur procède d'abord par la négative, avec une critique de l'usage que font ses contemporains de l'honos, puis de façon positive, par la formulation de règles et de modèles.

\subsection{La critique du dysfonctionnement de l'honos}

La définition par Caton d'un bon usage de l'honos se fait d'abord en creux: le Censeur dénonce des comportements qui ne lui semblent pas conformes à ce qu'exigent les mœurs romaines. Il en est ainsi dans un fragment d'un discours que Caton prononça lors de sa censure:

Honorem emptitauere, malefacta benefactis non redemptitauere.

«Elles avaient pour coutume d'acheter l'honneur, mais non de racheter leurs méfaits par de bonnes actions.»

(CAt. frg. XIX, 94 ORF).

Cet extrait s'inscrit dans la logique du discours De signis et tabulis ${ }^{3}$ qui, comme le suggère son titre, devait constituer une dénonciation des excès commis par les riches Romains en matière d'acquisition d'œuvres d'art au début du $\mathrm{II}^{\mathrm{e}}$ siècle. Caton s'en prend plus particulièrement aux femmes, comme nous l'indique Pline l'Ancien ${ }^{4}$, et leur reproche de se faire construire des statues, ce qui constitue d'après lui un double crime car il rend manifeste le goût du luxe et la vanité . Ces femmes ont obtenu un honneur à prix d'argent et Caton dénonce le caractère inadéquat de cette façon d'acquérir des honores. Il fait de

${ }^{1}$ Caton fut préteur en Sardaigne en 198 et en expulsa les usuriers (Lrv. XXXII, 27, 3-4). Sur sa préture, voir A.E.Astin, Cato the Censor, Oxford, Clarendon Press, 1978, p.20. On trouve aussi une critique de la faeneratio au début du De Agricultura, œuvre de la fin de sa vie. Voir également le propos de Caton identifiant l'usure au meurtre, rapporté par Cicéron (CIc. Off. II, 89).

${ }^{2}$ Sur les raisons de l'hostilité de Caton au luxe, voir Ibid., p. 94 sqq.

${ }^{3}$ Sur ce discours, Marmorale, Cato maior, p. 101.

${ }^{4}$ PLin. NH, XXXIV, 31.

${ }^{5}$ Sur les statues érigées en l'honneur de femmes à l'époque républicaine, voir FLoRY, «Livia and the History of Public Honorific Statues for Women in Rome». 
même dans un autre de ses discours qui rappelle des faits anciens, liés à sa présence comme légat auprès de M.Fulvius Nobilior en Étolie, en 189:

Iam principio quis uidit corona donari quemquam, cum oppidum captum non esset aut castra hostium non incensa essent?

"Qui a jamais vu qu'on donnât une couronne militaire à quelqu'un dès le début, sans qu'une cité soit conquise ou que soit incendié un camp ennemi ?»

(CAT. frg. XXXVIII, 148 ORF).

Caton fustige les largesses du général en chef lors de la campagne d'Étolie: l'honneur d'une corona militaire ne peut être octroyé qu'à celui qui a montré des qualités guerrières au combat, et non à l'auteur d'actes anodins ${ }^{6}$. La surveillance exercée par Caton sur cette pratique de la récompense militaire est particulièrement pointilleuse, puisqu'il n'a pas manqué d'intenter un procès à $\mathrm{Q}$. Minucius Thermus qui avait obtenu le triomphe alors qu'il n'avait pas atteint, lors de sa campagne, le nombre de cinq mille tués parmi les ennemis, condition nécessaire pour prétendre à l'hommage militaire suprême ${ }^{7}$. L'obtention de l'honos politique a également dû être surveillée par Caton: il est probable qu'il ait joué un rôle dans le contrôle, après la guerre, de l'accès à l'honos suprême, et dans le strict établissement du cursus honorum tel que le prévoit la lex Villia Annalis ${ }^{8}$ de 180.

Caton relève donc les cas qui lui paraissent s'écarter du comportement à suivre et les fustige avec toute la force de sa parole $^{9}$ : l'honos entre dans le répertoire de la rhétorique du blâme et dans le discours politique et militaire; il est constitué sous les yeux du public en enjeu qui concerne la cité et en pratique qui doit être régulée. Cette régulation de l'honos passe par une critique de tous les excès et dysfonctionnements, mais aussi par l'établissement de normes et la définition d'un bon usage.

${ }^{6}$ Aulu Gelle, qui nous a transmis ce fragment, indique en effet que M. Fulvius octroyait des coronae aux soldats pour avoir installé le camp (GeLL. V, 6, 24).

${ }^{7}$ C'est le discours In Q. Minucium Thermum de falsis pugnis (ORF VI): Caton estime que le décompte présenté par Minucius Thermus inclut des combats imaginaires (falsae pugnae) et que le triomphe est donc usurpé. Voir à ce sujet Marmorale, Cato maior, p. 75 et F. Della Corte, Catone Censore. La vita e la fortuna, Turin, Rosenberg \& Sellier, 1949, p. 20.

${ }^{8}$ Sur cette loi, voir p. 248-249.

9 Sur la rhétorique de Caton, voir A.D.LeEman, Orationis ratio. The Stylistic Theories and Practice of the Roman Orators, Historians and Philosophers, Amsterdam, A. M. Hakkert, 1963; Astin, Cato the Censor, p.131-156. 


\subsection{L'établissement de règles et de modèles}

Dans les fragments qu'il nous reste de son œuvre, Caton ne se livre pas à une définition précise du bon usage de l'honos. Cependant, il n'a pas manqué d'utiliser ses discours pour expliciter régulièrement la manière dont l'honos doit être réglé. Le constat des dysfonctionnements de l'honos le pousse à adopter une attitude réflexive inédite sur cette pratique, à formuler des normes et à dessiner des modèles de conduite.

La recherche d'une norme objective constitue un premier procédé de définition d'un cadre réglé pour l'hommage. Caton se réfère fréquemment, quand il est question d'honos, à un étalon, qui est celui de l'aequum. C'est un des arguments qu'il développe en faveur des Rhodiens, dans le discours qu'il prononce en 167 pour obtenir la clémence des Romains à leur égard après leur comportement ambigu lors de la troisième guerre de Macédoine ${ }^{10}$ :

Sed si honorem non aequum est haberi ob eam rem, quod bene facere uoluisse quis dicit, neque fecit tamen, Rodiensibus oberit, quod non male fecerunt sed quia uoluisse dicuntur facere?

«Mais s'il n'est pas équitable de recevoir une marque d'honneur quand on a dit qu'on a désiré bien faire et qu'on ne l'a pas fait, les Rhodiens subiront-ils un préjudice de ne pas avoir mal fait, mais de passer pour avoir désiré le faire? »

(CAT. frg. XLII, 168 ORF).

Pour Caton, ce n'est pas la volonté d'agir qu'il faut juger, mais l'action elle-même: de même que l'on n'honore pas celui qui déclare vouloir faire le bien mais ne le fait pas, il ne faut pas châtier celui qui passe pour vouloir faire le mal mais ne le fait pas. L'honos doit nécessairement être fondé sur un mérite concret: il ne serait pas aequum de donner une marque d'honneur à celui qui n'a pas bien agi. Les pratiques d'hommage doivent se conformer à ce principe supérieur qu'est l'aequum, l'équité, qui consiste à donner à chacun ce qui lui revient, à récompenser le mérite aussi bien qu'à punir la faute ${ }^{11}$. La réflexion de Caton, sans être à proprement parler philosophique, témoigne d'un souci de formaliser le comportement de ses contemporains en matière d'honneur en le sortant du pragmatisme absolu et en l'associant à des normes abstraites. C'est en se référant à un principe général que Caton codifie la pratique socio-politique de l'honneur et tente d'en rectifier les dysfonctionnements ${ }^{12}$. Une autre exigence liée

\footnotetext{
${ }^{10}$ Sur le discours dans son ensemble, voir l'édition commentée de Calboli, Catonis Pro Rhodiensibus.

${ }^{11}$ Sur la nature de l'aequum, voir notre étude p.302-304.

${ }^{12}$ D'autres fragments des discours de Caton témoignent d'une réflexion sur des réalités concrètes à l'aide d'un outillage relativement abstrait: le frg. I, $17 O R F$ aborde
} 
au respect de l'aequum apparaît à propos de l'attitude à avoir lorsque l'on détient l'honos dans un fragment d'un discours prononcé par Caton juste après son accession à la censure:

Nam periniurium siet, cum mihi ob eos mores quos prius habui honos detur, ubi datus est tum uti eos mutem atque alii modi sim.

"Ce serait très injuste, alors que, en raison de mes mœurs passées, je reçois un honneur, que je les change lorsqu'il m'est octroyé et que je vive d'une manière différente. »

(CAT. frg. XVIII, 93 ORF).

Pour Caton, son succès lors des comices élisant les censeurs s'explique par l'excellence de ses mœurs, qui a provoqué et rendu légitime l'honos qui lui a été fait. Tout l'enjeu est désormais de se montrer digne de cette charge tout au long de son exercice. Gagner un honneur impose d'avoir un comportement irréprochable, fidèle aux mœurs qui ont valu son obtention. Ne pas observer ce code de conduite serait periniurium, extrêmement injuste; ce serait violer le ius, le droit luimême. L'expression n'est sans doute pas à prendre au pied de la lettre, mais elle révèle bien l'emprise d'un modèle de pensée juridique chez Caton quand il cherche à définir l'honos. Ne pas respecter ce que l'honos impose est injuste et va aussi, dans un sens, à l'encontre de la norme du droit ${ }^{13}$. Le code de conduite imposé par la charge est un code d'honneur dont l'emprise est équivalente à celle d'un code légal.

Pour définir le bon fonctionnement de l'honos, Caton recourt, outre à ces normes, à des modèles. Les règles qu'il élabore ne passent donc pas seulement par la formulation de principes abstraits, mais aussi par l'utilisation de figures de référence. Il établit ainsi un code de conduite mimétique: c'est en imitant le comportement des modèles que l'on évitera les dérèglements ${ }^{14}$. La première de ces figures idéales est collective: il s'agit des ancêtres, les maiores. En les utilisant comme point de référence, Caton est fidèle à la morale ancestrale du mos maiorum, qui propose à l'imitation et à l'émulation des jeunes génerations la conduite exemplaire des ancêtres ${ }^{15}$.

ainsi par exemple la question de l'action bonne à l'aide d'une opposition entre labor et uoluptas. Sur les éléments d'une pensée philosophique chez Caton, Garbarino, Roma e la filosofia greca, vol.2, p. 334 sqq.

${ }^{13}$ Caton fait à plusieurs reprises référence au ius comme à quelque chose d'impérieux, qui ne souffre pas la contestation, et sert d'étalon absolu. C'est le ius qui doit prévaloir, au-delà de toute considération, dans la résolution des conflits entre le mari et sa femme par exemple (CAT. frg. LXIX, 222 ORF).

${ }^{14}$ Sur les exempla et leur fonction morale, voir p.414-415.

${ }^{15}$ Sur le mos maiorum comme pourvoyeur de normes, voir Rech, Mos maiorum. Caton est un des auteurs qui utilise le plus le mos maiorum comme point de référence de la conduite (p.80). Sur la nécessité pour Caton de respecter la coutume ancestrale, voir Mutschler, « Norm und Erinnerung: Anmerkungen zur sozialen Funktion von historischem Epos und Geschichtsschreibung im 2. Jh.v.Chr. », notamment p. 109. 
C'est le fonctionnement même de l'hommage qui doit suivre la coutume ancestrale:

Maiores seorsum atque diuorsum pretium parauere bonis atque strenuis, decurionatus, optionatus, hastas donaticas, aliosque honores.

"Les ancêtres ont établi des récompenses bien différenciées pour les soldats bons et valeureux: décurionats, optionats, lances de parade, et d'autres honneurs.»

(CAT. frg I, 18 ORF).

Caton rappelle le souci qu'avaient les maiores de récompenser par des honores les actes de bravoure des soldats. Ce discours étant adressé aux equites de l'armée ${ }^{16}$, on peut en déduire qu'il énonce aux soldats les modalités d'octroi des honneurs militaires et prend pour modèle la pratique des ancêtres en ce domaine. La même attention à la manière dont les ancêtres rendaient honneur aux hommes de mérite apparaît dans la préface du De agricultura où Caton se réfère à la définition que donnaient les maiores du uir bonus, définition qu'il reprend à son compte: Et uirum bonum quom laudabant, ita laudabant: bonum agricolam bonumque colonum ${ }^{17}$. Ces différents passages témoignent d'un souci de la part de Caton d'imiter l'honos pratiqué par les ancêtres.

Caton propose également des figures individuelles historiques comme modèles de bon usage de l'honos. Dans les Origines, il présente ainsi la figure exemplaire de Q. Caedicius, tribun militaire qui, pour sauver l'armée romaine placée dans une position très défavorable avant un combat contre les Carthaginois, proposa de se sacrifier avec quatre cents de ses hommes pour occuper l'ennemi et délivrer le reste de l'armée de sa mauvaise posture. Marchant courageusement à la rencontre d'une mort certaine, Caedicius survécut miraculeusement lors de l'affrontement avec les Carthaginois et parvint à tirer l'armée romaine du mauvais pas où elle se trouvait ${ }^{18}$. Cet acte de bravoure est comparé par Caton à celui de Léonidas aux Thermopyles mais une différence importante sépare les deux hommes car la réception de leur exploit n'a pas été identique:

Sed idem benefactum quo in loco ponas, nimium interest. Leonides Laco, qui simile apud Thermopylas fecit, propter eius uirtutes omnis Graecia gloriam atque gratiam praecipuam claritudinis inclitissimae decorauere monumentis: signis, statuis, elogiis, historiis aliisque rebus gratissimum id eius factum habuere; at tribuno militum parua laus pro factis relicta, qui idem fecerat atque rem seruauerat.

\footnotetext{
${ }^{16}$ Marmorale, Cato maior, p. 57-58.

17 «Et quand ils faisaient l'éloge d'un homme de bien, leur éloge était: bon agriculteur et bon cultivateur»(Сат. Agr. praef. 2 ; trad. Goujard).

${ }_{18}$ Sur ce passage des Origines, voir G.Calboli, "Die Episode des Tribunen Q. Caedicius (Cato, Orig. frg. 7-43 Peter)», Maia, 48, 1996, p.1-32.
} 
"Mais un même bienfait est considéré très différemment selon le lieu où on le place. Le Lacédémonien Léonidas, qui agit de la même façon aux Thermopyles, toute la Grèce rehaussa la gloire et la popularité extraordinaires que lui avaient values ses mérites par des monuments extrêmement célèbres: des portraits, des statues, des inscriptions, des récits, entre autres choses, montrèrent le très grand prix accordé à son exploit. Mais le tribun militaire ne reçut qu'une maigre louange pour ses hauts faits alors qu'il avait agi de même et avait sauvé la situation. »

(CAт. Orig. IV, 7 ; trad. Chassignet).

Le personnage de Caedicius sert à l'évidence d'exemplum historique: il s'est distingué par des qualités exceptionnelles, notamment par sa uirtus guerrière et par son dévouement à la patrie, et Caton mentionne de manière assez étendue ses hauts faits pour leur valeur édifiante. Cependant, le texte que nous citons jette comme une ombre sur cette bravoure en soulignant les faibles retombées de cette dernière en matière de prestige et d'honneurs. Caedicius n'a obtenu qu'une parua laus alors que le roi spartiate a reçu de multiples marques d'estime $^{19}$. Le commentaire de Caton a donné lieu à des interprétations contradictoires et l'ambiguïté du passage ne peut être totalement levée. Il nous semble cependant possible d'avancer quelques éléments sur le rapport entretenu par Caedicius avec les honores, tel que nous le présente Caton, et donc sur la pensée du Censeur à ce sujet. Il a été avancé que Caton déplorait par ce récit l'absence d'hommage rendu par les Romains à Caedicius pour son exploit, absence à laquelle il opposerait l'attitude des Grecs, plus généreux en la matière ${ }^{20}$. De fait, le terme de parua laus paraît un peu péjoratif et l'on pourrait penser que le récit élogieux que fait Caton de l'histoire de Caedicius a précisément pour fonction de corriger l'absence d'honneurs et de rétribuer justement celui qui s'est distingué par sa uirtus. Une telle interprétation nous paraît cependant présenter plusieurs difficultés. Il est d'abord curieux de penser que Caton décrit, indirectement, les Romains comme des ingrats et qu'il valorise à leurs dépens la pratique des Grecs alors que leurs mœurs font par ailleurs l'objet de très vives critiques ${ }^{21}$.

${ }^{19}$ Caton n'emploie pas le terme d'honores, mais c'est bien de cela qu'il s'agit ici: les signa, statua et elogia sont des marques d'honneur particulièrement appréciables. G. Calboli note d'autres divergences entre les deux événements: Léonidas est mort au combat, et sa bravoure et celle de ses hommes n'ont pas suffi à retenir les Perses. Caedicius, lui, est vivant et victorieux (Ibid., p. 12).

${ }^{20}$ Astin, Cato the Censor, p. 223, n. 63.

${ }^{21}$ Le caractère néfaste de leurs médecins et de leur littérature, leur penchant au mensonge, l'instabilité politique qui caractérise leurs régimes, sont quelques-uns des reproches que Caton leur adresse. Sans faire preuve d'un antihellénisme viscéral ni rejeter systématiquement tout ce qui est grec, Caton n'en était pas moins très méfiant envers certaines pratiques des Hellènes, jugées dangereuses pour les mœurs romaines. Pour une évaluation nuancée du rapport de Caton à l'hellénisme, voir Astin, Ibid., p. 157 sqq. et Gruen, Culture and National Identity, p. 52 sqq. 
Un tel jugement ne correspondrait pas à la volonté de Caton d'affirmer la supériorité de Rome sur le monde grec $^{22}$. En outre, la valorisation littéraire du personnage de Caedicius est limitée: Caton le pose certes en exemple, mais, fidèle en cela à la logique des Origines, il ne cite pas le nom du tribun ${ }^{23}$ et ne lui décerne pas d'éloges particuliers. Il ne nous paraît donc pas exact de considérer que Caton se lamente sur l'absence d'honneur rendu à Caedicius. Le récit même des faits que donne Caton nous le confirme d'ailleurs. L'historien ne présente pas en effet ce qui s'est passé avec une totale objectivité; nous savons, par d'autres historiens, que Caedicius a en réalité été récompensé pour son acte de vaillance, ce que Caton passe sous silence ${ }^{24}$. Pourquoi minimiser les honneurs qui lui ont été adressés? La présentation biaisée de l'hommage reçu peut s'expliquer par des motifs idéologiques; Caton souhaite mettre en avant, par opposition à la coutume grecque, une pratique romaine de l'hommage faite de modération et de retenue. À la différence des Grecs, qui récompensent Léonidas par des honneurs extrêmement brillants mais excessifs, l'honos romain prend une forme modeste, celle d'un court éloge ${ }^{25}$. L'honos, pour Caton, doit récompenser la bravoure, mais sans exalter l'individu. Les honneurs reçus par Léonidas sont symptomatiques de la pensée grecque sur l'héroïsme et la grandeur par l'action militaire; pour Caton, attaché aux coutumes romaines, l'honos doit récompenser la uirtus, mais sans élever l'homme trop au-dessus des autres.

Parmi les différents modèles du bon usage de l'honos proposés par Caton, il faut enfin remarquer qu'il a lui-même mis en pratique les recommandations qu'il formule et s'est, d'une certaine façon, constitué

${ }^{22}$ Gruen, Culture and National Identity, p. 52-83, montre combien Caton a permis à ses concitoyens de prendre conscience de leur propre supériorité face aux Grecs.

${ }^{23}$ Cornelius Népos nous indique que Caton n'a mentionné que les faits, sans donner les noms des personnages (Nep. Cat. 4). Une seule exception est faite dans les Origines, pour un éléphant, Surus (Gell. III, 7; Astin, Cato the Censor, p. 232-233). La présence ou l'absence du nom de Caedicius est sujette à controverse (Herzog et Schmidt (éds.), Handbuch der lateinischen Literatur der Antike, p. 392; M. CHASsignet (éd.), Caton, Les Origines (fragments), Paris, Les Belles Lettres, 1986, p. 87) mais il semble plus naturel de penser que Caton reste ici fidèle à son habitude de désigner les acteurs de l'histoire par leur fonction (consul, tribun militaire) et non par leur nom. Sur les motivations de l'anonymat, voir infra.

${ }^{24}$ Florus insiste sur la fama du tribun après son exploit (FLor. I, 18 (II, 2), 14). Pline l'Ancien évoque quant à lui l'octroi d'une récompense très rare, la couronne de gazon (NH XXII, 7-11).

${ }^{25}$ Marmorale, Cato maior, p. 235 va jusqu'à considérer que Caton attaque ici la démesure des Grecs. Gruen, Culture and National Identity, p. 82 estime, plus justement pensons-nous, que Caton ne rabaisse pas ici l'exploit de Léonidas, mais souligne et valorise la singularité de la réception de celui de Caedicius: "the historian indeed reckoned such anonymity as a proud characteristic of his nation." 
en figure exemplaire. C'est le cas lorsqu'il raconte son refus d'un honos qu’il juge déplacé:

Quom essem in prouincia legatus, quamplures ad praetores et consules uinum honorarium dabant: numquam accepi, ne priuatus quidem.

«Lorsque j'étais légat en province, bon nombre de gens offraient du vin aux préteurs et aux consuls à titre honorifique; jamais je n'en ai accepté, pas même à titre privé. »

(CAT. frg. XXXII, 132 ORF).

En refusant cet hommage, qui relevait sans doute plus de la corruption que du témoignage d'estime, Caton donne la preuve de son intégrité au sein d'un discours qui vise à répondre aux attaques dont il a été l'objet à sa sortie de charge ${ }^{26}$. Plusieurs autres passages montrent quelle est la pratique catonienne de l'hommage: il rappelle la manière tout à fait convenable dont il a récompensé les meilleurs éléments de son armée d'Espagne ${ }^{27}$, ou la façon dont il s'est montré digne de l'honos qui lui était échu lors de son élection à la censure ${ }^{28}$. Caton tend ainsi à se constituer lui-même en modèle de l'honos et à être l'artisan de son propre mythe ${ }^{29}$.

\subsection{La définition d'un honos idéal}

Ces critiques, ces normes et ces modèles dessinent, mis bout à bout, une image de ce qu'est pour Caton l'honos idéal. Trois traits principaux se dégagent: l'honneur, d'abord, doit être fondé sur le mérite de la personne qui le détient, mérite qui réside dans son action individuelle et ses qualités propres. L'honos, ensuite, doit être proportionné à la valeur de la personne qui le reçoit et doit, de manière générale, respecter la mesure. Enfin, si l'honneur distingue un individu parmi ses semblables, il ne doit pas l'élever de façon démesurée au-dessus de ses concitoyens ni au-dessus des lois et des coutumes de la république romaine.

Caton exerce donc sur l'honos un regard complexe fait de critiques, d'évaluations et de prescriptions. Son rapport à cette pratique sociale et politique nous semble révélateur de son attitude envers ses contemporains. Caton apparaît, conformément à l'image qui en a été propagée, comme un censeur impitoyable: la manière dont il fustige l'obtention indue de marques d'honneur est bien en accord avec sa rigueur

${ }^{26}$ Le passage est un fragment du De suis uirtutibus contra L. Thermum post censuram.

${ }^{27}$ ORF IV, 35.

${ }^{28}$ ORF XVIII, 93.

${ }^{29}$ Sur Caton comme artisan de sa propre image légendaire, S. AgAche, "Caton le Censeur, les fortunes d'une légende», Caesarodunum, 15bis, 1980, p. 71-107. 
morale, telle qu'elle a pu s'exprimer lors de sa censure ${ }^{30}$. Le Censeur observe des dysfonctionnements dans les normes de l'honos et ne manque pas de les blâmer. Mais le constat des dysfonctionnements l'amène à repenser et reformuler les normes de l'honos.Le blâme ne peut être dissocié chez Caton de la formulation de préceptes. Tout un pan de son œuvre, presque entièrement perdu aujourd'hui, témoigne de ce souci constant de proposer normes et modèles: ce devait être le cas du Carmen de moribus dans le domaine éthique ${ }^{31}$. Si sa censure a marqué les Romains, c'est parce qu'elle reposait sur un programme précis de rénovation des mœurs et non seulement sur la volonté de châtier les fautes morales ${ }^{32}$ : le Censeur est un juge sévère mais aussi un créateur de normes.

\section{L'HonNeUR Politioue dans L'IDÉOLOGIE de CATON}

Si l'attention portée par Caton à la pratique de l'honneur s'explique par une volonté de corriger son fonctionnement, ce souci de régulation doit lui-même être interrogé. Pourquoi Caton est-il si attaché à fonder l'honos sur le mérite? Pour répondre à cette question, il convient de replacer l'honos au sein de la pensée politique de Caton en s'intéressant à la conception catonienne de la charge publique et à la place que le Censeur ménage au prestige de l'homme public.

\subsection{L'honneur du pouvoir}

Caton a la singularité de penser l'action politique elle-même en termes d'honneur. On sait que le terme honos, qui signifie originellement « marque d'honneur » en est venu à désigner la " charge publique » et notamment la magistrature ${ }^{33}$. Les deux sens sont autonomes et, à ce titre, le lien qui les unit peut ne pas être toujours fortement ressenti. Chez Caton, cependant, il n'en est rien: la charge publique est explicitement considérée comme un honneur en tant que tel, avec toutes

${ }^{30}$ Liv. XXXIX, 44, 2-3; Astin, Cato the Censor, p. 79-81.

${ }^{31}$ Les quelques rares fragments que nous en avons apparaissent comme des sententiae de nature morale et placent le texte dans la lignée des maximes d'Appius Claudius Caecus. Mais l'œuvre présente une véritable originalité car il s'agit du premier ouvrage didactique de morale en latin (Ibid., p. 186). Malgré le nom de carmen, il n'est pas certain que ce texte se soit présenté sous la forme de vers, comme le pense P.KRUschwitz, "Lehre oder Dichtung? die archaische didaktische Poesie der Römer », in Horster, M. et ReITz, C.(éds.), Wissensvermittlung in dichterischer Gestalt, Stuttgart, F. Steiner, 2005, p.115-131. Voir sur ce point G.B.PIGHI, «Catonis Carmen de moribus», Latinitas, 14, 1966, p. 31-34.

${ }^{32}$ Astin, Cato the Censor, p. 86-87. Voir aussi D. Kienast, Cato der Zensor, 2e éd., Heidelberg, Quelle \& Meyer, 1954, p. 74.

${ }^{33}$ Voir notre étude sémantique p. 82 sqq. 
les conséquences que cela implique, comme l'obligation faite à son détenteur de suivre des règles de conduite qui s'apparentent à un code d'honneur. On le constate dans le passage du De uestitu et uehiculis de 184 que nous citions précédemment et qu'il nous faut rappeler ici:

Nam periniurium siet, cum mihi ob eos mores quos prius habui honos detur, ubi datus est tum uti eos mutem atque alii modi sim.

«Ce serait très injuste, alors que, en raison de mes mœurs passées, je reçois un honneur, que je les change lorsqu'il m'a été octroyé et que je vive d'une manière différente. »

(CAT. frg. XVIII, 93 ORF).

La charge politique oblige son bénéficiaire à se conformer aux mérites à l'origine de son obtention: les mores à la source de l'honos deviennent une règle absolue de conduite une fois consacrés par l'honos, ils se figent en un strict code d'honneur. On a là l'expression d'un des idéaux moraux de Caton, celui de la fidélité à soi-même, et cet idéal ne peut être oblitéré par l'exercice du pouvoir ${ }^{34}$. Caton considère donc la magistrature comme un véritable honneur pourvu de règles contraignantes. Cette façon de penser éclaire certaines de ses prises de position contre Scipion l'Africain et son entourage. Les attaques répétées contre le vainqueur de Zama ne procèdent pas en effet d'une hostilité de principe envers l'aristocratie ${ }^{35}$. Les cibles de Caton issues de la noblesse sont les hommes politiques qui, à ses yeux, se sont rendus indignes de l'honos qui leur avait été confié, qui ont failli au code imposé par l'exercice d'une magistrature publique, en se rendant coupables de mauvais gouvernement, comme Minucius Thermus ${ }^{36}$, ou de corruption, comme Scipion lui-même, accusé d'avoir perçu des sommes d'Antiochus $\mathrm{III}^{37}$. Les attaques contre ces différentes personnes s'expliquent en partie par la prégnance de l'idée d'honneur

${ }^{34}$ C'est le principe du perpetuus tenor uitae. Dans le portrait que fait Tite Live de Caton, ce dernier, quoique détenteur d'un honos doté d'imperium, continue d'accomplir toutes les tâches militaires pénibles et refuse tout traitement de faveur (LIV. XXXIV, 18, 5). Le thème de la continuité du mode de vie réapparaît dans le discours de Marius tel que le recompose Salluste dans le Bellum Iugurthinum, en s'inspirant probablement de Caton (Iug. 85, 1 et 8; voir Della Corte, Catone, p. 211).

${ }^{35}$ C'est l'avis de Flores, Letteratura latina e ideologia, p. 116.

36 Astin, Cato the Censor, p.66-67. Le discours prononcé contre Q. Minucius Thermus en 190, In Q. Minucium Thermum de decem hominibus, attaque des actes de barbarie et de cruauté commis par Thermus dans l'exercice de sa charge de proconsul en Ligurie $(O R F$ VI).

${ }^{37}$ C'est ce qui fait, en partie, l'objet du «procès » qui fut intenté à Lucius et Publius Scipion. Sa nature et son déroulement exact font encore débat. Voir N. W. Forde, Cato the Censor, Boston, Twayne, 1975, p. 175 sqq. ; Astin, Cato the Censor, p. 60 sqq.; Kienast, Cato der Zensor, p.57-67. Caton a aussi attaqué l'Africain sur sa fréquentation des palestres et des théâtres en Sicile (Plut. Cato mai., 3, 7), pratique incompatible avec la grauitas de l'homme politique. 
chez Caton, qui informe sa conception du pouvoir politique: à ses yeux, Scipion a failli au code de l'honos en se rendant coupable de fautes graves et en exerçant son pouvoir d'une manière non conforme à la tradition: les différents honores qu'il obtint ont donné lieu à une série d'innovations en rupture totale avec les pratiques habituelles ${ }^{38}$. Plus généralement, Scipion représente pour Caton la perversion de l'honos républicain, puisque certains de ses honores politiques furent plusieurs fois acquis de manière irrégulière et que d'autres se signalèrent par leur démesure ${ }^{39}$. Ce rapport différent des deux hommes à l'honneur, porte ouverte vers une supériorité politique inédite pour Scipion, pourvoyeur au contraire d'obligations contraignantes pour Caton, n'est pas le moindre de leurs points de désaccord ${ }^{40}$.

\subsection{L'honneur comme fin de l'action publique?}

Les critiques adressées par Caton à certains de ses contemporains concernant leurs pratiques d'honneur s'éclairent par le sérieux avec lequel il envisage l'honos. Mais on peut aussi se demander si elles ne procèdent pas d'un jugement plus profond sur la valeur de l'honos en soi et sur la pertinence de sa recherche. À l'époque de Caton, l'honneur est un bien valorisé qui constitue souvent un but de l'action politique $^{41}$, mais il n'est pas certain que le Censeur partage ce point de vue. Plusieurs indices montrent en effet un certain désintérêt de sa part, confinant parfois au mépris, à l'égard des honneurs. Il a ainsi toujours refusé que des statues lui soient élevées et la seule dont nous ayons connaissance était pourvue d'une inscription qui faisait état de ses qualités morales, contrairement à l'habitude qui voulait que l'on mentionnât les réussites militaires ou politiques, que Caton connut pourtant ${ }^{42}$. Un de ses discours évoque explicitement les honneurs qu'il a refusés alors qu'il était légat ${ }^{43}$. Quant à la recherche de l'honos

${ }^{38}$ Les innovations furent aussi bien militaires (sa tactique novatrice à Baecula contre Hasdrubal Barca - LIV. XXVII, 18), politiques (son opposition au Sénat et sa manière de s'appuyer sur le peuple), que culturelles (ses relations avec le poète Ennius, ou l'alimentation de sa propre légende par la propagation de rumeurs sur son origine divine).

${ }^{39}$ Il fut ainsi le premier à recevoir, pour mener les opérations en Espagne, l'imperium consulaire sans avoir été consul. Son triomphe après Zama fut extraordinaire (LIV. XXX, 45, 6; Pol. XVI, 23).

${ }^{40}$ Sur ce désaccord entre Scipion et Caton, Astin, Cato the Censor, p. 68 sqq., qui montre notamment qu'il ne faut pas faire du conflit entre les deux hommes une lutte idéologique entre philhellénisme et anti-hellénisme.

${ }^{41}$ Voir par exemple la valorisation de l'honos dans les épitaphes des Scipions (CIL $\mathrm{I}^{2}, 10,11$ et 15). Voir infra p. 611-612.

${ }^{42}$ La statue était localisée dans le temple du Salut (Амм. 14, 6; Plut. Cato mai., 19,

3). Voir Lahusen, Untersuchungen zur Ehrenstatue in Rom, p. 13 et 108.

${ }^{43}$ CAt. frg. XXXII, 132 ORF. 
et au désir de gloire en général, Caton ne manque pas, comme nous l'avons vu, de les épingler en critiquant l'ambition peu scrupuleuse de certains de ses contemporains et en présentant, comme modèle alternatif, Caedicius dont le dévouement se passe de grandes récompenses. Caton est également conscient du levier que peut constituer la littérature en termes de prestige individuel pour les hommes publics: certains hommes politiques, aux $\mathrm{III}^{\mathrm{e}}$ et $\mathrm{II}^{\mathrm{e}}$ siècles, ont su s'attacher des écrivains pour servir leur propre gloire et célébrer leurs actions ${ }^{44}$. Caton, lui, se démarque d'un tel usage: s'il a ramené avec lui Ennius de Sardaigne, il est désormais établi que ce n'est pas pour se l'attacher comme panégyriste personnel ${ }^{45}$. Et, dans les Origines, il ne mentionne jamais le nom des protagonistes et se contente de les désigner par leur fonction, évoquant ainsi «le consul», «le préteur» ou «le tribun». Cet anonymat des personnages vise, entre autres, à éviter de mettre au premier plan les grandes familles aristocratiques actives pendant les années dont Caton fait le récit. L'histoire ne doit pas, pour Caton, faire l'éloge des Flaminius, Fulvius et Scipion, et constituer un honos littéraire. Caton veut faire l'histoire de l'Italie entière et de son peuple et entend montrer que la puissance romaine est l'œuvre de la collectivité et non de pauci puissants ${ }^{46}$. Ce procédé témoigne d'un certain refus de l'hommage par le biais de l'écriture.

Cela ne doit pas cependant faire de Caton le champion de la négation de l'honos et de sa quête. Son opinion sur la place à accorder à l'honneur est en effet plus complexe qu'il n'y paraît, au point que sa pensée apparaît parfois ambiguë, voire contradictoire. S'il a refusé les statues, Caton s'est en revanche toujours appliqué à obtenir les honneurs que sont les charges politiques. Cet homo nouus a parcouru l'ensemble des étapes du cursus honorum, s'élevant jusqu'à la censure. Il a également obtenu en 194 l'honneur militaire le plus grand, le triomphe, après ses victoires contre les Turdetans d'Hispanie ${ }^{47}$. Caton n'éprouve pas d'aversion généralisée pour les honneurs et il n'est pas dépourvu d'ambition. Il en va de même pour l'honneur dont la littérature peut être le tremplin: il ne s'est pas attaché Ennius pour faire

${ }^{44}$ On le voit notamment dans les tragédies prétextes de l'époque: le Clastidium de Naevius célèbre les succès de Marcellus, et l'Ambracia d'Ennius, ceux de M. Fulvius Nobilior. La tragédie prétexte a fréquemment pour fonction de célébrer le passé et de faire l'éloge des grands hommes (G. PETRONE, «La praetexta repubblicana e il linguaggio della celebrazione», in ManuwaLd, G. (éd.), Identität und Alterität in der frührömischen Tragödie, Würzburg, Ergon, 2000, p.113-121).

${ }^{45}$ Voir la démonstration de Gruen, Studies in Greek Culture and Roman Policy, p. 107-108.

${ }^{46}$ Sur le sens à donner à l'omission des noms dans les Origines, FLores, Letteratura latina e ideologia, p.124-125, CALBOLI, "Die Episode des Tribunen Q. Caedicius (Cato, Orig. frg. 7-43 Peter)», p. 9; R. E. Sмітн, «Cato Censorius », G\&R, 27 (9), 1940, p. 150-165 et BlösEL, «Von der Familientradition zum Nobilitätsethos », p. 54-55.

${ }^{47}$ Liv. XXXIV, 21, 7. 
son éloge, mais plusieurs de ses discours ont contribué à lui donner une stature politique et à asseoir sa propre légende, tant il s'y met fréquemment en scène et $\mathrm{y}$ défend son action ${ }^{48}$. Certains d'entre eux ont d'ailleurs été inclus dans le texte des Origines ${ }^{49}$. Un fragment oratoire d'origine indéterminée se révèle particulièrement intéressant pour comprendre la valeur attachée par Caton à l'honneur et la place que sa recherche doit occuper dans la vie de l'homme public:

Iure, lege, libertate, re publica communiter uti oportet; gloria atque honore, quomodo sibi quisque struxit.

«Le droit, la loi, la liberté, la république, il faut en jouir de façon commune; la gloire et l'honneur, de la manière dont chacun se les ait bâtis. »

(CAT. frg. inc. 252 ORF).

Dans cette phrase en forme de maxime, Caton énonce sous la forme d'une asyndète vigoureuse un de ses principes politiques. Deux sphères différentes sont distinguées: d'un côté se trouvent les biens publics qui reviennent de droit à chaque citoyen, et dont tous peuvent jouir librement; il s'agit de la res publica, de la "chose publique» qui appartient à tous, c'est-à-dire le recours au droit (ius), la protection de la loi (lex) et la libertas, la liberté dans le cadre de la loi ${ }^{50}$. Pour Caton, ces biens ne peuvent être aliénés: ils appartiennent à la communauté (communiter uti oportet), ce sont des acquis propres au régime républicain. Face à eux, tous les citoyens doivent être placés sur un pied d'égalité. À ces biens publics sont opposées des conquêtes privées, la gloria, qui désigne la notoriété éclatante, et l'honos, qui renvoie ici à un prestige plus matériel, un statut supérieur dans la cité marqué par des signes extérieurs. Comme la gloria, l'honos est perçu comme un objet de conquête et n'a rien d'acquis, ainsi que le suggère la métaphore de la construction (struxit): l'honneur apparaît donc dans la pensée de Caton comme un point d'aboutissement de l'action. C'est un objectif que chacun peut avoir. L'honos est le lieu où l'individu, souvent écarté par Caton dans d'autres contextes, trouve une place: c'est ici qu'il peut se distinguer de la communauté, puisque c'est à chacun (quisque) de rechercher l'honneur et que cette quête implique un bénéfice personnel pour l'individu lui-même (sibi). La jouissance de la gloire et de l'honneur est elle aussi individuelle: on ne s'en sert pas communiter, mais d'une façon conforme à la manière dont ils ont été acquis (quomodo sibi quisque struxit), c'est-à-dire individuellement. On rencontre donc

\footnotetext{
${ }^{48}$ Sur l'œuvre de Caton comme source de son propre mythe, voir, à nouveau, Agache, "Caton le Censeur, les fortunes d'une légende».

${ }^{49}$ Astin, Cato the Censor, p. 233.

${ }^{50}$ Sur la libertas, C. WIRszUBSKI, Libertas as a Political Idea at Rome during the Late Republic and Early Principate, Cambridge, Cambridge University Press, 1950, p. 7. Sur le rapport entre loi et libertas à Rome, voir Ducos, Les Romains et la loi, p. 23-81.
} 
bien chez le Censeur une valorisation de l'honneur personnel, conçu comme fin de l'action publique.

Comment expliquer cette apparente discordance dans la réflexion politique de Caton sur la valeur de l'honneur? L'ambiguïté ne peut être totalement résorbée, notamment en ce qui concerne l'usage de la littérature à des fins de prestige, mais elle peut recevoir une explication. Caton ne rejette pas massivement la recherche de l'honneur pas plus qu'il n'en fait une apologie sans mesure; son jugement sur la valeur de l'honos est en fait réglé sur un critère précis, qui le conduit tantôt à rejeter sa recherche, tantôt à l'approuver: c'est à l'aune de son utilité pour l'État que Caton mesure le prix de l'honneur. Caton lie étroitement honos et service de la république. Il blâme la quête du prestige lorsque les honneurs demeurent dans la sphère privée, comme les statues que les riches matrones se font ériger, ou ne visent que la satisfaction de l'ambition personnelle, comme le triomphe que Q. Minucius Thermus a tenté de se faire octroyer. Pour Caton, l'honos n'a pas de valeur quand il ne sert qu'à flatter l'orgueil des individus sans apporter de bénéfice à la cité. En revanche, il mérite d'être recherché lorsqu'il s'accorde avec le service de l'État. C'est pourquoi la charge politique représente l'honos le plus digne d'intérêt car elle permet d'acquérir du prestige et de recueillir les fruits de son mérite, tout en plaçant l'individu au service de la res publica. Lanonymat des protagonistes des Origines, désignés par la magistrature qu'ils exercent, montre que pour Caton les hommes ne valent dans l'histoire que par la fonction qu'ils exercent au service de la république. C'est l'honos dévoué à l'État qui est digne de mémoire: la personne passe au second plan. On mesure tout ce qui sépare une telle conception de l'honneur de celle d'un Scipion l'Africain, pour qui l'honneur est au contraire le moyen de l'affirmation d'un charisme personnel et d'une supériorité sur les autres.

\subsection{Le moyen d'une aristocratie du mérite}

La réflexion de Caton sur l'honos doit être inscrite dans le contexte des luttes idéologiques de son temps pour que l'on puisse en mesurer pleinement la portée. Si Caton lie étroitement honos et mérite individuel, c'est pour imposer un autre chemin d'accès à l'autorité politique que celui fixé par la tradition. Caton insiste avec une remarquable constance sur la nécessité, pour que l'honos ne soit pas dénaturé, de le fonder sur le comportement méritoire de l'individu. C'est en effet, comme on l'a vu, l'absence de véritable mérite qui suscite presque à chaque fois les virulentes critiques que Caton adresse à ses contemporains en matière d'honos. Dans la pensée de Caton, 
l'honneur doit être absolument justifié et ne saurait être acquis sans efforts ${ }^{51}$. Comment expliquer cette valorisation du mérite personnel? Les origines et la vie même de Caton apportent une première réponse: Caton est un homo nouus, issu d'une famille plébéienne de Tusculum, qui est parvenu à mener une carrière militaire et politique sans pouvoir compter sur le prestige d'ancêtres consulaires ${ }^{52}$. Sa naissance et sa famille n'ayant joué aucun rôle dans son élévation, il est compréhensible qu'il ait valorisé le mérite et conçu l'honneur comme le salaire des qualités de l'individu ${ }^{53}$. Une telle conception n'est cependant pas le simple contrecoup de l'histoire personnelle de Caton; il s'est approprié cette représentation de l'honneur, jusqu'à en faire un point nodal de son idéologie politique. Il valorise le mérite pour éviter que les honores et l'accès au prestige ne soient exclusivement fondés sur la naissance. En associant étroitement honneur et mérite, il attaque le monopole de l'honneur que détient l'aristocratie et ouvre une brèche dans les modes de pensée romains traditionnels en matière de politique et de préséance sociale. Il ouvre à tous les homines noui la voie de l'honneur et conteste que ce dernier ne puisse qu'être le bien des grandes familles de Rome $^{54}$. Cette prise de position a pu être favorisée par le contexte historique. Dans les décennies qui suivirent la deuxième guerre punique, l'association au pouvoir des Italiens étrangers à Rome ainsi que des Romains n'appartenant pas à l'aristocratie subit un coup d'arrêt: on ne dénombre que quatre homines noui ayant obtenu le consulat entre la deuxième et la troisième guerre punique ${ }^{55}$. On comprend mieux, du coup, le sens du fragment sur la conquête de l'honos qu'il est utile de réexaminer en ce sens:

Iure, lege, libertate, re publica communiter uti oportet; gloria atque honore, quomodo sibi quisque struxit.

«Le droit, la loi, la liberté, la république, il faut en jouir de façon commune; la gloire et l'honneur, de la manière dont chacun se les ait bâtis.»

(CAT. frg. inc. 252 ORF).

${ }^{51}$ EARL, Tradition, p. 45, constate de même que pour Caton la uirtus seule peut fonder le prestige.

${ }^{52} \mathrm{~S}$. Agache note que plusieurs de ses déclarations s'éclairent par sa nouitas : l'éloge du travail, d'un mode de vie austère, ses références aux maiores,... (AgAche, "Caton le Censeur, les fortunes d'une légende», p.102). Curieusement, S. Agache ne parle pas de sa conception de l'honos qui est pourtant très liée elle aussi à cette nouitas. Voir aussi ce que dit Tite Live de l'influence du statut social de Caton sur sa vie (Liv. XXXIX, 41, 1).

${ }^{53}$ C'est un des points communs de la vie et de la pensée de Caton avec celles de Cicéron (KIEnast, Cato der Zensor, p. 31).

${ }^{54}$ D.C. Earl note que pour Caton "glory and honour too were personal, based on an individual's achievement. The play made by the nobility with the glory of their ancestors was irrelevant. What mattered in the final assessment were the actions and standards of the individual» (EARL, Tradition, p. 45).

${ }^{55}$ Hinard (éd.), Histoire romaine, p. 459. 
La métaphore de la «construction» de l'honos s'explique par la nouitas de Caton et par sa volonté de retirer aux nobiles la détention exclusive de l'honneur. Ce passage a fréquemment été opposé à une autre sententia célèbre dont l'auteur est un des aristocrates romains les plus remarquables, Scipion Émilien:

Ex innocentia nascitur dignitas, ex dignitate honor, ex honore imperium, ex imperio libertas.

«De l'intégrité naît le mérite, du mérite l'honneur, de l'honneur le pouvoir, du pouvoir la liberté.»

(ScIP. Aem. frg. inc. 32 ORF).

Ces deux affirmations programmatiques montrent les divergences entre la vision politique de Caton et celle de Scipion Émilien : le premier souligne l'importance des droits politiques communs comme socle de l'action publique, tandis que le second fonde l'obtention de l'imperium sur la dignitas. La conception de la libertas est également révélatrice: Caton en fait un bien commun alors qu'elle est pour Scipion une possession bien plus exclusive, réservée à ceux qui se sont élevés aux imperia, et susceptible d'entrer en conflit avec la libertas communis définie par Caton ${ }^{56}$. Qu'en est-il de l'honos? Les deux textes font état de deux modes d'acquisition différents: pour Caton, l'honos fait l'objet d'une construction individuelle, ouverte à chacun. Chez Scipion Émilien, la concaténation qui structure la sententia suggère qu'à partir de l'innocentia, puis de la dignitas, l'honos émerge de façon nécessaire; la métaphore est celle de la naissance spontanée (nascitur), pas de la construction. Et l'imperium et la libertas procèdent de cet honos. La vision de Scipion est celle d'un aristocrate pour qui l'honneur découle de manière naturelle d'une situation de dignitas sociale. C'est cette transmission fluide de l'honos, conçu comme un bien héréditaire, que Caton conteste. Il ne faut cependant pas opposer trop fermement les deux points de vue en faisant de Caton le représentant d'une idéologie "démocratique» divergente en tous points de la position aristocratique de Scipion ${ }^{57}$. Le fondement premier de l'honos chez Scipion n'est autre en effet que l'innocentia, c'est-à-dire l'intégrité, et cela n'a rien de propre à l'idéologie aristocratique: Caton étaie lui aussi l'honneur sur la vertu. La moralisation de la vie publique est un souci partagé par les deux hommes. p. 38 .

${ }^{56}$ Sur la conception de la libertas de Scipion Émilien, voir WIRszUBSKI, Libertas,

${ }^{57}$ L'antagonisme dressé par E. Flores, Latinità arcaica e produzione linguistica, Naples, Liguori, 1978, p. 90, est à relativiser. Caton a entretenu avec Scipion Émilien de meilleurs rapports qu'avec l'Africain. Sur les communautés de vue entre les deux hommes, A.E. Astin, "Scipio Aemilianus and Cato Censorius», Latomus, 15, 1956, p.159-180; EARL, Tradition, p. 45 les rapproche aussi sur plusieurs points. 
Que faut-il retenir, en dernière analyse, de la réflexion politique de Caton sur l'honneur? Sa pensée de l'honos est d'abord polémique. L'honneur était déjà un objet de luttes politiques, mais Caton fait de l'idée même d'honos, de sa définition, un élément de conflit idéologique. Les efforts de Caton visent à permettre aux homines noui de s'approprier une notion qui semblait jusque-là réservée aux membres des gentes les plus nobles de Rome. Cette requalification de l'honos est novatrice: l'ouverture de l'honneur aux hommes de mérite va à l'encontre de la pratique traditionnelle romaine en politique qui consiste à confier le pouvoir à une élite de gens qualifiés par leur prestige et leur excellence familiale. C'est contre cette tendance profonde que va Caton, hostile pour une fois à une pratique ancestrale ${ }^{58}$. Cela ne doit pas nous amener à conclure que Caton est un «démocrate » et encore moins un révolutionnaire: sa valorisation de l'honneur démontre une volonté de maintenir une catégorie d'hommes publics distingués par leur prestige; autrement dit, Caton cherche à établir une aristocratie, mais une aristocratie nouvelle, fondée sur le mérite et la vertu, et concurrente de celle qui est en place ${ }^{59}$. Il se conforme à la configuration romaine habituelle d'un "gouvernement des meilleurs» mais redéfinit les bases de leur excellence.

\section{L'honorabilité dANS LA PENSÉE MORALE DE CATON}

La représentation, véhiculée par la tradition, d'un Caton austère, intègre et dévoué à la patrie, invite à analyser la place de l'honneur dans sa pensée morale. De ce point de vue, ce sont surtout les références aux comportements honesti qui feront l'objet de notre attention.

\subsection{La définition de l'homme d'honneur}

De même que Caton analyse le fonctionnement de l'hommage et définit son bon usage, il ne manque pas de se prononcer sur le comportement attendu de l'homme d'honneur. La réflexion de Caton ne se présente pas sous une forme systématique mais il est tout de même possible de déceler dans ses textes les traits qui font, selon lui,

\footnotetext{
${ }^{58}$ Sur la nouveauté des idées politiques de Caton, C. Nicolet, Les Idées politiques à Rome sous la République, Paris, A.Colin, 1964, p. 23.

${ }^{59} \mathrm{Il}$ s'est d'ailleurs pensé lui-même comme le représentant de cette nouvelle aristocratie du mérite; voir sur ce point et sur la définition catonienne de l'aristocratie B. REAY, "Agriculture, Writing, and Cato's Aristocratic Self-Fashioning», ClAnt, 24 (2), 2005, p.331-361, notamment p.334-345. Sur le sens politique de la valorisation du mérite, voir aussi Astin, Cato the Censor, p.66-67.
} 
d'un individu un homme d'honneur. Nous prendrons comme point de départ un fragment du Carmen de moribus:

Vestiri in foro honeste mos erat, domi quod satis erat. Equos carius quam coquos emebant. Poeticae artis honos non erat: siquis in ea re studebat aut sese ad conuiuia adplicabat, grassator uocabatur.

"C'était la coutume de s'habiller de manière décente au forum, et de ne porter à la maison que le nécessaire. Ils achetaient leurs chevaux plus cher que leurs cuisiniers. La pratique de la poésie n'était pas en honneur: si quelqu'un s'y consacrait ou s'attachait aux banquets, ils l'appelaient traînard.»

(Cат. Carmen frg. 2 Sblendorio-Cugusi).

Le passage nous est transmis par Aulu Gelle qui a sans doute mis bout à bout trois propos de Caton initialement séparés au sein de l'œuvre ${ }^{60}$. Caton fait ici remarquer que plusieurs pratiques de ses contemporains ne sont pas en accord avec le mos maiorum et il réfère explicitement deux d'entre elles à l'honneur: concernant la tenue vestimentaire, les ancêtres s'habillaient honeste en public, de manière décente, ce qui leur permettait de préserver l'estime des autres; la poésie, quant à elle, n'était pas une pratique en honneur, elle n'était pas jugée honorable. Quelles qualités la conduite honeste dont parle Caton recouvre-t-elle? Concernant la tenue, il s'agit très vraisemblablement de se vêtir en évitant le luxe ou l'indécence: la conduite honesta implique donc deux qualités, la mesure et la décence. Le court développement sur la poésie nous permet de percevoir d'autres traits de la vie honorable selon Caton. Les anciens, dit Caton, adressaient à ceux qui pratiquaient la poésie le quolibet déshonorant de grassator. Le sens exact du terme a été compris de différentes façons ${ }^{61}$ : l'une des interprétations ${ }^{62}$, rapprochant le mot de grassor, intensif de gradior, en fait le qualificatif du poète itinérant, récitant une poésie de nature orale; cependant, l'aspect nettement péjoratif du terme ${ }^{63}$ nous amène à écarter une telle lecture, trop éloignée du contexte. En s'appuyant sur un passage de Festus qui identifie grassari et adulari, on a aussi compris le texte comme une condamnation de la poésie flat-

${ }^{60}$ GeLL. XI, 2, 5. La parataxe des phrases ainsi que la juxtaposition de trois thèmes qui ont certes une unité morale mais touchent tout de même à des domaines distincts (l'habit, la dépense somptuaire, l'honneur de la poésie) et se succèdent un peu brutalement nous invitent à le penser.

${ }^{61}$ Voir l'état des lieux bibliographique à la p. 202 de M. T. SBLENDorio-Cugusi et P. CugusI, «Problematica catoniana. Rassegna di studi 1978-1993 e contributi critici», BStudLat, 26, 1996, p. 82-218.

${ }^{62}$ Flores, Latinità arcaica, p. 113: «il termine grassator, nel senso di poeta itinerante, pertanto non doveva in origine essere connotato da nessun valore dispregiativo. ”

${ }^{63}$ La dimension péjorative du mot apparaît bien chez Lıv. III, 13. 
teuse qui fait l'éloge des grands hommes ${ }^{64}$, ce qui concorderait avec la posture adoptée par Caton vis-à-vis des personnages historiques dans les Origines. En revanche, ce sens nous paraît s'appliquer assez mal à ceux qui passent leur temps dans les banquets, catégorie également visée par le quolibet. L'interprétation à retenir nous semble être celle de J.Préaux qui observe que le mot est issu de la langue comique et désigne un "vagabond» ou un "parasite», un amuseur de profession incapable de tout sérieux, ce qui est bien en accord avec la critique morale qui anime le passage ${ }^{65}$. Ce qui est déshonorant dans la pratique de la poésie, c'est qu'elle est tournée vers l'amusement et la distraction, vers une oisiveté dommageable pour la cité66. Vivre de façon honorable, c'est au contraire, pour Caton, avoir une vie active et énergique. La poésie détourne l'homme de la tâche qui doit être la sienne, le plein exercice de sa citoyenneté et le dévouement à la cité. C'est ce mépris du loisir et ce souci de l'utilité publique qui font l'homme d'honneur.

La célèbre préface du De agricultura permet d'en parachever le portrait.

Est interdum praestare mercaturis rem quaerere, nisi tam periculosum sit, et item fenerari, si tam honestum sit. Maiores nostri sic habuerunt et ita in legibus posiuerunt, furem dupli condemnari, feneratorem quadrupli; quanto peiorem ciuem existimarent feneratorem quam furem, hinc licet existimare. Et uirum bonum quom laudabant, ita laudabant: bonum agricolam bonumque colonum; amplissime laudari existimabatur qui ita laudabatur.

«Il arrive qu'il vaille mieux chercher fortune dans le commerce, si ce n'était pas si périlleux, et aussi prêter à intérêt, si c'était aussi honorable. Nos ancêtres en ont ainsi pensé et dans leurs lois ils ont disposé que le voleur était condamné au double, l'usurier au quadruple; combien ils ont estimé l'usurier plus mauvais citoyen que le voleur, on peut en juger par là. Et quand ils faisaient l'éloge d'un homme de bien, leur éloge était: bon agriculteur et bon cultivateur; c'était recevoir le plus grand éloge, estimait-on, que de recevoir cet éloge.»

(CAT. Agr. praef. 1-2; trad. Goujard).

Au seuil de son traité, Caton compare les mérites des différentes activités économiques. L'agriculture est valorisée plus que tout, d'abord parce qu'elle est tuta: elle ne présente pas de risque et permet

${ }^{64}$ Fest. 86, 20: grassari antiqui ponebant pro adulari. C'est la lecture de Gruen, Culture and National Identity, p.72. L'auteur rappelle que Caton reprochait à Fulvius d'avoir emmené avec lui Ennius en Étolie pour que le poète puisse faire son éloge (CIc. Tusc. I, 3).

${ }^{65}$ J. PréAuX, «Caton et l'ars poetica », Latomus, 25, 1966, p.710-725. Le verbe grassari fait référence à une démarche lente et traînante et est souvent associé aux parasites (PL. Poen. 514). G. BRUGNOLI, «Funzione e valore del lavoro artistico in ambiente romano dell'età arcaica ", Index, 11, 1982, p.3-18 montre de même que Caton critique ici la poésie en raison de son pouvoir corrupteur sur la jeunesse de Rome (p.16).

${ }^{66}$ Voir ANDRÉ, L'Otium, p. 30, pour qui grassator désigne un oisif. 
de vivre de manière indépendante, alors que le commerce, lui, est considéré comme aléatoire et dangereux ${ }^{67}$; elle est aussi une activité noble et honorable, honesta, et s'oppose ainsi à l'usure ${ }^{68}$. L'agriculture est donc porteuse de sécurité mais également d'honneur. Un tel éloge du Romain comme paysan attaché à sa terre s'inscrit à contrecourant de l'évolution de l'agriculture dans l'Italie du $\mathrm{II}^{\mathrm{e}}$ siècle, qui voit un développement de la main d'œuvre servile et une augmentation de la taille des exploitations; Caton essaie sans doute ici de sauvegarder l'idéal, en perte de vitesse, du citoyen-paysan ${ }^{69}$. Qu'est-ce qui fait, pour Caton, que l'agriculture est honesta? Il s'agit avant tout, à la différence de l'usure, d'une manière de vivre qui permet des gains honnêtes et constants: elle ne tire pas son profit de l'endettement des

${ }^{67}$ Caton pense ici au commerce maritime, soumis aux attaques des pirates et aux caprices du mauvais temps. Le commerce n'est cependant pas totalement récusé par Caton, qui l'a lui-même pratiqué; la mercatura est simplement à déconseiller du point de vue de l'efficacité économique. Sur l'opposition entre le bonus agricola et le mercator, L. DE SALVo, "Il giudizio sulla mercatura nel mondo romano », AFLM, 20, 1987, p. 9-32. L'auteur souligne qu'à la fin de la République, le jugement sur le commerce n'est négatif que dans le discours, car la pratique économique romaine montre un véritable engouement pour ce type d'activité. L'époque impériale verra la revalorisation idéologique du commerce, notamment dans la partie orientale de l'Empire (p.32). Cf. l'évaluation par Cicéron dans le De officiis de l'honorabilité des différentes activités économiques (CIC. Off. I, 151).

${ }^{68}$ Les deux qualificatifs attribués par Caton à l'agriculture, tuta et honesta, sont rapprochés par LeEman, Orationis ratio, p. 22 sqq., de Rhet. Her. III, 2: Vtilitas in duas partes in ciuili consultatione diuiditur: tutam, honestam. Il n'est pas exclu que Caton emploie ici des catégories rhétoriques, d'autant que toute la préface présente des signes d'élaboration littéraire évidents. En revanche, nous n'irions pas dans le sens d'A. Leeman lorsqu'il affirme que le texte est tout empreint de principes rhétoriques grecs et que Caton défend l'agriculture en recourant à la catégorie des finalia capitula du genre délibératif. Il s'agit bien ici d'un traité, non d'un discours, et la praefatio se signale plus par des traits propres au latin littéraire archaïque (parataxe, allitérations, répétitions) que par une maîtrise de la technique des rhéteurs grecs dont l'influence sur Caton est d'ailleurs très discutée (voir M. JEHNE, «Cato und die Bewahrung der traditionellen Res publica. Zum Spannungsverhältnis zwischen mos maiorum und grieschischer Kultur im zweiten Jahrhundert v. Chr. », in Vogt-SpIRA, G. et Rommel, B. (éds.), Rezeption und Identität. Die kulturelle Auseinandersetzung Roms mit Griechenland als europäisches Paradigma, Stuttgart, F.Steiner, 1999, p.115-134 et Astin, Cato the Censor, p. 159-168). Sur le style de la préface, voir Astin, Cato the Censor, p.90; E. Courtney (éd.), Archaic Latin Prose, Atlanta, Scholars, 1999, p. 50. Des corrections à l'édition du texte ont récemment été suggérées par A.S. Gratwick, "A Matter of Substance: Cato's Preface to the De agri cultura», Mnemosyne, 4-55, 2002, p.41-72, et W.S. WATT, "Cato, De agricultura, praef. 1 », Mnemosyne, 4-56, 2003, p. 213.

${ }^{69}$ Il a aussi été souligné que cet éloge du bonus agricola, en plus de ne pas être conforme à la réalité nouvelle de l'agriculture, n'est pas en adéquation avec la réalité des exploitations agricoles dont parle Caton dans son œuvre: les grandes fermes décrites, tournées vers la recherche de la productivité, sont gérées par des intendants et ne font pas de place au paysan fermier (T. JAnson, Latin Prose Prefaces, Stockholm, Almqvist \& Wiksell, 1964, p.86). 
autres citoyens et n'accroît pas la dépendance des personnes les plus pauvres. On voit donc que l'honneur implique de se conduire avec probité vis-à-vis de l'entourage. L'agriculture a en outre des bienfaits sur les dispositions physiques: elle procure au corps force et endurance, capacités appréciables pour le Romain, toujours susceptible d'être amené à rejoindre les rangs de l'armée. On retrouve donc, de façon sous-jacente, l'idée que la conduite honorable est celle qui permet de se tenir à la disposition de la patrie. L'honneur de l'individu, pour Caton, n'a de sens que s'il est mis en relation avec la collectivité qui l'entoure. Enfin, vivre en agriculteur permet de se conformer au mos maiorum, de préserver le mode de vie traditionnel romain en enracinant les individus dans la campagne. L'agriculture est honesta parce qu'elle reproduit l'idéal vanté par les maiores et incarné dans des exempla célèbres dont Cincinnatus est peut-être le meilleur représentant ${ }^{70}$. L'homme d'honneur est celui qui imite la vie des ancêtres ${ }^{71}$. Chez Caton, la morale de l'honneur reste marquée par une profonde hétéronomie: vivre honeste revient à se conformer au mos maiorum, à imiter des modèles passés et extérieurs à l'individu. L'honneur est défini par le groupe, pas par le sujet, et les règles de comportement sont héritées et non créées.

Si l'on synthétise les éléments tirés des différents textes observés, on voit que les contours de l'honneur moral selon Caton sont les suivants: l'imitation du mos maiorum, le contrôle de soi et le dévouement à la cité, sensible à travers le refus de l'otium, la recherche du bien public et le souci de la probité.

\subsection{Une faible théorisation de l'honneur}

S’il est possible d'identifier les éléments qui constituent, selon Caton, une vie honorable, la réflexion du Censeur sur l'honorabilité n'a en revanche rien de théorique. Caton raisonne non pas en théoricien mais en moraliste. Son but est didactique: il formule des préceptes, susceptibles d'une application immédiate, mais n'analyse pas l'honestas ou l'honestum en soi ${ }^{72}$. Ces deux termes, d'ailleurs, n'apparaissent jamais: Caton parle de vivre honeste ou de s'adonner à une activité honesta mais ne donne jamais à "l'honneur» une unité conceptuelle. C'est sur le caractère honorable ou déshonorant de pratiques isolées (la poésie, l'usure, l'agriculture) qu'il statue et non sur une définition

\footnotetext{
${ }^{70}$ Voir sur cet exemplum JАсотот, «La représentation de Cincinnatus chez TiteLive: figure morale et mythe républicain ».

${ }^{71}$ Sur la place du mos maiorum chez Caton comme point de référence, RECH, Mos maiorum, p. 80.

${ }^{72} C f$. l'image que donne de Caton Cicéron comme d'un maître capable, dans sa vieillesse, de donner des préceptes aux jeunes gens pour les inciter à agir avec vertu (CIc. Cato Mai. 26).
} 
univoque et stable de la nature de l'honorabilité. L'honneur, pour Caton, doit bien plus être un objet de pratique qu'un objet de pensée: il s'agit de s'y conformer, pas d'en disserter ${ }^{73}$.

Le seul élément un tant soit peu englobant et abstrait que Caton articule aux différentes conduites honorables qu'il évoque est le bonum. À propos des femmes qui se font construire des statues, Caton déplore en effet que cette façon d'obtenir des honneurs ne repose pas sur des benefacta, sur des gestes consistant à faire le bien ${ }^{74}$; dans son discours en faveur des Rhodiens, il souligne qu'il ne suffit pas de se prétendre bienveillant et de montrer des intentions louables pour acquérir un honos, mais qu'il faut réellement bene facere ${ }^{75}$. La morale de l'honneur reste donc faiblement théorisée, puisque Caton recourt au terme générique de bonus pour qualifier l'excellence morale de celui qui mérite l'honos. La place prise par ailleurs par le bonum dans son œuvre montre que c'est cette notion qui est au centre de son axiologie. L'honestas n'est pas pensée en tant que telle et ne constitue pas une qualité morale de référence, capable de subsumer les traits qui font l'excellence. L'idéal de Caton n'est pas le uir honestus, mais le uir bonus. La préface du De agricultura est éloquente sur ce point: uirum bonum quom laudabant, ita laudabant: bonum agricolam bonumque colonum. C'est «l'homme de bien» qui constitue le modèle de l'accomplissement parfait du citoyen romain, comme cela apparaît dans la célèbre définition de l'orateur comme uir bonus dicendi peritus, "homme de bien habile à parler ${ }^{76}$. Les traits civiques et moraux du Romain idéal se concentrent donc dans la figure du uir bonus. Le fait d'être honestus n'est, à cette date, qu'un trait parmi d'autres du uir bonus; l'honestas n'est pas une conduite élevée au rang d'idéal.

${ }^{73}$ On retrouve là un trait caractéristique de l'attitude catonienne: l'une des raisons qui ont conduit Caton à s'opposer à l'ambassade des trois philosophes de 155 est précisément cette méfiance envers les subtilités séduisantes de la philosophie, dont le relativisme de Carnéade est alors le meilleur exemple, et qui risquent de détourner les jeunes gens de l'action et de la disciplina (GARBARINo, Roma e la filosofia greca, vol. 2, p. 314).

${ }^{74}$ CAT. frg. XIX, $94 O R F$.

${ }^{75}$ CAT. frg. XLII, 168 ORF.

${ }^{76}$ CAT. Ad Marc. frg. 18 Sblendorio-Cugusi. Sur le sens de cette définition, reliant excellence morale et compétence rhétorique, ainsi que sur la portée exacte de l'expression uir bonus, DAvid, Le Patronat judiciaire, p. 345 ; S. AUBERT, «Stoïcisme et romanité. L'orateur comme 'homme de bien habile à parler' ", Camenae [revue électronique], 1, 2007, http:/www.paris-sorbonne.fr/fr/spip.php?article4898 [consulté en janvier 2008]; F. Schöll, "Vir bonus dicendi peritus », RhM, 57, 1902, p. 312-314; L. RADERMACHER, "Vir bonus dicendi peritus », RhM, 57, 1902, p. 314. 


\section{CONCLUSION}

Le Censeur a la singularité de produire au sujet de l'honneur un discours normatif: il réprimande les incartades aux règles de l'honos et, surtout, régule de manière positive cette pratique en lui fournissant normes et modèles. Caton envisage surtout l'honneur en homme d'État, comme un rouage essentiel de la res publica. L'aspect moral de l'honos ou de l'honestas fait moins l'objet de son attention, et ne donne pas lieu à une analyse théorique ni à une élaboration conceptuelle. Enfin, une étude du rapport de Caton à l'honneur permet de saisir la pensée de ce dernier dans toute sa complexité: son désir d'honos est réel mais ne s'exerce que sous certaines conditions; et son rapport à la tradition romaine, que l'on pourrait imaginer tout d'un bloc, présente en réalité des variations: si Caton valorise la conformité au mos maiorum, cela n'implique pas d'immobilisme de sa part sur les pratiques politiques aristocratiques. Et s'il respecte l'honos comme valeur de la res publica, il ne manque pas non plus de mobiliser la notion de manière polémique, la constituant en enjeu des luttes de son temps. 


\section{LES ÉPITAPHES DES SCIPIONS: LA MOBILISATION DE L'HONOS PAR L'ARISTOCRATIE}

\section{INTRODUCTION}

Par leur longueur, leur qualité poétique et l'importance de leurs commanditaires, les épitaphes des Scipions font partie des inscriptions les plus remarquables de l'époque républicaine. Ces textes présentent, pour notre étude de la pensée de l'honneur, plusieurs intérêts. Ils nous donnent d'abord l'occasion d'observer le traitement de la notion d'honos sur un autre support qu'une œuvre littéraire, pourvu de règles et de fonctions propres, qui implique une modalisation particulière de la notion d'honos. Ces épitaphes, ensuite, concernent des individus qui ont appartenu à l'une des plus grandes familles de la Rome républicaine, la gens des Cornelii Scipiones, qui a joué aux III ${ }^{e}$ et $\mathrm{II}^{\mathrm{e}}$ siècles un rôle primordial sur les plans politique, militaire et culturel $^{1}$. Ces inscriptions constituent donc un champ privilégié pour l'observation des représentations de l'honos dans la pensée aristocratique de l'époque. Il serait cependant réducteur de n'y voir que des documents dépositaires des modes de pensée de la noblesse. Ce sont aussi des instruments de pouvoir: ces textes jouent, pour la famille des Scipions, un rôle publicitaire essentiel et remplissent des fonctions idéologiques et politiques qui accroissent encore leur intérêt. Ils élaborent une certaine image de la famille et font à ce titre un usage particulier de la notion d'honos. Après une présentation d'ensemble des inscriptions, nous étudierons les singularités aristocratiques de l'idée d'honos dans ces textes. Nous verrons ensuite comment cet honos est valorisé et déformé en un sens positif. Nous finirons par nous interroger sur les raisons et les fonctions d'une telle élaboration de l'honos.

\footnotetext{
${ }^{1}$ Les Cornelii Scipiones ne forment pas, à strictement parler, une gens, qui regroupe l'ensemble des descendants libres d'un même ancêtre dans la lignée des mâles. Mais leur groupe est bien plus large que celui d'une simple familia et nous emploierons donc, par commodité, la dénomination de gens à leur sujet. Le tombeau dont il est ici question ne regroupe par ailleurs qu'une partie des Cornelii Scipiones, autour de l'ancêtre Barbatus.
} 


\section{LES INSCRIPTIONS ET L'IDENTITÉ DES DÉFUNTS}

Les textes généralement rassemblés dans les recueils d'inscriptions sous le nom d'elogia Scipionum proviennent tous du tombeau de la famille des Scipions, placé quelques centaines de mètres après la porte Capène, entre la via Appia et la via Latina ${ }^{2}$. Non loin se trouvait un autre sépulcre, destiné à une autre branche des Cornelii, les Cornelii Scapulae, ce qui indique le lien privilégié noué par les Scipions avec cet espace géographique 3 . Le monument a été transformé au cours des siècles et il est aujourd'hui fortement détérioré mais encore partiellement visible 4 . Il contenait plus d'une trentaine de sarcophages, et a dû commencer à être utilisé au début du $\mathrm{III}^{\mathrm{e}}$ siècle, avec l'ensevelissement de Scipion Barbatus, ancêtre de la gens ${ }^{5}$. Le tombeau se distinguait par une façade monumentale ${ }^{6}$ sur deux niveaux, le premier étant percé de trois portes et le second formé d'un podium et décoré de semi-colonnes ainsi sans doute que de niches accueillant des statues ${ }^{7}$.

2 Cic. Tusc. I, 13; Arch. 22; Suet. De Poetis, p. 25; Liv.XXXVIII, 56; Plin.NH.7, 114. Sur l'emplacement du monument, CoARELLI, « Il sepolcro degli Scipioni »; LTUR IV, p. 282 et Richardson, A New Topographical Dictionary of Ancient Rome, Baltimore, The Johns Hopkins University Press, 1992, p.359-360. Les inscriptions elles-mêmes ont été retrouvées dans cette zone, entre la muraille servienne et la muraille aurélienne.

${ }^{3}$ Sur la tombe des Cornelii Scapulae, voir LTUR Sub. II, p. 164.

${ }^{4}$ Pour une description détaillée du tombeau, voir L. CREMA, L'architettura romana, Turin, Società Editrice Internazionale, 1959, p. 126; P. Nicorescu, « La tomba degli Scipioni », Ephemeris Dacoromana, 1, 1923, p. 1-56 (configuration de l'hypogée, disposition des tombes, matériaux mis en œuvre, matériel retrouvé) ainsi que CoARELLI, «Il sepolcro degli Scipioni », p.40, qui insiste sur les réaménagements successifs de l'hypogée et de la façade et présente un plan général.

${ }^{5}$ Son sarcophage occupe en effet une position centrale, au fond de l'hypogée, juste en face de l'entrée (voir CoARELLI, «Il sepolcro degli Scipioni », p. 43). Scipion Barbatus a été consul en 298 (MRR I, p. 174), ce qui nous permet de dater la première utilisation du tombeau du début du III ${ }^{\mathrm{e}}$ siècle. Selon F. Coarelli (Ibid. p.41), il devait comprendre 32 ou 33 tombes. Ni Scipion l'Africain, enterré, suppose-t-on, près de sa villa de Liternum (aucun reste n'a été trouvé à Rome, ce qui exclut la possibilité d'un ensevelissement près de l'Vrbs, envisagé par LIV. XXXVIII, 56, 1), ni Scipion Émilien, dont le lieu de sépulture est inconnu, ne sont ensevelis à cet endroit.

${ }^{6}$ Ibid., p. 62 sqq. Voir aussi LTUR IV, p. 283 pour les diverses hypothèses sur l'aspect extérieur de la façade.

7 Tite Live (LIV. XXXVIII, 56, 1-4) parle de trois statues (celles de Scipion l'Africain, de Scipion Asiagenes et d'Ennius). Leur présence coïnciderait avec la tripartition de la partie supérieure de la façade; on connaît d'autres exemples contemporains de statues liées à des sépulcres (sur la tombe des Marcelli, voir CoARELLI, Ibid. p. 70-71). La présence des statues de l'Africain et d'Ennius est à l'origine d'une tradition, erronée de l'avis des archéologues, selon laquelle ces deux personnages seraient enterrés dans le tombeau (Ibid., p.73-81). La mise en place des statues semble désormais pouvoir être attribuée de manière assez sûre à Scipion Émilien (LTUR IV, p. 284). 
Le monument était recouvert de fresques sur toute la longueur, et l'on $\mathrm{y}$ distingue encore quelques traces d'une scène de combat ${ }^{8}$.

Sur l'ensemble des inscriptions qui nous sont connues, cinq retiendront plus particulièrement notre attention, pour leur intérêt idéologique ou pour leur mention de l'honos. Nous en donnons ici la référence et le texte, auxquels nous nous permettrons de renvoyer dans la suite de notre étude ${ }^{9}$. Elles sont généralement composées selon le même modèle: la mention de l'identité (nom, filiation et charges exercées) précède un poème laudatif, l'elogium.

\subsection{Cornelius Scipio Barbatus (CIL I'2, 6-7 = ILLRP 309)}

\section{[L. Corneli]o Cn(aei) f(ilius) Scipio}

Cornelius Lucius Scipio Barbatus Gnaiod patre prognatus, fortis uir sapiensque quoius forma uirtutei parisuma fuit consol, censor, aidilis quei fuit apud uos. Taurasia, Cisauna Samnio cepit, subigit omne Loucanam opsidesque abdoucit.

«Lucius Cornelius Scipion, fils de Gnaeus

Cornelius Lucius Scipion Barbatus, fils de Gnaeus son père, homme courageux et avisé, dont la beauté égala parfaitement la valeur et qui fut consul, censeur et édile dans votre cité. Il prit Taurasia, et Cisauna dans le Samnium, il soumit toute la Lucanie et en ramena des otages. »

L'inscription, dont la première ligne est peinte en lettres rouges et les autres gravées, figure sur la face avant d'un sarcophage d'une facture tout à fait remarquable, qui prend la forme d'un autel et présente plusieurs affinités avec l'art hellénique ${ }^{10}$. Le texte de l'elogium proprement dit est composé en saturniens, le vers romain national ${ }^{11}$.

\footnotetext{
${ }^{8}$ Pour une hypothèse sur le sens de ces peintures, illustrant l'histoire familiale, voir Flower, Ancestor Masks, p. 163.

${ }^{9}$ Plusieurs d'entre elles ont été commentées en détail dans l'ouvrage de Kruschwitz, Carmina Saturnia Epigraphica.

${ }^{10}$ Coarelli, «Il sepolcro degli Scipioni », p. 45 sqq. ; Nicorescu, "La tomba degli Scipioni », p. 41 sqq.; V. Saladino, Der Sarkophag des Lucius Cornelius Scipio Barbatus, Würzburg, Triltsch, 1970. Il a la forme d'un grand autel rectangulaire, décoré d'une frise dorique (voir U.Scamuzzi, "L'ipogeo degli Scipioni in Roma. Il sarcofago di Lucio Cornelio Scipione Barbato », RSC, 5, 1957, p. 248-268, qui le rapproche d'autres sarcophages de même type). Sur la marque de l'hellénisme, E. Strong, Art in Ancient Rome, Londres, W. Heinemann, 1929, vol. 1, p. 46; A. La Regina, "L'elogio di Scipione Barbato ", DArch, II, 2, 1968, p.173-190 et Coarelli, Guide archéologique de Rome, p. 113.

${ }^{11}$ Les saturniens n'apparaissent pas dans le texte tel que nous le présentons, puisque nous suivons la disposition des lignes telles qu'elles apparaissent sur le monument. On les restitue en général de la façon suivante: Cornelius Lucius Scipio Barbatus / Gnaiod patre prognatus, fortis uir sapiensque / quoius forma uirtutei pari-
} 
Le défunt est connu: il s'agit de Scipion Barbatus, consul en 298, qui s'est illustré militairement au début de la troisième guerre samnite ${ }^{12}$. Le texte de l'inscription est plus récent que la date de l'ensevelissement et présente des traces de remaniement. Le nom peint doit dater du milieu du $\mathrm{III}^{\mathrm{e}}$ siècle (entre 270 et 230$)^{13}$; quant à l'elogium, sa datation est très controversée ${ }^{14}$. P. Kruschwitz ${ }^{15}$, au terme d'une minutieuse analyse linguistique, historique et épigraphique, le situe entre 270 et 150. Au regard des derniers arguments avancés sur ce point, il nous paraît possible de le situer, plus précisément, au début du $\mathrm{II}^{\mathrm{e}}$ siècle $^{16}$.

\title{
1.2. L. Cornelius Scipio (CIL $I^{2}, 8-9=$ ILLRP 310)
}

\author{
[L](ucius) Cornelio L(ucii) f(ilius) Scipio \\ [a]idiles, cosol, cesor.
}

\author{
Honc oino ploirume cosentiont R[omai] \\ duonoro optumo fuise uiro \\ Luciom Scipione. Filios Barbati \\ consol, censor, aidilis, hic fuet a [pud uos]. \\ Hec cepit Corsica Aleriaque urbe, \\ dedet Tempestatebus aide mereto[d].
}

«Lucius Cornelius Scipion, fils de Lucius, édile, consul, censeur.

C'est sur lui seul que tous s'accordent à Rome pour dire qu'il fut le meilleur des hommes de bien:

Lucius Scipion. Fils de Barbatus,

Consul, censeur, édile, voilà ce qu'il fut auprès de vous.

C'est lui qui s'empara de la Corse et de la ville d'Aléria;

Il offrit à juste titre un temple aux Tempêtes. »

suma fuit, / consol, censor, aidilis quei fuit apud uos. / Taurasia, Cisauna Samnio cepit, / subigit omne Loucanam opsidesque abdoucit. Sur ce point, voir G. RADKE, «Überlegungen zum Saturnier», REA, 93, 1991, p. 263-276.

${ }^{12}$ Liv. X, 11-12. Le texte de Tite Live parle seulement d'une bataille couronnée de succès contre les Étrusques, et non d'une conquête, même partielle, du Samnium. Sur cette discordance entre les indications fournies par les textes littéraires et celles données par l'inscription, voir ILLRP p. 179; C. FERONE, "Subigit omne Loucanam: a proposito dell'elogio di Scipione Barbato (CIL I² 6,7 = ILLRP 309) », Klio, 87 (1), 2005, p. 116-122; R. Till, "Die Scipionenelogien», in Baleitinger, D. et Gugel, H. (éds.), Festschrift Karl Vretska zum 70. Geburtstag, Heidelberg, C. Winter, 1970, p. 276-289 et surtout La RegINA, «L'elogio di Scipione Barbato», p. 175 sqq.

${ }^{13}$ Coarelli, Guide archéologique de Rome, p. 113.

${ }^{14}$ Voir le bilan critique dressé par Flower, Ancestor Masks, p. 171 sqq.

15 P. Kruschwitz, "Die Datierung der Scipionenelogien CLE 6 und 7 », ZPE, 122, 1998, p. 273-285.

${ }^{16}$ Voir T. FranK, "The Scipionic Inscriptions », CQ, 15, 1921, p. 169-171; CoARELLI, "Il sepolcro degli Scipioni». En revanche, WACHTER, Altlateinische Inschriften et RADKE, «Überlegungen zum Saturnier» proposent une datation plus haute. 
Cette inscription, elle aussi en saturniens, fait l'éloge de L. Cornelius Scipion, le fils de Scipion Barbatus, bien connu par les sources ${ }^{17}$. Il fut édile curule, consul en 259, censeur en 258. Ses conquêtes d'Aléria et de la Corse sont attestées, mais les fasti triumphales parlent à son sujet d'un triomphe que l'inscription ne mentionne pas. La dédicace d'un temple aux Tempestates s'explique par la protection dont sa flotte a bénéficié lors d'une tempête ${ }^{18}$. L'orthographe présente un aspect plus archaïque que dans l'épitaphe précédente. P. Kruschwitz la situe entre 230 et 150, et elle est volontiers datée des décennies suivant la mort de L. Cornelius Scipion, entre 240 et $200^{19}$, et se trouve donc être plus ancienne que celle de son père.

\subsection{P. Cornelius Scipio (CIL $I^{2}, 10=$ ILLRP 311)}

Quei apice insigne Dial[is fl]aminis gesistei,
mors perfe[cit] tua ut essent omnia
breuia, honos, fama, uirtusque,
gloria atque ingenium, quibus sei
in longa licu[i]set tibi utier uita,
facile facteis superases gloriam
maiorum. Qua re lubens tua in gremiu,
Scipio, rec[i]pit Terra, Publi,
prognatum Publio Corneli.

«Toi qui as porté l'apex, insigne du flamine de Jupiter,

La mort a mis un terme prématuré à toutes tes qualités:

Honneur, réputation et valeur,

gloire et talent, s'il t'avait été permis

d'en jouir au cours d'une longue vie,

tu aurais facilement surpassé par tes actes la gloire

de tes ancêtres. C'est pourquoi la Terre te reçoit volontiers en son sein,

Publius Cornelius Scipion,

fils de Publius Cornelius. »

L'inscription, qui figurait sur la partie antérieure d'un sarcophage, est en saturniens. Le premier vers a été rajouté ultérieurement, comme cela est visible sur la pierre, sans doute pour réparer un oubli ${ }^{20}$. Le texte est daté des années 170-145²1. L'identité du défunt n'est pas assurée;

${ }^{17}$ Liv. Ep. 17 ; FLor. I, 18, 15 ; Eutr. II, 20.

${ }^{18}$ Ov. Fast. VI, 193-194.

${ }^{19}$ Voir la datation de $C I L \mathrm{I}^{2}, I L L R P$, CoARelli, "Il sepolcro degli Scipioni » (240230). E. F. Fay en fait néanmoins une «scipionic forgery» de Scipion Metellus, à une date beaucoup plus basse (E. F. FAY, "Scipionic Forgeries », CQ, 14 (3/4), 1920, p. 163-171).

${ }^{20}$ Sur ce point, voir W.J. TAtum, "The Epitaph of Publius Scipio Reconsidered», CQ, 38 (1), 1988, p. 253-259, notamment p. 256, mais il nous paraît difficile d'y voir là un oubli volontaire. Voir aussi CoARELLI, «Il sepolcro degli Scipioni », p. 94.

${ }^{21}$ CoARELLI, «Il sepolcro degli Scipioni». Une date plus précise, autour des années 150, est avancée par les ILLRP. 
il est assez tentant d'y reconnaître le fils de l'Africain, père adoptif de Scipion Émilien ${ }^{22}$ : le nom et la date correspondent, et Cicéron indique qu'il était de santé fragile ${ }^{23}$, ce qui pourrait expliquer l'absence de charges publiques ${ }^{24}$ et la mort précoce mentionnées dans l'elogium. Une telle identification est cependant problématique car Tite Live dit de lui qu'il a été augure, ce qui n'est pas indiqué dans l'épitaphe ${ }^{25}$; l'historien, en outre, ne mentionne pas le flaminat de Jupiter. Le fait que le défunt soit mort jeune ne plaide pas non plus en faveur d'une identification au père adoptif de Scipion Émilien: le processus d'adoption est moins susceptible d'être intervenu alors que le père adoptif n'était pas encore d'âge mûr. On peut aussi s'étonner que la filiation à la fin du texte ne fasse pas état du glorieux surnom de son père, Africanus.

\subsection{Cornelius Scipio (CIL I'2, $11=$ ILLRP 312)}

L(ucius) Cornelius Cn(aei) F(ilius) Cn(aei) N(epos) Scipio. Magna sapientia multasque uirtutes aetate quom parua posidet hoc saxsum quoiei uita defecit, non honos, honore, is hic situs, quei nunquam uictus est uirtutei, annos gnatus $X X$ is l[oc]eis mandatus. Ne quairatis honore quei minus sit mandatus.

«Lucius Cornelius Scipion, fils de Gnaeus, petit-fils de Gnaeus. C'est une grande sagesse,

et de nombreuses vertus, malgré un âge peu avancé, que retient cette pierre. Celui dont la vie, et non l'honneur, manqua d'honneur gît ici, lui dont la valeur ne fut jamais vaincue; c'est à l'âge de vingt ans qu'il fut confié à ce lieu. Ne cherchez pas d'honneur car il n'en reçut jamais. »

${ }^{22}$ C'est l'avis de Coarelli, Guide archéologique de Rome, p. 114 et de E. WöLfFlin, "Die Dichter der Scipionenelogien», Sitzungsberichte der philosophisch-philologischen und der historischen Classe der Akademie der Wissenschaften zu München, 1892, p. 188-219, à la p. 196.

${ }^{23}$ Cic. Cato. mai. 35 ; Off. I, 121 ; Brut. 77.

${ }^{24}$ Cette absence de fonctions publiques peut aussi s'expliquer par le flaminat de Jupiter que le défunt exerçait: cette prêtrise était soumise à un grand nombre d'interdits, tels que l'impossibilité de quitter Rome ou de voir l'armée en armes, ce qui limite considérablement l'accès aux hautes charges. $C f$. Gell.X, 15 et J.H.VAnggaard, The Flamen: a Study in the History and Sociology of Roman Religion, Copenhague, Museum Tusculanum Press, 1988.

${ }^{25}$ Liv. XL, 42. L'identification au fils de l'Africain, qui remonte à T. Mommsen, a été mise en doute par l'article de Tatum, "The Epitaph of Publius Scipio Reconsidered», p. 258, et, de façon selon nous convaincante, par G. Bandelli, «P.Cornelio Scipione, prognatus Publio (CIL I², 10)», Epigraphica, 37, 1975, p. 84-99. 
Cette inscription en saturniens, qui concerne encore un Scipion décédé dans la fleur de l'âge, à vingt ans, est contemporaine de la précédente, et date des années 160-140 avant notre ère ${ }^{26}$. L'identité du personnage est incertaine; on pense parfois à un fils de Cn. Scipion Hispallus, le consul de 176.

\subsection{Cn. Cornelius Scipio Hispanus (CIL I', $15=$ ILLRP 316)}

Cn(aeus) Cornelius Cn(aei) F(ilius) Scipio Hispanus

pr(aetor) aid(ilis) cur(ulis) q(uaestor) tr(ibunus) mil(itum) II Xuir s(t) l(itibus) iudik(andis) Xuir sacr(is) fac(iundis).

Virtutes generis mieis moribus accumulaui, Progeniem genui, facta patris petiei.

Maiorum optenui laudem, ut sibei me esse creatum Laetentur: stirpem nobilitauit honor.

«Gnaeus Cornelius Scipio Hispanus, fils de Gnaeus, préteur, édile curule, questeur, deux fois tribun militaire, décemvir chargé de juger les litiges, décemvir chargé des sacrifices.

J'ai augmenté grâce à mes mœurs les vertus de ma race,

J'ai fondé une descendance et essayé d'égaler les exploits de mon père.

J'ai préservé la gloire de mes ancêtres, de sorte qu'ils se réjouissent de m’avoir engendré:

Mon honneur a ennobli ma lignée. »

Cette inscription figurait sur trois tablettes de pierre formant la partie avant d'un sarcophage. Elle mentionne d'abord l'identité et le cursus honorum du défunt puis en fait l'éloge, en recourant cette fois à des distiques élégiaques ${ }^{27}$. Le défunt est un fils de $\mathrm{Cn}$. Scipion Hispallus (et donc peut-être un frère du Scipion de l'inscription précédente), préteur pérégrin en 139 avant notre ère ${ }^{28}$. Le type de mètre employé et l'interruption de la carrière à la préture font pencher pour une datation vers les années $130^{29}$.

Avant d'en venir à l'étude de la notion d'honneur dans ces textes, il convient de souligner combien ces inscriptions et le tombeau dans lequel elles se situaient constituent eux-mêmes un honos d'une nature

26 Coarelli, «Il sepolcro degli Scipioni», p.90; Wölfflin, «Die Dichter der Scipionenelogien ».

${ }^{27}$ Sur cet usage du distique et sur la singularité de l'inscription, voir M. MASSARo, «L'epigramma per Scipione Ispano $\left(C I L \mathrm{I}^{2}, 15\right)$ », Epigraphica, 59, 1997, p. 97-124.

${ }^{28}$ VAL. MAX. I, 3, 3.

${ }^{29}$ CoArelli, «Il sepolcro degli Scipioni », p. 90. 
exceptionnelle ${ }^{30}$. Le sépulcre était placé à un endroit bien visible, à la sortie de Rome, entre deux axes majeurs de circulation; il était pourvu d'une façade monumentale, décorée de fresques et ornée de statues représentant certains des plus illustres membres de la gens. Le sarcophage de Barbatus, avec sa forme rappelant celle d'un autel de type hellénistique, fait du défunt un héros digne d'un culte et lui confère un prestige sans pareil. La facture littéraire soignée des inscriptions, qui trouve ses racines dans la tradition romaine des carmina conuiualia et de la laudatio funebris ainsi que dans la littérature grecque encomiastique et épigrammatique, contribue aussi à grandir le défunt. Sont ainsi réunies de remarquables marques d'honneur architecturales, iconographiques et épigraphiques qui concourent à augmenter le prestige du mort et celui de sa famille. Les inscriptions parlent d'honneur tout en participant activement, et sous une forme inédite, à l'hommage rendu au défunt.

\section{LA REPRÉSENTATION ARISTOCRATIQUE DE L'HONOS}

Les épitaphes des Scipions ont fréquemment été utilisées comme documents pour l'histoire des modes de pensée aristocratiques ${ }^{31}$. Elles montrent en effet de quoi un nobilis des $\mathrm{III}^{\mathrm{e}}-\mathrm{II}^{\mathrm{e}}$ siècles s'enorgueillit et nous renseignent ainsi sur les valeurs de la noblesse ${ }^{32}$.

\subsection{L'évolution des sources du prestige aristocratique}

Létendue chronologique des inscriptions retenues permet de dessiner des évolutions dans la représentation que les Scipions se font de l'excellence ${ }^{33}$. On remarque, de manière générale, une diminution progressive de l'importance de la valeur militaire au profit des qualités morales. L'épitaphe de Scipion Barbatus $\left(C I L \mathrm{I}^{2}, 6-7\right)$ présente trois sources de prestige: l'exercice de charges politiques (Barbatus a

${ }^{30}$ Cicéron est bien conscient de la gloire qu'un somptueux tombeau de famille apporte à ses membres et affirme, au livre II du De Legibus, la nécessité de limiter le luxe de ces tombeaux (Cic. Leg. II, 63-66).

${ }^{31}$ Voir par exemple l'usage qu'en fait EarL, Tradition: les épitaphes des Scipions montrent "the whole aristocratic ideal of a successful life» (p. 22). Voir aussi LTUR IV, p. 284 sur ces inscriptions qui «illuminano l'ideologia della nobilitas al potere nel passagio tra la media e la tarda età repubblicana». Voir encore THоме, Zentrale Wertvorstellungen der Römer, p. 82, qui voit dans ces textes la «Selbstverständnis der römischen Nobilität, das sich im 3. und 2. Jahrhundert herausgebildet hat ».

${ }^{32}$ Sur la définition des «valeurs », voir supra p. 403.

${ }^{33}$ Sur les qualités signalées dans les épitaphes, voir P. WitzmanN, "Kommunikative Leistungen von Weih-, Ehren- und Grabinschriften », in Braun, M., Haltenhoff, A. et Mutschler, F.-H.(éds.), Moribus antiquis res stat Romana. Römische Werte und römische Literatur im 3. und 2. Jh. v. Chr, Munich, K. G. Saur, 2000, p. 55-86. 
été édile, consul et censeur), les succès militaires (conquêtes dans le Samnium et en Lucanie), les qualités de la personne (il est fortis, sapiens, il détient forma et uirtus $)^{34}$. Les valeurs aristocratiques sont donc l'engagement politique au service de la res publica, la réussite militaire, et les qualités de cœur. La mention des qualités morales est particulièrement intéressante car, à l'éloge de traits conformes à la tradition tels que le fait d'être fortis et d'avoir de la uirtus, capacité de l'homme d'action, notamment lors du combat ${ }^{35}$, s'ajoutent ici des éléments plus originaux: Barbatus est sapiens, c'est-à-dire non pas «sage» au sens philosophique mais "avisé, prudent " $^{36}$, et il a de la forma, de la «beauté». Cette mention de la beauté physique du défunt est inhabituelle à Rome et traduit probablement une influence des

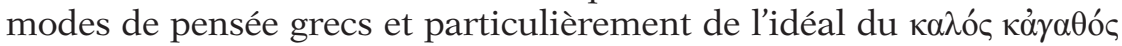
dont la présence est sensible dans l'association de la forma et de la uirtus ${ }^{37}$. À l'époque où cette inscription a été rédigée, Rome connaît en effet une seconde vague d'hellénisation, notamment au sein des élites cultivées $^{38}$, et la famille des Scipions, dont l'intérêt pour l'hellénisme est ancien, se trouve au cœur de ce phénomène.

L'inscription du fils de Barbatus $\left(C I L \mathrm{I}^{2}, 8-9\right)$ fait référence à des qualités similaires, mais sur un mode bien plus traditionnel, ce qui fait penser qu'elle est effectivement plus ancienne que celle de son père.

${ }^{34}$ Sur les qualités louées dans l'éloge, composants de la Nobilitätsethos, voir HölKesKamp, Die Entstehung der Nobilität, p.225-226 ainsi que Kruschwitz, Carmina Saturnia Epigraphica, p.50-51.

${ }^{35}$ Sur le sens de uirtus dans cette inscription, voir EIsEnhut, Virtus romana, p. 209 et McDonnell, Roman Manliness, p. 33.

${ }^{36}$ Ce recours à l'adjectif sapiens remplace le terme générique plus neutre de bonus (E. WölfFlin, «De Scipionum elogiis», RPh, n.s.14, 1890, p.113-122, à la page 121). ZevI, "Considerazioni sull'elogio di Scipione Barbato», p.67, considère que sapiens est ici l'équivalent du gr. pрóvıo et non бoфóc. C'est aussi l'avis d'A. Pignatelli, «Il concetto di sapientia a Roma fra III e II sec. a. C.», in PANI, M. (éd.), Epigrafia e territorio. Politica e società. Temi di antichità romane, VI, Bari, Edipuglia, 2001, p. 271-286 et de GARBARINO, «Evoluzione semantica dei termini sapiens e sapientia nei secoli III e II a. C. » : la sapientia désigne d'abord la sagesse pratique, dans le domaine politique (p.264). Il est intéressant de noter que cet usage de sapiens se démarque de la notion de sagesse grecque: on connaît en effet deux P. Sempronii qui portaient comme cognomen Sophus, décalque du бoøóc grec (Liv. IX, 45, 1 ; Liv. Per. 15; VeLL. I, 14, 7); le premier a été consul en 304, le second en 268 (MRR, vol.1, p. 167 et 199). La notion grecque de sagesse est donc intégrée à Rome par une transposition lexicale du grec; le cognomen de Sapiens, porté notamment par Laelius, apparaît plus tard, et élabore la notion de sagesse grecque dans un sens plus romain, par une acculturation avec la sapientia «nationale» (cf. CIc. Lael. 6).

37 Zevi, «Considerazioni sull'elogio di Scipione Barbato», p. 70; TILL, «Die Scipionenelogien ", p.281. On retrouve une semblable association dans le Miles gloriosus, v. 57 et 1042 (voir le commentaire de Thоме, Zentrale Wertvorstellungen der Römer, p. 80-81 ainsi que de Kruschwitz, Carmina Saturnia Epigraphica, p. 54).

${ }^{38}$ Voir Grimal, Le Siècle des Scipions, p. 143 sqq. et Gruen, Culture and National Identity. 
On retrouve la mention de l'excellence morale, mais avec la formule plus conventionnelle duonoro optumo ( «le meilleur des hommes de bien »), l'exercice de charges politiques (édilité, consulat, censure) et les exploits militaires (conquête d'Aléria et de la Corse). Il n'y a pas de référence à la beauté, ni de trace de pensée hellénique.

Les textes $C I L \mathrm{I}^{2}, 10$ et 11, qui sont contemporains et plus récents que les deux précédents et concernent deux défunts décédés dans la fleur de l'âge, présentent quelques innovations. Les charges politiques, d'abord, y tiennent une place bien moins importante, en raison de la mort prématurée des deux Scipions: ils n'ont pas eu le temps de commencer le cursus honorum. Pour la même raison, aucune mention n'est faite de réalisations militaires. La troisième catégorie de valeurs, les qualités morales, est en revanche bien représentée: les deux textes parlent de la uirtus des défunts, le texte $C I L \mathrm{I}^{2}, 11$ évoque la sapientia, et l'on rencontre dans chacun d'eux l'honos, qui apparaît donc ici pour la première fois dans les épitaphes des Scipions. Faut-il en déduire que la notion d'honos ne possède pas, avant les années 160-145, de place dans la pensée aristocratique? Plusieurs éléments nous amènent à repousser cette hypothèse. L'éloge du noble L.Caecilius Metellus, prononcé par son fils en 221, mentionne déjà l'honos comme titre de gloire du défunt ${ }^{39}$. L'édification d'un temple à Honos par Fabius Maximus Verrucosus autour de 233 montre également que la notion faisait déjà partie de l'arsenal idéologique de la noblesse romaine.

L'inscription de Scipion Hispanus $\left(C I L \mathrm{I}^{2}, 15\right)$ présente plusieurs évolutions notables dans les sources de prestige. Si les charges politiques sont encore un élément prépondérant, les hauts faits militaires, en revanche, sont totalement absents de l'elogium, alors même que le défunt a eu une carrière militaire, puisqu'il a été deux fois tribun. Il semblerait que, dans les années 130, la guerre ne soit plus un lieu privilégié pour le déploiement de l'excellence et l'obtention de la gloire; il est également possible que l'auteur de l'épitaphe ait voulu creuser la différence entre Hispanus et les Scipions les plus âgés dont la gloire était fondée sur les succès à l'armée. À cette déperdition en termes de prestige de la uirtus militaire fait pendant la valorisation de la uirtus morale: ce sont principalement les mores qui font l'objet de l'éloge. L'épitaphe fait état des uirtutes du défunt et non de sa uirtus générale, ce qui fait passer le terme de la désignation de la vaillance à celle des vertus éthiques et des bonnes mœurs. La mention d'une descendance est elle aussi nouvelle. On retrouve au terme de l'éloge la référence à l'honos du défunt, qui semble faire écho au premier mot de l'épitaphe, uirtutes $^{40}$. Les deux notions sont ici liées, comme c'est le cas dans le

${ }^{39}$ PuIn. NH. VII, 139-140.

${ }^{40}$ Sur cet écho entre le premier et le dernier terme, MASSARO, "L'epigramma per Scipione Ispano $\left(C I L \mathrm{I}^{2}, 15\right) »$, p. 109-110. 
temple consacré aux divinités Honos et Virtus, la première étant la conséquence de la seconde. Parmi les qualités qui composent l'idéal de la noblesse, l'honos occupe donc une place importante, aux côtés d'autres traits comme la réussite politique et l'excellence des mœurs qui tend progressivement à remplacer les succès militaires.

\subsection{L'honos comme objectif d'une vie}

Les modes de pensée aristocratiques ont comme singularité d'accorder un très grand prix à l'honos et d'en faire le but de l'existence. Cette importance cruciale se lit dans les deux réactions que suscite cet honos, grande fierté quand il est présent et affliction quand il est absent. Sa présence est en effet toujours mise en valeur par les textes: c'est le premier des biens mentionnés dans l'elogium de L. Scipion (CIL $\left.\mathrm{I}^{2}, 10\right)$. L'épitaphe $C I L \mathrm{I}^{2}, 11$ est encore plus remarquable: elle présente trois occurrences du mot qui jouent sur son sens ${ }^{41}$. C'est enfin, nous l'avons vu, le dernier mot de l'inscription d'Hispanus $\left(C I L \mathrm{I}^{2}, 15\right)$, qui couronne sa vie autant que son éloge. L'honos apparaît donc comme un titre de gloire de premier plan: il est promu au rang de qualité essentielle, au même titre que la uirtus. Son prix apparaît également quand il est absent puisqu'il donne alors lieu à une déploration pathétique: le défunt de $C I L \mathrm{I}^{2}, 10$ a joui de l'honos, mais de manière très brève car la mort a mis un terme à ce prestige, ce que le texte regrette amèrement, en s'adressant directement au mort, à la deuxième personne du singulier. La tonalité est similaire dans l'inscription consacrée à L. Scipion (CIL $\mathrm{I}^{2}, 11$ ), où le texte s'adresse cette fois au passant: il est inutile de chercher dans l'épitaphe la mention d'un honos, d'une charge publique, car Lucius Scipion est mort trop jeune pour qu'on lui en confie une. La fierté née de l'exercice de l'honos, de même que la tristesse provoquée par son absence, montrent qu'il s'agit d'un but essentiel pour le jeune nobilis, qui doit se montrer digne de ses ancêtres et préserver l'honneur de sa famille, notamment en exerçant des magistratures. On retrouve là l'idéal aristocratique du service de l'État ${ }^{42}$, sensible dans d'autres textes mettant en jeu les valeurs de la noblesse romaine, tels que l'éloge funèbre de Metellus où son fils rappelle en ces termes ce qui faisait l'objet de son ambition:

Voluisse enim primarium bellatorem esse, optimum oratorem, fortissimum imperatorem, auspicio suo maximas res geri, maximo honore uti [...].

«Il avait voulu en effet être le premier guerrier, le meilleur orateur, le général le plus courageux, diriger d'immenses affaires sous ses auspices, bénéficier du plus grand honneur [...].»

(Plin. NH VII, 140).

${ }^{41}$ Honos (1. 4) désigne l' «intégrité», honore (l. 4) le "prestige» et honore (1.6) la «charge publique». Sur ces distinctions, voir notre étude sémantique p. 92.

${ }^{42}$ EARL, Tradition, p. 22 sqq. 
Ici aussi, l'honos est d'une importance cruciale pour la définition d'une vie réussie, selon les normes de l'aristocratie; c'est l'une des decem maximas res optimasque, un des "dix objectifs suprêmes" que le défunt aurait tous atteints.

Il convient cependant de noter que cet attachement à l'honos, s'il est particulièrement fort au sein de la nobilitas, ne lui est pas propre. On trouve une semblable valorisation de l'honneur à la même époque chez des auteurs qui n'appartiennent pas à cette catégorie socio-politique. C'est notamment le cas dans les discours de Caton, homo nouus parvenu aux plus hautes charges, qui fait de l'honos un bien précieux à conquérir ${ }^{43}$. Ce qu'il y a de singulier à l'aristocratie, c'est que sa recherche du prestige ne vise pas le bénéfice personnel de celui qui l'entreprend. Le nobilis qui cherche l'honos tente d'entretenir le prestige de la gens, ce qui est, comme on l'a vu, une nécessité pour ne pas déchoir ${ }^{44}$. La notion d'un prestige individuel n'est pas centrale dans ces inscriptions où l'individu reste un élément d'un groupe familial prépondérant alors qu'un homo nouus comme Caton cherche l'honos pour son propre prestige.

\subsection{L'honos fondé sur la naissance}

C'est enfin la représentation que donnent ces textes des origines de l'honos, de ses motifs, qui relève d'un mode de pensée aristocratique. Les inscriptions présentent l'honos comme un bien inné, fondé sur la seule appartenance à une famille de la noblesse romaine. Dans le texte $C I L \mathrm{I}^{2}, 10$, l'honos est attaché à la personne et à sa vie: seule la mort a pu le faire disparaître. Dans l'inscription CIL $\mathrm{I}^{2}, 11$, l'honos au sens d' "honneur moral » est également conçu comme un trait naturel, que détenait L. Cornelius Scipion dès son plus jeune âge. Il est remarquable que, pour ces deux inscriptions, l'honos soit présent chez de très jeunes gens n'ayant pas encore véritablement eu de vie publique: il ne se fonde donc pas sur leur action politique ou militaire, mais sur leur haute naissance. La pensée aristocratique ne méconnaît pas l'importance des actions personnelles dans l'obtention du prestige, comme le prouve la mention des facteis dans l'inscription $C I L \mathrm{I}^{2}, 10$. Mais ces "hauts faits» ne sont pas créateurs d'honos; ils ne sont là que pour développer l'honneur inné de l'aristocrate. Ces inscriptions fondent l'honos sur l'excellence du genus et non sur la grandeur des actions. On mesure combien l'honos des Scipions diffère de celui de Caton: pour les Scipions, ce n'est jamais un objet dont il a fallu faire la conquête, alors que ce processus d'obtention, fondé sur la uirtus, est essentiel pour Caton; du nobilis à l'homo nouus, ce n'est pas le prix attaché à

\footnotetext{
${ }^{43}$ Voir notre étude sur Caton p. 588-591.

${ }^{44}$ Voir supra p. 441 sqq.
} 
l'honos mais ses fondements qui varient ${ }^{45}$. L'honos donne donc lieu au II ${ }^{\mathrm{e}}$ siècle à un affrontement sur deux terrains différents. Les luttes politiques visent l'obtention des honneurs suprêmes et de la considération publique, mais un conflit se dessine aussi sur le plan idéologique pour la définition de ce qu'est l'honos: les aristocrates tentent de se l'attacher en le caractérisant comme un bien inné tandis que leurs rivaux en font un bien acquis, qui s'obtient par le mérite personnel.

\section{LA VALORISATION DE L'HONOS DE LA GENS}

La notion d'honos est infléchie dans les épitaphes par les représentations propres à la noblesse, mais elle subit aussi des modifications d'un autre type. L'honos est en effet consciemment manipulé et mobilisé par les commanditaires de ces inscriptions. Ces textes ne doivent pas seulement être envisagés comme témoins mais aussi comme acteurs: les Scipions ont le souci de valoriser, à travers les épitaphes, l'honos de leur famille en le grandissant et en se l'attachant.

\subsection{L'amplification de l'honos}

Les épitaphes ne se contentent pas de rappeler les qualités des défunts: elles les exaltent et l'honos bénéficie pleinement de cette valorisation. Elles donnent d'abord à l'honos une ampleur temporelle: l'inscription $C I L \mathrm{I}^{2}, 10$ déplore que la mort ait mis un coup d'arrêt à l'honos de Scipion, mais ne dit pas que le décès l'annule. De fait, l'inscription fait perdurer cet honos par-delà la mort en préservant son souvenir, en ravivant son existence dans la mémoire des lecteurs de façon potentiellement infinie, puisque le nom, la vie et le prestige des Scipions sont gravés dans la pierre et bénéficient de la pérennité de ce matériau ${ }^{46}$. Le travail d'amplification de l'honos accompli par les elogia est encore plus intense quand il touche l'existence même de cet honos. Le Scipion de l'inscription $C I L \mathrm{I}^{2}, 10$ n'a pu, en raison de sa mort prématurée, faire une brillante carrière: aucune charge politique n'est mentionnée par l'inscription et son honos «prestige » est donc bien faible. C'est ici l'inscription qui crée de toutes pièces l'honos ou, au moins, le grandit considérablement en même temps qu'elle prétend en perpétuer le souvenir.

Un autre usage habile de la notion d'honos apparaît dans l'inscription $C I L \mathrm{I}^{2}, 11$. Le défunt est lui aussi mort jeune, à vingt ans, et n'a pu exercer de charge politique. Pourtant, le terme d'honos revient ici trois

${ }^{45} C f$. notre chapitre sur Caton.

${ }^{46}$ Voir Lamoine, "Les lecteurs de l'elogium de Scipion Barbatus » : "Par la composition de l'elogium, sa gravure dans la pierre et sa lecture, les Scipions du II ${ }^{\mathrm{e}}$ siècle offrent à Barbatus 'quelques instants de vie', annulent le passé donc l'oubli » (p. 363). 
fois. Tout se passe comme si le texte comblait un vide: le commanditaire de l'inscription a pallié l'absence d'honos du jeune homme en multipliant les occurrences du terme, ainsi qu'en utilisant le mot dans un sens très inhabituel, celui d' «honneur, dignité morale», afin que le défunt puisse tout de même être pourvu de cette qualité essentielle. Il faut en outre remarquer, pour toutes ces inscriptions, que les défunts concernés par ces textes très élogieux ne sont pas, selon notre regard moderne du moins, les membres les plus éminents de la gens des Cornelii Scipiones ni des personnages de premier plan dans l'histoire. Leur honos, célébré dans ces inscriptions, sans être une création totalement factice, n'en apparaît donc pas moins comme largement amplifié par les textes.

\subsection{L'appropriation gentilice de l'honos}

Le travail d'amplification de l'honneur mené par les inscriptions se double d'un autre procédé de valorisation: l'honos fait l'objet d'une appropriation exclusive par la gens des Cornelii Scipiones en étant présenté comme le bien de la famille. Ce sont les Scipions en tant que gens, et non comme membres de l'aristocratie, qui affirment leur mainmise sur cette notion-clef. Cette appropriation transparaît d'abord dans le statut de bien héréditaire conféré à l'honos par les inscriptions. Il n'est jamais explicitement présenté comme tel, mais tout concourt à implanter cette idée dans l'esprit du lecteur: les différentes inscriptions emploient le mot de façon répétée, en se faisant écho, et constituent l'honos en bien que chaque membre de la famille possède et, implicitement, se transmet. L'insistance de chacun de ces textes sur les ascendants du défunt et le rassemblement des sarcophages dans un même lieu contribuent à faire de l'honos et des différentes qualités célébrées des possessions entrées dans le patrimoine de la gens.

La localisation du tombeau est un autre moyen pour les Scipions d'associer leur gens à l'honos dans l'esprit des Romains. Le monument funéraire, nous l'avons vu, se situe juste à la sortie de Rome, après la porte Capène, à proximité de la via Appia. Or le temple consacré à Honos et Virtus se trouvait à proximité ${ }^{47}$. Le tombeau, qui a commencé d'être utilisé au début du $\mathrm{III}^{\mathrm{e}}$ siècle, est plus ancien que le temple, édifié par Fabius Maximus Verrucosus en 233 et remanié par Marcellus environ vingt ans plus tard, et sa localisation n'a donc pu être choisie en fonction de la présence du sanctuaire. En revanche, il est frappant de constater que les mentions répétées de l'honos dans les épitaphes n'apparaissent qu'à partir de la date où le temple est présent non loin de la sépulture. On peut donc émettre l'hypothèse selon laquelle les Scipions ont voulu établir un lien entre leur monument et le temple

\footnotetext{
${ }^{47}$ LIV. XXIX, 11. Voir notre chapitre 11 sur le dieu Honos.
} 
d'Honos voisin. Si tel est bien le cas, ce serait là une remarquable tentative de captation de l'honos: les Scipions, en effet, ne sont pour rien dans l'édification du bâtiment sacré. Ce dernier, primitivement rattaché à la gens Fabia, fut ensuite lié à Marcellus qui en a organisé la réfection ${ }^{48}$. Il semble en outre que la tombe des Marcelli se trouvait juste à côté de l'édifice ${ }^{49}$. Les Scipions essaient peut-être ainsi de déposséder les Marcelli ${ }^{50}$ de leur lien privilégié avec Honos au profit de leur seule gens, écartant du même coup les prétentions éventuelles des autres grandes familles dont les sépultures se trouvaient également dans l'entourage immédiat de la porte Capène ${ }^{51}$.

\section{LES FONCTIONS DE LA VALORISATION DE L'HONOS ET LE RÔLE DES ÉPITAPHES}

Après avoir vu la manière dont les inscriptions mettaient en valeur l'honos de la famille, il nous reste à statuer sur la fonction d'une telle valorisation et, plus généralement, sur le rôle des épitaphes. Pour ce faire, nous devons nous interroger sur l'identité des lecteurs de ces épitaphes ainsi que sur celle de leurs commanditaires.

\subsection{Célébrer et honorer les défunts}

L'affirmation de l'honos des défunts et le rappel de leur excellence ont pour but de les célébrer, en préservant leur souvenir d'une part, et en faisant leur éloge d'autre part. Les inscriptions, conformément à la fonction traditionnelle des épitaphes, rappellent à la mémoire des vivants les actions et les qualités des morts $^{52}$. Elles cherchent

${ }^{48}$ Les sources parlent plus volontiers, au sujet du temple, de Marcellus que de Fabius Maximus: Cic. ND II, 61; Liv. XXVII, 25, 6-10: VAL.-MAX. I, 1, 8.

${ }^{49}$ LTUR IV, p.282; CoArelli, Guide archéologique de Rome, p.112 et Lahusen, Untersuchungen zur Ehrenstatue in Rom, p. 138.

${ }^{50}$ Les deux familles responsables de l'édification et de la réfection du temple se sont opposées toutes les deux aux Scipions, à des dates différentes, dans des contextes d'affrontement militaire: les Fabii lors de la seconde guerre punique, et les Marcelli lors des opérations en Espagne: Marcus Claudius Marcellus, favorable à une paix négociée en 179, s'est heurté à l'opposition de Scipion Émilien qui souhaitait poursuivre la guerre. L'hostilité qui transparaît dans l'histoire de Polybe, proche de Scipion Émilien, à l'égard des Marcelli est un signe supplémentaire de l'antagonisme des deux familles. Sur Marcellus et Scipion, Astin, Scipio Aemilianus, p. 38-40.

${ }^{51}$ L'endroit, qui attirait beaucoup les convoitises, était en effet également occupé par les monuments funéraires des Servilii, des Metelli et des Calatini (CIc.Tusc. I, 13). Voir CoARelli, Guide archéologique de Rome, p. 112 et LTUR IV, p. 282. Le tombeau des Scipions paraît le plus ancien et semble à l'origine d'une convergence des monuments funéraires de la nobilitas vers cette zone.

${ }^{52} \mathrm{Cf}$. les propos que Cicéron fait tenir à Caton au sujet des épitaphes: his enim ipsis legundis in memoriam redeo mortuorum, «c'est en les lisant que les morts me reviennent en mémoire» (Cic. Cato Mai. 21). 
notamment à ancrer le souvenir du mort par un procédé d'adresse au lecteur, qui peut n'être qu'une convention littéraire, mais suppose tout de même une posture d'apostrophe à l'égard de la collectivité. C'est ce que l'on voit par exemple avec la mention "Ne quairatis honore» de l'inscription $C I L \mathrm{I}^{2}$, 11. Il faut cependant s'interroger, pour évaluer la portée de cette commémoration, sur l'identité exacte du lecteur concerné. À la différence de nombreuses autres épitaphes, celles-ci ne sont pas immédiatement visibles, puisque les tombes et leurs inscriptions se trouvent à l'intérieur d'un grand monument funéraire et ne sont pas placées directement au bord de la route, comme c'est le cas de bon nombre de sépultures. Il est difficile de savoir avec certitude si le public pouvait ou non accéder à l'intérieur du monument, et l'on a fait remarquer que, même si c'était le cas, l'obscurité régnant à l'intérieur ne devait pas faciliter la lecture des inscriptions ${ }^{53}$. Par conséquent, le cercle des lecteurs de ces inscriptions se réduirait aux membres de la gens eux-mêmes, qui auraient l'occasion de les lire lors de l'exécution de rites funéraires familiaux dans le tombeau. Si les membres de la famille sont à coup sûr des destinataires privilégiés de ces textes, il nous paraît cependant difficile de penser que les Scipions aient cherché à empêcher l'accès du public à l'intérieur du bâtiment. L'emplacement du monument entre les deux axes majeurs que sont la via Appia et la via Latina, la façade monumentale ornée de statues, le percement de trois portes, la riche décoration du sarcophage de Barbatus placé dans l'hypogée, témoignent d'une volonté d'attirer l'œil et de rendre visible à tous les illustres défunts de la gens. Les adresses au lecteur contenues dans les inscriptions sont en outre plus riches de sens si l'on imagine ce lecteur comme un citoyen romain quelconque plutôt que comme un membre de la famille. La fonction de commémoration s'applique donc à deux destinataires. Pour la collectivité, les textes rappellent à tous le souvenir prestigieux des Scipions. Pour les descendants des défunts, la commémoration s'inscrit dans le culte des ancêtres.

La commémoration ne va pas sans une valorisation des défunts. Nous l'avons remarqué à propos de la notion d'honos, mise en avant par les épitaphes, mais cela vaut aussi pour les autres qualités évoquées. Les textes présentent les défunts sous un jour très favorable et prolongent en quelque sorte l'éloge funèbre prononcé lors des funérailles: sans être exactement la transposition écrite de laudationes funebres prononcées, ces textes peuvent en constituer un résumé évocateur, fixant de manière pérenne l'essentiel des paroles prononcées ${ }^{54}$. L'accumulation d'éléments laudatifs dans l'épitaphe de Barbatus (fortis uir sapiensque quoius forma uirtutei parsiuma fuit), le recours

${ }^{53}$ Lamoine, "Les lecteurs de l'elogium de Scipion Barbatus»; Flower, Ancestor Masks, p. 160.

${ }^{54}$ Sur le rapport entre elogium inscrit et laudatio, voir Flower, Ancestor Masks, p. 179 . 
aux superlatifs dans l'inscription de son fils (optumo uiro) et plus généralement le ton admiratif des épitaphes contribuent à les rapprocher du genre rhétorique de l'éloge. Il s'agit là d'un honos en soi, qui adjoint la célébration à la commémoration.

\subsection{Valoriser les vivants}

Cette célébration des ancêtres a pour singularité de profiter, par effet de contagion, aux commanditaires mêmes de ces inscriptions. C'est la valeur personnelle de chacun des membres de la famille qui est louée mais aussi, puisque ces textes sont juxtaposés les uns aux autres et mis en scène dans le tombeau collectif, l'excellence de la gens tout entière et donc des derniers descendants. Le souci des Scipions d'attirer l'honos dans leur sphère familiale s'explique par la nature de ce dernier, élément de pouvoir essentiel dans la pratique politique romaine. La puissance d'une famille ne se mesure pas seulement à sa richesse ou à l'étendue de sa clientèle; la détention d'honores et de l'estime des concitoyens est aussi un facteur crucial $^{55}$. Signaler que les ancêtres ont bénéficié d'un large honos permet aux descendants de montrer la grandeur de leurs pères et de bénéficier de leur prestige, qui se propage selon la lignée familiale. Ce sont donc aussi les descendants des défunts qui sont mis en valeur par l'exaltation de l'honos des disparus. La mise en avant de l'honos par les épitaphes est liée à un moment d'affirmation des Scipions sur la scène publique. Les trois inscriptions qui mentionnent l'honos ont été réalisées dans les années 160-130 environ, à une période où la famille des Scipions sort d'une période d'affaiblissement ${ }^{56}$ : dans les deux décennies précédentes, elle a été touchée par les "procès", dont la nature exacte est encore très débattue, de l'Africain et de son frère Asiagenes, puis par la mort de l'Africain en 183, et par la concurrence de Caton et d'autres familles de la nobilitas comme les Fulvii et les Claudii ${ }^{57}$. À partir des années 160 et suivantes, les Scipions connaissent un regain de puissance: de nombreux membres de la famille exercent les plus hautes magistratures et certains d'entre eux jouent un rôle politique de première importance, tels que Scipion Nasica Corculum ${ }^{58}$ et surtout Scipion Émilien. Ce dernier, vainqueur de Carthage puis de Numance, censeur sévère en 142, domina la vie politique de l'époque et était également entouré de certains des écrivains et penseurs les plus brillants de son temps. Ce retour en force des Scipions s'est accompagné de multiples formes d'affirmation symbolique de leur pouvoir auxquelles partici-

${ }^{55}$ Voir supra p. 356 sqq. sur les avantages de l'honos.

${ }^{56}$ Voir Scullard, Roman Politics, 220-150 B.C, p. 133-152.

${ }^{57}$ Ibid., p. 153-189. Sur les procès des Scipions, voir p. 290-303.

${ }^{58}$ Censeur en 159, triomphateur sur la Dalmatie, grand pontife en 150 et princeps senatus en 147 et 142. Sur le personnage, voir Astin, Scipio Aemilianus, p. 276-280. 
pent les épitaphes. Il est possible que Scipion Émilien ait joué un rôle particulier dans cette valorisation de la famille: c'est à son époque que la façade monumentale du tombeau a subi une réfection assez importante ${ }^{59}$ et il a pu intervenir aussi dans la réalisation des inscriptions qui mentionnent l'honos. Nous avons en effet déjà vu, dans un fragment d'un de ses discours, que la notion d'honos occupait une place dans sa pensée politique $^{60}$. Les inscriptions et le tombeau lui-même ont donc tout autant pour fonction de commémorer l'honos des ancêtres que de mettre en avant leurs descendants afin de renforcer leur autorité ${ }^{6}$.

Ce souci qu'ont les Scipions d'affirmer symboliquement leur prestige s'explique par un contexte de rivalité persistante entre les grandes familles romaines. Les épitaphes présentent d'ailleurs des traces de cette lutte en manifestant la volonté qu'ont les Scipions de se distinguer des autres personnages influents de Rome. C'est ainsi que l'inscription du fils de Barbatus ( $\left.C I L \mathrm{I}^{2}, 8-9\right)$ affirme la supériorité du défunt sur l'ensemble de ses contemporains: tous reconnaissent, est-il écrit, qu'il est le meilleur des hommes ${ }^{62}$. Quant à Lucius Scipion $\left(C I L \mathrm{I}^{2}, 11\right)$, l'inscription précise que sa uirtus ne fut jamais vaincue: de ce point de vue, lui aussi surpasse ses rivaux. C'est donc bien la promotion de la gens des Scipions par rapport aux autres grandes familles romaines qui est visée par ces textes. Les épitaphes réactivent la promotion sur le plan symbolique des Cornelii Scipiones, dont Scipion l'Africain avait su donner un exemple éclatant, entre autres par l'affirmation de ses relations privilégiées avec Neptune, Hercule, et Jupiter ${ }^{63}$. La lutte entre les familles aristocratiques se déroule donc aussi sur le plan symbolique, par le biais des constructions architecturales et des textes épigraphiques.

${ }^{59}$ COARELl, «Il sepolcro degli Scipioni », p. 62 sqq.

${ }^{60}$ Ex innocentia nascitur dignitas, ex dignitate honor, ex honore imperium, ex imperio libertas. "De l'intégrité naît le mérite, du mérite l'honneur, de l'honneur le pouvoir, du pouvoir la liberté. » (ScIP. AEM. frg. inc. 32 ORF).

${ }^{61}$ La réfection de l'éloge de Barbatus, qui est bien postérieur à la date de sa mort, poursuit le même but. Si l'on retient la datation fixant la réalisation au début du $\mathrm{II}^{\mathrm{e}}$ siècle, on ne peut manquer de constater que c'est l'époque qui voit l'apogée de Scipion l'Africain, après la victoire de Zama, ainsi que de son frère Asiagenes qui bat Antiochos à Magnésie en 190. Il est tentant de supposer que l'un de ces deux Scipions est à l'origine de cette réfection élogieuse de l'inscription de Barbatus, personnage particulièrement important car placé à la racine de la gens. C'est l'hypothèse de F. Coarelli (CoARELLI, «Il sepolcro degli Scipioni », p. 95).

62 «Optumo uiro». Sur cette rivalité aristocratique perceptible à travers l'inscription, HöLKeSKamp, Die Entstehung der Nobilität, p. 226 et Flower, Ancestor Masks, p. 178.

${ }^{63}$ Scipion et Neptune: Pol. X, 11, 7; X, 14, 12. Hercule: Hor. carm. IV, 8, 15 sqq. ; Lact. Inst. I, 18, 11. Et Jupiter, Pol., X, 5, 5 ; Liv. XXVI, 19, 3-9; Gell.VI, 1. Voir aussi la synthèse de WaLBanK, "The Scipionic Legend». 


\subsection{Exhorter les descendants}

Au-delà de la commémoration des défunts et de la valorisation des commanditaires, les inscriptions s'adressent à une autre partie de la gens, ses membres les plus jeunes et ceux qui ne sont pas encore nés. Les épitaphes parlent du passé, ont un sens pour le présent, mais visent également l'avenir. Elles remplissent en effet une fonction à l'intérieur de la famille, en instituant les défunts en modèles pour les générations futures. Attribuer l'honos à quelqu'un revient en effet à sanctionner sa conformité aux normes sociales et morales de la cité et à le transformer en modèle ${ }^{64}$. Or les inscriptions ne cessent d'évoquer l'honos des défunts et donc d'affirmer leur légitimité à être constitués en personnages qu'il convient d'imiter. Toutes les qualités rappelées par ces textes dessinent l'image de l'homme romain accompli dont les descendants doivent se rapprocher. Nous avons la trace de cette mentalité mimétique dans deux des inscriptions: le texte $C I L \mathrm{I}^{2}, 10$ invoque l'impossibilité pour P.Scipion de dépasser la gloria maiorum en raison de sa mort prématurée; le texte $C I L \mathrm{I}^{2}, 15$ rappelle fièrement qu'Hispanus est parvenu à préserver la gloire de ses ancêtres (maiorum optenui laudem). Cette volonté d'égaler, voire de dépasser, le prestige des pères ${ }^{65}$ est entretenue par les inscriptions qui remplissent ainsi une fonction didactique: elles rappellent l'excellence des ancêtres pour exhorter les descendants à les imiter. La célébration de l'honos des défunts est un moyen de donner des normes de comportement aux jeunes membres de la famille; elle n'est pas tournée vers le passé mais vers l'avenir, et l'on pourrait faire à son propos la même remarque que celle faite par J.-F. Thomas à propos de la gloria dans les épitaphes: "La gloria maiorum ne se limite pas à l'émulation ni même à l'incitation pour acquérir une nouvelle gloire, mais oriente et impose la conduite actuelle ${ }^{66}$. " L'exhortation est même susceptible de s'adresser à l'ensemble des Romains et de constituer de la sorte le défunt en modèle universel et non seulement familial. Ainsi, dans le De finibus, Cicéron rappelle à Torquatus le contenu de l'éloge inscrit de Calatinus, dont le monument se situait lui aussi près de la porte Capène, pour lui prouver que les grands hommes de la République ne se glorifiaient pas de vivre dans le plaisir ${ }^{67}$.

${ }^{64}$ Voir supra p. 408-415.

65 Sur ce point Thomas, «Gloria maiorum» et KNoche, «Der römische Ruhmesgedanke».

${ }^{66}$ THOMAs, «Gloria maiorum », p. 135.

${ }^{67}$ Cic. Fin. II, 116. Le texte que cite Cicéron est étonnament proche d'un passage de l'inscription du fils de Barbatus (CIL $\left.\mathrm{I}^{2}, 8-9\right)$ : «Hunc unum plurimae consentiunt gentes populi primarium fuisse uirum.» 


\section{CONCLUSION}

Les elogia des Scipions offrent donc une représentation singulière de l'honos, qui demande à être interprétée en s'appuyant sur les fonctions que revêtent ces inscriptions. Il s'agit là d'un document de premier ordre pour comprendre comment l'aristocratie du IIe siècle envisage l'honos: elle lui assigne un très grand prix et le fonde sur l'excellence de son genus. Ces textes révèlent aussi l'idéologie d'une famille, celle des Cornelii Scipiones: ils dessinent en effet une image de l'honos à leur avantage et modèlent la notion jusqu'à se l'approprier. S'il faut parler d'idéologie à l'œuvre dans ces inscriptions, elle est donc plus gentilice qu'aristocratique. Les épitaphes ne mènent pas un travail réflexif sur la notion d'honos, mais elles la mobilisent au sein d'un mode de pensée familial qui lui donne une conformation unique, à des fins politiques précises. L'honos n'y est pas un concept, mais il est dépouillé de son statut vague pour devenir une idée politique. Ces textes, enfin, révèlent l'importance de l'image et du symbole dans le domaine de la vie civique. Il est primordial, pour une grande famille, de s'approprier l'idée de l'honos et pas seulement l'honos concret, le prestige ou la magistrature. Le IIe siècle présente de fortes rivalités pour la détention du pouvoir mais aussi pour les signes et les représentations de ce pouvoir, rivalités au sein desquelles l'épigraphie, moyen de communication efficace, joue un rôle de premier plan. 
CHAPITRE 15

\section{TÉRENCE: L'HONNEUR EN DEMI-TEINTE}

\section{INTRODUCTION}

Avec Térence, l'occasion nous est donnée de poursuivre l'étude de l'image dramaturgique et comique de l'honneur commencée avec Plaute. Comme son prédécesseur, Térence s'est en effet illustré dans le genre de la palliata et ses pièces présentent, quoique de façon moins fréquente, les notions d'honos et d'honestum. Notre approche de cet auteur ne peut cependant suivre la même voie que celle empruntée pour étudier Plaute. Le contexte historique, d'abord, est différent: les pièces de Térence ont été représentées entre 166 et 160, une vingtaine d'années après la mort de Plaute, à une époque où Rome s'affirme militairement et politiquement en Orient et en Occident, où Scipion Émilien commence à devenir une figure centrale de la vie publique et où les mœurs et les arts évoluent, sous l'influence d'une imprégnation hellénique plus réfléchie et plus élitiste ${ }^{1}$. Térence est directement concerné par ces évolutions puisque c'est un proche de Scipion Émilien ainsi que de son cercle de familiers cultivés et ouverts à l'hellénisme². Ce contexte historique particulier a eu une influence sur la transformation de la notion d'honneur. L'art de Térence, ensuite, est différent de celui de Plaute. Même s'il convient de ne pas opposer de manière trop tranchée la «farce bouffonne» de Plaute à la «comédie subtile et distinguée» de Térence ${ }^{3}$, on ne peut nier que leur construction de l'in-

${ }^{1}$ Sur cet aspect, voir Grimal, Le Siècle des Scipions, p. 251 sqq.

${ }^{2}$ Il s'agit du fameux "cercle de Scipion ». Si les liens intellectuels et amicaux entre ses membres sont avérés, de même que leur philhellénisme et leur goût pour les lettres, il ne faut cependant pas donner une trop grande cohérence à ce «cercle» dont l'image a été constituée par Cicéron dans ses dialogues. Le philhellénisme romain, en outre, ne se limite pas, au $\mathrm{II}^{\mathrm{e}}$ siècle, à l'entourage de Scipion, dont les amis ne sont d'ailleurs pas tous philhellènes. Sur ce point, voir H. STRASBURger, "Der 'Scipionenkreis' », Hermes, 94, 1966, p. 60-72; Astin, Scipio Aemilianus p. 294 sqq. et Ferrary, Philhellénisme, p. 589-602. Térence a été accusé en son temps de s'être fait aider par ses éminents amis pour écrire ses pièces; il se défend de l'accusation, assez mollement d'ailleurs, dans le prologue des Adelphes (15-21) et de l'Heautontimoroumenos (22-26).

${ }^{3}$ Voir sur ce point les avertissements de B. A. Taladoire, Térence. Un théâtre de la jeunesse, Paris, Les Belles Lettres, 1972, p. 1 et I.LanA, «Terenzio e il movimento filellenico in Roma ", RFIC, 75, 1947, p. 44-80 et 155-175. 
trigue et des personnages, leur usage du comique, leur langue et leur style sont distincts. Ces particularités nous conduiront à nous focaliser sur des éléments un peu différents de ceux qui ont retenu notre attention chez Plaute. Nous nous interrogerons sur la finesse particulière du traitement dramatique de l'honneur chez Térence et sur l'exploration intellectuelle et conceptuelle que conduit le dramaturge sur la notion. Quand Plaute opérait un renversement comique, Térence se livre à un enrichissement de l'honneur et en fait surgir les complexités et les nuances.

\section{L'USAGE DRAMATIQUE DU THÈME DE L'HONNEUR}

L'étude de la pensée de l'honneur chez Térence nous amène à prendre en compte, comme pour Plaute, les singularités du genre de la palliata. Or l'usage des notions d'honos et d'honestum dans l'économie de l'action dramatique et dans le déclenchement du rire est restreint: Térence ne fait pas de l'honneur un objet spectaculaire. Cela ne veut pas dire pour autant qu'il le délaisse: l'honneur reçoit en effet une fonction dramatique en rapport avec le développement du caractère des personnages, ce qui conduit le poète à présenter sur scène une facette de l'honneur jusqu'alors peu considérée, son aspect psychologique.

\subsection{Une présence restreinte du thème}

L'honneur n'est pas un thème central dans les comédies de Térence. La notion d'honos n'apparaît que quatre fois dans tout son théâtre, dans des contextes où elle est en outre loin d'être au premier plan ${ }^{4}$. Le prestige et les marques d'honneur qui l'accompagnent continuent à l'époque de Térence à jouer un grand rôle dans la vie publique mais ne reçoivent pas dans ses œuvres une place aussi grande que dans celles de Plaute. De manière plus générale, les questions de prestige social et de réputation occupent une place réduite. Certes, les problèmes traditionnels de la bonne renommée et de ses normes apparaissent: dans l'Andrienne, le jeune Pamphile a pris soin de ne pas encourir l'infamia par ses amours, aux dires de son esclave; dans les Adelphes, le père de famille se soucie de la fama de sa fille; dans l'Heautontimoroumenos, la fréquentation des courtisanes est une source de dommage pour la réputation ${ }^{5}$. Cependant, ces préoccupations apparaissent avec moins d'acuité que chez Plaute. On y voit beaucoup moins les jeunes gens perdre leur honneur par leur conduite, par exemple: peu de scènes

\footnotetext{
${ }^{4}$ Ter. Heaut. 687 ; Eun. 260 et 1023 ; Phorm. 928.

${ }^{5}$ Respectivement, Ter. Andr. 444; Ad. 340; Heaut. 334.
} 
représentent de manière directe des amours délurées ou en font le récit aux spectateurs. Les personnages sont moins aux prises avec des problèmes touchant l'aspect social de l'honneur, c'est-à-dire l'estime publique. Térence se montre plus intéressé par les questions morales que par les valeurs sociales et politiques romaines ${ }^{6}$. Une des raisons de cette occultation - relative - de l'honos réside peut-être dans la volonté du poète de donner dans ses pièces l'image d'un monde à la vérité plus universelle, ce qui passe par l'effacement de réalités trop spécifiquement romaines ou grecques. Le monde de Térence est plus épuré que celui de Plaute et moins pourvu de détails réalistes; il vise à donner une image de l'homme plutôt qu'une image de Rome. Or honos, et dans une moindre mesure honestum, sont des notions romaines pourvues d'une forte charge identitaire, ce qui a pu amener Térence à les placer à l'arrière-plan? .

\title{
1.2. Un fonctionnement conventionnel
}

À la différence de ce que nous avons observé chez Plaute, les mécanismes de l'honneur ne connaissent pas d'inversion radicale chez Térence. L'image que ce dernier donne de l'honneur est conforme aux normes collectives. Les commandements propres à l'honestum sont, par exemple, ceux en vigueur dans la tradition morale romaine. On le voit dans l'Andrienne, lorsque le personnage de Criton évoque la vie de sa cousine Chrysis, une courtisane:

\author{
In hac habitasse platea dictumst Chrysidem, \\ Quae sese inhoneste optauit parere hic ditias \\ Potius quam in patria honeste pauper uiueret. \\ «C'est sur cette place, m'a-t-on dit, qu'habitait Chrysis, \\ Qui a choisi de gagner ici malhonnêtement de l'argent \\ Plutôt que de vivre honnêtement, dans la pauvreté, dans sa patrie.»
}

(TER. Andr. 796-798).

\footnotetext{
${ }^{6}$ Sur la présence réduite chez Térence des valeurs de la vie publique romaine, voir EARL, «Terence and Roman Politics».

${ }^{7}$ Nous ne pensons pas en revanche, comme D.C.Earl, que Térence ait cherché, sous l'influence de Scipion Émilien, à séparer le monde de l'art marqué par l'hellénisme de la réalité politique romaine, ce qui l'aurait amené à occulter au théâtre les notions romaines comme la uirtus, la gloria ou l'honos (EARL, «Terence and Roman Politics »). La plus grande présence de ces notions chez Plaute ne peut pas non plus s'expliquer par le fait que c'est à son époque que se développe l'idéologie aristocratique de la uirtus (EARL, «Terence and Roman Politics», p. 475-476) : l'exemple des épitaphes des Scipions, dont plusieurs sont bien postérieures à Plaute, prouve que la uirtus et les notions connexes continuent d'être utilisées et élaborées tout au long du II ${ }^{e}$ siècle (voir chapitre 14).
} 
En considérant que ce n'est pas vivre honeste que de mener une vie de meretrix, le personnage de Criton est en parfaite adéquation avec les modes de pensée romains. Certains métiers provoquent une disgrâce sociale: les prostituées font partie, avec les acteurs ou les gladiateurs, de ces professions dégradées parce qu'elles supposent de faire commerce de son corps et de s'asservir au plaisir d'autrui ${ }^{8}$. La scène comique de Térence ne déforme donc pas, de ce point de vue, le réel ${ }^{9}$. L'adéquation des comédies aux normes de l'honneur apparaît aussi dans l'attachement à l'honestum et à l'honos que formulent les personnages: ces derniers n'affichent en effet jamais de mépris pour l'honneur. Dans l'Heautontimoroumenos, lorsqu'Antiphila est reconnue comme la fille du vieux Chrémès, son amoureux Clinia déclare:

Atque ita me di ament ut ego nunc non tam meapte causa Laetor quam illius; quam ego scio esse honore quouis dignam.

«Et, pour l'amour des dieux, comme je me réjouis, aujourd'hui, pas tant pour moi

Que pour elle; car je sais qu'elle est digne de tout hommage.»

(Ter. Heaut. 686-687).

La déclaration de Clinia sur le fait que la femme qu'il aime est «digne de tout hommage » indique que l'honos est perçu, de manière positive, comme un bienfait qui échoit à un individu qui l'a mérité. Ce type de conception est ici encore en adéquation avec la valorisation de l'honos et de la dignitas dans la culture romaine du $\mathrm{II}^{\mathrm{e}}$ siècle.

On ne rencontre guère qu'un seul passage où la notion d'honneur subisse une distorsion. Il s'agit d'une scène de l'Eunuque où le parasite Gnathon raconte comment il a suscité l'admiration d'un autre parasite moins habile à se faire entretenir en lui montrant la considération dont il jouit auprès des marchands :

Dum haec loquimur, interea loci ad macellum ubi aduentamus,

Concurrunt laeti mihi obuiam cuppedinarii omnes,

Cetarii, lanii, coqui, fartores, piscatores,

Quibus et re salua et perdita profueram et prosum saepe;

Salutant, ad cenam uocant, aduentum gratulantur.

Ille ubi miser famelicus uidet me esse tanto honore et

${ }^{8}$ Sur l'infamie de ces professions, voir supra p. 309.

${ }^{9}$ Sur la rareté des situations réellement subversives du point de vue de la morale chez Térence, M.BRaun, "Mos maiorum und humanitas bei Terenz", in Braun, M., Haltenhoff, A. et Mutschler, F.-H. (éds.), Moribus antiquis res stat Romana. Römische Werte und römische Literatur im 3. und 2. Jh. v. Chr, Munich, K. G.Saur, 2000, p. 205-215. Il y a des cas d'irrespect des conduites attendues mais ils sont peu fréquents et ne sont pas aussi radicaux que chez Plaute. Dans l'Andrienne par exemple, Pamphile ne consent qu'avec réticence à berner son père Simon et donc à enfreindre la pietas (TER. Andr. 375-403). 
Tam facile uictum quaerere, ibi homo coepit me obsecrare $V t$ sibi liceret discere id de me.

«Pendant que nous causons, nous arrivons au marché et, à cet instant, Accourent à ma rencontre, le sourire aux lèvres, tous les marchands de bonnes choses,

Les mareyeurs, les bouchers, les charcutiers, les rôtisseurs, les poissonniers, À qui, dans la richesse comme dans la misère, j'avais rendu et rends encore souvent des services;

Ils me saluent, m'invitent à dîner, me félicitent de ma venue.

Lorsqu'il voit, ce pauvre famélique, que je bénéficie de tant d'honneur

Et que je gagne mon pain si facilement, il commence à me supplier

De lui permettre de devenir mon élève. »

(TER. Eun. 255-262).

Ces vers font un usage comique de l'honos en détournant la notion de son contexte habituel ${ }^{10}$. Celui qui en bénéficie est en effet un parasite, personnage dont le statut social est très bas, et ceux qui ont pour lui de l'estime sont des individus également assez peu considérés à Rome, les petits commerçants. La manière pompeuse dont Gnathon déclare jouir de l'honos fait se rencontrer de manière amusante la noblesse du terme et la petitesse de la situation réelle. Il s'agit d'un honneur dégradé. Cependant, il n'y a pas ici d'inversion radicale et burlesque du fonctionnement de l'honneur: l'honos du parasite est en effet étayé par un comportement qui est, aux yeux des marchands, tout à fait méritoire puisqu'en s'efforçant de susciter des banquets, Gnathon leur apporte des bénéfices. Son prestige est en outre rendu manifeste par des marques d'honneur qui n'ont rien de paradoxal: les salutations et les gestes bienveillants font partie de la panoplie habituelle des honores. Le comique ne naît pas du renversement de l'honos mais de son usage décalé: en l'attribuant à un parasite, la comédie génère une discordance qui ne vise pas à susciter l'hilarité mais plutôt un rire amusé ${ }^{11}$.

Pour quelle raison le dramaturge donne-t-il de l'honneur cette représentation relativement conventionnelle? L’abandon des procédés de l'inversion comique est lié, en premier lieu, au projet littéraire de Térence. Son objectif n'est pas de créer un univers fantaisiste qui lui permettrait de détacher ses pièces du monde réel ou d'attaquer les normes sociales de son époque par de puissantes moqueries ${ }^{12}$. Il

${ }^{10}$ Le passage semble aussi parodier les philosophes, la manière dont ils exposent leurs doctrines et recrutent des élèves: le terme de Gnathonici rappelle celui de Platonici (GARBARINo, Roma e la filosofia greca, vol. 2, p. 563).

${ }^{11}$ Sur la différence entre le comique de Plaute et celui de Térence, CÈBE, $L a$ Caricature et la parodie dans le monde romain, p. 48 sqq.

${ }^{12}$ Sur cet aspect du rapport au monde de Térence, voir p. 33 de T. Piscitelli Carpino, «Riflessi della realtà politico-sociale del II secolo a. C. in alcuni personaggi terenziani », BStudLat, 7, 1977, p. 25-38. 
cherche au contraire à donner à ses comédies une certaine vraisemblance, comme le montrent d'autres procédés tels que la réduction des ruptures de l'illusion scénique et des effets de métathéâtre, la disparition du prologue explicatif ou la diminution des monologues ${ }^{13}$. Proposer de l'honneur une image conforme à la représentation qu'en ont ses contemporains contribue à cette vraisemblance humaine. En second lieu, le contexte historique, comme nous le soulignions dans notre introduction, n'est plus le même que celui des comédies de Plaute. Rome continue à connaître des difficultés et des conflits, mais ils sont moins importants que les périls encourus pendant la deuxième guerre punique; il est donc possible que la comédie ait moins eu à remplir une fonction de relâchement des tensions, qui passait chez Plaute par l'inversion de l'honneur, ou de mobilisation identitaire autour des valeurs romaines, opérée par les discours moralisateurs sur l'honos, entre autres. Enfin, la présentation de personnages se conformant aux normes de l'honneur est peut-être liée aussi à l'influence de Scipion Émilien et de son entourage: le grand homme était attaché aux normes traditionnelles du mos maiorum et a fait preuve à plusieurs reprises de rigueur morale pendant sa vie ${ }^{14}$.

\subsection{L'approfondissement psychologique}

L'originalité de la représentation de l'honneur chez Térence réside dans la mise en avant de la complexité psychologique de l'honestum et dans l'approfondissement du rapport mental de l'individu à ce dernier. Térence utilise le thème du sens de l'honneur pour enrichir et nuancer le caractère de ses personnages, ce qui contribue, en retour, à problématiser la conformité aux principes de l'honneur ${ }^{15}$. Plaute présentait une première approche réflexive du choix de vie et de la sélection de l'honos comme fin; Térence s'intéresse pour sa part à la question de la conformité du sujet aux règles de l'honneur, à l'interaction entre l'esprit individuel et les principes de conduite collectifs. Cet aspect psychologique du rapport à l'honneur est abordé dans une scène de l'Hécyre:

13 Sur ces aspects, O.BIAnco, Terenzio. Problemi e aspetti dell'originalità, Rome, Ateneo, 1962, p. 57.

14 Voir l'extrait de son discours fustigeant le déshonneur de jeunes nobiles qui fréquentent les écoles d'histrions (supra p.76-77). Plusieurs épisodes de sa vie, comme son traitement des déserteurs ou sa censure, témoignent de sa rigueur (voir H.H.Scullard, "Scipio Aemilianus and Roman Politics», JRS, 50, 1960, p.59-74 et Astin, Scipio Aemilianus, p. 17). Sur la coïncidence entre les préoccupations de Térence et celles d'une certaine catégorie de la classe politique, G. Cuparuolo, Terenzio. Teatro e società, Naples, Loffredo, 1991, p. 7. Ces rapprochements n'impliquent cependant nullement que le poète est l'instrument idéologique d'une faction.

${ }^{15}$ Sur l'intérêt de Térence pour la psychologie des personnages, Bianco, Terenzio. Problemi e aspetti dell'originalità, p. 203 et BRAUN, "Mos maiorum und humanitas bei Terenz », p. 205. 
Pamphile, de retour de voyage, vient d'apprendre que sa femme est sur le point d'accoucher et pense qu'il n'est pas le père. Il en ressent une vive douleur et se demande quelle conduite adopter:

\begin{abstract}
Nam de redducenda, id uero ne utiquam honestum esse arbitror,
Nec faciam, etsi amor me grauiter consuetudoque eius tenet.

Lacrumo, quae posthac futura est uita cum in mentem uenit Solitudoque.

"Quant à la reprendre, elle, je crois vraiment que ce ne serait nullement honorable

Et je ne le ferai pas, en dépit de l'amour et des liens qui m'attachent sérieu sement à elle.

Je pleure lorsque je songe à la vie qui sera désormais la mienne

Et à ma solitude.»
\end{abstract}

(TER. Hec. 403-405; trad. Marouzeau modifiée).

Par le recours à un monologue, Térence représente un personnage qui délibère sur le comportement à suivre. Deux principes contradictoires s'affrontent dans cette délibération, l'honneur et l'amour. Malgré l'affection qu'il a pour sa femme, Pamphile choisit l'action honesta, ne pas continuer à vivre à ses côtés, car il serait pour lui déshonorant de s'afficher avec une épouse infidèle. La scène représente donc ici un conflit traditionnel du théâtre comique, entre l'honneur et l'amour, mais elle renouvelle ce lieu commun en l'approfondissant. La conduite honorable fait l'objet d'un jugement rationnel de la part du sujet (arbitror), ce qui l'oppose à l'amor qui relève du sentiment. Les deux principes de conduite sont donc assez fermement isolés. La scène montre en outre un personnage conscient de ses affects et capable de les maîtriser: l'amor et la consuetudo ont une force réelle mais Pamphile parvient à s'en détacher. Il s'agit d'un personnage d'amoureux d'un nouveau genre, parce que Pamphile est un homme marié mais surtout parce qu'il parvient à repousser la force de l'amour ${ }^{16}$. La scène présente les conséquences affectives pour Pamphile de l'honorabilité: renoncer à vivre avec sa femme est honorable mais cela lui tire des larmes et suscite son désespoir. Le conflit entre honneur et amour est vécu comme un déchirement douloureux. Térence met donc en relief le caractère psychologiquement problématique de l'adéquation de l'individu à l'honneur. Il s'intéresse au caractère de l'homme d'honneur et non plus seulement à son action. La représentation de ce conflit de principes entre l'amour et l'honneur permet au poète de creuser la complexité du personnage de Pamphile et de transformer le type traditionnel comique de l'amoureux en lui donnant une épais

${ }^{16}$ À la différence de ce qui se passe dans le Miles gloriosus où Pleusiclès cède à l'inhonestum par amour (voir supra p. 559). 
seur psychologique ${ }^{17}$. Une autre scène de l'Hécyre, antérieure à celle que nous citons, présente de même une délibération sur la conduite à suivre et une confrontation entre deux guides possibles pour l'action, l'honneur et l'amusement, honestum et ludibrium ${ }^{18}$.

\section{LE DÉVELOPPEMENT ÉTHIQUE D’HONESTUS}

Térence, bien qu'il fasse un usage discret d'honestus, fait évoluer sa nature en développant ses potentialités éthiques. Ce développement passe par trois innovations: le poète éloigne le terme de la sphère du prestige social, l'enrichit d'un aspect esthétique et esquisse son éléva-

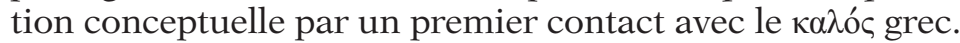

\subsection{L'effacement de l'extériorité sociale}

Térence représente une étape importante dans l'évolution de la notion romaine d'honneur car c'est avec lui que commence la transition d'un honneur majoritairement social, dominé par le souci de l'estime de l'entourage, à un honneur essentiellement moral où l'adéquation à des normes de conduite, sans considération de leur répercussion en termes de prestige, passe au premier plan. C'est dans les pièces de Térence que l'honestum commence une transition de l'honorabilité à l'honnêteté. La notion ne s'identifie pas encore au respect du bien moral mais elle va au-delà de l'observation des impératifs sociaux ou de l'adéquation à un code d'honneur. On observe en effet chez Térence une diminution du rôle joué par la collectivité dans l'établissement des normes: la dimension hétéronome de la conduite honesta régresse. C'est le cas dans un passage de l'Hécyre qui précède le texte que nous citions supra, où Pamphile refuse d'entretenir des relations intimes avec la femme qu'il a épousée parce que, à ce stade de la pièce, il ne ressent pas de sentiments pour elle et projette de s'en séparer. L'esclave Parménon rapporte les paroles du jeune homme à Philotis:

\footnotetext{
$P_{A .:}$ " Sed quam decrerim me non posse diutius

Habere, eam ludibrio haberi, Parmeno,

Quin integram itidem reddam ut accepi a suis,

Neque honestum mihi neque utile ipsi uirgini est.»

$P_{H .}$ : Pium ac pudicum ingenium narras Pamphili.
}

\footnotetext{
${ }^{17}$ Pamphile est de ce point de vue un personnage particulièrement fouillé puisque Térence a déjà pris soin de peindre en lui la naissance de l'amour pour une épouse qu'il n'appréciait initialement pas. Sur l'effacement des stéréotypes chez les personnages de Térence, Cupaiuolo, Terenzio. Teatro e società, p. 50.

${ }^{18}$ TER. Hec. 148-151. Le texte est étudié, d'un point de vue différent, infra p. 633.
} 
«Parmenon: 'Mais une femme dont j'ai décidé qu'il n'était pas possible de la garder

Plus longtemps, la garder pour m’amuser, Parménon,

Sans la rendre pure comme je l'ai reçue des siens,

Ce ne serait ni honnete pour moi, ni utile pour la jeune fille elle-même.'

Philotis: Tu me décris là un Pamphile qui a le souci du devoir et de la pudeur.»

(TER. Hec. 148-152).

Pamphile estime qu'il n'est pas honestum de conserver auprès de lui son épouse pour la seule satisfaction du plaisir sensuel ${ }^{19}$. Cette exigence de modération du désir sexuel et de préservation de la virginité féminine est parfaitement en accord avec les normes traditionnelles de l'honestum. Ce dernier ne se singularise donc pas par ses commandements: Pamphile apparaît comme un jeune homme pius ac pudicus, qualités qui appartiennent à la morale ancestrale romaine ${ }^{20}$. Ce n'est pas le contenu de l'honestum qui évolue mais les fondements de sa normativité. Si Pamphile se conforme à ce qui est honestum, ce n'est pas pour préserver sa bonne réputation. Le fait de garder celle qui est son épouse légitime auprès de lui ne susciterait pas de blâme de la part de son entourage: Philotis se montre au contraire surprise que Pamphile n'ait pas de relations intimes avec sa femme ${ }^{21}$. Pamphile oriente son comportement en recherchant ce qui est honnête pour lui (honestum mihi). Autrui n'est donc plus ici un critère incontournable de l'honestum et la règle suprême n'est plus de se conformer à ce qui est socialement prestigieux mais de tenir compte de ce qui est moralement acceptable. Le moi joue un rôle accru dans la normativité de l'honestum et le souci de la collectivité s'éloigne, de même que la prise en compte de la récompense sociale qui suit l'action honorable. C'est l'individu, et non pas un modèle ancestral, qui décide de la conduite à tenir; Pamphile déclare qu'il a pris sa décision seul (decrerim). Le personnage se fie à son jugement personnel plutôt qu'à la tradition ${ }^{22}$.

Cela ne signifie pas pour autant que la force contraignante du regard d'autrui ne joue plus aucun rôle. Elle n'est en effet pas systématiquement évacuée dans le théâtre de Térence. Dans le Phormion, le vieux Chrémès fait valoir qu'une action ne peut être accomplie honeste

${ }^{19}$ Sur le lien de l'honestum et de l'utile dans ce passage, voir infra p. 634.

${ }^{20}$ Voir L. Pereldi, Il teatro rivoluzionario di Terenzio, Florence, La Nuova Italia, 1973, p. 24, qui estime que Pamphile reste ici prisonnier de la conception traditionnelle de l'honneur.

${ }^{21}$ Ter. Hec. 138-140.

${ }^{22}$ Les personnages de Térence manifestent à plusieurs reprises cette autonomie par rapport aux normes collectives dans le domaine moral (PERELLI, Il teatro rivoluzionario di Terenzio, p. 10 et 110). Voir dans les Adelphes la volonté qu'a Micion d'éduquer son fils non par la contrainte extérieure mais par le développement de règles intérieures (TER. $A d$. 57-58). Déméa, qui procède à l'inverse par la pression d'une morale mimétique, est du coup victime du persiflage de l'esclave Syrus (Ad. 413-419). 
parce qu'elle susciterait, dit-il, un rumor populi très négatif: il y a donc ici, dans la considération de ce qui est honestum, prise en compte de la réaction de la collectivitééc. De même, dans l'Eunuque, Phédria, après avoir été ridiculisé, cherche à quitter la scène car c'est pour lui la seule façon de réagir honeste au tour qui lui a été joué: l'honneur l'amène à vouloir éviter le regard de son entourage, qui reste donc une instance extérieure efficace pour guider la conduite ${ }^{24}$. Il y a bien une dissociation entre l'honneur éthique et l'honneur social dans la comédie mais elle n'est pas tout à fait aboutie: l'honestum fonctionne tantôt comme un code d'honneur tantôt comme un ensemble de préceptes éthiques, et le second n'est pas encore totalement disjoint du premier. De la sorte, Térence perpétue sur la scène de son théâtre l'honneur traditionnel et ne lui fait pas subir de bouleversement radical; mais la notion d'honneur n'est pas pour autant figée puisqu'elle reçoit de nouvelles caractéristiques, introduites progressivement et discrètement. Térence tend ainsi à revitaliser la notion d'honneur par un apport inédit. Les mores de la coutume sont respectés mais aussi partiellement remodelés, ce qui place Térence à mi-chemin entre l'héritier et le novateur ${ }^{25}$. Une pièce comme les Adelphes porte elle aussi la marque de ce remodelage de la pensée traditionnelle; il a été souligné à juste titre que le personnage d'Hégion incarne le respect de la fides et des devoirs de l'amitié, qualités typiques du mos maiorum, mais qu'il se soucie également de vertus plus originales, harmonisant ainsi règles morales anciennes et exigences éthiques nouvelles ${ }^{26}$.

\subsection{L'enrichissement esthétique et ses implications éthiques}

Notre étude sémantique a mis en avant le développement chez Térence d'un sens nouveau d'honestus, celui de «beau » ${ }^{27}$. Cet aspect

23 TER. Phorm. 911-912.

24 Ter. Eun. 716.

${ }^{25}$ Braun, "Mos maiorum und humanitas bei Terenz» constate de même qu'il n'y a pas remise en cause radicale du mos maiorum mais volonté de le fonder en raison, de substituer la ratio à la consuetudo (p.215). Sur la revitalisation des valeurs traditionnelles par Térence, voir aussi Cupaiuolo, Terenzio. Teatro e società, p. 139 sqq. Térence ne récuse pas par exemple la patria potestas mais y agrège l'amour conjugal et filial; "Non si pensa infatti di sovvertire ordini e strutture tradizionali ma piuttosto solo di ristabilire equilibri antichi, dando motivazioni e valori umani a forme un po' logorate dal tempo » (p. 158).

${ }^{26}$ Sur ce personnage et sa portée, voir F. CALLIER, "À propos des Adelphes de Térence: le personnage d'Hégion et la morale aristocratique », Latomus, 41, 1982, p. 517-527. Sur la rénovation de la coutume dans les Adelphes, voir G. COMERcI, "Humanitas, liberalitas, aequitas : nuova paideia e mediazione sociale negli Adelphoe di Terenzio », BStudLat, 24 (1), 1994, p. 3-44 qui rapproche l'attitude de Térence de celle de Scipion Émilien, héritier et rénovateur du mos maiorum.

${ }^{27}$ Supra p. 143 sqq. Voir aussi A. Espigares Pinilla, «Claves para la historia de un cultismo: 'honesto'. 1, Antigüedad y Edad Media », p. 68-69. 
esthétique du mot se rencontre déjà chez Caton dans le De agricultura mais il n'y apparaît qu'une fois, alors que Térence l'emploie à cinq reprises sur les onze occurrences d'honestus que compte son œuvre. Il y a donc là une particularité propre au poète qu'il ne faut pas négliger, d'autant que cette innovation ne concerne pas seulement le sémantisme du mot mais aussi la représentation intellectuelle que se fait Térence de l'honestum dans son ensemble. Cet usage esthétique de la notion d'honestum confère une plasticité nouvelle à cette dernière qui relevait alors surtout du domaine du prestige social et de la bonne moralité. En la rendant apte à désigner la belle apparence physique, Térence accroît la portée de la notion et la rend propre à décliner l'excellence d'un objet ou d'une personne dans différents domaines. Parce que l'honestum touche désormais le champ social, moral et esthétique, il gagne en généralité et se rapproche d'une notion centrale comme le bonum, dont l'aspect est encore plus malléable et les applications plus larges. Le développement chez Térence de la dimension esthétique de l'honestum contribue en outre à rapprocher, au sein de cette notion, beauté physique et beauté morale. On remarque que Térence fait correspondre à plusieurs reprises chez un personnage la beauté honesta avec les bonnes mœurs. Dans l'Eunuque, la jeune Pamphila se caractérise par son beau visage (honesta facies); or c'est par ailleurs une Athénienne digne d'estime et de naissance libre ${ }^{28}$. À l'inverse, les courtisanes, quand elles ne sont pas fardées et apprêtées, sont d'une laideur repoussante:

Harum uidere inluuiem, sordes, inopiam, Quam inhonestae solae sint domi atque auidae cibi, Quo pacto ex iure hesterno panem atrum uorent, Nosse omnia haec salus est adulescentulis.

«De voir leur saleté, leur crasse, leur misère, comme elles sont disgracieuses quand elles sont seules à la maison, et gloutonnes, comment elles dévorent leur pain noir trempé dans la sauce de la veille... Connaître tout cela, c'est le salut pour les jeunes gens.»

(TER. Eun. 937-940; trad. Marouzeau).

Parménon se félicite d'avoir introduit Chéréa chez les courtisanes car Chéréa a ainsi pu voir comment elles sont en réalité: elles sont inhonestae, c'est-à-dire d'une laideur repoussante. Or cette laideur coïncide avec la misère sociale et les mauvaises mœurs propres aux meretrices. Le physique hideux est synonyme d'immoralité, tout comme la beauté accompagne les bonnes mours, union que la notion d'honestum parvient à restituer par la proximité de ses différents sens. L'adéquation entre la grâce physique et l'excellence morale apparaît

${ }^{28}$ TER. Eun. 123. 
parfois plutôt comme une injonction ou un idéal. Bacchis déclare ainsi à Antiphila dans l'Heautontimoroumenos:

Edepol te, mea Antiphila, laudo et fortunatam iudico

Id cum studuisti isti formae ut mores consimiles forent.

«Par Pollux, ma chère Antiphila, je te félicite et t'estime heureuse

De t'être efforcée de rendre tes mœurs semblables à ta beauté.»

(TER. Heaut. 381-382).

La beauté physique et l'excellence morale sont ici une paire indissociable et il faut s'efforcer de maintenir l'une au même niveau que l'autre. L'association, à la faveur de la notion d'honestum, de la beauté du corps et de celle de l'âme n'est pas sans rappeler l'idéal grec du $\kappa \alpha \lambda o ́ \varsigma \kappa a ̉ y \alpha \theta o ́ \varsigma$, qui fait correspondre qualité physique et qualité morale en envisageant de manière indissociable l'éducation du corps et celle de l'âme ${ }^{29}$. Térence a pu subir l'influence de cette notion à travers ses modèles grecs, Ménandre et Apollodore de Caryste; on sait en outre

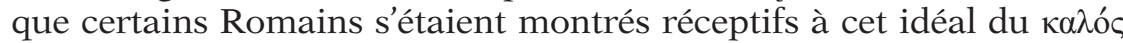

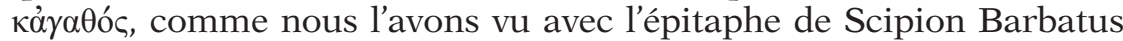
qui fait l'éloge de la uirtus et de la forma du défunt ${ }^{30}$. On ne peut aller jusqu'à dire qu'honestus, avec ses deux polarités éthique et esthétique, serve à restituer ce concept grec précis mais il est possible qu'une rémanence de cet idéal hellénique soit présente de manière plus diffuse chez Térence ${ }^{31}$. L'association d'un aspect éthique et d'un aspect esthétique porte également la marque de Panétius, que Térence

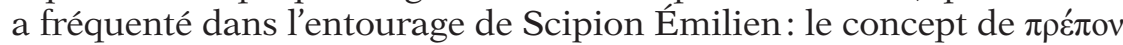
que le philosophe a élaboré, et qui nous est connu par le decorum au moyen duquel Cicéron le transpose en latin dans le De officiis, possède de façon caractéristique cette double facette ${ }^{32}$.

\subsection{L'avancée conceptuelle}

Dans son œuvre philosophique et rhétorique, Cicéron a donné une place prééminente au concept d'honestum, après en avoir réalisé un approfondissement intellectuel sans précédent. Il l'a notamment

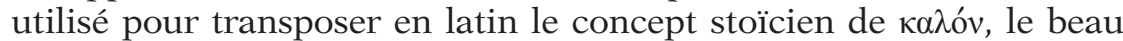
moral $^{33}$. Cependant, l'Arpinate n'est pas le premier à avancer concep-

${ }^{29}$ Sur la présence de cette notion grecque à Rome, SETAIOLI, «La notion éthique de kalós / kalón en latin».

${ }^{30}$ Supra p. 603.

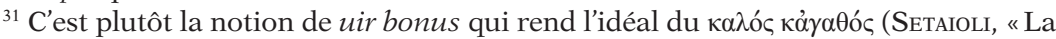
notion éthique de kalós / kalón en latin », p. 179).

${ }^{32}$ Sur le decorum, voir Cic. Off. I, 93-99.

${ }^{33}$ Voir, parmi de nombreux passages, les définitions de l'honestum stoïcien dans Cic. Fin. II, 49; III, 14; V, 20. 
tuellement dans le traitement de l'honestum et à tenter une acculturation de $\kappa \alpha \lambda$ óv. On rencontre en effet chez Lucilius un effort comparable et, avant lui encore, chez Térence. Le dramaturge, s'il ne se livre certes pas à une puissante élaboration théorique de l'honestum, fait cependant un usage de la notion qui la rend disponible pour une telle avancée conceptuelle. On rencontre chez lui les premières traces d'un travail conceptuel allant de pair avec un contact avec la philosophie

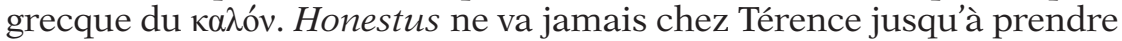
le sens de «beau moral» et à renvoyer à l'excellence éthique et au souverain bien, mais il commence à évoluer depuis la notion, élément peu systématisé et non rationnellement fondé, vers le concept, à la richesse théorique plus grande. On remarque en premier lieu qu'on ne rencontre plus chez Térence, comme c'était le cas chez Plaute, d'usages d'honestus au comparatif ${ }^{34}$. L'honestum n'est plus une réalité qui connaît des variations de degré; il se caractérise exclusivement par son existence ou son absence et gagne de la sorte une consistance ontologique, même si la substantivation de l'adjectif n'a pas encore eu lieu. En outre, on rencontre dans les comédies des usages d'honestus

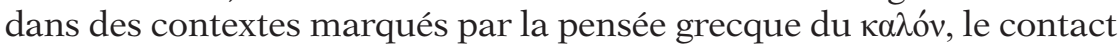
entre les deux notions étant facilité par le développement d'un sens esthétique de l'adjectif latin. Nous pouvons en donner deux exemples. Le premier est un texte de l'Hécyre déjà cité mais qui mérite un nouvel examen:

$P_{A .:}:$ Sed quam decrerim me non posse diutius

Habere, eam ludibrio haberi, Parmeno,

Quin integram itidem reddam ut accepi a suis,

Neque honestum mihi neque utile ipsi uirgini est. »

«PARmenon: 'Mais une femme dont j'ai décidé qu'il n'était pas possible de la garder

Plus longtemps, la garder pour m’amuser, Parménon,

Sans la rendre pure comme je l'ai reçue des siens,

Ce ne serait ni honnête pour moi, ni utile pour la jeune fille elle-même.'

(TER. Hec. 148-151).

Le terme d'honestus a ici son sens d' "honnête» car Pamphile veut faire preuve de bonne moralité plus que préserver son prestige social. Mais le plus intéressant est le contexte dans lequel intervient cette considération. Comme nous l'avons vu, il est question de ce qui est honestum dans le cours d'un débat intérieur, au moment où il faut faire un choix ${ }^{35}$ : il y a une considération éthique sur le comportement honestus, considération qui trouve sa place dans la conscience du sujet.

${ }^{34}$ Voir Pl. As. 820; Cap. 392 ; Poen. 1232.

35 "Das decrerim setzt einen inneren Kampf und Entschluß voraus. " (K. BücHNER, Das Theater des Terenz, Heidelberg, C.Winter, 1974, p. 123). 
Surtout, honestum est associé à utile, et l'on retrouve ainsi un couple notionnel bien connu de la philosophie grecque, celui de $\kappa \alpha \lambda$ óv et

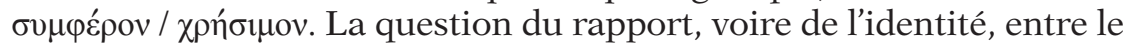
beau et l'utile a déjà été posée par Platon ${ }^{36}$; les stoïciens ont également rapproché les deux concepts: Zénon en identifiant bon, beau et utile ${ }^{37}$, Panétius en esquissant la question du conflit du beau et de l'utile ${ }^{38}$. La philosophie péripatéticienne, qui a marqué les modèles qu'imite Térence, permet aussi d'éclairer ce passage ${ }^{39}$. On trouve chez Aristote deux idées que l'on peut rapprocher des vers de Térence: d'abord, le beau est ce qui fait l'objet d'un choix préférable, c'est ce qui, dans une chose, fait qu'elle est choisie ${ }^{40}$; or on retrouve chez Térence honestum dans un contexte réflexif où le personnage statue sur un choix à faire. Ensuite, il y a pour Aristote trois facteurs qui entraînent notre choix:

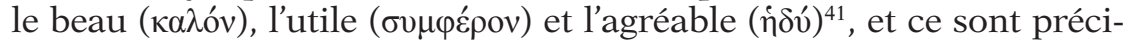
sément les trois éléments que l'on retrouve ici avec honestum, utile

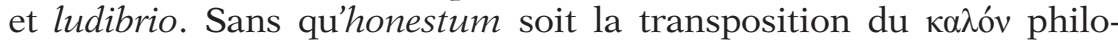
sophique grec, il est possible que le mot latin rende un terme grec proche, employé par le modèle de Térence. On voit une autre trace de

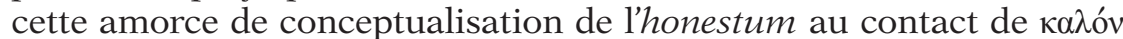
dans un passage du Phormion. Le fils du vieux Démiphon a, par un stratagème, épousé la jeune femme qu'il aime. Son père, quand il l'apprend, veut rompre cette union en donnant la jeune femme en mariage à Phormion. Mais il revient sur sa décision et fait valoir à Phormion un argument de son frère Chrémès: on ne peut forcer la jeune femme à quitter son mari pour en prendre un autre.

\begin{abstract}
DE. : At hic dehortatus est me ne illam tibi darem: "Nam qui erit rumor populi, inquit, si id feceris? Olim cum honeste potuit, tum non est data;

Nunc uiduam extrudi turpest. »

«Demiphon: Mais celui-ci m’a dissuadé de te la donner: 'Car quelle sera la rumeur publique, dit-il, si tu fais cela?

Autrefois, quand on pouvait le faire honorablement, on ne la lui a pas donnée; Ce serait honteux de la pousser dehors à présent sans mari.»
\end{abstract}

(TER. Phorm. 910-913).

\footnotetext{
${ }^{36}$ Plat. Hipp. mai 295e-296e, où est envisagée, avant d'être rejetée par Socrate, la

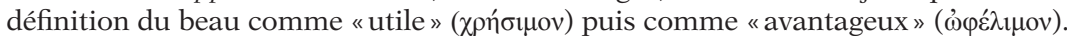

${ }^{37}$ Stoв., Ecl. II p.28. Voir P.M.Valente, L'Éthique stoïcienne chez Cicéron, Paris, Saint-Paul, 1956, p. 135-139.

${ }^{38}$ Cic. Off. III, 7.

${ }^{39}$ La source de Térence pour l'Hécyre ainsi que pour le Phormion est Apollodore de Caryste, auteur très influencé par Ménandre qui était lui-même l'élève de Théophraste. Sur l'aristotélisme chez Térence, P. GRImAL, "Térence et Aristote à propos de l'Héautontimoroumenos », BAGB, 1979, p. 175-187.

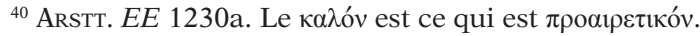

${ }^{41}$ ARSTT. EN 1104 a et 1126 b.
} 
Elle aurait pu épouser Phormion honeste quand elle était encore célibataire; agir honeste, c'est se comporter de telle manière que le rumor populi reste favorable, que l'on conserve l'estime des gens. Mais cette idée, assez traditionnelle, intervient, ici encore, lors d'une délibération sur la conduite à tenir. Honeste est à nouveau mis en système, avec turpe, auquel il est opposé, comme cela est fréquent en latin. Mais ce couple de notions antagonistes en rappelle fortement un autre,

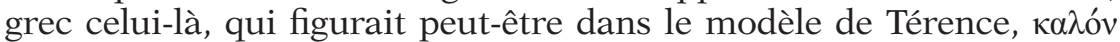
et $\alpha i \sigma \chi \rho{ }^{4} v^{42}$. On les rencontre plusieurs fois chez Platon ${ }^{43}$ et encore chez Aristote ${ }^{44}$. La notion grecque de $\kappa \alpha \lambda$ óv trouve donc à nouveau un moyen de s'immiscer, de manière discrète, auprès d'honestum. Cela n'a rien de massif, et l'on en reste aux premiers pas de l'acculturation. Les traits sémantiques d'honestum sont bien romains; seuls son usage réflexif et sa mise en relation avec d'autres notions sont peut-être dus à un contact avec le $\kappa \alpha \lambda$ óv grec, par le biais des modèles dont s'inspire la palliata.

\section{CONCLUSION}

L'usage de la notion d'honneur dans l'œuvre de Térence reste discret: elle n'apparaît que de manière restreinte dans les comédies et ne fait pas l'objet d'importantes manipulations à des fins comiques. On ne rencontre pas, comme chez Plaute, d'inversions radicales du fonctionnement de l'honos ni de discours paradoxaux sur ce qui est honestum. Cela ne signifie pas pour autant que l'honneur et ses règles ne connaissent aucune évolution chez Térence. Les inflexions de la notion sont peu visibles et contribuent faiblement au spectacle de la palliata mais existent bel et bien. Térence est le premier auteur à accentuer la portée éthique d'honestum: il en réduit les fondements sociaux et en développe la dimension esthétique en la reliant à l'éthique. Ce faisant, il engage une évolution d'honestum depuis l'honneur vers l'honnêteté. La discrétion avec laquelle Térence mobilise la notion est donc inversement proportionnelle à l'importance de la mutation qu'il lui fait subir puisqu'il enrichit sa dimension morale et la place sur la voie d'une évolution théorique menée par les auteurs postérieurs.

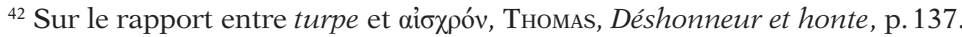

${ }^{43}$ Par exemple Phaed. 70e; Gorg. 459d.

${ }^{44}$ EN 1179b; Metaph. 985a.
} 



\section{LUCILIUS: L’HONNEUR À LA CROISÉE DES CHEMINS}

\section{INTRODUCTION}

La représentation intellectuelle des notions d'honos et d'honestum et leur évaluation axiologique prennent un tour nouveau dans le dernier tiers du $\mathrm{II}^{\mathrm{e}}$ siècle avec Lucilius. Si ce dernier prolonge certaines des postures morales de ses prédécesseurs sur l'honneur, comme la recherche de normativité d'un Caton, il a cependant la particularité de donner à la pensée romaine de l'honneur un tour inédit qui peut être caractérisé par trois aspects innovants, qui sont autant de fils directeurs pour la lecture des Satires. Lucilius est d'abord le premier auteur latin à élaborer sur l'honneur une pensée réflexive développée: son œuvre prend de la hauteur théorique vis-à-vis de l'honos et de l'honestum et, sans atteindre un caractère systématique hors de propos pour un poète, gagne en densité conceptuelle. En second lieu, l'intérêt de Lucilius pour la philosophie grecque, visible dans ses textes ${ }^{1}$ et nourri par son voyage en Grèce ${ }^{2}$, tout comme les liens qu'il a pu nouer dans l'entourage hellénisé de Scipion Émilien avec Panétius, Polybe et les autres familiers du second Africain ${ }^{3}$, donnent à son approche de l'honneur une dimension nouvelle. Il faudra mesurer l'influence de la pensée grecque et notamment du stoïcisme, dont Lucilius semble s'être senti plus particulièrement proche $^{4}$, sur le regard qu'il porte

${ }^{1}$ Les satires évoquent les noms de Carnéade, Socrate, Aristippe et Euclide, ce qui témoigne d'une certaine culture philosophique. On y rencontre des moqueries contre les syllogismes et les paradoxes, mais aussi des réflexions sérieuses sur la modération des plaisirs ou sur la vertu, par exemple. Voir le passage consacré à Lucilius par GarBARINo, Roma e la filosofia greca, vol. 2, p. 484-537.

${ }^{2}$ Lors de son voyage en Grèce, Lucilius a rencontré Clitomaque, qui fut scholarque de l'Académie de 126 à 110 environ. Certains fragments des satires parlent de l'Académie ou de sa philosophie. Voir I. Mariotti, Studi luciliani, Florence, La Nuova Italia, 1961, p. 40. Clitomaque aurait dédié à Lucilius un livre sur la connaissance (GARBARINO, Roma e la filosofia greca, vol.2, p. 486 sqq.).

${ }^{3}$ Sur le «cercle de Scipion», voir supra p. 621 n. 2.

${ }^{4}$ Lucilius n'est pas lié à une école de manière exclusive, mais semble avoir une inclination pour le stoïcisme modéré d'un Panétius. Voir l'analyse nuancée faite par G. Garbarino et sa conclusion à « uno stoicismo moderato che, liberatosi dal rigore scolastico dello stoicismo antico, poté esercitare in Roma un fascino così grande proprio perché, nel campo dell'etica, veniva ad avvicinarsi alla visione romana tradizionale» (GARBARINO, 
sur l'honos et l'honestum. Enfin, Lucilius s'est illustré dans le genre de la satire, dont le poète est reconnu comme le fondateur même s'il n'en est pas le primus inuentor ${ }^{5}$. Il nous appartiendra de mesurer l'incidence de cette forme littéraire sur les notions d'honos et d'honestum. En outre, il ne faudra pas perdre de vue que l'époque à laquelle Lucilius écrit représente une charnière dans l'histoire romaine. Les satires sont en effet toutes parues entre 133 et 105, c'est-à-dire au temps des Gracques et des premiers affrontements civils ${ }^{6}$. Il conviendra de prendre en compte les incidences éventuelles de ce contexte historique troublé. Pour mesurer l'originalité de la pensée de l'honneur chez Lucilius, nous étudierons d'abord la manière dont la notion d'honos est traitée dans la satire: le poète s'y livre à une évaluation différenciée de l'honneur, allant de la valorisation de l'honos funéraire à la définition subversive d'un honos poétique et érotique inédit. Nous verrons ensuite que la satire est le cadre d'une exhortation à la uita honesta, alliant l'invective à la prédication morale. Nous nous intéresserons enfin à la manière dont est élaboré le concept éthique d'honestum, entre tradition romaine et pensée grecque.

\section{LE TRAITEMENT DE L'HONOS DANS LA SATIRE: ÉVALUATION ET DÉTOURNEMENT}

La satire privilégiant dans ses objets les mœurs de son temps, Lucilius ne pouvait manquer de juger la pratique de l'honos. Il statue de fait à plusieurs reprises sur sa valeur, par la critique ou la définition positive. On voit se dessiner, à travers ces évaluations, une attitude originale et parfois iconoclaste.

\subsection{La valorisation de l'honos funéraire}

Lucilius n'évalue pas toutes les formes de l'honos de la même façon. L'honos adressé aux morts fait ainsi l'objet d'une révérence particulière. Il s'agit pour Lucilius d'un honos sacré qui relève des devoirs fondamentaux de l'homme romain et ne souffre aucun manquement. Un fragment déplore ainsi l'absence d'une sépulture pour un défunt:

Nullo honore, heredis fletu $\langle$ nullo $>$, nullo funere

«Pas d'honneurs, pas d'héritier pour le pleurer, pas de funérailles»

(LucIL. frg. XXVII, 10 Charpin = 691 Marx).

Roma e la filosofia greca, vol.2, p. 530).

${ }^{5}$ Ennius semble avoir été à l'origine de ce genre littéraire, bien que ses œuvres n'aient sans doute pas porté le nom de saturae. Voir sur les satires d'Ennius J. WaszinK, "Problems Concerning the Satura of Ennius », in Skutsch, O. (éd.), Ennius. Sept exposés suivis de discussions, Genève, Fondation Hardt, 1972, p. 97-147.

${ }^{6}$ Sur la chronologie des satires, voir C. Cichorius, Untersuchungen zu Lucilius, Berlin, Weidmann, 1908, p. 63 sqq. et J.Christes, «Lucilius», in Adamietz, J. (éd.), Die römische Satire, Darmstadt, Wissenschaftliche Buchgesellschaft, 1986, p. 57-122. 
On s'accorde en général à reconnaître ici l'écho d'un événement récent, la mort violente de Tiberius Gracchus ${ }^{7}$. Tué au cours de l'émeute provoquée par ses adversaires et menée par le grand pontife Scipion Nasica, il fut précipité dans le Tibre et ne reçut donc pas l'honos d'une sépulture ${ }^{8}$. Lucilius dénonce le mépris de l'honos funéraire et rappelle son caractère nécessaire, même pour un personnage controversé comme Tiberius Gracchus9. L'honos pour un défunt apparaît comme un dû dont l'absence est indigne. Lucilius se démarque ici de la position de Scipion Émilien, encore vivant à la publication de cette satire ${ }^{10}$ et qui, s'il ne peut être considéré comme le patron de Lucilius, entretient tout de même avec lui une relation privilégiée. Interrogé sur la mort de l'aîné des Gracques, Scipion aurait répondu que Tiberius "semblait avoir été tué à bon droit » (iure caesum uideri) ${ }^{11}$. Sa mort ne provoque pas la même réaction chez le satiriste qui s'en indigne et marque par là son indépendance d'esprit ${ }^{12}$. Cette défense de l'honos dû à Tiberius revient à attaquer le sénat et ses membres les plus conservateurs, partisans de la répression. Lucilius, qui appartient à l'ordre équestre, a pu ressentir une certaine sympathie pour Tiberius, auteur de mesures favorables aux chevaliers. Un autre fragment du livre XXVII gagne à être rapproché de notre passage ${ }^{13}$ :

$$
\begin{gathered}
\text { proferat } \\
\text { ergo iam <nunc> uester ordo scelera quae in se admiserit. } \\
\text { "que votre ordre révèle donc maintenant les crimes qu'il a commis. » }
\end{gathered}
$$

(LucIL. frg. XXVII, 9 Charpin $=690$ Marx).

${ }^{7}$ C'est l'identification faite par Cichorius, Untersuchungen zu Lucilius, p. 145-146; W. J.RaschKe, "Arma Pro Amico. Lucilian Satire at the Crisis of the Roman Republic», Hermes, 115, 1987, p.299-318 à la p.313; B. Zucchelli, L'indipendenza di Lucilio, Florence, La Nuova Italia, 1977, p. 120; N. Terzaghi, Lucilio, Turin, L'Erma, 1934, p. 155. En revanche, G. Coppola, Gaio Lucilio, cavaliere e poeta, Bologne, N.Zanichelli, 1941, p. 46, pense qu'il est question de Scipion Émilien, mais la mention de l'absence d'honos nous paraît inapplicable à ce dernier. Nous adoptons ici les corrections proposées par Bücheler et Terzaghi, qui lisent heredis fletu <nullo $>$ au lieu du displetu des manuscrits.

${ }^{8}$ Plut. Tib. Gracchus, 20.

${ }^{9}$ L'attitude de Cicéron, exprimant quelques décennies plus tard son dégoût de voir Clodius sans sépulture, n'est pas sans rappeler celle de Lucilius (CIC. Mil. 33).

${ }^{10}$ Le fragment appartient au livre XXVII, un des premiers livres de satires de Lucilius. Sur la datation, voir ZucchelLI, L'indipendenza di Lucilio, p. 120.

${ }^{11}$ Cic. Mil. 8; De or. II, 106. D'autres sources font état, pour toute réponse, d'un vers d'Homère prononcé par Scipion (Plut. Tib. Gracchus 21 évoque Il. I, 47).

${ }^{12}$ Il n'y a jamais eu de concordance de vue totale entre Scipion et Lucilius. L'ouverture d'esprit de Scipion à l'hellénisme ne se retrouve pas, par exemple, chez Lucilius dont le jugement est beaucoup plus nuancé. Sur ces divergences, voir G. CLEMENTE, «Lucilio e la società romana », Index, 13, 1985, p. 47-62.

${ }^{13}$ Le rapprochement est suggéré par TerZaghi, Lucilio, p. 154-155. 
Lucilius s'en prend probablement aux sénateurs (uester ordo) en leur demandant d'avouer leurs crimes (scelera), parmi lesquels figure le déchaînement de violence contre Tiberius et ses partisans. La protestation de Lucilius contre l'oubli de l'honos le conduit à appeler au respect de règles de conduite qui doivent dépasser les appartenances politiques. Un examen attentif des cibles visées dans les satires montre que Lucilius s'en prend à tout type de personne, sans logique partisane précise, et qu'il n'est pas possible d'en faire un poète inféodé à une faction qui attaquerait les ennemis de cette dernière. On relève en effet des attaques contre des puissants aussi bien que des personnages modestes, contre des optimates ou des populares, contre des ennemis de Scipion ou ses relations ${ }^{14}$.

\subsection{La mise en question de la valeur du prestige}

Lucilius est le premier auteur latin à envisager l'honos sous un jour critique et, plus généralement, un des premiers à réfléchir sur le prix de la gloire et de la notoriété à Rome ${ }^{15}$.

\subsubsection{L'interrogation sur les fondements de l'honos militaire}

Lucilius observe l'honos sous un jour critique mais la mise en question du prix de l'honos ne prend pas la forme d'une vitupération violente; elle se fait sur le mode d'une interrogation de forme complexe, qui apparaît dans un passage du livre XIII:

Aut forte omnino ac fortuna uincere bello;

Si forte ac temere omnino, quid cursum ad honorem?

«Ou bien c'est totalement par le hasard et la fortune qu'on vainc à la guerre; Si c'est totalement par le hasard et par la chance, pourquoi avoir couru après l'honneur?»

(LucIL. frg. XIII, 8 Charpin $=450-451$ Marx).

Ce fragment présente une difficulté dans l'établissement du texte qu'il faut éclaircir pour donner au passage son sens précis. Le premier vers présente la branche d'une alternative, introduite par aut : on vainc à la guerre par le hasard. L'autre branche devait concerner la possibilité de vaincre par un moyen opposé, c'est-à-dire par l'effort et la

${ }^{14}$ Voir l'étude de Gruen, Culture and National Identity, p. 282 sqq. Voir aussi Zucchelli, L'indipendenza di Lucilio, p.107 sqq.; Clemente, "Lucilio e la società romana», p.57. Les cibles connues de Lucilius se trouvent être fréquemment des ennemis de Scipion Émilien, mais cela ne doit pas nous amener à conclure que Lucilius les attaque pour lui complaire.

${ }^{15}$ Voir à ce sujet M. ЈАсотот, "L'honneur et la gloire dans les Satires de Lucilius », in Bona, E.et Curnis, M.(éd.), Linguaggi del potere, poteri del linguaggio, Alessandria, Edizioni dell'Orso, 2010, p. 219-232. 
uirtus ${ }^{16}$. Le second vers envisage les conséquences d'une telle victoire si la première branche est retenue. Les manuscrits donnent la leçon quid cursum ad honorem? corrigée par Marx en quid? quorsum? ad honorem? "si on vainc à la guerre par le hasard, à quoi bon <s'y donner de la peine>? pour l'honneur?». Mais cette lecture a l'inconvénient d'impliquer beaucoup de sous-entendus et de faire intervenir la notion d'honos de manière périphérique, sans que le sens global du passage y trouve son homogénéité. F. Charpin lit quid rursum ad honorem? "qu'en est-il dans ce cas de l'honneur? ». Rursum convient bien pour exprimer le passage à la seconde branche de l'alternative mais une position après le si serait syntaxiquement plus adaptée qu'après le quid, malgré les contraintes de la métrique. Cette lecture peut se justifier mais il nous paraît aussi possible de conserver la leçon des manuscrits et de comprendre quid cursum <est $>$ ad honorem avec un passif impersonnel de curro, attesté par ailleurs, dans un texte un peu plus récent, précisément avec $a d+$ accusatif $^{17}$. Lucilius, envisageant que l'on puisse vaincre grâce à la fortuna et non grâce à la uirtus se demande alors: «à quoi bon a-t-on couru après l'honneur? " puisque l'effort personnel n'a pas d'impact sur le succès et le prestige que l'on obtient.

Que l'on adopte le texte de F. Charpin ou celui des manuscrits, la question posée par Lucilius dans ce passage suscite une mise en question du prix de l'honos: le satiriste se demande quelle est la valeur de l'honos (ou de sa recherche) si la victoire repose sur le hasard. Même si l'hypothèse d'une victoire par hasard n'est pas retenue in fine, Lucilius envisage la possibilité qu'il y ait une part de hasard à la guerre et que l'honos ne vienne pas récompenser un mérite. L'idée est nouvelle à Rome, et subversive. Elle a cependant un précédent dans la pensée stoïcienne de Panétius, familier de Lucilius ${ }^{18}$. Au premier livre du De officiis, Cicéron formule en termes latins la théorie, panétienne, de la personnalité morale ${ }^{19}$. L'être humain a quatre personae, quatre rôles à jouer, et le troisième d'entre eux est celui que le hasard et les circonstances lui imposent. Relèvent de ce hasard les éléments de la personne comme les commandements, la noblesse, la richesse, ainsi que, écrit Cicéron, les honores ${ }^{20}$. Il est possible que Lucilius se soit souvenu, dans son interrogation sur les fondements du prestige militaire, de la réflexion panétienne sur ces objets accidentels de l'identité personnelle pour souligner l'aspect incertain de l'honos et mettre en question la constance avec laquelle il est prisé à Rome. La critique n'est cependant pas directe: elle opère, sur un mode mineur, au travers d'une hypothèse, et il n'est pas certain que le poète l'ait retenue.

${ }^{16} \mathrm{~F}$. Charpin signale, dans une note à ce passage, un semblable contraste entre uirtus et fors chez SALL. Iug. I,1.

${ }^{17}$ CIc. Verr. II, V, 92, curritur ad praetorium, « on court au prétoire».

${ }^{18}$ Voir infra notre étude du fragment sur la vertu.

${ }^{19}$ Cic. Off. I, 105 sqq.

${ }^{20}$ Cic. Off. I, 115 : regna, imperia, nobilitatem, honores, diuitias, opes. 


\title{
1.2.2. L'évaluation du prix véritable de l'honos
}

Une autre approche, plus prescriptive qu'interrogative, préside au célèbre fragment sur la vertu. Il ne s'agit pas cependant, ici non plus, de critiquer de front une valeur du mos maiorum mais de se livrer à son évaluation. Pour ce faire, Lucilius recourt à un outillage conceptuel nouveau, comme on le voit dans les huit premiers vers du passage, sur lesquels nous nous concentrerons pour l'instant:

\author{
Virtus, Albine, est pretium persoluere uerum \\ Quis in uersamur, quis uiuimus rebus potesse; \\ Virtus est homini scire id quod quaeque habeat res; \\ Virtus, scire homini rectum, utile quid sit, honestum, \\ Quae bona, quae mala item, quid inutile, turpe, inhonestum; \\ Virtus quaerendae finem rei scire modumque; \\ Virtus diuitiis pretium persoluere posse; \\ Virtus id dare quod re ipsa debetur honori;
}

«La vertu, Albinus, c'est pouvoir attribuer leur vraie valeur

Aux choses auxquelles nous avons part, au milieu desquelles nous vivons;

La vertu c'est savoir ce que vaut pour l'homme chaque chose;

La vertu c'est savoir ce qui pour l'homme est droit, utile, honnête,

Quels sont les biens et de même quels sont les maux, ce qui est inutile, honteux, malhonnête;

La vertu c'est savoir limiter et modérer la recherche des possessions;

La vertu c'est pouvoir attribuer leur vraie valeur aux richesses;

La vertu c'est accorder l'intérêt qui lui est réellement dû à l'honneur;

(LucIL. frg. hex. inc. 23 Charpin = frg 1326-1333 Marx).

Nous aurons à revenir sur la notion d'honestum développée dans ce fragment. Qu'il nous suffise pour le moment de déterminer le sens de la présence de l'honos dans le huitième vers. Lucilius développe dans ce texte l'idée selon laquelle la vertu consiste à savoir attribuer à l'honos et à d'autres objets matériels leur juste valeur. Une telle définition recèle deux aspects importants. Le premier réside dans la conception de la uirtus. Le terme ne désigne plus ici la notion traditionnelle romaine de "valeur" ou de "vaillance" guerrière. Elle reçoit une forte charge morale qui la rapproche de la "vertu» au sens éthique. Et cette vertu a la singularité d'être définie comme un savoir: uirtus est [...] scire (v. 3 et 4). La vertu est donc connaissance. Une telle approche porte la marque de la pensée stoïcienne de l'ảpetń qui définit chacune des vertus cardinales comme la science d'un objet particulier, la modération étant, par exemple, la science de ce qui doit être choisi ou évité21. L'enrichissement de la uirtus par la notion stoïcienne d'ỏpetń n'est cependant qu'un aspect de la définition de Lucilius. La

${ }^{21}$ SVF III, 262 et 264. Sur l'influence de l'ảpetń sur la uirtus, BüchNER, « Altrömische und horazische virtus ». 
seconde caractéristique réside dans l'approche de la uirtus comme science de la valeur des choses, comme capacité de donner son prix aux objets. Cette idée est développée par une métaphore filée de nature financière: il appartient à l'homme de savoir persoluere pretium, s'acquitter du prix de ces objets, et de leur accorder ce qui leur est dû (debeatur). Il y a une transposition morale des images de la dette et du paiement par lesquelles Lucilius invite Albinus à donner à l'honos sa vraie valeur, à ne pas lui accorder plus qu'il ne lui est dû et donc à faire preuve à son égard de mesure, le modus évoqué quelques vers avant l'honos. Lucilius range ainsi l'honos au rang des objets matériels, les res, au même titre que les diuitiae, et remet de la sorte en question le trop grand prix accordé par la tradition au prestige, qu'il soit militaire, social ou politique. La uirtus, qui a évolué en un sens éthique, se trouve ainsi entretenir une relation inédite avec l'honos: elle n'est plus son fondement, son origine, mais un savoir qui prend le pas sur l'honos et exerce sur ce dernier un regard évaluatif. Lucilius défait le lien traditionnel entre honos et uirtus et établit entre les deux notions une hiérarchie nouvelle.

La pensée de Lucilius sur l'honos prend donc un tour critique et réflexif en s'appuyant sur les idées de valeur et de prix. Ces dernières appartiennent au monde des représentations mentales romaines comme on le voit, par exemple, avec la façon dont les Romains se représentent la notion d'estime. Le terme d'existimatio n'est guère utilisé avant le $\mathrm{I}^{\mathrm{er}}$ siècle avant notre ère; en revanche, avant cette date, mais aussi ensuite pendant toute la latinité classique, les textes présentent des tournures du type magni facere, avec un génitif de prix, pour dire «faire grand cas de quelqu'un», "l'estimer à grand prix » ${ }^{22}$. On rencontre aussi, pour dire de quelqu'un que ce n'est pas un homme de bien, la formule parui preti, "de peu de prix», "vaurien » ${ }^{23}$. La métaphore financière de Lucilius n'est donc pas, dans sa forme, en rupture avec les modes de pensée romains. Cependant, l'usage fait par le satiriste de la «valeur» est enrichi en profondeur, comme pour la notion de uirtus, par la philosophie stoïcienne. Le pretium du fragment est en effet doté des significations de l' $\alpha \dot{\xi} \mathfrak{i}^{24}$, la «valeur» en termes moraux, concept surtout développé par Antipater et Diogène de Babylone ${ }^{25}$, les deux maîtres de Panétius, dont l'influence sur Lucilius est ici encore

${ }^{22}$ Pl. As. 407 ; Pseud. 944; Ter. Hec. 260.

${ }^{23}$ PL. Aul. 790; Trin. 257. Qualifier quelqu'un de nihili est aussi une façon de le traiter de vaurien (PL. Bac. 1207; Cic. Deiot. 21).

${ }^{24}$ Cela a été noté par M. Pohlenz, Die Stoa. Geschichte einer geistigen Bewegung, $4{ }^{\mathrm{e}}$ éd., Göttingen, Vandenhoeck \& Ruprecht, 1970.

${ }^{25}$ Diogène est le premier à utiliser le concept de "valeur » en son sens moral et à lui donner un autre sens que celui, concret, de «valeur» économique (GörLER, "Zum Virtus-Fragment des Lucilius »). Sur la notion stoïcienne, voir SVF III, 124 et III, 126, ainsi que M. Pohlenz, Die Stoa, p. 119-121. 
probable. La pensée stoïcienne vient donc enrichir chez Lucilius les notions romaines traditionnelles. Il revient à Antipater d'avoir fait le premier de la vertu un art d'estimer la valeur des choses, art devenu ensuite une des parties de l'éthique du Portique. Tout objet possède une valeur précise, positionnable sur une échelle, et qui donne à la chose concernée son plus ou moins grand prix ${ }^{26}$. Les biens (ả $\gamma \alpha \theta \alpha$ ), c'est-à-dire, selon l'éthique stoïcienne, ce qui relève de la seule beauté morale, ont la plus grande $\dot{\alpha}^{\xi} \xi \alpha^{27}$. Viennent ensuite, pour les stoïciens orthodoxes qui ne considèrent pas que tout est absolument indifférent en dehors du vice et de la vertu ${ }^{28}$, des objets qui, sans être à strictement parler des biens puisqu'ils ne contribuent pas au bonheur ou au

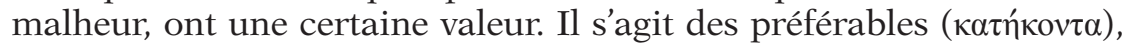
qui ont un rapport à la conservation de soi ou à la réalisation de sa nature, à l'oíksí $\sigma$ бı personnelle, et ne sont donc pas totalement indifférents. Ils tirent leur «valeur » du fait qu'ils sont conformes à la nature ou sont liés aux mouvements d'impulsion et de répulsion ${ }^{29}$. Antipater a creusé l'à '́ía des préférables en considérant que leur valeur est une «valeur de choix» qui fait que, quand les circonstances le permettent, nous choisissons telle chose plutôt que telle autre parce qu'il existe une justification rationnelle de ce choix, une raison préférentielle ${ }^{30}$ : il est raisonnable, dans certaines conditions, de préférer la santé à la maladie car elle est en accord avec l'impulsion d'auto-conservation. Cet aspect de l'éthique stoïcienne éclaire la définition de la vertu, donnée par Lucilius, comme évaluation correcte des réalités, octroi du pretium juste. Il est crucial de pouvoir statuer sur le pretium des objets afin de les catégoriser convenablement, et de ne pas mélanger, par exemple, les biens et les préférables. Le jugement que porte Lucilius sur l'honos est partiellement informé par la conception stoïcienne de l'à'ía: en indiquant que la vertu doit accorder ce qui est dû re ipsa à l'honos, il suggère que ce dernier ne relève pas des «biens", des bona dont il a été question quelques vers plus haut. L'honos n'a pas en effet part à la beauté morale. Il ne s'agit pas non plus d'un vice mais d'un indifférent. Lucilius indique bien, cependant, que quelque chose est dû à l'honos, et qu'il ne s'agit pas d'un indifférent absolu: l'honos paraît avoir le statut de "préférable». Une telle évaluation du prestige et de la notoriété trouve d'ailleurs un parallèle dans la doxographie de l'éthique stoïcienne de Diogène Laërce, où la gloire est catégorisée parmi les indif-

${ }^{26}$ Sur les différences de valeur parmi les préférables, voir SVF III, 133.

${ }^{27}$ SVF III, 128.

${ }^{28}$ L'indifférentisme d'Ariston nie l'existence de tout "préférable» (LS III, $58 \mathrm{~F}$ et SVF I, 131).

${ }^{29}$ LS III, 58C.

${ }^{30}$ SVF III, 124. Sur Antipater, voir GörLER, "Zum Virtus-Fragment des Lucilius », p. 459 sqq. Sur la «raison préférentielle», voir SVF III, 128. 
férents préférables ${ }^{31}$. On trouve donc des points de convergence entre la pensée de Lucilius sur le prestige et celle du stoïcisme ${ }^{32}$. Lucilius étaye son évaluation de l'honos sur des principes philosophiques qui viennent se couler dans des formes de pensée romaines mais mettent en question une notion centrale de la morale romaine.

Cette mise en cause de la haute valeur de l'honos repose sur l'examen de ses fondements. Un fragment du livre XIV explique pourquoi le prestige ne saurait être prisé par-dessus tout:

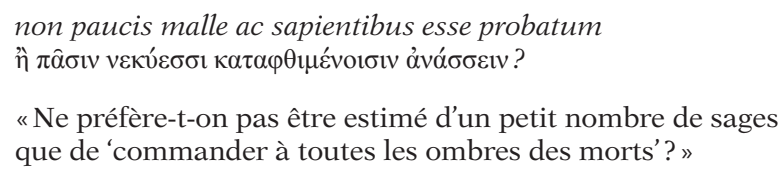

(LucIL. frg. XIV, 7 Charpin = 462 Marx).

Lucilius introduit dans la satire un vers tiré de la véкvia de l'Odyssée où Achille déclare qu'il préférerait être vivant et vivre modestement plutôt que mort et régnant sur ses semblables ${ }^{33}$. Le fragment indique clairement qu'il vaut mieux être probatus, "approuvé» et "estimé », par un petit nombre de gens sages que par la foule. L'honos, en tant que large considération, présente l'inconvénient de reposer sur le jugement du grand nombre. Or cette collectivité est composée d'individus qui ne détiennent pas la sagesse, ce que Lucilius suggère en faisant référence, par contraste, aux paucis sapientibus. Cette opposition entre une foule d'ignorants et un petit nombre de sages témoigne encore une fois de la marque du stoïcisme selon lequel la majorité des hommes vit dans l'erreur ou, à tout le moins, dans l'opinion, alors que seul le sage possède le savoir ${ }^{34}$. Cette défaillance cognitive du grand nombre rend problématique le statut de l'honos qui repose précisément sur le jugement de la foule.

\subsubsection{Le rejet de l'ambition}

Cette évaluation critique de l'honneur amène Lucilius à tenir une position nuancée sur la cupiditas honoris qu'il observe chez ses contemporains. L'honneur n'étant pas un bien au sens plein du terme,

${ }^{31}$ DL. VII, 101.

${ }^{32}$ La place faite à l'honneur dans le fragment sur la vertu est un autre indice, note W. Görler, de l'influence d'Antipater, qui a traité du statut éthique de la gloire et de la bonne réputation (GöRLER, «Zum Virtus-Fragment des Lucilius », p. 465-466).

${ }^{33}$ Od. XI, 491.

${ }^{34}$ LS III, 41C ; C. Lévy, Les Philosophies hellénistiques, Paris, Le livre de poche, 1997, p. 120-121. Le sage contrôle de manière parfaite son assentiment et possède de ce fait un véritable savoir, fermement établi. Le reste des hommes n'a accès, au mieux, qu'au vrai mais non à la vérité qui doit être systématique. 
il convient de ne le rechercher que de manière mesurée, ainsi que le suggère le fragment sur la vertu que nous citons à nouveau partiellement:

Virtus quaerendae finem rei scire modumque;

Virtus diuitiis pretium persoluere posse;

Virtus id dare quod re ipsa debetur honori;

«La vertu c'est savoir limiter et modérer la recherche des possessions;

La vertu c'est pouvoir attribuer leur vraie valeur aux richesses;

La vertu c'est accorder l'intérêt qui lui est réellement dû à l'honneur. »

(LucIL. frg. hex. inc. 23 Charpin = frg 1331-1333 Marx).

L'honos est, comme les richesses, une res, un objet matériel dont la recherche doit être sérieusement contrôlée: il convient de connaître la finis, les bornes d'une telle attitude, et le modus, la mesure. La modération apparaît ainsi comme un composant essentiel de la vertu. Cette recommandation faite par Lucilius prend tout son sens quand on l'éclaire par le contexte historique. Après la crise gracquienne, la multiplication des guerres extérieures, notamment en Afrique, semble répondre en partie au souci de certaines familles d'asseoir leur influence par des succès militaires prestigieux: les Caecilii Metelli, notamment, accumulèrent les victoires et les triomphes ${ }^{35}$. Ce désir d'honos conduisit même à cette époque à des dissensions au sein de l'aristocratie, comme en 121 et en 120 quand Cn. Domitius Ahenobarbus et Q. Fabius Maximus s'affrontèrent pour emporter la gloire de triompher sur les Allobroges. Lucilius a assisté à ces déchaînements pour l'obtention de l'honos et a pu vouloir marquer la nécessité de montrer plus de mesure. Le rejet de l'ambition est explicite dans un fragment dont l'emplacement reste indéterminé:

aurum atque ambitio specimen uirtutis utrique est:

tantum habeas, tantum ipse sies tantique habearis.

«L'or et l'ambition sont pour tous deux le signe de la vertu:

Autant on possède, autant on est soi-même et autant on est considéré.»

(LuciL. frg. hex. inc. 36 Charpin =1119-1120 Marx).

Recourant à nouveau à une métaphore financière (tanti habearis), Lucilius déplore que l'ambition soit confondue par certains avec la vertu, que l'avoir soit pris pour l'être et que seules la richesse et l'obtention du pouvoir et de la considération publique soient les buts de l'action. Ici encore, la foule se trompe en révérant ces faux biens, mais 
ceux qui sont consumés par cette ambition se trompent plus encore ${ }^{36}$.

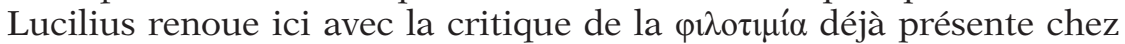
Platon ou Aristote ${ }^{37}$. Semblable rejet de la quête immodérée des honneurs trouve un écho dans la vie même de Lucilius. Ce dernier, chevalier et propriétaire terrien, ne s'est jamais engagé dans le cursus honorum. Quand il se met en scène dans le livre XXVI des Satires, il se présente comme soucieux de conserver son indépendance et refuse pour cela toute recherche de la gloire. À son interlocuteur qui lui suggère d'entreprendre une carrière de publicain pour gagner fructus et laus, Lucilius répond qu'il veut rester lui-même ${ }^{38}$. La seule laus qu'il se flatte d'obtenir est celle, dérisoire et parodique, que lui apporte son voyage en Sicile; exagérant l'importance des événements survenus pendant le trajet, il se compare ironiquement à un général menant une armée et regrette qu'un de ses amis ne puisse se joindre à lui:

Tu partem laudis caperes

« Tu prendrais part à ma gloire»

(LucIL. frg. III, 1 Charpin = 97 Marx)

Lucilius renonce ainsi à ce qui, aux yeux de ses contemporains, apparaît comme digne d'un intérêt soutenu ${ }^{39}$. Le satiriste est le premier à Rome à examiner de manière aussi complète et nuancée la valeur de l'honos et à remettre en cause, de façon directe et en son nom propre, son statut de bien supérieur.

\subsection{L'honos badin de la poésie}

La notion d'honos connaît dans la satire une inflexion inédite car elle reçoit une place au sein même de la pratique poétique. Le poète déclare accorder volontiers l'honos par sa poésie, mais ce dernier se démarque totalement de la marque d'honneur traditionnelle:

cuius uultu ac facie, ludo ac sermonibus nostris

Virginis hoc pretium atque hunc reddebamus honorem.

${ }^{36}$ Voir aussi le frg. XXVI, 6 où Lucilius se moque des ambitieux qui considèrent que l'ignobilitas est une chose monstrificabile.

${ }^{37}$ Plat. Phed. 68c et Phaedr. 256c opposent le $\varphi \imath \lambda o ́ \tau t \mu o \varsigma$ attaché aux biens corporels au $\varphi \imath \lambda$ óбофоৎ qui a appris à s'en détacher. Voir aussi Rep. IX, 549a et 583a. Pour Aristote,

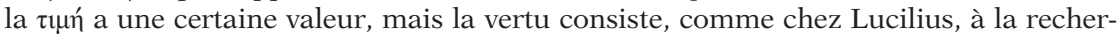
cher avec modération. Il faut rechercher les honneurs, mais pas à la manière de l'ambitieux (qui les recherche trop) ni à la manière de l'indifférent (qui s'en désintéresse). Voir ARSTT. EN $1107 \mathrm{~b}$ et $1147 \mathrm{~b}$.

${ }^{38}$ XXVI, 30 et 31.

${ }^{39}$ Voir XXVI, 57: ut ego effugiam, quod te in primis cupere apisci intellego ; «si bien que moi je fuis ces biens que toi, à ce que je comprends, tu désires atteindre.» 
"Au visage et à la beauté de cette fille, dans nos jeux et nos conversations, Nous donnions cette récompense et cet hommage.»

(LucIL. frg. XXX, 85 Charpin = 1039-1040 Marx).

Ces deux hexamètres appartiennent au livre XXX des satires où il est à plusieurs reprises question des femmes. Le poète rappelle qu'il a autrefois octroyé des honores à une uirgo. Un tel type d'honos est original à plus d'un titre. Le motif en est d'abord inhabituel: l'honos est adressé uultu ac facie, au visage et à la beauté de la jeune femme; c'est sa belle apparence physique qui justifie qu'on lui rende honneur ${ }^{40}$. L'innovation est de taille: l'honneur ne répond à aucune action précise, ni bienfait, ni geste vertueux, ni acte de vaillance, mais à un trait extérieur, superficiel. Qui plus est, l'honos est octroyé à une femme, ce qui est très rare. La forme prise par l'honos est aussi inédite, puisque il s'agit de vers de poésie légère, d'inspiration amoureuse et érotique. C'est ludo, par un badinage, que le satiriste rend honneur à la femme célébrée, ce qui fait basculer l'honos dans le domaine de l'agrément et du jeu. C'est en outre dans les sermones que l'honos s'incarne. Le terme est utilisé ailleurs par Lucilius pour désigner ses satires et c'est aussi le mot qu'emploie Horace en ce sens ${ }^{41}$. Le sermo renvoie à un discours écrit dans le style de la conversation courante; caractériser le discours du poète par le sermo est un moyen de l'opposer à la tragédie ou à l'épopée ${ }^{42}$. Et considérer que le sermo est un honos infléchit considérablement cette notion et ses connotations de sérieux et d'autorité en l'attirant dans le domaine de l'otium et de la poésie légère ${ }^{43}$. Il y a là, nous semble-t-il, un autre exemple de la liberté de parole et de pensée du satiriste qui manipule de façon originale des notions et des pratiques romaines jusque-là peu sujettes à de radicales transformations. Une illustration de cet «hommage» poétique est donnée par un fragment du livre XXX:

euplocamo digitis discerniculumque capillo

${ }^{40}$ W. Schmitт, Satirenfragmente des Lucilius aus den Büchern XXVI-XXX, Diss., Munich, 1914, p.78, pense que le passage est ironique et s'adresse à une vieille femme hideuse, et il le rapproche de Hor. Sat. IV, 13, 2: fis anus et tamen uis formosa uideri. L'hypothèse nous semble hasardeuse bien que les autres fragments du même livre soient en effet assez critiques. L'interprétation de TeRZAGHI, Lucilio, p. 241-242, est peutêtre plus vraisemblable: il s'agirait d'une prostituée appartenant à un leno. Le poète s'est épris d'elle, mais elle reste distante et avide.

${ }^{41}$ LucIL. frg. XXX, 18; Hor. Ep. I, 4, 1: Albi, nostrorum sermonum candide iudex.

${ }^{42}$ Sur le sermo chez Lucilius, voir Coppola, Gaio Lucilio, cavaliere e poeta, p. 13-14; Christes, "Lucilius», passim; E.S.Ramage, D.L.Sigbee et S.C.Fredericks, Roman Satirists and their Satire, Park Ridge, Noyes, 1974, p. 31.

${ }^{43}$ U.W.Scholz, "Die sermones des Lucilius", in Braun, M., Haltenhoff, A. et Mutschler, F.-H. (éds.), Moribus antiquis res stat Romana: römische Werte und römische Literatur im 3. und 2. Jh. v. Chr., Munich, K. G. Saur, 2000, p. 217-234, notamment p. 223. 
«dans sa chevelure aux belles tresses, de ses doigts, (elle ajuste...) et une épingle»

(LucIL. frg. XXX, 92, Charpin = 991 Marx; trad. Charpin).

Par cette description maniériste, dans le goût alexandrin, Lucilius adresse un hommage à la femme décrite dans le poème.

Ce détournement de l'honos traditionnel tout comme l'interrogation de ses fondements réels et l'évaluation rationnelle de son prix contribuent à remettre en cause le statut de l'honos comme valeur. Le propos de Lucilius nous paraît posséder une réelle teneur subversive, à la différence de celui de Plaute. Alliant l'irrévérence à l'analyse réflexive, Lucilius procède, à la première personne, à une réflexion critique sur l'honos et à un déplacement de ce dernier dans des espaces inédits. Son originalité consiste à faire surgir le statut problématique de cette valeur ancestrale et à l'interroger ${ }^{44}$. Une telle attitude répond à une sensibilité personnelle et à un contexte historique perturbé mais laisse aussi entrevoir la marque du stoïcisme d'Antipater et de Panétius. Si le stoïcisme donne bien une assise philosophique à la pensée éthique romaine, on voit ici qu'il ne consolide pas toujours les jugements moraux ancestraux, comme on le dit parfois de façon trop unilatérale ${ }^{45}$. Cette requalification de l'honos a une conséquence de taille: l'honos se trouve écarté du domaine des bona moraux. Il ne peut constituer une fin éthique viable, et va se voir supplanté en ce domaine par honestum. Pour la même raison, cette notion d'honestum va alors perdre une partie de sa dimension sociale et indiquer une conformité à des normes plus spécifiquement morales.

\section{L'EXHORTATION À LA VITA HONESTA}

Le choix que fait Lucilius du genre littéraire de la satire nous impose de nous interroger sur les singularités de ce type de poésie quand il y est question d'honneur et d'honnêteté. Il apparaît que Lucilius prend vis-à-vis de ces notions la posture d'un moraliste et exhorte à la uita honesta en alliant deux procédés propres à la satire, l'invective destructrice et la prédication morale.

\subsection{Une poésie d'ignominia}

La satire peut user de l'attaque violente et détruire la bonne réputation. Elle est de ce point de vue l'inverse d'un honos, c'est-à-dire

${ }^{44}$ La satire a ainsi, dans la typologie que donne F.-H. Mutschler des rapports de la littérature aux valeurs, une fonction de Problematisierung, de réflexion critique (MutschleR, «Virtus und kein Ende?», p. 43).

${ }^{45}$ Grimal, Le Siècle des Scipions, p. 303 sqq. 
une ignominia ${ }^{46}$. Lucilius ne se contente pas, en effet, de relever les vices de ses contemporains: il les attaque au point de les faire tomber en disgrâce. Pour autant, il ne serait pas exact de dire que les satires «déshonorent» leurs victimes car cela semblerait suggérer qu'elles les salissent gratuitement. Il s'agit plutôt de donner une marque d'infamie à celui qui s'est rendu coupable de méfaits. La poésie de Lucilius a ainsi un fonctionnement qui est le négatif de celui de l'honos; elle distingue les vicieux, mais pour les flétrir. On voit ainsi le poète s'en prendre à Lupus ${ }^{47}$ au livre I:

Occidunt, Lupe, saperdae te et iura siluri.

«Ce qui te tue, Lupus, ce sont les coracins et le jus de silure.»

(LuCIL. frg. I, 33 Charpin = 54 Marx).

Après avoir traité Lupus de "vautour» et avoir déclaré que son visage ne reflétait que "mort, maladie et poison ${ }^{48}$, Lucilius se représente ici la mort de celui qu'il fustige et imagine que c'est sa goinfrerie qui met un terme à sa vie de débauche. L'expression iura siluri comporte en outre un jeu de mot sur ius ( «jus » et " droit ») qui suggère que Lupus s'est rendu coupable de malversations dans des procès ${ }^{49}$. Les attaques sont donc vives et d'autant plus destructrices pour la réputation de la victime que cette dernière est citée nommément, pratique qui a rendu Lucilius célèbre dès l'Antiquité ${ }^{0}$. La satire est ignominia au sens étymologique du mot, privation du nomen positif, le «nom» de la personne, chargé d'une grande valeur symbolique et d'une force quasi magique ${ }^{51}$. On le voit ailleurs attaquer Publius Gallonius, un autre goinfre, le poète Accius ou encore l'ancien consul L. Aurelius Cotta, pour son avarice ${ }^{52}$. Lucilius n'hésite pas à jeter à la face de ses contemporains leurs propres vices. L'impact réel de ces textes sur les contemporains peut se mesurer aux jugements que de tels assauts suscitent. Horace notait que Lucilius avait repris le flambeau de l'ancienne comédie et Perse qu'il broyait ses victimes entre ses mâchoires ${ }^{53}$. Au livre XXX, Lucilius se met d'ailleurs lui-même en scène face à un contemporain qui se plaint de ses attaques, déplore que

${ }^{46}$ Sur l'antonymie entre honos et ignominia, voir l'étude sémantique p. 66.

${ }^{47}$ Sur l'identité exacte de ce Lupus, voir l'édition de F. Charpin, vol.I, p. 81-86.

${ }^{48}$ Frg. I, 28 et 29.

${ }^{49} \mathrm{Cf}$. la fameuse expression ius uerrinum imaginée par Cicéron à propos de Verrès (Cic. Verr. II, I, 121).

${ }^{50}$ Horace et Perse se souviennent des attaques de Lucilius contre Lupus (Hor. Sat. II, 1, 68; Pers. I, 115).

${ }^{51}$ Sur le sens premier d'ignominia, Tномаs, Déshonneur et honte, p.301-303. Sur l'importance du nomen, voir p. 332-333.

${ }^{52}$ Frg. inc. 30; XXVIII, 41; XI, 9.

${ }^{53}$ Hor. Sat. I, 4, 1-7; II, 1, 62-70; Pers. I, 114-115. 
Lucilius "déchire» les hommes ${ }^{54}$ et compare ses vers aux morsures d'un scorpion ${ }^{55}$. On s'est étonné que Lucilius ait pu ainsi insulter ses contemporains sans apparemment avoir été inquiété. Ses attaques ad hominem semblent en effet tomber sous le coup d'une des lois des XII Tables interdisant la diffamation sous la forme de l'infamia et du flagitium $^{56}$; la loi, précisée ultérieurement par des édits, a bien été utilisée, quoique peu fréquemment semble-t-il: Accius et Lucilius lui-même l'ont invoquée contre les attaques d'un acteur. Lucilius, pourtant, n'a pas été poursuivi: la diffusion restreinte de ses textes et la puissance de ses amis et notamment de Scipion Émilien peuvent expliquer un tel état de fait. Il est aussi possible, comme le suggère E. S. Gruen, que les personnages visés aient préféré ignorer les attaques plutôt que s'en défendre et leur donner par là une publicité dommageable ${ }^{57}$. Cette poésie de réprimande qui provoque la disgrâce sociale s'exerce notamment contre ceux qui se donnent des apparences d'honesti sans l'être en réalité. Deux fragments du livre XIX, que l'éditeur F. Marx associe, décrivent, de façon métaphorique, l'attitude du satiriste:

peniculamento uero reprehendere noli...

ut pueri infantes faciunt, mulierculam honestam.

«Mais n'arrête pas par le pan de son manteau,

Comme les petits enfants le font, une bonne femme considérée.»

(LuCIL. frg. XIX, 6-7 Charpin = 565-566 Marx).

Un interlocuteur qui semble s'adresser au satiriste l'invite à ne pas «tirer par le manteau» la muliercula honesta. L'action de retenir le pan du vêtement est un moyen pour arrêter quelqu'un dans la rue et l'interroger ${ }^{58}$; il s'agit sans doute ici d'une nouvelle image, comme celle du scorpion, évoquant l'attitude du satiriste qui prend à parti ses contemporains pour leur faire prendre conscience de leurs défauts ${ }^{59}$. L'association d'honesta à muliercula, substantif pourvu d'un diminutif moqueur, invite à donner à l'adjectif le sens de "considérée », mais en supposant que cette «bonne femme en vue» jouit d'une estime qui

${ }^{54} \mathrm{XXX}, 25$.

$55 \mathrm{XXX}, 31$. Sur le livre XXX, qui constitue une défense de la satire comme moyen d'attaquer les vices des contemporains, voir J.CHRISTES, Der frühe Lucilius: Rekonstruktion und Interpretation des XXVI. Buches sowie von Teilen des XXX. Buches, Heidelberg, C. Winter, 1971, p. 141.

${ }^{56}$ La loi est rapportée par Cic. Rep. IV, 12. La question est soulevée par N. RUDD, Themes in Roman Satire, Londres, Duckworth, 1986, p.40-43 et Gruen, Culture and National Identity, p. 295-296.

${ }^{57}$ Gruen, Culture and National Identity, p. 296. E. S. Gruen y voit aussi le reflet de la maturité intellectuelle des Romains qui respectent l'indépendance des poètes.

${ }^{58}$ PL. Mil. 59.

${ }^{59}$ Terzaghi, Lucilio, p. 394. 
repose sur des bases peu solides; elle est estimée sans être honorable, et c'est pourquoi Lucilius l'arrête par le pan de son manteau, pour la réprimander. La satire démasque ceux que l'on prend, à tort, pour des gens honnêtes parce qu'ils possèdent une certaine distinction sociale.

\subsection{La prédication sur la vie honorable}

Lucilius sait flétrir l'immoralité mais aussi exhorter à une vie honnête. Une telle posture n'est pas nouvelle dans la littérature latine: Caton l'Ancien l'avait déjà adoptée en adressant à son fils Marcus des préceptes moraux. Au poids de cette tradition romaine s'ajoute sans doute chez Lucilius l'influence de la prédication cynico-stoïcienne ${ }^{60}$, ce qui situe à nouveau le satiriste au confluent de deux cultures. On remarque en effet chez lui une intense volonté de convaincre son lecteur et de l'inciter à se tourner vers un mode de vie honestus. Lucilius ne se contente pas d'indiquer où réside ce qui est honestum; il essaie d'y convertir son destinataire. L'adoption d'une telle attitude est justifiée de deux manières. En premier lieu, le satiriste détient un savoir sur la nature des hommes. Il déclare ainsi à son interlocuteur qu'il peut scire tuas omnes maculas notasque, "connaître toutes tes taches et toutes tes souillures ${ }^{61}$. C'est le regard pénétrant du poète sur le déshonneur des hommes qui légitime son discours moral et donne un poids à ses exhortations. Ce scire qui est, on l'a vu, l'essence de la vertu ${ }^{62}$, doit donc déboucher sur une attitude de conseil. Elle se justifie, en second lieu, par l'identité des personnes à qui s'adressent les satires. Dans le livre XXVI, plusieurs fragments donnent des recommandations morales à un interlocuteur qui n'est pas identifié mais dont il apparaît que le poète le considère comme un ami. C'est parce que Lucilius écrit pour des amis qu'il doit donner des conseils:

\footnotetext{
porro amici est bene praecipere, tueri, bene praedicere.

«enfin le devoir d'un ami est de bien conseiller, de protéger, de bien prévenir.»
}

(LucIL. frg. XXVI, 75 Charpin = 611 Marx; trad. Charpin).

L'amitié consiste à donner des règles de conduite (praecipere), à protéger (tueri) en rendant les divers officia propres aux amis, et à intervenir dans la vie quotidienne par des actions et des avis préventifs (praedicere $)^{63}$. On comprend dès lors que Lucilius prenne à cœur sa tâche de moraliste et invite avec insistance ses interlocuteurs à

${ }^{60}$ FISKe, Lucilius and Horace, p. 143 sqq.

${ }^{61} \mathrm{XXX}, 32$.

${ }^{62}$ Supra p. 642.

${ }^{63}$ Sur la relation d'ami à ami que suppose la satire de Lucilius, MARchese, La morale e il singolo, p. 24-26. 
préférer ce qui est honestum. C'est sensible dans ce fragment de lieu incertain:

quod sumptum atque epulas uictu praeponis honesto.

«Parce que tu préfères la dépense et les banquets à un mode de vie honnête. »

(LucIL. frg. hex. inc. 52 Charpin = 1288 Marx).

Ce texte comporte certes une dimension critique mais n'est pas une réprimande violente. Lucilius s'adresse à une personne dont il veut réformer les principes de conduite: il convient de faire passer le uictus honestus avant la vie de plaisir. Le satiriste essaie de toucher efficacement son interlocuteur: il s'adresse à lui directement, à la deuxième personne, et donne par les allitérations en $p$ et $t$ un caractère frappant à son propos. La volonté d'amener le lecteur à changer son mode de vie est encore plus frappante dans le fragment sur la vertu qui prend le ton d'une prédication morale. Ici encore, le poète s'adresse directement à quelqu'un, Albinus, qui semble être un ami que le poète essaie de corriger ${ }^{64}$. Il délivre des praecepta et étaye son propos sur une forte structure rhétorique, marquée par l'anaphore du uirtus est, par les rythmes ternaires, les effets de rimes et d'opposition ${ }^{65}$. C'est pourquoi le fragment, s'il représente un indéniable effort de conceptualisation de l'honos et de l'honestum, n'est pas un travail purement réflexif: la satire dans laquelle il s'insérait devait constituer une œuvre militante qui exhortait à la vertu un destinataire sur le chemin de la sagesse ${ }^{66}$.

Ce vif encouragement à la vertu procède bien du savoir du satiriste mais échappe à toute pédanterie. Le discours que tient Lucilius sur le uictus honestus n'est jamais celui d'un savant prétentieux car il vise l'efficacité et non la spéculation pure, d'une part, et parce qu'il se coule

64 L'identité d'Albinus est incertaine. Les différentes possibilités sont relevées et étudiées par Cichorius, Untersuchungen zu Lucilius, p.349-355 et ZuccheLLI, L'indipendenza di Lucilio. Parmi les différentes interprétations, nous paraissent devoir être écartées celles qui voient en Albinus un ennemi du poète: Lucilius ne prendrait pas la peine de lui délivrer son savoir mais se contenterait de le briser par ses vitupérations. Or il essaie de corriger Albinus pour l'améliorer, et non de le vilipender (TERZAGHI, Lucilio, p.20). Notre fragment gagne à être rapproché de l'épître d'Horace à Lollius Maximus (Ep. I, 2), qui est un protreptique à la vertu.

${ }^{65}$ Pour une analyse stylistique de ce fragment, Mariotti, Studi luciliani, p. 8-10. L'aspect rhétorique est relevé par S. MorTON BRAUnD, «Declamation and Contestation in Satire", in Dominik, W. J. (éd.), Roman Eloquence. Rhetoric in Society and Literature, Londres, Routledge, 1997, p.147-165. Nous ne dirons cependant pas, comme le fait ce dernier article, que les notions d'honestum, fas, aequum, utile, etc. ne sont ici que des «rhetorical concepts» (p.152). Leur poids éthique et conceptuel, nous allons le voir, est réel.

${ }^{66}$ Lucilius s'adresse non pas à un sage, mais à un individu qui vise peut-être cet état, un "progressant», selon la terminologie stoïcienne, figure qui fait l'objet dans le stoïcisme panétien d'une plus grande attention que dans l'Ancien Portique. 
dans la forme du sermo, d'autre part. Les caractéristiques de cette «conversation », comme l'usage d'un vocabulaire courant ou l'oralité, sont sensibles dans le fragment sur la vertu et apparaissent aussi dans d'autres textes qui font usage de la notion d'honestum. On les remarque par exemple dans le livre III, qui narre le voyage en Sicile effectué par le poète ${ }^{67}$. C'est dans le contexte d'un récit, faisant état d'événements assez banals, qu'il est question de ce qui peut être honestum. La notion ne fait pas l'objet d'une méditation; elle est insérée dans un cadre narratif plaisant qui donne vivacité et efficacité au discours éthique.

La notion d'honneur occupe donc chez Lucilius une place conforme aux trois pôles de la satire identifiés par N. Rudd, l'attaque, la prédication et l'agrément ${ }^{68}$. Lucilius attaque les vices de ses contemporains en les menaçant d'une disgrâce sociale; il joue son rôle d'ami et exhorte son lecteur au uictus honestus; il délivre un savoir plaisant et jamais pédant. La satire fournit donc un cadre nouveau pour une forme inédite de discours sur l'honestum.

\section{L'ÉLABORATION ÉTHIQUE D'HONESTUS}

Les satires de Lucilius sont un des lieux du passage d'une morale de l'honneur à une éthique de l'honnêteté. Chez Lucilius, honestus s'écarte de la sphère sociale pour se situer plus nettement dans celle de la morale. Cette moralisation, en outre, s'accompagne d'un travail de conceptualisation d'honestus au contact de la notion stoïcienne

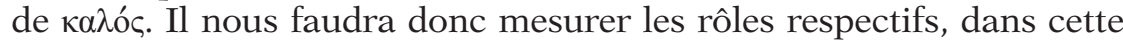
évolution d'honestus, de la tradition romaine et de la pensée stoïcienne, au carrefour desquels semble se situer Lucilius.

\subsection{L'évolution morale d'honestus}

Le mouvement qu'avait amorcé Térence en orientant honestus vers l'honnêteté se poursuit avec Lucilius. La notion connaît une double évolution qui renforce sa dimension morale: la nature du comportement honestus est plus systématiquement délimitée; les règles de conduite propres à l'honneur sont fondées sur un socle plus individuel et moins collectif.

\subsubsection{La nature de la vie honesta chez Lucilius}

À première vue, le mode de vie honestus tel qu'il est appréhendé par Lucilius ne présente pas de différence sensible par rapport à la

${ }^{67}$ LucIL. III, 25 et 33.

${ }^{68}$ RudD, Themes in Roman Satire, p. 1 : «attack, entertainment, preaching». 
définition traditionnelle de l'honorabilité. Nous avons vu que le uictus honestus se définit par opposition au sumptus et aux epulae et suppose donc la parsimonia et le refus des plaisirs de la table. La condamnation des dépenses inconsidérées et celle du luxe excessif sont des thèmes récurrents chez Lucilius et constituent aussi des traits caractéristiques du mos maiorum ${ }^{69}$. Les affinités du uictus honestus avec la morale traditionnelle apparaissent au livre III:

et spatium curando corpori honestum sumemus.

«...et nous prendrons une durée de temps convenable pour soigner notre corps.»

(LuCIL. frg. III, 25 Charpin = 115-116 Marx).

Faisant le récit de son voyage en Sicile ${ }^{70}$, Lucilius évoque la nécessité de prendre du repos en chemin et de donner des soins à son corps. Il convient cependant de ne pas y passer trop de temps et de ne pas transformer l'hygiène en attention excessive à l'apparence corporelle, laquelle est associée à la mollitia et à un caractère efféminé ${ }^{71}$. De ce point de vue, Lucilius se rapproche des recommandations formulées par Caton quant à l'importance de se vêtir honeste au forum ${ }^{72}$. Les deux moralistes envisagent ce qui est honestum dans le rapport de l'individu au corps, au luxe et aux plaisirs. Le contexte historique dans lequel évoluent Caton et Lucilius est différent, mais la teneur éthique de leur œuvre présente certaines affinités, par leur conception de l'honestum mais aussi par leur attachement à l'agriculture, leur lutte contre luxe ou contre l'hellénomanie ${ }^{73}$. Lucilius, cependant, paraît faire d'honestum une catégorie morale plus fermement délimitée, notamment parce qu'elle est plus régulièrement associée à une qualité précise, à savoir la mesure. Le spatium honestum qu'il faut accorder au corps n'est autre en effet qu'une attitude médiane entre la négligence totale et l'attention excessive. De même, le uictus honestus s'interdit les dépenses inconsidérées et les banquets, mais on voit par ailleurs Lucilius railler le uictus sordidus de ceux qui vivent dans un dénuement extrême et une austérité déplacée ${ }^{74}$. Lucilius rapproche ainsi la notion d'honestum de celle de mesure qui, sans être véritablement nouvelle dans les modes de pensée romains, n'est pas sans rappeler la définition

${ }^{69}$ LUCIL. XIII, 4 ; XIII, 5 ; XX, 2 ; XXX, 72.

${ }^{70}$ Sur le livre III et sur ce voyage (thème qui sera imité par Horace), voir A. DE LorenzI, "Il viaggio di Lucilio al 'fretum Siculum' ed alcuni allusioni oraziane», Il Mondo Classico, 3, 1933, p. 337-351 ; Terzaghi, Lucilio, p. 289 sqq.; J. Heurgon, Lucilius, Paris, C.D.U., 1959, p. 76 sqq.

${ }^{71}$ Sur la mollitia et le soin du corps, voir EDWARDs, The Politics of Immorality, p. 68.

${ }^{72}$ CAт. Carmen frg. 2 Sblendorio-Cugusi; voir notre analyse p. 595.

${ }^{73}$ Pour une comparaison de Lucilius et Caton, voir Scholz, "Die sermones des Lucilius », p. 225-229 et CLEMENTE, «Lucilio e la società romana », p. 50-51.

${ }^{74}$ LuCIL. XXVI, 38. 
aristotélicienne de la vertu comme juste milieu entre deux extrêmes ${ }^{75}$. L'idée se rencontre aussi chez Panétius, à propos, justement, du soin du corps ${ }^{76}$. La définition de l'homme honestus commence ainsi à se faire plus systématique en se trouvant élaborée autour d'un idéal de mediocritas.

\subsubsection{Vers l'autonomie de la norme morale}

Prolongeant un mouvement déjà sensible chez Térence, Lucilius se représente l'exigence de l'honestas comme une règle de conduite dont les fondements cessent d'être exclusivement collectifs et hétéronomes. Est honestum non pas ce qui répond à des devoirs imposés par la préservation de la considération de l'entourage, mais ce qui est conforme à des normes morales dont autrui, s'il est peut-être encore l'origine, n'est plus le juge. L'invitation de Lucilius à prendre un spatium honestum pour s'occuper de soi répond certes à une règle de la morale sociale qui bannit la mollitia, mais cette règle est imposée par une éthique personnelle, dans l'intimité du voyage, comme on le voit avec l'exhortation à la première personne sumemus. Le poète ne prend pas en compte les conséquences de cette attitude en termes de rétribution sociale et d'honneur. La mise à l'écart de la collectivité doit être, en premier lieu, reliée à l'évaluation nuancée que fait Lucilius de l'honos ${ }^{77}$ : puisque le satiriste le met en question et s'interroge sur la viabilité de ses fondements, il en vient à le séparer de la notion d'honestum et à remettre en cause sa capacité à fournir des normes morales. L'honestum n'est pas totalement opposé à l'honos mais gagne une autonomie plus grande. En second lieu, cette évolution morale d'honestum est motivée par le développement du moi dans les Satires. Nous avons vu que Lucilius interpelle nommément des individus dans son œuvre et ne s'adresse pas à la collectivité perçue comme un tout, mais à des personnes bien identifiées. En outre, il se représente lui-même dans ses satires ${ }^{78}$ : il parle de ses voyages, de sa santé, cite son propre nom ${ }^{79}$. Le livre XXVI, surtout, permet à Lucilius de manifester sa singularité en refusant de prendre le munus de publicain pour «rester Lucilius ${ }^{80}$. Cette affirma-

\footnotetext{
${ }^{75}$ Voir par exemple la définition que donne Aristote des quatre vertus cardinales: Arstt. EN 1115b sqq. Sur Lucilius et Aristote, voir M. Puelma Piwonka, Lucilius und Kallimachos, Frankfurt, Klostermann, 1949, p. 53-54.

${ }^{76}$ Voir le passage, panétien, du De officiis consacré à la mesure dans le soin de son corps: Cic. Off. I, 130. Pour une définition de la vertu comme mesure, Cic. Off. II, 5.

${ }^{77}$ Supra p. 642 sqq.

${ }^{78}$ Sur la singularité d'une telle attitude, M. Coffey, Roman Satire, Londres, Bristol Classical Press, 1989, p. 46.

${ }^{79}$ Voyages: livre III ; frg. VI, 21 ; santé: V, 1 ; citations de son nom: XXVII, 5 ; XXVIII, $20 ;$ XXIX, 48.

${ }^{80}$ XXVI, 31. Sur ces passages et l'affirmation de son moi par Lucilius, MARCHESE, $L a$ morale e il singolo, p. 28-29.
} 
tion de soi, associée au souci de sa réalisation personnelle et au refus de certains rôles sociaux et de l'honos, donnent une épaisseur nouvelle à la personne du poète et la placent au centre des jugements moraux qui émanent de l'œuvre. Cette irruption du moi dans la littérature, dans un genre marqué par le discours moral, est propice à faire de l'individu le support nouveau des normes éthiques portées, auparavant, par la collectivité. Lucilius représente donc une étape importante dans le passage d'une morale holistique à une éthique plus individuelle ${ }^{81}$. Lévolution n'est cependant pas totale: il y a effacement de la collectivité mais le sujet n'édicte pas encore lui-même ses propres normes de conduite: c'est un individu qui les donne à un autre. On le voit parfaitement dans le fragment sur la vertu qui est une longue adresse d'un «moi » à un autre individu, un «tu». Albinus ne s'impose pas luimême de règles de comportement: il les reçoit d'un tiers qui détient sur la question un savoir. On passe donc avec Lucilius d'une injonction sociale, portée par la collectivité, à une injonction philosophique, portée par le satiriste comme individu s'adressant à un autre individu.

\subsection{La naissance d'un concept philosophique}

Lévolution éthique d'honestum prend aussi la forme d'un autre type de déplacement: il s'agit du passage de la notion, idée singulière mais aux traits relativement imprécis, au concept, dont les contours sont plus nets et la richesse théorique plus grande.

\subsubsection{L'émergence d'une catégorie éthique}

Le fragment sur la vertu a ceci de particulier pour honestum qu'il l'invoque pour la première fois dans une réflexion morale de nature assez abstraite:

Virtus, Albine, est pretium persoluere uerum Quis in uersamur, quis uiuimus rebus potesse;

Virtus est homini scire id quod quaeque habeat res;

Virtus, scire homini rectum, utile quid sit, honestum,

Quae bona, quae mala item, quid inutile, turpe, inhonestum;

Virtus quaerendae finem rei scire modumque;

Virtus diuitiis pretium persoluere posse;

Virtus id dare quod re ipsa debetur honori;

Hostem esse atque inimicum hominum morumque malorum,

Contra defensorem hominum morumque bonorum,

Hos magni facere, his bene uelle, his uiuere amicum,

Commoda praeterea patriai prima putare,

Deinde parentum, tertia iam postremaque nostra.

${ }^{81}$ Sur l'émergence de l'individu dans la poésie, Ibid., p.9-10 et p.20-21 sur cette émergence dans la satire. 
«La vertu, Albinus, c'est pouvoir attribuer leur vraie valeur Aux choses auxquelles nous avons part, au milieu desquelles nous vivons; La vertu c'est savoir ce que vaut pour l'homme chaque chose; La vertu c'est savoir ce qui pour l'homme est droit, utile, honnête, Quels sont les biens et de même quels sont les maux, ce qui est inutile, honteux, malhonnête;

La vertu c'est savoir limiter et modérer la recherche des possessions; La vertu c'est pouvoir attribuer leur vraie valeur aux richesses; La vertu c'est accorder l'intérêt qui lui est réellement dû à l'honneur; C'est être l'ennemi et l'adversaire des gens de mœurs mauvaises, Et à l'inverse le défenseur des gens de bien et des bonnes mœurs, Les estimer grandement, leur vouloir du bien, vivre en étant leur ami; C'est en outre penser que l'intérêt de la patrie passe en premier, Puis celui de nos parents et en troisième et dernière position le nôtre.»

(LucIL. frg. hex. inc. 23 Charpin = frg 1326-1338 Marx).

Honestum apparaît dans une définition approfondie de la vertu dont quatre aspects sont tour à tour examinés: la vertu est savoir (v.1-5); la vertu est refus des passions (v. 6-8); la vertu consiste à aimer les bons et rejeter les méchants (v. 9-10); la vertu consiste à hiérarchiser correctement les préférables (v.11-12). Honestum est ainsi mis en relation avec la uirtus puisque cette dernière consiste à savoir ce qui est rectum, utile et honestum. L'association d'honestum avec ces deux termes, rectum et utile, et l'opposition morphologiquement limpide à inhonestum confèrent à la notion une place précise au sein d'un système, ce qu'elle ne possédait pas auparavant. Ce qui est honestum entre en relation avec les bona, les biens, et peut constituer un but de la vie ${ }^{82}$. Cette élévation d'honestum, sa mise en relation avec les notions d'utile et de rectum, tout comme son inclusion dans une analyse approfondie de la uirtus lui donnent une épaisseur nouvelle qui le rapproche du concept, propre à être employé de manière réflexive et théorique et situé à un certain niveau de généralité. De fait, l'adjectif honestus ne sert pas à qualifier un objet ou un acte précis comme un uictus ou un spatium, ainsi que cela apparaît dans les autres fragments. Il est plutôt question de savoir ce qui est honestum en général, ce qui mérite, au sein de l'expérience, d'entrer dans le champ de ce concept. Cependant, comme chez Térence, l'adjectif n'est pas encore substantivé, ce qui limite quelque peu l'élévation théorique ${ }^{83}$. Quoiqu'il en soit, ce travail conceptuel, ajouté à l'enrichissement de la morale romaine par la pensée stoïcienne et à la vivacité rhétorique du propos,

${ }^{82}$ Sur le fragment comme définition d'une finis au sens philosophique, GörLER, «Zum Virtus-Fragment des Lucilius».

${ }^{83}$ Il ne s'agit pas de savoir "ce qu'est l'honnête», mais «ce qui est honnête». Un parallèle avec Hor. Epist. I, 2, 3 (quid sit pulchrum, quid utile, quid non) où l'adjectif est clairement prédicatif, comme le montre l'emploi du non, nous incite à le penser. Voir Setaioli, «La notion éthique de kalós / kalón en latin», p. 164. 
nous paraît mettre hors de doute le sérieux et la sincérité de Lucilius dans ce fragment. Il a été avancé que cette définition de la vertu était ironique, voire parodique ${ }^{84}$. Mais, contrairement à ce qui a été affirmé, le passage n'est pas une «collection de platitudes ${ }^{85}$ mais au contraire une tentative de conceptualisation sans précédent et une réorientation de l'éthique de la uirtus sous l'influence de Panétius. Quant au rapprochement suggéré par W. Raschke ${ }^{86}$ avec deux passages d'Horace et de Juvénal qui ironisent sur la figure du sapiens, il nous paraît sans fondement. On ne rencontre aucune preuve que ces deux satiristes se seraient inspirés du texte de Lucilius et force est de constater que, dans ce dernier, le ton n'est absolument pas comique alors que le texte d'Horace, par exemple, est ouvertement humoristique et moqueur.

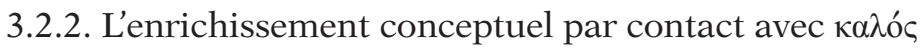

Lélévation théorique observée est le premier aspect de la conceptualisation d'honestus. Le second, tout aussi important, réside dans

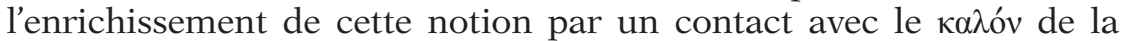
pensée grecque et notamment des stoïciens. Au moyen d'un calque sémantique, Lucilius est l'initiateur d'une transfusion de sens depuis

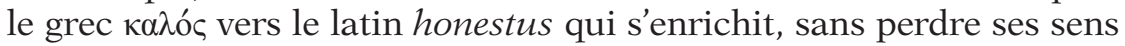
anciens, d'une nouvelle signification, celle de «beau moral». Nous avons eu l'occasion d'analyser, dans notre étude sémantique, le fonctionnement de ce calque ainsi que les facteurs culturels et linguistiques qui l'ont provoqué ${ }^{87}$. Pour compléter notre analyse, nous pouvons ici mesurer les effets de cette transposition sur la notion. En raison de

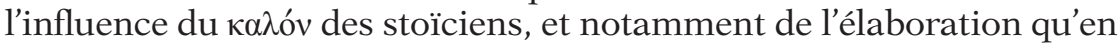
donne Panétius ${ }^{88}$, l'adjectif honestus entre dans le domaine de la philo-

${ }^{84}$ C'est la lecture que fait W. Raschke du fragment (W.J. RAschKe, "The Virtue of Lucilius», Latomus, 49, 1990, p.352-369). E. Gruen considère que le passage sur la uirtus, comme les autres propos moralisants "add up nothing insightful or profound" et que "the more likely interpretation is parody» (GRUEN, Culture and National Identity, p. 309).

${ }^{85}$ L'expression est employée par E. Gruen.

${ }^{86}$ RaschKe, "The Virtue of Lucilius ».

${ }^{87}$ Supra.p. $158-160$.

${ }^{88}$ On trouve plusieurs parallèles entre notre fragment et le De officiis, inspiré de Panétius: la définition de la vertu comme savoir (Off. I, 5, 18), l'association de l'honnête et de l'utile (livre III du Off.), la concordance entre vertu et mesure (Off. II, 5, 18), et surtout la hiérarchie des devoirs présente dans les deux derniers vers. Mais on rencontre aussi plusieurs termes qui relèvent de l'éthique de l'ancien stoïcisme et sont traduits pour la première fois en latin (GöRLER, "Zum Virtus-Fragment des Lucilius », p.446). Sur l'influence de Panétius et du stoïcisme en général sur le fragment, voir Cichorius, Untersuchungen zu Lucilius, p. 47 n. 2 et p. 350 ; Fiske, Lucilius and Horace, p.72; Mariotti, Studi luciliani, p.9; W. KrenKel, "Römische Satire und römische Gesellschaft», WZRostock, 15, 1966, p.471-477; GARBARINo, Roma e la filosofia greca, p. 519; Görler, "Zum Virtus-Fragment des Lucilius»; Setaioli, «La notion éthique de 


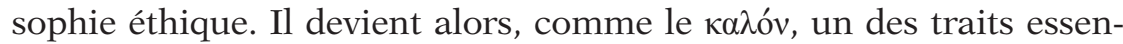
tiels du bien, et rejoint le rang des concepts que sont l'utile, l'avantageux, le juste, etc. ${ }^{89}$ Lucilius participe ainsi activement à la création d'un vocabulaire philosophique latin, même si la correspondance entre $\kappa \alpha \lambda$ ó e et honestus n'est pas encore d'une parfaite rigueur ${ }^{90}$. Le

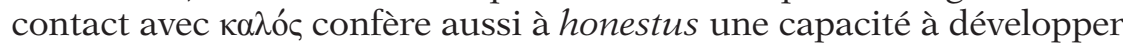
des caractéristiques théoriques encore latentes chez Lucilius mais qui seront exploitées par Cicéron, telles que l'identification à la vertu, l'adéquation du beau moral et du bien ou la valeur per se de la beauté morale ${ }^{91}$. Enfin, avec cet enrichissement sémantique, l'ancienne norme de comportement désignée par honestus devient une norme philosophique et esthétique dont la portée est beaucoup plus large: la beauté morale ne dépend pas en effet d'une définition posée par un groupe social qui la détermine mais se trouve fondée sur la raison et sur la nature et possède donc une validité universelle, en phase avec le cosmopolitisme stoïcien.

\subsubsection{Une conceptualisation en harmonie avec la tradition romaine}

Si l'innovation de Lucilius a une réelle portée et sera reprise et approfondie par Cicéron, c'est parce qu'elle ne constitue pas une brutale immixtion de la réflexion grecque dans un contexte romain. La conceptualisation d'honestus est réalisée en harmonie avec la morale romaine de l'honneur. Lucilius, qui est en cela représentatif de son époque et de l'entourage de Scipion Émilien, accueille les valeurs helléniques et essaie de les intégrer dans la culture romaine. Ce souci d'introduire un concept inédit sans brusquerie apparaît quand on s'interroge sur les motifs qui ont pu conduire Lucilius à recourir en

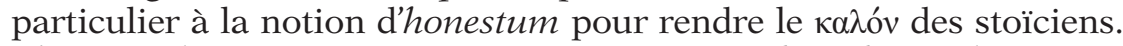
Chacune de ces raisons peut être ramenée à la volonté de réussir l'adaptation d'une notion étrangère aux modes de pensée romains.

Le fait qu'honestus soit un terme ancien du vocabulaire latin, marqué comme autochtone, est une des raisons qui expliquent qu'il ait été choisi: c'est une façon d'introduire un élément de philosophie

kalós / kalón en latin », p.164. W. Raschke conteste le rapprochement avec le stoïcisme, mais sa lecture «ironique» du fragment ne nous semble pas fondée (RAschKE, "The Virtue of Lucilius»).

${ }^{89}$ Voir par exemple l'énumération des caractéristiques du bien par Cléanthe, SVF I, 557.

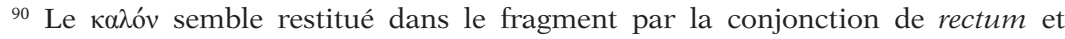
honestum, qui est à comprendre comme un hendiadyn; rectum, en effet, ne correspond à aucune notion stoïcienne clairement autonome. Voir GörLER, «Zum Virtus-Fragment des Lucilius ».

${ }^{91}$ Notamment dans le livre II du De finibus et le De officiis. Tous ces traits sont des

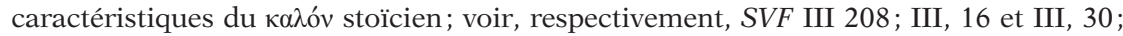
III, 23. 
grecque en le fondant parfaitement dans la latinité; le calque sémantique, nous l'avons vu, est d'excellente facture, et le choix d'honestus permet donc un enrichissement de la langue qui n'apparaît pas comme une inclusion étrangère. Cela rend cette création moins propice aux diverses répréhensions auxquelles s'exposent parfois l'hellénisme et la philosophie grecque dans le courant du $\mathrm{II}^{\mathrm{e}}$ siècle de la part des Romains conservateurs. Il est significatif que Lucilius, à qui il peut arriver d'utiliser des grécismes dans le vocabulaire philosophique ${ }^{92}$, se garde bien de le faire quand il traite de morale ${ }^{93}$, domaine important pour la définition de l'identité romaine: dans le fragment sur la vertu, aucun mot n'a un aspect étranger, bien que plusieurs notions grecques soient indirectement présentes dans le passage. Le fait qu'honestus soit aussi un terme du vocabulaire courant est d'importance. Lucilius, comme il le dit lui-même, n'écrit pas pour les doctissimi ${ }^{94}$ mais emploie, pour parler d'éthique, des mots de la langue de tous les jours ${ }^{95}$. Honestus, issu du vocabulaire social, est un de ces termes usuels propres à supporter une transition vers le conceptuel. De même, l'emploi par Lucilius de mots du vocabulaire économique, tels que pretium, pour parler d'éthique n'a rien d'étrange ni de déplacé, comme on a pu le dire ${ }^{96}$ : cette technique permet d'intégrer la pensée conceptuelle de façon harmonieuse et d'éviter tout pédantisme.

Honestus a également été choisi parce qu'il s'agit d'une notion qui joue un rôle important dans la morale romaine, notamment dans celle de l'aristocratie. Se conduire honeste, c'est, dans la tradition, suivre un code de conduite réglé et faire preuve des qualités typiques du mos maiorum, pour préserver ou obtenir l'honos: l'honestas est proche d'un code de l'honneur. Lucilius rend acceptable et parlant pour les aristocrates romains de son entourage un élément de la philosophie grecque ${ }^{97}$. Lucilius participe ainsi à l'élaboration d'une éthique

\footnotetext{
${ }^{92}$ Mariotti, Studi luciliani, p. 67 sqq. Les grécismes de Lucilius apparaissent surtout dans les fragments traitant de grammaire ou de théorie littéraire.

${ }^{93}$ Voir T.Baier, "Lucilius und die griechischen Wörter», in Manuwald, G. (éd.), Der Satiriker Lucilius und seine Zeit, Munich, C.H.Beck, 2001, p. 37-50. R. ARgENIO, "I grecismi di Lucilio", RSC, 11, 1963, p.5-17, remarque que Lucilius évite l'usage des grécismes dans les passages où il défend les vertus proprement romaines. I. MARIOTTI, "I grecismi di Lucilio», StudUrb (B), 28, 1954, p.357-386 note de même l'absence de grécismes dans les fragments dont le ton est élevé et le caractère romain accentué.

${ }^{94}$ LuCIL. XXXVI, 15 sqq.

${ }^{95} \mathrm{~F}$. Charpin relève de nombreuses concordances entre les termes du fragment sur la vertu et la prose courante de Plaute par exemple (voir son édition, au vol. III, p. 254).

${ }^{96}$ RAschKe, "The Virtue of Lucilius», p. 360-361.

${ }^{97}$ Ce n'est donc pas, comme le suggère Puelma Piwonka, Lucilius und Kallimachos, p.41, le changement de l'aristocratie romaine et de ses valeurs qui permettent d'ac-

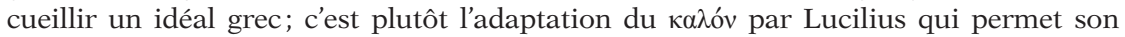
insertion dans la pensée aristocratique. Voir FISKE, Lucilius and Horace, p. 67: Lucilius a fait perdre au stoïcisme hellénistique de sa «rigidité scholastique».
} 
nouvelle, nourrie du mos maiorum romain et enrichie de l'apport de la pensée grecque, dans un mélange particulièrement heureux. Il est exact que le mot n'est pas un décalque parfait du grec, mais cela n'est pas un défaut, bien au contraire ${ }^{98}$; c'est le résultat d'un travail d'adaptation mené par Lucilius qui, à une époque d'intense hellénisation, intègre, tout en le contrôlant, un élément grec dans la culture romaine ${ }^{99}$.

On peut enfin avancer une dernière raison pour expliquer le choix d'honestus au détriment d'autres termes, tels que pulcher, qui auraient rendu de façon plus explicite l'idée de beauté. Si honestus a été choisi par Lucilius et confirmé par Cicéron, c'est sans doute pour estomper l'aspect très esthétique de $\kappa \alpha \lambda$ ó en grec. À Rome, l'excellence morale n'est pas liée comme en Grèce à la beauté physique ${ }^{100}$; un terme tel que pulcher est pourvu d'une dénotation esthétique trop puissante pour pouvoir devenir un élément clef de l'éthique romaine ${ }^{101}$. Aux III $^{\mathrm{e}}$ et $\mathrm{II}^{\mathrm{e}}$ siècles, la beauté physique masculine trouve difficilement une place au sein d'une morale qui fait la part belle à l'austérité, à la virilité, et dénonce de manière récurrente les soins trop attentifs portés au

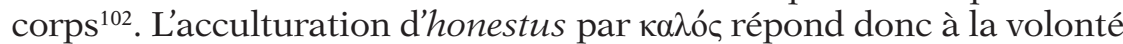
de créer un vocabulaire philosophique propre au latin mais aussi à l'ambition d'élaborer une morale originale qui s'inspire de l'éthique grecque sans la décalquer.

Le choix d'honestus pour procéder à une acculturation philosophique du concept grec de beauté morale est révélateur de la transition morale qu'incarne Lucilius dans la pensée de l'honneur. Le satiriste est encore marqué par les normes de comportement romaines mais sait, d'une part, en faire une évaluation critique, comme on le voit dans son traitement de l'honos, et enrichit, d'autre part, l'idée du "code de l'honneur» par la transfusion de l'éthique grecque qui l'amène vers l' «honnêteté ». Il est donc vain d'opposer chez Lucilius inspiration

${ }^{98}$ J.-M. Fontanier estime qu'honestum est mal adapté et que c'est decorum qui porte

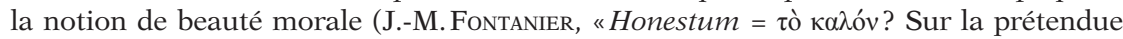

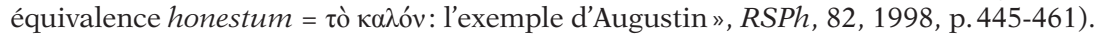

${ }^{99}$ Sur ce contrôle des notions grecques au $\mathrm{II}^{\mathrm{e}}$ siècle, Gruen, Culture and National Identity, à la fin du chap. 6.

${ }^{100}$ L'inscription de Scipion Barbatus faisant l'éloge de sa forma comme de sa uirtus fait à cet égard exception $\left(C I L \mathrm{I}^{2}, 6-7=I L L R P\right.$ 309).

${ }^{101}$ Sur le sens de pulcher, MonteIL, Beau et laid, p. 105 sqq. F. Klose suggère aussi comme raison de sa disqualification au profit d'honestus son appartenance à un vocabulaire trop «bas» et trop quotidien (KLose, Bedeutung, n. 11, p. 111). La pulchritudo est liée à la uenustas (CIc. Off. I, 130) qui ne saurait entrer dans la sphère de l'éthique (SETAIOl, «La notion éthique de kalós / kalón en latin», p. 166).

102 Voir les fragments de Lucilius cités supra et la polémique de Scipion Émilien contre Sulpicius Galus (ORF IV, 17); chez Térence, les belles personnes sont les femmes ou bien l'eunuque, mais beaucoup moins les hommes. 
traditionnelle et influence grecque ${ }^{103}$. Ces dernières sont à penser en termes de convergence et non d'alternative. L'ensemble du fragment sur la vertu présente un mélange intime d'une morale romaine et d'une éthique philosophique d'inspiration stoïcienne et il est parfois difficile de distinguer exactement ce qui relève de l'une ou de l'autre ${ }^{104}$.

\subsubsection{Les limites de la conceptualisation}

Le travail de conceptualisation à l'œuvre dans le fragment sur la vertu ne constitue néanmoins qu'un premier essai d'inclusion d'honestus dans une réflexion éthique. Le texte lui-même reste une satire relevant de la prédication morale, une exhortation à la vertu adressée à Albinus. Le passage d'honestum de la notion au concept n'est pas encore pleinement réalisé. D'autres vers de Lucilius le montrent: l'adjectif honestus y apparaît dans des contextes très variés et conserve une plasticité qui l'éloigne du concept. Dans la lignée de Térence, Lucilius développe l'aspect esthétique de la notion, propre à désigner la belle apparence extérieure:

et pedibus laeua Sicyonia demit honesta.

«Et, de sa main gauche, elle retire de ses pieds les belles sandales de Sicyone.»

(LucIL. frg. inc. 111 Charpin = 1161 Marx; trad. Charpin).

Dans ce fragment de lieu incertain, qui décrit une femme en train de se déchausser ${ }^{105}$, l'adjectif honestus qualifie des Sicyonia, des chaussures de Sicyone: il est utilisé dans un sens purement esthétique, très éloigné de la sphère de l'honos comme de celle de la morale. La notion d'honestum est ainsi convoquée dans un contexte très différent de celui du fragment sur la vertu: le vers fait penser aux passages de Lucilius marqués par le maniérisme dans le goût alexandrin, qui s'attardent

${ }^{103}$ C'est ce que fait W. Raschle qui considère que la uirtus de Lucilius est un idéal aristocratique, ce qui exclut la possibilité de devenir un concept philosophique (RASCHKE, "The Virtue of Lucilius», p. 363).

${ }^{104}$ L'idée que la vertu consiste à modérer la recherche des richesses appartient à l'une aussi bien qu'à l'autre tradition. Sur cette fusion des aspects romains et stoïciens, voir GARBARINo, Roma e la filosofia greca, vol.2, p. 520: "è molto difficile riuscire a distinguere [...] gli aspetti propriamente romani (cioè appartenenti all'etica tradizionale del cittadino romano) e quelli derivanti invece da una visione della morale influenzata dal pensiero filosofico greco. "Voir aussi U. GärTnER, "Lucilius und die Freundschaft», in Manuwald, G. (éd.), Der Satiriker Lucilius und seine Zeit, Munich, C. H. Beck, 2001, p.90-110; K. BüchNer, "Vtile und honestum», in Büchner, K. (éd.), Studien zur römischen Literatur. Band IX, Wiesbaden, F.Steiner, 1978, p.111-127, à la p. 124.

${ }^{105}$ Voir Hass, «Lucilius und die Frauen ». Il est également possible que le fragment soit une attaque contre un débauché. Les chaussures de Sicyone étaient en effet portées par les femmes ou par les efféminés (Cic. De or. I, 231 ; Lucr. DRN IV, 1123). 
par un badinage poétique sur un détail à valeur esthétique. Un usage assez similaire se rencontre au livre III :

Cernuus extemplo plantas conuestit honestas

«Se penchant en avant, aussitôt il chausse ses nobles pieds. »

(LucIL. frg. III, 33 Charpin = 129 Marx).

Il s'agit ici encore d'un emploi esthétique d'honestus, qui recèle peut-être en outre une dimension comique. Ladjectif, qui est appréciatif et de registre assez soutenu, est en effet employé pour qualifier une réalité particulièrement prosaïque, des plantas, des pieds ${ }^{106}$. Le fragment se situe dans le livre III qui fait le récit du voyage en Sicile et semble décrire un personnage en train de se chausser pour prendre la route. Lucilius donne à la scène une grandiloquence amusante, dans la veine héroï-comique. À la figure du voyageur se surimprime peutêtre ici celle de Mercure que la tradition épique représente en train d'ajuster ses sandales ailées avant le départ. Honestus est donc ici employé dans une scène de comique irrévérencieux, ce qui témoigne encore de sa capacité à s'adapter à différents contextes: la notion n'est pas tombée de manière définitive dans le domaine éthique.

\section{CONCLUSION}

La réflexion de Lucilius sur l'honneur se situe à la croisée des chemins. Le poète se place entre tradition et innovation: il est l'héritier d'une posture morale ancienne quand il tient sur l'honos et l'honestum un discours évaluatif. Cependant, son rapport à ces notions prend, simultanément, un tournant inédit: il les mobilise de manière originale dans la satire, interroge leurs fondements et développe une pensée réflexive sur l'honestum. Lucilius se situe en outre au carrefour des modes de pensée de l'aristocratie romaine et de la spéculation d'origine grecque. Fidèle à certains aspects ancestraux du code de l'honneur, le satiriste est aussi réceptif à la philosophie grecque, qui l'amène à une requalification critique de l'honos et à une redéfinition de ce qui est honestum. Cette redéfinition, néanmoins, ne doit pas être opposée à l'honneur ancestral: elle le remodèle sans l'effacer. Lucilius n'est pas en effet un simple vecteur du stoïcisme mais travaille à son intégration harmonieuse dans la romanité. Les satires montrent une

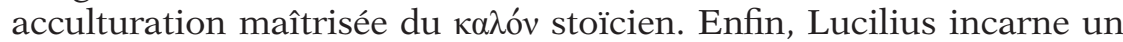
basculement éthique au sein des normes de conduite romaines. La dépréciation du prestige social et militaire de l'honos s'accompagne

${ }^{106}$ Dans son sens de «beau», il est plutôt utilisé pour caractériser le visage. Voir notre étude sémantique p. 144. 
d'une appréciation de la conduite honesta qui prend une place plus grande au sein de la morale. L'émergence du moi et l'intériorisation de certaines normes de conduite déplacent l'attention depuis l'honos vers l'honestum et font de Lucilius une charnière importante dans le passage d'une morale de l'honneur à une éthique de l'honnêteté. 



\section{LA RHÉTORIQUE À HERENNIUS : LA MATURATION CONCEPTUELLE D'HONESTUM}

\section{INTRODUCTION}

S’intéresser à la Rhétorique à Herennius peut a priori sembler une entreprise peu féconde pour comprendre la manière dont est pensée la notion d'honneur à Rome. Rédigée dans les années 86-83 av. J.-C. par un auteur inconnu ${ }^{1}$, la Rhétorique à Herennius est un traité qui aborde les cinq parties canoniques de la rhétorique et expose à des fins pratiques immédiates des préceptes sur l'art de la parole ${ }^{2}$. L'objet oratoire de l'œuvre, son allure technique et sa dette à l'égard de la production théorique grecque la rendent au premier abord peu propice à nous délivrer des informations sur la représentation intellectuelle de l'honneur par les Romains du $\mathrm{I}^{\mathrm{er}}$ siècle. Ce serait cependant une erreur que de négliger l'utilisation que fait la Rhétorique à Herennius des notions qui nous intéressent. Si honos n'apparaît que de manière restreinte dans le texte, et le plus souvent à l'arrière-plan, dans des exemples destinés à illustrer des procédés rhétoriques, honestus occupe une place plus importante. C'est précisément le fait que la Rhétorique à Herennius soit un ouvrage technique consacré à l'éloquence, dans la lignée des œuvres grecques de rhétorique, qui rend le traité particulièrement intéressant pour notre étude. La notion d'honneur, d'abord, s'y trouve utilisée dans un contexte nouveau, celui de l'ars dicendi, où elle s'enrichit d'applications inédites et gagne en souplesse. Sa présence

\footnotetext{
${ }^{1}$ Nous adoptons la datation proposée par G. Achard dans son édition de la Rhétorique à Herennius, p. VI-XIII. Le texte, qui semble avoir été perdu juste après sa parution, a été attribué à Cicéron dès sa réapparition. Dès le $\mathrm{XV}^{\mathrm{e}}$ siècle, cependant, la paternité cicéronienne a été contestée par A. Decembrio et plusieurs arguments avancés depuis ont amené à l'écarter définitivement. Une autre interprétation, formulée pour la première fois au $\mathrm{XVI}^{e}$ siècle et soutenue à l'époque moderne par W. Kroll et surtout G. Calboli (G. CALboli, Cornificiana 2. L'autore e la tendenza politica della Rhetorica ad Herennium, Bologne, Tipografia Compositori, 1965, p.1-57), attribue le texte à Cornificius, sur la base notamment de rapprochements entre des citations de cet auteur par Quintilien et des passages de l'Ad Herennium. Mais cette thèse a été très discutée et l'on admet en général aujourd'hui qu'elle est difficile à soutenir (voir l'édition de G. Achard, p. XIX-Xx).

${ }^{2}$ L'ouvrage affirme vouloir donner des préceptes directement exploitables par son destinataire, C.Herennius (Rhet. Her. I, 1). Sur l'identité de C.Herennius, voir l'édition Achard, p.XXXI-XXXII.
} 
dans un traité technique, ensuite, la met en relation avec une pensée théorique qui classe, définit et conceptualise, et cette approche intellectuelle la fait évoluer en profondeur. La marque de la rhétorique grecque sur l'œuvre ${ }^{3}$, enfin, place la notion d'honestum en contact - à un degré jusqu'ici jamais atteint - avec des concepts helléniques qui contribuent à l'infléchir. L'un des enjeux sera de mesurer l'influence

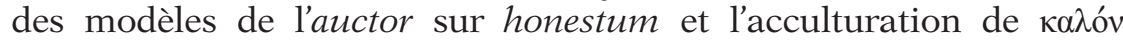
par cette notion romaine, dont nous avions observé les débuts avec Térence et Lucilius. Il sera également utile de comparer le traitement d'honestum dans la Rhétorique à Herennius et dans le De inuentione de Cicéron, traité proche du précédent par la date de composition et le contenu ${ }^{4}$. Notre étude procédera en deux temps: nous commencerons par analyser la manière dont la Rhétorique à Herennius construit, au contact de ses sources grecques, le concept rhétorique d'honestum qui

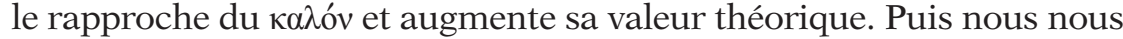
interrogerons sur la portée éthique de ce travail conceptuel et sur la manière dont l'auctor fait évoluer la notion d'honestum vers l'honnêteté.

\section{LE DÉVELOPPEMENT D'UN CONCEPT RHÉTORIQUE}

\subsection{Les trois usages rhétoriques d'honestus}

L'adjectif honestus entre, avec la Rhétorique à Herennius, dans le lexique spécialisé de la rhétorique, ce qui a deux effets. En premier lieu, la notion est insérée dans un riche vocabulaire technique qui le charge de significations et d'applications nouvelles. En second lieu,

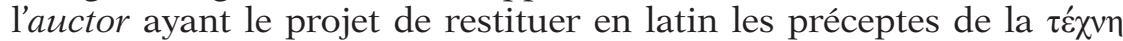
grecque, honestus se trouve en contact direct avec une pensée théorique étrangère. Malgré le dédain qu'il affiche à l'égard des manuels grecs et l'affirmation de son originalité ${ }^{5}$, le maître d'Herennius est en effet tributaire du travail des rhéteurs qui l’ont précédé. Honestus connaît trois usages dans le domaine de la technique oratoire; notre étude sémantique a déjà permis de les distinguer, en se fondant principalement sur le De inuentione ${ }^{6}$, et nous ne les rappellerons donc que brièvement, en soulignant la singularité de la Rhétorique à Herennius et le lien avec les sources grecques. Il est question d'honestum pour

${ }^{3}$ Sur les sources diverses de la Rhétorique à Herennius, voir l'édition Achard, p.XL-XLIV.

${ }^{4}$ Voir l'édition Achard de la Rhétorique à Herennius, p.XLVI-XLIX sur les similitudes et les différences. Malgré leurs ressemblances, il est très probable que les deux traités n'avaient pas connaissance l'un de l'autre (p. XLVII).

${ }^{5}$ Rhet. Her. I, 1 et IV, 1.

${ }^{6}$ Voir supra p.123-124 pour le genus honestum et p. 155 sqq. pour les deux autres emplois d'honestum, comme finis et locus. 
la première fois dans la Rhétorique à Herennius à propos de l'exorde. L'auctor indique que l'orateur, pour bien commencer son discours, doit savoir à quel type de cause appartient celle qu'il soutient. Le maître d'Herennius distingue quatre genres de cause:

Genera causarum sunt quattuor: honestum, turpe, dubium, humile. Honestum causae genus putatur cum aut id defendimus quod ab omnibus defendendum uidetur, aut id obpugnamus quod ab omnibus uidetur obpugnari debere ut pro uiro forti, contra parricidam. Turpe genus intellegitur, cum aut honesta res obpugnatur aut defenditur turpis. Dubium genus est, cum habet in se causa et honestatis et turpitudinis partem. Humile genus est, cum contempta res affertur.

«Il y a quatre genres de causes: l'honorable, le vil, l'incertain, l'insignifiant. Le genre est jugé honorable quand nous défendons une cause que tous semblent devoir défendre ou quand nous en combattons une que tous semblent devoir combattre (comme quand on plaide pour un homme courageux, contre un criminel). Le genre est considéré comme vil quand on attaque une conduite honorable ou qu'on défend une conduite vile. Le genre est incertain quand la cause est en partie honorable, en partie vile. Le genre est insignifiant quand se présente un sujet qui laisse indifférent. »

(Rhet. Her. I, 5 ; trad. Achard modifiée).

La Rhétorique à Herennius distingue les genres de cause selon l'état d'esprit du public vis-à-vis de l'affaire. La cause relève du genus honestum lorsqu'elle suscite de manière spontanée la faveur de l'auditoire. Elle appartient au contraire au genus turpe quand l'orateur soutient un point de vue contraire au jugement général et que le public est prévenu défavorablement. L'exorde indirect sera employé dans le cas du genus turpe, pour contourner les préventions du public, et l'exorde direct s'appliquera dans toutes les autres situations ${ }^{7}$. L'adjectif honestus connaît donc ici un usage technique mais ce dernier n'altère pas la notion en profondeur. Le terme sert en effet à désigner une situation où l'orateur suscite la bienveillance de l'auditoire parce que sa position dans l'affaire est en conformité avec les représentations morales de la collectivité. Le contenu social et moral d'honestus est transposé dans le domaine technique de la rhétorique sans profonde altération. Cicéron propose une classification assez similaire et définit lui aussi le genus honestum comme le genre qui provoque immédiatement la faveur de l'auditeur ${ }^{8}$.

La seconde utilisation rhétorique d'honestus a lieu à propos de la définition de la «fin» (finis) des discours délibératifs, c'est-à-dire de l'objectif que l'orateur a en vue et à quoi il ramène tout son propos.

${ }^{7}$ Sur ces aspects et fonctions de l'exorde, Guérin, Persona. L'Élaboration d'une notion rhétorique au I'r siècle av.J.-C., vol. 1, p. 349-353.

${ }^{8}$ Cic. Inu. I, 20. 
Le but premier de ce genre rhétorique est l'utile, qui se subdivise en deux éléments:

Omnem orationem eorum qui sententiam dicent finem sibi conueniet utilitatis proponere, ut omnis eorum ad eam totius orationis ratio conferatur. Vtilitas in duas partes in ciuili consultatione diuiditur: tutam, honestam.

«Tous les orateurs qui donneront leur avis devront dans leur discours se proposer pour but l'utile, en ramenant à cette fin toute l'économie de l'ensemble de leur discours. Dans un débat politique, l'utile se subdivise en deux parties: la sécurité et l'honnêteté. »

(Rhet. Her. III, 3 ; trad. Achard).

L'orateur qui parle en faveur d'une décision de nature politique doit donc montrer qu'elle est avantageuse: l'utile est la fin de l'éloquence délibérative. Cet utile se subdivise en tutum et en honestum: l'orateur soulignera que la proposition qu'il soutient est sûre, d'une part, et honnête, d'autre part. Cette définition se situe dans la lignée de celle d'Aristote qui s'intéresse, au début de sa Rhétorique, à la fin de chaque genre oratoire 9 . Le Stagirite pose lui aussi comme fin ( $\tau \dot{\lambda} \lambda \circ \varsigma)$

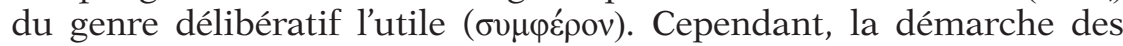
deux auteurs diverge: la définition d'Aristote s'insère dans un tableau général des genres oratoires et pose une fin précise pour chacun d'eux, envisagée sous son aspect positif et négatif: l'utile et le nuisible pour le délibératif, le juste et l'injuste pour le judiciaire, le beau et le laid pour l'épidictique. Dans la Rhétorique à Herennius, la présentation est beaucoup moins systématique puisque l'auctor ne s'intéresse, dans le passage que nous citons, qu'au genre délibératif. En outre, le maître d'Herennius établit des distinctions internes à la fin qu'est l'utile, en distinguant tutum et honestum, ce qui n'est pas fait par Aristote. Chez

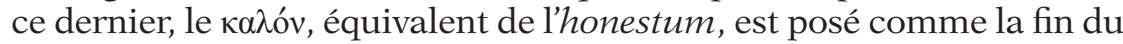
genre démonstratif; il peut avoir partie liée avec le délibératif, mais seulement de façon accessoire, comme élément emprunté à un autre genre. La Rhétorique à Herennius accorde une place plus importante à ce qui est honestum puisqu'elle considère que l'utile est "scindé» (diuiditur) en deux éléments, honestum et tutum. La catégorie de l'honnête n'est pas cantonnée par l'auctor au domaine de l'éloquence d'apparat mais rejoint celui du discours politique, sans doute en raison de l'importance prise dans les modes de pensée romains par honestum comme règle de conduite. Cicéron s'écarte encore davantage de la doctrine péripatéticienne dans le De Inuentione puisque l'adjectif honestus est présent dans chacun des genres rhétoriques. L'honestum est, comme

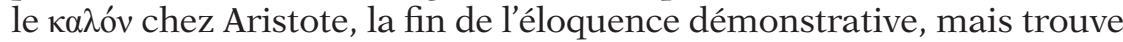
aussi une place dans l'éloquence judiciaire, dont le but est l'équité qui n'est, dit Cicéron, qu'une partie de l'honestas; on la rencontre égale-

\footnotetext{
${ }^{9}$ ARstr. Rhet. I, 3 (1358b).
} 
ment dans le genre délibératif dont la fin est pour l'Arpinate à la fois l'honestas et l'utilitas: l'honnête n'est plus une subdivision de l'utile comme dans la Rhétorique à Herennius mais une autre catégorie d'importance parfaitement équivalente ${ }^{10}$. La rhétorique romaine du $\mathrm{I}^{\mathrm{er}}$ siècle altère donc la tripartition aristotélicienne et confère une place grandissante au terme d'honestum parmi les différentes fines de l'éloquence ${ }^{11}$.

Le troisième et dernier usage rhétorique d'honestus concerne les «lieux» de l'éloquence, ces gisements d'arguments dans lesquels l'orateur peut puiser pour nourrir son discours ${ }^{12}$. Apparaissant chez Antiphon et dans les discours de Thucydide, ils ont été théorisés par Aristote qui a élaboré une science des lieux en distinguant les lieux communs des lieux propres et des lieux logiques ${ }^{13}$; les rhéteurs les ont aussi regroupés en différentes listes plus ou moins détaillées, comme celle des lieux relatifs aux circonstances (personne, action, temps, lieu, manière, cause, matière) ou celle des lieux relatifs aux fins (justice, utilité, possibilité, beauté morale). L'honestum est un des lieux de cette

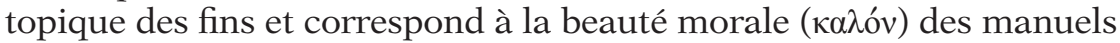
grecs. Il est utilisé comme locus dans les recommandations que donne la Rhétorique à Herennius sur la manière de traiter une cause qui repose sur l'interprétation d'un texte ambigu:

Deinde id quod nos interpretemur et fieri posse et honeste, recte, lege, more, natura, bono et aequo fieri posse; quod aduersarii interpretentur, ex contrario.

« $<$ Il faut montrer $>$ ensuite que notre interprétation est possible et conforme à l'honneur, à la droiture, à la loi, à la coutume, à la nature, au bien et à l'équité; que celle de nos adversaires, c'est tout le contraire.»

(Rhet. Her. II, 16).

Le terme d'honestus est un des prédicats que l'orateur doit appliquer à l'interprétation qu'il veut soutenir pour emporter l'adhésion de l'auditoire. C'est ici un lieu commun, qui serait applicable dans d'autres circonstances $^{14}$. Cet usage de l'honnête comme locus de la topique des

${ }^{10}$ Sur ces divisions, Cic. Inu. II, 12 et 156. La conjonction de l'utile et de l'honestum en rhétorique prélude aux développements sur l'identité de l'honnête et de l'utile véritable au livre III du De officiis. Voir Miches, Les Rapports de la rhétorique et de la philosophie dans l'ouuve de Cicéron, p. 577.

${ }^{11}$ Sur la gêne que cause la tripartition d'Aristote aux rhéteurs postérieurs, PERnot, La Rhétorique de l'éloge, p. 32 sqq.

${ }^{12}$ Voir les images utilisées par Cicéron pour les désigner: argumentorum sedes et argumentorum domicilia (Cıc. De or. II, 166; Top.7-8). Sur les lieux de la rhétorique, PERNOT, «Lieu et lieu commun dans la rhétorique antique».

${ }^{13} \mathrm{Ibid}$., p. 258 sqq.

${ }^{14}$ Voir un autre usage de ce lieu commun en Rhet. Her. IV, 33. Le De inuentione fait également d'honestus un usage topique en l'incluant dans une liste de lieux commodes pour l'orateur: c'est un locus exploitable pour soutenir une interprétation (CIc. Inu. II, 119) mais aussi dans le cas d'une alternative (Cı́.Inu.II, 77) ou pour l'état de définition (Сıc. Inu. II, 54). 
fins a été codifié par la Rhétorique à Alexandre au IV siècle. Le traité du pseudo-Aristote établit une liste des prédicats que l'orateur peut appliquer à des actions, des propos ou des options, et qui comporte le $\kappa \alpha \lambda o ́ v$, le beau, ainsi que le juste, le légal, l'utile, l'agréable, le facile, le possible et le nécessaire ${ }^{15}$. Cette liste sera systématisée par la rhétorique grecque postérieure ${ }^{16}$. La Rhétorique à Herennius ne paraît pas sur ce point se singulariser de la pensée théorique antérieure; on peut tout au plus remarquer que le traité accorde davantage d'importance, parmi les différents lieux de cette topique, à l'honestum et l'utile alors que la tradition grecque a établi quatre rubriques centrales de même importance, le juste, l'utile, le possible et le beau moral ${ }^{17}$.

L'emploi d'honestus par la Rhétorique à Herennius amène ainsi la notion sur le terrain de la rhétorique et plus particulièrement sur celui de l'inuentio puisqu'elle intervient dans la détermination de la fin et des lieux du discours. La notion préserve certains de ses traits traditionnels, comme on le voit quand elle désigne un des genera causarum, mais connaît aussi des usages nouveaux où elle entre en contact avec des objets qui lui étaient jusqu'alors très peu associés, comme l'utile. Il faut à présent déterminer les effets théoriques de cette mobilisation rhétorique.

\subsection{Le rapprochement entre honestus et $\kappa \alpha \lambda o ́ \varsigma$}

L'utilisation d'honestus pour restituer des éléments de la rhéto-

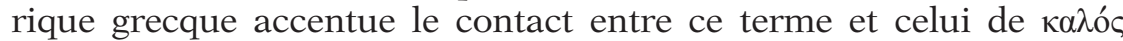
et prolonge donc l'acculturation esquissée par Térence et Lucilius. L'emploi d'honestus relève en effet dans la Rhétorique à Herennius, comme dans le De inuentione, d'un véritable procédé de traduction. Les Romains n'en sont plus au début du I ${ }^{\text {er }}$ siècle aux balbutiements du calque sémantique mais opèrent de manière consciente et régulière une translation conceptuelle. Les premiers contacts d'honestus

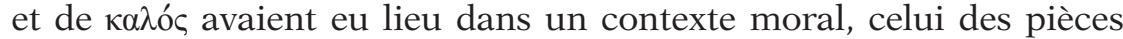
de Térence et du fragment sur la vertu de Lucilius. Mais c'est dans le domaine de la rhétorique que se confirme la connexion établie entre grec et latin; il faut la rigueur d'un traité technique pour pousser plus loin le rapprochement. La transposition dans le domaine rhétorique repose sur les facteurs que nous avions précédemment identifiés pour expliquer le calque ${ }^{18}$ et elle est en outre facilitée par la définition que

${ }^{15}$ Rhet. Alex. I, 4. Voir l'édition de P.Chiron, n. 57, p. 122.

${ }^{16}$ Hermog., Progymnasmata 12, 10 et 25, 22; Sur les états, 52, 20. Voir Pernot, «Lieu et lieu commun dans la rhétorique antique», p. 261 sqq.

${ }^{17}$ Ibid., p. 266. Cette accentuation de l'honestum et de l'utile est plus visible dans le De inuentione.

${ }^{18}$ Supra p. 159 sqq. 


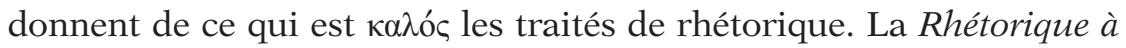
Alexandre déclare:

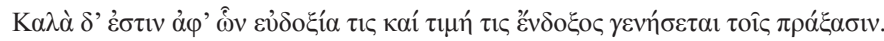

«Sont belles les actions d'où leurs auteurs retireront du renom ou une distinction honorifique.»

(Rhet. Alex. I, 12; trad. Chiron).

Kaגóc reçoit ici un sens esthétique et moral: c'est ce qui procure une bonne réputation et de la $\tau$ uń. Nous sommes donc, avec cette définition, très proches de l'honestum romain traditionnel, qui s'applique à une conduite qui vaut à son auteur une renommée favorable et de l'honos, équivalent latin de la $\tau \iota \mu$. La relation établie par l'auteur de la

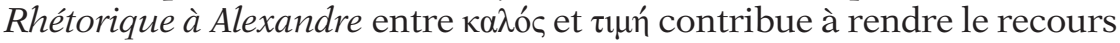
à honestus, lui-même très proche d'honos, incontournable. Il ne faut pas, néanmoins, exagérer le rôle joué dans cette transposition du $\kappa a \lambda$ ós rhétorique en latin par la Rhétorique à Herennius. On retrouve

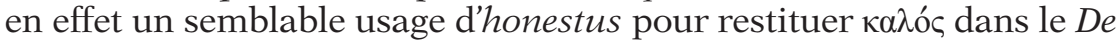
inuentione. Or, vu que les deux traités semblent indépendants mais se situent dans un même contexte culturel et intellectuel, il est probable que l'acculturation poussée de $\kappa \alpha \lambda$ ó non d'un individu isolé mais d'un milieu cultivé et bilingue plus large, qui est peut-être celui des rhetores Latini du début du $\mathrm{I}^{\mathrm{er}}$ siècle. Il faut aussi souligner que, malgré l'avancée visible du rapprochement entre honestus et $\kappa \alpha \lambda o ́ s$ dans la Rhétorique à Herennius, la transposition n'est pas parfaitement stable. L'expression de ce qui est moralement beau passe parfois dans le traité par d'autres termes, comme pulcher ${ }^{19}$. L'usage d'honestus n'est donc pas automatique. En outre, l'adjectif latin conserve sa plasticité car il continue d'être employé dans des contextes non techniques, par exemple lorsqu'il désigne l'excellence sociale des chevaliers dont l'ordo est dit honestissimus ${ }^{20}$.

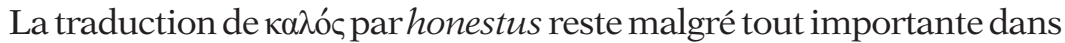
le traité. Si l'auctor y recourt si volontiers, c'est parce que le terme sert parfaitement son entreprise de latinisation de la $\tau_{\varepsilon}^{\prime} \chi \vee \eta$ rhétorique grecque: à la différence du Cicéron du De inuentione, il affecte à l'endroit des Grecs un certain mépris, comme quand il souligne leur vaine arrogance et la nature contournée de leurs exposés sur l'art de parler ${ }^{21}$. Concernant la langue grecque elle-même, l'auteur prend soin de transcrire en latin les termes grecs qu'il citeet deleurdonner systématiquement une traduction ${ }^{22}$.

${ }^{19}$ Rhet. Her. IV, 65.

${ }^{20}$ Rhet. Her. IV, 47.

${ }^{21}$ Rhet. Her. I, 1. Voir aussi la critique de leur méthode en III, 38 et IV, 1.

${ }^{22}$ Voir par exemple Rhet. Her. I, 6: principium, quod Graece procmium appellatur, et insinuatio quae ephodos nominatur: "le simple début que l'on appelle en grec prooimion et l'exorde indirect que l'on dénomme ephodos » (trad. Achard). Voir aussi I, 26 sur 
Il se soucie en outre de ne pas utiliser de termes d'allure trop technique et s'excuse quand il est obligé de le faire:

[...] nomina rerum Graeca quae uertimus, ea remota sunt a consuetudine. Quae enim res apud nostros non erant, earum rerum nomina non poterant esse usitata.

«[...] les termes techniques grecs que nous avons traduits sont éloignés de l'usage courant. En effet les désignations de réalités qui n'existaient pas chez nous ne pouvaient pas faire partie du vocabulaire usuel. »

(Rhet. Her. IV, 10; trad. Achard).

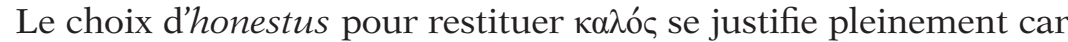
il permet de ne pas, cette fois, s'éloigner de la consuetudo, de l'usage courant. Ladjectif honestus est en effet un terme parfaitement usuel.

\subsection{L'approfondissement théorique}

Lucilius avait commencé à élaborer l'adjectif honestus de façon conceptuelle ${ }^{23}$, mais c'est surtout avec la Rhétorique à Herennius que cette élaboration se développe. Sous l'égide de la pensée grecque, et en raison de la formalisation que réclame la présentation systématique de l'ars dicendi, le maître d'Herennius fait un usage plus théorique du terme honestus. Il est en cela représentatif de son époque qui voit différentes notions romaines traditionnelles redéfinies et approfondies ${ }^{24}$. En premier lieu, la Rhétorique à Herennius donne à la notion une plus grande portée en la faisant entrer dans le domaine de la rhétorique. En devenant un terme technique de l'éloquence, honestus sort du domaine social et moral et devient un outil plus général. Térence avait déjà assoupli la notion en l'entraînant dans le domaine esthétique ${ }^{25}$; le maître d'Herennius contribue à lui donner de la hauteur en l'amenant sur le terrain de la rhétorique. L'entreprise de théorisation d'honestus se ressent, en deuxième lieu, dans le travail de définition opéré par le maître d'Herennius. Les définitions précédentes sont le plus souvent énumératives et descriptives: l'honestum consiste à faire preuve de modération, de décence, etc. Lucilius commence à synthétiser ces différents traits, mais c'est la Rhétorique à Herennius qui en donne une définition plus générale, plus stable et plus pertinente. On le voit dans

iudicatio / crinomenon; II, 2 sur argumentationes / epicheremata; II, 47 sur conclusiones lepilogi.

${ }^{23}$ Voir supra p. 654 sqq.

${ }^{24}$ Le De inuentione, presque contemporain, présente une élaboration théorique de l'honestum au moins aussi poussée que celle de la Rhétorique à Herennius. Pour d'autres notions qu'honestum, voir Тноме, Zentrale Wertvorstellungen der Römer, p.50-55. L'auteur remarque notamment que la notion de iustitia est considérablement enrichie par la Rhétorique à Herennius, sous l'influence d'Aristote.

${ }^{25}$ Voir supra p. 630 sqq. 
le texte concernant le genus honestum où l'honestum est ce qui suscite immédiatement la faveur: l'auctor définit l'honestum non par sa nature mais par son action, ce qui permet de sortir d'un relevé des conduites honorables, potentiellement indéfini ${ }^{26}$. La rhétorique, parce qu'elle utilise des termes à des fins techniques, est contrainte d'en préciser le sens et la portée, ce qui bénéficie à la précision des concepts ${ }^{27}$. Le troisième procédé développant l'usage théorique d'honestus est celui de la division. Le terme se trouve, dans la Rhétorique à Herennius, convoqué dans un processus de dichotomie des fins du genre délibératif qui situe le concept dans une hiérarchie précise. Cela apparaît dans le texte du livre III que nous citons à nouveau de manière plus étendue:

Omnem orationem eorum qui sententiam dicent finem sibi conueniet utilitatis proponere, ut omnis eorum ad eam totius orationis ratio conferatur. Vtilitas in duas partes in ciuili consultatione diuiditur: tutam, honestam. Tuta est quae conficit instantis aut consequentis periculi uitationem qualibet ratione. Haec distribuitur in uim et dolum quorum aut alterum separatim aut utrumque sumemus coniuncte. [...] Honesta res diuiditur in rectum et laudabile.

«Tous les orateurs qui donneront leur avis devront, dans leur discours, se proposer pour but l'utile, en ramenant à cette fin toute l'économie de l'ensemble de leur discours. Dans un débat politique, l'utile se subdivise en deux parties: la sécurité et l'honnêteté. La sécurité permet d'éviter par quelque moyen que ce soit un danger présent ou à venir. Elle se subdivise en force et en ruse, que l'on traitera séparément ou ensemble. [...] L'honnêteté comporte ce qui est droit et ce qui est louable.»

(Rhet. Her. III, 3 ; trad. Achard).

La fin du genre délibératif est l'utile. Ce dernier se divise en deux parties, l'honestum et le tutum. L'honestum est lui-même à son tour divisé en deux, le rectum et le laudabile, comme le tutum, qui comprend la uis et le dolus. La détermination de la fin du discours délibératif procède donc par une division systématique en deux parties de chaque élément, en partant de l'utile, comme le montre le schéma ci-dessous:

La fin du genre délibératif dans la Rhétorique à Herennius (III, 3)

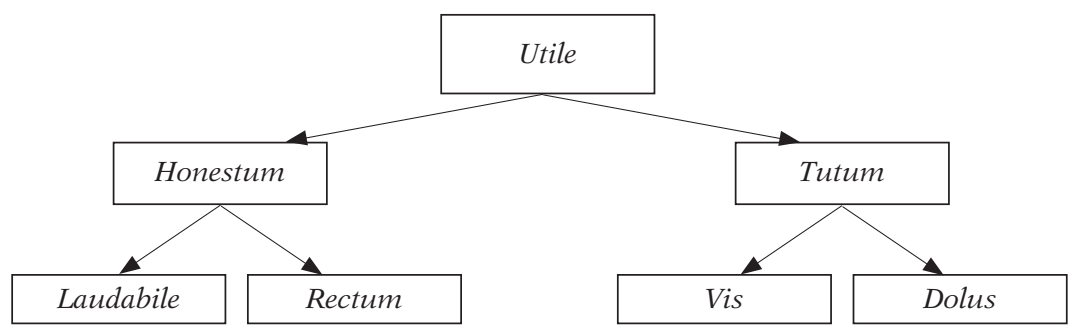

${ }^{26}$ Rhet. Her. I, 5. Voir le texte supra p. 669.

${ }^{27}$ De manière plus générale, tous les savoirs scientifiques réorganisés au I ${ }^{\text {er }}$ siècle (grammaire, architecture, rhétorique, droit, etc.) imposent le recours à la dénomination et à la définition (Mонтті, La Raison de Rome, p. 241). 
L'honestum participe donc à une entreprise de dichotomie de l'utile. Il est de ce fait intégré dans un système complexe au sein duquel il occupe une place précise: d'une part, il est situé au même niveau d'importance hiérarchique que le tutum, qu'il complète pour la désignation de l'utile; d'autre part, l'honestum se subdivise à son tour en laudabile et rectum, ce qui est une façon de définir sa nature et de le mettre en relation avec d'autres notions perçues comme proches parce qu'appartenant à la sphère morale. Cette analyse dichotomique permet de classer l'honestum au sein d'un système et de lui conférer un pouvoir taxinomique inédit, ce qui accentue encore sa dimension conceptuelle. Cette présentation de la fin du genre délibératif doit beaucoup à l'analyse du genre et des espèces pratiquée par la philosophie grecque. Platon a fréquemment recouru au procédé de la dichotomie à des fins analytiques et indique que le philosophe doit être capable de fendre en deux l'essence selon les espèces ${ }^{28}$. Le maître d'Herennius pratique cette séparation en deux mais son procédé est peut-être plus proche de la pratique aristotélicienne de la division. En effet, Aristote a fait un usage critique de la dichotomie platonicienne, qui descend du genre vers les espèces de façon hiérarchique, en lui ajoutant la technique de la "partition ", qui consiste à déterminer les parties dont les espèces sont elles-mêmes constituées ${ }^{29}$. Or le maître d'Herennius adjoint précisément à la division une énumération des parties des quatre derniers éléments du bas du tableau; la uis, par exemple, se compose des armées, flottes, armes légères, artilleries et levées d'hommes; le rectum repose lui sur la sagesse, la justice, le courage et la modération, c'est-à-dire les quatre vertus cardinales ${ }^{30}$.

L'adjectif honestus bénéficie donc du travail de théorisation opéré par la Rhétorique à Herennius au moyen de trois procédés, la généralisation, la définition et la division. La systématisation de la pratique oratoire rejaillit sur les notions employées et leur donne une profondeur théorique. La Rhétorique à Herennius se livre, dans le domaine de l'art oratoire, à un travail de classification et de mise en ordre que l'on retrouve au $\mathrm{I}^{\mathrm{er}}$ siècle dans d'autres domaines, comme la topographie, l'administration ou le droit ${ }^{31}$. Une volonté d'organisation et de rationalisation des savoirs se manifeste à cette époque; l'entreprise de la Rhétorique à Herennius n'est pas sans rappeler la systématisation du droit que Crassus appelle de ses vœux dans le De oratore et qui se

${ }^{28}$ Sur la dichotomie, voir Plat. Soph. 235d. La méthode de la division est au cœur de la dialectique «descendante».

${ }^{29}$ Sur la division et la partition chez Aristote puis à Rome, voir D. NöRR, Divisio und Partitio. Bemerkungen zur römischen Rechtsquellenlehre und zur antiken Wissenschaftstheorie, Berlin, Schweitzer, 1972 et Mолтті, La Raison de Rome, p. 235-237. Le procédé a surtout été utilisé à Rome chez les théoriciens du droit.

${ }^{30}$ Rhet. Her. III, 3.

${ }^{31}$ Mostтi, La Raison de Rome, p. 244 sqq. 
fonde, elle aussi, sur la définition des éléments et sur la division en espèces de quelques préceptes de base ${ }^{32}$. C'est donc dans un ouvrage de rhétorique que se forge le concept d'honestum destiné à une si grande fortune dans le domaine de la philosophie éthique.

\section{L'ASPECT ÉTHIQUE DE LA CONCEPTUALISATION RHÉTORIQUE}

La réflexion rhétorique du maître d'Herennius possède des répercussions éthiques car la formulation de préceptes concernant l'action honesta amène l'auctor sur le terrain des conduites humaines et introduit, indirectement, une brèche dans la morale ancestrale de l'honneur.

\subsection{La distinction de l'aspect social et de l'aspect moral}

Des trois usages rhétoriques de l'adjectif honestus dans le traité, c'est l'emploi de la notion à propos de la fin du discours délibératif qui nous paraît le plus riche de répercussions éthiques et c'est donc à ce dernier que nous nous intéresserons ${ }^{33}$. Comme nous l'avons vu, le traité divise honestum en laudabile et en rectum. Ce dernier est défini de la sorte:

Rectum est quod cum uirtute et officio fit. Id diuiditur in prudentiam, iustitiam, fortitudinem, modestiam.

«Est droit ce qui est en accord avec la vertu et le devoir. On y distingue la sagesse, la justice, le courage et la modération.»

(Rhet. Her. III, 3 ; trad. Achard).

Au moyen de la notion de rectum, le maître d'Herennius développe un aspect essentiel d'honestus, l'adhésion à des principes de comportement (uirtus et officium) et la manifestation de qualités morales, qui sont énumérées par le texte. Cette dimension morale d'honestus n'est pas en soi nouvelle car le code d'honneur traditionnel suppose la conformité à des règles de conduite. C'est le fait qu'elle soit reportée

${ }^{32}$ Cic. De or. I, 190. Sur l'entreprise voulue par Crassus, voir Ibid., p. 230 avec une bibliographie indicative.

${ }^{33}$ L'intégration de l'honestum dans la topique des fins est elle aussi intéressante mais sa portée éthique est moins originale vis-à-vis de la tradition: cette topique relève en effet d'une analyse de type philosophique de la nature des fins de l'action et de la notion de valeur (PERNot, "Lieu et lieu commun dans la rhétorique antique», p. 267). La définition du genus honestum de la cause est quant à elle moins exploitable philosophiquement. 
sur le rectum et confinée dans cette notion qui l'est. Quant au laudabile, il est défini de la sorte:

Laudabile est quod conficit honestam et praesentem et consequentem commemorationem.

«Est louable ce qui procure pour le présent et l'avenir une honorable renommée.»

(Rhet. Her. III, 7 ; trad. Achard).

À travers le laudabile, le traité met en avant un autre aspect d'honestum, l' "honorabilité", la capacité à provoquer l'estime de l'entourage et à préserver une bonne réputation. Il s'agit d'un trait tout à fait conventionnel du terme, mais qui est, ici aussi, reporté sur une autre notion, le «louable». La dichotomie n'altère donc pas la nature profonde d'honestum mais elle provoque, en revanche, une dissociation de deux éléments jusqu'alors fermement unis en son sein, la conformité aux règles morales et la capacité à susciter la considération de l'entourage. Une telle distinction confère à la bonne moralité, d'un côté, et au prestige social, de l'autre, une indépendance grandissante. Une telle distinction recèle des potentialités très importantes: elle permet par exemple d'envisager une action morale dissociée d'une récompense sociale ou bien une approbation collective dépourvue de fondements moraux. Nous avons vu que, chez Térence et Lucilius, honestus évoluait vers la désignation de l'honnêteté, moralité dépourvue de retombées sociales, et s'écartait de l'honneur où ces retombées sont essentielles ${ }^{34}$. La Rhétorique à Herennius consacre quant à elle cette évolution de la notion par une nette distinction conceptuelle. Elle ne la pousse pas néanmoins jusqu'à la rupture avec l'honneur traditionnel.

L'évolution d'honestus vers l'éthique est cependant bien avancée. On le mesure à l'importance accordée par la Rhétorique à Herennius au rectum au sein de ce qui est honestum. Il est soigneusement distingué du laudabile:

Laudabile est, quod conficit honestam et praesentem et consequentem commemorationem. Hoc nos eo separauimus a recto, non quod hae quattuor partes quae subiciuntur sub uocabulum recti hanc honestatis commemorationem dare non soleant, sed quamquam ex recto laudabile nascitur, tamen in dicendo seorsum tractandum est hoc ab illo: neque enim solum laudis causa rectum sequi conuenit, sed si laus consequitur, duplicatur recti adpetendi uoluntas. Cum igitur erit demonstratum rectum esse, laudabile esse demonstrabimus aut ab idoneis hominibus - ut si qua res honestiori ordini placeat, quae a deteriore ordine inprobetur - aut quibus sociis aut omnibus ciuibus, exteris nationibus, posterisque nostris.

«Est louable ce qui procure pour le présent et l'avenir une honorable renommée. Si nous l'avons séparé de la rectitude, ce n'est pas que les quatre

\footnotetext{
${ }^{34}$ Voir supra p. 628 sqq. et 654 sqq.
} 
parties regroupées sous ce mot ne procurent pas généralement une honorable renommée, mais les actions louables, bien qu'ayant leur source dans la rectitude, doivent néanmoins en être dissociées dans le discours. Et il ne convient pas en effet d'agir avec rectitude pour mériter des éloges, mais si ceux-ci viennent de surcroît, la volonté d'atteindre la rectitude est doublée. Après avoir démontré que l'action est droite nous prouverons qu'elle mérite les éloges soit des personnes compétentes (au cas où une action plairait à un ordre plus honorable de citoyens et déplairait à un ordre inférieur), soit de certains alliés, soit de tous les citoyens, soit de nations étrangères, soit de la postérité. »

(Rhet. Her. III, 7 ; trad. Achard).

Le texte pose clairement que l'action droite est susceptible de procurer une bonne réputation à celui qui en est l'auteur mais que cette réception favorable par la collectivité demeure secondaire pour qu'une conduite soit recta. L'action droite n'a pas en effet pour but de recevoir des éloges (laudis causa). L'auteur du traité ne formule pas explicitement l'objectif réel de l'action droite et se contente de le définir par la négative; cette déficience théorique n'empêche cependant pas de percevoir ce qui est passé sous silence, à savoir que l'action droite vaut pour elle-même et non pour les avantages sociaux qu'elle procure $^{35}$. Cette première élaboration, peu maîtrisée, d'une droiture valant pour soi se fait surtout par la mise en jeu de la notion de uoluntas. Le passage mentionne en effet une recti adpetendi uoluntas, c'est-à-dire une volonté droite, visant le bien pour lui-même. L'auctor ne méconnaît pas le rôle de l'honos dans l'orientation de la conduite mais ne le place qu'au second plan: les honneurs ne font que redoubler la recti uoluntas et ne lui donnent pas son impulsion première. Cela suppose donc qu'elle existe indépendamment des éloges et qu'elle prend naissance par la considération du seul bien. La Rhétorique à Herennius contribue à creuser la distance entre honestum et honos et à orienter honestum vers une honnêteté éthique. Ce qui est rectum, en outre, doit passer en premier: l'orateur commencera par montrer que l'action est droite et ce n'est qu'ensuite qu'il en évoquera les conséquences sous forme d'éloges et d'hommages pour convaincre son public. La considération de ce qui a une valeur morale en soi devient une préoccupation de premier plan.

\subsection{Entre honneur et moralité}

Comme la distinction des deux faces, sociale et morale, d'honestum n'est pas menée jusqu'à une dissociation complète, l'adjectif

${ }^{35}$ Le jeune Cicéron se montre lui plus complet dans son approche d'honestum dans le De inuentione puisqu'il le définit positivement comme quod aut totum aut aliqua ex parte propter se petitur, "ce que l'on recherche, totalement ou en partie, pour ses qualités propres» (Cic. Inu., II, 159; trad. Achard). 
devient, dans la Rhétorique à Herennius un concept complexe, qui a trait simultanément à l'honneur traditionnel et à la beauté morale

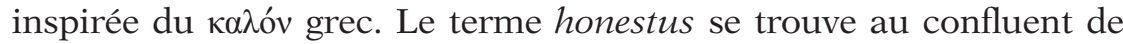
deux éthiques, une morale sociale et une morale rationnelle du bien, et au carrefour de deux traditions culturelles, celle de Rome et celle de l'hellénisme. Cette position intermédiaire se ressent dans la définition du rectum: rectum est quod cum uirtute et officio fit. Id diuiditur in prudentiam, iustitiam, fortitudinem, modestiam ${ }^{36}$. On voit ici se mêler des éléments traditionnels et d'autres inédits. La mention de la uirtus et de l'officium comme guides de l'action droite n'est pas nouvelle: ces notions sont régulièrement associées au code de l'honneur qu'est honestum dans les textes plus anciens. Mais elles prennent ici un sens éthique plus marqué que dans la tradition morale. Comme dans le fragment sur la vertu de Lucilius, uirtus ne désigne plus la «vaillance» ou la «valeur» globale de l'individu mais sa vertu éthique, équivalent de l'åpetń grecque. L'officium, de même, n'est plus l'obligation qui s'impose en fonction de l'identité sociale mais le devoir moral. Il y a donc persistance au sein du concept d'honestum de notions traditionnelles mais qui sont chargées d'un contenu nouveau. Un procédé inverse se rencontre également: des notions inédites sont pourvues d'un contenu traditionnel. On voit en effet, dans la suite de la définition citée, que les quatre vertus cardinales de la tradition platonicienne et péripatéticienne entrent dans la composition de rectum et donc d'honestum. Ce dernier ne regroupe plus des conduites multiples et variées mais quatre qualités éthiques fondamentales ${ }^{37}$. Le contenu de chacune de ces vertus, cependant, est loin d'être en rupture totale avec la matière traditionnelle de l'honneur. La iustitia, par exemple, englobe des exigences ancestrales du code d'honneur: le maître d'Herennius indique ainsi, entre autres, qu'elle consiste à être reconnaissant envers ceux qui ont rendu des services, à être fidèle à la parole donnée, à maintenir les lois et usages de la cité, à observer les devoirs envers les parents, les dieux et la patrie. Ces quatre traits renvoient à la gratia, à la fides, au respect du mos et à la pietas qui sont des impératifs de la conduite honesta conventionnelle ${ }^{38}$. Le cadre conceptuel est emprunté à la pensée grecque mais le contenu moral est dans la droite ligne de la

${ }^{36}$ Rhet. Her. III, 3.

${ }^{37}$ Sur ces quatre vertus canoniques, fixées et formalisées par le livre IV de la République de Platon, et leur histoire, H.NoRTH, "Canons and Hierarchies of the Cardinal Virtues in Greek and Latin Literature », in WaLLACH, L.(éd.), The Classical Tradition: Literary and Historical Studies in Honor of Harry Caplan, Ithaca, Cornell University Press, 1966, p. 165-183.

${ }^{38}$ Voir supra p. 469. 
coutume romaine. Il y a, ici encore, mélange de deux traditions ${ }^{39}$. Un autre passage permet de mesurer encore mieux l'association des deux formes d'éthique; il s'agit de celui qui évoque les lieux que l'orateur peut employer quand il doit soutenir ce qui est honestum:

Qui tutae rei praeponet rationem honestam his locis utetur: uirtutem nullo tempore relinquendam; uel dolorem si is metuatur, uel mortem si ea formidetur, dedecore et infamia leuiorem esse; considerare quae sit turpitudo consecutura: at non inmortalitatem neque aeternam incolumitatem consequi, nec esse exploratum illo uitato periculo nullum in aliud periculum uenturos; uirtute uel ultra mortem proficisci esse praeclarum; fortitudini fortunam quoque esse adiumento solere; eum tute uiuere qui honeste uiuat, non qui in praesentia incolumis, et eum qui turpiter uiuat incolumem in perpetuum esse non posse.

"Celui qui fera passer les considérations d'honnêteté avant celles de sécurité emploiera les lieux suivants: on ne doit en aucune circonstance renoncer au courage; même la douleur, si on la craint, même la mort, si on la redoute, sont plus supportables que le déshonneur et l'infamie; il faut réfléchir à la honte qui s'ensuivra: on ne gagnera ni l'immortalité, ni une éternelle sauvegarde, ni l'assurance que, ce danger évité, on ne tombera pas dans un autre; il est très beau grâce à son courage d'aller au-delà même de la mort; la fortune seconde habituellement le courage; c'est celui qui vit dans l'honneur et non celui qui échappe provisoirement au péril qui vit en sûreté; celui qui vit dans la honte ne peut éternellement conserver la vie.»

(Rhet. Her. III, 9; trad. Achard).

La rationem honestam mentionnée à la première ligne est une

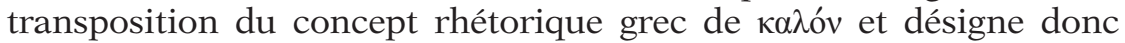
l' «honnêteté» et non pas l'honneur. Néanmoins, les exemples proposés par l'auctor montrent bien que le négatif de cet honestum reste le déshonneur et n'est pas le mal moral: l'orateur devra montrer les affres du dedecus, de la turpitudo et de l'infamia, c'est-à-dire de la disgrâce sociale et non de la méchanceté. Le fond des arguments avancés repose en outre sur le thème traditionnel de la mort honorable. On voit ainsi que sous le concept d'honestum se trouvent réunis les traits du code de l'honneur traditionnel. Il y a une acculturation du

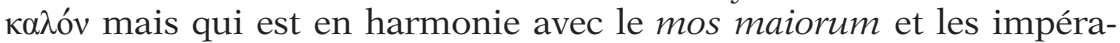
tifs anciens de l'honneur. Le maître d'Herennius importe un concept étranger mais le fond adroitement dans la culture qui le reçoit et réunit de la sorte deux systèmes, la morale ancestrale et l'éthique grecque.

${ }^{39}$ Ce mélange est sensible également chez Cicéron, dans l'énumération qu'il donne du contenu de l'honestum dans le De inuentione (II, 159 sqq.), mais la présentation qu'il en fait est plus théorique et plus marquée par la pensée grecque. Voir par exemple la définition de la justice, qui consiste à sauvegarder l'intérêt général tout en accordant à chacun ce qu'il mérite (II, 160). 


\section{CONCLUSION}

La Rhétorique à Herennius constitue un terrain privilégié pour l'observation de l'approfondissement conceptuel d'honestus. L'ouvrage permet d'appréhender trois emplois de l'adjectif dans le domaine de la technique rhétorique; ces derniers donnent à la notion latine une plus grande richesse théorique, notamment en accentuant le rappro-

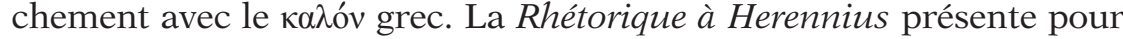
la première fois en latin un travail conceptuel abouti sur honestus. Ce dernier n'est cependant pas propre à ce traité, puisqu'on le rencontre aussi dans le De inuentione qui est presque contemporain; cela nous amène à penser que c'est l'ensemble du monde savant des années 80 qui a développé le concept d'honestum. C'est donc, de manière inattendue, dans le domaine de l'ars dicendi que la notion d'honneur reçoit une portée nouvelle et s'enrichit d'applications théoriques inédites, pour lesquelles le théâtre et la satire avaient constitué, dans les décennies précédentes, une sorte de laboratoire. L'enrichissement conceptuel d'honestus se produit avant la rédaction des traités philosophiques cicéroniens de la fin de la République. Le travail effectué par le maître d'Herennius est d'autant plus important qu'il possède des répercussions dans le domaine éthique. Le recours au procédé de la division accentue la distinction entre l'aspect social et l'aspect moral d'honestus et ouvre la voie à la prise en compte de la valeur per se de l'action morale. L'évolution d'honestus vers l'honnêteté et son écart avec l'honneur s'en trouvent formalisés et accentués, mais la morale de l'honnête continue à coexister avec celle de l'honneur. Il faut souligner, enfin, que le contact avec la pensée grecque joue un rôle décisif aussi bien pour la théorisation d'honestus que pour son évolution éthique. La marque de la $\tau \dot{\varepsilon} \chi v \eta$ ne vient pas néanmoins bouleverser radicalement la composition du comportement honestus puisqu'elle est intimement mêlée aux éléments romains traditionnels. L'étude de l'honneur dans la Rhétorique à Herennius invite donc à penser le rapport du mos maiorum et de la pensée grecque sur le modèle de la complémentarité et non de l'alternative ou du conflit. 


\section{LUCRÈCE: LA CRITIQUE ÉPICURIENNE DE L'HONOS}

\section{INTRODUCTION}

Les occurrences de la notion d'honneur dans le De rerum natura sont peu nombreuses mais elles témoignent parfaitement de l'originalité de la pensée de Lucrèce sur la question. En effet, le poète est le premier à donner de l'honos et de sa recherche une image très négative et à les critiquer de manière virulente, en contradiction avec la tradition romaine. En outre, Lucrèce occulte totalement dans son poème le concept d'honestum, qui était pourtant à son époque en plein développement ${ }^{1}$. Le poète a aussi la singularité d'associer l'axiologie à la génétique de l'honneur: sa critique du désir d'honneur se fonde sur l'identification de son origine, qui n'est autre que la peur de la mort. L'honos n'est plus le praemium promis au courageux qui brave les dangers mais l'illusoire secours recherché par l'homme hanté par la peur du trépas. Pour expliquer ces particularités de la pensée lucrétienne de l'honneur, plusieurs éléments doivent être pris en compte. Il convient en premier lieu de prêter attention aux spécificités du genre pratiqué par Lucrèce, la poésie philosophique. Le De rerum natura vise à délivrer en latin l'enseignement d'Épicure et s'adresse à un destinataire romain, Memmius. C'est une œuvre poétique qui recourt largement aux images et aux rythmes pour faciliter l'assimilation de la doctrine: selon la célèbre comparaison, il s'agit de rendre moins amer le remède qui doit être bu en enduisant du miel de la poésie les bords de la coupe qui le contient ${ }^{2}$. En second lieu, le jugement et la réflexion de Lucrèce sur l'honneur doivent être évalués à l'aune de son épicurisme: le poète est imprégné de la pensée d'Épicure qu'il admire sans réserve. Comment la doctrine du Jardin s'articule-t-elle avec le rejet de

${ }^{1}$ Il n'y a qu'une seule occurrence de l'adjectif honestus dans l'œuvre de Lucrèce, avec le sens traditionnel d' "honorable» (DRN IV, 1181). La plupart des éditeurs rejettent au profit de [h]onustum la leçon honestum donnée par $O Q V$ en $D R N$ III, 113 pour qualifier le corps en train de dormir. A. PIERI, «Un problema di psicologia epicurea nell'esegesi di Lucr. III, 113 ", Prometheus, 4, 1978, p.243-260 la maintient et considère que l'adjectif a le sens de «beau», mais onustus nous semble mieux correspondre: le terme renvoie ainsi à l'idée d'un corps rendu pesant par le sommeil et contraste bien avec la mention de l'agitation de l'esprit pendant la nuit (III, 114).

${ }^{2}$ LUCR. DRN IV, 11-25. 
l'honneur formulé dans le De rerum natura? En dernier lieu, nous ne pourrons négliger le poids du contexte historique, marqué notamment par le développement de la violence et des luttes internes avec, entre autres, la guerre sociale et les affrontements entre Marius et Sylla.

\section{UNE VISION CRITIQUE DU DÉSIR D'HONOS}

Dans son traitement du thème de l'honos, Lucrèce s'intéresse principalement à la recherche et au désir d'honneur et en donne dans ses vers une représentation très critique. Deux aspects sont particulièrement importants: sur le plan formel, Lucrèce dessine de l'ambition une image misérable et dégradée, qui est à dessein très frappante; sur le fond, il montre le cortège de maux qui accompagne la recherche de l'honos. La mise en forme poétique fonctionne de concert avec une démonstration didactique pour délivrer les hommes de l'ambition ${ }^{3}$.

\subsection{L'image misérable de l'ambition}

Deux passages du De rerum natura abordent de manière relativement étendue la question de l'ambition. Le premier se situe au début du livre III, consacré à l'âme, au moment où Lucrèce dépeint les terribles conséquences de la peur de la mort:

\footnotetext{
Denique auarities et honorum caeca cupido

Quae miseros homines cogunt transcendere fines

Iuris et interdum socios scelerum atque ministros

Noctes atque dies niti praestante labore

Ad summas emergere opes, haec uulnera uitae

Non minimam partem mortis formidine aluntur.

[...]

Consimili ratione ab eodem saepe timore

Macerat inuidia: ante oculos illum esse potentem,

Illum aspectari, claro qui incedit honore,

Ipsi se in tenebris uolui caenoque queruntur.

Intereunt partim statuarum et nominis ergo.

«Enfin l'avidité et le désir aveugle des honneurs

Qui poussent les misérables hommes à enfreindre les limites

Du droit et parfois à se faire complices ou auteurs d'un crime,

Les efforts faits nuit et jour avec un labeur sans égal

Pour atteindre la plus haute opulence, ces plaies de la vie

Sont nourries, pour une très grande part, par la peur de la mort.

$[\ldots]$

Par un procédé très semblable, l'envie, naissant souvent de la même peur

Les tourmente: celui-ci affiche sous leurs yeux sa puissance, gémissent-ils,

Celui-là attire les regards et s'avance dans l'éclat de l'honneur,
}

${ }^{3}$ Sur la critique lucrétienne de l'ambition, voir BenFERHAT, Ciues Epicurei, p. 83-87. 
Alors qu'eux-mêmes se roulent dans les ténèbres et la fange.

Certains périssent pour des statues et pour un nom. »

(LuCR. DRN III, 59-64 et 74-78).

Le second texte, dont l'étude doit être menée en parallèle se situe au livre $\mathrm{V}$, quand le poète retrace les origines de la civilisation. Lucrèce évoque l'apparition des cités et de la richesse:

At claros homines uoluerunt se atque potentes,

$V t$ fundamento stabili fortuna maneret

Et placidam possent opulenti degere uitam,

Nequiquam, quoniam ad summum succedere honorem

Certantes iter infestum fecere uiai,

Et tamen e summo, quasi fulmen, deicit ictos

Inuidia interdum contemptim in Tartare taetra;

Inuidia quoniam, ceu fulmine, summa uaporant

Plerumque et quae sunt aliis magis edita cumque;

$V t$ satius multo iam sit parere quietum

Quam regere imperio res uelle et regna tenere.

«Mais les hommes ont voulu être illustres et puissants

Pour que leur destin fût fondé sur des bases solides

Et pour pouvoir mener une vie paisible grâce à l'opulence;

En vain, car pour parvenir au sommet de l'honneur

Ils luttent et se rendent le chemin dangereux,

Et même s'ils arrivent au sommet, ils tombent, souvent, frappés par

L'envie, telle la foudre, qui les précipite honteusement dans l'horrible Tartare.

L'envie, en effet, comme la foudre, embrase les sommets,

En général, et toutes les hauteurs;

Aussi vaut-il bien mieux obéir paisiblement

Que vouloir tout soumettre à son pouvoir et obtenir la royauté.»

(LuCR. DRN V, 1120-1130).

Ces deux extraits présentent une image très négative du désir d'honos. Le premier dépeint de manière générale et intemporelle l'honorum cupido des hommes et en propose une analyse psychologique, en l'expliquant par la peur de la mort. C'est cette attitude, dépourvue de tout fondement pour l'épicurien qu'est Lucrèce, qui est à la racine de la recherche des honneurs et d'une vie perturbée. Le second texte est de nature plus historique: il situe l'ambition dans le temps, à l'époque des rois, et associe sa naissance à l'élargissement des dimensions de la communauté; il montre aussi l'incohérence de ceux qui recherchent l'honos pour être puissants alors que ce prestige est synonyme de dangers et de retournement de fortune: la lecture historique évolue donc vers le jugement moral. Les deux passages donnent de l'ambition une image très noire et se caractérisent par la présence d'images qui visent à impressionner le lecteur. Au livre III, l'avidité et le désir des honneurs sont qualifiés de uulnera uitae, "plaies de la vie», métaphore qui les assimile à des pathologies dangereuses. 
L'idée d'une souffrance physique et psychique est convoquée par l'utilisation de macerat, queruntur et intereunt qui font des hommes les victimes de l'ambition et de la cupidité. Ces deux dernières sont en outre personnifiées puisque ce sont elles qui poussent les hommes (cogunt) et se nourrissent (alunt) de la peur de la mort. La tonalité des vers du livre $\mathrm{V}$ est aussi sombre: Lucrèce ne dépeint pas la misère des ambitieux mais s'attarde sur leur destin fatal. Comme dans le passage du livre III, il recourt à des analogies, en comparant les ambitieux à ceux qui gravissent les montagnes et sont frappés, une fois arrivés au sommet, par la foudre. Ces procédés d'analogie, fréquemment employés par Lucrèce quand il s'agit d'expliquer des phénomènes naturels complexes, lui servent aussi dans des passages moins théoriques comme ceux que nous citons ${ }^{4}$. Ils permettent de constituer une scène très visuelle qui marque de manière émotionnelle le lecteur. D’autres procédés poétiques, comme les allitérations (Tartare taetra) ou le contraste violent entre la lumière et les ténèbres (claro / in tenebris $)^{5}$ contribuent à créer une représentation très frappante des malheurs de l'ambition. Lucrèce emploie donc toutes les ressources de l'expression poétique pour donner une image terrifiante et résolument négative des ambitieux et des hommes in honore. Son usage de la poésie, qui peut paraître à première vue paradoxal dans la mesure où l'orthodoxie épicurienne ne le recommande pas, trouve une de ses raisons d'être dans le rôle didactique qui lui est assigné: elle soutient la démonstration et permet d'agir puissamment sur le lecteur' ${ }^{6}$.

\footnotetext{
${ }^{4}$ Sur l'usage des analogies dans le poème, notamment dans les passages scientifiques, voir P.H. SchriJvers, «Le regard sur l'invisible. Étude sur l'emploi de l'analogie dans l'œuvre de Lucrèce ", in Gigon, O. (éd.), Lucrèce, Genève, Fondation Hardt, 1977, p. 77-121; G. Garbugino, «Immagine, mito e allegoria in Lucrezio », in Mantero, T. (éd.), Analysis, II: Varia poetica, Gênes, Facoltà di Lettere, 1989, p. 9-107, notamment p.40-44 et A.Setaioli, «L'analogie et la similitude comme instruments de démonstration chez Lucrèce", in Armisen-Marchetti, M. (éd.), Demonstrare. Voir et faire voir: forme de la démonstration à Rome. Actes du colloque international de Toulouse, 18-20 novembre 2004, Toulouse, Presses Universitaires du Mirail, 2005, p. 117-142.

${ }^{5}$ Sur cette imagerie de la lumière et des ténèbres, GaRBUGINo, "Immagine, mito e allegoria in Lucrezio », p. 28-32.

${ }^{6}$ Sur la position d'Épicure à l'égard de la poésie, voir LAERT. X, 120. Sur le problème de l'usage de la poésie par Lucrèce, voir P.Boyancé, Lucrèce et l'épicurisme, Paris, P.U.F., 1963, p. 58 et 315; F. Giancotti, Il preludio di Lucrezio, Messine, G. d'Anna, 1959, p. 15-28 et E. PARATORE, "La problematica sull'epicureismo a Roma », ANRW, I, 4, 1973, p.116-204, particulièrement p.173-179. Sur la fonction de l'expression poétique chez Lucrèce, M.BatTisti, "Metafore e similitudini in Lucrezio. Funzione e rapporti reciproci», Quaderni dell'Istituto di filologia latina, 4, 1976, p.75-91; W.Cox, "Didactic Poetry: Lucretius", in Classen, C.J.(éd.), Probleme der Lukrezforschung, Hildesheim, G. Olms, 1986, p. 221-235; C. J. Classen, «Poetry and Rhetoric in Lucretius », in Classen, C. J.(éd.), Probleme der Lukrezforschung, Hildesheim, G.Olms, 1986, p.331-372; Garbugino, "Immagine, mito e allegoria in Lucrezio» et D.Clay, "An Anatomy of Lucretian Metaphor», in Giannantoni, G. et Gigante, M.(éds.), Epicureismo greco e
} 
Le rejet de l'honos est total et sans nuance: on mesure son intensité si on le compare au fragment sur la vertu de Lucilius où le satiriste recommande de donner seulement à l'honos «ce qui lui est dû » et donc de s'adonner avec modération à sa recherche ${ }^{7}$. Rien de tel ici où c'est le désir d'honneur lui-même (cupido, III, 59) qui est misérable. La recherche de l'honneur n'a que des conséquences néfastes. Lucrèce adopte donc un discours très polémique qui va à l'encontre de la valorisation coutumière de l'honos et de la compétition pour le prestige ${ }^{8}$. Cette présentation corrosive des faits humains observés correspond à la volonté qu'a Lucrèce de dévoiler toutes les vérités nécessaires au bonheur; le poète montre dans ces vers la misère de l'honneur afin que son lecteur connaisse sa vraie valeur et s'en détourne. Reprenant l'exigence épicurienne de $\pi \alpha \rho \rho \eta \sigma i ́ \alpha$, il préfère dire en toute franchise l'horreur de l'honos plutôt que de conformer son jugement à celui de la collectivité qui le valorise?.

\subsection{Les maux de l'ambition}

La puissance des images convoquées par Lucrèce est telle qu'elle tend à faire passer au second plan l'argumentation qui étaye le rejet de l'honos présenté dans ces vers. Cependant la critique de l'ambition repose sur l'identification de deux maux objectifs, la peine et la violence. Le poète montre la douleur qu'implique inévitablement la quête des honores: il faut fournir, pour les atteindre, un effort à nul autre pareil (praestante labore) qui dure nuit et jour (noctes atque dies niti). Le labeur à déployer entre en contradiction avec l'idéal de repos et de calme qui est celui de l'épicurisme: le vers 1129 du chant V cité supra signale qu'il est bien meilleur d'obéir en étant quietus, dans le repos, que de commander en vivant dans un état de perturbation constante. L'ambition s'accompagne d'un trouble infini, incompatible avec l'état de l'homme heureux. Cette idée réapparaît dans le livre III, lorsque Lucrèce passe en revue les suppliciés célèbres des enfers ${ }^{10}$. La convocation des mythes infernaux s'explique par la volonté de délivrer

romano: atti del congresso internazionale: Napoli, 19-26 maggio 1993, Naples, Bibliopolis, 1996, vol.2, p.779-793. Voir aussi, sur l'image en relation avec le mythe, M. GALE, Myth and Poetry in Lucretius, Cambridge, Cambridge University Press, 1994.

${ }^{7}$ Supra p. 642.

${ }^{8}$ Sur cette valorisation traditionnelle, supra p. 430 sqq. Sur les discordances entre le De rerum natura et le mos maiorum, voir J. D. MinYARD, Lucretius and the Late Republic, Leiden, Brill, 1985, qui souligne les infractions à la pietas et aux principes de la ciuitas.

${ }^{9}$ Cf. EPIC. Sent. Vat. 29: «Pour ma part, je préférerais, usant de la liberté de parole de celui qui étudie la nature, dire prophétiquement les choses utiles à tous les hommes, même si personne ne devait me comprendre, plutôt que, en donnant mon assentiment aux opinions reçues, récolter la louange qui tombe en abondance, venant de la foule» (trad. Conche modifiée).

${ }^{10}$ LUCR. DRN III, 978 sqq. 
les esprits de la peur du Tartare: le poète montre l'inanité et l'invraisemblance de ces histoires. Cependant, il ne les écarte pas totalement mais les rationalise: il renonce à leur donner un sens littéral mais leur confère un sens symbolique, chargé d'une vérité sur le monde réel et présent ${ }^{11}$. Ainsi, le supplice de Tityos écartelé et déchiré par les oiseaux ne doit pas être pris au pied de la lettre: il représente l'homme amoureux torturé par sa passion. Quant à Sisyphe:

\author{
Sisyphus in uita quoque nobis ante oculos est, \\ Qui petere a populo fasces saeuasque secures \\ Imbibit et semper uictus tristisque recedit. \\ «Sisyphe est lui aussi bien vivant, sous nos yeux: \\ C'est celui qui prétend obtenir les faisceaux et les cruelles haches \\ Et s'en revient, toujours triste et vaincu. »
}

(LuCR, DRN III, 995-997).

Sisyphe est pour Lucrèce le symbole de l'homme ambitieux: sa tâche interminable, qui consiste à rouler un rocher en haut d'une pente dont il redescend toujours, représente la recherche des honneurs, rappelés dans le texte par les faisceaux et les haches. Les allers retours du rocher renvoient aux échecs répétés du candidat mais aussi au fonctionnement romain de l'assignation des charges publiques, remises en jeu chaque année. La quête des honores est interminable et laborieuse; elle reçoit ici encore une image très péjorative en étant superposée à un supplice infernal. Lucrèce réutilise donc le mythe dans un sens symbolique pour nourrir d'une manière nouvelle sa dénonciation de l'ambition.

Le second mal objectif qui accompagne l'ambition reçoit un traitement plus ample dans les deux textes que nous citions au début de ce chapitre. Il s'agit des violences illégales et destructrices auxquelles recourent ceux qui recherchent les honores. La quête de l'honneur est donc néfaste pour soi, parce qu'elle met en jeu un labor infini, mais aussi pour les autres, parce qu'elle recourt à des moyens dangereux.

11 Sur le sens de ces mythes, J.SALEM, La Mort n'est rien pour nous. Lucrèce et l'éthique, Paris, Vrin, 1990, p. 151-154; Boyancé, Lucrèce et l'épicurisme, p.179-181 et surtout A. Gigandet, Fama deum: Lucrèce et les raisons du mythe, Paris, Vrin, 1998, p.359-394 et A.GIGANDET, "L'interprétation des mythes comme lieu et enjeu de la polémique philosophique dans le De rerum natura", in AlgRA, K.A., Koenen, M.H. et SchriJvers, P.H.(éds.), Lucretius and his Intellectual Background, Amsterdam, Royal Netherlands Academy of Arts and Sciences, 1997, p. 209-213. A. Gigandet souligne que la méthode de Lucrèce va à l'encontre de l'interprétation allégorique de type stoïcien et traite les figures mythiques comme des "symptômes » résultant de la méconnaissance des hommes. Sur les mythes chez Lucrèce, voir aussi J. CHOMArat, «La mythologie de Lucrèce ", in Martin, P.-M. et Ternes, C. M. (éds.), La mythologie, clef de lecture du monde classique: hommage à R. Chevallier, Tours, Centre de recherches A. Piganiol, 1986, vol. 1, p. 53-64 et Gale, Myth and Poetry in Lucretius. 
Ceux qui entreprennent de les obtenir commettent en effet des crimes ${ }^{12}$. La mention du droit et la description des effets néfastes de l'ambition sur la collectivité sont particuliers à Lucrèce: on ne les rencontre pas dans la critique que fait Épicure de l'ambition ${ }^{13}$. Lucrèce recourt ici à un argument auquel le lecteur romain sera plus particulièrement sensible, à savoir la mise en danger de la patrie. C'est aussi le cas dans le texte du livre $\mathrm{V}$ qui dépeint les luttes qui mettent aux prises les hommes les uns avec les autres lors de la conquête des honores:

Nequiquam, quoniam ad summum succedere honorem
Certantes iter infestum fecere uiai [...].
"En vain, car pour parvenir au sommet de l'honneur
Ils luttent et se rendent le chemin dangereux [...]. »

(LuCR. DRN V, 1123-1124).

Lucrèce fait référence à la rivalité pour l'accès aux charges et aux distinctions publiques. Le poète réutilise une image courante, celle de l'affrontement pour l'accès à l'honos ${ }^{14}$, mais il insiste, ce qui est nouveau, sur le caractère foncièrement dangereux et malsain d'un tel antagonisme. Ce dernier n'apparaît pas à Lucrèce comme un ingrédient essentiel de la vie politique mais comme un élément destructeur pour le lien social, contraire à l'idéal épicurien d'une société d'amis vivant en paix.

L'image très négative de l'ambition que donne Lucrèce est à éclairer par le contexte historique dans lequel le De rerum natura a été écrit. Si les dates de naissance et de mort de Lucrèce ne sont pas parfaitement assurées, on peut tout de même avancer avec assez de certitude que son œuvre, qui porte des traces d'inachèvement, a été interrompue entre 55 et 53 avant notre ère, lors du décès du poète ${ }^{15}$. Lucrèce a donc connu les affrontements sanglants de Marius et de Sylla, la conjuration de Catilina de 63 et d'autres événements violents moins directement liés à la conquête de l'honos, comme la guerre sociale, les révoltes serviles ou les massacres perpétrés par Mithridate VI Eupator contre les Romains. Il a grandi à une époque de grande instabilité

${ }^{12}$ Il est question de scelera qui brisent les règles du ius (III, 61).

13 R.C. Monti, "Lucretius on Greed, Political Ambition and Society: De Rerum Natura III, 59-86 ", Latomus, 40, 1981, p.48-66 estime que Lucrèce rend ici les thèses d'Épicure sur l'ambition plus acceptables pour des Romains en se souciant de ses effets sur la patria. La manière dont un désir d'honos mal réglé conduit à l'injustice apparaît dans la bouche d'un autre épicurien romain, Torquatus, dans Cic. Fin. I, 51.

${ }^{14}$ Sur cette image, voir supra p. 436.

${ }^{15}$ Sur les dates de la mort de Lucrèce, voir le résumé des hypothèses dans BoyancÉ, Lucrèce et l'épicurisme, p. 332-335. Sur la date de composition du De rerum natura, P. Grimal, "Le poème de Lucrèce en son temps », in Gigon, O. (éd.), Lucrèce, Genève, Fondation Hardt, 1977, p. 233-270. 
et a assisté à l'effondrement du système politique républicain sous la corruption et les massacres fratricides. La description des misères de l'ambition semble fondée sur ce qu'il a vu lui-même. Les deux passages que nous citions au début de ce chapitre trouvent d'ailleurs un écho dans le tableau que donne Salluste du règne de l'ambition et de la cupidité à la fin de la République. Les deux auteurs dénoncent, chacun à leur manière, le progrès accompli par le goût de l'argent et du pouvoir et leurs conséquences funestes pour l'État ${ }^{16}$. Il nous paraît difficile, cependant, de considérer que Lucrèce vise dans ses vers du livre $\mathrm{V}$ des personnes en particulier, César notamment, comme le pense J.-M. André. La condamnation nous paraît plus morale que politique: elle s'en prend de manière générale à tous les ambitieux, quelle que soit leur appartenance idéologique ${ }^{17}$. On peut tout au plus considérer qu'elle constitue un avertissement destiné surtout à Memmius, le destinataire du De rerum natura, qu'on s'accorde généralement à identifier avec le préteur de 58, homme politique de haute lignée, lettré et philhellène, qui gouverna la Bithynie ${ }^{18}$. Memmius semble en effet avoir été un homme politique peu scrupuleux: il a soutenu Pompée puis César, par opportunisme, et fut accusé de brigue lors de sa candidature au consulat de 54, qui se solda par un échec ${ }^{19}$. Le De rerum natura vise à le convertir à l'épicurisme et les deux passages sur l'ambition à lui faire entrevoir l'inanité et le danger de la quête des honores.

${ }^{16}$ Cf. par exemple SALL. Cat.10, 3-5. Sur le thème de l'ambition chez Salluste, voir infra p. 736 sqq. Pour une comparaison de la critique faite par Lucrèce et Salluste des vices de la République finissante, se reporter à D.P. Fowler, "Lucretius and Politics », in Griffin, M. et Barnes, J.(éds.), Philosophia togata. Essays on Philosophy and Roman Society, Oxford, Clarendon Press, 1989, p. 120-150.

17 ANDRÉ, L'Otium, p. 248: "Politiquement, l'allusion cadre parfaitement avec l'année 56, celle des accords de Lucques, et le texte fait écho aux inquiétudes de Cicéron $(A d$ Att. IV , 5, 1). » Les tentatives pour associer Lucrèce à un parti ont abouti à des résultats totalement contradictoires, ce qui témoigne de la difficulté qu'il y a à statuer sur son appartenance politique: le poète a été assimilé tantôt aux césariens, tantôt aux traditionalistes conservateurs (voir le bilan établi sur ce point par PARATORE, «La problematica sull'epicureismo a Roma», p. 181-184).

${ }^{18}$ LUCR. DRN I, 42-43 indique que Memmius est un homme politique de bonne extraction; $D R N$ I, 26-28 qu'il a quelque lien avec Vénus, ce qui correspond avec le fait que la famille de Memmius prétendait remonter à Énée ( $c f$.Verg. Aen. V, 116 sqq.). Sur l'identité de Memmius, P. BoyancÉ, "Lucrèce et son disciple», REA, 1950, p.212-233; A. Grilli, Lucrezio, Milan, La Goliardica, 1970, p.4-9; Paratore, «La problematica sull'epicureismo a Roma», p.167-170; R. KeEN, "Lucretius and his Reader», Apeiron, 19, 1985, p. 1-10. Giancotti, Il preludio di Lucrezio, p. 122 sqq. a mis en doute l'identification de Memmius au préteur de 58, mais ses arguments sont peu convaincants et n'ont pas été retenus.

${ }^{19}$ Voir l'article de F. Múnzer dans la RE s. v. Memmius n ${ }^{\circ} 8$. 
La critique de l'ambition formulée par Lucrèce est étayée philosophiquement par la doctrine épicurienne. L'honneur est rejeté car il se révèle inutile, voire nuisible, pour atteindre deux objectifs que vise le sage épicurien, la sécurité et l'ataraxie.

\title{
2.1. L'honos inutile à la sécurité
}

L'honos se révèle inutile pour l'obtention de la sécurité, qui est l'une des conditions de la vie heureuse. Cette idée se trouve à la racine de la critique de l'ambition dans le livre III. Deux vers du premier texte que nous citions sont essentiels pour comprendre toute la portée de ce passage:

\author{
[...], haec uulnera uitae \\ Non minimam partem mortis formidine aluntur. \\ [...] ces plaies de la vie, \\ Sont nourries, pour une très grande part, par la peur de la mort.»
}

(LuCR. DRN III, 63-64).

Lucrèce se livre à une élucidation psychologique de ces deux "plaies de la vie» que sont l'ambition et la cupidité. Dans un vers très ramassé et peu explicatif, le poète déclare que le désir d'honneur et de richesse procède de la peur de la mort. Il ne se contente donc pas de dénoncer les méfaits de l'ambition mais va jusqu'à en extirper les fondements à l'intérieur de l'esprit. Il tente de réduire tous les désirs irrationnels à une seule perturbation psychologique qui les explique tous et se situe à leur fondement, la peur de la mort, c'est-à-dire, ici, la crainte de l'au-delà et des punitions des enfers ${ }^{20}$. La critique de cette peur est traditionnelle dans l'épicurisme et Lucrèce y revient à plusieurs reprises dans le livre III du De rerum natura mais il se singularise ici en l'articulant à la quête des honores, ce que ne font ni Épicure ni Philodème dans les œuvres qui nous restent d'eux ${ }^{21}$. Une telle mise en relation ne va pas de soi et elle a d'ailleurs suscité la perplexité de plusieurs commentateurs: quel est le rapport entre l'ambition

${ }^{20}$ Boyancé, Lucrèce et l'épicurisme, p. 145.

${ }^{21}$ Sur la critique lucrétienne de la crainte de la mort en général, L. Perelli, Lucrezio poeta dell'angoscia, Florence, La Nuova Italia, 1969, p.75-138; SALEM, La Mort n'est rien pour nous, p. 97-168. 
et la peur de mourir? L'explication se trouve quelques vers plus loin, comme l'a bien montré J. Perret ${ }^{22}$ :

Turpis enim ferme contemptus et acris egestas

Semota ab dulci uita stabilique uidetur,

Et quasi iam leti portas cunctarier ante.

«Car l'ignoble mépris et l'amère pauvreté

Paraissent éloignés d'une vie douce et stable:

C'est comme si l'on séjournait aux portes du trépas. »

(LuCR. DRN III, 65-67).

Les hommes estiment que le mépris et la pauvreté, c'est-à-dire le contraire de l'honneur et de la richesse, sont des états dangereux, où l'on se trouve à la merci des autres et où l'on risque beaucoup plus facilement de trouver la mort. L'ambition et la cupidité s'expliquent par la volonté d'échapper à une position de faiblesse sociale et économique synonyme de danger de $\operatorname{mort}^{23}$. Il s'agit là, comme le souligne Lucrèce, d'une erreur capitale de jugement: l'opposition entre mépris et sécurité n'est qu'apparente (uidetur). Le poète a déjà posé au livre II que la maladie ne quitte pas plus vite celui qui vit dans le luxe ou qui est issu d'une famille noble que le pauvre ou le plébéien ${ }^{24}$. L'identification de la crainte de la mort à la racine de l'ambition est un développement propre à Lucrèce mais il s'appuie sur la doctrine épicurienne de la sécurité $\left(\alpha \dot{\sigma} \sigma \varphi \alpha^{\prime} \varepsilon \varepsilon \alpha\right)^{25}$. Épicure dessine en effet un lien entre l'ambition et la recherche de la sécurité dans deux «maximes capitales»:

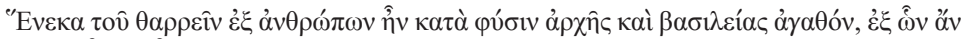

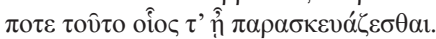

«Pour s'assurer la sécurité du côté des hommes, le bien du pouvoir et de la royauté est un bien selon la nature, pour autant qu'à partir d'eux on puisse se le procurer.»

(EpIc. Max. Cap. VI; trad. Conche).

22 J. PeRret, "L'amour de l'argent, l'ambition et la crainte de la mort (Lucrèce III, 59-86) » in Mélanges de philologie, de littérature et d'histoire anciennes offerts à A. Ernout, Paris, C. Klincksieck, 1940, p. 277-284.

${ }^{23}$ « On n'est ambitieux et cupide, croit Lucrèce, que pour fuir la misère ou le mépris et ce qu'on hait dans l'une comme dans l'autre, c'est que ces états humiliés sont gros d'une proche menace de mort» (Ibid., p. 279). Sur l'articulation entre la peur de la mort et l'ambition et la cupidité, voir aussi A. Desmouliez, "Cupidité, ambition et crainte de la mort chez Lucrèce (De Rerum Natura, III, 59-93) ", Latomus, 17, 1958, p.317-323, de même que MonTI, "Lucretius on Greed, Political Ambition and Society: De Rerum Natura III, 59-86».

${ }^{24}$ LUCR. DRN II, 34-36

${ }^{25}$ Sur la notion de sécurité chez Épicure, A. BARIGAZZI, «Sul concetto epicureo della sicurezza esterna » in Syzètèsis. Studi sull'epicureismo greco e latino offerti a M. Gigante, Naples, G. Macchiaroli, 1983, vol. 1, p. 73-92, qui s'interroge notamment sur l'établissement du texte des maximes concernées et sur leur ordre. 


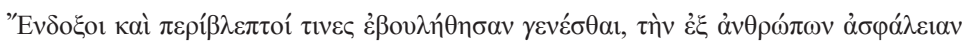

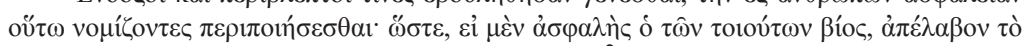

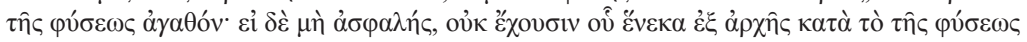

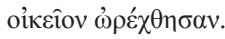

"Certains ont voulu avoir renom et considération, pensant se procurer ainsi la sécurité du côté des hommes; si, de la sorte, leur vie se passe dans la sécurité, ils ont obtenu le bien selon la nature, mais s'ils ne vivent pas dans la sécurité, ils n'ont pas ce à quoi ils ont tendu dès l'origine, en suivant le propre de la nature. »

(EpIc. Max. Cap. VII; trad. Conche).

Les maximes assignent, comme le De rerum natura, une origine humaine au désir de pouvoir et de prestige. Ce dernier réside dans la volonté d'obtenir la "sécurité du côté des hommes»"26: le renom procure en effet une protection contre le mépris qui est, selon l'opinion commune, un état dangereux et instable. Épicure, comme Lucrèce, pose au fondement de la recherche des honneurs un souci de conservation de soi, bien qu'il ne soit pas question, comme chez le poète latin, de la peur de la mort, ce qui est une première différence entre les deux auteurs. Une seconde, plus marquée, se situe dans l'évaluation qui est faite du désir d'honneur. Lucrèce, comme nous l'avons vu, le condamne radicalement, ce qui n'est pas le cas d'Épicure. Ce dernier concède que, pour certains, l'honneur puisse apporter une relative sécurité et permettre d'atteindre, selon leurs représentations, le «bien selon la nature»: la possibilité d'atteindre la sécurité par l'honneur reste hypothétique mais elle est envisagée ${ }^{27}$. La recherche de la gloire n'est donc pas disqualifiée de manière aussi radicale que chez Lucrèce. Elle doit, en somme, entrer dans le calcul des plaisirs et des peines et être retenue si elle permet réellement d'amener vers le plaisir. La position d'Épicure sur la question est précisée dans une autre maxime:

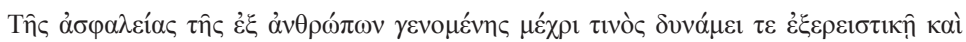

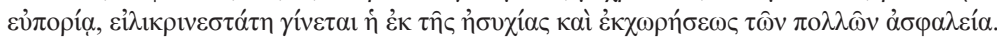

"Si la sécurité du côté des hommes existe jusqu'à un certain point grâce à la puissance solidement assise et à la richesse, la sécurité la plus pure naît de la vie tranquille et à l'écart de la foule.»

(EpIc. Max. Cap. XIV; trad. Conche).

${ }^{26}$ La traduction de M. Conche est plus juste que celle que l'on rencontre habituellement de "sécurité contre les hommes » : $\varepsilon^{\xi} \xi$ indique bien d'où provient cette sécurité et non contre qui il s'agit de se protéger. C'est aussi l'interprétation de G. Roskam, Live Unnoticed (Lathè biôsas). On the Vicissitudes of an Epicurean Doctrine, Leiden, Brill, 2007, p. 39: il peut y avoir pour les épicuriens différents moyens d'obtenir la sécurité, par les lois, par les amis, ou par les hommes en général, comme dans les deux maximes citées.

${ }^{27}$ Cf. la manière dont les épicuriens, selon Plutarque, envisageaient la sécurité que peuvent apporter les lois, les institutions et le gouvernement (Plut. Contre Colotès, $1124 \mathrm{~d}=L S 22 \mathrm{R})$. 
Épicure reconnaît que la sécurité obtenue par les honneurs et le pouvoir existe «jusqu'à un certain point » mais que les cas où le prestige et la puissance apportent une réelle $\dot{\alpha} \sigma \varphi \alpha \lambda \varepsilon i ́ \alpha$ sont rares: une vie à l'écart de la foule est un moyen bien plus assuré d'y parvenir.

Lucrèce se situe donc globalement dans la lignée de la doctrine épicurienne sur la sécurité en articulant peur de la mort et ambition mais se singularise par plusieurs éléments: il n'évoque pas le souci de sécurité, sentiment positif, mais la crainte de la mort, affection négative; il nie l'existence d'une quelconque protection apportée par les honneurs et insiste au contraire sur l'envie destructrice que suscite chez les autres l'homme de pouvoir; il développe la contradiction tragique habitant les hommes qui recherchent l'honos pour atteindre la sécurité alors que l'honneur est synonyme de péril ${ }^{28}$; il fait reposer son exposé sur des images poétiques variées et ne dessine pas de manière très nette le rapport entre ambition et peur de la mort: la logique du poème est différente de celle de la maxime ${ }^{29}$.

\title{
2.2. L'honos inutile à l'ataraxie
}

La seconde composante essentielle au bonheur est l'ataraxie, un état psychologique qui se caractérise par l'absence de souffrance et de trouble. Or Lucrèce représente l'honos comme un élément qui ne peut ôter le trouble de l'âme et se trouve donc inutile pour atteindre cette ataraxie. Au début du livre VI, dans l'éloge qu'il fait d'Épicure, Lucrèce décrit le maître au milieu des autres hommes:

\author{
Nam cum uidit hic ad uictum quae flagitat usus \\ Omnia iam ferme mortalibus esse parata \\ Et, proquam possent, uitam consistere tutam, \\ Diuitiis homines et honore et laude potentis \\ Adfluere atque bona gnatorum excellere fama, \\ Nec minus esse domi cuiquam tamen anxa corda [...]. \\ «Il vit que le nécessaire réclamé pour vivre \\ Était pour la plupart déjà assuré aux mortels, \\ Et que leur vie était, autant qu'ils le pouvaient, à l'abri du danger; \\ Il vit aussi les puissants regorger de richesses, d'honneur et de gloire \\ Et se prévaloir encore de la bonne renommée de leurs enfants, \\ Et que chacun, néanmoins, gardait chez lui un cœur plein d'anxiété [...]. »
}

(LuCR. DRN VI, 9-14; trad. Ernout modifiée).

${ }^{28}$ Sur cette contradiction, voir Desmouliez, "Cupidité, ambition et crainte de la mort chez Lucrèce (De Rerum Natura, III, 59-93)».

${ }^{29}$ D'après J. Jope, «Lucretius' Psychoanalytic Insight: His Notion of Unconscious Motivation", Phoenix, 37, 1983, p.224-238, le manque de clarté du rapport entre ambition et peur de la mort sert à présenter les choses de manière plus conforme à ce que les hommes ressentent: le poète reconstitue de la sorte l'état d'anxiété des hommes qui ne perçoivent pas clairement la raison pour laquelle ils recherchent les honneurs. 
Pour mieux louer la manière dont Épicure a apporté le bonheur aux hommes, Lucrèce revient sur leur situation avant que le maître n'ait commencé à dispenser son enseignement. Les plus puissants d'entre eux bénéficiaient d'une situation de remarquable notoriété, soulignée par l'usage de trois termes en relation de synonymie, honos (l'honneur), laus (la gloire) et fama (la bonne réputation). Cette plénitude n'est pourtant d'aucun secours contre l'anxiété: les hommes les plus renommés sont en proie à une terrible peur des dieux et de la mort $^{30}$. Lucrèce est ici en conformité avec Épicure:

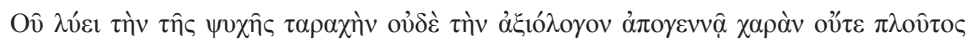

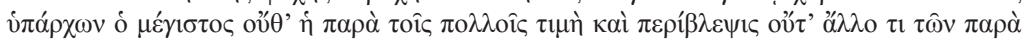

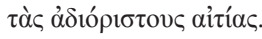

«Ne délivrent du désordre de l'âme ni non plus n'engendrent une joie digne qu'on en parle: ni la richesse la plus grande qui soit, ni l'honneur et la considération dont on jouit auprès du grand nombre, ni rien d'autre qui dépende de causes sans limites définies.»

(EpIc. Sent. Vat. 81 ; trad. Conche).

Épicure convoque ici la notion de $\tau \mu \eta$, ressentie par les Latins comme proche d'honos, et déclare qu'elle échoue à délivrer l'âme du

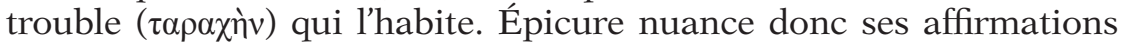
sur les effets de l'honneur: il concède qu'il puisse procurer, à certaines personnes et dans certaines circonstances, une sécurité mais récuse en revanche sa capacité à ôter les perturbations de l'âme et à apporter l'ataraxie essentielle au bonheur. L'obtention de l'honneur dépend en effet d'une cause "sans limites définies », c'est-à-dire d'un désir qui ne connaît pas de bornes et ne peut jamais être réellement satisfait. Il ne relève pas de la catégorie des désirs naturels et nécessaires, dont la satisfaction est source de plaisir et de bonheur, mais de celle des désirs vains qui sont source de trouble ${ }^{31}$. Ces désirs n'ont pas d'objet bien défini et ne consistent qu'à vouloir toujours plus, ce qui conduit nécessairement le sujet à rester insatisfait et à ne pouvoir connaître un état de stabilité heureuse. Une scholie à l'une des Maximes Capitales d'Épicure définissant les différents désirs précise ce qu'Épicure enten-

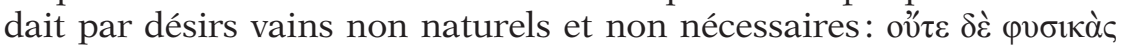

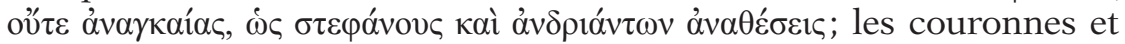
les statues, deux sortes de marques d'honneur, font l'objet d'un désir vide et impossible à satisfaire ${ }^{32}$. Lucrèce ne théorise pas de manière aussi nette qu'Épicure la place de l'ambition parmi les différents types de désirs. Cependant, la marque de la réflexion épicurienne sur son

\footnotetext{
${ }^{30}$ Voir aussi LucR. DRN II, 38-46 où Lucrèce demande à Memmius, dans une question rhétorique, si la noblesse, la richesse ou le fait de voir ses légions au Champ de Mars permetttent de délivrer l'esprit des superstitions et de la crainte de la mort.

${ }^{31}$ Sur la classification des désirs, voir Epic. Men. 127.

${ }^{32}$ Voir schol. ad EpIc. Max. Cap. XXIX (éd. Conche).
} 
œuvre est visible: il qualifie la quête des honores de cupido, c'est-àdire de désir irrationnel ${ }^{33}$; dans le passage du livre VI que nous citions supra, il distingue les honores de ce qui est directement utile ad uictum (v. 9), ce qui écarte le désir d'honneur des désirs nécessaires, d'autant que l'ambition est rapprochée à plusieurs reprises chez le poète de la cupidité, autre passion blâmable et visant un objet inutile; enfin, au livre II, Lucrèce déclare que la natura ne réclame rien d'autre que la disparition de la douleur, ce qui rejette toutes les autres entreprises humaines, et notamment la richesse et le prestige évoqués juste après, du côté des désirs non naturels ${ }^{34}$. Rechercher l'honos, c'est donc s'asservir à un désir superflu et impossible à satisfaire, qui prive de l'ataraxie et du bonheur. L'épicurien Torquatus indique semblablement dans le De finibus que le désir des honneurs est insatiable et conduit à l'injustice ${ }^{35}$.

Un dernier aspect de l'honos achève de le rendre inutile pour l'ataraxie et même nuisible à la réalisation de cet état: il s'agit de sa versatilité. Au livre $\mathrm{V}$, comme nous l'avons vu, Lucrèce dépeint à propos de la royauté la manière dont l'homme in honore est brusquement jeté à bas de son piédestal par l'envie destructrice des autres hommes ${ }^{36}$. Or il s'agit d'un thème que le poète se plaît à développer puisque la description du renversement des rois repose sur la même image d'un honos mis à terre:

\author{
Ergo regibus occisis subuersa iacebat \\ Pristina maiestas soliorum et sceptra superba, \\ Et capitis summi praeclarum insigne cruentum \\ Sub pedibus unlgi magnum lugebat honorem; \\ Nam cupide conculcatur nimis ante metutum. \\ «Donc, une fois les rois assassinés, l'ancienne majesté \\ Des trônes et les sceptres hautains gisait renversée, \\ Et l'emblème éclatant de la tête souveraine, ensanglanté, \\ Sous les pieds de la foule pleurait son grand honneur; \\ Car on piétine avec passion ce que l'on a autrefois trop redouté. »
}

(LUCR. DRN. V 1137-1141).

Renouvelant le motif classique du retournement de la fortune, Lucrèce représente par une hypotypose la couronne royale tombée à terre, maculée de sang et foulée aux pieds, en train de pleurer son honos perdu. L'honos est un objet qui peut rapidement disparaître car il dépend des autres: la foule changeante est passée de l'amour

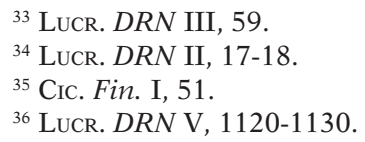


à la haine pour le souverain ${ }^{37}$. La versatilité de l'honos est à nouveau affirmée par Lucrèce à propos de la manière dont les hommes, quand ils ont découvert un nouveau métal, ont rejeté systématiquement celui qu'ils avaient en usage auparavant:

Nunc iacet aes, aurum in summum successit honorem.

Sic uoluenda aetas commutat tempora rerum:

Quod fuit in pretio, fit nullo denique honore.

«Maintenant le bronze est délaissé, l'or est tenu en très grand honneur. Ainsi le cours du temps change les moments favorables pour les choses: Ce qui avait du prix se retrouve finalement dépourvu de tout honneur. »

(LuCR. DRN V, 1275-1277).

L'honos repose sur le jugement inconstant des hommes et possède donc une instabilité qui ne permet pas de le constituer en objet désirable.

La critique philosophique de l'honos place Lucrèce dans une position antagoniste vis-à-vis de la tradition. Elle montre aussi que le poète est, dans son rapport à l'ambition, moins nuancé qu'Épicure: il ne se réfère pas à des cas exceptionnels où l'honos peut être recherché ni ne montre ses éventuels attraits mais le rejette de façon apodictique ${ }^{38}$.

\section{LES CONSÉQUENCES DE LA CRITIQUE: LE RENONCEMENT À L'HONNEUR}

L'incapacité de l'honos à amener les hommes à une vie heureuse doit, pour Lucrèce, conduire les hommes à y renoncer. Il apparaît dans le De rerum natura que le sage doit suivre une voie opposée à celle de l'ambition et se retirer des affaires politiques de la cité. Lucrèce écarte également le principe de conduite qu'est l'honestum, qu'il s'agisse du code de l'honneur ou de la beauté morale, pour structurer son éthique autour de la noluptas.

\subsection{Renoncer à l'honos}

Lucrèce rejette de manière explicite dans les passages que nous avons étudiés la recherche de l'honos et la compétition politique et tire les conséquences de cette position critique en proposant pour le

${ }^{37}$ Le tableau n'est pas sans rappeler l'épisode romain du renversement de la royauté, avec la présence des insignes de la monarchie (trône, sceptre et couronne), l'adjectif superba qui fait écho au surnom de Tarquin le Superbe et pristina qui rappelle celui de Tarquin l'Ancien (voir Fowler, «Lucretius and Politics», p. 144). On notera cependant qu'à Rome le Superbe n'a pas été tué, comme dans le récit de Lucrèce, mais chassé.

${ }^{38}$ Sur cet aspect original de Lucrèce par rapport à Épicure, Roskam, Live Unnoticed, p. 97-98. 
sage une attitude alternative. Pour repérer ce que Lucrèce oppose à la recherche des honneurs, nous pouvons nous appuyer sur deux vers de la critique de l'ambition du chant III (v. 62-63):

Noctes atque dies niti praestante labore

Ad summas emergere opes, haec uulnera uitae

Il s'agit là d'une reprise de vers situés dans la fameuse ouverture du chant II :

Suaue, mari magno turbantibus aequora uentis,

E terra magnum alterius spectare laborem;

Non quia uexari quemquamst iucunda uoluptas,

Sed quibus ipse malis careas quia cernere suaue est.

[...]

Sed nil dulcius est bene quam munita tenere

Edita doctrina sapientium templa serena,

Despicere unde queas alios passimque uidere

Errare, atque uiam palantis quaerere uitae,

Certare ingenio, contendere nobilitate,

Noctes atque dies niti praestante labore

Ad summas emergere opes rerumque potiri.

«Il est doux, quand sur la grande mer les vents soulèvent les flots

De regarder depuis la terre les rudes épreuves d'autrui;

Non que la souffrance de quiconque soit un plaisir voluptueux,

Mais voir à quels maux on échappe soi-même est doux.

[...]

Mais rien n'est plus doux que d'occuper solidement les hauts lieux fortifiés

Par la science des sages, régions sereines

D'où l'on peut abaisser ses regards sur les autres hommes, les voir de toutes parts

Errer et chercher au hasard le chemin de la vie,

Rivaliser de talent, se disputer la noblesse,

S'efforcer nuit et jour, par un labeur sans égal,

De s'élever au comble des richesses ou de s'emparer du pouvoir.»

(LuCR. DRN II, 1-13; trad. Ernout modifiée; nous soulignons).

Les deux derniers vers désignent ici encore les efforts des ambitieux, notamment dans le domaine politique, comme le suggère l'utilisation d'un vocabulaire habituellement employé dans des contextes de rivalité électorale (contendere, niti, emergere) ${ }^{39}$. Mais l'image de l'homme avide d'honores est placée dans un système binaire où elle est très nettement distinguée de la figure du sage. Lucrèce élabore ainsi une antithèse entre le sage heureux en son for intérieur et la masse des non-sages qui ne parviennent pas à apaiser leur esprit. Recourant à nouveau à l'analogie, le poète compare la situation du sage à celle de l'individu qui observe de loin les efforts des marins dans une mer

\footnotetext{
${ }^{39}$ Voir sur ce point FowLen, «Lucretius and Politics», p. 134-135.
} 
déchaînée; puis, à cette image de distance horizontale s'en superpose une autre, de nature verticale: il est doux de se trouver dans les hauteurs d'une forteresse de sagesse d'où l'on peut observer les autres errer plus bas (despicere). Tout le passage entrelace le lexique du plaisir, souverain bien pour l'épicurien (suaue, uoluptas, dulcius), à celui de l'effort et de la peine (labor, certare, contendere), lot des hommes qui n'ont pas proscrit l'ambition. La souffrance liée à la recherche des honneurs est définitivement écartée par Lucrèce qui lui préfère une vie sereine et isolée, synonyme de plaisir et de bonheur.

Ce renoncement à l'honneur au profit du plaisir est en accord avec l'orthodoxie épicurienne et rappelle notamment deux impératifs d'Épicure. Le premier recommande de ne pas prendre part volontairement à l'activité politique ${ }^{40}$ : il ne s'agit pas de refuser absolument toute présence dans la cité mais de ne pas chercher à y jouer un rôle actif en y assumant des charges importantes, sauf circonstances exceptionnelles ${ }^{41}$. C'est le choix qu'a opéré Atticus, comme le reconnaît Cicéron: l'Arpinate a choisi l'honos pendant que son ami préférait se consacrer à l'otium ${ }^{42}$. Le second impératif est la fameuse injonction $\lambda \alpha \dot{\theta} \theta \varepsilon \beta 1 \omega ́ \sigma \alpha \varsigma$, "vis caché» ou "cache ta vie ${ }^{43}$. Cette maxime possède une coloration politique et reformule les avertissements sur l'engagement dans les affaires de la cité; mais elle recèle aussi une injonction à ne pas rechercher la gloire et à se tenir à l'écart de la foule en général, pour le bien de l'âme et la sécurité du corps ${ }^{44}$. Dans une de ses lettres, Epicure déclarait à propos de son amitié avec Métrodore que leur bonheur était si grand qu'il leur était indifférent de vivre inconnus de tous ${ }^{45}$.

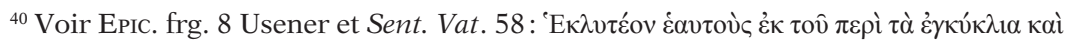

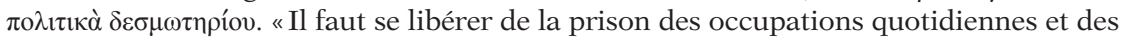
affaires publiques» (trad. Conche).

${ }^{41}$ Sur cet aspect de la doctrine épicurienne, voir Fowler, "Lucretius and Politics », p. 122-133 et Rosкам, Live Unnoticed, p. 44 sqq. Cette position a été très vivement critiquée par Cicéron (Rep.I, 1-12 et Pis.53-63). Sénèque précise que le sage épicurien peut, dans certaines circonstances, prendre part aux affaires publiques (SEN. De otio, VIII, 3, 2). Plutarque, dans le Contre Colotès, révèle que, pour les épicuriens, il y a un bénéfice de la loi et des institutions et qu'il n'est pas question pour eux de supprimer les cadres de la société civile (Plut. Contre Colotès 1124d = LS $22 \mathrm{R}$ ).

${ }^{42}$ Cic. Att. I, 17, 5.

${ }^{43}$ EpIC. frg. 551 Usener. Sur cette maxime chez Épicure, Grilli, Lucrezio, p. 44 et surtout RosKam, Live Unnoticed, p. 29-66.

${ }^{44}$ Voir aussi la fin de la maxime capitale XIV, citée supra: "la sécurité la plus pure naît de la vie tranquille et à l'écart de la foule. »

${ }^{45}$ EPIc. frg. 188 Usener. 


\subsection{Renoncer à l'honestum}

L'adjectif honestus n'apparaît qu'une seule fois dans le De rerum natura, avec le sens "honorable ${ }^{46}$. Le sens éthique du mot, "moralement beau», n'apparaît, lui, jamais. Ce silence est remarquable car à l'époque de Lucrèce la notion d'honestum atteint, dans la vie intellectuelle et philosophique romaine, une importance morale et une richesse conceptuelle très grandes. Après le travail de Térence, de Lucilius et de la Rhétorique à Hérennius sur la notion, Cicéron, contemporain de Lucrèce, a donné à l'honestum une place centrale dans l'éthique, en l'élevant, sous l'influence du stoïcisme, au rang de souverain bien ${ }^{47}$. Le silence de Lucrèce doit être comparé, pour être éclairé, au silence semblable de deux contemporains, Catulle et César. L'absence d'honestum chez Catulle se joint à celle de la notion d'honos et peut s'expliquer par la nature des sujets abordés, assez peu propices à la présence de ces termes, notamment quand il s'agit de poèmes d'inspiration amoureuse ou mythologique. Le mépris du poète pour les codes traditionnels et les valeurs ancestrales romaines, avec son éloge des plaisirs charnels, sa valorisation de l'otium littéraire ou son recours à un langage obscène, contribue aussi sans doute à ce rejet de l'honos et de l'honestum. Cette absence chez Catulle ne nous aide donc pas à comprendre le silence de Lucrèce sur l'honestum. Il en va en revanche tout autrement du cas de César. Ce dernier, comme Lucrèce mais à la différence de Catulle, recourt de façon régulière à la notion d'honos; il ne convoque jamais cependant le concept d'honestum. Or César a des sympathies pour l'épicurisme (doctrine à laquelle Lucrèce adhère) même si elle est moins apparente dans son œuvre que dans celle du poète ${ }^{48}$. L'absence de l'honestum éthique dans le De rerum natura nous paraît donc pouvoir être éclairée par la philosophie d'Épicure. Différents aspects de la pensée du Jardin ont pu amener Lucrèce à occulter délibérément dans son œuvre le concept de «beauté morale». L'honestum, d'abord, possède une forte coloration stoïcienne: il renvoie de manière privilégiée au «beau moral » de l'éthique du Portique, comme on le voit dans des ouvrages à peu près contemporains du De rerum natura, dans le De legibus de Cicéron, par exemple ${ }^{49}$. Le renoncement à ce concept peut donc être stratégique:

${ }^{46}$ LuCR. DRN IV, 1181. Il est dit que l'amoureux qui essaie d'éviter sa belle cherche des causae honestae pour s'éclipser.

${ }^{47}$ Voir, sur Térence, Lucilius et la Rhétorique à Hérennius, les p.628, 654 et 677, respectivement. Sur le travail de conceptualisation éthique de Cicéron, voir notre analyse sémantique p. 149 sqq. Le De officiis consacre la place centrale de l'honestum au sein de l'éthique cicéronienne (voir notamment le livre I).

${ }^{48}$ Sur l'épicurisme de César, voir infra p. 715 n. 30.

${ }^{49}$ Cic. Leg. I, 37. Le De legibus a été composé en 52, quelques années après la mort de Lucrèce. Il est marqué par le stoïcisme de Panétius et Posidonius. 
Lucrèce se refuse à utiliser une notion centrale du stoïcisme romain dont il conteste par ailleurs les théories. Plusieurs passages du $D e$ rerum natura s'en prennent en effet, sans les nommer, aux stoïciens, et notamment à ceux du $\mathrm{I}^{\mathrm{er}}$ siècle avant notre ère ${ }^{50}$. L'occultation de l'honestum par Lucrèce provient également de la contestation par l'épicurisme de sa valeur théorique et pratique. L'ignorance superbe dans laquelle il tient le concept est comparable aux propos que Cicéron fait tenir à l'épicurien Torquatus dans le De finibus. Torquatus, lorsqu'il décrit les tourments des hommes qui ne savent pas borner leurs désirs et profiter des plaisirs présents, évoque l'honestum avec dédain:

Igitur neque stultorum quisquam beatus neque sapientium non beatus. Multoque hoc melius nos ueriusque quam Stoici. Illi enim negant esse bonum quicquam nisi nescio quam illam umbram, quod appellant honestum non tam solido quam splendido nomine; uirtutem autem nixam hoc honesto nullam requirere uoluptatem atque ad beate uiuendum se ipsa esse contentam.

«Ainsi, parmi les insensés, il n'en est pas un qui soit heureux, parmi les sages, pas un qui ne soitpas heureux. Et c'est une vérité qui se justifie beaucoup mieux chez nous que chez les Stoïciens: pour eux en effet il n'y a pas d'autre bien que cette espèce d'ombre qu'ils appellent moralité, dénomination moins solide que brillante; et la vertu, appuyée sur cette moralité, n'a nullement besoin du plaisir et se suffit à elle-même pour atteindre la vie heureuse. »

(CIc. Fin. I, 61 ; trad. Martha modifiée).

Torquatus fait ici état de la définition stoïcienne du souverain bien qui réside tout entier dans la moralité. L'épicurien rejette cette théorie, puisque pour lui c'est la uoluptas et non l'honestum qui constitue la fin suprême, mais ce rejet est prononcé sur un ton méprisant: l'honestum est considéré comme une "espèce d'ombre» (nescio quam illam umbram) à la bien faible solidité théorique, une notion invoquée de manière irréfléchie, pour jeter de la poudre aux yeux. Torquatus, comme Lucrèce, rejette dédaigneusement la notion; le poète va même plus loin que Torquatus puisqu'il n'engage pas de réflexion argumentée sur l'honestum mais en reste à un silence obstiné. Dans les Tusculanes, Cicéron attribue à Épicure cette attitude désinvolte à l'égard du

\footnotetext{
${ }^{50}$ Sur les attaques de Lucrèce contre la doctrine stoïcienne, voir J. SснміDт, Lukrez, der Kepos und die Stoiker, Frankfurt am Main, P. Lang, 1990 et C. LÉVY, «Lucrèce et les stoïciens ", in Poignault, R. (éd.), Présence de Lucrèce: actes du colloque tenu à Tours, 3-5 déc. 1998, Tours, Centre de recherches A. Piganiol, 1999, p. 87-98. Ce dernier montre que, malgré ce qu'affirme D. N. SEDLEY, Lucretius and the Transformation of Greek Wisdom, Cambridge, Cambridge University Press, 1998, qui récuse les allusions de Lucrèce au stoïcisme, Lucrèce connaît parfaitement les théories contemporaines du Portique et ne manque pas de les réfuter avec précision. Voir par exemple DRN I, 1053-1113 sur le géocentrisme, V, 156-234 sur l'origine et la durée des mondes ou encore V, 22-24 qui rapproche de façon polémique Épicure et Hercule, figure héroïque centrale pour le stoïcisme.
} 
concept stoïcien puisqu'il déclare que le maître du Jardin «se moque » (inrideat) de la distinction entre honestum et turpe et considère ces dénominations comme des «mots creux» (sonos inanis) ${ }^{51}$.

\subsection{La recherche de la gloire poétique: un paradoxe?}

Lucrèce délaisse l'honestum au profit du plaisir et rejette l'honos pour choisir une vie sans engagement politique, à l'écart de la foule. Le poète tire donc toutes les conséquences de sa critique de l'honneur. Il est dès lors surprenant, et apparemment paradoxal, de le voir signifier à deux reprises son espoir de rencontrer la gloire avec son œuvre poétique. Cette envie apparaît dans le «second prologue» du livre I quand Lucrèce évoque son projet d'exposé sur la nature:

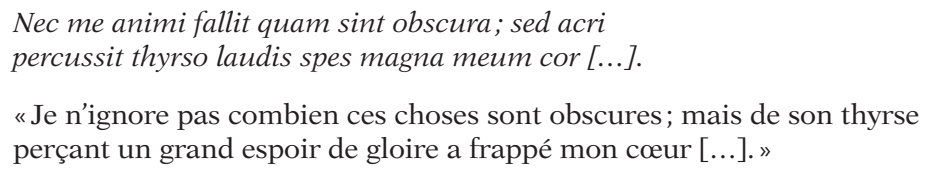

(LuCR, DRN I, 922-923).

Au livre VI, Lucrèce demande en outre à Calliope la possibilité d'obtenir cum laude coronam, "une couronne glorieuse ${ }^{52}$. Ces deux passages semblent en contradiction avec l'injonction épicurienne du "vis caché» et la critique de l'ambition ${ }^{53}$. Le paradoxe ne peut sans doute pas être totalement résorbé mais plusieurs éléments permettent de réduire la contradiction. Il faut bien voir, d'abord, que Lucrèce s'attache à rechercher une gloire de nature poétique et non politique; l'ambition dont il a mis en évidence les pièges et les souffrances n'est pas la même que celle qu'il reconnaît pour lui-même: le poète ne cherche pas l'approbation de la collectivité pour son action publique mais pour sa capacité à répandre en vers la doctrine épicurienne ${ }^{54}$. Mis à part Épicure, dont la gloria monte jusqu'au ciel' ${ }^{55}$, les personnages qui détiennent dans le De rerum natura une renommée positive

${ }^{51}$ CIC. Tusc. V, 73.

${ }^{52}$ LUCR. DRN VI, 95.

${ }^{53}$ Sur ce problème, voir GiancotTI, Il preludio di Lucrezio, p. 47-50; P. H. SchriJvers, Horror ac divina voluptas. Études sur la poétique et la poésie de Lucrèce, Amsterdam, A. M. Hakkert, 1970, p. 79-81 ; E. SEgAL, "Poetic Immortality and the Fear of Death: The Second Proem to the De rerum natura », HSCPh, 92, 1989, p.193-212; Roskam, Live Unnoticed, p. 99-101.

${ }^{54}$ Nous ne pensons pas qu'il faille, avec SEGAL, «Poetic Immortality and the Fear of Death", distinguer chez Lucrèce la personne du poète de celle du philosophe: la pratique de la poésie est, chez Lucrèce, indissociable de celle de la philosophie et de l'exposé de la doctrine épicurienne qu'elle rend plus agréable.

${ }^{55}$ LuCR. DRN VI, 7-8. 
sont des poètes: Ennius a obtenu une couronne et une grand célébrité, et la gloire d'Homère est éternelle ${ }^{56}$. La poésie apparaît donc comme un lieu possible de la recherche de la gloire. Epicure luimême envisageait l'obtention d'une décoration identique à celle que cherche Lucrèce, une couronne, pour celui qui atteindrait l'ataraxie ${ }^{57}$. Toute marque d'honneur n'est donc pas irrémédiablement disqualifiée, pourvu qu'elle ne soit pas gagnée sur le terrain politique. La gloire que vise Lucrèce, ensuite, peut se justifier par son utilité pour le bonheur des autres. Lucrèce recherche la gloire au moyen d'une poésie qui délivre un enseignement salvateur et doit inciter Memmius et les autres lecteurs à rejoindre les rangs du Jardin afin de trouver le bonheur. Le poète recherche la notoriété pour pouvoir toucher plus de gens et les convertir à la doctrine d'Épicure. L'épicurisme est marqué par un certain prosélytisme, visible dans l'enthousiasme de Lucrèce et dans sa volonté d'entraîner l'adhésion du lecteur ${ }^{58}$. Enfin, le désir de gloire manifesté par Lucrèce n'implique en aucun cas d'affrontement direct: Lucrèce rejette le modèle de la compétition aristocratique car il ne cherche nullement à rivaliser avec Épicure mais à marcher dans ses traces ${ }^{59}$.

\section{CONCLUSION}

Le De rerum natura représente une double rupture vis-à-vis de la pensée de l'honneur à Rome. L'œuvre rompt, d'abord, de façon radicale avec la valorisation de l'honos dans les mentalités. D'autres auteurs ont, avant Lucrèce, mis en question le prix de l'honneur mais aucun n'a dressé du prestige et de l'ambition une image aussi noire, en l'étayant sur une éthique qui en démontre la vanité et l'incapacité à réaliser le bonheur. Lucrèce rompt, ensuite, avec la construction du concept d'honestum progressivement opérée par les écrivains et philosophes qui l'ont précédé ou sont ses contemporains: il occulte totalement dans son poème les notions d'honnêteté et de beauté morale. Cette pensée singulière développée par Lucrèce sur l'honneur s'explique par deux facteurs principaux. Le premier est le contexte historique dans lequel a vécu le poète: Lucrèce a assisté à la destruction des

${ }^{56}$ Respectivement, Lucr. DRN I, 117-119; I, 124 ; I, 729.

${ }^{57}$ EpIC. frg. 556 Usener.

${ }^{58}$ Cicéron donne une image plaisante de ce prosélytisme, en déclarant que les épicuriens font la tournée des villages pour recruter des gens fort peu instruits (Cic. Fin. II, 12). Sur le prosélytisme épicurien, voir L.CANFORA, "La première réception de Lucrèce à Rome», in Monet, A. (éd.), Le Jardin romain. Épicurisme et poésie à Rome. Mélanges offerts à Mayotte Bollack, Lille, Presses de l'Université Lille III, 2003, p. 43-50 et la réponse de C. Lévy à cette communication (p. 51-55).

${ }^{59}$ Lucrèce n'est pas certandi cupidus (DRN III, 5). 
mécanismes fondamentaux de l'honos et à l'exacerbation des luttes motivées par l'ambition, allant jusqu'à la guerre civile. Il est particulièrement sensible au délitement de la res publica et cela se ressent dans l'image qu'il donne de ce rouage essentiel qu'est l'honos. Le second facteur n'est autre que l'adhésion du poète à la doctrine épicurienne: on retrouve, dans la représentation lucrétienne de l'honneur, les thèses d'Épicure sur la sécurité, sur les désirs vains, sur l'ataraxie et sur le rapport du sujet à la vie politique. Le rapprochement avec l'œuvre du maître du Jardin permet aussi de mesurer toute l'originalité du poète, qui se manifeste aussi bien sur le fond, avec l'articulation inédite de la peur de la mort et de l'ambition, par exemple, que sur la forme, avec l'exploitation de toutes les ressources de la langue poétique, analogies, images, ellipses,... pour rendre plus frappante la leçon sur la nature des choses. L'œuvre de Lucrèce montre donc parfaitement que la pensée romaine sur l'honneur n'évolue pas de manière téléologique ni linéaire mais peut connaître de violentes inflexions critiques. 


\section{CÉSAR: L'HONOS ET LA FIGURE DE L'IMPERATOR}

\section{INTRODUCTION}

L'honneur est un thème assez peu fréquent dans l'œuvre de César alors qu'on aurait pu s'attendre à ce que l'historien en fasse un usage étendu, puisque ses textes font le récit d'événements militaires et politiques, sont destinés à valoriser leur auteur, et sont écrits par un homme d'État de premier plan, à l'idéologie marquée et, qui plus est, parfait connaisseur de la langue latine. Expliquer cette faible présence de l'honneur dans l'œuvre césarienne sera l'un des objectifs de ce chapitre. Un autre but de notre étude sera de comparer la pratique césarienne de l'honneur, singulière à bien des égards, comme nous avons pu l'observer dans notre deuxième partie ${ }^{1}$, et la représentation qu'en fait César dans son œuvre. Quelle image donne-t-il de sa recherche des honores et comment présente-t-il les nombreuses marques d'honneur qu'il a obtenues au cours de sa vie? Rend-il compte des innovations qu'il a introduites en ce domaine? Enfin, on s'interrogera sur le rôle que joue la représentation de l'honos au sein de ce genre littéraire particulier qu'est le commentarius. Nous aurons ainsi l'occasion d'observer la place prise par la notion dans un récit de type historique et sa fonction dans la propagande césarienne. Notre étude portera sur le corpus césarien dont l'authenticité est assurée, les livres I à VII du Bellum Gallicum et l'ensemble du Bellum ciuile. Elle sera concentrée sur l'image que César donne de lui-même dans son œuvre.

\section{La REPRÉSENTATION DE CÉSAR EN DisPensateur DE L'HONNEUR}

À la différence des autres auteurs du $\mathrm{I}^{\mathrm{er}}$ siècle, César ne développe pas dans ses textes de réflexion sur l'honos ni d'évaluation critique de cet objet. La dimension narrative des commentarii le conduit en revanche à faire le récit d'événements où interviennent des pratiques d'honos. L'œuvre césarienne a ceci de singulier que les passages où il est question d'honos concernent surtout César lui-même. Et, singularité supplémentaire, César ne se figure pas en destinataire mais en donateur de l'honos.

\footnotetext{
${ }^{1}$ Voir p. 237-238 et 296-297.
} 


\subsection{L'image du donateur}

Les hommes politiques des $\mathrm{II}^{\mathrm{e}}$ et $\mathrm{I}^{\text {er }}$ siècles qui ont parlé de leur propre pratique de l'honneur ont très majoritairement évoqué les honores qu'ils ont obtenus: Caton souligne les obligations auxquelles le contraint l'honos de la censure, les épitaphes des Scipions rappellent que les défunts ont augmenté le prestige de leur famille et Cicéron raconte comment il a brisé le monopole établi par la nobilitas sur les honneurs en devenant consul ${ }^{2}$. César, en revanche, se concentre sur la manière dont il a octroyé des honores à son entourage politique et militaire. Il se peint ainsi dans une posture jusqu'alors peu mise en valeur, celle du donateur d'honneurs. Dans le Bellum Gallicum, il rappelle les marques d'estime qu'il a octroyées aux Héduens ou l'honneur dont il a entouré les Senons, par exemple ${ }^{3}$. Dans le Bellum ciuile, on le voit distribuer des honores à des cités espagnoles et à certains de ses soldats ${ }^{4}$. La construction dans son œuvre de cette figure de dispensateur d'honores possède plusieurs avantages dont César tire parti. En se représentant comme donateur, César apparaît maître des honores. Il est détenteur d'un pouvoir de décision et de gratification, aspect que le récipiendaire de l'honos ne peut mettre en valeur. On le remarque dans un passage du Bellum Gallicum qui évoque l'Héduen Dumnorix, frère de Diviciacos:

[...] odisse etiam suo nomine Caesarem et Romanos, quod eorum aduentu potentia eius deminuta et Diuiciacus frater in antiquum locum gratiae atque honoris sit restitutus.

«[...] en outre, il nourrissait une haine personnelle contre César et les Romains, parce que leur arrivée avait diminué son pouvoir et rendu à son frère Diviciacos crédit et honneur d'autrefois. »

(CAEs. BG I, 18, 8; trad. Constans modifiée).

César est présenté dans ce passage comme celui qui contrôle la répartition de l'honos parmi les Héduens: son arrivée a suffi à réduire le pouvoir de Dumnorix et à rendre à son frère Diviciacos le prestige qu'il possédait autrefois et qu'il avait perdu. César est capable de faire et de défaire l'honos des chefs gaulois par sa seule présence. Dans le Bellum Gallicum, cette emprise de César sur l'honos apparaît d'autant plus forte qu'il est le principal foyer d'honneurs; ce n'est pas le sénat, qui contrôle en principe la politique étrangère, qui donne des marques d'honneur, mais César lui-même. Ce dernier détient une sorte d'exclusivité sur les honores, ce qui renforce son image d'homme de pouvoir. Dans la représentation qu'il donne de lui-même, ainsi que dans sa

\footnotetext{
${ }^{2}$ CAt. frg. XVIII, 93 ORF; CIL I' 15 = ILLRP 316; Cic. Verr. II, V, 35.

${ }^{3}$ CAES. BG I, 43, 6-8; V, 54, 4.

${ }^{4}$ CAES. BC II, 21, 5; III, 59, 2-3.
} 
pratique politique, César tend à se substituer aux autres instances donatrices d'honneurs pour en détenir le monopole ${ }^{5}$. Cette figuration de César dessine un nouveau modèle de fonctionnement de l'honos. Prenant acte de la dislocation de l'honos à la fin de la République, César ne cherche pas, comme Cicéron, à revitaliser ses mécanismes traditionnels en redéfinissant ses normes de fonctionnement. Il élabore en lieu et place un autre modèle de l'homme d'honos et illustre ce modèle par sa propre personne. En prenant la posture du donateur d'honores, il se prive de la possibilité de mettre l'accent sur ses mérites, fréquemment évoqués quand un individu reçoit l'honos. Mais cela lui permet aussi de ne pas signaler les contraintes qui pèsent sur celui qui obtient l'honos. César rompt avec la figure traditionnelle de l'homme d'État chargé d'honores pour ses mérites et contraint par conséquent à la gratia et à l'honestas. Il la remplace par le modèle d'un chef utilisant l'honos comme moyen d'affirmer son pouvoir; l'arbitre de l'honos se déplace dans le champ du privé: ce n'est plus le peuple mais un individu.

\subsection{Les qualités du donateur}

Les textes de César, malgré leur apparence d'objectivité, sont nettement favorables à leur auteur. Ils cherchent à imposer au lecteur une image positive de César, que ce soit le Bellum Gallicum, qui expose la gloire et la puissance du général, ou le Bellum ciuile, qui justifie le déclenchement de la guerre civile et dénigre l'adversaire. Tout est mis en œuvre pour grandir la réputation du chef, et lui donner un statut supérieur à celui de son rival Pompée, que ce soit en voilant ses fautes ou en mettant en lumière ses qualités ${ }^{6}$. Le récit par César de ses usages de l'honos sert directement cet objectif de mise en avant de soi. La narration des hommages rendus par César à d'autres personnes est en effet l'occasion pour lui de mettre en avant des qualités morales qui complètent avantageusement la figure du donateur d'honos qu'il se construit. César apparaît de la sorte comme un chef à la fois puissant et vertueux. Deux qualités se manifestent plus particulièrement dans les

${ }^{5}$ Sur la façon dont César fait et défait l'honneur de ses contemporains, voir l'anecdote de Labérius (MAcr. Sat. II, 7): Labérius, forcé par César à monter sur scène pour jouer dans un mime dont il était l'auteur, perdit son statut de chevalier en raison de l'infamie du métier d'acteur. Mais à l'issue de la représentation, César lui fit attribuer de nouveau l'anneau d'or des chevaliers, le restaurant ainsi dans son rang.

${ }^{6}$ Voir M. Rambaud, L'Art de la déformation historique dans les Commentaires de César, Paris, Les Belles Lettres, 1966, p. 18 et p.243-293 sur les thèmes abordés lors de la mise en valeur de soi par César. Sur la "propagande» développée par l'œuvre césarienne, C.E.STEvens, "The Bellum Gallicum as a Work of Propaganda », Latomus, 11, 1952, p. 3-18 et 165-179; J.H. Collins, "Caesar as Political Propagandist », ANRW, I, 1, 1972, p. 922-966 ; F.-H. Mutschler, Erzählstil und Propaganda in Caesars Kommentarien, Heidelberg, C. Winter, 1975. 
honores rendus par César, la libéralité et la clémence. Elles ne font pas partie des qualités traditionnelles du chef aristocratique mais préfigurent en revanche les vertus d'Auguste ${ }^{7}$, ce qui montre combien César élabore, entre autres par le récit des honores qu'il a octroyés, une image nouvelle de princeps. La première qualité de César lorsqu'il accorde des honneurs est la générosité ${ }^{8}$. Il se représente comme soucieux de l'honneur de son entourage et prêt à donner largement des marques de distinction. Lorsqu'il évoque les relations d'amitié qui unissent Rome aux Héduens, il rappelle que c'est une tradition à Rome que les alliés ne subissent pas de diminution de leur dignitas et de leur honos mais qu'il faut au contraire veiller à ce que ces derniers soient augmentés9 . En tenant un tel discours, César souligne sa générosité vis-à-vis des peuples étrangers, dont il est prêt à soutenir le prestige. Au livre II du Bellum ciuile, à l'issue de la campagne contre les pompéiens en Espagne, César prend différentes mesures favorables aux Espagnols; il récompense leur fidélité par des remises de dettes, par la restitution de leurs biens ainsi que par l'octroi d'honores:

Eadem ratione priuatim ac publice quibusdam ciuitatibus habitis honoribus Tarracone discedit pedibusque Narbonem atque inde Massiliam peruenit.

"Comme à Cordoue, tant à la collectivité qu'aux particuliers, César distribue des honneurs dans certaines cités, puis il quitte Tarragone et gagne par voie de terre Narbonne, puis Marseille.»

(CAES. BC II, 21, 5; trad. Fabre modifiée).

Le don d'honores apparaît, dans le récit qu'en fait César, non pas tant comme un signe d'estime que comme une largesse accordée par un bienfaiteur. Sa générosité vise à construire de lui l'image d'un princeps exceptionnel, en rupture avec la pratique ancestrale de l'honos.

La deuxième qualité de César rendue manifeste par l'usage de l'honos fait également de lui une figure de chef particulier; il s'agit de la clémence ${ }^{10}$. Cette qualité est rapportée à César par de nombreux

${ }^{7}$ La clementia est l'une des quatre vertus figurant sur le clipeus uirtutis augustéen (P.ZAnker, The Power of Images in the Age of Augustus, Ann Arbor, University of Michigan Press, 1988, p. 95 sqq.). Suétone donne plusieurs exemples de la libéralité d'Auguste (SuEt. Aug. 41 et 43).

${ }^{8}$ Sur le désintéressement et la libéralité de César dans son œuvre, Rambaud, L'Art de la déformation historique, p. 71.

${ }^{9}$ CAES. BG I, 43, 8.

${ }^{10}$ La notion de clementia apparaît peu dans l'œuvre césarienne (BG II, 14, 5; 31, 4) mais les manifestations de clémence ou de mansuétude de César y sont nombreuses, notamment dans le Bellum ciuile. La bibliographie sur la question est très abondante. Voir notamment J.H.DAhlmanN, «Clementia Caesaris», NJW, 1934, p. 17-26; C. C. Coulter, "Caesar's Clemency», CJ, 26, 1931, p.513-524; Rambaud, L'Art de la déformation historique, p. 83-293; M. JEHNE, «Caesars Bemühungen um die Reintegration der Pompeianer », Chiron, 17, 1987, p. 313-341; Weinstock, Divus Julius, p. 233 sqq.; CAmPI, A., "La clementia di Cesare nel De bello Gallico », in SordI, M. (éd.), Amnistia, perdono e 
auteurs $^{11}$; elle n'est pas inédite dans le domaine des concepts politiques, mais César lui confère une place particulièrement importante et l'oriente dans un sens nouveau, en en faisant une caractéristique personnelle. Ce n'est plus avec lui la clementia populi Romani républicaine mais la clementia Caesaris d'un chef victorieux et puissant ${ }^{12}$. Cette clémence s'exprime en différentes occasions, et l'octroi d'honores est l'une d'entre elles. Dans le Bellum Gallicum, après sa victoire sur les Bellovaques, César accepte de les épargner et de ne prendre que six cents otages. S'il agit ainsi, c'est pour honorer l'Héduen Diviciacos qui lui a prêté main forte et lui fait cette demande ${ }^{13}$. L'honos est lié à la clémence de manière plus directe encore quand César octroie des honores aux ennemis qu'il a vaincus dans la guerre civile. Lors des opérations contre le pompéien Afranius devant Ilerda, des soldats du camp adverse passent dans celui de César:

Sed ex numero tribunorum militum centurionumque nonnulli sua uoluntate apud eum remanserunt. Quos ille postea magno in honore habuit; centuriones in priores ordines, equites Romanos in tribunicium restituit honorem.

«Mais parmi les tribuns et les centurions, quelques-uns restèrent, de leur propre volonté, dans son camp. César, ensuite, les tint en grand honneur; il rendit aux centurions le grade qu'ils avaient auparavant et aux chevaliers romains la charge de tribun.»

(CAEs. BC I, 77, 2).

César fait à cette occasion preuve de grande clémence envers ces transfuges puisqu'il leur restitue leur rang alors que ce sont des ennemis faisant leur soumission ${ }^{14}$. Le geste a pour effet d'impressionner les pompéiens et de les rallier à César; ce dernier essaye, par ce moyen, de frapper l'opinion publique et de se la concilier ${ }^{15}$. Quant au récit de cette action clémente, il sert à valoriser son auteur en soulignant une de ses vertus. La narration des hommages octroyés par César sert ainsi directement la propagande du Bellum ciuile puisqu'elle participe à la construction d'une image de chef bon et vertueux. La manifestation de cette qualité au sein de la relation d'honos permet aussi de dessiner un nouveau mode de fonctionnement de l'honos; elle provoque en effet une altération de la relation d'échange sur laquelle l'honos est construit. En se posant en donateur généreux et clément, César prend

vendetta nel mondo antico, Milan, 1997, p.253-270; M.Ducos, "César et la clémence», $A C D, 40-41,2004-2005$, p. 117-127.

${ }^{11}$ Cicéron lui-même en parle dans ses discours césariens (Cic. Lig. 37; Marc. 8 et

27). Voir aussi Sall. Cat. 54; Vell. II, 50; 52 ; 55-57; Plin. NH VII, 9, 3; Suet. Caes. 74, 1.

${ }^{12}$ Ducos, «César et la clémence», p. 126-127.

${ }^{13} B G$ II, 15,1 .

${ }^{14}$ Sur la clémence de César à l'égard des pompéiens, voir JEHnE, "Caesars Bemühungen um die Reintegration der Pompeianer ».

${ }^{15}$ Sur cet aspect de la clémence de César, voir Ducos, «César et la clémence», p. 121. 
une nette supériorité sur celui qui reçoit l'honos, qui lui est extrêmement redevable de son geste et peut difficilement répondre à la grandeur de l'hommage qui lui est fait ${ }^{16}$. Les centurions pompéiens qui retrouvent leur rang ne peuvent égaler par leur gratia la largesse de César qui les épargne et les honore. Il y a de la sorte une modification de la relation entre donateur et destinataire et l'émergence d'une figure de dispensateur d'honos à l'incommensurable prééminence. Sur ce point aussi les commentarii élaborent une nouvelle figure de l'homme public et de son usage des honores ${ }^{17}$.

\section{LA REPRÉSENTATION DE CÉSAR EN DÉTENTEUR DE L'HONNEUR}

L'historien se peint également en détenteur de l'honneur mais il s'agit d'un aspect sur lequel il insiste assez peu: il se décrit en effet, d'une part, comme un homme au désir d'honos très mesuré et ne met pas en valeur, d'autre part, l'honneur comme l'une de ses qualités essentielles, qu'il s'agisse de l'honos ou de l'honestas. Il nous faut apprécier les raisons de cette relative occultation et voir si elle correspond à la réalité des faits.

\subsection{Une quête de l'honos mesurée}

César donne de lui à plusieurs reprises l'image d'un individu peu touché par l'ambition. Il ne se présente pas comme dénué de tout désir d'honos, ce qui serait peu vraisemblable vu son statut de chef militaire et d'homme politique, mais dit faire preuve en ce domaine d'une grande modération. C'est notamment le cas dans le Bellum ciuile où il évoque la manière désintéressée dont il envisage les honores. Au tout début de l'œuvre, il rappelle ainsi à ses troupes qu'il ne s'est jamais montré jaloux de l'honos de Pompée et l'a au contraire soutenu:

Omnium temporum iniurias inimicorum in se commemorat; a quibus deductum ac deprauatum Pompeium queritur inuidia atque obtrectatione laudis suae, cuius ipse honori et dignitati semper fauerit adiutorque fuerit.

${ }^{16}$ Sur la supériorité que présuppose la clémence de César, voir CAMPI, «La clementia di Cesare nel De bello Gallico ».

${ }^{17}$ Il ne nous semble donc pas, comme le dit F.-H. Mutschler, que César se présente dans le Bellum Gallicum comme le dernier exemple du parfait aristocrate ("Caesars erste Kommentarienwerk erweist sich somit als eines der letzten (und eindrücklichsten) Beispiele aristokratischer Selbstdarstellung in republikanischer Zeit»; MutschleR, Erzählstil und Propaganda in Caesars Kommentarien, p.105). Il se différencie déjà, par ses qualités nouvelles et son usage de l'honos, du prototype ancien du princeps. 
«Il rappelle les continuelles injustices de ses ennemis à son égard; il se plaint qu'ils aient entraîné et détourné Pompée par la jalousie et le dénigrement de sa gloire, à lui, qui a toujours favorisé et soutenu l'honneur et le rang de Pompée.»

(CAES. BC I, 7, 1; trad. Fabre modifiée).

César, à la différence de Pompée, n'a jamais montré d'inuidia, de haine jalouse, pour les honneurs de son contemporain. Le fait qu'il ait travaillé au prestige de Pompée, ce qui ne servait pas sa propre carrière politique, est utilisé par César comme la preuve de son absence d'ambition excessive. Un autre épisode historique le montre. Alors que César avait obtenu grâce à un plébiscite de pouvoir se porter candidat aux élections consulaires de 49 sans être présent à Rome, Pompée avait peu après fait promulguer une loi rappelant que tout candidat devait briguer en personne cette magistrature, ce qui revenait à annuler le privilège accordé à César ${ }^{18}$. Rappelant cet épisode, César écrit à propos de lui-même:

Tamen hanc iacturam honoris sui rei publicae causa aequo animo tulisse.

"Cependant, il a supporté avec résignation de sacrifier cet honneur dans l'intérêt de l'État.»

(CAEs. BC I, 9, 3).

César présente à son avantage l'opposition qu'il a rencontrée dans cette affaire: son impossibilité de briguer le consulat, à cause de l'hostilité de Pompée, est l'occasion pour César de prouver son désintéressement et sa soumission à la res publica. Il affirme qu'il a supporté avec résignation la destruction (iactura) de son honos, parce que cela servait l'intérêt de l'État. En réalité, la iactura honoris à laquelle il fait allusion dégrada encore plus ses relations avec Pompée et le climat politique général. César n'était nullement prêt, contrairement à ce qu'il semble affirmer dans le Bellum ciuile, à renoncer à l'honos et, plus largement, au pouvoir. Il a d'ailleurs ardemment recherché les honores dès les débuts de sa carrière: en 60 , il avait réclamé le triomphe pour ses campagnes victorieuses en Espagne ultérieure et avait déjà essayé de briguer le consulat sans être présent à Rome, ce que le sénat, poussé par Caton, lui avait refusé ${ }^{19}$. Dans la suite de son action politique, il a tâché, le plus souvent avec succès, d'accumuler des honores à la fois nombreux et variés, statues, supplications ou triomphes, qui ont contribué à étayer son pouvoir à Rome ${ }^{20}$. Les commentarii visent

${ }^{18}$ Suet. Caes. 26 et 28. Sur cet épisode, voir M. Rambaud, César, 4e éd., Paris, P.U.F., 1983; M. Gelzer, Caesar: Politician and Statesman, 4e éd., Cambridge (MA), Harvard University Press, 1994, p.152-153 et E.T.SALMON, "Caesar and the Consulship for 49 B.C. », CJ, 34, 1939, p. 388-395.

${ }^{19}$ Gelzer, Caesar: Politician and Statesman, p. 64-66.

${ }^{20}$ Voir supra p. 296-297. 
à souligner la modération de son désir d'honos alors que ce dernier est manifestement puissant. Ils ont aussi pour fonction d'effacer l'aspect novateur des honores obtenus par César. On le remarque encore à propos de la candidature au consulat de 49 , lorsque César plaide sa cause devant le sénat:

Docet se nullum extraordinarium honorem appetisse, sed exspectato legitimo tempore consulatus eo fuisse contentum, quod omnibus ciuibus pateret.

«Il montre qu'il n'a pas brigué une charge extraordinaire mais que, après avoir attendu la durée légale pour le consulat, il s'est contenté d'y être candidat, ce qui était permis à tous les citoyens. »

(CAEs. BC I, 32, 2).

César affirme ici que son désir d'honos s'exerce dans le plus parfait respect des institutions: il déclare ne pas rechercher d'honos extraordinarius et se conduire comme n'importe quel citoyen en présentant sa candidature. En réalité, sa prétention à l'honos n'est pas si banale que cela: d'une part, César a déjà été consul, et, s'il respecte certes l'intervalle de dix ans requis par la loi entre deux consulats, sa réélection ne serait pas un événement d'importance secondaire. D'autre part, il avait obtenu, comme nous l'avons vu, de pouvoir se porter candidat alors qu'il était absent de Rome, ce qui constitue une irrégularité, rendue possible grâce à l'appui des tribuns de la plèbe. Sa recherche d'honos ne se coule donc pas dans les coutumes et les lois romaines, comme il veut le faire entendre. Il est également intéressant de voir César déclarer qu'il ne recherche aucun honneur inhabituel alors que c'est un des grands hommes de Rome qui a le plus obtenu d'honores extraordinaires, que ce soit des supplications de plusieurs dizaines de jours, le port permanent de la tenue triomphale, la multiplication des statues à son effigie ou le développement d'un culte dont il est le centre, prélude au culte impérial ${ }^{21}$. L'image qu'il donne de son rapport à l'honos nous apparaît donc déformée dans un sens qui l'avantage considérablement, en le montrant modeste et respectueux des institutions et du mos maiorum. Le traitement du thème des honores illustre les distorsions que César fait subir à la réalité historique, distorsions qui ont été soulignées pour la première fois, si l'on en croit Suétone, par Asinius Pollion qui accusait César de ne pas respecter la vérité des faits ${ }^{22}$.

${ }^{21}$ Sur les honneurs hors du commun obtenus par César, en quantité et en qualité, voir supra p. 296-297 ainsi que Weinstock, Divus Julius, passim; Gelzer, Caesar: Politician and Statesman, p. 278; 307-308; 315-321 et Doвеsch, Caesars Apotheose zu Lebzeiten, qui établit la chronologie des honneurs qui lui ont été accordés. Sur les honneurs obtenus à la fin de sa vie, voir J.-L. FerRary, «À propos des honneurs décernés à César entre 48 et 44 » in URso, G. (éd.), Cesare: precursore o visionario?, Pise, ETS, 2010, p. 9-30.

${ }^{22}$ Suet. Caes. 56, 4. Sur la question de la véracité de l'œuvre césarienne et sur les procédés de la déformation, voir l'étude d'ensemble de Rambaud, L'Art de la déforma- 


\subsection{L'honos comme qualité secondaire}

Il reste à expliquer une particularité du récit césarien, qui est le peu d'insistance sur ces honores remarquables et l'absence de mention de son honos, c'est-à-dire de son prestige, qualité pourtant traditionnellement valorisée. S'agissant des marques d'honneur, elles représentent, dans les faits, un élément incontestable de son pouvoir mais César leur donne peu d'ampleur dans son œuvre. S'agissant par exemple des supplications qu'il a obtenues à plusieurs reprises pendant la campagne des Gaules, il les mentionne avec une grande brièveté, comme on le voit à la fin du livre II du Bellum Gallicum:

Ob easque res ex litteris Caesaris dies quindecim supplicatio decreta est, quod ante id tempus accidit nulli.

«En raison de ces événements, à la suite du rapport de César, on décréta quinze jours de supplications, ce qui n'était arrivé à personne auparavant. »

(CAES. BG II, 35 ; trad. Constans modifiée).

César indique que l'honos qu'il a obtenu est sans précédent mais ne s'attarde pas sur sa mention et passe directement après ce passage au récit de la suite des événements. Le livre IV et le livre VII font état, avec une concision encore plus grande, des vingt jours de supplications obtenus au terme des opérations ${ }^{23}$. César adopte ici, non sans une certaine affectation, le style extrêmement simple des rapports de victoire $^{24}$. Quant au «prestige» qu'est l'honos, César ne le mentionne jamais comme l'un des traits de sa personne alors qu'il a dû en jouir dans les faits: il parle de sa popularité et de l'enthousiasme qu'il suscite parmi l'armée, mais pas de son estime ${ }^{25}$. Dans son œuvre littéraire, il ne mobilise donc que faiblement les honores qu'il a gagnés et n'évoque jamais son honos de général pour se mettre en valeur; il privilégie la figure du donateur à celle du détenteur de l'honos. Plusieurs raisons peuvent expliquer ce choix mais elles tournent toutes autour d'une même idée, qui est la sclérose de cette notion à l'époque où écrit César. L'honos est, d'abord, une valeur dont le prix est interrogé et contesté à la fin de la République: Cicéron lui-même, qui y est pourtant attaché, n'a pas manqué de l'évaluer avec un regard lucide; Lucrèce en a mené une sévère critique et César a pu lui aussi éprouver une certaine répulsion à trop le mettre en avant ${ }^{26}$. Ensuite, la notion d'honos a déjà été

tion historique et celles de J.P.V.D. BALsDon, «The Veracity of Caesar», G\&R, 4, 1957, p. 19-28 et Coluins, "Caesar as Political Propagandist», qui relèvent un certain nombre de distorsions de la réalité mais soulignent qu'il n'y a pas de grossières falsifications.

${ }^{23}$ CAES. IV, 38 ; VII, 90.

${ }^{24}$ Rambaud, L'Art de la déformation historique, p. 26.

${ }^{25}$ Sur le thème de la popularité de César, Ibid., p.272-283.

${ }^{26}$ Cicéron est surtout critique à l'égard de l'honos dans les Tusculanes (voir par exemple Tusc. V, 45 et 104). Sur la critique de Lucrèce, voir le chapitre précédent. 
mobilisée à plusieurs reprises par de grands généraux romains. Il s'agit d'une valeur-clef pour Marius, homo nouus qui attache du prix à la uirtus et à l'honos, au point de vouer un culte au dieu Honos. Cette divinité a également été honorée par Pompée, chargé d'honneurs pendant sa carrière, et il est fort possible que César ait voulu se démarquer de son adversaire principal en ne faisant pas une place trop grande à l'honos au sein de son idéologie ${ }^{27}$. De manière générale, la notion d'honos est présente dans les modes de pensée aristocratiques depuis longtemps et César, attaché à imposer un nouveau modèle de chef militaire et d'homme de gouvernement, a sans doute voulu s'éloigner des valeurs traditionnelles des nobles romains. Le renouveau de la pratique politique va de pair avec un renouveau idéologique. Il y a cependant des qualités caractéristiques du mos maiorum auxquelles César reste attaché, peut-être parce qu'elles ne sont pas liées autant que l'honos à la pratique des grands imperatores qui l'ont précédé28. César mentionne par exemple la dignitas qui est la sienne: c'est parce qu'elle a été bafouée qu'il a été contraint à l'affrontement avec Pompée ${ }^{29}$. Toutes les valeurs du mos maiorum ne sont donc pas abandonnées par César mais l'honos, qui a été régulièrement utilisé par ses prédécesseurs pour construire leur image publique, paraît, lui, délaissé.

\subsection{L'absence de l'honestas}

Avec Catulle et Lucrèce, César est le troisième auteur majeur du I ${ }^{\text {er }}$ siècle avant notre ère à ne jamais mentionner les notions d'honestas ou d'honestum. Nous avons déjà observé, chez Lucrèce, les raisons de ce silence et les remarques que nous avons faites à propos de cet auteur peuvent en partie s'appliquer aussi à César. César connaît et

${ }^{27}$ Sur Marius et l'honos, voir p. 336 sqq. et p. 529 sqq. sur le culte rendu au dieu. Sur celui de Pompée, voir p. 534 sqq. On connaît l'existence d'une colonie nommée Colonia Iulia Iuuenalis Honoris et Virtutis, mais il n'est pas certain que César en soit à l'origine. Il s'agit peut-être d'une fondation augustéenne. Voir F.VitTingHoFf, Römische Kolonisation und Bürgerrechtspolitik unter Caesar und Augustus, 1952, p. 112-113.

${ }^{28}$ César a moins œuvré contre les valeurs traditionnelles qu'on ne pourrait s'y attendre. Voir sur ce point F.-H. Mutschler, "Caesars Kommentarien im Spannungsfeld von sozialer Norm und individuellem Geltungsanspruch », in Haltenhoff, A., HeIL, A. et Mutschler, F.-H.(éds.), O tempora, o mores! Römische Werte und römische Literatur in den letzten Jahrzehnten der Republik, Munich, K. G. Saur, 2003, p.93-117 et l'ouvrage de G.Zecchini, Cesare e il mos maiorum, Stuttgart, F.Steiner, 2001 qui présente, de manière cependant peut-être trop univoque, l'image d'un César sensible aux valeurs romaines et soucieux de respecter le mos maiorum, dans les domaines politique, religieux et militaire.

${ }^{29}$ CAES. BC I, 7, 7. Sur la dignitas comme motif de la guerre civile, K. RaAflaub, Dignitatis contentio. Studien zur Motivation und politischen Taktik im Bürgerkrieg zwischen Caesar und Pompeius, Munich, C.H.Beck, 1974, p. 149-152; R. MorsteINMARX, "Dignitas and res publica: Caesar and Republican Legitimacy , p. 115-140. 
utilise les concepts de l'épicurisme et a peut-être eu des sympathies pour cette école $\mathrm{e}^{30}$; cela a pu l'amener à rejeter un concept doté d'une forte coloration stoïcienne et dont la valeur théorique et pratique est contestée par les adeptes de la philosophie du Jardin ${ }^{31}$. L'opposition de César à Caton, lisible dans le Bellum ciuile et réaffirmée à la mort de ce dernier dans l'Anticato de César, œuvre qui répond à l'éloge de Caton composé par Cicéron, se jouait aussi sur le terrain philosophique, Caton étant un des meilleurs représentants du Portique à Rome. César devait éprouver de la répulsion pour l'honestum qui était un concept central dans la pensée d'un de ses plus farouches adversaires. Cependant, d'autres raisons plus spécifiques à César expliquent aussi ce rejet. L'ancienneté de la notion d'honestum et sa sclérose à la fin de la République motivent, comme pour l'honos, son abandon par César; alors que Cicéron, conscient lui aussi de cette dégradation de l'honneur, cherche à le sauver en lui donnant de nouvelles bases éthiques et en reformulant son contenu ${ }^{32}$, César estime qu'il n'y a plus rien à tirer de cet élément trop ancré dans le code de conduite traditionnel, dont la débâcle est totale. Il est fort possible, en outre, que César ait délibérément renoncé à utiliser dans son œuvre une notion devenue, dans les années 40, très cicéronienne en raison des modifications profondes que l'Arpinate lui a fait subir: César renonce à une idée très utilisée par celui qui est, malgré l'amitié qu'il lui témoigne, un adversaire politique.

\section{LA REPRÉSENTATION DU RAPPORT DES AUTRES À L'HONNEUR}

Si le personnage de César est la principale figure liée à l'honos dans les commentarii, on rencontre aussi quelques autres individus ou groupes dont l'usage de l'honneur est évoqué. Mais la représentation de leur relation à l'honos sert en réalité presque à chaque fois à construire, indirectement, une image positive de César.

${ }^{30}$ César a été lié à plusieurs épicuriens de son époque et différents thèmes des Commentarii portent une coloration épicurienne: l'utilité de la justice, le trouble apporté par les passions, l'absence de crainte des dieux, le rôle assigné à la Fortune (RAmbaud, "César et l'épicurisme d'après les Commentaires " in Actes du vIII Congrès de l'Association Guillaume Budé, Paris, Les Belles Lettres, 1969, p.411-434; R. G. Mulgan, «Was Caesar an Epicurean? », CW, 72, 1979, p.337-339 et F.C.Bourne, "Caesar the Epicurean ", $C W, 70,1977$, p. 417-432). Il est cependant difficile de savoir s'il a adhéré réellement à cette doctrine. Sur la question de l'épicurisme de César, voir les bilans nuancés récents de Benferhat, Ciues Epicurei, p. 285-293 et G. Garbarino, «Cesare e la cultura filosofica del suo tempo » in URso, G. (éd.), Cesare: precursore o visionario?, Pise, ETS, 2010, p. 207-221.

${ }^{31}$ Voir supra p. 700.

${ }^{32}$ Cicéron se livre notamment à une dissociation de l'honos et de l'honestum (Fin. II, 45 ; Off. I, 14; III, 33) et fonde l'honestum sur la nature et la raison (Fin. V, 58). 


\subsection{L'honneur des Gaulois}

César fait usage de la notion d'honos à propos des Gaulois au cours de l'excursus ethnographique qui leur est consacré au livre VI du Bellum Gallicum ${ }^{33}$. Dans sa description des catégories sociales gauloises, il souligne la place supérieure qu'occupent les cavaliers et les druides:

In omni Gallia eorum hominum qui aliquo sunt numero atque honore genera sunt duo.

«Dans toute la Gaule, il y a deux catégories d'hommes qui comptent et sont honorés. »

(CAEs. BG VI, 13, 1).

Les druides et les cavaliers sont deux genera de la population qui jouissent, dit César, de l'honos. César utilise ainsi la notion romaine d'honos pour décrire les hiérarchies socio-politiques des Gaulois, ce qui montre que son regard reste ethnocentrique ou qu'il cherche à exposer les réalités étrangères dans des termes compréhensibles pour ses lecteurs. Son usage du terme d'equites pour désigner une catégorie gauloise est révélateur du même état d'esprit, tout comme l'usage de senatus, plebs, clientes pour décrire le monde gaulois ou le recours aux représentations romaines de l'art militaire pour juger les capacités guerrières des Gaulois ${ }^{34}$. César fait donc une lecture des réalités gauloises au travers d'un prisme romain; l'honos devient un outil pour la description ethnographique, au même titre que la gratia ou la dignitas, qui sont aussi rapportées au monde gaulois ${ }^{35}$. César fait un second usage de l'idée d'honneur à propos des Gaulois, pour désigner cette fois leur qualité morale. Il n'utilise pas directement la notion d'honestas, pour les raisons que nous avons vues, mais montre que ses adversaires ont une claire conscience de ce qui est turpe, le contraire de ce qui est honestum. Lors du siège d'Alésia, dans le discours qu'il

${ }^{33}$ Sur ce passage et sur la représentation de la culture et de la société gauloises par César, voir F. Beckmann, Geographie und Ethnographie in Caesars Bellum Gallicum, Dortmund, Ruhfus, 1930; G.Dobesch, "Caesar als Ethnograph», WHB, 31, 1989, p.18-51 ; A. A. Lund, "Caesar als Ethnograph », $A U$, 39 (2), 1996, p. 12-23; J.-M.ANDRÉ, "Ethnographie et sociologie 'barbare' chez César (1)», Vita Latina, 161, 2001, p. 15-28; J.-M. ANDRÉ, "Ethnographie et sociologie 'barbare' chez César (2)», Vita Latina, 162, 2001, p. 2-10 ; E. Campanile, "La Gallia di Cesare», in Poli, D. (éd.), La cultura in Cesare, Rome, Il Calamo, 1993, vol. 1, p.17-28.

${ }^{34}$ Sur l'usage des concepts militaires romains à propos des Gaulois, L. RawLINGS, "Caesar's Portrayal of Gauls as Warriors», in Welch, K. et Powell, A.(éds.), Julius Caesar as Artful Reporter. The War Commentaries as Political Instruments, Londres, 1998, p.171-192. César crée aussi parfois de nouveaux termes latins pour décrire les étrangers, tels que soldurii ou uergobretus (voir B. M. BELL, «The Contribution of Julius Caesar to the Vocabulary of Ethnography », Latomus, 54, 1995, p. 753-767).

${ }^{35}$ CAEs. BG I, 18,8 et I, 43, 8 . 
attribue à Critognatos, qui est favorable à une sortie, César place dans la bouche du Gaulois des propos sur la turpissimam seruitutem, sur le caractère totalement déshonorant de la servitude, et sur la nécessité de faire preuve de uirtus en attaquant de front les Romains ${ }^{36}$. César dépeint ainsi les Gaulois comme habités d'un certain sens de l'honneur et dotés d'un authentique courage: ils préfèrent risquer leur vie plutôt que tomber dans la servitude. Le thème de la mort honorable est ici discrètement réactivé et localisé, de manière inattendue, du côté des Gaulois. César ne fustige pas dans le Bellum Gallicum la lâcheté gauloise pour discréditer ses ennemis. Il critique parfois leur irrationalité à la guerre mais souligne aussi leur bravoure ${ }^{37}$. Cette mise en avant de leurs qualités est en effet pour lui doublement avantageuse. Elle montre d'abord que ce sont des combattants vaillants et qu'il est donc particulièrement glorieux de les avoir vaincus. L'insistance sur leur courage et leur dignité permet ensuite de justifier le recours à l'action militaire agressive contre ce peuple qui aurait été sans cela impossible à dompter ${ }^{38}$. César cherche toujours, dans son œuvre, à justifier les guerres qu'il a engagées, que ce soit dans le Bellum Gallicum ou dans le Bellum ciuile, et il utilise à cette fin le thème de l'honneur des Gaulois, qui légitime son action. La digression ethnographique est liée à la politique et à la propagande ${ }^{39}$.

\subsection{L’honneur de l'armée césarienne}

César donne de ses soldats une image valorisée, en leur attribuant notamment des qualités morales comme la uirtus et la magnitudo animi. Mais il est aussi question de l'honneur, non pas sous la forme de l'honestas, mais sous celle du pudor, c'est-à-dire du sens de l'honneur ${ }^{40}$. Au premier livre du Bellum Gallicum, les soldats de l'armée de César sont confrontés aux Germains et cherchent des prétextes pour quitter le camp et éviter le combat car ils sont terrifiés par ces ennemis. Cependant, plusieurs d'entre eux sont retenus par le sens de l'honneur, qui les empêche de se comporter lâchement:

Non nulli pudore adducti, ut timoris suspicionem uitarent, remanebant.

«Un certain nombre pourtant, retenus par le sentiment de l'honneur et voulant éviter le soupçon de lâcheté, restaient au camp. »

(CAES. BG I, 39, 3; trad. Constans).

${ }^{36}$ CAEs. BG VII, 77, 3-4.

${ }^{37}$ Sur l'image guerrière des Gaulois chez César, voir RAwLings, "Caesar's Portrayal of Gauls as Warriors ». L'auteur remarque que le qualificatif de uirtus est autant appliqué aux Gaulois qu'aux Romains dans le Bellum Gallicum (p. 180).

${ }^{38}$ Sur cet aspect, voir les remarques de McDonnell, Roman Manliness, p. 303.

${ }^{39}$ Voir ANDRÉ, «Ethnographie et sociologie 'barbare' chez César (2)».

${ }^{40}$ Sur le lien entre honestum et pudor, voir supra p. 462 sqq. 
C'est le pudor qui les empêche d'accomplir une action déshonorante en se soustrayant au combat. Cette mention de la dignité de certains soldats, et de la couardise d'une autre partie d'entre eux, ne vise cependant pas tant à évaluer de manière différenciée les qualités morales des troupes qu'à valoriser César. En effet, ce flottement au sein de l'armée est immédiatement perçu par César qui réunit un conseil et exhorte ses troupes à faire preuve, précisément, de pudor ${ }^{41}$. Ce discours rassure les soldats qui marchent alors vaillamment contre les Germains. C'est donc César qui sort valorisé de l'épisode, pour avoir su réveiller le sens de l'honneur des soldats défaillants. Le récit de l'honneur retrouvé de l'armée tourne au bénéfice de son chef qui a su faire preuve de clairvoyance et de persuasion ${ }^{42}$. Il en va de même dans le Bellum ciuile, quand, après une défaite face aux Pompéiens, César décrit ses soldats comme soucieux d'effacer la honte de la débâcle (studium infamiae sarciendae) ${ }^{43}$. Il met ainsi en avant le souci qu'ont les légionnaires de leur honneur mais, ce faisant, il montre aussi sa propre importance au sein de l'armée: c'est en effet devant César que les soldats ont honte, parce qu'ils sont placés sous son regard. Le sens de l'honneur et la volonté de laver l'affront trouvent leur fondement dans une instance extérieure, qui est le général. C'est son discours de blâme qui a suscité chez eux ce sentiment de honte après la défaite.

\subsection{Le dérèglement de l'honos chez les pompéiens}

Dans le Bellum ciuile, l'image des pompéiens, qu'il s'agisse des soldats ou des chefs, est régulièrement déformée par César qui essaye de les discréditer ${ }^{44}$. La manière dont il représente leur usage de l'honos s'inscrit parfaitement dans cette logique. César montre en effet à plusieurs reprises ses adversaires en train de donner ou de recevoir des honores, et leur comportement en ces occasions apparaît à chaque fois déréglé. César se garde bien dans son œuvre de souligner l'aspect inha-

${ }^{41}$ CAEs. BG I, 40, 14.

${ }^{42} C f$. la manière dont le récit du rôle joué par les lieutenants de César permet également de valoriser le chef suprême (Rambaud, L'Art de la déformation historique, p. 297).

${ }^{43}$ CAES. BC III, 74, 2.

${ }^{44}$ Voir sur ce point Rambaud, L'Art de la déformation historique, p.339 sqq. Voir notamment la manière dont César fait appel à des images négatives pour caractériser les pompéiens: A. F. RossI, «The Camp of Pompey: Strategy of Representation in Caesar's Bellum Ciuile », CJ, 95, 1999-2000, p. 239-256 montre que César dépeint le camp ennemi après Pharsale comme celui d'un roi oriental, rempli de mollesse et de débauche. L'article de A. Tronson, "Pompey the Barbarian: Presentation of 'the other' in Bellum Civile 3 ", in Joyal, M. (éd.), In altum. 75 years of Classical Studies in Newfoundland, St John's, Memorial University of Newfoundland, 2001, p. 73-104, insiste sur la manière dont César fait de Pompée un non-Romain, proche de la barbarie. Collins, "Caesar as Political Propagandist», p.949-954 montre comment César accentue la couardise, la cruauté, la rapacité et l'incompétence des pompéiens. 
bituel de ses propres usages de l'honos ou l'écart de son attitude par rapport au mos maiorum, alors que cet écart est, dans les faits, avéré; en revanche, s'agissant des pompéiens, il ne cesse de montrer leurs multiples infractions aux convenances propres à l'honos. César donne l'image d'un dysfonctionnement total de la pratique pompéienne de l'honneur pour dresser un contraste frappant avec sa propre attitude, qu'il présente comme respectueuse des traditions. Cette manipulation apparaît dès le début du Bellum ciuile, dans le texte cité précédemment où César affirme avoir toujours soutenu l'honos de Pompée:

Omnium temporum iniurias inimicorum in se commemorat; a quibus deductum ac deprauatum Pompeium queritur inuidia atque obtrectatione laudis suae, cuius ipse honori et dignitati semper fauerit adiutorque fuerit.

«Il rappelle les continuelles injustices de ses ennemis à son égard; il se plaint qu'ils aient entraîné et détourné Pompée par la jalousie et le dénigrement de sa gloire, à lui, qui a toujours favorisé et soutenu l'honneur et le rang de Pompée.»

(CAES. BC I, 7, 1; trad. Fabre modifiée).

César réagit ici aux levées de troupes qui ont été décrétées par le sénat et les consuls et sont visiblement dirigées contre lui. Pompée, qui a appuyé ces mesures, est ici habilement présenté par César sous un jour défavorable. Le narrateur juxtapose en effet l'injustice commise par Pompée contre lui et les bienfaits qu'il lui a autrefois accordés. César, en rappelant qu'il a autrefois soutenu l'honos de Pompée et en dépeignant à présent l'hostilité de Pompée à son égard, présente ce dernier comme un ingrat; il enfreint une des règles essentielles de l'honos qui consiste à manifester de la gratitude à celui par qui on a été honoré. César attire également l'attention sur le dérèglement de l'honos chez ses adversaires quand ces derniers l'octroient. Dans un discours prononcé après la capitulation des pompéiens à Ilerda, il déclare:

In se uno non seruari, quod sit omnibus datum semper imperatoribus, ut rebus feliciter gestis aut cum honore aliquo aut certe sine ignominia domum reuertantur exercitumque dimittant.

"Contre lui seul on supprime ce qui a toujours été accordé à tous les généraux, de rentrer à Rome, après une campagne heureuse, ou avec quelque honneur, ou en tout cas sans flétrissure, et de licencier ensuite leur armée.»

(CAES. BC I, 85, 10; trad. Fabre).

César fait état des différentes injustices dont il a été victime et rappelle notamment qu'on lui a refusé un triomphe. Ce comportement de ses adversaires, dit-il, est inique; on n'a en effet jamais refusé à un général vainqueur l'honos qui lui revenait après une victoire. Cette affirmation de César, cependant, est fausse: on connaît plusieurs cas où un triomphe n'a pas été octroyé à un imperator victorieux lors de 
son retour à Rome ${ }^{45}$. César, en systématisant de manière outrancière l'attribution des triomphes, vise à montrer que ses ennemis, en le lui refusant, se sont comportés d'une manière tout à fait contraire à la tradition. César manipule ici les faits historiques pour persuader ses lecteurs que ses adversaires ont fait, pour lui, une exception injuste. Il les montre, ici encore, en infraction avec une règle fondamentale de l'honos, qui veut que le mérite soit récompensé par une marque d'honneur. Les pompéiens se sont à nouveau écartés d'une coutume ancestrale.

Le dernier aspect du rapport déréglé des pompéiens à l'honos apparaît dans le tableau que fait César du camp de Pompée avant la bataille de Pharsale. Il dessine dans ce passage un autre contraste saisissant entre lui-même et les chefs pompéiens: alors qu'il se présente comme un homme d'État animé d'un désir d'honos très maîtrisé, il peint chez ses adversaires les ravages d'une ambition démesurée. Avant même que la bataille ne commence, il montre les généraux pompéiens occupés à se partager à l'avance les dépouilles de leur ennemi. Le récit évoque ainsi les affrontements qui opposent Domitius, Scipion et Lentulus Spinther pour savoir lequel d'entre eux, après la victoire qu'ils s'imaginent déjà acquise, exercera la charge de pontifex maximus détenue pour le moment par César. Le narrateur conclut ainsi :

Postremo omnes aut de honoribus suis aut de praemiis pecuniae aut de persequendis inimicitiis agebant, nec quibus rationibus superare possent, sed quemadmodum uti uictoria deberent, cogitabant.

«Bref, chacun ne se préoccupait que d'obtenir pour soi des charges publiques, ou des avantages financiers ou de poursuivre ses haines personnelles; ils ne réfléchissaient pas aux moyens de l'emporter mais à la façon dont ils devaient consommer leur victoire.»

(CAEs. BC III, 83, 4).

Dans le récit de César, les pompéiens sont des êtres dévorés d'ambition, obnubilés par les honores qu'ils pensent pouvoir acquérir à l'issue du combat. Leur désir d'honos est totalement déréglé et les conduit à l'outrecuidance: avant même d'avoir fait la preuve de leur uirtus militaire, ils se voient entourés d'honores. Dans la suite du récit, la défaite qu'ils essuient à Pharsale apparaît comme la punition implacable de cette présomption insensée ${ }^{46}$. L'attitude des pompéiens vis-à-vis de l'honos est ainsi présentée, par le biais d'une adroite manipulation, comme contraire aux usages traditionnels et diamétralement opposée à celle de César.

${ }^{45}$ Voir supra p. 438.

${ }^{46}$ César se plaît à montrer ses ennemis présomptueux dans un premier temps puis humiliés dans un second. $C f$. l'attitude d'Afranius et Libon qui envoient trop tôt des bulletins de victoire (CAES. BC I, 53; II, 17; III, 23). Sur cet aspect, RAMBAUD, L'Art de la déformation historique, p. 347. 


\section{CONCLUSION}

Au terme de ce chapitre, c'est toute la complexité du rapport de César à la notion traditionnelle d'honos qui apparaît. D'un côté, l'image qu'il dessine de lui-même paraît novatrice en bien des points. César assume en effet une posture jusqu'alors peu mise en valeur, celle de donateur d'honores, et les qualités qui apparaissent lors de la construction de cette image, la générosité et la clémence, ne sont pas les vertus les plus proéminentes de la tradition aristocratique romaine. Le fait qu'il s'étende peu, en outre, sur les honores obtenus et que le prestige qu'est l'honos occupe une place secondaire parmi les traits de sa personne est également singulier, tout comme l'absence totale de l'honestas. Cette place réduite faite à l'honneur doit être rapportée à ses conceptions philosophiques et politiques qui l'éloignent d'une valeur déjà manipulée par ses prédécesseurs et sclérosée à la date des commentarii. Mais, d'un autre côté, César tente de placer son rapport à l'honos sous le signe de la tradition et du respect de ses normes. Il n'insiste pas, en effet, sur le caractère innovant de sa posture de donateur d'honos et ne se livre pas à une critique directe de la valeur qu'est l'honneur: prenant acte de sa fossilisation, il l'occulte mais ne la discrédite pas. On le voit, surtout, en tant que détenteur de l'honos, gommer son ambition et montrer que son exercice des honores est désintéressé, conformément à l'ancien idéal de dévouement à la res publica. À l'inverse, ses adversaires de la guerre civile méprisent toutes les règles de fonctionnement de l'honos et sont dévorés par un désir de pouvoir démesuré. Lélaboration par César de cette représentation de lui-même et de ses adversaires est naturellement tendancieuse. Elle passe par la déformation de certaines réalités et notamment de l'attitude historique de César à l'égard des marques d'honneur, qu'il a à la fois recherchées et accumulées. Cette reconstruction littéraire est destinée à le valoriser en tant que chef militaire et politique et à discréditer les pompéiens. Même l'honneur propre aux Gaulois et aux soldats de l'armée rejaillit sur le prestige de César. L'utilisation dans les commentarii de la notion d'honos nous semble donc s'inscrire parfaitement dans la propagande mise en œuvre par ces textes en faveur de leur auteur. 



\section{SALLUSTE: L'HISTORIEN D'UN HONNEUR EN CRISE}

\section{INTRODUCTION}

Comme César, Salluste a mené une carrière politique et a également produit une œuvre historique. Cependant, notre étude de l'honneur chez cet auteur ne peut emprunter la même voie que celle suivie pour César. En effet, l'activité littéraire de Salluste n'a pas été pour lui un complément de l'activité politique mais un substitut à cette dernière: c'est après avoir essuyé plusieurs revers dans le domaine des affaires publiques et avoir été dégoûté, dit-il, de la corruption qui y régnait qu'il s'est détourné du cursus honorum pour devenir historien ${ }^{1}$. Il est donc moins légitime, le concernant, de rechercher à donner un sens politique à son œuvre et il est d'ailleurs difficile de déceler dans ses textes l'expression d'une idéologie précise, comme la critique l'a remarqué2. En outre, Salluste n'est pas, à la différence de César, l'acteur principal des événements dont il fait le récit: il n'évoque sa personne que dans les prologues, et de manière assez fugace. Les mentions de l'honneur dans son œuvre ne sont donc pas à examiner pour la manière dont elles mettent en avant un homme public ou légitiment la politique d'un parti. La notion d'honneur, sous la forme de l'honos et de l'honestum, trouve surtout une place chez Salluste comme élément du récit, de l'analyse et des jugements de l'historien. C'est en ce sens qu'il nous faudra l'interpréter, en prenant en compte le genre auquel appartiennent le De coniuratione Catilinae, le Bellum Iugurthinum et les Historiae. Nous laisserons de côté dans cette analyse les deux lettres à César ainsi que l'invective contre Cicéron, textes dont l'authenticité est trop controversée pour qu'ils puissent être exploités dans une étude de la pensée de Salluste ${ }^{3}$. Une première approche consiste à s'interroger sur l'usage

${ }^{1}$ Voir le récit de cette conversion en Sall. Cat. 3, 3-4, 2 et Iug. 3, 1-4, 4.

${ }^{2}$ Les lectures de l'œuvre de Salluste comme un texte partisan, favorable aux populares et à César, ont rapidement montré leurs limites. Voir le bilan, avec bibliographie, établi par A. La Penna, Sallustio e la 'rivoluzione' romana, Milan, Feltrinelli, 1968, p. 68-83 et 159-174 et C. BECKER, "Sallust», ANRW, I, 3, 1973, p. 720-754.

${ }^{3}$ La question de l'authenticité de ces œuvres a suscité une très abondante bibliographie. Longtemps considérées comme apocryphes, leur attribution à Salluste a été défendue par plusieurs savants allemands mais leurs arguments n'ont pas emporté l'adhésion de tous. Voir le bilan fait par M. Сноuet, Les Lettres de Salluste à César, Paris, Les 
de l'honos par la narration historique: comment est-il décrit? Sert-il à établir les causes des événements? Il faudra aussi tâcher d'éclairer la place de l'honneur dans la philosophie sallustéenne de l'histoire: quel est le rôle assigné au désir d'honos dans une pensée marquée par l'idée de décadence? L'histoire étant, à Rome, fortement liée à un discours moral, un autre point à aborder sera le jugement formulé par Salluste sur l'honneur. Quelle attitude l'historien adopte-t-il vis-à-vis de la notion traditionnelle d'honneur? Se livre-t-il comme Cicéron, à sa refondation ou, comme César, cherche-t-il à s'en détacher ou à l'orienter dans un sens tout à fait nouveau? Le dernier aspect que nous examinerons tout au long de ce chapitre est la marque de la pensée grecque sur Salluste: sans entrer dans le détail de la Quellenforschung, nous tâcherons d'apprécier l'influence de l'histoire et de la philosophie helléniques sur sa conception de l'honneur. Ce chapitre s'organisera en trois temps. Dans un premier moment, nous étudierons la représentation historique que donne Salluste du délitement des pratiques de l'honos et du mépris pour l'honestum. Dans un deuxième temps, nous nous intéresserons à l'analyse que Salluste fait du désir d'honos et de l'ambition en général. Enfin, nous tâcherons d'établir la place que revêt, dans ses représentations morales, le concept d'honestum.

\section{LA REPRÉSENTATION HISTORIQUE DU DÉLITEMENT DE L'HONNEUR}

Salluste exerce sur la notion d'honneur un regard d'historien. Par l'utilisation des deux moyens traditionnels de l'historiographie, le récit et les discours, il donne une image de l'usage de l'honos et de l'honestum à l'époque décrite par ses textes, c'est-à-dire la première moitié du Ir siècle avant notre ère, lato sensu. Or cette représentation historique est très sombre: Salluste fait le tableau d'un honos dont le fonctionnement est totalement perverti et d'une honorabilité qui n'est plus que de façade, quand elle n'est pas ouvertement foulée aux pieds. Les monographies de Salluste représentent la désagrégation complète de l'honneur et de son système, dans le cadre d'un processus de décadence généralisée.

\subsection{Le vol des honores par la noblesse}

Le premier grave dysfonctionnement de l'honos mis en avant par l'œuvre de Salluste est de nature politique: il s'agit de la déprédation des honores par la noblesse romaine. Nous avons vu précédemment que, dans le Bellum Iugurthinum, Salluste plaçait dans la bouche de

Belles Lettres, 1950, celui d'A.Ernout dans son édition de ces œuvres du Ps.-Salluste dans la C.U.F., p. 7-23 (qui conclut à l'inauthenticité) et celui de BECKER, «Sallust ». 
Marius un discours hostile aux nobles romains: il leur reproche de s'arroger les honores alors qu'ils n'ont aucun mérite ${ }^{4}$. La même idée apparaît, avec encore plus de véhémence, dans le discours du tribun de la plèbe Memmius qui exhorte les plébéiens à agir contre les excès de la nobilitas:

Itaque postremo leges, maiestas uostra, diuina et humana omnia hostibus tradita sunt. Neque eos qui ea fecere pudet aut paenitet, sed incedunt per ora uostra magnifici, sacerdotia et consulatus, pars triumphos suos ostentantes, proinde quasi ea honori, non praedae habeant.

"Aussi ont-ils fini par livrer aux ennemis les lois, la majesté de votre nom, tous les droits des dieux et des hommes. Et les auteurs de ces excès n'ont ni honte, ni remords; ils défilent insolemment devant vos yeux, étalant leurs sacerdoces et leurs consulats, quelques-uns même leurs triomphes; comme s'ils avaient ces charges à titre d'honneur et non de butin.»

(SALL. Iug. 31, 9-10; trad. Ernout).

Memmius développe l'idée d'un monopole criminel exercé par la noblesse sur les charges publiques. Le tribun accuse les aristocrates d'avoir obtenu les honores que sont les sacerdoces, consulats et triomphes en toute illégalité: les pauci les détiennent à titre de praeda, de butin. Un grave dysfonctionnement de l'honos est ici mis en avant: l'honos est arraché au peuple par les nobles et n'est donc plus lié à l'estime du donateur qu'il est supposé signifier; il se trouve donc totalement vidé de son sens. Les populares ont donc chez Salluste une vision très critique de la noblesse et sont aussi ceux qui perçoivent le mieux le dysfonctionnement de l'honneur. L'historien semble d'ailleurs partager leur vision des choses. On voit en effet réapparaître, dans des passages pris en charge par le narrateur lui-même, l'idée d'un monopole de la noblesse sur les honneurs publics. Dans l'excursus du Bellum Iugurthinum qui vise à éclairer l'origine du mos partium et factionum qui a détruit la prospérité romaine, Salluste souligne que, depuis la chute de Carthage, c'est à la nobilitas que reviennent provinces, magistratures, triomphes et gloire ${ }^{5}$. Quand l'historien évoque le début de la carrière de Marius, il remarque qu'avant lui

[...] consulatum nobilitas inter se per manus tradebat. Nouos nemo tam clarus neque tam egregiis factis erat, quin is indignus illo honore et quasi pollutus haberetur.

«[...] la noblesse se réservait le consulat qu'elle se passait de main en main. Il n'y avait pas d'homme nouveau, si grand fût-il par sa gloire et ses exploits, qui ne fût jugé indigne de cet honneur et comme entaché de quelque souillure. »

(SALL. Iug. 63, 6-7; trad. Ernout modifiée).

${ }^{4}$ Voir SaLL. Iug. 85, 1-43 et supra p. 342 sqq.

${ }^{5}$ SALl. Iug. 42, 7-9. 
Salluste semble donc partager, jusqu'à un certain point, les idées des populares en ce qui concerne la mainmise des nobles sur les fonctions publiques. Cela est conforme avec la représentation peu flatteuse qu'il donne de la nobilitas dans l'ensemble de son œuvre et avec ce que l'on sait de sa propre vie: Salluste a été, comme tribun de la plèbe en 52, du côté des populares lors de l'agitation contre Milon, puis a été proche de César, notamment quand il fut nommé par lui, après Thapsus, gouverneur de l'ancien royaume de Juba devenu province d'Africa Noua ${ }^{6}$. Ces affinités avec les populares et l'hostilité à la noblesse ne signifient pas cependant que son œuvre historique soutienne, de manière tendancieuse, un parti. Salluste écrit en effet alors qu'il s'est retiré de la politique; on rencontre également dans son œuvre des critiques dirigées contre la plèbe et ses représentants ${ }^{7}$. Si la responsabilité des dérèglements de l'honos est surtout rejetée sur la nobilitas, l'ambition des populares y participe aussi. L'œuvre de Salluste n'est pas un texte pamphlétaire dirigé exclusivement contre un parti.

\subsection{L'inversion des motifs d'honos}

Dans la pratique traditionnelle, l'octroi de l'honos repose sur certains mérites et notamment sur l'exercice de la uirtus. Ce fondement est essentiel car l'honneur fonctionne comme une rétribution donnée pour une qualité ou un service ${ }^{8}$. Or Salluste dépeint dans son œuvre une inversion complète de ce fonctionnement car la vertu n'est plus une source d'honneur. Nous avons vu que Plaute mettait en scène dans ses comédies une telle inversion ${ }^{9}$; cependant, le bouleversement plautinien a un rôle dramatique et comique et diffère donc de celui représenté par Salluste. Chez ce dernier, le renversement des motifs

${ }^{6}$ Sur la biographie de Salluste, voir les cinq premiers chapitres de R. Syme, Salluste, Paris, Les Belles Lettres, 1982 ainsi que J. MaLITz, Ambitio mala. Studien zur politischen Biographie des Sallust, Bonn, R. Habelt, 1975 et É. TIFfou, «Biographie de Salluste», CEA, 7, 1977, p. 91-138.

${ }^{7}$ La plèbe apparaît souvent apathique ou servile (voir par exemple SALL. Iug. 73, 6); Marius est un homme nouveau de valeur mais il est aussi violent et dévoré d'ambition (SAll. Iug. 63, 6). Dans le De coniuratione Catilinae, César n'est pas non plus totalement positif et il ne fait pas l'objet d'une apologie. Sur l'absence de parti pris de Salluste, voir La Penna, Sallustio e la 'rivoluzione' romana, p. 209-220; É. Tiffou, Essai sur la pensée morale de Salluste à la lumière de ses prologues, Paris, C. Klincksieck, 1974, p. 386 sqq.; K. E. Petzold, «Der politische Standort des Sallust», Chiron, 1, 1971, p. 219-238; O.S. Due, «La position politique de Salluste», $C \& M$, 34, 1983, p. 113-139. La dimension non pamphlétaire de l'œuvre ne signifie cependant pas qu'elle soit dépourvue de toute réflexion politique, au contraire; l'aspect moral de l'histoire de Salluste est ancré dans l'étude d'un contexte politique (J.Hellegovarc'H, «Le proøium du Bellum Iugurthinum. Actualité et signification politique. », Kentron, 3, 1987, p. 7-16).

${ }^{8}$ Sur ce mécanisme, voir supra p. 224 sqq.

${ }^{9}$ Voir le chapitre 12. 
de l'honos est le signe d'une destruction des repères traditionnels et d'une disparition des bonnes mœurs. Il s'inscrit dans la description d'une dégradation générale de la situation socio-politique romaine et est abordé comme un fait historique, localisé à une époque assez précise. Dans l' "archéologie» du De coniuratione Catilinae, quand l'historien remonte aux origines de Rome pour observer la progression dans le temps de la corruption et de l'immoralité ${ }^{10}$, il observe, à la fin du passage, les conséquences de la domination de Sylla. C'est à partir de sa dictature que les affrontements civils se sont généralisés et que la mollesse et la cupidité ont pris le pas sur la vaillance et le désintéressement. L'inversion des motifs d'honos est un des aspects de ce bouleversement moral:

Postquam diuitiae honori esse coepere et eas gloria, imperium, potentia sequebatur, hebescere uirtus, paupertas probro haberi, innocentia pro maliuolentia duci coepit.

«Lorsque la richesse fut en honneur, qu'elle s'accompagna de la gloire, du commandement, de la puissance, bientôt le mérite personnel perdit de sa valeur, la pauvreté devint une honte, l'intégrité, de la malveillance.»

(SAlL. Cat. 12, 1 ; trad. Ernout modifiée).

À partir de cette époque, un phénomène de substitution s'observe parmi les motifs d'honos: ce dernier a été octroyé à la richesse et non plus à la uirtus. Salluste étudie également les conséquences de cet événement, qui sont essentiellement morales: en raison de la fonction d'orientation des mœurs exercée par l'honos, la modification de la voie pour y accéder provoque une modification du comportement des hommes; tous se sont détournés de la uirtus pour rechercher la richesse, qui seule ouvrait le chemin de l'honneur et du pouvoir ${ }^{11}$. Le bouleversement des motifs d'honos provoque une inversion générale des représentations morales: la pauvreté devient un probrum et l'intégrité de la maliuolentia. Salluste semble ici se souvenir de la description que fait Thucydide des effets de la guerre civile à Corcyre où s'observe une altération du sens usuel des mots: l'audace irréfléchie devient un courage remarquable et la prudence de la lâcheté; Thucydide associe lui aussi ces perturbations dans la représentation des vertus et des vices à une modification du fonctionnement de l'honneur puisqu'il remarque que

${ }^{10}$ Sall. Cat. 6-13. Sur l'importance de ce passage pour la compréhension de la pensée de Salluste, voir Tiffou, Essai sur la pensée morale de Salluste, p. 378 sqq. et K. Büchner, Sallust, 2 ééd., Heidelberg, C. Winter, 1982, p. 132-143.

${ }^{11}$ Sur cette fonction d'orientation de l'honos, voir supra p. 394 sqq. Sur la conception sallustéenne de la uirtus, voir D. C. EARL, The Political Thought of Sallust, Cambridge, Cambridge University Press, 1961, p. 28 et Tiffou, Essai sur la pensée morale de Salluste, p. 153-154. 
ce sont les vices qui reçoivent alors les plus grandes louanges ${ }^{12}$. Ce thème de l'inversion des motifs d'honneur réapparaît chez Salluste en deux endroits du Bellum Iugurthinum; il est utilisé par Memmius qui remarque que l'intégrité est plus une source de dangers que d'honos ${ }^{13}$. Le discours du tribun de la plèbe présente donc encore une analogie avec la pensée de Salluste. Il est surtout évoqué, de manière peut-être encore plus frappante, dans le prologue de l'œuvre ${ }^{14}$ : Salluste y développe en effet non seulement l'idée selon laquelle la uirtus ne conduit plus vers l'honos mais suggère aussi que ce sont le vice et le crime qui y mènent. L'historien évoque dans le prologue la dégradation de la vie politique à son époque:

Verum ex eis magistratus et imperia, postremo omnis cura rerum publicarum minime mihi hac tempestate cupiunda uidentur, quoniam neque uirtuti honos datur neque illi, quibus per fraudem is fuit, tuti aut eo magis honesti sunt.

«Mais parmi ces moyens de trouver la gloire, les magistratures, les commandements, bref, toute activité politique ne me semblent nullement désirables à notre époque, parce que ce n'est pas à la vertu que l'honneur est donné, et parce que les gens qui l'ont acquis par fraude n'en sont ni plus en sûreté ni plus considérés. »

(SALL. Iug. 3, 1; trad. Ernout modifiée).

L'engagement dans le cursus honorum ne paraît pas à Salluste le moyen adéquat pour obtenir la gloire car les honores ne sont plus le lieu de la vertu, seul moyen vers la véritable notoriété selon l'historien $^{15}$ : il est possible de faire preuve d'un grand mérite sans que ce dernier ne soit récompensé par l'honos. Ce n'est plus la uirtus qui est à la base de l'honos mais la fraus, le crime. Au moment où Salluste écrit (hac tempestate), la dégradation des mécanismes de l'honneur s'est encore accentuée par rapport à la période de l'après-Sylla évoquée dans l'archéologie du De coniuratione Catilinae et les malversations sont devenues un moyen privilégié pour accéder à l'honneur. Il remarque quelques lignes plus loin que même les homines noui, qui s'appuyaient

12 Thuc. III, 82, 4-5. Sur l'influence de Thucydide sur Salluste, voir P. Perrochat, Les Modèles grecs de Salluste, Paris, Les Belles Lettres, 1949 et T.F. Scanlon, The Influence of Thucydides on Sallust, Heidelberg, C.Winter, 1980, notamment p.172 sqq. sur la marque de l'épisode de Corcyre sur Salluste.

${ }^{13}$ SALL. Iug. 31, 1 : innocentiae plus periculi quam honoris est.

${ }^{14}$ Les prologues des œuvres de Salluste ont suscité de nombreuses recherches. Sont particulièrement éclairantes, pour l'approche qui est la nôtre, BüchNER, Sallust, p.93-105 et p.106-113 et Tiffou, Essai sur la pensée morale de Salluste. Voir aussi E. BolafFI, «I proemi delle monografie di Sallustio», Athenaeum, 16, 1938, p. 128-157, qui recherche les sources et compare les prologues de Salluste avec ceux de l'historiographie précédente, et $\mathrm{M}$. RAmBAUD, «Les prologues de Salluste et la démonstration morale dans son œuvre », $R E L, 24,1946$, p. 115-130, qui montre les liens existant entre les prologues et le contenu des récits.

${ }^{15}$ Sur cet aspect de sa pensée, voir infra p. 740. 
traditionnellement sur leur uirtus, agissent dorénavant furtim et per latrocinia, "par le vol et le brigandage», pour arriver au pouvoir ${ }^{16}$. La rupture totale du lien entre uirtus et honos provoque, en raison de son rôle essentiel, une destruction des autres rouages de l'honos: l'honos perd de ce fait sa capacité de signifier l'estime et le mérite mais il voit aussi s'évanouir ses effets positifs. Le bénéficiaire de l'honos n'est pas en sécurité et il n'est pas considéré: l'honos, quand il n'est plus fondé sur la uirtus n'apporte plus son aura protectrice et prestigieuse ${ }^{17}$. Salluste dépeint donc le bouleversement total de l'honos, dans ses motifs, son sens et ses effets. La vision des luttes civiles à Rome a directement influé sur sa façon de voir les choses mais l'historien a également pu vouloir reprendre un thème de l'historiographie grecque. Nous avons vu ce que sa peinture de l'inversion des vices et des vertus devait à Thucydide; la description du dysfonctionnement total de l'honos fait aussi penser au dérèglement de la $\tau \mu$ ń dont Xénophon fait le récit à propos des Perses, après la mort de Cyrus, dans la Cyropédie ${ }^{18}$. Deux éléments de ce récit trouvent en effet leur parallèle chez Salluste: d'abord, Xénophon relève, comme Salluste, une inversion totale des marques d'honneur, décernées aux traîtres et aux menteurs, et non aux individus dévoués et talentueux. Ensuite, cette inversion est rattachée par Xénophon à une rupture dans l'histoire de l'empire perse et au début de la décadence, qui commence à la mort de Cyrus. Comme on l'a vu, Salluste inscrit de même la dislocation de l'honos dans une phase de décadence générale de Rome, particulièrement sensible à partir de la domination de Sylla.

\subsection{Le mépris de l'honestum}

Salluste a la singularité de mettre en avant la manière dont la crise morale touche non seulement les pratiques traditionnelles mais aussi les représentations intellectuelles des Romains. Salluste souligne en effet que la dislocation de l'honneur s'observe aussi dans la corruption morale profonde qui touche l'axiologie ${ }^{19}$. Il dépeint la destruction des mécanismes de l'honos mais aussi la dévalorisation de l'honestum. Salluste donne l'image d'une cité où l'honneur perd son statut de principe moral et son pouvoir de régulation, ce qui n'avait jusqu'alors pas été montré. L'historien identifie chez certains protagonistes de son

${ }^{16}$ SAll. Iug. 4, 7. Ce coup de griffe contre les homines noui vise, plutôt que Cicéron, Cornelius Balbus et Salvidienus Rufus, d'après Syme, Salluste, p. 180-181.

${ }^{17}$ Sur ces effets positifs de l'honos, voir supra p. 361 sqq.

18 Xen. Cyr. VIII, 8.

${ }^{19}$ Sur la corruption morale dépeinte par Salluste, voir EARL, The Political Thought of Sallust, p. 90 sqq. 
récit un mépris assumé de l'honneur, comme chez ceux qui excitent l'ambition de Jugurtha dans l'espoir d'en tirer profit:

Ea tempestate in exercitu nostro fuere conplures noui atque nobiles, quibus diuitiae bono honestoque potiores erant, factiosi domi, potentes apud socios, clari magis quam honesti, qui Iugurthae non mediocrem animum pollicitando accendebant, si Micipsa rex occidisset, fore uti solus imperi Numidiae potiretur.

"À cette époque il y avait dans notre armée nombre d'hommes nouveaux et de nobles, qui préféraient la richesse au bien et à l'honneur, influents à Rome, puissants auprès des alliés, plus célèbres qu'honorables, qui enflammaient l'ambition déjà vive de Jugurtha à force de lui promettre que, si le roi Micipsa venait à disparaître, il deviendrait seul maître du royaume de Numidie. »

(SALL. Iug. 8, 1; trad. Ernout).

Les Romains qui ont éveillé l'animus de Jugurtha se sont montrés bien plus sensibles à l'argent qu'au bonum et à l'honestum. Ils ont ainsi modifié la hiérarchie des valeurs de la tradition ancestrale, où l'honestum passe avant la considération des richesses. L'honestum n'est plus un principe directeur fondamental: il est rejeté au second plan au profit de l'argent qui occupe désormais la première place et oriente l'action. Salluste stylise ainsi les transformations morales de Rome sur le mode d'un conflit entre sens de l'honestum et cupidité, la seconde finissant par prendre le dessus. Mais le plus intéressant réside dans l'utilisation historiographique qu'en fait Salluste. Il faut en effet souligner que cette identification du mépris de l'honestum est faite aux commencements de l'œuvre, au moment où Salluste n'a pas encore commencé le récit de la guerre mais en examine les causes profondes. Parmi ces dernières, Salluste repère la manière dont certains Romains, de manière intéressée, ont éveillé l'appétit de Jugurtha par des flatteries. Or cette cause de la guerre reçoit elle-même une explication d'ordre moral: s'ils ont agi ainsi, c'est, note Salluste, parce qu'ils préféraient les richesses au bien et à l'honestum. La racine du conflit se trouve dans l'altération de l'axiologie romaine et l'oubli de l'honestum. La mise en péril de l'honneur par la vénalité prend aussi une autre forme, que le tribun Memmius évoque dans son discours hostile aux pauci:

At qui sunt ei qui rem publicam occupauere? Homines sceleratissumi, cruentis manibus, immani auaritia, nocentissumi et idem superbissumi, quibus fides, decus, pietas, postremo honesta atque inhonesta omnia quaestui sunt.

«Mais quels sont ces hommes qui se sont emparés de la république? Des gens couverts de crimes, aux mains sanglantes, d'une cupidité sans bornes, se faisant orgueil de leurs forfaits, pour qui loyauté, honneur, piété, bref tout ce qui est vertu ou vice, est une occasion de profits.»

(SALl. Iug. 31, 12; trad. Ernout).

Le conflit entre richesses et honorabilité va ici au-delà d'une compétition pour la première place dans la hiérarchie des valeurs: la cupidité menace directement l'honestum car elle en vient à l'utiliser 
comme source de profit. L'honestum sert de moyen et non plus de fin. En outre, le trafic organisé par les pauci tend à occulter la différence entre ce qui est honnête et ce qui ne l'est pas: il subordonne tout à la quête des richesses et regroupe sous un même désir criminel l'usage des honesta et des inhonesta. Lélévation de l'argent comme valeur remplace l'honestum mais elle abolit aussi le partage du vice et de la vertu dans les esprits ${ }^{20}$.

Cette description de la subversion axiologique de l'honestum et de l'abandon de son usage en tant que norme directrice s'accompagne d'une analyse historique de ce phénomène, qui est situé dans le temps et dont les causes sont recherchées. Le mépris de l'honestum est, comme l'inversion des motifs d'honos, rattaché à la décadence qui frappe Rome après la chute de Carthage et s'amplifie après Sylla. Ce processus de déchéance est essentiel dans la conception sallustéenne de l'histoire de Rome: malgré quelques périodes de crises comme l'expulsion des rois, Rome apparaît globalement bien gouvernée à Salluste et connaît une logique ascendante qui culmine dans la première moitié du $\mathrm{II}^{\mathrm{e}}$ siècle avant notre ère ${ }^{21}$. Puis, après la victoire finale sur les Puniques en 146, commence une phase de déclin de plus en plus sensible, notamment sur le plan moral. Cette représentation de la décadence de Rome n'est pas propre à Salluste: les Romains tendent à faire une lecture morale de l'histoire de leur cité et font souvent la part belle à la notion de décadence des mœurs pour expliquer les crises politiques, économiques, militaires et culturelles ${ }^{22}$. Mais Salluste articule de manière étroite le début de la décadence, le mépris pour l'honestum et cet événement essentiel qu'est pour lui la destruction de Carthage. Avant la troisième guerre punique, Rome connaît une période d'excellence morale et de souci de l'honestum. Dans l'archéologie du De coniuratione Catilinae, les qualités des Romains fleurissent pendant la République et les vertus $\mathrm{y}$ sont à l'honneur, en temps de paix et en temps de guerre ${ }^{23}$. Salluste

${ }^{20}$ Le thème du trafic des honesta atque inhonesta apparaît plusieurs fois chez Salluste: voir Sall. Cat. 30, 4 et Iug. 80, 5.

${ }^{21}$ Sur cette représentation de l'histoire de Rome par Salluste, voir B. Mineo, «Philosophie de l'histoire chez Salluste et Tite-Live», in Poignault, R. (éd.), Présence de Salluste, Tours, Centre de recherches A.Piganiol, 1997, p. 45-60.

${ }^{22}$ Surces discours dela décadence, G. Thоме, «Otempora, omores! Wertvorstellungen bei den Rednern der republikanischen Zeit ", in Braun, M., Haltenhoff, A. et Mutschler, F.-H.(éds.), Moribus antiquis res stat Romana. Römische Werte und römische Literatur im 3. und 2. Jh. v. Chr., Munich, K.G.Saur, 2000, p.125-139 et Gruen, The Last Generation of the Roman Republic, p. 498 sqq. qui souligne que le thème du déclin moral a une portée polémique et un aspect rhétorique important. Sur la conception morale de l'évolution historique, voir EARL, Tradition, p. 18 sqq. Les phases de croissance sont elles aussi analysées par Salluste en termes moraux: voir dans le De coniuratione Catilinae le discours de Caton qui souligne que ce n'est pas par les armes que la res publica est devenue grande et puissante mais par l'excellence de ses mœurs (SAll. Cat. 59, 19-20).

${ }^{23}$ SALL. Cat. 7-9. 
mentionne qu'à cette époque les ancêtres recherchaient des diuitias honestas, des «richesses honorables »: il n'y avait alors ni dichotomie ni concurrence entre l'argent et l'honneur ${ }^{24}$. Tout change cependant à partir de la troisième guerre punique. La perturbation de l'honestum est concomitante de la destruction de Carthage qui signale aussi le début de la déchéance morale de Rome ${ }^{25}$. Dans le De coniuratione Catilinae, l'épisode de 146 n'est cependant qu'un tournant historique et n'apparaît pas encore comme la cause de la décadence. En revanche le rapport causal apparaît dans les autres œuvres de Salluste. Dans le Bellum Iugurthinum, la destruction de Carthage est la source des conflits entre le sénat et le peuple et l'origine du développement des vices. En effet, en vainquant définitivement les Puniques, les Romains ont fait disparaître le metus hostilis, la crainte des ennemis, qui maintenait la concorde dans la cité et contraignait les citoyens à faire preuve de vertu ${ }^{26}$. Cette idée selon laquelle la crainte d'un adversaire extérieur maintient dans le droit chemin se retrouve chez Diodore et on a souvent fait remonter cette théorie à Posidonius, dont s'inspire Diodore ${ }^{27}$. Cependant, il s'agit d'un thème qui court également dans les milieux romains des $\mathrm{II}^{\mathrm{e}}$ et $\mathrm{I}^{\mathrm{er}}$ siècles $^{28}$. Salluste a en tout cas la singularité de fonder la disparition du metus hostilis sur la destruction de Carthage et de présenter le changement qui s'ensuivit comme particulièrement radical:

Postquam remoto metu Punico simultates exercere uacuom fuit, plurumae turbae, seditiones et ad postremum bella ciuilia orta sunt, dum pauci potentes, quorum in gratiam plerique concesserant, sub honesto patrum aut plebis nomine dominationes adfectabant.

«Une fois disparue la peur des Carthaginois, les rivalités eurent le loisir de s'exercer, de nombreux troubles, des séditions et enfin des guerres civiles firent leur apparition, tandis qu'un petit nombre de puissants, dont la plupart étaient devenus populaires, sous le prétexte honorable de défendre le Sénat ou la plèbe, aspiraient à la souveraineté absolue. »

(SALL. Hist. frg. I, 12 Reynolds).

Ici encore, la disparition de la peur suscitée par les Carthaginois est analysée comme la cause des troubles intérieurs (turbae, seditiones, bella ciuilia). Et elle représente aussi le moment où l'honestum n'est

${ }^{24}$ SAll. Cat. 7, 6.

${ }^{25}$ Sur l'importance de cette césure, voir E. Koestermann, «Das Problem der römischen Dekadenz bei Sallust und Tacitus », ANRW, I, 3, 1973, p. 781-810.

${ }^{26}$ SALl. Iug. 41, 2: Metus hostilis in bonis artibus ciuitatem retinebat. "La peur de l'ennemi maintenait la cité dans la vertu. »

${ }^{27}$ DS. XXXIV-XXXV 33, 5. Sur l'attribution à Posidonius, voir W. Schur, Sallust als Historiker, Stuttgart, Kohlhammer, 1934, p.69. L. AlfonsI, "Sul metus Punicus Sallustiano », Athenaeum, 51, 1973, p.383-384 a repéré, outre Posidonius, d'autres sources à cette idée, chez Aristote et Platon.

${ }^{28}$ La Penna, Sallustio e la 'rivoluzione' romana, p. 233-237. 
plus qu'une façade visant à dissimuler le crime: les pauci prennent des dehors honorables, en prétendant agir au nom du peuple ou du sénat, mais ne cherchent en réalité que la tyrannie. Salluste reprend le thème, employé par Térence et Cicéron ${ }^{29}$, de l'honesta oratio, du discours honorable cachant une intention dévoyée, et montre que la dissociation entre le discours et les intentions se produit à la faveur d'une dissolution de la communauté causée par la disparition de l'ennemi héréditaire. Le mépris pour l'honestum est ici d'autant plus grave qu'il se dissimule sous le masque de l'honneur. Cette forme de destruction de l'honorabilité est reliée par Salluste à la tyrannie, puisque les pauci ont un net désir de dominatio; on le voit aussi quand l'historien fait état de la manière dont Sylla déguise sous des prétextes honesti le maintien de sa domination autocratique ${ }^{30}$. La dissimulation de la turpitude sous l'honestum, qui constitue le sommet de la corruption de l'honneur, est ainsi directement liée à la forme la plus corrompue de régime politique, l'oppression tyrannique.

\section{L'ANALYSE DU DÉSIR D'HONOS}

La seconde approche de la notion d'honneur par Salluste réside dans l'analyse du désir qui porte les hommes vers l'honos. Salluste est un des auteurs du Ir siècle qui s'est le plus intéressé à l'ambition, à sa nature et ses effets. Il l'aborde dans son œuvre à la fois en historien et en moraliste, deux façons de faire liées dans la pratique antique de l'historiographie ${ }^{31}$.

\subsection{L'ambition comme facteur historique}

Dans la pensée de Salluste, le désir d'honos apparaît comme l'un des moteurs des événements historiques. De manière générale, Salluste assigne en effet un rôle important aux passions dans l'infléchissement du cours de l'histoire. L'analyse de l'ambition revêt donc fréquemment une fonction explicative: elle éclaire les motivations des individus et contribue ainsi à expliquer certains faits. Dans le De coniuratione Catilinae, ce désir d'honos est identifié chez les principaux protagonistes de la conjuration et apparaît comme l'un des aliments du complot. Salluste le fait percevoir à son lecteur par l'entremise du discours qu'il attribue à Catilina. Le chef de la conjuration,

${ }^{29}$ TER. Andr. 141 ; Cic. Verr. II, V, 5.

${ }^{30}$ SAll. Hist. frg. I, 55, 7-8. Cf. aussi SAll. Cat. 38, 3, où des agitateurs jettent le trouble dans l'État honestis nominibus, sous de beaux prétextes.

${ }^{31}$ Sur Salluste moraliste, voir Tiffou, Essai sur la pensée morale de Salluste, p. 580. 
patricien d'une famille obscure, s'adresse à ses complices et s'en prend aux hommes situés à la tête de l’État:

Itaque omnis gratia, potentia, honos, diuitiae apud illos sunt aut ubi illi uolunt; nobis reliquere repulsas, pericula, iudicia, egestatem. Quae quousque tandem patiemini, o fortissumi uiri? Nonne emori per uirtutem praestat quam uitam miseram atque inhonestam, ubi alienae superbiae ludibrio fueris, per dedecus amittere?

«Aussi toute influence, tout pouvoir, tout honneur, toute richesse sont à eux, ou aux gens qu'ils veulent; ils nous ont laissé les échecs, les périls, les condamnations, la misère. Jusques à quand enfin, mes braves, le supporterez-vous? Ne vaut-il pas mieux mourir courageusement que de perdre honteusement une vie misérable et sans honneur, après avoir servi de jouet à l'insolence d'autrui ? »

(SAlL. Cat. 20, 8-9; trad. Ernout modifiée).

Ce passage comporte plusieurs thèmes déjà observés, tels que celui de la monopolisation des honneurs par la noblesse et celui de la mort honorable. Salluste place ici ces idées dans la bouche de Catilina pour montrer combien ce dernier vit péniblement le fait d'être écarté de l'honos. Catilina apparaît particulièrement sensible à l'obscurité dans laquelle il vit et c'est son désir d'honneur, combiné à la soif de pouvoir et à la cupidité, qui gouverne sa personne et ses actes. Son ambition est donc à la racine de son action politique. Salluste éclaire par un autre procédé, celui de la lettre, cet aspect de la personnalité de Catilina. Il retranscrit en effet un peu plus loin dans l'œuvre la missive que Catilina a envoyée à Q. Catulus, représentant des aristocrates conservateurs, dans laquelle Catilina justifie son action ${ }^{32}$. Dans cette lettre, supposée confidentielle, l'historien met au jour les motivations de Catilina: c'est, dit ce dernier, parce qu'il a été victime d'iniuriae, d'injustices, et de contumeliae, d'affronts, qu'il a décidé de défendre les malheureux ${ }^{33}$. Le fait de voir des gens indignes recevoir l'honos lui est insupportable et explique son entreprise. Il entre assurément de la mauvaise foi dans ces propos, qui servent à déguiser la poursuite de fins égoïstes, mais le lecteur y perçoit tout de même le désir d'honos de Catilina, son aversion pour la contumelia et le rôle moteur que joue cette disposition d'esprit. À travers le discours puis la lettre, Salluste met donc au jour le rôle des facteurs psychologiques dans la naissance de la conjuration. Il procède de même dans le Bellum Iugurthinum: dès l'entrée en scène de Marius, l'historien souligne le

${ }^{32}$ La lettre telle que Salluste la présente a pu être inspirée par un vrai courrier de Catilina (EarL, The Political Thought of Sallust, p.94-95). Sur l'usage des lettres dans l'historiographie sallustéenne, voir M. L. PALADINI, "Osservazioni ai discorsi e alle lettere del Sallustiano Bellum Catilinae », Latomus, 20, 1961, p. 3-32.

${ }^{33}$ Sur la place de l'iniuria et de la contumelia dans le propos de Catilina, voir le commentaire sur ce passage de VRETSKa (éd.), Sallust. De Catilinae coniuratione. 
désir qui l'anime d'obtenir l'honos du consulat ${ }^{34}$. Cette ambition est la cause directe de l'opposition entre Marius et Metellus et la cause plus lointaine du changement à la tête du commandement romain, qui passe de Metellus à Marius, et de l'accélération des opérations contre les Numides, qui s'achèvent sur une victoire des Romains. Ici encore, le désir d'honos est utilisé par Salluste dans la recherche des causes des épisodes historiques

Ce désir d'honneur est aussi appréhendé par Salluste avec davantage de recul, en étant articulé au phénomène de la décadence de Rome $^{35}$. Élargissant le champ de l'observation, notamment dans les prologues de ses œuvres, Salluste décèle deux effets majeurs du développement de l'ambition sur la situation politique de Rome. Le premier d'entre eux est une modification de la nature du régime. Après la chute de Carthage et la disparition du metus hostilis, cause première de la décadence selon Salluste, deux funestes passions ont fait leur apparition, la cupidité et l'ambition, qui représentent quasi materies omnium malorum, "pour ainsi dire l'aliment de tous les maux ${ }^{36}$. Or le développement de l'ambition a provoqué différentes perturbations, énumérées par Salluste dans le prologue du De coniuratione Catilinae, au chapitre 10, et la plus grave de toutes, celle sur laquelle l'historien termine sa liste, est la métamorphose de l'imperium:

Post, ubi contagio quasi pestilentia inuasit, ciuitas inmutata, imperium ex iustissimo atque optumo crudele intolerandumque factum.

«Ensuite, lorsque la contagion se fut répandue comme une maladie, la cité fut transformée et le plus juste et le meilleur des gouvernements devint cruel et impossible à supporter. »

(Sall. Cat. 10, 6).

Salluste unit de manière étroite l'altération morale des Romains, caractérisée par la naissance de l'ambition, et le bouleversement politique de la cité tout entière: l'imperium de la république change complètement de nature et il est affublé de traits traditionnellement associés à la tyrannie (crudele intolerandumque). Le désir d'honos et de pouvoir a donc des conséquences à l'échelle institutionnelle. Ces réflexions de Salluste ne sont pas sans rappeler les développements que consacre Platon au cycle des régimes politiques. Dans la République, le philosophe associe en effet l'élucidation psychologique

${ }^{34}$ SALL. Iug. 64.

35 Sur le lien de la décadence et de l'ambition chez Salluste, voir Koestermann, «Das Problem der römischen Dekadenz bei Sallust und Tacitus ». Sur les auteurs ayant développé ce thème avant lui, J. Korpanty, "Sallust, Livius und ambitio », Philologus, 127, 1983, p.61-71.

${ }^{36}$ Sall. Cat. 10, 3. Sur ces deux vices et l'ordre de leur apparition, Heldmann, Antike Theorien über Entwicklung und Verfall der Redekunst. Sur leur rapport à la décadence, Koestermann, "Das Problem der römischen Dekadenz bei Sallust und Tacitus », p. 790. 
des dispositions de l'individu à l'étude des régimes: l'observation du gouvernement timocratique est ainsi, par exemple, associée à celle des dispositions de l'homme timocratique ${ }^{37}$. Salluste n'élabore pas un parallèle aussi fouillé que celui de Platon, mais il relie tout de même l'apparition d'un nouveau désir chez l'homme à la dégradation de la cité. La description de la décadence dans le chapitre 10 du De coniuratione Catilinae fait aussi en partie écho à la manière dont Platon envisage le passage de l'oligarchie à la timocratie. Dans la République, c'est en effet l'ambition qui, en s'élevant, entraîne ce changement de

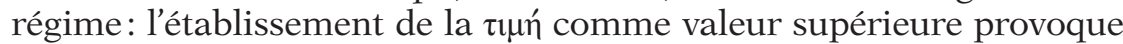
le passage vers la timocratie ${ }^{38}$. Chez Salluste, le désir d'honos, équivalent latin de la $\tau \mu \eta$, provoque pareillement une transformation du régime, mais la nature exacte de cette dernière n'est pas clairement évoquée et les traits que Salluste donne au nouvel imperium ressemblent plus à ceux de la tyrannie qu'à ceux de la timocratie ${ }^{39}$.

Le second effet du désir d'honos est tout aussi grave: il s'agit de l'émergence des troubles civils. Pour Salluste, l'ambition de Catilina débouche sur une conjuration majeure qui a mis en péril l'existence de la res publica et a opposé des Romains à d'autres Romains. Sur un mode mineur, le désir d'honos de Marius le conduit à intriguer contre Metellus et à manœuvrer pour se concilier l'armée et les Numides alliés à Rome, contre l'intérêt du commandement suprême romain ${ }^{40}$. Dans un cas comme dans l'autre, l'ambition provoque donc des troubles à l'intérieur de la cité ou du camp romain. En fondant ainsi la sédition civile sur l'ambition, Salluste retrouve Thucydide et la description de la révolte de Corcyre. L'historien grec montre en effet dans ce récit que

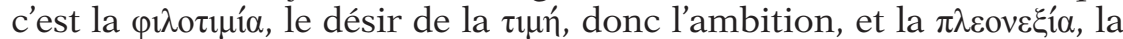
cupidité, qui poussent à rechercher la domination et sont à l'origine des affrontements civils ${ }^{41}$.

\subsection{La critique morale de l'ambition}

À cette analyse historique du désir d'honos, Salluste joint une évaluation morale de l'ambition. Comme le laissent présager les effets

${ }^{37}$ Plat. Resp. VIII, 547b-550a.

${ }^{38}$ Plat. Resp. VIII, 548a.

${ }^{39}$ Sur ce parallèle entre Salluste et Platon à propos du changement de régime et de l'ambition, voir B. D. MACQueEn, Plato's Republic in the Monographs of Sallust, Chicago, Bolchazy-Carducci, 1982, p. 49 et A. Michel, «Entre Cicéron et Tacite: aspects idéologiques du Catilina de Salluste », ACD, 5, 1969, p. 83-91, à la p. 87.

${ }^{40}$ Sur ces manœuvres, SALL. Iug. 65.

${ }^{41}$ Thuc. III, 82, 8. Sur la place de la $\tau \mu \mu ́$ dans l'analyse historique de Thucydide, voir De Romilly, «Le thème du prestige dans l'œuvre de Thucydide». Après Thucydide,

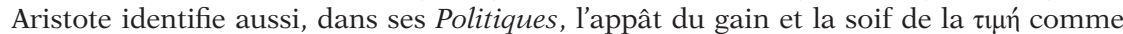

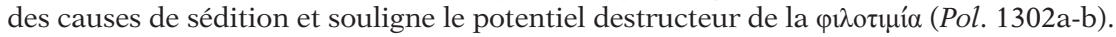


destructeurs de l'ambition mis en avant dans les monographies, le jugement de l'historien sur le désir de prestige et de pouvoir est sévère et certaines de ses idées rejoignent les critiques formulées, quelques années auparavant, par Lucrèce ${ }^{42}$. Mais le désir de l'honos a l'originalité, chez Salluste, de ne pas être seulement évalué de manière extérieure: l'historien l'envisage dans son expérience personnelle et revient sur la manière dont il a été lui-même porté vers l'honos dans sa jeunesse ${ }^{43}$. Dans le prologue du De coniuratione Catilinae, il évoque en effet la manière dont il s'est engagé dans la vie politique, en des termes qui ne sont pas sans rappeler le passage autobiographique de la lettre VII de Platon où le philosophe fait le récit de ses expériences politiques à Athènes ${ }^{44}$ : Salluste raconte qu'il désirait ardemment participer à la direction des affaires publiques mais qu'il a été déçu par la corruption qu'il y a rencontrée, ce qui l'a amené à se retirer dans l'otium littéraire. Cependant, reconnaît-il, l'ambition l'a poussé à persister pendant un certain temps dans la fréquentation de ce milieu corrompu:

Quae tametsi animus aspernabatur, insolens malarum artium, tamen inter tanta uitia imbecilla aetas ambitione corrupta tenebatur; ac me, cum ab relicuorum malis moribus dissentirem, nihilo minus honoris cupido eadem quae ceteros fama atque inuidia nexabat.

«Et bien que mon âme méprisât ces tares, peu accoutumée qu'elle était au mal, ma faible jeunesse, gâtée par l'ambition, demeurait pourtant attachée à de tels vices. Et moi, bien que je me distinguasse de l'immoralité de mon entourage, je n'en étais pas moins tourmenté comme eux par le désir d'honneur qui les laissait en proie à la médisance et à l'envie.»

(SALl. Cat. 3, 4-5).

Salluste reconnaît avoir été retenu dans le monde politique à cause de son ambitio. Le désir d'honos qui le tenaillait est perçu par Salluste comme une force particulièrement puissante, exerçant son emprise sur l'individu, et la source d'un véritable tourment psychologique (uexabat) dont il a été extrêmement difficile de se débarrasser. Ce désir apparaît comme un vice puisque l'historien signale que son âme était corrompue (corrupta) par l'ambition.

Cette critique morale du désir d'honos réapparaît dans le prologue du Bellum Iugurthinum sous un jour un peu différent. Le proomium de cette œuvre s'ouvre par une investigation sur la nature de l'homme;

${ }^{42}$ Voir supra p. 684 sqq.

${ }^{43}$ Parler de soi est commun dans les prologues de l'historiographie grecque. Voir par exemple DH. I, 6, 5. Sur ce point, voir La PENNA, Sallustio e la 'rivoluzione' romana, p.24-25. Sur la confession de Salluste dans le De coniuratione Catilinae, voir Tiffou, Essai sur la pensée morale de Salluste, p. 203 sqq.

${ }^{44}$ Voir la lettre VII, 324b sqq. Sur cette probable influence de Platon sur Salluste, Perrochat, Les Modèles grecs de Salluste, p.49; MacQueen, Plato's Republic in the Monographs of Sallust, p. 67-68. 
il y est établi, dans la lignée de la pensée platonicienne, que ce dernier est composé d'un corps et d'une âme et que celle-ci est la partie souveraine de l'individu (Iug. 1) $)^{45}$. La suite du prologue, jusqu'à l'annonce du sujet traité, la guerre contre Jugurtha (Iug. 5 sqq.), paraît plus confuse et l'on a parfois reproché à Salluste d'y aligner des lieux communs ou de reformuler des passages mal assimilés de Platon ou d'autres sources grecques. Il est exact que Salluste réutilise des topoi philosophiques mais son propos est en réalité construit d'une manière qui est, sinon parfaitement rigoureuse, du moins logique, et dont la clef nous est donnée par le début du chapitre 2:

Nam uti genus hominum compositum ex corpore et anima est, ita res cunctae studiaque omnia nostra corporis alia, alia animi naturam secuntur.

"Car l’homme étant composé du corps et de l'âme, toutes nos activités, tous nos penchants procèdent de la nature de l'un ou de l'autre. »

(SAll. Iug. 2, 1 ; trad. Ernout).

Cette phrase ménage une transition entre l'examen de la double nature de l'homme, âme et corps, et l'observation des activités humaines qui en découlent (res cunctae studiaque). Salluste passe, autrement dit, d'un développement sur la nature de l'homme à une réflexion sur les genres de $v^{4}{ }^{46}$. La dispersion apparente des remarques qui suivent se résorbe si l'on y reconnaît la description des trois genres de vie canoniques: Salluste commence par critiquer le fait que certains individus vivent dans le luxe et la paresse en s'adonnant aux plaisirs du corps (vie de plaisir; Iug. 2, 3-4); il remarque ensuite que les honneurs et le pouvoir ne sont nullement désirables à son époque (vie pragmatique; Iug. 3); il souligne enfin que l'histoire est l'une des activités intellectuelles les plus utiles (vie contemplative; Iug. 4). Salluste examine donc dans le prologue les différents genres de vie et évalue chacun d'eux, à la lumière de son analyse de la nature de l'homme. C'est dans ce contexte que l'honos et l'ambition sont jugés, à propos de la vie pragmatique. Salluste passe donc de l'analyse psychologique rétrospective, dans le De coniuratione Catilinae, à l'examen philosophique des genres de vie, dans le Bellum Iugurthinum. Dans cette œuvre, c'est le prix de l'honos lui-même qui est mis en question et non plus le statut

${ }^{45}$ Cf. notamment Plat. Resp. 586a et Phaedr. 80a. Sur l'influence du platonisme et de sa dichotomie entre âme et corps sur l'anthropologie sallustéenne, Tiffou, Essai sur la pensée morale de Salluste, p. 38-39; MacQueEn, Plato's Republic in the Monographs of Sallust, p. 52 et RambaUd, "Les prologues de Salluste et la démonstration morale dans son œuvre», p. 119-120 et 125 .

${ }^{46}$ Sur la question des genres de vie, voir supra n. 35 p. 562. 
problématique du désir d'honos. La vie pragmatique, caractérisée par l'exercice de l'honos, est en effet rejetée par Salluste:

Verum ex eis magistratus et imperia, postremo omnis cura rerum publicarum minime mihi hac tempestate cupiunda uidentur, quoniam neque uirtuti honos datur neque illi, quibus per fraudem is fuit, tuti aut eo magis honesti sunt.

«Mais parmi ces moyens de trouver la gloire, les magistratures, les commandements, bref, toute activité politique ne me semblent nullement désirables à notre époque, parce que ce n'est pas à la vertu que l'honneur est donné, et parce que les gens qui l'ont acquis par fraude n'en sont ni plus en sûreté ni plus considérés. »

(SALL. Iug. 3, 1 ; trad. Ernout modifiée).

Salluste signale ici clairement que les magistratures, les commandements et tout type d'honos ne sont nullement à rechercher car le milieu politique dans lequel ils s'inscrivent est totalement corrompu. L'honos n'est pas compatible avec la uirtus. D'une manière originale, car contraire à la tradition, Salluste conteste donc à l'honos et à la vie pragmatique la capacité de faire accéder à la gloire et de réaliser la perfection de l'âme. Salluste n'indique pas clairement à quelle partie de l'homme se rapporte ce genre de vie: la vie de plaisir est nettement rattachée au corps et la vie contemplative à l'âme, mais le statut de la vie politique est plus confus, même si la mention des magistratus et imperia semble la tirer du côté des réalités matérielles et donc du corps. Or les choses corporelles possèdent une fragilité qui les rend peu désirables ${ }^{47}$. Il s'agit là d'un argument supplémentaire pour renoncer à la recherche des honores. On voit donc que la critique sallustéenne de l'ambition rejoint, en surface, celle de Lucrèce mais qu'elle repose en réalité sur des fondements radicalement différents: Lucrèce montre l'inanité de l'ambition qui procède de la peur irrationnelle de la mort, alors que Salluste reproche au désir d'honos de tourner le dos à la vertu et à l'âme pour s'ancrer dans la corruption et le corps. La critique de l'ambition par Salluste se poursuit, au-delà du prologue, tout au long du Bellum Iugurthinum. L'historien la formule notamment à travers le personnage de Marius dont il montre l'évolution négative: Marius, homme de la uirtus, tombe progressivement dans un désir de prestige et de pouvoir mal maîtrisé qui le mène à la violence et à l'illégalitét8.

Plusieurs facteurs nous semblent pouvoir expliquer la présence récurrente de cette critique de l'ambition chez Salluste. L'historien, en premier lieu, est manifestement marqué, dans les prologues, par

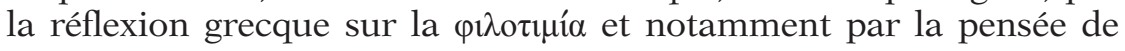

${ }^{47}$ SALl. Iug. 2, 2.

${ }^{48}$ Sur le passage de Marius de la uirtus à l'ambitio, voir EARL, The Political Thought of Sallust, p.66. Sur le thème de l'ambition dans le Bellum Iugurthinum, voir Iug. 10, 2; 63,$2 ; 95,3$. 
Platon ${ }^{49}$. L'idée selon laquelle l'homme de bien se tiendra éloigné des honneurs de la cité quand elle est corrompue est développée, comme nous l'avons signalé, par la lettre VII et c'est aussi un thème de la République $^{50}$. Cependant, on ne saurait rapporter la présence de ce thème aux seuls modèles grecs. L'expérience politique de Salluste est aussi, comme le suggèrent les prologues des deux monographies, une des raisons pour lesquelles sa vision de l'honos est critique. La carrière de Salluste a été marquée par des déceptions répétées. Malgré son ambition, il n'a jamais réussi à s'élever jusqu'au consulat et il a connu plusieurs déboires: il a été exclu du sénat pour immoralité puis accusé de repetundis après son gouvernement de la province nouvelle d'Africa Nova, même si l'intervention de César a empêché l'accusation d'aboutir ${ }^{51}$. Salluste n'a jamais pu jouer un rôle de premier plan comme ses contemporains César et Cicéron. Ces échecs lui ont sans doute inspiré une vision assez noire de l'honos. Enfin, l'établissement par Salluste d'un lien entre désir d'honos et sédition civile doit aussi à l'expérience des affrontements internes à la cité qu'il a vécus personnellement: les luttes entre Marius et Sylla, l'entreprise de Catilina, le conflit entre César et Pompée lui ont montré les effets destructeurs de l'ambition. Malgré ces expériences négatives et la critique de l'ambition développée dans son œuvre, Salluste n'a pas cependant renoncé à rechercher un certain prestige. C'est à la nature de ce dernier qu'il faut à présent nous intéresser.

\section{3. À la recherche d'une autre forme de notoriété: l'historien et la gloire}

La critique du désir d'honos faite par Salluste a ceci de singulier qu'elle est concentrée sur l'ambition qui s'exerce dans le domaine politique et emprunte des voies corrompues. C'est l'envie d'honos comme charge publique et les compromissions que cela implique qui sont récusées, et non la volonté de prestige ou la recherche de la notoriété. La position de Salluste sur la gloire et l'honneur est donc assez nuancée, comme le montre un passage de l'archéologie du De coniu-

${ }^{49}$ Sur les sources des prologues, BoLAfFI, «I proemi delle monografie di Sallustio ». Sur la diversité des sources et l'éclectisme de Salluste, G.M.Paul, A Historical Commentary on Sallust's Bellum Iugurthinum, Liverpool, F. Cairns, 1984, qui souligne l'absence d'un système philosophique précis chez Salluste (p.10).

${ }^{50}$ Voir Plat. Ep. VII, 325d-326b et Resp. IX, 592a: l'homme juste doit fuir les $\tau \mu$ aí qui ne peuvent le rendre meilleur ou qui risquent de troubler son $\tilde{\varepsilon}_{\xi} \iota_{\text {c. }}$.

${ }^{51}$ Sur ces deux épisodes, DC. XL, 63 et Ps.-Cic. Invective contre Salluste, 16 et 19. Voir aussi MaLitz, Ambitio mala. Studien zur politischen Biographie des Sallust, p. 72-77 et $85-88$. 
ratione Catilinae où Salluste fait état de l'apparition de l'ambition à Rome:

Sed primo magis ambitio quam auaritia animos hominum exercebat, quod tamen uitium propius uirtutem erat. Nam gloriam, honorem, imperium bonus et ignauos aeque sibi exoptant; sed ille uera uia nititur, huic, quia bonae artes desunt, dolis atque fallaciis contendit.

«Mais tout d'abord c'était l'ambition plus que la cupidité qui tourmentait les âmes, et ce défaut-là malgré tout était assez voisin de la vertu. Car la gloire, l'honneur, le pouvoir, l'homme de bien et le paresseux y aspirent également; mais l'un s'efforce d'y parvenir par la vraie voie, l'autre, faute de qualités, y tend par les ruses et les tromperies.»

(SALl. Cat. 11, 1-2; trad. Ernout modifiée).

L'ambition est qualifiée de vice (uitium), ce qui est en accord avec la critique morale du désir de pouvoir et de prestige que nous avons précédemment observée chez Salluste, mais c'est un vice qui a la particularité d'être propius uirtutem, "assez proche de la vertu» ${ }^{52}$. Il faut, pour expliquer cette formulation paradoxale, distinguer avec Salluste le but et le moyen de l'ambition. Par son but, l'ambitio est proche de la uirtus car elle vise des objets qui ne sont pas en soi défectueux, la gloria, l'honos et l'imperium. Il y a, note Salluste, des gens vertueux qui les visent $^{53}$. Mais l'ambition, malgré son objet positif, demeure cependant un vice car elle recourt à des moyens répréhensibles, les ruses et tromperies (dolis et fallaciis). Salluste laisse la porte ouverte à une rédemption du désir d'honos car il souligne qu'on peut atteindre l'honos et la gloria par la uera uia, celle des bonae artes, des qualités morales. Mais que désignent exactement ces bonae artes? Pour le comprendre, il faut remonter au prologue du De coniuratione Catilinae. Au tout début de sa monographie, Salluste aborde la question de la recherche de la notoriété et affirme explicitement qu'elle n'est pas critiquable. Bien au contraire, il est nécessaire que l'homme sorte de l'obscurité pour atteindre la gloire:

Omnis homines qui sese student praestare ceteris animalibus summa ope niti decet ne uitam silentio transeant ueluti pecora, quae natura prona atque uentri oboedientia finxit.

«Il convient que tout homme désireux de s'élever au-dessus des autres êtres œuvre de toutes ses forces à ne pas passer sa vie dans le silence comme les bêtes que la nature a penchées vers la terre et asservies à leur estomac. »

(SAll. Cat. 1, 1; trad. Ernout modifiée).

${ }^{52}$ Sur cette proximité de l'ambition et de la vertu chez Salluste, voir EARL, The Political Thought of Sallust, p. 10.

${ }^{53}$ L'ambition est en cela différente de la cupidité, qui est totalement du côté du vice car la fin qu'elle s'assigne, la richesse, n'est pas un bien. L'auaritia est toujours mauvaise car son objet est mauvais (SALL. Cat. 11, 3). 
La notoriété apparaît ici comme une fin non seulement louable mais même souhaitable car c'est elle qui fait la grandeur de l'homme et le différencie des animaux. Sortir de l'obscurité est une exigence du decet humain. Cette affirmation n'est nullement contradictoire avec la critique de l'ambition car il y a, ici encore, une différenciation au sein des moyens pour l'obtention du prestige. C'est en fonction du chemin emprunté que se détermine la nature de l'effort vers la notoriété, uitium ou uirtus. Pour définir le bon chemin de l'ambition, Salluste s'appuie sur une analyse anthropologique de la nature de l'homme, assez semblable à celle développée dans le prologue du Bellum Iugurthinum ${ }^{54}$ : l'homme, note l'historien, est fait d'une âme et d'un corps, et c'est l'âme, qui nous est commune avec les dieux, qui est faite pour commander au corps, qui nous est commun avec les bêtes. C'est donc par l'âme et par son accomplissement dans l'exercice de la vertu que passe le bon chemin vers la notoriété55. L'ambition qui s'exerce en politique et recourt au crime n'est donc qu'une forme dévoyée d'un désir d'honos initialement positif. L'homme de bien doit rechercher la gloire mais en se souvenant qu'il est avant tout une âme et donc en suivant la route de la vertu. Cette idée apparaît également dans le prologue du Bellum Iugurthinum qui affirme que l'âme est en pleine possession de sa puissance quand «elle marche vers la gloire par la voie de la vertu» (ad gloriam uirtutis uia grassatur) ${ }^{56}$. Salluste illustre ce désir de gloire correctement orienté dans l'archéologie du De coniuratione Catilinae, quand il évoque le désir de notoriété qui animait les jeunes gens aux premiers siècles de la République: les Romains d'autrefois étaient portés par une grande cupido gloriae qui les a conduits à rivaliser de courage et de vertu et à soutenir la grandeur de Rome ${ }^{57}$.

À l'époque où Salluste écrit, en revanche, les Romains semblent avoir abandonné la route de la vertu pour rechercher l'honos par des moyens répréhensibles. Il n'y a plus adéquation entre vertu et ambition, et cette dernière est devenue un vice. Salluste lui-même s'est fourvoyé sur la route de l'honneur. Mais il a pris conscience de son erreur et a choisi d'emprunter un autre chemin, plus propice à la perfection de l'âme. La bonne voie vers la gloria, néanmoins, n'a plus le même aspect que celle suivie par les ancêtres. Les bonae artes ne s'identifient plus

${ }^{54}$ L'analyse du Bellum Iugurthinum est cependant plus approfondie et elle a la singularité d'opposer le corps à l'âme, ce qui n'est pas le cas dans le De coniuratione Catilinae. Voir Tiffou, Essai sur la pensée morale de Salluste, p. 63-65.

${ }^{55}$ Sall. Cat. 1, 2-3. Sur la conception de la gloire comme fruit de l'ingenium et de l'âme, B. Compagno, "Gloria nelle Epistulae ad Caesarem e nelle monografie di Sallustio " in Studi di filologia classica in onore di Giusto Monaco, Palerme, Università di Palermo, 1991, vol.2, p. 869-877.

${ }^{56}$ Sall. Iug. 1, 3. VRetSKa (éd.), Sallust. De Catilinae coniuratione, p. 220, souligne que le thème de la «voie de la vertu » est présent dans l'historiographie grecque. Voir par exemple Xen. Mem. II, 1, 21.

${ }^{57}$ Sall. Cat. 7, 3 et 7, 6. 
au courage et à la saine émulation. Salluste a pris acte de la décadence qui frappe Rome et choisit une nouvelle façon d'obtenir la gloire tout en respectant l'excellence de l'âme: il s'agit de l'écriture de l'histoire. Nous avons vu, à propos du prologue du Bellum Iugurthinum, que la vie intellectuelle représentait le seul genre de vie acceptable pour Salluste, qui méprise la vie de plaisir, liée au corps, et a été dégoûté de la vie politique, trop corrompue. La même idée apparaît dans le De coniuratione Catilinae. Salluste considère que l'existence pragmatique n'est plus le lieu de la uirtus et que cette dernière ne peut trouver son expression que dans l'otium littéraire:

Igitur, ubi animus ex multis miseriis atque periculis requieuit et mihi relicuam aetatem a re publica procul habendam decreui, non fuit consilium socordia atque desidia bonum otium conterere [...]; statui res gestas populi Romani carptim, ut quaeque memoria digna uidebantur, perscribere.

"Aussi lorsqu'après bien des misères et des périls mon esprit eut retrouvé le calme, et que je fus résolu à passer le reste de ma vie loin de la politique, je ne songeai pas à gaspiller dans la paresse et l'inaction de précieux loisirs [...]; je résolus d'écrire l'histoire du peuple romain, en en détachant les faits qui me semblaient dignes de mémoire.»

(SALl. Cat. 4, 1-2; trad. Ernout).

L'exercice de la uirtus et l'obtention de la gloire ne passe plus par l'activité publique mais trouve sa place dans l'exercice d'un otium de bon aloi, non pas une inactivité paresseuse, mais un loisir intellectuel consacré à l'écriture de l'histoire de Rome. Ce lien à l'otium littéraire de la uirtus et de la notoriété, notions traditionnellement associées à l'activité publique, est novateur ${ }^{58}$. On remarquera cependant que ce changement de perspective amène Salluste à préciser la nature de la notoriété recherchée par l'écriture de l'histoire: plutôt que l'honos, notion associée à la vie publique et aux charges de la cité, l'historien vise la gloria ${ }^{59}$. Comme Salluste le reconnaît lui-même, la gloire que vise l'écrivain n'est néanmoins pas la même que celle de l'homme d'action: c'est une gloire posthume, dans la mémoire des hommes ${ }^{60}$. Salluste fait de son otium une vie paradoxalement active, qui ne s'identifie pas totalement à la vie contemplative. L'écriture de l'histoire permet en effet, à ses yeux, de présenter aux hommes des modèles de comportement et elle est donc très fructueuse pour la res publica $^{61}$. Il n'y a pas, chez Salluste, de solution de continuité entre

${ }^{58}$ Voir EarL, The Political Thought of Sallust, p. 21 et André, L'Otium, p. 339.

${ }^{59}$ SAll. Cat. 3, 2 et Iug. 1, 3.

${ }^{60}$ SALL. Cat. 3, 2. Salluste vise une gloria in memoria plutôt qu'une gloria in uita (EARL, The Political Thought of Sallust, p. 8-9). Sur la conception sallustéenne de la gloria, Tiffou, Essai sur la pensée morale de Salluste, p. 116-117.

${ }^{61}$ SALL. Iug. 4, 5-6. Salluste se fait une conception pédagogique de l'histoire (voir J.-L. FERRARY, "Quelques réflexions à propos du Catilina de Salluste», Vita Latina, 80, 1980, p.17-23). 
la pratique des lettres et l'action publique car la première débouche in fine sur la seconde, mais d'une manière qui permet de contourner les compromissions habituelles. Dans le passage que nous venons de citer, Salluste écarte radicalement l'otium de la desidia: le loisir qu'il envisage a l'originalité d'être actif et utile ${ }^{62}$. L'amélioration de son âme et la recherche par l'individu d'une vraie gloire, dépouillée de l'ambition traditionnelle, peut donc être profitable à la res publica dans son ensemble. L'analyse par Salluste du désir d'honos débouche ainsi sur une critique de l'ambition dans ses formes traditionnelles et sur la mise en avant d'une nouvelle voie pour atteindre le prestige, qui passe par l'écriture de l'histoire et le soin de son âme.

\section{La morale de L'honestum chez SALluste}

Après avoir examiné l'analyse historique et morale du désir d'honos chez Salluste, il nous reste à apprécier son jugement sur un autre aspect de l'honneur, l'honestum, qui fait l'objet d'importantes investigations à la fin de la République. Â la différence de Lucrèce et de César, Salluste ne laisse pas en effet ce concept de côté.

\subsection{L'enrichissement de la valeur morale de l'honestum}

Face au mépris que suscite à son époque l'honestum, Salluste est amené à reconsidérer la nature de l'honneur et à retoucher certains de ses aspects traditionnels pour sauvegarder cette valeur à laquelle il est attaché. Il enrichit ainsi la dimension morale de l'honestum, qui apparaît dès lors comme un élément central de sa pensée. Salluste procède en premier lieu à une différenciation de la moralité et du prestige, éléments non dissociés dans la notion ancienne d'honestas. Les individus corrompus qui se trouvent dans l'armée romaine à l'époque de la campagne contre Numance sont ainsi, d'après Salluste, clari magis quam honesti, "plus célèbres qu'honorables " ${ }^{63}$. Malgré leur statut et leur célébrité, ils foulent aux pieds l'honestum et sont animés par la cupidité. Leur prestige n'est nullement le signe de leur bonne moralité. Salluste creuse ainsi l'écart entre la considération sociale et l'honestum et rapproche ce dernier de la vertu et de la pure excellence morale.

On rencontre également dans l'œuvre de Salluste une vigoureuse affirmation de la valeur supérieure de l'honestum. Prenant le contrepied du mépris affiché par certains de ses contemporains vis-à-vis de

${ }^{62}$ SAll. Iug. 4, 4: maiusque commodum ex otio meo quam ex aliorum negotiis rei publicae uenturum; "et mon loisir sera plus utile à la république que l'activité de bien des autres gens ». Voir André, L'Otium, p. 345 et Tiffou, Essai sur la pensée morale de Salluste, p. 217 sqq.

${ }^{63}$ SALL. Iug. 8, 1. 
l'honneur, Salluste lui assigne une importance capitale, allant au-delà de la valorisation traditionnelle de cette notion. Le discours de Marius fait ainsi de l'honestum un des buts essentiels de la vie. Dans sa péroraison, Marius déclare à la plèbe:

Etenim nemo ignauia inmortalis factus est, neque quisquam parens liberis uti aeterni forent optauit, magis uti boni honestique uitam exigerent.

"La lâcheté n’a jamais exempté personne de la mort; et jamais père n'a souhaité que ses enfants fussent immortels, mais qu'ils vécussent dans la vertu et dans l'honneur.»

(SALL. Iug. 85, 49; trad. Ernout).

Salluste développe ici l'idée selon laquelle l'honneur est préférable à une longue vie: les pères ne souhaitent pas à leurs fils d'être immortels, mais de vivre conformément au bien et à l'honneur. Le propos est sous-tendu par le thème traditionnel de la mort honorable, perçue comme préférable à une vie dans le déshonneur. Mais Salluste fait confluer ce lieu commun avec un passage du Ménéxène dont il semble s'inspirer: il s'agit de l'exhortation des morts à leurs fils figurant dans l'oraison funèbre prononcée par Aspasie ${ }^{64}$. Dans ce texte, les pères athéniens soulignent qu'il n'est pas de vie possible dans le déshonneur et ils incitent leurs enfants à vivre dans la vertu pour maintenir la gloire de leurs ancêtres. Salluste réunit donc dans ce passage la tradition romaine de l'honneur et la valorisation grecque de l'héroïsme guerrier et de la belle mort, ce qui a pour effet de donner une très haute valeur à l'honestum et au bonum, qui apparaissent comme la fin que doivent viser les jeunes gens.

\subsection{La fidélité aux représentations traditionnelles de l'honneur}

Salluste constate à plusieurs reprises dans son œuvre que l'honestum est en perte de vitesse et il déplore son oubli. Sa réaction à cette déréliction de l'honneur n'est pas cependant du même ordre que celle d'un Cicéron, qui tâche de le refonder en renouvelant son contenu et ses principes de fonctionnement. Salluste répond à la dislocation de l'honestum en se tournant, avec nostalgie, vers la pratique ancestrale pour l'opposer au temps présent. L'honestum ancien reste pour lui la norme de référence et il tente de lui redonner son lustre en en rappelant les règles, sans modifier la notion en profondeur. Cette fidélité aux représentations anciennes de l'honneur se voit en premier lieu dans le statut qu'il donne à l'honestum. Ce dernier ne devient jamais chez lui un concept et ne fait pas l'objet d'un approfondissement théo-

${ }^{64}$ PLat. Menex. 246d-247d. La phrase de Salluste apparaît presque comme une transposition de Menex. 247d. 
rique $^{65}$. On le remarque dans le Bellum Iugurthinum, quand le consul Calpurnius se laisse acheter par Jugurtha, tout comme Scaurus qui l'accompagne:

Qui, tametsi a principio, plerisque ex factione eius conruptis, acerrume regem inpugnauerat, tamen magnitudine pecuniae a bono honestoque in prauom abstractus est.

"Scaurus qui, au début, bien que presque tous les gens de son parti se fussent laissé gagner, s'était déclaré l'adversaire acharné du roi, mais qui, devant les sommes énormes qu'on lui offrait, avait abandonné pour la voie du vice celle du bien et de l'honneur.»

(SALL. Iug. 29, 2; trad. Hellegouarc'h).

L'honestum ne fait pas l'objet d'une définition précise et il n'est appréhendé que par le biais d'une de ses manifestations concrètes, l'intégrité, qui est ici enfreinte. On voit également que son statut exact par rapport au bonum, autre principe de conduite, n'est pas clairement marqué: les deux termes sont coordonnés sans plus de précision, selon un procédé fréquent chez Salluste ${ }^{66}$. En outre, Salluste garde vis-à-vis de cet honestum la position d'un moraliste: il critique la manière dont Scaurus s'est écarté du droit chemin, comme le suggère la métaphore du texte (in prauom abstractus est). L'honestum est envisagé comme une règle de comportement, pourvue de commandements et d'interdits, à l'aune de laquelle on juge la conduite des personnages historiques. L'honestum est, comme dans la tradition, la norme centrale d'un code d'honneur; ce n'est pas un concept abstrait.

La fidélité de Salluste à l'honestum traditionnel se ressent aussi dans son traitement de l'extériorité sociale de l'honneur. Alors que plusieurs auteurs travaillent à détacher l'honestum de l'honos et à rompre son lien avec la collectivité, comme Lucilius, l'auteur de la Rhétorique à Herennius et Cicéron, l'attitude de Salluste, quant à elle, est moins tranchée. Comme nous l'avons vu, il distingue bel et bien la moralité

${ }^{65}$ Cela nous semble aller contre l'idée d'une affinité profonde entre Salluste et le stoïcisme, développée par l'article de V.CIAFFI, «Il pensiero filosofico di Sallustio », in Ciaffi, V. (éd.), Scritti inediti o rari, Turin, Giappichelli, 1978, p.161-173 et par Schur, Sallust als Historiker, pour qui Salluste aurait été marqué par Posidonius. Si Salluste avait réellement adhéré à la doctrine du Portique, il n'aurait pas manqué de donner un relief nouveau à l'honestum comme «beau moral ", notion d'importance cruciale dans l'éthique stoïcienne. Par ailleurs, plusieurs des éléments relevés par V.Ciaffi comme stoïciens (supériorité de l'âme sur le corps, mépris pour la mort, etc.) appartiennent au fonds commun de la philosophie grecque et se rencontrent aussi dans la morale du mos maiorum. Des points importants de la pensée de Salluste, comme la nécessité de rechercher la gloire, sont étrangers au stoïcisme: la similarité de certaines idées de Salluste et du stoïcisme est donc seulement superficielle (voir É. TIFFou, «Salluste et la tradition stoïcienne », EMC, 12, 1968, p.13-19 et MaCQueEn, Plato's Republic in the Monographs of Sallust, p. 21-26).

${ }^{66}$ Cf. Sall. Iug. 8, 1; 82, 2 et 85, 49. 
de la notoriété mais il ne va jamais jusqu'à opposer honos et honestum. En outre, il ne semble pas identifier totalement l'honestum à la vertu ou au bien moral ni lui ôter toute sa dimension sociale. Le fait qu'il associe régulièrement honestum et bonum, comme dans le texte cité supra, est assez révélateur: si Salluste recourt à ces deux notions pour recouvrir l'ensemble des normes morales enfreintes par Scaurus, c'est qu'elles ne s'identifient pas l'une à l'autre. L'honestum est distinct du bonum car il naît des représentations de la collectivité et tire sa force contraignante du regard des autres. Salluste a la notion d'un «bien moral » dépourvu d'assise sociale, mais il ne l'intègre pas pleinement dans honestum mais le désigne par bonum. Quand Scaurus enfreint l'honestum et le bonum, il se déshonore auprès des autres, d'une part, et tombe dans le vice, d'autre part. Il y a chez Salluste un enrichissement éthique de l'honestum, qui n'est cependant pas mené jusqu'à son terme parce qu'il n'ôte pas à la notion toute forme d'hétéronomie. Cela est confirmé par un autre passage où bonum et honestum sont à nouveau conjoints:

Interim Roma per litteras certior fit prouinciam Numidiam Mario datam; nam consulem factum ante acceperat. Quibus rebus supra bonum atque honestum perculsus, neque lacrumas tenere neque moderari linguam; uir egregius in aliis artibus nimis molliter aegritudinem pati.

«Cependant, il apprend par une lettre de Rome que la province de Numidie a été donnée à Marius; il avait déjà été informé que celui-ci avait été nommé consul. Plongé par ces nouvelles dans un abattement qui dépassait ce qui est bon et honorable, il ne put retenir ses larmes, ni modérer sa langue. Cet homme, si éminent d'autre part, était sans force pour supporter son chagrin. »

(SALL. Iug. 82, 2; trad. Ernout modifiée).

Honestum et bonum sont ici encore deux entités conjointes mais non identiques. L'honestum fait toujours référence à ce qui est socialement acceptable et permet de ne pas perdre la considération des autres: c'est en effet aux exigences sociales de son rang que contrevient Metellus en se mettant à pleurer ${ }^{67}$.

La continuité de la pensée sallustéenne de l'honestum avec les représentations anciennes de cette notion s'observe, enfin, dans le contenu que donne l'historien à l'honneur. Les qualités morales que recouvre l'honestum sont les exigences ancestrales du code de l'honneur. Un passage du discours de Memmius dans le Bellum Iugurthinum est significatif:

At qui sunt ei qui rem publicam occupauere? Homines sceleratissumi, cruentis manibus, immani auaritia, nocentissumi et idem superbissumi, quibus fides, decus, pietas, postremo honesta atque inhonesta omnia quaestui sunt.

${ }^{67}$ Sur le déshonneur des larmes, voir supra p. 480. 
«Mais quels sont ces hommes qui se sont emparés de la République? Des gens couverts de crimes, aux mains sanglantes, d'une cupidité sans bornes, se faisant orgueil de leurs forfaits, pour qui loyauté, honneur, piété, bref tout ce qui est vertu ou vice est une occasion de profits.»

(SALL. Iug. 31, 12; trad. Ernout).

Le terme honesta recouvre les différentes vertus mentionnées, fides, decus et pietas, qui appartiennent toutes aux commandements les plus anciens de l'honneur ${ }^{68}$. L'honestum n'est donc pas enrichi de qualités morales nouvelles; ce sont les traits du mos maiorum qui continuent à le composer ${ }^{69}$. Les modèles qui illustrent l'honorabilité parfaite sont eux aussi conformes à la tradition, puisque ce sont chez Salluste les maiores, les ancêtres, qui incarnent de façon exemplaire l'obéissance à l'honestum.

\section{CONCLUSION}

Chez Salluste, les notions d'honos et d'honestum ne reçoivent pas un contenu particulièrement novateur: la particularité de sa démarche réside dans l'usage historiographique de ces notions. L'honneur est d'abord un objet historique: Salluste fait le tableau du fonctionnement de l'honos et de l'honestum aux époques qui l'intéressent et en montre la déréliction. L'honneur est également utilisé par l'historien dans l'établissement des causes des faits rapportés: le désir d'honos, par exemple, est un facteur de l'action humaine et de la marche des événements. Ce même désir occupe enfin une place dans la philosophie de l'histoire puisque l'ambition est étroitement articulée à la décadence morale. À cet usage historiographique de l'honneur s'ajoute une évaluation, notamment morale, de cet objet. Concernant l'honos, Salluste critique l'ambition qui tourmente les hommes politiques et les errements auxquels le désir d'honos donne lieu. Ces reproches formulés par Salluste sont directement liés à son retrait de la vie publique et éclairent sa volonté, en réaction, de rechercher une autre forme de notoriété, la gloire de l'historien, plus en accord avec sa conception de l'homme et l'importance qu'il attache à la vertu. Concernant l'honestum, Salluste critique, comme pour l'honos, sa dislocation et déplore le mépris dans lequel il est tenu. Cependant, il ne réagit pas à cette dernière de façon aussi originale qu'il le fait devant l'erreur de trajectoire de ses contemporains pour atteindre la gloire. Face à l'oubli de l'honestum, il réaffirme la valeur morale de cette notion et tâche de

${ }^{68}$ Voir supra p. 466 sqq.

${ }^{69}$ Salluste recourt parfois à d'autres normes que celles du mos maiorum pour évaluer la conduite des individus, mais cela reste rare. Sur ces critères nouveaux, comme le uerum ou le decorum, voir BüchNer, Sallust, p.313-318. Ces normes, cependant, ne sont pas intégrées à l'honestum; elles coexistent tout au plus à côté de lui. 
réactiver les normes traditionnelles qui l'animent. Salluste s'illustre ainsi par un rapport complexe au mos maiorum, fait d'innovation, avec le rejet d'une vie consacrée au cursus honorum, et de fidélité, avec l'attachement aux règles anciennes du code de l'honneur.

\section{CONCLUSION DE LA TROISIÈME PARTIE}

L'étude chronologique de la pensée de l'honneur à Rome, de Plaute à Salluste, nous a permis d'observer les différentes façons dont les notions d'honos, d'honestum et d'honestas étaient envisagées par les auteurs de la période républicaine. Cette histoire intellectuelle met en lumière la plasticité de l'honneur dans les représentations des Romains : il peut être notion fluctuante ou concept théorique, idée politique ou valeur morale, image littéraire ou ressort idéologique. Malgré cette diversité, il est possible de repérer certaines lignes de force dans l'approche qu'en font les auteurs latins. On remarque d'abord qu'apparaissent précocement une analyse critique et une évaluation de l'honos, qui se développent ensuite tout au long de notre période. Dès les premières décennies de sa maturité, la littérature latine est le lieu d'une approche ludique de l'honos, avec les pièces de Plaute. Par la suite, Caton et Salluste critiquent, chacun à leur manière, le dysfonctionnement des mécanismes de l'honos à leur époque. Le regard critique des auteurs latins s'exerce aussi fréquemment sur la recherche de l'honos. Le désir d'honneur et l'ambition deviennent, avec la crise de la cité, hautement problématiques. Lucrèce, nourri de la doctrine épicurienne, dépeint les ravages de ce désir vain et en débusque les fondements psychologiques; Salluste, quant à lui, en historien, inscrit l'ambition dans un processus généralisé de décadence et en observe les conséquences dans les faits. C'est enfin la valeur même de l'honos qui est interrogée. Si Caton et les Scipions attachent du prix au prestige et aux marques d'honneur qui apparaissent comme la juste rétribution du mérite et la marque de l'excellence, la dégradation de la vie publique romaine et le développement des luttes intestines amènent les Romains à douter de plus en plus de la validité de cet objet: dès le II ${ }^{\mathrm{e}}$ siècle, Lucilius commence à s'interroger sur le prix réel du prestige. Le regard sur l'honos semble donc se faire, tout au long de la période qui nous concerne, de plus en plus critique.

Une deuxième ligne de force dans l'approche que font de l'honneur les Romains de la République réside dans l'élaboration théorique progressive de l'honestum. Ce qui n'était au début du $\mathrm{II}^{\mathrm{e}}$ siècle qu'une notion assez floue devient, par étapes successives, un concept à la forte densité théorique et à la place centrale dans l'éthique. Au début de notre période, il est surtout question, de façon un peu dispersée, des différents comportements attendus de l'homme honestus: des auteurs comme Plaute et Caton, s'ils dessinent chacun à leur manière les traits de l'homme d'honneur, ne s'intéressent pas à l'honestum lui-même, 
qui n'est pas défini de manière synthétique. C'est dans le courant du $\mathrm{II}^{\mathrm{e}}$ siècle que se développe une approche plus réfléchie, qui bénéficie de l'influence de la philosophie péripatéticienne et surtout du stoïcisme. C'est chez Térence et Lucilius qu'honestum devient une catégorie éthique: il gagne en consistance, entre en relation avec d'autres concepts comme utile ou turpe et s'enrichit d'un contact avec le concept

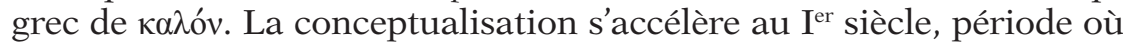
l'honestum bénéficie de la réflexion théorique menée par les Romains sur différents champs du savoir. On l'observe d'abord dans le domaine de la rhétorique, à travers les traités que sont la Rhétorique à Herennius et le De inuentione, où se rencontre le premier travail théorique abouti sur l'honestum: ce dernier y devient en effet un terme technique et s'enrichit d'applications théoriques inédites. Cicéron conduira la conceptualisation de l'honestum à maturité en en faisant un concept central de la philosophie éthique.

À cet approfondissement théorique de l'honestum est lié l'enrichissement éthique de la notion au fil du temps, qui évolue depuis la sphère de l'honneur vers celle de l'honnêteté et de la beauté morale. La notion d'honestum possède une réelle plasticité. Les exigences morales qu'elle implique sont à l'origine les commandements du code de l'honneur ancestral mais on voit progressivement s'ajouter à ces derniers des qualités nouvelles, telles que les vertus cardinales de la tradition philosophique grecque. Un contenant ancien reçoit ainsi un contenu inédit. La souplesse de l'honestum se lit aussi dans la modification de ses mécanismes par les penseurs des $\mathrm{II}^{\mathrm{e}}$ et $\mathrm{I}^{\mathrm{er}}$ siècles. C'est d'abord le fondement de l'honestum sur le regard d'autrui et les normes collectives qui s'efface peu à peu. L'extériorité sociale de l'honneur est de moins en moins prégnante et laisse une place grandissante à la régulation de l'individu par lui-même et à l'intériorité. Se développe aussi, en parallèle, l'idée que l'honestum vaut en soi, indépendamment des rétributions qu'il apporte en termes de prestige social. L'honestum est ainsi détaché de l'honos et peut même lui être opposé. Cependant, malgré la nette influence de la pensée grecque et du stoïcisme sur le développement moral de l'honestum, on observe régulièrement une permanence, en son sein, de traits appartenant à la tradition, chez Lucilius et surtout Salluste qui reste fidèle à un modèle ancien de l'honneur. L'honestum est au centre d'une alchimie complexe mais harmonieuse entre la tradition morale romaine et la réflexion philosophique grecque. Son assomption éthique n'est par ailleurs ni linéaire ni irrésistible, car des résistances à cette évolution s'observent chez Lucrèce et César. Ces deux auteurs ignorent délibérément ce concept dans leurs œuvres, par fidélité à la doctrine du Jardin qui conteste la valeur théorique et pratique de cet honestum, pourvu d'une coloration trop stoïcienne mais aussi peut-être, pour César, trop cicéronienne.

La plasticité de la notion d'honneur s'observe enfin dans une pratique récurrente à l'époque républicaine. Il s'agit de l'utilisation littéraire de l'honos et de l'honestum et des inflexions apportées à ces 
notions par les différentes œuvres en fonction de leur genre et de leurs objectifs propres. Le théâtre utilise le thème de l'honneur comme une ressource dramatique: Plaute comme ressort comique par l'image inversée qu'il en donne, Térence comme moyen d'approfondissement psychologique des personnages. Du côté de la satire, Lucilius amène l'honos vers le discours badin qu'est le sermo, non sans un certain iconoclasme. Dans le domaine de la prose historique, Salluste constitue l'honos en objet historiographique et l'emploie comme élément explicatif dans la recherche des causes des événements; César, de son côté, en fait un outil de description ethnographique. Mais il se singularise surtout par la mobilisation de cette notion à des fins de mise en avant de sa personne. Il y a, tout au long de notre période, une utilisation politique et idéologique de l'honos, que ce soit dans la propagande césarienne, chez les homines noui qui le placent, avec la uirtus, au centre d'une nouvelle aristocratie du mérite, ou au sein de la nobilitas, qui s'efforce de mettre en avant sa détention à des fins de prestige, comme le montrent les épitaphes des Scipions. 



\section{CONCLUSION GÉNÉRALE}

Les trois éclairages successifs que nous avons apportés sur les notions d'honos, d'honestum et d'honestas et la mobilisation d'outils d'analyse divers et de sources nombreuses ont permis de faire ressortir l'importance, la complexité et la singularité de ces objets. Au terme de cette recherche, il nous faut essayer de répondre aux cinq problèmes principaux que posent ces notions et que nous avions soulevés dans notre introduction: l'honos, l'honestum et l'honestas sont-ils totalement mouvants et caractérisés par une irréductible diversité? Quel est leur place par rapport aux autres grandes notions sociales, politiques et morales de Rome? Comment s'articulent en leur sein la théorie et la pratique? Quelle est leur évolution historique? Quel rapport entretiennent ces notions avec le concept anthropologique d' «honneur»?

\section{Richesse, cohérence et singularité sémantiques}

Létude sémantique des mots honos, honestus et honestas a constitué pour notre investigation un fondement essentiel, à l'intérêt à la fois méthodologique, heuristique et culturel. L'approche du lexique a permis de noter la fréquence de ces mots et leur richesse sémantique. Ces trois termes touchent en effet à quatre sphères sémantiques différentes, celles du social, du politique, du moral et de l'esthétique, ce qui témoigne de leur souplesse sémantique aussi bien que de leur position centrale dans le vocabulaire, à la croisée de différentes aires de sens. La polysémie ne doit pas, cependant, occulter la cohérence. Honos possède des significations nombreuses mais les trois sens principaux ("marque d'honneur, hommage », "considération » et "charge publique») orientent le mot principalement vers la désignation du prestige socio-politique et de ses marques extérieures. Honestas et honestus appartiennent davantage au domaine moral puisqu'ils renvoient de façon privilégiée à l'honorabilité et à l'honnêteté, étayées par des qualités éthiques. On observe donc une spécialisation d'honos vers une aire de sens et d'honestus / honestas vers une autre, spécialisation qui n'est cependant pas totale car ces termes possèdent des sens en commun.

Dans la diachronie, le sémantisme d'honos a une grande stabilité et évolue peu. Honestus et honestas connaissent, en revanche, des changements plus marqués; on voit notamment apparaître et se déve- 
lopper des sens éthiques, avec l'émergence d'une acception «honnête / honnêteté » dans un premier temps, puis «moralement beau / beauté morale», dans un second, à la faveur d'un calque sémantique depuis

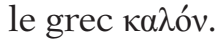

L'analyse sémantique a permis en outre de montrer que, malgré les apparences, il n'y a pas de parfaite synonymie entre honos et d'autres termes. Seule la dignitas peut avoir plusieurs traits communs avec l'honos. Le lexique latin des Wertbegriffe est particulièrement riche et nuancé. La singularité d'honos et de ses dérivés ne signifie cependant pas qu'ils soient isolés, bien au contraire: des liens sont constamment établis, dans la langue et la pensée, entre différents concepts. Honos entretient un rapport privilégié avec la dignitas, qui peut être à la fois la source, l'équivalent et l'effet de l'honos. L'auctoritas est quant à elle une conséquence fréquente de l'honos. Concernant l'honestum, il apparaît comme le principe de conduite de l'individu habité par le pudor ou la uerecundia; comme somme de qualités morales, il peut également englober la uirtus ou s'identifier à elle quand le mot possède son sens éthique.

\section{Les paradigmes de l'honneur}

L'identification des sens sociaux, politiques et moraux des notions étudiées a conduit à en observer la place et la fonction dans la vie des Romains. L'enquête sur les pratiques de l'honneur à Rome nous a permis de constater leur diversité: diversité des formes prises par les marques concrètes d'honneur, diversité des motifs pour lesquels l'honos est octroyé, ou encore diversité de ses effets. Il convient cependant de ne pas en rester à cette hétérogénéité de surface. Un examen systématique permet de dégager deux paradigmes qui structurent en profondeur l'honneur. L'honos fonctionne selon un paradigme symbolique: la marque d'honneur est un signe qui dit l'estime, et le prestige est vécu comme une image de marque. L'honos romain est polysémique car il dit aussi la reconnaissance du donateur ou encore le mérite du détenteur. Il sert également, de ce fait, à rendre visible l'excellence et à illustrer les qualités morales essentielles du mos maiorum. Sa logique symbolique explique qu'il soit fortement ancré dans l'espace et fasse appel à la vision. L'honneur opère aussi selon un paradigme économique. La marque d'honneur est une rétribution pour un acte remarquable ou un statut particulier. Le mérite d'un individu crée une dette qu'il convient d'acquitter par des honores, ce qui explique l'importance de leur valeur d'échange. Leur accumulation permet à celui qui les reçoit de se constituer un patrimoine de prestige (honos), qui augmente ou diminue et doit être protégé et transmis. Ce capital peut servir d'instrument de pouvoir. L'honneur fonctionne donc comme un «capital symbolique», pour reprendre le concept de P. Bourdieu.

Ces deux aspects de l'honneur, symbolique et économique s'articulent de différentes manières. Nous avons vu, notamment, que 
la dépense économique liée à un hommage en augmente le pouvoir symbolique et que l'estime signifiée par la marque d'honneur peut servir à occulter l'échange économique constitué par l'octroi d'honores. Le symbolique et l'économique à l'œuvre dans l'honos ont comme matrice commune le processus de l'échange. L'honos se situe en effet au centre d'une interaction entre individus ou groupes sociaux. L'échange est symbolique car il y a émission de signes et communication avec autrui. Mais il est aussi économique: il y a un paiement en retour d'un service ou d'une qualité, et cette prestation doit donner lieu à de la reconnaissance, qui génère un autre bienfait. L'échange s'observe aussi à d'autres niveaux de l'honos, comme à celui de ses effets: l'honneur procure à qui le reçoit un certain nombre d'avantages mais ces derniers s'accompagnent de contraintes qui les contrebalancent. L'honneur instaure donc perpétuellement des rapports de réciprocité.

\section{Une structure sociale et morale}

L'honneur est apparu dans notre étude comme un élément important de régulation et de structuration de la société romaine. L'honos est, sur le plan moral, un instrument pour orienter l'action des membres du corps social: dans la pratique, il rétribue les conduites qui visent l'utilité publique; dans l'axiologie, il définit les valeurs prisées et les modèles à imiter. L'honestas impose quant à elle un ensemble de règles à observer, sous peine de discrédit aux yeux de l'entourage.

Dans le domaine des relations sociales, l'honneur regroupe et associe les individus. Il implique de nombreux protagonistes dans son fonctionnement et crée entre eux des liens de dépendance et de reconnaissance. Il assume une fonction identitaire en regroupant des individus au sein de mêmes rituels d'hommage. Il symbolise les liens sociaux existant entre ceux qui y participent.

Dans le champ politique, il peut conférer un vrai pouvoir institutionnel sur l'entourage ou, le plus souvent, une autorité diffuse. Il a surtout la particularité d'instituer des rapports de pouvoir réciproques: le détenteur de l'honos gagne en influence, mais le donateur en bénéficie lui aussi car le prestige rejaillit sur lui et l'hommage qu'il octroie fait de la personne honorée son obligée. S'il y a donc une diversité des formes de l'honneur, il y a aussi une cohérence et une unité en profondeur de ses fonctions.

L'étude de l'honos et de l'honestas a également permis de voir la façon dont le domaine social est à Rome étroitement lié au domaine moral. La détention d'un statut dans la société et la possession de qualités éthiques constituent ainsi les deux voies d'accès au prestige et, si elles sont théoriquement distinctes, elles se combinent souvent dans la pratique. On voit aussi, à travers l'étude de l'honneur, que l'honestas mène à l'influence sociale et que, réciproquement, une position élevée dans la cité impose de bonnes mœurs. L'honestas, enfin, apparaît comme un code de conduite moral dont les bases sont sociales: 
ses normes sont édictées par le groupe et sont observées en raison du regard porté par l'entourage sur l'individu.

\section{De la pratique à la théorie}

La pratique de l'honos et de l'honestum n'est pas à Rome quelque chose qui va de soi: elle est précocement pensée, évaluée et théorisée par les Romains. C'est pourquoi notre étude a dû passer d'une approche de la praxis à une analyse de la réflexion sur cette praxis.

En ce qui concerne l'honos, les auteurs de la République s'interrogent sur ses mécanismes, en critiquent les dysfonctionnements et lui assignent des normes. Plusieurs écrivains l'ont également adapté au genre dans lequel ils se sont illustrés: Plaute et Lucilius en ont fait l'objet d'un jeu littéraire comique et satirique, ce qui montre qu'il est possible à Rome de jouer avec une notion comme l'honos. La société romaine, que l'on pourrait imaginer rigide et sévère, fait en réalité place à la plaisanterie et à la dérision vis-à-vis de l'honneur. D'autres inflexions importantes ont été apportées à l'idée d'honneur par Salluste, qui en a fait une donnée historique. Certains auteurs en ont également perçu l'utilité politique et idéologique: la nobilitas a essayé de s'approprier la notion, ainsi que le montrent les épitaphes des Scipions, tout comme les homines noui, puisque Caton en a fait une donnée centrale de sa pensée politique. On observe également dans la plupart des œuvres de la République une évaluation du prestige et des marques d'honneur. Plaute a fait surgir la dimension problématique de l'honos en lui faisant subir des distorsions importantes. Après ces expériences dramaturgiques, qui sont comme le laboratoire d'une approche réflexive, Lucilius a été, au $\mathrm{II}^{\mathrm{e}}$ siècle, l'un des premiers à interroger la valeur de l'honos d'un point de vue plus philosophique, en questionnant la solidité de ses fondements et le prix qu'il convient de lui attacher parmi les biens. Ce type d'approche devient plus systématique au I ${ }^{\text {er }}$ siècle, période où l'honos est rattaché à des problématiques comme celles de l'ambition, des genres de vie, de l'otium et de la fin de l'existence humaine. Lucrèce donne dans son œuvre une vision très critique du désir d'honos, fondée sur son adhésion à la doctrine épicurienne qui souligne l'inutilité du prestige pour atteindre sécurité et ataraxie. Salluste constate les ravages provoqués par l'ambition à Rome et souligne le rôle historique de cette passion dans la décadence qui frappe l'Vrbs. La vision, assez critique dans l'ensemble, de ces auteurs du I ${ }^{\text {er }}$ siècle, laisse cependant parfois la place à une autre forme de notoriété positive, gloire poétique pour Lucrèce, gloire de l'historien pour Salluste. Les représentations intellectuelles de l'honneur chez ces auteurs ont été influencées par la philosophie grecque ainsi que par le contexte historique dans lequel ils ont vécu, qui a vu le dérèglement du fonctionnement de l'honos et une crise politique et morale généralisée. 
En ce qui concerne l'honestum, la réflexion des auteurs de la République se caractérise par plusieurs importantes évolutions. L'honestas, qui est aux origines un code d'honneur étayé par les règles morales du mos maiorum et illustré par les ancêtres, reçoit progressivement des contenus, des fondements et des archétypes nouveaux qui le font évoluer vers le concept de bien moral. Il n'y a pas, cependant, destruction totale des éléments les plus anciens: certains disparaissent, d'autres sont transformés, mais d'autres encore persistent et sont inclus au sein d'un concept inédit. Il y a une stratification partielle au cours du temps des différentes formes de l'honestum. Trois évolutions essentielles peuvent être observées entre la fin du III ${ }^{\mathrm{e}}$ siècle et la disparition de la République. Il y a, en premier lieu, une élaboration théorique de l'honestum, qui passe de la notion au concept. Par un nouvel usage du lexique, la recherche d'une définition précise, le recours à la division et à la classification, Térence et Lucilius, puis surtout l'auteur de la Rhétorique à Herennius et Cicéron enrichissent le sens et la portée de l'honestum. En deuxième lieu, ce concept se rapproche de

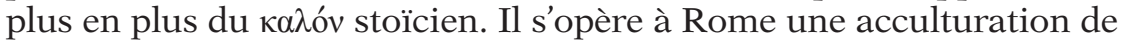
cette notion grecque, au point que l'honestas, qui était initialement l' "honorabilité», devient au I ${ }^{\text {er }}$ siècle un concept éthique, celui de «beauté morale». C'est donc, de façon originale, par le truchement d'une notion socio-politique, et non d'un terme esthétique comme dans le monde grec, que les Romains ont exprimé l'idée d'excellence éthique et de souverain bien. Le concept d'honestum ne s'est d'ailleurs jamais totalement dépouillé de ses caractéristiques ancestrales; il se distingue par une remarquable confluence en son sein de la tradition romaine et de la pensée philosophique grecque. En dernier lieu, l'honestas a évolué depuis une morale hétéronome vers une éthique autonome; elle s'est écartée de l'honorabilité pour se rapprocher de l'honnêteté et du bien moral. Initialement, le code de conduite régi par l'honestum est extériorisé: c'est la collectivité et non l'individu qui définit ce qui est honestum; c'est le regard d'autrui et la crainte de perdre son estime qui motivent l'observation des règles de comportement; c'est par l'imitation de la conduite des ancêtres, archétypes de l'honneur, que l'on atteint l'honestas. Puis, avec la crise du mos maiorum au dernier siècle de la République et l'influence grandissante de la philosophie grecque et notamment du stoïcisme, l'honestum a rompu ses liens avec l'honos et avec la collectivité et s'est retrouvé au centre d'une éthique faisant une place plus importante au sujet.

Il y a donc à Rome une théorisation de la pratique. Mais on remarque aussi une action de la pratique sur la théorie: les changements dans les conduites liées à l'honneur influent sur la pensée. Le monopole des honores par les grands imperatores ou l'usage qu'ils en font à des fins de pouvoir personnel entraînent au ${ }^{\text {er }}$ siècle une réévaluation de l'honneur, une mise en question de son prix et la redéfinition de nouvelles formes de prestige plus authentiques. 


\section{De l'honos à l'honneur?}

Il nous faut, pour clore ce travail, essayer de préciser le rapport entretenu par l'honos, l'honestum et l'honestas avec la notion anthropologique d' "honneur», située à l'horizon de notre travail. Trois aspects de cet honneur peuvent être rapprochés des notions romaines.

Une première proximité apparaît entre ces notions et ce que l'anthropologue F. Stewart nomme l'honneur «externe »" la bonne réputation d'un individu et la reconnaissance sociale dont il bénéficie. L'honos consiste en effet à jouir du prestige au sein de la collectivité à laquelle on appartient. Cependant, à Rome, les marques d'honneur concrètes et les hommages jouent un rôle essentiel dans la constitution de ce prestige, aspect que les anthropologues mettent rarement en avant. Il y a également une proximité de l'honos avec d'autres phénomènes sociaux que l'honneur, comme le don et la bienfaisance. En outre, l'honos romain joue moins que l'honneur sur la renommée et la réputation d'une personne; le prestige qu'il désigne est bien plus visuel.

Un second aspect de l'honneur peut être rapproché de nos notions: il s'agit de l'honneur «interne», c'est-à-dire la qualité morale qu'est l'honorabilité. L'honestas s'identifie à cette qualité par l'existence en son sein de vertus et par le fait qu'elle ouvre la voie à l'estime des autres par ces vertus. Il y a bien à Rome, nous semble-t-il, un «code de l'honneur »: l'honestum est au cœur d'un ensemble de règles morales contraignantes qui permettent à un acteur social de préserver sa considération. Cependant, on ne peut identifier l'honestum à une "émotion » ou à un «sentiment»: il s'agit d'une règle au cœur d'un faisceau de représentations morales à base sociale et collective. En outre, s'il est légitime, par certains aspects, d'évoquer le «sens de l'honneur» des Romains, il ne faut pas perdre de vue que ce dernier est, à l'époque républicaine, en perpétuelle fluctuation et élaboration: il est constamment pris comme objet de réflexion par une société en pleine effervescence intellectuelle. Identifier purement et simplement l'honestum à l'honneur serait l'amputer de la dimension éthique et conceptuelle que les auteurs latins lui ont progressivement donnée.

Le dernier aspect de l'honneur, tel qu'il est analysé par les sciences sociales, nous paraît plus difficile à rapprocher de l'honos ou de l'honestum. Il s'agit de l'honneur "subjectif», le savoir qu'a un individu de sa propre valeur, qui le conduit à prétendre à un certain degré de considération. Cette forme d'honneur est différente de l'honos et éloignée de l'honestas: l'honorabilité romaine, même sous la forme éthique que lui ont donnée les penseurs de la fin de la République, ménage une place limitée à la conscience de soi et à l'évaluation par le

\footnotetext{
${ }^{1}$ Sur les travaux de F. Stewart, voir notre introduction, p. 5-6.
} 
sujet de sa propre personne. L'honneur implique ici une appréciation de soi-même et intègre la notion d'une dignité de l'être humain qui reste étrangère à l'honos et à l'honestas. S'il est assurément fructueux d'analyser ces notions romaines à la lumière du concept d'honneur, il est donc indispensable d'y recourir avec esprit critique, de mettre l'honneur "en question », et de ne pas vouloir le faire entrer en parfaite adéquation avec des objets romains dont la singularité demeure irréductible. 



\section{SOURCES ET BIBLIOGRAPHIE}

Textes anciens

Les textes latins et grecs cités dans notre étude le sont généralement d'après l'édition de la Collection des Universités de France. Nous signalons seulement ici les autres éditions utilisées, pour les œuvres qui n'ont pas été publiées dans la C.U.F. ou n'y figurent que de manière incomplète. Nous mentionnons également quelques éditions auxquelles nous avons eu recours en complément de celle de la C.U.F.

Aristote, Ethica Nicomachea, éd. I. Bywater, Oxford, Clarendon Press, 1991. , Metaphysica, éd. W. Jaeger, Oxford, Clarendon Press, 1989.

Asconius, Orationum Ciceronis quinque enarratio, éd. A. Kiessling et R. Schoell, Berlin, Weidmann, 1875.

Augustin, De ciuitate Dei, éd. B.Dombart et A.Kalb, Stuttgart, Teubner, 1993 (5 éd.).

Caton, Ad Marcum filium, in P.Cugusi et M.T.Sblendorio-Cugusi (éd.), Opere di Marco Porcio Catone Censore, Turin, UTET, 2001.

_., Carmen de moribus, in P.Cugusi et M. T. Sblendorio-Cugusi (éd.), Opere di Marco Porcio Catone Censore, Turin, UTET, 2001.

Charisius, Artis grammaticae libri V, éd. C. Barwick, Stuttgart, Teubner, 1997 (stéréotype de l'éd. de 1964).

Cić́ron, Academicorum reliquiae cum Lucullo, éd. O. Plasberg, Stuttgart, Teubner, 1922.

De diuinatione, De fato, Timaeus, éd. O. Plasberg, Stuttgart, 1965 (stéréotype de l'éd. de 1938).

_. De natura deorum, éd. W. Ax, Stuttgart, Teubner, 1964 (stéréotype de l'éd. de 1933).

_, Fragmenta epistularum, éd. D. R. Shackleton Bailey, Stuttgart, Teubner, 1988.

—, The Fragmentary Speeches, éd. J. A. Crawford, Atlanta, Scholars Press, 1994 ( $2^{e}$ éd).

Hortensius, éd. A. Grilli, Milan, Istituto editoriale cisalpino, 1962.

Denys d'Halicarnasse, Antiquitatum Romanarum quae supersunt, éd. C. Jacoby, Stuttgart, Leipzig, 1995-1998 (réimpr.).

Diodore de Sicile, Bibliotheca historica, éd. I. Bekker et L. Dindorf, Stuttgart, Teubner, 1985-1991 (stéréotype de l'éd. de 1888-1906).

Diogene LaËrce, Vitae philosophorum, éd. H. S. Long, Oxford, Oxford Classical Texts, 1964.

, Vies et doctrines des philosophes illustres, trad. sous la dir. de M.-O. GouletCazé, Paris, Librairie générale française, 1999. 
Dion Cassius, Historia romana, éd. L. Dindorf et J. Melber, Leipzig, Teubner, 1890-1928.

Ennius, The Annals, éd. O. Skutsch, Oxford, Clarendon Press, 1985. , Poesis reliquiae, J. Vahlen (éd.), Leipzig, Teubner, 1903 (2éd.). , The Tragedies, éd. H. D. Jocelyn, Cambridge, Cambridge University Press, 1967.

ÉPICURE, Epicurea, éd. H. Usener, Leipzig, Teubner, 1887.

— Lettres et maximes, éd. M. Conche, Villers sur Mer, Éditions de Mégare, 1977.

Festus, De uerborum significatu quae supersunt cum Pauli epitome, éd. W. M. Lindsay, Stuttgart, Teubner, 1997 (réimpr.).

Hermogène, Opera, éd. H. Rabe, Stuttgart, Teubner, 1985 (stéréotype de l'éd. de 1913).

IsIdore de SÉville, Etymologiarum siue originum libri $X X$, éd. W. M.Lindsay, Oxford, Clarendon Press, 1957.

Lactance, Institutions divines, éd. P. Monat, Paris, Le Cerf, 1986. L'Ouvrage du Dieu Créateur, éd. M. Perrin, Paris, Le Cerf, 1974.

Lucilius, Carminium reliquiae, éd. F. Marx, Leipzig, Teubner, 1904-1905.

Macrobe, Saturnalia, éd. J. Willis, Leipzig, Teubner, 1970 ( $2^{\mathrm{e}}$ éd.).

Naevius, Fragmenta, in A. Traglia (éd.), Poeti latini arcaici, Turin, UTET, 1986, vol. 1.

Ovide, Fastorum libri sex, éd. E. H. Alton, D. E. W. Wormell et E. Courtney, Leipzig, Teubner, 1978.

Publilius Syrus, Mimi Sententiae, éd. G. Meyer, Leipzig, Teubner, 1880.

Salluste, Historiarum fragmenta selecta, éd. L. D. Reynolds, Oxford, Clarendon Press, 1981.

SÉNÈQue LE RHÉTEUR, Oratorum et rhetorum sententiae, diuisiones, colores, éd. L. Håkanson, Leipzig, Teubner, 1989.

Servius, Qui feruntur in Vergilii carmina commentarii, éd. G. Thilo et H. Hagen, Leipzig, Teubner, 1878-1902.

Sтове́E, Eclogarum physicarum et ethicarum libri duo, éd. A. Meineke, Leipzig, Teubner, 1855-1864.

SuÉTone, Praeter Caesarum libros reliquiae, éd. A. Reifferscheid, Leipzig, Teubner, 1860.

Tertullien, De corona, éd. J. Fontaine, Paris, P.U.F., 1966. , Les Spectacles, éd. M. Turcan, Paris, Le Cerf, 1986.

Tite Live, Ab Vrbe condita libri VI-X, éd. C. F. Walters et R. S. Conway, Oxford, Clarendon Press, 1958 (réimpr).

, Ab Vrbe condita libri XXI-XXV, éd. C. F. Walters et R. S. Conway, Oxford, Clarendon Press, 1958 (réimpr). , Ab Vrbe condita libri XXVI-XXX, éd. R. S. Conway et S. K. Johnson, Oxford, Clarendon Press, 1957 (réimpr. corr.). , Ab Vrbe condita libri XXXI-XXXV, éd. A. H. MacDonald, Oxford, Clarendon Press, 1965.

VARron, Antiquitates rerum diuinarum, éd. B. Cardauns, Wiesbaden, F. Steiner, 1976.

, De uita populi Romani, éd. B. Riposati, Milan, Celuc, 1974 (2éd.). , Satires Ménipées, éd. J.-P. Cèbe, Rome, E.F.R., 1972-1999. 
Recueils de textes anciens

CGL Corpus glossariorum Latinorum, éd. G. Löwe et G. Götz, Leipzig, Teubner, 1888-1923.

CIL Corpus inscriptionum Latinarum, Berlin, W. De Gruyter, 1863-.

CLE Carmina Latina epigraphica, éd. F. Bücheler, Stuttgart, Teubner, 1982 ( $2^{\mathrm{e}}$ éd.).

CRF Comicorum Romanorum fragmenta, éd. O. Ribbeck, Leipzig, Teubner, 1873 (2e éd.).

Dig. Digesta, éd. P. Krueger, et T. Mommsen, in Corpus Iuris Ciuilis, vol. 1, Berlin, Weidmann, 1988 (réimpr. de l'éd. de 1872).

FIRA Fontes iuris Romani anteiustiniani, éd. S. Riccobono, G. Baviera, C. Ferrini et al., Florence, G. Barberà, 1968.

FPL Fragmenta poetarum Latinorum epicorum et lyricorum, éd. J. Blänsdorf, Stuttgart, Teubner, 1995 (3e éd.).

GLK Grammatici Latini, éd. H. Keil, Leipzig, Teubner, 1855-1880.

Glossaria Latina, éd. W. M. Lindsay et al., Paris, Les Belles Lettres, 1926-1931.

HRR Historicorum Romanorum reliquiae, éd. H. Peter, Stuttgart, Teubner, 1993 (stéréotype de la 2e éd.).

ILLRP Inscriptiones latinae liberae Rei publicae, éd. A. Degrassi, Florence, La Nuova Italia, 1957-1963.

ILS Inscriptiones Latinae selectae, éd. H. Dessau, Berlin, Weidmann, 18921916.

LS Long, A. A. et Sedley, D. N., (éd.), Les Philosophies hellénistiques, Paris, Flammarion, 2001.

ORF Oratorum Romanorum fragmenta liberae Rei publicae, éd. H. Malcovati, Turin, Paravia, 1955 (2e éd.).

RLM Rhetores Latini minores, éd. C. Halm, Leipzig, Teubner, 1863.

ROL Remains of Old Latin, éd. E. H. Warmington, Londres, W. Heinemann, 1935-1938.

SVF Stoicorum ueterum fragmenta, éd. H. von Arnim, Leipzig, Teubner, 1903-1905.

TRF Tragicorum Romanorum fragmenta, éd. O. Ribbeck, Leipzig, Teubner, 1871 (2éd.).

Ouvrages de référence

CAH The Cambridge Ancient History, Cambridge, Cambridge University Press, $2^{\mathrm{e}}$ éd., 1970-2006.

DAGR Daremberg, C., Saglio, E., Pottier, E. et al., Dictionnaire des antiquités grecques et romaines d'après les textes et les monuments, Paris, Hachette, 1877-1919.

DELL Ernout, A. et Meillet, A., Dictionnaire étymologique de la langue latine, 4e éd., Paris, C. Klincksieck, 1994.

EAA Enciclopedia dell'arte antica classica e orientale, Rome, Istituto della Enciclopedia italiana, 1958-.

LEW Walde, A. et Hofmann, J. B., Lateinisches etymologisches Wörterbuch, $3^{2}$ éd., Heidelberg, C. Winter, 1938-1954.

LIMC Lexicon iconographicum mythologiae classicae, Zürich, Artemis, 19811999. 
LTUR Steinby, E. M. (éd.), Lexicon topographicum urbis Romae, Rome, Quasar, 1993-2000.

LTUR Sub. La Regina, A. (éd.), Lexicon topographicum urbis Romae : Suburbium, Rome, Quasar, 2001-.

MRR Broughton, T. R. S., The Magistrates of the Roman Republic, New York, American Philological Association, 1951.

NP Cancik, H. et Schneider, H. (éd.), Brill's New Pauly, Leiden, Brill, 2002-

OCD Hornblower, S. et Spawforth, A. (éd.), The Oxford Classical Dictionary, $3^{e}$ éd. révisée, Oxford, Oxford University Press, 2003.

OLD Glare, P. G. W. (éd.), Oxford Latin Dictionary, Oxford, Clarendon Press, 2005.

RE Pauly, A., Wissowa, G. et Kroll, W., Real-Encyclopädie der classischen Altertumswissenchaft, Stuttgart, J. B. Metzler, 1893-.

RRC Crawford, M. H., Roman Republican Coinage, Cambridge, Cambridge University Press, 1974.

TLL Thesaurus linguae latinae, Leipzig, Teubner, 1900-.

\section{Littérature secondaire}

Pour ne pas trop alourdir cette bibliographie, nous ne reprenons pas les titres cités une seule fois dans le corps du développement et dont l'objet est assez éloigné du thème de notre travail. Les abréviations des périodiques sont celles en usage dans L'Année philologique.

Aberson, M., Temples votifs et butin de guerre dans la Rome républicaine, Genève, Institut suisse de Rome, 1994.

Abu-Lughod, L., Veiled Sentiments : Honor and Poetry in a Bedouin Society, Berkeley, University of California Press, 1986.

Achard, G., La Communication à Rome, Paris, Payot, 1994.

Adams, J. N., Bilingualism and the Latin Language, Cambridge, Cambridge University Press, 2003.

Afzelius, A., "Zur Definition der römischen Nobilität in der Zeit Ciceros», $C \& M, 1,1938$, p. 40-94.

Agache, S., "Caton le Censeur, les fortunes d'une légende», Caesarodunum, 15bis, 1980, p. 71-107.

Aldrete, G. S., Gestures and Acclamations in Ancient Rome, Baltimore, Johns Hopkins University Press, 1999.

Alexandre, R., Guérin, C. et Jacotot, M. (éds.), Rubor et pudor. Vivre et penser la honte à Rome, Paris, Éditions Rue d'Ulm, 2012.

Alexiou, E., Ruhm und Ehre: Studien zu Begriffen, Werten und Motivierungen bei Isokrates, Heidelberg, C. Winter, 1995.

AlföLDI, A., Der frührömische Reiteradel und seine Ehrenabzeichen, BadenBaden, Verlag für Kunst und Wissenschaft, 1952.

, "The Main Aspects of Political Propaganda on the Coinage of the Roman Republic » in Essays in Roman Coinage Presented to H. Mattingly, Oxford, Oxford University Press, 1956, p. 63-95.

, "Hasta - Summa Imperii. The Spear as Embodiment of Sovereignity in Rome », AJA, 63 (1), 1959, p. 1-27. 
Alfonsi, L., «Sul metus Punicus Sallustiano», Athenaeum, 51, 1973, p.383384.

Амiотті, G., «Il trionfo come spettacolo » in Sordi, M. (éd.), Guerra e diritto nel mondo greco e romano, Milan, Vita e Pensiero, 2002, p. 201-206.

Amirante, L., "Il concetto unitario dell'auctoritas» in Studi in onore di S. Solazzi, Naples, Jovene, 1948, p. 375-390.

Anderson, W. S., "Plautus' Trinummus: the Absurdity of Officious Morality», Traditio, 35, 1979, p. 333-345.

ANDRÉ, J.-M., L'Otium dans la vie morale et intellectuelle romaine des origines à l'époque augustéenne, Paris, P.U.F., 1966.

"Ethnographie et sociologie 'barbare' chez César (1)», Vita Latina, 161, 2001, p. 15-28.

— " Ethnographie et sociologie 'barbare' chez César (2)», Vita Latina, 162, 2001, p. 2-10.

Argenio, R., "I grecismi di Lucilio », RSC, 11, 1963, p. 5-17.

Armengaud, F., La Pragmatique, 4e éd., Paris, P.U.F., 1999.

Arnaud-Lesot, S., "Les aspects médicaux de la honte dans le De medicina de Celse » in Alexandre, R., Guérin, C. et Jасотот, M. (éds.), Rubor et pudor. Vivre et penser la honte à Rome, Paris, Éditions rue d'Ulm, 2012, p. 45-59.

Astin, A. E., «Scipio Aemilianus and Cato Censorius », Latomus, 15, 1956, p. 159-180.

, The Lex Annalis before Sulla, Bruxelles, Latomus, 1958.

— Scipio Aemilianus, Oxford, Clarendon Press, 1967.

— Cato the Censor, Oxford, Clarendon Press, 1978. «Regimen morum», JRS, 78, 1988, p. 14-34.

Aubert, S., "Stoïcisme et romanité. L'orateur comme 'homme de bien habile à parler' », Camenae [revue électronique], 1, 2007, http://www.parissorbonne.fr/fr/spip.php?article4898 [consulté en janvier 2008].

Auliard, C., Victoires et triomphes à Rome, Besançon, Presses universitaires franc-comtoises, 2001.

Austin, J. L., Quand dire, c'est faire, Paris, Seuil, 1962.

Axtell, H. J., The Deification of Abstract Ideas in Roman Literature and Inscriptions, Diss., University of Chicago, Chicago, 1907.

BADEl, C., La Noblesse de l'Empire romain. Les masques et la vertu, Seyssel, Champ Vallon, 2005.

Baier, T., «Lucilius und die griechischen Wörter» in Manuwald, G. (éd.), Der Satiriker Lucilius und seine Zeit, Munich, C. H. Beck, 2001, p. 37-50.

Bакноuche, B. (éd.), L'Ancienneté chez les anciens, Montpellier, Université de Montpellier III, 2003, 2 vol.

Baldwin, B., "Greek in Cicero's Letters », Acta Classica, 35, 1992, p. 1-17.

Balmaceda, C. E., “'Virtus Romana' en el siglo I a.C. », Gerión, 25 (1), 2007, p. 285-303.

Balsdon, J. P. V. D., «The Veracity of Caesar», G\&R, 4, 1957, p. 19-28. , "Auctoritas, dignitas, otium», CQ, 10, 1960, p. 43-50.

Baltrusch, E., Regimen morum. Die Reglementierung des Privatlebens der Senatoren und Ritter in der römischen Republik und frühen Kaiserzeit, Munich, C. H. Beck, 1988.

Bandelli, G., «P. Cornelio Scipione, prognatus Publio $\left(C I L \mathrm{I}^{2}, 10\right)$ », Epigraphica, 37, 1975, p. 84-99. 
Baratin, M. et Desbordes, F., L'Analyse linguistique dans l'Antiquité classique. I. Les théories, Paris, C. Klincksieck, 1981.

Bardon, H., "Q. Lutatius Catulus et son 'cercle littéraire' », Études classiques, 18,1950 , p. $145-164$.

"L'honnêteté à Rome : du De officiis à La Rochefoucauld» in GAREAU, E. (éd.), Valeurs antiques et temps modernes, Ottawa, Éditions de l’Université d'Ottawa, 1972, p. 128-140.

BARIgAzZI, A., "Sul concetto epicureo della sicurezza esterna » in Syzètèsis. Studi sull'epicureismo greco e latino offerti a M. Gigante, Naples, G. Macchiaroli, 1983, vol. 1, p. 73-92.

Baroja, J. C., "Honour and Shame : A Historical Account of Several Conflicts » in Peristiany, J. G. (éd.), Honour and Shame. The Values of Mediterranean Society, Londres, Weidenfeld \& Nicolson, 1966, p. 79-95.

Barton, C. A., "Savage Miracles : the Redemption of Lost Honor in Roman Society and the Sacrament of the Gladiator and the Martyr», Representations, 45, 1994, p. 41-71.

-, Roman Honor : the Fire in the Bones, Berkeley, University of California Press, 2001.

Bastien, J.-L., Le Triomphe romain et son utilisation politique à Rome aux trois derniers siècles de la République, Rome, E.F.R., 2007.

Battisti, M., "Metafore e similitudini in Lucrezio. Funzione e rapporti reciproci", Quaderni dell'Istituto di filologia latina, 4, 1976, p. 75-91.

BAYET, J., Histoire politique et psychologique de la religion romaine, Paris, Payot, 1957.

Baylon, C. et Mignot, X., Initiation à la sémantique du langage, réimpr., Paris, A. Colin, 2007.

Beard, M., "Priesthood in the Roman Republic» in Beard, M. et North, J. (éds.), Pagan Priests : Religion and Power in the Ancient World, Ithaca, Cornell University Press, 1990, p. 17-48.

The Roman Triumph, Cambridge (MA), Harvard University Press, 2007.

Веск, H., Karriere und Hierarchie : die Römische Aristokratie und die Anfänge des cursus honorum in der mittleren Republik, Berlin, Akademie Verlag, 2005.

Becker, C., "Sallust», ANRW, I, 3, 1973, p. 720-754.

Beckmann, F., Geographie und Ethnographie in Caesars Bellum Gallicum, Dortmund, Ruhfus, 1930.

Bell, B. M., "The Contribution of Julius Caesar to the Vocabulary of Ethnography », Latomus, 54, 1995, p. 753-767.

Bell, D. A., "La critique de l'honneur à la fin du siècle des Lumières : ses origines et ses conséquences » in Drévillon, H. et Venturino, D. (éds.), Vivre et penser l'honneur à l'époque moderne, Rennes, P.U.R., 2011, p. 143-149.

Bell, S. et Hansen, I. L. (éds.), Role Models in the Roman World. Identity and Assimilation, Ann Arbor, University of Michigan Press, 2008.

Benedict, R., Le Chrysanthème et le sabre, Arles, Picquier, 1995.

Benferhat, Y., Ciues Epicurei. Les Épicuriens et l'idée de monarchie à Rome et en Italie de Sylla à Octave, Bruxelles, Latomus, 2005.

Benveniste, É., Noms d'agent et noms d'action en indo-européen, Paris, A. Maisonneuve, 1948. 
« Don et échange dans le vocabulaire indo-européen », L'Année sociologique, 3, 1948-1949, p. 7-20.

, "Le sens du mot emolumentum », Latomus, 8, 1949, p. 3-7.

, Problèmes de linguistique générale, Paris, Gallimard, 1966, 2 vol.

—_ Le Vocabulaire des institutions indo-européennes, Paris, Minuit, 1969, 2 vol.

Benz, L., "Megaronides Censorius - Eine anticatonische Konzeption im plautinischen Trinummus ? » in BLÄNSDORF, J. (éd.), Theater und Gesellschaft im Imperium Romanum, Tübingen, Francke, 1990, p. 55-68.

BÉRANGER, J., Recherches surl'aspect idéologique du principat, Bâle, F. Reinhardt, 1953.

Berrendonner, C., «La formation de la tradition sur M'. Curius Dentatus et C. Fabricius Luscinus : un homme nouveau peut-il être un grand homme ? " in Coudry, M. et SPÄTH, T. (éds.), L'Invention des grands hommes de la Rome ancienne, Paris, De Boccard, 2001, p. 97-116.

Bettini, M., "Mos, mores und mos maiorum : Die Erfindung der 'Sittlichkeit' in der römischen Kultur » in Braun, M., Haltenhoff, A. et Mutschler, F.-H. (éds.), Moribus antiquis res stat Romana. Römische Werte und römische Literatur im 3. und 2. Jh. v. Chr., Munich, K. G. Saur, 2000, p. 303-352.

_. "Death and its Double. Imagines, Ridiculum and Honos in the Roman Aristocratic Funeral » in Mustakallio, K., Hanska, J., Sainio, H.-L. et al. (éds.), Hoping for Continuity: Childhood, Education and Death in Antiquity and the Middle Ages, Rome, Institutum Romanum Finlandiae, 2005, p. 191-202.

Bianchi Biandinelli, R. Rome, le centre du pouvoir, Paris, Gallimard, 1969.

Bianco, O., Terenzio. Problemi e aspetti dell'originalità, Rome, Ateneo, 1962.

BIEBER, M., "Honos and Virtus », AJA, 49, 1945, p. 25-34.

Blake, M. E. et Van Deman, E. B., Ancient Roman Construction in Italy from the Prehistoric Period to Augustus, Washington, Carnegie Institution, 1947.

BlänSDORf, J., «Plautus » in LefÈvRe, E. (éd.), Das römische Drama, Darmstadt, Wissenschaftliche Buchgesellschaft, 1978, p. 135-222.

Bleicken, J., Lex publica. Gesetz und Recht in der römischen Republik, Berlin, W. De Gruyter, 1975.

BLoK, A., «Rams and Billy-goats : a Key to the Mediterranean Code of Honour », Man, 16, 1981, p. 427-440.

Blösel, W., "Von der Familientradition zum Nobilitätsethos. Die Geschichte des Begriffes mos maiorum von den Anfängen bis zu Cicero » in Linke, B. et Stemmler, M. (éd.), Mos maiorum. Untersuchungen zu den Formen der Identitätsstiftung und Stabilisierung in der römischen Republik, Stuttgart, F. Steiner, 2000, p. 25-97.

Blümlein, C., "Zum Wortspiele onus-honor», Archiv für lateinische Lexikographie, 8, 1893, p. 586.

Boehringer, S., "Sexe, genre, sexualité: mode d'emploi (dans l'Antiquité)», Kentron, 21, 2005, p. 83-110.

Bolaffi, E., «I proemi delle monografie di Sallustio », Athenaeum, 16, 1938, p. 128-157.

Bonfante-Warren, L., "Roman Triumphs and Etruscan Kings. The Changing Face of the Triumph », JRS, 60, 1970, p. 49-66.

Bonnefond-Coudry, M., Le Sénat de la République romaine de la guerre d'Hannibal à Auguste, Rome, E.F.R., 1989. 
BounEaU, C., "Les ingénieurs à la recherche de la considération sociale en Europe occidentale, du milieu du $\mathrm{XIX}^{\mathrm{e}}$ siècle au milieu du $\mathrm{XX}^{\mathrm{e}}$ siècle» in Pontet, J. (éd.), À la recherche de la considération sociale, Bordeaux, MSHA, 1999, p. 185-208.

Bourdieu, P., Passeron, J.-C., La Reproduction. Éléments pour une théorie du système d'enseignement, Paris, Minuit, 1970.

Bourdieu, P., Le Sens pratique, Paris, Minuit, 1980.

_., Raisons pratiques, Paris, Seuil, 1994.

, Esquisse d'une théorie de la pratique, Paris, Seuil, 2000.

, Trois études d'ethnologie kabyle, Paris, Seuil, 2000.

, Langage et pouvoir symbolique, Paris, Seuil, 2001.

Bourne, F. C., «Caesar the Epicurean », $C W, 70,1977$, p. 417-432.

BoyancÉ, P., "Aedes Catuli », MEFRA, 57, 1940, p. 64-71.

_. "Lucrèce et son disciple », REA, 1950, p. 212-233.

, Lucrèce et l'épicurisme, Paris, P.U.F., 1963.

, «Les Romains peuple de la Fides » in Études sur la religion romaine, Paris, 1972, p. 135-152.

Braun, M., "Moribus vivito antiquis ! Bemerkungen zur Moral in Plautus' Trinummus » in Braun, M., Haltenhoff, A. et Mutschler, F.-H. (éds.), Moribus antiquis res stat Romana. Römische Werte und römische Literatur im 3. und 2. Jh. v. Chr, Munich, K. G. Saur, 2000, p. 185-203.

, "Mos maiorum und humanitas bei Terenz» in Braun, M., Haltenhoff, A. et Mutschler, F.-H. (éds.), Moribus antiquis res stat Romana. Römische Werte und römische Literatur im 3. und 2. Jh. v. Chr, Munich, K. G. Saur, 2000, p. 205-215.

Braun, M., Haltenhoff, A. et Mutschler, F.-H. (éds.), Moribus antiquis res stat Romana. Römische Werte und römische Literatur im 3. und 2. Jh. v. Chr., Munich, K. G. Saur, 2000.

Bréal, M. et Bailly, A., Dictionnaire étymologique latin, $4^{\text {e }}$ éd., Paris, C. Klincksieck, 1967.

Breeze, D. J., «Pay Grades and Ranks below the Centurionate », JRS, 61, 1971, p. 130-135.

Brennan, T. C., "Triumphus in Monte Albano» in Wallace, R. W. et Harris, E. M. (éds.), Transitions to Empire. Essays in Greco-Roman History, 360-146 B. C., in honor of E. Badian, Norman, University of Oklahoma Press, 1996, p. 315-337.

Brezina, M., Ehre und Ehrenschutz im nationalsozialistischen Recht, Augsburg, $\mathrm{AV}, 1987$.

Brilliant, R., "'Let the Trumpets roar !' The Roman Triumph» in Bergmann, B. et Kondoleon, C. (éds.), The Art of Ancient Spectacle, New Haven, Yale University Press, 1999, p. 221-228.

BrizzI, «Honos et Virtus, Fortuna Huiusce Diei. Idéologies et propagande au dernier siècle de la République» in Le BoHec, Y.(éd.), État et société aux deux derniers siècles de la République romaine. Hommage à François Hinard, Paris, De Boccard, 2010, p. 13-22.

Brugnol, G., «Funzione e valore del lavoro artistico in ambiente romano dell'età arcaica ", Index, 11, 1982, p. 3-18.

Brunschwig, J., "Le modèle conjonctif» in Études sur les philosophies hellénistiques, Paris, P.U.F., 1995, p. 161-187. 
Brunt, P. A., «Amicitia in the Late Roman Republic », PCPhS, 11, 1965, p. 1-20. «Nobilitas and Nouitas», JRS, 72, 1982, p. 1-17.

BüchNer, K., "Altrömische und horazische virtus» in OpPERMANN, H. (éd.), Römische Wertbegriffe, Darmstadt, Wissenschaftliche Buchgesellschaft, 1967, p. 376-401.

Das Theater des Terenz, Heidelberg, C. Winter, 1974.

"Vtile und honestum » in BüchNer, K. (éd.), Studien zur römischen Literatur.

Band IX, Wiesbaden, F. Steiner, 1978, p. 111-127.

, Sallust, $2^{\mathrm{e}}$ éd., Heidelberg, C. Winter, 1982.

Burckhardt, L., "The Political Elite of the Roman Republic : Comments on Recent Discussion of the Concepts nobilitas and homo nouus ", Historia, 39, 1990, p. 77-99.

Burton, P. J., Amicitia in Roman Social and International Relations (350-146 B.C.), Ph. D., University of Maryland, College Park, 2000.

BütTnER, A., «Untersuchungen über Ursprung und Entwicklung von Auszeichnungen im römischen Heer», Bonner Jahrbücher, 157, 1957, p. 127-180.

CAIRns, D. L., Aidôs. The Psychology and Ethics of Honour and Shame in Ancient Greek Literature, Oxford, Clarendon Press, 1993.

Calabi Limentani, I., Epigrafia latina, 4e éd., Milan, Cisalpino, 1991.

Calboli, G., Cornificiana 2. L'autore e la tendenza politica della Rhetorica ad Herennium, Bologne, Tipografia Compositori, 1965.

_ «Die Episode des Tribunen Q. Caedicius (Cato, Orig. frg. 7-43 Peter)», Maia, 48, 1996, p. 1-32.

_. Marci Porci Catonis Oratio Pro Rhodiensibus. Catone, l'oriente greco e gli imprenditori romani, 2e éd., Bologne, Pàtron, 2003.

Callier, F., «À propos des Adelphes de Térence : le personnage d'Hégion et la morale aristocratique», Latomus, 41, 1982, p. 517-527.

_. "Einige Bemerkungen über das ius und das aequum bei Terenz» in BlänsDorf, J. (éd.), Theater und Gesellschaft im Imperium Romanum, Tübingen, 1990, p. 81-92.

Campanile, E., "La Gallia di Cesare» in Poli, D. (éd.), La cultura in Cesare, Rome, Il Calamo, 1993, vol. 1, p. 17-28.

Campbell, J. K., Honour, Family and Patronage, Oxford, Clarendon Press, 1964. , "Honour and the Devil» in Peristiany, J. G. (éd.), Honour and Shame. The Values of Mediterranean Society, Londres, Weidenfeld \& Nicolson, 1966, p. 139-170.

CAmpI, A., "La clementia di Cesare nel De bello Gallico» in Sord, M.(éd.), Amnistia, perdono e vendetta nel mondo antico, Milan, 1997, p. 253-270.

Cancelli, F., "Saggio sul concetto di officium in diritto romano », RISG, 19571958, p. 351-402.

CANFora, L., "La première réception de Lucrèce à Rome» in Monet, A. (éd.), Le Jardin romain. Épicurisme et poésie à Rome. Mélanges offerts à Mayotte Bollack, Lille, Presses de l'Université Lille III, 2003, p. 43-50.

CARdascia, G., "L'apparition dans le droit des classes d'honestiores et d'humiliores ", $R D, 1950$, p. 305-337 et 461-485.

CÈBE, J.-P., «Le niveau culturel du public plautinien », $R E L, 38,1960$, p. 101106.

, La Caricature et la parodie dans le monde romain antique des origines à Juvénal, Paris, De Boccard, 1966. 
Cerami, P., "Aequum iudicium e 'giusto processo' : prospettive romane e moderne », ASGP, 46, 2000, p. 115-130.

Chalmers, W. R., "Plautus and his Audience» in Dudley, D. R. et Dorey, T. A. (éds.), Roman Drama, Londres, Routledge, 1965, p. 21-50.

Chantraine, P., Dictionnaire étymologique de la langue grecque, Paris, C. Klincksieck, 1968.

Chauchadis, C., Honneur, morale et société dans l'Espagne de Philippe II, Paris, CNRS, 1984.

Chauvaud, F., «Les experts judiciaires au XIX ${ }^{\mathrm{e}}$ siècle : un groupe social en quête de reconnaissance» in PonTET, J. (éd.), À la recherche de la considération sociale, Bordeaux, MSHA, 1999, p. 79-88.

Сhomarat, J., "La mythologie de Lucrèce» in Martin, P.-M. et Ternes, C. M. (éds.), La mythologie, clef de lecture du monde classique : hommage à $R$. Chevallier, Tours, Centre de recherches A. Piganiol, 1986, vol. 1, p. 53-64.

Chouet, M., Les Lettres de Salluste à César, Paris, Les Belles Lettres, 1950.

CHristes, J., Der frühe Lucilius : Rekonstruktion und Interpretation des XXVI. Buches sowie von Teilen des XXX. Buches, Heidelberg, C. Winter, 1971. "Lucilius» in Adamietz, J. (éd.), Die römische Satire, Darmstadt, Wissenschaftliche Buchgesellschaft, 1986, p. 57-122.

Christol, A., "De l'accent phonologique à la suffixation : les thèmes en *-sen latin» in Bammesberger, A. et Heberlein, F. (éds.), Akten des VIII internationalen Kolloquiums zur lateinischen Linguistik, Heidelberg, C. Winter, 1996, p. 78-93.

CiafFI, V., «Il pensiero filosofico di Sallustio » in CiafFI, V. (éd.), Scritti inediti o rari, Turin, Giappichelli, 1978, p. 161-173.

Ciccolini, L., «Honte et conversion chez Tertullien et Cyprien » in Alexandre, R., GuÉRIN, C. et JАсотот, M. (éds.), Rubor et pudor. Vivre et penser la honte à Rome, Paris, Éditions rue d'Ulm, 2012, p. 99-117.

Cichorius, C., Untersuchungen zu Lucilius, Berlin, Weidmann, 1908.

Ciulei, G., L'Équité chez Cicéron, Amsterdam, A. M. Hakkert, 1972.

Clark, A. J., Divine Qualities. Cult and Community in Republican Rome, Oxford, Oxford University Press, 2007.

Classen, C. J., "Poetry and Rhetoric in Lucretius» in Classen, C.J. (éd.), Probleme der Lukrezforschung, Hildesheim, G.Olms, 1986, p.331-372.

, «Virtutes Romanorum nach dem Zeugnis der Münzen republikanischer Zeit », MDAI (R), 93, 1986, p. 257-279.

Clay, D., "An Anatomy of Lucretian Metaphor » in Giannantoni, G. et Gigante, M. (éds.), Epicureismo greco e romano : atti del congresso internazionale : Napoli, 19-26 maggio 1993, Naples, Bibliopolis, 1996, vol. 2, p. 779-793.

Clemente, G., "Lucilio e la società romana », Index, 13, 1985, p. 47-62.

Coarelli, F., "L'identificazione dell'Area Sacra dell'Argentina», Palatino, 12 (4), 1968, p. 365-373. , «La porta trionfale e la via dei trionfi », DArch, 2, 1968, p. 55-103. "Il sepolcro degli Scipioni », DArch, 6 (1), 1972, p. 36-106.

"Frammento di affresco dall'Esquilino con scena storica ", in Affreschi romani dalle raccolte dell'antiquarium comunale, Rome, 1976, p. 13-21. ,Il foro romano, $3^{e}$ éd., Rome, Quasar, 1992, 2 vol. 
«Il complesso pompeiano di Campo Marzio e la sua decorazione scultorea » in CoARelli, F. (éd.), Revixit ars. Arte e ideologia a Roma. Dai modelli ellenistici alla tradizione repubblicana, Rome, Quasar, 1996, p. 360-381. "Le théâtre de Pompée », DHA, 23 (2), 1997, p. 105-124.

, Guide archéologique de Rome, Paris, Hachette, 1998.

Coffey, M., Roman Satire, Londres, Bristol Classical Press, 1989.

Cogrossi, C., "Gli onori a Cesare nella tradizione storiografica e nelle monete del 44 a. C. », CISA, 3, 1975, p. 136-156.

Coleman-Norton, P. R., "Philosophical Aspects of Early Roman Drama », CPh, 31, 1936, p. 320-337.

Collart, J., Varron, grammairien latin, Paris, Les Belles Lettres, 1954.

__ "À propos du mot auctoritas », Helikon, 1, 1961, p. 211-216.

—_ "Quelques remarques sur l'emploi prépositionnel de gratia chez les comiques " in Collart, J. (éd.), Varron, grammaire antique et stylistique latine, Paris, Les Belles Lettres, 1978, p. 293-297.

Collins, J. H., "Caesar as Political Propagandist», ANRW, I, 1, 1972, p. 922966.

Combìs, R., Imperator. Recherches sur l'emploi et la signification du titre d'imperator dans la Rome républicaine, Thèse principale de doctorat, Université de Paris (Sorbonne), Paris, 1966.

Comerci, G., "Carmen, occentatio ed altre voci magico-diffamatorie delle XII Tavole a Cicerone », BStudLat, 7, 1977, p. 287-306.

_. "Humanitas, liberalitas, aequitas : nuova paideia e mediazione sociale negli Adelphoe di Terenzio », BStudLat, 24 (1), 1994, p. 3-44.

Compagno, B., "Gloria nelle Epistulae ad Caesarem e nelle monografie di Sallustio » in Studi di filologia classica in onore di Giusto Monaco, Palerme, Università di Palermo, 1991, vol. 2, p. 869-877.

Coppola, G., Gaio Lucilio, cavaliere e poeta, Bologne, N. Zanichelli, 1941.

Corbeill, A. P., Controlling Laughter : Political Humor in the Late Roman Republic, Princeton, Princeton University Press, 1996.

_. "Dining Deviants in Roman Political Invective» in Hallett, J. P. et Skinner, M. B. (éds.), Roman Sexualities, Princeton, Princeton University Press, 1997, p. 99-128.

Nature Embodied. Gesture in Ancient Rome, Princeton, Princeton University Press, 2004.

Cordier, P., «Les habits grecs du baigneur romain» in Dupont, F. et ValetteCagnac, E. (éds.), Façons de parler grec à Rome, Paris, Belin, 2005, p. 81102.

, Nudités romaines. Un problème d'histoire et d'anthropologie, Paris, Les Belles Lettres, 2005.

Coudry, M., "Camille : construction et fluctuations de la figure d'un grand homme » in Coudry, M. et Sрӓтн, T. (éds.), L'Invention des grands hommes de la Rome ancienne, Paris, De Boccard, 2001, p.47-81.

Coudry, M. et Späth, T. (éds.), L'Invention des grands hommes de la Rome antique, Paris, De Boccard, 2001.

Coulter, C. C., «Caesar's Clemency», CJ, 26, 1931, p. 513-524.

Courtney, E. (éd.), Archaic Latin Prose, Atlanta, Scholars, 1999.

Cox, W., «Didactic Poetry : Lucretius» in Classen, C. J. (éd.), Probleme der Lukrezforschung, Hildesheim, G. Olms, 1986, p. 221-235. 
Crawford, M. H., "Roman Imperial Coin Types and the Formation of Public Opinion » in Brooker, C. N. L., Stewart, B. H. I. H., Pollard, J. G. et al. (éds.), Studies in Numismatic Method Presented to P. Grierson, Cambridge, Cambridge University Press, 1983, p.47-64.

, Roman Statutes, Londres, Institute of classical studies, 1996, 2 vol.

Crawford, O. C., "Laudatio funebris », CJ, 37, 1941, p. 17-27.

Crema, L., L'architettura romana, Turin, Società Editrice Internazionale, 1959 (Enciclopedia classica, sezione III, vol. XII).

Croisille, J.-M., La peinture romaine, Paris, Picard, 2005.

Cugusi, P., «Plauto e Catone», BStudLat, 21, 1991, p. 291-305.

Cupaiuolo, G., Terenzio. Teatro e società, Naples, Loffredo, 1991.

Curti, E., «From Concordia to the Quirinal» in Bispham, E. et Smith, C. (éds.), Religion in Archaic and Republican Rome and Italy, Londres, Routledge, 2000, p. 77-91.

Cusin-Berche, F., «Le lexique en mouvement : création lexicale et production sémantique ", Langages, 136, 1999, p. 5-26.

D’Agostino, V., «La Fides Romana », RSC, 9 (1), 1945, p. 73-86.

D'Arms, J. H., Commerce and Social Standing in Ancient Rome, Cambridge (MA), Harvard University Press, 1981.

"The Roman Conuiuium and the Idea of Equality» in Murray, O. (éd.), Sympotica: a Symposium on the Symposion, Oxford, Clarendon Press, 1990, p. 308-320.

Dahlmann, J. H., «Clementia Caesaris », NJW, 1934, p. 17-26.

Dangel, J., «Les mots suffixés en -tudo chez Accius : étude stylisticolinguistique» in Lavency, M. et Longrée, D. (éds.), Actes du ve colloque de linguistique latine, Louvain-la-Neuve / Borzée, 31 mars - 4 avril 1989, Louvain, Peeters, 1989, p. 91-102.

Daube, D., "Ne quid infamandi causa fiat. The Roman Law of Defamation » in Moschetti, G. (éd.), Atti del congresso internazionale di diritto romano e di storia del diritto, Milan, 1951, p. 411-450.

Daude, J., "Les substantifs abstraits de qualité » in Kircher-Durand, C. (éd.), Grammaire fondamentale du latin, tome IX. Création lexicale: la formation des noms par dérivation suffixale, Louvain, Peeters, 2002, p. 225-305.

DAvid, J.-M., « Maiorum exempla sequi : l'exemplum historique dans les discours judiciaires de Cicéron » in David, J.-M. et Berloz, J. (éds.), Rhétorique et histoire. L'exemplum et le modèle de comportement dans le discours antique et médiéval, Rome, E.F.R., 1980, p. 67-86.

, Le Patronat judiciaire au dernier siècle de la République romaine, Rome, E.F.R., 1992.

, «Les enjeux de l'exemplarité à la fin de la République et au début du principat » in DAVID, J.-M. (éd.), Valeurs et mémoire à Rome. Valère Maxime ou la vertu recomposée, Paris, De Boccard, 1998, p.9-17.

, La République romaine de la deuxième guerre punique à la bataille d'Actium. 218-31, Paris, Seuil, 2000.

, "Les étapes de la construction de la figure de Coriolan» in CoudRY, M. et Spätн, T. (éds.), L'Invention des grands hommes de la Rome ancienne, Paris, De Boccard, 2001, p. 17-25.

(éd.), Valeurs et mémoire à Rome. Valère Maxime ou la vertu recomposée, Paris, De Boccard, 1998. 
David, J.-M., Demougin, S., Deniaux, E. et al., "Le Commentariolum petitionis de Quintus Cicéron : état de la question et étude prosopographique», $A N R W, \mathrm{I}, 3$, 1973, p. 239-277.

De Lorenzi, A., "Il viaggio di Lucilio al 'fretum Siculum' ed alcuni allusioni oraziane », Il Mondo Classico, 3, 1933, p. 337-351.

De Romilly, J., "Le thème du prestige dans l'œuvre de Thucydide », Ancient Society, 4, 1973, p. 39-58.

De Rosalia, A., "I sostantivi in -tūdō in L. Accio », ALGP, 11-13, 1974-1976, p. 255-271.

De Salvo, L., "Il giudizio sulla mercatura nel mondo romano », AFLM, 20, 1987, p. 9-32.

De Saussure, F., Cours de linguistique générale, Paris, Payot, 1974.

Debrunner, A., "Honor», IF, 51, 1933, p. 195.

Degl'Innocenti Pierini, R., Studi su Accio, Florence, CLUSF, 1977.

Delbrück, R., Hellenistische Bauten in Latium, Strasbourg, Trübner, 1907, 2 vol.

Della Corte, F., Catone Censore. La vita e la fortuna, Turin, Rosenberg \& Sellier, 1949.

_. Da Sarsina a Roma. Ricerche plautine, 2e éd., Florence, La Nuova Italia, 1967.

Deniaux, E., «De l'ambitio à l'ambitus : les lieux de la propagande et de la corruption électorale à la fin de la République» in Gros, P. et Nicolet, C. (éds.), L'Vrbs. Espace urbain et histoire, Rome, E.F.R., 1987, p. 279-304.

Deschamps, L., «Épidaure ou Rome ? À propos du Curculio de Plaute», Platon, 32-33, 1980-1981, p. 144-177.

_. "Rites funéraires de la Rome républicaine» in Hinard, F. (éd.), La Mort au quotidien dans le monde romain, Paris, De Boccard, 1995, p. 171-180.

Desmouliez, A., "Cupidité, ambition et crainte de la mort chez Lucrèce (De Rerum Natura, III, 59-93) », Latomus, 17, 1958, p. 317-323.

Detienne, M., Comparer l'incomparable, Paris, Seuil, 2000.

Develin, R., "Scipio Africanus Imperator», Latomus, 36, 1977, p. 110-113.

_ " "Religion and Politics at Rome during the Third Century B. C. », JRH, 10, 1978, p. 3-19.

, Patterns in Office-Holding 366-49 B.C, Bruxelles, Latomus, 1979.

The Practice of Politics at Rome, 366-167 B. C., Bruxelles, Latomus, 1985.

Dixon, K. R. et Southern, P., The Roman Cavalry, Londres, Batsford, 1992.

Dobesch, G., Caesars Apotheose zu Lebzeiten und sein Ringen um den Königstitel. Untersuchungen über Caesars Alleinherrschaft, Vienne, Österreichisches Archäologisches Institut, 1966. , «Caesar als Ethnograph», WHB, 31, 1989, p. 18-51.

DodDs, E. R., Les Grecs et l'irrationnel, Paris, Flammarion, 1977.

Dondin-Payre, M., «Homo novus : un slogan de Caton à César? », Historia, 30, 1981, p. 22-81.

Dorothée, S., À l'origine du signe, le latin signum, Paris, L’Harmattan, 2006.

Drerup, H. "Totenmaske und Ahnenbild bei den Römern », MDAI, 87, 1980, p. 81-129.

Drévillon, H. et Venturino, D. (éds.), Vivre et penser l'honneur à l'époque moderne, Rennes, P.U.R., 2011. 
DreXler, H., «Dignitas» in Klein, R. (éd.), Das Staatsdenken der Römer, Darmstadt, Wissenschaftliche Buchgesellschaft, 1966, p. 231-244.

"Honos» in OppermanN, H. (éd.), Römische Wertbegriffe, Darmstadt, Wissenschaftliche Buchgesellschaft, 1967, p. 446-467.

"Gratia» in Politische Grundbegriffe der Römer, Darmstadt, Wissenschaftliche Buchgesellschaft, 1988, p. 159-187.

Politische Grundbegriffe der Römer, Darmstadt, Wissenschaftliche Buchgesellschaft, 1988.

Dubuisson, M., «Le grec à Rome à l'époque de Cicéron. Extension et qualité du bilinguisme », Annales ESC, 47 (1), 1992, p. 187-206.

Ducos, M., "La crainte de l'infamie et l'obéissance à la loi (Cicéron, De republica, V,4,6)», REL, 57, 1979, p. 145-165.

, Les Romains et la loi, Paris, Les Belles Lettres, 1984.

" La condition des acteurs à Rome. Données juridiques et sociales » in BlänSDORF, J. (éd.), Theater und Gesellschaft im Imperium Romanum, Tübingen, 1990, p. 19-33.

"Le tombeau, locus religiosus» in Hinard, F. (éd.), La Mort au quotidien dans le monde romain, Paris, De Boccard, 1995, p 135-144.

, Rome et le droit, Paris, Librairie générale française, 1996.

"Le droit romain et la polémique » in Declerco, G., Murat, M. et Dangel,

J. (éds.), La Parole polémique, Paris, H. Champion, 2003, p. 283-296. , "César et la clémence», ACD, 40-41, 2004-2005, p. 117-127.

Due, O. S., "La position politique de Salluste», $C \& M, 34,1983$, p. 113-139.

DumÉzIL, G., Idées romaines, Paris, Gallimard, 1969. , La Religion romaine archaïque, $2^{\mathrm{e}}$ éd., Paris, Payot, 1974.

Dumont, J.-C. et François-Garelli, M.-H., Le Théâtre à Rome, Paris, Librairie générale française, 1998.

Dunkel, G. E., «Remarks on Code-switching in Cicero's Letters to Atticus », $M H, 57$ (2), 2000, p. 122-129.

Dupont, F., L'Acteur-roi, Paris, Les Belles Lettres, 1986. , «Les morts et la mémoire : le masque funèbre » in La Mort, les morts et l'audelà dans le monde romain, Caen, Centre de publications de l'Université de Caen, 1987, p. 167-172.

, Le Théâtre latin, Paris, A. Colin, 1988.

, Le Citoyen romain sous la République. 509-27 avant J.-C., Paris, Hachette, 1994.

, L'Orateur sans visage. Essai sur l'acteur romain et son masque, Paris, P.U.F., 2000.

, «Plaute 'fils du bouffeur de bouillie' : la palliata est-elle une comédie grecque en latin ? " in Dupont, F. et Valette-Cagnac, E. (éds.), Façons de parler grec à Rome, Paris, Belin, 2005, p. 175-209.

Dupont, F. et Éloi, T., L'Érotisme masculin dans la Rome antique, Paris, Belin, 2001.

Dupont, F. et Valette-Cagnac, E. (éds.), Façons de parler grec à Rome, Paris, Belin, 2005.

DurRY, M., «Laudatio funebris et rhétorique», RPh, 16, 1942, p. 105-114.

Dyck, A. R., A Commentary on Cicero, De Officiis, Ann Arbor, University of Michigan Press, 1996. 
EARL, D. C., «Political Terminology in Plautus », Historia, 9, 1960, p. 235-243. The Political Thought of Sallust, Cambridge, Cambridge University Press, 1961. "Terence and Roman Politics», Historia, 11, 1962, p. 469-485.

- The Moral and Political Tradition of Rome, Londres, Thames \& Hudson, 1967.

Edwards, C., The Politics of Immorality in Ancient Rome, Cambridge, Cambridge University Press, 1993.

_. "Unspeakable Professions : Public Performance and Prostitution in Ancient Rome » in Hallett, J. P. et Skinner, M. B. (éds.), Roman Sexualities, Princeton, Princeton University Press, 1997, p. 66-95.

Ehrhardt, C. T. H. R., "Roman Coin Types and the Roman Public », JNG, 34, 1984, p. 41-54.

EISENHUt, W., Virtus romana. Ihre Stellung im römischen Wertsystem, Munich, W. Fink, 1973.

EISNER, M., Zur Typologie der Grabbauten im Suburbium Roms, Mainz, P. von Zabern, 1986.

Elfassi, J., "De la honte classique à la honte chrétienne ? Quelques réflexions d'après l'œuvre d'Isidore de Séville » in Alexandre, R., Guérin, C. et JAcotot, M. (éds.), Rubor et pudor. Vivre et penser la honte à Rome, Paris, Éditions rue d'Ulm, 2012, p. 119-126.

Elias, N., La Société de cour, Paris, Calmann-Lévy, 1974.

ÉLOI, T., "La sexualité de l'homme romain antique : actualité bibliographique » in Chaperon, S. et Fine, A. (éds.), Utopies sexuelles, Toulouse, Presses Universitaires du Mirail, 2005, p. 167-184.

ERnout, A., Morphologie historique du latin, 3e éd., Paris, C. Klincksieck, 1953. Aspects du vocabulaire latin, Paris, C. Klincksieck, 1954.

—_ Recueil de textes latins archä̈ques, 4e éd., Paris, C. Klincksieck, 1973.

Ernout, A. et Thomas, F., Syntaxe latine, 2 éd., Paris, C. Klincksieck, 1953.

Espigares Pinilla, A., " Claves para la historia de un cultismo : 'honesto'. 1, Antigüedad y Edad Media », $C F C(L), 28$ (2), 2008, p. 65-81.

Evans, E. C., Physiognomonics in the Ancient World, Philadelphie, American Philosophical Society, 1969.

Evans, R. J., «Popillia, mater uestra : a Note on Cicero, de Orat. 2.11.44 », LCM, 17, 1992, p. 35.

FAY, E. F., «Scipionic Forgeries », CQ, 14 (3/4), 1920, p. 163-171.

FEARS, J. R., "The Cult of Virtues and Roman Imperial Ideology », ANRW, II, 17, 2, 1981, p. 827-946.

" "The Theology of Victory at Rome: Approaches and Problems », ANRW, II, 17, 2, 1981, p. 736-826.

Febvre, L., Honneur et patrie, Paris, Perrin, 1996.

FËDorov, N. A., «La genèse de la composante esthétique dans la sémantique du groupe lexical decus-decorum-decere-dignitas (d'après les textes de Cicéron)», VMUfilol, 1, 1981, p. 49-61.

Ferone, C., «Subigit omne Loucanam : a proposito dell'elogio di Scipione Barbato (CIL I $\mathrm{I}^{2}$ 6,7 = ILLRP 309) », Klio, 87 (1), 2005, p. 116-122.

FERrary, J.-L., "Quelques réflexions à propos du Catilina de Salluste», Vita Latina, 80, 1980, p. 17-23.

, "Le idee politiche a Roma nell'epoca repubblicana» in FirPo, L.(éd.), Storia delle idee politiche, economiche e sociali, Turin, UTET, 1982, vol. 1, p. 723-804. 
, Philhellénisme et impérialisme, Rome, E.F.R., 1988.

"The Hellenistic World and Roman Political Patronage » in Cartledge, P., Garnsey, P. et Gruen, E. S. (éds.), Hellenistic constructs, Berkeley, University of California Press, 1997, p. 105-119.

«À propos de deux passages des Philippiques (1, 11-13 et 2, 110). Remarques sur les honneurs religieux rendus à César en 45-44 et sur la politique d'Antoine après les ides de Mars », $A R G, 1,1999$, p. 215-232.

"Res publica restituta et les pouvoirs d'Auguste» in Franchet D'EsPÈreY, S. (éd.), Fondements et crises du pouvoir, Bordeaux, Ausonius, 2003, p. 419-428.

Feuvrier-Prévotat, C., "'Donner et recevoir' : remarques sur les pratiques d'échanges dans le De officiis de Cicéron », DHA, 11 (1), 1985, p. 256-290.

Fiske, G. C., Lucilius and Horace, Madison, 1920.

Flaig, E., «Die pompa funebris. Adlige Konkurrenz und annalistische Erinnerung in der römischen Republik» in OexLe, O. G. (éd.), Memoria als Kultur, Göttingen, Vandenhoeck und Ruprecht, 1995, p. 115-148.

«Keine Performanz ohne Norm - keine Norm ohne Wert. Das Problem der zwingenden Gesten in der römischen Politik» in Haltenhoff, A., Heil, A. et Mutschler, F.-H. (éds.), Römische Werte als Gegenstand der Altertumswissenschaft, Munich, K. G. Saur, 2005, p. 209-221.

Flores, E., Letteratura latina e ideologia del III-II a. C., Naples, Loffredo, 1974. Latinità arcaica e produzione linguistica, Naples, Liguori, 1978.

FlORY, M. B., «Livia and the History of Public Honorific Statues for Women in Rome», TAPhA, 123, 1993, p. 287-308.

Flower, H. I., Ancestor Masks and Aristocratic Power in Roman Culture, Oxford, Clarendon Press, 1996.

, "The Tradition of the Spolia Opima : M. Claudius Marcellus and Augustus », ClAnt, 19, 2000, p. 34-64.

FögEn, T., Patrii sermonis egestas. Einstellungen lateinischer Autoren zu ihrer Muttersprache : ein Beitrag zum Sprachbewußtsein in der römischen Antike, Munich, K. G. Saur, 2000.

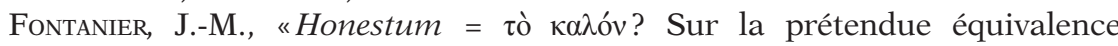

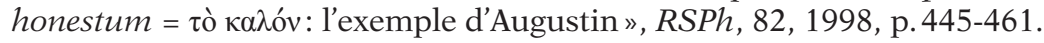

Forbis, E., Municipal Virtues in the Roman Empire. The Evidence of Italian Honorary Inscriptions, Stuttgart, Teubner, 1996.

Forde, N. W., Cato the Censor, Boston, Twayne, 1975.

Fowler, D. P., "Lucretius and Politics» in Griffin, M. et Barnes, J. (éds.), Philosophia togata. Essays on Philosophy and Roman Society, Oxford, Clarendon Press, 1989, p. 120-150.

FräNKel, E., Plautinisches im Plautus, Berlin, Weidmann, 1922.

François-Garelli, M.-H., "Le danseur dans la cité : quelques remarques sur la danse à Rome », REL, 73, 1995, p. 29-43.

Frank, T., «The Scipionic Inscriptions », CQ, 15, 1921, p. 169-171. , «Some Political Allusions in Plautus' Trinummus », AJPh, 53, 1932, p. 152 156.

Freyburger, G., Fides. Étude sémantique et religieuse depuis les origines jusqu'à l'époque augustéenne, Paris, Les Belles Lettres, 1986.

Frischer, B., "Monumenta et Arae Honoris Virtutisque Causa. Evidence of Memorials for Roman Civic Heroes », BCAR, 88, 1982-1983, p. 51-86. 
Fruyt, M., « Nature et limites de la polysémie » in Soutet, O. (éd.), La Polysémie, Paris, P.U.P.S., 2005, p. 23-36.

Fuhrmann, M., "Das Exemplum in der antiken Rhetorik» in Koselleck, R. et Stempel, W. D. (éds.), Geschichte, Ereignis und Erzählung, Munich, Fink, 1973, p. 449-452.

_, «Lizenzen und Tabus der Lachen. Zur sozialen Grammatik der hellenistisch-römischen Komödie» in Preisendanz, W. et Warning, R. (éds.), Das Kömische, Munich, Fink, 1976, p. 65-101.

Fürst, F., Die Bedeutung der auctoritas im privaten und öffentlichen Leben der römischen Republik, Diss., Marburg, 1934.

GabBA, E., «Ricchezza e classe dirigente romana fra III e I sec. a C. », RSI, 93 (3), 1981, p. 541-548.

Gagliardi, D., "Aspetti del teatro comico latino : la 'politica' di Plauto », Le Parole e le Idee, 5, 1963, p. 167-174.

GaILLARD, J., "Auctoritas exempli : pratique rhétorique et idéologie au $\mathrm{I}^{\mathrm{er}} \mathrm{s}$. av. J-C. », REL, 56, 1978, p. 30-34.

Gale, M., Myth and Poetry in Lucretius, Cambridge, Cambridge University Press, 1994.

GARBARINO, G., «Evoluzione semantica dei termini sapiens e sapientia nei secoli III e II a. C. », AAT, 100, 1965-1966, p. 253-284.

_. Roma e la filosofia greca dalle origini alla fine del II secolo a. C., Turin, Paravia, 1973, 2 vol.

_. "Cesare e la cultura filosofica del suo tempo» in Urso, G. (éd.), Cesare : precursore o visionario ?, Pise, ETS, 2010, p. 207-221.

Garbugino, G., «Immagine, mito e allegoria in Lucrezio » in MAntero, T. (éd.), Analysis, II : Varia poetica, Gênes, Facoltà di Lettere, 1989, p. 9-107.

Garland, R., "The Mockery of the Deformed and Disabled in Graeco-Roman Culture » in JäKel, S. et Timonen, A. (éds.), Laughter down the centuries, vol. I, Turku, Turun Yliopisto, 1994, p. 71-84.

Gärtner, U., "Lucilius und die Freundschaft» in Manuwald, G. (éd.), Der Satiriker Lucilius und seine Zeit, Munich, C. H. Beck, 2001, p.90-110.

Gastaldi, S., Bios hairetotatos : generi di vita e felicità in Aristotele, Naples, Bibliopolis, 2003.

Gaudemet, J., Institutions de l'Antiquité, Paris, Sirey, 1967.

Gavoille, É., Ars. Étude sémantique de Plaute à Cicéron, Louvain, Peeters, 2000.

GAzICH, R., "Teoria e pratica dell'exemplum in Quintiliano» in Vincenzo, C. V. (éd.), Aspetti della paideia di Quintiliano, Milan, Vita e Pensiero, 1990, p. 61-141.

Gély, S., Le Pouvoir et l'autorité. Avatars italiens de la notion d'auctoritas d'Auguste à Domitien (27 av. J.-C. - 96 ap. J.-C.), Louvain, Peeters, 1995.

Gelzer, M., Die Nobilität der römischen Republik. Die Nobilität der Kaiserzeit, $2^{\mathrm{e}}$ éd., Stuttgart, Teubner, 1983.

_. Caesar : Politician and Statesman, 4e éd., Cambridge (MA), Harvard University Press, 1994.

Gendre, M. et Loutsch, C., «C. Duilius et M. Atilius Regulus » in Coudry, M. et Sрётн, T. (éds.), L'Invention des grands hommes de la Rome ancienne, Paris, De Boccard, 2001, p. 131-172.

Gernet, L., Anthropologie de la Grèce antique, Paris, Flammarion, 1982.

Giancotti, F., Il preludio di Lucrezio, Messine, G. d’Anna, 1959. 
Giardina, A., "Le marchand» in Giardina, A. (éd.), L'Homme romain, Paris, Seuil, 2002, p. 315-347.

Gigandet, A., Fama deum : Lucrèce et les raisons du mythe, Paris, Vrin, 1998. , "L'interprétation des mythes comme lieu et enjeu de la polémique philosophique dans le De rerum natura» in Algra, K. A., Koenen, M. H. et Schrisvers, P. H. (éds.), Lucretius and his Intellectual Background, Amsterdam, Royal Netherlands Academy of Arts and Sciences, 1997, p. 209-213.

Gildenhard, I., Paideia Romana. Cicero's Tusculan Disputations, Cambridge, Cambridge Philological Society, 2007.

Gizewski, C., "Mores maiorum, regimen morum, licentia. Zur Koexistenz catonischer und plautinischer Sittlichkeitsvorstellungen», Xenia, 22, 1989, p. 81-105.

Godelier, M., "Objet et méthodes de l'anthropologie économique », L'Homme, 5 (2), 1965, p. 32-91.

_. L'Énigme du don, Paris, Flammarion, 1996.

_. La Production des grands hommes. Pouvoir et domination masculine chez les Baruya de Nouvelle-Guinée, Paris, Flammarion, 1996.

Goffman, E., La Mise en scène de la vie quotidienne. 2. Les relations en public, Paris, Minuit, 1973.

, Les Rites d'interaction, Paris, Minuit, 1974.

_. Stigmate. Les usages sociaux des handicaps, Paris, Minuit, 1975.

Goldberg, S. M., "Plautus on the Palatine», JRS, 88, 1998, p. 1-20.

Golfetto, A., «Das Grabmal des C. Publicius Bibulus », Raggi, 5 (2), 1963, p. 9-11.

_. «Das Grabmal des C. Publicius Bibulus in Rom», AW, 10 (4), 1979, p. 56-57.

Goltz, A., "Maiestas sine uiribus - Die Bedeutung der Lictoren für die Konfliktbewältigungsstrategien römischer Magistrate» in LinKE, B. et Stemmler, M. (éds.), Mos maiorum. Untersuchungen zu den Formen der Identitätsstiftung und Stabilisierung in der römischen Republik, Stuttgart, F. Steiner, 2000, p. 237-267.

Goode, W. J., The Celebration of Heroes. Prestige as a Social Control System, Berkeley, University of California Press, 1978.

Goodwin, J. E., "Cicero’s Authority», Ph\&Rh, 34 (1), 2001, p. 38-60.

Gordon, A. E., Album of Dated Latin Inscriptions, Berkeley, University of California Press, 1958, 2 vol.

Gori, S., «Le nozioni di honos e munus in Plinio il Giovane» in PANI, M. (éd.), Epigrafia e territorio, Bari, Edipuglia, 1994, vol. 3, p.353-373.

Görler, W., "Zum Virtus-Fragment des Lucilius », Hermes, 112, 1984, p. 445468.

GraF, F., "The Gestures of Roman Actors and Orators » in Bremmer, J.et Roodenburg, H. (éds.), A Cultural History of Gesture, Oxford, Polity Press, 1991, p. 36-58.

Gratwick, A. S., «A Matter of Substance : Cato's Preface to the De agri cultura », Mnemosyne, 4-55, 2002, p. 41-72.

Green, W. M., "The Status of Actors at Rome », CPh, 28, 1983, p. 301-304.

Greenidge, A. H. J., Infamia. Its Place in Roman Public and Private Law, Oxford, Clarendon Press, 1894. 
GRILLI, A., Il problema della vita contemplativa nel mondo greco-romano, Milan, Fratelli Bocca, 1953. , Lucrezio, Milan, La Goliardica, 1970.

Grimal, P., "Existe-t-il une morale de Plaute ? », BAGB, 4 (4), 1975, p. 485-498. , "Jeu et vérité dans les comédies de Plaute», Dioniso, 46, 1975, p. 137-152. Le Siècle des Scipions. Rome et l'hellénisme au temps des guerres puniques, $2^{\mathrm{e}}$ éd., Paris, Aubier, 1975.

_ _, «Le poème de Lucrèce en son temps » in Gigon, O. (éd.), Lucrèce, Genève, Fondation Hardt, 1977, p. 233-270.

__ «Térence et Aristote à propos de l'Héautontimoroumenos », BAGB, 1979, p. 175-187.

"Analyse du Trinummus et les débuts de la philosophie à Rome ?" in Grimal, P. (éd.), Rome. La littérature et l'histoire, Rome, E.F.R., 1986, vol. 1, p. 283-293.

_ - "Le modèle et la date des Captiui de Plaute» in Grimal, P. (éd.), Rome. La littérature et l'histoire, Rome, E.F.R., 1986, vol. 1, p. 297-314.

Gros, P., "Les premières générations d'architectes hellénistiques à Rome » in L'Italie préromaine et la Rome républicaine. Mélanges offerts à Jacques Heurgon, Paris, De Boccard, 1976, p. 387-410.

_. Architecture et société à Rome et en Italie centro-méridionale aux deux derniers siècles de la République, Bruxelles, Latomus, 1978.

_. «Les statues de Syracuse et les 'dieux' de Tarente», REL, 57, 1979, p. 85114.

Gruen, E. S., The Last Generation of the Roman Republic, Berkeley, University of California Press, 1974.

_., Studies in Greek Culture and Roman Policy, Leiden, Brill, 1990.

—. Culture and National Identity in Republican Rome, Ithaca, Cornell University Press, 1992.

GuÉRIN, C., Persona. L'Élaboration d'une notion rhétorique au Ir siècle av. J.-C., Paris, Vrin, 2009-2011, 2 vol.

Halévi, R., «La pensée politique de l'honneur » in Drévillon, H. et Venturino, D. (éds.), Vivre et penser l'honneur à l'époque moderne, Rennes, P.U.R., 2011, p. 109-126.

Halkin, L., La Supplication d'action de grâces chez les Romains, Paris, Les Belles Lettres, 1953.

Halperin, D. M. (éd.), Before Sexuality. The Construction of Erotic Experience in the Ancient World, Princeton, Princeton University Press, 1990.

Haltenhoff, A., "Wertbegriff und Wertbegriffe» in Braun, M., Haltenhoff, A. et Mutschler, F.-H. (éds.), Moribus antiquis res stat Romana. Römische Werte und römische Literatur im 3. und 2. Jh. v. Chr, Munich, K. G. Saur, 2000, p. 15-29.

HANI, J., "Aidôs personnifiée et sa portée réelle chez les Grecs » in Duchemin, J. (éd.), Mythe et personnification, Paris, Les Belles Lettres, 1980, p. 103-112.

Harmand, J., L'Armée et le soldat à Rome de 107 à 50 avant notre ère, Paris, Picard, 1967.

Harris, W. V., War and Imperialism in Republican Rome 327-70 B. C., Oxford, Clarendon Press, 1985.

Hass, K., "Lucilius und die Frauen» in Manuwald, G. (éd.), Der Satiriker Lucilius und seine Zeit, Munich, C. H. Beck, 2001, p. 111-120. 
Натсн, E., "Theories of Social Honor », American Anthropologist, 91, 1989, p. 341-353.

Hayashi, N., "Die pecunia in der pollicitatio ob honorem», Klio, 71, 1989, p. 383-398.

Heinze, R., "Auctoritas », Hermes, 60, 1925, p. 348-366. , «Fides », Hermes, 64, 1929, p. 140-166.

Hellegouarc'H, J., Le Vocabulaire latin des relations et des partis politiques sous la République, Paris, Les Belles Lettres, 1963.

—, "Le proomium du Bellum Iugurthinum. Actualité et signification politique. », Kentron, 3, 1987, p. 7-16.

Herzfeld, M., "Honour and Shame : Some Problems in the Comparative Analysis of Moral Systems ", Man, 15, 1980, p. 339-351.

Herzog, R. et Schmidt, P. L. (éds.), Handbuch der lateinischen Literatur der Antike, Munich, C.H. Beck, 1989-, 5 vol.

Heurgon, J., Lucilius, Paris, C.D.U., 1959.

Hillard, T. W., "Popilia and 'laudationes funebres' for Women », Antichthon, 35, 2001, p. 45-63.

Hinard, F., "Sur une autre forme de l'opposition entre uirtus et fortuna", Kentron, 3, 1987, p. 17-20.

(éd.), Histoire romaine. Tome I. Des origines à Auguste, Paris, Fayard, 2000.

Hoffmann, Z., "The Parody of the Idea of the Mos Maiorum in Plautus", Oikumene, 3, 1982, p. 217-233.

«Der Wertbegriff honos in den Komödien von Plautus », ACD, 24, 1988, p. 24-35.

HölKeskamp, K.-J., Die Entstehung der Nobilität. Studien zur sozialen und politischen Geschichte der Römischen Republik im 4. Jhdt. v. Chr., Stuttgart, F. Steiner, 1987.

__, "Exempla und mos maiorum : Überlegungen zum kollektiven Gedächtnis der Nobilität» in Senatus Populusque Romanus. Die politische Kultur der Republik, Stuttgart, F. Steiner, 2004, p. 169-198.

_., "Krieg, Konkurrenz und Konsens : die Expansion in Italien und die Entstehung der Nobilität» in Senatus Populusque Romanus. Die politische Kultur der Republik, Stuttgart, F. Steiner, 2004, p. 11-48.

_, Reconstruire une République. La «culture politique» de la Rome antique et la recherche des dernières décennies, Nantes, Les Éditions Maison, 2008.

HöLscher, T., "Die Anfänge römischer Repräsentationskunst», MDAI(R), 85, 1978 , p. $315-357$.

Hooker, J. T., «Homeric Society : A Shame-Culture ?», G\&R, 34 (2), 1987, p. 121-125.

Hopkins, A. G., «On a Misunderstood Passage in the Trinummus of Plautus, v. 642-4 », CR, 9, 1895 , p. 307-309.

Hopkins, K., Death and Renewal, Cambridge, Cambridge University Press, 1983. , «From Shamelesness to Guilt. The Roman Moral Revolution», PCA, 81, 1984, p. 23-24.

Hugoniot, C., « De l'infamie à la contrainte. Évolution de la condition sociale des comédiens sous l'Empire romain" in Hugoniot, C., Hurlet, F. et Milanezi, S. (éds.), Le Statut de l'acteur dans l'Antiquité grecque et romaine, Tours, P.U.F.R., 2004, p. 213-240.

Huizinga, J., Homo ludens : essai sur la fonction sociale du jeu, Paris, Gallimard, 1951. 
Humm, M., Appius Claudius Caecus, Rome, E.F.R., 2005.

Hunter, R., "Philemon, Plautus and the Trinummus», MH, 37, 1980, p. 216230.

Inglebert, H., Gros, P. et Sauron, G., Histoire de la civilisation romaine, Paris, P.U.F., 2005.

ItgenshoRst, T., Tota illa pompa. Der Triumph in der römischen Republik, Göttingen, Vandenhoeck \& Ruprecht, 2005.

Јасотот, M., "L'honneur et la gloire dans les Satires de Lucilius », in Bona, E. et Curnis, M. (éd.), Linguaggi del potere, poteri del linguaggio, Alessandria, Edizioni dell'Orso, 2010, p. 219-232.

"La représentation de Cincinnatus chez Tite-Live : figure morale et mythe républicain ", in Blandenet, M., Chillet, C. et Courrier, C. (éds.), Figures de l'identité. Naissance et destin des modèles communautaires dans le monde romain, Lyon, ENS Éditions, 2011, p. 71-85.

__ "De re publica esset silentium. Pensée politique et histoire de l'éloquence dans le Brutus ", in Aubert, S. (éd.), Prosopographie et rhétorique : le Brutus, paradigme de l'histoire culturelle, Louvain, Peeters, à paraître.

JAL, P., La Guerre civile à Rome. Étude littéraire et morale de Cicéron à Tacite, Paris, P.U.F., 1963.

JAmous, R., Honneur et baraka. Les structures sociales traditionnelles dans le Rif, Paris, Maison des Sciences de l'Homme, 1981.

Janson, T., Latin Prose Prefaces, Stockholm, Almqvist \& Wiksell, 1964.

Jehne, M., "Caesars Bemühungen um die Reintegration der Pompeianer», Chiron, 17, 1987, p. 313-341.

_, "Cato und die Bewahrung der traditionellen Res publica. Zum Spannungsverhältnis zwischen mos maiorum und grieschischer Kultur im zweiten Jahrhundert v. Chr.» in Vogt-Spira, G. et Rommel, B. (éds.), Rezeption und Identität. Die kulturelle Auseinandersetzung Roms mit Griechenland als europäisches Paradigma, Stuttgart, F. Steiner, 1999, p. 115-134.

Jocelyn, H. D., "The Roman Nobility and the Religion of the Republican State», JRH, 4 (2), 1966, p. 89-104.

Joly, R., Le Thème philosophique des genres de vie dans l'Antiquité classique, Bruxelles, Académie royale de Belgique, 1956.

Jope, J., «Lucretius' Psychoanalytic Insight : His Notion of Unconscious Motivation », Phoenix, 37, 1983, p. 224-238.

Jounnna, A., "Recherches sur la notion d'honneur au $\mathrm{xvI}^{\mathrm{e}}$ siècle», Revue d'histoire moderne et contemporaine, 15, 1968, p. 597-623.

Jurewicz, O., "Plautus, Cato der Aeltere und die römische Gesellschaft » in Irmscher, J. et Kumaniecki, K. (éds.), Aus der Altertumswissenschaftlichen Arbeit Volkspolens, Berlin, Akademie Verlag, 1959, p. 52-72.

KASER, M., "Infamia und ignominia in den römischen Rechtsquellen », ZRG, 73, 1956, p. 220-278.

Kaster, R. A., Emotion, Restraint and Community in Ancient Rome, Oxford, Oxford University Press, 2005.

KeEn, R., "Lucretius and his Reader», Apeiron, 19, 1985, p. 1-10.

Kelly, J. M., Studies in the Civil Judicature of the Roman Republic, Oxford, Clarendon Press, 1976.

KiEnast, D., Cato der Zensor, 2éd., Heidelberg, Quelle \& Meyer, 1954. 
KIERDORF, W., Laudatio funebris. Interpretationen und Untersuchungen zur Entwicklung der römischen Leichenrede, Meisenheim am Glan, A. Hain, 1980.

KLeIBer, G., La Sémantique du prototype. Catégories et sens lexical, Paris, P.U.F., 1990.

KuIma, U., Untersuchungen zu dem Begriff Sapientia von der republikanischen Zeit bis Tacitus, Bonn, R. Habelt, 1971.

KLose, F., Die Bedeutung von honos und honestus, Diss., Breslau, 1933. , «Altrömische Wertbegriffe (honos und dignitas)», NJAB, 1938, p. 268-278.

KLucкнонn, C., "Values and Value-Orientations in the Theory of Action» in Parsons, T. et Shils, E. (éds.), Toward a General Theory of Action, Cambridge (MA), Harvard University Press, 1951, p. 388-433.

Knoche, U., « Der römische Ruhmesgedanke» in Oppermann, H. (éd.), Römische Wertbegriffe, Darmstadt, Wissenschaftliche Buchgesellschaft, 1967, p. 420445.

Косн, R., Comment peut-on être Dieu ? La secte d'Épicure, Paris, Belin, 2005.

Koestermann, E., "Das Problem der römischen Dekadenz bei Sallust und Tacitus », $A N R W, \mathrm{I}, 3,1973$, p. 781-810.

Konstan, D., "The Social Themes in Plautus' Aulularia», Arethusa, 10, 1977, p. 307-320.

Kornhardt, H., Exemplum. Eine bedeutungsgeschichtliche Studie, Diss., Göttingen, 1936.

Korpanty, J., "Sallust, Livius und ambitio », Philologus, 127, 1983, p.61-71.

KRENKEL, W., «Römische Satire und römische Gesellschaft», WZRostock, 15, 1966, p. 471-477.

Krostenko, B. A., Cicero, Catullus and the Language of Social Performance, Chicago, University of Chicago Press, 2001.

Kruschwitz, P., «Die Datierung der Scipionenelogien CLE 6 und 7 », ZPE, 122, 1998, p. 273-285.

, Carmina Saturnia Epigraphica, Stuttgart, F. Steiner, 2002.

, "Lehre oder Dichtung ? die archaische didaktische Poesie der Römer » in Horster, M. et Reitz, C. (éds.), Wissensvermittlung in dichterischer Gestalt, Stuttgart, F. Steiner, 2005, p. 115-131.

KüNZL, E., Der römische Triumph. Siegesfeiern im antiken Rom, Munich, C. H. Beck, 1988.

La Penna, A., Sallustio e la 'rivoluzione' romana, Milan, Feltrinelli, 1968. , «Aspetti e conflitti della cultura latina dai Gracchi a Silla», DArch, 4-5, 1970-1971, p. 193-211.

La Regina, A., «L'elogio di Scipione Barbato », DArch, II, 2, 1968, p. 173-190.

La Rocca, E. «Fabio o Fannio. L'affresco medio-repubblicano dell’Esquilino come riflesso dell'arte rappresentativa e come espressione di mobilità sociale », DArch, 2, 1984, p. 31-53.

Lacey, W. K., «Patria potestas » in Rawson, B. (éd.), The Family in Ancient Rome : New Perspectives, Londres, 1986, p. 121-144.

Lahusen, G., "Statuae et imagines » in Hausmann, U., Von Löringhoff, B., Mannsperger, D. et al. (éds.), Praestant interna. Festschrift für Ulrich Hausmann, Tübingen, E. Wasmuth, 1982, p. 101-109. , Untersuchungen zur Ehrenstatue in Rom, Rome, G. Bretschneider, 1983. 
Lamoine, L., "Les lecteurs de l'elogium de Scipion Barbatus », ArchClass, 51 (N.S. 1), 1999-2000, p. 361-368.

LaNA, I., "Terenzio e il movimento filellenico in Roma », RFIC, 75, 1947, p. 44-80 et $155-175$.

Langlands, R., Sexual Morality in Ancient Rome, Cambridge, Cambridge University Press, 2006.

Laqueur, R., "Über das Wesen des römischen Triumphs », Hermes, 44, 1909, p. 215-236.

LatTe, K., Römische Religionsgeschichte, Munich, C. H. Beck, 1960.

Lavagne, H., "Le tombeau, mémoire du mort» in La Mort, les morts et l'audelà dans le monde romain, Caen, Centre de publications de l'Université de Caen, 1987, p. 159-165.

Schmidt, P. L., "Zwischen Werttheorie, Begriffsgeschichte und Römertum. Zur Politisierung eines wissenschaftlichen Paradigmas» in Haltenhoff, A., Heil, A. et Mutschler, F.-H. (éds.), Römische Werte als Gegenstand der Altertumswissenschaft, Munich, K. G. Saur, 2005, p. 3-21.

Leeman, A. D., Orationis ratio. The Stylistic Theories and Practice of the Roman Orators, Historians and Philosophers, Amsterdam, A. M. Hakkert, 1963, 2 vol.

Lefèvre, E., «Saturnalien und Palliata », Poetica, 20, 1988, p. 32-46.

_ _, "Politics and Society in Plautus' Trinummus » in Scodel, R. (éd.), Theater and Society in the Classical World, Ann Arbor, University of Michigan Press, 1993, p. 177-190.

Lehmann, A. et Martin-Berthet, F., Introduction à la lexicologie, 2e éd., Paris, A. Colin, 2005.

Lehmann, W. P., A Gothic Etymological Dictionnary, Leiden, Brill, 1986.

Lehmann, Y., Varron théologien et philosophe romain, Bruxelles, Latomus, 1997.

Lejay, P., Plaute, Paris, Boivin, 1925.

Lendon, J. E., Empire of Honour. The Art of Government in the Roman World, Oxford, Clarendon Press, 1997.

"Spartan Honor» in Hamilton, C. D. et Krentz, P. (éds.), Polis and Polemos. Essays on Politics, War, and History in Ancient Greece in Honor of Donald Kagan, Claremont, Regina, 1997, p. 105-126.

"Roman Honor» in PEAchin, M., The Oxford Handbook of Social Relations in the Roman World, Oxford, Oxford University Press, 2011, p. 377-403.

Lenel, O., Essai de reconstitution de l'édit perpétuel, Paris, L. Larose, 1901, 2 vol.

Lentano, M., «Il dono e il debito. Verso un'antropologia del beneficio nella cultura romana» in Haltenhoff, A., Heil, A. et Mutschler, F.-H. (éds.), Römische Werte als Gegenstand der Altertumswissenschaft, Munich, K. G. Saur, 2005, p. 125-142.

Lepointe, G., "L'occentatio de la loi des XII Tables d'après saint Augustin et Cicéron », RIDA, 2, 1955, p. 287-302.

Lepoutre, D., Coeur de banlieue. Codes, rites et langages, Paris, Odile Jacob, 1997.

Letta, C., "L'Italia dei mores Romani nelle Origines di Catone», Athenaeum, 62,1984, p. 3-30 et 416-439.

Leumann, M., Hofmann, J. B. et Szantyr, A., Lateinische Grammatik, Munich, C. H. Beck, 1963-1979, 3 vol. 
LÉvy, C., Les Philosophies hellénistiques, Paris, Librairie générale française, 1997.

«Lucrèce et les stoïciens » in Poignault, R. (éd.), Présence de Lucrèce : actes du colloque tenu à Tours, 3-5 déc. 1998, Tours, Centre de recherches A. Piganiol, 1999, p. 87-98.

"Lâme et le moi dans les Tusculanes ", REL, 80, 2002, p. 78-94.

Lind, L. R., "The Tradition of Roman Moral Conservatism» in Deroux, C. (éd.), Studies in Latin Literature and Roman History 1, Bruxelles, Latomus, 1979 , p. 7-58.

Linke, B. et Stemmler, M., "Institutionalität und Geschichtlichkeit in der römischen Republik» in Linke, B. et Stemmler, M. (éds.), Mos maiorum. Untersuchungen zu den Formen der Identitätsstiftung und Stabilisierung in der römischen Republik, Stuttgart, F. Steiner, 2000, p. 1-23.

Lintott, A., "Prouocatio. From the Struggle of the Orders to the Principate», ANRW, I, 2, 1972, p. 226-267.

The Constitution of the Roman Republic, Oxford, Clarendon Press, 1999. Violence in Republican Rome, Oxford, Oxford University Press, 1999.

Liscu, M. O., Étude sur la langue de la philosophie morale chez Cicéron, Paris, Les Belles Lettres, 1930.

Litchfield, H. W., "National Exempla Virtutis in Roman Literature », HSCPh, 25,1914 , p. 1-71.

Lloyd-Jones, H., "Ehre und Schande in der griechischen Kultur », $A \& A, 33$, 1987, p. 1-28.

LuCARelli, U., Exemplarische Vergangenheit. Valerius Maximus und die Konstruktion des sozialen Raumes in der frühen Kaiserzeit, Göttingen, Vandenhoeck \& Ruprecht, 2007.

LucE, T. J., «Political Propaganda on Roman Republican Coins (92-82 B. C.) », AJA, 72, 1968, p. 25-39.

Lugli, G., I monumenti antichi di Roma e suburbio, Rome, G. Bardi, 1930, 3 vol.

Roma antica. Il centro monumentale, Rome, G. Bardi, 1946.

Lumpe, A., "Exemplum », RLAC, 6, 1966, p. 1229-1257.

Lund, A. A., "Caesar als Ethnograph», $A U, 39$ (2), 1996, p. 12-23.

MacMullen, R., «Romans in Tears », CPh, 75, 1980, p. 254-255. , Les Rapports entre les classes sociales dans l'Empire romain, 50 av. J.-C.284 ap. J.-C., Paris, Seuil, 1986.

MacQueen, B. D., Plato's Republic in the Monographs of Sallust, Chicago, Bolchazy-Carducci, 1982.

Magdelain, A., Auctoritas principi, Paris, Les Belles Lettres, 1947.

Maier-EichHorn, U., Die Gestikulation in Quintilians Rhetorik, Frankfurt am Main, P. Lang, 1989.

Malitz, J., Ambitio mala. Studien zur politischen Biographie des Sallust, Bonn, R. Habelt, 1975.

Manessy-Guiton, J., Recherches sur les dérivés nominaux à bases sigmatiques en sanscrit et en latin, Dakar, Publications de l'Université, 1963.

Manfredini, A. D., Contributi allo studio della iniuria in età repubblicana, Milan, A. Giuffrè, 1977.

, La diffamazione verbale nel diritto romano, Milan, A. Giuffrè, 1979.

Mannsperger, B., «Libertas - Honos - Felicitas. Zur Prägung des Münzmeisters Palikanus », Chiron, 4, 1974, p. 327-342. 
Marchese, R. R., La morale e il singolo. Individualismo, modelli etici e poesia romana. Lucilio, Orazio, Catullo, Lucrezio, Properzio, Ovidio, Palerme, Palumbo, 1998.

MARINO, R., «Fra diritto e morale : il concetto metagiuridico di beneficium nel trattato senecano » in Rocca, S. (éd.), Latina didaxis, 18, Gênes, Compagnia dai Librai, 2003, p. 79-118.

Mariotti, I., "I grecismi di Lucilio », StudUrb (B), 28, 1954, p. 357-386.

_., Studi luciliani, Florence, La Nuova Italia, 1961.

Marmorale, E. V., Cato maior, 2e éd., Bari, Laterza, 1949.

Marouzeau, J., Quelques aspects de la formation du latin littéraire, Paris, C. Klincksieck, 1949.

Marshall, A. J., "Symbols and Showmanship in Roman Public Life: the Fasces ", Phoenix, 38, 1984, p. 120-141.

Marshall, C. W., The Stagecraft and Performance of Roman Comedy, Cambridge, Cambridge University Press, 2006.

Martin, F., "The Importance of Honorific Statues : a Case-Study », BICS, 41, 1996, p. 53-70.

Martin, R., Pour une logique du sens, Paris, P.U.F., 1983.

Maslakov, G., "Valerius Maximus and Roman Historiography : a Study of the Exempla Tradition ", ANRW, II, 32, 1, 1984, p. 437-496.

Massaro, M., «L'epigramma per Scipione Ispano $\left(C I L \mathrm{I}^{2}, 15\right)$ », Epigraphica, 59, 1997, p. 97-124.

Mattingly, H., «The Roman 'Virtues' », HTR, 30, 1937, p. 103-117.

Mattioli, U. (éd.), Senectus. La vecchiaia nel mondo classico, Bologne, Pàtron, 1995.

Mauss, M., Sociologie et anthropologie, 5e éd., Paris, P.U.F., 1993.

Maxfield, V., The Military Decorations of the Roman Army, Londres, B.T. Batsford, 1981.

Mazzoli, G., "Il frammento enniano Laus alit artis e il proemio al XVI libro degli Annales », Athenaeum, 42, 1964, p. 307-333.

McDonnell, M., Roman Manliness. Virtus and the Roman Republic, Cambridge, Cambridge University Press, 2006.

McGinn, T. A., Prostitution, Sexuality, and the Law in Ancient Rome, Oxford, Oxford University Press, 1998.

MeIER, C., Res publica amissa. Eine Studie zu Verfassung und Geschichte der späten römischen Republik, Wiesbaden, F. Steiner, 1966.

MeIllet, A., Introduction à l'étude comparative des langues indo-européennes,

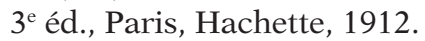

_. Esquisse d'une histoire de la langue latine, $7^{\mathrm{e}}$ éd., Paris, C.Klincksieck, 1966.

Meillet, A. et Vendryes, J., Traité de grammaire comparée des langues classiques, $5^{\mathrm{e}}$ éd., Paris, H. Champion, 1966.

Meister, K., «Die Tugenden der Römer» in Oppermann, H. (éd.), Römische Wertbegriffe, Darmstadt, Wissenschaftliche Buchgesellschaft, 1967, p. $1-22$.

Mellet, S., Joffre, M.-D. et Serbat, G., Grammaire fondamentale du Latin. Le signifié du verbe, Louvain, Peeters, 1994.

Ménard, H., Maintenir l'ordre à Rome (II $e^{e}-I^{e}$ siècles ap. J.-C.), Seyssel, Champ Vallon, 2004.

Meslin, M., L'Homme romain, Paris, Complexe, 1985. 
Meyerson, I., Les Fonctions psychologiques et les oeuvres, Paris, Vrin, 1948.

Michel, A., "Entre Cicéron et Tacite : aspects idéologiques du Catilina de Salluste ", $A C D, 5,1969$, p. 83-91.

, Les Rapports de la rhétorique et de la philosophie dans l'ouvre de Cicéron. Recherches sur les fondements philosophiques de l'art de persuader, $2^{\mathrm{e}}$ éd., Louvain, Peeters, 2003.

Milhous, M. S., Honos and Virtus in Roman Art, Ph. D., Boston University, Boston, 1992.

Millar, F., "The Political Character of the Classical Roman Republic, 200-151 B.C. », JRS, 74, 1984, p. 1-19.

, "Political Power in Mid-Republican Rome : Curia or Comitium ?», JRS, 79, 1989, p. 138-150.

_., The Crowd in Rome in the Late Republic, Ann Arbor, University of Michigan Press, 1998.

Mineo, B., "Philosophie de l'histoire chez Salluste et Tite-Live» in Poignault, R. (éd.), Présence de Salluste, Tours, Centre de recherches A. Piganiol, 1997, p. 45-60.

Miniconi, P.-J., Causa et ses dérivés. Contribution à l'étude du vocabulaire latin, Paris, Les Belles Lettres, 1951.

Minyard, J. D., Lucretius and the Late Republic, Leiden, Brill, 1985.

Mitchell, R. E., Patricians and Plebeians : the Origin of the Roman State, Ithaca, Cornell University Press, 1990.

Mix, E. R., "Cicero and Regulus », $C W, 58,1965$, p. 156-159.

Moatti, C., La Raison de Rome. Naissance de l'esprit critique à la fin de la République (II ${ }^{e}-I^{e r}$ siècle avant Jésus-Christ), Paris, Seuil, 1997.

Molsberger, H. J., Abstrakter Ausdruck im Altlatein, Frankfurt am Main, Athenäum, 1989.

Mommsen, T., Le Droit public romain, 2e éd., Paris, E. Thorin, 1892, 8 vol.

Monaco, G., "Qualche considerazione sullo sfondo politico e sociale del Teatro di Plauto », Dioniso, 43, 1969, p. 301-307.

MonteIL, P., Beau et laid. Contribution à une étude historique du vocabulaire esthétique en latin, Paris, C. Klincksieck, 1964. , Éléments de phonétique et de morphologie du latin, Paris, Nathan, 1970.

Monti, R. C., «Lucretius on Greed, Political Ambition and Society : De Rerum Natura III, 59-86», Latomus, 40, 1981, p. 48-66.

Moore, T. J., The Theater of Plautus, Austin, University of Texas Press, 1998.

Moreau, P., Incestus et prohibitae nuptiae. L'inceste à Rome, Paris, Les Belles Lettres, 2002.

, «Positions du corps, gestes et hiérarchie à Rome» in Moreau, P. (éd.), Corps romains, Grenoble, J. Millon, 2002, p. 179-200.

, "Quem honoris causa appello. L'usage public des noms de personne et ses règles à Rome» in Champeaux, J. et Chassignet, M. (éds.), Aere perennius. Hommage à Hubert Zehnacker, Paris, P.U.P.S., 2006, p. 293-308.

Morel, J.-P., «L'artisan» in Giardina, A. (éd.), L'Homme romain, Paris, Seuil, 2002, p. 277-314.

Morstein-Marx, R., "Dignitas and res publica : Caesar and Republican Legitimacy» in HöLKeskamp, K.-J. (éd.), Eine politische Kultur (in) der Krise ? Die "letzte Generation » der römischen Republik, Münich, Oldenbourg, 2009, p. 115-140. 
Morton Braund, S., «Declamation and Contestation in Satire» in DominiK, W. J. (éd.), Roman Eloquence. Rhetoric in Society and Literature, Londres, Routledge, 1997, p. 147-165.

Moussy, C., Gratia et sa famille, Paris, P.U.F., 1966.

_ - «Les métaphores lexicalisées et l'analyse sémique» in LAVENCY, M.et Longrée, D. (éds.), Actes du vìme colloque de linguistique latine, Louvain, CILL, 1989, p. 309-319.

Mulgan, R. G., "Was Caesar an Epicurean ?", $C W$, 72, 1979, p. 337-339.

Murray, O. et Tecusan, M. (éds.), In vino veritas, Londres, British School at Rome, 1995.

Mutschler, F.-H., Erzählstil und Propaganda in Caesars Kommentarien, Heidelberg, C. Winter, 1975.

«Norm und Erinnerung : Anmerkungen zur sozialen Funktion von historischem Epos und Geschichtsschreibung im 2. Jh. v. Chr.» in BRAUN, M., Haltenhoff, A. et Mutschler, F.-H. (éds.), Moribus antiquis res stat Romana. Römische Werte und römische Literatur im 3. und 2. Jh. v. Chr., Munich, K. G. Saur, 2000, p. 87-124.

"Virtus und kein Ende?", Poetica, 32, 2000, p. 23-49.

—, "Caesars Kommentarien im Spannungsfeld von sozialer Norm und individuellem Geltungsanspruch » in Haltenhoff, A., Heil, A. et Mutschler, F.-H. (éds.), O tempora, o mores ! Römische Werte und römische Literatur in den letzten Jahrzehnten der Republik, Munich, K. G. Saur, 2003, p. 93117. , «Virtus 2002: zurRolle der'römischen Werte' in derAltertumswissenschaft », Gymnasium, 110 (4), 2003, p. 363-385.

NARDo, D., Il Commentariolum petitionis. La propaganda elettorale nella 'ars' di Quinto Cicerone, Padoue, Liviana Editrice, 1970.

Nash, E., Bildlexikon zur Topographie des Antiken Rom, Tübingen, E. Wasmuth, 1962, 2 vol.

Nassiet, M., La Violence, une histoire sociale. France, XVI $-X V I I I^{e}$ siècles, Seyssel, Champ Vallon, 2011.

"L'honneur au XVIe siècle : un capital collectif» in H. Drévillon et D. Venturino (éds.), Vivre et penser l'honneur à l'époque moderne, Rennes, P.U.R., 2011, p. 71-90.

Naudet, J., De la noblesse et des récompenses d'honneur chez les Romains, Paris, A. Durand, 1863.

Nicols, J., "Zur Verleihung öffentlicher Ehrungen in der römischen Welt», Chiron, 9, 1979, p. 243-260.

Nicolas, C., Vtraque lingua. Le calque sémantique : domaine gréco-latin, Louvain, Peeters, 1996.

Nicolet, C., Les Idées politiques à Rome sous la République, Paris, A. Colin, 1964.

, L'Ordre équestre à l'époque républicaine (312-43 av. J.-C.), réimpr. de la 1 ère éd., Paris, De Boccard, 1974, 2 vol.

"L'idéologie du système centuriate et l'influence de la philosophie politique grecque» in La filosofia greca e il diritto romano, Rome, Accademia nazionale dei Lincei, 1976, p. 111-137.

"Le cens sénatorial sous la République et sous Auguste», JRS, 66, 1976, p. 20-38. 
Le Métier de citoyen dans la Rome républicaine, 2e éd., Paris, Gallimard, 1976.

Rome et la conquête du monde méditerranéen. Tome 1: Les structures de l'Italie romaine, 4e éd., Paris, P.U.F., 1991.

Nicorescu, P., "La tomba degli Scipioni », Ephemeris Dacoromana, 1, 1923, p. $1-56$.

Nippel, W., Public Order in Ancient Rome, Cambridge, Cambridge University Press, 1995.

North, H., "Canons and Hierarchies of the Cardinal Virtues in Greek and Latin Literature» in WaLlach, L. (éd.), The Classical Tradition : Literary and Historical Studies in Honor of Harry Caplan, Ithaca, Cornell University Press, 1966, p. 165-183.

Oppermann, H. (éd.), Römische Wertbegriffe, Darmstadt, Wissenschaftliche Buchgesellschaft, 1967.

Orlin, E. M., Temples, Religion and Politics in the Roman Republic, Leiden, Brill, 1997.

Paladini, M. L., "Osservazioni ai discorsi e alle lettere del Sallustiano Bellum Catilinae », Latomus, 20, 1961, p. 3-32.

Pansiéri, C., Plaute et Rome ou les ambiguïtés d'un marginal, Bruxelles, Latomus, 1997.

Paratore, E., «La problematica sull'epicureismo a Roma », ANRW, I, 4, 1973, p. 116-204.

Passerini, A., "Caio Mario come uomo politico », Athenaeum, 12, 1934, p. 1044.

Paul, G. M., A Historical Commentary on Sallust's Bellum Iugurthinum, Liverpool, F. Cairns, 1984.

Pedersen, H., Vergleichende Grammatik der keltischen Sprachen, Göttingen, Vandenhoeck und Ruprecht, 1909-1913, 2 vol.

Peiper, R., "Vermischte Bemerkungen und Mittheilungen zu römischen Dichtern zum Theil aus Handschriften», RhM, 32, 1877, p. 519-520.

PeIRce, C. S., Écrits sur le signe, Paris, Seuil, 1978.

Perelli, L., Lucrezio poeta dell'angoscia, Florence, La Nuova Italia, 1969. , Il teatro rivoluzionario di Terenzio, Florence, La Nuova Italia, 1973. , "Società romana e problematica sociale nel teatro plautino », StudRom, 26, 1978, p. 307-327.

Perfigli, M., Indigitamenta. Divinità funzionali e funzionalità divina nella religione romana, Pise, ETS, 2004.

Peristiany, J. G. (éd.), Honour and Shame : the Values of Mediterranean Society, Londres, Weidenfeld \& Nicolson, 1966.

Perna, R., L'originalità di Plauto, Bari, Leonardo da Vinci, 1955.

Pernot, L., "Lieu et lieu commun dans la rhétorique antique», $B A G B, 1986$, p. 253-284.

_., La Rhétorique de l'éloge dans le monde gréco-romain, Paris, Brepols, 1993, 2 vol.

Perret, J., «L'amour de l'argent, l'ambition et la crainte de la mort (Lucrèce III, 59-86) » in Mélanges de philologie, de littérature et d'histoire anciennes offerts à A. Ernout, Paris, C. Klincksieck, 1940, p. 277-284.

Perrochat, P., Les Modèles grecs de Salluste, Paris, Les Belles Lettres, 1949. 
Petrone, G., Morale e antimorale nelle commedie di Plauto, Palerme, Palumbo, 1977.

«La praetexta repubblicana e il linguaggio della celebrazione» in Manuwald, G. (éd.), Identität und Alterität in der frührömischen Tragödie, Würzburg, Ergon, 2000, p. 113-121.

Petzold, K. E., «Der politische Standort des Sallust », Chiron, 1, 1971, p. 219 238.

Picard, G. C., Les Trophées romains, Paris, De Boccard, 1957.

PIERI, A., "Un problema di psicologia epicurea nell'esegesi di Lucr. III, 113 », Prometheus, 4, 1978, p. 243-260.

Pieri, G., L'Histoire du cens jusqu'à la fin de la République romaine, Paris, Sirey, 1968.

Pighi, G. B., «Catonis Carmen de moribus », Latinitas, 14, 1966, p. 31-34.

Pignatelli, A., "Il concetto di sapientia a Roma fra III e II sec. a. C. » in PANI, M. (éd.), Epigrafia e territorio. Politica e società. Temi di antichità romane, VI, Bari, Edipuglia, 2001, p. 271-286.

Pisani, V., «Latino honos », Paideia, 2, 1947, p. 27-28.

Piscitelli CARPINO, T., «Riflessi della realtà politico-sociale del II secolo a. C. in alcuni personaggi terenziani », BStudLat, 7, 1977, p. 25-38. , "Dignitas in Cicerone», BStudLat, 9, 1979, p. 253-267.

PITT-Rivers, J. A., Anthropologie de l'honneur : la mésaventure de Sichem, Paris, Le Sycomore, 1983.

Platner, S. B. et Ashby, T., A Topographical Dictionary of Ancient Rome, Oxford, Oxford University Press, 1929.

Plumpe, J. C., Wesen und Wirkung der Auctoritas Maiorum bei Cicero, Diss., Munich, 1932.

_ , "Roman Elements in Cicero's Panegyric on the Legio Martia », CJ, 36, 1940-1941, p. 275-291.

Pociña, A., El tragediógrafo latino Lucio Acio, Grenade, Universidad de Granada, 1984.

Pohlenz, M., Die Stoa. Geschichte einer geistigen Bewegung, 4e éd., Göttingen, Vandenhoeck \& Ruprecht, 1970.

PokoRny, J., Indogermanisches etymologisches Wörterbuch, Bern, Francke, 1959, 2 vol.

Pólay, E., Iniuria Types in Roman Law, Budapest, Akademiai Kiadó, 1985.

_ , "Der Schutz der Ehre und des guten Rufes im römischen Recht », ZRG, 106, 1989, p. 502-534.

Pommeray, L., Etudes sur l'infamie en droit romain, Paris, Sirey, 1937.

Poncelet, R., Cicéron traducteur de Platon. L'expression de la pensée complexe en latin classique, Paris, De Boccard, 1953.

Pöschl, V., «Politische Wertbegriffe in Rom», A\&A, 26, 1980, p. 1-17.

Pottier, B., "Vers une sémantique moderne», Travaux de Linguistique et de Littérature, 2, 1964, p. 107-137. , Sémantique générale, Paris, P.U.F., 1992.

Powell, J., "Friendship and its Problems in Greek and Roman Thought» in Innes, D., Hine, H. et Pelling, C. (éds.), Ethics and Rhetoric : Classical Essays for Donald Russell on his Seventy-fifth Birthday, Oxford, Clarendon Press, 1995, p. 31-45.

PréAux, J., "Caton et l'ars poetica », Latomus, 25, 1966, p. 710-725.

Puccini-Delbey, G., La Vie sexuelle à Rome, Paris, Tallandier, 2007. 
Puelma Piwonka, M., Lucilius und Kallimachos, Frankfurt, Klostermann, 1949.

Quellet, H., Les Dérivés latins en -or. Étude lexicographique, statistique, morphologique et sémantique, Paris, C. Klincksieck, 1969.

RaAflaub, K., Dignitatis contentio. Studien zur Motivation und politischen Taktik im Bürgerkrieg zwischen Caesar und Pompeius, Munich, C. H. Beck, 1974.

RABE, H., Autorität, Elemente einer Begriffsgeschichte, Konstanz, Universitätsverlag, 1972.

RABER, F., Grundlagen klassischer Injurienansprüche, Vienne, Böhlau, 1969.

RADERMACHeR, L., "Vir bonus dicendi peritus », RhM, 57, 1902, p. 314.

RADKE, G., «Überlegungen zum Saturnier », REA, 93, 1991, p. 263-276.

Ramage, E. S., Sigbee, D. L. et Fredericks, S. C., Roman Satirists and their Satire, Park Ridge, Noyes, 1974.

Rambaud, M., «Les prologues de Salluste et la démonstration morale dans son œuvre », REL, 24, 1946, p. 115-130.

, L'Art de la déformation historique dans les Commentaires de César, Paris, Les Belles Lettres, 1966.

"César et l'épicurisme d'après les Commentaires " in Actes du vIII Congrès de l'Association Guillaume Budé, Paris, Les Belles Lettres, 1969, p. 411434.

,César, 4e éd., Paris, P.U.F., 1983.

Ranouil, P.-C., Recherches sur le patriciat (509-366 av. J.-C.), Paris, Les Belles Lettres, 1975.

Raschke, W. J., "Arma Pro Amico. Lucilian Satire at the Crisis of the Roman Republic », Hermes, 115, 1987, p. 299-318. , "The Virtue of Lucilius », Latomus, 49, 1990, p. 352-369.

Rastier, F., Sémantique interprétative, Paris, P.U.F., 1987.

Rawlings, L., "Caesar's Portrayal of Gauls as Warriors» in WeLCH, K.et Powell, A. (éds.), Julius Caesar as Artful Reporter. The War Commentaries as Political Instruments, Londres, 1998, p. 171-192.

REAY, B., "Agriculture, Writing, and Cato's Aristocratic Self-Fashioning , ClAnt, 24 (2), 2005, p. 331-361.

ReBEnich, S., «Römische Wertbegriffe : Wissenschaftsgeschichtliche Anmerkungen aus althistorischer Sicht» in Haltenhoff, A., Heil, A. et Mutschler, F.-H. (éds.), Römische Werte als Gegenstand der Altertumswissenschaft, Munich, K. G. Saur, 2005, p. 23-46.

Rech, H., Mos maiorum. Wesen und Wirkung der Tradition in Rom, Diss., Marburg, 1936.

Renkema, E. H., «Ad Plauti Trinummum », Mnemosyne, 58, 1930, p. 114-120.

Reynaud, J.-D., Les Règles du jeu. L'action collective et la régulation sociale, Paris, A. Colin, 1989.

Ricca-Barberis, M., "Auctoritas e potestas », AG, 16, 1954, p. 129-131.

RichaRD, J.-C., «La victoire de Marius », MEFRA, 77, 1965, p. 69-86. Les Origines de la plèbe romaine : essai sur la formation du dualisme patricio-plébéien, Rome, E.F.R., 1978.

Richardson, J. S., "The Triumph, the Praetors and the Senate in the Early Second Century B. C. », JRS, 65, 1975, p. 50-63.

Richardson, L. J., "Honos et Virtus and the Sacra Via», AJA, 82 (2), 1978, p. 240-246. 
, "A Note on the Architecture of the Theatrum Pompei in Rome», AJA, 91, 1987, p. 123-126.

A New Topographical Dictionary of Ancient Rome, Baltimore, The Johns Hopkins University Press, 1992.

RidLEY, R. T., "Falsi triumphi, plures consulatus », Latomus, 42, 1983, p. 372-382.

Riedinger, J.-C., "Remarques sur la timè chez Homère », REG, 89, 1976, p. 244-264.

RiLinger, R., Humiliores - Honestiores. Zu einer sozialen Dichotomie im Strafrecht der römischen Kaiserzeit, Munich, R. Oldenbourg, 1988.

__, "Ordo und dignitas als soziale Kategorien der römischen Republik » in Ordo und dignitas. Beiträge zur römischen Verfassungs- und Sozialgeschichte, Stuttgart, F. Steiner, 2007, p. 95-104.

Rix, H., Lexikon der indogermanischen Verben, Wiesbaden, L. Reichert, 2001. , Sabellische Texte, Heidelberg, C. Winter, 2002.

RoBert, R., "Quelques usages du portrait peint à l'époque médio-républicaine », in Auvray-Assayas, C. (éd.), Images romaines, Paris, Presses de l'E.N.S., 1998, p. 73-89.

Rochette, B., «Le bilinguisme gréco-latin et la question des langues dans le monde gréco-romain », RBPh, 76 (1), 1998, p. 177-196.

Roesch, S., "Le rapport de res et uerbum dans le De Lingua latina de Varron» in Baratin, M. et Moussy, C. (éds.), Conceptions latines du sens et de la signification, Colloque du centre A. Ernout, Université de Paris IV, 4, 5 et 6 juin 1996, Paris, P.U.P.S., 1996, p. 65-80.

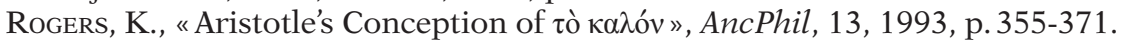

Roman, D. et Roman, Y., Rome, l'identité romaine et la culture hellénistique (21831 avant J.-C.), Paris, SEDES, 1994.

Romeyer-Dherbey, G., "Zénon appelle les choses par leur nom. La chasteté de la langue d'après les stoïciens ", Mesure, 3, 1990, p. 47-59.

Roscher, W. H., Ausführliches Lexikon der griechischen und römischen Mythologie, Leipzig, Teubner, 1884.

Roskam, G., Live Unnoticed (Lathè biôsas). On the Vicissitudes of an Epicurean Doctrine, Leiden, Brill, 2007.

Rossi, A. F., «The Camp of Pompey : Strategy of Representation in Caesar's Bellum Ciuile », CJ, 95, 1999-2000, p. 239-256.

" "The Tears of Marcellus : History of a Literary Motif in Livy », G\&R, 47 (1), 2000, p. 56-66.

Rotond, G., Leges publicae populi Romani, réimpr. de l'éd. italienne, Hildesheim, G. Olms, 1962.

Royo, M., "Catulus et les infortunes de la Virtus », Kentron, 5, 1989, p. 151-160.

Rudd, N., Themes in Roman Satire, Londres, Duckworth, 1986.

Ruelle, A., "L'anathème en chantant. Scandale, fascinatio et fatalité » in KLIMIs, S. et Van Eynde, L. (éds.), Littérature et savoir(s), Bruxelles, Publications des Facultés universitaires Saint-Louis, 2002, p. 127-173.

«Le citoyen face aux pratiques collectives de la honte à Rome : le droit et les dieux, ou deux poids, deux mesures » in Alexandre, R., Guérin, C. et JАсотот, M. (éds.), Rubor et pudor. Vivre et penser la honte à Rome, Paris, Éditions Rue d'Ulm, 2012, p. 61-82.

RÜPKE, J., Fasti sacerdotum, Stuttgart, F. Steiner, 2005, 3 vol.

Ryan, F. X., Rank and Participation in the Republican Senate, Stuttgart, F. Steiner, 1998. 
SAhlins, M. D., "Poor Man, Rich Man, Big Man, Chief : Political Types in Melanesia and Polynesia », Comparative Studies in Society and History, 5, 1963, p. 285-303.

Saladino, V., Der Sarkophag des Lucius Cornelius Scipio Barbatus, Würzburg, Triltsch, 1970.

Salem, J., La Mort n'est rien pour nous. Lucrèce et l'éthique, Paris, Vrin, 1990.

SALmon, E. T., "Caesar and the Consulship for 49 B. C. », CJ, 34, 1939, p. 388-395.

Sarsila, J., "Some Notes on Virtus in Sallust and Cicero ", Arctos, 12, 1978, p. 135-143.

SAURON, G., Quis deum ? L'expression plastique des idéologies politiques et religieuses à Rome à la fin de la République et au début du principat, Rome, E.F.R., 1994.

Sblendorio-Cugusi, M. T. et Cugusi, P., "Problematica catoniana. Rassegna di studi 1978-1993 e contributi critici », BStudLat, 26, 1996, p. 82-218.

Scamuzzi, U., "L'ipogeo degli Scipioni in Roma. Il sarcofago di Lucio Cornelio Scipione Barbato », RSC, 5, 1957, p. 248-268.

Scanlon, T. F., The Influence of Thucydides on Sallust, Heidelberg, C. Winter, 1980.

SchäFER, T., Imperii insignia, sella curulis und fasces : zur Repräsentation römischer Magistrate, Mainz, P. von Zabern, 1989. "Der Honor bisellii », MDAI(R), 97, 1990, p. 307-346.

Schanz, M. et Hosius, C., Geschichte der römischen Literatur, $4^{\mathrm{e}}$ éd., Munich, C. H. Beck, 1927.

Scheid, J., "Le flamine de Jupiter, les Vestales et le général triomphant. Variations romaines sur le thème de la figuration des dieux ", Le temps de la réflexion, 7,1986, p. 213-230.

_, «Nouveaux éléments concernant les Fastes des frères arvales» in Epigrafia. Actes du Colloque international d'épigraphie latine en mémoire d'Attilio Degrassi, Rome, E.F.R., 1991, p. 75-92.

, Religion et piété à Rome, 2 éd., Paris, A. Michel, 2001.

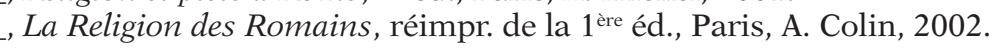

—_, "Le prêtre " in Giardina, A. (éd.), L'Homme romain, Paris, Seuil, 2002, p. 73-109.

_, Quand faire c'est croire. Les rites sacrificiels des Romains, Paris, Aubier, 2005.

Scherer, B. F., «Metamorphosis of Officium. Late Roman Republic to Early empire », $C B, 41,1964$, p. 1-4.

Schilling, R., La Religion romaine de Vénus, depuis les origines jusqu'au temps d'Auguste, Paris, De Boccard, 1954. , "Le culte de l'Indiges à Lauinium », REL, 57, 1979, p. 49-68.

Sснміdт, J., Ethos. Beiträge zum antiken Wertempfinden, Leipzig, R. Noske, 1941.

, Lukrez, der Kepos und die Stoiker, Frankfurt am Main, P. Lang, 1990.

Sснмітт, W., Satirenfragmente des Lucilius aus den Büchern XXVI-XXX, Diss., Munich, 1914.

SchöLl, F., "Vir bonus dicendi peritus », RhM, 57, 1902, p. 312-314.

Scholz, U. W., "Die sermones des Lucilius» in Braun, M., Haltenhoff, A. et Mutschler, F.-H. (éds.), Moribus antiquis res stat Romana : römische Werte und römische Literatur im 3. und 2. Jh. v. Chr., Munich, K. G. Saur, 2000, p. 217-234. 
SchriJvers, P. H., Horror ac divina voluptas. Études sur la poétique et la poésie de Lucrèce, Amsterdam, A. M. Hakkert, 1970.

" Le regard sur l'invisible. Étude sur l'emploi de l'analogie dans l'œuvre de Lucrèce» in Gigon, O. (éd.), Lucrèce, Genève, Fondation Hardt, 1977, p. 77-121.

Schur, W., Sallust als Historiker, Stuttgart, Kohlhammer, 1934.

Scullard, H. H., "Scipio Aemilianus and Roman Politics», JRS, 50, 1960, p. 59-74.

_, Roman Politics, 220-150 B.C, 2e éd., Oxford, Clarendon Press, 1973.

— Festivals and Ceremonies of the Roman Republic, Londres, Thames and Hudson, 1981.

Searle, J. R., Les Actes de langage. Essai de philosophie du langage, Paris, Hermann, 1972.

Sedley, D. N., Lucretius and the Transformation of Greek Wisdom, Cambridge, Cambridge University Press, 1998.

Segal, C., "Poetic Immortality and the Fear of Death : The Second Proem to the De rerum natura », HSCPh, 92, 1989, p. 193-212.

Segal, E., Roman Laughter. The Comedy of Plautus, Cambridge (MA), Harvard University Press, 1968. , "The Purpose of the Trinummus », AJPh, 95, 1974, p. 252-264.

Sehlmeyer, M., Stadtrömische Ehrenstatuen der republikanischen Zeit, Stuttgart, F. Steiner, 1999.

«Die kommunikative Leistung römischer Ehrenstatuen» in BRAUN, M., Haltenhoff, A. et Mutschler, F.-H. (éds.), Moribus antiquis res stat Romana. Römische Werte und römische Literatur im 3. und 2. Jh. v. Chr., Munich, K. G. Saur, 2000, p. 271-284.

Setaioli, A., "L'analogie et la similitude comme instruments de démonstration chez Lucrèce » in Armisen-Marchetti, M. (éd.), Demonstrare. Voir et faire voir : forme de la démonstration à Rome. Actes du colloque international de Toulouse, 18-20 novembre 2004, Toulouse, Presses Universitaires du Mirail, 2005, p. 117-142.

" "La notion éthique de kalós / kalón en latin», Prometheus, 34 (2), 2008, p. 160-180.

Shackleton Bailey, D. R., «Nobiles and Novi reconsidered», AJPh, 107, 1986, p. 255-260.

Slater, N. W., Plautus in Performance. The Theatre of the Mind, Princeton, Princeton University Press, 1985.

(éd.), Dining in a Classical Context, Ann Arbor, University of Michigan Press, 1991.

Sмiтh, R. E., «Cato Censorius », G\&R, 27 (9), 1940, p. 150-165.

SolazzI, A., "La forma della tutoris auctoritas e della patris auctoritas », Jura, 2, 1951, p. 133-139.

SpanNAGEL, M., "Zur Vergegenwärtigung abstrakter Wertbegriffe in Kult und Kunst der römischen Republik» in Braun, M., Haltenhoff, A. et Mutschler, F.-H. (éds.), Moribus antiquis res stat Romana. Römische Werte und römische Literatur im 3. und 2. Jh. v. Chr., Munich, K. G. Saur, 2000, p. 237-269.

SpÄтн, T., "Faits de mots et d'images. Les grands hommes dans la Rome ancienne», Traverse, 5 (1), 1998, p. 35-56. 
«Erzählt, erfunden : Camillus. Literarische Konstruktion und soziale Normen » in CoudrY, M. et Späth, T. (éds.), L'Invention des grands hommes de la Rome ancienne, Paris, De Boccard, 2001, p. 341-412.

Stawecka, K., "Spuren der philosophischen uirtus in den Komödien von Plautus », Eos, 57, 1967-1968, p. 211-218.

Stein, J. P., «Morality in Plautus' Trinummus », $C B, 47,1970$, p. 7-13.

Steinkopf, G., Untersuchungen zur Geschichte des Ruhmes bei den Griechen, Diss., Halle, 1937.

Steinmeyer, H., "Der virtus-Begriff bei Cicero und Seneca», $A U, 17,1974$, p. 50-59.

Stemmler, M., "Auctoritas exempli. Zur Wechselwirkung von kanonisierten Vergangenheitsbildern und gesellschaftlicher Gegenwart in der spätrepublikanischen Rhetorik» in Linke, B. et Stemmler, M. (éds.), Mos maiorum. Untersuchungen zu den Formen der Identitätsstiftung und Stabilisierung in der römischen Republik, Stuttgart, F. Steiner, 2000, p. 141-205.

Stevens, C. E., «The Bellum Gallicum as a Work of Propaganda », Latomus, 11, 1952, p. 3-18 et 165-179.

Stewart, F. H., Honor, Chicago, University of Chicago Press, 1994.

Stewart, P., Statues in Roman Society. Representation and Response, Oxford, Oxford University Press, 2003.

STIPPEL, F., Ehre und Ehrerziehung in der Antike, Würzburg, K. Triltsch, 1939.

Strasburger, H., «Der 'Scipionenkreis' », Hermes, 94, 1966, p. 60-72.

Strong, E., Art in Ancient Rome, Londres, W. Heinemann, 1929, 2 vol.

Studi sull'arco onorario Romano, Rome, L'Erma di Bretschneider, 1979.

Stutz, I., Honos. De vocabuli significatione Romana, Diss., Berlin, 1924.

Sumner, G. V., «The lex Annalis under Caesar », Phoenix, 25, 1971, p. 246-271.

Suolahti, J., The Roman Censors, Helsinki, Suomalaien Tiedeakatemia, 1955.

Syme, R., La Révolution romaine, Paris, Gallimard, 1967. , Salluste, Paris, Les Belles Lettres, 1982.

Szemler, G. J., The Priests of the Roman Republic, Bruxelles, Latomus, 1972.

Tackmann, S., "Die moralische Begriffe Ehre und Würde in der sowjetischen Ethikliteratur », Deutsche Zeitschrift für Philosophie, 23, 1975, p. 172-177.

Taladoire, B. A., Térence. Un théâtre de la jeunesse, Paris, Les Belles Lettres, 1972.

TAmBa, I., La Sémantique, 5e éd., Paris, P.U.F., 2005.

Tatum, W. J., "The Epitaph of Publius Scipio Reconsidered », CQ, 38 (1), 1988, p. 253-259.

TAYloR, L. R., Roman Voting Assemblies from the Hannibalic War to the Dictatorship of Caesar, Ann Arbor, University of Michigan Press, 1966.

Terraillon, E., L'Honneur, sentiment et principe moral, Paris, F. Alcan, 1912.

Terzaghi, N., Lucilio, Turin, L’Erma, 1934.

THILl, A., Alter ab illo. Recherches sur l'imitation dans la poésie personnelle à l'époque augustéenne, Paris, Les Belles lettres, 1979.

Tномаs, J.-F., «Les fonctions linguistiques de la synonymie lexicale en latin » in Moussy, C. (éd.), De lingua latina nouae quaestiones. Actes du $x^{e}$ colloque international de linguistique latine, Paris-Sèvres, 19-23 avril 1999, Louvain, Peeters, 2001, p. 875-890. , «Les genres nobles dans les comédies de Plaute et de Térence: l'exemple du thème de la gloire », CGITA, 14, 2001, p. 115-137. 
Gloria et laus. Étude sémantique, Louvain, Peeters, 2002.

"Gloria maiorum, gloria antiqua. La conscience du passé dans la conception de la gloire à Rome » in BaKhouche, B. (éd.), L'Ancienneté chez les Anciens, Montpellier, Université de Montpellier III, 2003, vol. 1, p. 133153.

, Déshonneur et honte en latin : étude sémantique, Louvain, Peeters, 2007.

Thomas, Y., "Vitae necisque potestas. Le père, la cité, la mort " in Du châtiment dans la cité. Supplices corporels et peine de mort dans le monde antique, Paris, De Boccard, 1984, p. 499-548.

Thome, G., "O tempora, o mores ! Wertvorstellungen bei den Rednern der republikanischen Zeit» in Braun, M., Haltenhoff, A. et Mutschler, F.-H. (éds.), Moribus antiquis res stat Romana. Römische Werte und römische Literatur im 3. und 2. Jh. v. Chr., Munich, K. G. Saur, 2000, p. 125-139.

_. Zentrale Wertvorstellungen der Römer, Bamberg, C. C. Buchner, 2000, 2 vol.

Thuillier, J.-P., «Le corps du sportif romain» in Moreau, P. (éd.), Corps romains, Grenoble, J. Millon, 2002, p. 251-266.

Tiffou, É., «Salluste et la tradition stoïcienne», EMC, 12, 1968, p. 13-19.

_., Essai sur la pensée morale de Salluste à la lumière de ses prologues, Paris, C. Klincksieck, 1974. "Biographie de Salluste », CEA, 7, 1977, p. 91-138.

Till, R., "Die Scipionenelogien» in Baleitinger, D. et Gugel, H. (éds.), Festschrift Karl Vretska zum 70. Geburtstag, Heidelberg, C. Winter, 1970, p. 276-289.

Tolosana, C. L., "The Ever-Changing Faces of Honour» in Albera, D., Blok, A. et Bromberger, C. (éds.), L’Anthropologie de la Méditerranée, Paris, Maisonneuve et Larose, 2001, p. 133-147.

Tomassetti, A., «Un edificio antico lungo il cliuus Argentarius : il monumentum di Gaio Publicio Bibulo », BCAR, 101, 2000, p. 39-80.

Toynbee, J. M. C., Death and Burial in the Roman World, Londres, Thames \& Hudson, 1971.

Tronson, A., "Pompey the Barbarian : Presentation of 'the other' in Bellum Civile 3 " in Joyal, M. (éd.), In altum. 75 years of Classical Studies in Newfoundland, St John's, Memorial University of Newfoundland, 2001, p. 73-104.

UsEner, H., Götternamen, Bonn, F. Cohen, 1896. , «Italische Volksjustiz», RhM, 56, 1901, p. 2-28.

Valente, P. M., L'Éthique stö̈cienne chez Cicéron, Paris, Saint-Paul, 1956.

Valette-Cagnac, E., "Vtraque lingua. Critique de la notion de bilinguisme» in Dupont, F. et Valette-Cagnac, E. (éds.), Façons de parler grec à Rome, Paris, Belin, 2005, p. 7-35.

Van Omme, A. N., Virtus. Een semantiese studie, Diss., Utrecht, 1946.

Van Ooteghem, J., Caius Marius, Bruxelles, Académie Royale de Belgique, 1964.

VAN Sickle, J., «The Elogia of the Cornelii Scipiones and the Origin of Epigram at Rome », AJPh, 108 (1), 1987, p. 41-55.

VAn Wees, H., "A Brief History of Tears : Gender Differentiation in Archaic Greece» in Foxhall, L. et Salmon, J. (éds.), When Men were Men. Masculinity, Power and Identity in Classical Antiquity, Londres, Routledge, 1998, p. 10-53. 
Vanggaard, J. H., The Flamen : a Study in the History and Sociology of Roman Religion, Copenhague, Museum Tusculanum Press, 1988.

Vaubel, E., Pudor, verecundia, reverentia. Untersuchungen zur Psychologie von Scham und Ehrfurcht bei den Römern bis Augustin, Münster, 1969.

Veblen, T., Théorie de la classe de loisir, Paris, Gallimard, 1970.

Vernant, J.-P., Mythe et pensée chez les Grecs. Études de psychologie historique, nouvelle éd., Paris, La Découverte, 1996.

Versnel, H.-S., Triumphus. An Inquiry into the Origin, Development and Meaning of the Roman Triumph, Leiden, Brill, 1970.

"Two Types of Roman devotio », Mnemosyne, 29, 1976, p. 365-410.

"Saturn and the Saturnalia : the Question of Origin» in SANCISIWeerdenburg, H. (éd.), De agricultura : in memoriam Pieter Willem De Neeve (1945-1990), Amsterdam, Gieben, 1993, p. 98-120.

Veyne, P., Le Pain et le cirque. Sociologie historique d'un pluralisme politique, Paris, Seuil, 1976. , La Société romaine, Paris, Seuil, 1991.

Vidal-Naquet, P., Le Chasseur noir, Paris, La Découverte, 1983.

Vigourt, A., " M'. Curius Dentatus et C. Fabricius Luscinus : les grands hommes ne sont pas exceptionnels » in Coudry, M. et Späтн, T. (éds.), L'Invention des grands hommes de la Rome ancienne, Paris, De Boccard, 2001, p. 117-129.

Vollmer, F., Laudationum funebrium Romanorum historia et reliquiarum editio, Leipzig, Teubner, 1891.

Von Domaszewski, A., "Die Religion des römischen Heeres», Westdeutsche Zeitschrift für Geschichte und Kunst, 14, 1895, p. 1-121. , Abhandlungen zur römischen Religion, Leipzig, Teubner, 1909.

Von Hesberg, H., Römische Grabbauten, Darmstadt, Wissenschaftliche Buchgesellschaft, 1992.

Vout, C., «The Myth of the Toga : Understanding the History of Roman Dress », $G \& R, 43$ (2), 1996, p. 204-220.

Vretska, K. (éd.), Sallust. De Catilinae coniuratione, Heidelberg, C.Winter, 1976.

WACHTER, R., Altlateinische Inschriften. Sprachliche und epigraphische Untersuchungen zu den Dokumenten bis etwa 150 v. Chr., Bern, P.Lang, 1987.

Walbank, F. W., «The Scipionic Legend», PCPhS, 13, 1967, p. 54-69.

WaLdE, A., Vergleichendes Wörterbuch der indogermanischen Sprachen, Berlin, W. De Gruyter, 1927-1932, 3 vol.

Wallace-HadRILl, A., "Roman Arches and Greek Honours : the Language of Power at Rome », PCPhS, 36, 1990, p. 143-181.

Walters, J., "Invading the Roman Body : Manliness and Impenetrability in Roman Thought» in Hallett, J. P. et Skinner, M. B. (éds.), Roman Sexualities, Princeton, Princeton University Press, 1997, p. 29-43.

Wanscher, O., Sella curulis : the Folding Stool : an Ancient Symbol of Dignity, Copenhague, Rosenkilde and Bagger, 1980.

Waszink, J., « Problems Concerning the Satura of Ennius » in Skutsch, O. (éd.), Ennius. Sept exposés suivis de discussions, Genève, Fondation Hardt, 1972, p. 97-147.

Watt, W. S., "Cato, De agricultura, praef. 1 », Mnemosyne, 4-56, 2003, p. 213.

Webster, E. W., Virtus and Libertas. The Ideals and Spirit of the Roman Senatorial Aristocracy from the Punic Wars through the Time of Augustus, Diss., University of Chicago, Chicago, 1934. 
Wegehaupt, H., Die Bedeutung und Anwendung von dignitas in den Schriften der republikanischen Zeit, Diss., Breslau, 1932.

Weinstock, S., "Victor and Inuictus », HTR, 50, 1957, p. 211-247. Divus Julius, Oxford, Clarendon Press, 1971.

Wesch-KLein, G., Funus publicum. Eine Studie zur öffentlichen Beisetzung und Gewährung von Ehrengräbern in Rom und den Westprovinzen, Stuttgart, F. Steiner, 1993.

WiKan, U., "Shame and Honour : a Contestable Pair», Man, 19, 1984, p. 635652.

Wirszubski, C., Libertas as a Political Idea at Rome during the Late Republic and Early Principate, Cambridge, Cambridge University Press, 1950.

Wiseman, T. P., New Men in the Roman Senate 139 B.C. - 14 A.D., Oxford, Oxford University Press, 1971.

, "Competition and Co-operation» in Wiseman, T. P. (éd.), Roman Political Life, 90 BC - AD 69, Exeter, University of Exeter Press, 1985, p. 3-19.

Wissowa, G., Religion und Kultus der Römer, Munich, C. H. Beck, 1902.

Witzmann, P., "Kommunikative Leistungen von Weih-, Ehren- und Grabinschriften» in Braun, M., Haltenhoff, A. et Mutschler, F.-H. (éds.), Moribus antiquis res stat Romana. Römische Werte und römische Literatur im 3. und 2. Jh. v. Chr, Munich, K. G. Saur, 2000, p. $55-86$.

WLosoK, A., «Nihil nisi pudorem. Über die Rolle der Scham in der römischen Rechtskultur» in Неск, E. et SснміDт, E. A. (éds.), Res humanae - res divinae. Kleine Schriften, Heidelberg, C. Winter, 1990, p. 84-100.

WöLfFLIN, E., «De Scipionum elogiis», RPh, n.s. 14, 1890, p. 113-122.

_ _ "Die Dichter der Scipionenelogien», Sitzungsberichte der philosophischphilologischen und der historischen Classe der Akademie der Wissenschaften zu München, 1892, p. 188-219.

Wood, F. A., «Some Latin Etymologies », CPh, 11, 1916, p. 208-211.

_. Post-Consonantal ' $w$ ' in Indo-European, Philadelphie, Linguistic Society of America, 1926.

Yavetz, Z., "Existimatio, Fama, and the Ides of March », HSCPh, 78, 1974, p. 35-65.

Zanker, P., "Grabreliefs römischer Freigelassener», JDAI, 90, 1975, p. 267315.

The Power of Images in the Age of Augustus, Ann Arbor, University of Michigan Press, 1988.

Zecchini, G., Cesare e il mos maiorum, Stuttgart, F. Steiner, 2001.

Zehnacker, H., Moneta. Recherches sur l'organisation et l'art des émissions monétaires de la République romaine (289 - 31 av. J.-C.), Rome, E.F.R., 1973, 2 vol.

" Plaute et la philosophie grecque. À propos du Mercator» in Mélanges $P$. Boyancé, Rome, E.F.R., 1974, p. 769-785.

ZEID, A. A. M., "Honour and Shame Among the Bedouins of Egypt» in Peristiany, J. G. (éd.), Honour and Shame. The Values of Mediterranean Society, Londres, Weidenfeld \& Nicolson, 1966, p. 243-259.

ZEvi, F., "Considerazioni sull'elogio di Scipione Barbato», Studi Miscellanei, 15, 1969-1970, p. 63-73.

Zimmermann, A., Etymologisches Wörterbuch der lateinischen Sprache, Hanovre, Hahnschen, 1915. 
Ziolkowski, A., The Temples of Mid-Republican Rome and Their Historical and Topographical Context, Rome, L'Erma, 1992.

ZorzetTI, N., «Dimostrare et convincere : l'exemplum nel ragionamento induttivo e nella communicazione» in DAVID, J.-M. et Berlioz, J. (éds.), Rhétorique et histoire. L'exemplum et le modèle de comportement dans le discours antique et médiéval, Rome, E.F.R., 1980, p. 33-65.

Zucchelli, B., L'indipendenza di Lucilio, Florence, La Nuova Italia, 1977. 


\section{INDEX LOCORUM}

Cet index recense les passages d'auteurs latins ou grecs cités dans le corps du texte de l'ouvrage.

\section{Caecilius (CAEcIL.)}

Caecil. frg. $224 C R F$ : 502

\section{César (CAes.)}

Caes. $B C$ I, 7, $1: 711,719$

Caes. $B C$ I, 9, $3: 711$

Caes. $B C$ I, 32, $2: 83,712$

Caes. BC I, 77, $2: 709$

Caes. BC I, 85, $10: 55,719$

Caes. BC II, 21, $5: 708$

Caes. BC III, 59, 2-3 : 307

Caes. $B C$ III, $83,1: 325$

Caes. $B C$ III, $83,4: 720$

Caes. $B G$ I, $18,8: 706$

Caes. $B G$ I, 39, $3: 717$

Caes. $B G$ I, 43, 6-7 : 286, 419

Caes. BG II, $35: 713$

Caes. $B G$ V, 54, $4: 310,425$

Caes. $B G$ VI, 13, $1: 716$

\section{Caton l'Ancien (CAT.)}

Cat. Agr. 80, $3: 143$

Cat. Agr. praef. 1-2: 596

Cat. Carmen frg. 2 : 395, 595

Cat. frg I, $18: 291,582$

Cat. frg. inc. $252: 590,592$

Cat. frg. IV, 35 : 136, 409

Cat. frg. VI, $60: 486$

Cat. frg. XII, $73: 328$

Cat. frg. XVIII, $93: 581,587$

Cat. frg. XIX, 94 : 203, 578

Cat. frg. XXXII, $132: 585$

Cat. frg. XXXVIII, $148: 579$

Cat. frg. XLII, $168: 301,580$

Cat. Orig. IV, $7: 583$

\section{Cicéron (Cic.)}

Cic. Ac. Post. I, 11 : 1, 383

Cic. Agr. II, $1: 57$

Cic. Agr. II, $46: 292$

Cic. Agr. II, 77 : 386

Cic. Agr. II, 91 : 439-440

Cic. Att. II, $18: 206$

Cic. Att. III, 10, $2: 361$

Cic. Att. IV, 16, $3: 385$

Cic. Att. VII, 11, $1: 158$

Cic. Att. VII, 14, $3: 495$

Cic. Att. VIII, 15, $2: 465$

Cic. Att. XVI, 16a, 4 : 418

Cic. Balb. 7 : 56, 288

Cic. Brut. 117 : 456

Cic. Brut. 281 : 54, 90, 130

Cic. Cael. $40: 145$

Cic. Cael. $44: 126$

Cic. Cael. 5 : 215

Cic. Catil. I, $28: 335$

Cic. Catil. II, 18 : 132

Cic. Catil. II, $25: 170$

Cic. Catil. III, $2: 69$

Cic. Catil. III, $26: 222$

Cic. Catil. IV, 5 : 272

Cic. Cato mai. 38 : 399

Cic. Cato mai. 63 : 264

Cic. Cato mai. $80: 360$

Cic. Clu. $39: 95$

Cic. Clu. 119-120: 450

Cic. Clu. $150: 389$

Cic. Clu. $153: 84$

Cic. Clu. $154: 355$

Cic. Clu. $177: 88$

Cic. De or. I, 34 : 68

Cic. De or. I, 194 : 408

Cic. De or. II, $44: 285$

Cic. De or. II, $248: 482$

Cic. De or. III, $125: 176$

Cic. Deiot. $12: 238$ 
Cic. Diu. Caec. $22: 443$

Cic. Diu. Caec. 71 : 401

Cic. Dom. $46: 367$

Cic. Dom. $65: 137$

Cic. Fam. X, 2, $1: 321$

Cic. Fam. X, 6, $2: 407$

Cic. Fam. X, 10, 1-2: 225

Cic. Fam. X, 23, $7: 378$

Cic. Fam. XII, 4, $1: 245,369$

Cic. Fam. XIII, 77, $1: 219,271$

Cic. Fam. XV, 10, $2: 65$

Cic. Fin. I, $36: 177$

Cic. Fin. I, $61: 701$

Cic. Fin. II, $34: 150$

Cic. Fin. II, $44: 153$

Cic. Fin. II, $48: 177$

Cic. Fin. II, 49 : 154

Cic. Fin. III, $14: 151$

Cic. Fin. III, $27: 155$

Cic. Fin. V, $20: 153$

Cic. Fin. V, $58: 151$

Cic. Fin. V, $62: 178$

Cic. Fin. V, $64: 179$

Cic. Flac. $18: 120$

Cic. Flac. $40: 133$

Cic. Flac. $49: 174$

Cic. Flac. $52: 93$

Cic. Flac. $56: 48$

Cic. Flac. $72: 363$

Cic. Flac. $103: 63$

Cic. Flac. $104: 289$

Cic. Imp. Pomp. 2 : 371

Cic. Inu. I, $20: 123$

Cic. Inu. II, $2: 122$

Cic. Inu. II, $12: 155$

Cic. Inu. II, 35 : 139

Cic. Inu. II, $54: 157$

Cic. Inu. II, $55: 180$

Cic. Inu. II, $66: 67,366$

Cic. Inu. II, $107:$ 49, 169

Cic. Inu. II, $108: 98$

Cic. Inu. II, $159: 156$

Cic. Inu. II, $166:$ 73, 75, 138, 300

Cic. Lael. $34: 438$

Cic. Leg. I, $32: 166$

Cic. Leg. I, $41: 152$

Cic. Leg. II, $28: 510$

Cic. Leg. II, $58: 519$

Cic. Leg. III, 31-32 : 412

Cic. Leg. III, $32: 67$
Cic. Luc. $135: 182$

Cic. Luc. 140 : 149, 179

Cic. Mil. $18: 140$

Cic. Mur. $8: 365$

Cic. Mur. $13: 473$

Cic. Mur. $23: 51$

Cic. Mur. $55: 452$

Cic. Mur. $60: 174$

Cic. Mur. $70: 204$

Cic. Mur. $87: 183,231$

Cic. Mur. $89: 66,306,441$

Cic. ND I, $3: 424$

Cic. ND II, $61: 521$

Cic. ND II, 61-62: 511

Cic. ND III, $50: 397$

Cic. Off. I, $14: 154$

Cic. Off. I, $39: 319$

Cic. Off. I, $42: 268$

Cic. Off. II, $21: 212,423$

Cic. Orat. $142: 496$

Cic. Part. $83: 184$

Cic. Part. $87: 181$

Cic. Phil. V, $37: 227$

Cic. Phil. VII, 5 : 382

Cic. Phil. IX, $2: 276$

Cic. Phil. IX, 5 : 199

Cic. Phil. IX, $15: 226$

Cic. Phil. XIV, $13: 205$

Cic. Pis. $1: 342$

Cic. Pis. $2: 83$

Cic. Planc. $13: 87$

Cic. Planc. $22: 200$

Cic. Planc. $50: 52$

Cic. Planc. $59: 345$

Cic. Prou. $11: 167$

Cic. Prou. $27: 271$

Cic. Prou. $38: 362,427$

Cic. Prou. $41: 51,426$

Cic. Q. fr. I, 1, $31: 237$

Cic. Q. fr. I, 3, $6: 465$

Cic. Q. fr. III, 5, $3: 213$

Cic. Quinct. 14 : 249

Cic. Quinct. $28: 282$

Cic. Quinct. $99: 169$

Cic. Rab. Perd. $3: 400$

Cic. Rab. Perd. $23: 171$

Cic. Red. Sen. 2 : 364

Cic. Rep. I, $53: 103$

Cic. Rep. I, 67 : 109

Cic. Rep. II, $59: 388$ 
Cic. Rep. III, 15 : 500

Cic. Rep. III, $28: 211$

Cic. Rep. IV, 13, frg. $1:$ 56, 309

Cic. Rosc. Amer. $16: 197$

Cic. Rosc. Amer. 44 : 78

Cic. Rosc. Amer. 50 : 489

Cic. Rosc. Amer. 108 : 97

Cic. Rosc. Amer. 114 : 165

Cic. Rosc. Amer. $136: 332$

Cic. Rosc. Amer. $147: 503$

Cic. Rosc. Com. 18 : 119

Cic. Sest. $49: 245$

Cic. Sest. $57: 283$

Cic. Sest. $109: 185$

Cic. Sest. $113: 290$

Cic. Sest. $116: 515$

Cic. Sull. $24: 210$

Cic. Sull. $26: 221$

Cic. Sull. $49: 436$

Cic. Sull. $73: 166$

Cic. Sull. $88: 448$

Cic. Top. $91: 180$

Cic. Tusc. I, 3-4: 394

Cic. Vat. 1-2: 50

Cic. Vat. $10: 217$

Cic. Verr. I, $7: 55$

Cic. Verr. II, I, $10: 375$

Cic. Verr. II, I, $21: 122$

Cic. Verr. II, I, 37 : 332

Cic. Verr. II, I, $38: 97$

Cic. Verr. II, I, $64: 363$

Cic. Verr. II, I, 139-140 : 463

Cic. Verr. II, II, $23: 131$

Cic. Verr. II, II, $87: 205$

Cic. Verr. II, II, $112: 314$

Cic. Verr. II, II, 150-151 : 252

Cic. Verr. II, III, $56: 132$

Cic. Verr. II, III, $75: 130$

Cic. Verr. II, IV, $25: 58,370$

Cic. Verr. II, IV, $79: 196$

Cic. Verr. II, IV, $81: 87$

Cic. Verr. II, IV, $123: 524$

Cic. Verr. II, V, $37: 387$

Cic. Verr. II, V, $84: 301$

Cic. Verr. II, V, $107: 131$

Cic. Verr. II, V, $157: 63,327$

Cic. Verr. II, V, 181 : 341
Corpus Inscriptionum Latinarum

(CIL)

CIL I ${ }^{2}$ p. 195, XVIII : 529

CIL I ${ }^{2}, 6-7: 603$

CIL I $\mathrm{I}^{2}, 8-9: 604$

CIL I I $, 10: 457,605$

$C I L \mathrm{I}^{2}, 11: 92,606$

CIL I $\mathrm{I}^{2}, 15: 199,312,607$

CIL I $\mathrm{I}^{2}, 31: 516$

CIL I $\mathrm{I}^{2}, 594: 293$

CIL I $\mathrm{I}^{2}, 612: 421$

CIL I ${ }^{2}, 834: 279$

CIL I ${ }^{2}, 1347: 498$

CIL I ${ }^{2}, 1632: 250,422$

CIL X, $1236: 250$

Comicorum Romanorum

fragmenta (CRF)

$C R F$ inc. frg. $63: 386$

Digeste (Dig.)

Dig. XXIV, 1, 51 : 501

Ennius (EnN.)

Enn. Evh. frg. X : 323

Enn. Trag. frg. CVII : 81

Enn. Trag. inc. frg. CCXV : 124, 479

Épicure (EPIc.)

Epic. Max. Cap. VI : 692

Epic. Max. Cap. VII : 693

Epic. Max. Cap. XIV : 693

Epic. Sent. Vat. $81: 695$

Euripide (EUR.)

Eur. Ion 62 : 108

Aulu Gelle (GeLl.)

Gell. II, 3, 1-4 : 36

Hérodote (HER.)

Hér. I, 59 : 111

Isocrate (Isoc.)

Isoc. Ant. $219: 110$

Isoc. Phil. $107: 112$

Tite Live (Lrv.)

Liv. VII, 30, $4: 322$

Liv. XXII, 30, 4 : 37 
Liv. XXVII, 25, $10: 525$

Liv. XXX, 26, $8: 458$

Liv. XXXVIII, 53, $4: 366$

Liv. XXXIX, 29, 4-5 : 348

\section{Lucilius (LucIL.)}

Lucil. frg. I, $33: 650$

Lucil. frg. III, $1: 647$

Lucil. frg. III, $25: 655$

Lucil. frg. III, 33 : 145, 664

Lucil. frg. VIII, $7: 146$

Lucil. frg. XIII, $8: 640$

Lucil. frg. XIV, $7: 645$

Lucil. frg. XIX, 6-7 : 651

Lucil. frg. XXVI, $75: 652$

Lucil. frg. XXVII, $9: 639$

Lucil. frg. XXVII, $10: 638$

Lucil. frg. XXX, 85 : 647

Lucil. frg. XXX, $92: 648$

Lucil. frg. hex. inc. $23: 150,642$, 646,657

Lucil. frg. hex. inc. $36: 646$

Lucil. frg. hex. inc. $52: 653$

Lucil. frg. inc. $111: 663$

\section{Lucrèce (Lucr.)}

Lucr. $D R N$ I, 922-923 : 702

Lucr. DRN II, 1-13: 698

Lucr. DRN III, 59-65 : 684

Lucr. DRN III, 63-64 : 691

Lucr. DRN III, 65-67 : 692

Lucr. DRN III, 74-78 : 65, 684

Lucr. DRN III, 995-997 : 688

Lucr. DRN IV, 1160-1163 : 99

Lucr. DRN IV, 1171-1174 : 100

Lucr. $D R N$ V, 1108-1114 : 64

Lucr. $D R N$ V, 1120-1130 : 70, 685

Lucr. $D R N$ V, 1123-1124 : 689

Lucr. DRN V, 1137-1141: 696

Lucr. DRN V, 1275-1277 : 697

Lucr. $D R N$ VI, 9-14 : 694

Lucr. $D R N$ VI, 417-420 : 100

\section{Martial (MART.)}

Mart. Ep. X, 50, 1-4 : 517

Odyssée (Od.)

Od. XI, $534: 107$

Ovide (Ov.)

Ov. Her. IX, $30: 37$
Publilius Syrus (P. Syr.)

P. Syr. frg. H 15 : 230

P. Syr. frg. H 24 : 358

\section{Pacuvius (Pacuv.)}

Pacuv. frg. 268-269 : 480

\section{Plaute (PL.)}

Pl. Amp. 486-490 : 79

Pl. Amp. 486-495 : 207

Pl. Amp. 867-870 : 80

Pl. As. 79-83: 308

Pl. As. 80-83 : 50, 550

Pl. As. 190-194 : 48

Pl. Aul. 15-19 : 45, 246, 380

Pl. Aul. 23-27 : 45, 380

Pl. Bac. 438-439 : 289

Pl. Bac. 612-613 : 91, 94, 551

Pl. Cap. 245-248 : 53, 324

Pl. Cap. 320-323 : 125, 464

Pl. Cap. 355-357 : 269

Pl. Cap. 391-392 : 47, 119

Pl. Cap. $1029: 569$

Pl. Cap. 1034-1036 : 570

Pl. Curc. 178-180 : 305, 333, 558

Pl. Curc. $198: 561$

Pl. Epid. 29-35 : 551

Pl. Merc. 403-411: 446

Pl. Mil. 624 : 561

Pl. Mil. 1074-1075 : 202

Pl. Mil. 1284-1289 : 491, 559

Pl. Pers. 510-512 : 381

Pl. Poen. 1232 : 126, 462

Pl. Rud. 195-196 : 406

Pl. Rud. 284-289 : 554

Pl. Rud. 406-410 : 136

Pl. Rud. 1249-1253 : 570

Pl. St. 48-50 : 262, 377

Pl. Trin. 223-234 : 573

Pl. Trin. 267-273: 566

Pl. Trin. 272-273: 64, 434

Pl. Trin. 481-483 : 334, 560

Pl. Trin. 642-648 : 208, 311, 454, 567

Pl. Trin. 650-651: 312

Pl. Trin. 662-664: 68

Pl. Trin. 688-694 : 209

Pl. Trin. 693-694 : 225

Pl. Trin. 695-697 : 467

Pl. Trin. $697: 93$

Pl. Trin. 705-707 : 575 
Pl. Trin. 731-733 : 139

Pl. Trin. 1028-1032 : 319

Pl. Trin. 1028-1035 : 567

Pl. Truc. 572-574 : 69, 444

Pl. Truc. 589-591: 300

Pl. frg. $101: 62,444,560$

\section{Platon (Plat.)}

Plat. Apol. 29d-e : 110

Plat. Apol. 35b : 111

Plat. Conv. 178c : 110

Plat. Resp. VIII, 562d : 109

\section{Pline (Plin.)}

Plin. NH VII, 139-140 : 431

Plin. NH VII, 140 : 359, 611

\section{Properce (Prop.)}

Prop. III, 1, 16-19 : 512

\section{Pseudo-César (Ps.-CAEs.)}

Ps.-Caes., B. Al. 77, 2 : 256

\section{Quintus Cicéron (Q. Cic.)}

Q. Cic. Comm. $13: 86$

Q. Cic. Comm. $18: 374$

Q. Cic. Comm. $38: 228$

Rhétorique à Alexandre (R. Alex.) Rhet. Alex. I, $12: 673$

\section{Rhétorique à Herennius (Rhet.}

Her.)

Rhet. Her. I, 5 : 669

Rhet. Her. II, $3: 47$

Rhet. Her. II, $16: 671$

Rhet. Her. III, $3: 670,675,677$

Rhet. Her. III, $5: 122,467$

Rhet. Her. III, $7:$ 396, 678

Rhet. Her. III, $9: 681$

Rhet. Her. IV, $10: 674$

Rhet. Her. IV, $23: 140$

Rhet. Her. IV, $29: 435$

Rhet. Her. IV, 57 : 316

\section{Salluste (SALL.)}

Sall. Cat. 1, $1: 741$

Sall. Cat. 3, 4-5 : 737

Sall. Cat. 4, 1-2: 743

Sall. Cat. 10, $6: 735$
Sall. Cat. 11, 1-2 : 741

Sall. Cat. 12, $1:$ 404, 727

Sall. Cat. 13, 1-2 : 473

Sall. Cat. 20, 8-9: 430, 734

Sall. Cat. 49, $2: 338$

Sall. Cat. 52, $22: 405$

Sall. Hist. frg. I, 12 : 732

Sall. Hist. frg. I, 55, 7-10 : 387

Sall. Hist. frg. II, 47, $9: 471$

Sall. Iug. 2, $1: 738$

Sall. Iug. 3, $1:$ 52, 728, 739

Sall. Iug. 8, $1: 134,730$

Sall. Iug. 11, $3: 357$

Sall. Iug. 25, $4: 373$

Sall. Iug. 29, 2 : 127, 746

Sall. Iug. 31, 9-10: 291, 725

Sall. Iug. 31, $12: 730,748$

Sall. Iug. 49, $4: 49$

Sall. Iug. 63, 6-7 : 336, 725

Sall. Iug. 82, $2: 747$

Sall. Iug. 85, 17-20: 342

Sall. Iug. 85, 19-20: 124

Sall. Iug. 85, 29-30 : 258

Sall. Iug. 85, $49: 745$

Sall. Iug. 86, $3: 499$

Scipion Émilien (ScIP. AEM.)

Scip. Aem. frg. IX, $30: 477$

Scip. Aem. frg. inc. $32: 85,293,300$, 593

Sénèque (SEN.)

Sen. Ben. I, 6, 1 : 268

Sénèque le Rhéteur (SEN. RHET.)

Sen. Rhet. Contr. II, 1, $8: 489$

\section{Symmaque (Sумм.)}

Symm. Ep. I, 20, $1: 514$

\section{Térence (TER.)}

Ter. Andr. 121-124 : 146

Ter. Andr. 796-798: 623

Ter. Eun. 230-231 : 144

Ter. Eun. 255-262 : 71, 220, 263, 625

Ter. Eun. 472-476 : 144

Ter. Eun. 716-717 : 482

Ter. Eun. 937-940 : 631

Ter. Eun. 1021-1023 : 97

Ter. Heaut. 381-382 : 632 
Ter. Heaut. 686-687 : 624

Ter. Hec. 148-151 : 141, 475, 633

Ter. Hec. 148-152: 628

Ter. Hec. 403-404 : 468

Ter. Hec. 403-405: 627

Ter. Phorm. 910-913: 484, 634

Ter. Phorm. 927-929: 81

Thucydide (Thuc.)

Thuc. II, 55, $8: 108$

Thuc. II, 63, $1: 110$

Tragicorum Romanorum

fragmenta (TRF)

$T R F$ inc. frg. 30-31:224, 313

Valère Maxime (VaL. MAx.)

Val. Max., I, 1, $8: 525$

\section{Varron (VARR.)}

Varr. $L L$ V, $73: 35$

Varr. $R D$ XIV, frg. 189 : 511

Varr. $R R$ I, 17, $6: 216$

Varr. $R R$ I, 3, $1: 372$

Varr. Vita Pop. Rom. frg. 121 : 435

Volcacius Sedigitus (Volc. SED.)

Volc.-Sed. frg. 4 : 247 


\section{TABLE DES MATIÈRES}

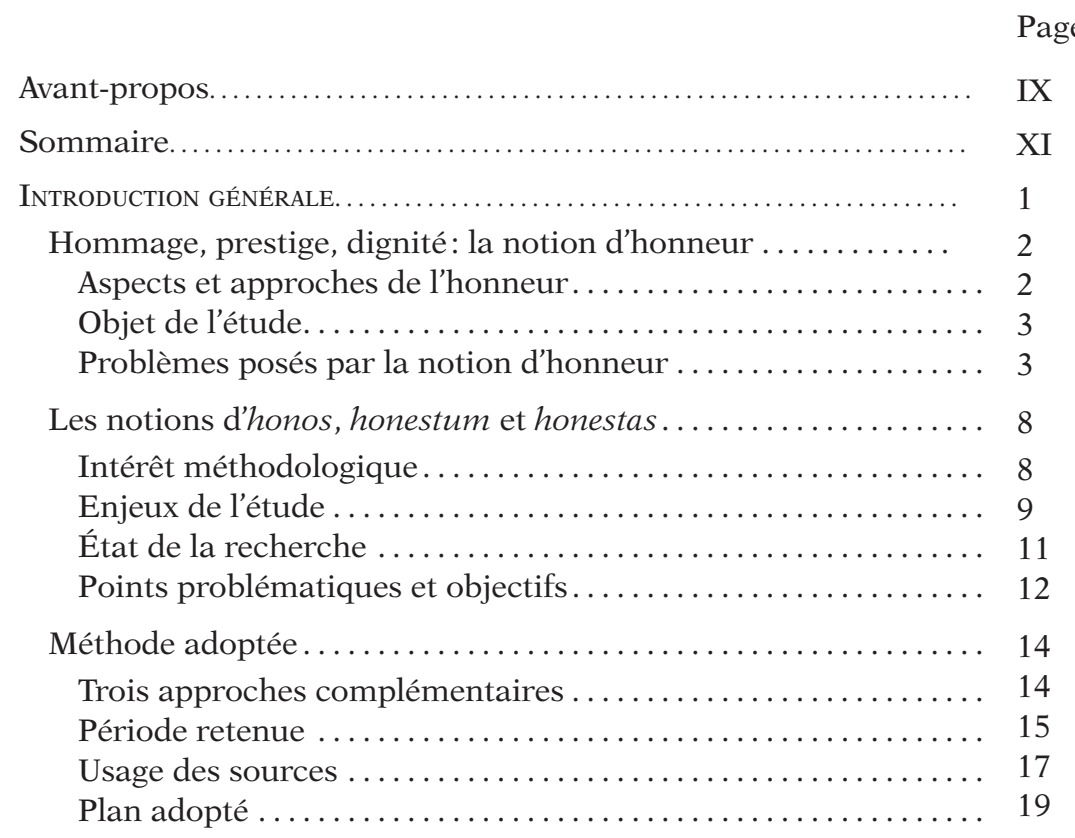

Première PARTIE

LE LEXIQUE: LES MOTS ET LEUR SENS

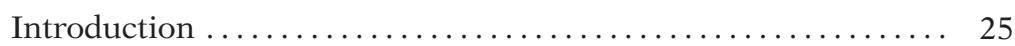

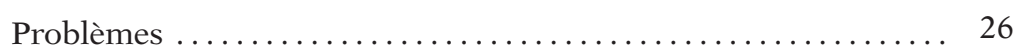

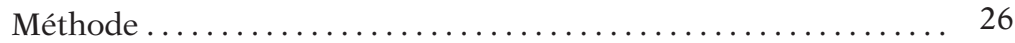

Plan de la première partie ................................. 29

Chapitre 1 - Analyse sémantioue d'Honos................... 31

1. Préambule linguistique et étymologique sur honos ............ 31

1.1. Morphologie ............................. 31

1.2. La présence du mot dans la langue latine ............ 33

1.3. L'étymologie d'honos .......................... 34

1.3.1. Honos issu de onus..................... 34 


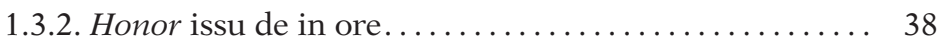

1.3.3. Honos et la racine ${ }^{*} \mathrm{zg}^{\mathrm{h}} \mathrm{O}-\ldots \ldots \ldots \ldots \ldots \ldots \ldots \ldots . \ldots \ldots$

1.3.4. Honos et la racine *guhen-................. 39

1.3.5. Honos et la racine ${ }^{*} \mathrm{~g}^{\mathrm{h}} \mathrm{en}-\ldots \ldots \ldots \ldots \ldots \ldots \ldots \ldots \ldots \ldots$

1.3.6. Honos et le lexique italique ............... 40

2. Identification des sens d'honos ................... 41

3. «Marque d'honneur, hommage» (S1).............. 44

3.1. Acception active et acception passive ............. 45

3.2. Un bienfait.............................. 47

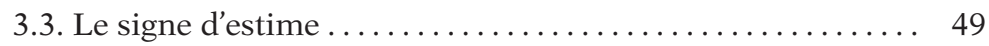

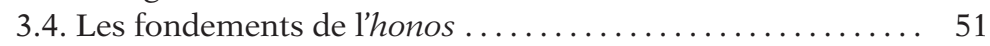

3.5. L'effet social de l'honos ....................... 54

3.6. Les autres effets de l'honos .................. 57

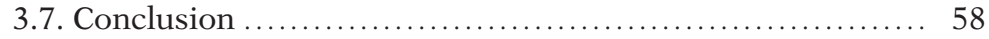

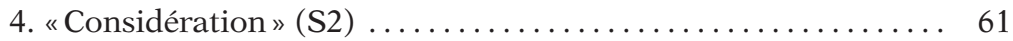

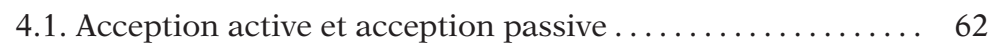

4.2. Une situation d'estime ....................... 64

4.3. Un bénéfice social connexe.................... 66

4.4. Les fondements de la considération .............. 68

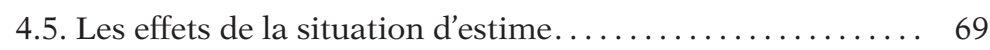

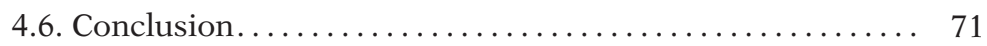

4.7. Deux emplois lexicalisés : honoris gratia et honoris causa .. 78

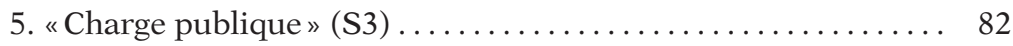

5.1. La fonction publique $\ldots \ldots \ldots \ldots \ldots \ldots \ldots \ldots \ldots \ldots \ldots$

5.2. Le pouvoir apporté par la fonction $\ldots \ldots \ldots \ldots \ldots \ldots \ldots . . \ldots 5$

5.3. Le bénéfice social de la charge $\ldots \ldots \ldots \ldots \ldots \ldots \ldots . \ldots 6$

5.4. Les fondements de la charge $\ldots \ldots \ldots \ldots \ldots \ldots \ldots \ldots . \ldots \ldots$

5.5. L'influence procurée par la charge .............. 88

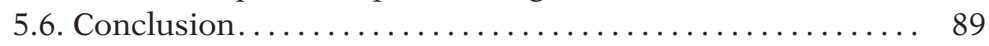

6. "Dignité, honorabilité » (S4) ................... 91

6.1. Un droit à la considération..................... 91

6.2. Les fondements moraux de l'honorabilité............ 93

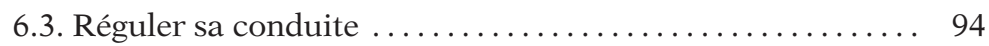

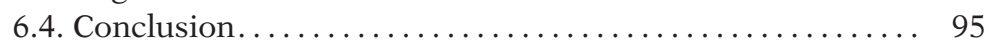

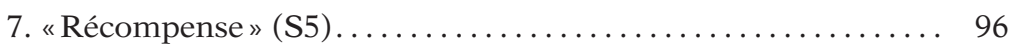

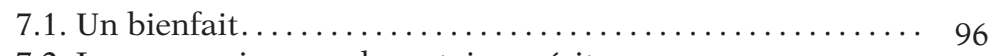

7.2. La reconnaissance de certains mérites............. 97

7.3. Conclusion................................ 98

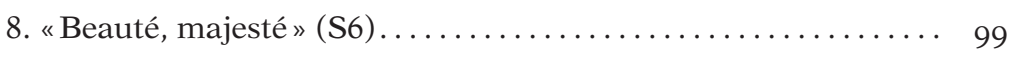

8.1. Analyse sémique $\ldots \ldots \ldots \ldots \ldots \ldots \ldots \ldots \ldots \ldots$ 
8.2. Conclusion................................... 101

9. La divinité Honos (S7) . . . . . . . . . . . . . . . . . . 102

10. Conclusion générale sur le sémantisme d'honos........... 103

10.1. La question du sens premier ..................... 103

10.2. Honos, terme du vocabulaire religieux ?............ 105

10.3. Le fonctionnement sémantique d'honos ............. 106

11. Appendice: honos et le lexique grec ................ 106

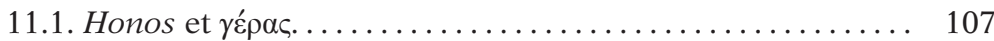

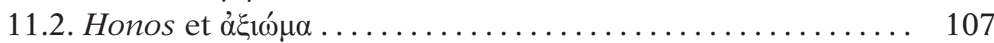

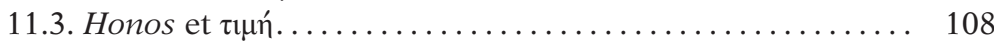

Chapitre 2 - AnaLYSE SÉmantique d'Honestus .................. 115

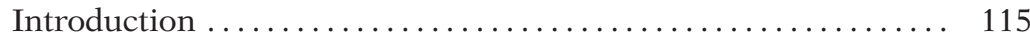

1. «Considéré, estimé, distingué» (S1) .................. 118

1.1. Bénéficier de la considération et de ses marques ......... 118

1.2. Les avantages sociaux associés à l'estime ............. 120

1.3. Conclusion................................ 121

2. «Honorable, source de considération» ................ 121

2.1. Une source d'estime et de marques d'honneur.......... 121

2.2. La préservation du rang social ................... 124

2.3. Les fondements de l'estime suscitée: convenances sociales et règles morales.......................... 125

2.4. Un guide pour la conduite ...................... 126

2.5. Conclusion............................... 128

3. «Honorable, digne de considération» (S2bis) ............. 129

3.1. Le droit à l'estime et à ses marques................. 130

3.2. Les fondements du droit à l'estime: qualités morales et convenances sociales ......................... 131

3.3. Les bases sociales du droit à l'estime ..................... 132

3.4. Savoir guider sa conduite ....................... 133

3.5. Conclusion.................................. 134

4. «Honorifique » (S3) ............................. 135

4.1. Analyse sémique ............................ 136

4.2. Conclusion.................................. 137

5. «Honnête, probe» (S4) .......................... 138

5.1. La conformité à la morale collective ................. 138

5.2. La droiture ............................... 139

5.3. Guider la conduite.......................... 140

5.4. Conclusion.............................. 141 
6. «Beau, admirable» (S5) ........................... 143

6.1. Une source d'estime et d'admiration................ 143

6.2. Les qualités de l'aspect extérieur ................. 145

6.3. Une beauté distinctive et éminente ............... 146

6.4. Conclusion.......................... 147

7. «Moralement beau, vertueux, honnête» (S6) ............ 148

7.1. Honestus en contexte philosophique................ 149

7.1.1. L'adéquation à la vertu éthique................. 149

7.1.2. Un guide pour la conduite ................ 152

7.1.3. La valeur en soi ........................ 153

7.1.4. Une source d'estime admirative.............. 154

7.2. Honestus en contexte rhétorique ................ 155

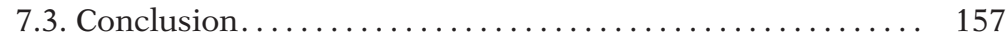

8. Conclusion générale sur honestus ................... 161

Chapitre 3 - Analyse sémantique d'Honestas ................ 163

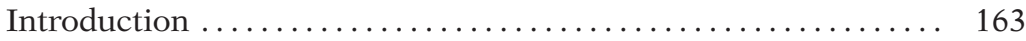

1. "Considération » (S1) ........................... 165

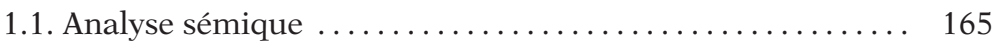

1.2. Conclusion................................. 167

2. «Honorabilité, dignité, honneur» $(\mathrm{S} 2) \ldots \ldots \ldots \ldots \ldots \ldots \ldots$

2.1. Analyse sémique $\ldots \ldots \ldots \ldots \ldots \ldots \ldots \ldots \ldots \ldots \ldots \ldots \ldots$

2.2. Conclusion............................. 171

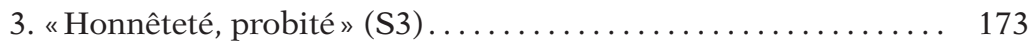

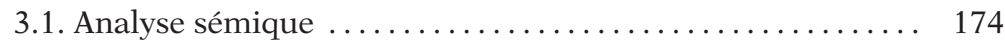

3.2. Conclusion................................. 174

4. «Beauté admirable» (S4) ........................ 175

4.1. Analyse sémique ......................... 175

4.2. Conclusion............................. 176

5. «Beauté morale, moralité, honnêteté » (S5) ............. 177

5.1. Analyse sémique ........................ 177

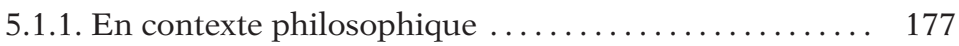

5.1.2. En contexte rhétorique ................. 180

5.2. Conclusion........................... 181

6. «Marque d'honneur» $(\mathrm{S} 6) \ldots \ldots \ldots \ldots \ldots \ldots \ldots \ldots \ldots \ldots \ldots \ldots$

6.1. Analyse sémique $\ldots \ldots \ldots \ldots \ldots \ldots \ldots \ldots \ldots \ldots \ldots \ldots \ldots$

6.2. Conclusion................................ 184

7. «Notabilité, personne considérée» $($ S7 $\ldots \ldots \ldots \ldots \ldots \ldots \ldots$ 
7.1. Analyse sémique .............................. 185

7.2. Conclusion............................... 185

8. Conclusion générale sur honestas .................... 186

Conclusion de la première partie ...................... 187

DeuXiÈme PARTIE

LA PRATIQUE: FONCTIONNEMENTS ET USAGES

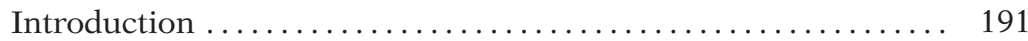

Problèmes ......................................... 191

Méthode ........................................ 191

Chapitre 4. Les structures de L'HonNeUR...................... 195

Introduction ...................................... 195

1. Les protagonistes de l'honos: soi-même et autrui .......... 195

1.1. L’honos possédé: les détenteurs de l'honneur........... 195

1.1.1. Individu et collectivité........................ 196

1.1.2. La propagation de l'honos .................... 198

1.2. L'honos conféré : le rôle d'autrui..................... 201

1.2.1. Auteur de l'hommage...................... 202

1.2.2. Garant et témoin de l'hommage................ 204

1.2.3. Fondement du prestige.................... 207

1.2.4. Du geste au discours fondamental ............. 208

2. Le paradigme symbolique: signe et représentation .......... 211

2.1. La marque d'honneur comme signe d'estime du donateur .................................... 211

2.1.1. L'estime à l'origine de l'hommage .............. 211

2.1.2. L'honos comme signe d'estime .................. 214

2.2. Le prestige comme représentation................ 218

2.2.1. Un signe performatif $\ldots \ldots \ldots \ldots \ldots \ldots \ldots \ldots \ldots, 218$

2.2.2. L'insigne de prestige..................... 221

2.3. Bilan: le paradigme symbolique................. 222

3. Le paradigme économique: rétribution et capital ......... 223

3.1. La marque d'honneur comme rétribution............. 224

3.1.1. Récompense et salaire....................... 224

3.1.2. La dette et l'échange $\ldots \ldots \ldots \ldots \ldots \ldots \ldots \ldots \ldots . \ldots 226$

3.1.3. L'honos signe de gratia...................... 228

3.2. La considération comme capital ................... 229

3.2.1. Laccumulation et la gestion d'un capital d'honneur ... 230

3.2.2. L'honos comme «capital symbolique»............ 231 
3.3. Bilan: le paradigme économique .............. 233

3.4. Conclusion globale: le symbolique et l'économique...... 234

Conclusion et mise en perspective historique............. 236

Chapitre 5 - LES FORMES DE L'HONOS ...................... 241

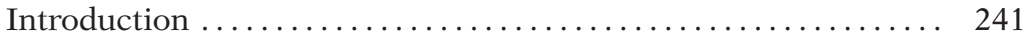

1. Honos, insigne, ornamentum ................... 241

2. L'échelle de l'honneur ......................... 244

3. Typologie des formes de l'hommage ................ 249

3.1. L'objet ................................. 249

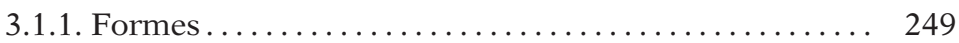

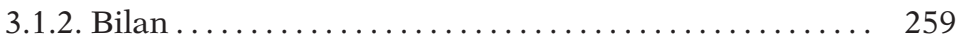

3.2. Le geste.............................. 262

3.2.1. Formes ............................ 262

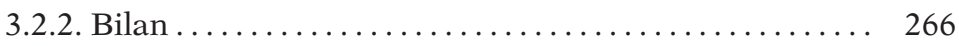

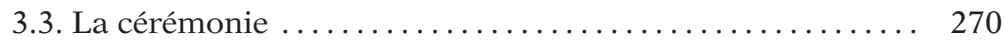

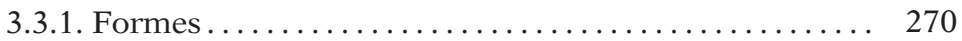

3.3.2. Bilan ............................. 280

3.4. L'honos uerborum .......................... 281

3.4.1. Formes.......................... 282

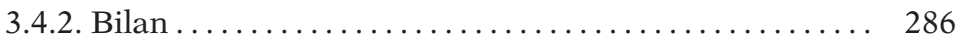

3.5. La responsabilité publique ................ 287

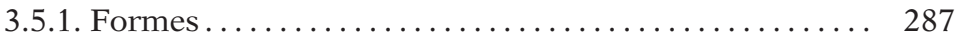

3.5.2. Bilan .............................. 292

Conclusion et mise en perspective historique.............. 295

Chapitre 6 - L'ACCÈs À L'HONNEUR: CAUSES ET CONDITIONS. . . . . . . . . . . . 299

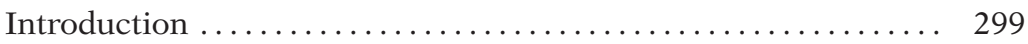

1. Le mérite au fondement de l'honos : dignitas et aequum ...... 299

2. Typologie des motifs de l'honos .................. 304

2.1. Comportements et qualités. ..................... 304

2.1.1. Mérites militaires ...................... 305

2.1.2. Mérites moraux........................ 308

2.1.3. Bienfaits et services ..................... 314

2.1.4. Bilan : la matrice de ces comportements ........ 315

2.2. Statut et identité ..................... 320

2.2.1. Identité sociale distinctive ................ 320 
2.2.2. Statut social supérieur ................. 323

2.2.3. Statut civique et politique supérieur.......... 327

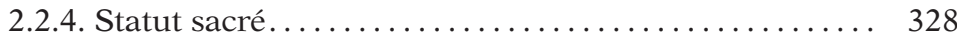

2.2.5. Bilan : la matrice de ces statuts ............. 329

3. Ouverture ou fermeture de l'accès à l'honos ? ............. 331

3.1. L'accès privilégié de l'aristocratie ............... 331

3.1.1. Le prestige comme bien propre de l'aristocratie..... 332

3.1.2. La mainmise sur les marques d'honneur ......... 333

3.1.3. La mainmise sur les charges publiques.......... 334

3.1.4. L'honos source de l'honos .................. 338

3.2. La controverse sur la nature du mérite ........... 339

3.2.1. Genus contre uirtus ..................... 340

3.2.2. Les limites de cette opposition idéologique ........ 344

3.3. La réglementation de l'accès à l'honos ............. 346

Conclusion et mise en perspective historique............. 349

Chapitre 7 - Les efFETS DE L'HONNEUR $\ldots \ldots \ldots \ldots \ldots \ldots \ldots \ldots \ldots \ldots \ldots \ldots$

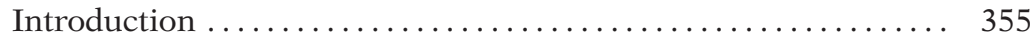

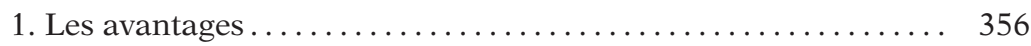

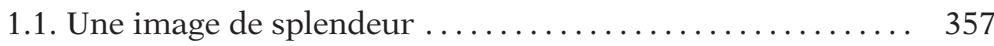

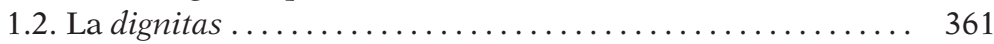

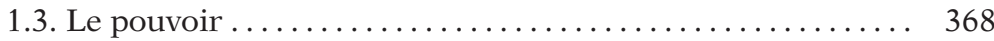

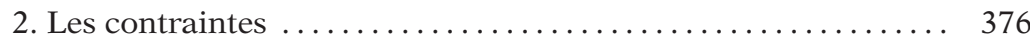

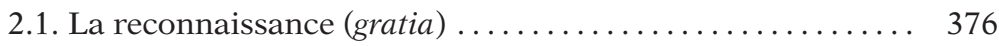

2.2. La dignité et l'honorabilité (dignitas et honestas) ....... 382

2.3. Le poids des responsabilités (onus) ............. 385

3. L'articulation des avantages et des contraintes .......... 385

Conclusion................................... 390

Chapitre 8 - LES FONCTIONS DE L'HONNEUR .................. 393

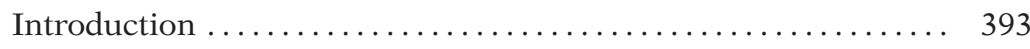

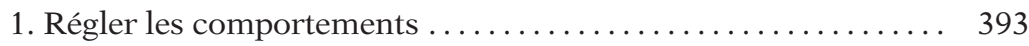

1.1. L'orientation pratique des conduites ................ 394

1.1.1. "Honos alit artes » : stimuler des pratiques ......... 394

1.1.2. Contrôler le corps social.................... 398

1.2. L'orientation axiologique des modes de pensée ........ 402

1.2.1. Définir des valeurs ....................... 403

1.2.2. Définir des modèles ...................... 408 
Page

2. Structurer la société ........................... 415

2.1. Contribuer à la cohésion du groupe ............... 415

2.2. Symboliser le lien social ..................... 418

3. Obtenir du pouvoir........................ 420

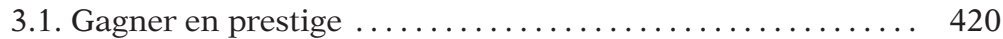

3.2. "Do ut des» : s'attirer bienfaits et partisans ........... 423

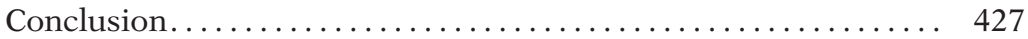

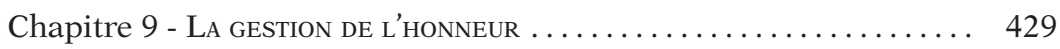

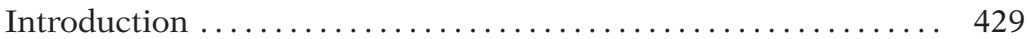

1. La recherche de l'honneur ..................... 429

1.1. La valeur de l'honos ....................... 430

1.2. La compétition pour l'honos ................... 434

2. La préservation de l'honneur.................... 440

2.1. La vulnérabilité de l'honneur personnel.............. 441

2.2. Les menaces d'autrui sur l'honos ................. 444

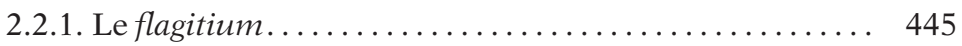

2.2.2. La condamnation en justice $\ldots \ldots \ldots \ldots \ldots \ldots \ldots .448$

2.2.3. Le blâme des censeurs..................... 449

3. La transmission de l'honneur familial ............... 451

3.1. Nécessité et difficulté de la transmission............ 452

3.2. Reproduire l'honneur ancestral ................. 454

3.3. Dépasser l'honos des ancêtres ....................... 457

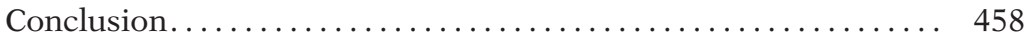

Chapitre 10 - Le code de L'HonNEur..................... 461

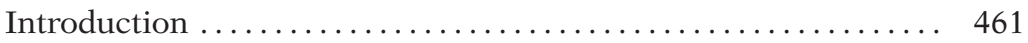

1. Le sens de l'honneur ....................... 462

1.1. La conscience de l'honestum: le pudor.............. 462

1.2. L'attachement à l'honestas ..................... 463

2. Les normes de l'honneur ..................... 466

2.1. La normativité de l'honneur................... 466

2.2. Les commandements du code d'honneur ............... 469

2.2.1. Conduites honorables et motifs d'honneur........ 470

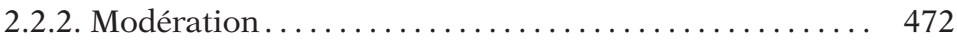

2.2.3. Décence et pudeur ....................... 476

2.2.4. Impassibilité et sérieux .................... 479

3. L'extériorité du code d'honneur.................. 483 
3.1. Un critère extérieur: la définition de l'honorabilité par la collectivité ......................... 484

3.2. Une motivation extérieure : le rôle d'autrui dans

l'adoption du code d'honneur....................... 485

3.3. Un archétype extérieur : les ancêtres.............. 488

3.3.1. L’archétype de l'honestas................... 488

3.3.2. Une morale mimétique .................... 490

3.3.3. Une morale traditionnelle et identitaire ......... 492

4. La relativité du code d'honneur ...................... 493

4.1. La relativité de l'existence de l'honestas ............... 494

4.1.1. La nature aristocratique de l'honestas ............. 494

4.1.2. Le souci partagé de l'honestum .............. 496

4.2. La relativité des commandements de l'honestas ......... 498

4.2.1. Le clivage du statut social .................. 499

4.2.2. Le clivage de l'ethnie ...................... 499

4.2.3. Le clivage du genre..................... 501

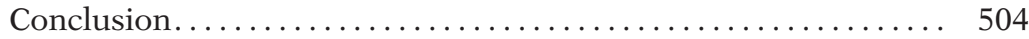

Chapitre 11 - Le dieu Honos .............................. 507

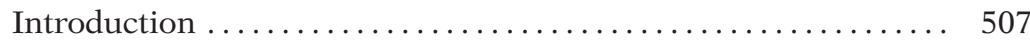

1. La nature d'Honos ............................. 508

1.1. Le statut d'Honos dans le panthéon ................. 508

1.2. Les attributions d'Honos..................... 510

1.2.1. Le dieu de l'hommage .................. 510

1.2.2. Le dieu de la juste rétribution du mérite; Honos et Virtus............................... 513

1.2.3. Une divinité militaire . . . . . . . . . . . . . . . . 515

2. Le culte d'Honos et sa signification idéologique et

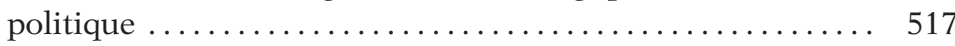

2.1. Les rites attestés. ........................ 518

2.2. Le temple de la porte Colline.................. 519

2.3. Le temple de la porte Capène (1): la dévotion de

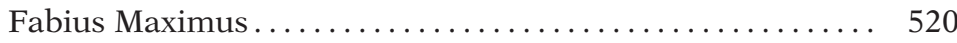

2.4. Le temple de la porte Capène (2): la transformation de

M. Claudius Marcellus ............................. 524

2.5. Le sanctuaire de Marius ......................... 529

2.6. Honos dans le complexe de Pompée................. 534

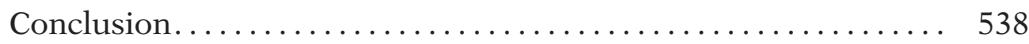

Conclusion de la deuxième partie $\ldots \ldots \ldots \ldots \ldots \ldots \ldots \ldots \ldots . \ldots \ldots$ 


\section{TROISIÈME PARTIE \\ APPROCHES INTELLECTUELLES ET REPRÉSENTATIONS}

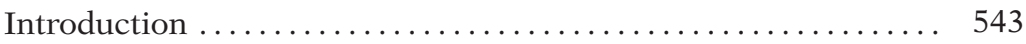

Objets d'étude...................................... 543

Méthode .......................................... 544

Chapitre 12 - Plaute : L'Honneur à L'éPreuve de la comédie ....... . 547

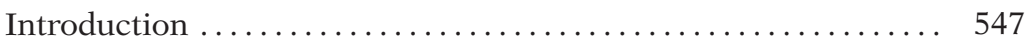

1. L'inversion de l'honos sur la scène de la comédie.......... 550

1.1. Des règles de fonctionnement inversées............ 550

1.2. La question de la subversion morale............. 553

1.3. La fonction régénérante ................... 556

1.4. La fonction comique.................... 557

2. L'évaluation de l'honneur par les personnages de comédie.... 558

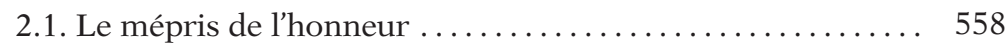

2.1.1. Lamoureux et le glouton $\ldots \ldots \ldots \ldots \ldots \ldots \ldots \ldots \ldots \ldots$

2.1.2. La portée morale de ce mépris ................ 560

2.1.3. L'amorce d'une réflexion sur l'honneur .......... 562

2.1.4. Les fonctions dramatiques................. 564

2.2. L'attachement à l'honneur. ...................... 565

2.2.1. La valorisation de l'honneur par les personnages..... 566

2.2.2. La portée morale de cette valorisation........... 568

2.2.3. L'aspect réflexif de la leçon morale ............ 571

2.2.4. Les fonctions dramatiques............... 574

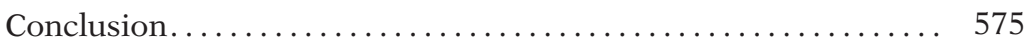

Chapitre 13 - Caton : L'Honneur du Censeur................. 577

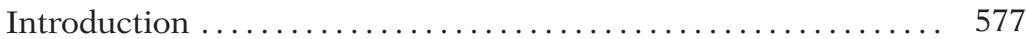

1. Une approche normative de l'hommage ............... 577

1.1. La critique du dysfonctionnement de l'honos.......... 578

1.2. L'établissement de règles et de modèles ............. 580

1.3. La définition d'un honos idéal .................... 585

2. L'honneur politique dans l'idéologie de Caton........... 586

2.1. L'honneur du pouvoir..................... 586

2.2. L'honneur comme fin de l'action publique? ........... 588

2.3. Le moyen d'une aristocratie du mérite.............. 591

3. L'honorabilité dans la pensée morale de Caton............ 594 
3.1. La définition de l'homme d'honneur ................. 594

3.2. Une faible théorisation de l'honneur............... 598

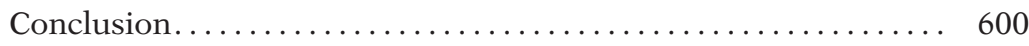

Chapitre 14 - Les ÉPITAPHES des SCIPIONS : LA MOBILISATION DE L'HONOS PAR L'ARISTOCRATIE ............................... 601

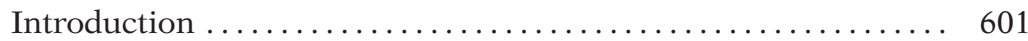

1. Les inscriptions et l'identité des défunts ................ 602

1.1. L. Cornelius Scipio Barbatus $\left(C I L \mathrm{I}^{2}, 6-7=I L L R P\right.$ 309) $\ldots .603$

1.2. L. Cornelius Scipio $\left(C I L \mathrm{I}^{2}, 8-9=I L L R P\right.$ 310)......... 603

1.3. P. Cornelius Scipio $\left(C I L \mathrm{I}^{2}, 10=I L L R P 311\right) \ldots \ldots \ldots \ldots \ldots 605$

1.4. L. Cornelius Scipio $\left(C I L \mathrm{I}^{2}, 11=I L L R P\right.$ 312) ........ 606

1.5. Cn. Cornelius Scipio Hispanus $\left(C I L I^{2}, 15=I L L R P\right.$ 316) $\ldots 607$

2. La représentation aristocratique de l'honos ............ 608

2.1. L'évolution des sources du prestige aristocratique ....... 608

2.2. L'honos comme objectif d'une vie............... 611

2.3. L'honos fondé sur la naissance ................ 612

3. La valorisation de l'honos de la gens ................ 613

3.1. L'amplification de l'honos ........................ 613

3.2. L'appropriation gentilice de l'honos .............. 614

4. Les fonctions de la valorisation de l'honos et le rôle des

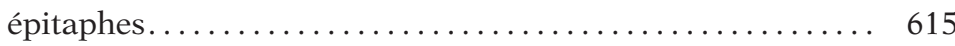

4.1. Célébrer et honorer les défunts.................. 615

4.2. Valoriser les vivants ......................... 617

4.3. Exhorter les descendants ................... 619

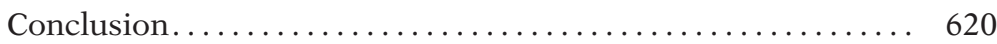

Chapitre 15 - Térence: L'HONNEUR EN DEMI-TEINTE $\ldots \ldots \ldots \ldots \ldots \ldots 621$

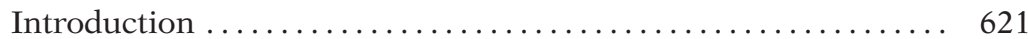

1. L'usage dramatique du thème de l'honneur ............. 622

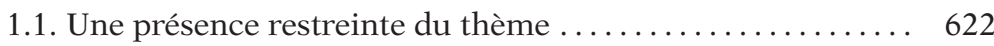

1.2. Un fonctionnement conventionnel................ 623

1.3. L'approfondissement psychologique ............... 626

2. Le développement éthique d'honestus ................ 628

2.1. L'effacement de l'extériorité sociale.............. 628

2.2. L’enrichissement esthétique et ses implications éthiques... 630

2.3. L'avancée conceptuelle....................... 632

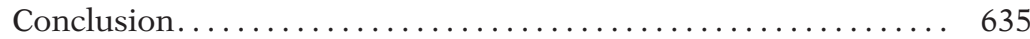

Chapitre 16 - Lucilius : L'HONNEUR À LA CROISÉE DES CHEMINS . . . . . . . . 637 
1. Le traitement de l'honos dans la satire : évaluation et détournement .............................. 638

1.1. La valorisation de l'honos funéraire ............... 638

1.2. La mise en question de la valeur du prestige .......... 640

1.2.1. L'interrogation sur les fondements de l'honos militaire 640

1.2.2. L'évaluation du prix véritable de l'honos ........... 642

1.2.3. Le rejet de l'ambition.................... 645

1.3. L’honos badin de la poésie ................... 647

2. L'exhortation à la uita honesta . . . . . . . . . . . . . . . . . 649

2.1. Une poésie d'ignominia ....................... 649

2.2. La prédication sur la vie honorable............. 652

3. Lélaboration éthique d'honestus ................... 654

3.1. L'évolution morale d'honestus ..................... 654

3.1.1. La nature de la vie honesta chez Lucilius . . . . . . . . 654

3.1.2. Vers l'autonomie de la norme morale........... 656

3.2. La naissance d'un concept philosophique ........... 657

3.2.1. L'émergence d'une catégorie éthique ........... 657

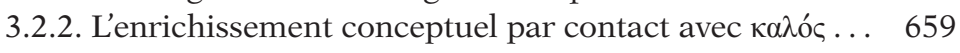

3.2.3. Une conceptualisation en harmonie avec la tradition romaine......................... 660

3.2.4. Les limites de la conceptualisation ............. 663

Conclusion........................................... 664

Chapitre 17 - La RHÉTORIQUe À HeRENNIUS : LA MATURATION CONCEPTUELLE

D'HONESTUM .............................. 667

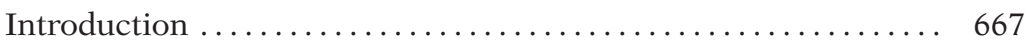

1. Le développement d'un concept rhétorique ............ 668

1.1. Les trois usages rhétoriques d'honestus ............. 668

1.2. Le rapprochement entre honestus et $\kappa \alpha \lambda$ ó $\ldots \ldots \ldots \ldots \ldots .672$

1.3. Lapprofondissement théorique................ 674

2. L'aspect éthique de la conceptualisation rhétorique ....... 677

2.1. La distinction de l'aspect social et de l'aspect moral ..... 677

2.2. Entre honneur et moralité ..................... 679

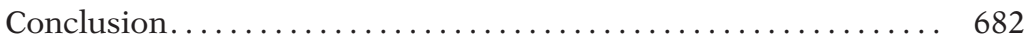

Chapitre 18 - LuCRÈCE : LA CRITIQUe ÉPICURIENNE DE L'HONOS........ . 683

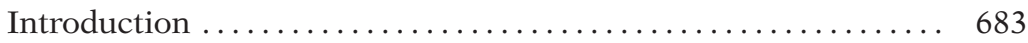


1. Une vision critique du désir d'honos ................. 684

1.1. L’image misérable de l'ambition .................. 684

1.2. Les maux de l'ambition ........................ 687

2. Les fondements philosophiques de la critique: la vanité de l'honos .................................... 691

2.1. L'honos inutile à la sécurité ...................... 691

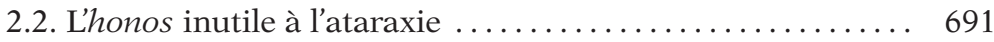

3. Les conséquences de la critique : le renoncement à l'honneur. . 697

3.1. Renoncer à l'honos ............................ 697

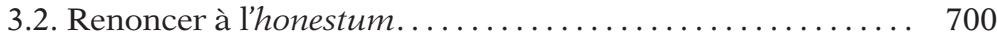

3.3. La recherche de la gloire poétique : un paradoxe?...... 702

Conclusion.................................. 703

Chapitre 19 - CÉSAR : L'HONOS ET LA FIGURE DE L'IMPERATOR .......... 705

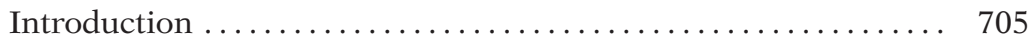

1. La représentation de César en dispensateur de l'honneur..... 705

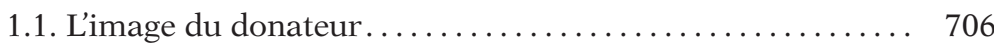

1.2. Les qualités du donateur.................... 707

2. La représentation de César en détenteur de l'honneur ....... 710

2.1. Une quête de l'honos mesurée................... 710

2.2. L'honos comme qualité secondaire ................ 713

2.3. L'absence de l'honestas ....................... 714

3. La représentation du rapport des autres à l'honneur ....... 715

3.1. L'honneur des Gaulois ...................... 716

3.2. L’honneur de l'armée césarienne ................ 717

3.3. Le dérèglement de l'honos chez les pompéiens ........ 718

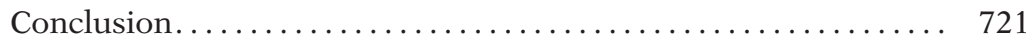

Chapitre 20 - SALLUSTE: L'HISTORIEN D'Un HONNEUR EN CRISE ......... 723

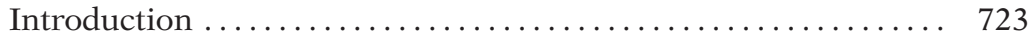

1. La représentation historique du délitement de l'honneur ..... 724

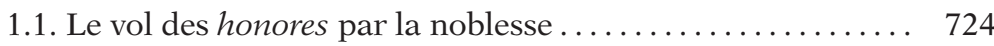

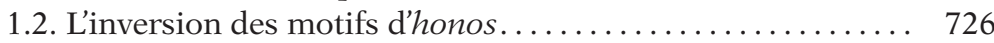

1.3. Le mépris de l'honestum ............................ 729

2. L'analyse du désir d'honos ....................... 733

2.1. L'ambition comme facteur historique............ 733

2.2. La critique morale de l'ambition $\ldots \ldots \ldots \ldots \ldots \ldots \ldots .736$

2.3. À la recherche d'une autre forme de notoriété:
historien et la gloire $\ldots \ldots \ldots \ldots \ldots \ldots \ldots \ldots \ldots \ldots \ldots \ldots \ldots \ldots \ldots, 740$ 
Page

3. La morale de l'honestum chez Salluste ............... 744

3.1. L'enrichissement de la valeur morale de l'honestum ...... 744

3.2. La fidélité aux représentations traditionnelles de l'honneur 745

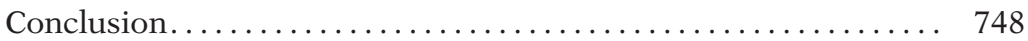

Conclusion de la troisième partie.................... 749

Conclusion génÉrale ............................ 753

Richesse, cohérence et singularité sémantiques .......... 753

Les paradigmes de l'honneur.................. 754

Une structure sociale et morale .................... 755

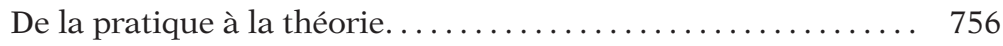

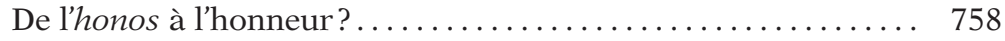

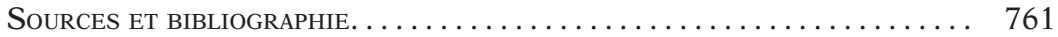

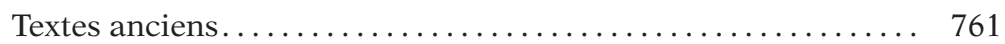

Recueils de textes anciens..................... 763

Ouvrages de référence $\ldots \ldots \ldots \ldots \ldots \ldots \ldots \ldots \ldots \ldots \ldots \ldots \ldots \ldots \ldots \ldots \ldots$

Littérature secondaire .......................... 764

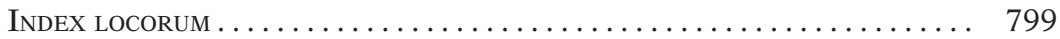

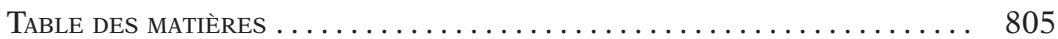



Achevé d'imprimer en octobre 2013

sur les presses de la

Scuola Tipografica S. Pio X

Via degli Etruschi, 7

00185 Roma 